\title{
Adaptive Management and Planning Models for Cultural Resources in Oil and Gas Fields in New Mexico and Wyoming
}

\author{
DE-FC26-02NT15445
}

Final Technical Report

January 2003 - December 2005

Principal Authors:

Eric Ingbar, Lynne Sebastian, Jeffrey Altschul, Mary Hopkins, William Eckerle, Peggy Robinson, Judson Finley, Stephen A.Hall, William E. Hayden, Chris M. Rohe, Tim Seaman, Sasha Taddie, and Scott Thompson

December 2005

DOE Award Number: DE-FC26-02NT15445

Submitting Organization Gnomon, Inc. 1601 Fairview Drive, Suite F Carson City, Nevada 89701

Subcontractors SRI Foundation

333 Rio Rancho Drive, NE, Suite 103

Rio Rancho, New Mexico 87124

New Mexico Historic Preservation Division

228 East Palace Avenue, Room 320

Santa Fe, New Mexico 87501

Wyoming State Historic Preservation Office

Barrett Bldg., 2301 Central Avenue Cheyenne, Wyoming 82022

William Eckerle

Professional Geologist, PG-3509

Western GeoArch Research

P. O. Box 521124

Salt Lake City, Utah 84152-1124

Stephen A. Hall

Red Rock Geological Enterprises

3 Cagua Road

Santa Fe, New Mexico 87508-8116 



\section{DISCLAIMER}

This report was prepared as an account of work sponsored by an agency of the United States Government. Neither the United States Government nor any agency thereof, nor any of their employees, makes any warranty, express or implied, or assumes any legal liability or responsibility for privately owned rights. Reference herein to any specific commercial product, process, or service by trade name, trademark, manufacturer, or otherwise does not necessarily constitute or imply its endorsement, recommendation, or favoring by the United States Government or any agency thereof. The views and opinions of authors expressed herein do not necessarily state or reflect those of the United States Government or any agency. 



\section{ABSTRACT}

In 2002, Gnomon, Inc., entered into a cooperative agreement with the U.S. Department of Energy (DOE) National Energy Technology Laboratory (NETL) for a project entitled, Adaptive Management and Planning Models for Cultural Resources in Oil and Gas Fields in New Mexico and Wyoming (DE-FC26-02NT15445). This project, funded through DOE's Preferred Upstream Management Practices grant program, examined cultural resource management practices in two major oil- and gas-producing areas, southeastern New Mexico and the Powder River Basin of Wyoming (Figure 1). The purpose of this project was to examine how cultural resources have been investigated and managed and to identify more effective management practices. The project also was designed to build information technology and modeling tools to meet both current and future management needs.

The goals of the project were described in the original proposal as follows:

Goal 1. Create seamless information systems for the project areas.

Goal 2. Examine what we have learned from archaeological work in the southeastern New Mexico oil fields and whether there are better ways to gain additional knowledge more rapidly or at a lower cost.

Goal 3. Provide useful sensitivity models for planning, management, and as guidelines for field investigations.

Goal 4. Integrate management, investigation, and decision-making in a real- time electronic system.

Gnomon, Inc., in partnership with the Wyoming State Historic Preservation Office (WYSHPO) and Western GeoArch Research, carried out the Wyoming portion of the project. SRI Foundation, in partnership with the New Mexico Historic Preservation Division (NMHPD), Statistical Research, Inc., and Red Rock Geological Enterprises, completed the New Mexico component of the project.

Both the New Mexico and Wyoming summaries concluded with recommendations how cultural resource management (CRM) processes might be modified based on the findings of this research. 



\section{INTRODUCTION}

Eric Ingbar, Lynne Sebastian, and Mary Hopkins

\section{Overview}

In 2002, Gnomon, Inc., entered into a cooperative agreement with the U.S. Department of Energy (DOE) National Energy Technology Laboratory (NETL) for a project entitled, Adaptive Management and Planning Models for Cultural Resources in Oil and Gas Fields in New Mexico and Wyoming (DE-FC26-02NT15445). This project, funded through DOE's Preferred Upstream Management Practices grant program, examined cultural resource management practices in two major oil and gas-producing areas, southeastern New Mexico and the Powder River Basin of Wyoming (Figure 1). The purpose of this project was to examine how cultural resources have been investigated and managed and to identify more effective management practices. The project also was designed to build information technology and modeling tools to meet both current and future management needs.

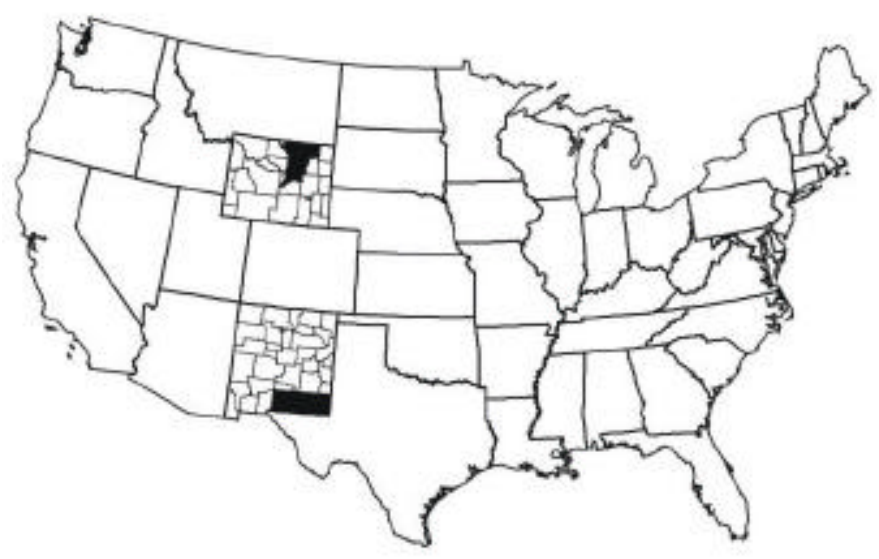

Figure 1. New Mexico and Wyoming project areas

Oil and gas exploration and development are long-term, enduring, uses of public lands. Every exploration and development effort on public lands for the past 30 years has in some fashion addressed impacts to cultural resources, especially archaeological sites. Today, far more archaeological fieldwork is done because of oil and gas development than because of traditional, academic research. The volume of work is truly stunning: within the Powder River Basin, Wyoming study area of this project over 16,000 archaeological sites have been revealed by more than 10,000 archaeological inventories. In the southeastern New Mexico study area, more than 21,000 inve ntories have been conducted and over 8,000 archaeological sites are known to be present. 
Cultural resources are often considered an impediment to development of oil and gas fields, in part because they differ from many other regulated environmental resources. Some classes of regulated resources have the potential to be regenerated as a means to offset their destruction. Loss of a wetland can be mitigated by creating new wetlands. Loss of habitat for a rare species can be offset by protection or even creation of appropriate habitat elsewhere. Cultural resources are different from these examples, for they exist only once and cannot be re-created in some other locale; indeed, integrity of location is one of the primary analytical values of an archaeological site.

The National Historic Preservation Act of 1966 (NHPA) and subsequent federal land management legislation and policy (e.g., the Federal Land Policy Management Act [FLPMA, 1976]) recognize that part of the value of cultural resources is the scientific information they contain. This is especially true of historic and prehistoric archaeological sites. Management of archaeological resources on public lands over the past 30 years has focused on retaining high-information sites and site settings. Other factors are important too but far less common: historically important places, important examples typical of a time or place in our past, places of deep religious interest to Native Americans, and places or sites amenable to interpretation for the public.

An important consideration in this study was whether current practices in archaeological fieldwork, management, and decision- making are efficient. Management of cultural resources has focused on the identification, evaluation, and mitigation of impacts to resources through standard field and management procedures that, through time, have become routine. Familiarity has not necessarily bred efficiency, by any one of a number of measures. Cultural resource clearances were identified as a problem in a 1996 interagency document on applications for permits to drill entitled "Report on Problems Identified with Processing Timeframes and Recommendations to Resolve Identified Issues". More recently, the Bureau of Land Management's 2002 Application for Permit to Drill (APD) Task Force identified cultural resource management practices as being in need of practical reform as they relate to oil and gas leasing

The study was staged in two locations because oil and gas development and the management of its effects varies. There are many reasons for this, but foremost among them is that exploration and extraction vary by the sort of resource, and by land ownership and management .The archaeological record itself is different from one place to the next, so different sorts of investigation, mitigation, and management strategies are used even under similar modes of energy development. By using two study areas in very different settings, the project avoided bogging down in issues pertinent to a particular energy development mode or specific archaeological record.

During the course of this study, we sought opinions about how to reform cultural resource management within the multi-use mandates of the federal land-managing agencies. We collected a variety of ideas covering the full range of land use planning. From resource management plans to pre-lease sale stipulations to mitigation strategies, there was no lack of interesting and potentially useful recommendations from industry, 
government, and private consultants. Some of these thoughts affected how we achieved the goals of the project.

Gnomon, Inc., served as the managing partner in a consortium effort that involved many other firms and agencies. Our primary partnerships included: the Wyoming State Historic Preservation Office (WYSHPO), and Western GeoArch Research, the SRI Foundation, the New Mexico Historic Preservation Division (NMHPD), Statistical Research, Inc., and Red Rock Geological Enterprises. The Bureau of Land Management state offices in Wyoming and New Mexico, the Carlsbad and Las Cruces Field Offices (New Mexico), and the Buffalo, Worland, Kemmerer, and Casper field offices were federal partners. The oil and gas commissions, oil and gas industry associations, and specific energy firms were helpful collaborators.

Early on, this project was given the shorthand designation "PUMP III" in reference to the funding source - the third round of PUMP grants. Like most nicknames, "PUMP III" seems to have become a permanent label despite our best efforts to find some other, more descriptive name. And at that, it is probably a big improvement over the alternative, which would most likely have been some unpronounceable acronym, using the first letters of the formal project title: AMPMCROGF? PUMP III it is!

\section{Goals and Outcomes}

The goals of the project, and a short summary of the project outcome are described below:

Goal 1. Create seamless information systems for the project areas.

Both New Mexico and Wyoming state historic preservation offices have long-term investments in automated data systems. These have been "internal" systems for the most part. As part of this project, both New Mexico and Wyoming added large volumes of data to the information systems used by cultural resources professionals to plan, report, and evaluate archaeological fieldwork. These same data systems are used by cultural resource managers in federal and state agencies to evaluate land use proposals, including oil or gas proposals. Tens of thousands of existing paper information was converted to readily accessible digital formats (available via secured internet access). The Wyoming part of this study includes an analysis of the time and cost savings from automating basic archaeological site and investigation records Both states improved the accessibility of the information as well by improving the on-line services already available and by adding new kinds of information services.

Goal 2. Examine what we have learned from archaeological work in the southeastern New Mexico oil fields and whether there are better ways to gain additional knowledge more rapidly or at a lower cost.

This question was addressed in consultation with the Bureau of Land Management (BLM) and the New Mexico Office of Cultural Affairs, Historic Preservation Division. Examining this question involved the project team assessing how much new archaeological information (not just observations) has been gained over the past twenty 
years of fieldwork. Unfortunately, the consensus was that professional knowledge of the archaeology of southeastern New Mexico had gained in volume, but not in quality. Our recommendations discuss this finding in detail.

The project examined different field inventory techniques that could have been used to gain similar archaeological knowledge more rapidly. Here, we used the ability to rapidly analyze inventory results at different times (by using the electronic data system populated by the project). This allowed us to simulate several inventory configurations (e.g., project-based, lease-based, and energy-field-based inventory strategies). We did find that there are more effective means of doing inventory within oil and gas fields, at least using the measures of "knowledge" that we employed.

In the New Mexico study area, there is an obvious bias in the archaeological sites that have been recorded. This is an outcome of the way in which management and activities have proceeded: avoiding archaeological sites is the common practice. This biased view of the archaeological record, the study suggests, has limited management of archaeological sites to aself-perpetuating management process, in which one cannot let of a particular site (so it is avoided) because so little knowledge has actually been gained.

A related question addressed in the simulation studies and in our discussions with participants in the development and management process is when archaeological information is most useful and can be gathered most effectively. The unsurprising outcome is that most participants desire more information far in advance of any proposed action, including leasing. The paradox is that no one is willing to pay the cost of fieldwork (even in its most efficient configurations) without a project in sight. The common good is served by work in advance.

Despite these findings, there are junctures at which one can gain significant widespread archaeological knowledge efficiently and fairly early in the oil and gas development timeline. The study finds that three-dimensional seismic work could provide an excellent means of gaining a widespread archaeological sample. Again, there are economic exigencies to be overcome; these are discussed in the New Mexico study report.

Recommending ways to change field and information practices is relatively fruitless unless there is a means to capture the outcomes of these new ways of doing archaeology and management. In both the Wyoming and New Mexico studies, this project provided applications and guidelines for retaining new sorts of results.

Goal 3. Provide useful sensitivity models for planning, management, and as guidelines for field investigations.

Geomorphic processes affect the surface occurrence of archaeological sites. Buried archaeological materials present one of the greatest challenges to management and development of cultural resources in oil and gas settings. Surprise "discoveries during ground-disturbing actions hamper development. So, one goal of this project was to provide assessments of the risk of finding materials in archaeologically useful buried 
contexts. The project is to provide assessments of the risk of finding materials in archaeologically useful buried contexts. The "burial risk" model has utility in several ways. Prior to lease formulation, an agency can assess the likelihood of buried cultural materials being present and reformulate a lease area appropriately. A prospective bidder can make a better-informed decision about a given lease and its potential for undesirable (from the bidder's viewpoint) cultural resource complications. In planning on-the-ground actions, the least sensitive locations could be favored for ground-disturbing actions. Using information on the potential for buried sites, agency staff can better evaluate areas with existing inventory data to determine whether additional effort to identify cultural resources are needed.

Goal 4. Integrate management, investigation, and decision-making in a real-time electronic system.

New Mexico and Wyoming have been developing on-line information services available to state and federal agencies and private cultural resource consultants. To date, these systems have not included a shared application between land-managing federal agencies, the state historic preservation offices (SHPOs), and consultants doing the work on the ground. Currently, the investigation-decision-management process for actions like APDs is mostly done via paper. A consultant originates the document, the federal agency reviews the document and its findings, then the SHPO may review and comment, and only then will a finding be made on the undertaking (e.g., as APD) itself. In Wyoming, for example, the transit time from fieldwork to presence in the data system required three months of more.

Using a web-based project tracking application, enhanced and improved by this project, Wyoming cultural resource consultants and agencies have a single database of fieldwork and results. This system increases the efficiency of managers as they cope with the paper flood of permit-related requests, reports, and records.

\section{Project Funding}

This project is primarily funded by Department of Energy (DOE) funds. DOE is contributing $\$ 1,416,121$, which is $79.0 \%$ of the total project budget. The remaining $21 \%$ of the project budget was comprised of matching goods and services provided by the primary project partners. 



\section{EXECUTIVE SUMMARY}

In 2002, Gnomon, Inc., entered into a cooperative agreement with the U.S. Department of Energy (DOE) National Energy Technology Laboratory (NETL) for a project entitled, Adaptive Management and Planning Models for Cultural Resources in Oil and Gas Fields in New Mexico and Wyoming (DE-FC26-02NT15445). This project, funded through DOE's Preferred Upstream Management Practices grant program (which we refer to as PUMP III), examined cultural resource management practices in two major oil and gas-producing areas, southeastern New Mexico and the Powder River Basin of Wyoming. The purpose of this project was to examine how cultural resources have been investigated and managed and to identify more effective management practices. The project also was designed to build information technology and modeling tools to meet both current and future management needs.

The final report for the PUMP III project contains separate summaries for the two different study areas: one for southeastern New Mexico (New Mexico Study Area) and one for the Powder River Basin of Wyoming (Wyoming Study Area).

The New Mexico component of the PUMP III project includes development of:

- digitized archaeological survey and site location information for the entire project area; this information will be made available through the New Mexico Cultural Resource Information System (NMCRIS) maintained by the New Mexico Historic Preservation Division (NMHPD)

- a geomorphology study for each of the three study areas

- predictive models of archaeological site locations based on correlations with environmental variables for each of the three study areas

- inventory simulations to reconstruct the history and evaluate the effectiveness of archaeological survey within each of the study areas

- management recommendations for more predictable, efficient cultural resource compliance processes for oil and gas development as well as better management of cultural resources on public lands 
The Wyoming component of the PUMP III project includes development of:

- digitized archaeological survey and site location information for the entire northeastern corner of Wyoming. These records are available through the Wyoming State Historical Preservation Office (WYSHPO) Cultural Records Office (WYCRO)

- predictive modeling of locations where the geology is suitable for the burial of prehistoric archaeological sites within the hydrological Powder River and Tongue River basins (PRB/TRB)

- web-based applications to enable integration of management, investigation, and decision- making using realtime electronic systems

- recommendations for the use of a risk model by potential categories of users to facilitate more predictable, efficient cultural resource compliance processes for oil and gas development, as well as better management of cultural resources

Both the New Mexico and Wyoming summaries conclude that the cultural resource management (CRM) procedures currently in place could be improved to better protect avoided cultural resource sites and to streamline the lease application process in the oil and gas fields in these two resource-rich areas. 


\section{Adaptive Management and Planning Models for Cultural Resources in Oil and Gas Fields}

\section{Wyoming PUMP III Project}

Principal Authors:

William Eckerle, Mary Hopkins, Eric Ingbar, Sasha Taddie, Judson Finley

DECEMBER 2005 



\section{ACKNOWLEDGEMENTS}

Western GeoArch Research: William Eckerle, Professional Geologist (PG-3509), was the principal investigator for Chapter 4 . He conducted field reconnaissance, determined model parameters, authored or co-authored much of this chapter, and is responsible for any errors or omissions. Sasha Taddie acted as GIS specialist, wrote portions of the methodology, and produced the graphics for this chapter. He also prepared accompanying digital products. Judson Finley co-authored the Protocol Handbook (Appendix C), parts of the chapter, performed drafting, and assisted with chapter editing. Rebecca Hanna co-authored the conclusions and authored the summary section, as well as assisted in editing and chapter compilation. Mary Hopkins and Eric Ingbar assisted in evaluating the model. Reese Tietje and Mike Drews, of Gnomon, Inc., assisted with model creation. Aaron Geery and Marissa Taddie helped edit and compile the chapter. .

Wyoming State Historic Preservation Office (WYSHPO): Mary Hopkins was the primary author of chapter 3 and a co-author with Eric Ingbar of Chapters 2, 5, and 6. Ross Hilman, Chris Young, and Ben Blasko helped write the procedural sections in chapter 3 and the user manuals. Ross Hilman, Chris Young, Ben Blasko Tom Furgeson, Terri Given, and Greg Willson diligently worked to create the spatial and attribute data. They also continually offered suggestions to improve the data creation process and insure data consistency. Ross Hilman provided his years of archeological experience in interpreting the resources. Jeff Keahey worked to quality control the GIS data and incorporate new information from the BLM field offices. Steve Sutter contributed his years of experience and practical skills of ma naging a ton of paper. Gretchen Keahey tirelessly scanned all of the site forms for the eight counties without a complaint. Judy Wolf and Mark Miller provided excellent final editing for the chapters.

Staff from the Bureau of Land Management participated in progress and design meeting. They offered continual support to the goals of the project. Elizabeth Burghard, Alice Tratebas, Chris Arthur, Patrick Walker, Lynn Harrell, Mike Bies, and Colleen Sievers all provided substantial comments to the project. Tim Nowak and James Gazewood provided support within the BLM management team as well as the national fluid minerals section of the BLM. James Gazewood continues to promote this project among oil and gas operators and we are very appreciative of his efforts. Ian Ritchie from the U.S. Forest Service participated in project meetings.

Jana Pastor and staff from Western Archeological Services, especially Deanna Court, continually worked to help implement CRMtracker. They reported problems, made sugge stions, and didn't give up when the application wasn't working. They have done the bulk of the testing of the application and have helped to make this effort go forward. We also want to thank all of the private consultants who attended our training for their time and effort. Many traveled long distances and sent additional staff to the training. We thank them for participating without complaint. 
Gnomon, Inc.: Eric Ingbar was the principal author of Chapters 2, 5, and 6. Mary Hopkins co-authored with him. Eric Ingbar, Theo McCormick and Hong Li did much of the work on the two web-based applications: Cultural Resource Management Tracker (CRMTracker) and Cultural Resources Information Summary Program (CRISP). Peggy Robinson and Darlene Cobbey provided editing assistance for the final report. Peggy Robinson served as the project coordinator, ensuring that all aspects of the work stayed on task and well focused. 


\section{TABLE OF CONTENTS}

ACKNOWLEDGMENTS .................................................................. ii

TABLE OF CONTENTS .................................................................... iv

\section{CHAPTER 1}

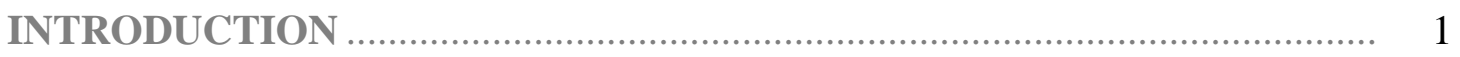

The Wyoming Component .......................................................................... 2

Digitization of Archaeological Survey and Site Locations ............................ 4

Geoarchaeological Predictive Model........................................................ 4

Web-Based Applications ..................................................................... 5

Management Recommendations ...................................................... 5

\section{CHAPTER 2}

\section{INFORMATION TECHNOLOGY AND CULTURAL RESOURCE}

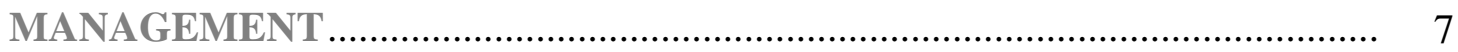

The Current Situation in Powder River Basin of Wyoming ........................... 7

Information Technology Goals ......................................................... 7

WYSHPO Technology Goals ............................................................. 9

\section{CHAPTER 3}

OVERVIEW OF WYOMING CULTURAL RESOURCE INFORMATION

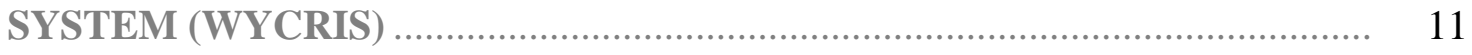

Generating Datasets for the Modeling Project ........................................... 13

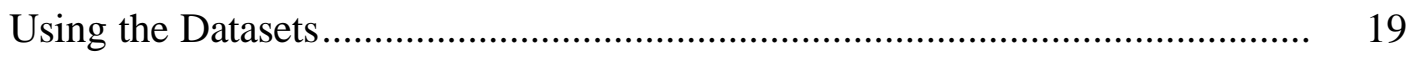

Data Lineage .................................................................................... 21

Data Limitations ............................................................................ 22

Implications of the Adaptive Management and Planning Project for WYCRIS 24

Revised Internet Mapping Web Site ................................................... 28 
User Manuals, System Administration, and Install Instructions .......................... 30

Overview of Digitizing Methodology ………………….................................... 31

Data Quality................................................................................... 33

Cost Analysis of the Work Effort .................................................................. 36

Examples of Time and Expense Savings Using New and Improved

Technologies......................................................................................... 37

\section{CHAPTER 4}

EXPERIMENTAL: ARCHAEOLOGICAL BURIAL MODEL FOR POWDER RIVER AND TONGUE RIVER HYDROLOGICAL BASINS,

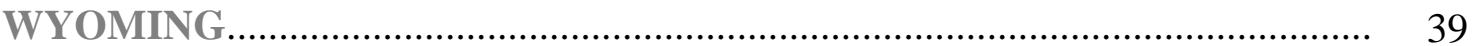

Burial Model Framework ............................................................................. 40

Buried Sites and Site Formation Processes in the Powder River Basin:

Definition, Discovery, and Preservation Issues ………………………......... 42

Factors Affecting Site Discovery: Plan View Versus Profile ........................ 42

Site Formation and Destruction Processes................................................... 44

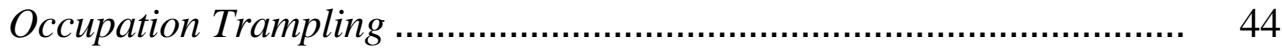

Post-Occupational Dispersal ............................................................ 45

Burial Dispersal ....................................................................... 46

Post-Burial Dispersal ........................................................................ 46

Description of Project ................................................................................. 47

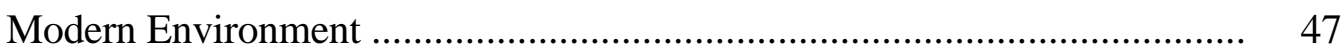

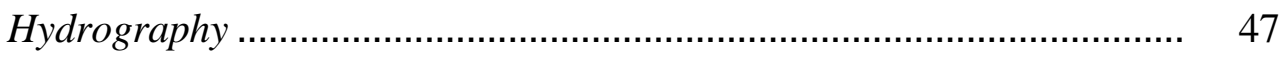

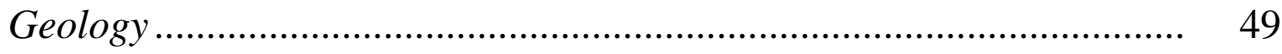

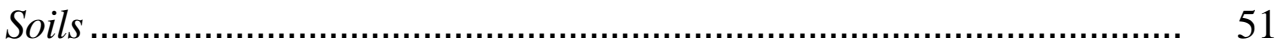

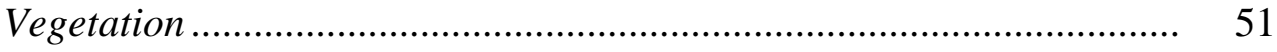

Climate

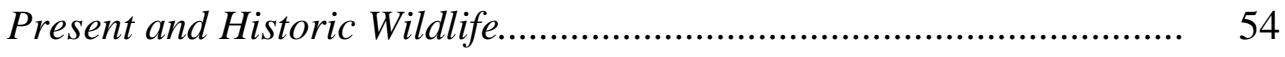

Patterning of Surface Geology and Soils in the Project Area ............................ 54 
Bedrock and Residuum ....................................................................... $\quad 57$

Exposed Bedrock ......................................................................... 57

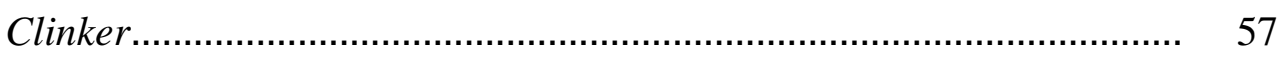

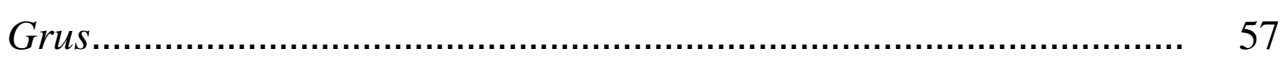

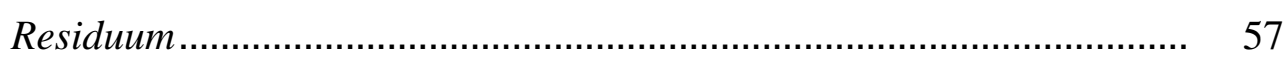

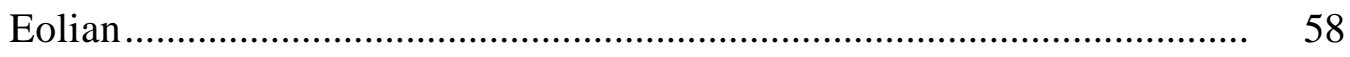

Eolian Sand …….................................................................. 58

Glacial and Proglacial.......................................................................... 58

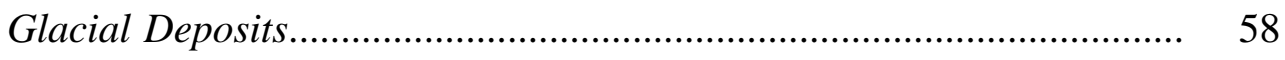

High Energy Mass Wasting .................................................................... 58

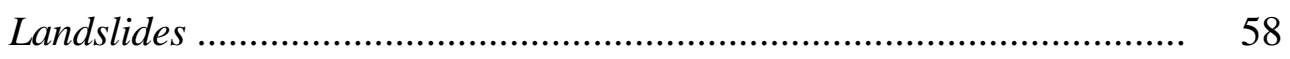

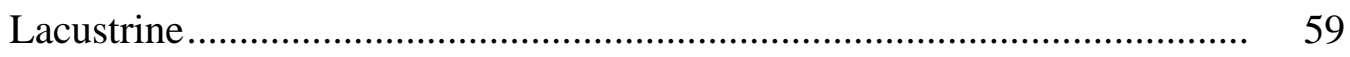

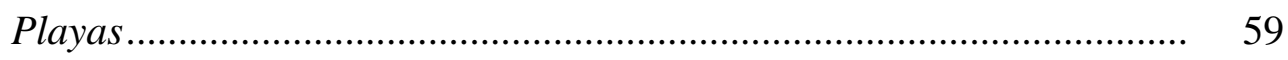

Piedmont and Bench Alluvium............................................................... $\quad 59$

Alluvial Fans ................................................................................ 59

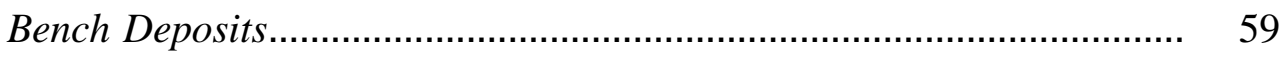

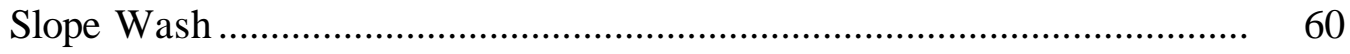

Slope Wash and Colluvium ............................................................. 60

Valley Alluvium.................................................................................... $\quad 60$

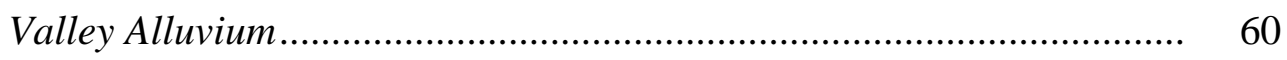

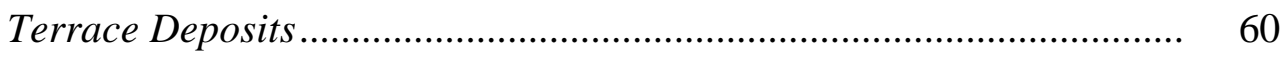

Dissected Terrace Deposits ............................................................. $\quad 60$

Shallow Terrace Deposits ................................................................. 60

Valley Bottom Deposits ............................................................................. 61

Powder River Basin Alluvial Model......................................................... $\quad 61$

The Leopold and Miller Model ........................................................... 61

The Alluvial Sequence in the Eastern Powder River Basin ................... 65 
Significance of Alluvial Models for the Present Project....................... 65

Sensitivity Modeling of Valley Bottom Deposits ............................................... 66

Stream Buffering Using Sample Streams .................................................... 66

Stream Buffer Models: Mana gement and Analytical ................................ 69

Management Stream Valley Buffers..................................................... 69

Analytical Stream Valley Buffers ...................................................... $\quad 70$

Sensitivity Modeling for Non-Valley Locations ................................................. 71

Scale of Soil Map Data ..................................................................... 72

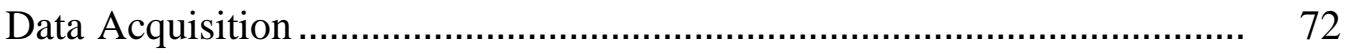

Sensitivity Considerations ......................................................................

NRCS Data Categories ....................................................................... 73

Map Units...........................................................................

Depth to Bedrock …………………………………………...... 75

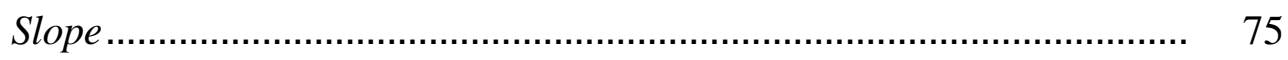

Soil Taxonomic Classification ……………………………….......... 75

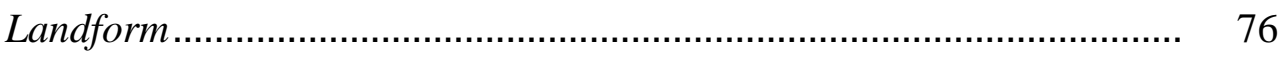

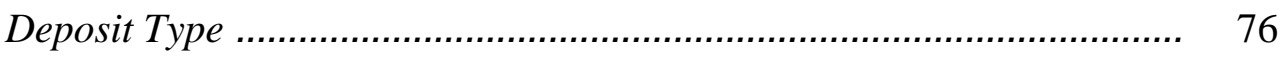

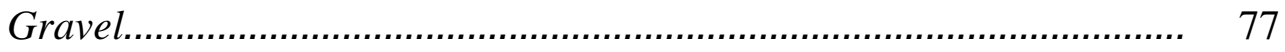

Cobbles and Boulders ……………………………………….... 77

Archaeological Landscape Sensitivity Outline ……………………………... 77

Summary of Four Sensitivity Models ……………….................................... 80

Evaluation of Sensitivity Models Using WYCRO Data ................................... 84

Cultural Resources Management Recommendations for Sensitivity Zones ....... 98

Very High Sensitivity Zone ……………………………………......... 98

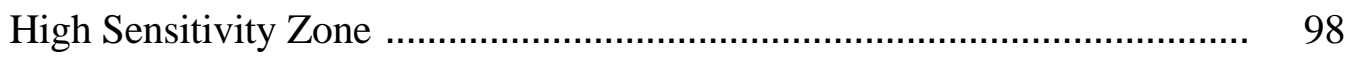

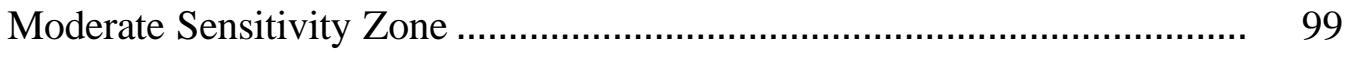

Low Sensitivity Zone ……...................................................................... 99 
Very Low Sensitivity Zone …………..................................................... 99

Maintaining the Model................................................................................. 100

Adjust Process.................................................................................... 101

\section{CHAPTER 5}

CULTURAL RESOURCE MANAGEMENT APPLICATIONS ..................... 103

\section{CHAPTER 6}

RESULTS AND DISCUSSION .............................................................. 107

Accomplishments within Wyoming ………………...................................... 107

Relevance to Wyoming Energy Development ………………………...... 108

Forecast Models - Implementing and Using the Buried Deposit Model............ 111

\section{CHAPTER 7}

CONCLUSIONS: FUTURE DIRECTIONS FOR MANAGEMENT AND

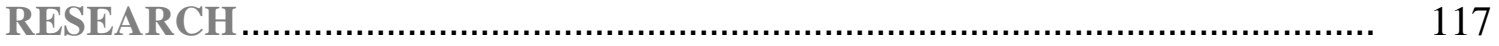

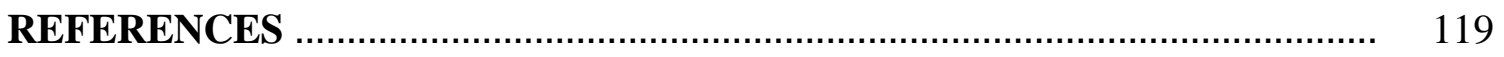

ACRONYMNS

APPENDIX A: DIGITIZING MANUAL

APPENDIX B: FIELD PROTOCOL HANDBOOK

APPENDIX C: FIELD OBSERVATIONS

APPENDIX D: CRISP USER MANUAL

APPENDIX E: PROJECT TRACKING MANUAL

APPENDIX F: LIST OF PRESENTATIONS 



\section{LIST OF FIGURES}

Figure 1. New Mexico and Wyoming project areas ................................................. 1

Figure 2. Map illustrating the extent of the Powder River and Tongue River hydrological sub-basins in northeastern Wyoming ..................................... 3

Figure 3. Wyoming Web queries by year from 2000-2004 …................................... 12

Figure 4. Diagram of WYSHPO Cultural Resources Information System ................... 14

Figure 5. Screen shot of the "General" site tab of the WYCRIS DOE PUMP III site

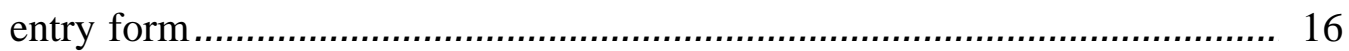

Figure 6. Work history section of WYCRIS database ............................................ 17

Figure 7. Age matrix section of WYCRIS database ............................................... 18

Figure 8. Prehistoric artifact encoding form in the WYCRIS database......................... 18

Figure 9. Prehistoric feature encoding form in the WYCRIS database ........................ 19

Figure 10. Number of sites with buried components ………....................................... 20

Figure 11. Distribution of stone circle sites in study area........................................... 25

Figure 12. Distribution of sites with ceramic artifacts ................................................ 26

Figure 13. Distribution of Paleoindian sites within the study area ................................. 27

Figure 14. Previous WYCRIS Internet mapping server user interface ............................ 29

Figure 15. Current WYCRIS Internet mapping server user interface ……………....... 30

Figure 16 Digitized projects and sites user interface with customized tools .................. 32

Figure 17. ArcMap customized site and project attribute tool....................................... 33

Figure 18. Cultural resource site GIS attributes form................................................ 34

Figure 19. Horizontal position accuracy field ………............................................... 34

Figure 20. Horizontal position source field ……….................................................. 35

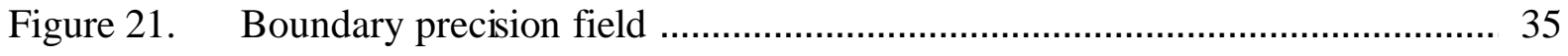

Figure 22. Notes field (digitizing comments) …………………………………..... 35

Figure 23. Adaptive management flow chart............................................................ 39

Figure 24. Map of the project area illustrating its location in the Powder River and Tongue River basins, northeastern Wyoming ................................................ 41

Figure 25. Map illustrating the extent of the Powder River and Tongue River hydrological sub-basins in northeastern Wyoming ........................................ 48

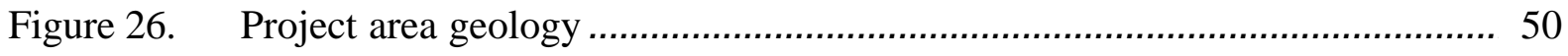


Figure 27. Tertiary bedrock geology of the Powder River and Tongue River basins showing axis of Powder River structural basin ..................................... 52

Figure 28. Map (1:500,000) illustrating the distribution and composition of soil-map units classified by soil taxon groups................................................... 53

Figure 29. Surface geology map of the Powder River and Tongue River basins ............ 55

Figure 30. Schematic cross section of the study area illustrating topography and

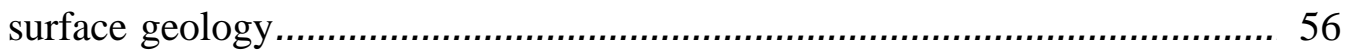

Figure 31. Schematic cross section of typical stream valleys in the Powder River and Tongue River basins illustrating relationships between Late Quaternary alluvial deposits and landforms

Figure 32. Map of drainage networks in the Powder River and Tongue River basins showing stream orders, gradient classes, and lakes

Figure 33. Map illustrating steam buffers created for the risk-sensitivity model for the

Powder River and Tongue River basins

Figure 34. Soils mapping availability for SSURGO (1:24,000 base soil mapping) soils data

Figure 35. Sensitivity map based on STATSGO (1:250,000 base soil mapping) and stream buffers

Figure 36. Sensitivity map based on SSURGO (1:24,000 base soil mapping) and stream buffers

Figure 37. Side-by-side comparison of SSURGO and STATSGO (1:24,000 and 1:250,000 base) sensitivity maps 82

Figure 38. Area in hectares by sensitivity class for each model for total study area ....... 84

Figure 39. Percent sensitivity class for each model for total study area ....................... 85

Figure 40. Inventoried area in hectares of sensitivity classes for each model ............... 86

Figure 41. Percent inventoried area of sensitivity classes for each model ................... 87

Figure 42. Number of sites by sensitivity class for each model …............................. 89

Figure 43. Number of sites with reported buried components by sensitivity class for each model.

Figure 44. Percent of sites with reported buried components by sensitivity class for each model 
Figure 45. STATSGO management sensitivity model with known buried

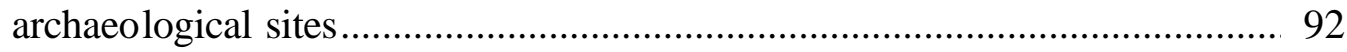

Figure 46. Percent of sites with surface component only ....................................... 93

Figure 47. Number of sites with radiocarbon dates by sensitivity class for each model ................................................................................... 94

Figure 48. Percent of sites with radiocarbon dates by sensitivity class for each model 95

\section{LIST OF TABLES}

Table 1. Number of sites with buried components ......................................... 20

Table 2. Occupation churn zone thickness and predicted archaeological implications ... 45

Table 3. Summary of Leopold and Miller alluvial model for the Powder River Basin... 64

Table 4. Summary characteristics for sensitivity classes .................................... 83

Table 5. Area in hectares by sensitivity class for each model for total study area ......... 84

Table 6. $\quad$ Percent sensitivity class for each model for total study area ......................... 85

Table 7. Inventoried area in hectares of sensitivity classes for each model .................. 86

Table 8. Percent inventoried area of sensitivity classes for each model....................... 87

Table 9. Number of sites by sensitivity class for each model ................................... 89

Table 10. Number of sites with reported buried components by sensitivity class for

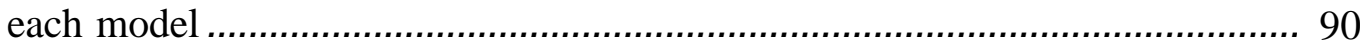

Table 11. Percent of sites with reported buried components by sensitivity class for

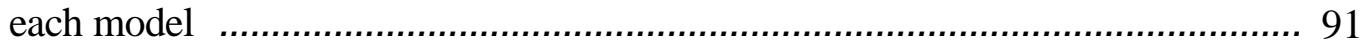

Table 12. Percent of sites with surface components only .......................................... 93

Table 13. Number of sites with radiocarbon dates by sensitivity class for each model.... 94

Table 14. Percent of sites with radiocarbon dates by sensitivity class for each model ..... 95

Table 15. Summary table of study area archaeological characteristics by sensitivity class for each model........................................................................... 96 



\section{CHAPTER 1}

\section{INTRODUCTION}

In 2002, Gnomon, Inc., entered into a cooperative agreement with the U.S. Department of Energy (DOE) National Energy Technology Laboratory (NETL) for a project entitled, Adaptive Management and Planning Models for Cultural Resources in Oil and Gas Fields in New Mexico and Wyoming (DE-FC26-02NT15445). This project, funded through DOE's Preferred Upstream Management Practices grant program, examined cultural resource management practices in two major oil and gas-producing areas, southeastern New Mexico and the Powder River Basin of Wyoming (Figure 1). The purpose of this project was to examine how cultural resources have been investigated and managed and to identify more effective management practices. The project also was designed to build information technology and modeling tools to meet both current and future management needs.

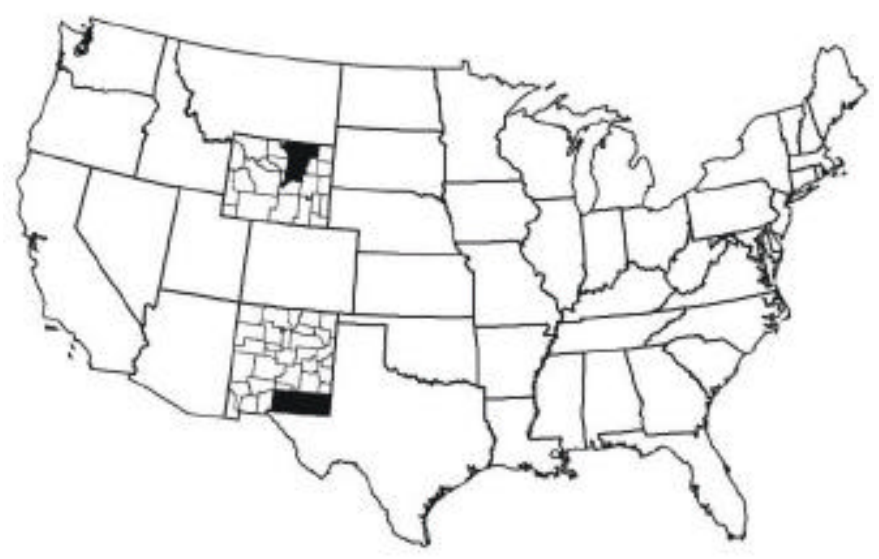

Figure 1. New Mexico and Wyoming project areas

Gnomon, Inc., served as the managing partner in a consortium effort that involved many other firms and agencies. Our primary partnerships included: the Wyoming State Historic Preservation Office (WYSHPO), and Western GeoArch Research, the SRI Foundation, the New Mexico Historic Preservation Division (NMHPD), Statistical Research, Inc., and Red Rock Geological Enterprises. The Bureau of Land Management state offices in Wyoming and New Mexico, the Carlsbad and Las Cruces Field Offices (New Mexico), and the Buffalo, Worland, Kemmerer, and Casper field offices were federal partners. The oil and gas commissions, oil and gas industry associations, and specific energy firms were helpful collaborators. 
Early on, this project was given the shorthand designation "PUMP III" in reference to the funding source - the third round of PUMP grants. Like most nicknames, "PUMP III" seems to have become a permanent label despite our best efforts to find some other, more descriptive name. And at that, it is probably a big improvement over the alternative, which would most likely have been some unpronounceable acronym, using the first letters of the formal project title: AMPMCROGF? PUMP III it is!

\section{The Wyoming Component}

The project area for the Wyoming component of the PUMP III project encompasses the Wyoming portion of the Powder River and Tongue River hydrological sub-basins (Figure 2). Both drainages are tributaries to the Yellowstone River. Bounding drainage basins include the North Platte River to the south, Cheyenne River to the southeast, Belle Fourche to the east, Little Missouri to the northeast, Little Bighorn River to the north, Bighorn River to the west, and Sweetwater River to the southwest.

The current report highlights the work completed in the Wyoming component of the project. It includes:

1. Digitization of archaeological survey and site location information for the entire northeastern corner of Wyoming, including areas outside of the Powder River and Tongue River sub-basins. These records are available through the Wyoming State Historical Preservation Office (WYSHPO) Cultural Records Office (WYCRO);

2. Predictive modeling of locations where the geology is suitable for the burial of prehistoric archaeological sites within the hydrological Powder River and Tongue River basins;

3. Development of web-based applications to enable integration of management, investigation, and decision-making using realtime electronic systems

4. Development of recommendations for the use of a risk model by potential categories of users to facilitate more predictable, efficient cultural resource compliance processes for oil and gas development, as well as better management of cultural resources. 


\section{POWDER-TONGUE RIVER DRAINAGE BASINS}

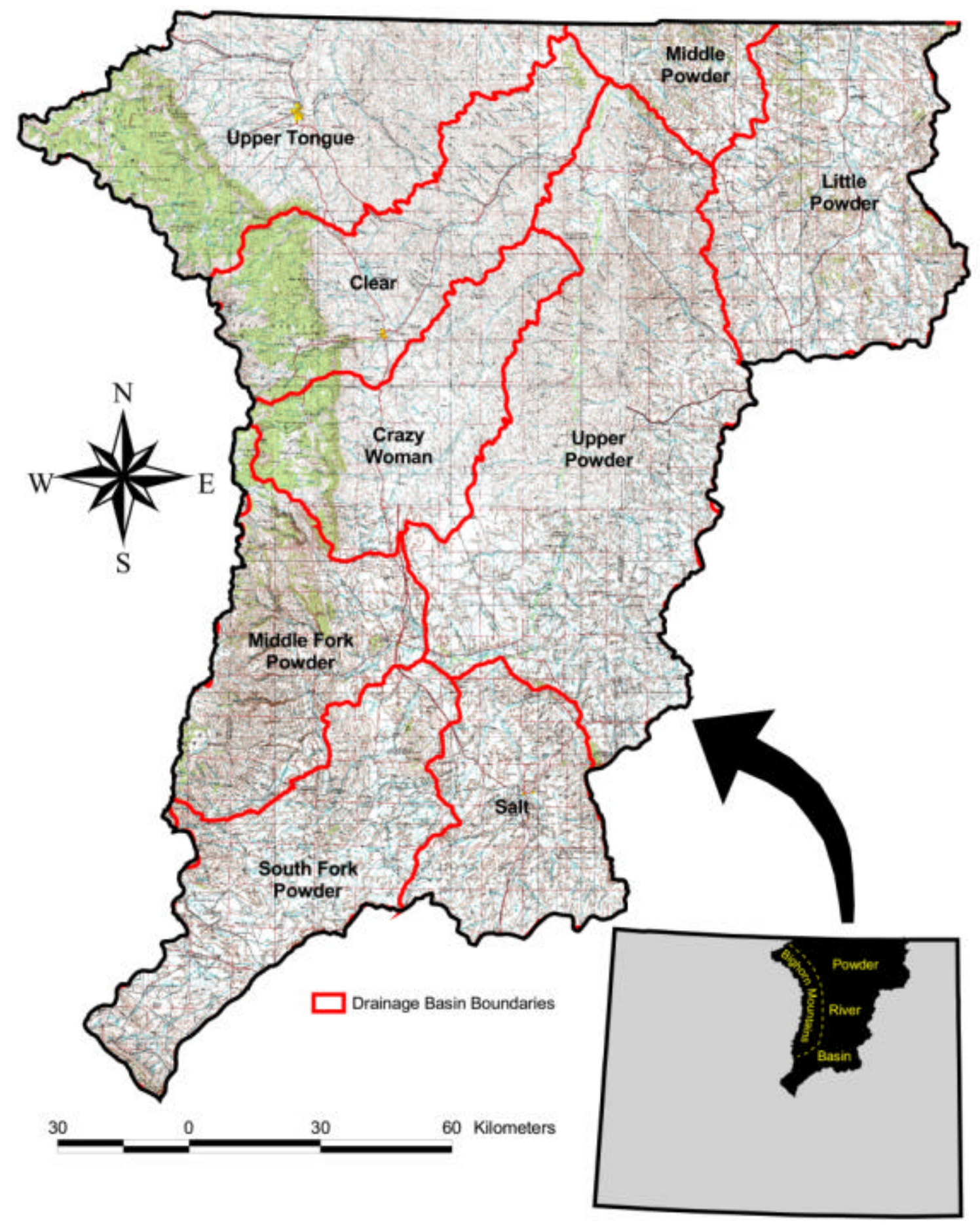

Figure 2. Map illustrating the extent of the Powder River and Tongue River hydrological sub-basins in northeastern Wyoming 


\section{Digitization of Archaeological Survey and Site Locations}

WYCRO digitized all archaeological projects for the eight counties within the study area boundary. A total of 12,660 new survey areas were entered into a geographic information system (GIS) for a total of 38,200 inventory spatial entities statewide. A total of 13,858 new site locations were entered into GIS for a total of 46,456 sites in GIS statewide. A total of 16,634 sites were encoded into the extensive site attribute database. This database was then used to test the geomorphological predictive model that was created by Bill Eckerle of Western GeoArch Research (see Chapter 4). Also, a total of 13,747 site forms were imaged into Adobe .pdf format for a total of 64,340 total imaged site forms statewide.

\section{Geoarchaeological Predictive Models}

Expanded development of energy resources in northeastern Wyoming brings with it the risk that archaeological sites are inadvertently damaged. Sites containing buried, intact, and well-preserved, archaeological material are some of the most scientifically important cultural resources within the project area. In such sites they contain all categories of data that contribute to the significance of surface sites, as well as a number of additional categories that surface sites lack. The level of management effort buried sites receive should be in proportion to their scientific importance. However, burial sites are difficult to find and manage due to a poor understanding of the geological and soil processes that lead to burial and preservation. This leads to poor predictions of which sites have potential for preserved and intact subsurface cultural materials. Consequently, some sites are subjected to more investigation than is warranted given the data categories they contain while other subsurface cultural levels remain undiscovered until they are destroyed or are unearthed during construction activity. These outcomes lead to unexpected development costs from construction and production delays, as well as loss of valuable scientific information.

Having identified the potential problem, this report presents a geoarchaeological model that predicts the location of deposits that might contain buried and intact archaeological material. This model informs the user who wants to know if a particular known site is located within an area where the burial of subsurface cultural material is possible. Likewise, the model informs the user that certain landscapes have the geological qualities conducive to site burial. If applied properly, then this burial model will lead to more efficient management of cultural resources so that both resource preservation and energy extraction are facilitated.

The proposed model will need to be implemented within the Section 106 process by land management agencies in order to achieve its potential. In anticipation of this implementation, we suggest how to monitor, evaluate, and adjust the model so that it might fulfill its function under changing development scenarios. 


\section{Web-Based Applications}

Currently, the investigation-decision-management process for actions like Applications for a Permit to Drill (APDs) is mostly completed by filling out paper forms. A consultant originates the document, the federal agency reviews the document and its findings, then the SHPO may review and comment, and only then will a finding be made on the undertaking (e.g., an APD) itself. In Wyoming, for example, the transit time from fieldwork to presence in the data system may require three months or more.

Gnomon developed an information management system that both mirrors the flow of paper documents and improves upon it. The greatest value of this Cultural Resources Management Tracker (CRMTracker) is to save time through a shared database application accessible via a secure Internet connection. CRMTracker efficiently captures the inventory and associated resources suite of data early in the process and provides online access to this information back to the project applicant.

Another web-based management tool Gnomon developed for the Wyoming component of the project is the Cultural Resources Information Summary Program (CRISP.) CRISP is an information tool for non-archaeological experts. It is useful for rapid assessment of potential project areas (PPAs). A PPA could be a contemplated well pad and road, a borrow pit, or any other action. Using CRISP, one draws a PPA on to a map image and then runs a report on the PPA. CRISP is a web-based application, and uses cultural resource inventory layers, cultural resource summary layers, and cultural resource forecasts (models) to provide the user with a summary of knowledge about their PPA.

CRISP is a planning tool for land-users and managers. It does not replace consultation with appropriate agencies, landowners, land managers, and other participants in the cultural resource management process. Although CRISP summarizes the results of scientific investigations, it also does not replace discussions with cultural resource managers or other experts. What CRISP does provide is a way to gain a quick overview of what might be present on or in the ground, and information about what is already known. CRISP's greatest utility is as a project planning tool. It is not a compliance tool.

\section{Management Recommendations}

In the past all Section 106 applications have been evaluated in the same manner, no matter where in the state the project was proposed. The result of the work completed in this project recommends varying the application process and mitigation requirements based on information provided by the geoarchaeological model. Those areas where there is a high probability of encountering buried archaeological sites could be either avoided by the developers using the new web-based tool and sensitivity model, or could require different mitigation from those sites located in areas with a low prediction of finding buried resources. The use of the web-based tools and the predictive model has the potential to save both dollars and time for oil and gas developers. 



\section{CHAPTER 2}

\section{INFORMATION TECHNOLOGY AND CULTURAL RESOURCE MANAGEMENT}

\section{The Current Situation in Powder River Basin of Wyoming}

According to the Bureau of Land Management (BLM), approximately 21,100 coalbed natural gas wells have been drilled in the Powder River Basin (PRB) since 1996. Over $23 \%$ or 4,100 of these wells are on federal lands and another $77 \%$ or 13,400 are on private fee lands where the surface ownership is private and the minerals are federal, otherwise referred to as split-estate. The Wyoming Oil and Gas Commission anticipates an additiona1 10,000 wells will be developed in the next two years in the PRB. BLM reports that during the last two years, 673 billion cubic feet of natural gas have been produced from coalbed natural gas (CBNG) wells. This constitutes $44 \%$ of all natural gas produced in Wyoming during this same timeframe, with over $\$ 440$ million dollars in federal mineral royalty being generated.

In 2004, the Buffalo Field Office of the BLM approved 2,383 CBNG APDs for new wells. This single field office's number of approved APDs exceeds the total actions handled by many other western states. Minimizing the impact of this development on cultural resources as well as aiding in efficient compliance with the National Historic Preservation Act is a goal of this project. Under the current administration's National Energy Policy, Wyoming plays a key role in producing natural gas, coal, traditional oil resources, and electricity for the nation. Additional methods employed for enhanced mineral extraction in the state are being touted. Enhanced oil recovery and the development of new technologies will continue to be developed and pursued. Historic oil fields, National Register eligible sites themselves, are located within the eight county study area. Salt Creek and Teapot Dome oil fields are some of the earliest developed areas in Wyoming and have played a historic role in the nation's energy development. In addition, the Teapot Dome field is associated with the federal bribery scandal of 1922 which rocked the developing Wyoming petroleum industry for a number of years. Sparsely populated, yet key to America's economy, Wyoming's Powder River Basin is again at the forefront of America's energy needs.

\section{Information Technology Goals}

One of the project goals was to make information more readily available to all interested parties in a timely manner in this active oil and gas producing area of America. The AMP study examines how resources are managed in light of the information that is known about the $\mathrm{m}$. This chapter examines technologies that convey information into the practice of archaeological resources management as it is currently performed and as it might be transformed in the future. We also discuss how information technology was used in the project analytical and management studies. 
The term "information technology" has come to mean digital data storage, query, and display in a wide variety of ways. This digital meaning of the term "information technology" is overly limiting in the context of cultural resource management. Cultural resource experts and managers utilize many forms of information that are not digital in any comprehensive way. These information forms include paper records and maps, traditional photographs, documentary sources, experience in the field and laboratory, artifact assemblages, and a considerable body of person to person communications both formal (e.g., professional presentations) and informal (e.g., professional discourse). Although we cannot address all of these different forms of information in anything like a comprehensive fashion, it is important to remember that "information technology" in its digital sense (which we shall refer to as "IT" throughout the chapter) is only one of several important information technologies.

The link between sound information and sound management and decision-making is so well known as to be a truism. Truisms are nonetheless true for being shop-worn, however, and in archaeology a high value has always been placed on sound sources of information. Fieldwork and decision-making are greatly facilitated by reliable information. For instance, archaeological fieldwork is guided by a series of questions that can often be answered by sound information:

- Where have investigations been performed already?

- What did prior investigations find?

- How reliable are the findings?

If these questions can be answered well, then the fieldworker has more secure answers to some important operational questions:

- Where does one need to look for new, undiscovered, resources?

- What sorts of archaeological materials are likely to be encountered?

- What level of effort will a new investigation require?

Until recently, these questions were answered using paper maps and records. So long as these were comprehensive and up-to-date, they worked very well. Paper records, especially large format maps, are not necessarily difficult to keep, but they are very limited in their distribution. Most paper archives of archaeological investigation and resource information are unique collections of materials that must be visited to be used. Travel costs and the time it takes to conduct research that is usually geographic in extent in records that are filed by date (e.g., site records are filed in sequential order regardless of site location) make the use of paper archives expensive. Digital information technology addresses many of these problems because it allows records (and maps) to be retrieved in many different ways: geographically, by index number, by information attributes or content, and by combinations of these methods. Digital information provides for overall increased efficiency for researchers. 


\section{WYSHPO Technology Goals}

WYSHPO had several technology goals in this project. First, they wanted to create cultural resource information that is readily accessible and available to a variety of users and land managers. A major component of the project was to update the cultural resource database. Knowing where resources have been sought in the area, where they have been located, what is the current regulatory status of the resource, and how resources fit into or have the potential to address contextual or research questions in the future are all desired information system components. Before completion of this project, information was tedious to compile. Using the new applications developed during this project (which are described in Chapter 5) along with the updated database has made information searches much easier and quicker. The updated database was also used to confirm the modeling component of the project and is available for future research and context development.

WYCRO also wanted to update and improve their Wyoming Cultural Resource Information System (WYCRIS), which is described in detail in Chapter 3. During this project WYSHPO and Gnomon worked together to develop the final parts of a fully developed cultural resources information system.

GIS creation tools were also developed for use by BLM field office staff in ESRI ArcGIS 8.3, upgrading their previous entry tool from ESRI ArcView 3.3. This upgrade allows for much more efficient updating of the statewide GIS as it reduces data entry errors, reduces the possibility of users making changes to the underlying data structure, and ensures values in the table have a presence in the master WYCRIS information system. Security of WYCRIS was also a project goal. With funding provided by BLM, a CISCO firewall was installed for the WYCRO group. The firewall is configured and administered by the University Wyoming Information Technology Section (UW IT) and is similar and compatible with other systems on campus. Being housed within a university environment has its pros and cons: systems analysts are readily available to aid campus users, but university students are notorious for attempting to infiltrate campus computer systems. The firewall protects the system from intruders, but it also prevents the possibility of our systems being exposed to other campus users. UW IT has set our group to be invisible on the campus network.

One information technology goal has not been met: installation and implementation of ESRI ArcSDE (spatial database engine). One reason is that the current ability of the WYCRO to maintain and administer such a system is not clear. Assessment of the needed resources and long-term costs to WYCRO will need to be completed. The advantage to using ArcSDE in WYCRO is that it would allow for the use of an enterprise geodatabase rather than numerous personal geodatabases. An enterprise geodatabase allows multiple users to check out "versions" of a GIS master dataset and return them to the master GIS. Personal geodatabases require administration in order to merge edited copies into one master file.

This implementation could be duplicated within the BLM field offices for staff use, but this possibility needs to be first assessed. Due to the BLM's wide area network, the 
available bandwith for this product might not be adequate and security issues would need to be addressed as well. Within the WYCRO network, ArcSDE would be an optimal configuration, because updates and additions to the information would be immediately available to all staff and the ability to version the dataset would be an advantage.

However, the current server capacity is maximized and disk space will need to be added. The use of Microsoft Sequel Language (MSSQL) Server with ArcSDE will require inhouse staff expertise or contracted services to maintain the GIS with the relational database. User level access and security in ArcSDE will need to be administrated locally and when data conflicts arise, an administrator will be needed to resolve the issue.

Currently WYCRO staff have not received training on ArcSDE nor on MSSQL Server. ESRI (the primary software manufacturer of GIS software) recommends a thorough knowledge of MSSQL Server prior to their training on ArcSDE. As the master geodatabase continues to grow, the WYCRO will be faced with the task of implementing ArcSDE due to the size limitations of personal geodatabases (2GB). Another option would be to contract for this technical service for a long-term period. Day-to-day administration of this system, once established, should not require a tremendous amount of administration. At this point, the use of enterprise geodatabases in SHPO offices is very limited, and may not be in use at all. The implementation of this technology in BLM is also limited. The most aggressive implementation of ArcSDE in Wyoming has been undertaken at the Wyoming Geographic Information Sciences Center (WYGISC) in supporting generally static datasets served in ArcIMS. They have not been using this to administer a production dataset, which is updated on a per each user keystroke. It would be optimal to have a strong local user community or another SHPO office implement this technology prior to the WYCRO implementation so that there would be an available support base. 


\section{CHAPTER 3}

\section{OVERVIEW OF WYOMING CULTURAL}

\section{RESOURCE INFORMATION SYSTEM (WYCRIS)}

Pursuant to state and federal law and in conjunction with data sharing agreements, the Wyoming Cultural Records Office (WYCRO) maintains a comprehensive statewide information system for cultural resources regardless of land status. This function was established by the Smithsonian Institution in the early 1940s, passed to the Wyoming Archaeological Society (WAS), then to the University of Wyoming, Department of Anthropology, and in the late 1970s became part of the Wyoming State Historic Preservation Office (WYSHPO) per requirements of the National Historic Preservation Act (NHPA). Before the NHPA, many Wyoming citizens felt this information was important to compile, maintain, make accessible for academic research, and preserve for future generations. The Wyoming State Archaeologist's Statute (§ 36-4-106.d) enacted in 1967 specifies this collection be "permanently deposited at the University of Wyoming." Other policy and agreement documents have affirmed this arrangement.

During the past decade, the WYCRO has worked toward creating sophisticated electronic data systems for the efficient management and distribution of cultural resources information. The implementation of a more robust information system has been done via a phased implementation approach. The first phase was to redesign the 1970s version of the database into a relational system and post the information on a secured Internet website. This was completed in the fall of 1999. Next was the integration and redesign of the Historic Preservation Section 106 compliance dataset. GIS technologies were piloted in southwestern Wyoming using ESRI's ArcView shapefile format in 2000.

Through the current DOE sponsored project, significant additional parts of the information system have been created and implemented. Custom mapping applications have been created to increase the quality and efficiency of managing cultural resource inventories and sites in the GIS. An upgrade to ESRI's personal geodatabase format has been used to better manage the extensive spatial data. The applications have also been transferred to all BLM field offices in Wyoming so data creation can be shared between the BLM and the SHPO. An extensive site attribute database was also created and implemented following the format of the Wyoming Cultural Properties Form, available at: http://wyoshpo.state.wy.us/shpoweb2002/2002webpages/cpforms.htm.

Over 16,000 sites have been entered into this system during the past two years through this project.

The Wyoming Cultural Resource Internet Map Server (WYCRIMS) was revised and upgraded during the project. Additional user tools were customized and the map interface was streamlined. On-line as well as on-site training was made available to users around the state of Wyoming and at the University of Wyoming. Overall, use of the 
WYSHPO website has increased 850 percent since 2000, with use more than doubling between 2002 to 2004 (Figure 3). Because of significant modifications and upgrades to the information available, including imaged site forms, private consultants, researchers, and federal agencies are using this information service on a day-to-day basis within their standard work process.

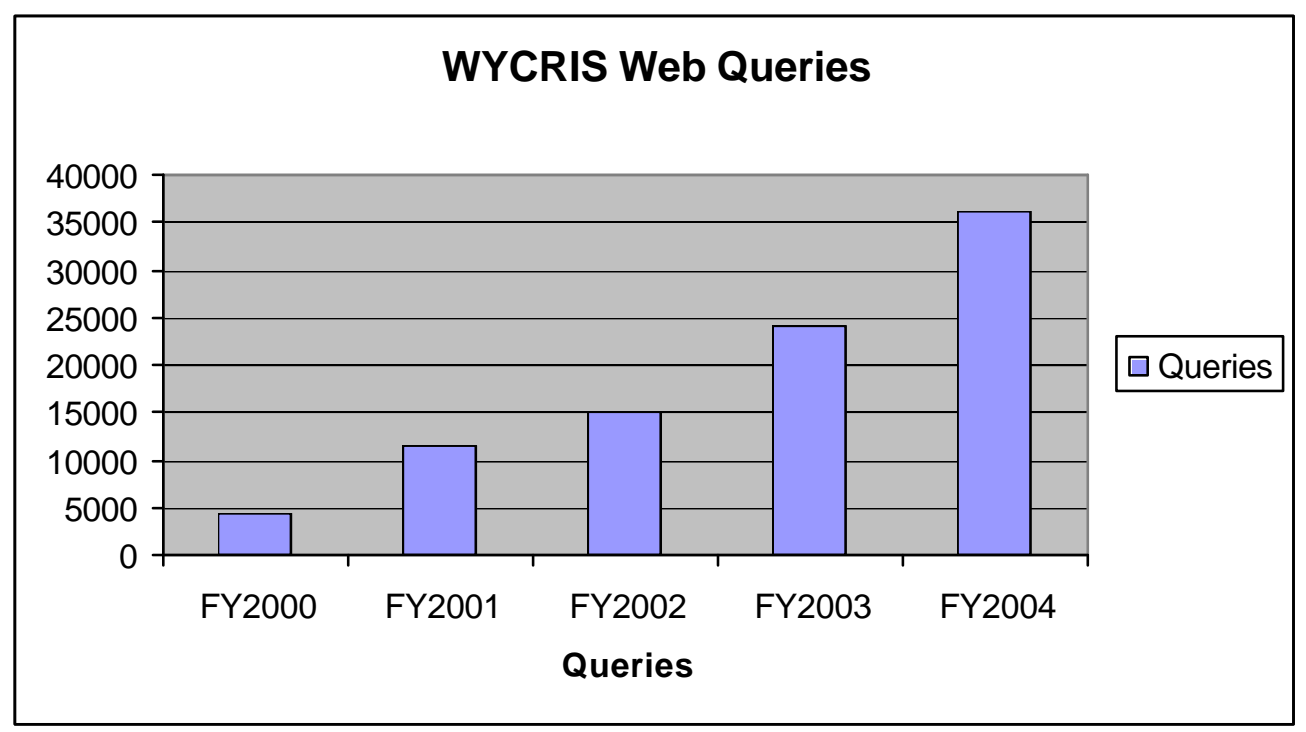

Figure 3. Wyoming web queries by year from 2000-2004

One of the most important tasks under this project was to create an Internet-based information tracking system for projects under Section 106 of the National Historic Preservation Act (NHPA). "Project Tracking" has been discussed in Wyoming, beginning in 1995, as a method to streamline the information system and reduce duplication of effort between private cultural resources consultants, the federal land managing agency, and the SHPO. It is anticipated this application will have a long-term effect on how information is managed and accessed. Because the implementation of this application is in its infancy, and many users are still adjusting to the change in their dayto-day workflow, the long-term benefit to the system is hard to quantify at this time. This truly is a paradigm shift for cultural resource consultants, federal agencies, and SHPO staff. Not only have day-to-day processes changed, but also the responsibility for information is now closer to the data creator. Private cultural resource consultants initiate the electronic record used by the federal agencies and the SHPO. We are still experiencing a learning curve among users and are making modifications of the application based on their comments.

Below is a diagram of the current configuration of the overall Wyoming Cultural Resources Information System (WYCRIS). It is a mixture of on-line systems as well as in-house databases. The datasets are interrelated and address different information needs for different types of uses. Some information systems are developed for the cultural resource professional, while others have been customized for planning and use by industry. Many of these information system parts provide or "feed" data to other parts. 
The items displayed in the diagram below (Figure 4) in blue were created, modified, or updated under this project. For example, CRMtracker provides information to both the WYSHPO RandC Database and the WYCRO2 database via a web-based interface. The relationships among these system parts are displayed in Figure 4.

At this time, the information modules are in place: the WYCRIS, which is comprised of the on-line systems, and the internal databases and GIS maintained by the WYSHPO and federal partners. Each part is in a different stage of development and use, yet the information system foundation has been created.

\section{Generating Datasets for the Modeling Project}

The creation of a fully integrated GIS for the project area allows for expanded analysis of the prehistoric and historic resources in the area. The development of archaeological burial models for the Powder and Tongue River Basins was created independently from the creation of the cultural resources GIS and site attribute tables. The sensitivity models are described fully in Chapter 4 and will not be repeated in this section. The following discussion is on the methods and results of queries run to test whether or not the sensitivity model is supported by the existing archaeological information.

After the soil sensitivity models were developed by William Eckerle et al. (see Chapter 4), WYCRO generated datasets of sites located within the Powder and Tongue River Basins (PRB/TRB). For the analysis, a site table was generated using ESRI's ArcMap 8.3, Microsoft Access, and Excel. Each site was assigned a sensitivity code based upon each of the four soil models to the major sensitivity class it fell within. The first query selected sites which fell within the highest sensitivity area. Those sites were then eliminated from the selection set. The next highest sensitivity class was queried and again sites were eliminated from the selection and so on. This method reduced the likelihood of sites being counted more than once in the model. All known prehistoric rock shelters were also removed from the site list. In general, rock shelters in the study area are found in the foothills and mountains in rocky terrain. These shelters generally contain subsurface deposits within the shelter itself, but the formations around these sites are not usually of the same depositional context. Consequently it was felt that their inclusion in the list would skew the results, and the model does not forecast rockshelter locations. The modeling effort does not attempt to locate anomalies of deposition or cultural remains, but attempts to determine locations where soils are of the correct age, energy regime, and type to contain in situ buried deposits have potential to exist. 
WYCRO2 Database

(system orig. 1978)

Project data, user information, billing application, technical assistance, master site tables, file search applications, used in on-line web searches

\section{WYCRIS GIS}

Spatial data - points, lines, polygons for sites (cultural resources) and inventories (surveyed space), districts, landscapes and transportation routes used

\author{
WYSHPO RandC Database \\ Section 106 review, site \\ eligibility status and \\ concurrence, review \\ correspondence, and mail logs
}

\section{CRMTracker \\ Automated project information on associated sites; Documents \\ Section 106 actions}

\section{CRISP}

Industry planning tool for cultural resource

management

\section{WYCRIS Site \\ Database}

Site content, time periods

represented, artifact types

and counts, feature types

and counts, buildings,

prehistoric rock art, work

history, site narrative

description, recording status

\section{WYCRIS On-line \\ Database \\ Provides access to databases and site forms to professional cultural resource specialists}

\section{WYCRIS IMS}

On-line access to cultural resources spatial data and site forms for professional cultural resource specialists

\author{
WYCRO Ledger \\ Master control center \\ for assigning site \\ numbers, tracking \\ resource ids (unique \\ numbers for sites), site \\ segments, districts and \\ landscapes
}

Figure 4. Diagram of WYSHPO Cultural Resources Information System 
Over 11,000 sites in the study area were entered into the WYCRIS database during this project. An additional 1,581 sites were included from a project conducted by the University of Wyoming, Department of Anthropology in 1991 entitled 12,000 Years of Hunting and Gathering in Northeast Wyoming by Marcel Kornfeld and Charles A. Reher. A customized MS Access database was created following the current Wyoming Cultural Properties form jointly developed by the WYSHPO, the professional archaeological consulting community, and federal agencies involved in cultural resource management in Wyoming. The 3.0 revision, developed during 2003, has been used for all Section 106 related projects since this time and many of the encoded resources follow the current format. Each site form was read and reviewed for information content and site attributes. The record developed is reported as a compilation of all previous recordings; for example, if the site was originally reported in 1989 and again in 2003, all associated features and artifacts were compiled into the one record.

The initial entry screen (Figure 5) is comprised of the general information for each resource and the source of the information. The site property category as defined in National Register Bulletin 15 along with the Smithsonian number is included in the header. Added to this data is a segment identifier for sites which have sub-parts, such as archaeological or historic districts, or sites with linear segments. This addition to the data structure allows for a direct linkage to the GIS database using the "resource id" number for each individual site. The status of the record, whether it is a first recording, a full rerecord, an update of parts of previous recordings, etc. is encoded. The "data profile" refers to the original encoding source for the record. "DOEPump3" records refer to everything encoded under this current project. Other profiles include "Moxa" or "CROW" records, which were other past data capture projects conducted by the SHPO and the University of Wyoming, Department of Anthropology. These records were brought forward to the current database so all encoded sites in the state can be easily accessed. The record also tracks the editing status, who originally created the electronic record, the last edit to the record, and whether or not the content has been verified for accuracy and quality. Data entry notes are included so any additional information pertinent to the site record can be captured and made available to users. 


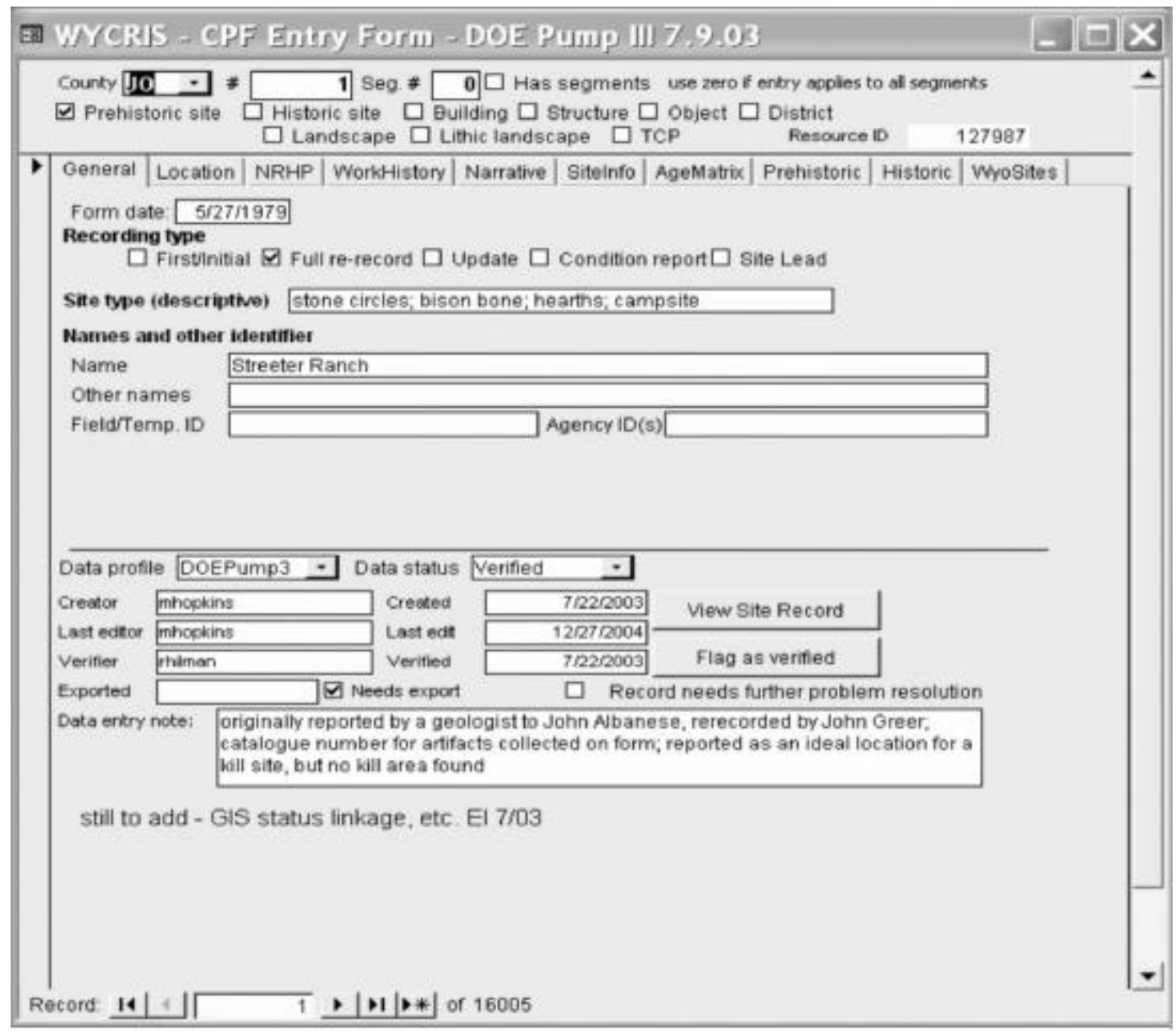

Figure 5. Scre en shot of the "General" site tab of the WYCRIS DOE Pump III site entry form

For this discussion, only a few of the database forms will be described. The other forms pertain to historic period sites, are narrative forms, or are links to other parts of the information system. The "Work History" section of the database collects the most current recording dates and name of the most recent investigator of the site (Figure 6). The context in which the site was originally recorded and what work has been done on the site is described. The section indicating whether the site was discovered on the surface, revealed subsurface, or during construction is used in the modeling queries. Only 18 sites in the entire study area had been discovered in a subsurface context. 


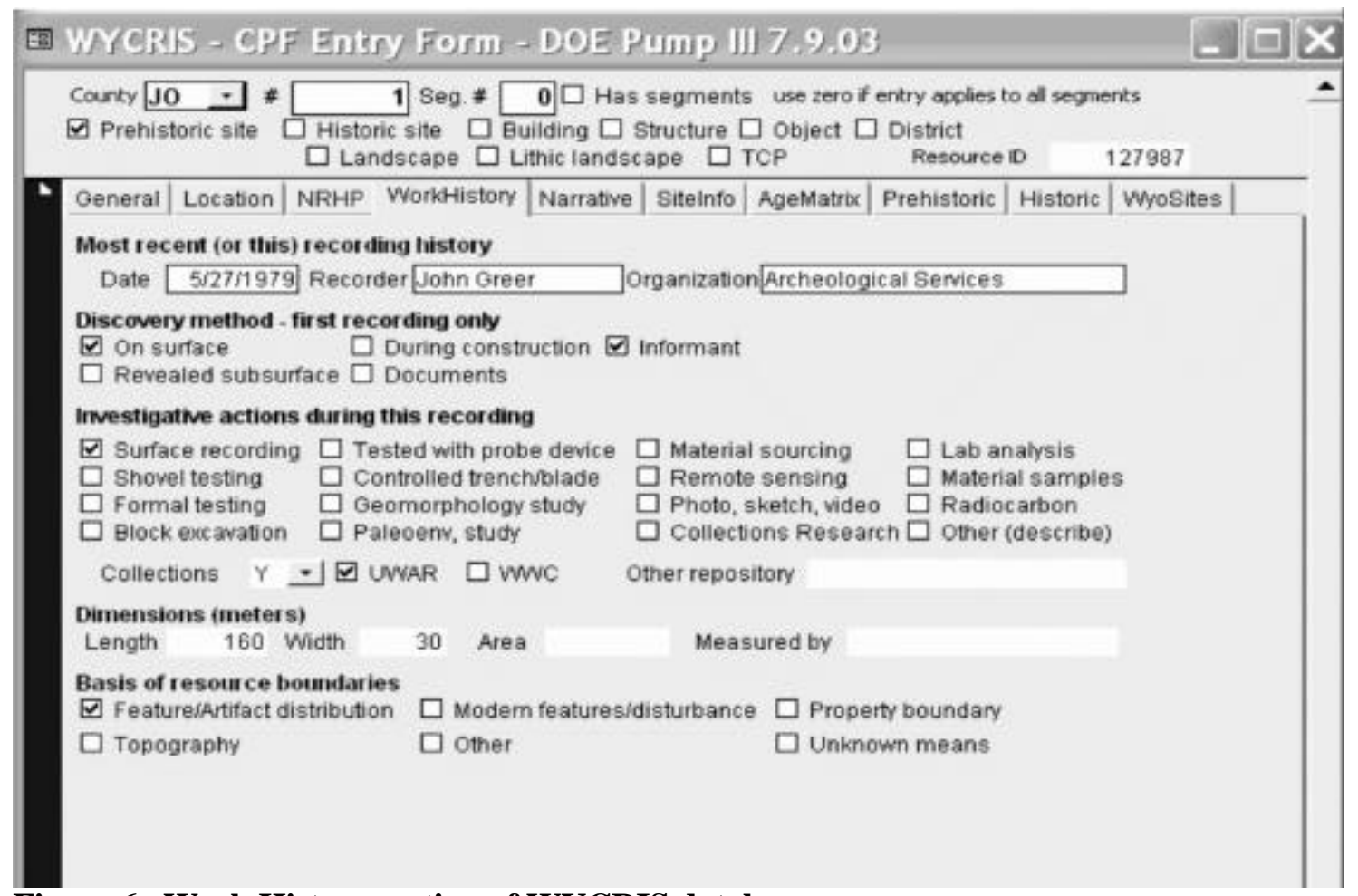

\section{Figure 6. Work History section of WYCRIS database}

The original database designed in the late 1970s was limited to 172 characters of ASCII text. This limited programmers to a very minimal set of site attributes. Other database revisions which occurred in the 1980s did not incorporate information on site content or associated time periods. The addition of a user-friendly temporal description of a particular resource has been a goal of this project. The "Age Matrix" tab (Figure 7) allows the user and encoder to quickly identify all known time periods represented on the site, if they are surface or subsurface manifestations, and if they are represented by artifacts or features. Because prehistoric rock art and historic buildings are important archaeological and historic features, these are included so the user can immediately identify their presence on site. This set of attributes was used for the queries to test the sensitivity models (see Chapter 4).

Prehistoric and historic assemblage data was collected for the project area. Types of artifacts and features, many with associated counts if available, are encoded into the database (Figure 8). The total estimated assemblage size is a useful attribute for determining site artifact densities along with the spatial extent or area of a site. 


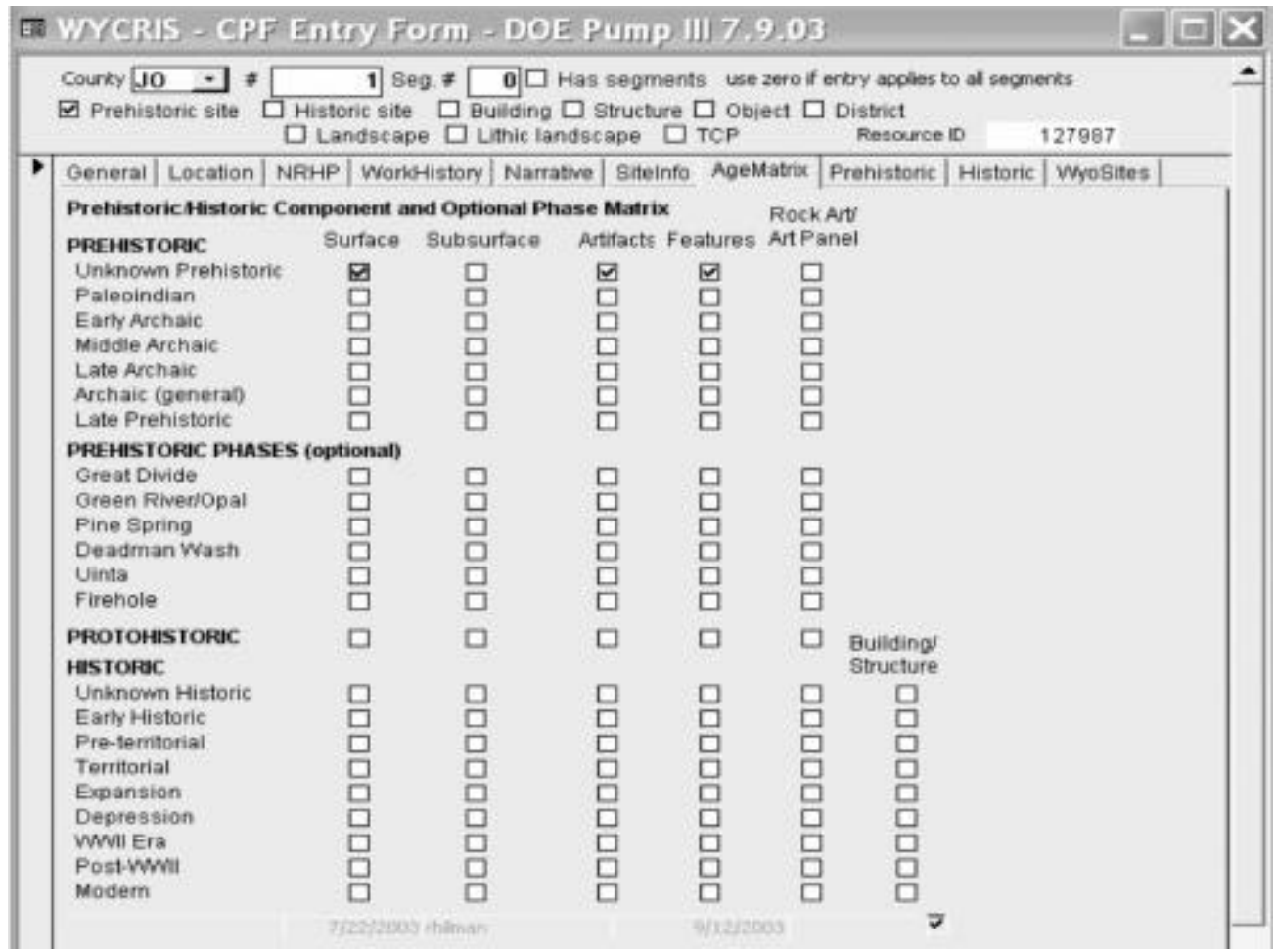

Figure 7. Age matrix section of WYCRIS database

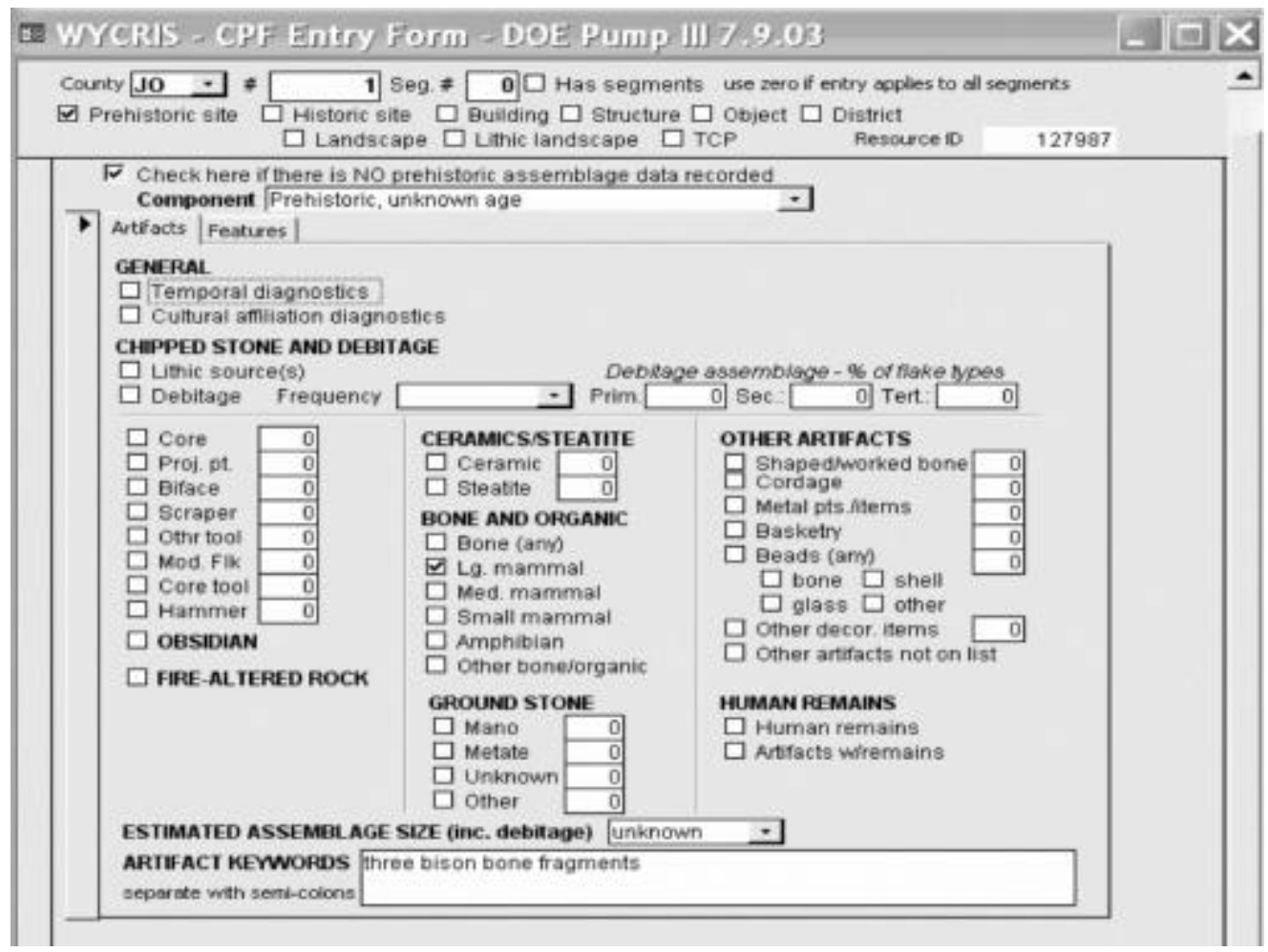

Figure 8. Prehistoric artifact encoding form in the WYCRIS database 
Feature information (Figure 9) is also encoded to indicate types and counts of prehistoric features present. Up until this project, this information was almost impossible to quickly access. In previous studies conducted by graduate students, this type of information would require a long process of reviewing the paper documents. This tabulated information will be made available to land managers, cultural resource professionals and academic researchers and should reduce the tedious work to synthesize and compile archaeological information for a particular area of the state. Future revisions and updates of land management plans and historic contexts on specific cultural resources will be done more efficiently and produce more accurate and complex information.

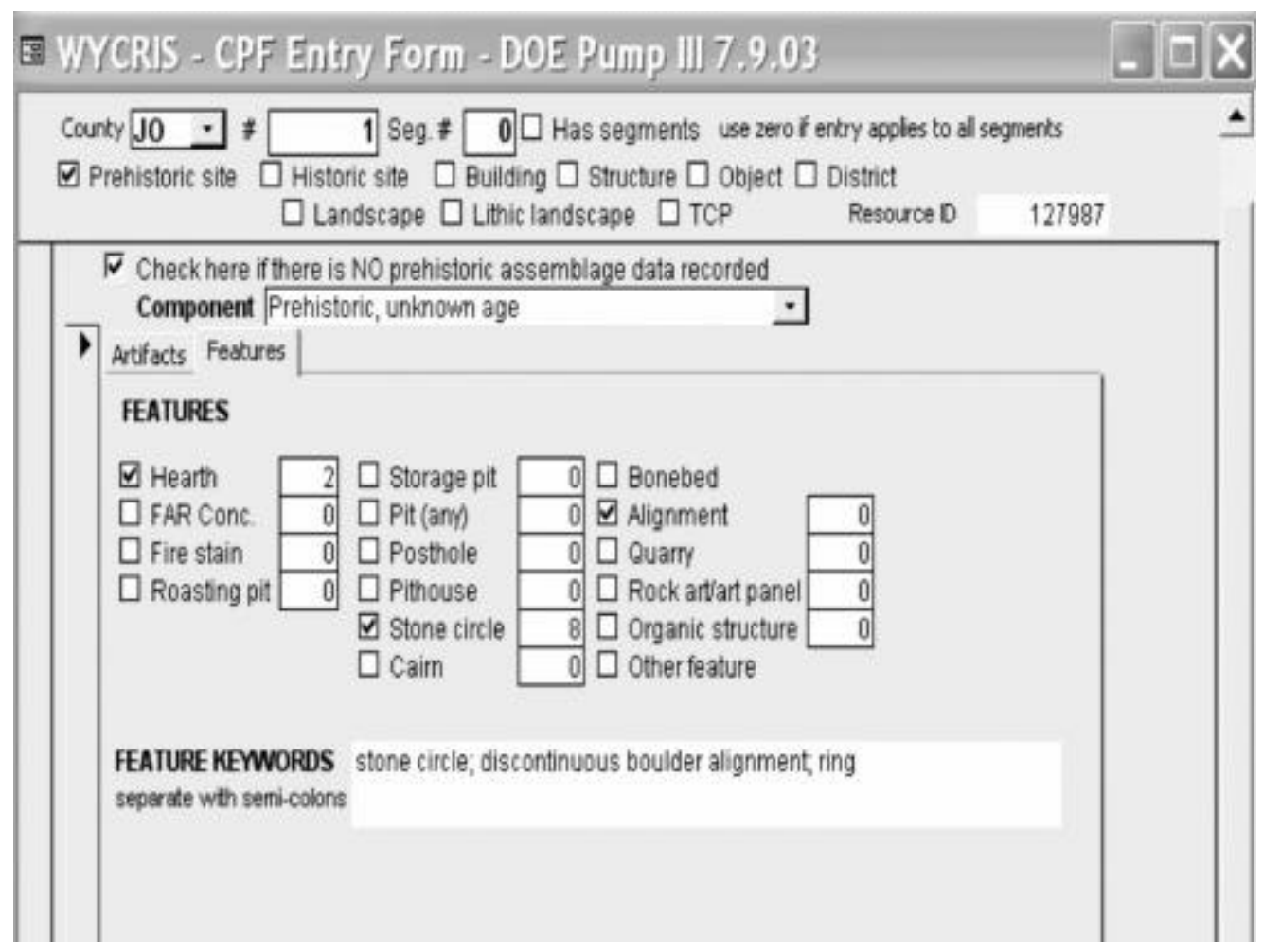

Figure 9. Prehistoric feature encoding form in the WYCRIS database

\section{Using the Datasets}

As an example of the value of this dataset, consider the relationship between sites and potential burial (discussed in detail in Chapter 4). Queries were run against WYCRIS database tables for this project. For each sensitivity model (Buried Archaeology-Fine (1:24k) (FINE) Analytical (A) and Management (M); Buried Archaeology-Coarse (1:250k) (COARSE) A and M) described in Chapter 4, percentages and counts of sites with buried components, sites occurring on the surface only, sites producing radiocarbon dates, and sites with formal shovel testing and excavation units were calculated. Using the information systems it was straightforward to generate a cross-tabulation (Table 1). The correlation between the known buried archaeological sites and the very high 
sensitivity zone is strong across all four models (Figure 10). After counts and percentages of sites were tallied within MS Access, these tables were exported to MS Excel to produce charts of the information (Table 1).

Table 1. Number of sites with buried components

\begin{tabular}{l|ccccc} 
MODEL & Very High & High & Moderate & Low & Very Low \\
\hline FINE A & 132 & 19 & 65 & 5 & 16 \\
FINE M & 175 & 14 & 49 & 5 & 9 \\
COARSE A & 132 & 19 & 65 & 5 & 16 \\
COARSE M & 185 & 40 & 64 & 2 & 8
\end{tabular}

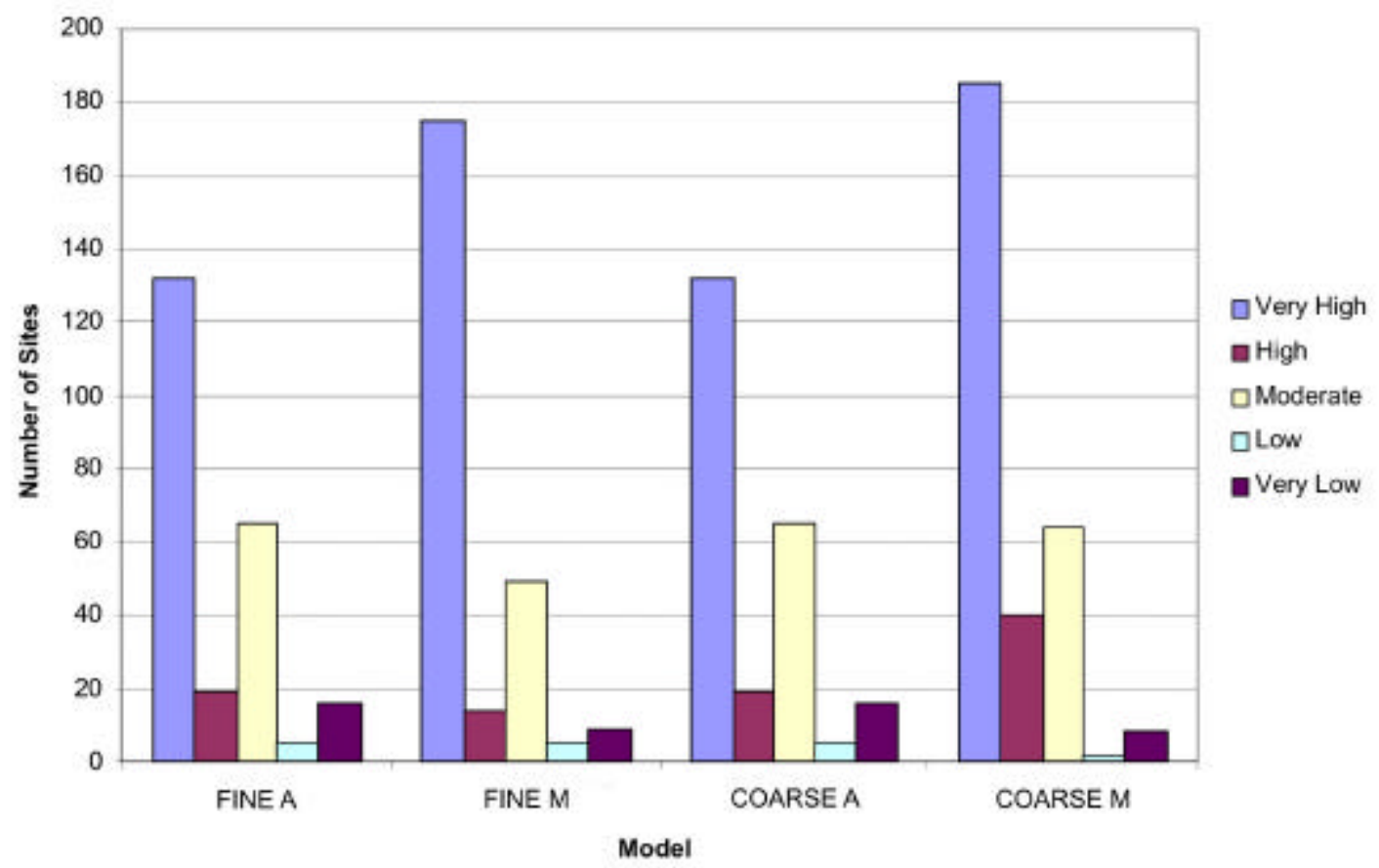

Figure 10. Number of sites with buried components

As another example, site types and feature types were also compiled for the models. Fire hearths and fire cracked rock scatters occurred in all sensitivity zones. Ceramic scatters and the highest number of bone beds, or bison kill sites, were reported within the very high sensitivity zone. This might be the result of the depositional environment in these areas better preserving these types of fragile resources and the fact that very high sensitivity zones follow permanent water sources. Areas with less deposition are more prone to wind, water, and other natural factors which can displace or degrade the archaeological item. Prehistoric use of ceramics is generally associated with long term occupations, thus finding these artifact types only occur in the high sensitivity zone 
seems reasonable given the associated water source. Further analysis testing the sensitivity models is discussed in Chapter 4.

\section{Data Lineage}

The quality of information recorded on archaeological and historic sites has varied over the past forty years. Some of the earliest inventories by professional archaeologists were conducted by the Smithsonian Institution in the late 1940s and early 1950s as part of the Works Program Administration (WPA) River Basin Surveys. Sites were recorded on forms which included basic site information including legal location, site setting, site size, material collected, material observed, and recommendations for further work. Tool counts and types are generally given, but lithic debitage is listed only as to presence, or qualitatively using language such as "few" or "many". The site forms do not include artifact illustrations, site sketch maps, or United States Geological Survey (USGS) topographic maps (which were not available at the time). Sites are plotted on small-scale project maps, making the relocation and identification of many of the sites recorded during the WPA River Basin Surveys difficult, especially in areas with high site density.

During the 1960s and 1970s members of the Wyoming Archaeological Society (WAS) actively recorded and submitted a number of site forms on archaeological sites in the state. These forms, completed by amateur and paraprofessionals, vary widely in quality. Many only indicate there is a site (such as a campsite) in some generalized location (often by quarter section). On the other hand, there are some recordings that are quite detailed with comprehensive descriptions of artifact assemblages and detailed instrument maps. Standard topographic maps are almost never provided. Relocating and identifying many of these sites is difficult, and the sites can be plotted in the GIS database only as dots in the center of the specified legal locations. Results of excavations conducted by the WAS are often published in The Wyoming Archaeologis and are readily available.

During the 1970s, after Congress passed the National Historic Preservation Act of 1966 (NHPA) and the National Environmental Protection Act of 1969 (NEPA), there was an increase in the number of inventories conducted and sites recorded by professional archaeologists. Many of these studies were conducted in the newly developed coal mines in the Powder River Basin. Early in the 1970s, the quality of these recordings varied widely with a number of forms having vague references to "chips" or "a large number of tipi rings", sometimes covering several sections. Sites were recorded on forms that varied by agency and/or contractor with many consisting only of descriptions on notebook paper. Artifact illustrations and maps were often lacking and site boundaries were not defined.

By the late 1970s most sites were recorded on various site forms that contained fairly standardized information including site setting, soil, and artifact descriptions. Some consulting firms developed their own internal standard forms and some used the Colorado site form. Site sketch maps, positions of sites on topographic maps, and illustrations of diagnostic artifacts were often provided. Around 1981 a standard Wyoming Site form was developed by the WYSHPO that required standard data and 
information categories. Much of the data recorded is similar to current site forms and has served as the basis for standardized recording and required documentation. The 1981 form was designed to facilitate data entry into a rudimentary computer system. Data fields were encoded for presence/absence or with numeric codes for specified text strings. However, due to funding restraints and other political issues, a computerized database using most of the encoded information was not implemented at the time.

In 1982, the Intermountain Antiquities Computer System (IMACS) form was adopted for statewide use. The IMACS form provided most of the information required on the current Wyoming site form, however it was designed for use by several states (UT, NV, and ID) and in some sections was unnecessarily complicated or not entirely appropriate for Wyoming cultural resources. The IMACS form required standardized responses to administrative, environmental, artifact, and feature data fields. Again, Wyoming data was not entered into this system, even with several automation attempts. There was professional consensus to develop a more state appropriate recording format.

The current Wyoming Cultural Properties Form (WCPF), designed in part to increase data collection consistency, was developed in 2000 and substantially revised in 2003. The current form provides a more consistent method of encoding archaeological and historic components than was provided by previous forms. The data encoding portion of this project follows the current format of the WCPF. If sites are documented using the WCPF, encoding is a straightforward process and the standard documentation is complete with sketch maps, topographic maps, artifact illustrations, and photographs. Consistent documentation increases the consistency of the encoded information.

\section{Data Limitations}

Data deficiencies and inconsistencies from earlier forms can significantly hamper efforts to accurately digitize, encode, and relocate sites. Of particular concern is the lack of standard maps accurately depicting site location and site boundaries. These sites must frequently be digitized as site points with site placement based on the center of cadastral locations. As the potential to use GIS to model site distributions (such as the site sensitivity modeling described in Chapter 4) increases, the accuracy of sites plotted by legal location may not be of sufficient quality for use in some modeling projects. Further, there are instances when sites which lack sufficient maps could not be accurately identified during subsequent fieldwork, requiring the assigning of new site numbers.

Site boundary definitions have also varied widely over time and by recorder. In the 1970s, those recording sites during block survey tended to lump nearby cultural manifestations into large, sprawling sites with considerable gaps between artifacts and features. In addition, a number of sites have been recorded with noncontiguous segments. For example, stone circles on a series of ridges have been recorded as a single site, even though no cultural materials were found in intervening drainages. More recently, sites are usually defined to be much smaller and more spatially confined. A gap of 30 meters or more between artifacts or features is now sufficient justification to 
record separate sites. Additionally, some of the large, previously recorded sites are now being redefined and rerecorded into smaller, individual sites.

Imprecise descriptions of the contents of early recordings reduce the amount of information that can be encoded. Artifact types and counts, as well as feature counts, are often not recorded. Sites are often described simply as "chips and tools" or "many stone circles on ridges". As a result, artifacts and features are only encoded as "presence/absence" and specific tool types cannot be determined. This lack of detailed recording can require additional fieldwork in order to determine the nature and extent of the resource and whether or not it meets the criteria for inclusion in the National Register of Historic Places (NRHP).

Inconsistent use of artifact terminology on older site forms may not always be easily redefined into currently used categories. For example, the term "knife" is used in older recordings can include: a) a large thin biface; or b) any lithic tool with a sharp, low angle working edge that could have been used for cutting. "Knife" is no longer a category used in the current recording standard. It now is generally categorized as a "biface" or "modified flake." When there is insufficient information for the encoder to make a determination, the artifact is encoded as "other tool" and "knife" entered in a textual field describing "other tool". As a result, "bifaces" or "modified flakes" may be underrepresented in recordings that use the term "knife".

One of the major conceptual shifts which has occurred in the past 20 years is how soil type and deposition are documented. On forms prior to the IMACS form, soils (if discussed at all) are generally recorded by textural classes (i.e. clay; silty sand; sand). With the introduction of the IMACS form and continuing with the current Wyoming forms, the emphasis is on categories reflecting depositional processes (aeolian, alluvial, or colluvial) or lack of deposition (bare rock, regolith). The textural classes cannot be directly trans lated to current categories and deposition must be encoded as unknown for most sites recorded prior to the IMACS form. This limits the number of early-recorded sites that can be accurately used in the modeling part of this project.

Inconsistencies in categorizing deposition even continue in current site recordings. Deposition on nearly all sites recorded by one investigator may be characterized as aeolian while another working in the same area may record nearly all sites as containing colluvial deposits or even regolith. Inconsistencies such as these could be a result of several factors. Deposition frequently results from the interaction of several processes (such as aeolian deposits reworked by slope wash) and various recorders may emphasize one process over another. Also, soft sandstone and clay deposits weathered in situ can be difficult to distinguish from materials transported short distances from the corresponding parent materials. Whatever the explanation, the existence of these inconsistencies should be considered when type of deposition is a factor used in site modeling.

Site age is one variable that is of great interest to many investigators. Only a small percentage of the sites recorded in the AMP project area have been dated by absolute dating techniques such as radiocarbon. Most sites have been encoded to time periods 
based on surface artifact manifestations and can be compromised by a variety of factors. Users of this information should consider these limitations and use professional judgment when drawing conclusions or inferences from this data. These types of limitations are inherent in the nature of the resource and recoding methodologies. The majority of the site ages encoded for this project are based solely on surface manifestations with very little or no subsurface testing. While surface sites can address site distribution questions and many other data gaps, they also can contain compromised data and may not accurately reflect human use or occupations on the landscape.

\section{Implications of the Adaptive Management and Planning Project for WYCRIS}

In terms of information services and improving the quality and quantity of accessible data, this project will have a long term, noticeable benefit to Wyoming cultural resource management. Implications for Wyoming energy development have yet to be fully realized, but it is anticipated the information systems, the on-line project tracking application, and the CRISP tool will enable industry to better plan projects to reduce impacts to resources. Access to inventory information and risk models will reduce time and cost for oil and gas developers. An interview in April of 2004 was conducted with then current Wyoming State Geologist, Lance Cook, to gain a better insight of the needs of industry. Mr. Cook's background includes a close working relationship with oil and gas officials and past work history with Shell Oil and Union Pacific Resources. His main comment was that the surveyed space information would be very helpful to oil and gas planning, since having this information would reduce the likelihood of redundant inventory. This has been a goal of both Wyoming and New Mexico project participants. The implementation of the CRISP tool will allow industry to have easy access to this information in the early stages of their planning process.

The most prominent change to the WYCRIS information system is the addition of the WYCRIS SITE database. Several encoding attempts have occurred in the past without becoming an integral part of the overall information system. Consistently, users have asked for this detailed information in order to conduct research, write management plans, and develop historic contexts. Up to this point, this information has been difficult to gather and compile. Consensus on data content and format to the Wyoming Cultural Properties Form (WYCPF) was reached among academic and agency partners in 2001. The automated format and content for this project was in turn based upon the most current version of the site recording standard.

With the addition of the eight county area of detailed site information, future requests for specific site information will be more quickly and accurately processed. Since the 1980s, a major drawback to the data system has been the lack of site temporal information. The ability to encode this data into a standard system based upon the current WYCPF is now available. However, due to limitations in the original documentation, all sites are not encoded equally. Many of the early resources lack the detailed information required on the WYCPF. Users will need to be aware of this issue when using the data system. As explained above, each record is identified as to the "profile" or source of each record and the original type of record. If a record is encoded to "DOEPump3" it has been 
encoded as fully as possible given the available information. If certain feature types or artifacts are encoded to presence/absence only, it most likely infers the resource is inadequately documented. Procedures have been incorporated into the day-to-day information management process to include detailed site data into the master data system. Additional funds will need to be acquired to bring the rest of the legacy data forward. Additional technical products will need to be developed in order to automate the site information from consultants to the archive. This will require users to enter information and the WYCRO to review and insure the accuracy of the data.

Three examples of common user requests are displayed below (Figure 11). The first map represents the distribution of aboriginal stone circle sites within the study area. The rings have been normalized by the number of stone circles at each site. Many of the points in the " $0-2$ " range are sites where the count of circles is not reported by the original investigator - only the presence/absence. Until this project, a map of this kind could not be easily generated. The inventory areas are also represented to show where investigations have occurred so the user does not assume a lack of resources in areas where stone circles are not reported.

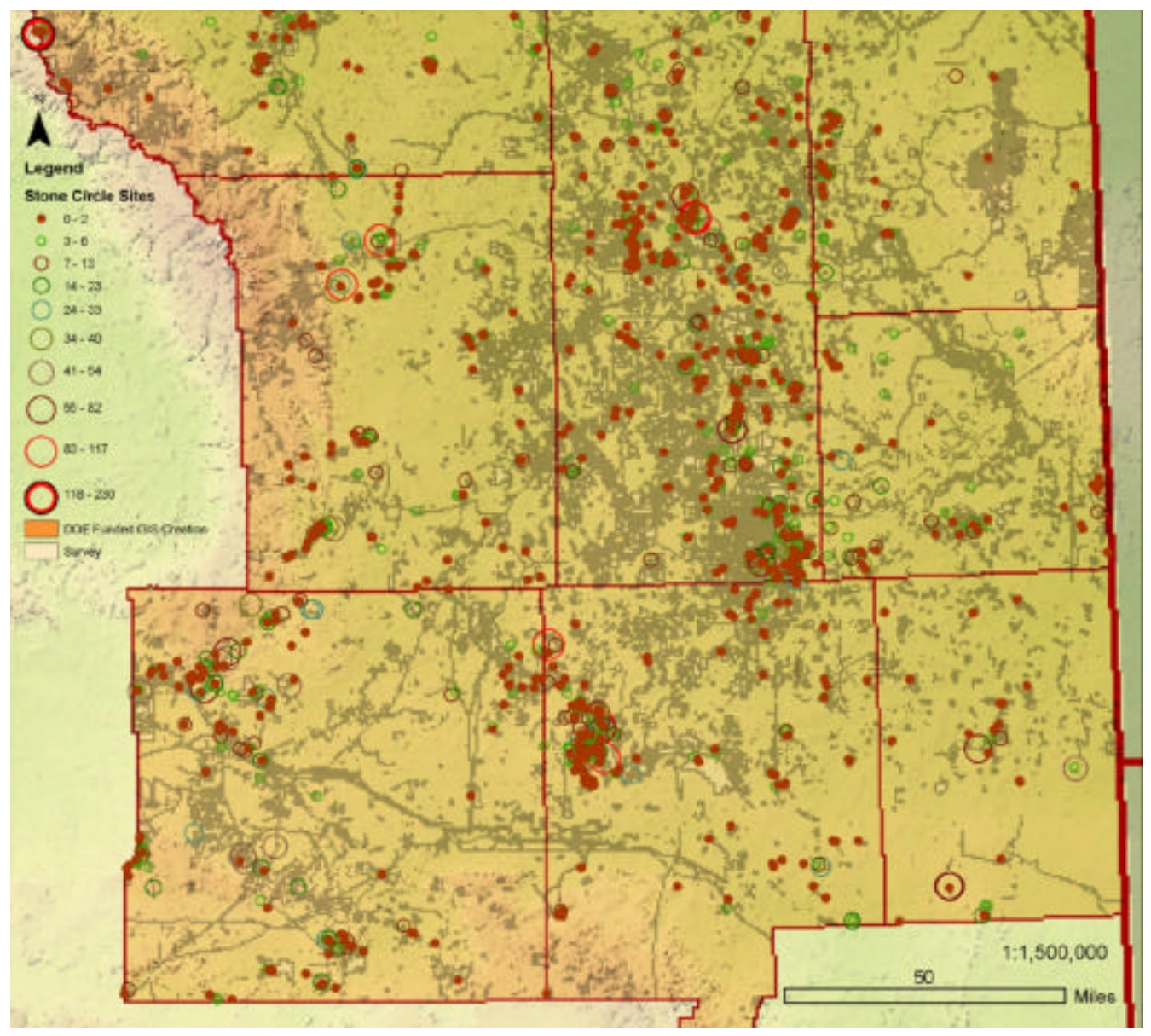

Figure 11. Distribution of stone circle sites in study area; displayed by number of stone circles reported 
Subsequent queries could include sites with other types of associated features (i.e. hearths, cairns, stone alignments) and associated artifact types (i.e. tools, projectile points, ceramics). The query can be easily customized for the researcher and land manager.

The next example (Figure 12) displays the distribution of sites with ceramic artifacts. Generally, the presence of ceramics is relatively rare in Wyoming. The distribution of ceramics in the Belle Fourche drainage has been reported to be of higher frequency than other drainages. There are 111 sites reported with ceramics in the project study area. Again, the distribution of this artifact type seems to be predominately based upon areas of inventory. However, there is a strong correlation of ceramic site locations in association with river drainages. Subsequent queries could include counts and types of associated features and other related artifact types. In general, ceramics may represent the presence of distinct cultural groups (Frison 1991; Reher 1979) during Late Prehistoric times.

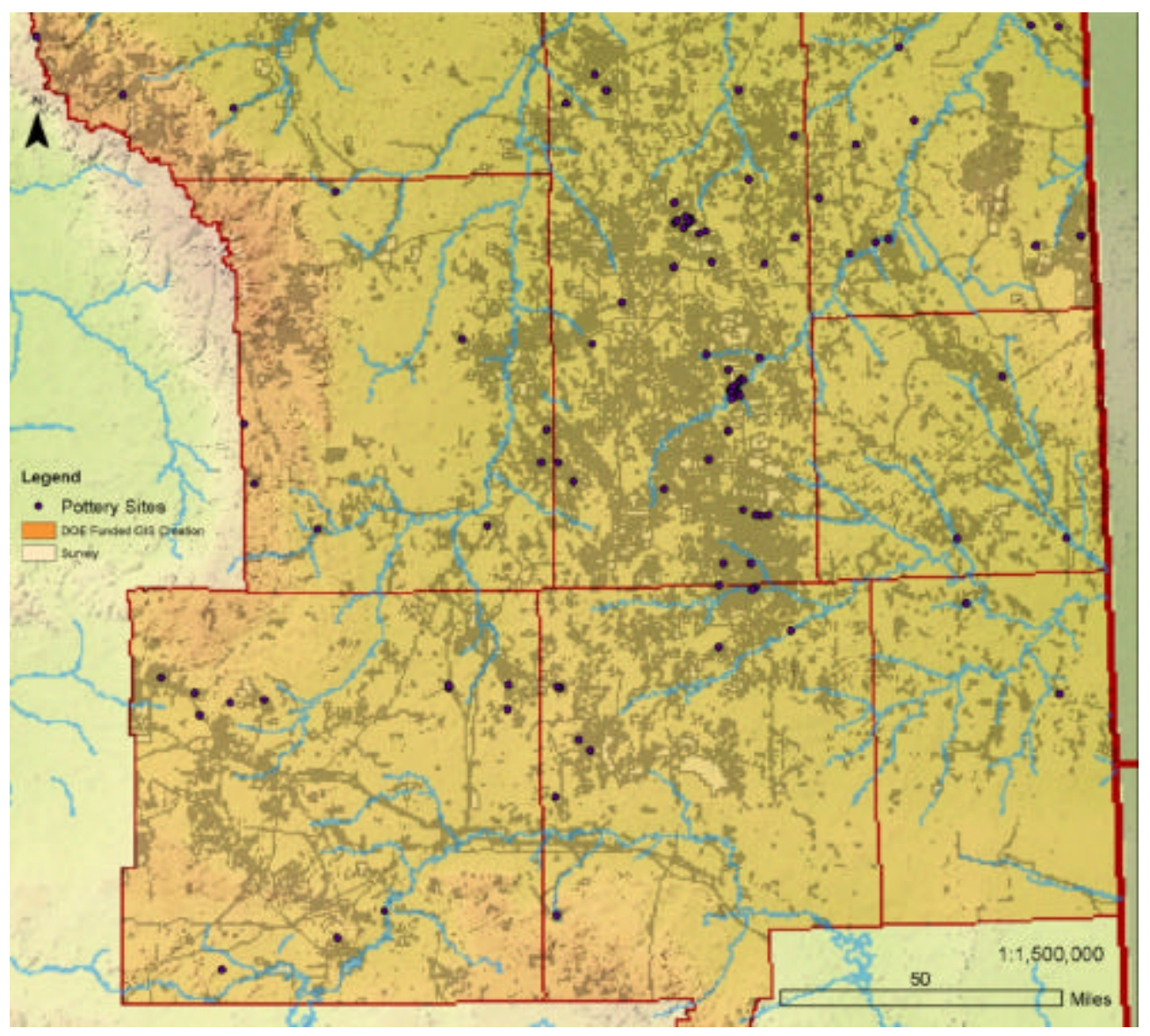

Figure 12. Distribution of sites with ceramic artifacts

Analysis of ceramic artifacts may yield answers to settlement and subsistence questions that other artifacts types cannot provide. For years, researchers and land managers have requested efficient access to sites with ceramic artifacts. 
The third example (Figure 13) displays the distribution of sites with artifacts dating to the Paleoindian period (approx. 12,000-8,000 BP) in the study area. Of all research related questions, this time period is the most requested. One hundred eight sites within the study area have materials dating to this period.

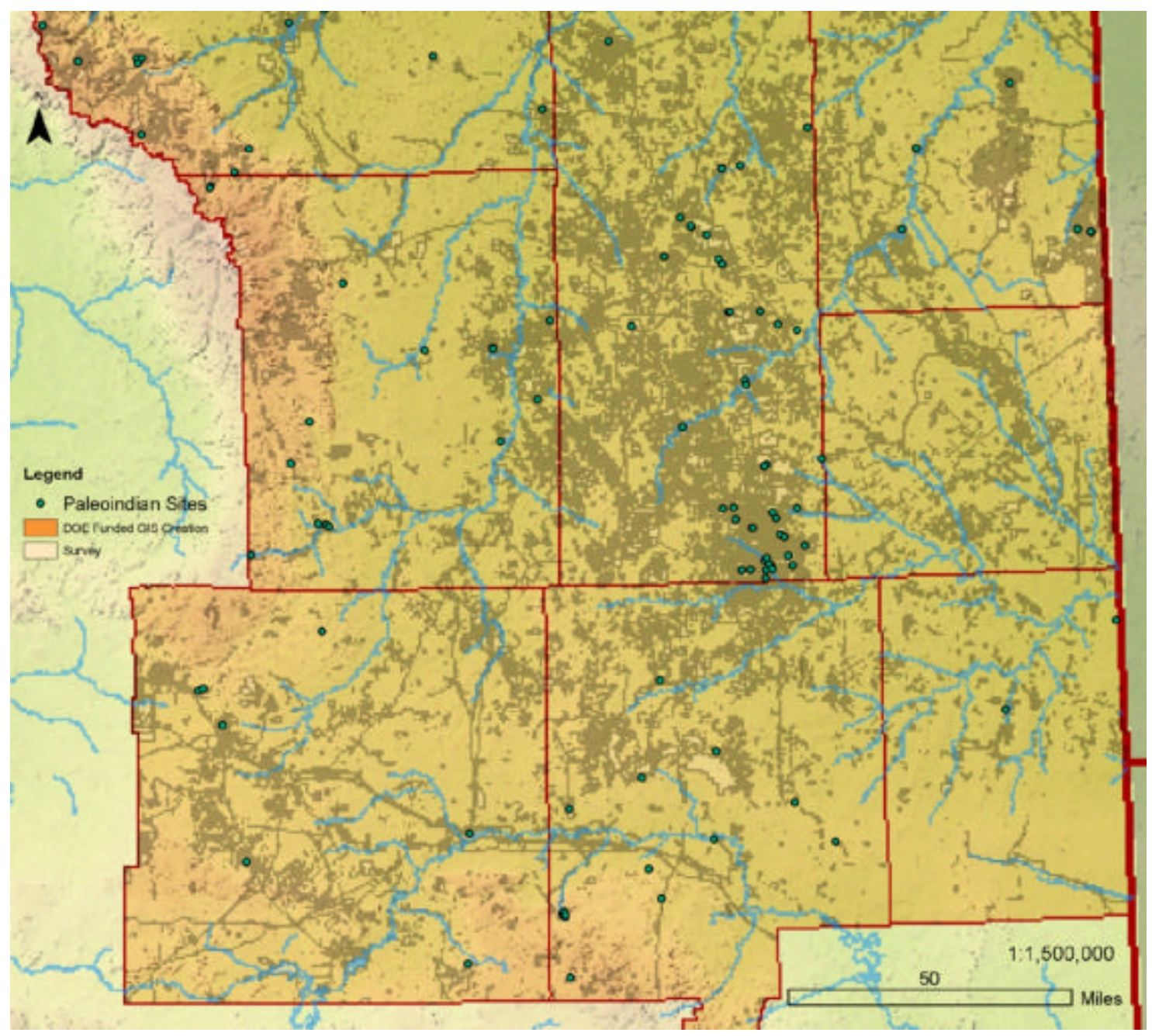

Figure 13. Distribution of Paleoindian sites within the study area

Past research projects have required the investigator to physically review each individual site form to gather the information needed for the study. WYCRIS does not attempt to provide all information required for an academic project, but it is designed to aid in reducing the number of site forms someone would have to review to gain the needed information. This information system serves as the first selection of information, rather than exhaustive information. Researchers can expand on this information and digital files can be created as a subset for them. Specific artifact measurements and materials have not been included since these items can be very project-specific and unrelated to the overall SHPO data system. Ultimately integration of the WYCRIS records and artifact curation records will provide a rich suite of observations and collections. However, the 
information currently in WYCRIS meets the needs of land managing agencies to assist in making decisions on resource eligibility and future protection goals.

\section{Revised Internet Mapping Web Site}

During the fall of 2003, a major revision of the WYCRIS Internet Mapping Service (ESRI ArcIMS) was undertaken. The map service software was updated to the most current version and the user interface was redesigned. The original hosting of the cultural resource data (sites and inventories) was in point, line, and polygon format. To make the map services easier to use, all sites (points, lines and polygons), and all inventories (point, lines and polygons) were buffered and merged into one polygon file. This format helps to reduce the number of "selects" a user must perform in order to gather information on sites and projects in a particular geographic area or by common attributes. Since ArcIMS currently only supports ArcView shapefiles, the current geodatabase files are buffered, saved as polygons, then merged into one master polygon file for both sites and inventories. After this process, each file is projected to UTM Zone 12 and UTM Zone 13 (NAD27), indexed, and posted to the web.

Gnomon created a new map interface with a more sophisticated table of contents for this project. The map layers can be customized by the user to their needs. Additional themes were added, primarily more available base map data such as the 1:100k and 1:250k quadrangles. The tool bar was also redesigned for easier use. When the original ArcIMS was hosted, many of the cultural resource professionals were not accustomed to GIS software tools. The tools were redesigned to be more self-explanatory and additional tools were added so a user could make a finished map for a report, or for use in the field. They can set the scale, add a title, and export the map for use in other applications such as MS Word. Buffering and select tools and a "drill down" tool, which allows a user to identify all of the information available on screen in one query, were also added. The results of the "drill down" tool create a report of all themes displayed on the map. Figure 14 below displays the previous user map interface prior to the redesign. The "Map Layers" table of contents displays the previous user options and the point, line, polygon format for sites and projects. This required more effort on the user's part to identify sites and projects in a potential project area. User tools are located on the bottom of the map and require more effort to understand and use properly. 


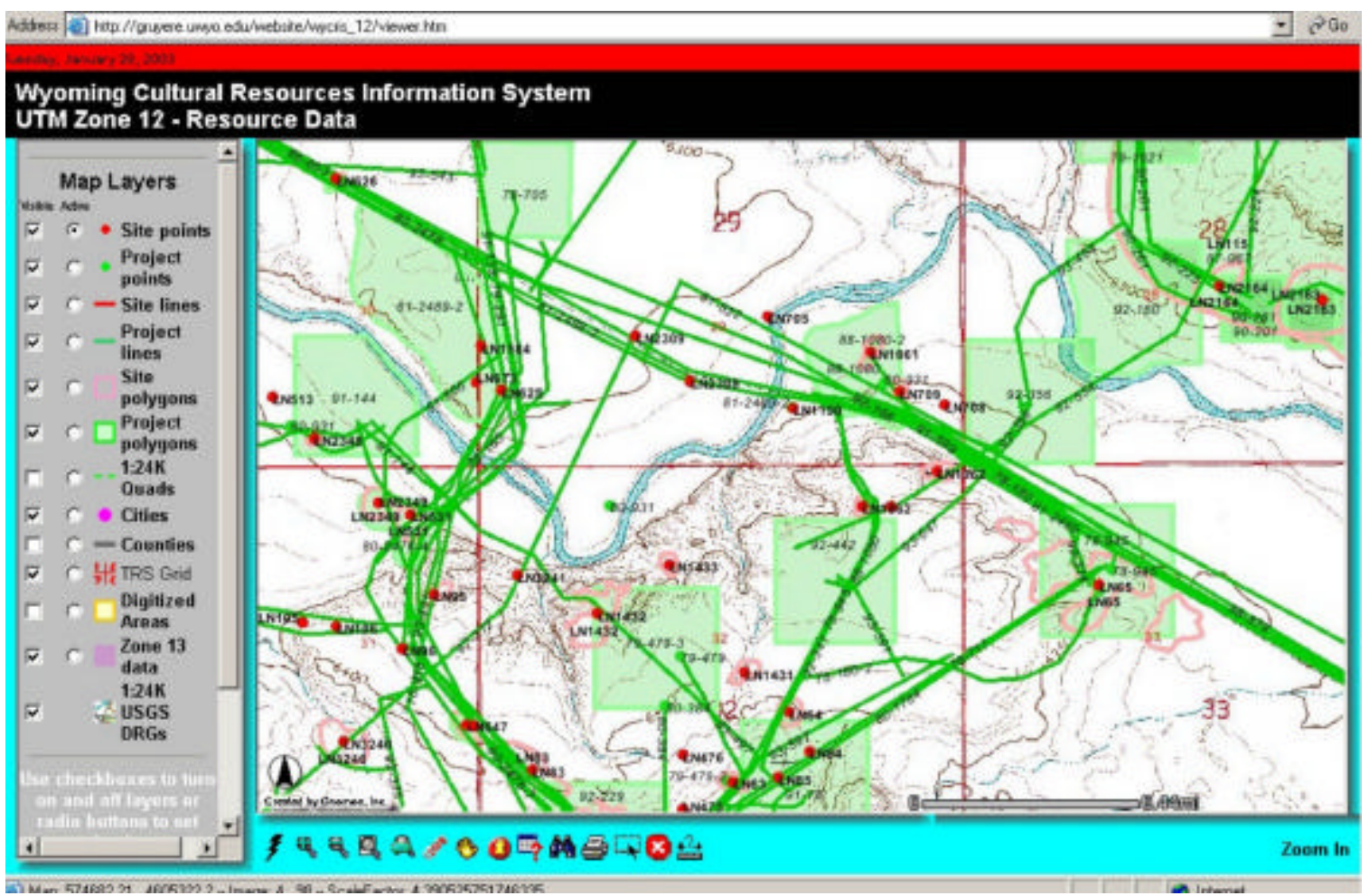

Figure 14. Previous WYCRIS Internet mapping server user interface

Below is the revised map interface developed by Gnomon (Figure 15). Note the revised "map layers" and table of contents along with the updated map tools on the top of the window. A help folder and more explanation of the overall application are available. Buffering and map production choices help to create selections of information for report preparation. The WYSHPO conducted training on this application for all permittees and BLM cultural resource field office staff in April of 2003. After this training, the use of the ArcIMS saw a considerable increase. All of the GIS data compiled for this project is available on this map service along with a portable document format (PDF) of all site forms and the historic General Land Office (GLO) maps. 


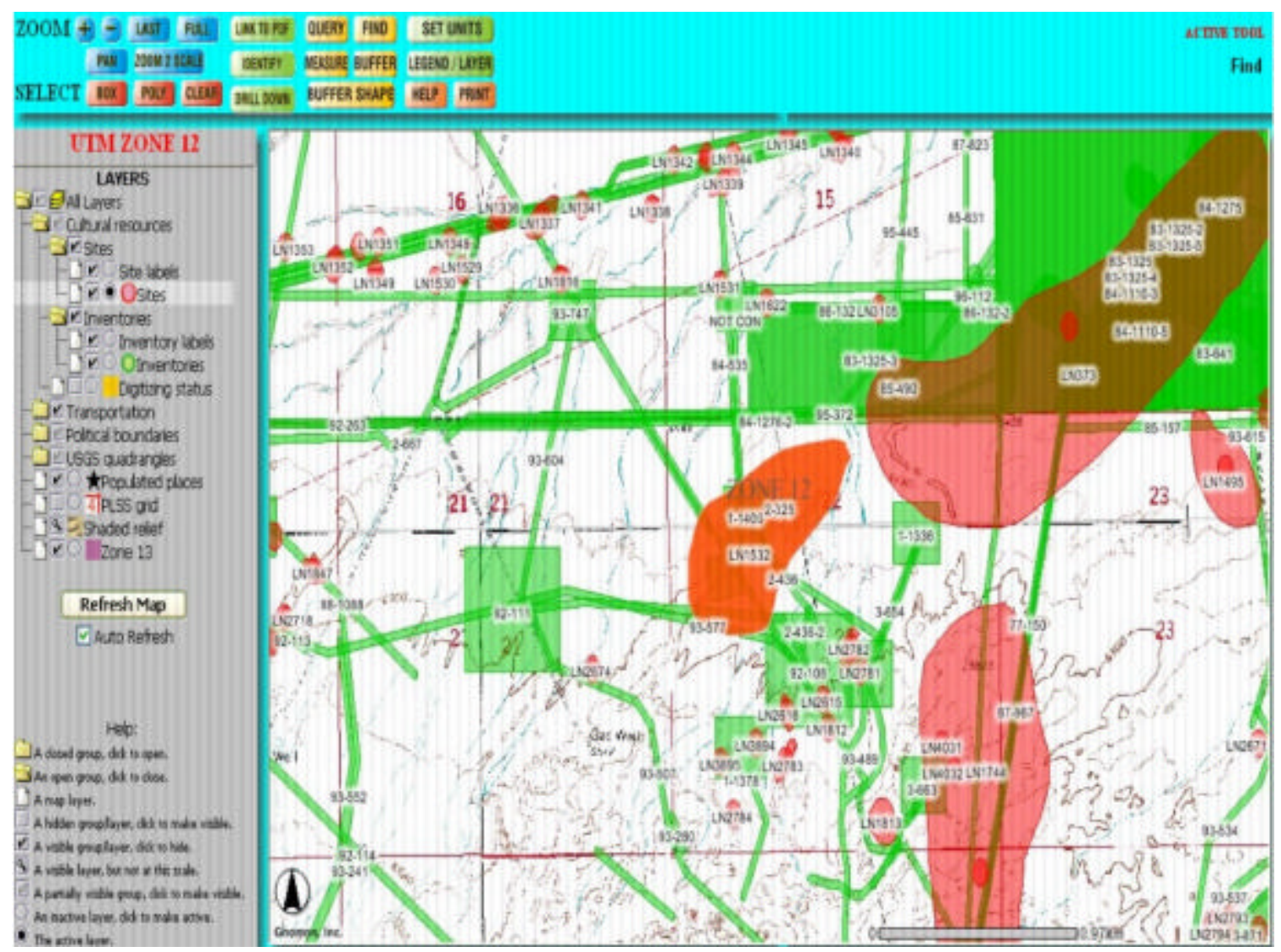

Figure 15. Current WYCRIS Internet mapping server user interface (note expandable choice in the "Layers" menu)

Because of the geographic format of the USGS digital raster graphic (DRG) topographic maps, the maps are served in Zone 12 and Zone 13. The Zone is prominently displayed as the header of the table of contents. The user must navigate between zones, but the revision of the display has helped to reduce confusion. Fewer user assists are needed due to the hands-on training and the available help products.

\section{User Manuals, System Administration, and Install Instructions}

Updated user manuals for digitizing were created for training and documentation purposes for this project. Specific installation instructions of the customized ESRI map document (.MXD), system ODBC drivers, and ArcGIS ODBC connections were written for BLM's systems administrators. The installation instructions were approved by BLM's Wyoming State Office and distributed via their network to the field offices. WYSHPO staff have been available for technical assistance to the field offices when they had any type of question on the application and the installation. BLM field offices had to first have all of their ArcGIS licenses upgraded to version 8.3 prior to the application. A typical installation takes less than ten minutes on an individual computer system. 
A detailed digitizing manual was written for BLM staff as a training document and for future reference as they map new projects and sites (see Appendix A). The manual contains visual aids as well as text explaining the steps to process and map new information. The manual is required to use the customized application and associated tools when creating new data.

Each field office has an identical personal geodatabase and can enter sites and projects in point, line, and polygon format. They also have the option of creating polygons for historic districts and isolated artifacts. To date, one merge of the information created in the field office has occurred.

Documentation of system administration within the WYCRO has also been written. Documentation for the administration of user names and passwords on the web site has been written and is available to office staff. Accessioning, scanning, and file search instruction manuals were written for staff training purposes and documentation of the overall system configuration. A mirrored server was configured as a system back-up of all data and applications and a detailed back-up and system recovery document was prepared.

\section{Overview of Digitizing Methodology}

A revised digitizing methodology was developed by Gnomon in 2002, specifically for this project. The purpose of the revision was to maximize data entry efficiency, gain more consistency, and increase accuracy in the spatial data. The process of digitizing inventory and site data begins by reviewing the project report, paying special attention to the cover sheet (a standard Wyoming format), and descriptive survey methodology sections. A review of the project report provides basic information about the project, including the survey area, survey standards, and the number of sites located. This information is necessary to properly digitize the inventory and cultural resources. Locational information and surveyed acreage provided in the project report is then compared with the project maps to check for inconsistencies. If no inconsistencies are found among the legal locations in the project report, project map, site forms, and site maps, then the entire project is digitized (Figure 16). 


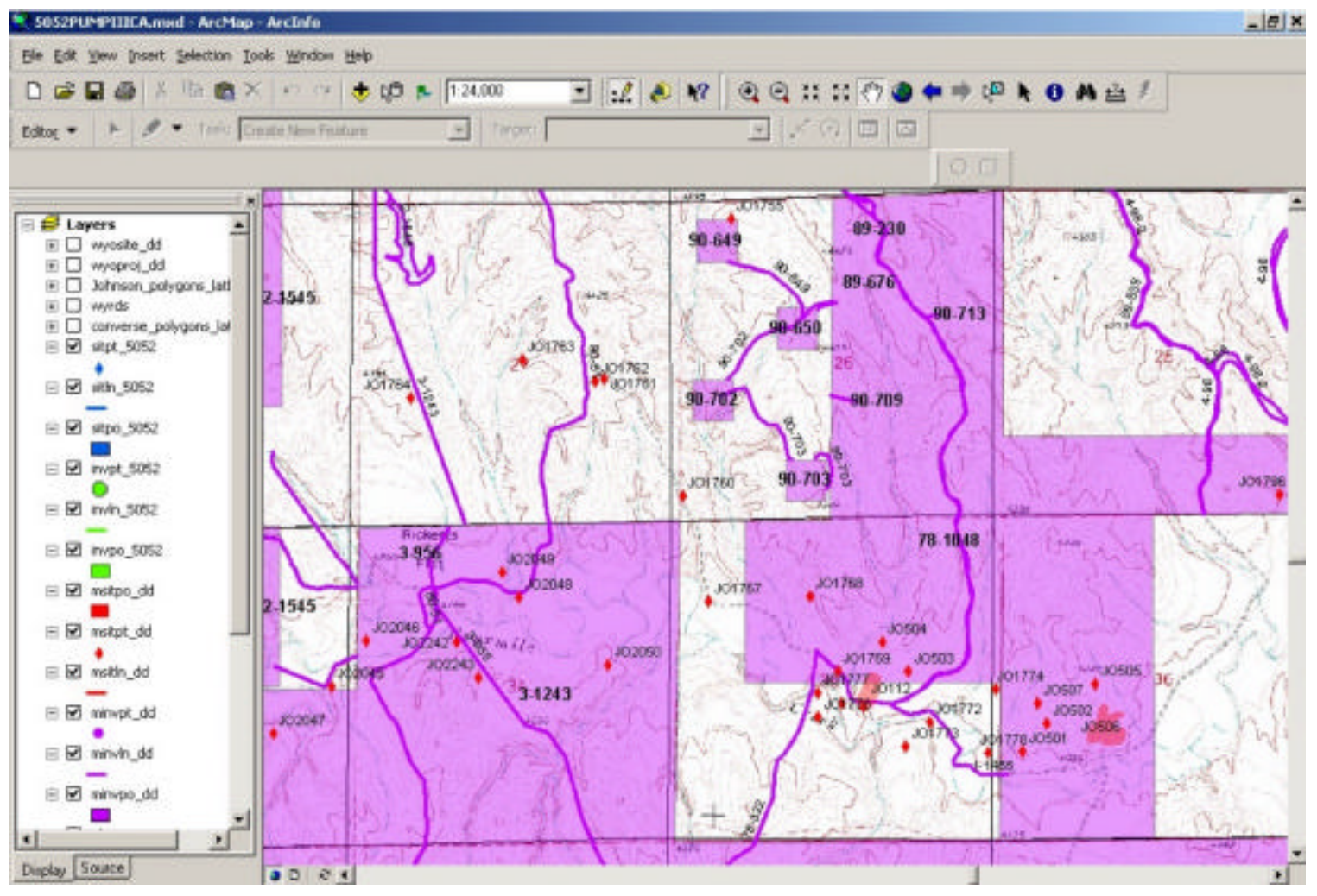

\section{Figure 16. Digitized projects and sites user interface with customized tools}

During this process, several decisions must be made in order to provide the most complete and accurate data set. If the project is small and there are no inconsistencies between the project report and the project map, then the data can be relatively quickly and accurately digitized. However, there are several problems that could arise, each of which requires the digitizer to make decisions that have the potential to introduce inaccuracies into the data set. The lack of a map, an unreadable map, inconsistent legal location for a project or site, and inconsistent project or site areas are the most commonly encountered problems.

In some cases, no map or an unreadable map, was included with the project report or the site forms. If no legal location was provided, the project or site was not digitized. However, if legal location was provided in the form of UTMs or township, range, and section, then the site could be digitized. An entity digitized using township, range, and section information has much lower horizontal position accuracy than entities digitized heads- up using topographic maps or a georeferenced image.

Another very common problem is inconsistency in the stated size of a site (in square meters) and the area over which the site is represented on topographic maps. In some cases the difference has been in the tens of thousands of square meters. It is almost impossible to know if the text or the map is correct. For recently surveyed sites, it is possible to contact the survey organization to determine the correct placement of the site. However, for sites that have not been surveyed recently, it will often be necessary to 
digitize what could be a large site (greater than 10,000 sq m) as a site point in the GIS database.

The most common problem encountered is the presence of inconsistent legal locations between project reports or site forms and the maps depicting the location of the project or site. In most cases, the site or project will be digitized as it is shown on the map. The correct legal location must be determined by matching the topographic map provided with its proper legal location.

\section{Data Quality}

The quality of the data in the geodatabase is dependant upon, and limited by, the quality of the data provided by the survey organization. A number of factors, including the presence/absence of a map, the scale of the map, and the method used to digitize, influence the accuracy of site and project placement within the geodatabase. Data quality is tracked within the geodatabase using the customized attribute tool (Figure 17).

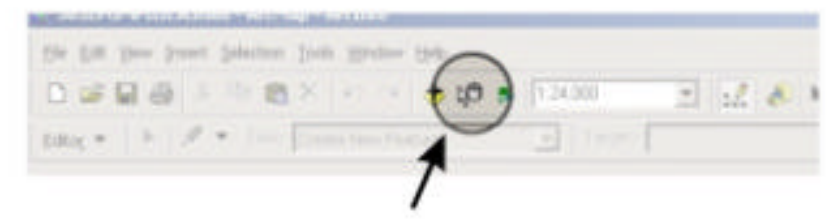

Figure 17. ArcMap customized site and project attribute tool

The attribute tool is used to open the "Cultural Resource Site GIS Attributes" form (Figure 18). Four fields are used to describe the accuracy of the digitized spatial data. The Horizontal Position Accuracy (Figure 19) tracks the confidence that can be given to the location at which the entity has been digitized. Digitizing from a 1:24,000 standard USGS topographic map will produce a Horizontal Position Accuracy of $<20 \mathrm{~m}$, meaning the center of the digitized entity is within $20 \mathrm{~m}$ of the actual location of the site. The Horizontal Position Source field (Figure 20) tells the user if a map was used to digitize an entity and, if so, the scale of the map used. The Boundary Precision field (Figure 21) tracks the confidence assigned to a site's boundaries as digitized. UTM coordinates, topographic maps, and georeferenced images provide the highest site boundary precision while aliquot (quarter-sections) provides the lowest precision. 


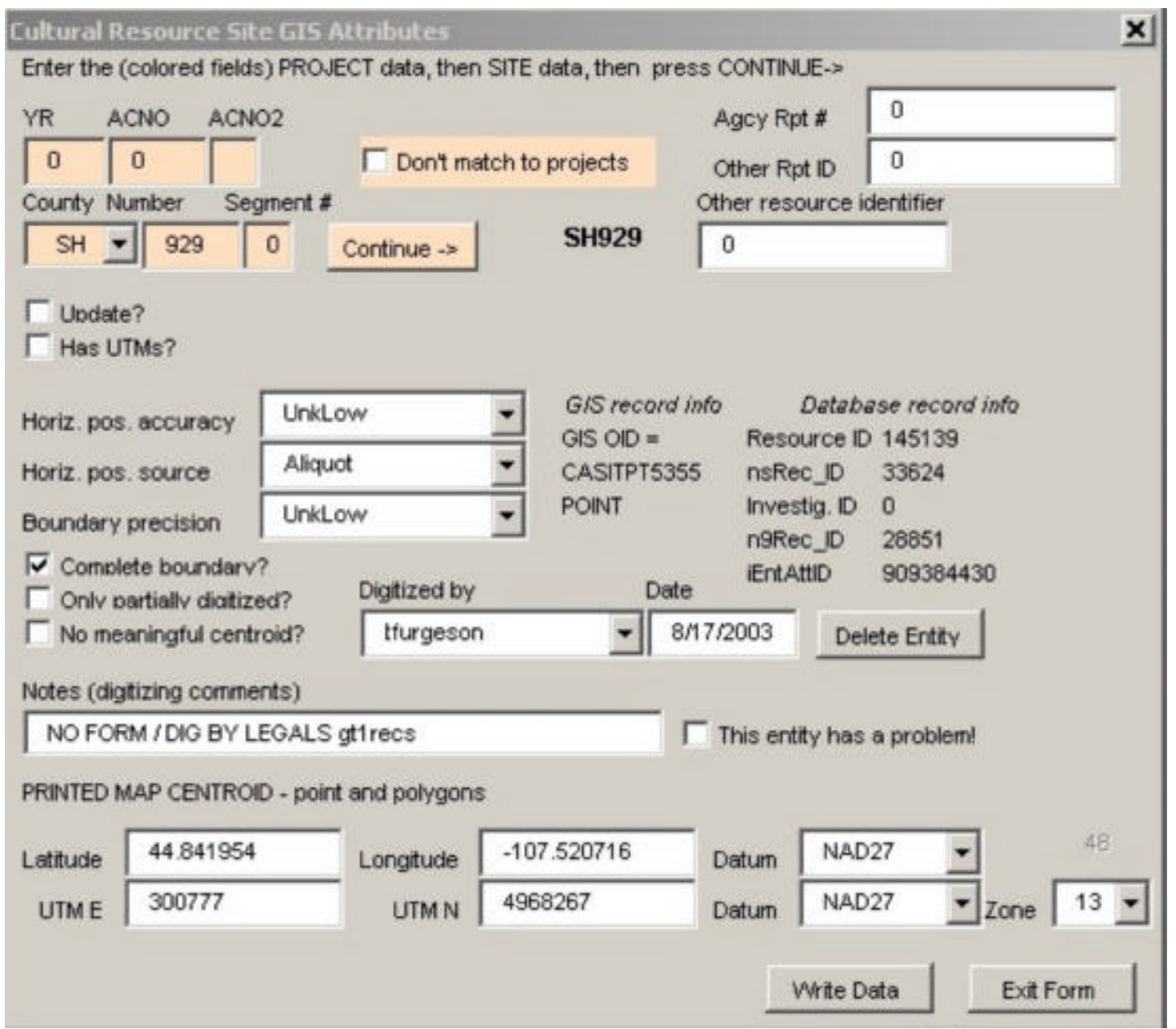

Figure 18. Cultural resource site GIS attributes form

\begin{tabular}{|c|c|c|}
\hline Horiz, pos. accuracy & UnkLow & 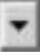 \\
\hline Horiz. pos. source & $\begin{array}{l}<1 m \\
<10 m\end{array}$ & \\
\hline Boundary precision & $\begin{array}{l}<20 \mathrm{~m} \\
\leqslant 100 \mathrm{~m}\end{array}$ & \\
\hline I Comnlete boundarv & UnikLow & \\
\hline $\begin{array}{l}\Gamma \text { Onlv partiallv ciaitiz } \\
\Gamma \text { No meaningful cent. }\end{array}$ & $\begin{array}{l}\text { Unidhi } \\
\text { UnikUnk }\end{array}$ & \\
\hline
\end{tabular}

\section{Figure 19. Horizontal position accuracy field}




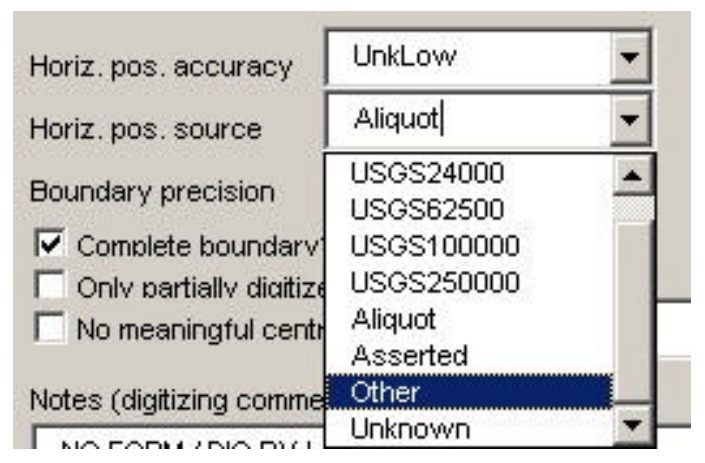

Figure 20. Horizontal position source field

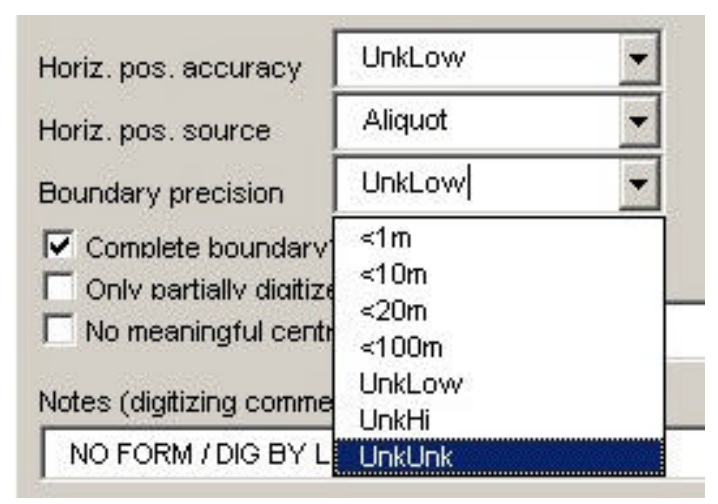

\section{Figure 21. Boundary precision field}

The final field used to describe the accuracy of the digitized data is the Notes (digitizing comments) field (Figure 22). This field will describe any digitizing problems and will indicate the method used to digitize the entity. Three digitizing methods have been employed to digitize sites, the most common of which is known as heads- up digitizing. Heads-up digitizing is used when a good quality USGS topographic map has been provided for small to medium-sized projects and sites. Project and site boundaries are digitized by visually matching features from the paper USGS map to the features on

$$
\begin{aligned}
& \text { Notes (digitizing comments) } \\
& \text { NO FORM / DIG BY LEGALS gt1 recs }
\end{aligned}
$$

\section{Figure 22. Notes field (digitizing comments)}

the digital topographic map files in the geodatabase. Digitizing is also accomplished using a tablet or georeferenced image. In both of these cases, the entity to be digitized is traced after the image has been georeferenced. Tablet digitizing and digitizing using georeferenced images are used primarily when dealing with large, intricate survey areas, such as seismic projects. In theory, georeferenced images should provide the highest degree of accuracy in both horizontal position accuracy and in site boundary precision. 
However, in practice all three methods provide comparable data accuracy due to human error.

Each project report and site form was treated individually so that the most accurate information possible could be added to the geodatabase. The quality of the information for each project and site varied by survey organization and through time, so the quality of the information contained within the geodatabase also varies. However, by tracking certain key elements that contribute to variations in the quality of the data, a database has been created that is as accurate as possible, contains the most data possible, and makes possible the comparison of data of varying quality.

In order to keep GIS data current and up-to-date the digitizing application has also been customized and installed in all BLM field offices. All of the BLM's cultural resource staff were trained on the use of the application in April of 2004. Newly recorded sites and inventories received by BLM are being digitized when they review and process reports. The Wyoming BLM state office is coordinating the inclusion of the BLM dataset into the master WYCRIS GIS.

\section{Cost Analysis of the Work Effort}

Technologies the WYSHPO uses to provide on-line information systems are industry standard and were already in place in the WYCRO prior to the commencement of the AMP project. The challenge of maintaining these systems in the long term and finding stable funding sources to support the day-to-day maintenance and upkeep of the system will continue to be challengs for the WYSHPO. Because this project has developed fully populated GIS and information datasets for an eight county study area, the northeastern part of Wyoming, including the Buffalo, Casper, and Newcastle BLM field offices have current information as of December 31, 2004. Since the posting of the Wyoming Cultural Resource Information System (WYCRIS) on the Internet, almost 100,000 queries have been conducted. In the future, cost savings are anticipated with CRMTracker and fully populated GIS systems throughout Wyoming. To date, approximately 50 percent of all spatial information is included in WYCRIMS. This project targeted the northeastern portion of Wyoming due to the high volume of energy related projects being conducted and proposed in the area. 


\section{Examples of Time and Expense Savings Using New and Improved Technologies}

$\checkmark$ Savings to WYSHPO -Assuming all queries completed on the website save SHPO time and expenses:

- If each query saves on average 0.25 hours of SHPO staff time, then 47,526 work hours were saved. This equates to eleven and a half years of staff time since FY2000. An average wage paid by SHPO is $\$ 15.00$ per hour. Over the four year time period, approximately $\$ 356,445$ has been saved in staff salaries.

- If each request requires a long distance phone call (since most federal agencies and consultants are not local), and if each call on average costs conservatively $\$ .50$, then $\$ 48,450.40$ has been saved in telecommunication costs.

- If each query requires a document to be mailed, postage savings is $\$ 35,853$.

- If the mail takes a minimum of two days transit time, the savings in "wait time" for decision-making equates to 530 years since FY2000.

- If we assume each site form is on average five pages in length, and 3,000 forms are accessed on-line each year, $\$ 1,500.00$ per year is saved in copy costs.

- Annually the WYSHPO saves approximately 2.85 fulltime employees (FTE) per year, which is approximately $\$ 88,918$ per year in salary $+\$ 12,112$ in telecommunications $+\$ 8,963$ in postage $+\$ 1,500$ in copy costs +133 years "wait time". Total annual cost savings is $\$ 101,493+133$ years in project delay.

$\checkmark$ Savings to the Bureau of Land Management - BLM queries to WYSHPO web data: 23,763 queries

- If each query saves 0.25 hours of BLM staff time, then 5,941 work hours were saved. This equates to 2.9 staff years since FY2000. Assuming an average wage paid by BLM is $\$ 20.00$ per hour, over the four year time period approximately $\$ 118,820$ has been saved in staff salaries.

- If each request requires a long distance phone call (most federal agencies are not local), and if each call on average costs conservatively $\$ .50$, then $\$ 11,881$ has been saved in telecommunication costs.

- If each query requires a document to be mailed, postage savings is $\$ 8,792$.

- If the mail takes a minimum of two days transit time, the savings in "wait time" for decision-making equates to 130 years since FY2000.

- Annually BLM saves approximately .7 FTE per year, which is approximately $\$ 29,705$ per year in salary $+\$ 2,970$ in telecommunications $+\$ 2,198$ in postage + 130 years "wait time". Total BLM annual cost savings is $\$ 34,873+32.5$ years in project delay.

$\checkmark$ Savings to Industry - This section assumes all private consultant queries are generally on behalf of Industry. Consultant queries to WYSHPO web data: 34,168 queries

- If each query saves 0.25 hours of Consultant staff time, then 8,542 work hours were saved. This equates to 4.1 staff years since FY2000. If an average wage paid to consultants is $\$ 9.00$ per hour (a very conservative hourly wage), over the four year time period approximately $\$ 76,878$ has been saved in staff salaries. 
- If each request requires a long distance phone call (most consultants are not local), and if each call on average costs conservatively $\$ .50$, then $\$ 17,084$ has been saved in telecommunication costs.

- If each query requires a document to be mailed, postage savings is $\$ 12,642$.

- If the mail takes a minimum of two days transit time, the savings in "wait time" for decision- making equates to 187 years.

- Since most costs are passed from consultant to client, on an annual basis Industry save approximately 1 FTE per year, which is conservatively $\$ 18,700$ per year in salary $+\$ 4,271$ in telecommunications $+\$ 3,161$ in postage +46 years "wait time". Total Consultant annual cost savings is $\$ 81,168+46.75$ years in project delay.

Overall total annual cost savings to WYSHPO, BLM, and Oil and Gas Industry in Wyoming: Dollars saved is $\$ 217,534$ and 212.25 years of time is saved per year. This analysis did not include the US Forest Service, Bureau of Reclamation, Wyoming Department of Transportation or the National Resources Conservation Service. They are also daily users of the on-line information system. Additional costs, for computer support and infrastructure, are roughly $10 \%$ of this total annually. So, even including these costs, the system is very efficient. 


\section{CHAPTER 4}

\section{EXPERIMENTAL:}

\section{ARCHAEOLOGICAL BURIAL MODEL FOR THE POWDER RIVER AND TONGUE RIVER HYDROLOGICAL BASINS, WYOMING}

Adaptive management is an on-going process. The adaptive management paradigm process model facilitates self-correction and continual improvement (Figure 23). Within the context of the AMP project, adaptive management refers to implementing a selfcorrective process to minimize management conflicts between cultural resources and oil and gas extraction on federal land. This project poses possible solutions to be implemented, monitored, evaluated, adjusted, and assessed.

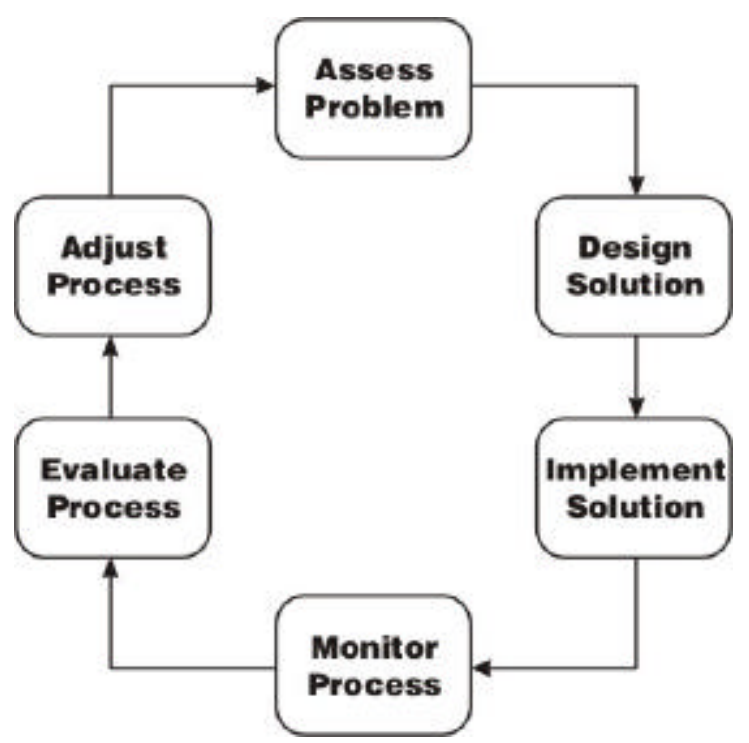

Figure 23. Adaptive management flow chart

Expanded development of energy resources in northeastern Wyoming brings with it the risk that archaeological sites are inadvertently damaged. Sites containing buried, intact, and well-preserved archaeological material are some of the most scientifically important cultural resources within the project area. They may contain all categories of data that contribute to the significance of surface sites, as well as a number of categories of other information that surface sites lack. For example, buried sites contain durable artifacts as do surface sites, but they also can preserve organic debris and chronological relationships through stratigraphy. The level of management effort buried sites receive should be in proportion to their scientific importance. However, managers often have a poor understanding of the geological and soil processes that lead to burial and preservation of such sites. In turn, this leads to faulty prediction of sites having potential for preserved 
and intact subsurface cultural materials. Consequently, some sites are subjected to more investigation than they warrant, while other sites having subsurface cultural levels remain undiscovered until they are destroyed or unearthed during construction activity. Failure to understand the formation of the archaeological record causes unexpected development costs from construction and production delays, and a loss of valuable scientific information.

Having identified the potential problem, this chapter presents two geoarchaeological models that predict the location of deposits that might contain buried and intact archaeological material: Buried Archaeology-Fine Scale (1:24k) (FINE) and Buried Archaeology-Coarse Scale (1:25k) (COARSE). These models inform users as to the likelihood of discovering buried, intact archaeological sites in specific areas of interest. If applied properly, these burial models will lead to more efficient management of cultural resources, so that both resource preservation and energy extraction are facilitated.

The proposed models will need to be implemented within the Section106 process by land management agencies in order to achieve their potential. In anticipation of this implementation, we suggest how to monitor, evaluate, and adjust the models so that they might fulfill their function under changing development scenarios.

These models are specific to the Wyoming portion of the hydrological Powder River and Tongue River basins (Figure 24). The models produce digital maps that contain polygons coded by the sensitivity or risk of encountering sediments that have suitable age and energy regime to contain buried cultural material. It is recommended the models be used at an appropriate scale (1:24,000 for FINE model or 1:250,000 for COARSE model). The sensitivity criteria presented in outline form below should not be used outside of the geographic area described in this report. To do so might lead to erroneous conclusions regarding the sensitivity of locations not modeled within this report. In principal, however, similar models could be constructed for any area. Four components were used to construct the models: (1) field reconna issance; (2) literature review; (3) data acquisition; and (4) GIS visualization. Field reconnaissance was conducted in Campbell, Johnson, Natrona, and Sheridan counties, Wyoming, April 26-30 and May 5-7, 2003.

\section{Burial Model Framework}

A systematic attempt to model and map the spatial location of deposits in the study area that might contain preserved, buried sites has not been undertaken until now. However, a number of informative geoarchaeological studies have been conducted and provide valuable background information. John Albanese has investigated numerous sites in the Powder River Basin (Albanese 2000) and authored several regional summaries. This work has been supplemented by the soils studies of Richard Reider (Reider 1990). Much of their work has been conducted as part of archaeological research undertaken by Dr. George Frison, University of Wyoming. In addition, archaeological burial models (landscape sensitivity frameworks) have been developed and successfully applied to other areas of Wyoming (Eckerle and Taddie 1997; Eckerle et al. 1999; Eckerle et al. 2000) as well as areas in Nevada (Drews et al. 2004) and southern California (Horne et al. 2001). 
The modeling framework presented in this report is based on the assumption that intact cultural resources (from a National Register of Historic Places [NRHP] perspective) are found in geological strata that were deposited since the end of the last Ice Age. As used here, the date for this event is 14,000 radiocarbon years ago. As well, archaeological

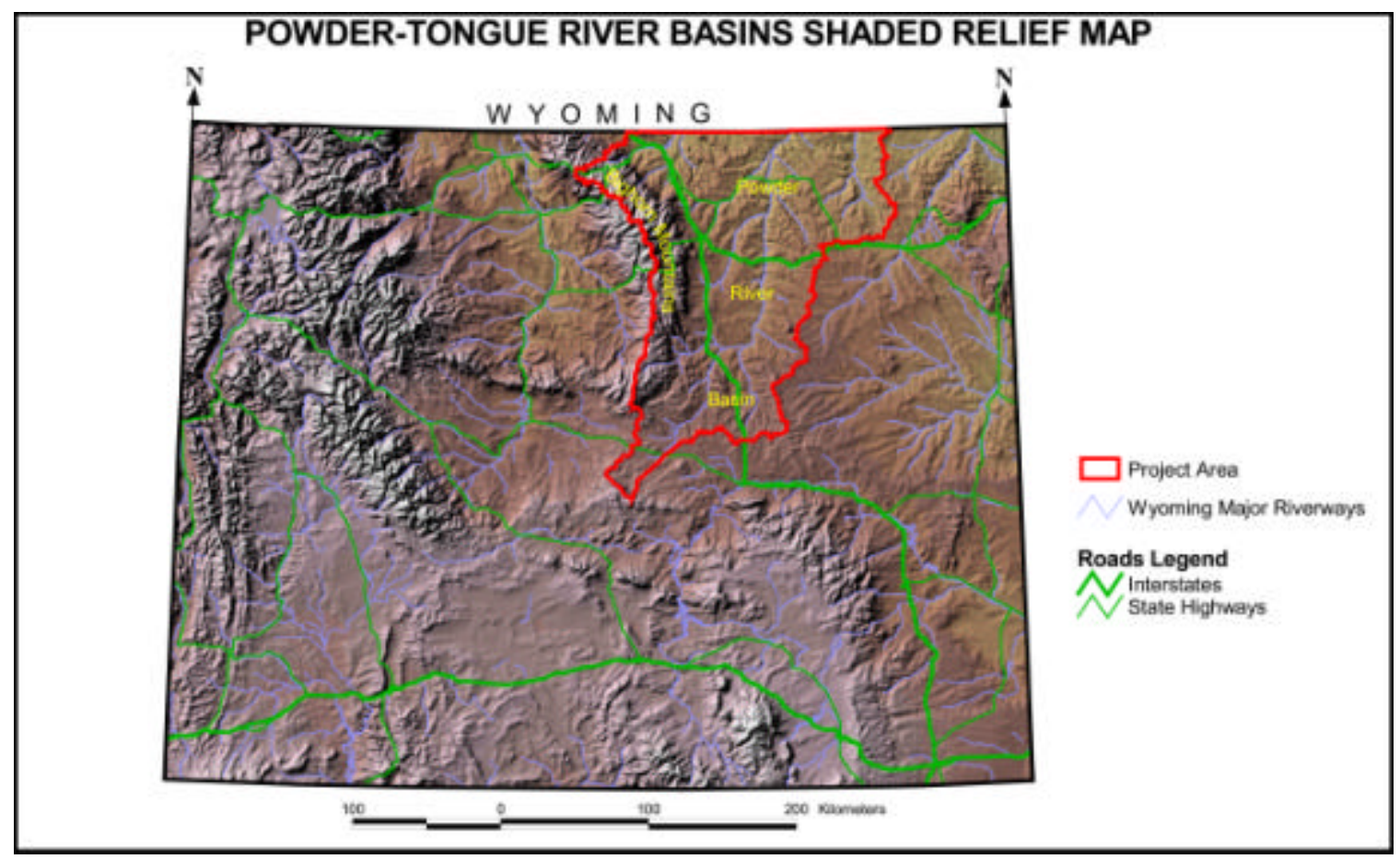

Figure 24. Map of the project area illustrating its location in the Powder River and Tongue River basins, northeastern Wyoming (USGS EROS Data Center 2003)

materials that accumulated within moderate to low energy depositional environments are likely to have been buried close to where prehistoric peoples used and discarded them. Also many of these depositional environments buried cultural occupations deeply and rapidly enough to have escaped the effects of long-term surface and near-surface disturbance processes, thus maintaining stratigraphic and behavioral integrity. Buried prehistoric archaeological sites with high stratigraphic integrity are extremely important from many perspectives; however, such sites are difficult to identify and manage and expensive to treat under Section 106 of the National Historic Preservation Act (NHPA). These factors form the rationale for constructing models specifically designed to assist in predicting areas where these types of sites might occur.

The models divide the landscape into archaeological site burial sensitivity categories ranked in a continuum from very high, high, moderate, low, to very low sensitivity. These sensitivity categories reflect the potential of a landscape to contain buried and relatively intact occupation strata, which exhibit both contextual and associational integrity. Of course, all fine-grained deposits may be subjected to bioturbation, freezethaw deformation, and other disturbances. Modern earth-disturbing activities put any buried and intact sites at risk of the loss of scientific information and thus, data that might 
contribute to NRHP eligibility for the sites. Following from the models' predictions, buried sites in these locations are likely to contain perishable archaeological residues, such as bone and charcoal, which are rare and valuable remains useful in archaeological interpretation.

Geological landform and soils data are used in GIS to create multiple, overlaying map images that illustrate the burial sensitivity of areas specific to the project area. Digital data used in the GIS are available in multiple forms: geological data are from the Wyoming Surficial Geology Map (Case et al. 1998); soils data at the state level from the National Resources Conservation Service (NRCS) State Soil Geographic (STATSGO) database (Soil Conservation Service 1994); and soils at the county level from the NRCS Soil Survey Geographic (SSURGO) database (Natural Resources Conservation Service 1998, 1999, 2000, 2002a, 2002b, 2003a, 2003b; United States Forest Service 1999).

Ultimately, modeled data can be used as the basis for informing and guiding individual, project-specific management decisions at the 1:250,000 (COARSE) scale or, where available, at a 1:24,000 (FINE) scale (see qualifications below). Land managers can use this information to anticipate areas of archaeological compliance concern, while developers can use it to project the costs of development in targeted and alternative areas. Cultural resource management firms can use this information in the planning stages of their Section 106 consultations; their field archaeologists can make practical use of the models to better understand the geoarchaeological settings where they are likely to discover significant, buried archaeological sites. A field protocol handbook manual (see Appendix B) accompanies this report. It is designed for use by four categories of users: (1) agencies; (2) industry; (3) cultural resource consultants; and (4) field archaeologists. This is a practical, condensed guide that informs users of the logic behind the models, as well as how they might implement it given their varying needs.

\section{Buried Sites and Site Formation Processes in the Powder River Basin: Definition, Discovery, and Preservation Issues}

Subsurface cultural material is not equivalent in meaning to a buried site. As discussed below, artifacts from surface occupations are often turbated into the subsurface. Rarely, subsurface artifacts can be documented within buried natural strata. More often, zonation, which might be confused with buried strata, are simply soil horizons. Albanese (1981) proposed a minimum depth of burial of $20 \mathrm{~cm}$ to indicate a stratigraphically buried site. Although artifacts can be turbated much deeper, $20 \mathrm{~cm}$ seems a reasonable limit for management purposes.

\section{Factors Affecting Site Discovery: Plan View Versus Profile}

The archaeological record, as a landscape phenomenon, has both horizontal and vertical components. Human occupations deposit artifacts and features in horizontal distributions across the landscape. In time, they may become buried, adding a vertical component to the archaeological record. Archaeological survey is designed to discover horizontal distributions. Thus, buried sites often remain undiscovered until earth-moving activities 
occur during development. Alluvial settings are ideal for the formation and preservation of vertical deposits, but, as Albanese (1978) noted, relatively few buried sites in the Powder River Basin have been discovered in such contexts, when compared to other areas in Wyoming despite the frequent presence of cutbanks that expose appropriate sediment. He accounted the rarity of buried sites by the fact that streams destroy many sites over time. Alternatively, it is notable that discovery of buried sites is difficult in alluvial settings compared with their upland counterparts. An experienced field archaeologist is simply less likely to discover eroding cultural material at the base of a cutbank than on flat or rolling landscapes. Surface occupations and the horizontal degradation of buried occupations leave artifacts behind as a horizontal lag deposit. Whereas artifacts that erode out of arroyo walls are generally flushed downstream during subsequent flood events, thus, failing to accumulate to any significant surface density below the cutbank. A site exposed in cross-section rather than plan view logically makes fewer artifacts visible for discovery, further reducing the probability that buried sites will be discovered during survey.

Pedestrian archaeological surface inventory (survey) involves walking the landscape looking for artifacts. Generally artifacts with a long axis of $2 \mathrm{~cm}$ are visible for $2 \mathrm{~m}$ on either side of the archaeologist. For example, suppose a circle of $2 \mathrm{~m}$ in radius $(125,600$ $\mathrm{cm}^{2}$ ) representing an archaeological site (activity area) contains 100 artifacts (flakes), all about $2 \times 2 \times 0.2 \mathrm{~cm}$ in size. The total area of artifacts is $400 \mathrm{~cm}^{2}$. The ratio of the site area to the flake area is 314:1. From the center of the circle all 100 artifacts are visible. Now, take a string line $1 \mathrm{~mm}$ in diameter and randomly transect the site (plan view) circle. The probability of encountering a single flake along the $1 \mathrm{~mm}$ string line can be calculated as:

$$
\operatorname{Pr}(\text { flake })=400 / 125600=0.003
$$

and for not encountering a flake as:

$$
\operatorname{Pr}(\text { no flake })=125200 / 125600=0.997
$$

This action is equivalent to viewing artifacts exposed in a cutbank. Base rate probabilities of encountering a single flake exposed in a cutbank are around 0.3 percent, so 99.7 percent of the time no artifact will be encountered.

Note that artifacts are usually exposed on edge in a buried context. If a 1-m deep trench were excavated through the $2 \mathrm{~m}$ wide buried occupation $\left(100 \mathrm{~cm} \times 200 \mathrm{~cm}=20,000 \mathrm{~cm}^{2}\right)$ to expose the artifact-laden (400 total artifacts) surface in profile, at best, one or two flakes might be encountered (on edge; $2(2 \mathrm{~cm} \mathrm{x} 0.2 \mathrm{~cm})=0.08 \mathrm{~cm}^{2}$ ). In that instance, the ratio of site area to flake area increases to $250,000: 1\left(20,000 \mathrm{~cm} 2 / 0.08 \mathrm{~cm}^{2}\right)$. It is easy to see why site areas exposed in arroyo walls are difficult to identify in profile. In fact, it is a wonder that buried sites are ever found in cutbanks through visual inspection.

Typically, it is the presence of generally rarer, larger indications such as culturally stained carbonaceous sediment, large animal bone, or the presence of fire-cracked rock 
that give the location of buried sites away. Unfortunately, many of the sediments in the Powder River Basin are dark in color and this makes cultural stains more difficult to identify than, for instance in the Wyoming Basin where many post-Glacial sediments are lighter colored. In any case, since most surface sites are flake scatters, it is difficult to evaluate the frequency of buried versus surface sites from archaeological inventory data. From this perspective, the grassy Powder River Basin is a problematic setting to locate buried sites as opposed to the rolling dunal landscapes in the Wyoming Basin. Buried sites in the latter are easily found by observing artifacts in plan view at the base of dunes and then identifying the highest elevation on the dune slope at which artifacts appear. This highest elevation often marks the position of an eroding zone of cultural material.

\section{Site Formation and Destruction Processes}

The purpose of the modeling is to more effectively manage buried prehistoric sites. In order to accomplish this, it is important that archaeologists understand the types of site formation and destruction processes that act to create and destroy buried sites. This section discusses common site formation and destruction processes, and provides a basis for evaluating the types of landscape settings and deposits that are conducive to the burial and preservation of sites. It is also important that concerned parties understand how various types of erosion can influence the discovery process for buried sites.

Archaeological materials originate within a behavioral context as objects used and produced by people. After the objects are lost, discarded, or abandoned, they enter the archaeological record. The archaeological record is valuable to modern society, in part, because archaeological science can derive information about history, lifestyles, and cultural processes that influenced the people who produced the objects now categorized as artifacts and archaeological features. One of the realities of archaeology is that when artifacts are found as close as possible to the original positions where they were lost, discarded, or abandoned, the archaeologist is able to learn much more than if the artifacts were moved from their original positions sometime between their abandonment and when the archaeologist recovers them. Various cultural and natural processes can move the artifacts from their original positions and these processes make it more difficult to extract information about the original behavior of the people who left them. A discussion of pertinent site formation and destruction processes is presented here. The following categories are summarized, which generally follow Gifford (1978): occupation trampling, post-occupational (preburial) dispersal, burial dispersal, and post-burial turbation.

Occupation Trampling. The magnitude of occupation trampling (treading and scuffing) varies with respect to substrate texture, occupation traffic intensity (Rapp and Hill 1998; Schiffer 1987), and moisture content (Deal 1985). Experimental studies indicate that an occupation trample zone (or "churn zone") is formed in loose substrates. Well-sorted sands produce the thickest occupation trample zone that ranges from 5-16 cm (2-6 in) in thickness (Table 2) (Gifford-Gonzalez et al. 1985; Stockton 1973). Loamy sand will develop a 3-8 cm (1-3 in) trample zone (Villa and Courtin 1983), whereas loams produce almost no occupation trample zone (Gifford-Gonzalez et al. 1985). Dry clayey sediments, likewise, require extremely high levels of traffic or saturation before any 
occupation trample zone is produced (Eckerle, unpublished field observations).

Pedestrian traffic on cobble or larger size clasts will not produce a trample zone at all (Hughes and Lampert 1977).

Occupation trample zones can be viewed as both a positive and a negative aspect of site formation. Occupation trample zone development on a soft substrate has the effect of blurring the occupational record of finely stratified and reoccupied sites (Hughes and Lampert 1977; Villa 1982). The positive aspect of occupation trample zones is that their formation quickly hides artifacts and makes them unavailable for site cleaning and secondary refuse disposal (Schiffer 1987). In addition, items are much easier to lose in soft substrates (Schiffer 1987). As a result there is a higher potential for discriminating areas of high primary-discard (lodges, hearth activity areas, etc.) from those of low primary-discard. Additionally, scuffage (horizontal artifact dispersal due to foot traffic) is minimal on loose substrates because items are less likely to skid.

The most important aspect of trample zones is that their thickness, as predicted by the substrate texture, can be used as a baseline for comparing the thickness of actual occupation zones. If the thickness of an actual occupation zone is much thinner than predicted, then that occupation zone is probably stratigraphically truncated. On the other hand, if the thickness is much thicker than predicted, then either the zone is a specialized feature (hearth, house pit) or it is over-thickened as a result of reoccupation under an aggradational depositional regime. Truncated and over- thickened trample zones suggest some loss of site integrity.

Post-Occupational Dispersal. Post-occupational (but preburial) dispersal can alter the contextual integrity of surface archaeological materials. In general, soft substrates tend to

Table 2. Occupation churn zone thickness and predicted archaeological implications

\begin{tabular}{|c|c|c|c|c|c|c|}
\hline $\begin{array}{c}\text { SOIL } \\
\text { TEXTURE }\end{array}$ & $\begin{array}{c}\text { COMMON } \\
\text { DEPOSITIONAL } \\
\text { ENVIRONMENT }\end{array}$ & $\begin{array}{c}\text { CHURN } \\
\text { ZONE } \\
(\text { in } \mathrm{cm})\end{array}$ & $\begin{array}{c}\text { HORIZONTAL } \\
\text { SCUFFING }\end{array}$ & $\begin{array}{c}\text { EASE OF } \\
\text { CLEANING }\end{array}$ & $\begin{array}{c}\text { IDENTIFY } \\
\text { ACTIVITIES }\end{array}$ & $\begin{array}{c}\text { IDENTIFY } \\
\text { DOMESTIC } \\
\text { AREAS }\end{array}$ \\
\hline sand & $\begin{array}{c}\text { eolian dunes, } \\
\text { well-sorted fluvial } \\
\text { sands }\end{array}$ & $5-16$ & low & low & high & low \\
\hline loamy sand & $\begin{array}{l}\text { some slope deposits } \\
\text { and alluvium }\end{array}$ & $3-8$ & moderate & moderate & moderate & moderate \\
\hline $\begin{array}{l}\text { sandy loam } \\
\text { and finer }\end{array}$ & $\begin{array}{l}\text { overbank deposits, } \\
\text { lacustrine deposits, } \\
\text { and most slope } \\
\text { deposits }\end{array}$ & $<5$ & high & high & low & high \\
\hline
\end{tabular}

hold onto artifacts after they have settled into the surface (Wandsnider 1988). Additional trampling by animals, slope processes, and eolian movement are the major categories of post-occupational dispersal. However, trampling by animals, even in environments with 
high populations of hoofed ungulates, is a slow process (Gifford and Behrensmeyer 1976).

Slope wash and colluviation are two common processes that transport surface artifacts. The process of colluviation occurs commonly on relatively steep ( $>15$ percent) slopes (Rick 1976). Colluviation is gravity-driven transport in which heavier and denser materials move further down slope than lighter, less dense items (Rick 1976). Slope wash, on the other hand, involves transport in a sheet flow layer of water during storms (Butzer 1982; Reineck and Singh 1980). It can occur on low angle slopes, especially if vegetation is sparse and infiltration levels are low. This type of transport follows hydrodynamic rules in that smaller, less dense material is transported the furthest down slope.

Eolian transport of surface artifacts can occur whenever wind shear exceeds the hold of gravity (Bagnold 1941). This can be a major source of dispersal for small artifacts unless they quickly become buried (Wandsnider 1988). Eolian transport is not confined to dune fields but can occur whenever wind conditions are suitable. It is most effective on locations with minimal vegetation cover.

Burial Dispersal. Artifact dispersal occurs in most depositional environments (Butzer 1982). An exception to this is eolian silt (loess) environments. Lack of dispersal in loess is the result of a low surface wind shear (because vegetation is usually present) also causing low impact energy of silt particles. Size sorting of artifacts and patterned long axis orientation are common indicators of artifact redeposition (Brown 1997; Dibble et al. 1997).

Many surface sites on flat, vegetated surfaces are eventually, albeit slowly, buried by silt. Other depositional environments can be ranked into two categories of potential burial dispersal. The relatively low energy category includes alluvial overbank, sheet flow (including slope wash), and eolian sand environments. The high-energy category includes alluvial channel, debris flow, and colluvial depositional environments. For most water and air entrained sediments, artifact movement is a function of size and density (Gifford and Behrensmeyer 1976). Frison et al. (1988) propose a simple rule-of-thumb for determining the depositional dispersal of buried lithic artifacts. This rule states that any artifacts smaller than the break off point for the coarsest 10 percent of a sediment sample (finer than the 90th percentile) were probably moved during burial.

Post-Burial Dispersal. A wide range of processes can act to disperse archaeological residues after burial. Erosion and subsequent redeposition can produce a secondary deposit that contains no contextual integrity (Butzer 1982; Schiffer 1987; Stein 2001). Many other dispersal processes are possible (Butzer 1982; Schiffer 1987; Waters 1992; Wood and Johnson 1978), including soil formation, bioturbation (including insect and rodent burrowing [Paton et al. 1995]), plant growth (including tree tip-out), and turbation from repeated ground freezing (frost heave). 
The discussions of site formation and destruction processes suggest that many factors, especially geological and soil process can degrade archaeological sites. This necessitates thorough, project-specific descriptions of surficial geology and soils.

\section{Description of Project}

\section{Modern Environment}

Hydrography. The project area encompasses the Wyoming portion of the Powder River and Tongue River hydrological basins (Figure 25). Both drainages are tributaries to the Yellowstone River. Bounding drainage basins include the North Platte River to the south, Cheyenne River to the southeast, Belle Fourche to the east, Little Missouri to the northeast, Little Bighorn River to the north, Bighorn River to the west, and Sweetwater River to the southwest.

The Tongue River heads in the Bighorn Mountains near Burgess Junction and flows northeastward into Montana. Major tributaries are (from north to south with associated headwaters elevations): North Tongue River (3,098 m [10,164 ft]), South Tongue River (3,300 m [10,827 ft]), Goose Creek (3,528 m [11,575 ft]), Little Goose Creek (3,600 m $[11,811 \mathrm{ft}])$, and Piney Creek, which heads on Cloud Peak (4,014 m [13,169 ft]), the highest peak in the Bighorn Mountains. The Tongue River crosses the Wyoming State line at an elevation of $1,061 \mathrm{~m}(3,481 \mathrm{ft})$.

Major northeast-flowing tributaries of the Powder River also head in the Bighorn Mountains and their foothills. They include (from north to south with associated headwaters elevations): Clear Creek (3,744 m [12,283 ft]), Crazy Woman Creek (3,218 m [10,558 ft]), North Fork of the Powder River (3,216 m [10,551 ft]), Middle Fork of the Powder River (2,659 m [8,724 ft]), and South Fork of the Powder River (2,513 m [8,245 $\mathrm{ft}]$ ). Northwest-flowing tributaries head at much lower elevations and include (from north to south): Little Powder River (1,390 m [4,560 ft]), Wild Horse Creek (1,330 m $[4,364 \mathrm{ft}])$, and Salt Creek $(1,686 \mathrm{~m}[5,531 \mathrm{ft}])$. The elevation of the Powder River as it leaves Wyoming is near $1,037 \mathrm{~m}(3,402 \mathrm{ft})$.

Structural and lithologic controls affect the drainage patterns of the basin (Albanese 1990). Areas underlain by permeable substrates are dominated by low to medium density drainages. Some shallow, internally drained basins are water collection areas. Drainage

basin extent for the Tongue River basin is $13,980 \mathrm{~km}^{2}\left(5,398 \mathrm{mi}^{2}\right)$ and $34,160 \mathrm{~km}^{2}$ $\left(13,189 \mathrm{mi}^{2}\right)$ for the Powder River (Zelt et al. 1999). Together, the Powder River and Tongue River drainage basins encompass an area approximately $48,140 \mathrm{~km}^{2}$ $\left(18,587 \mathrm{mi}^{2}\right)$. 


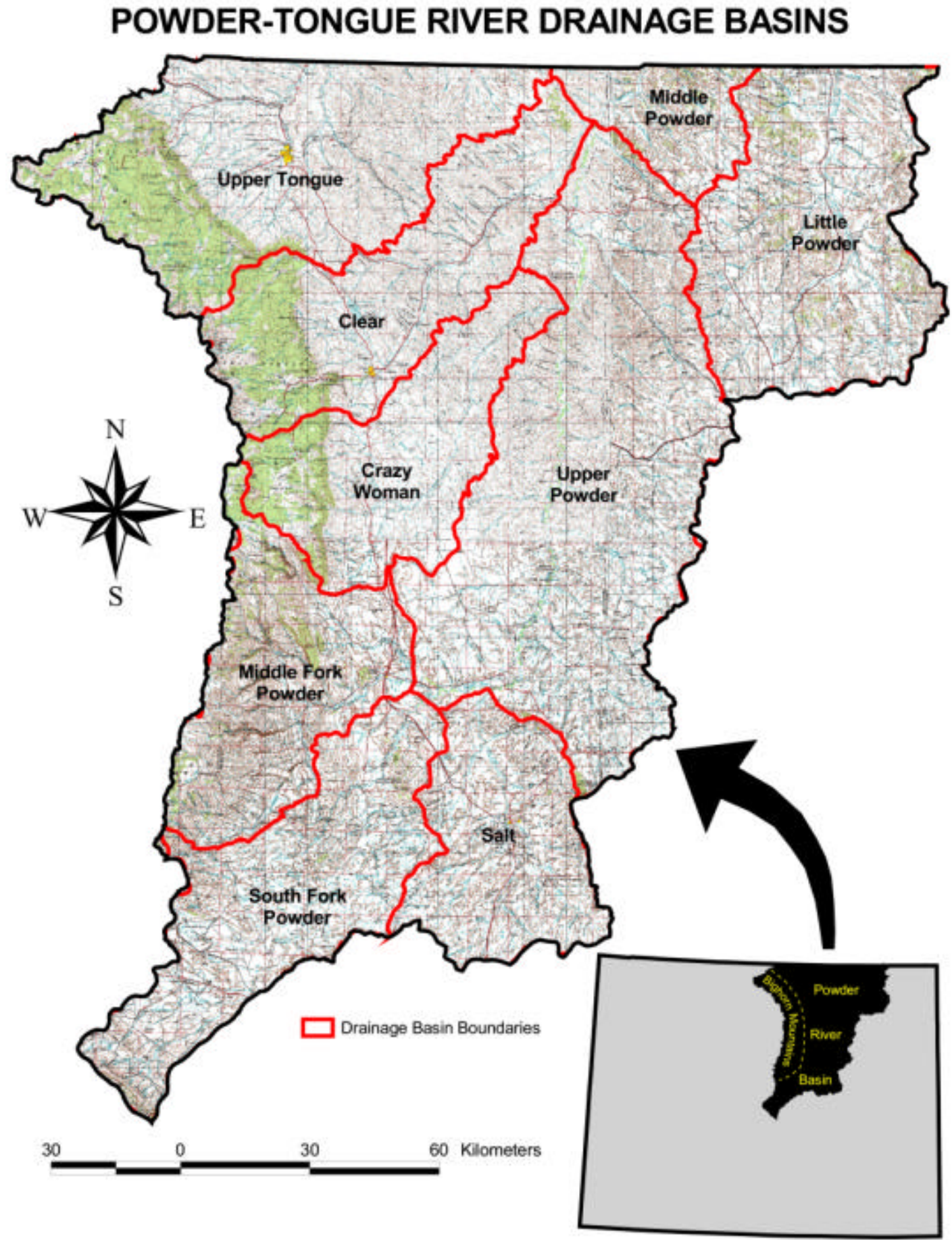

Figure 25. Map illustrating the extent of the Powder River and Tongue River hydrological sub-basins in northeastern Wyoming (Steeves et al. 1994) 
Geology. The project area includes part of the physiographic Powder River Basin (Figure 24) and adjacent Bighorn Mountains. This basin is a structural and depositional depression formed from the downward displacement of Paleozoic and Mesozoic sedimentary rocks associated with the Laramide Orogeny, where many sedimentary strata are offset in relationship to adjacent, uplifted areas (Thornbury 1965). The axis of the basin plunges gently to the northwest (Zelt et al. 1999). Major structural features bound the Powder River Basin including the Pryor-Bighorn-Casper Arch to the west, Laramie Range-Hartville Uplift to the south, Bear Lodge-Black Hills to the east, and Miles City Arch to the north. Traditionally, the Powder River Basin is divided into two parts based on surface drainage. The western Powder River Basin (WPRB) includes the Powder River and Tongue River hydrological basins, whereas the eastern Powder River Basin (EPRB) is drained by the Cheyenne, Belle Fourche, and Little Missouri rivers. Thus, the western Powder River structural basin, along with the portion of the Bighorn Mountains drained by the Powder and Tongue rivers, correspond to the project area discussed in this report.

The Bighorn Mountains, the most prominent landform visible to the west of the Powder River Basin, formed during the Late Cretaceous and Tertiary Periods, and like the nearby Black Hills, are cored by Precambrian basement rocks. Unlike other Laramide uplifts in Wyoming, thrust faults are present on both the west and east sides of the range (Lageson and Spearing 1988). Additionally, two cross-cutting faults divide the range into three blocks: the first fault trends northeast-southwest near Tongue River Canyon, and the second trends east-west nearly parallel to Tensleep Canyon. During the Laramide Orogeny, the north block was thrust southwest over the Bighorn Basin along the Big Trails fault, the middle block moved eastward over the Powder River Basin, and the south block was shoved west over the Five Springs thrust fault (Lageson and Spearing 1988).

Geology of the project area is illustrated in Figure 26. Crystalline granitic rocks core the Bighorn Mountains, while Paleozoic and Mesozoic sandstones, limestones, and dolomites dip steeply down the eastern flank of the Bighorns into the Powder River Basin (Love and Christiansen 1985). The heavily glaciated resistant core is exposed in the middle portion of the Bighorn Mountains, which Tertiary erosion has plainated into two erosional surfaces: the Summit and Subsummit surfaces, respectively. The subsummit surface was erosionally modified by cirque carving during Pleistocene glaciation (Thornbury 1965). Cretaceous sandstone and shale crop out in the belt of foothills along the eastern flank of the Bighorns. Conglomerates shed as alluvial fans from the youthful Bighorn Range interfinger with the Eocene Wasatch Formation at many places along the foothills (Lageson and Spearing 1988). 


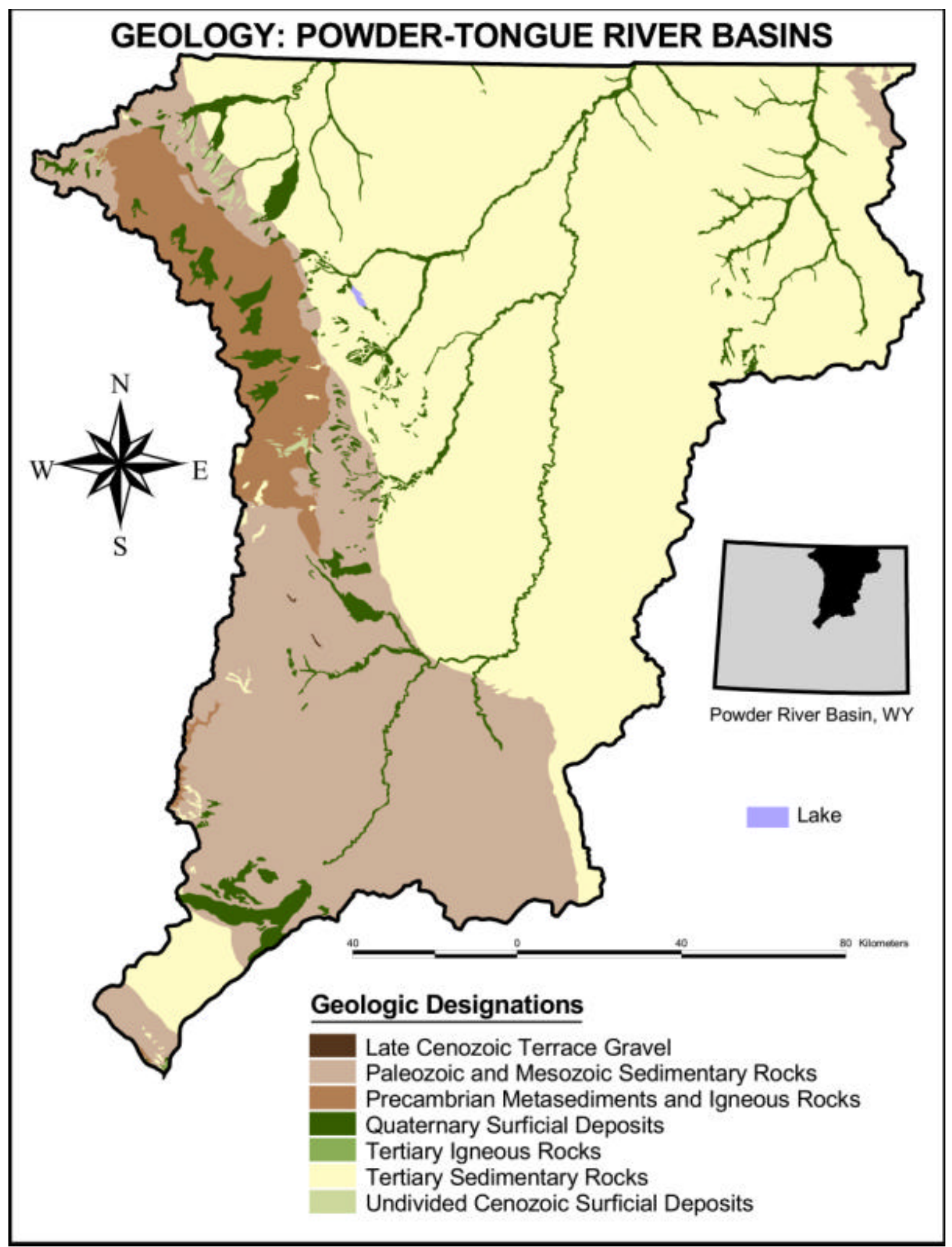

Figure 26. Project area geology (U.S. Geological Survey 1994) 
The basin areas are underlain by pre-Cenozoic-age rocks, which were downwarped during the Laramide Orogeny to form a basin. This basin filled with sediment from the adjacent uplands until late Miocene or early Pliocene times when regional uplift initiated a period of basin degradation (Mears et al. 1991). The most common formations encountered formed during the basin filling cycle include (from oldest to youngest): (1) Paleocene Fort Union Formation (Tullock, Lebo, and Tongue River members); (2) Eocene Wasatch Formation (Moncrief and Kingsbury Conglomerate members); and (3) Oligocene White River Formation (Love and Christiansen 1985) (Figure 27). Coal beds are common in Cretaceous through early Tertiary units, and lightning-induced ignition of the coal seams has resulted in baked sediments, clinker beds, and pyro-karst collapse features. Quaternary gravel capped and plainated benches occur near the foot of the Bighorn Mountains, and Quaternary alluvium occupies river valleys in the basin. Eastern-flowing streams draining into the Powder River Basin carry sediments derived mostly from granite, limestone, and dolomite. Stream valley alluvium is the predominant type of Quaternary deposit along the flanks of the mountains (Hunt 1986). Basin-area drainages erode and carry sediments derived from younger, mostly sandstone and shale, rocks.

Soils. Soils of the project area are illustrated in Figure 28. Although a variety and diversity of soils are illustrated on this map, several trends are apparent. Soils along the foothills-basin margin reflect a relatively moist precipitation regime (Kronenberger et al. 1977). Most of the soils receive enough precipitation to support the vegetation necessary for the development of humic A horizons. Areas of hard, resistant bedrock are mantled by thin, weakly formed soils (Lithic Ustic Torriorthents). Soils on soft, easily eroded bedrock are thick but only weakly horizonated (Ustic Torriorthents). More geomorphically stable locations exhibit soils with weathered and structured B horizons (Camborthids). Landscapes that have remained relatively uneroded for the longest period of time contain soils with clay-enriched B horizons (Ustollic Haplargids). Soil temperature regimes are generally frigid in the northwest and mesic in the remainder of the basin. Soil moisture regimes range from aquic along perennial streams to aridic in the drier portions of the basin.

Vegetation. Porter (1962) indicates that vegetation zonation in Wyoming is dependent on elevation. Küchler (1966) delineated various zones of potential vegetation in the project area. A west-to-east transect from the crest of the Bighorn Mountains out into the basin yields the following vegetation types: (1) Alpine meadow along the crest of the range; (2) Western spruce- fir forest on the upper montane slopes; (3) Douglas fir forest on the lower mountain slopes; (4) grama-needlegrass-wheatgrass grassland in the western basin; and (5) sagebrush steppe along incised river breaks. As well, an area of eastern Ponderosa forest is present between the Tongue and Powder rivers. 


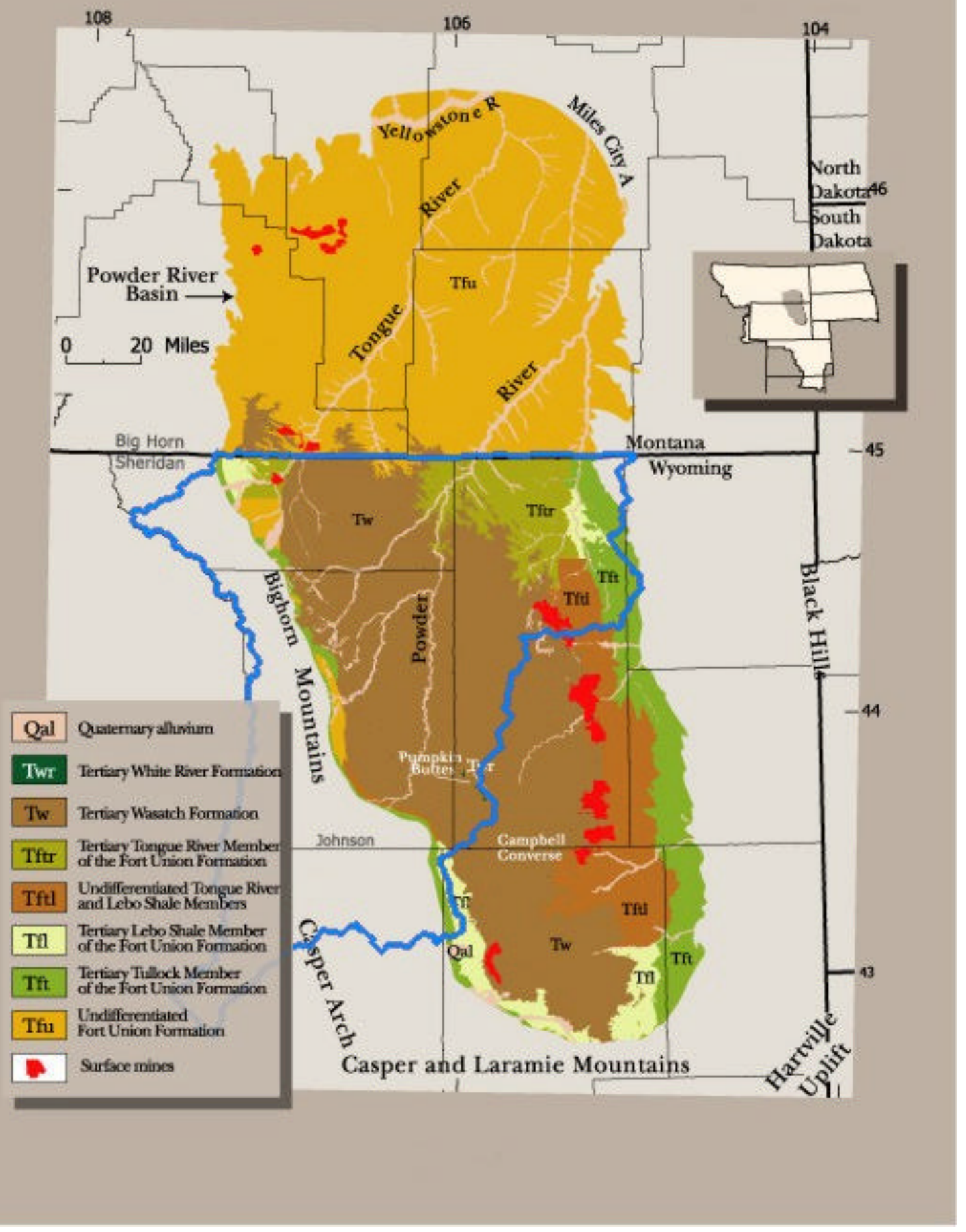

Figure 27. Tertiary bedrock geology of the Powder River and Tongue River basins showing axis of Powder River structural basin (Flores et al. 2001, Figure PS-50) 


\section{POWDER-TONGUE RIVER BASINS CLASSIFIED SOILS MAP}

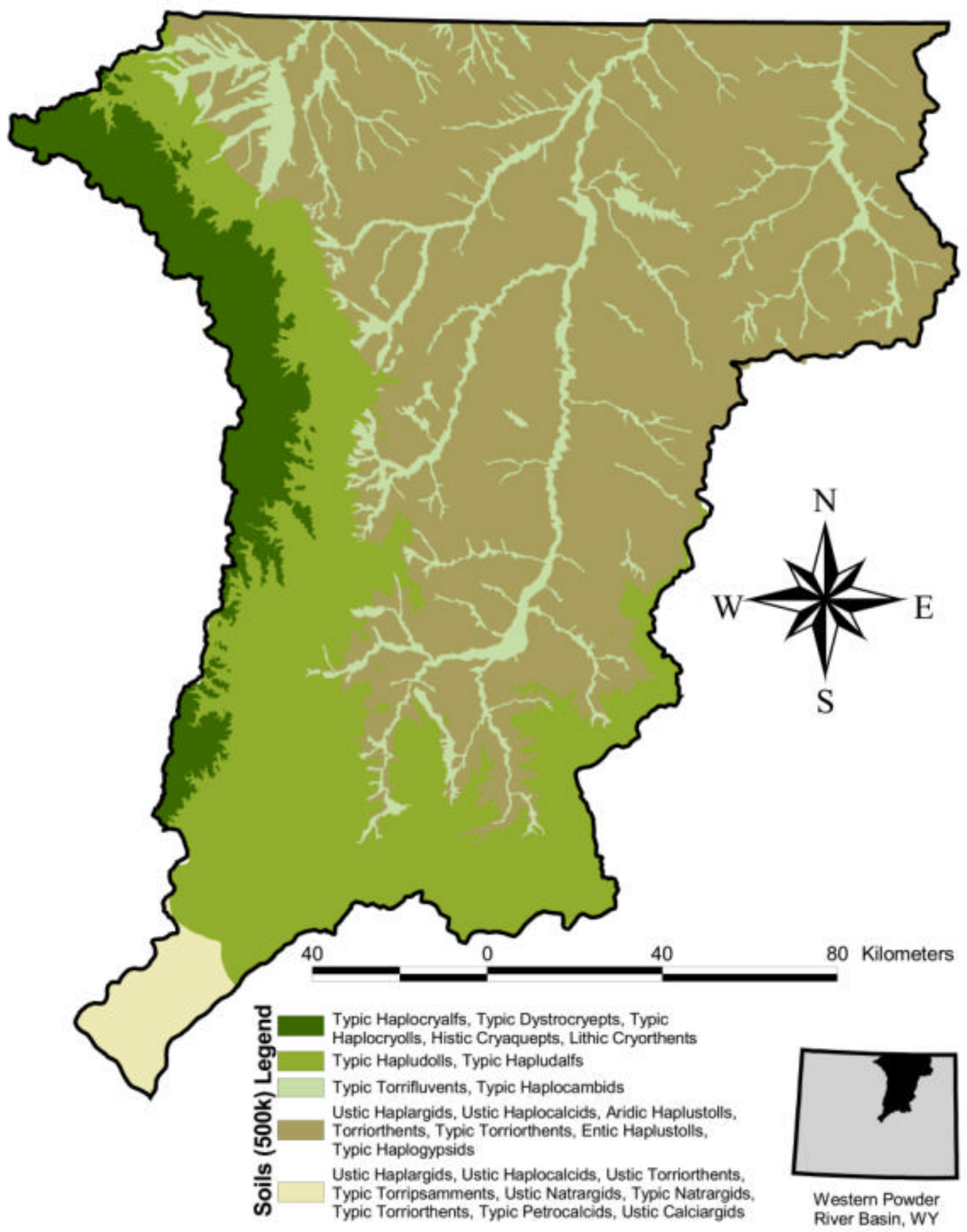

Figure 28. Map (1:500,000) illustrating the distribution and composition of soil-map units classified by soil taxon groups (Munn and Arneson 1998) 
Climate. Climate of the study area is continental and characterized by cold winters and warm summers. Precipitation is distributed throughout the year and varies by elevation. Mountains are cold and moist whereas the basin is warmer and drier. In the high mountains the average maximum January temperature is $-4.4^{\circ} \mathrm{C}\left(24^{\circ} \mathrm{F}\right)$ (all temperatures are monthly means); and the average maximum July temperature is $22.2^{\circ} \mathrm{C}\left(72^{\circ} \mathrm{F}\right)$ (National Oceanic and Atmospheric Administration 1985). Minimum temperatures for January and July are $-17.8^{\circ} \mathrm{C}\left(0^{\circ} \mathrm{F}\right)$ and $2.2^{\circ} \mathrm{C}\left(36^{\circ} \mathrm{F}\right)$, respectively (National Oceanic and Atmospheric Administration 1985). Temperatures in the basin vary but are colder in the winter due to the intrusion of cold continental air masses.

Maximum basin January temperature is $2.2^{\circ} \mathrm{C}\left(36^{\circ} \mathrm{F}\right)$ and the average maximum July temperature is $31.1^{\circ} \mathrm{C}\left(88^{\circ} \mathrm{F}\right)$. Minimum basin temperatures for January and July are $17.8^{\circ} \mathrm{C}\left(0^{\circ} \mathrm{F}\right)$ and $11.1^{\circ} \mathrm{C}\left(52^{\circ} \mathrm{F}\right)$, respectively (National Oceanic and Atmospheric Administration 1985). Average precipitation varies from $76.2 \mathrm{~cm}$ (30 in) in the high mountains to $35.6 \mathrm{~cm}$ (14 in) in the basins (Soil Conservation Service 1983). Most of the precipitation falls in the spring, and winds typically arrive from the northwest (Martner 1986).

Present and Historic Wildlife. Some of the fauna found within the area were important to prehistoric peoples. Various avian species are sagebrush specialists, with the sage grouse being an example. Big game species such as wapiti, mule deer, whitetail deer, and pronghorn are found in the area. Bison, grizzly bear, and wolf were present prehistorically. Smaller species include jackrabbits, cottontail rabbits, various rodents, coyote, mountain lion, badger, and bobcat (Soil Conservation Service n.d.).

\section{Patterning of Surface Geology and Soils in the Project Area}

The patterning of deposits and soils in the project area is complex but structured (Hallberg et al. 1999; Hallberg et al. 2000a, Hallberg et al. 2000b; Love and Christiansen 1985; USGS 1994). Bedrock formed during a long history of structural and depositional events, but surficial sediments were derived from bedrock and were redeposited in the relatively recent geological past (Case et al. 1998; Hunt 1986). Soils result from the interaction of soil formation factors such as parent material, surficial deposits, climate, topography, vegetation, and the duration of soil formation (Jenny 1941; Soil Conservation Service 1994).

Several important surficial regimes are described in the following section as outlined in the digital Wyoming Surficial Geology (Case et al. 1998): exposed bedrock, clinker, grus, residuum, eolian sand, glacial deposits, landslides, playas, alluvial fans, bench deposits, slope wash, colluvium, valley alluvium, terrace deposits, dissected terraces, and shallow terrace deposits (Figure 29). Each category is described using standard U.S. Geological Survey (USGS) geologic map terms, and common soil types are summarized from NRCS maps and reports. Soils types found on each surficial unit are characterized by visually overlaying 250k soils mapping over the surficial geology map. Some of these landforms are illustrated in Figure 30. 


\section{SURFICIAL GEOLOGY: POWDER-TONGUE RIVER BASINS}

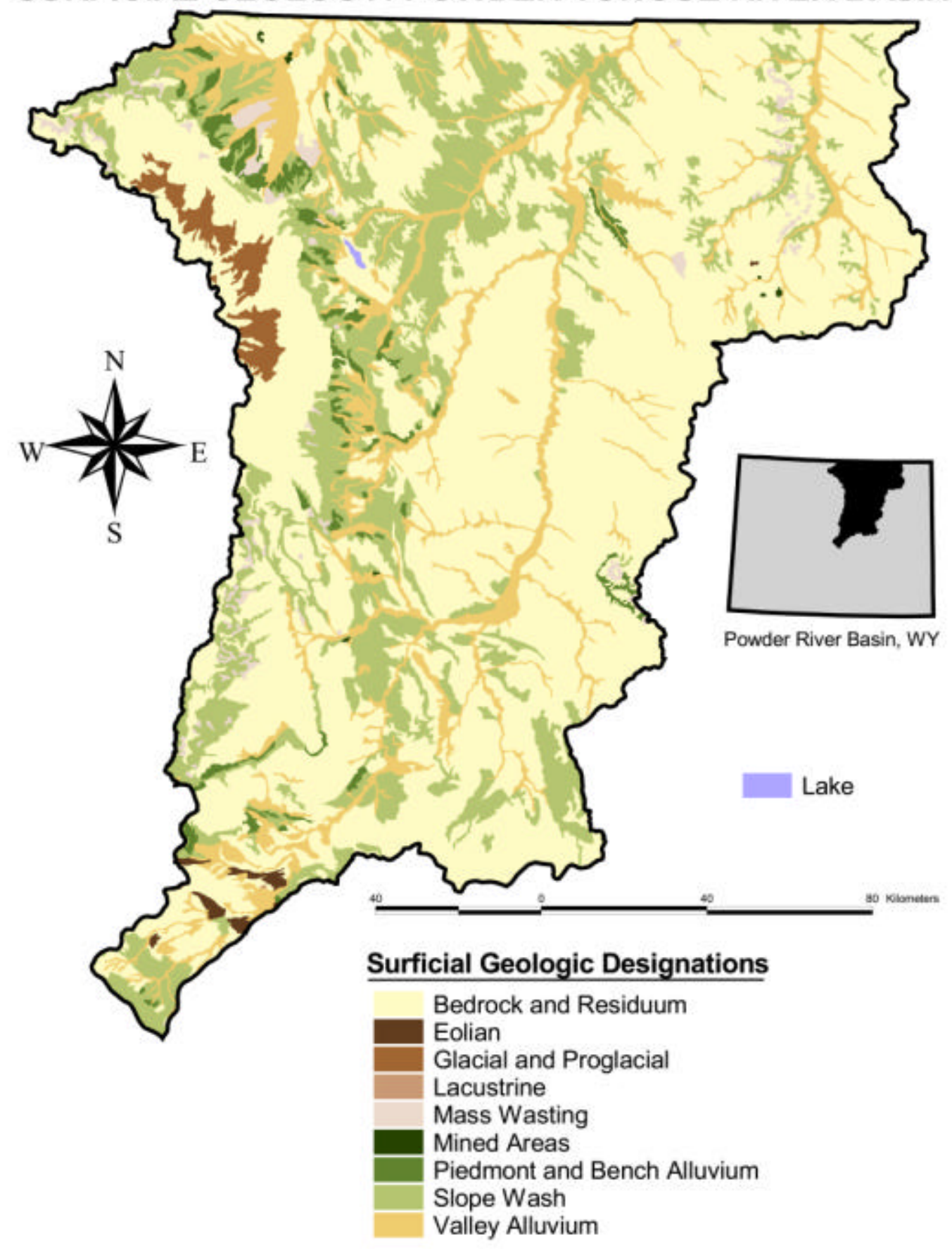

Figure 29. Surface geology map of the Powder River and Tongue River basins illustrating the distribution of major landforms and depositional environments (Case, et al. 1998) 
POWDER-TONGUE RIVER BASINS C-X

NORTH OF BUFFALO, WY (1.5)
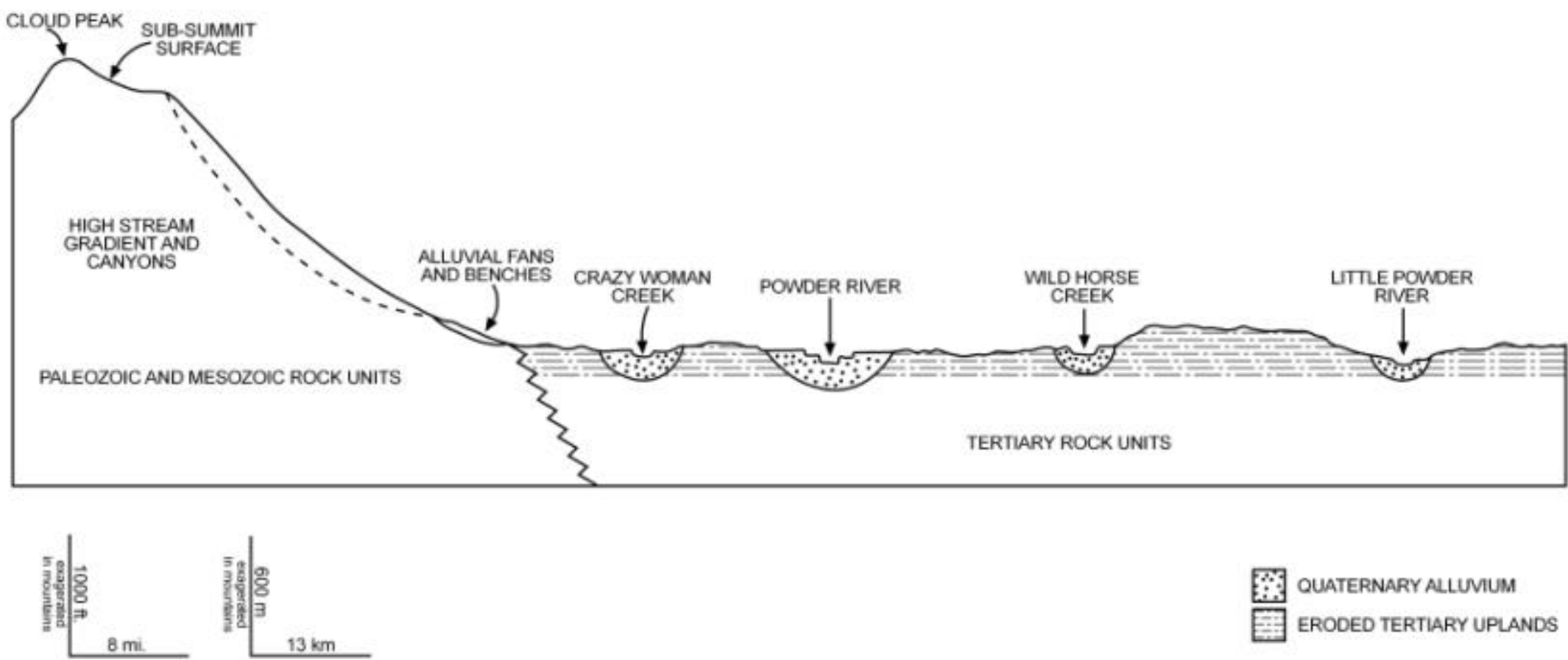

:3. QUATERNARY ALLUUVIUM

ERODED TERTIARY UPLANDS

Figure 30. Schematic cross section of the study area illustrating topography and surface geology 
The surficial geology map and the visual associations observed when overlaying the soils maps are used to identify the types of landscapes, deposits, and soils that are important to the model building undertaken in this report. The surficial geology map was not used as a digital database in the model compilation.

\section{Bedrock and Residuum}

Exposed Bedrock. Areas of exposed bedrock and glaciated bedrock have hard rock that is exposed at the ground surface or only covered by a thin zone of residuum or surficial deposits. The se areas occur in several settings, including the steep eastern slope of the Bighorns, dissected uplands in the basin, and alpine areas that were scoured by glaciers. In glaciated areas, older soils with clay accumulation in their B horizons (Cryoboralfs) are common, as are soils lacking well-developed B horizons (Cryoborolls, Cryumbrepts). Soils on the bedrock areas in the basins are sensitive to slope position with more welldeveloped soils (Haplargids) occurring on flat areas, and less well-developed soils (Torriorthents, Haploborolls) on steeper slopes.

Clinker. Areas mapped as clinker are situated on geologic formations that contain coal, primarily the Fort Union and Wasatch formations. The clinker is formed from the heat alteration of lithic impurities when coalbeds burn. It consists of altered non-coal rocks (sandstone, shale, mudstone) that are lensed within or adjacent to the burning coal seam. Areas of clinker are common in the basin and its presence is often an indication that bedrock is close to the surface. Like bedrock areas, flat areas have soils with welldeveloped B horizons (Argiustolls, Haplargids) while steeper areas have thinner and poorly horizonated soils (Torriorthents).

Grus. In some areas of the high mountains, granitic rocks are exposed at the surface. Intercrystalline weathering of these granitic rocks has produced a grus deposit consisting of loose individual crystals derived from the granite. Grus is essentially a regolith that is formed into the upper part of the granite. It is most common in the northwestern portion of the project area. Predominant soil formation consists of clay-enriched B horizons (Cryoboralfs) with smaller areas of less developed soils that have organic accumulation in the A horizon (Cryoborolls).

Residuum. Residuum consists of bedrock that is weathered in place. Areas mapped as residuum are very common in the project area, and occur on a variety of rocks such as Mesozoic bedrock in the foothills and Tertiary bedrock in the basin. Soil formation in most areas is controlled primarily by slope with well-developed basin soils (Haplargids) on flatter areas and poorly developed soils (Torriorthents) on slopes. Well-developed soils (Argiustolls and Paleustolls) predominate on more stable areas within the foothills. 


\section{Eolian}

Eolian Sand. Eolian sand occurs in the project area, although it is not as common as in the adjacent areas of the Wyoming Basin to the west and south. Mapped areas of eolian sand are most common near the head of the South Fork of the Powder River and the head of Casper Creek, north of the Powder River, Wyoming. These areas consist of mostly stabilized dunes and sandy interdune areas. The majority are downwind of the easily eroded Wind River Formation. Soils vary from poorly horizonated recent sands (Torripsamments) to buried or stabilized middle Holocene sands capped with clayenriched B horizon (Haplargids).

\section{Glacial and Proglacial}

Glacial Deposits. Areas mapped as glacial deposits occur in the mountains along the western margin of the project area. They are common at the base of the higher peaks in the Bighorn Mountains and in stream valleys draining these areas. Deposits consist primarily of till, which is a mixture of sand and gravel within a matrix of mud. These deposits are derived from Precambrian gneiss and granite. The sediment was transported by glaciers and emplaced in morainal deposits. Soils consist of well-developed mountain types with clay-enriched B horizons (Cryoboralfs), as well as some less well-developed types (Cryoborolls, Cryumbrepts). A single area of glacial outwash is mapped on a tributary of Big Goose Creek in the high mountains. The surface soils in this map unit are classified as Cryoboralfs, with clay accumulation present in the B horizon.

\section{High Energy Mass Wasting}

Landslides. Landslide deposits are mapped in a variety of areas, but generally occur directly below steep slopes. Landslides have occurred on the flank of the Bighorn Mountains where large sections of Paleozoic bedrock have detached and fallen. Several landslide deposits also occur in the extreme southern part of the project area in an area where deformed Mesozoic rocks are overlain by Tertiary deposits. Only a few landslide deposits occur in the basin. One such area where they occur is around the flat-topped mesas named Pumpkin Buttes. The mesas are erosional remnants capped by the Tertiary White River Formation.

Soil formation on landslides in the project area is variable and relates primarily to local climate and age of the landslide deposit. In both the mountains and basins, some landslides have clay-enriched B horizons (Cryoboralfs, Paleborolls, Paleustolls, and Argiborolls in the mountains, and Haplargids in the basins), whereas less well-developed soils occur elsewhere (Cryoborolls in the mountains, and Torriorthents in both the mountains and basins). 


\section{Lacustrine}

Playas. Two playas, which are internally-drained seasonal lakes, are mapped in the project area. Lacustrine sediments accumulate in playas where they interfinger with slope wash and intermittent alluvial deposits. One playa occurs on the divide between the Little Powder River and Donkey Creek, near Moorcroft, Wyoming, in an area underlain by Fort Union Formation rocks. It has soils characterized by clay accumulation in the B horizon as well as less well-developed soils (Torriorthents). The other playa is in the sand hills area on the South Fork of the Powder River north of Powder River, Wyoming. It is underlain by Cody Shale, and soils exhibit evidence of clay accumulation in the B horizon (Haplargids). These playas probably contain Holocene-age lacustrine sediments.

\section{Piedmont and Bench Alluvium}

Alluvial Fans. Alluvial deposits are poorly sorted and accumulate in moderate to highenergy depositional environments at the mouths of drainages. Sometimes fans from separate, adjacent drainages coalesce into a fan-apron. Other fans merge laterally with slope wash. Fans, while generally subdued, occur in several locations within the project area, including the mouths of mountain canyons, and within the basin where side streams flow into a main stream. Fans that occur at the mouths of mountain canyons are debrisflow dominated, and include material derived from intrusive igneous rocks as well as Paleozoic and Mesozoic bedrock. Soils formed on this type of fan are relatively old and well developed, containing humic surface horizons as well as thick, clay-enriched B horizons (Argiustolls, Paleustolls, Argiborolls). Fans formed within the basin contain some debris flows, but also a high percentage of intermittent stream overbank sediment and slope wash. They also include more sediment derived from locally occurring Tertiary bedrock sources. Basin fans have less organic matter in their A horizons. They are younger and generally possess less well developed or no B horizons (Ustorthents, Torrifluvents, Ustifluvents, Torriorthents, Haplargids, Calciorthids, Camborthids). Dissected alluvial fans are mapped separately from non-dissected fans, but are otherwise similar.

Bench Deposits. Bench deposits are gravel-capped, isolated remnants of old river valleys and stand at the elevations of former basin floors. They are formed by topographic inversion whereby gravel-armored valleys erode slower than the surrounding softer (nongravelly) bedrock, resulting in elevated, flat-topped features that are often dissected into several isolated planar remnants. Only one non-dissected bench is mapped in the project area; however, soil evidence suggests that other deposits might have been included within this map unit. Typically, well-developed soils occur on benches; however, the mixed variety of soil types (Torrifluvents, Ustifluvents, Argiustolls, Paleustolls, Haplargids, Torriorthents) present on the mapped areas suggests that some of the landforms may have a different origin. Dissected benches are slightly more common than undissected benches and have similar characteristics. 


\section{Slope Wash}

Slope Wash and Colluvium. A large portion of the project area is mapped as slope wash and colluvium. Deposition of this material occurs by overland flow and rill fill during runoff events. Some debris flows and intermittent stream sediments are also present. The unit occurs in both the basins and the mountains. Generally, it is found on gently to moderately sloping ground. Most occurrences are probably Holocene-age, which is reflected by relatively weak soil formation at these locations. In the mountains, soil formation is predominantly limited to humus accumulation in the A horizon (Cryoborolls), and only a few areas of slope wash have weathered (Cryochrepts) or clayenriched (Cryoboralfs) B horizons. In the basins, poorly-developed soils (Torriorthents) are common although soils with weathered (Camborthids) or clay-enriched (Haplargids) B horizons also occur.

\section{Valley Alluvium}

Valley Alluvium. Alluvium occurs in valleys and consists of post-glacial (less than 14,000 years old) sediment (Albanese 1990). Included in this category are channel and overbank sediments which grade laterally into slope wash and post-glacial alluvial fan deposits along the valley margins. Mapped areas of alluvium are found mostly in the foothills and the basins proper, in active and former floodplains. Much of the alluvium in the mountains is mapped as minor components of larger stratigraphic units. The few units that were mapped separately in the mountains have soil with well-developed A horizons (Cryoborolls) or clay-enriched B horizons (Cryoboralfs). In the basins, soils with some clay accumulation in the ir B horizons (Haplargids, Argiustolls, Natrargids) occur on slightly higher terraces while more poorly developed soils (Torrifluvents, Torriorthents, Ustifluvents) are common on lower terraces and floodplains.

Terrace Deposits. Terrace deposits are present in some areas, both in the mountains and the basin. They are mapped adjacent to valley deposits along perennial streams on relatively flat-lying landforms. Some of these are probably too high above stream level or have very well-developed soils (Paleustolls) to be Holocene terraces. Many others have poor horizon development (Torrifluvents, Torriorthents, Ustifluvents) and might be Holocene-age. Still others have soils that are moderately developed (Haplargids, Natrargids, Argiustolls) and might be Holocene occurrences.

Dissected Terrace Deposits. Dissected terrace deposits occur in the project area and are found adjacent to and slightly higher in elevation than post-glacial valley alluvium. They have a similar range of soil types as the terrace deposits (Argiustolls, Paleustolls, Torrifluvents, Ustifluvents, Haplargids, Camborthids, Natrargids), along with the potential range in ages. Dissected terrace deposits occur at the foot of the Bighorn Mountains as well as throughout the basin.

Shallow Terrace Deposits. A few areas with shallow terrace deposits are mapped on intermittent tributaries of the Powder River in the vicinity of Kaycee, Wyoming. These occur in drainage ways within a setting underlain by a variety of Mesozoic and Tertiary 
rocks. Soil types are varied (Torriorthents, Natrargids, Haplargids) and range in age from Late Pleistocene to Holocene.

\section{Valley Bottom Deposits}

As identified on the surficial geology map (Figure 29), post-glacial valley alluvium and alluvial terraces are common surface deposit types within the project area. In addition, alluvial processes deposit large volumes of sediment in a low-to-moderate energy regime and so are conducive to the preservation of buried archaeological sites. Because of the potential of alluvium to preserve buried archaeological remains, deposits found in and adjacent to valley bottoms are investigated in more detail in this study.

\section{Powder River Basin Alluvial Model}

The Powder River Basin is a classic landscape for understanding the Late Quaternary history of alluvial valleys in western North America. Leopold and Miller's (1954) seminal work set the stage for decades of subsequent investigation (e.g., Albanese 1990). These previous studies are very important for understanding how valley bottom locations fit into our sensitivity and burial model, which is discussed in detail below.

A considerable amount of work has been done to decipher the alluvial history of Quaternary river valleys in the Powder River Basin. Initial investigations were performed by Leopold and Miller (1954) and Haynes and Grey (1965). Subsequent testing of the model was conducted by a variety of investigators, but especially Albanese (1990). Mears et al. (1991) provide a review of some of these studies. The results of these investigations are discussed here and are used to help derive a valley bottom sensitivity model later in this chapter.

The Leopold and Miller Model. Leopold and Miller recognize strong patterning in the geomorphic relationships of Late Quaternary river valleys within the Powder River Basin. They designate three inner-valley terraces (from lowest to highest): (1) Lightning (1.2-2.1 m [4-7 ft]); (2) Moorcroft (2.4-3.7 m [8-12 ft]); and (3) Kaycee (6-15.2 m [20-50 $\mathrm{ft}$ ) (Figure 9)(Leopold and Miller 1954). Leopold and Miller also propose that these terraces are underlain by a predictable set of sediments they designate as geologic formations. Deposits associated with the youngest Lightning terrace (the Lightning Formation) are composed of fine-textured overbank alluvium. The Kaycee Formation is composed of mixed slope wash and alluvium underlying the Moorcroft terrace, and also forms the uppermost bed on the Kaycee terrace. Leopold and Miller identify a "modern" soil with a "columnar" structure on the Kaycee terrace that formed into Kaycee Formation alluvium. The Ucross Formation, a recent (post-Wisconsin) pebbly gravel, underlies the Kaycee formation within the Kaycee terrace. They observe a welldeveloped calcium carbonate enriched paleosol that formed in the upper 0.6-0.9 $\mathrm{m}$ (2-3 $\mathrm{ft}$ ) of the Ucross formation; where the Ucross was absent this soil occurs in underlying sediment. Finally, the Arvada Formation, the oldest Late Quaternary deposit observed, is a weathered, periglacially modified, limonitic stained, cobbly gravel containing the 
remains of extinct late Pleistocene fauna. Arvada sediments fill deeply cut channels on the valley floors and overlie a bedrock strath under the Kaycee terrace.

Based on the relationships between the terraces and deposits, Leopold and Miller reconstruct a sequence of erosional and depositional events that they correlate with extant alluvial chronologies in the western U.S. During the early 1950s, these chronologies were calibrated, predominantly with relative dates (mostly archaeologically derived) supplemented by a handful of dendrochronological and radiocarbon dates.

Leopold and Miller propose the following alluvial sequence for the Powder River Basin (Figure 31; Table 3) (Leopold and Miller 1954). The history of the alluvial sequence begins with cutting a relatively wide valley floor into bedrock. This took place at some unspecified time, presumably during the Pleistocene, and was followed by deposition of the Arvada Formation onto the valley floor. Subsequently, an inner valley was entrenched into this Arvada "floodplain", an event that occurred during the Late Wisconsin. This was followed by aggradation of floodplain gravel up to and possibly overtopping the former Arvada floodplain. An indeterminate interval of chemical weathering (i.e., redoximorphic processes) took place, resulting in limonitic staining within the Arvada gravel. Renewed deposition occurred with aggradation of finer textured gravel at canyon mouths near the mountains, and sand aggradation predominating further into the basin. This resulted in the deposition of the post-glacial age Ucross formation, which is correlated to the early Paleoindian period based on the presence of extinct megafauna associated with Folsom-Plainview artifacts. Then an erosional cycle removed part of the Ucross formation, partially rescouring Arvada-filled channels. Following this was the formation of a well-developed, calcium carbonate enriched paleosol into the Ucross Formation. Leopold and Miller correlate this soil formation with the Altithermal interval. Deposition of slope wash and alluvium of the Kaycee Formation followed. These deposits are associated with the presence of modern fauna and an age estimate of late Paleoindian to 4000 years before present (BP) is postulated. Erosion followed the deposition of the Kaycee Formation, during which the Kaycee Formation was incised down to the Moorcroft floodplain. Stabilization occurred at the Moorcroft strath or floodplain, an event that is correlated to approximately 25001000 years BP.

After 800 years BP, erosion and entrenchment reoccurred below the Moorcroft tread, producing the Moorcroft terrace. This was followed by overbank aggradation on the Lightning floodplain sometime around or after 800 years BP. Finally, entrenchment of the modern channel occurred, resulting in the formation of the Lightning terrace tread. 


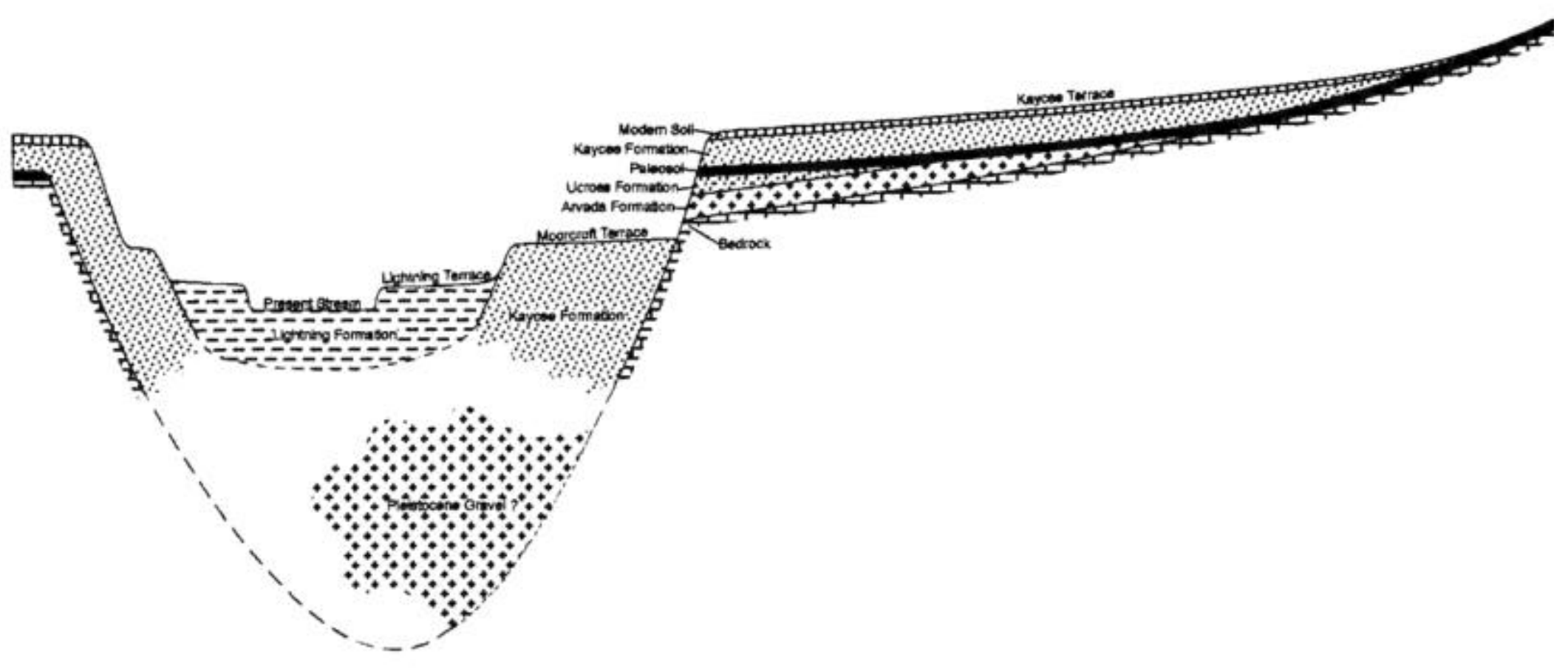

Figure 31. Schematic cross section of typical stream valleys in the Powder River and Tongue River basins illustrating relationships between Late Quaternary alluvial deposits and landforms (Leopold and Miller 1954, Figure 5) 
Table 3. Summary of Leopold and Miller (1954) alluvial model for the Powder River Basin

\begin{tabular}{|c|c|c|c|c|}
\hline $\begin{array}{c}\text { Formation/Post- } \\
\text { depositional Modification }\end{array}$ & $\begin{array}{l}\text { Landform or } \\
\text { Parent Material }\end{array}$ & $\begin{array}{c}\text { Depositional, } \\
\text { Environmental, or } \\
\text { Pedogenic Regime }\end{array}$ & $\begin{array}{l}\text { Deposit/Soil } \\
\text { Characteristics }\end{array}$ & $\begin{array}{l}\text { Age Indicators } \\
\text { and/or Pro posed } \\
\text { Age }\end{array}$ \\
\hline 2. Basal gravel & $\begin{array}{l}\text { Fill underlying } \\
\text { Recent channels }\end{array}$ & Fluvial channel & Gravel & Pleistocene \\
\hline \multicolumn{5}{|l|}{ 3. Unconformity } \\
\hline 4. Arvada Fm. (very rare) & $\begin{array}{l}\text { Deposit on cut } \\
\text { bedrock strath }\end{array}$ & Fluvial channel & $\begin{array}{l}\text { Gravel and gra velly } \\
\text { sand }\end{array}$ & Extinct fauna \\
\hline $\begin{array}{l}\text { 5. Weathering - } \\
\text { poor drainage on bedrock } \\
\text { and lower part of gravel }\end{array}$ & $\begin{array}{l}\text { Formed into } \\
\text { bedrock }\end{array}$ & $\begin{array}{l}\text { Possible perched } \\
\text { drainage }\end{array}$ & $\begin{array}{l}\text { Red iron staining } \\
\text { on gravel (but not } \\
\text { lower parts of } \\
\text { wedges) }\end{array}$ & $\begin{array}{l}\text { Evidence for iron } \\
\text { mobilization }\end{array}$ \\
\hline $\begin{array}{l}\text { 6. Evidence for perig lacial } \\
\text { conditions on bedrock }\end{array}$ & Bedrock & Periglacial & Periglacial wedges & Pleistocene \\
\hline \multicolumn{5}{|l|}{$\begin{array}{l}\text { 7. Possible erosional } \\
\text { unconformity }\end{array}$} \\
\hline 8. Ucross Fm. & $\begin{array}{l}\text { Deposit overlying } \\
\text { Arvada Fm. on } \\
\text { bedrock strath }\end{array}$ & $\begin{array}{l}\text { Channel and } \\
\text { floodplain }\end{array}$ & $\begin{array}{l}\text { Fine gravel with silt } \\
\text { in upper part and } \\
\text { redeposited, red - } \\
\text { stained Arvada } \\
\text { clasts }\end{array}$ & Anathermal \\
\hline 11. Kaycee Fm. & $\begin{array}{l}\text { Deposit overlying } \\
\text { Ucross and } \\
\text { forming Kaycee fill } \\
\text { terrace }\end{array}$ & $\begin{array}{l}\text { Slope grading into } \\
\text { alluvium along valley } \\
\text { axis }\end{array}$ & $\begin{array}{l}\text { Generally silty with } \\
\text { lenses of sand and } \\
\text { gravel }\end{array}$ & $\begin{array}{l}\text { Post-Altithermal, } \\
\text { no extinct fauna }\end{array}$ \\
\hline $\begin{array}{l}\text { 12. Surface soil on Kaycee } \\
\text { Fm. }\end{array}$ & $\begin{array}{l}\text { Non-deposition/ } \\
\text { non-erosion of } \\
\text { Kaycee terrace } \\
\text { tread }\end{array}$ & B horizon formation & $\begin{array}{l}\text { Columnar or cloddy } \\
\mathrm{B} \text { horizon with some } \\
\mathrm{CaCO}_{3}\end{array}$ & Post-Altithermal \\
\hline $\begin{array}{l}\text { 13. Channel incision cutting } \\
\text { to Moorcroft surface }\end{array}$ & $\begin{array}{l}\text { Incised into } \\
\text { Kaycee alluvium }\end{array}$ & Occasional deposits & & $\begin{array}{l}\text { Post-Altithermal - } \\
\text { no flakes on this } \\
\text { surface? }\end{array}$ \\
\hline $\begin{array}{l}\text { 14. Renewed channel } \\
\text { incision }\end{array}$ & $\begin{array}{l}\text { Cont inued incision } \\
\text { into Kaycee } \\
\text { alluvium }\end{array}$ & No deposits & None & $\begin{array}{l}\text { During or slightly } \\
\text { before Historic era }\end{array}$ \\
\hline 15. Lightning Fm. & $\begin{array}{l}\text { Fill terrace inset } \\
\text { into Kaycee Fm. }\end{array}$ & Alluvium & $\begin{array}{l}\text { Silty, fine or medium } \\
\text { sand; lenses of fine } \\
\text { gravel and coarse } \\
\text { sand }\end{array}$ & Historic era \\
\hline
\end{tabular}


Leopold and Miller (1954) conclude that the reconstructed alluvial sequence resulted from regional climatic events. Although subsequent work by Schumm (1981) indicates that alluvial sequences can be affected by factors other than climate, some aspects of the Leopold and Miller model remain viable.

The Alluvial Sequence in the Eastern Powder River Basin. Albanese (1990; 1984; 1978; Albanese and Wilson 1974) has spent several decades in an ongoing effort to test and evaluate Leopold and Miller's model, especially as it pertains to the eastern Powder River Basin.

He makes several important observations:

1. Terraces in the eastern Powder River Basin are not always underlain by the age of sediments predicted by the Leopold and Miller model.

2. Local processes can lead to local terrace sequences.

3. The number of terraces present at any particular location varies by stream order.

As well, Albanese reports that at some locations the Kaycee correlative is capped by overbank alluvium which contains dates as young as $1580 \pm 20 \mathrm{BP}$. This suggests continued aggradation at some locations on the Kaycee floodplain, long after the date for its incision proposed by Leopold and Miller.

Significance of Alluvial Models for the Present Project. Complexities of alluvial system dynamics are well known and have been adequately described elsewhere (Schumm 1973, 1981; Schumm and Brakenridge 1987; Schumm and Hadley 1957; Wolman and Leopold 1957). For the present study there are two significant aspects of the Albanese (1990) and Leopold and Miller (1954) alluvial models. First, is the presence of a textural contrast between potential archaeological bearing deposits (latest Pleistocene and Holocene) and older Pleistocene deposits (>14,000 B.P) (Porter et al. 1983). Both Albanese (1990) and Leopold and Miller (1954) indicate that this contact can be identified by a distinct break in grain size (Hunt 1953). Typically, older Pleistocene gravel deposits (>14,000 BP) underlie Holocene sand and silt near the mountains and grade into coarse Pleistocene sand which underlies Holocene silt and clay in the interior basin. In addition, both Albanese (1990) and Leopold and Miller (1954) note that non-gravelly valley fill younger than 14,000 years old is present in most valleys. Finally, both studies agree that the upper part of this post-glacial era valley fill underlies the highest Holocene-age terrace (the Kaycee). Although the Kaycee tread is referred to as an alluvial terrace, it should be noted that as the tread rises as it approaches the valley wall, the surface transitions from an alluvial terrace to a slope wash-deposited footslope. The wedge of slope wash thins as the valley wall becomes steeper, whereupon weathered bedrock and colluvium begin to crop out and eventually predominate on the back slope. Here, we use points of agreement between the alluvial models to delimit the width of non-gravelly valley fill, including alluvium and slope wash, along the watercourses in the project area. Other details of the alluvial models are not pertinent to the burial model. Our purpose is to provide as much specificity to the location of Holocene alluvial fills as possible and to characterize the sedimentary geometry of post-glacialera deposits. 
Specific occurrences of fine-textured valley fill are important to delineate since stream valleys are known to contain Holocene alluvium deposited within a low depositional energy regime, and these settings are likely to preserve archaeological sites. Thus, we use existing alluvial models (Leopold and Miller 1954; Albanese 1990) to predict the relative width (and height) of fine textured Holocene alluvial and slope wash deposits within the valleys of the project area.

\section{Sensitivity Modeling of Valley Bottom Deposits}

The predicted width of valley bottom deposits are modeled using the height above stream of the highest portion of the highest Holocene terrace (Kaycee) as derived from the literature and field reconnaissance (Appendix C). Width of valley deposits was calculated from contours on 1:24,000 topographic maps. The position of the valley fill is mapped onto a digital version of the stream courses (hydrography). This process is discussed more fully below.

A 1:100,000 (100k), digital hydrography dataset was used to model the width of valley bottom deposits (Wyoming Gap Analysis 1996). Examination of USGS 1:100,000 scale topographic maps indicate the presence of various permanent and intermittent stream channels in the project area (Figure 32). The topographic variability of the mountain and basin areas requires treating drainages in the respective areas differently. The mountains consist of rugged peaks with high gradient streams, a sub-summit surface (plateau) that has relatively low gradient streams, and a steep mountain front consisting again of high gradient streams. By contrast, the basins have much less diversity in gradient. Because of this contrast in topography we used gradient to classify stream segments within the mountains, whereas, we used stream order for basin streams. In both cases, stream channels serve as the centerline for defining valley fill (here referred to as stream buffers). Note that all streams indicated on the 100k maps are buffered, regardless of if they are permanent or intermittent streams. Buffering proceeds through a number of stages as discussed below.

\section{Stream Buffering Using Sample Streams}

The mountain-basin distinction is based on the break in slope at the base of the mountains as observed on topographic maps. The elevation used to reflect this break is different for the Bighorn Mountains versus the Rattlesnake Hills (1900 m [6232 ft] versus $2000 \mathrm{~m}$ [6560 ft], respectively). Everything below these elevations, for their respective areas, is automatically grouped into the basin areas.

Stream orders and stream gradient classes are used to classify the varying widths of different valley bottom reaches. Stream order follows Strahler's (1952) system and is a way of categorizing streams into orders to show their hierarchical position within the entire stream network. The higher the stream order number, the larger the stream, and the further from the stream source within the network. Stream gradient classes are a way to classify streams into groups based on slope gradient, again to model different widths of valleys based on similar gradient. 
POWDER-TONGUE RIVER BASINS DEPICTING LAKES, STREAM ORDERS, AND STREAM GRADIENTS
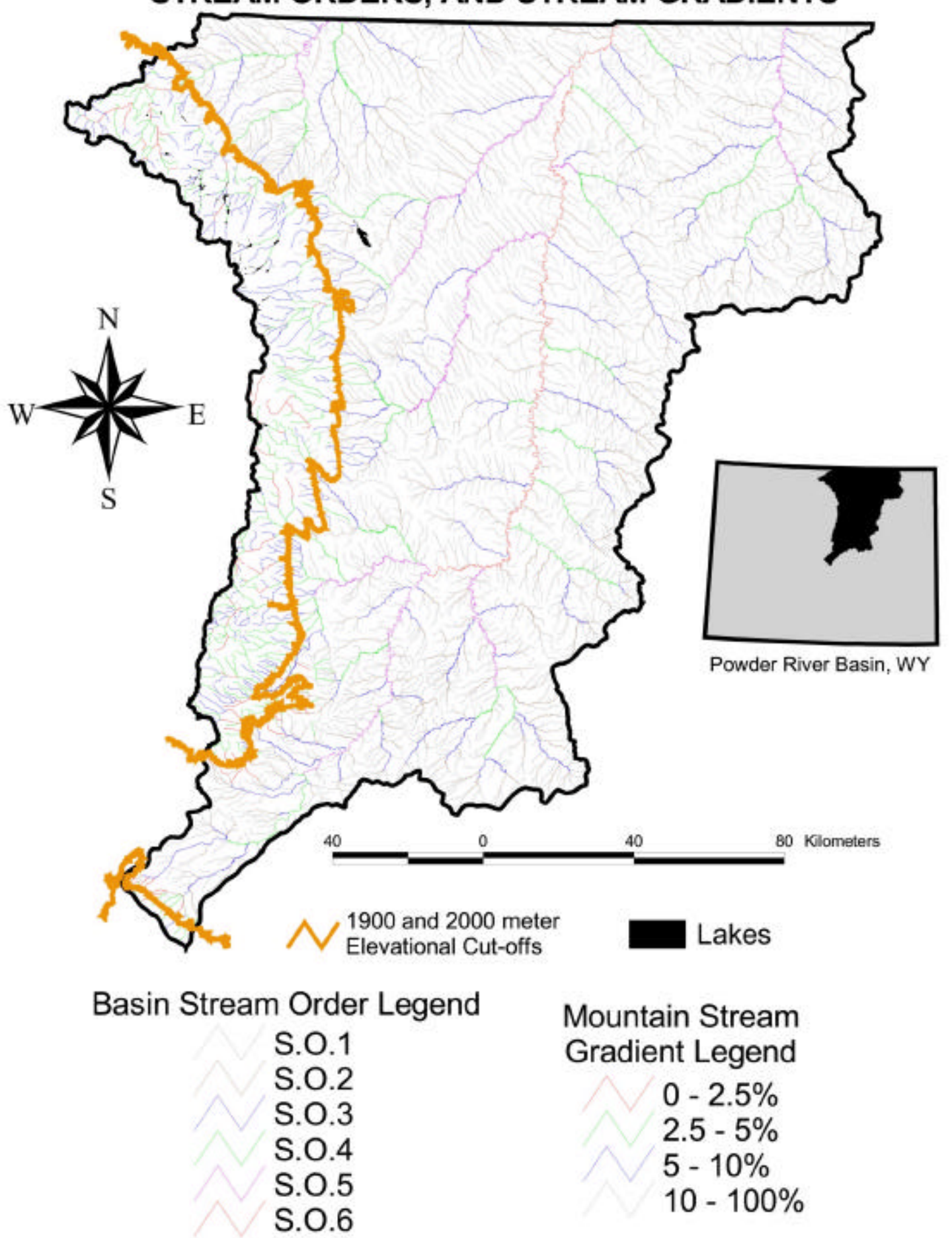

Figure 32. Map of the drainage networks in the Powder River and Tongue River basins showing stream orders, gradient classes, and lakes 
We estimated the height of the highest post-glacial valley fill for each gradient or stream order class. Since a footslope grades to and merges with the highest alluvial terrace within most valleys, we estimate the upper height of this footslope. This is the elevation above stream level where the footslope pinches out on bedrock on the upper part of the footslope. This height is generally marked by a distinct break in slope where the generally gently sloping and non-gravelly valley fill meets the steeper and rocky valley wall slope. Height of valley fill (relative to active stream channel) is calculated from: (1) survey of the literature; (2) observations acquired during field reconnaissance; and (3) inspection of landforms on topographic maps.

Reconnaissance indicated that there were very few instances where Ice Age gravel terraces stood within valleys but above post-glacial era fine-textured terraces. These gravel terraces are most common in foothills locations. Gravelly terraces can generally be identified in map view due to the presence of illustrated gravel pits. Thus, for many stream gradient or stream order classes it was a simple matter to identify upper terrace/footslope tread on 1:24,000 topographic maps. Maximum height above the active stream channel reflects the thickness of the valley bottom deposits. Estimated thicknesses of post-glacial fill (upper elevation footslope grading to highest fine textured terrace) for basin streams used in this report are: Stream Order $6=24.38 \mathrm{~m}(80 \mathrm{ft})$, Stream Order $5=$ $21.34 \mathrm{~m} \mathrm{(70} \mathrm{ft),} \mathrm{Stream} \mathrm{Order} 4=18.29 \mathrm{~m}(60 \mathrm{ft})$, Stream Order $3=15.24 \mathrm{~m}(50 \mathrm{ft})$, Stream Order $2=12.19 \mathrm{~m}(40 \mathrm{ft})$, and Stream Order $1=9.14 \mathrm{~m}(30 \mathrm{ft})$; whereas for mountain streams: 0-2.5 percent Gradient $=12.19 \mathrm{~m}(40 \mathrm{ft}), 2.5-5$ percent Gradient $=$

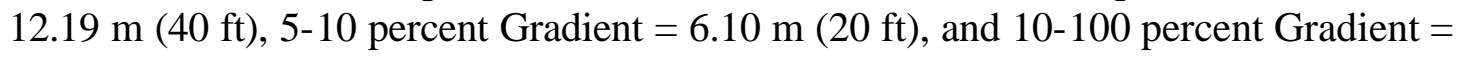
$3.96 \mathrm{~m}(13 \mathrm{ft})$.

Height above the stream was projected cross-valley to the valley walls to establish the width of various stream order and stream gradient classes. For this exercise we select stream gradient and stream order segments from a variety of sub-basins within the project attempting to sample diverse stream types. Identifying the intersection of any topographic contour line with the stream channel on USGS 1:24k topographic maps provides a reference point for projecting the height of valley fill. At each intersection, a line is drawn from the stream-contour line intersection in an upslope direction (perpendicular to the stream channel) until the required elevation above stream shoreline is plotted. The longest line segment (stream-right or stream-left) is chosen to represent the half-valley width of the valley fill. When half-valley widths are determined for all sample streams, the measurements for each stream order or stream gradient class are summed and averaged. The half valley width is then used as the value to create a buffer (corridor) along each stream class within the digital hydrographic dataset $(1: 100,000)$ using GIS software.

Next, the buffers or corridors, representing the width of post-glacial valley fill, were overlain on a sample of USGS 1:24k topographic maps. The buffer width was then examined visually to see if it encompassed the valley width. Buffer width was then judgmentally adjusted in width in a consistent way for each gradient or stream order class so as to encompass the valley bottom width at the 1:24,000 scale. 
Natural lakes were also buffered because they generally are situated in low slope depositional basins and usually in stream valleys. Like stream valleys, lakes generally have a toe slope that grades to their shoreline. A GIS dataset containing the lakeshore boundaries was procured (Wyoming Gap Analysis 1996). All lakes within the mountain regions were included, and also one lake within the basin region, Lake De Smet, was included. Although the latter is now dammed, a natural lake preceded the reservoir. Most of the other lakes situated in the basin are reservoirs that are not treated as lakes. Also, mountain reservoirs were buffered to their existing shorelines, since many reservoirs in the mountains are dammed and inundated prehistoric lakes.

\section{Stream Buffer Models: Management and Analytical}

Management Stream Valley Buffers. The map resulting from the analysis described above is termed the "management" stream buffer map (Figure 33). It is designed for use as a non-technical management dataset in the sensitivity models we constructed that are described later in this report. It provides an estimate of valley fill, which strongly favors a site preservation goal. The map is constructed to illustrate the maximum extent of postglacial valley fill at scales of 1:100,000 or smaller. A considerable amount of visual checking and judgmental readjusting of the buffer width was conducted in this way to make the map as useful as possible at the 1:24k scale. We achieved a satisfactory level of success; however, no warranty is made for the accuracy of the stream buffers at a scale larger than 1:100,000.

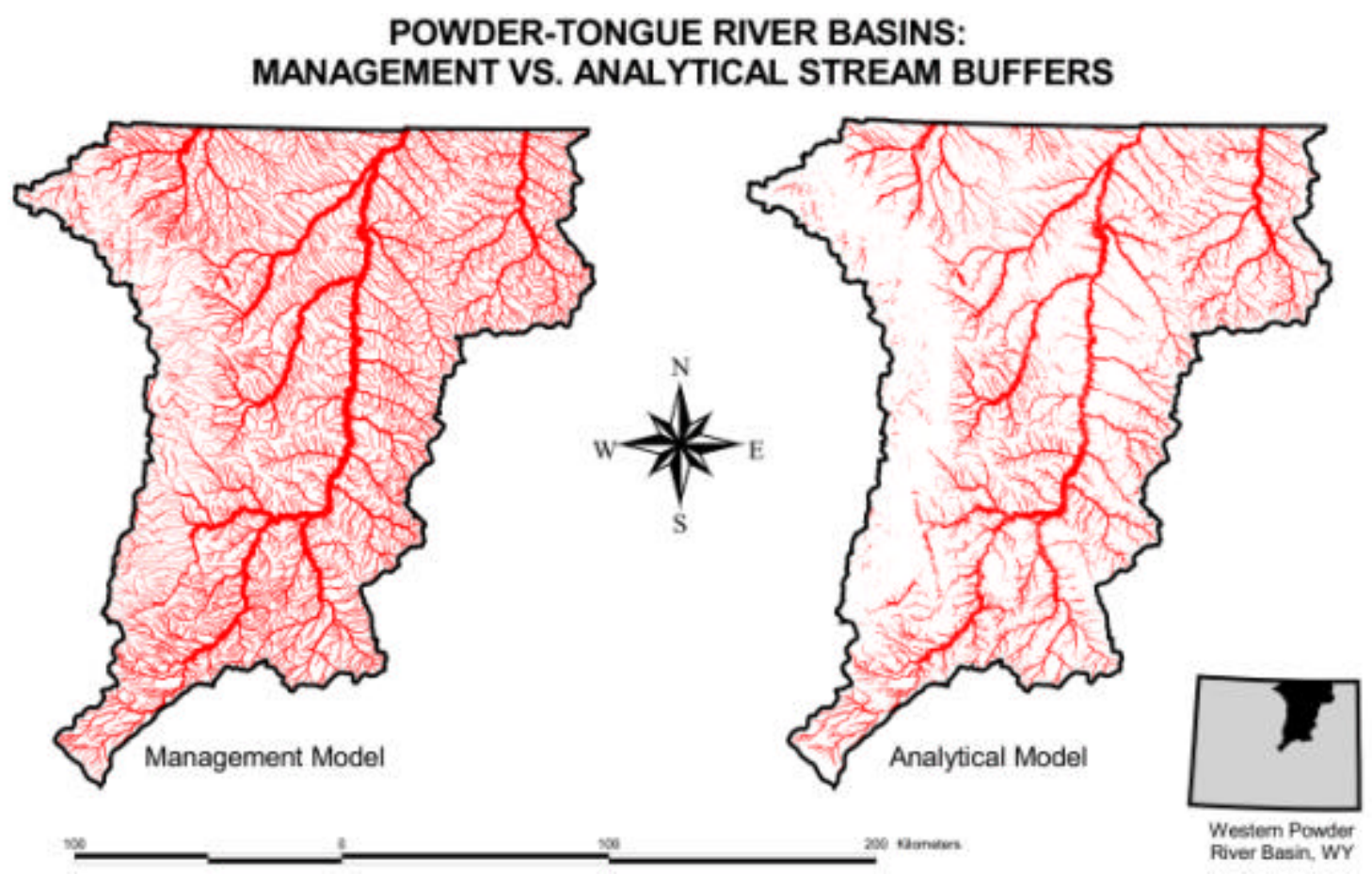

Figure 33. Map illustrating stream buffers created for the risk-sensitivity model for the Powder River and Tongue River basins 
Analytical Stream Valley Buffers. We developed an "analytical" stream buffer map that removes portions of the management buffer. In this buffer, we remove areas adjacent to valley fill that are included within the management map but which have streams with steep gradients or steep valley walls. We constructed this map for the purpose of testing the buffering method using site data from the WYCRO. The "steep area" cutoff is any area with a slope greater than 10 percent. Therefore, areas within the management buffer which contain a slope greater than 10 percent are excluded from the buffered streams areas. Removal of the steep areas results in the elimination of bedrock-cut valley walls from the buffers, as well as some stream segments that are too steep to have consistently preserved occupation zones from the ravages of burial disturbance.Steep areas were identified using a 30-m digital elevation model (DEM) grid to create a slope map for our project area. The slope map was divided into two zones: areas with 10 percent or greater slope and areas with less than 10 percent slope.

A stream layer was developed to use in conjunction with the slope map. To create this dataset, vector streams were split into segments approximately $250 \mathrm{~m}(820 \mathrm{ft})$ in length. This provided a good balance between detail and size. Larger segments did not reveal short, steep sections, while smaller segments made the dataset too complex. The elevations for the beginning and ending nodes of each segment were added using the 30-m elevation grid. Change in elevation along with length was used to calculate the gradient of each segment. Those segments with 10 percent or greater gradients were removed from the dataset.

The remaining segments were buffered based on stream order as described above for the management buffers. The buffers were then converted to a 30-m grid and adjacent areas with a 10 percent or greater slope were subtracted from the buffers. The resulting valley bottom buffers have slopes less than 10 percent. Small areas were removed by running a majority filter on the resulting grid twice. That grid was converted back into polygons and further filtered by removing all polygons less than $10,000 \mathrm{~m}^{2}\left(107,639 \mathrm{ft}^{2}\right)$ area. In addition, any non-buffer "island" polygons within the buffers that are less than $30,000 \mathrm{~m}^{2}$ $\left(322,917 \mathrm{ft}^{2}\right)$ in area were removed. Finally, lakes were added back into the model. These manipulations reduced the complexity of the dataset while retaining its salient characteristics. The "analytical" stream buffer model (illustrated in Figure 33) is ultimately incorporated along with non-valley areas into the Archaeological Land scape Sensitivity Model using both STATSGO and SSURGO data, which is discussed in more detail below.

It is important to understand that each model (analytical and management) has an appropriate use. The analytical model is more precise and is best used to evaluate the validity of the model itself, e.g., to compare results of fieldwork with predictions. The management model is more conservative as a management tool (because the high sensitivity areas are larger) and so it is used in the management tools created by this project (such as CRISP). This application is discussed in detail in Chapter 5. The management model is best used as a planning tool, e.g., to determine where one is least likely to encounter buried archaeological material. 


\section{Sensitivity Modeling for Non-Valley Locations}

Modeling the alluvial valleys comprises one part of the model we present here. Nonvalley locations are modeled using a different method. Here, we outline a methodology for subdividing the non-valley portion of the project area into zones, which are more or less likely to contain depositional settings conducive to preservation of buried and relatively intact prehistoric occupations. This is accomplished by: (1) estimating if the depositional energy regime of the sediment which buried the site is low enough to preserve the site during burial, (2) considering post-burial site formation and destruction factors that might have affected the contextual integrity of the site, and (3) assessing if the age of the deposits is within the range of human occupation $(<14,000$ years old).

Thus, sediments that are either too old or were deposited within a high-energy depositional regime, or were subject to high levels of post-burial site destruction are predicted to have very low or low sensitivity. Conversely, sediments that are younger than 14,000 radiocarbon years old, were deposited within lower energy depositional environments, and have not been subject to extensive site destruction processes, are more likely to contain prehistoric cultural occupations that possess stratigraphic and behavioral integrity. Landscapes possessing characteristics conducive to site preservation are considered to be more "sensitive" (at greater risk) from the perspective of site burial potential.

Spatial variation in the intensity of site destruction processes across the landscape is primarily a function of depositional environment. This variation is controlled by slope, transport energy, and resultant sediment. Artifact dispersal occurs in most depositional environments (Butzer 1982), though an exception to this is eolian silt (loess) environments. Lack of significant burial dispersal in loess is the result of a low surface wind shear (because vegetation is usually present) and the low impact energy of the silt particles. Many surface sites on flat, vegetated surfaces are eventually, albeit slowly, covered with a shallow mantle of loess. As mentioned in the methodology section above, other common depositional environments can be ranked into two categories of potential burial dispersal. A relatively low to moderate energy category includes alluvial overbank, sheetflow (including slope wash), and eolian sand environments. The moderate-to- high-energy category would include alluvial channel, debris flow, and colluvial depositional environments. For most water and air entrained sediments, artifact movement is a function of their size and density (Gifford and Behrensmeyer 1976).

The considerations discussed above, allow the construction of two models that classify the landscape in terms of its archaeological sensitivity (1:24k model, FINE and 1:250k model, COARSE). These models are used to predict the spatial occurrence of sediment younger than 14,000 years BP at non-valley locations. They also predict locations where site formation processes might better preserve significant archaeological resources (very high and high archaeological landscape sensitivity). Favorable locations are mapped and differentiated from locations with surface sediments older than 14,000 BP and/or with little potential to preserve reasonably intact archaeological sites (very low and low archaeological landscape sensitivity). 
NRCS soil maps were used to help classify the relevant depositional and site formation criteria. Individual soil map units are the smallest spatial unit used in the analysis. Map unit descriptions acquired from the NRCS contain information on the soil taxon, sediment type, and landform type within each map unit. Early attempts to classify archaeological sensitivity utilized a light table to superimpose soil taxon, deposit type, and landscape characteristics to determine archaeological landscape sensitivity (Eckerle and Eakin 1989). A GIS approach is used in this project to simplify the process of assigning archaeological sensitivity to soil map units.

\section{Scale of Soil Map Data}

Two scales of soils mapping (1:24,000 and 1:250,000) were utilized in this project. Coverage at 1:24,000 (county-level, SSURGO) was incomplete during the critical stage of project data acquisition (winter 2003-2004) (Figure 34). SSURGO mapping was available for southern Campbell, southern Johnson, Natrona, Sheridan, as well as the small portions of Washakie, Converse, and Crook counties within the project area. Bighorn National Forest soils mapping was available from the United States Forest Service (1999), and provided nearly identical spatial geometry as would be provided by SSURGO. Unfortunately, parts of Johnson County and Campbell County were not available in a digital format and were omitted from the 1:24k analysis. To adjust for the lack of coverage in the areas lacking digital 1:24k mapping, we supplemented the SSURGO data with multi-county NRCS soils mapping data (STATSGO at 1:250,000 scale).

\section{Data Acquisition}

Both 1:250,000 (STATSGO) and 1:24,000 (SSURGO) scale soil mapping data was extracted from NRCS sources and entered into a custom Microsoft Access database designed for sensitivity modeling. Population of the database required two primary data sources: (1) hard copies of NRCS soil surveys for individual survey areas (mostly defined by county), and (2) a digital Soil Survey database. For the hard copy surveys, all attribute values were taken from the survey, including series descriptions. Three parts of the NRCS soil surveys were primarily used: (1) the map unit number description section, (2) the soil series description section, and (3) the engineering table appendix.

Series name, parent material, landform, precipitation, slope, and percent composition were all extracted directly from the map unit description section of the soil survey reports. Depth to bedrock, percent coarse sediment $>2.0 \mathrm{~mm}(0.08 \mathrm{in})$, and range site were all extracted directly from the soil series description section of the soil survey reports. Great group taxon names are from the Classification of the Soils table contained within the soil survey reports. Percent gravel $>7.6 \mathrm{~cm}$ (3.0 in) are all taken directly from the Engineering Index Properties table contained within the soil survey reports. For soil survey areas that did not have a hard copy soil report, we used a digital database provided by the NRCS. Unfortunately, this digital database did not contain all of the data provided by hard-copy series descriptions, thus we had to use the Official Soil Survey Descriptions 
(http://soils.usda.gov/technical/classification/osd/index.html) provided by the NRCS to supplement the digital information. These descriptions are virtually identical to the ones provided within the soil survey reports, however they are more generalized to the entire geographic range where an individual soil series occurs.

\section{Sensitivity Considerations}

The goal of the archaeological landscape sensitivity models was to use the soils mapping, surficial geology, and alluvial valley information to help predict the location of sediments that are the right age and type to contain significant buried archaeological sites. Soils mapping generates information on a number of variables relevant to this goal. For this analysis the following variables were tabulated from the NRCS soil mapping data: (1) map unit number; (2) depth to bedrock; (3) slope; (4) soil taxonomic classification; (5) landform; (6) deposit type; (7) percent gravel; and (8) percent coarse gravel.

The sensitivity analysis systematically followed rules presented in a sensitivity outline (presented below) using the criteria provided therein. Each step was done separately and saved to an ESRI ArcView shapefile. The shapefiles were then either intersected with each other, or added to the final intersection, based on the individual criterion and its operator (i.e., AND/OR). A discussion of each of the variables follows.

\section{NRCS Data Categories}

NRCS soils mapping that was used in the model is described below. NRCS soil scientists are not geoarchaeologists and soils mapping is not designed specifically to facilitate geoarchaeological modeling. Despite this, NRCS mapping contains valuable information about landscapes that is relevant and useful for constructing burial sensitivity models.

Map Units. Soil map units delineate areas of similar soils. Map units consist of a single series, an association composed of two series, or a complex of three or more soil series. The soil map units are described in the following NRCS county soil survey reports and related SSURGO digital soils data: Soil Survey of Crook County, Wyoming (Elwonger 1983); Soil Survey of Bighorn National Forest (Nesser 1986); Soil Survey of Natrona County, Wyoming (Malnor and Arnold 1997); Soil Survey of Sheridan County, Wyoming (Lupcho 1998); Soil Survey of Washakie County, Wyoming (Liams 1983); Soil Survey of Converse County, Wyoming (Reckner, 1986); Soil Survey of Johnson County, Wyoming, Southern Part (Stephens 1975); and SSURGO data for Campbell County, Southern part (National Resource Conservation Service 1998). County surveys were clipped to the project area so not all areas of the listed counties are included. Some of the important variables extracted from the map unit descriptions are described below. 


\section{POWDER-TONGUE RIVER BASINS: SSURGO COVERAGE AVAILABILITY}

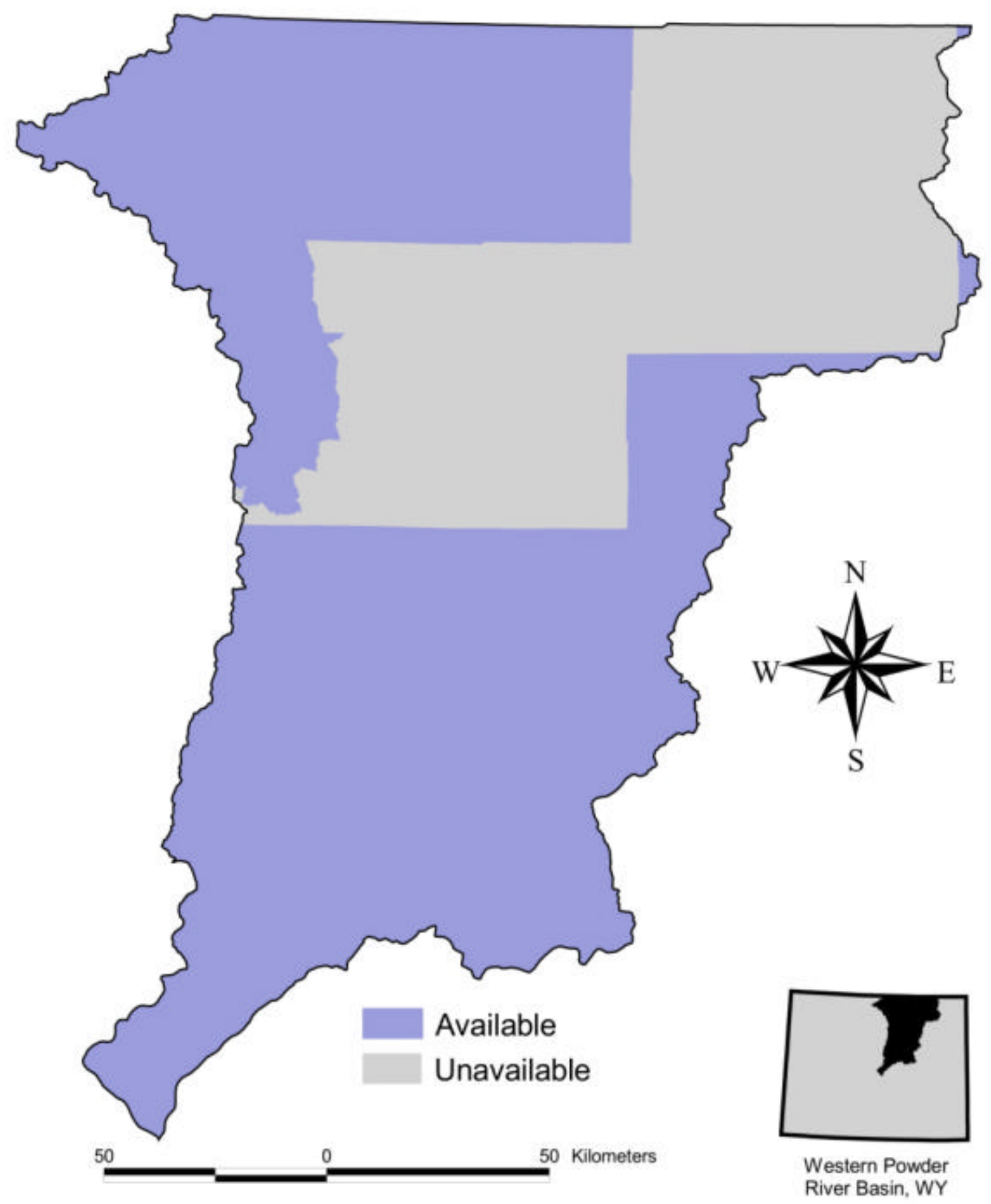

Figure 34. Soils mapping availability for SSURGO (1:24,000 base soil mapping) soils data. 
Depth to Bedrock. Depth to bedrock is used to estimate the potential for a sedimentary mantle over bedrock, which would protect and preserve archaeological deposits. The NRCS sets the maximum recordable limit to bedrock at $1.5 \mathrm{~m}$ (60 in), so for this report we did the same. Sedimentary environments aggrading at a moderate to rapid rate generally offer a better chance of site preservation than do sites that form a soil surface for many thousands of years. Exceptions are made, however, for high-energy depositional regimes transporting gravel size material, as destruction of archaeological context is likely to have occurred. Other depositional environments often allow differentiation of multiple occupations, especially when sterile sediment occurs between the occupation zones. Perishables, including charcoal and butchered animal bone, are more likely to be preserved in aggradational environments, than in environments where little aggradation is occurring and the perishables are exposed to the elements or destructive soil processes.

Slope. Slope steepness characterization provides one measure of depositional energy. Steeper slopes occur in colluvial and mass wasting environments as well as high gradient alluvial channel environments. More moderate slopes produce slope wash environments and moderate gradient stream channels, while low slope characterizes floodplains.

Soil Taxonomic Classification. The taxonomic classification of the principal surface soil(s) in each map unit is tabulated. These are listed to the family or great group level of classification. Implicit in the classification are soil features that have genetic and chronological significance (Soil Survey Staff, 1975), and thus provide insight to where sediment younger than 14,000 years old is located. Both the regional and local studies (Birkeland 1999; Birkeland et al. 1991; Reider and Karlstrom 1987; Reider 1983; Reider 1980; Albanese 1991; Albanese 2000; Eckerle 1986a) suggest that a general, timedependent sequence of horizon development can be identified and includes from youngest to oldest: A (surface organic accumulation); $\mathrm{Bw}$ (oxidation or weak structural development); $\mathrm{Bt}$ and $\mathrm{Bk}$ (clay accumulation and calcium carbonate accumulation, respectively); K (very well-developed calcium carbonate accumulation); and Bym (very strongly developed gypsum accumulation). In terms of the taxonomic classes present in our study area, a relevant sequence would be as follows from youngest to oldest: (1) Orthents and Fluvents; (2) Camborthids at the great group leve l, and calcic and argic variants at the family level of other great groups; (3) Argids and Calciorthids; and (4) Paleargids and Paleorthids. According to the authors above (especially Birkeland), a tentative age estimate for these taxonomic groupings is: (1) <1,000 year BP; (2) 1,000 to 10,000 years BP; (3) 10,000 to100,000 years BP; and (4) >100,000 years BP. Rare exceptions to this chronological sequence exist. Nevertheless, these estimates can be used to calculate the age of the deposits on which a soil is formed. We use these estimates to identify soils that are unlikely or questionably formed on Holocene-age sediment.

In Wyoming Haplargids are mapped on sandy-textured Middle to Late Holocene deposits, most commonly on eolian sand (Eckerle 1997), but also on slope wash and intermittent stream alluvium. Haplargids such as the Hiland (and catena-related Vonalee) soil series have been observed in map units containing extensive areas of Holocene-age 
eolian sand sediment. Although as indicated above, Haplargids are considered to be 'Pleistocene-age' soils, their occurrence on Holocene-age eolian suggests that they be considered potential Holocene-age soils when they occur on sandy sediments.

Landform. Landform is a good indicator of depositional setting. Good potential depositional settings for archaeological sites are often found in floodplains, low (overbank) terraces, inset alluvial fans, and footslopes. Some areas such as badlands, rock outcrops, and cliffs contain no significant soil mantle and are poor settings for the potential preservation of buried archaeological materials with integrity. Limited areas where sediments are captured and held, like caves or shelters, are exceptions to this generalization. The NRCS maps these areas as non-soil areas. Landform was specifically used to help identify the locations of eolian sand sediment forming sand dunes.

Deposit Type. Parent material characterizations in the NRCS data provide an estimate of both the depositional energy regime and depth of burial (or lack of as in 'badlands', or 'residual'). Like landform, we used deposit type (eolian sand) to help identify dune fields and to informally crosscheck other categories to assure that they compared favorably to sensitive deposit types. Depositional settings most likely to contain sites with good integrity are floodplain deposits, low energy alluvial fan deposits, and slope wash deposits. In contrast, locations not likely to preserve site integrity include residuum, regolith, channel gravel, and talus. Note that regardless of the map unit deposit type, stream buffers are mapped through and crosscut all deposit types, including residuum and regolith. Thus, locations likely to preserve buried sites within these overall locations of poor burial potential can be classified appropriately. Analysis of deposit type was supplemented by the use of a digital map of Wyoming surficial deposits (Case et al. 1998).

As mentioned earlier in this report, the intent of these models is to predict the location of deposits that might contain stratigraphically buried cultural levels. As such, there is no attempt to predict locations where features and occupation debris from surface occupations (0-20 cmbs) might intrude into or be turbated into the occupation substrate. For instance, archaeological materials might be found to have intruded into or be turbated into residuum. Despite the fact that these intrusive or turbated zones might contain preserved bone or charcoal, they are not stratigraphically buried. This is not intended to obviate the need to evaluate other potentially important data categories in these surface occupations (that just so happen to have deeper turbated or intrusive cultural material).

Historically, there has been some variability among earth scie ntists as to the use of the term slope wash. Some have grouped it with colluvium. As discussed earlier in this report, we distinguish between colluvium as gravity-derived deposits from slope wash that is a sheetwash (alluvial) deposit. Thus, we consider colluvium, which generally forms at the foot of a cliff or other very steep slope from more typical footslope deposits that are made up mostly of slope wash. 
Gravel. Percent gravel (clasts $>2 \mathrm{~mm}$ ) is tabulated for the soils. Percent gravel for each horizon within each soil series is presented as a range of values from which the median percent is selected to represent the series. This variable provides a good proxy measure for the energy regime of the deposit. Note that the gravel is measured within the surface soil thickness (as defined by the NRCS as 0-1.5 m [0-60 in] below surface). There are situations where nongravelly sediment may be located stratigraphically under the surface soil. In these situations there is a possibility that these less gravelly deposits formed at a lower energy regime might contain intact cultural zones. However, these situations are uncommon.

Cobbles and Boulders. The content of cobbles and boulders (clasts $>7.6 \mathrm{~cm}$ ) present in each map unit is tabulated. The maximum percentage for each soil series is weighted according to percent that the soil series comprises of the total map unit. Rock outcrop and/or bedrock are considered to contain 100 percent fragments $>7.6 \mathrm{~cm}$. For this size of sedimentary clasts the weighted averages for each soil series is derived and then all the component series are averaged to get a representative figure for the map unit as a whole.

\section{Archaeological Landscape Sensitivity Outline}

The criteria discussed above are used to construct rules that are used to categorize sensitivity classes. These rules are outlined to facilitate the intersection and reclassification of the soil map units into archaeological landscape sensitivity areas. GIS tools are used to classify and display the sensitivity criteria into sensitivity areas using the rules specified in the outline. The process used to generate the final sensitivity areas is analogous to classifying each sensitivity criterium, displaying the classification on a transparent map, and then overlaying all the transparent maps on a light table and outlining the intersection of all the similarly classified criteria.

The analysis utilized the stream buffer data and NRCS map unit data to identify the sensitivity zones in a sequential manner based on what we determined to be the most clear-cut and reliable characteristics. Class boundaries were confined by the distribution of data within particular variables and between several variables. The overall goal in determining various percent cut-off figures used in the outline was to find some balance in the relative distributions of the various sensitivity classes while at the same time not violate the theoretical and methodological precepts outlined earlier in this report. This involves a certain amount of subjectivity, which is tempered by geoarchaeological experience. Once an area (NRCS map unit or stream buffer) was assigned to a particular sensitivity zone, it was excluded from further analysis. The sensitivity zones are classified as very high, high, very low, and low. Remaining areas are classified as moderate. Manual inspection of post-classification variables/values suggests that the moderate category is transitional between high and low with regards to sensitivity criteria. A soil component generally means a soil series and some adjustments were needed to accommodate both the COARSE and the FINE databases specified below. Note that the term "inclusion" refers to a soil series that is present in a map unit, but which composes a very low proportion of the map unit. Inclusions were excluded from the analysis. 
Below we use the NRCS soils mapping variables either in combination or alone to define sensitivity classes within a series of 'and/or' statements, respectively. Due to the fact that there are no recognized empirically derived values to use as absolute limits for burial sensitivity, we selected a combination of values linked by 'and' statements for defining the limits of depth of burial, slope steepness, and gravel content for high, poor, and very poor settings. Since these variables are interrelated this method provides built in redundancy and increased confidence in our method.

1. VERY HIGH SENSITIVITY AREAS meet the following criteria:

a) are defined as "very high sensitivity" on the stream valley model both analytical and management stream buffer model), or;

b) contain a soil component where the parent material is eolian sand (only used for CPOARSE), or;

c) contain Soil Series (Decolney, Dwyer, Hawkstone, Hiland, Moskee, Orpha, Ryan Park, Tullock, Vale nt, Vonalee, Whiteriver) that are formed in eolian sand, or sand dunes, and the sum of the included soil components compose 30 percent for COARSE, 50 percent for FINE, or more $(\geq 30 / \geq 50)$ of the map unit.

2. HIGH SENSITIVITY AREAS meet the following criteria:

a) contain Soil Series (Decolney, Dwyer, Hawkstone, Hiland, Moskee, Orpha, Ryan Park, Tullock, Valent, Vonalee, Whiteriver) that are formed in eolian sand, or sand dunes, and the sum of the included soil components compose less than 30 percent for COARSE, 50 percent for FINE, $(<30 /<50)$ of the map unit, or;

b) contain a soil component where the depth to bedrock is $1-1.5 \mathrm{~m}$ (40-60 in), and the sum of the included soil components compose 30 percent or more $(\geq 30)$ of the map unit, and;

c) contain a soil component where the minimum slope is 10 percent or less $(\leq 10)$ (excluding map unit inclusions), and;

d) contain a soil component where clasts $7.6 \mathrm{~cm}$ (3 in) or greater in diameter compose less than 3 percent $(<3)$ by volume of the soil matrix (excluding map unit inclusions), and;

e) contain a soil component where clasts $2 \mathrm{~mm}(0.08 \mathrm{in})$ or greater compose 14 percent or less $(\leq 14)$ by volume of the soil matrix (excluding inclusions), and the sum of the included soil components compose 50 percent or more $(\geq 50)$ of the map unit, and;

f) contain a soil component having a likely Holocene-age soil taxon (Camborthids, Cryaquolls, Cryoborolls, Cryochrepts, Cryorthents, Cryumbrepts, Fluvaquents, Haploborolls, Haplocambids, Haplustepts, Haplustolls, Torrifluvents, Torriorthents, Torripsamments, Ustifluvents, Ustipsamments, Ustochrepts, Ustorthents), and the sum of the included soil components compose 25 percent or more $(\geq 25)$ of the map unit. 
3. VERY LOW SENSITIVITY AREAS meet the following criteria:

a) are made up of non-soil land including badlands, cirque land, colluvial land, gravel pits, gullied land, pits, dumps, rock land, rock outcrop, rubble land, shale outcrop, shale rock land, water, and the sum of the included non-soil land compose 75 percent or more $(\geq 75)$ of the map unit, or;

b) contain a soil component having a very unlikely Holocene-age soil taxon (Paleargids, Paleborolls, Paleustalfs, Paleustolls), and the sum of the included soil components composes 75 percent or more $(\geq 75)$ of the map unit, or;

c) contain soil components where the depth to bedrock is $63.5 \mathrm{~cm}$ (25 in) or less $(\leq 63.5)$ (excluding inclusions), and the sum of the included soil components compose 30 percent or more $(\geq 30)$ of the map unit, and;

d) contain a soil component where the average slope is 20 percent or more $(\geq 20)$, and;

e) contain a soil component where clasts $7.6 \mathrm{~cm} \mathrm{(3} \mathrm{in)} \mathrm{or} \mathrm{greater} \mathrm{in} \mathrm{diameter}$ compose 7 percent or more $(\geq 7)$ by volume of the soil matrix, and;

f) contain a soil component where clasts $2 \mathrm{~mm}$ (0.08 in) or greater compose 40 percent or more $(\geq 40)$ by volume of the soil matrix, and the sum of the included soil components compose 25 percent or more $(\geq 25)$ of the map unit.

4. LOW SENSITIVITY AREAS meet all of the following criteria:

a) are made up of non-soil land including badlands, cirque land, colluvial land, gravel pits, gullied land, pits, dumps, rock land, rock outcrop, rubble land, shale outcrop, shale rock land, water, and the sum of the included non-soil land compose 55 percent or more $(\geq 55)$ of the map unit, or;

b) contains a soil component where the depth to bedrock is $64-90 \mathrm{~cm}$ (25.1-35 in) (excluding inclusions), and the sum of the included soil components compose 30 percent or more $(\geq 30)$ of the map unit, and;

c) contains a soil component where the average slope is 15 percent or more $(\geq 15)$, and;

d) contains a soil component where clasts $7.6 \mathrm{~cm}$ (3 in) or greater in diameter compose $3-6.9 \%$ by volume of the soil matrix, and;

e) contains a soil component where clasts $2 \mathrm{~mm}$ (0.08 in) or greater compose 30$39.9 \%$ by volume of the soil matrix, and the sum of the included soil components compose 10 percent or more $(\geq 10)$, and;

f) contains a soil component having a questionable Holocene-age soil taxon (Argiaquolls, Argiborolls, Argiustolls, Calciargids, Calciborolls, Calciorthids, Cryoboralfs, Eutroboralfs, Gypsiorthids, Haplustalfs), and the sum of the included soil components compose 25 percent or more $(\geq 25)$ of the map unit. 


\section{MODERATE SENSITIVITY AREAS}

a) Since the process is subtractive, moderate sensitivity constitutes the areas that remain after the previous operations have occurred, i.e., after the previous sensitivity areas have been delineated.

\section{Summary of Four Sensitivity Models}

This chapter describes four sensitivity maps for the study area: two derived from 1:250,000 base mapping using STATSGO data (COARSE) (Figure 35), and two derived from 1:24,000 base mapping using SSURGO data (FINE) (Figure 36). Both maps contain stream buffering that is constructed at a scale of 1:100,000. Figure 35 presents COARSE sensitivity maps using STATSGO data for both the management and analytical stream buffer models. Likewise, Figure 36 presents FINE sensitivity maps using SSURGO data for both the management and analytical stream buffer models. Figure 37 presents a comparison of the two maps using the management stream buffers. STATSGO data were used because digital SSURGO data are incomplete for parts of the study area. Areas lacking SSURGO soil mapping include northern Campbell County and southern Johnson County. The COARSE sensitivity map should be viewed at a scale no larger than 1:250,000, whereas the FINE sensitivity map, excluding stream buffers, is appropriate for viewing the sensitivity classes at a scale no larger than 1:24,000. Stream buffer data are accurate at a scale of 1:100,000. Note that some effort was made with the 1:100,000 stream buffer data to make it useful at a scale of 1:24,000. We feel that this process was relatively successful, but no warranty is made. The COARSE sensitivity map (Figure 35) uses the same attributes and values as the FINE sensitivity map (Figure 36), with some minor exceptions noted in the outline presented above. A similar comparison is presented for the management maps in Figure 37.

The sensitivity classification system ranks areas according to potential geological conditions that favor buried site preservation (Table 4). Zones rated as very high and high predict locations where conditions are favorable for: (1) retention of archaeological behavioral-spatial context; (2) preservation of perishable archaeological materials (bone and charcoal); and (3) stratigraphic separation of archaeological occupation zones. The very high sensitivity class reflects the distribution of landscapes of previously known important burial contexts, eolian sand and valley alluvium, respectively. Otherwise, the very high and high sensitivity classes might be viewed as similar in terms of their management implications. 


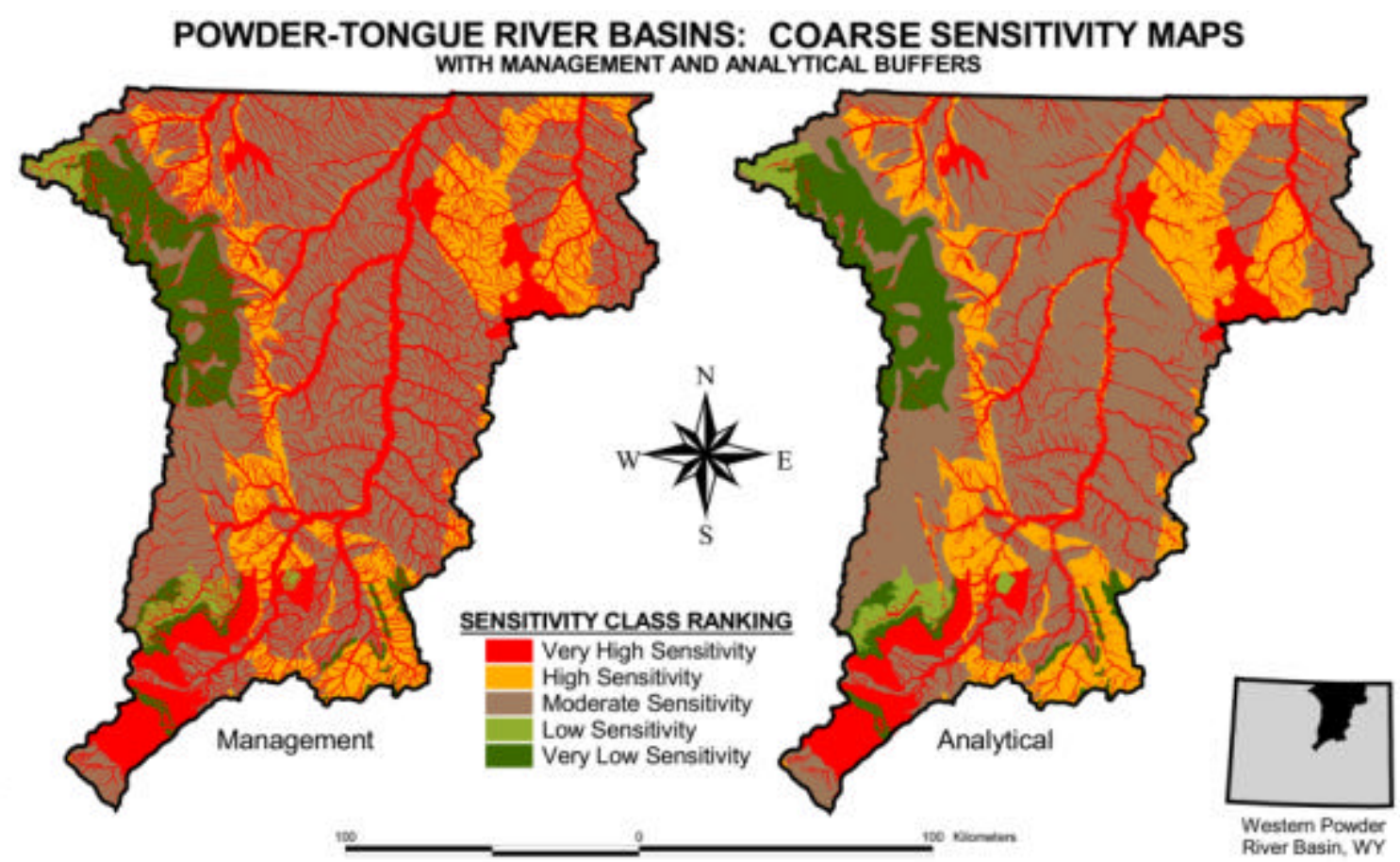

Figure 35. Sensitivity maps (COARSE) based on STATSO (1:250,000 base soil mapping) and stream buffers

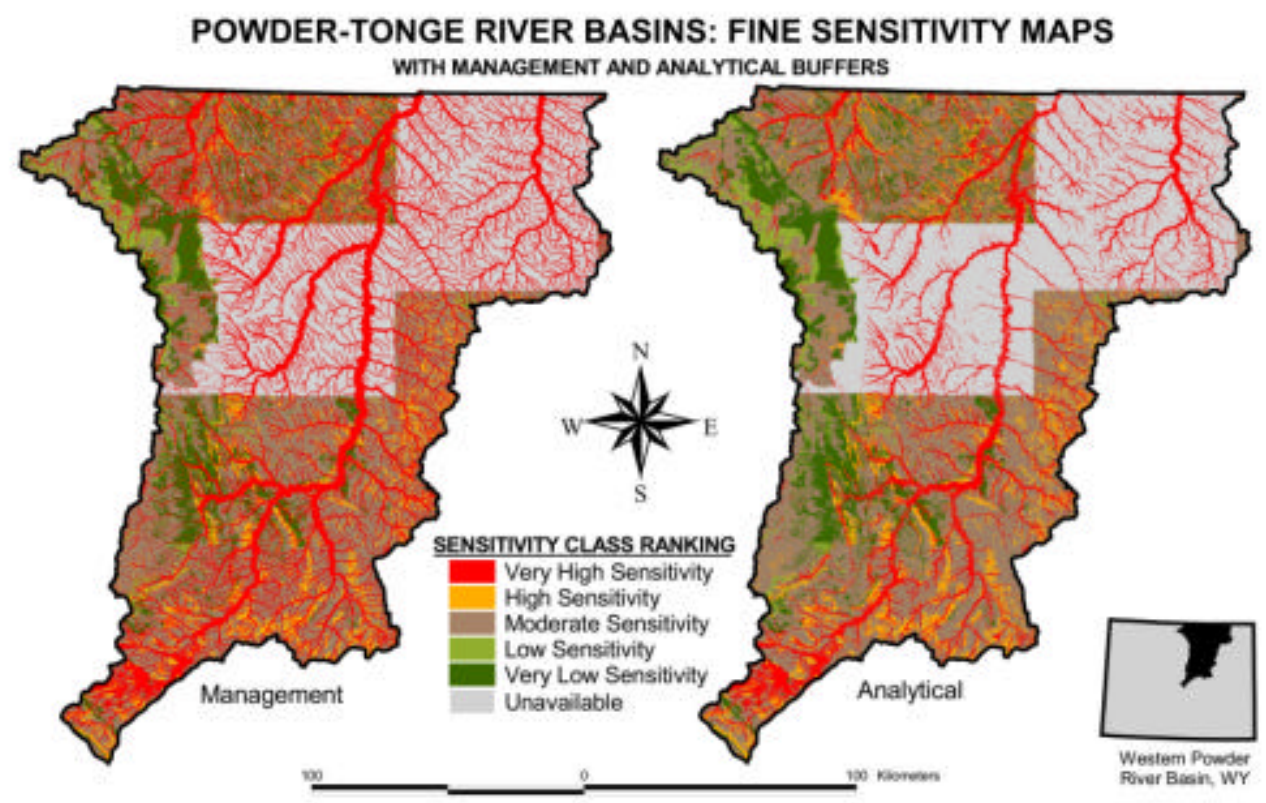

Figure 36. Sensitivity maps (FINE) based on SSURGO (1:24,000 base soil mapping) and stream buffers 


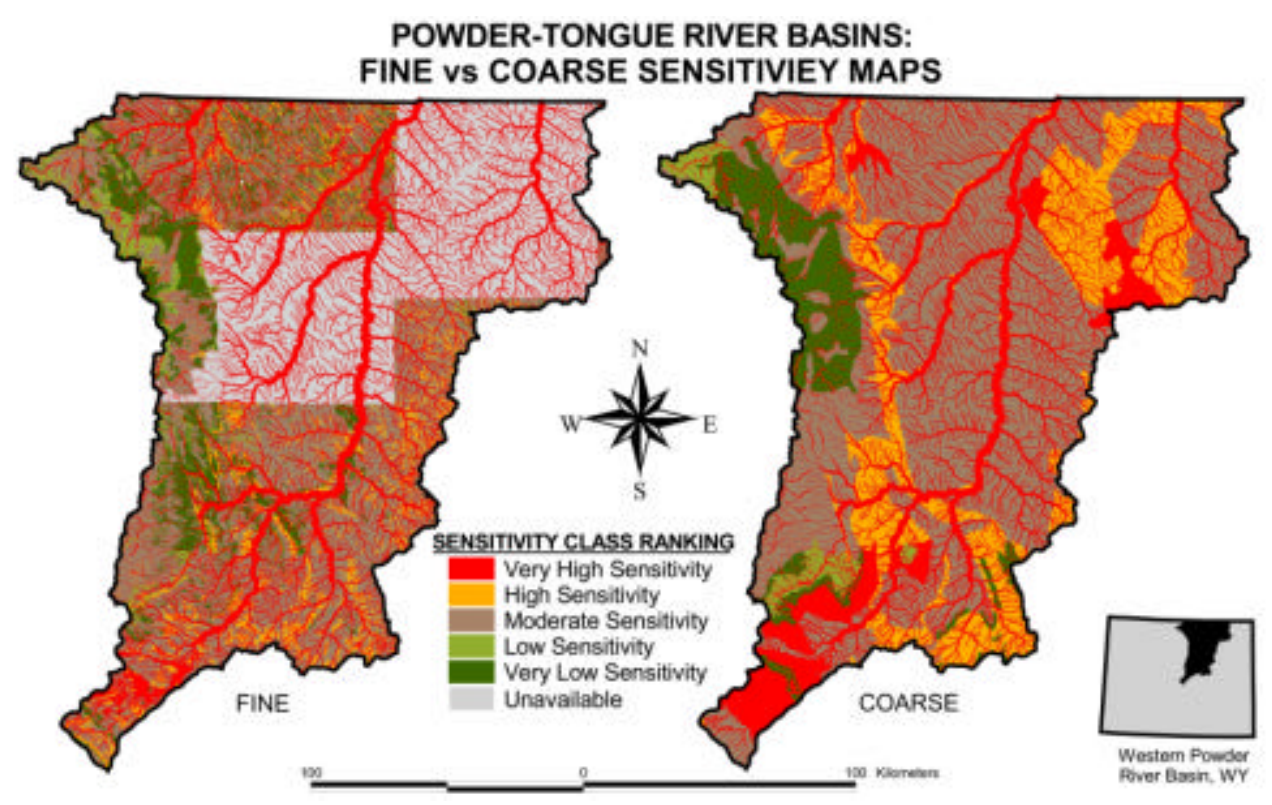

Figure 37. Side -by-side comparison of FINE and COARSE (1:24,000 and 1:250,000 base) sensitivity maps using management stream buffers

Ultimately, this information should be supplemented by training in its use. The proper application of this information will require targeted field visits by agency and project archaeologists. A Field Protocol Handbook (Appendix B) facilitates use of the sensitivity maps in the field, and provides a quick reference to their recommended use.

Moderate, low, and very low sensitivity classes predict areas where there is a lessened chance of buried site preservation. Caution is warranted as the sensitivity model only predicts where site preservation conditions might be favorable, and not locations that may have been attractive to human activity. Note that there are some special considerations concerning the use of the moderate category, especially within the COARSE model (discussed below). 
Table 4. Summary characteristics for sensitivity classes

\begin{tabular}{|c|c|c|c|c|c|c|c|c|}
\hline $\begin{array}{l}\text { Sensitivity } \\
\text { Ranking }\end{array}$ & Landforms & $\begin{array}{l}\text { Soil } \\
\text { Parent } \\
\text { Material }\end{array}$ & $\begin{array}{l}\text { Engulfing/ } \\
\text { Overlying } \\
\text { Soil Age }\end{array}$ & $\begin{array}{l}\text { Depth to } \\
\text { Bedrock } \\
(\max 1.5 \mathrm{~m})\end{array}$ & $\begin{array}{l}\text { Minimur } \\
\text { Slope }\end{array}$ & $\begin{array}{l}\text { n Average } \\
\text { Slope }\end{array}$ & $\begin{array}{l}\% \text { Clasts } \\
=7.6 \mathrm{~cm}\end{array}$ & $\begin{array}{l}\% \text { Clasts } \\
=2 \mathrm{~mm}\end{array}$ \\
\hline Very High & $\begin{array}{l}\text { Low-Gradient Stream Valleys } \\
\text { Floodplains, Terraces, } \\
\text { Sand Dunes }\end{array}$ & $\begin{array}{l}\text { Alluvium } \\
\text { Eolian }\end{array}$ & - & - & - & - & - & - \\
\hline High & $\begin{array}{c}\text { Moderate-Gradient Stream Valleys } \\
\text { Alluvial Fans }\end{array}$ & $\begin{array}{l}\text { Alluvium } \\
\text { Eolian } \\
\text { Slope Wash }\end{array}$ & $\begin{array}{l}\text { Holocene Age } \\
\text { Soils }\end{array}$ & $1-1.5 m$ & $0-10 \%$ & $\mathrm{n} / \mathrm{a}$ & $0-2.9 \%$ & $0-14 \%$ \\
\hline Moderate & $\begin{array}{l}\text { All Moderate areas fail to completely meet } t \\
\text { can't really be given value ranges that woul }\end{array}$ & $\begin{array}{l}\text { the criteria for } \\
\text { lld produce the }\end{array}$ & $\begin{array}{l}\text { other sensitivity } \mathrm{c} \\
\text { selected areas } \mathrm{W}\end{array}$ & $\begin{array}{l}\text { lasses. They may } \\
\text { vithin ArcView. }\end{array}$ & meet one or $n$ & many criteria, & but not all. Thi & is category \\
\hline Low & $\begin{array}{l}\text { Non-Soil-Bearing Landforms } \\
\text { (Badlands, Cirques, Bedrock, etc.) } \\
\text { Steep-Gradient Stream Valleys } \\
\text { Uplands, Interfluves }\end{array}$ & $\begin{array}{l}\text { Colluvium } \\
\text { Residuum } \\
\text { Channel }\end{array}$ & $\begin{array}{l}\text { Questionable } \\
\text { Holocene Age } \\
\text { Soils }\end{array}$ & $64-90 \mathrm{~cm}$ & $\mathrm{n} / \mathrm{a}$ & $15-19.9 \%$ & $3-6.9 \%$ & $30-39.9 \%$ \\
\hline Very Low & $\begin{array}{c}\text { Non-Soil-Bearing Landforms } \\
\text { Very Steep-Gradient Stream } \\
\text { Valleys } \\
\text { Uplands, Interfluves }\end{array}$ & $\begin{array}{l}\text { Colluvium } \\
\text { Residuum } \\
\text { Channel }\end{array}$ & $\begin{array}{l}\text { Very Unlikely } \\
\text { Holocene Age } \\
\text { Soils }\end{array}$ & $0-63.5 \mathrm{~cm}$ & $\mathrm{n} / \mathrm{a}$ & $20-100 \%$ & $7-100 \%$ & $40-100 \%$ \\
\hline
\end{tabular}




\section{Evaluation of Sensitivity Models Using WYCRO Data}

Data from the WYCRO are used to evaluate the fit between archaeological data and the sensitivity models. Area and percent of study area within the sensitivity zones for each model (FINE [1:24k base]) analytical, FINE management, COARSE [250k base] analytical, and COARSE management) are presented in Tables 5 and 6 and Figures 38 and 39. Moderate sensitivity composes the highest proportion of the study area in all four models although less so in the FINE models. Additionally, the FINE analytical model exhibits the most even aerial distribution of very high and high combined compared to low and very low combined.

Table 5. Area in hectares by sensitivity class for each model for total study area

\begin{tabular}{l|ccccc} 
MODEL & Very High & High & Moderate & Low & Very Low \\
\hline FINE A & 413358 & 185780 & 1036473 & 66218 & 320363 \\
FINE M & 746570 & 153686 & 895480 & 62139 & 279676 \\
COARSE A & 519127 & 516868 & 1501808 & 58645 & 241361 \\
COARSE M & 837562 & 430224 & 1301170 & 50481 & 218415
\end{tabular}

Total Study Area

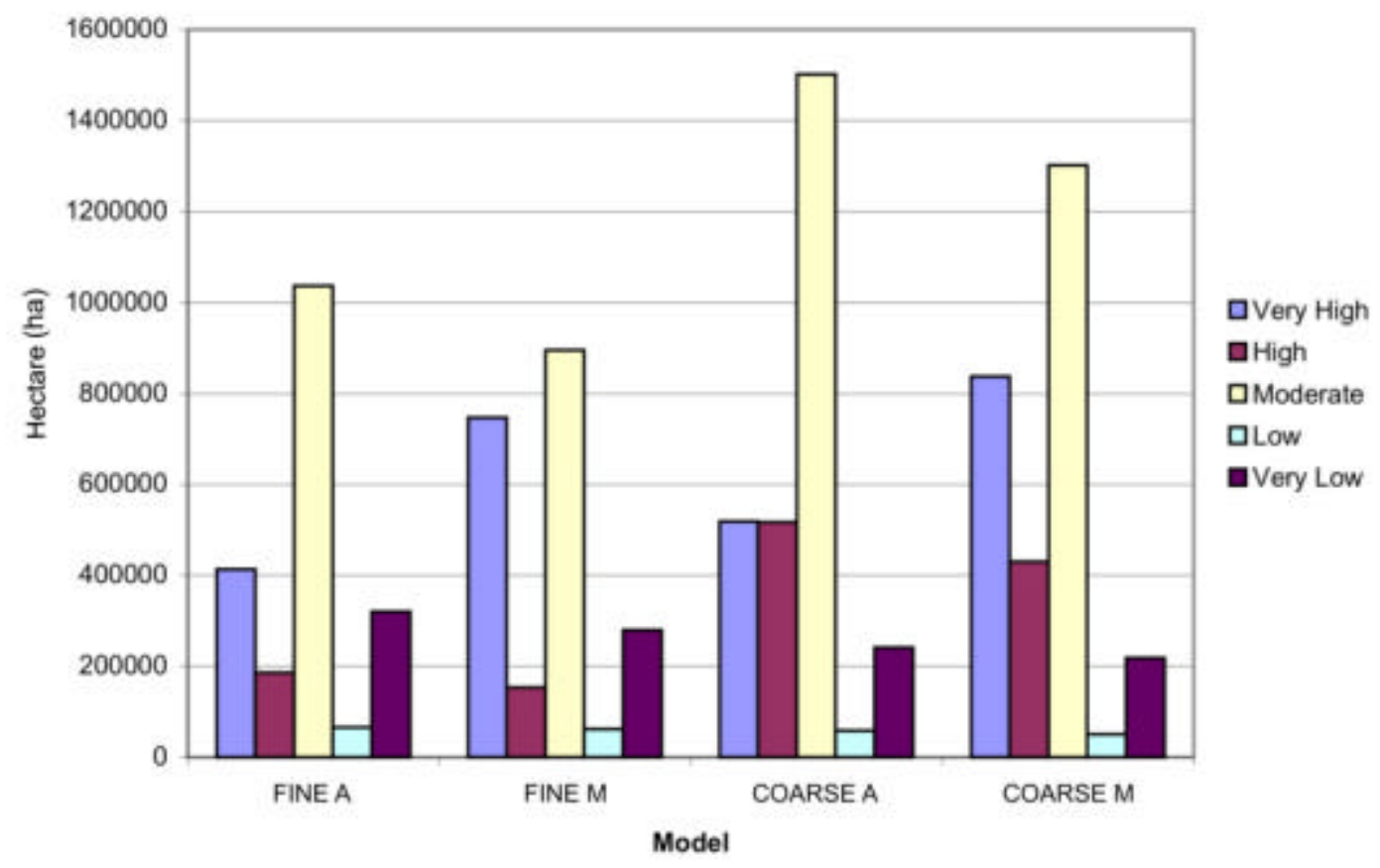

Figure 38. Area in hectares by sensitivity class for each model for total study area 
Table 6. Percent sensitivity class for each model for total study area

\begin{tabular}{l|ccccc} 
MODEL & Very High & High & Moderate & Low & Very Low \\
\hline FINE A & 20.44 & 9.19 & 51.25 & 3.27 & 15.84 \\
FINE M & 34.93 & 7.19 & 41.89 & 2.91 & 13.08 \\
COARSE A & 18.29 & 18.21 & 52.92 & 2.07 & 8.51 \\
COARSE M & 29.51 & 15.16 & 45.85 & 1.78 & 7.70
\end{tabular}

Total Study Area

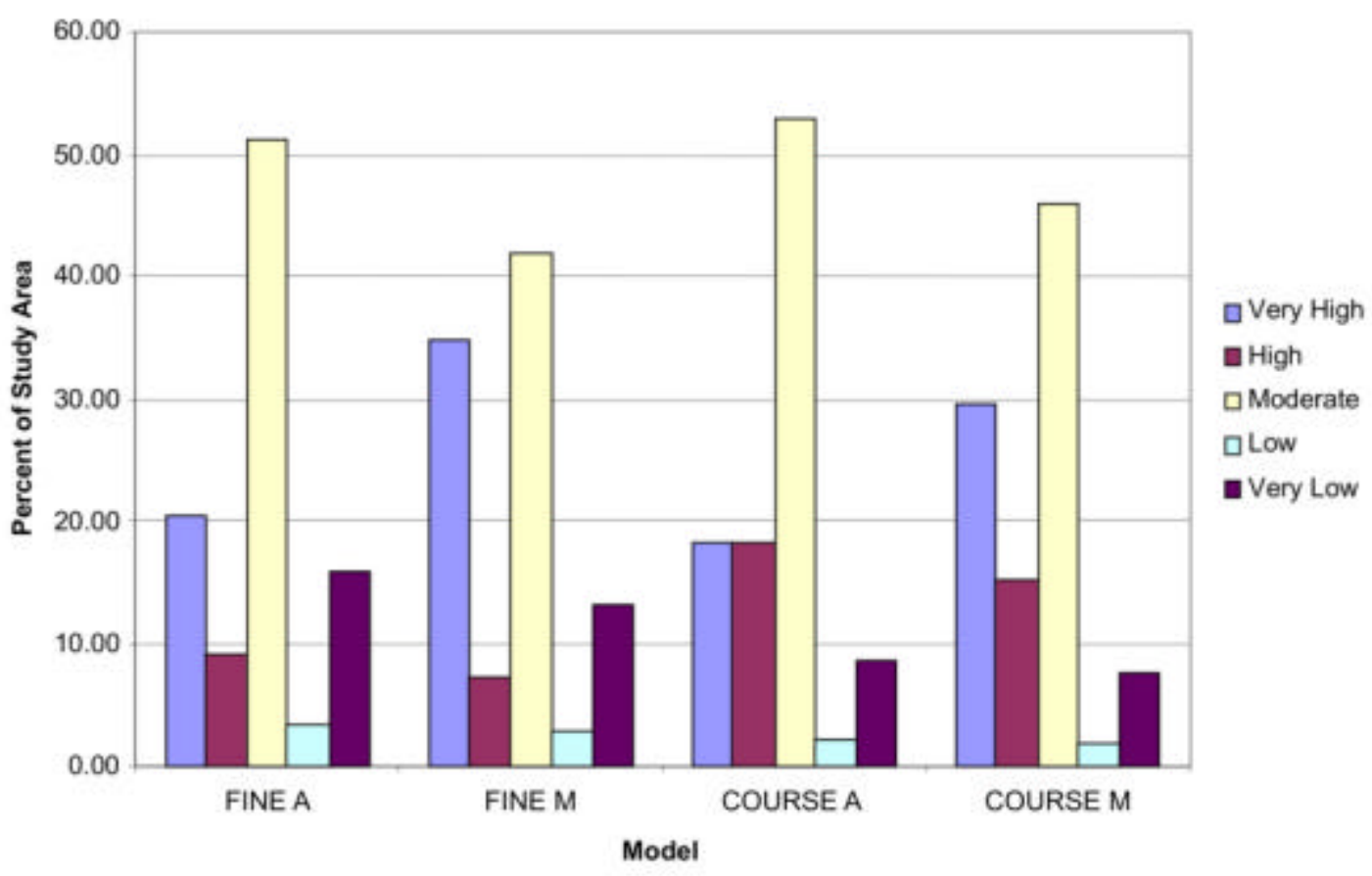

Figure 39. Percent sensitivity class for each model for total study area

Note that components within rockshelter sites, caves, and other unusual locales are omitted from the analysis presented below. Because of their small aerial extent, the sensitivity model makes no attempt to model the location of rockshelters, despite the fact that these geomorphic features are important archaeological sites. In fact, rockshelters are often located on areas otherwise exhibiting low or very low burial sensitivity due the fact that they occur in steep, rocky locations. 
Table 7. Inventoried area in hectares of sensitivity classes for each model

\begin{tabular}{l|ccccc} 
MODEL & Very High & High & Moderate & Low & Very Low \\
\hline FINE A & 41116 & 16738 & 93940 & 6865 & 14448 \\
FINE M & 71959 & 14001 & 80931 & 6464 & 12148 \\
COARSE A & 62334 & 54554 & 127366 & 5780 & 21213 \\
COARSE M & 91061 & 45819 & 110206 & 5211 & 18951
\end{tabular}

Inventoried Study Area

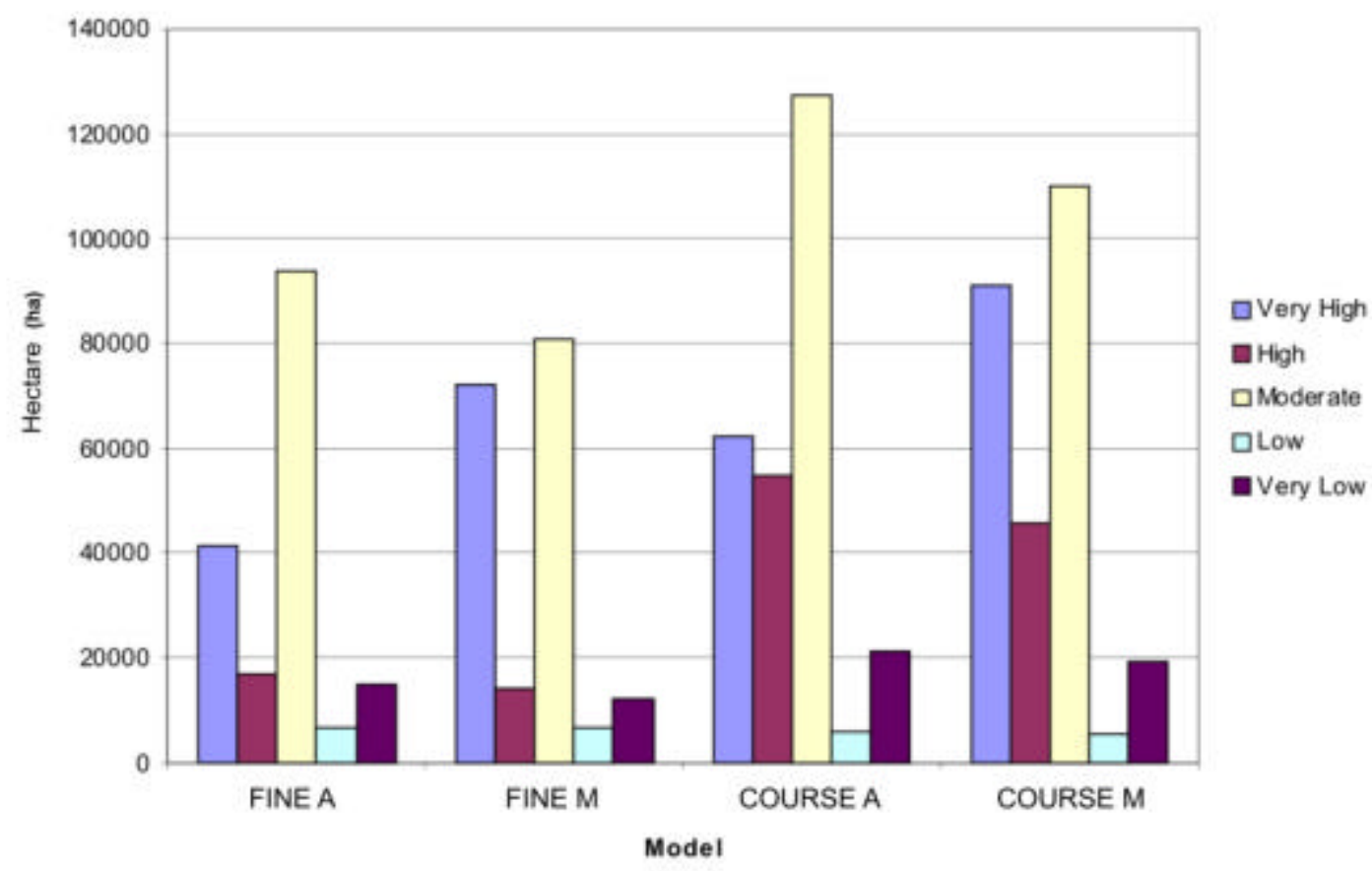

Figure 40. Inventoried area in hectares of sensitivity classes for each model 
Table 8. Percent inventoried area of sensitivity classes for each model

\begin{tabular}{l|ccccc} 
MODEL & Very High & High & Moderate & Low & Very Low \\
\hline FINE A & 9.95 & 9.01 & 9.06 & 10.37 & 4.51 \\
FINE M & 9.64 & 9.11 & 9.04 & 10.40 & 4.34 \\
COARSE A & 12.01 & 10.55 & 8.48 & 9.86 & 8.79 \\
COARSE M & 10.87 & 10.65 & 8.47 & 10.32 & 8.68
\end{tabular}

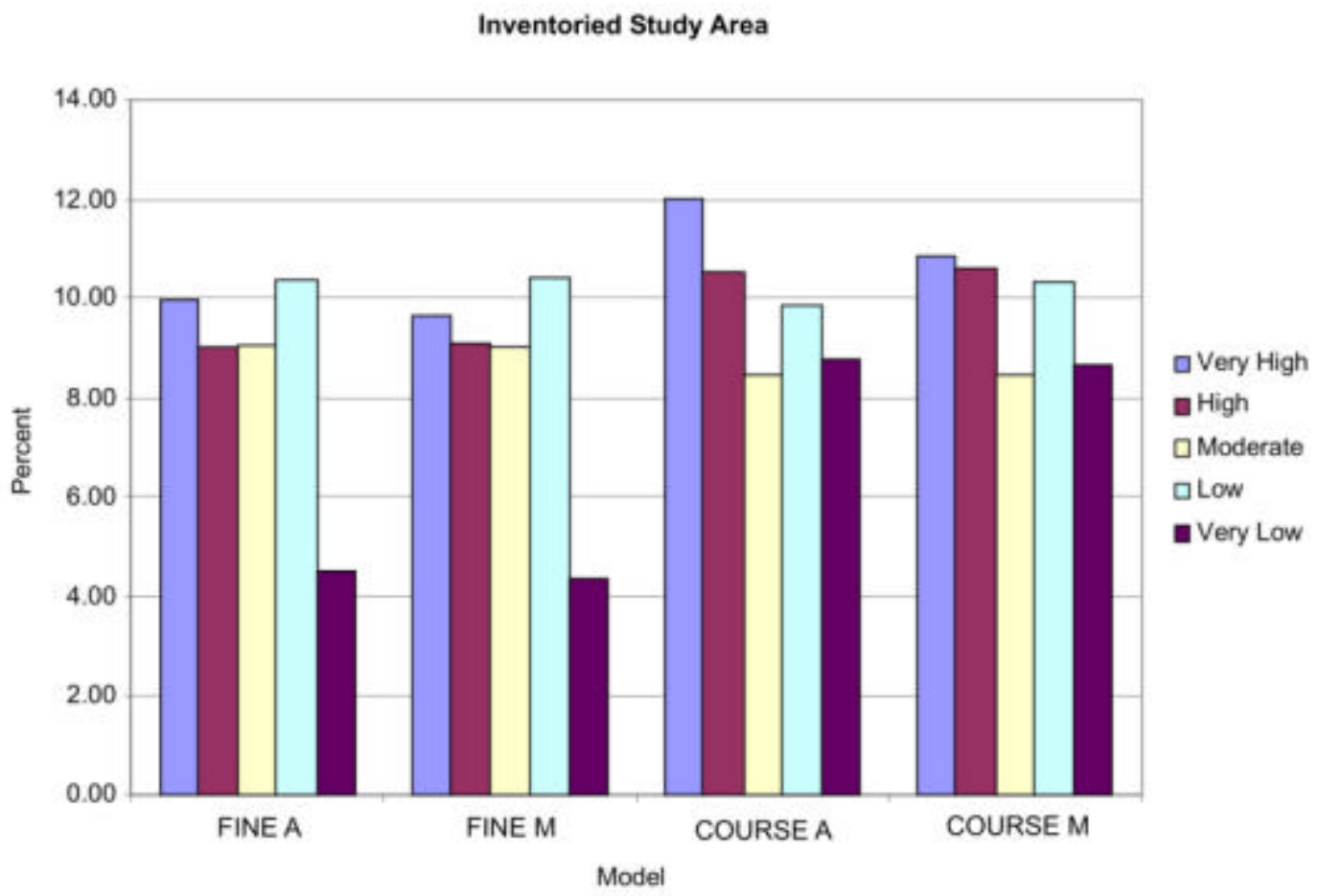

Figure 41. Percent inventoried area of sensitivity classes for each model 
Inventory (archaeological pedestrian survey) coverage (Table 7, Figure 40) provides important data to help evaluate the evenness of archaeological investigation among the different sensitivity zones. When evaluated on a percentage basis (Table 8, Figure 41) there is a relatively equitable distribution of inventory among all sensitivity zones. It can be seen that the very high sensitivity class has had the most inventoried acreage at 12 percent, with all other classes falling around or below 11 percent inventoried. The very low sensitivity classes within FINE Analytical and FINE Management models have had the least amount of previous inventory. The highest concentration of previous inventory has occurred in Campbell and northern Converse Counties. Areas within the Tongue River Basin and the Powder River Basin have just begun to see more Class III inventory due to the increase in coalbed natural gas development. However, a very consistent percentage of the very high, high, moderate and low are represented within the study area. Site occurrence within the sensitivity zones indicates that more surface sites occur within the very high and moderate zones (Table 9, Figure 42). The frequent occurrence of sites in the very high sensitivity zones is probably a result of an association of sites near drainages. The low frequency of sites in the high sensitivity zone may be an artifact of thick deposits and limited testing.

Buried components (Tables 10 and 11, Figures 43 and 44) were evaluated to see if their distribution parallels the sensitivity classes. One consideration in evaluating any association of buried cultural materials with the sensitivity model is defining a subsurface component. Artifacts found at depths of less than $20 \mathrm{~cm}$ below surface are easily bioturbated downward to this depth from an occupation on the existing soil surface (Albanese 1981). One of the problems in compiling this data on subsurface components is variation among investigators (crew chiefs) regarding their individual concept of subsurface and stratigraphic context.

Subsurface, as used in the site form, refers to any buried materials. This includes artifacts in the 1-20 cm layers that in many settings result from a combination of bioturbation, trampling, freeze-thaw cycling, or churning. However, the near-surface mixed materials should NOT be considered in good stratigraphic context. Stratigraphic context, as used in the site form, means the presence of one or more distinct depositional episodes (excluding the surface context). This can be demonstrated by geological stratigraphy, by buried soil horizon associations, or cultural stratigraphy, e.g. (by multiple artifact vertical-frequency peaks). Nearly all surface sites, however, contain at least a few artifacts in the near surface deposits. For the purposes of the AMP data encoding summarized here, a site is described as having a potential for subsurface components only when cultural remains are found $20 \mathrm{~cm}$ or more below the ground surface, or when a subsurface component with good stratigraphic context is demonstrated to exist in the upper $20 \mathrm{~cm}$ of deposition. 
Table 9. Number of sites by sensitivity class for each model

\begin{tabular}{l|ccccc} 
MODEL & Very High & High & Moderate & Low & Very Low \\
\hline FINE A & 552 & 134 & 811 & 34 & 184 \\
FINE M & 921 & 98 & 649 & 29 & 137 \\
COARSE A & 731 & 453 & 853 & 60 & 162 \\
COARSE M & 1071 & 337 & 671 & 47 & 133
\end{tabular}

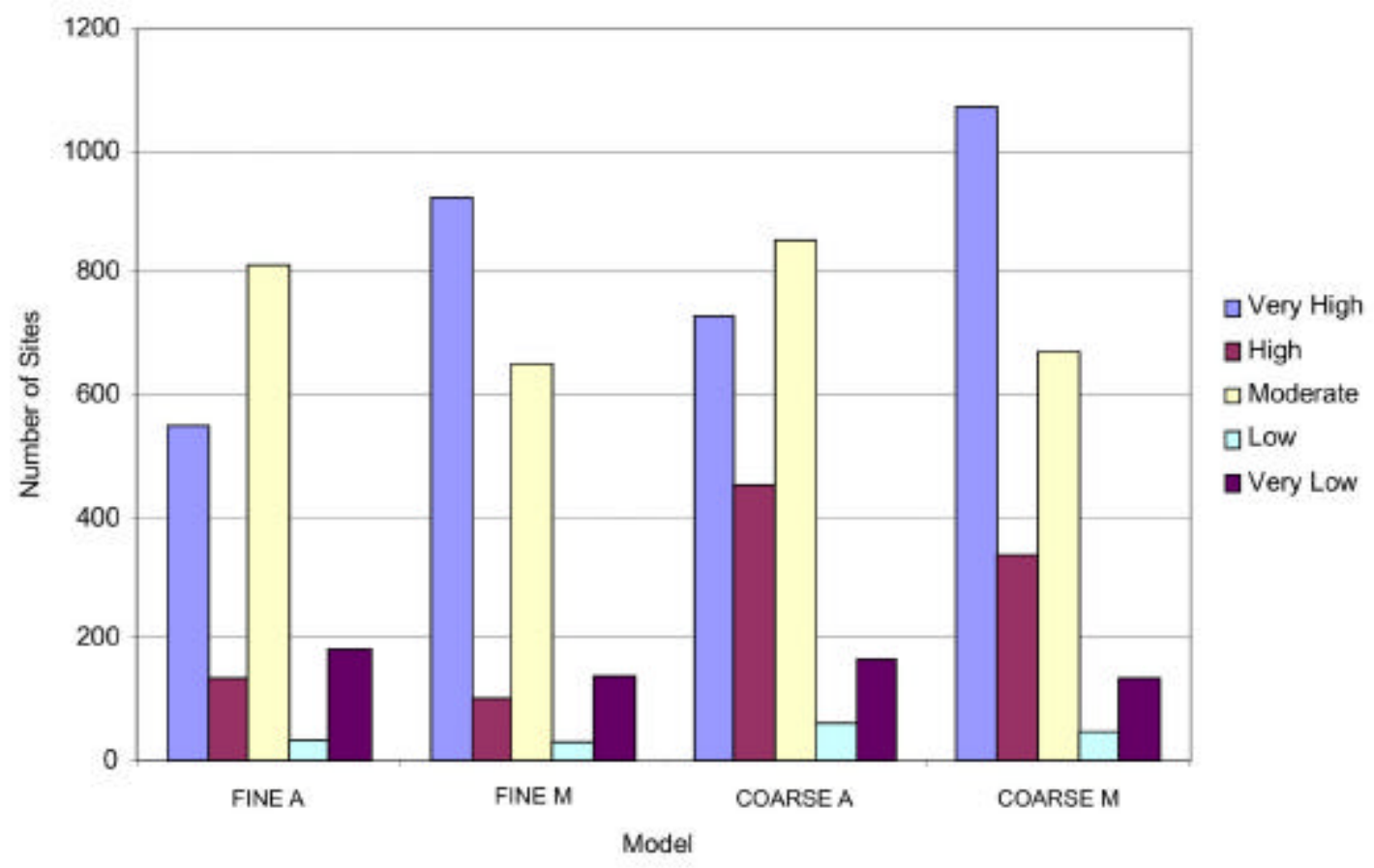

Figure 42. Number of sites by sensitivity class for each model 
Table 10. Number of sites with reported buried components by sensitivity class for each model

\begin{tabular}{l|ccccc} 
MODEL & Very High & High & Moderate & Low & Very Low \\
\hline FINE A & 132 & 19 & 65 & 5 & 16 \\
FINE M & 175 & 14 & 49 & 5 & 9 \\
COARSE A & 132 & 19 & 65 & 5 & 16 \\
COARSE M & 185 & 40 & 64 & 2 & 8
\end{tabular}

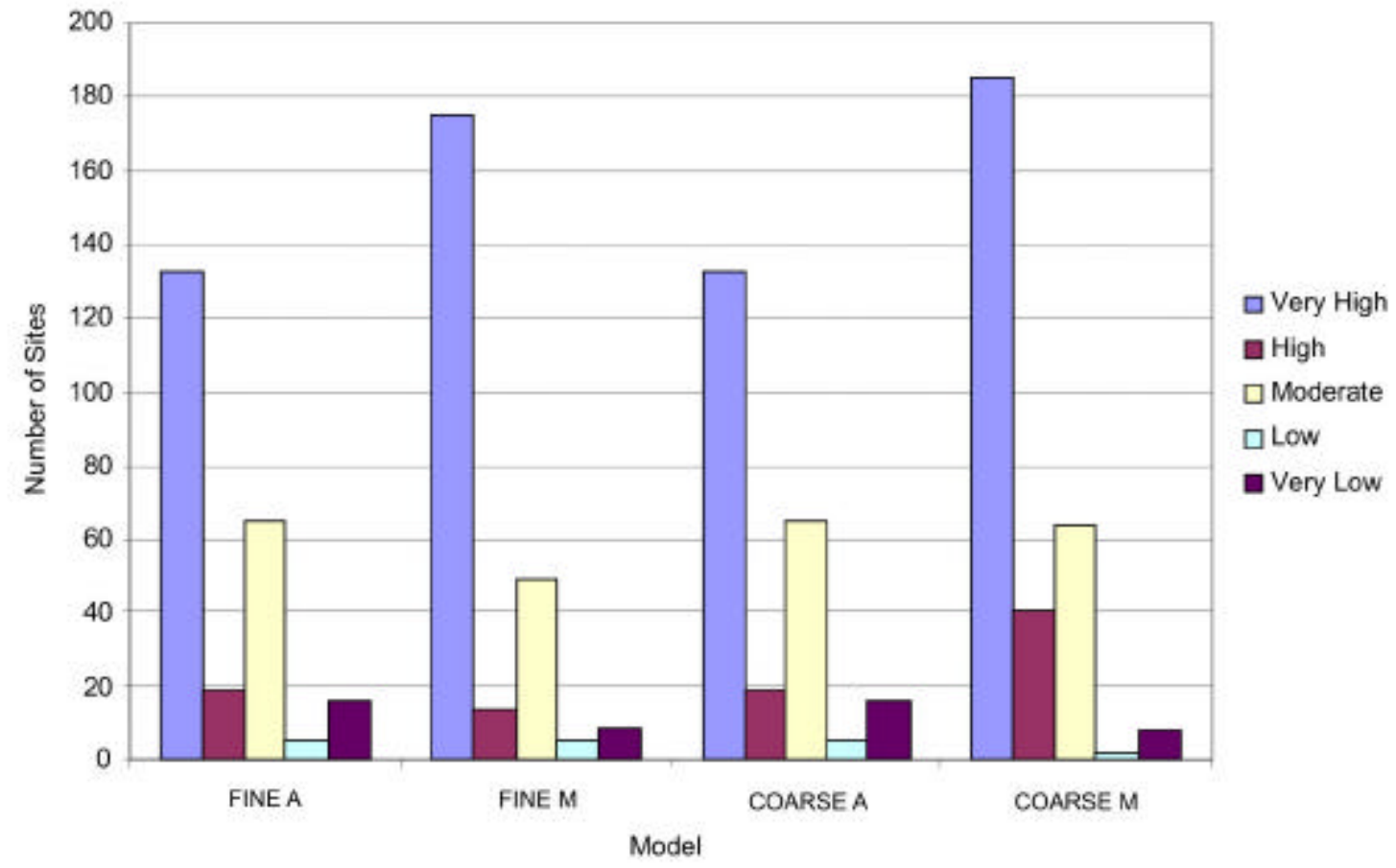

Figure 43. Number of sites with reported buried components by sensitivity class for each model 
Table 11. Percent of sites with reported buried components by sensitivity class for each model

\begin{tabular}{l|ccccc} 
MODEL & Very High & High & Moderate & Low & Very Low \\
\hline FINE A & 23.91 & 14.18 & 8.01 & 14.71 & 8.70 \\
FINE M & 19.00 & 14.29 & 7.55 & 17.24 & 6.57 \\
COARSE A & 18.06 & 4.19 & 7.62 & 8.33 & 9.88 \\
COARSE M & 17.27 & 11.87 & 9.54 & 4.26 & 6.02
\end{tabular}

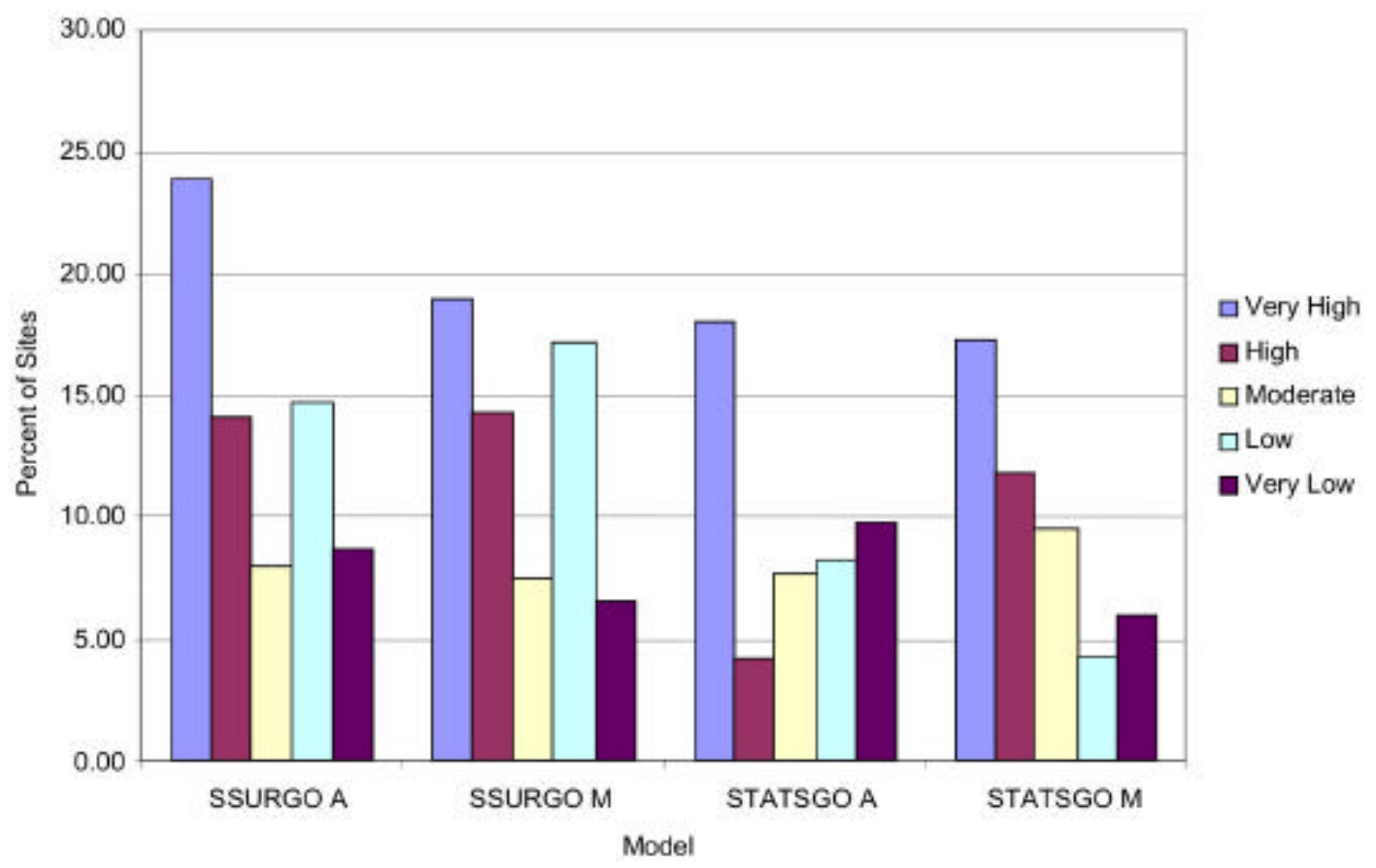

Figure 44. Percent of sites with reported buried components by sensitivity class for each model

There is a very high correlation with reported sites having buried components within the very high sensitivity class across all four models. The high number of buried sites which fall into the very high sensitivity classes is a strong indication that the model adequately predicts the potential of buried resources within the very high sensitivity class. The high sensitivity class does not seem to represent the reported sites as well as the very high sensitivity class. Additional fieldwork would be helpful to determine if sites are properly reported and evaluated. Figure 45 shows where known buried sites occur superimposed over the COARSE sensitivity model.

Surface components are also analyzed (Table 12, Figure 46). In general the analysis indicates sites that contain only surface components are more likely to occur in the lower sensitivity classes. 


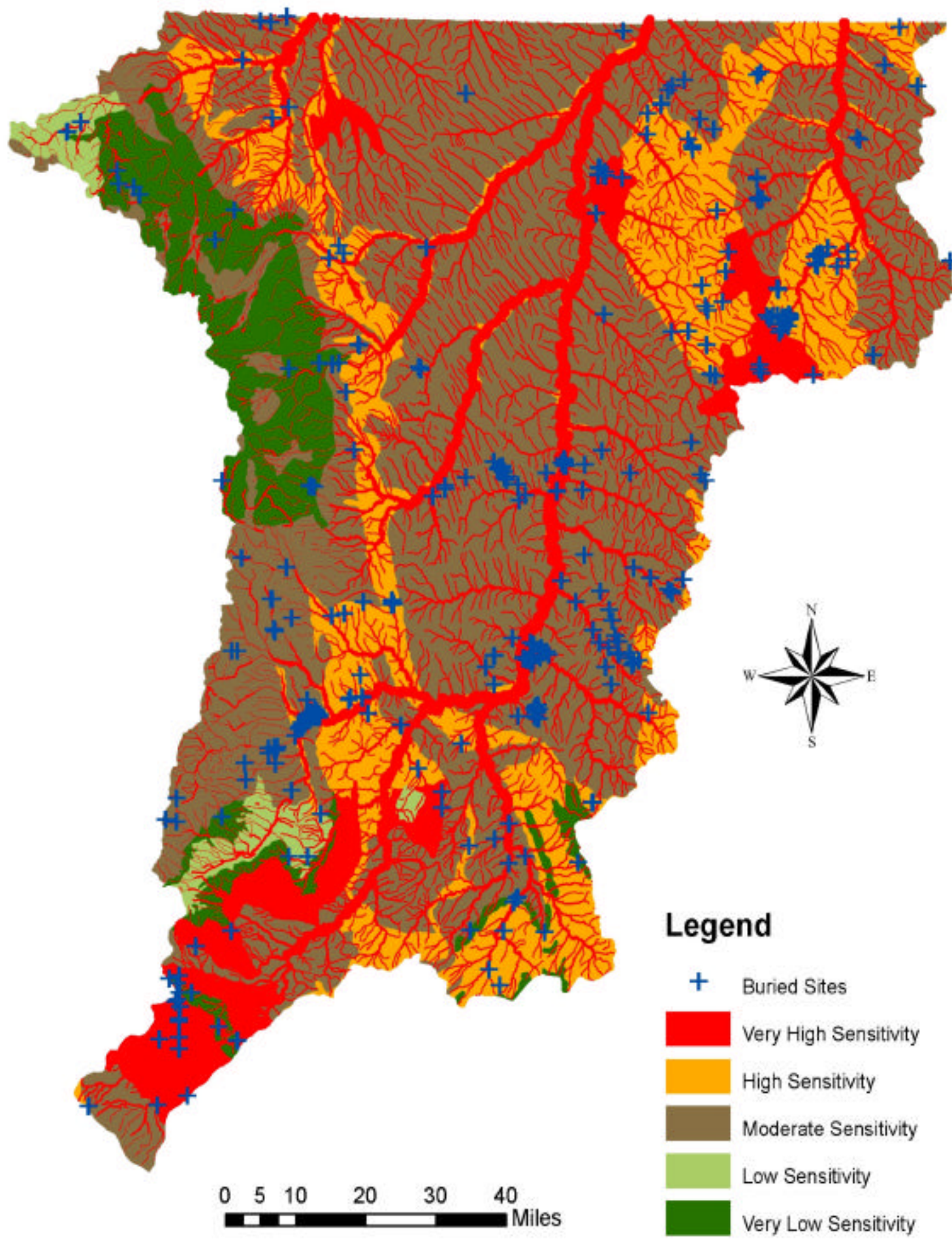

Figure 45. COARSE management sensitivity model with known buried archaeological sites

Sites that have produced radiocarbon dates (Tables 13 and14; Figures 47 and 48) are a suitable measure to use in the evaluation of the sensitivity model. Because of their 
substantial cost, radiocarbon dates are derived from either relatively intact hearth features, or organic remains within known or suspected intact archaeological components - both the types of remains we assume to be important data categories for buried components. Sites in the Powder River Basin have a greater sod cover than sites in more arid and more deflated portions of Wyoming, so most of the radiocarbon dates are expected to be from components that are subsurface. There is a high correlation of number of sites producing radiocarbon dates with the very high sensitivity classes. The majority of radiocarbon dates, approximately 75 percent, collected within the study area fall within the very high sensitivity class. It is interesting to note there are no sites producing radiocarbon dates within the low sensitivity classes. Table 15 is a summary of the site data.

Table 12. Percent of sites with surface components only

\begin{tabular}{l|ccccc} 
MODEL & Very High & High & Moderate & Low & Very Low \\
\hline FINE A & 76.09 & 85.82 & 91.99 & 85.29 & 91.30 \\
FINE M & 81.00 & 85.71 & 92.45 & 82.76 & 93.43 \\
COARSE A & 81.94 & 95.81 & 92.38 & 91.67 & 90.12 \\
COARSE M & 82.73 & 88.13 & 90.46 & 95.74 & 93.98
\end{tabular}

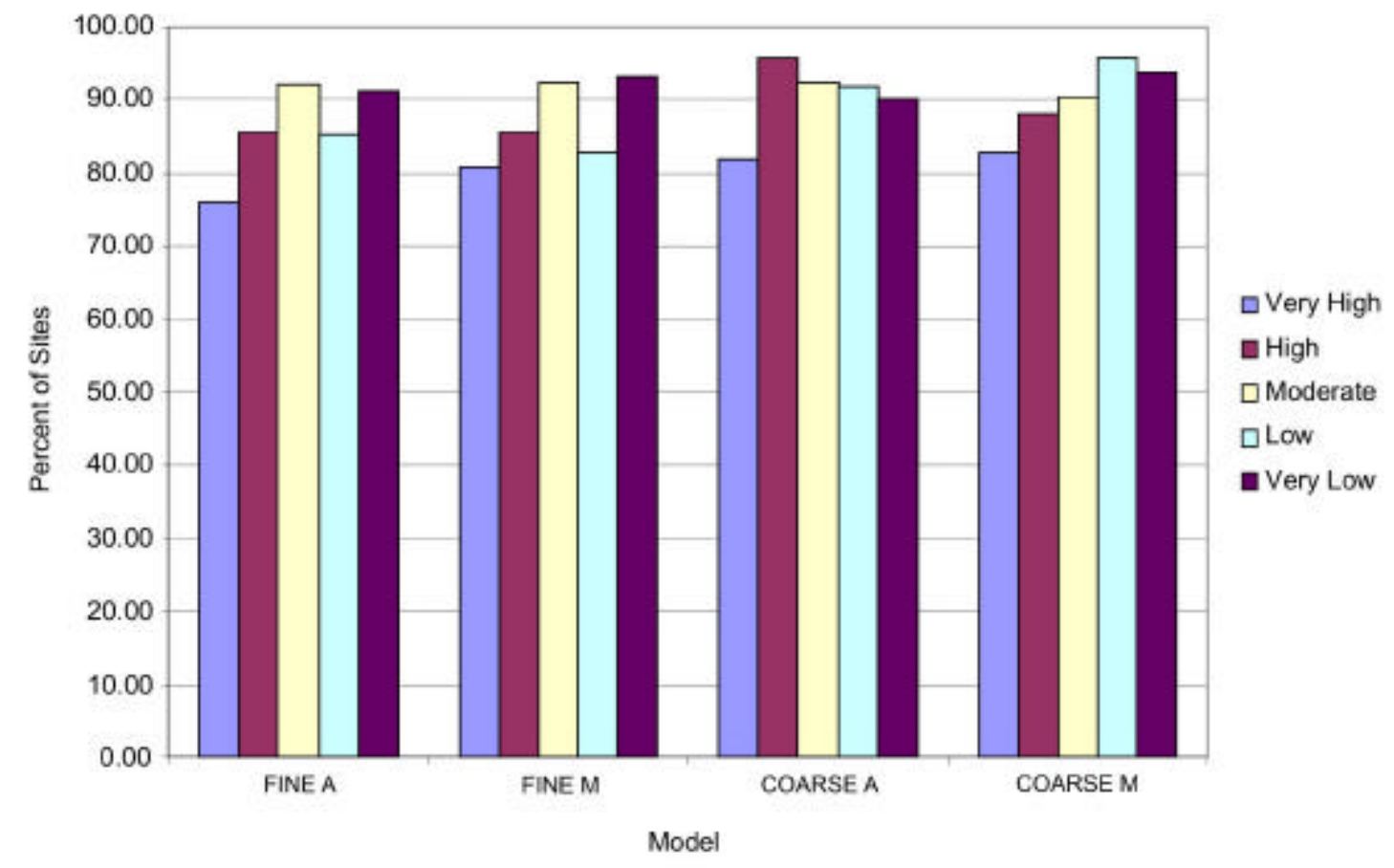

Figure 46. Percent of sites with surface components only 
Table 13. Number of sites with radiocarbon dates by sensitivity class for each model

\begin{tabular}{l|ccccc} 
MODEL & Very High & High & Moderate & Low & Very Low \\
\hline FINE A & 50 & 7 & 11 & 0 & 3 \\
FINE M & 63 & 5 & 7 & 0 & 2 \\
COARSE A & 50 & 7 & 11 & 0 & 3 \\
COARSE M & 67 & 3 & 10 & 0 & 0
\end{tabular}

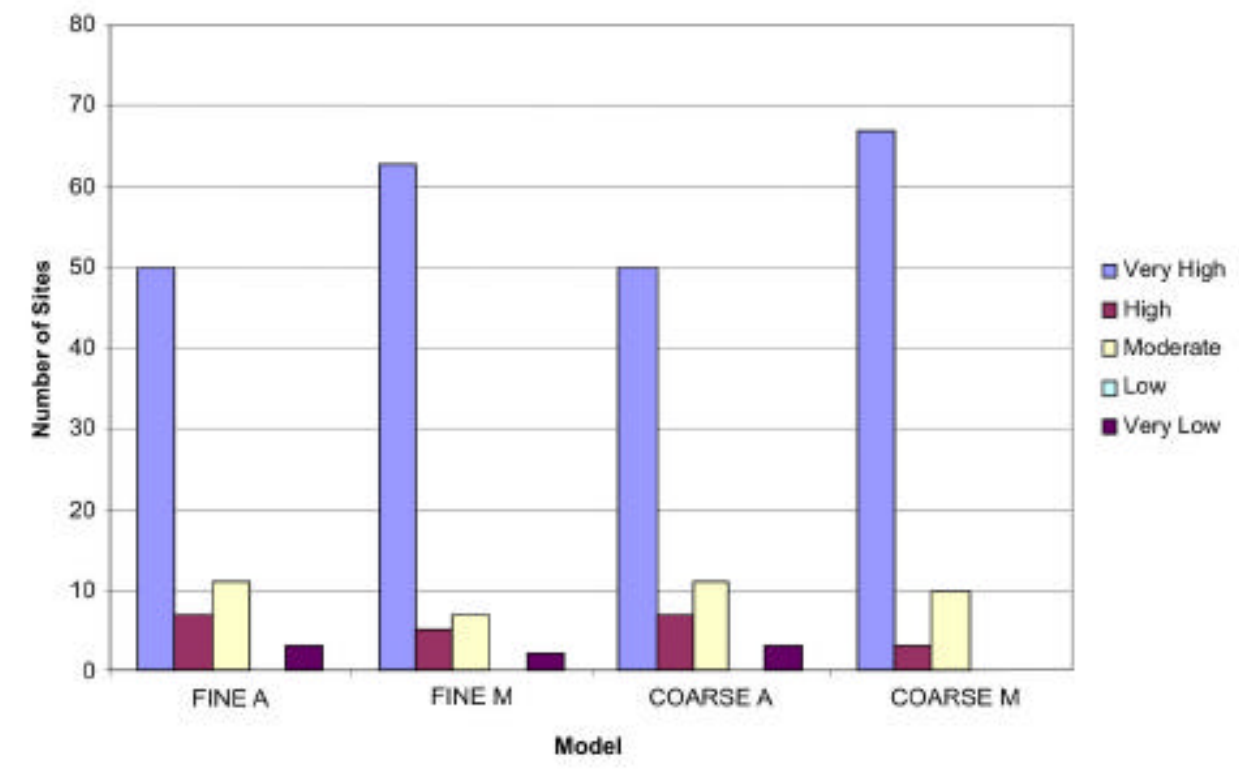

Figure 47. Number of sites with radiocarbon dates by sensitivity class for each model 
Table 14. Percent of sites with radiocarbon dates by sensitivity class for each model

\begin{tabular}{l|ccccc} 
MODEL & Very High & High & Moderate & Low & Very Low \\
\hline SSURGO A & 9.06 & 5.22 & 1.36 & 0.00 & 1.63 \\
SSURGO M & 6.84 & 5.10 & 1.08 & 0.00 & 1.46 \\
STATSGO A & 6.84 & 1.55 & 1.29 & 0.00 & 1.85 \\
STATSGO M & 6.26 & 0.89 & 1.49 & 0.00 & 0.00
\end{tabular}

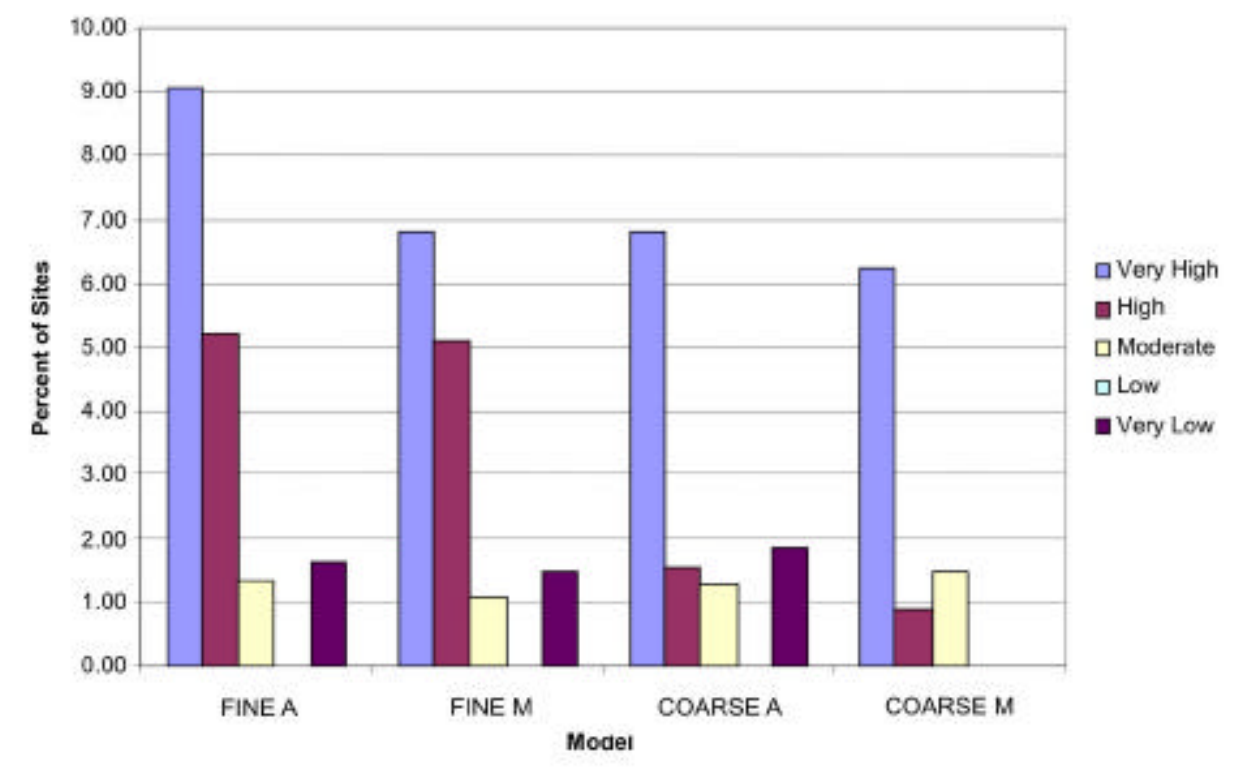

Figure 48. Percent of sites with radiocarbon dates by sensitivity class for each model 
Table 15. Summary table of study area archaeological characteristics by sensitivity class for each model

\begin{tabular}{|c|c|c|c|c|c|c|c|c|c|c|c|c|}
\hline Category & $\begin{array}{c}\text { Area } \\
\text { (ha) }\end{array}$ & $\begin{array}{c}\text { Percent } \\
\text { Study } \\
\text { Area }\end{array}$ & $\begin{array}{c}\text { Area } \\
\text { Inventoried } \\
\text { (ha) }\end{array}$ & \begin{tabular}{|} 
Percent of \\
Category \\
Inventoried
\end{tabular} & $\begin{array}{c}\text { Number } \\
\text { of Sites } \\
\text { per } \\
\text { Category }\end{array}$ & $\begin{array}{c}\text { Number of } \\
\text { Sites with } \\
\text { Buried } \\
\text { Component }\end{array}$ & \begin{tabular}{|} 
Percent \\
Sites with \\
Buried \\
Component
\end{tabular} & $\mid \begin{array}{c}\text { Percent Of } \\
\text { Sites with } \\
\text { Surface } \\
\text { Component } \\
\text { Only }\end{array}$ & \begin{tabular}{|c|} 
\\
Number of \\
Sites with \\
Radiocarbon \\
Dates \\
\end{tabular} & \begin{tabular}{|c|} 
Percent Of \\
Sites \\
Producing \\
Radiocarbon \\
Date \\
(excluding \\
rockshelters)
\end{tabular} & $\begin{array}{c}\text { Number of } \\
\text { Buried Sites } \\
\text { with Shovel } \\
\text { Tests and } \\
\text { Formal } \\
\text { Excavations }\end{array}$ & $\begin{array}{c}\text { Percent of } \\
\text { Buried Sites } \\
\text { with Shovel } \\
\text { Tests and } \\
\text { Formal } \\
\text { Excavations }\end{array}$ \\
\hline \multicolumn{13}{|c|}{ 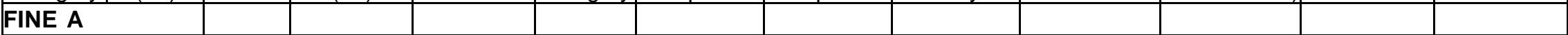 } \\
\hline \begin{tabular}{|l|} 
Very \\
High
\end{tabular} & 413358 & 20.44 & 41116 & 9.95 & 552 & 132 & 23.91 & 76.09 & 50 & 9.06 & 10 & 7.58 \\
\hline High & 185780 & 9.19 & 16738 & 9.01 & 134 & 19 & 14.18 & 85.82 & 7 & 5.22 & 2 & 10.53 \\
\hline Moderate & 1036473 & 51.25 & 93940 & 9.06 & 811 & 65 & 8.01 & 91.99 & 11 & 1.36 & 5 & 7.69 \\
\hline \begin{tabular}{|l|l|} 
Low \\
\end{tabular} & \begin{tabular}{|l|}
66218 \\
\end{tabular} & 3.27 & 6865 & 10.37 & 34 & 5 & 14.71 & 85.29 & 0 & 0 & 0 & 0 \\
\hline Very Low & 320363 & 15.84 & 14448 & 4.51 & 184 & 16 & 8.7 & 91.3 & 3 & 1.63 & 1 & 6.25 \\
\hline Total & 2022192 & & & & & 237 & & & & & 18 & 7.59 \\
\hline \multicolumn{13}{|l|}{ FINE M } \\
\hline $\begin{array}{l}\text { Very } \\
\text { High }\end{array}$ & 746570 & 34.93 & 71959 & 9.64 & 921 & 175 & 19 & 81 & 63 & 6.84 & 13 & 7.43 \\
\hline High & 153686 & 7.19 & 14001 & 9.11 & 98 & 14 & 14.29 & 85.71 & 5 & 5.1 & 1 & 7.14 \\
\hline Moderate & 895480 & 41.89 & 80931 & 9.04 & 649 & 49 & 7.55 & 92.45 & 7 & 1.08 & 5 & 10.2 \\
\hline \begin{tabular}{|l|l} 
Low \\
\end{tabular} & 62139 & 2.91 & 6464 & 10.4 & 29 & 5 & 17.24 & 82.76 & 0 & 0 & 0 & 0 \\
\hline Very Low & 279676 & 13.08 & 12148 & 4.34 & 137 & 9 & 6.57 & 93.43 & 2 & 1.46 & 0 & 0 \\
\hline \begin{tabular}{|l|l|} 
Total \\
\end{tabular} & 2137551 & & & & & 252 & & & & & 19 & 7.54 \\
\hline \multicolumn{13}{|c|}{\begin{tabular}{|l|} 
COARSE A \\
\end{tabular}} \\
\hline \begin{tabular}{|l|l} 
Very \\
High \\
\end{tabular} & 519127 & 18.29 & 62334 & 12.01 & 731 & 132 & 18.06 & 81.94 & 50 & 6.84 & 10 & 7.58 \\
\hline \begin{tabular}{|l|l} 
High \\
\end{tabular} & 516868 & 18.21 & 54554 & 10.55 & 453 & 19 & 4.19 & 95.81 & 7 & 1.55 & 2 & 10.53 \\
\hline Moderate & 1501808 & 52.92 & 127366 & 8.48 & 853 & 65 & 7.62 & 92.38 & 11 & 1.29 & 5 & 7.69 \\
\hline \begin{tabular}{|l|l} 
Low \\
\end{tabular} & 58645 & 2.07 & 5780 & 9.86 & 60 & 5 & 8.33 & 91.67 & 0 & 0 & 0 & 0 \\
\hline Very Low & 241361 & 8.51 & 21213 & 8.79 & 162 & 16 & 9.88 & 90.12 & 3 & 1.85 & 1 & 6.25 \\
\hline \begin{tabular}{|l|l} 
Total \\
\end{tabular} & 2837809 & & & & & 237 & & & & & 18 & 7.59 \\
\hline
\end{tabular}




\begin{tabular}{|c|c|c|c|c|c|c|c|c|c|c|c|c|}
\hline Category & $\begin{array}{c}\text { Area } \\
\text { (ha) }\end{array}$ & $\begin{array}{c}\text { Percent } \\
\text { Study } \\
\text { Area }\end{array}$ & $\begin{array}{c}\text { Area } \\
\text { Inventoried } \\
\text { (ha) }\end{array}$ & $\begin{array}{c}\text { Percent of } \\
\text { Category } \\
\text { Inventoried }\end{array}$ & $\begin{array}{c}\text { Number } \\
\text { of Sites } \\
\text { per } \\
\text { Category }\end{array}$ & $\begin{array}{c}\text { Number of } \\
\text { Sites with } \\
\text { Buried } \\
\text { Component }\end{array}$ & $\begin{array}{l}\text { Percent } \\
\text { Sites with } \\
\text { Buried } \\
\text { Component }\end{array}$ & \begin{tabular}{|} 
Percent Of \\
Sites with \\
Surface \\
Component \\
Only \\
\end{tabular} & \begin{tabular}{|c|} 
Number of \\
Sites with \\
Radiocarbon \\
Dates
\end{tabular} & \begin{tabular}{|c|} 
Percent Of \\
Sites \\
Producing \\
Radiocarbon \\
Date \\
(excluding \\
rockshelters) \\
\end{tabular} & $\begin{array}{c}\text { Number of } \\
\text { Buried Sites } \\
\text { with Shovel } \\
\text { Tests and } \\
\text { Formal } \\
\text { Excavations }\end{array}$ & \begin{tabular}{|c|} 
Percent of \\
Buried Sites \\
with Shovel \\
Tests and \\
Formal \\
Excavations \\
\end{tabular} \\
\hline \multicolumn{13}{|c|}{ COARSE M } \\
\hline \begin{tabular}{|l|} 
Very \\
High
\end{tabular} & 837562 & 29.51 & 91061 & 10.87 & 1071 & 185 & 17.27 & 82.73 & 67 & 6.26 & 19 & 10.27 \\
\hline High & 430224 & 15.16 & 45819 & 10.65 & 337 & 40 & 11.87 & 88.13 & 3 & 0.89 & 5 & 12.5 \\
\hline Moderate & 1301170 & 45.85 & 110206 & 8.47 & 671 & 64 & 9.54 & 90.46 & 10 & 1.49 & 4 & 6.25 \\
\hline Low & 50481 & 1.78 & 5211 & 10.32 & 47 & 2 & 4.26 & 95.74 & 0 & 0 & 1 & 50 \\
\hline Very Low & 218415 & 7.7 & 18951 & 8.68 & 133 & 8 & 6.02 & 93.98 & 0 & 0 & 1 & 12.5 \\
\hline Total & 2837852 & & & & & 299 & & & & & 30 & 10.03 \\
\hline
\end{tabular}




\section{Cultural Resources Management Recommendations for Sensitivity Zones}

Recommendations presented here supplement and suggest, but should not be inferred to require any changes to minimum Section 106 management practices. No reductions in inventory are recommended. Minimal testing requirements are supported and deeper testing is recommended where indicated. This description of sensitivity zones will give stakeholders an idea of where the risk of encountering sediments that might contain buried sites is high or low.

\section{Very High Sensitivity Zone}

Locations predicted to have very high archaeological landscape sensitivity (Figure 37) are situated, either within fine-textured alluvial fill located in low gradient, basin valleys, or in eolian deposits. Earth-disturbing construction activities within this zone should only occur under the most controlled circumstances. Intensive archaeological inventory, subsurface prospecting of areas without surface archaeology, and complete construction monitoring are recommended to prevent inadvertent destruction of significant archaeological resources within this zone. Experience within other areas in Wyoming suggests that it is reasonable to postpone data recovery efforts at some site types slated for impact by pipeline trenching until after archaeological open-trench inspections are completed. The reason for this is that often highly significant buried components are found during open trench inspection whereas, these components are difficult to locate using traditional site prospecting and testing methods. To facilitate data recovery at discoveries made during open trench inspection, it is generally desirable to have administrative and budgetary contingencies built into the permit process.

\section{High Sens itivity Zone}

Some locations not necessarily situated along major drainages in the project area are mapped as having high archaeological landscape sensitivity. These areas are derived from NRCS map units and have low slope, exhibit thick accumulations of surficial sediment, lack evidence of old surface soils, and contain little large and small gravel. At the COARSE scale $(1: 24 \mathrm{k})$ (Figure 37$)$, high sensitivity zones occur in fine-textured alluvial, eolian, alluvial fan, and slope wash depositional environments. The high sensitivity zone is predicted to contain buried cultural occupation zones that exhibit similar site preservation as those in the very high sensitivity zone. Management implications and suggested recommendations are identical for high and very high sensitivity zones. As with the very high sensitivity zone, earth disturbing construction activities within the high sensitivity zone should only occur under controlled circumstances. Intensive archaeological inventory, prospecting, and construction monitoring, including 100 percent inspection of construction trenches, will be necessary to totally prevent the inadvertent destruction of significant archaeological resources. 


\section{Moderate Sensitivity Zone}

Some areas within the project area failed to meet the distinctive criteria that characterized the very high, high, low, and very low sensitivity classes. These areas are classified as moderate sensitivity (Figure 37). At the FINE scale, the moderate class encompasses low and very low areas delineated by the COARSE map, especially in the basin area. While sizeable tracts of the moderate zone have a low risk, other, smaller areas (especially at the COARSE scale) might be more sensitive. As the NRCS makes SSURGO data available for the remaining portions of the project area, it will be desirable and possible to reclassify additional areas of low and very low concern within basin areas. Until that time, professional archaeologists working in areas mapped as a moderate zone in the COARSE model will need to carefully assess slope, depth to bedrock, percent sediment less than $7.62 \mathrm{~cm}$ ( $3 \mathrm{in})$, and percent sediment less than $2 \mathrm{~mm}(0.08 \mathrm{in})$ to distinguish areas of higher sensitivity from those of lower sensitivity within the basin. Projectspecific, geoarchaeological evaluations are highly recommended for projects in this zone as they can help identify which portions of the moderate zone are more or less sensitive. In addition to normal Section 106 process inventory and evaluation, this zone would benefit from construction monitoring of known archaeological resources and monitoring of construction trenches as recommended by a geoarchaeologist. The moderate sensitivity zone has the potential to contain some deep deposits.

\section{Low Sensitivity Zone}

Areas predicted to have low archaeological landscape sensitivity include NRCS map units that exhibit characteristics such as a thin mantle of sediment, steep slope, and coarse-grained texture. As well, this zone is mostly mantled by questionable Holoceneage surface soils (i.e., Argiaquolls, Argiborolls, Argiustolls, Calciargids, Calciborolls, Calciorthids, Cryoboralfs, Eutroboralfs, Gypsiorthids, and Haplustalfs). Although small areas of probable Holocene-age soils are included, the surface soil age of the bulk of the included map units suggests that the sediments in and under the soils are too old to contain intact archaeological material. Thus, the potential for preserving occupation integrity, perishables, and stratigraphic separation of occupations in this zone is lower in comparison to the higher-ranked (very high, high, moderate) sensitivity zones. In addition to normal Section 106 process inventory and evaluation, construction monitoring would be necessary on a case-by-case basis, as identified by agency or project archaeologists.

\section{Very Low Sensitivity Zone}

Areas at the lowest extreme of the sensitivity scale are characterized as the very low sensitivity zone. Some areas within the project area contain a combination of attributes that render them unlikely to contain intact, well-preserved, and stratigraphically separable occupation zones. This prediction is based on one or more of the following attributes, which correspond to the NRCS map units they occupy: (1) a large amount of non-soil land is present (e.g., badlands, gravel pits, rock outcrops, etc.); (2) surface soil type is thought to be too old to engulf any intact and buried cultural material; (3) depth to 
bedrock is very shallow; (4) slopes are steep; and/or (5) gravel comprises a relatively large proportion of the soil component. Generally speaking, much of this zone is situated on steep slopes in mountainous areas. As with the low sensitivity zone, small inclusions of other soils occur within the boundaries of the very low sensitivity zone, and thus some of these areas could potentially contain intact, well-preserved, and stratigraphically separable occupation zones. However, if smaller potential sensitive inclusions are not identified in the field by agency or project archaeologists, construction monitoring and other post-inventory discovery techniques can be omitted without overt risk to sensitive cultural resources.

In addition to the recommendations presented above, we also recommend project-specific geoarchaeological evaluations be conducted for projects that will impact large areas. These evaluations should include field reconnaissance and be performed during the permitting of linear projects such as pipelines and highway construction that exceed $1 \mathrm{~km}$ in length. These investigations can help test the model presented here and also provide larger scale and more detailed project-specific predictions on burial risk. Also, geoarchaeologists should be involved in the documentation and interpretation of buried archaeological discoveries during the open trench inspection phase, especially at locations that might be considered for data recovery. The geoarchaeologist can lend expertise to evaluating the site formation and destruction processes at these locations and potentially help discriminate sites with good context from those that might have poor burial context, thus maximizing effective data recovery and eliminating unwanted, poorly conceived data recovery efforts.

\section{Maintaining the Model}

When implemented, the model will need to be subjected to ongoing maintenance to fulfill its adaptive management goal. This should include monitoring, additional testing, periodic reevaluation, and adjustment. Monitoring should include the specific tracking of cultural resource management (CRM) and field archaeological actions taken in which the model was used. This should especially include tracking any construction monitoring such as open trench inspections. A logical way to do this is to periodically retest the model against the growing WYCRO database.

Additional testing of the model is a priority. Spatial association of the sensitivity zones with WYCRO site data gives initial support to the model and warrants implementation. However, additional testing is recommended as part of the adaptive management process. Although open trench inspections can be minimized or eliminated in the low and very low areas, adequate testing of the model can only occur if some percentage of open trench inspections occurs through the entire range of sensitivity zones, including low and very low sensitivity zones. Data from these open trench inspections in all sensitivity zones must then be evaluated to test the model.

Two geoarchaeological issues to consider when testing the model are: (1) NRCS data that was used in the model should be field tested; (2) areas the model predicts having the 
correct age and depositional energy regime to bury and preserve sites should be field tested.

In addition to the above (essentially geological questions), there is an important archaeological question: What is the frequency with which buried cultural material occurs within each sensitivity zone? Although this has nothing to do with actually testing the age and depositional energy aspects of the model, it is an important part of evaluating how useful the model might be in a management context. The usefulness of the model as a management tool can be judged within overall management goals. These goals refer to prevailing management risk-comfort levels with the rate at which buried cultural materials are accidentally encountered by heavy equipment in pipeline trenches, but then overlooked (by lack of investigation) and not included within the Section 106 process. As discussed above, the model was not designed to predict the density of surface or subsurface cultural materials.

Field-testing of the model by a geoarchaeologist will facilitate formal testing of the model. Geoarchaeological testing on a small percentage of open trench inspections can lead to an assessment of the adequacy of the sensitivity outline and the accuracy of the NRCS data. It is recommended that geoarchaeological review of the model be included as part of open trench inspections. The geoarchaeologist can spot check and assess the fit of the field data with the NRCS mapping data and also assess the adequacy of the sensitivity outline. This assessment can be accomplished at a much-reduced cost if the geoarchaeologist is ordinarily retained to perform a geoarchaeological assessment at discovery locations found during open trench inspection that might have data recovery potential.

Data gathering by non-geoarchaeologists during open trench inspections might also provide useful (but more limited) data to formally test the model. Equally important, discoveries documented by archaeologists as part of open trench inspections can be used to determine the encounter rate of archaeological material within the different sensitivity zones. Appendix B contains a field form that can be used to facilitate this goal. Results of open trench inspections need to be carefully evaluated with regard to the encounter rate of archaeological material, and a geoarchaeologist should be involved in this evaluation, since site preservation and visibility of cultural materials require careful consideration. We caution that any conclusions that are drawn from the evaluation of cultural material encounter rates should take into consideration both the difficulty of seeing cultural stains in the Powder River Basin and also the very low probability at which artifacts will be visible in a vertical cutbank (trench wall), even if the trench cuts through a site (discussed earlier in this report).

\section{Adjust Process}

Yearly review of the use of the model and the results of the open trench inspection monitoring by the relevant agencies is recommended. These reviews should recommend changes to the model when appropriate. In addition to periodically testing and evaluating the burial model in open trenches, it is desirable to add coverage to the model at two-year 
intervals as 1:24,000 NRCS data becomes available. The current model is hampered by the absence of 1:24,000 NRCS soils maps for the entire area. The COARSE model based on 1:250,000 scale soils maps contains few very low and low sensitivity zones within the basin area, although these classes are mapped in the mountains. Areas within the basin for which SSURGO (1:24,000 scale) data are available (FINE model) do have areas mapped as low and very low. With more complete coverage, additional areas of low and very low sensitivity within the basins could be delineated with the result that the moderate class could be reduced in size. This would allow better planning and help reduce conflicts between management goals of site preservation and resource development. 


\section{CHAPTER 5}

\section{CULTURAL RESOURCE MANAGEMENT APPLICATIONS}

One aim of AMP was to create tools to improve the Section 106 process itself. The Section 106 review, determination of National Registry eligibility, and mitigation decisions all rely upon timely and accurate information. Toward these ends, as part of this project Gnomon created one entirely new information tool (Cultural Resources Information Summary Program, or CRISP) and enhanced a prototype application (Cultural Resource Management Tracker, or CRMTracker). These software applications are described in this chapter.

Two kinds of information are of fundamental importance in Section 106. The first is knowledge of the archaeology of an area. This information assists fieldworkers as to expected types of sites, length of time that fieldwork may require, and so on. General archaeological knowledge is also the basis for many of the decisions that the evaluation processes require. Criterion D of the National Register criteria is the most commonly applied criterion for archaeological sites considered as eligible to the National Register. Criterion D essentially states that an historic property is important because of its potential to yield valuable scientific information. In general, archaeologists decide the scientific value based upon what is already known about the sites in an area, which is known as the archaeological context of a particular site. The CRISP information tool is one means for conveying such information to non-specialists. WYCRIS - the professionally accessible database and automated map system that was augmented by this project - is a second such tool.

The second kind of information relevant to Section 106 is more work-oriented than the first. As the phrase implies, cultural resources identification, evaluation, and mitigation are processes themselves. Workflows that span more than a few days generally have some identifiable milestones. So, this second kind of information is about where a given project - a field investigation spawned by a proposed land use - lies along the Section 106 workflow curve. Examples of questions are: Which milestones have been achieved? Which have not? Who is currently reviewing the project document? These sorts of questions can be answered by utilizing the CRMTracker application.

CRMTracker is a web-based application, requiring only web browser software. It captures major milestones in cultural resources driven by the Section 106 process. These include:

- Initiation of fieldwork by a third party seeking lead agency authorization

- Review and Approval/Disapproval by the lead agency

- Reporting of the results of fieldwork

- Creation of summary information and a printed report cover sheet when fieldwork is reported

- Logging of review decisions 
The application uses role-based security to ensure confidentiality and to prevent conflicting edits to the same information.

Currently, the investigation-decision-management process for actions like Applications for a Permit to Drill (APD's) is mostly completed by filling out paper forms. A consultant originates the document, the federal agency reviews the document and its findings, and then the SHPO may review and comment. Only then will a finding be made on the undertaking (e.g., an APD) itself. In Wyoming, for example, the transit time from fieldwork to presence in the data system may require three months or more.

Gnomon developed CRMTracker, which is an information management system that both mirrors the flow of paper documents and improves upon it. The greatest value of this application is saving time through a shared database application accessible via a secure Internet connection. CRM Tracker efficiently captures the inventory and associated resources suite of data early in the process and provides on-line access to this information back to the project applicant. All concerned parties have ready access to all information as the application process proceeds. CRMTracker has been utilized for more than a year in Wyoming by several field offices and major consulting firms.

Estimating how much time and effort CRMTracker saves is difficult. First, CRMTracker is intended to accumulate information as work "flows" through the Section 106 process. Because it has only been used for a year and a typical review cycle is about six to eight months, we do not have as much longitudinal information as one would like. A second difficulty is that use of the application is inconsistent. Some consultants are consistent users, some field offices of BLM request or require its use, and others do not. It is extremely difficult to gain the benefits of an information management system when information is populated partially or inconsistently. A third problem is that the expectations of CRMTracke,r from BLM in particular, exceed its original design. For example, BLM field offices in Wyoming routinely require consultants to provide the office with a statement of project effect and proposed mitigation measures. Because consultants do not assess project effect (agencies do so), CRMTracker does not contain data columns or entry fields for these statements.

Nevertheless, we have some information that supports CRMTracker as a timesaving tool. Fieldwork authorizations are transmitted instantly. This saves at least a one day turnaround time in many cases. Similarly, the ability for BLM to communicate a decision about a proposed fieldwork instantly saves time for consultants and their clients. Extraction of information from CRMTracker to the statewide data systems that support WYCRIS and CRISP will save about one person-year of effort within the records archive. Automated generation of many of the "widget counts" required in annual reporting saves each field office approximately three to five person-days yearly (we have run two trials with the Worland Field Office). These savings accrue if the system is utilized and populated comprehensively. 
The second application, CRISP, is an information tool for non-archaeological experts. It is useful for rapid assessment of potential project areas (PPA's). A PPA could be a contemplated well pad and road, a borrow pit, or any other action. Using CRISP, one draws a PPA onto a map image and then runs a report on the PPA. CRISP is a web-based application, and uses cultural resource inventory layers, cultural resource summary layers, and cultural resource forecasts (models) to provide the user with a summary of knowledge about their PPA.

The first step in the development of CRISP was to digitize all of the archaeological survey and site location information for the entire northeastern corner of Wyoming. These records are available through the WYCRO. This enables easy access to large quantities of data through a web-based application. The second step was to develop the cultural resource sensitivity models (see Chapter Four for how Eckerle developed the models).

CRISP is a planning tool for land-users and managers. It reports how many cultural resource inventories have been completed in an area of interest, and also what percentage of the area of interest falls into sensitivity zones ranging from very low to very high. The user can also view the sensitivity model results throughout the Powder River Basin study area.

CRISP is designed to be easy to use for common forms of analysis. The steps to create a CRISP report are simply:

1. Locate your proposed project area (PPA) by navigating to the appropriate part of the map.

2. Draw the PPA, buffering each feature as needed, to create one or more polygon search masks ("cookie cutters") for analysis.

3. Run the report (the analysis) and save the report as a PDF format file if you wish.

There are two ways to zoom to an area of interest: use a zoom tool or type in a desired township and range. There are layers present in the application that help the user navigate in the study area. Examples are:

- USGS topo maps at three scales

- Major waterways and major highways

- Township and range grid

- Hillshade relief

- Populated places

- UTM zone boundaries

- County boundaries

- State boundary

- BLM office locations and district boundaries 
The final step is to create a report for the PPA. The report summarizes several things about the PPA and provides maps of it. These include:

- The size of the PPA

- The percent of the PPA that has already been inventoried for archaeology

- Known cultural resources and a count of the number of inventory reports within each section touched by the PPA. Note that a PPA may have no inventoried ground within it and yet still be in a section with inventories - this summary is by section, not by PPA.

- The forecast from the COARSE model (currently a model of the likelihood of finding buried archaeological sites in scientifically useful contexts using statewide STATSGO data).

- $\quad$ The forecast from the FINE model (using county-wide SSURGO data).

The report can also be saved locally on a computer as a Portable Document Format (PDF) file.

The benefit of CRISP to lease applicants is that it helps remove some of the unknowns from the application process. By seeing areas where there is a very high probability of encountering buried cultural resources and areas where cultural resources have been discovered in the past, applicants can make decisions early in the project development process, which should save time and money.

CRISP does not replace consultation with appropriate agencies, landowners, land managers, and other participants in the cultural resource management process. Although CRISP summarizes the results of scientific investigations, it also does not replace discussions with cultural resource managers or other experts. What CRISP does provide is a way to gain a quick overview of what might be present on or in the ground, and information about what is already known. CRISP's greatest utility is as a projectplanning tool. It is not a compliance tool.

A copy of the User Manual for CRISP is attached as Appendix D.

CRMTracker is currently in place in Wyoming and CRISP will be in place by the end of 2005. It is currently in the testing phase. More information on CRMTracker can be found in Appendix E, Project Tracking Handbook. 


\section{CHAPTER 6}

\section{RESULTS AND DISCUSSION}

This project, Adaptive Management and Planning (AMP), was sought because the project team thought it had a high likelihood of yielding practical reforms to management practices. In this chapter, we consider the project outcomes from the standpoint of upstream management practices. First, we define "upstream" in terms of the most common cultural resources investigation and decision processes. We then consider how the products produced in AMP have practical utility in creating better management of archaeological resources and, especially, more adaptive management of the entire cultural resource regulatory mechanisms and procedures.

\section{Accomplishments within Wyoming}

Within the Wyoming study area, we have accomplished several important goals. These have been discussed above. We list them here in a more geographic form to emphasize the general benefits and how these contribute to a more rational management process.

\section{- Region-specific accomplishments}

- Data creation and update

- Forecast models for buried archaeology

- Better knowledge of the archaeology and contexts for decision-making about archaeology in the region ○ Example: count of Paleoindian sites

- General (state-wide) accomplishments

- CRMTracker

- Established common core fields

- Created initial summary report capability

○ 1+ years of field use

- Prototype use has interested other states

- CRISP

○ Established mechanism for industry and manager planning

- Integrates statewide data and models appropriately

- Has utility in planning especially, but also in review

- IT user education

- Training sessions for CRMTracker

- Manual for CRMTracker

- GIS tool training

- GIS manual

- GIS data entry system for BLM and other agencies

- ArcGIS entry tool for interaction with WYCRIS

- Standardized entry processes aid quality control 
- Shortens time frame for release of information to users through WYCRIS, CRISP, CRMTracker

- Upgrades to WYCRIS for ease of use and better performance

\section{Relevance to Wyoming Energy Development}

Oil and gas field development in Wyoming has historically been accomplished through field development projects. An oil and gas field is established through exploration on leases and then oil and gas operators develop their leases within the field. A large field may involve many operators; at least there will be many leases in different stages of development. Although a large area may be targeted for development, ultimately, on-theground permitting and associated work required by the National Environmental Policy Act of 1969 (NEPA) and the NHPA occurs at the lease level or, more frequently, on an action-by-action basis.

Archaeological resources at the field level of development have been treated in an overview fashion. Individual development actions have triggered action-specific fieldwork. Most of the time, action-specific fieldwork follows a standard course: identification of archaeological resources from surface inventory, evaluation under the National Register of Historic Places (NRHP) of the archaeological materials found which may require some limited excavation (testing) at particular locations, and then if potentially NRHP eligible sites are within the area of potential effect (APE), the site will either be mitigated to offset damage that it will incur or the APE will be redesigned. The overview approach to cultural resources at the field level meets the requirements of NEPA but does not change the most common parts of the management process for archaeology: APE-specific fieldwork, reporting, and decision-making.

Coalbed natural gas (CBNG) development differs from the scenario sketched above in some significant ways. First, coalbed development exploits a widespread potential that is fairly uniform in occurrence - there are no "fields" in the usual oil and gas sense of the term. Each lease has a fairly consistent potential to yield gas, so development does not necessarily focus on "hot spots", instead being driven by other economics like transport, dewatering costs, and accessibility. Lease development does not have to "prove" value with an exploratory well so much as it must simply extract natural gas in a rational way. Lease development occurs in plans of development (PODs) that lay out the extraction, processing, transport, and access infrastructure in a single pass. CBNG development is generally less costly than "traditional" oil and gas, so companies tend to implement PODs as a whole. Increases in well density are usually foreseen in the original POD, if not put in place as part of the initial POD implementation.

Cultural resources investigation in CBNG development settings tend to be "one pass" across a lease. Identification, evaluation, and mitigation or redesign on a lease take place once. Once done, little further cultural resources investigation is likely to ensue, because little additional disturbance will be called for in the POD. In essence, each lease (if developed) gets treated as a single unitized NEPA and NHPA action. This is distinctly different from the action-driven NEPA and NHPA processes that occur in petroleum 
lease development. This is not to say that CBNG leases have no further actions in them at all. Wells and PODs are extraction locations. Gathering facilities and transport facilities will continue to develop throughout $\mathrm{CBNG}$ regions as sheer volume of gas produced demands more pipelines, tanks, and other distribution infrastructure. Archaeological investigations to assess APEs for these activities will continue.

This project is relevant to Wyoming energy development in several ways: information, process, and upstream best practices. All three of these benefits are intertwined. Nevertheless, each is discussed individually, if somewhat redundantly.

Information is a key to adaptive, rational, decision-making about use of the public lands. The full population of the WYCRIS database, shortening data availability time frames with CRMTracker, the CRISP information tool, and the forecast models for buried archaeology all provide decision-makers, energy developers, land managers, and consultants with far more knowledge of the study area than they had before. Too, the study area encompasses almost all of the Wyoming Powder River Basin and Upper Tongue River Basin in which CBNG development is contemplated, including areas that are not yet leased.

Oil and gas developers consider cultural resources to be a hurdle to development on public lands. This project does not abolish or remove these hurdles - we have neither the authority nor the brief to do so. Archaeology occurs unpredictably from an oil and gas developer's viewpoint: sites occur in the strangest places, and their importance to the archaeological experts seems to have no grounding in the developer's own world view. Even if a developer disagrees with the need for the regulatory process, cannot understand why archaeology occurs where it does, and sees the evaluative process as arcane and idiosyncratic, a forecast of what is likely to be found and how it may be evaluated is tremendously useful.

The regional benefits of better, faster, more available information on known and forecasted archaeology has statewide, and multi-state implications. The Montana portions of the Powder River Basin and Tongue River Basin (PRB/TRB) are obvious candidates for extending the "information environment". On a more general level, a sound information infrastructure - in advance of development - will yield benefits because development decisions can be made that avoid legal, administrative, and procedural entanglements. For example, a member of the company that held a very contentious lease in Weatherman Draw, Montana, told us that if the company had known the archaeological "risk" was so high, they probably would not have bid on the lease at all.

Process change is another area in which AMP has relevance to energy development in the $\mathrm{PRB} / \mathrm{TRB}$, in Wyoming, and on public lands in general. AMP makes process change feasible in three significant ways. One of these has to do with timing and the use of consulting experts; the second is in how fieldwork is conducted; and the third is in how management plans and requirements are presented to developers and planners. 
The first process and management change is in the timing of decision-making and the role of archaeological consultants in the decision. In the PRB/TRB, the CRISP tool involves oil and gas developers directly in assessing the "risks" their project may face. Until now, this has usually been done by hiring a consultant and in discussion with the land managing agency cultural resource specialists. This makes possible a change in the process of development from the standpoint of cultural resource management because developers can employ consultants at more appropriate points in the process. For instance, rather than hiring a consulting archaeologist as part of creating a first pass at a POD, a developer could create several fairly informed POD alternatives and then hire a consulting archaeologist to aid in finding the most efficient (from an archaeological standpoint). The decision- making locus is moved earlier in development. Downstream from this decision nexus, the lead agency staff will receive PODs that are clearer in their assessment of potential archaeology. Consulting archaeologists can be brought in early in the process too - and will no doubt have very high value in it - but there may be less fieldwork to evaluate alternative plans. This change is especially important because archaeology can consume a significantly higher portion of CBNG development costs than it does in traditional petroleum development due to the generally lower cost of CBNG development.. Using consultants and staff time efficiently is sound business practice anywhere, but probably essential in CBNG development.

The second process and management change in the PRB/TRB lies in archaeological field protocol, especially for finding buried cultural materials. The buried archaeology model created in this project can change the requirements for how sites are evaluated and even when they must be evaluated. Appendix B of this volume is a field protocol for assessing whether a site is likely to contain buried materials. Using this protocol as the basis for an agreement about evaluation fieldwork could be in the best interests of federal agencies and the SHPO. The field protocols provide an objective, standard assessment tool. This can become a baseline for evaluations (rather than the sole means of evaluation).

How can such a baseline procedure work in practice? Each archaeological crew chief working in the PRB/TRB can be required to understand the observation and evaluation criteria (this could be done through workshops, for instance). Upon encountering an archaeological site, the crew chief then makes the appropriate observations. This is part of the standard site documentation in the PRB/TRB. In order to avoid confirming the consequent - not finding anything buried because the protocol says one need never look for anything buried - a random sample of "surface only" evaluations should be reexamined by a geoarchaeologist and a small crew. This re-evaluation can be done years later and in one pass throughout the study area, i.e., as a distinct investigation funded separately. The geoarchaeological investigation's purpose is to validate and refine the field protocols (and the buried site model), not to review the management decisions made already. Participating in the evaluation process could be made part of lease stipulations pushing the change far upstream from development actions.

Open trench inspection (OTI) needs to be treated like any other form of archaeological investigation until confidence in the buried site model is gained. If this confidence is gained, then OTI needs can be forecast and even presented as a layer in the CRISP tool. 
The benefits of these changes in the PRB/TRB extend beyond the study area. Again, the CBNG development in southern Montana is obviously suited to a similar approach. Even in areas of petroleum development, though, similar approaches can work well. Indeed, at the Beaver Creek Field south of Lander, Wyoming, a programmatic agreement uses geoarchaeological research results to justify changes in inventory procedure. This sort of approach can be part of a regional stipulation package, whether in the PRB/TRB or in specific regions of the public-lands-dominated western U.S, avoiding the well-by-well time and costs by which work is currently done.

One frustration of energy developers that we encountered is they think management requirements for cultural resources are inconsistent and obscure. Above, we refer to creating stipulations that are appropriate for different settings and areas within energy development on public lands. For cultural resources planning and assessment, this project has already created the tool - CRISP - that can convey these different management requirements or stipulations. If they can be mapped, then they be displayed using CRISP. We think this would be beneficial within the PRB/TRB and in any area of development on public lands. Stipulation packages in general could be conveyed using the CRISP tool. This will enhance the ability of industry to plan for cultural resources management.

\section{Forecast Models - Implementing and Using the Buried Deposit Model}

Archaeologists have created models as hypotheses or propositions amenable to testing for more than 50 years. Models take many, many forms, ranging from subjective "crayonon the map" to elegant formal sets of equations. They all share the same basic goal: to systematically extend our knowledge about something by both simplifying it into fewer key observations and extending knowledge by generalizing across unexamined cases. For example, the simple prediction that "sites are near water" means we need to seek water if we wish to find sites (a simplification of what we must observe to find sites), and furthermore that any new water location should or may have sites near it (a generalization about unexamined cases). Models continue to find favor because they are useful (Clarke 1968).

Cultural resource management has used modelbased approaches since the early 1970s, and saw a major period of interest and use in the 1980s (Judge and Sebastian 1988). Models as management aids or tools fell out of use in the 1990s due to deficiencies perceived in the models of the 1980s. Many of the deficiencies noted in the 1980s models are still characteristic of models today. These include a lack of provision for realistic testing that then leads to a lack of confidence in the model; overly complicated predictions that cannot be observed in the field; and no way to revise a model once it is created. Some other shortcomings have been made up in part or full. These include the ability to gather basic spatial and attribute data swiftly (once it is in a GIS and database system), the ability to do calculations rapidly (e.g., spreadsheets), and the ability to communicate results in useful, often geographic, forms (GIS and on-line map services).

Archaeological model building has often been characterized as "predictive" modeling. "Forecast" is a better, more appropriate, verb, for it conveys the generalized and 
probabilistic nature of archaeological models. Archaeological models summarize the likelihood of observing something that is the outcome of one or more complex, hard-toknow, historical processes. Whether one chooses a deductive approach, an inductive approach or a combination (Kohler 1988), the resulting model is more of a forecast than a certainty. Too, when it comes to testing forecasts, like testing a weather model, one can never be certain that a test outcome is what it seems. For instance, if we had a weather model in which we forecast rain, and a few drops fell at the right time and place, was the model upheld? What if we had instead phrased the prediction as "not sunny" - would the outcome have been more easily interpreted? Archaeological models face these same challenges. Finding a site where none was anticipated does not mean the model is falsified, does it? What about finding nothing where we expected something?

Shifting the frame of reference in archaeological models from prediction to forecast is important, because it also changes the actions one considers reasonable to implement, test, and develop an archaeological forecast.

This report presents a forecast of where one is likely to find buried archaeological sites in the PRB/TRB. This forecast has immediate utility (which we have discussed above), and like all models, immediate problems. First, the model is formed using imperfect data. The soil surveys, geomorphology, and maps that were used to define areas of fine-grained, Holocene or Late Pleistocene, gently deposited sediments are not equally accurate. Where their errors overlap, the forecast will be poorest. Second, the model is difficult to test. A priori, if one uses the model as we have suggested and avoids trenching in areas of high buried archaeological probability, then a sample of observations to test the validity of this forecast can never be assembled.

Archaeological models need maintenance to stay useful, and the models presented here are no exception. If models are not improved over time, then the users of the model stop trusting the model when anomalies build up. Long-term maintenance of the PRB/TRB model requires regular, periodic, investment in its maintenance. Maintenance for the PRB/TRB model consists of these actions:

Improve the source information Map and evaluate areas of effective model testing Reformulate the model, perhaps in part

The PRB/TRB model sources rely upon soils information, topography, landform maps, and valley fill definition. We can expect that better information on soils, topography, and valley fill will be forthcoming, especially as development continues in northern Wyoming. For instance, if a $10 \mathrm{~m}$ digital elevation model became available, then slope and flat valley floor definitions should be re-created and the model should be updated with the new definitions, at least in those areas where the new information exists and there is management or scientific information.

One of the reasons why models do not get updated with new information is because "getting the data" the first time is expensive and no funding is available for a second 
round. However, the update of information and recalculation of a model is usually far less costly than building a new model. The most significant difficulty is in knowing that new information of relevance is available. The Geospatial Portal managed by the Wyoming Oil and Gas Commission is a logical place to require posting of new datasets so that one would seek them in a single Internet-accessible place.

Mapping areas where the model has been evaluated is essential. As Eckerle noted in Chapter 4, no systematic large-area trenching has been conducted to test this model. There is no reason to expect that there will ever be sufficient basin-wide geomorphological or gearchaeological projects to really test the deposit model in one pass. Instead, one must rely upon individual excavation projects to accumulate information. Every trenching project needs to be mapped accurately and should receive some examination for archaeological materials in trench walls and backdirt. The entire extent of an examined trench should be mapped by survey instrument (resource-grade global positioning system [GPS] is sufficient) - this is the "survey area" for buried cultural materials. New archaeological finds within the trench (i.e., with no surface expression) need to be mapped in their extent along the trench. Buried archaeological materials (more than $20 \mathrm{~cm}$ deep) observed in the trench walls within existing surface sites need to be mapped too. Then, for each trench inspection, a summary page should be created. An example of an Open Trench Project Administration Documentation Form can be found in Appendix B.

Each completed trench inspection report should be treated as an investigation in the WYCRIS database. It should be entered in WYCRIS, the coordinates or GIS data provided used to populate one or more GIS layers of subsurface investigations, and the associated sites (if any) should be given standard site numbers. This will create an accessible, systematic, database of records to be used in evaluating the model's forecast capabilities and revising the model too. Site testing is essentially the same as a small subsurface investigation and should be reported in a similar, non-burdensome, fashion.

These protocols can be established as part of stipulations made on each oil and gas lease, cultural resource use permit, or other regulatory mechanism. They need not require a geomorphologist, so long as the field archaeologists have been properly trained in how to check for subsurface materials and take other appropriate observations. BLM Wyoming and Wyoming SHPO may wish to consider one or more workshops on geoarchaeology and reporting for consultants and staff doing fieldwork within the model forecast area.

Reformulation of the model is an expert task. Calculating a new model is only warranted if the current forecast is ineffective or wrong and there are good reasons to think a better forecast can be made. Above, we have noted that inventory and excavations in the study area are not equally distributed across the forecast strata of the depositional model. It would not be surprising to find that strata with almost no investigations in them have poor forecasts. Until we have some new information (investigation results, base data, etc.) with which to improve the model there would be no point in recalculating it. We would simply not rely upon the forecast of the current model in those particular settings. 
The model need not be recalculated or revised as a whole. As the example above provides, one could ins tead take a particular setting or geographic area and update only that part of the model. A user of the model would of course want to know that different "parts" have different issue dates - in essence the model becomes a quilt of sub-models. This has been provided for already in the CRISP tool model presentation and documentation.

The strongest model will only have value if its use is sanctioned and even promoted. This is a management issue, not a problem of archaeology or information technology. Cultural resource specialists, in the BLM field office and the SHPO, must be willing to utilize the model. This involves a degree of experimentation that some may find unacceptable in a regulatory environment. Yet, this would be "experimentation" only if one decides it falls outside of the consultative process. Kincaid, writing in a BLM issued volume published in 1988 on the very topic of models in cultural resource management, stated:

The decision as to whether or not modeling should be part of an inventory and evaluation approach depends on individual circumstances. A decision to use modeling complies with the regulations if it was reached in accordance with the consultation procedures [of Section 106 of the National Historic Preservation Act]. (Kincaid 1988:550)

For the DOE Wyoming study area an ideal management solution would be a programmatic agreement between the BLM and the Wyoming SHPO defining how the model will be implemented and maintained. If this agreement is well-crafted, then it should add little to anyone's current workload because much of the model use, evaluation, and implementation tasks occur anyway.

Administrative and management support may be easy to obtain over the next two to three years, while the model is new. If history is any guide, the n support will either be solidified or wane, depending upon the perceived utility of implementing the model. Measuring whether the model is "working" in planning, compliance, and preservation is the key to making support decisions objectively. In brief, one really wants to know how much the model "saved": in lost time, in dollars, in archaeological sites, or some other measure. There is a paradox here though - how does one evaluate what would have happened if the model did not exist?

The CRISP tool allows time and money to be saved by project proponents, at essentially no cost. Buy using the CRISP tool, proponents have the opportunity to modify the design of a project to avoid very high and high sensitivity areas. Delays and costs will be reduced by avoiding discovery of buried archaeological materials during construction. The cost of late discoveries can be very high -- typical mitigation costs are below $\$ 250,000$, but can even be as high as a million dollars for a large or complicated archaeological site. Avoiding even a single late discovery can thus be a significant savings. Direct costs are only one way to evaluate the savings from better information. The savings described above benefit a project proponent. Streamlining the evaluation of permit applications indirectly saves both project proponents and regulatory agencies who 
permit and review projects. However, the CRISP tool, as with many other outcomes of this project, cannot aid each and every development project or review. Like most planning tools, the benefit of models, information availability, and other outcomes of the AMP benefits accrue over time through use, as better decisions are made -- as adaptive planning and management continue to mature.

Over time, the cost of inspection and monitoring in high sensitivity areas should be compared to the cost of doing work (with whatever inspection is required) in low sensitivity areas. The cost per unit of ground disturbance should be compared to determine if the model is saving money. Similarly, CRMTracker and the Wyoming SHPO review database should be queried to see if low sensitivity projects proceed faster from fieldwork start to decision date than high sensitivity projects. Finally, one of the most important things that the buried deposit model can do is to open up areas for ground disturbance without requiring inspection or monitoring. Here, one can measure what was "lost" by allowing disturbance without monitoring - so long as discoveries (buried unexpected sites) are reported anyway. These long-term costs and benefits will take time to calculate - we think 10 years is not too short a period over which to accumulate this information.

The modeling approach taken here could be broadened in several ways. First, within the area of CBNG development itself, it would be straightforward to extend this model northward into the Montana portions of the PRB/TRB. Second, a similar approach for buried deposits would use very different analyses but would be equally useful in southwestern Wyoming where ground disturbance is just as intense. Third, the buried deposit model should be seen as one of several models that could be created and have great utility. A surface archaeological density model might be useful, as might a model of historic settlements (this might even just be a thorough map drawn from historic records). The framework for making these models available will accommodate any number of models - CRISP will simply analyze each appropriate model for a proposed project area.

There are many reasons to think that the use of models of cultural resources occurrence and character will continue to grow, as it has over he past five to ten years. Model-based management is sensible because, even if the models are flawed, they summarize and communicate knowledge. Models broaden the availability of information, and as the complexity of decision-making in which cultural resources are a factor grows, the use of models as summaries of information will grow too. Model outcomes can be various and still be quite useful: the risk of encountering something (buried or on the surface); the character of resources likely to be encountered (site content or likely NRHP significance); the potential to find materials of a particular age. Models are also popular because they aid in rough planning of work effort to conduct an investigation. The use of public lands, where field investigations are nearly always mandated, has escalated in the past 25 years, and consequently so has the acreage and cost of archaeological inventory needed to use those lands. Managers and land use proponents have a keen interest in reducing these costs through more tightly defined land use envelopes and through eliminating redundant or useless inventory. Models are an important basis and have value for both of these purposes. 



\section{CHAPTER 7}

\section{CONCLUSIONS:}

\section{FUTURE DIRECTIONS FOR MANAGEMENT AND RESEARCH}

Much of the AMP is concerned with summarizing information in ways that are useful to land users and land managers. Management on public lands is guided by management documents that go through public review processes. BLM's Resource Management Plans, for example, are formal documents that state management goals and procedures for specific areas under BLM management. Cultural resources are always an element of such plans.

An immediate bene fit of the AMP is that by making information much more available, the cultural resources elements of management plans should be far less costly and timeconsuming to create. Whether this will result in higher quality, more appropriately tailored resource management plans, or simply lower costs and faster delivery times for planning documents remains to be seen; these are decisions that managing agencies need to make. Potentially, better cultural resource elements in management plans will make the plans more informative for land users, and also give more explicit rationales for decisionmaking about cultural resources preservation. For example, a "better" cultural resource management plan can consider whether a particular kind of archaeological site is common or rare in the management area, and thus justify preserving or allowing destruction of a particular site of that type.

The use of models as tools in the cultural resource managers' toolbox is, generally, lacking. In our discussion of models, we touched on the importance that they can have for effective planning. During the course of this project, we spoke with many agency cultural resource specialists. All were interested in the outcome of model-formation. Few were comfortable with the notion of using a model of archaeological phenomena to guide decision- making about the appropriate treatment of archaeological sites. We think this reluctance stems from three systemic sources, which we might call the model-phobia syndrome. First, many cultural resource specialists do not understand the improbabilities of model formation: they wish for a "right" answer. Above, we have taken some pain to dispel this idea about models, for they are always "wrong" in some way. Second, and in turn then, cultural resource managers think that using a model to justify a decision will be seen as insufficiently thorough. Third, there is no management mandate or support for changing the work process by using model-based approaches, even just as a component of the regular management actions. These three system conditions create the modelphobia syndrome.

Addressing the model-phobia syndrome is an important management need for implementing changes that the Wyoming and New Mexico portions of the AMP are 
suggesting. Better education of field staff about how models are used effectively and upper management insistence that models get used (and maintained) once they are created will alleviate the syndrome. Perhaps an analogy will make this clearer. In the early years of aviation engineering, the only way to determine whether a design worked was to build it and then fly it - with all the attendant perils and costs. As aviation engineering advanced, engineers realized they could use an actual model in a wind tunnel to forecast some aspects of aircraft behavior. At some point, a commitment was made to rely upon these model-generated results in assessing aircraft designs. Further tests still relied upon the actual aircraft prototype, but forecasts generated by a model were considered okay. There must have been some point at which a leap of faith was made, and an engineer (and manager, and investor) made a decision to rely upon the model. Cultural resource management in oil and gas settings has reached the point at which the leap of faith is needed. This project has done its best to make that leap as little a jump as possible. 


\section{REFERENCES}

Albanese, John P.

1978 Archaeogeology of the Powder River Basin, Wyoming. In Western Powder River Basin Consultant Reports Vol. III, edited by Charles Reher, pp. 9-94. Office of the Wyoming State Archeologist. Submitted to the Bureau of Land Management. Copies available from the Office of the Wyoming State Archeologist, Laramie.

1981 Appendix B: Geological Factors Affecting Site Distribution in the Powder River Basin. In A Class II Cultural Resources Inventory of the Eastern Powder River Basin, Wyoming, edited by T. C. Peebles, pp. 88-95. MetcalfZier Archaeologists. Submitted to the U.S. Department of the Interior Bureau of Land Management, Wyoming State Office. Copies available from MetcalfZier Archaeologists.

1984 Geologic Reconnaissance of the Proposed Reservoir Area Located in the Middle Fork of the Powder River; Johnson County, Wyoming. Submitted to Wyoming Recreation Commission by John Albanese, Geologist, Casper, Wyoming. Copies available from John Albanese, Consulting Geoarchaeologist.

1990 Geoarchaeology of the Eastern Powder River Basin. Submitted to The Wyoming State Historic Preservation Office, Wyoming Archives Museum and Historical Department. Copies available from the Wyoming State Historic Preservation Office, Cultural Records Office, Laramie.

1991 Geologic Investigations of Prehistoric Site 48CO1556, Converse County, Wyoming. Copies available from John Albanese, Consulting Geoarchaeologist.

2000 Resume of Geoarchaeological Research on the Northwestern Plains. In Geoarchaeology in the Great Plains, edited by Rolfe C. Mandel, pp. 199-249. University of Oklahoma Press, Norman.

Albanese, John P., and Michael Wilson

1974 Preliminary Description of the Terraces of the North Platte River at Casper, Wyoming. In Applied Geology and Archaeology: The Holocene History of Wyoming, edited by Michael Wilson, pp. 8-18. Geological Survey of Wyoming Report of Investigations No. 10.

Bagnold, R. A.

1941 The Physics of Blown Sand and Desert Dunes. Methuen, London. 
Birkeland, Peter W.

1999 Soils and Geomorphology: Third Edition. Oxford University Press, New York.

Birkeland, Peter W., Michael N. Machette, and Kathleen M. Haller

1991 Soils as a Tool for Applied Quaternary Geology. Utah Geological and Mineral Survey Miscellaneous Publication 91-3. Salt Lake City.

Brown, Tony

1997 Alluvial Geoarchaeology: Floodplain Archaeology and Environmental Change. Cambridge, New York.

Butzer, Karl W.

1982 Archaeology as Human Ecology: Method and Theory for a Contextual Approach. Cambridge University Press, London.

Case, James C., Christopher S. Arneson, and Laura L. Hallberg 1998 Wyoming Surficial Geology. Spatial Data and Visualization Center, Laramie, Wyoming. http://www.sdvc.uwyo.edu/24k/surfgeol.html

Clarke, David L. 1968 Analytical Archaeology. Metheun, London.

Deal, Michael

1985 Household Pottery Disposal in the Maya Highlands: An Ethnoarchaeological Interpretation. Journal of Anthropological Archaeology 4:243-291.

Dibble, Harold L., Philip G. Chase, Shannon P. McPherron, Alain Tuffreau

1997 Testing the Reality of a "Living Floor" with Archaeological Data. American Antiquity 62(4):629- 651.

Drews, Michael, Eric Ingbar, David Zeanah, and William Eckerle

2004 A Cultural Resources Model for Pine Valley, Nevada. Submitted to the Department of Energy, Agreement DE-FC26-01BC15337. Bureau of Land Management Nevada Cultural Resource Publications Series Report No. 13. Reno.

Eckerle, William

1986a Soils of Project Area. In Archeological Investigations at Middle Fork Reservoir vol I., edited by Julie Francis, A.D. Darlington, William Eckerle, and Skylar S. Scott, pp. 402-409. Office of the Wyoming State Archeologist. Submitted to Wyoming Water Development Commission. Copies available from Office of the Wyoming State Archeologist. 
1997 Eolian Geoarchaeology of the Wyoming Basin: Changing Environments and Archaic Subsistence Strategies in the Holocene. In Changing Perspectives of the Archaic on the Northwestern Plains and Rocky Mountains, editedby Mary Lou Larson and Julie Francis. pp. 138-167. University of South Dakota Press, Vermillion.

Eckerle, William, and Daniel H. Eakin

1989 Geoarchaeological Model. In Archaeological Investigations Near Seminoe Reservoir: The 1987 Season, edited by Mark Miller and William Eckerle, pp 123-141. Office of the Wyoming State Archaeologist. Submitted to the United States Bureau of Reclamation. Copies available from the Office of the Wyoming State Archaeologist, Laramie.

Eckerle, William, and Marissa Taddie

1997 Archaeological Landscape Sensitivity Model for the Bureau of Land Management, Burma Road Soil Survey Area/Jonah Natural Gas Field, Sublette County, Wyoming. Western GeoArch Research. Submitted to Current Archaeology. Copies available from Western GeoArch Research, Salt Lake City.

Eckerle, William, Eric Ingbar, and Marissa Taddie

1999 Geoarchaeology of the Moxa Arch Natural Gas Lease Area: A Spatial Analysis. Submitted to Gnomon Inc, Wyoming Office of Cultural Records, and the Department of Anthropology, University of Wyoming by Western GeoArch Research. Copies available from Wyoming Office of Cultural Records, Laramie.

Eckerle, William, Marissa Taddie, and Eric Ingbar

2000 Landscape Archaeology. In "Seeds-Kee-Dee" Riverine Adaptation in Southwest Wyoming, edited by J. V. Pastor, K. W. Thompson, R. K. Talbot, W. P. Eckerle, and E. E. Ingbar, pp. 451-460. Brigham Young University, Museum of Peoples and Cultures, Technical Series No. 99-3. Copies available from the Office of Public Archaeology, Brigham Young University, Provo, Utah.

Elwonger, W. G.

1983 Soil Survey of Crook County, Wyoming. United States Department of Agriculture, Soil Conservation Service, Washington D. C.

Flores, Romeo M., Gary D. Stricker, Joseph F. Meyer, Thomas E. Doll, Jr., Pierce H. Norton, Robert J. Livingston, and M. Craig Jennings

2001 A Field Conference on impacts of Coalbed Methane Development in the Powder River Basin, Wyoming. United States Geological Survey. Open-File Report 01-126. 
Frison, George C., Eric E. Ingbar, and William P. Eckerle

1988 Geoarchaeological Research and Archaeological Research in the Jackson Lake Reservoir Pool Area, 1987. Department of Anthropology, University of Wyoming. Submitted to the U.S. National Park Service, Midwest Archaeological Center. Copies available from the University of Wyoming, Laramie.

Gifford, Diane P.

1978 Ethnoarchaeological Observations of Natural Processes Affecting Cultural Materials. In Explorations in Ethnoarchaeology, edited by R. A. Gould, pp. 77-101. University of New Mexico Press, Albuquerque.

Gifford-Gonzalez, Diane P., David B. Damrosch, Debra R. Damrosch, John Pryor, and Robert L. Thunen

1985 The Third Dimension in Site Structure: An Experiment in Trampling and Vertical Dispersal. American Antiquity 5(4):803-18.

Gifford, Diane P., and A. Kay Behrensmeyer

1976 Observed Depositional Events at a Modern Human Occupation Site in Kenya. Quaternary Research 8:245-266.

Hallberg, L.L., J.C. Case, C.A. Jessen, and A.L. Kirkaldie

1999 Preliminary digital surficial geologic map of the Sheridan 30' x 60' Quadrangle, Sheridan, Johnson, and Campbell Counties, Wyoming, and southeastern Montana.

Hallberg, L.L., J.C. Case, and A.L. Kirkaldie

2000a Preliminary digital surficial geologic map of the Buffalo 30' x 60' Quadrangle, Johnson and Campbell Counties, Wyoming.

2000b Preliminary digital surficial geologic map of the Kaycee 30' x 60' Quadrangle, Johnson and Campbell Counties, Wyoming.

Haynes, C. Vance, and Donald C. Grey

1965 The Sister's Hill Site and it's Bearing on the Wyoming post-Glacial Alluvial Chronology. Plains Anthropologist 10:196-207.

Horne, Melinda C., Susan K. Goldberg, Jill A. Onken, Dennis P. McDougall, and Marilyn J. Wyss

2001 Metropolitan Water District of Southern California Eastside Reservoir Project, Final Report of Archaeological Investigations, Volume I: Project Overview and Summary of Archaeological Investigations. Prepared by Applied Earth Works, Inc., Hemet, California. 
Hughes, P. J., and R. J. Lampert

1977 Occupational Disturbance and Types of Archaeological Deposit. Journal of Archaeological Science 4:13

Hunt, Charles B.

1953 Pleistocene-Recent Boundary in the Rocky Mountain Region: A Contribution to General Geology. Geological Survey Bulletin 996-A. United States Government Printing Office, Washington.

1986 Surficial Deposits of the United States. Van Nostrand Reinhold Company, New York.

Jenny, Hans

1941 Factors of Soil Formation. McGraw-Hill, New York.

Judge, W. James, and Lynne Sebastian

1988 Quantifying the Past and Predicting the Present: Theory Method and Application of Archaeological Predictive Modeling. U.S. Department of Interior, Bureau of Land Management, Denver.

Kincaid, C.

1988 "Predictive Modeling and Its Relationship to Cultural Resource Management Applications." In Quantifying the Past and Predicting the Present: Theory Method and Application of Archaeological Predictive Modeling, edited by W.J. Judge and L. Sebastian, pp. 549-580. U.S. Department of Interior, Bureau of Land Management, Denver.

Kohler, Timothy A.

1988 "Predictive Locational Modeling: History and Current Practice." In Quantifying the Past and Predicting the Present: Theory Method and Application of Archaeological Predictive Modeling, edited by W.J. Judge and L. Sebastian, pp. 19-60. U.S. Department of Interior, Bureau of Land Management, Denver.

Kronenberger, R. C., Jack F. Young, James R. Stephens, and Clarence J. Fowkes 1977 Wyoming General Soils Map. Wyoming Agricultural Experiment Station Research Journal 117.

Küchler, A. W.

1966 Potential Natural Vegetation: Map Sheet 90. Scale 1:7,500,000. U.S. Geological Survey, Washington, D.C.

Lageson, David, and Darwin Spearing

1988 Roadside Geology of Wyoming. Mountain Press Publishing Company, Missoula. 
Leopold, Luna B., and John Miller

1954 A Postglacial Chronology for Some Alluvial Valleys in Wyoming. U.S. Geological Survey Water-Supply Paper 1261.

Liams, John E.

1983 Soil Survey of Washakie County, Wyoming. United States Department of Agriculture, Soil Conservation Service in cooperation with University of Wyoming Agricultural Experiment Station.

Love, J. D., and Ann Coe Christiansen

1985 Geologic Map of Wyoming. U.S. Geological Survey, Laramie.

Lupcho, Paul

1998 Soil Survey of Sheridan County Area, Wyoming. United States Department of Agriculture, Natural Resources Conservation Service; in cooperation with University of Wyoming Agricultural Experiment Station.

Malnor, Lawrence K., and Susan Arnold

1997 Soil Survey of Natrona County Area, Wyoming. United States Department of Agriculture, Natural Resources Conservation Service; in cooperation with United States Department of the Interior, Bureau of Land Management and the Wyoming Agricultural Experiment Station.

Martner, Brooks E.

1986 Wyoming Climate Atlas. University of Nebraska Press, Lincoln.

Mears, Brainerd Jr., Sherry S. Agard, and Wayne M. Sutherland

1991 Powder River Basin. In The Geology of North America Volume K-2, Quaternary Nonglacial Geology: Conterminous U.S., edited by Roger Morrison and Associates, pp. 446-448. Geological Society of America, Boulder, Colorado.

Munn, Larry, and Christopher S. Arneson

1998 1:500,000-Scale Digital Soils Map of Wyoming. University of Wyoming Agricultural Experiment Station. Laramie, Wyoming.

National Resource Conservation Service

1998 Soil Survey Geographic (SSURGO) Database for Campbell County, Wyoming, Southern Part. U.S. Department of Agriculture, Fort Worth, Texas.

1999 Soil Survey Geographic (SSURGO) Database for Washakie County, Wyoming. U.S. Department of Agriculture, Fort Worth, Texas.

2000 Soil Survey Geographic (SSURGO) Database for Natrona County Area, Wyoming. U.S. Department of Agriculture, Fort Worth, Texas. 
2002a Soil Survey Geographic (SSURGO) Database for Converse County, Wyoming, Northern Part. U.S. Department of Agriculture, Fort Worth, Te xas.

2002b Soil Survey Geographic (SSURGO) Database for Sheridan County Area, Wyoming. U.S. Department of Agriculture, Fort Worth, Texas.

2003a Soil Survey Geographic (SSURGO) Database for Johnson County Area, Wyoming, Southern Part. U.S. Department of Agriculture, Fort Worth, Texas.

2003b Soil Survey Geographic (SSURGO) Database for Crook County, Wyoming. U.S. Department of Agriculture, Fort Worth, Texas.

National Oceanic and Atmospheric Administration (NOAA)

1985 Climates of the States. Gale Research Company; Book Tower, Detroit.

Nesser, J. A.

1986 Soil Survey of Bighorn National Forest, Wyoming. United States Department of Agriculture, Forest Service and Soil Conservation Service.

Paton, T. R., G. S. Humphreys, and P. B. Mitchell

1995 Soils: A New Global View. Yale University Press, New Haven.

Porter, C. L.

1962 Vegetation Zones of Wyoming. University of Wyoming Publications, 27(2):512. Laramie, Wyoming.

Porter, Stephen C., Kenneth L. Pierce, and Thomas D. Hamilton

1983 Late Wisconsin Mountain Glaciation in the Western United States. In The Pleistocene, edited by Stephen C. Porter, pp. 71-114. Late-Quaternary Environments of the United States, H. E. Wright, Jr., general editor. University of Minnesota Press, Minneapolis.

Rapp, George (Rip) Jr., and Christopher L. Hill

1998 Geoarchaeology: The Earth-Science Approach to Archaeological Interpretation. Yale University Press, New Haven, Connecticut.

Reckner, Ronald L.

1986 Soil Survey of Converse County, Wyoming: Northern Part. United States Department of Agriculture, Soil Conservation Service; in cooperation with United States Department of Agriculture, Forest Service; United States Department of the Interior, Bureau of Land Management; and Wyoming Agricultural Experiment Station.

Reider, Richard G.

1980 Late Pleistocene and Holocene Soils of the Carter/Kerr McGee Archeological Site, Powder River Basin, Wyoming. Catena 4(7):301-16. 
1983 Soils and Late Pleistocene-Holocene Environments of the Sister's Hill Archeological Site Near Buffalo, Wyoming. University of Wyoming Contributions to Geology 22(2):117-127.

1990 Late Pleistocene and Holocene Pedogenic and Environmental Trends at Archaeological Sites in Plains and Mountain Areas of Colorado and Wyoming. In The Archaeological Geology of North America, edited by N. P. Laska and J. Donahue, pp. 335-360. Geological Society of America, Boulder, Colorado.

Reider, Richard G., and Eric T. Karlstrom

1987 Soils and Stratigraphy of the Laddie Creek Site (48BH345), an AltithermalAge Occupation in the Big Horn Mountains, Wyoming. Geoarchaeology: An International Journal 2(1):29-47.

Reineck, H. E., and I. B. Singh

1980 Depositional Sedimentary Environments. Springer-Verlag, New York.

Rick, John W.

1976 Downslope Movement and Archaeological Intrasite Spatial Analysis. American Antiquity 41:133-144.

Schiffer, Michael B.

1987 Formation Processes of the Archaeological Record. University of New Mexico Press, Albuquerque.

Schumm, Stanley A.

1973 Geomorphic thresholds and complex response of drainage systems. In Fluvial Geomorphology edited by M. Morisawa, pp. 299-310. State University of New York Press, Binghamton.

1981 Evolution and Response of the Fluvial System, Sedimentologic Implications. Society of Economic Paleontologists and Mineralogists Special Publication 31:19-29.

Schumm, Stanley A., and R. F. Hadley

1957 Arroyos and the Semiarid Cycle of Erosion. American Journal of Science 255:161-174.

Schumm, Stanley A., and G. R. Brakenridge

1987 River Responses. In North America and Adjacent Oceans During the Last Deglaciation, edited by W. F. Ruddiman and H. E. Wright, Jr., pp. 221-240. The Geology of North America Vol. K-3. Geological Society of America, Boulder, Colorado. 
Soil Conservation Service

1983 Wyoming Average Annual Precipitation (map). U.S. Department of

Agriculture, Soil Conservation Service, Fort Worth, Texas.

1994 State Soil Geographic (STATSGO)Database for Wyoming. U.S. Department of Agriculture, Soil Conservation Service, Fort Worth, Texas.

n.d. Technical Range Guides for Wyoming. U.S. Department of Agriculture, Soil Conservation Service, Casper.

Soil Survey Staff

1975 Soil Taxonomy: A Basic System of Soil Classification for Making and Interpreting Soil Surveys. U.S. Department of Agriculture Soil Conservation Service Agriculture Handbook 436. United States Government Printing Office, Washington D.C.

Stein, Julie K

2001 Archaeological Sediments in Cultural Environments. In Sediments in Archaeological Context, edited by J.K. Stein and W.R. Farrand, pp29-66. University of Utah Press, Salt Lake City.

Steeves, Peter, Douglas Nebert, and Tom Kohley

1994 Hydrologic units map of Wyoming, modified from USGS fourth level units. U.S. Geological Survey. University of Wyoming Spatial Data and Visualization Center. Laramie, Wyoming.

Stevens, James Jr.

1975 Soils Survey of Johnson County, Wyoming, Southern part. United States Department of Agriculture, Soil Conservation Service, in Cooperation with the Wyoming Agricultural Experiment Station.

Stockton, E. D.

1973 Shaw's Creek Shelter: Human Displacement of Artifacts and its Significance. Mankind 9:112- 17.

Strahler, A. N.

1952 Dynamic BASIS of geomorphology. Geological Society of America Bulletin, 63, 923-938.

Thornbury, William D.

1965 Regional Geomorphology of the United States. John Wiley and Sons, New York.

\section{United States Forest Service (USFS)}

1999 Common Land Unit (CLU) coverage for Bighorn National Forest, Wyoming. United States Forest Service, Bighorn National Forest, Sheridan, Wyoming. 
United States Geological Survey (USGS)

1994 Bedrock Geology of Wyoming. U.S. Geological Survey, Denver, Colorado. http://www.sdvc.uwyo.edu/24k/geol.html.

United States Geological Survey (USGS) EROS Data Center

2003 North America Shaded Relief No. 3. Electronic document accessed 08/25/2004. http://nationalatlas.gov/atlasftp.html.

Villa, Paola

1982 Conjoinable Pieces and Site Formation Processes. American Antiquity 47:276-290.

Villa, Paola, and Jean Courtin

1983 The Interpretation of Stratified Sites: A View From Underground. Journal of Archaeological Science 10:267-281.

Wandsnider, LuAnn

1988 Experimental Investigation of the Effect of Dune Processes on Archeological Remains. American Archeology 7(1):18-29.

Waters, Michael R.

1992 Principles of Geoarchaeology: A North American Perspective. University of Arizona Press, Tucson.

Wolman, M. G., and L. B. Leopold

1957 River Flood Plains: Some Observations on their Formation. U.S. Geological Survey Professional Paper 282-c, pp 86-109.

Wood, W. Raymond, and Donald L. Johnson

1978 A Survey of Disturbance Processes in Archaeological Site Formation. In Advances in Archaeological Method and Theory, vol. 1, edited by M. B. Schiffer, pp. 315-81. Academic Press, New York.

Wyoming GAP Analysis

1996 1:100,000-scale Hydrography for Wyoming (Enhanced DLGs). Spatial Data and Visualization Center, Laramie, Wyoming.

Zelt, R.B, G. Broughton, K. A. Miller, J. P. Mason, and L. M. Gianakos

1999 Environmental Setting of the Yellowstone River Basin, Montana, North Dakota, and Wyoming. United States Geological Survey Water-Resources Investigations Report 98-4269. 


\section{ACRONYMS}

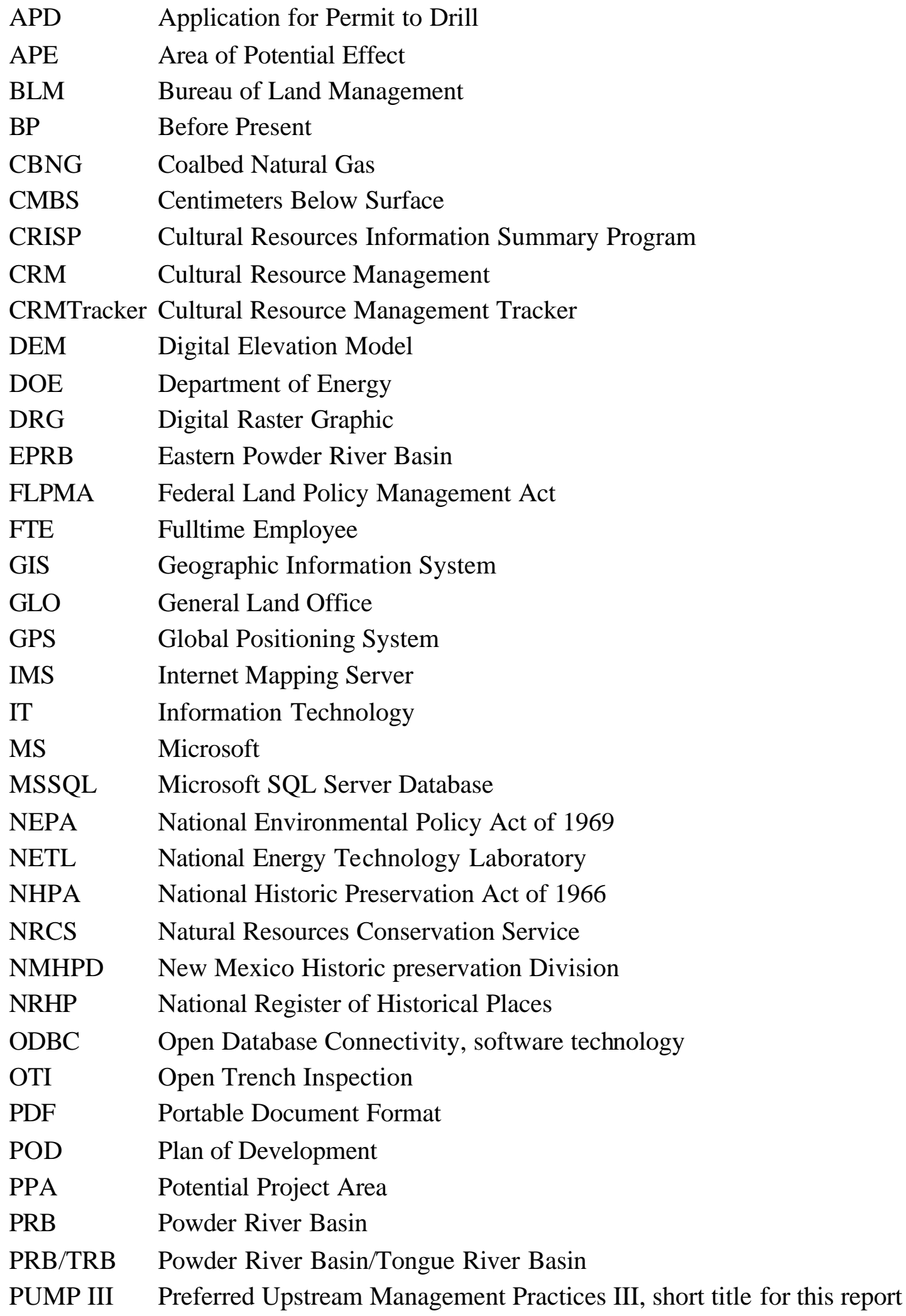


RCYBP Radiocarbon Years Before Present

SDE Spatial Data Engine, a software tool for web-based GIS

SSURGO Soil Survey Geographic Database

STATSGO State Soil Geographic Database

UTM Universal Transverse Mercator

UW IT University Wyoming Information Technology Section

WAS Wyoming Archaeological Society

WPA Works Progress Administration

WPRB Western Powder River Basin

WYCRIMS Wyoming Cultural Resources Internet Map Server

WYCRIS Wyoming Cultural Resource Information System

WYCRO Wyoming Cultural Records Office

WYGISC Wyoming Geographic Information Sciences Center

WYSHPO Wyoming State Historical Preservation Office 


\section{APPENDIX A}

\section{DIGITIZING BACKGROUND AND INSTRUCTIONAL MANUAL}

Wyoming State Historic Preservation Office

Cultural Resources GIS

Mary Hopkins and Ben Blasko 


\section{The Customized Application}

\section{Background}

The digitizing application consists of three files, each of which must be present for all features of the application to function. Your GIS administrator or Field Office Systems administrator should have this set up for your use. The files needed are:

\section{WYCRO_MXD_FIELD.MXD \\ 2. WYCRO_GIS_FIELD.MDB \\ 3. WYCRO_REF_FIELD.MDB}

The above files should be on a server where daily backups are created. Many field offices already have a "CRDATA" directory structure created for the cultural resources staff. This directory can be used for this application.

\section{File Descriptions}

1. WYCRO_MXD_FIELD.MXD is an ArcMap 8.3 map document This file is the application itself. It does not use Arc extensions or any other software other than an ODBC (Open Database Connectivity) connection. Most users will think of this as "the GIS project file." It actually contains no data, because when opened it starts the GIS software. If you receive a message that this file "lacks extensions" or cannot be read by ArcGIS, then it is time to upgrade to version ArcGIS 8.3.

This file should be part of a daily backup stream, since it contains the user's current map location, interface settings, and so forth.

\section{WYCRO_GIS_FIELD.MDB - A JET 4.0 (Access 2000) ESRI Personal \\ Geodatabase}

This file is an ESRI Personal Geodatabase that also contains other (non-geodatabase) tables. We have established a series of naming conventions for GIS Feature Classes within this geodatabase. Layer names must contain the following strings to be correctly associated with their dialogs (in the digitizing application):

Site layers - SIT

Investigation/inventory/project layers - INV

Isolates (no dialogs currently built) - ISO

Districts (no dialogs currently built) - DIS

The feature classes have very specific attribute table structures. DO NOT CHANGE THEM. Also, do not use the strings above in any other GIS layers in your geodatabase! If you must include layers with names that contain one or more of the above strings, make them un-selectable in the application (in ArcMap go to Selection -> Set Selectable Layers and remove checkmarks next to the layers that do not contain the data you are digitizing and whose attributes you are inputting). 
The feature classes, by default, have a useful set of names consisting of DE for data entry, the kind of entity (per the above string), the geography type (PT - point, PO polygon, LN - line), an underscore, and the coordinate system (DD for degrees decimal). For example: DESITPT_DD is a data entry, site, point, decimal degrees layer. Hint: don't change the coordinate system - let ArcMap change it on the fly for you. By default for BLM, the geodatabase classes are in geographic (latitude-longitude) decimal degrees, North American Datum of 1983. ArcMap will project the data to the coordinate system of your base map. So if you are using DRG's in UTM NAD83, the software will use this as the map coordinate system. Remember to bring your base map into your data frame first.

The personal geodatabase contains four master attribute tables. These contain the GIS attribute data for all geography types of a given cultural resource entity. So, all attribute data for site GIS feature classes (points, lines, polygons) is combined in tbl_SIT_GIS_Attrib. The application handles updates and deletes to these master attribute tables automatically. These tables have very specific structures and should not be changed.

Because the updates are handled automatically by the application - DO NOT CHANGE OR EDIT ATTRIBUTE TABLES OR DELETE GIS ENTITIES OUTSIDE OF THE WYCRO GIS ATTRIBUTE TOOL. This is very important to keep the tables synchronized.

This file should be part of a daily backup stream, for it contains the GIS and attribute data entered and edited by the application user.

3. WYCRO_REF_FIELD.MDB - A JET 4.0 (Access 2000) database

This Microsoft JET 4.0 (Access 2000) database contains tables of data extracted from the master WYCRO2 statewide database for sites, projects, and isolates. It also contains queries that utilize these tables. The data in these tables is static - that is, the field user does not update these tables. They are used for look up of site and project identifiers. The WYCRO staff can provide fresh copies of this database as needed. When given a fresh copy, REPLACE the entire file. Do NOT open the database and try to update tables. Just throw the old one away and put the new one in the exact same place.

In general, the user will never need to actually open this database. Because the contents do not change frequently, this file should be backed up weekly for the sake of convenience. 


\section{Sending data to WYCRO}

The Wyoming BLM State Office will collect your geodatabase containers on a periodic basis. You will be notified prior to the collection date so you can review all information for accuracy and completeness. When the container has been collected by the BLM state office, make sure you get a new "empty" file to put in its place! The empty geodatabase containers are located in your backup directory. You will want to make a copy of this and place it in the CRDATA/GIS folder. If you want to keep the old file around perhaps as a reference (background) layer while the SHPO updates the master dataset, then:

Move the file WYCRO_GIS_FIELD.MDB before you replace it with a fresh empty copy. Rename the copy you moved to some other name, for example:

WYCRO_GIS_FIELD_AS_OF_APRIL_4_2003.MDB

Bring the "old" feature classes into your ArcMap document again. RENAME THESE

LAYERS so that they don't have INV, SIT, etc. in their names.

DO NOT EDIT THE OLD DATA LAYERS!

Put a clean, empty copy of WYCRO_GIS_FIELD in the appropriate (original folder). This will become your new working file for digitizing and attributes. 


\section{Background Materials on ArcGIS (from ESRI.com)}

\section{ArcGIS}

\section{Comparing ArcView GIS 3 to ArcView 8.x}

ArcView 8. $x$ is a GIS data visualization, query, and map creation solution designed for the Windows desktop. It is based on the same architectural technology on which Arclnfo 8 and other ArcGIS products are based. ArcView 8.x is composed of three applications:

If ArcMap, the application for mapmaking and analysis

\& ArcCatalog, a tool for accessing and managing your data

ArcToolbox, a complete environment for performing data processing operations such as geodata conversion

\section{Making the transition to ArcView 8.x}

If you're an ArcView GIS 3 user who is transitioning to ArcView 8.x, you'll notice some differences between the two versions. ArcCatalog and ArcToolbox are completely new to existing ArcView GIS users and offer additional functionality. ArcMap also offers some functionality that is new or different to existing ArcView GIS users.

If you currently use ArcView GIS 3, ArcMap will likely be familiar to you because ArcMap and ArcView GIS 3 have a similar "look and feel". However, there are differences between the ArcView GIS 3 and ArcMap interfaces, as well as different terminology to describe them. The main differences are outlined in the following section.

\section{Terminology}

Some of the terminology used to describe features and interface elements in ArcMap is new to ArcView GIS 3 users. However, most new ArcMap terms have equivalent terms in ArcView GIS 3. This section compares some of the main terminology used to describe features of ArcMap and ArcView GIS 3.x. For a quick reference of this and additional terminology, view a comparison table. To view an illustration of the ArcMap interface, see The ArcMap window. For definitions of any ArcView 8.x terms, see the glossary.

\section{Projects and map documents}

ArcView GIS 3 stores the maps, charts, and tables you create in a project. A project is a file that organizes all the information you need to do your work. A project has an .apr file extension.

ArcMap stores maps, graphs, and tables in a map document. A map document is the disk-based representation of a map. Map documents have an .mxd file extension.

If you have an ArcView GIS 3 project that you want to work with in ArcMap, you can import it and many of its elements, including views, themes, and layouts. See Importing an ArcView GIS 3 project into ArcMap.

\section{Themes and layers}

In ArcView GIS 3, you display geographic information on a map as themes. Each theme represents a set of features of the same type such as streams, lakes, or highways.

In ArcMap, sets of features of the same type are represented by layers. Layers are identical to themes in their role and function. When you import an ArcView GIS 3 project into ArcMap, themes become layers.

\section{Views and data frames}

In ArcView GIS 3, sets of features (themes) are displayed in views. Each view contains the themes that you want to display together on a map.

In ArcMap, sets of features (layers) are displayed in data frames. A data frame simply groups, in a separate frame, the layers that you want to display together. When you import an ArcView GIS 3 project into ArcMap, views become data frames. 


\section{Table of contents}

In ArcView GIS 3, views and themes are listed in the table of contents on the left side of the ArcView GIS window. Theme names are listed under the name of the view that displays them.

In ArcMap, data frames and layers are listed in the table of contents. Layer names are listed under the name of the data frame that displays them.

\section{Layouts and layout view}

In ArcView GIS 3, views and other elements are displayed in layouts. A layout is the design or arrangement of elements - such as geographic data, North arrows, tables, and charts -in a digital map display or printed map. An ArcView GIS project can contain one or multiple layouts.

In ArcMap, data frames and other map elements are displayed in layouts. An ArcMap document can support only one layout; however, you can change a layout by applying a standard or custom template (see the following section).

You can see the layout of your virtual map in layout view. See Looking at a map in data view and layout view.

\section{Templates}

Templates take on a broader and richer role in ArcView 8.x than what was available in ArcView 3. With ArcView 3, users could use a template to create a map from their view document. They could choose a template to change how their layout looked or manage templates by adding, changing, or deleting them.

In ArcView 3, templates were specifications for the page layout-that is, which elements were present, where they were on the page, and the description of the page.

In ArcMap, templates are more than specifications for a page layout. They are also where users can specify additional functionality, user interface arrangements, and additional data to be included in the data frames of the template. In other words, templates in ArcMap define how the application looks and works.

Templates in ArcView 8.x can contain the following: If Arrangement of elements on the page H Page orientation \& Page size \& Page units - for example, some templates can have metric page units, others can have inches \& Output image quality \& Printer setup information (if Map size is set to Same as Printer) \& Guides \& Layout options \& Data view options \& Style references If Data \& Customized interface \& Visual Basic for Applications (VBA) customization For ArcMap users, templates may be applied in two ways: if As the basis for a new map document (.mxd file). If To change the way the page looks by choosing the page layout specification from another template. This does not apply data or user interface customizations from the template they are changing to, only the map layout. In ArcMap, this command is called Change Layout.

Templates can be used to enhance productivity in ArcMap in a variety of ways:

If Templates can serve as base maps. If you always start out with the same sets of background data and always use the same symbols and page specification, a template is an ideal solution. With a template, you don't have to manually re-create your maps, and you don't need a complex set of instructions to tell another user how to make the same map.

If Templates are an excellent way to share VBA functionality. All the VBA code and forms can be stored in the template. Additionally, the user interface for this functionality can also be stored in the template.

H H $n$ ArcMap, templates can be categorizied by placing them in a different directory within the ArcMap templates directory. Each additional directory a user creates will be shown as a tab in the templates and new map dialogs. 


\title{
ArcGIS
}

\section{ArcGis products}

-Scalable desktop applications

\author{
-ArcView \\ -ArcEditor \\ -Arcinfo \\ -ArcGIS extensions
}

-All support data creation, management, analysis, and storage

-All can work with the same data

-All share a common operational interface

\section{ArcGIS functionality}

\section{ArcView}

-ArcMap

- ArcCatalog

-ArcToolbox

ArcEditor $=$ ArcView +

- Coverage and ArcSDE Geodatabase editing

- Create and edit feature with behavior

-Geometric networks

-Feature linked annotation

-Subtypes

- Relationship classes

Arcl nfo $=$ ArcEditor +

-Advanced ArcToolbox

-Advanced Geoprocessing

-Workstation Arclnfo: Arc, ArcEdit, ArcPlot, GRID, TIN, ...

\section{Choose ArcView if you want to...}

- Create, edit personal geodatabases and shapefiles

- Create high quality maps, graphs, and reports

- Perform advanced geopgraphic query and analysis

- Perform network tracing analysis

- Create, apply attribute domains

-Geocode addresses

\section{Choose ArcEditor if you want to...}

- Create, edit, and manage coverages and ArcSDE geodatabases

- Create, edit subtypes and relationship classes

-Build the geodatabase from CASE diagrams

- Create, edit geometric networks

- Create and edit feature-linked annotation

-Create, edit custom features

\section{Choose Arcl nfo if you want to...}

- Create, edit, and analyze coverages using Arclnfo Workstation -Run AML programs from ArcToolbox

- Convert from multiple GIS data formats into coverage format

- Use the Geoprocessing Server to perform ArcToolbox operations on a designated computer 


\section{ArcGis Spatial data formats}

ArcGIS works with multiple spatial data formats

- Raster, (GRID) data

-CAD

-Shapefile

- Coverage

- Geodatabase

-Internet Map Service

-Tables

\section{ArcGis tabular data formats}

Tabular data formats associated with spatial formats

- Coverages - INFO

-Shapefiles - dBASE

-Geodatabase - RDBMS 


\section{ArcView terminology}

The table below compares the terminology used to describe core ArcView GIS 3 and ArcView 8.x. For more information on the similarities and differences between the two versions of ArcView, see Comparing ArcView GIS 3 to ArcView 8.x. To find out how ArcView GIS extensions are delivered in version 8.x, see ArcView GIS

ArcView GIS 3

Project

Theme

View, View frame

Table of contents

Layout

Projection

Hotlink

Charts

Avenue scripts

Select by Theme

SQL Select

Active theme

AVL (legend file)

Ftab

Spatial join

Legend Frame

North Arrow Frame

Table Frame

Scale Bar Frame

Picture Frame

DDE

Symbol window

Symbol files

Promote Selected

Multiple layouts

Database theme

CAD Reader

\section{ArcView 8.x}

Map document

Layer

Data frame

Table of contents

Layout, Layout view

Coordinate system

Hyperlink

Graphs

Visual Basic for Applications (VBA) macros

Select by Location

Select by Attributes

Selectable layers (Each tool presents a list of layers to use.)

Import symbology from layer file

Recordset

J oin by Location

Insert Legend

Insert North Arrow

Add table to layout (Table menu)

Insert Scale Bar

Insert Picture

OLE

Symbol Selector

Styles

Open Table for Selected

Multiple documents

Geodatabase layer

CAD layer 


\section{ArcView GIS 3}

Grid theme

I mage theme

I mage catalog

TIN theme

Feature theme

Convert to Shapefile

Add theme

Extensions

Brightness theme (ArcView Spatial Analyst)

Blurb/Callout tool

Add/Remove field

Create index

New shapefile

Sort

Summarize

SQL Connect

View (Avenue)

Application (Avenue)
ArcView 8.x

Raster layer

Raster layer

Raster catalog

TI N layer

Feature layer

Data>Export

Add data

Extensions and toolbars

Transparency

Text Callout tool

Properties >Fields (ArcCatalog) or Table window (ArcMap)

Properties > Fields (ArcCatalog)

New shapefile (ArcCatalog)

Table window $>$ column ( right-click) $>$ Sort

Dissolve Wizard

Add OLE DB Connection (ArcCatalog)

FocusMap (VBA)

Mxapplication (VBA) 


\section{Why the geodatabase?}

The geodatabase format offers many unique advantages for geographic data storage.

\section{Scalability}

As user needs for security and data management grow, the geodatabase can meet them.

\section{Custom Features}

Because of its COM architecture, custom objects can be programmed that Represent real-world features more accurately

\section{Domains and subtypes}

These properties, easily created and maintained in the geodatabase, make

Data creation, editing, and maintenance much more efficient and would require special programming to be achieved in other formats.

\section{Geometric Networks}

Using the geodatabase, you can create geometric networks for modeling connectivity and performing trace and path finding analysis

\section{Geodatabase types}

\section{Personal}

-MDB formats

-Edit with ArcView, ArcEditor, ArcInfo

\section{ArcSDE}

-RDBMS format (Oracle, SQL Server, Informix, DB2)

-Edit with ArcEditor or ArcInfo 


\section{Using ArcCatalog}

-Provides a uniform view of all your data

-Define or modify table and feature class definitions

-Manage data: Copy, Rename, orlete

NOTE: DO NOT USE "WINDOWS EXPLORER" TO MANAGE DATA ALWAYS USE ARCCATALOG TO COPY, RENAME, OR DELETE

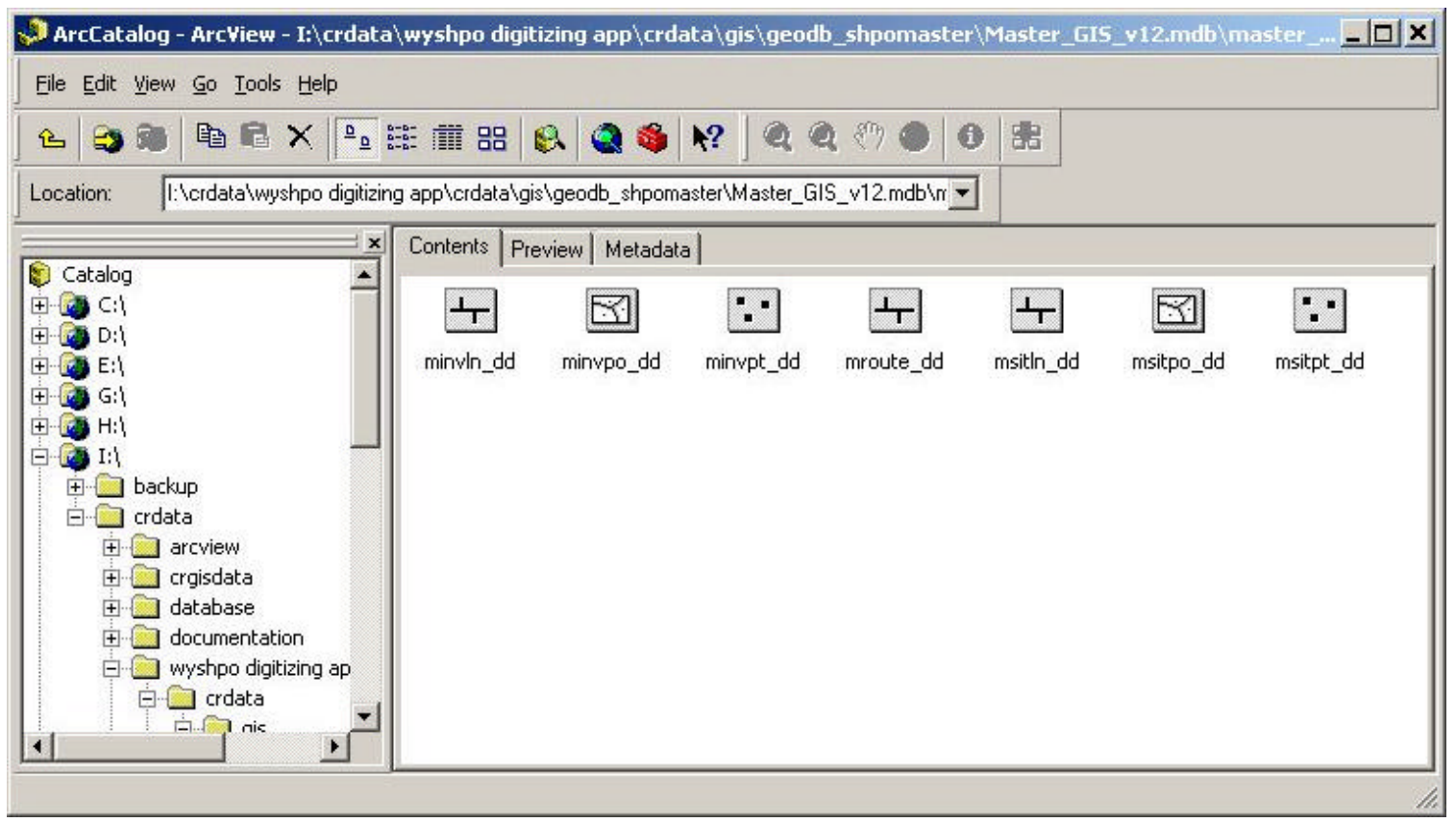

Raster Datasets

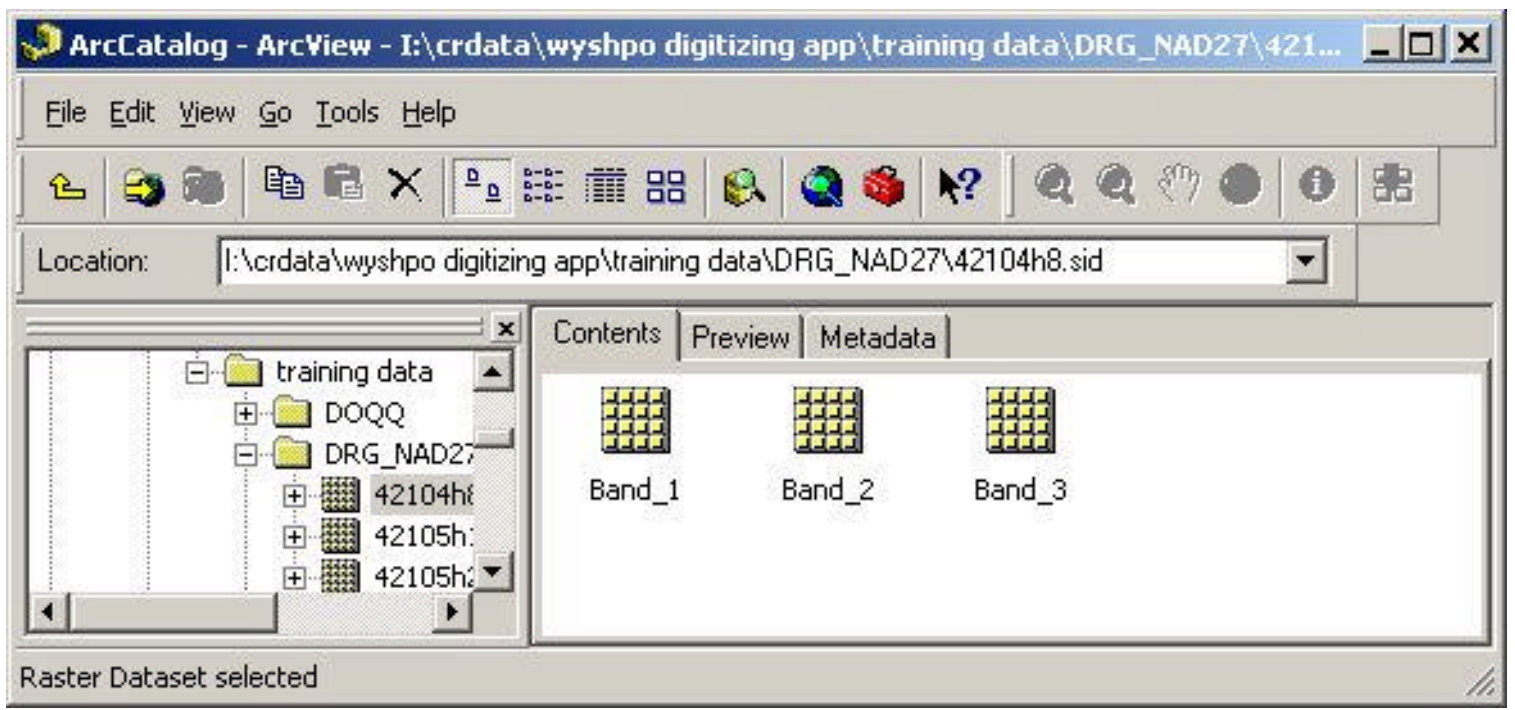




\section{ArcGIS Data entry procedures for the Bureau of Land Management Field Office Archeological Staff, 4/1/2004.}

First daily step is to Open Arc Catalog and check to be sure your ODBC connections are still working.

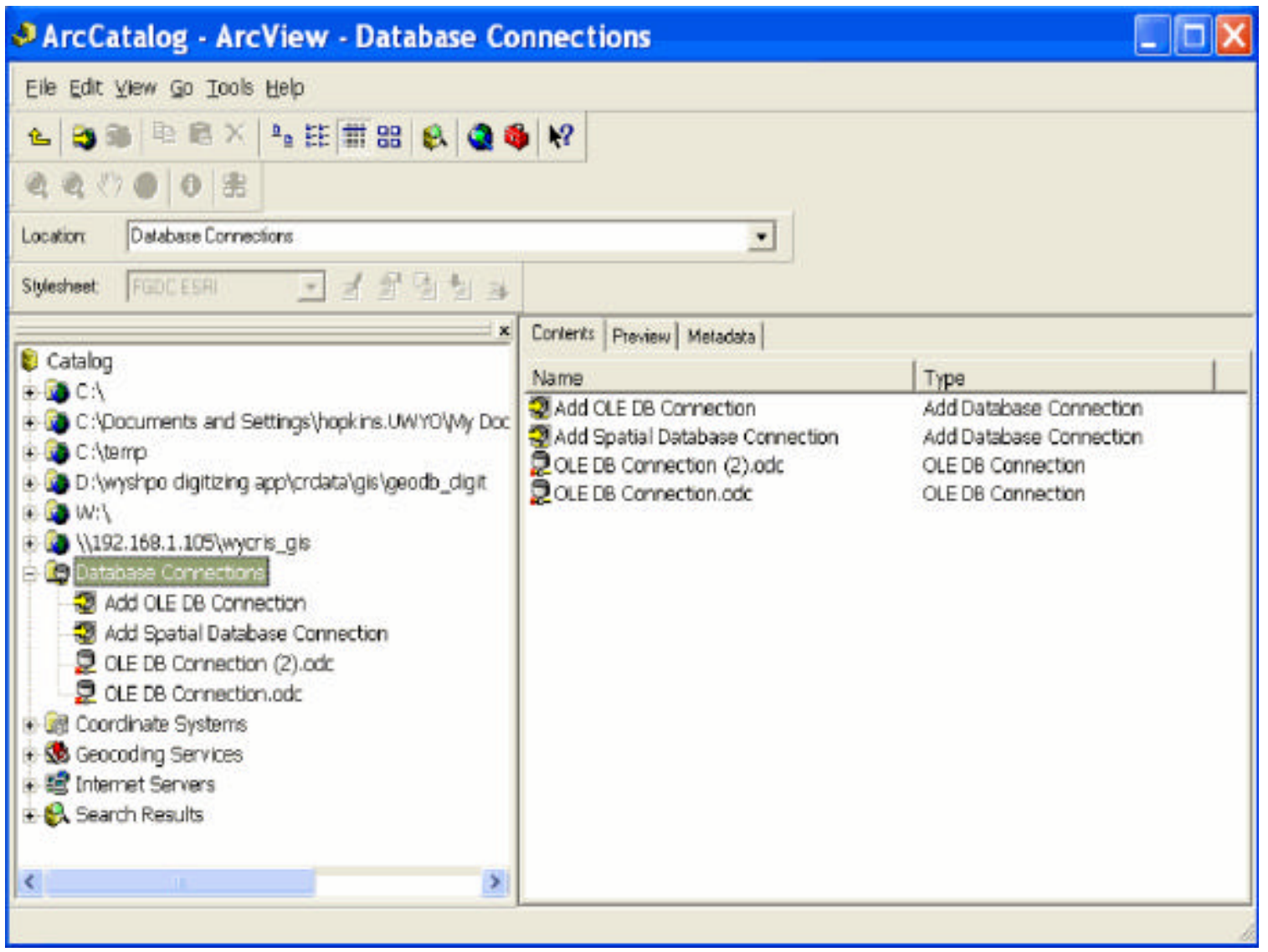

In the Right Frame, you should see two Ole DB Connections. If they are missing, check with your GIS or IT administrator. 


\section{Using the WYCRO Field Digitizing Application}

\section{Start the application}

Start the application by double-clicking the shortcut placed on your desktop called:

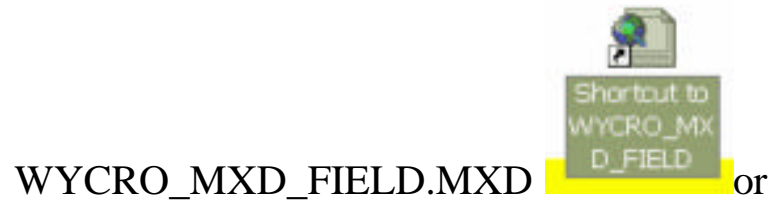

Go to "Start" "All Programs" "ArcGIS" "ArcMap" and navigate to CRDATAIGISIGEODB_DIGITIWYCRO_MXD_FIELD.MXD

(A "MXD" is an ESRI "map document" and is similar to an ArcView .APR or ArcView project.)

Bring the digitizing data layers into the document from the geodatabase.

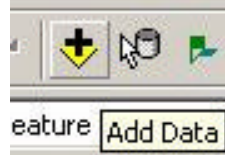

Add the fallowing layers by clicking on the Plus button or,

File - Add data and navigating to the layers you would like to use. You can also drag them directly from ArcCatalog

The following are typical layers used when digitizing.

\section{$\underline{\text { Background Layers }}$}

DRG's (Digital Raster Graphics or quadmaps for backgrounds)

PLSS (Public Land Survey System, for navigation)

WYQUAD (Wyoming Quad map grid for finding DRG's)

GCDB (Geographic Coordinate Database, grid system that closely

resembles the PLSS, divides the sections into quarter-quarters)

Master Layers (Master inventory and site data provided by SHPO)

msitpo_dd -Site Polygons

msitpt_dd -Site Points

msitln_dd -Site Lines

minvpo_dd -Inventory Polygons

minvpt_dd -Inventory Points

minvln_dd -Inventory Lines

\section{BLM Layers}

$\begin{array}{ll}\text { dedispo_dd } & \text {-District Polygons } \\ \text { deinvln_dd } & \text {-Inventory Lines } \\ \text { deinvpo_dd } & \text {-Inventory Polygons } \\ \text { deinvpt_dd } & \text {-Inventory Points } \\ \text { deisopt_dd } & \text {-Isolates Points }\end{array}$




$\begin{array}{ll}\text { desitln_dd } & \text {-Site Lines } \\ \text { desitpo_dd } & \text {-Site Polygons } \\ \text { desitpt_dd } & \text {-Site Points }\end{array}$

You can change the way the symbols are drawn and the order in which they appear by doing the fallowing

To change the order in which they draw on the map highlight or single click on the layer in the table of contents.

Then, single click and "drag" the layer up or down the table of contents

To change the symbol style, double click on the layer.

In the Layer Properties dialog box you can change many features about the layer.

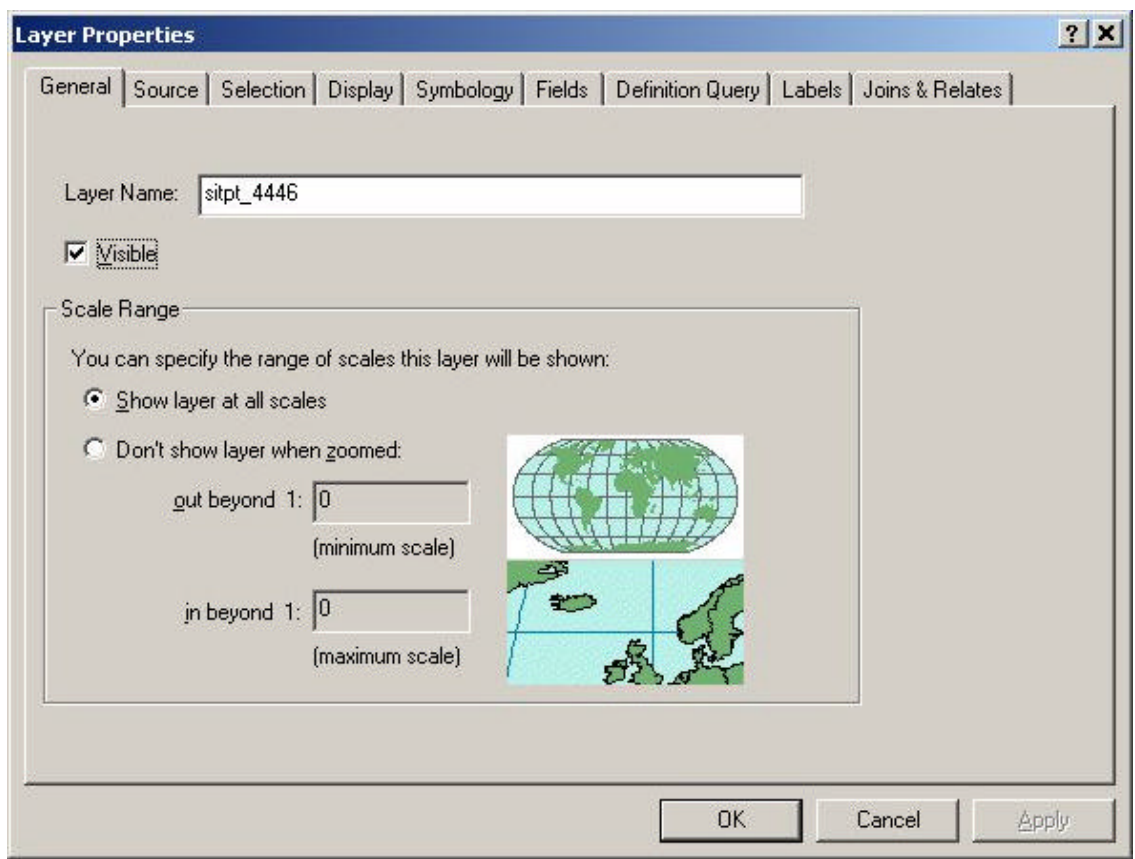


Click on Symbology and then click on the symbol.

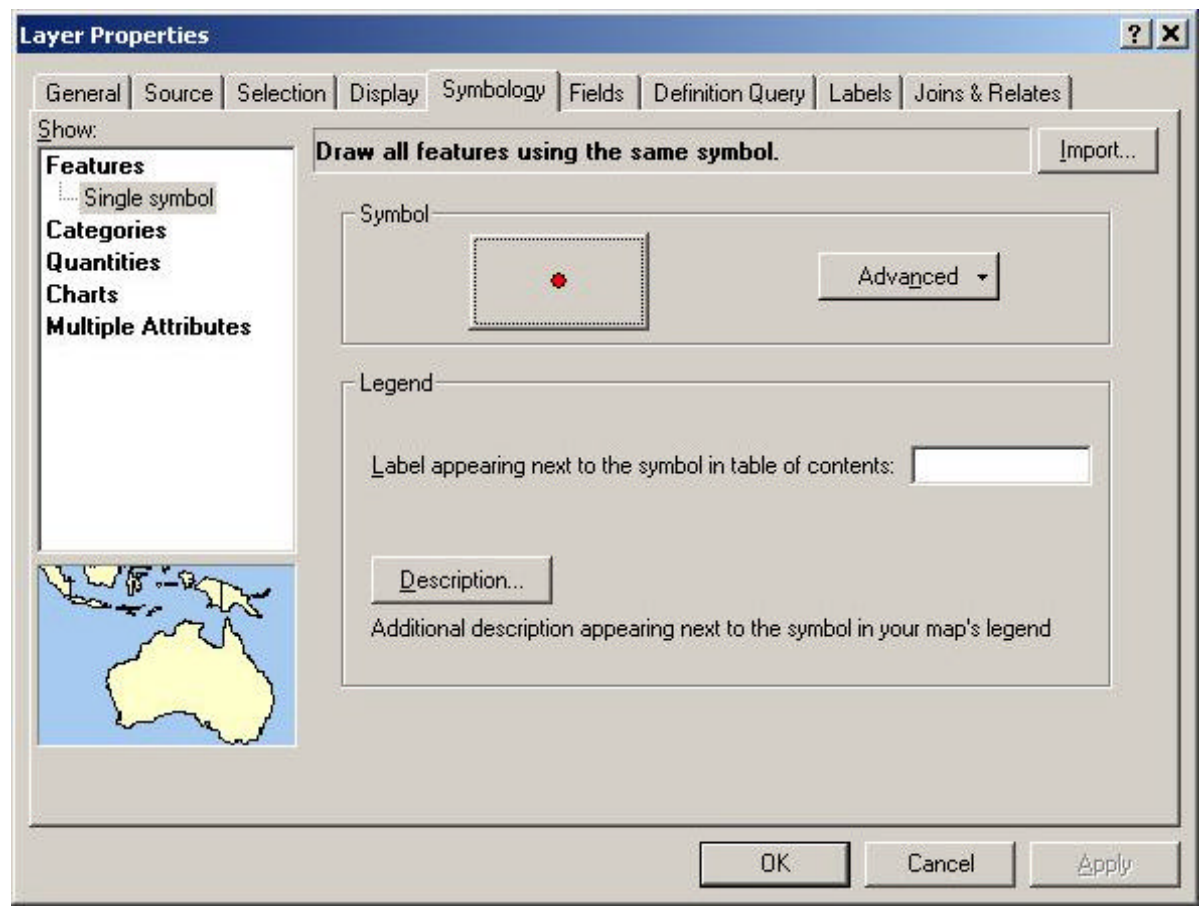

You can now change the symbol properties. Typical Layer Symbols for this project are shown below.

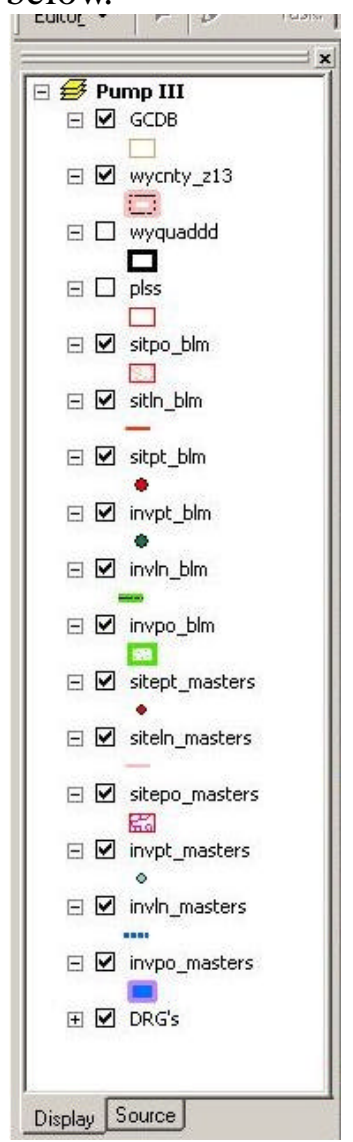




\section{Changing the Projection of your map}

In the table of contents, "right click" layers and go to "properties." Click on the Coordinate System Tab. If you have brought in the cultural resources information before any base maps, your default project is GCS_North_American_1983.

\section{Data Frame Properties}

Annotation Groups |
General | Data Frame
Coordinate System | Illumination | Grids | Labels

Current coordinate system.

GCS_North_American_1983

Clear
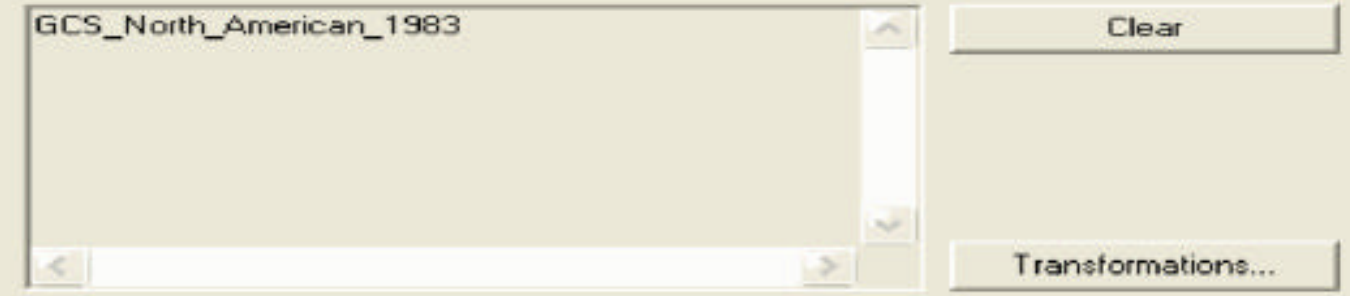

Select a coordinate system:

$+\square$ Favorites
$+\square$ Predefined
$+\square$ Lavers
$+\square$ <customs

(4) GDS_Worth_Amencan_1983

Transformations...

OK

To change the coordinate system, click on Predefined.

Navigate to "Projected Coordinate System/UTM/Nad83

Choose the appropriate zone - for Wyoming it is either 12 or 13 


\section{Data Frame Properties}

Annotation Groups |

General | Data Frame

Current coordinate system:

NAD_1983_UTM_Zone_12N

Transverse_Mercator

False Easting 500000.000000

False_Northing: 0.000000

Central_Meridian: -111.000000

Scale Factor: 0.999600

Latitude_Of_Origin: 0.000000
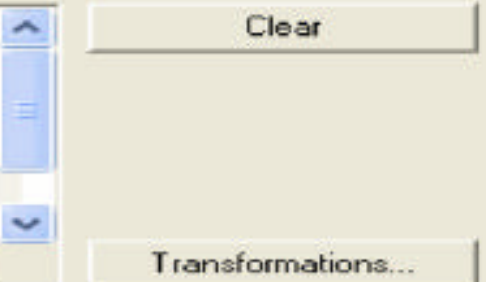

Clear

Transformations...

Select a coordinate system:

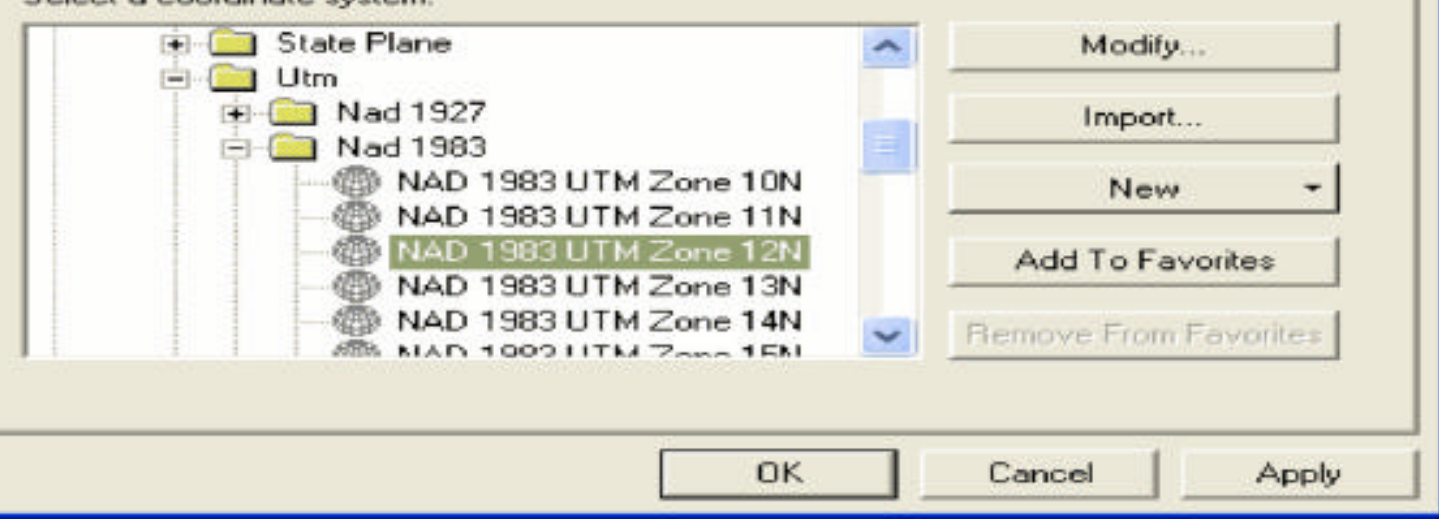

Click "Apply" and your map is now in the proper projection to use with other available GIS data.

\section{Navigating on screen}

Identify the location of your project on the source document (Township, Range and Section, UTM's)

Zoom to Location using the Find tool that looks like binoculars

T. Find
Features $\mid$ Route Locations | Addresses |
Find:
In layers: plss
『 Find features that are similar to or contain the search string
Search: $C$ All fields
\[ \text { In fields FiD } \]
$C$ Each layer's primary display field


In the In Layers dropdown, use - PLSS

Next, type in the location in the "Find" field (township-range-section) Then click on the Find button.

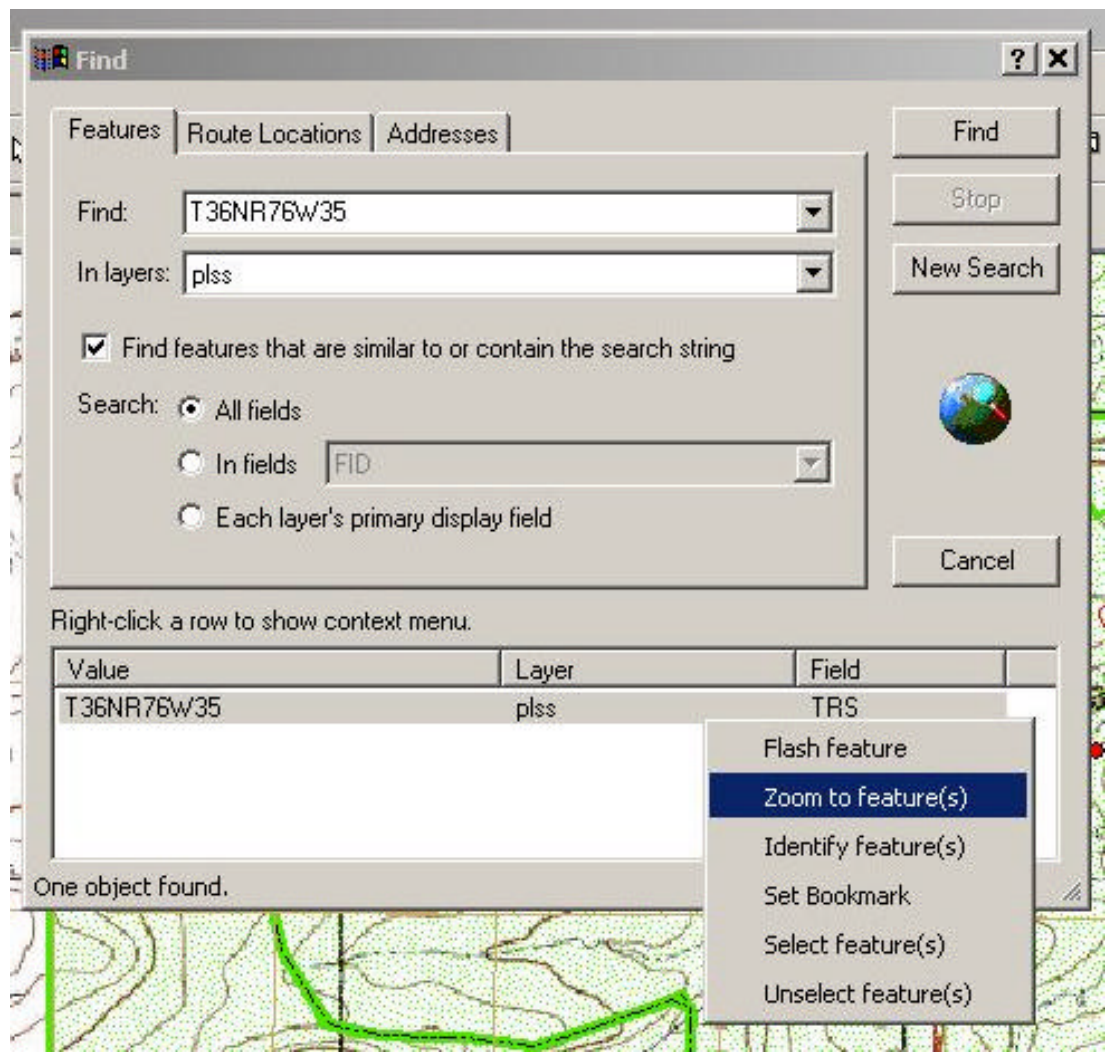

Highlight the result - Right click - Zoom to feature

Close or Cancel the Find wizard when finished zooming

You should now be in the right township, range and section of your project.

Next, use the Identify tool that is just to the left of the binoculars.

Click on the screen somewhere. When the Identify window appears, change the Layer to "wyquaddd" 


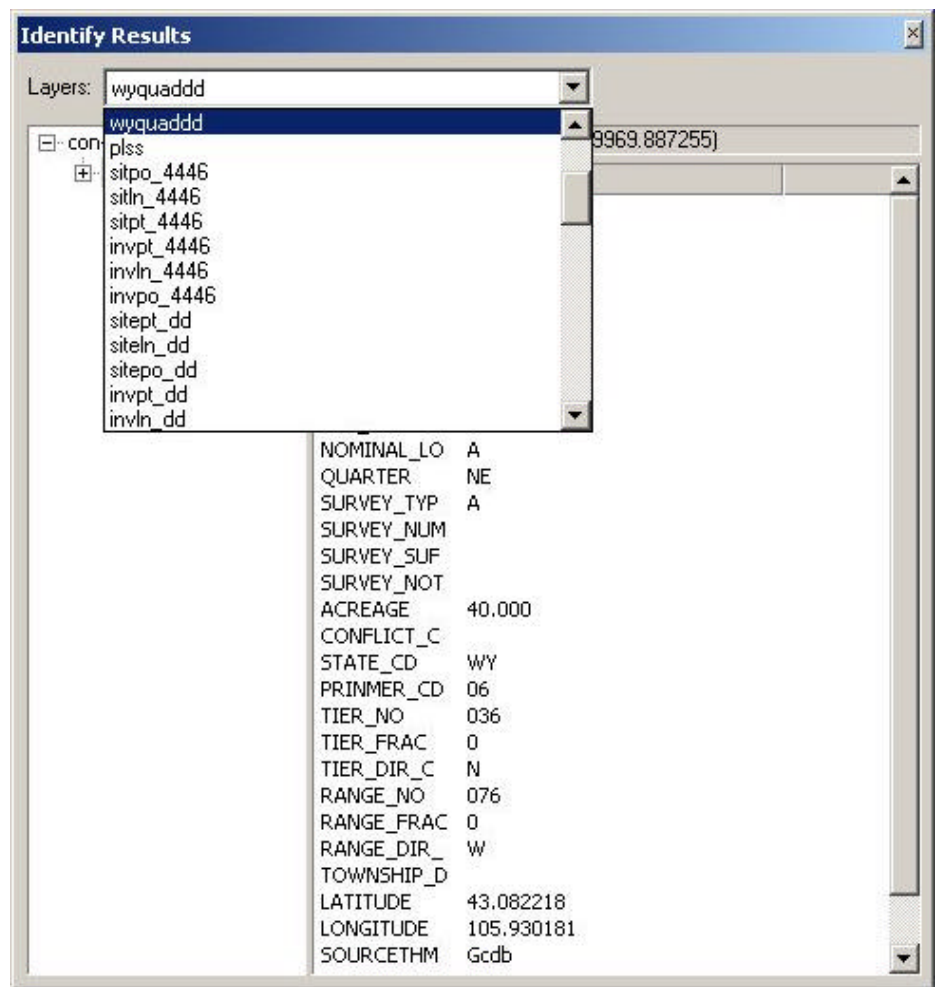

Click on the screen again and identify the Quad-map that you will want to add for a background map.

\begin{tabular}{|c|c|c|c|}
\hline \multicolumn{3}{|l|}{ Identify Results } & $\underline{x}$ \\
\hline \multicolumn{3}{|l|}{ Layers: Wyquaddd } & \\
\hline \multirow{4}{*}{$\begin{array}{l}\text { Đ. wyquaddd } \\
\qquad \text { Gumbo Hill }\end{array}$} & \multicolumn{2}{|c|}{ Location: (425424.371764 } & \\
\hline & Field & Value & \\
\hline & $\begin{array}{l}\text { FID } \\
\text { Shape } \\
\text { WEST_ID } \\
\text { NAME } \\
\text { STATE } \\
\text { LAT } \\
\text { LONG } \\
\text { MRC } \\
\text { BLMSCAN }\end{array}$ & $\begin{array}{l}708 \\
\text { Polygon } \\
9611 \\
\text { Gumbo Hill } \\
\text { WY } \\
43.000 \\
-105.875 \\
43105-A 8\end{array}$ & \\
\hline & 11 & & 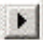 \\
\hline
\end{tabular}


Use the Add Data button eature Add Data

You will receive a warning like this

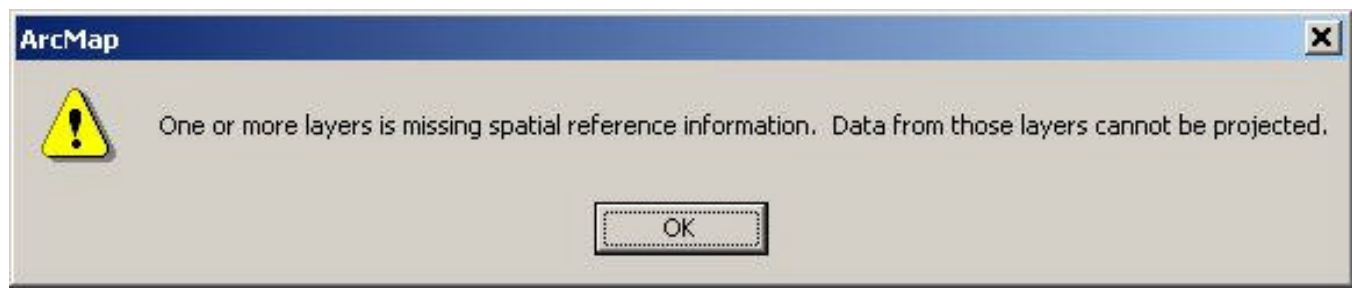

Just click "OK" (ArcMap will Project on the Fly)

Compare the source map with the quad map on screen to confirm your location 


\section{Data Entry}

5 WAYS TO ENTER DATA

\section{HEADS UP}

Digitizing with the mouse while looking at a map. This can be easily done when you have a good source map and an accurate background. It is the most common type of data entry.

\section{UTM COORDINATES}

Digitizing "Point" data using its UTM Coordinates. This is easily done by "right clicking" while in the "point editor" and then enter the "Absolute xy" for that position. This is handy when maps are poor.

\section{DIGITIZING TABLET}

Digitizing using a "digitizing tablet". Good for large projects with many points, lines, and polygons.

\section{SCANNED MAPS}

Digitizing on-screen using a "Geo-referenced" image of the source map. This is also good for poor maps or large projects with many features.

\section{CORRECTED GPS DATA}

Typical Digitizing Order for a project containing sites

1. Digitize the Inventory Polygons (Well Pad, Block Surveys)

2. Digitize the Inventory Lines (Access, Pipeline, Seismic line, Utility line, etc..)

3. Digitize the Inventory Point (Site Revisit, poor map)

4. Digitize the Site Polygons

5. Digitize the Site Points (small sites, revisit, shovel test)

6. Digitize the Site Lines (ditches, linear sites)

Read the project description very carefully to determine exactly what was inventoried and what wasn't. 


\section{Polygon Data Entry (Inventory/Site)}

Block surveys will be entered as Polygon features. Inventory reports and Site reports can have polygon features.

To begin entering data, click Editor - Start Editing

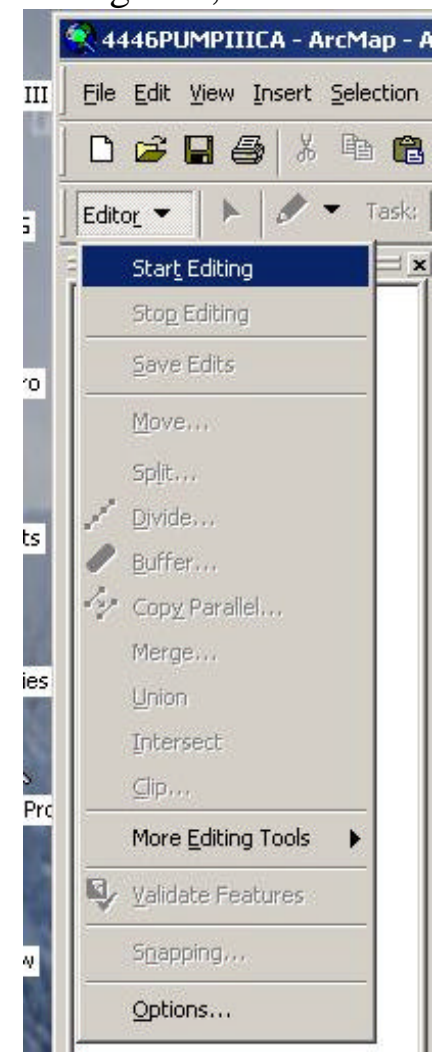

Then select the Geodatabase container that contains the layers you want to edit.

Now change the Target layer to the layer you want to edit. In this case it would be either "desitpo_dd" or "deinvpo_dd"

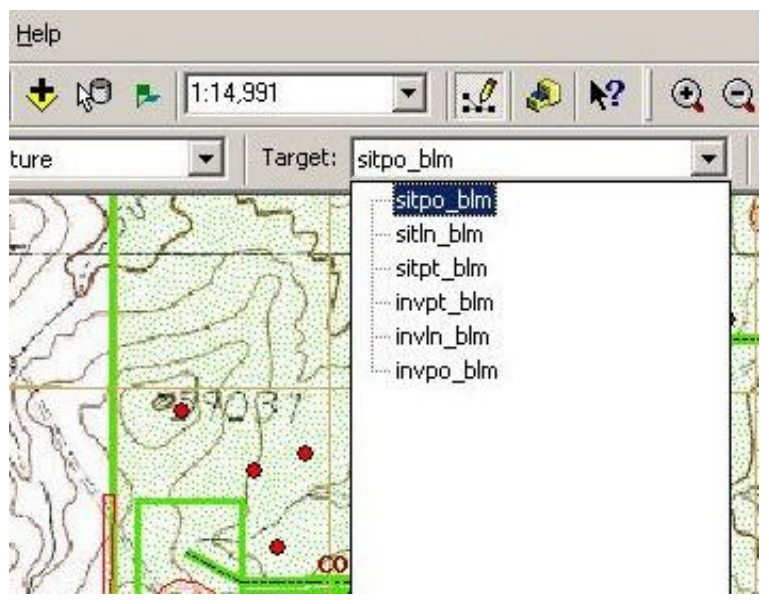


When you have the Target Layer selected, you can click on the Sketch Tool

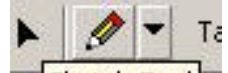

Sketch Tool

to start sketching out the boundary of the project or site. Try to be as accurate as possible while using features on your map to maintain the boundaries(contours,streams, wells, roads,powerlines,etc.) Continue clicking or "Adding Vertices" until you are satisfied with the sketch. If you do not like where you placed a "Vertex", you can delete it or back up in your drawing by typing Control-Z, then continue on until you are finished.

When you are satisfied with your sketch, double-click to end or Right-click and select "Finish Sketch" or F2.

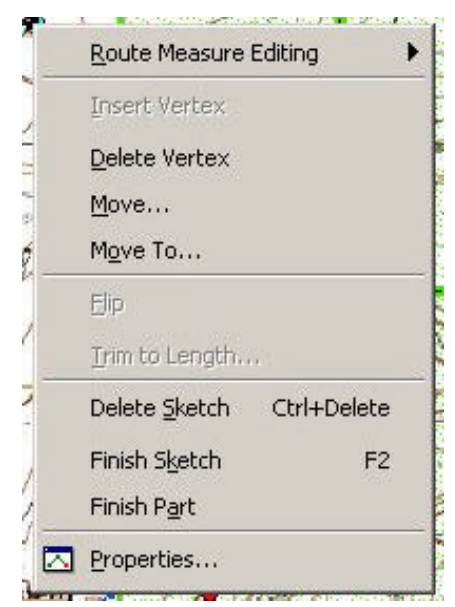

The Polygon feature you just sketched should now appear highlighted in blue.

Now add the attributes to the feature using the attribute dialog box. To activate this box click on the Attribute Tool then right click on your new polygon feature. 
A dialog box should appear for entering attribute data

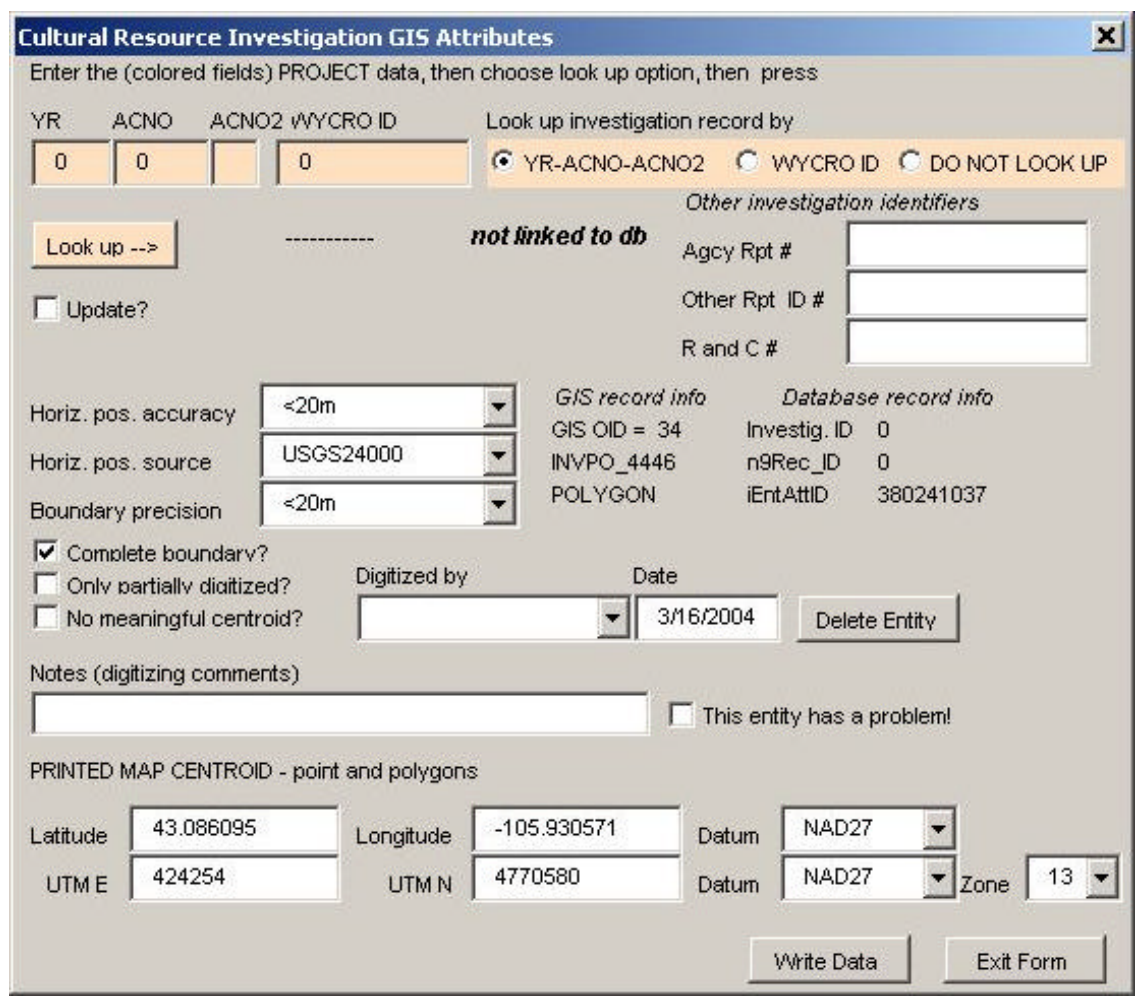

Enter the Year and ACNO number and then click on the Look Up button. You will need to re-enter the Year and ACNO number (88-327) and enter. This will verify the Project you are working on. If the Project matches the source document, continue to fill in the spaces. 
The Dialog Box for Site Polygons is similar

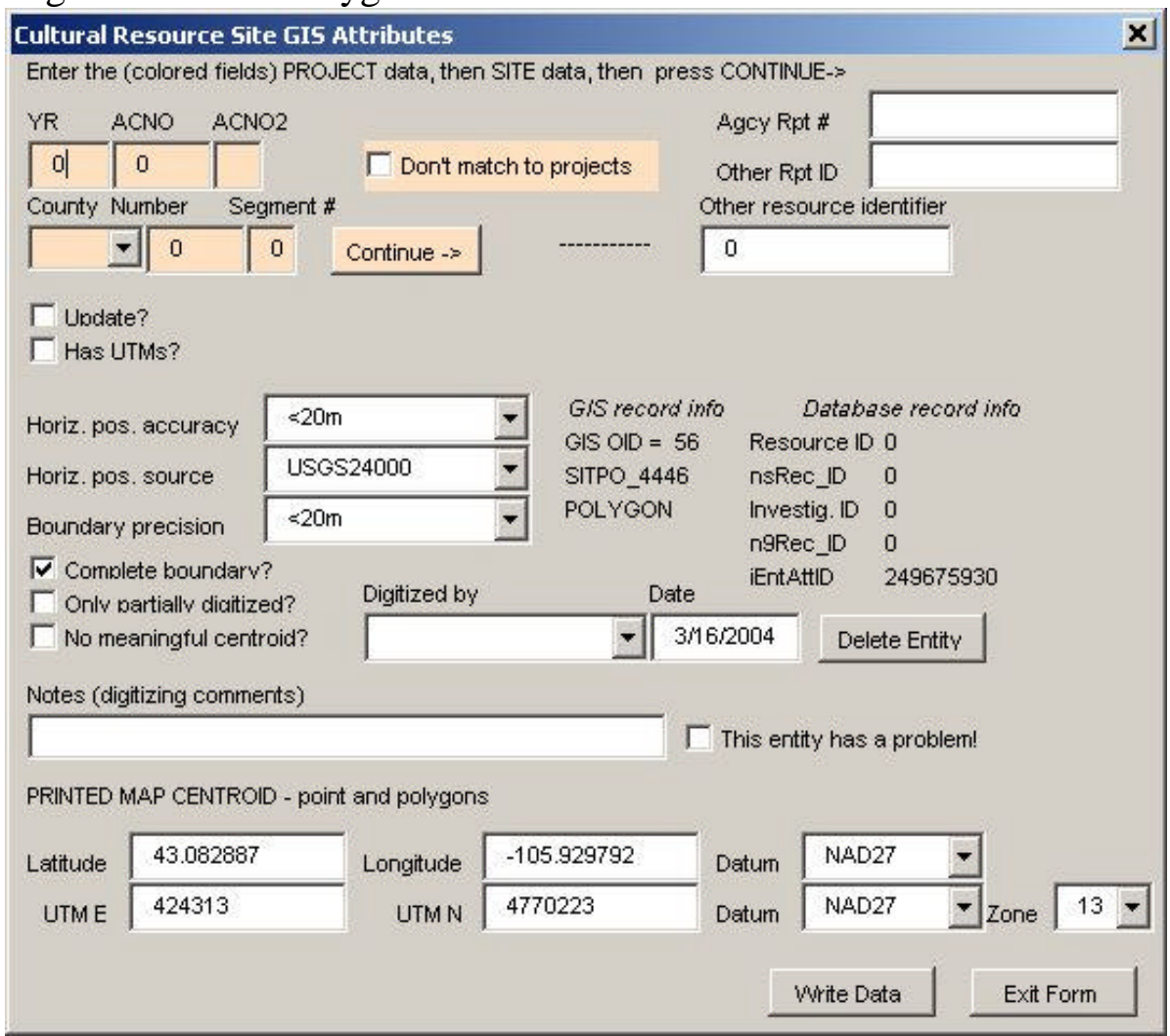

When done, select Write Data - OK - Exit Form.

Then select the Editor button and Save Edits. 


\section{Point Data Entry (Inventory/Site)}

The procedure for entering point data is similar to that of Polygon data entry.

First you start editing by clicking on the Editor Toolbar. Start Editing, and change the Target Layer to either "deinvpt_dd" or "desitpt_dd".

Then use the Sketch Tool $\stackrel{\text { sketch Tool }}{=}$ to add the point on screen.

When you are done entering the point, use the Attribute Tool (looks like a cylinder) to add attributes to the point feature using the dialog box shown above.

When done, select Write Data - OK - Exit Form. Then select the "Editor" button and "Save Edits."

If you have a poor map, or you would rather enter the point feature using the UTM Coordinates provided by the source report, you can do the following:

\section{Point Data Entry Using UTM Coordinates}

Start the data entry the same way using the Editor Button. Click on the Sketch $\rightarrow-T a$

Tool sketch Tool , but instead placing a point on the screen with the left button of your mouse, "Right click" with the mouse and select the Absolute xy feature

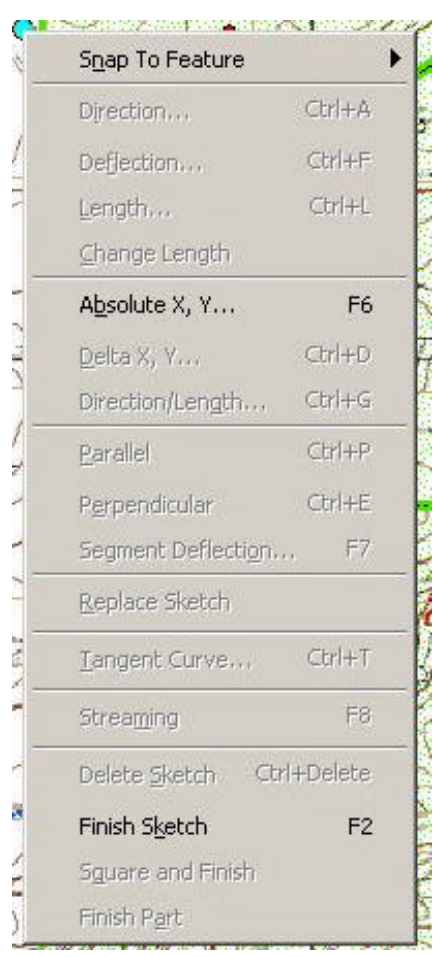


Then enter the UTM coordinates in the fields provided. When the point feature redraws, use the Attribute Tool to add the attribute data to the feature.

After you enter the site point using the UTM's, you can zoom to the feature just entered. This is handy when you don't have a good map but you have UTM coordinates

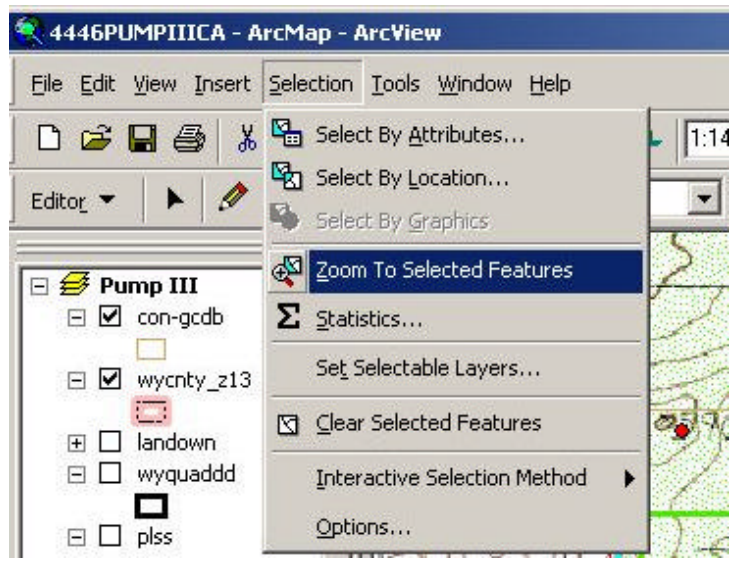

When done, select Write Data - OK - Exit Form. Then select the "Editor" button and "Save Edits." 


\section{$\underline{\text { Linear Data Entry (Inventory/Site) }}$}

Start Editing using the Editor Toolbar and change the Target Layer to either "deinvln_dd" or "desitln_dd."

When adding Linear features to a map, it may be useful to use the Snapping features in ArcGIS. This is useful when wanting to snap an inventory line, such as an access route or pipeline, with its block survey. To do this, select the Editor toolbar then, Snapping.

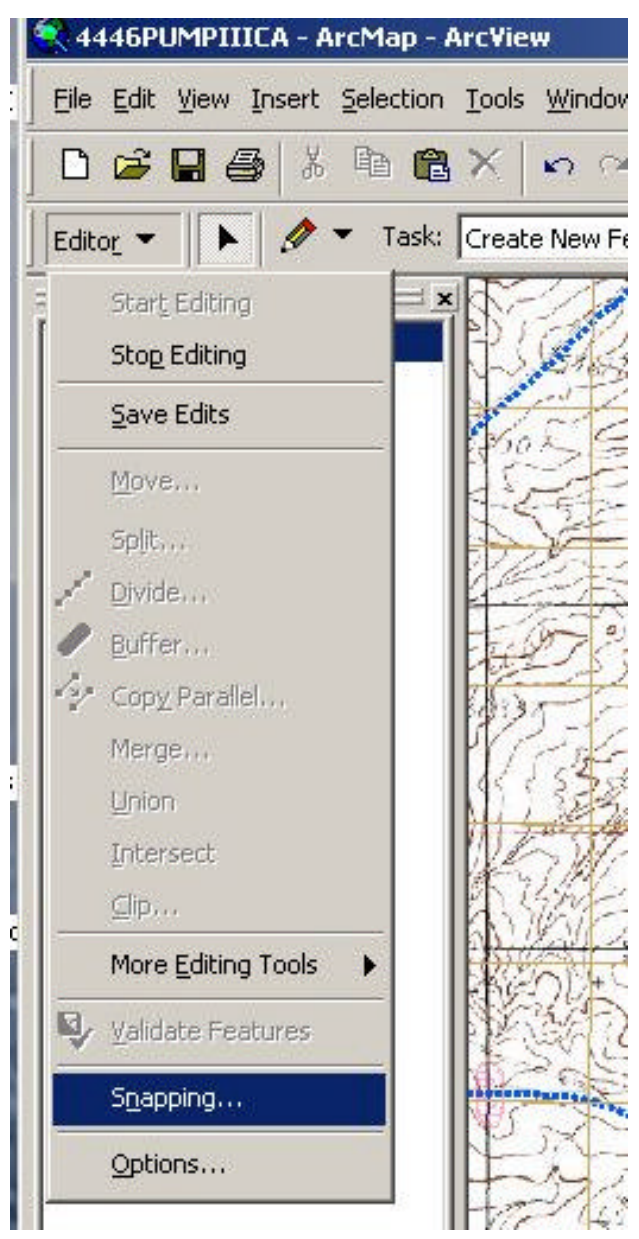


Then select the layer that you would like to snap your linear feature to.

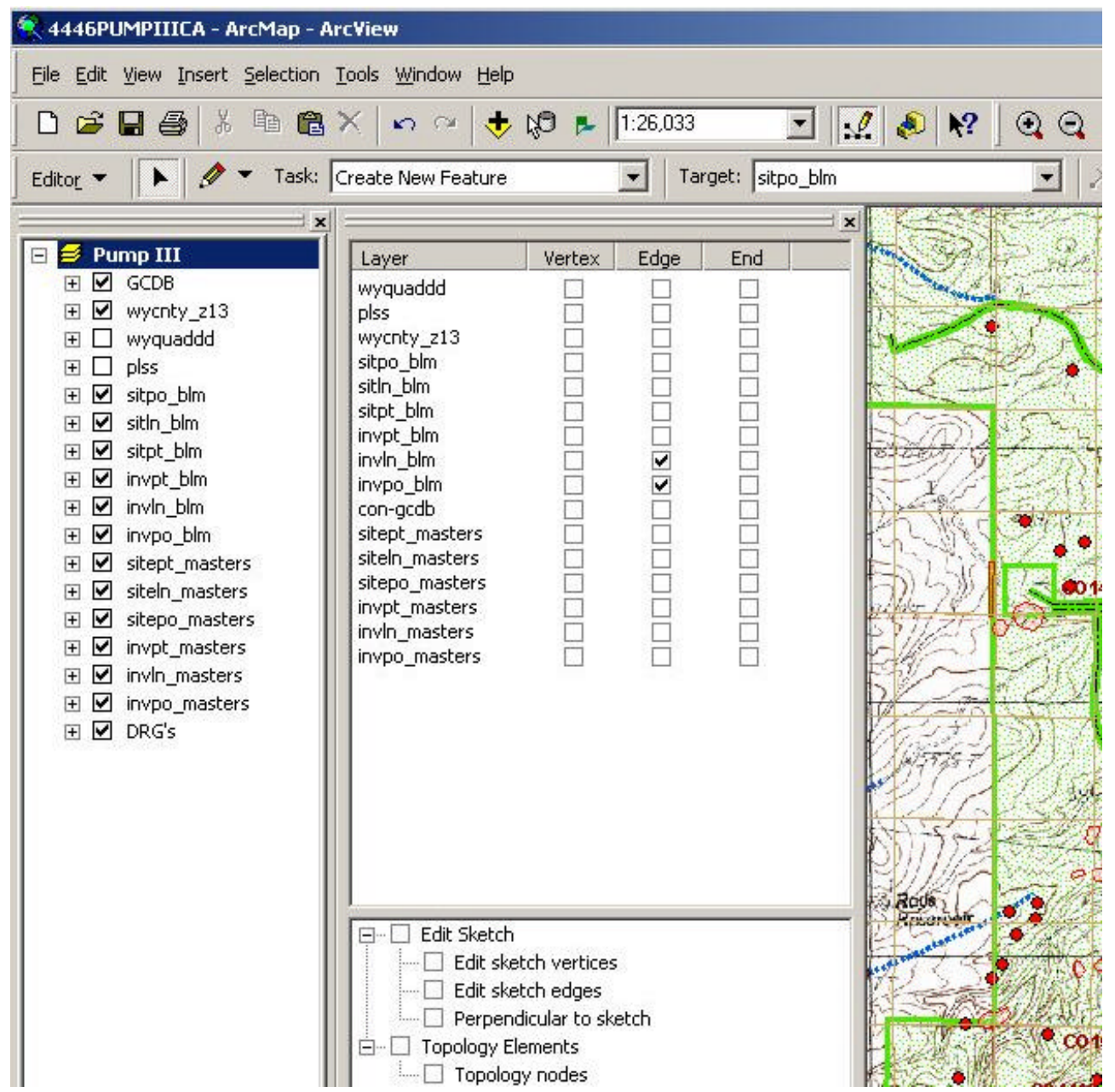

Typically you would want to snap your linear feature to another inventory line or perhaps the inventory polygon layer.

Continue sketching the linear feature on the map until you are satisfied with the drawing and double click to finish the sketch. 
Use your Attribute tool to add the attributes to the linear feature.

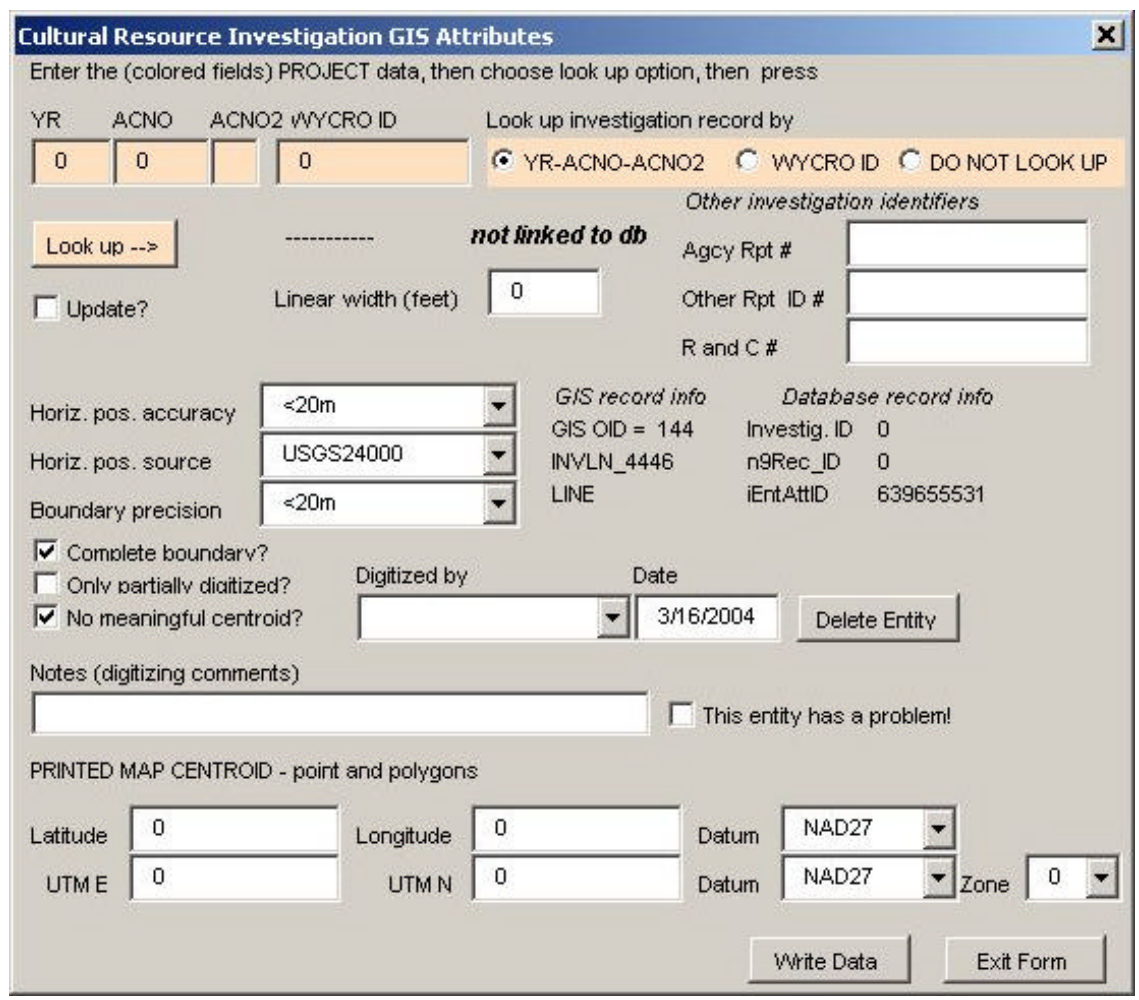

The biggest difference with this dialog box is the "Linear Width" field that must be populated in feet. If no measurement is given, use $100 \mathbf{~ F t}$.

When done, select Write Data - OK - Exit Form. Then select the "Editor" button and "Save Edits."

If you are not happy with the placement of a feature on your map, you can delete it and redraw it or highlight it and move it.

To highlight a feature, use the Select Feature tool W Layer set to the feature you want to select and edit. You must have the Target You can then limit the layers to select by going to Selection - Set Selectable Layers . 


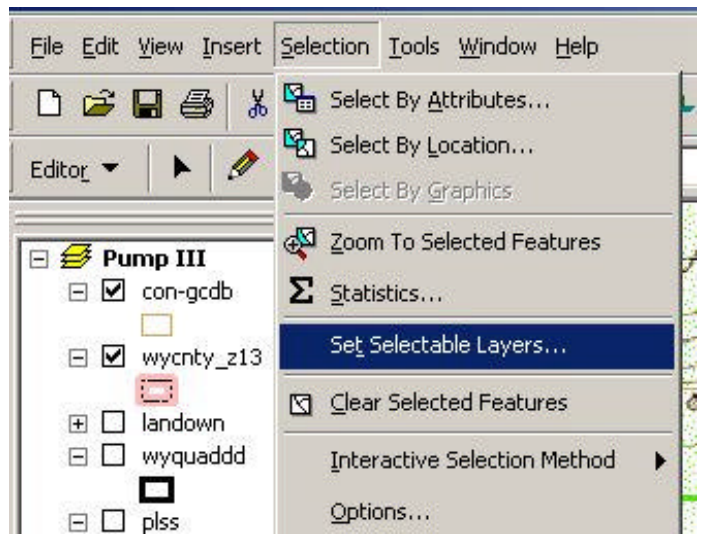

Then select the layers you want to be selected.

You can move this selected feature if you have not "written" the data to the database yet by using the Edit Tool that looks like an arrow This tool can be used to Drag the feature to where you want it. 


\section{Using a Scanned Map to Heads -up Digitize}

Add the (sourcemap.tif) to your map using the Add Data tool any other data.

You will receive a warning like this

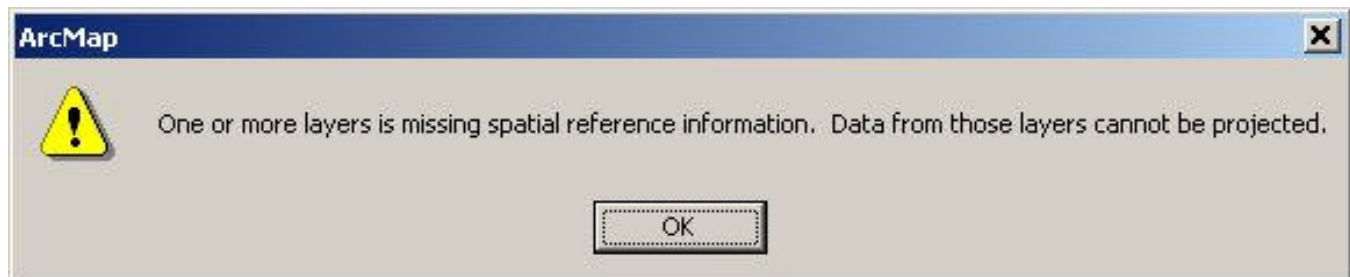

Just click "OK"

\section{Make sure your image(sourcemap.tif) is above your DRG in the Table of Contents}

You will want to identify a section on your source map that has clear section lines.

Navigate to that section on the DRG using the Find tool and dialog box described earlier

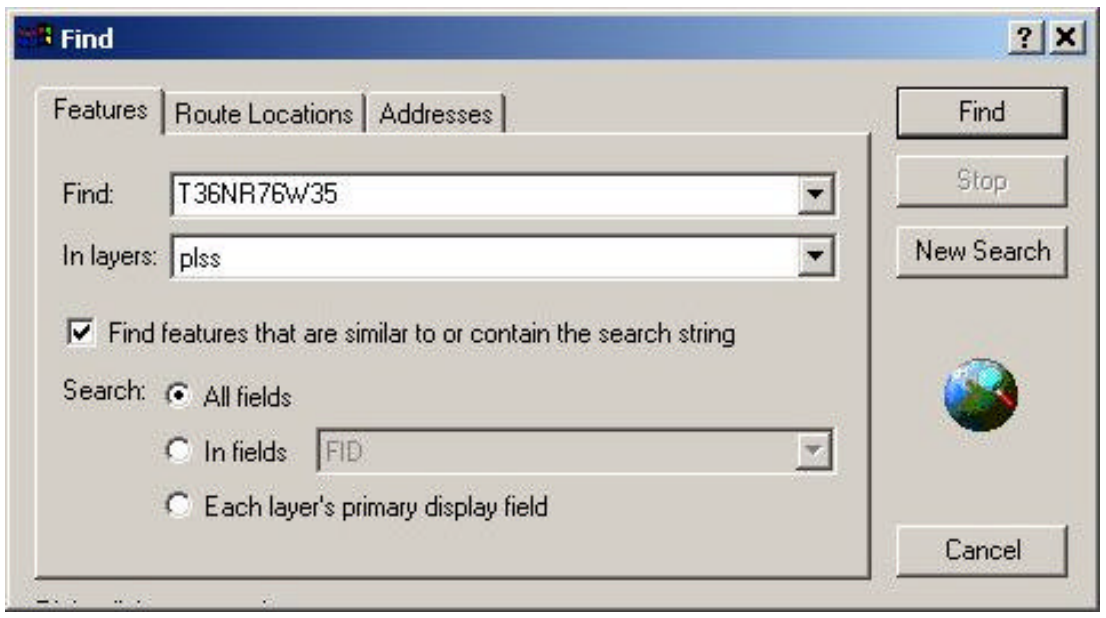

When you have zoomed to the selected section on the DRG, save that extent as a

bookmark. This will come in handy when you want to return to this extent many times.

To do this, click on View - Bookmark - Create 


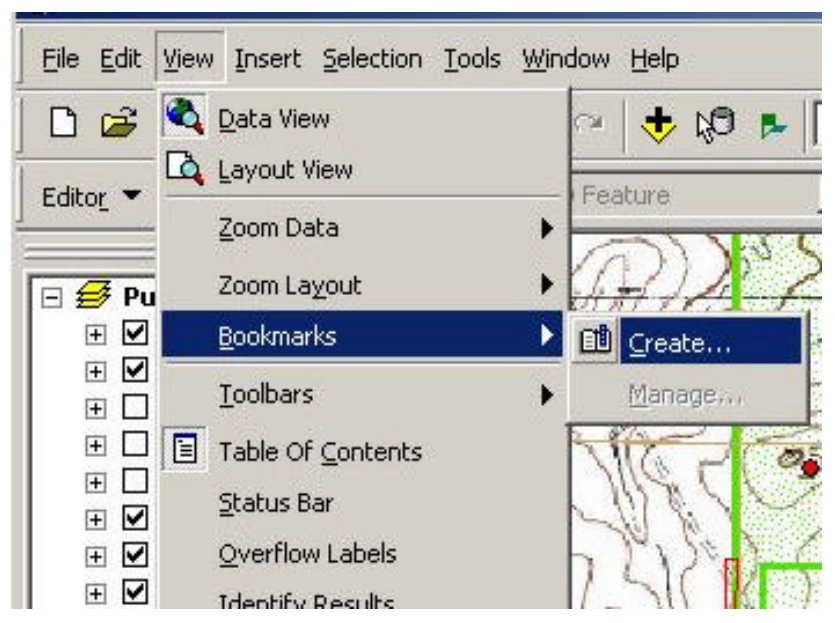

Create a bookmark with the name of the section you are zoomed to (section18)

Add the Georeferencing Toolbar to your ArcMap Project by clicking on View Toolbars - Georeferencing

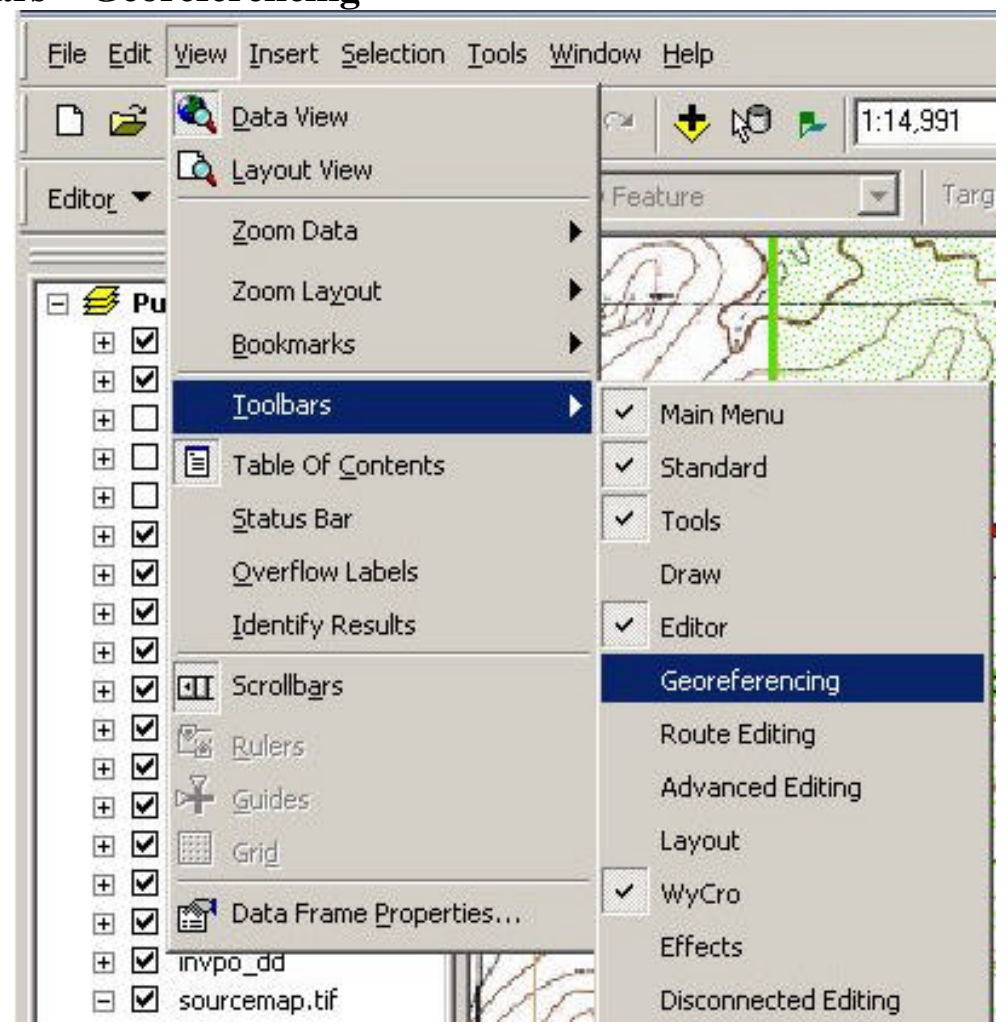

Pull this toolbar down to the bottom of the window and make sure the "sourcemap.tif" is selected as the Layer

Georeferencing $-\mid$ Layer: Sourcemaptif

Highlight or Single click on the "Sourcemap.tif" in the Table of Contents, then right click it so you can zoom to the layer 


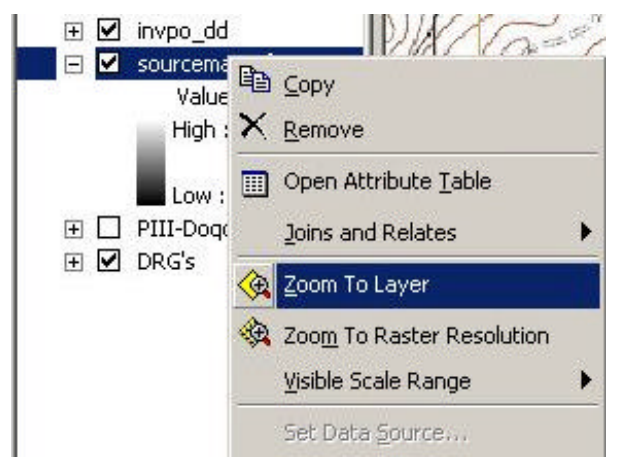

Then use the Zoom tool (looks like a magnifying glass) $\Theta$ to zoom into the area of the section you are planning on georeferencing to (same section as your saved bookmark) You will now use the "Add Control Points" tool in the Georeferencing toolbar (looks like a green and red $x$ connected with a line) $\$$ to link your section corners from your Sourcemap.tif, to the section corners on your background quad-map in your ArcMap Project. I like to start with the upper-right hand corner and work my way around clockwise.

1. Zoom to the upper-right hand corner of the "section" on your sourcemap.tif and use the "Add Control Points" tool to click as close to the intersection as possible.

2. Then, go back to your bookmark by clicking on View - Bookmark - "Saved Bookmark".

3. Use your "Zoom" tool to zoom in closely to the upper, right-hand corner of the section.

4. Again, click on the "Add Control Points" tool and click as closely to the center of the intersection as possible. You have just created your first link.

You will have to have at least 4 control points before the match becomes accurate. (The more the better)

After the second link, you will have to make the Sourcemap.tif transparent so you can view both it and the background Quad-map.

To do this, Double-click the Sourcemap.tif in the Table of Contents When the Layer Properties dialog box appears, click on Display 


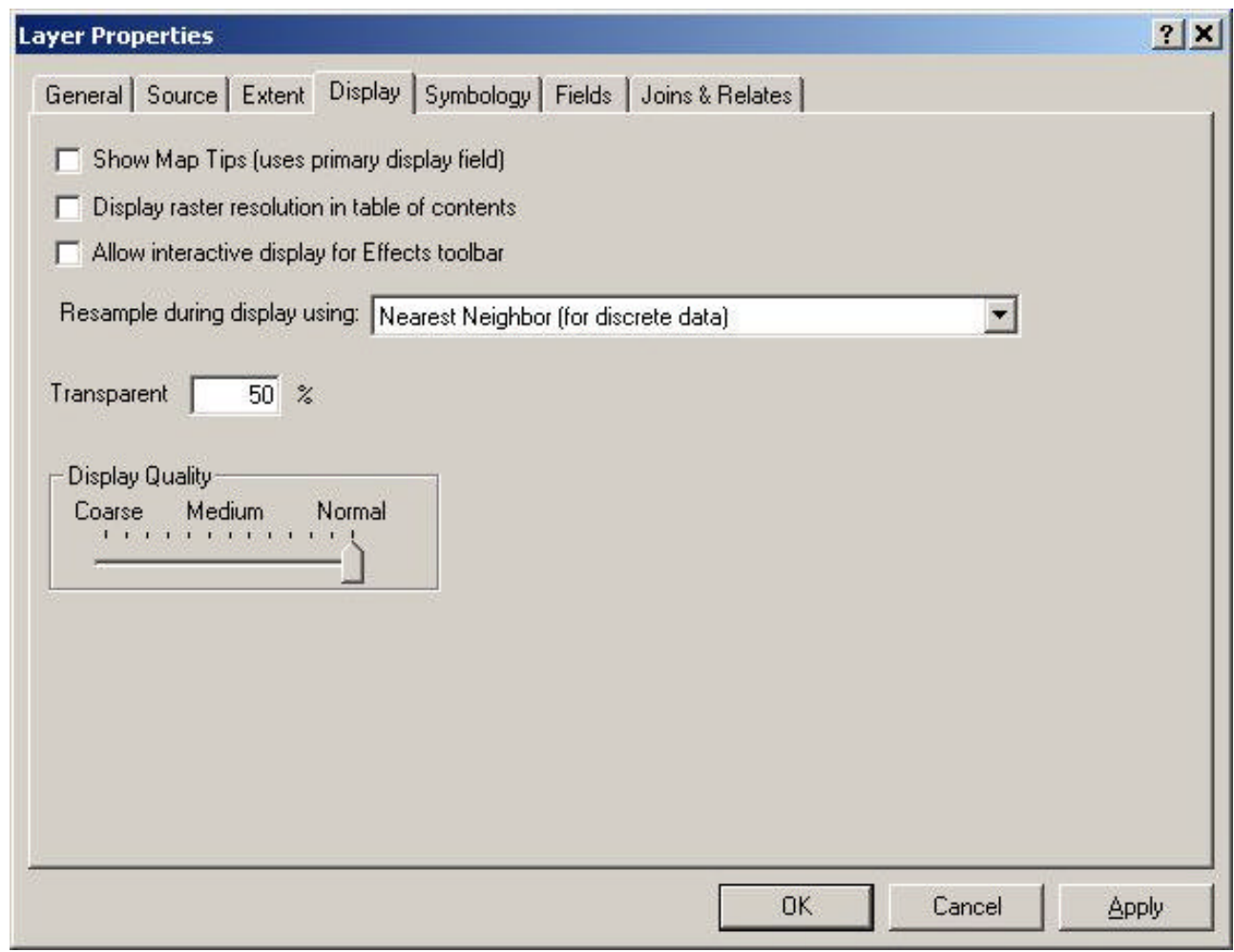

Make the transparency $\mathbf{5 0 \%}$, then click $\mathbf{O K}$

Repeat Steps 1-4 for the remaining corners. You may want to Pan around to other locations and add Control Points.

When you have 4 or more links and are satisfied with the way the image is being displayed, you can save the link table by selecting the Link table tool found on the Georeferencing toolbar $\$$. Click Save and give your link table a name like sourcemap.txt. You can now reload this link table if you happen to close out of your project and want to reopen and return later.

You can now use this georeferenced image of the project map as a backdrop for heads up digitizing on screen. When you are done with the project, simply highlight the Sourcemap.tif Layer in the Table of Contents and Remove it with a right click or delete it. 


\section{Digitizing Procedures}

\section{Initiating ArcMap and beginning the project}

1. Tape down the map on the tablet as flat and smooth as possible, using drafting tape as needed. Ensure that the entire area to be digitized including your control points is within the active area of the tablet.

2. Turn on ArcMap

3. Either begin a new project or navigate to, and turn on an existing project

4. If a new project, add the applicable layers needed.

5. Now you can begin registering your map.

\section{Registering the map for the first time}

1. Click the Editor menu and click Start Editing.

2. Click the Editor menu and click Options.

3. Click the Digitizer tab.

A record appears in the $X$ D igitizer and $Y$ Digitizer columns for each control point you digitized.

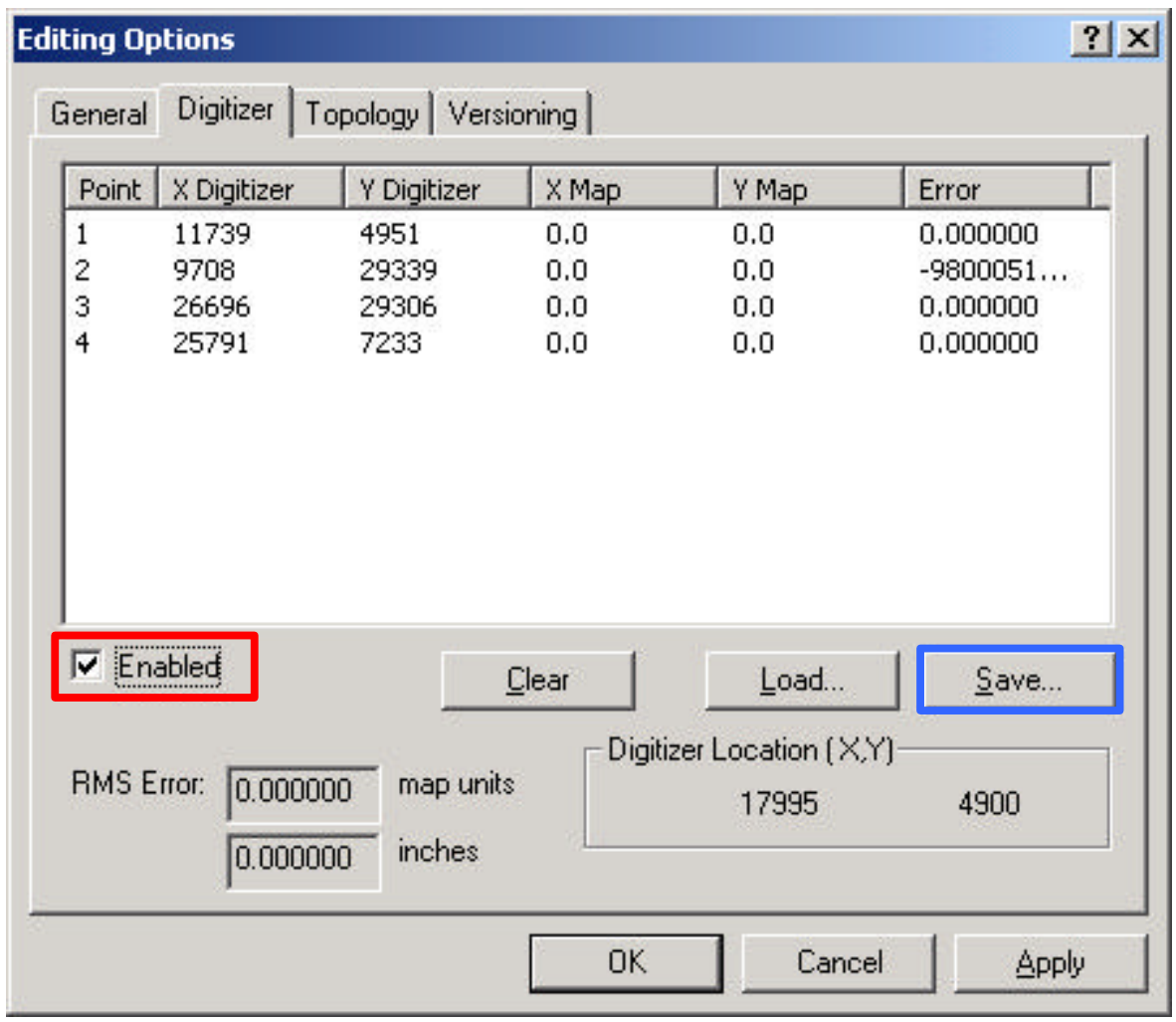

4. Coordinate the Digitizer tablet to the geographic coordinates 
A. If there is no existing Tic file,

I. With the digitizer puck, digitize the control points you established earlier on your paper map (with the puck over each control point on the map, press the button 0 to perform a left mouse click).

II. Type the actual ground coordinates for each control point in the $\mathrm{X}$ Map and Y Map fields.

B. If there is an existing Tic file, then Click Load if there is an existing Tic File

I. Navigate to the file you want to use.

II. Click Open. [The ground coordinates appear under the X Map and Y Map fields.]

5. Click Save to save the ground coordinate values entered for future use and archiving. Name this saved file the same as the map being digitized.

6. Click the first record and digitize the first control point with the digitizer puck.

7. An error in map units is displayed at each control point. A root mean square (RMS) error is displayed in map units and in digitizer inches. [The lower RMS value the better. National Mapping Standards is 0.004.]

8. Click Save to save the ground coordinate values entered for future use and archiving. Name this saved file the same as the map being digitized.

9. Click Enabled to utilize the digitizing puck and tablet in the associated geographic coordinates

10. Click OK to register the map and close the Editing Options dialog box.

\section{Tips}

- If you want to remove all the ground coordinate records and start over, click Clear on the Digitizer tab. To remove an individual record, click the number in the Point column corresponding to the coordinates you want to remove and press the Delete key.

- If you want to add additional control points after entering a few, click below the last record with the mouse and digitize the new points with the digitizer puck.

\section{Registering the map using existing tic files or saved coordinates}

2. After adding a layer to your map, click the Editor menu and click Start Editing.

3. Click the Editor menu and click Options. 


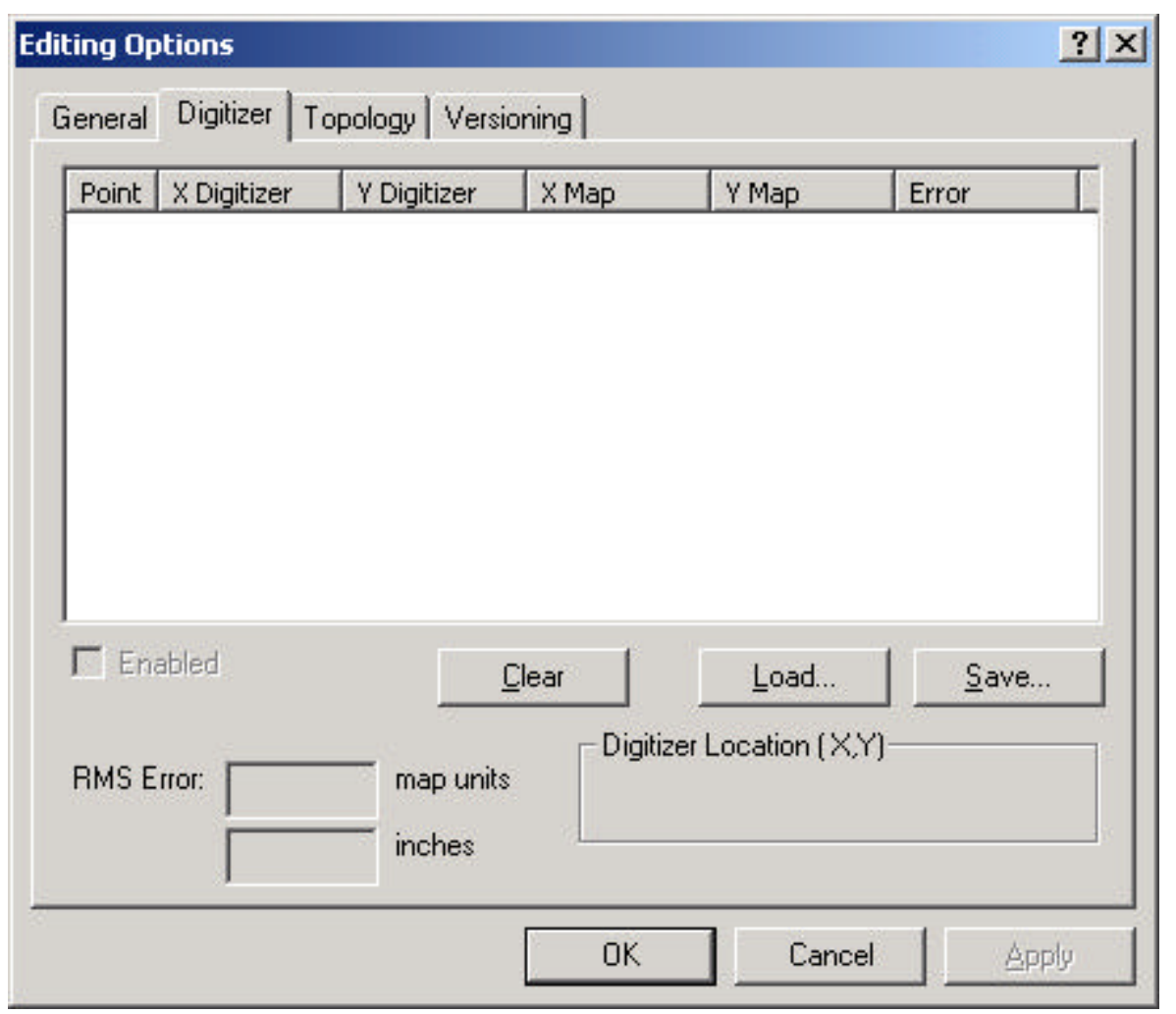

4. Click the Digitizer tab.

5. Coordinate the Digitizer tablet to the geographic coordinates

A. If there is no existing Tic file, then type the actual ground coordinates for each control point in the X Map and Y Map fields.

B. If there is an existing Tic file, then Click Load if there is an existing Tic File

I. Navigate to the file you want to use.

II. Click Open. [The ground coordinates appear under the X Map and Y Map fields.]

6. Click the first record and digitize the first control point with the digitizer puck.

7. Digitize each of the remaining control points.

[The digitized coordinates appear in the X Digitizer and Y Digitizer columns. An error is displayed for each control point, and an RMS error is displayed in map units and in digitizer inches.]

8. Click OK to register the map.

\section{Digitizing features in stream mode}

1. Click the Editor menu and click Start Editing.

2. Click the Editor menu and click Options.

3. Click the General tab. 


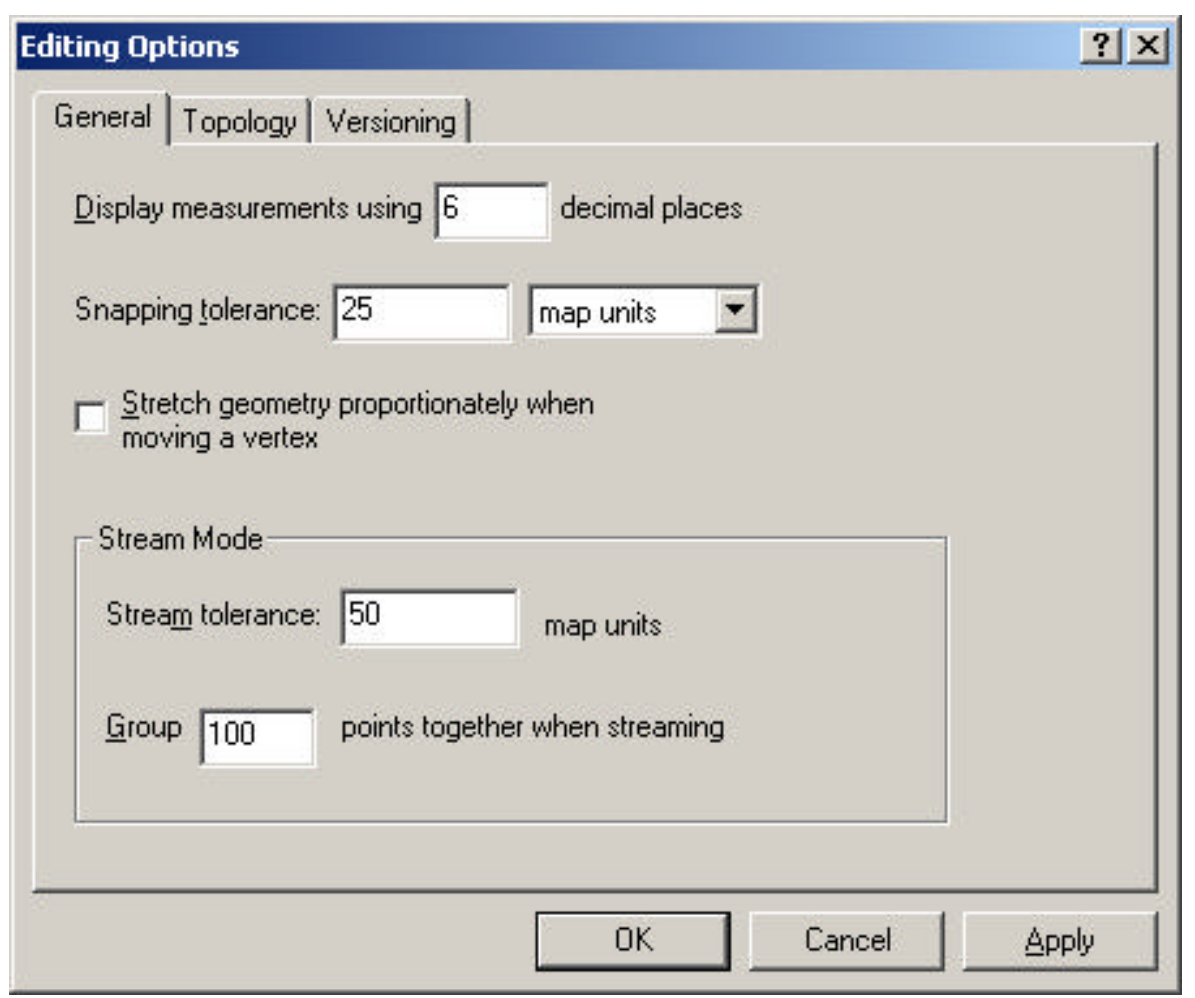

4. Type the stream tolerance (in map units) in the Stream tolerance text box. Click OK. [50 units suggested]

5. Type the number of vertices you want to group together. Click OK. [100 suggested]

Now when you click the Undo button while digitizing in stream mode, the number of vertices you specify will be deleted.

6. Click the Digitizer tab. 


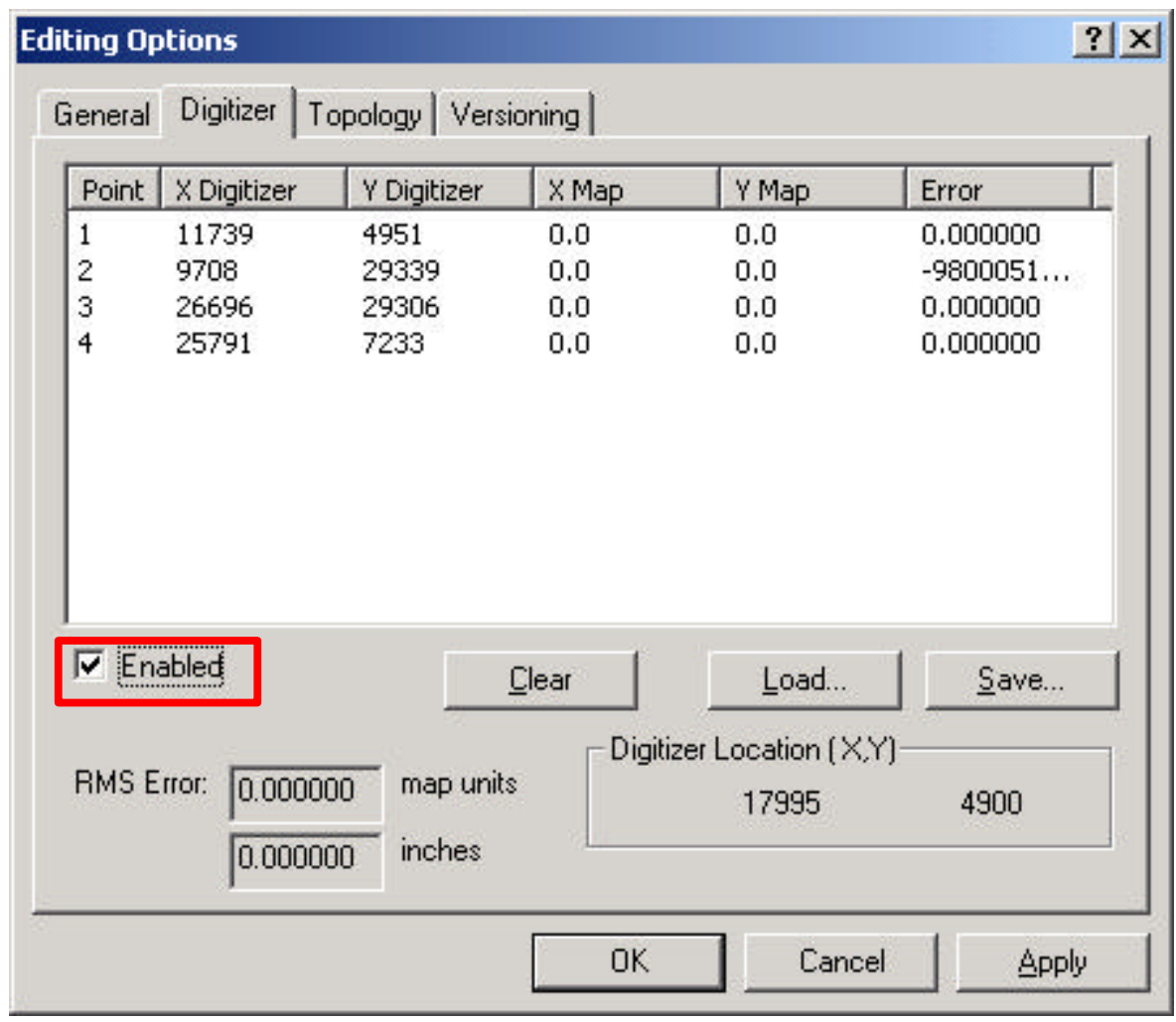

7. Check Enabled to use the puck in digitizing mode.

8. Click OK.

9. Click the tool palette dropdown arrow and click the Sketch tool.

10. Point or Stream mode for Digitizing

1. If digitizing in Point mode (clicking one point at a time), with the digitizer puck, digitize the line or polygon feature by pressing the 0 key.

2. With the mouse pointer, right-click anywhere on the map and click "Streaming".

11. With the digitizer puck, digitize the first vertex of the line or polygon feature (press the puck button you configured to perform a left mouse click).

12. Trace the puck over the feature on the paper map.

NOTE: ArcMap creates vertices at the stream tolerance you specified.

13. Finish the feature by pressing the puck button you configured to perform a left double-click.

14. The feature is created. 


\section{Tips}

- To digitize features in a precise location on an existing layer, you can use the snapping environment.

- When you're in the process of digitizing a feature in stream mode and want to interact with the ArcMap interface using your mousefor example, to change the stream tolerance or undo an action-you must first switch back to point mode by pressing F8. After you have finished interacting with the interface, you can resume streaming by pressing F8 again.

\section{How to use the snapping environment}

\section{Setting the snapping tolerance}

1. Click the Editor menu and click Options.

2. Click the General tab.

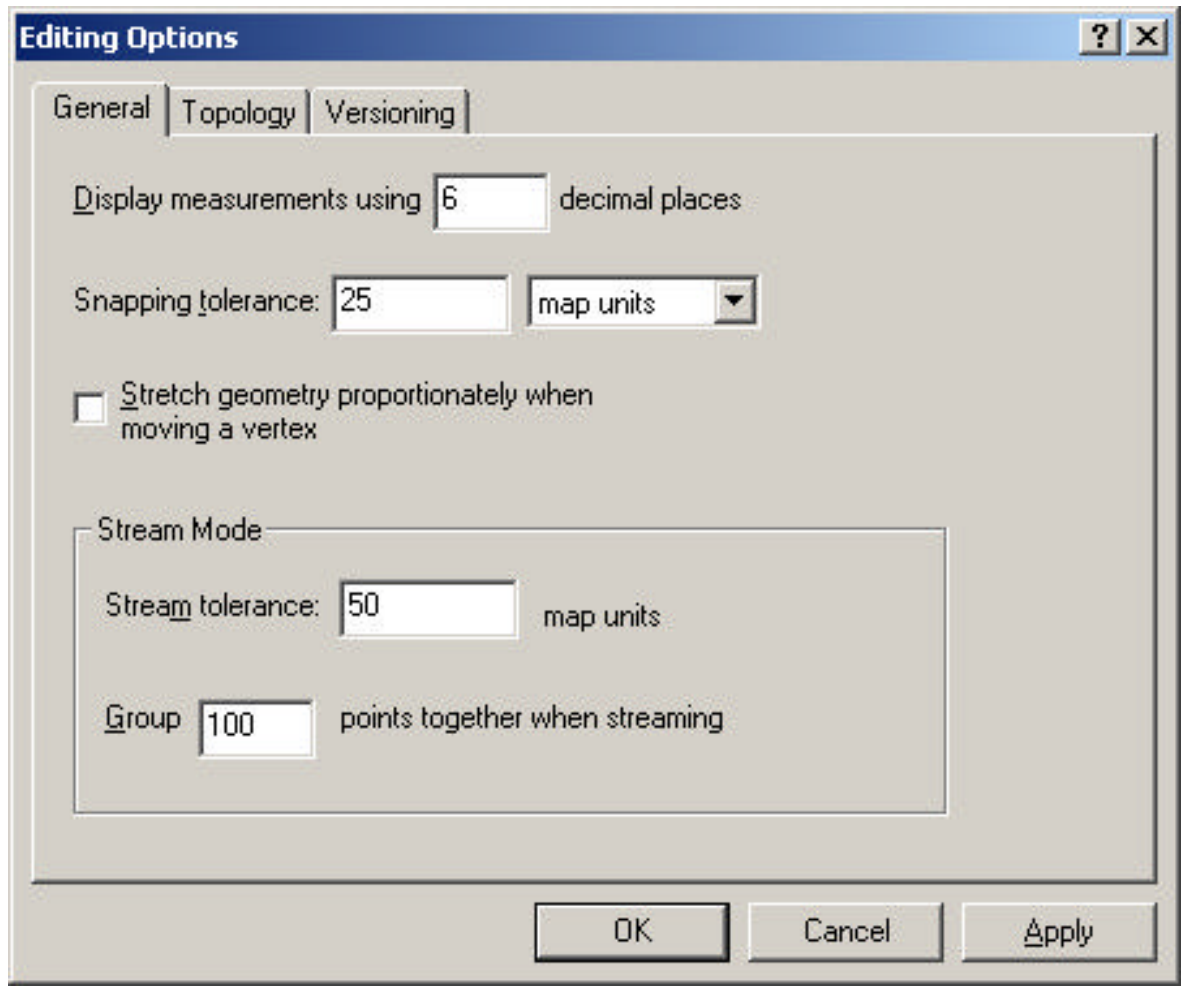

3. Click the Snapping tolerance dropdown arrow and click the type of measurement unit you want to use for snapping tolerance-pixels or map units. 
4. Type the desired number of measurement units in the Snapping tolerance text box.

5. Click OK.

\section{Setting the snapping properties}

1. Click the Editor menu and click Snapping.

The Snapping Environment window appears.

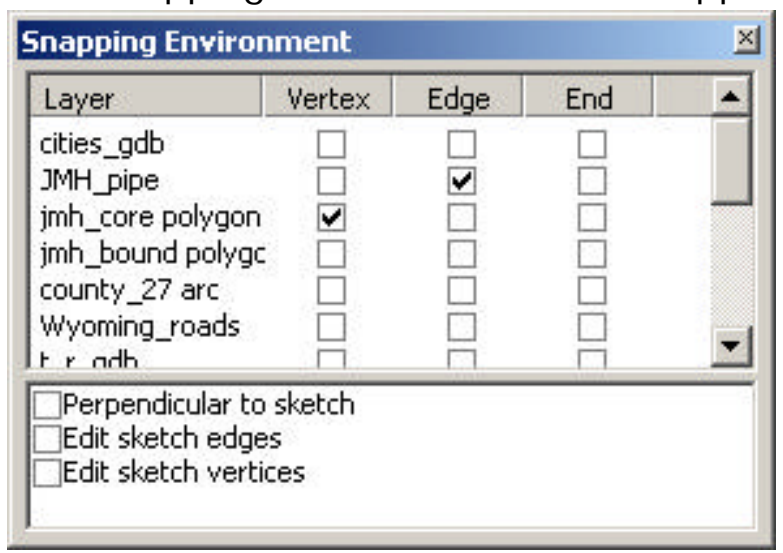

2. Check the snapping properties you want.

The snapping properties are effective as soon as they are checked or unchecked

\section{Setting the snapping priority}

1. Click the Editor menu and click Snapping.

2. The Snapping Environment window appears.

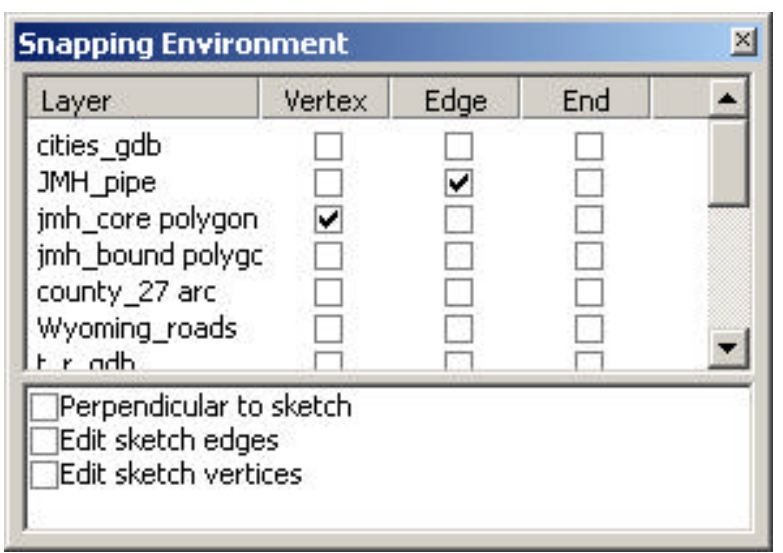

3. Click and drag the layer names to arrange them in the order in which you want snapping to occur. (The first layer in the list will be snapped to first.)

4. The snapping priorities you set are effective immediately. 


\section{Relating the attributes in one table to another}

1. In the table of contents, right-click the layer you want to relate, point to Joins and Relates, and click Relate.

2. Click the dropdown arrow and click the field in the layer the relate will be based on.

3. Click the dropdown arrow and click the table or layer to relate to or load the table from disk.

4. Click the dropdown arrow and click the field in the related table to base the relate on.

5. Type a name for the relate. You'll use this name to access the related data.

6. Click OK.

The relate is now established between the two tables. You can now access records using the relate (see below).

Tip

* If a feature class in a geodatabase participates in a relationship class, that relationship

class will be immediately available for use. You don't need to relate the tables in ArcMap.

\section{₹ Accessing related records}

1. Open the attribute table for which you've set up a relate.

2. Select the records in the table for which you want to display related records.

3. Click Options, point to Related Tables, and click the name of the relate you want to access. The related table displays with the related records selected.

\section{Tips}

Once you define a relate, you can access the related records from either table participating in the relationship.

You must set up a relationship before you can access related records. See 'Relating the attributes in one table to another' (above). 
If your map contains layers from a geodatabase that participate in relationship classes, those relationship classes will be listed automatically along with any relates you define.

\section{₹ Removing a related table}

1. In the table of contents, right-click the layer containing a relate you want to remove and point to Joins and Relates.

2. Point to Remove Relate(s) and click the relate you want to remove.

₹ Managing related table

1. In the table of contents, right-click a layer or table and click Properties.

2. Click the Joins and Relates tab.

All the relates for the layer or table are listed on the right side of the dialog. You can add new relates or remove existing ones.

Relates. The table can only be related to in one direction. For example, you can add a relate on a shapefile to an OLE DB table, but you can't add a relate or an OLE DB table to a shapefile. However, you will not be able to propagate a selection from the shapefile to the table. Instead, you can use the identify tool to access the related data.

\section{Reporting Problems}

Please report problems with this application to the Wyoming Cultural Records Office, attention Mary Hopkins (hopkins@uwyo.edu; 307 766-5324). 



\section{APPENDIX B}

FIELD PROTOCOL HANDBOOK AND GUIDE TO AN ARCHAEOLOGICAL BURIAL MODEL: POWDER RIVER AND TONGUE RIVER HYDROLOGICAL BASINS, WYOMING

William Eckerle, Judson Finley, Sasha Taddie, and Rebecca Hanna 



\begin{abstract}
This document is a protocol handbook and guide for users of Archaeological Burial Model: Powder River And Tongue River Hydrological Basins, Wyoming (see Chapter 4). Four categories of users are envisioned for this model: (1) land managing agencies; (2) oil and gas industry organizations seeking development permits on public land; (3) cultural resource management (CRM) consultants; and (4) field archaeologists. The model uses geomorphic and soils data in a geographic information system (GIS) to assess the sensitivity (probability of finding buried cultural resources) of specific localities within the study area in order to facilitate effective implementation of Section 106 compliance and the effective management of archaeological sites. Buried prehistoric sites often have great potential for listing on the National Register of Historic Places (NRHP) and are often considered (in the sense of management and development) to be at risk in Section 106 compliance. Importantly, buried sites consume a disproportionate amount of effort, time, and cost to manage under the Section 106 Process. In the following manual, we outline the logic and principles behind the model and suggest how different users might implement the model outcomes given individual, project-specific needs.
\end{abstract}


B-3 


\section{INTRODUCTION}

A model having the ability to predict the location of sediments of a suitable age and depositional type to bury and preserve archaeological sites can help to effectively manage archaeological resources. Such a model has value both to cultural resource management and proponents of oil and gas development on public land. Geographic Information System (GIS) tools facilitate the model. Since the archaeological record is a landscape-scale phenomenon, any practical predictive model must be designed at this scale and GIS is an effective tool to build, visualize, and analyze the model. Where potential buried cultural resources might be found is based not only on whether or not people lived and worked on the land, but also whether or not the soils have the characteristics that would have enabled a record of their habitation to be preserved intact and buried. Thus, an appropriate model of potential locations where archaeological sites might be buried has its foundations in geological (i.e., geomorphic and soils) data.

This project is designed for specific use in the hydrological Powder River Basin and Tongue River Basin in northeastern Wyoming, an area sometimes referred to as the western Powder River Basin (WPRB). Much of the archaeology identified and evaluated in this area during cultural resource investigations is prehistoric in nature. Cultural resource managers must determine if a prehistoric site should be listed in the National Register of Historic Places (NRHP). Such sites are often designated because they "... have yielded, or may be likely to yield, information important in prehistory or history" (Criterion D, 36 CFR 60.4). Many sites that exhibit significance under Criterion D owe their value to the fact that they became buried and thus preserved in a secure stratigraphic context that maintains inferred behavioral integrity and preserves perishable remains. While such sites are essential to advancing our understanding of ancient lifeways, land developers and agency managers consider such sites as high risk sites, because they are difficult to manage, costly to mitigate, and may add months to completion of the Section 106 process. Thus a model predicting the sensitivity (or potential risk of specific localities within a proposed project area to contain significant, buried archaeological sites) is an effective tool for use by developers, agencies, CRM consultants, and field archaeologists in project planning and implementation. 


\section{BUILDING A RISK-SENSITIVITY MODEL FOR THE WESTERN POWDER RIVER BASIN}

Several types of geoarchaeological models are possible. The first type uses earth science data to predict which portions of the landscape contain deposits of the right age and appropriate depositional type to bury and preserve archaeological materials (Eckerle et al. 1999; 2000). Another type of model employs biological survey data to predict the intensity of human land use on the landscape (Raven and Elston 1989; Zeanah 1996). Still another type of landscape modeling uses biological survey information in conjunction with climatic modeling to predict changes in human use of the landscape over time (Eckerle et al. 2003; Eckerle and Taddie 2002). Finally, several types of modeling can be combined (Drews et al. 2004; Eckerle et al. 2000). The modeling used in this report uses earth science data and is designed to predict appropriate geological settings that might contain buried and intact sites. This type of modeling is particularly applicable to the management of cultural resources because intensity of landscape use is generally of less interest than the potential to destroy a widely recognized category of important sites.

The risk-sensitivity models developed for the study area are based on the assumption that most buried prehistoric archaeological sites are found in geological deposits less than 14,000 years old. Archaeological deposits that accumulated within moderate-to-low-energy depositional environments are likely buried deeply enough to have escaped the effects of long-term surface and near-surface disturbance processes, maintaining stratigraphic and behavioral integrity. The models divide the landscape into archaeological site burial sensitivity categories ranked in a continuum from very high, high, moderate, low, to very low sensitivity (Table B-1). Sensitivity categories reflect the potential of a landscape to contain buried and relatively intact occupation strata, which exhibit both contextual and associational integrity. Sensitivity categories also predict the preservation potential of sites to yield perishable archaeological residues (primarily bone and charcoal). 


\section{THE PROJECT STUDY AREA}

The study area (Figure B-1) is both a hydrologic and structural basin. In hydrologic terms, it is part of the greater Yellowstone River Basin (Zelt et al. 1999). Major streams draining the area include the Powder River and Tongue River. Numerous tributaries add to the network of drainages in the study area. Structurally, the Powder River Basin formed during the Laramide Orogeny (ca. 60 million years ago) as a function of the downward displacement of rock layers associated with upthrusting of the nearby Bighorn Mountains, Black Hills, Casper Arch, and Miles City Arch. Thick Tertiary-age basin-fill rocks are targets of economic development but play a lesser role in the human prehistory of the region. In general, the study area has a cold, continental climate with January and July extremes and relatively low average annual precipitation (approximately $35 \mathrm{~cm}$ [14 in] in the basin but increasing with elevation in the nearby mountain ranges). The area has a long and significant human history spanning the last 11,000 years (Frison 1991). Into Historic times the Powder River country was important to Indian peoples, remaining unceded Indian Territory well into the 1870 s, and the source of much conflict between indigenous populations and colonizing Americans.

Stream systems were an important resource to both prehistoric and historic populations. While the recycling of alluvium over time can have a cumulative, detrimental effect on valley bottom sites (Albanese 1978), flood plain alluvium and adjacent low-angle toe slopes can bury and preserve sites. Thus, valley bottoms continue to be important today, because they may contain buried preserved sites, and because traditional archaeological surface survey may fail to make necessary discoveries. Because they have substantial potential to contain significant, buried archaeological deposits, all valley bottoms are considered to have very high sensitivity within the guidelines of this project. 


\begin{tabular}{|c|c|c|c|c|c|c|c|c|}
\hline $\begin{array}{l}\text { Sensitivity } \\
\text { Ranking }\end{array}$ & Landforms & $\begin{array}{l}\text { Soil } \\
\text { Parent } \\
\text { Material }\end{array}$ & $\begin{array}{l}\text { Engulfing/ } \\
\text { Overlying } \\
\text { Soil Age }\end{array}$ & $\begin{array}{l}\text { Depth to } \\
\text { Bedrock } \\
(\max 1.5 \mathrm{~m})\end{array}$ & $\begin{array}{l}\text { Minimu } \\
\text { Slope }\end{array}$ & $\begin{array}{l}\text { Average } \\
\text { Slope }\end{array}$ & $\begin{array}{l}\% \text { Clasts } \\
=7.6 \mathrm{~cm}\end{array}$ & $\begin{array}{l}\% \text { Clasts } \\
=2 \mathrm{~mm}\end{array}$ \\
\hline Very High & $\begin{array}{l}\text { Low-Gradient Stream Valleys } \\
\text { Floodplains, Terraces, } \\
\text { Sand Dunes }\end{array}$ & $\begin{array}{l}\text { Alluvium } \\
\text { Eolian }\end{array}$ & - & - & - & - & - & - \\
\hline High & $\begin{array}{c}\text { Moderate-Gradient Stream Valleys } \\
\text { Alluvial Fans }\end{array}$ & $\begin{array}{l}\text { Alluvium } \\
\text { Eolian } \\
\text { Slope Wash }\end{array}$ & $\begin{array}{l}\text { Holocene Age } \\
\text { Soils }\end{array}$ & $1-1.5 \mathrm{~m}$ & $0-10 \%$ & $\mathrm{n} / \mathrm{a}$ & $0-2.9 \%$ & $0-14 \%$ \\
\hline Moderate & $\begin{array}{l}\text { All Moderate areas fail to completely meet } \\
\text { can't really be given value ranges that wou }\end{array}$ & $\begin{array}{l}\text { the criteria for } \\
\text { ld produce the }\end{array}$ & $\begin{array}{l}\text { other sensitivity cl } \\
\text { selected areas wi }\end{array}$ & $\begin{array}{l}\text { lasses. They may } \\
\text { vithin ArcView. }\end{array}$ & neet one or & nany criteria, b & but not all. Thi & is category \\
\hline Low & $\begin{array}{c}\text { Non-Soil-Bearing Landforms } \\
\text { (Badlands, Cirques, Bedrock, etc.) } \\
\text { Steep-Gradient Stream Valleys } \\
\text { Uplands, Interfluves }\end{array}$ & $\begin{array}{l}\text { Colluvium } \\
\text { Residuum } \\
\text { Channel }\end{array}$ & $\begin{array}{l}\text { Questionable } \\
\text { Holocene Age } \\
\text { Soils }\end{array}$ & $64-90 \mathrm{~cm}$ & $\mathrm{n} / \mathrm{a}$ & $15-19.9 \%$ & $3-6.9 \%$ & $30-39.9 \%$ \\
\hline Very Low & $\begin{array}{c}\text { Non-Soil-Bearing Landforms } \\
\text { Very Steep-Gradient Stream Valleys } \\
\text { Uplands, Interfluves }\end{array}$ & $\begin{array}{l}\text { Colluvium } \\
\text { Residuum } \\
\text { Channel }\end{array}$ & $\begin{array}{l}\text { Very Unlikely } \\
\text { Holocene Age } \\
\text { Soils }\end{array}$ & $0-63.5 \mathrm{~cm}$ & n/a & $20-100 \%$ & $7-100 \%$ & $40-100 \%$ \\
\hline
\end{tabular}

Table B-1. Summary Characteristics for Sensitivity Classes 


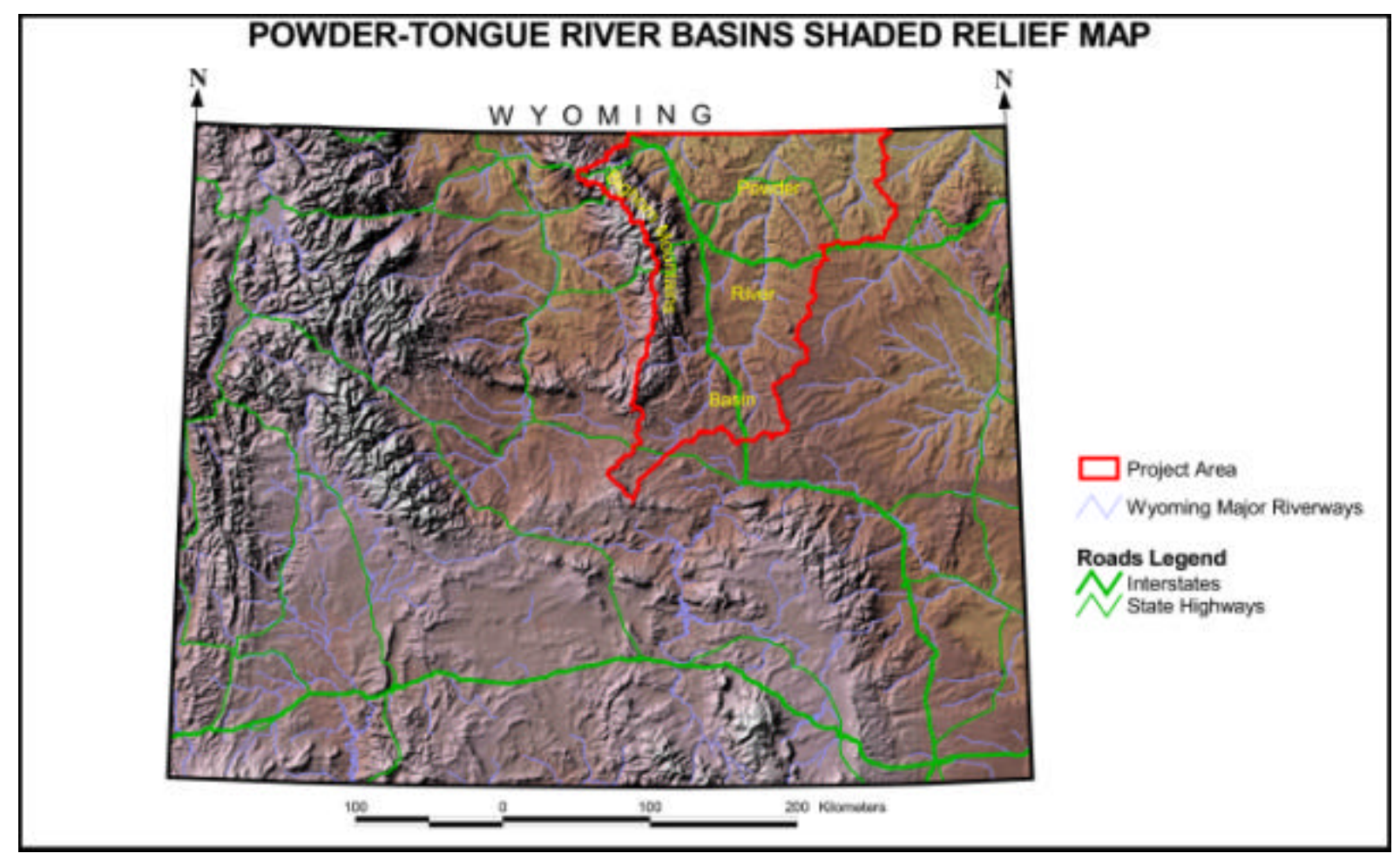

Figure B-1. Map of Wyoming illustrating the project area location in the Powder River and Tongue River Basins in northeastern Wyoming

The risk-sensitivity models are based on geomorphic and geoarchaeological investigations (Albanese 1990; Leopold and Miller 1954) that have investigated the historical development of the Powder River landscape, particularly in relation to river and tributary valleys. These studies are summarized below followed by the logic incorporated in the model design to create buffers around streams as very high sensitivity areas within the risk-sensitivity model.

\section{THE MODEL DATA}

Geological landform and soils data are used in a GIS to create multiple, overlaying map images that illustrate burial sensitivity categories for specific localities within the study area. Digital data used in the GIS are available in multiple forms: geological data are from the Wyoming Surficial Geology Map (Case et al. 1998); soils data are available at the state level from the Natural Resource Conservation Service (NRCS) State Soil Geographic (STATSGO; 1:250,000) database (Soil Conservation Service 1994); soils data are also available at the 
county level from the USDA NRCS Soil Survey Geographic (SSURGO; 1:24,000) database. Since SSURGO data was not available for the entire Wyoming study area during the time period the models were created, models were created at two scales: 1:250,000 scale (COARSE) for the entire study area and a 1:24,000 scale (FINE) in areas were SSURGO data was available. NRCS map data also provide information important for understand ing the potential age of specific land surfaces and the depth to which archaeology-bearing deposits may be found. These data have significant implications within a risk-sensitivity model, and subsequent sections discuss the logic in using soils data. Finally, this manual concludes with a discussion of how the model output specific to the study area can be applied within a variety of decision-making arenas.

The Powder River Basin Alluvial Sequence. Leopold and Miller (1954) recognized strong patterning in the geomorphic relationships of Late Quaternary (Late Pleistocene and Holocene) river valleys in the Powder River Basin (Figure B-2). They defined three innervalley terraces (from lowest to highest): 1) Lightning (1.2-2.1 m [4-7 ft]), 2) Moorcroft (2.4$3.7 \mathrm{~m}$ [8-12 ft]), and 3) Kaycee (6-15.2 m [20-50 ft]). Leopold and Miller also proposed that a predictable set of sediments, designated as geologic formations, underlies these terraces. Deposits associated with the youngest Lightning terrace (the Lightning Formation) are composed of fine-textured overbank alluvium. The Kaycee Formation is composed of mixed slope wash and alluvium underlying the Moorcroft terrace and also forming the uppermost bed of the Kaycee terrace. The Ucross Formation, an early Holocene pebbly gravel, underlies the Kaycee formation within the Kaycee terrace. Finally, the Arvada Formation, the oldest Late Quaternary deposit, is weathered, cobbly gravel containing extinct late Pleistocene fauna. Arvada sediments fill deeply cut channels on the valley floors and overlay a bedrock strath under the Kaycee terrace. Thus these terraces provide a way to estimate the age of surfaces and sediments along drainages throughout much of the Powder River Basin.

Leopold and Miller's (1954) model guided several decades of subsequent work by fluvial geomorphologists; however, their proposed chronology and the climatic processes they invoked to explain the depositional and erosional cycles oversimplified an otherwise complex geological environment. Albanese (1990) demonstrated that terraces are not always underlain 
by sediments of the age Leopold and Miller proposed, local depositional/erosional processes produced unique terrace sequences, and the number of terraces may vary according to stream order. Regardless, Leopold and Miller's alluvial model applies to the risk-sensitivity model in two ways: 1) a textural difference exists between potential archaeological bearing deposits (latest Pleistocene and Holocene) and older, Glacial/Post Glacial (18,000-14,000 BP) deposits; and 2) non- gravelly, post-14,000 BP valley fill, which was deposited in moderate depositional regimes, is present in most valleys. Thus, at a minimum, most river valleys in the project area should have very high or high risk-sensitivity in the GIS model.

Site Formation and Post-Depositional Processes. An important aspect of archaeological research, and criterion determining NRHP significance, deals with the degree of preservation, or integrity, that individual sites possess. In an ideal situation, archaeological sites are preserved in a 'Pompeii-like' setting, representing a snapshot of time frozen for eternity. Such situations are rare, and archaeologists have become intimately familiar with many factors that alter archaeological deposits. These are referred to generally as site formation or post-depositional processes (Schiffer 1987; Wood and Johnson 1978). Among these factors are trampling by both humans and animals; dispersal due to wind, water, or gravity; frostheaving; rodent and insect burrowing; and plant growth (including tree throw) resulting from soil formation. Alluvial settings are ideal for archaeological preservation because the rates of sediment deposition are often rapid enough to preserve sites without the impact of significant post-depositional processes. Sites exposed for millennia on bedrock surfaces or those with shallow soils likely have relatively poor preservation.

Factors Affecting Site Discovery in Plan View Versus Profile. The archaeological record, as a landscape phenomenon, has both horizontal and vertical components. Human occupation leaves artifacts and features in horizontal distributions across the landscape. With time, these artifacts become buried adding a vertical component to the archaeological record.

Archaeological survey is designed to discover horizontal distributions; thus, buried sites often remain undiscovered until earth- moving activities occur during development. Alluvial settings are ideal for the formation and preservation of vertical deposits; but as Albanese 


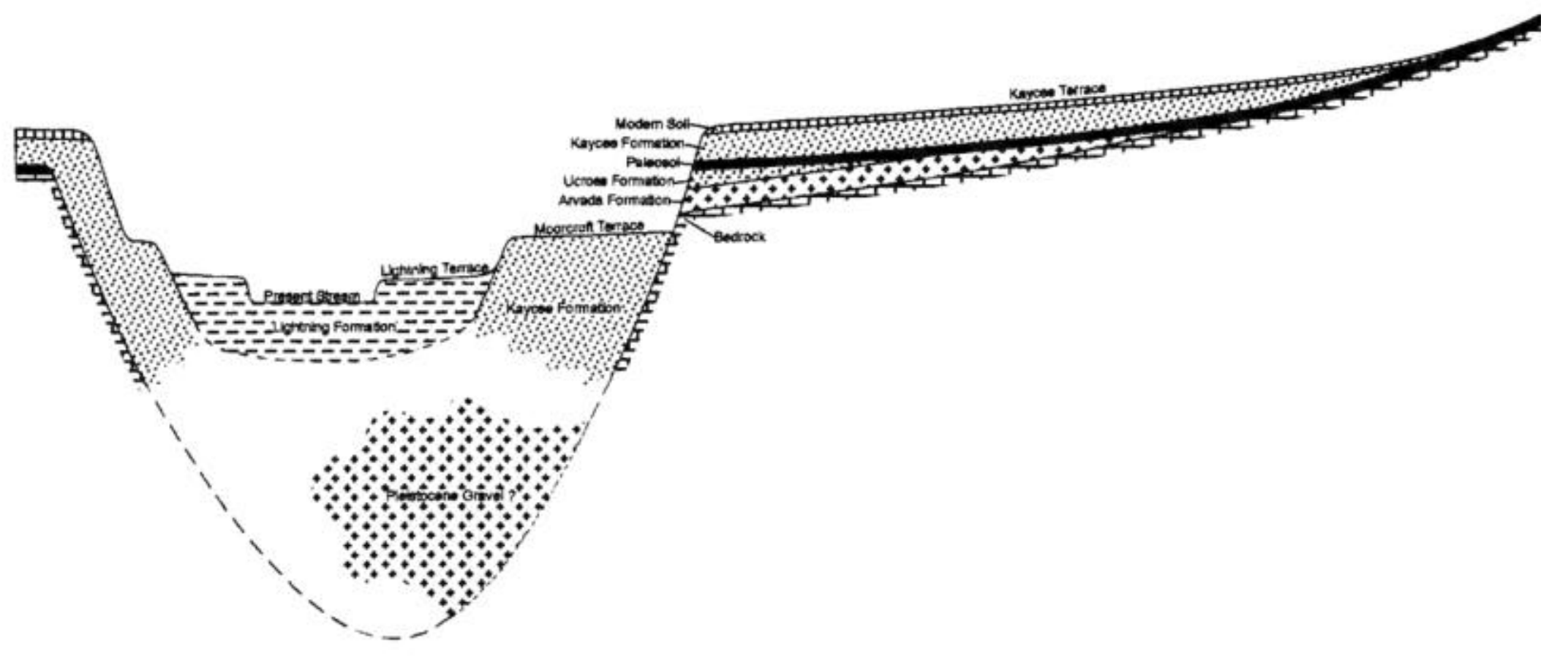

Figure B -2. Schematic cross section of typical Powder River and Tongue River basins stream valley illustrating relationships between Late Quaternary alluvial deposits and landforms (Leopold and Miller 1954) 
(1978) noted, few sites in the Powder River Basin have been discovered in such contexts. He accounted for this by the fact that streams destroy many sites over time. However, site discovery is difficult in alluvial settings compared with uplands. It is more difficult to locate eroded cultural material at the base of a cutbank than on flat or rolling landscapes. Erosion in non-alluvial settings leaves artifacts behind as a horizontal lag deposit, whereas artifacts that erode out of arroyo walls are flushed downstream during subsequent flood events, thus failing to accumulate to any significant surface density below the cutbank. A site exposed in crosssection rather than plan view logically makes fewer artifacts visible for discovery, further reducing the probability that buried sites will be discovered during survey.

\section{Role of Buried Stone Features in Subsurface Site Identification}

Stone features (stone circles, stone cairns, thermally altered rock features) are common feature types in the study area. Given that chipped stone artifact scatters are so difficult to locate in cutbanks it is important that field archaeologists be alert for possible stone features when inventorying cutbanks or monitoring pipeline trenches. Rocks transported, moved, or arranged at archaeological sites but otherwise unmodified are termed manuports. As defined here, manuports are rocks between $10 \mathrm{~cm}$ diameter and the upper limits of the size of a rock that an average adult human can carry $(30 \mathrm{~cm})$. These can be part of a site's 'furniture' or part of a feature. Manuports are not modified and thus not artifacts (and are not individually protected under law; but note that two or more manuports that compose a cultural feature [stone circle, cairn] are protected). There is no justification for recording single, isolated rocks as cultural items. But field archaeologists need to consider that the presence of manuports might be an indication that other, smaller cultural items might be associated with them; therefore, more care and attentiveness should be exercised when rocks the size of manuports are encountered.

For the purposes here, a manuport is defined as a rock that is at least 1000 times the size of the average sediment matrix size, but within the transport capabilities of a person. For instance, if the average sediment size is pebbly (10 $\mathrm{mm}$ diameter) then using the formula described above yields a clast $10 \mathrm{~mm}$ X $1000=10,000 \mathrm{~mm}(1000 \mathrm{~cm}$ or $10 \mathrm{~m})$. Obviously, a 
rock this size is too massive for a single person to transport and thus does not fit into our definition of a manuport. But if the sediment matrix is sand $(0.1 \mathrm{~mm})$ then a suspected manuport is a rock that is $>100 \mathrm{~mm}$ or $>10 \mathrm{~cm}$ in diameter, easily within the capability of a person to transport. For sediments smaller than sand, a potentially smaller manuport (siltsized matrix $=0.01 \mathrm{~mm}=1 \mathrm{~cm}$ suspected manuport; clay-sized matrix $=0.001 \mathrm{~mm}=1 \mathrm{~mm}$ suspected manuport) might be accounted for by biotransport by animals other than humans, or by other mechanisms. Thus, the $10 \mathrm{~cm}$ cutoff is the minimum recommended for identifying suspected manuports in silt and clay-sized sediment matrices. Although there are some natural terrestrial deposits and soils that might have the extremely poor sorting necessary to exhibit sediment ranges that might include particles 1000 times their average matrix size, by and large these (landslide, debris flows, ice-rafted sediments; frost-excluded-clast-soils) are much less common than more typical size graded deposits.

Creating a Stream Buffer. Alluvial settings have the potential to preserve significant, intact, archaeological deposits that may escape discovery during traditional archaeological survey. Within the risk-sensitivity model for the study area all alluvial settings (i.e., valley bottoms) in basin and montane settings are ranked as 'very high' sensitivity. These valley bottoms are defined using the stream course and then the valley-sensitivity-zone is defined by using the buffering capability of the GIS.

Widths for stream buffers are constructed using both a vertical and horizontal component. The Leopold and Miller alluvial model provides the basis for the vertical component, calculated in the model as elevation above stream shoreline, and is determined by the maximum upper elevation at which fine-textured alluvium is found, or where toeslope that merges with the highest fine textured terrace thins laterally onto the backslope. An increase in the estimated elevation provides for a margin of error in these approximations; however, the maximum elevations were field checked as part of the project. The horizontal component was constructed with 1:24,000 scale maps by fixing a horizontal line, perpendicular to the trend of the valley, from sample locations where contour intervals crossed streams to the estimated elevation above shoreline. This method provided a sample of half-valley widths, which were calculated for different stream orders. The half-valley-width calculations often 
overlap with local topography that may include steep valley walls or bedrock slopes that should not be included into the 'very high' sensitivity category. Areas possessing slopes greater than 10 percent were removed from the very high sensitivity class.

A slightly different technique was used for montane settings of the study area (i.e., the crest and eastern slope of the Bighorn Mountains). There, stream buffers were calculated in four categories according to stream gradient: very low gradient $(<2.5$ percent), low gradient $(2.5-5$ percent), moderate gradient (5-10 percent), and high gradient (10-100 percent). As in the basin configuration, elevation above shoreline was calculated for a sample of streams producing an average half-valley width approximation to calculate stream buffers.

For this project we created four different models based on stream buffers: management stream valley buffers (FINE M and COARSE M) and analytical stream valley buffers (FINE A and COARSE A). The analytical stream buffer is a refinement of the management stream buffer based on excluding areas of steep slopes within a stream buffered area, thus its high sensitivity areas tend to be narrower than those in the management model. The analytical model is more precise than the management model. The management model is more conservative (because the high sensitivity areas are larger), and so it is used in the management tools created by this project. It is important to understand that each model (analytical and management) has an appropriate use. The analytical model is best used to evaluate the validity of the model itself, e.g., to compare results of fieldwork with predictions. The management model is best used as a planning tool, e.g., to determine where one is least likely to encounter buried archaeological material.

Soil Map Units. Time, temperature, topography, parent material, and biota all interact to form soils. As many soil characteristics require sufficiently long periods of time to develop, time is one of the key factors of soil formation. Soil taxonomic terms are less than user friendly, but a few key concepts can ease the pain of the uninitiated. This study is concerned with soils that formed primarily during the Holocene, which fall mostly within the orders of Entisols, Aridisols, and Mollisols. Consider these as recent or young soils, desert soils, and grassland soils respectively. One might encounter bewildering names at the family or great 
group level such as Fluvent, Calciorthid, or Haploboroll. The first syllable of the order name typically forms the final syllable of the family or great group name. Other syllables denote temperature and/or moisture regimes or other criteria that give a soil its distinct characteristics. For this model, soil taxonomy was used to estimate the age of the underlying deposits using the following: 1) Entisols (Orthents and Fluvents) <1,000 BP; Camborthids (weak Aridisols) 1,000-10,000 BP; Argids and Calciorthids (clay-rich and $\mathrm{CaCO}_{3}$ indurated Aridisols) 10,000-100,000 BP; and Paleargids and Paleorthids (ancient Aridisols) >100,000 BP.

Soil studies provide a robust data set crucial to the risk-sensitivity model. Key variables encoded as part of soil surveys include landform type, parent material or deposit type, depth to bedrock, percent slope, percent gravel, and percent cobbles. As already noted, most alluvial landforms (valley bottoms, floodplains, and terraces) are prime settings for archaeological preservation. Alluvial fans, footslopes, and dunes also have excellent preservation potential. Deposit types are closely related to landforms and include alluvium, low angle alluvial fans and colluvial slopes, and eolian dunes or sandsheet deposits. These are typically deep deposits with high burial potential. Shallow deposit types with little or no preservation potential include residuum, regolith, channel gravels, or talus. The remaining variables all relate to the energy of the sedimentary depositional environment. Areas with steep slopes are subject to high-energy movements (typically a function of gravity or mass wasting) with poor burial or preservation potential. Relative percentages of gravel (clasts 2 $\mathrm{mm})$ are an indication of either energy regime or proximity of bedrock— high gravel percentages equate to high-energy alluvial settings or shallow depth to bedrock. Relative percentages of cobbles $(>55 \mathrm{~mm}$ ) provide similar information.

\section{SUMMARY OF THE RISK SENSITIVITY MODEL}

The risk-sensitivity models use a variety of data sources that are manipulated to create layers in a GIS. The foundation is a historical model based on the fluvial geomorphology of the study area. Fine-grained alluvium deposited in low-energy environments has significant potential to preserve buried archaeological sites; hence, all valley bottoms are given a very 
high sensitivity classification and buffered through a set protocol. Soils data, available at two spatial scales, provide a suite of information that aids in projecting the model predictions to non-alluvial environments. Variables fundamental to soil classification are relevant to archaeological site burial and preservation. In the GIS, these data are output at the two spatial scales to provide set criteria for specified sensitivity areas, which ultimately act as a land development and management tool. Model output and management recommendations are discussed below.

\section{THE MODEL OUTPUT}

The two sensitivity maps illustrate the distribution of sensitivity zones within the study area: FINE, at 1:24,000 (Figure B-3), and COARSE at 1:250,000 (Figure B-4).

County-level soils data (SSURGO) were not available for the entire study area making projections at 1:24k scale impossible across the entire study area; STATSGO data (1:250k) supplement missing SSURGO data. Both models (FINE at 1:24k and COARSE at 1:25k) use the same criteria to define the sensitivity-area categories (Table B-1). When planning or implementing projects, we caution model users to remember that the sensitivity models only forecast where site preservation conditions might be favorable, and not locations that may have been attractive to human activity.

All trunk and tributary stream valley bottoms in the study area except for those with very high gradients are given a very high sensitivity classification. Very high sensitivity areas also include areas with extensive eolian sand deposits located in the southwestern Powder River Basin (near Powder River, Wyoming and Hell's Half Acre).

High sensitivity zones are sometimes proximal to fluvial and eolian depositional environments. These areas meet stringent criteria which indicate a setting conducive to the burial and preservation of cultural remains. These criteria include sediment accumulation depth (depth to bedrock), depositional energy regime (minimum slope, bedload transport energy [e.g., percent of $7.62 \mathrm{~mm}$ clasts and percent of clasts greater than $2 \mathrm{~mm}$ ]), and 
sediment age using likely Holocene-age surface soils as a proxy. Post-glacial age, fine textured alluvial fans fall within this category. Remnant and dissected fluvial terraces like those to the west of Kaycee are also high sensitivity areas. Some areas within the study area are similar in many respects to the very high and high sensitivity zones, except for the fact that they contain smaller areas of probable Holocene-age deposits and soils within larger areas where deposits and soils are only of questionable Holocene age. It is possible that Early Archaic and Paleoindian age occupations might be buried in or under these surface soils. Dating of the soil taxon under local soil formation conditions, however, would be necessary to demonstrate this potential. Given that smaller areas of younger soils are present, the moderate sensitivity zone still presents a management concern for the protection of archaeological resources. Professional on-site, project-specific geoarchaeological evaluations might help identify the smaller and more sensitive portions of this zone. Low sensitivity areas are characterized by landscapes having thin sediment/soil mantle or high energy (violent) depositional regimes. Comparing surface geology maps with the model maps will help users recognize these types of sediments and soils in the field. In some basin areas upland, interfluvial landforms are characterized by surface or near-surface bedrock. All areas where clinker and/or residuum occur near the surface are classified as low sensitivity. In the Bighorn Mountain uplands, low sensitivity areas are landforms with exposed bedrock, glaciated bedrock, grus (decomposed granite bedrock), or landslide deposits. Generally, low sensitivity areas have a thin sediment mantle, steep slope, and coarse-grained texture. Most surface soils are of questionable Holocene-age, although small areas of probable Holoceneage soils are included. The potential for preserving occupation integrity, perishable materials, and stratigraphic separation of occupations is lower in comparison to the moderate sensitivity zone. 


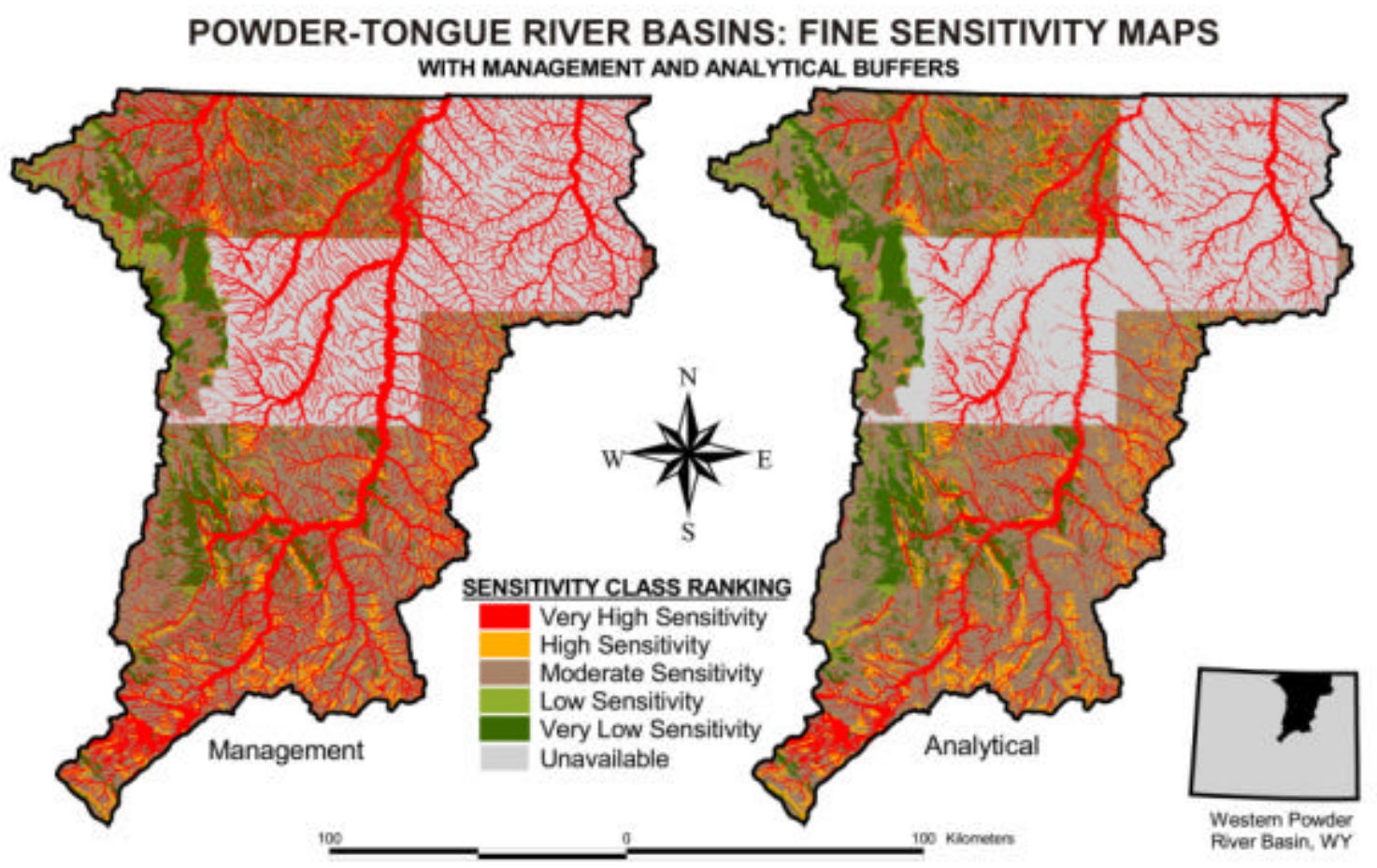

Figure B-3. FINE sensitivity map based on SSURGO (1:24,000 base soil mapping) and stream buffers 


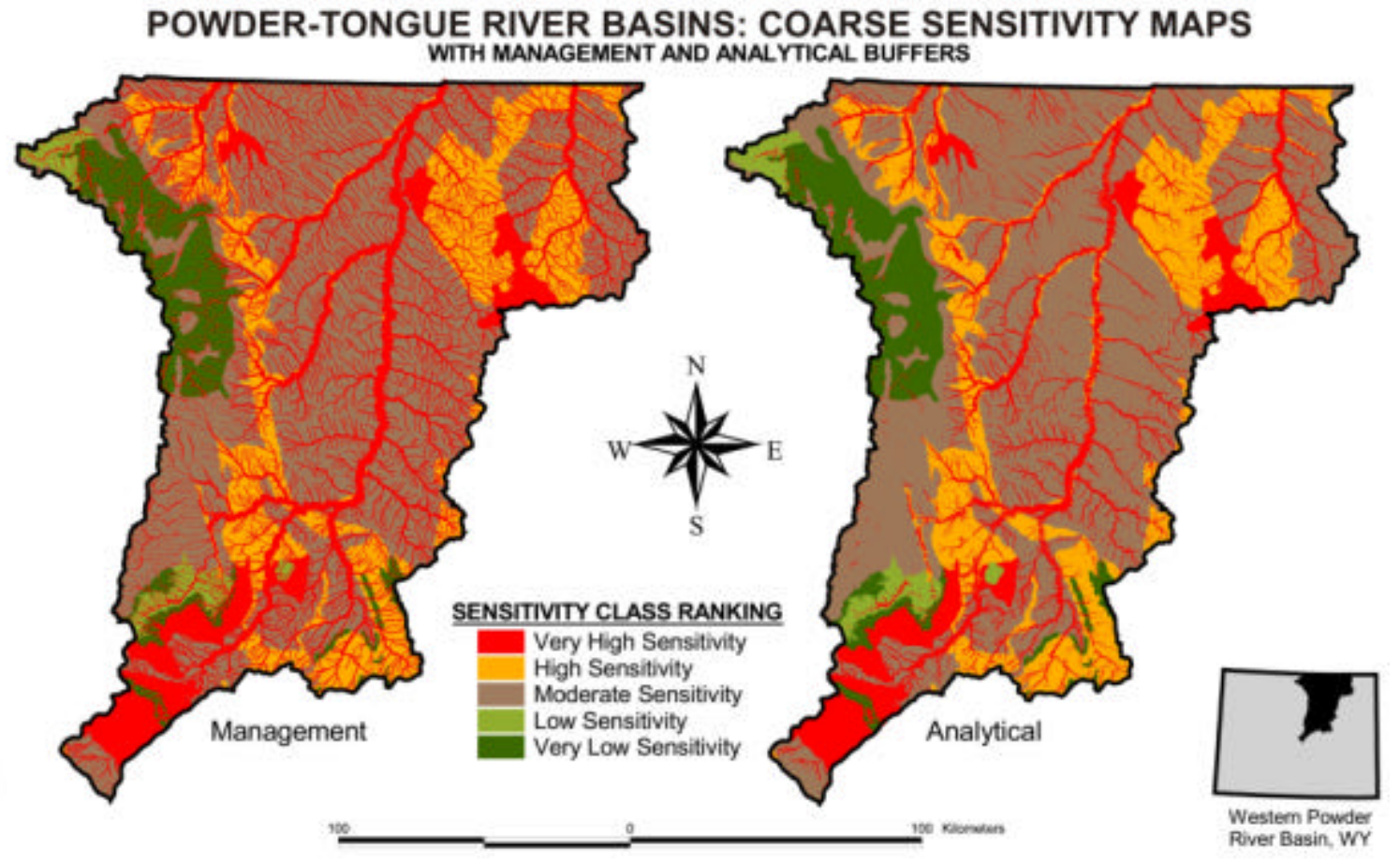

Figure B-4. COARSE sensitivity map based on STATSGO (1:250,000 base soil mapping) and stream buffers 
Like the low sensitivity category, the key defining variable of the very low sensitivity category is sediment/soil depth. Very low sensitivity areas also have a similar distribution in the study area and are often adjacent to low sensitivity zones. Areas that contain a combination of attributes rendering them unlikely to contain intact, well-preserved, and stratigraphically separable occupations include a soil type thought to be too old to hold buried cultural material, very shallow depth to bedrock, steep slopes, and/or gravel comprising a relatively large proportion of the soil component. Generally speaking, most of the low and very low sensitivity zones are situated on upland, interfluvial landforms in the basin interior and steep slopes in montane areas.

\section{SITE DATA FROM THE WYOMING SHPO CULTURAL RECORDS OFFICE}

Site data from the Wyoming State Historic Preservation Office, Cultural Records Office (WYCRO) were used to evaluate the model. This process is more fully described in Chapter 4 of this volume. The frequency of sites that contain buried components generally corresponds to sensitivity zones, with the higher sensitivity zones containing more buried components (Figure B-5.). Sites that have produced radiocarbon dates are another measure of the presence of relatively intact cultural material. The distribution of sites with radiocarbon dates also corresponds to the sensitivity zones (Figure B-6.). High and very high zones contain the majority of the radiocarbon-dated sites. 


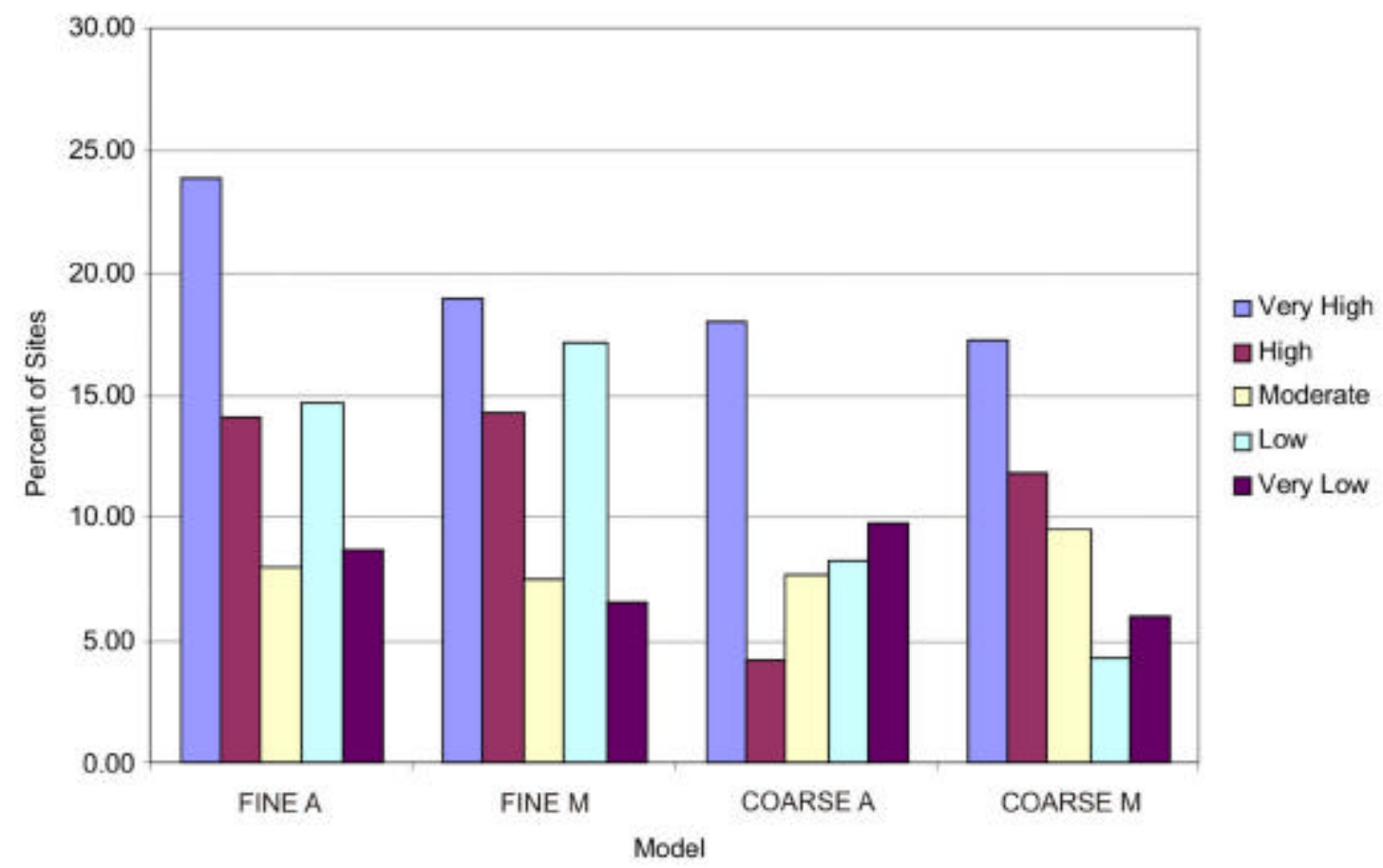

Figure B-5. Percent of sites with reported buried components by sensitivity class for each model

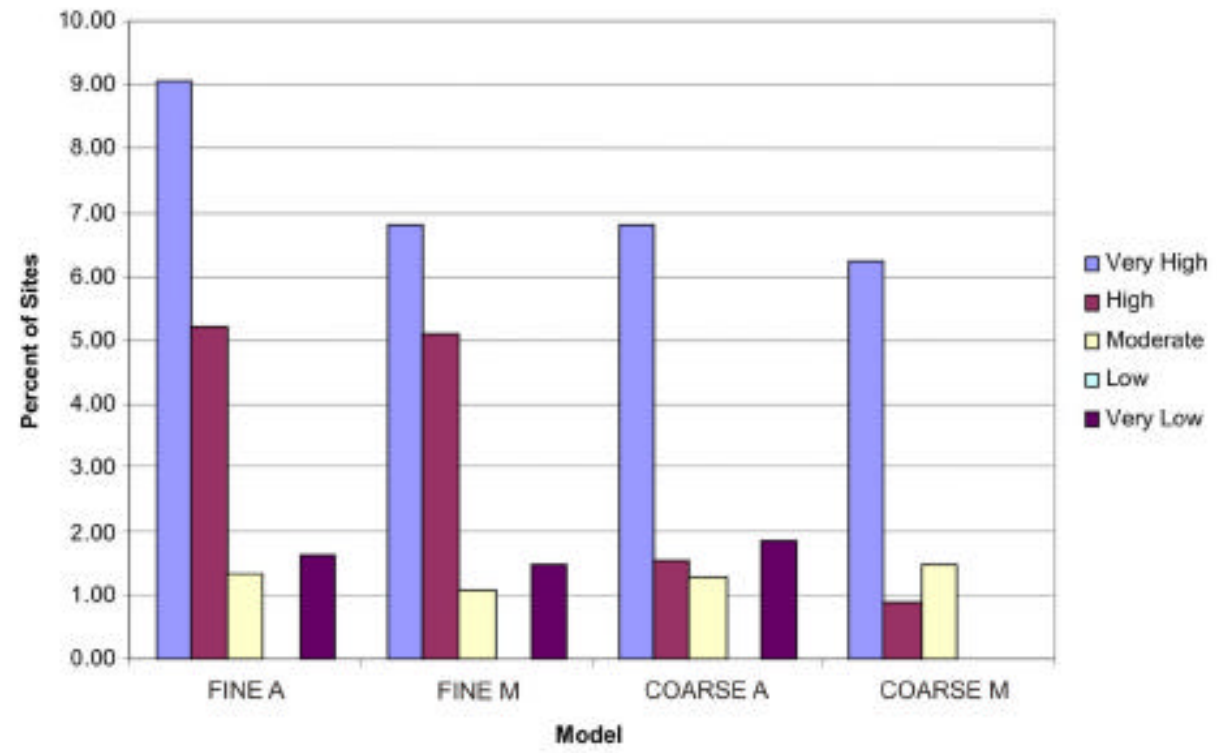

Figure B-6. Percent of sites with radiocarbon dates by sensitivity class for each model 


\section{APPLYING THE RISK-SENSITIVITY MODEL}

Ultimately, we have envisioned the model data serving as the basis for guiding individual, project-specific management decisions. Given this, the models need to be used at an appropriate scale. All stream buffers are based on 1:100,000 hydrography. An attempt has been made to make the stream buffers useful at a scale of 1:24,000 but no warranty is made. The COARSE model should be used at a scale no larger than 1:250,000. The FINE model should be used at a scale no larger than 1:24,000. From a project standpoint, the models are most useful for forecasting risk in planned fields, as opposed to individual well pads. We anticipate that the models will be very useful for assessing the risks of pipeline construction and believe that the model output can be useful for predicting where open trench inspection is warranted. Adequate open trench inspection will require a project-specific plan and perhaps a pre-plan reconnaissance by a geoarchaeologist. An example of an "Open Trench Project Administration Documentation Form" is attached at the end of this appendix.

Within this limitation and context, land managers can use this information to anticipate areas of archaeological concern. Meanwhile, developers can use it to project the costs of development in targeted and alternative areas to anticipate compliance with Section 106. We offer the following suggestions for applying the models to the planning and implementation stages of projects.

Very High Sensitivity Zone. All model users should recognize that virtually any low to moderate gradient alluvial valley in the study area is a very high sensitivity area. Intensive archaeological inventory, subsurface testing (hand, mechanical, geophysical), and complete construction monitoring would be necessary to limit the inadvertent destruction of significant archaeological resources. Construction activities within this zone should only occur under the most controlled circumstances. Developers and consultants should plan on having archaeologists monitor all earth- moving activities. Open trench inspection of all pipeline construction is recommended.

High Sensitivity Zone. As with the very high sensitivity zone earth-disturbing construction activities within the high sensitivity zone should occur only under the most controlled 
circumstances. Intensive archaeological inventory, prospecting, and complete construction monitoring would be necessary to totally prevent the inadvertent destruction of significant archaeological resources. As with the very high sensitivity zone open trench inspections of any pipeline construction are highly recommended.

Moderate Sensitivity Zone. Some areas within the project area failed to meet the distinctive criteria that characterized the very high, high, low, and very low sensitivity classes. It seems fair to characterize the sensitivity of such areas as moderate. In the FINE model, the moderate class encompasses low and very low areas delineated in the COARSE model, especially in the basin area. While sizeable tracts of the moderate zone have a low risk, other smaller areas (especially in the COARSE model) might be more sensitive. As the NRCS makes SSURGO data available for the remaining portions of the project area, it will be possible to delineate areas of low and very low concern from the basin areas. Until that time, professional archaeologists working in areas mapped as moderate zone in the COARSE model will need to estimate slope, depth to bedrock, percent sediment $>7.62 \mathrm{~cm}$, and percent sediment $>2 \mathrm{~mm}$ to distinguish areas of higher sensitivity from those of lower sensitivity within the basin. Project-specific, geoarchaeological evaluations can help identify which portions of the moderate zone are more or less sensitive. In addition to normal Section 106 process inventory and evaluation, this zone would require construction monitoring of known archaeological resources and monitoring of construction trenches.

Low Sensitivity Zone. The possibility of preserved significant buried archaeological deposits is minimal within the low sensitivity zone. This is because the deposits are generally thin and the sediments may be too old to contain cultural remains within this zone. Within this zone, construction monitoring should be planned on a case-by-case basis following archaeological inventory and evaluation. Field archaeologists evaluating known archaeological sites for NRHP significance should consider subsurface testing to a reasonable depth based on sitespecific circumstances, but at least $90 \mathrm{~cm}$ or as depth to bedrock necessitates. Although occasional buried site components might be found in this zone, open trench inspections might be dispensed with, except in areas where the low sensitivity is intermixed with mapped areas of very high or high sensitivity at the 1:24,000 scale. 
Very Low Sensitivity Zone. Like low sensitivity zones, here little potential exists for the presence of intact, buried archaeological deposits. Development activities following inventory and evaluation procedures need to be considered on a case-by-case basis as determined by field archaeologists. Field archaeologists should consider subsurface testing to a reasonable depth based on site-specific circumstances but to at least $65 \mathrm{~cm}$ or as depth to bedrock necessitates. Younger Holocene-age soils could occur within the boundaries of the very low sensitivity zone. Thus sites with well-preserved, stratigraphically distinct occupations may be present. However, if potential archaeologically sensitive inclusions are not identified during inventory and evaluation, construction monitoring and other postinventory discovery techniques can be minimized or dispensed with without overt risk to sensitive cultural resources. Like the low sensitivity zone, open trench inspections could be dispensed. The exceptions are areas where the low sensitivity is intermixed with mapped areas of very high or high sensitivity at the 1:24,000 scale.

\section{SUMMARY AND CONCLUSIONS}

The study area is the scene of extensive oil and gas development on federal lands that must be considered within NEPA and NHPA guidelines prior to development. Consultation under Section 106 of the NHPA can become a lengthy process due to unexpected discovery and mitigation of significant archaeological resources. The sensitivity models use geomorphic, geologic, and soils data to categorically identify the risk of encountering buried archaeological sites. Very high sensitivity zones in the study area occur in all stream valleys and sand dune areas. Here, geologic processes contribute to site formation in a manner conducive to spatial integrity, one factor essential to determination of archaeological significance. Developers, managers, consultants, and field archaeologists should assume encounters with buried archaeological sites as a rule rather than an exception in these zones. High sensitivity categories are sometimes adjacent to very high zones, and warrant the same concern as the very high sensitivity category. Model users should consider a similar approach in utilizing these areas as they would in very high sensitivity zones. Moderate sensitivity areas are the most common category and cover the largest array of depositional settings and landforms. They also require the broadest management strategy. Conservative model users should prepare for extensive archaeological consultation in alluvial or near alluvial settings where probability of burial is high. Geoarchaeological fieldwork and mapping will be 
beneficial in identifying areas of higher potential within the moderate sensitivity zone and may allow strategies to shift to a less-conservative approach as conditions warrant. Low and very low categories occur where bedrock occurs at or near the surface, defined in model terms as a depth to bedrock of less than $90 \mathrm{~cm}$. Low and very low sensitivity areas occur in the study area as upland, interfluvial landforms and in montane areas where bedrock or glaciated bedrock outcrops. Although the likelihood of significant, buried archaeological sites occurring in these areas is small, model users should be prepared for occasional significant discoveries.

In conclusion, we would like to clarify that predictive models, such as the one presented here, can only serve as the basis for informed decision making. It should in no way replace the common-sense, on-the-ground, archaeological fieldwork. Yet, we know the importance of knowing what to look for and where to look goes without saying, regardless of which end of the project you are on. We see the archaeological record as both a geologic and cultural phenomenon. Thus it is a valid and useful model for predicting where sites possessing archaeological significance (or risk, if that is your perspective) are located. These are predicated by geological data. But one should be wary of model "theism," as the physicist Niels Bohr implored, for models are only analogs for the way the world operates, at best. We should be prepared to use models only when they work within given circumstances. Use other models when circumstances change, and abandon all models if and when the time comes to adopt a new one. As such, the site burial models will function best within an adaptive management paradigm. To facilitate this, the models need to be expanded and reevaluated at periodic intervals. Users of these models should seek some way of funding and implementing reevaluation of the models at appropriate intervals. Since archaeology is a cumulative discipline that builds on the knowledge base of previous work, applications of these models and new data generated from their application will result in refining them for future use. 


\section{REFERENCES CITED}

Albanese, John P.

1978 Archeogeology of the Powder River Basin, Wyoming. In Western Powder River Basin Consultant Reports Vol. III, edited by Charles Reher, pp. 9-94. Office of the Wyoming State Archeologist. Submitted to the Bureau of Land Management. Copies available from the Office of the Wyoming State Archeologist, Laramie.

Albanese, John P.

1990 Geoarchaeology of the Eastern Powder River Basin. John Albanese, Consulting Geoarchaeologist. Submitted to The Wyoming State Historic Preservation Office, Wyoming Archives Museum and His torical Department. Copies available from the Wyoming State Historic Preservation Office, Cheyenne.

Case, James C., Christopher S. Arneson, and Laura L. Hallberg

1998 Wyoming Surficial Geology. Spatial Data and Visualization Center, Laramie, Wyoming. URL:http://www.sdvc.uwyo.edu/24k/surfgeol.html

Drews, Michael, Eric Ingbar, David Zeanah, and William Eckerle

2004 A Cultural Resources Model for Pine Valley, Nevada. Submitted to the Department of Energy, Agreement DE-FC26-01BC15337. Bureau of Land Management Nevada Cultural Resource Publications Series Report No. 13. Reno.

Eckerle, William, Eric Ingbar, and Marissa Taddie

1999 Geoarchaeology of the Moxa Arch Natural Gas Lease Area: A Spatial Analysis. Report to Gnomon, Inc., Wyoming Office of Cultural Records, and the Department of Anthropology, University of Wyoming by Western GeoArch Research. Copies available from Wyoming Office of Cultural Records, Laramie.

Eckerle, William, Rebecca Hanna, and Sasha Taddie

2003 Geoarchaeological Assessment of the South Haystack Project Testing, 2002, Uinta County, Wyoming. Report to Wyoming Archaeological Services. Copies available from Western GeoArch Research, Salt Lake City.

Eckerle, William, and Sasha Taddie

2002 Modeled Paleoenvironmental and Archaeo-Resource Frames of Reference for the Southwestern Green River Basin. In Data Recovery Excavations at Site 48UT 375, Uinta County, Wyoming, Thomas P. Reust and others, 2002, pp. 171-196. Report to Pioneer Pipe Line Company by TRC Mariah Associates, Inc. Copies available from TRC Mariah Associates Inc., Laramie.

Eckerle, William, Marissa Taddie, and Eric Ingbar

2000 Landscape Archaeology. In "Seeds-Kee-Dee" Riverine Adaptation in Southwest Wyoming, edited by J. V. Pastor, K.W. Thompson, R. K. Talbot, W. P. Eckerle, and E.E. Ingbar, pp. 451-460. Brigham Young University, Museum of Peoples and Cultures, Technical Series No. 99-3. Copies available from the Office of Public Archaeology, Brigham Young University, Provo, Utah. 
Frison, George C.

1991 Prehistoric Hunters of the High Plains. Second edition. Academic Press, San Diego.

Leopold, Luna B., and John Miller

1954 A Postglacial Chronology for Some Alluvial Valleys in Wyoming. U.S. Geological Survey Water-Supply Paper 1261.

Raven, Christopher, and Robert G. Elston

1989 Prehistoric Human Geography in the Carson Desert: Part I: A Predictive Model of Land-Use in the Stillwater Wildlife Management Area. Intermountain Research. Submitted to the U.S. Fish and Wildlife Servic. Copies available from Intermountain Research, Silver City, Nevada.

Schiffer, Michael B.

1987 Formation Processes of the Archaeological Record. University of New Mexico Press, Albuquerque.

Soil Conservation Service

1994 State Soil Geographic (STATSGO) data base for Wyoming. U.S. Department of Agriculture, Soil Conservation Service, Fort Worth, Texas.

Wood, W. Raymond, and Donald L. Johnson

1978 A Survey of Disturbance Processes in Archaeological Site Formation. In Advances in Archaeological Method and Theory, vol. 1, edited by M. B. Schiffer, pp. 31581. Academic Press, New York.

Zeanah, David William

1996 Predicting Settlement Patterns and Mobility Strategies: an Optimal Foraging Analysis of Hunter-Gatherer Use of Mountain, Desert, and Wetland Habitats in the Carson Desert. Unpublished Ph.D. dissertation, Department of Anthropology, University of Utah.

Zelt, R.B, G. Broughton, K.A. Miller, J.P. Mason, and and L.M. Gianakos

1999 Environmental Setting of the Yellowstone River Basin, Montana, North Dakota, and Wyoming. United States Geological Survey Water-Resources Investigations Report 98-4269. 


\section{OPEN TRENCH PROJECT ADMINISTRATION DOCUMENTATION FORM}

\begin{tabular}{||l|l||}
\hline \hline Consultant Project No. & A gency No. \\
\hline Review/Compliance No. & WY CRO No. \\
\hline
\end{tabular}

To be completed for both negative and positive inspections. Record the deepest artifact or features at any one location defined as a point and $10 \mathrm{~m}$ on either side (up or down trench).

Open trench inspection date:

Project tracking number from CRMtracker:

Project name:

Project proponent:

Cultural resource firm and field staff:

Total length of pipeline corridor in meters:

Total length of open trench inspection in meters:

How trench inspection segments were selected. Circle one and check zones (if appropriate):

A. By Sensitivity Model

a. Sensitivity Zones Inspected (Check Boxes)
i. Very High
ii. High
iii. Moderate
iv. Low
v. Very Low

A. Judgmentally (Explain In Detailed Text)

Inspection points (expand as necessary):

\begin{tabular}{|c|c|c|c|c|c|c|c|c|c|}
\hline Zone & Datum & Northing & Easting & $\begin{array}{l}\text { Elevation } \\
\text { (m) }\end{array}$ & $\begin{array}{l}\text { Elevation in } \\
\text { Meters above } \\
\text { Adjacent } \\
\text { Stream }\end{array}$ & $\begin{array}{l}\text { Cultural } \\
\text { material } \\
\mathrm{y} / \mathrm{n}\end{array}$ & $\begin{array}{l}\text { Artifact or } \\
\text { Feature }\end{array}$ & $\begin{array}{l}\text { Depth of } \\
\text { cultural } \\
\text { material in } \\
\text { cbms* }\end{array}$ & $\begin{array}{l}\text { Depth to } \\
\text { bedrock in } \\
\text { cbms }\end{array}$ \\
\hline & & & & & & & & & \\
\hline & & & & & & & & & \\
\hline & & & & & & & & & \\
\hline & & & & & & & & & \\
\hline & & & & & & & & & \\
\hline
\end{tabular}

*cbms - centimeters below surface

Attach discussion of findings if appropriate 



\section{APPENDIX C}

FIELD OBSERVATIONS:

ESTIMATED HEIGHTS OF THE HIGHEST FINE-TEXTURED TERRACE ALONG

STUDY AREA STREAMS 

Field reconnaissance was conducted as part of this project. Fieldwork consisted of a vehicular reconnaissance focused on observing valley fill. It was possible to observe the highest, finetextured Holocene alluvial fill (Hfh) at almost all observation points. A general decrease in the height of the highest Holocene fills from high stream order and low gradient classes to low stream order and high gradient classes was observed. Height of the highest Holocene alluvial fill was visually estimated at each stop. These heights are classified into three classes: (a) $\leq 5 \mathrm{~m}$, (2) $>5$ to $\leq 8 \mathrm{~m}$, and (3)>8 to $\leq 20 \mathrm{~m}$. The classified observations are plotted in Figure D 1 that illustrates stream order and gradient class. As can be seen, the relationship between stream order and terrace height is strong, although not invariant. The highest Holocene terrace fills are generally located along stream orders $4-6$, moderately high fills generally on stream orders $2-3$, and the lowest fills on the lowest stream orders. These observations were used to help refine terrace heights presented in the regional literature and used to help guide the estimation of the highest Holocene valley fill for the stream buffering in this report. 


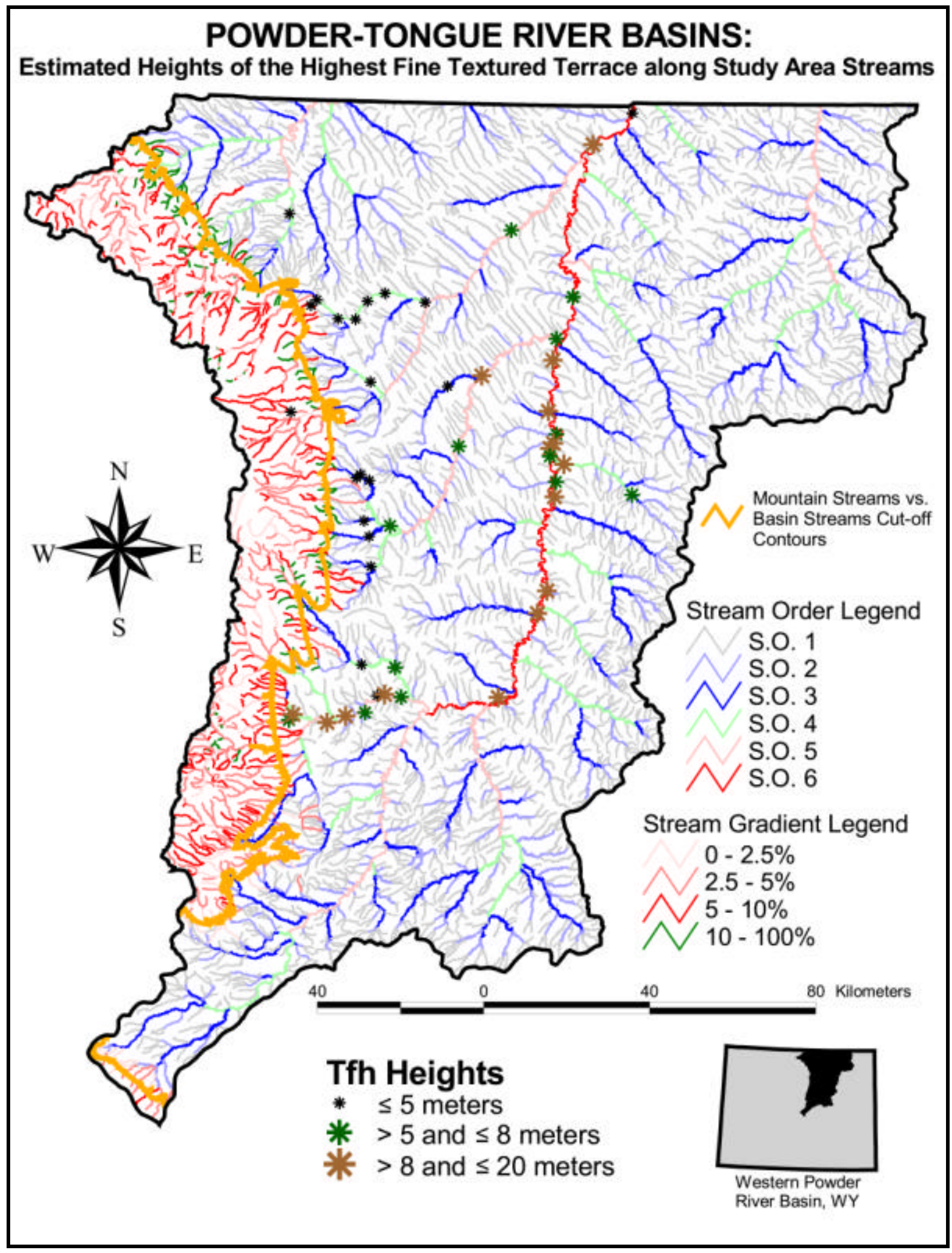

Figure C-1. Estimated heights of the highest fine-textured terrace along study area streams 


\section{APPENDIX D}

\section{CRISP USER MANUAL}





\section{CRISP User Documentation}

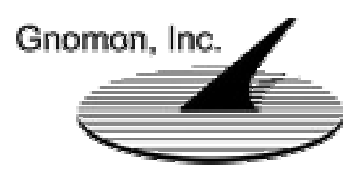

Department of Energy Cooperative Agreement DE-FC26-02NT15445

\section{INTRODUCTION}

The Cultural Research Information Summary Program (CRISP) is an information tool for non-archaeological experts. It is useful for rapid assessment of potential project areas (PPA's). A PPA could be a contemplated well pad and road, a borrow pit, or any other action. Using CRISP, one draws a PPA onto a map image and then runs a report on the PPA. CRISP is a web-based application, and uses cultural resource inventory layers, cultural resource summary layers, and cultural resource forecasts (models) to provide the user with a summary of knowledge about their PPA.

CRISP is a planning tool for land-users and managers. It does not replace consultation with appropriate agencies, landowners, land managers, and other participants in the cultural resource management process. Although CRISP summarizes the results of scientific investigations, it also does not replace discussions with cultural resource managers or other experts. What CRISP does provide is a way to gain a quick overview of what might be present on or in the ground, and information about what is already known. CRISP's greatest utility is as a project planning tool. It is not a compliance tool

CRISP development was supported, in part, by the Department of Energy Cooperative Agreement DE-FC26-02NT15445. Other supporters included the Wyoming State Historic Preservation Office, the Bureau of Land Management, and Gnomon, Inc. CRISP was developed by Gnomon, Inc. of Carson City, Nevada

\section{GENERAL CONCEPTS FOR ON-LINE MAP USE}

Some general information about on-line map servers may be useful for the first time user. On-line map systems ("web-based GIS"), present the application user with map images. The images are usually made up of map "layers". Sheets of acetate are good analogs for map layers. Like acetate sheets, the map layers are laid on top of each other to form the image. A layer placed out of order - for instance, putting a quadrangle map image on the top of all the other layers - can obscure other information.

Layers can be turned off or on to change whether they are displayed. This allows the map display to be changed. Some map layers are not relevant at particular display scales. The application controls these scale-dependent map layers by turning them off or on as appropriate. Visible layers (shown at the current image scale) can be queried. A special form of visible layer is the active map layer. The active map layer is a single layer selected by the application user as a target layer for further inquiry. CRISP provides two tools that query information from map layers. One operates on the active map layer and the other on all map layers. 


\section{CRISP User Documentation}

On-line map systems are typically less robust than full desktop applications. Nevertheless CRISP provides a wide variety of functions. These functions include spatial identify (identification by "clicking" on a map feature), spatial intersection (assessing the composition of one or more map layers that lie within a particular geographic feature set), simple digitization (creating spatial entities), reporting that summarizes geographic features and their attributes (associated information), and maps.

\section{SYSTEM REQUIREMENTS}

CRISP has relatively few system requirements:

- A computer connected to the internet

○ Because of the map images, higher speed connections will be much more effective than low speed (less than 56kbps) connections.

- The Microsoft Internet Explorer web browser, version 5 or higher

○ Other browsers may work but they have not been tested

- Your browser must allow cookies from the web site.

- Your browser must allow popups from the web site.

- Adobe Acrobat, or some other software that will read Adobe Acrobat format (PDF) files generated as report output. This software is optional.

○ www.adobe.com contains links to the most current versions of Adobe Acrobat reader

\section{ERROR REPORTING AND QUESTIONS}

Errors, problems, questions, and feature requests can be sent to the following email address: crisp@gnomon.com. If you are reporting a problem or error, please be as specific as possible:

- Which page of the application were you using when the error occurred

- What were you doing, or attempting to do, when the error occurred?

- Is the error consistent or intermittent? In other words, if you try the same operation again, do you get the same error?

\section{OBTAINING A USER LOGIN}

To obtain a user login and password, please send an email to crisp@ gnomon.com. A user questionnaire will be returned to you. Please complete the user agreement. Please complete the form and return it following the instructions on the form.

\section{USING THIS GUIDE}

This user guide is organized in two further sections: a tutorial, which a new user should go through step by step, and a CRISP interface reference guide, which discusses all of the application's elements, options, and tools. We recommend that one go through the tutorial first, and then read the CRISP interface reference guide, experimenting with each of the features described in that section. 


\section{CRISP User Documentation}

\section{USING CRISP - AN INTRODUCTION AND TUTORIAL}

To begin browse to: http://crisp.gnomon.net This is the current Uniform Resource

Locator (URL) for the application.

\section{LOG IN TO CRISP}

The first page you will be shown is the CRISP Login Page, shown below.

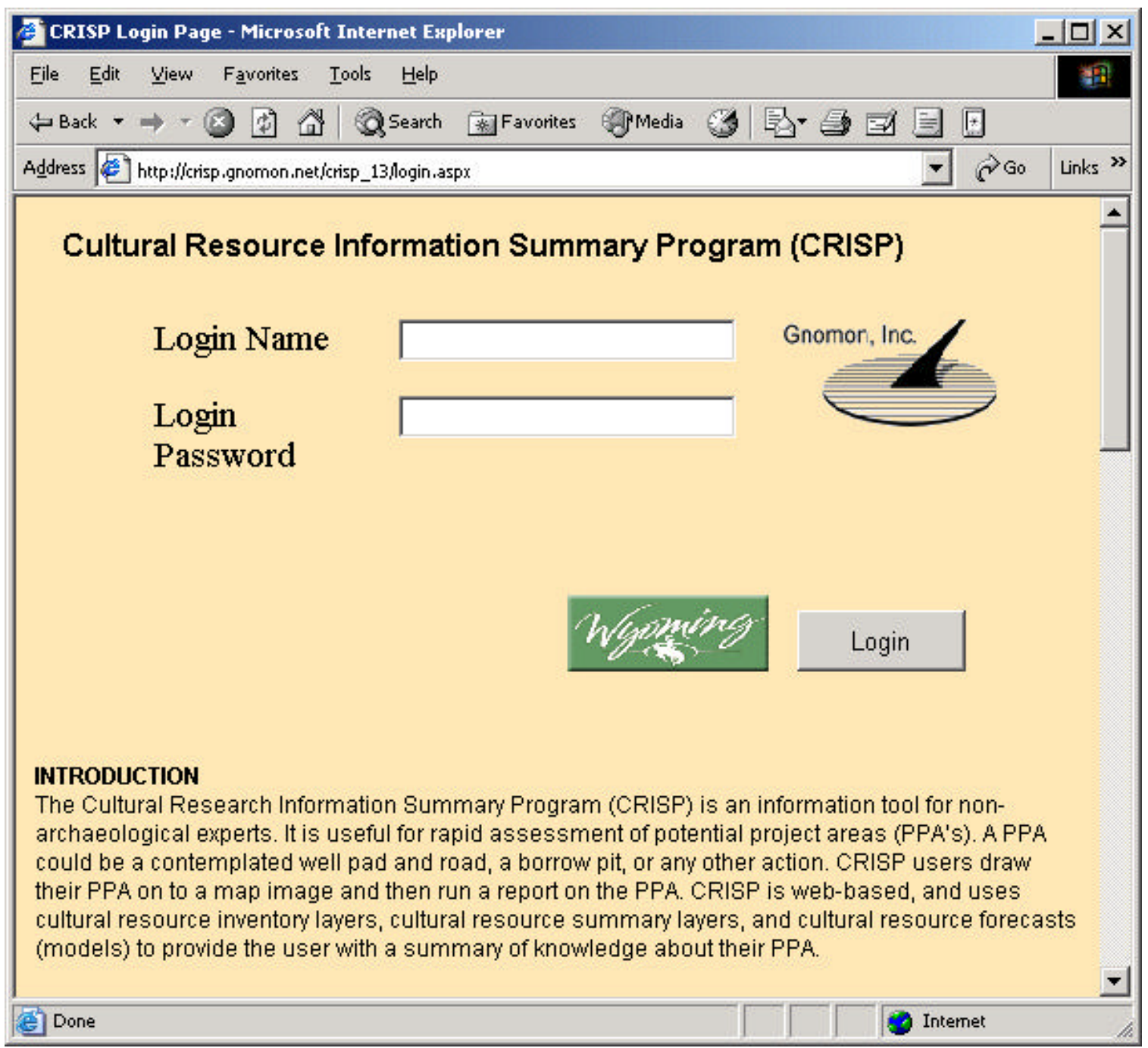

Enter your login name and password and press the "Login" button.

\section{SELECT UTM ZONE}

Because Wyoming base maps (paper and electronic) lie in two different map projection zones (Universal Transverse Mercator, or UTM, Zones), the CRISP application must first know which UTM zone one wishes to utilize. With the exception of the base maps, the 


\section{CRISP User Documentation}

data are the same for both UTM zones. All of the map images (and thus the map service itself) are in the North American Datum of 1927 (NAD 1927) coordinate basis.

The first choice a user must make is where in the state their project lies. The UTM zone selection web page, shown below prompts you to select either the appropriate zone by clicking on it. Please note that while the Wind River Reservation lies within Zone 12, no data are provided for this area.

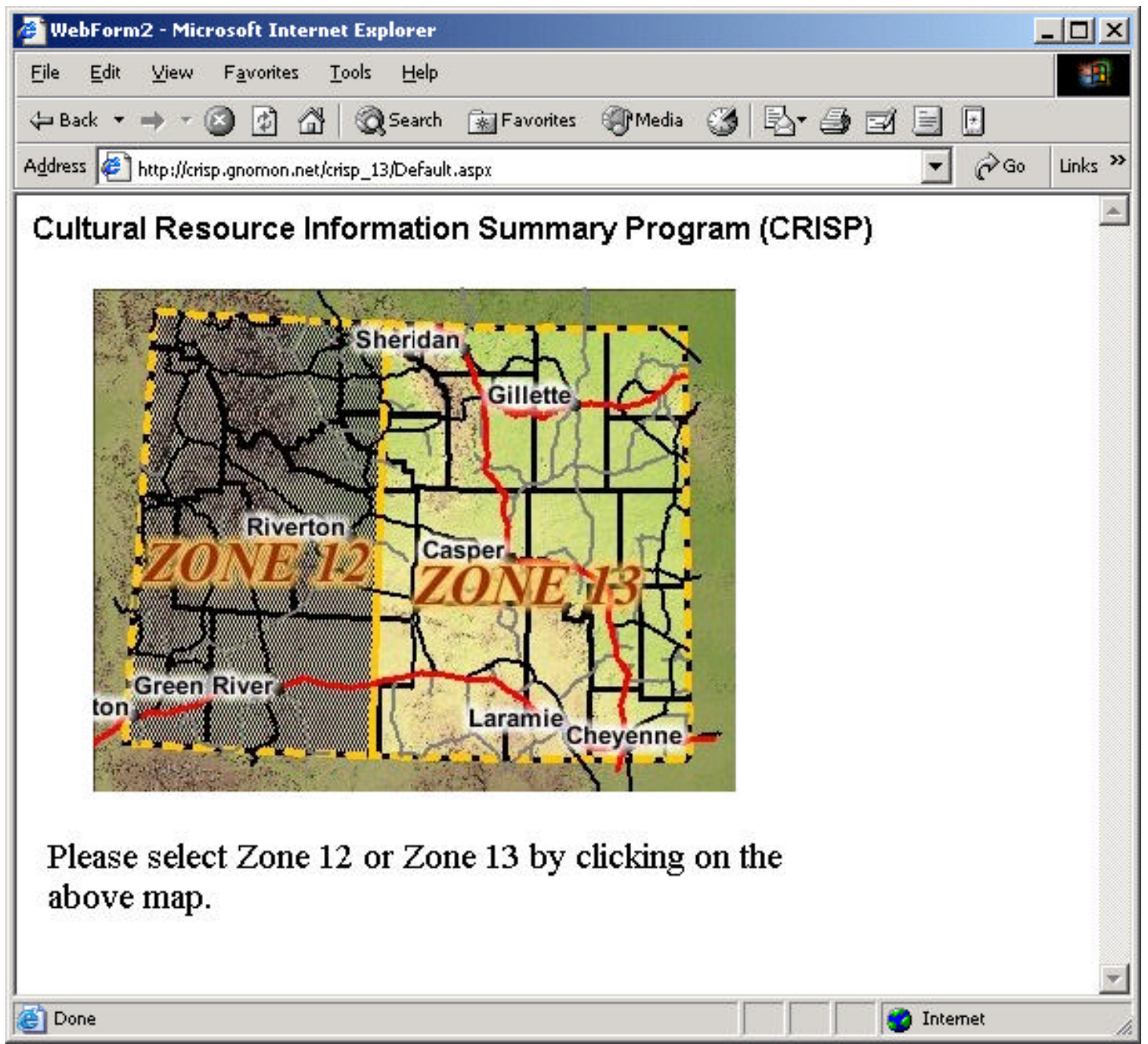

\section{THE MAIN MAP PAGE}

Once your login is successful you will see the Main Map Page. Almost all operations are conducted on the main map page, so it is important to understand the different areas of this page. The main map page contains five major regions:

- The map region

- The map toolbar region 


\section{CRISP User Documentation}

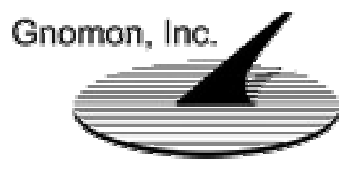

- The application status region

- The tab region

- The tab function region

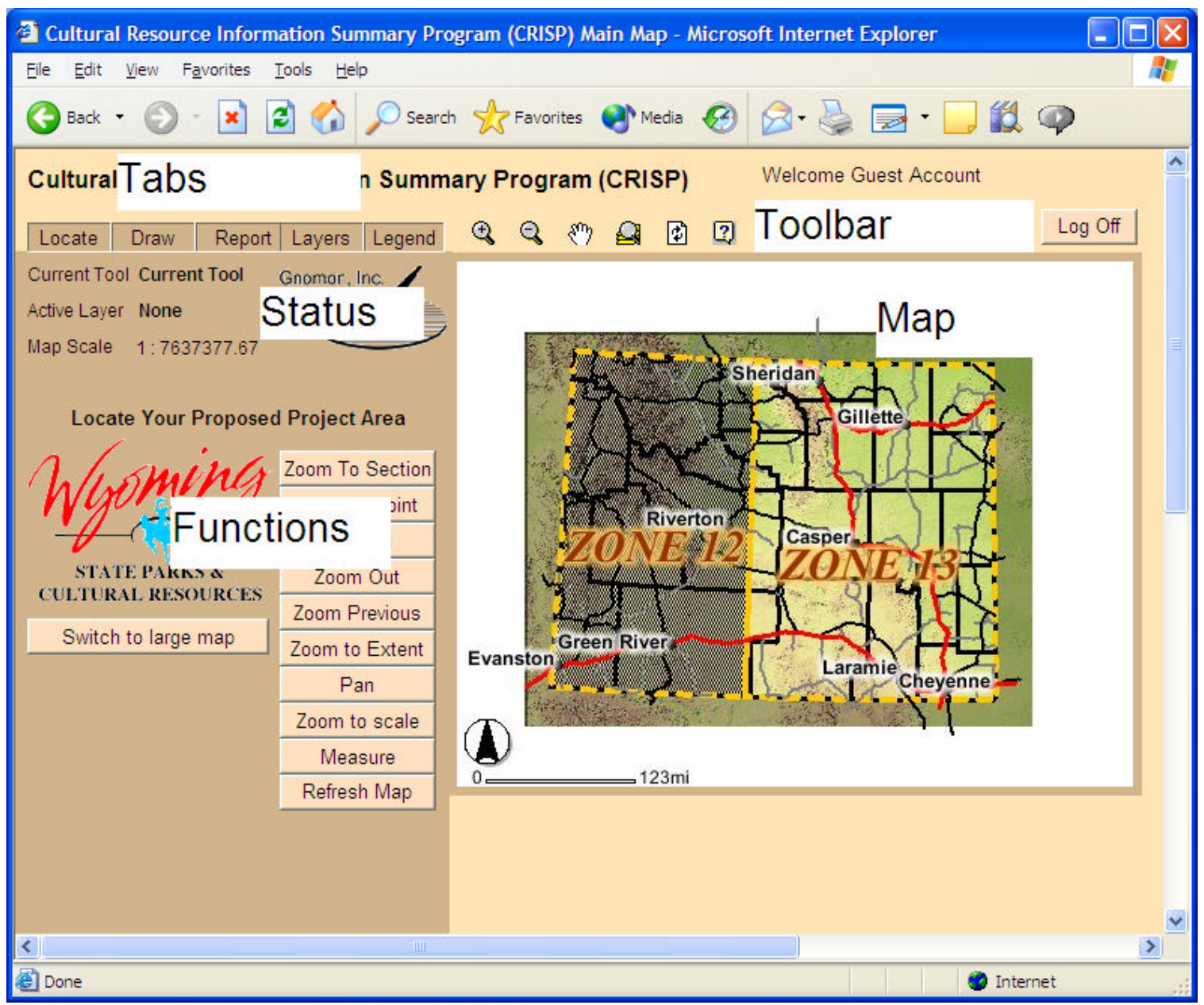

The map region displays the current map. Many of the tools and actions act upon the current map. You can switch from the initial, smaller, map image to a larger map image by clicking the Switch to large map button on the Locate tab. Because the map image is larger, the application will perform more slowly in the large map display mode.

The status region displays three pieces of information:

- The tool or action is currently selected. Typically, this is the action that will occur if you click on the map region.

- The currently active map layer (if any). The active layer is the "target" layer for queries and the individual layer identify tool.

- The current map display scale, in ratio measure. 


\section{CRISP User Documentation}

The map toolbar region contains tools that, when clicked to select them, turn the mouse into a tool. The figure below shows the toolbar, and the list below the figure describes the toolbar functions from left to right.

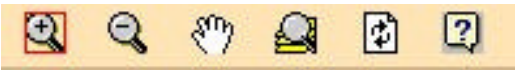

- Zoom in by left-clicking and dragging with the mouse. This will zoom in to fill the map region and center the display on the zoomed area.

- Zoom out and center on point clicked by clicking on any part of the map

- Pan (move) the map display without changing the map scale by left-clicking and dragging with the mouse.

- Zoom to the extent of the active layer (or if no active layer is chosen, the entire map).

- Refresh the map display (redraw the map). When the map does not appear the way you think it should, please try refreshing the map display!

- Get help for the CRISP application and also find links to the support email address and the location of the Adobe Acrobat ${ }^{\mathrm{TM}}$ Reader software.

The status region, shown in the figure below, always displays the current tool, the active layer, and the map scale.

\begin{tabular}{|c|c|c|c|c|}
\hline Locate & Draw & Report & Layers & Legend \\
\hline \multicolumn{3}{|c|}{ Current Tool Rectangle } & \multicolumn{2}{|c|}{ Gnomor, Inc. } \\
\hline Active Layer & None & & & \\
\hline Map Scale & $1: 574$ & 7.65 & & \\
\hline
\end{tabular}

The $\boldsymbol{t a b}$ region, shown in the figure above, provides a means to navigate between five different function areas of the program. The five tabs are:

- Locate contains functions that let one go to different parts of the map window. These include the zoom and pan functions described above and other functions as well. The goal of actions on this tab is to display the appropriate part of the world in the map region, so that the user can draw a proposed project area (PPA), and report upon it.

- Draw contains functions that let one draw a PPA, either using a simple one-twothree process or using advanced drawing features. The goal of actions on this tab is to create one or more polygons that define the PPA.

- Report creates a report that uses the PPA defined in the Draw tab. The PPA report is presented to the user as a separate browser window, which contains an option to save the report to the user's computer as a portable document format (PDF) file. This report is the goal of the CRISP tool 


\section{CRISP User Documentation}

- Layers allows one to change the information shown in the map by turning layers on and off, allows one to query map features, and allows one to search for map features. As well, the active layer can be changed on this tab. The goal of this layer is to provide map information to the user and allow the user to customize the displayed map appropriately.

- Legend shows the map symbols for the current map. Layers that are not displayed will not have a legend key shown for them.

The tab functions region contains buttons, tools, and information appropriate to the selected tab. The various functions are explained for each tab in the following section on the CRISP user interface.

\section{CREATING AN ANALYSIS WITH CRISP - OVERVIEW OF STEPS}

CRISP is designed to be easy to use for common forms of analysis. The steps to create a CRISP report are simply:

1. Locate your proposed project area (PPA) by navigating to the appropriate part of the map.

2. Draw the PPA, buffering each feature as needed, to create one or more polygon search masks ("cookie cutters") for analysis.

3. Run the report (the analysis) and save the report as a PDF format file if you wish.

\section{STEP ONE -- LOCATE THE PROPOSED PROJECT AREA (PPA)}

First, if you have changed tabs, then navigate to the Locate tab by clicking on the tab labeled "Locate".

Second, navigate to an appropriate part of the map using the tools and functions of the Locate Tab.

Try "Zoom To Section". Enter the information shown in the figure below into the dialog box and then press "Go To Section". (Note, you do not need to enter a "T" in front of the township value or an " $R$ " in front of the range - you can do so if you wish - but, the cardinality ("N" or "S" for township, "E" or "W" for range) must be entered. Donated land claims (DLC) and block or tract searches are not supported reliably. 


\section{CRISP User Documentation}

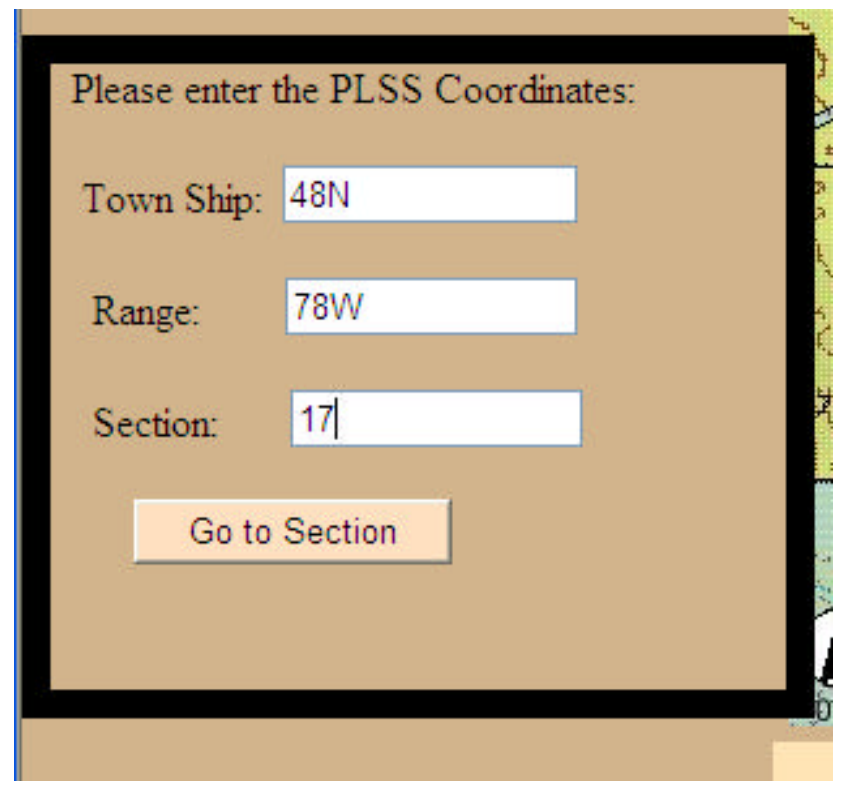

The resulting map display should look like this (as of December, 2004):

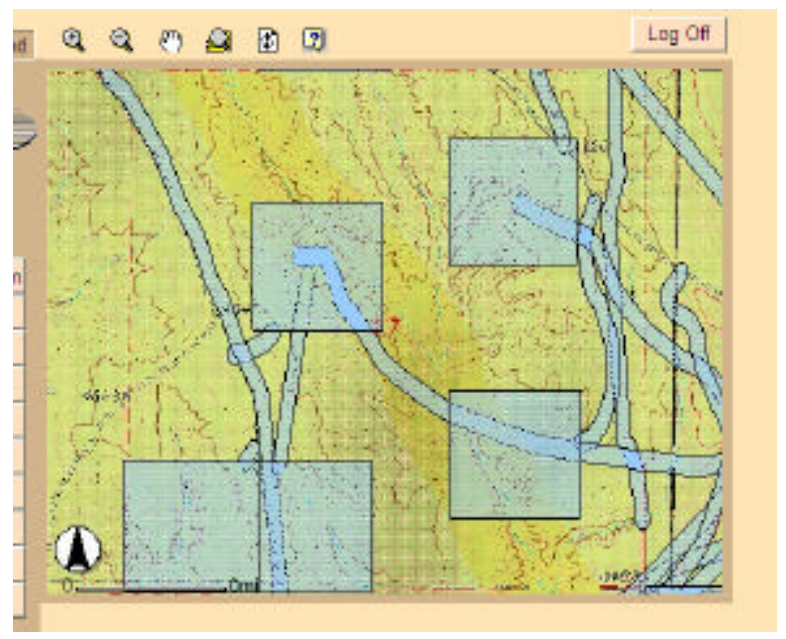

Section 17 contains both block and linear archaeological surveys (shown in blue). Surveys overlap on each other in some places.

Our PPA for this tutorial straddles the southeast corner of Section 17, so the map display needs to be changed.

Click on either the "Pan" tool button in the tab functions region or by clicking on the hand icon above the map. Then, click in the southeast corner of Section 17, and without releasing the left button of the mouse, drag the cursor up to the center of the map display before releasing the left mouse button (i.e., click and drag). You might also notice that the current tool now says "Pan" and the hand icon has a red square around it. The map display should now look like this: 


\section{CRISP User Documentation}
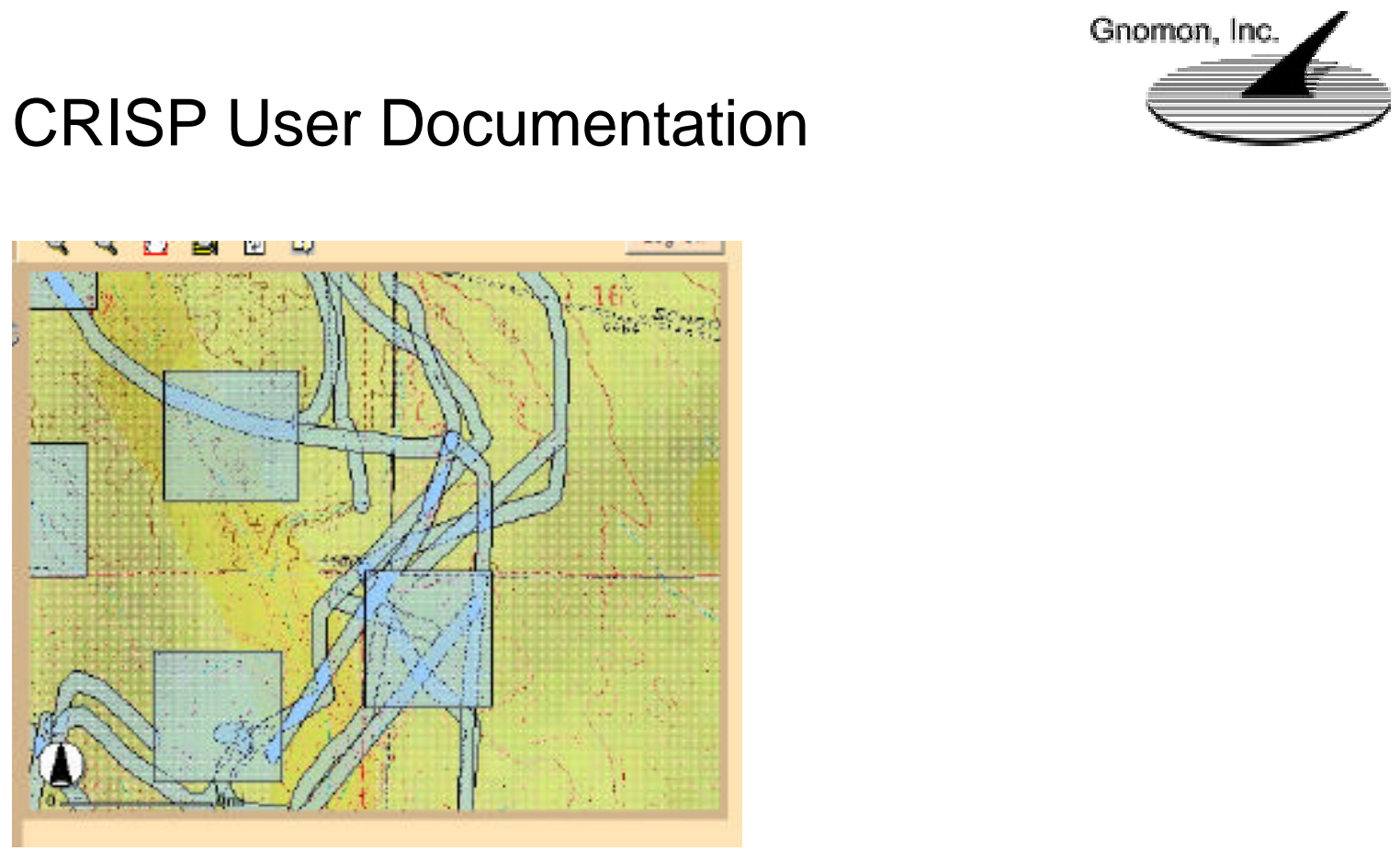

To make sure we get the PPA in the right place, we need to refer to some map features that are just outside of the current map, so we need to zoom the map "out" (make the map scale smaller).

Click the Zoom Out button in the tab function region or click on the magnifying glass with the minus icon. Then, click in the center of the map region. The map will zoom out by a factor of $75 \%$ :

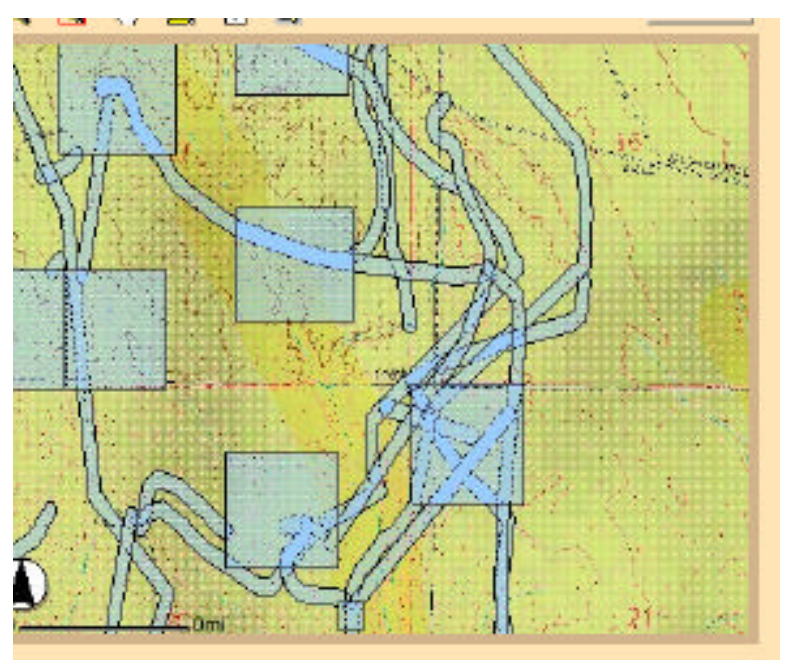

We have now located the appropriate map area for our proposed project.

\section{STEP TWO - DRAW THE PPA MASK SHAPE $(S)$}

The PPA is a new pipeline and service road that starts in Section 20 (the southeastern section), runs north-northeast into Section 17, and then doglegs into the northwest corner of Section 21. 


\section{CRISP User Documentation}

A small lay-down area will be required in Section 20 to house materials and equipment during construction.

In this step, we will use the simple drawing wizard tool to create PPA map features, building a polygonal mask as we work.

Click on the Draw tab. The tab function area will show the simple drawing tools. The process of drawing is straightforward and always follows the same sequence:

- Select an appropriate tool to create a map shape (point, line, or polygon)

- Draw the shape

- Buffer the shape to form a polygon (if it is not one already) or to add an additional space around a polygonal shape

- Name the shape (all shapes can have the same designator, but all shapes must have a name).

- Save the shape

You can cancel the shape creation process at any time by pressing "Cancel". You can clear everything you have drawn by going to the Advanced Drawing tab and choosing clear - see the interface guide section for more information).

To start this PPA, we will first create the lay-down project. Click on the "Polygon" button. Then create a small polygon by clicking each point (wait for the screen to refresh) around the perimeter of the polygon. Do not cross over to create "bowties"! If you do, then choose "Cancel" and start over. Press the "Done" button when finished. When done, your polygon should look something like the red square shown below:

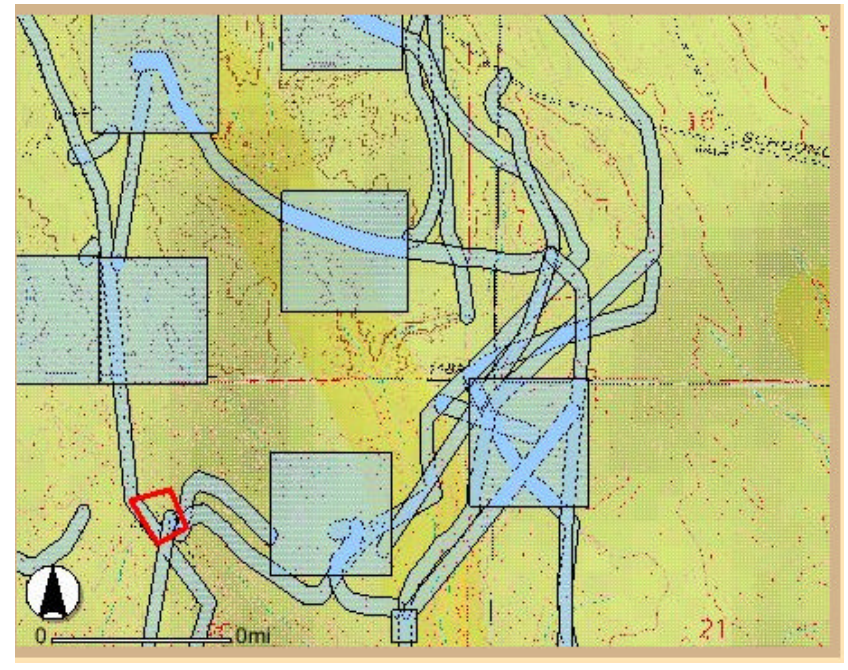

The "Buffer Shape" dialog area will now be enabled (not grayed out). We do not have to buffer a polygon, but often one wants to include a buffer just to be "safe". So, for this example, put " 30 " in the buffer text box (representing a 30m buffer). Then press the Buffer Shape button. After a brief pause, the shape should be redrawn with a larger buffer. Note that we could also have made the shape smaller by entering a negative 


\section{CRISP User Documentation}

number. The figure below shows the result after the "Buffer Shape" button has been clicked.

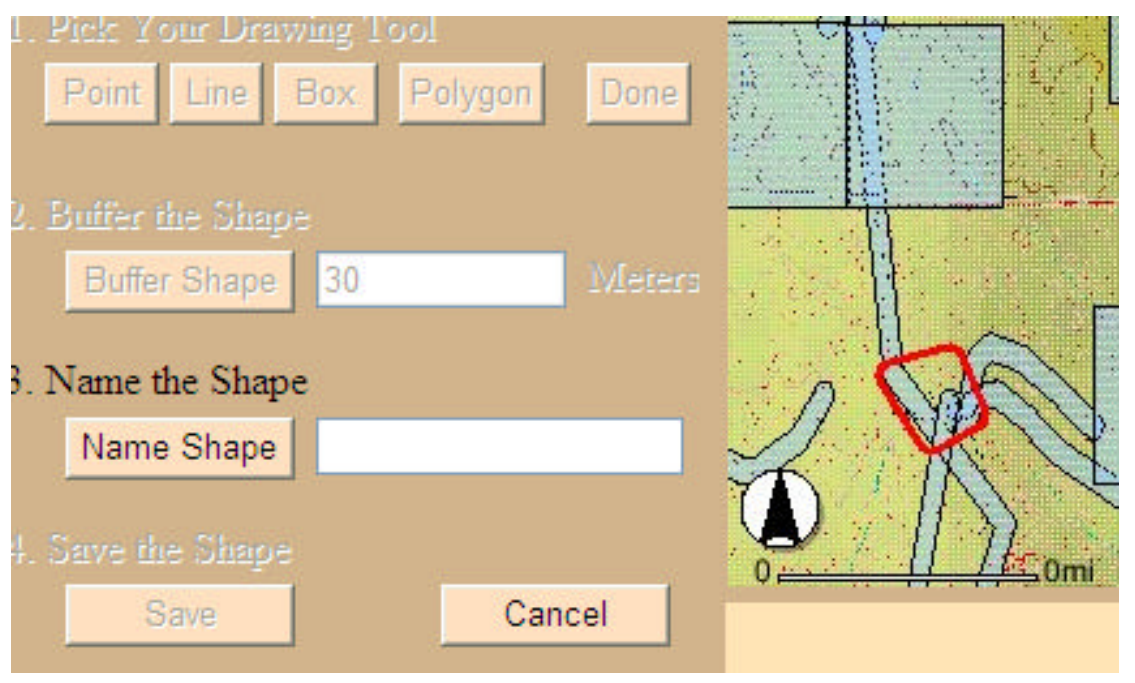

Now the shape needs to be given a designation, or name, before it can be saved. Enter "Lay-down" in the "Name the Shape" textbox and then press the "Name Shape" button.

The "Save" button will now be enabled. Click the "Save" button. Congratulations, you have just created the first element of the PPA. The tab functions region should look as it first did when you started drawing.

Now we will create the linear map feature that represents the pipeline and service road. To do this, we will use the "Line" tool and then buffer the resulting line to create a polygon mask.

Choose the "Line" tool.

Click inside of the lay-down area. This will start the line. Each place where you click becomes a sequential point on the line.

Click to the north of the lay-down, and continue to extend the line until it looks something like the line shown below. 


\section{CRISP User Documentation}

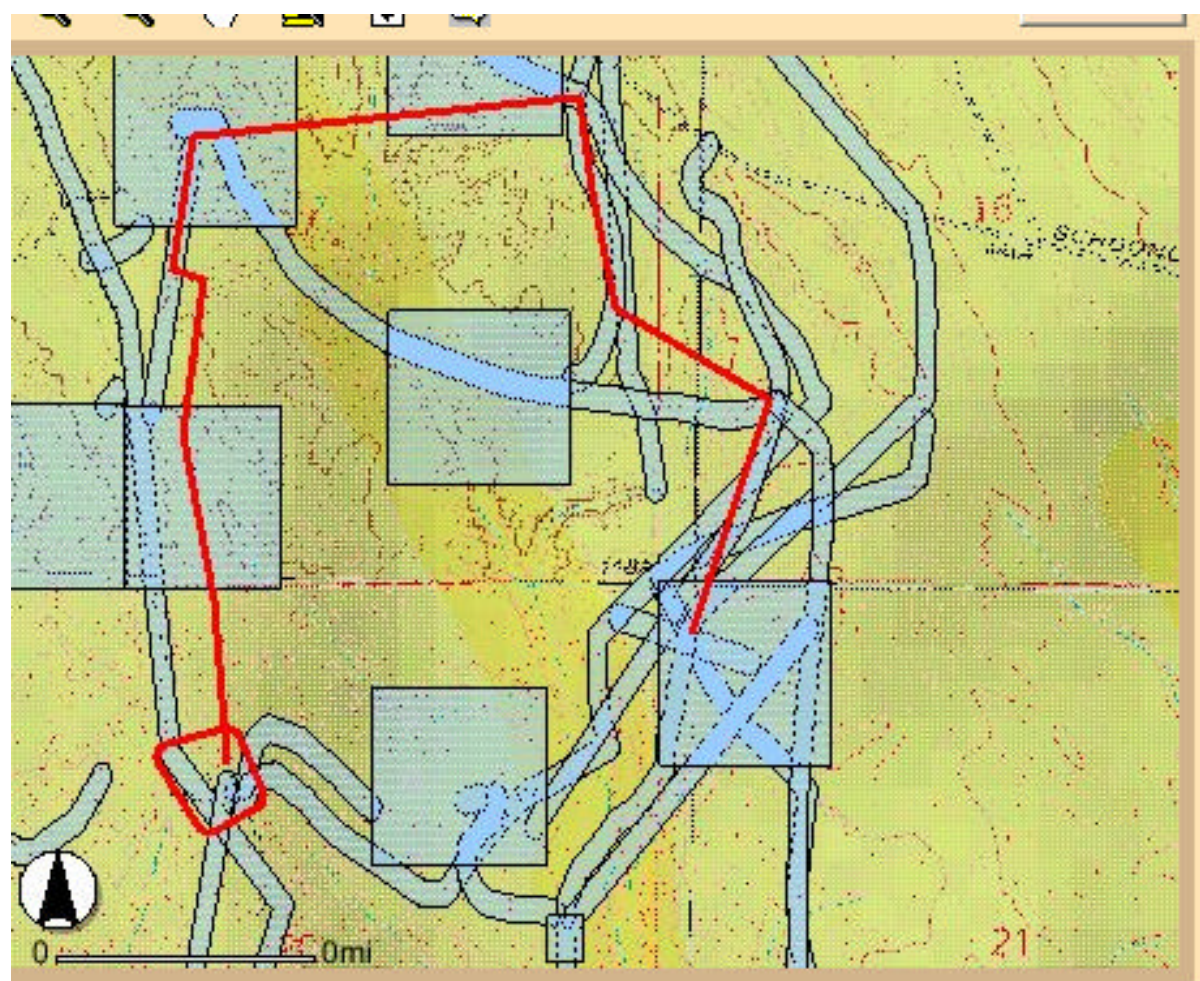

Choose "Done" to stop drawing the line.

Enter a buffer distance of 35 (meters). Remember that this will create a corridor $70 \mathrm{~m}$ ( $35 \mathrm{~m}$ to each side) centered on the line. Press "Buffer the Shape".

Enter a name of "pipeline" and press "Name the Shape"

Click on "Save". The line will be merged with the existing lay-down polygon to form a contiguous search masks. Note that search masks do not have to be contiguous and you can have as many separate (non-contiguous) masks in an analysis as you wish.

The completed PPA mask should look something like the one shown in the figure below. 


\section{CRISP User Documentation}

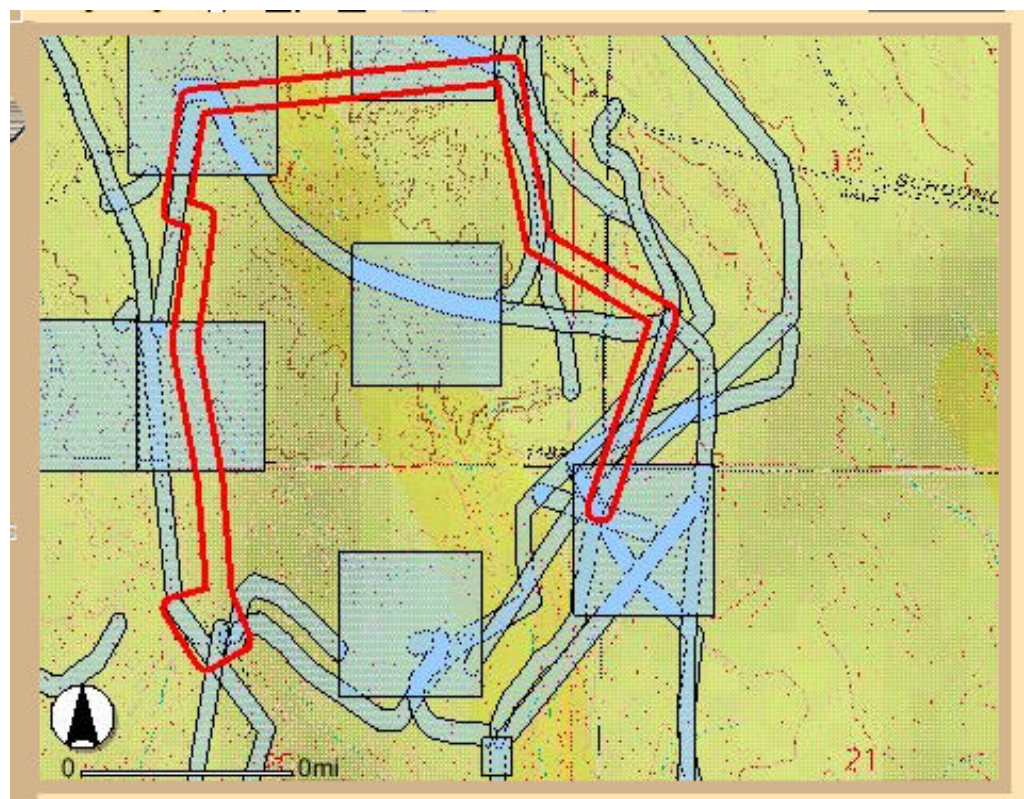

\section{STEP THREE - RUN THE SUMMARY ANALYSIS}

The final step in the tutorial is to get a summary of the known cultural resources in the PPA and a forecast of the likelihood of other cultural resources.

Click on the Report tab. This opens the report functions.

Enter a name for your report. For example - "New Pipeline, First Proposed Configuration"

Enter a name for the title of the project. For example: "Pipeline 1107, Lease 04-12".

Enter any description of the project or report. The entry can be up to about 10 full lines in length (1000 characters). For example:

"Pipeline, service road, and lay-down area for Pipeline 1107, Lease 04-12. This report was run to assess the optimum route without regard for areas of prior archaeological inventory" 


\section{CRISP User Documentation}

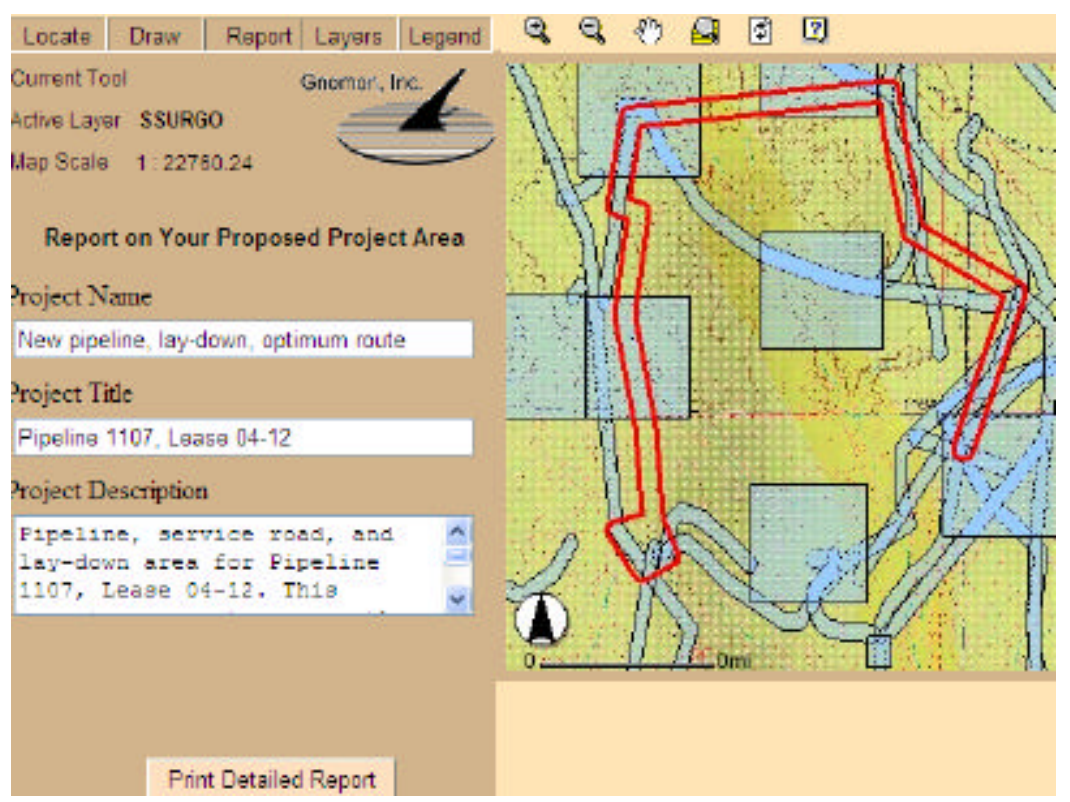

Click on the "Print Detailed Report" button. A new window will open with a browser version of the report.

The report summarizes several things about the PPA and provides maps of it. These include:

- The size of the PPA

- The percent of the PPA that has already been inventoried for archaeology

- Known cultural resources and a count of the number of inventory reports within each section touched by the PPA. Note that a PPA may have no inventoried ground within it and yet still be in a section with inventories - this summary is by section, not by PPA.

- The forecast from the first model (currently a model of the likelihood of finding buried archaeological sites in scientifically useful contexts using statewide STATSGO data).

- The forecast from the second model (using county-wide SSURGO data).

The report can also be saved locally on your computer as a Portable Document Format (PDF) file. At the top of the report page, click on the "View PDF Report" button. The server will generate a formatted version of the browser report, and then give you the option of opening or saving it. 


\section{CRISP User Documentation}

\section{CRISP INTERFACE AND FEATURE GUIDE}

The remaining document provides a reference to the features in the CRISP tool

Locate Tab Page

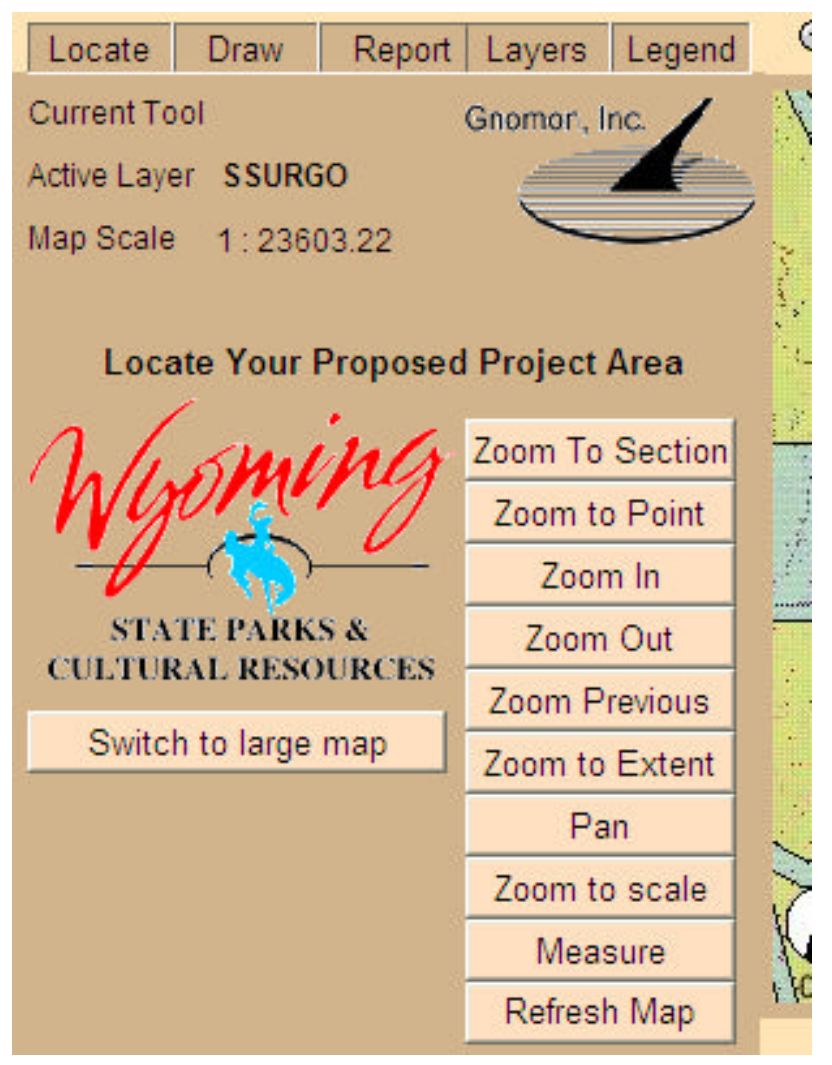

Zoom to Point - Zoom to the specific UTM point.

Zoom In - Sets the Current Tool to zoom in. To zoom, drag a box around the area of interest.

Zoom Out - Sets the Current tool to Zoom Out. Click on the map and you will zoom out and the location you clicked on will be at the center of the map.

Zoom Previous - Zoom to the last view of the map. Will 'Undo' Pan and zoom.

Zoom to Extent - This will return you to the maps full extent.

Pan - Allows you to drag the map to view adjacent areas.

Zoom to Scale - Allow the scale to be set by the user and then Zooms to that scale 


\section{CRISP User Documentation}

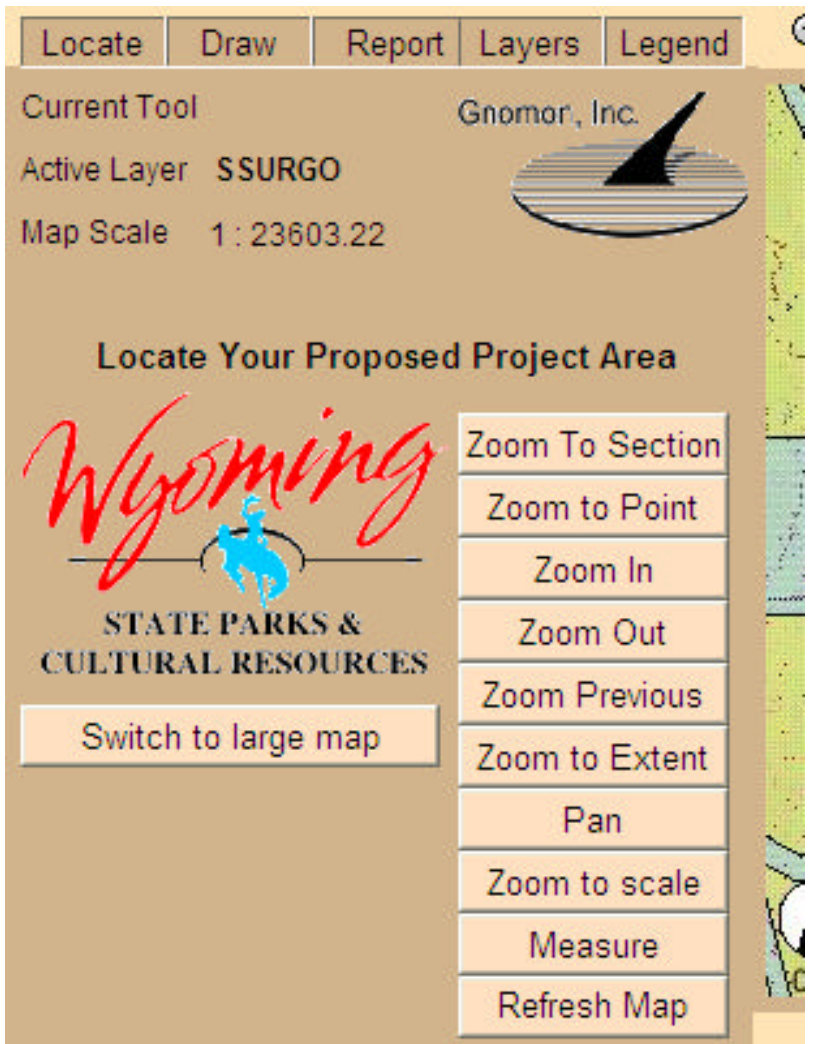




\section{CRISP User Documentation}

Measure - Brings up a measure tool for measuring line length and area

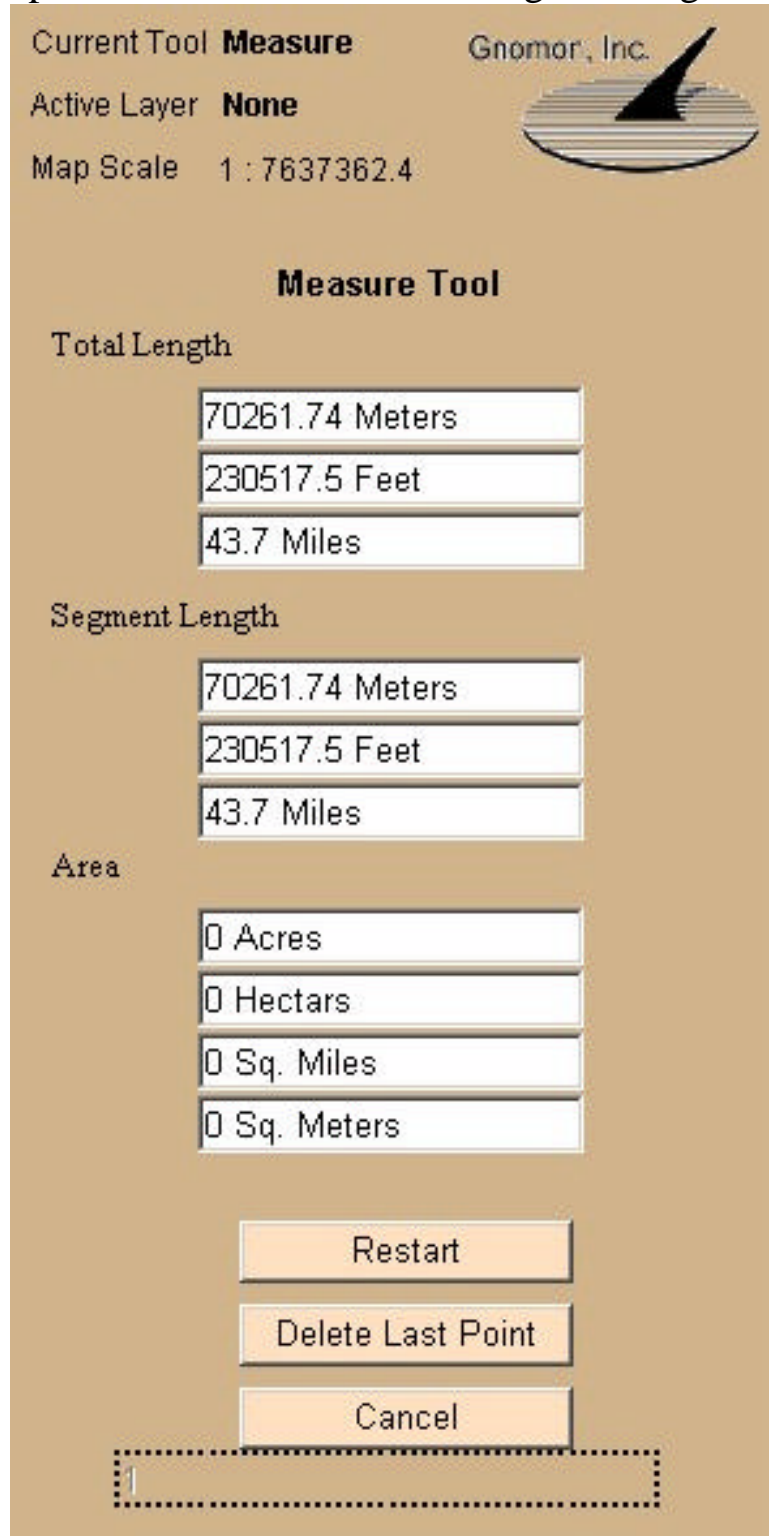

Restart - Starts the measuring process over

Delete Last Point - The last point placed will be removed Cancel - remove the measure tab page

Refresh Map - Forces the map image to redraw

Switch to large map / Switch to small map - Sets the visible screen size of the map.

Identify All Visible Layers - This tool will allow you to click on the map in an area of interest and see all of the data associated with the layers. 


\section{CRISP User Documentation}

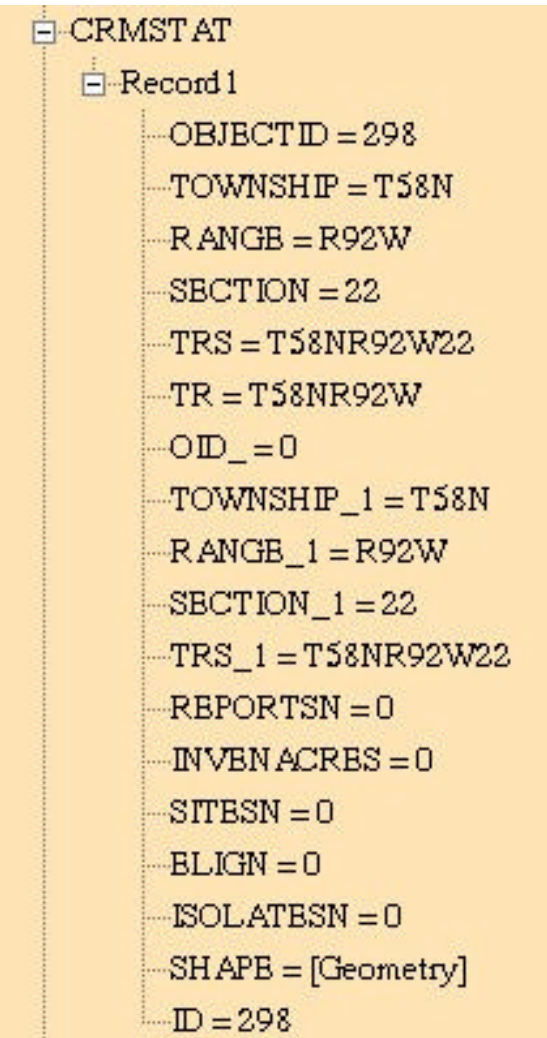

The layer name and records found will list. This is for general map investigation and is not a reporting tool.

Query - This tool will allow you to query the attributes of the Active Layer.

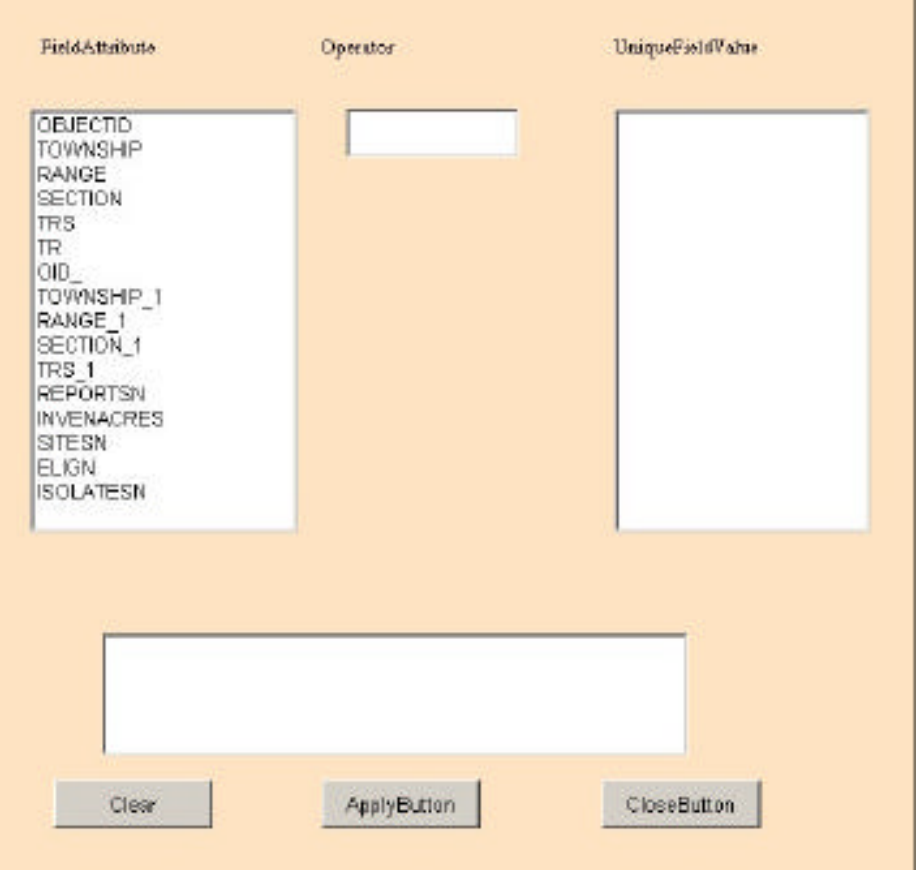




\section{CRISP User Documentation}

Draw Tab Page

This page provides a wizard type interface for drawing your PPA.

1. Pick Your Drawing Tool

Point - Allows you to place a point on the map. You must buffer the point to give it area. Use points for sites that have circular features.

Line - Allows you to draw a line or a series of line segments. You must buffer the line to give it area. Use lines for roads or linear features that can be buffered to a width.

Box - This tool allows you to draw rectangles. Buffering is optional on rectangles because they already have area..

Polygon - This tool will allow you to rubber band a polygon shape for you project area. Buffering is optional for polygons.

Done - this is used to stop drawing lines and polygons.

2. Buffer shape - This step will allow you to create a larger shape or to give a point or line area. Roads are often buffered from lines. Points and lines must be buffered.

3. Name Shape - Give the shape a name.

4. Save - save the newly drawn shape

Cancel - remove the shape.

Advanced Draw - This takes you to a paint type interface for drawing your PPA.

\section{Advanced Draw Tab Page}

This page provides a paint type interface for drawing your PPA. You must reme mber to buffer lines and points for the report to use. Points and lines that are not buffered will be ignored. You must also remember to dissolve shapes when you are done. Any PPA polygons that overlap will cause the report to calculate incorrect area. Polygon shapes should never cross themselves creating 'bow tie' shapes.

Point - Selects Current Drawing Tool

Line - Selects Current Drawing Tool

Box - Selects Current Drawing Tool

Polygon - Selects Current Drawing Tool

Done - Selects Complete a line or polygon

Edit Point - If you select an objects point from the tree view. 


\section{CRISP User Documentation}

$$
\begin{aligned}
& \text { - 2-Line: Line } \\
& \mathrm{x}=\text { "270234.428290793" } \mathrm{y}=4984845.8241802 " \\
& \mathrm{x}=\text { "270684.393473579" } \mathrm{y}=\text { "4984318.27879349" } \\
& x=" 271584.323839151 " y=" 4984613.08356841 "
\end{aligned}
$$

And then click the Edit Point Button.

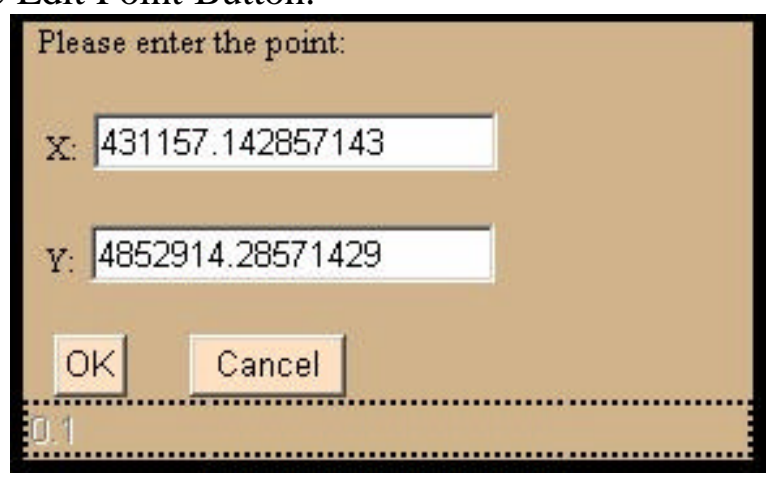

Enter in the desired point and click OK.

Reset Point - This works like Edit Point but it allows you to reset the point by clicking on the map.

Clear - Clears all user drawn shapes Remove - Removes the shape selected on the treeview.
+ 1-Poly: Poly
+ 2-Poly: Poly
+ 3-Poly: Poly

This example would remove Poly 2

Shape Name - If you wish to name the shape complete this field prior to drawing the shape.

Buffer Shape - This will buffer the current select shape.

Dissolve shape - This will dissolve all user drawn polygons that overlap into a single polygon. This prevents calculation errors due to overlap.

Download Shapefile - This button will create a shapefile of all user drawn shapes and zip it for download to the client machine.

Project Draw - This will return you to the normal draw tab page. 


\section{CRISP User Documentation}

Report Tab Page

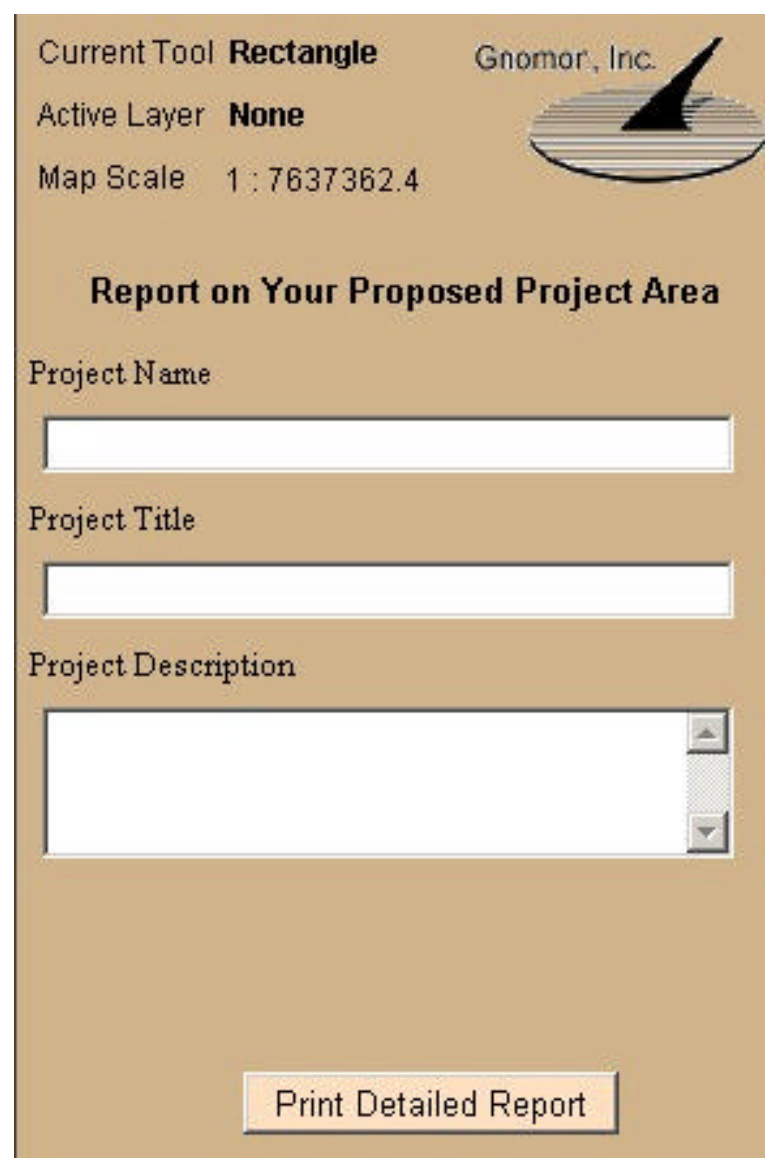

Project Name - Enter the project name to appear on the report.

Project Title - Enter the project title to appear on the report.

Project Description - enter the project description to appear on the report.

Print Detailed Report Button - This will generate a report to view on the screen.

\section{CULTURAL RESOURCES INFORMATION SUMMARY PROGRAM (CRISP) \\ POTENTIAL PROJECT AREA ANALYSIS REPORT PREVIEW}

View PDF Report

From the report you can generate a PDF version for printing or emailing.

Note: The complexity of your search mask will affect how long the report takes to generate. The complexity of the model and inventory layers in the PPA will also slow down the report.

A maximum of 36 square miles can be investigated using this tool.

\section{Layers Tab Page}

This page shows all the available layers. You can make layers visible by checking them. Unchecked layers will not be visible. Some layers are scale dependant and will not be visible until you zoom in. 


\section{CRISP User Documentation}

Note the active layer is always shown.

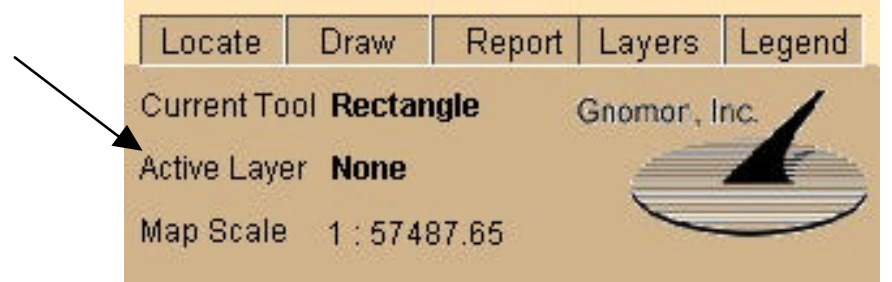

Identify Active Layer - This tool will allow you to identify and look at the attributes of the active layer.

\section{Legend Tab Page}

This page shows information about the visible layers. Layers that are not visible or are not in scale range of the map will not show up.

Legend at full extent:

Legend at 1:24000
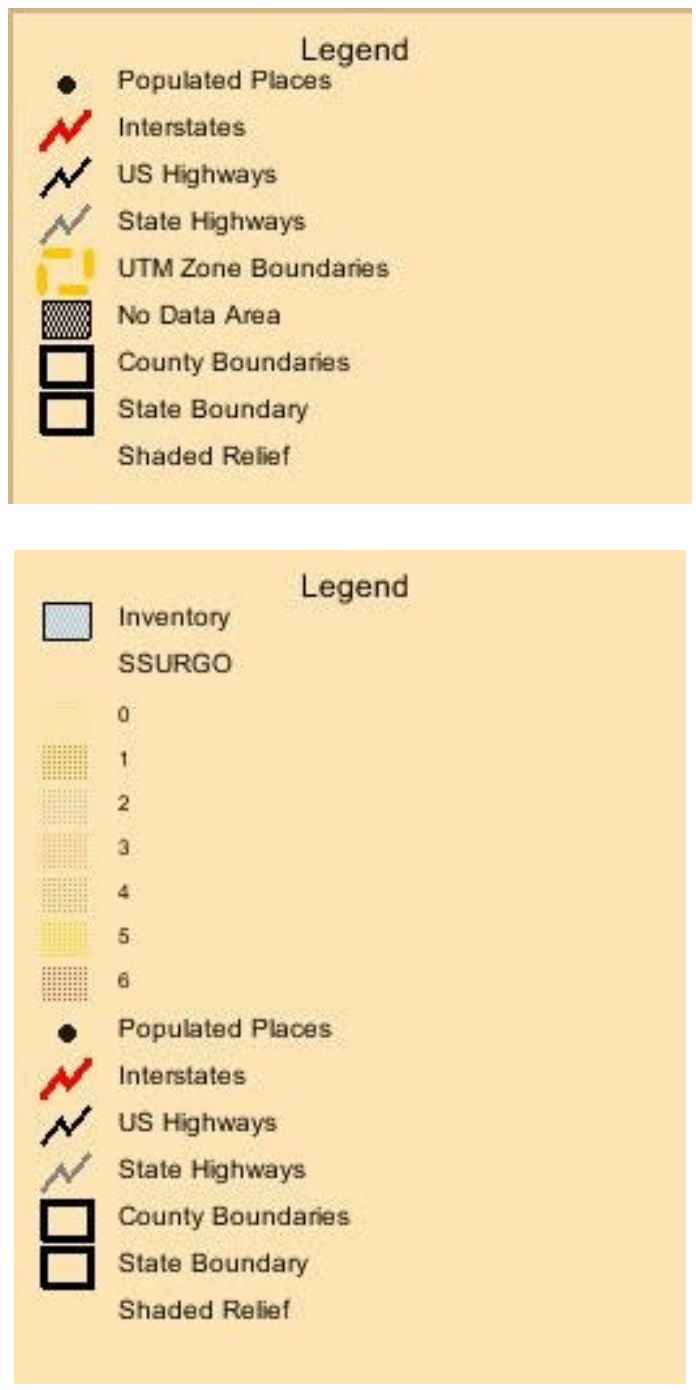


\section{CRISP User Documentation}

Other Features

Toolbar - \& $Q$ \&in $\Leftrightarrow$ 过

Zoom In, Zoom Out, Pan, Full Extent, Refresh Map, Help

This toolbar makes features from the Locate Tab Page available on any page.

Log Off - This button will end your session and prevent someone who has access to your machine from getting unauthorized access.

Version Information

Date Initials $\quad$ Notes

12/29/04 Gnomon

Begin document

$12 / 3 / 04$

Gnomon

Add content

$12 / 4 / 04$

Gnomon

Add content 

APPENDIX E

PROJECT TRACKING HANDBOOK 



\section{PROJECT TRACKING HANDBOOK}

Introduction: What is Project Tracking?

"Project Tracking" is a web-based database application that follows the workflow of common cultural resource management processes. It has been created to reduce redundancy in the way information is collected, reported, and handed from consultant, to lead agency, to SHPO. Current redundancy and time lags can create constraints and problems to agencies and project proponents. "Project Tracking" was and is being developed to address these known concerns.

The application is intended to collect information from the information creators. A field organization creates information about the fieldwork it proposes to do (or has done). This is more appropriate than having "down the line" entry in which, sometimes years after the fact, a technician enters the details of field work into the statewide database. Why not have the information entered at the time of the project allowing it to be available and accessible to other cultural resource permittees, for annual reporting, and other program uses?

The application is being piloted by the Wyoming Bureau of Land Management BLM and the Wyoming State Historic Preservation Office. Wyoming is the prototype state for this project. We are collecting user comments, concerns and will be working towards a product which meets agency and private consultant needs. We are open to your constructive comment. We ask you put your comments in writing and preferably print portions of the application and mark the pages with your suggestions. We are currently working with the initial version of this program and anticipate revisions in the future per your suggestion and comment.

The application follows a common work model:

Fieldwork notification is provided to the lead land managing agency along with project details in order for the agency to make a decision on the proper procedure for compliance with Section 106 of the NHPA. This can include various type of recommendations such as Class III inventory or other types of treatment appropriate to the type of action.

If field work proceeds, an investigation report is generated with a standard cover sheet that summarizes the investigation and results.

The report is reviewed and either returned for revision to the field investigator, accepted and commented upon. The report may be routed to other reviewers including consultation with other federal agencies, or field offices and the SHPO.

Ultimately, the document is reviewed and considered to have completed the review and consultation process. It then becomes part of the state information system housed at the SHPO office.

The electronic record process becomes part of the overall information system.

The records in the application are much like "banking" records. The ownership of these records is associated with various user permissions. To make this work, we have defined user roles based upon their organization role. There are roles for the field investigator, the lead agency, the SHPO, and system administrators. Users can belong to more than one role in the system, for example a lead agency can be may be the field organization and the review organization.

The basic steps to the application are:

One creates a fieldwork authorization record

After fieldwork is complete, one coverts the authorization into an "investigation cover sheet"

Next the "investigation cover sheet" is submitted to the lead federal agency.

**Note: You can create "investigation" records without creating field authorization records if applicable or appropriate. This could occur if you are entering legacy data or if the lead federal agency is performing the investigation. 
After review of the electronic "investigation cover sheet" along with the documentation submitted by the field investigator (assuming approval) the record and associated documentation is submitted to the SHPO for consultation and concurrence.

\section{Field Investigators Step by Step Guide}

How to create Field Work Notification:

Go to http://wyoshpo.state.wy.us hover over "on-line data" and choose "Project Tracking Prototype"

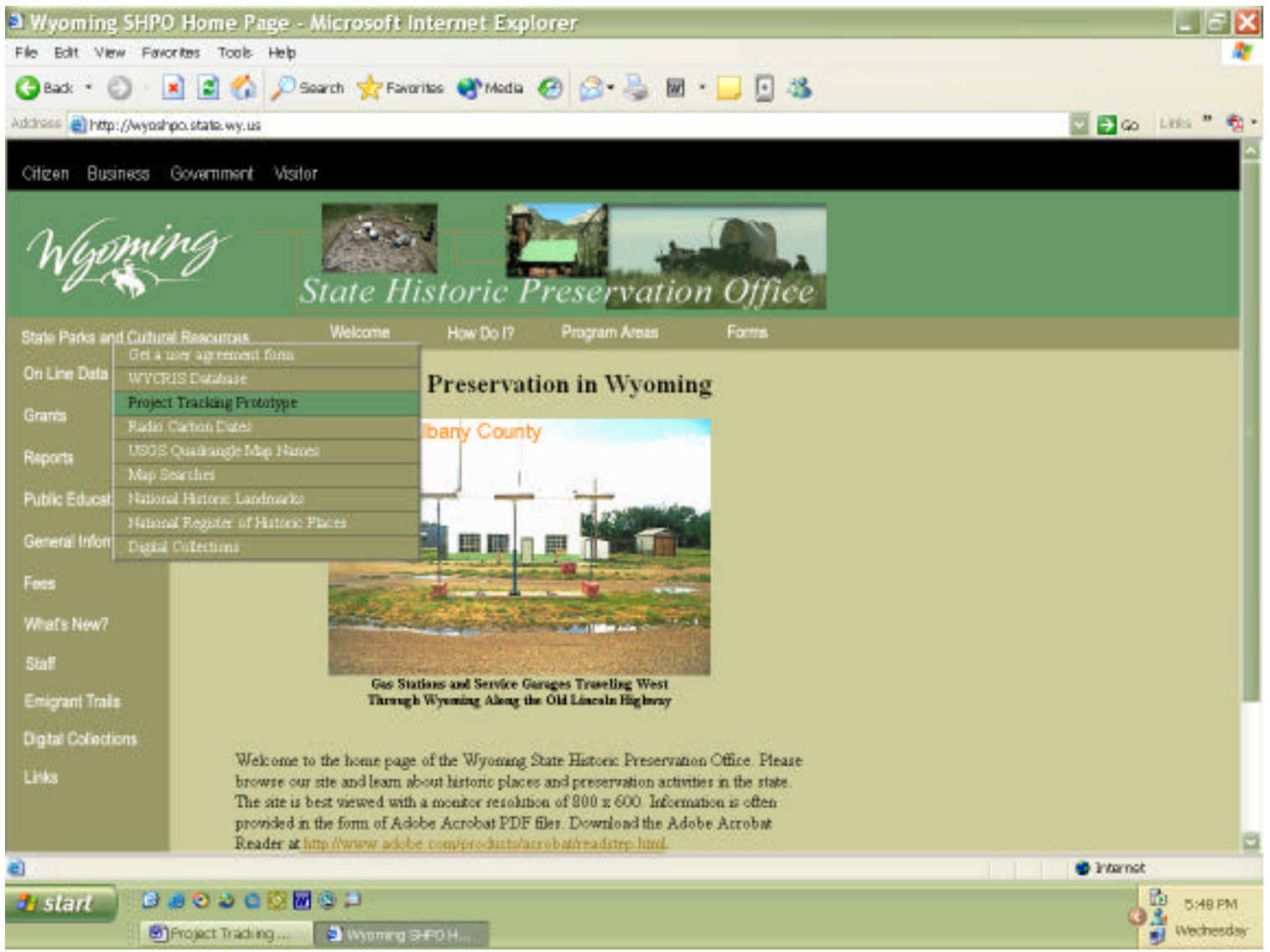


There will be a "Security Alert" page. You want to proceed, so check "Yes." You are being directed to a secure website at www. Gnomon.comwhere all transactions are encrypted.

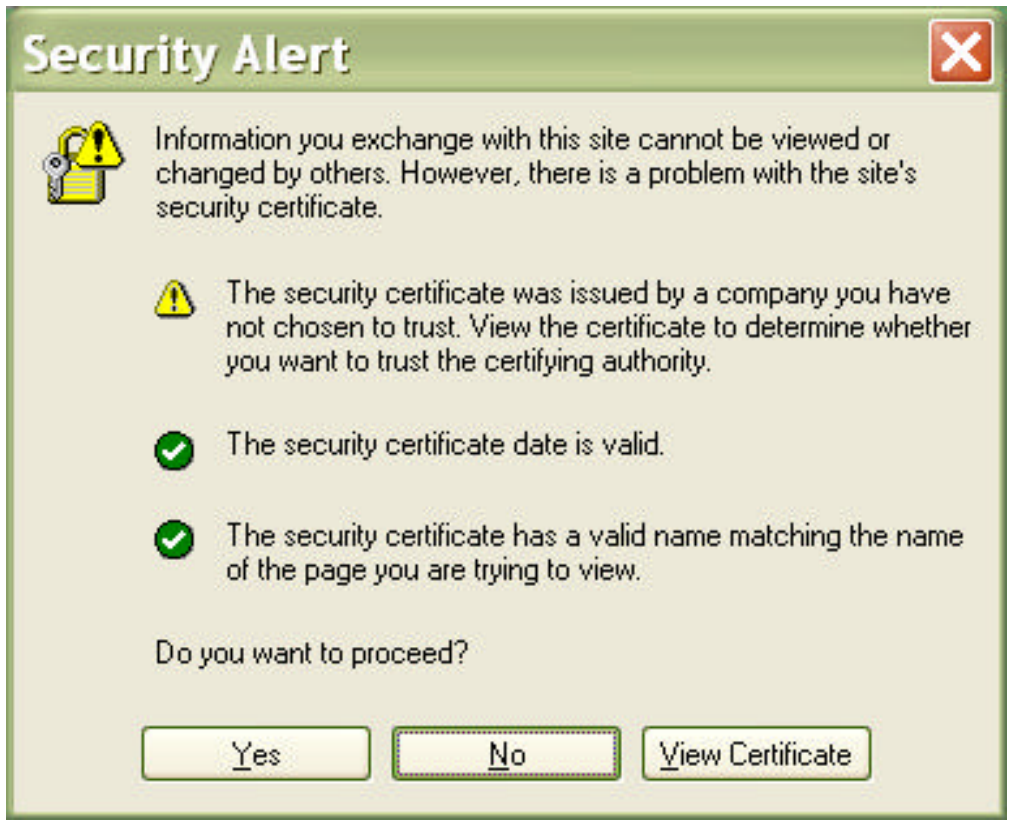

Now you have been directed to the log on page. This page can be bookmarked, but each time you enter it will ask you to accept the security alert above. 


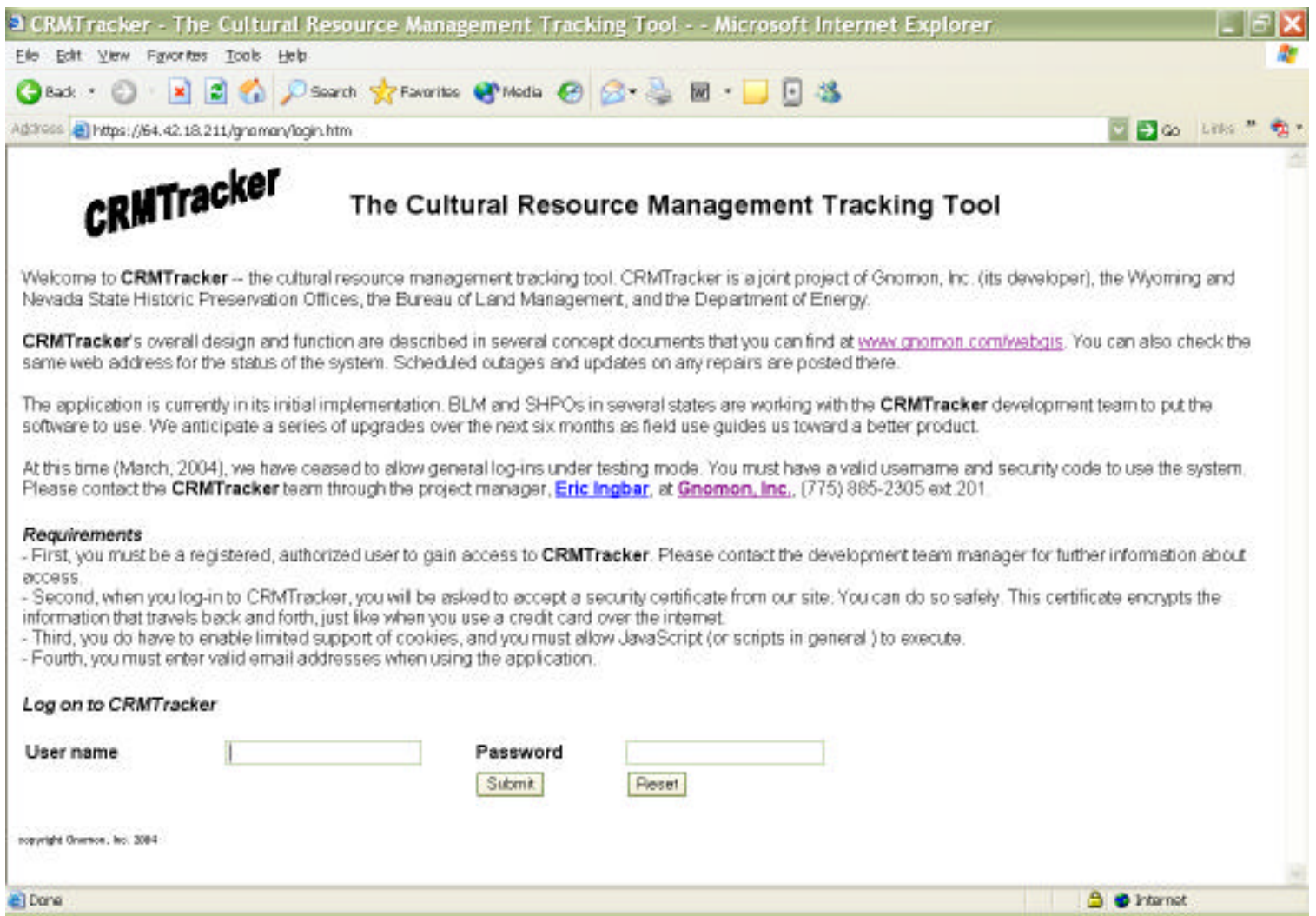

The User name and Password for the application is the same as your username for other Wyoming SHPO on-line database and mapping applications. If you do not have a valid username or password, please contact Mary Hopkins at the Wyoming SHPO at 307-766-5324 or Hopkins@ uwyo.edu to check your account. You must submit a signed user application to gain access. The user agreement form is available at: http://wyoshpo.state.wy.us/shpoweb2002/2002webpages/regform1.pdf and can be faxed to 307-7664262. We ask you not share usernames and passwords.

For training purposes only, we have enabled two Yahoo mail accounts:

The consultant account is wyarchcons@yahoo.com the password is mckean. The lead agency account is wyleadfed@yahoo.com the password is wardell.

aprehistorian logon aprehistorian password

aleadarch logon aleadarch password 
When you logon, you will see a fairly plain web page. We have created these pages so they load quickly and can be easily accessed via a telephone line. The main menu for the application is on the left side of the page and as you make different menu choices, different parts of the application become available to the user.
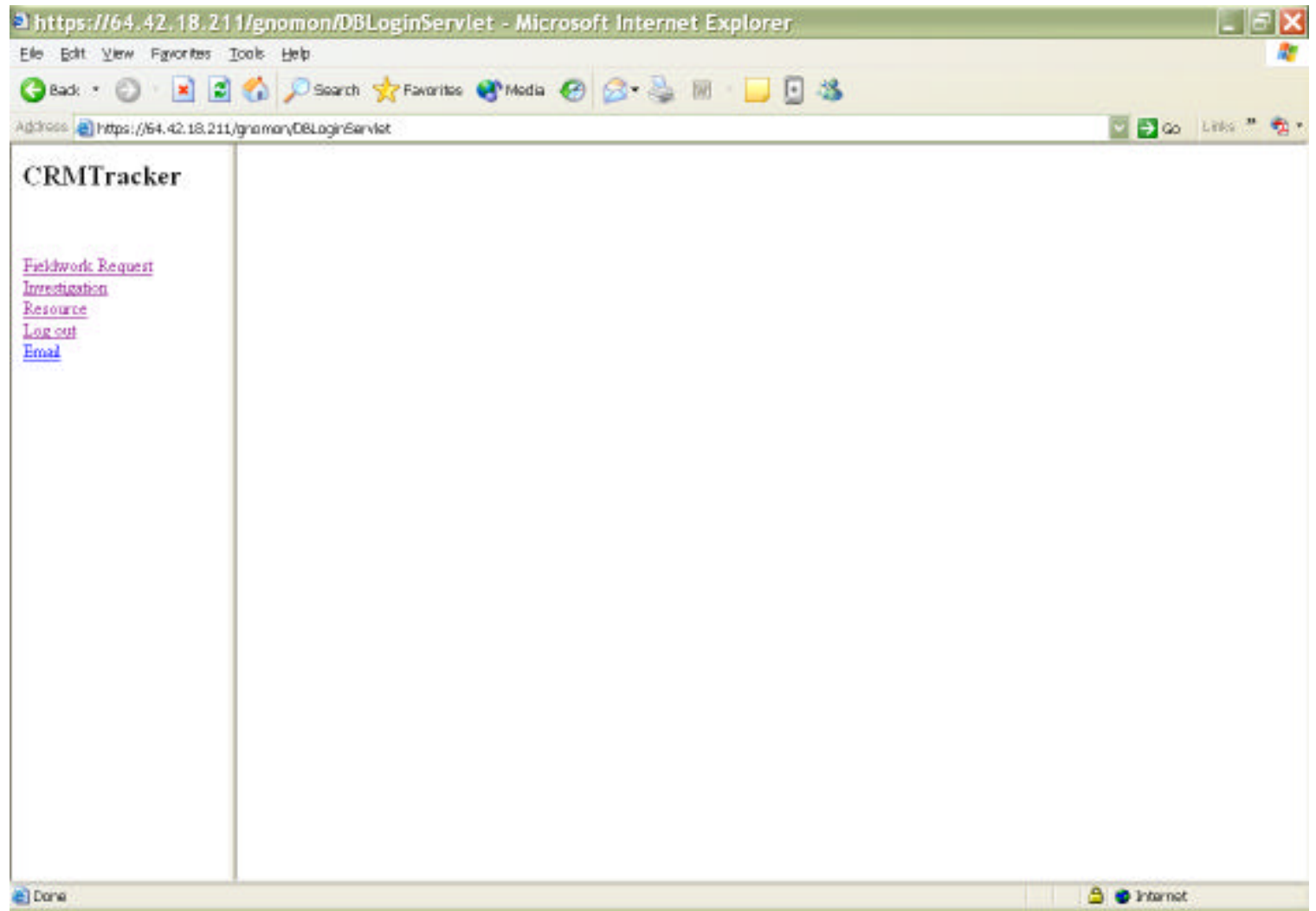

When you choose "Fieldwork Request" you will be directed to the Fieldwork Notice or Authorization Request page. You have two choices as a field investigation (remember users have different roles). You can "Create a new field work requests" or "Check existing requests." 
Choose "Create a new field work requests"

Ehttpst/l64 42. 18.211/gnomeniDBLoginServlet - Wicrosoft Internet Expleres:

a

Flo Edt Vew Fangrtes Took Hep

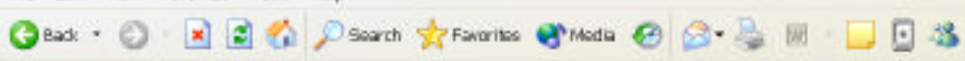

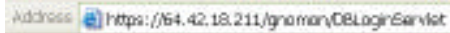

Fif

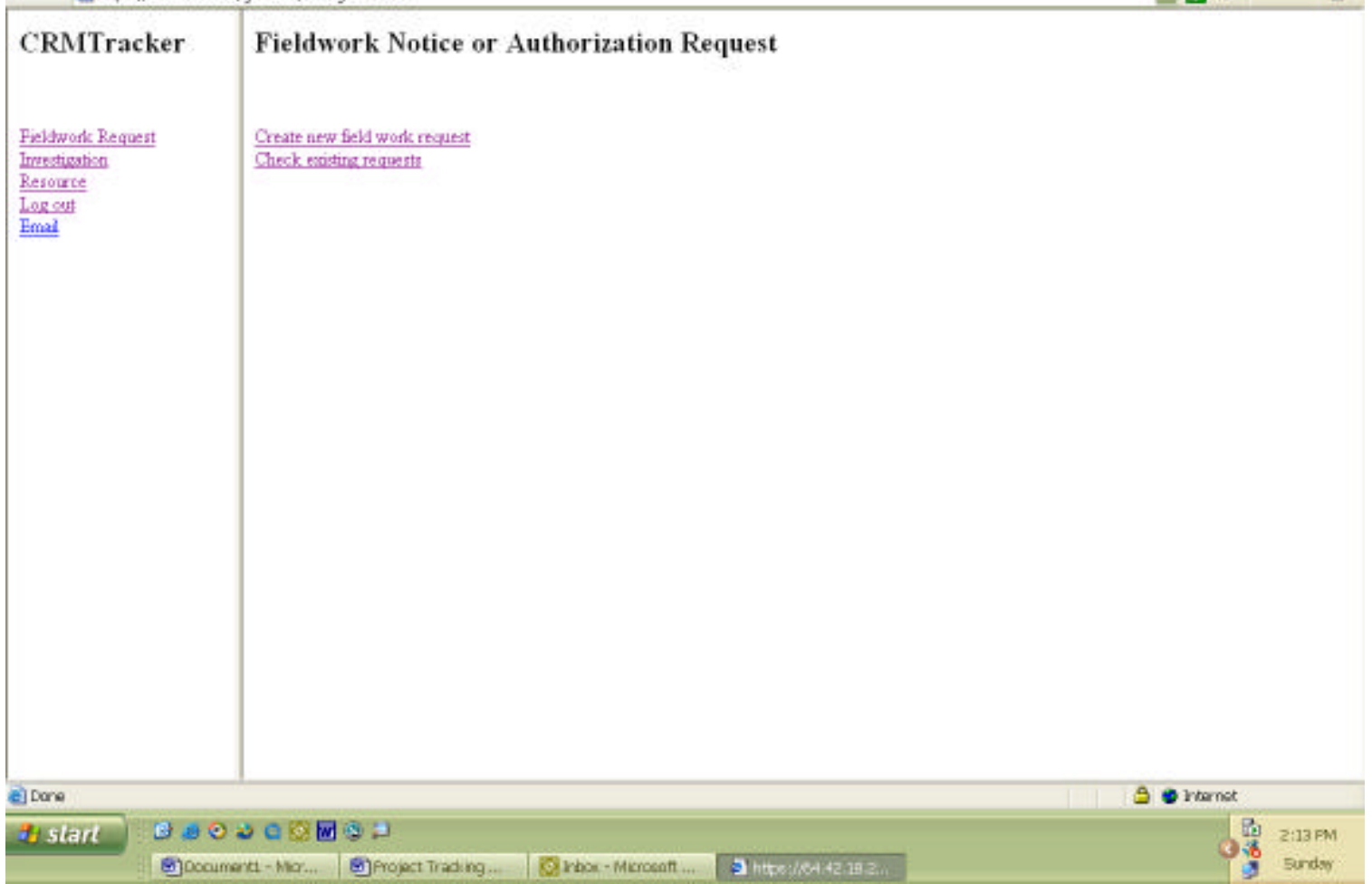


Choose the state. The application does not allow for the entry of multiple states. If the project is in more than one state, you will need to create an appropriate record for each state. When you choose "Wy" the application recognizes only the appropriate forms for Wyoming. (This application is being customized for each state's requirements.)

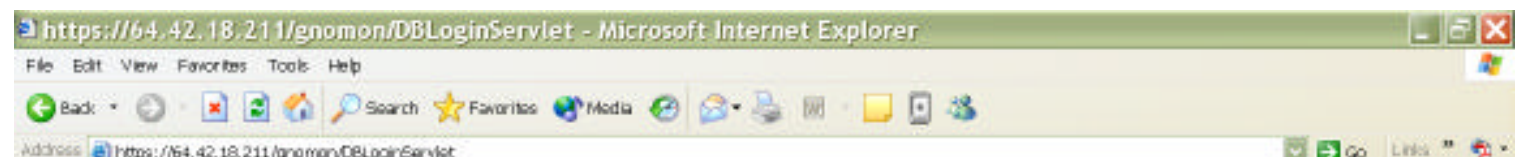

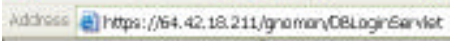

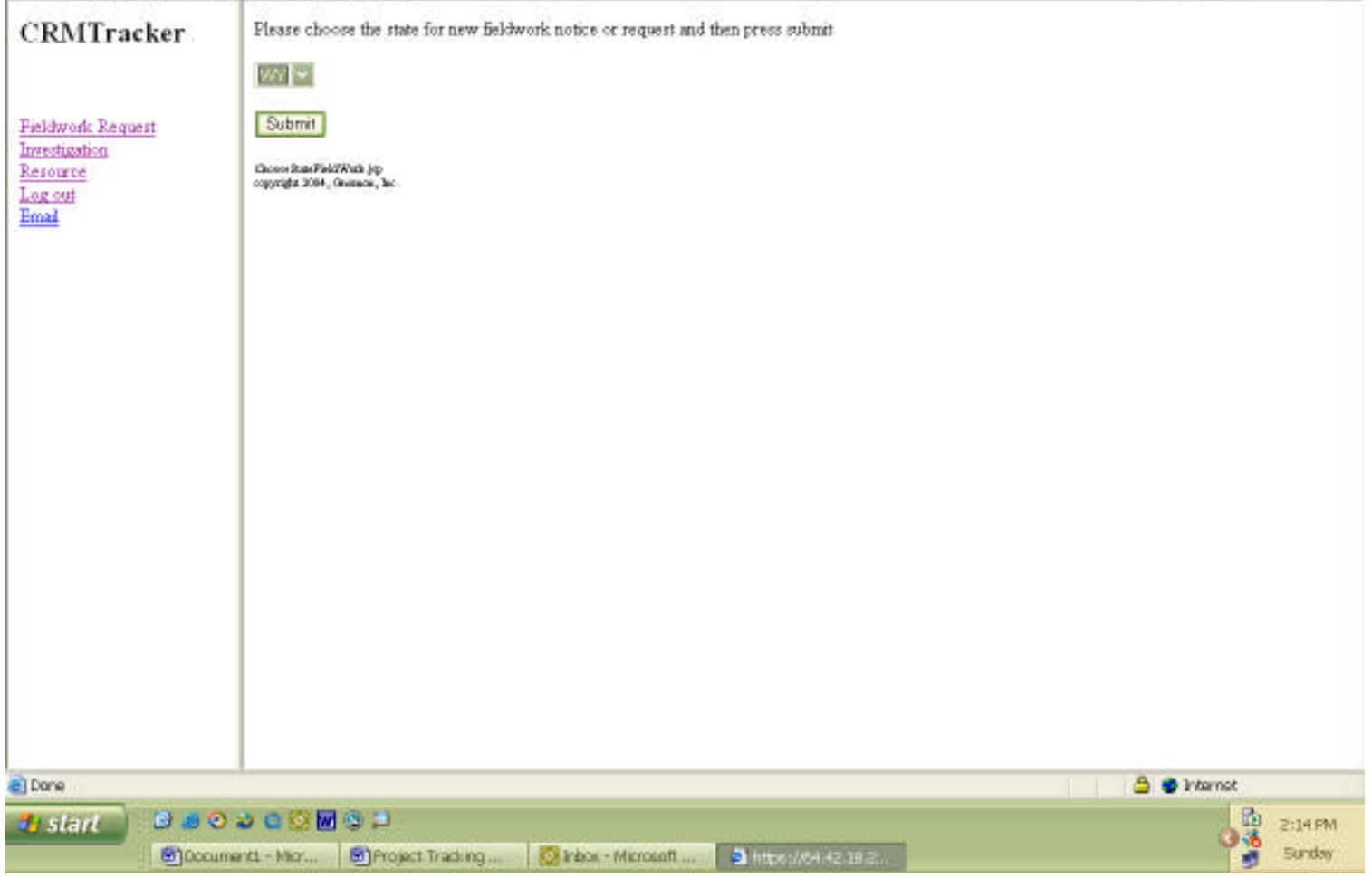


Once you have chosen the state, you are directed to a "Fieldwork description" page.

$* * *$ Note - on the top of each page, the application has a status bar of where you are in the database. The header below shows each step - Fieldwork description/County/Municipality/Cadastral/Maps/Report

(The data entered in the fields below are only for demonstration purposes.)***

All strings of text in this application should be separated by a semicolon (;)

FIELDWORK Fieldwork description-->County-->Municipality-->Cadastral-->Maps--

$>$ Report

\section{Cultural Resources Management Tracking Tool (CRMTRACKER) New Fieldwork Notification or Authorization Request}

Fill in ALL fields (use "unknown" as needed). Red fields are mandatory in all cases When finished, choose CONTINUE ENTRY to move to next page of request.

General Location

State

WY

Performing

Organization and Point

of Contact (POC)

Performing Organization

Permit \#

AAA Consultants

ZZ-2004 ARPA 12345

Organization POC

Prehistorian, Anne

POC Telephone

$999000-0000$

POC Email

wyarchcons@yahoo.com

POC Fax

$999000-0000$

Lead Agency

Lead Agency Office

Lead Agency POC

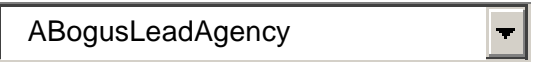

LeadArchaeologist, Andrew

Lead Agency Email

Lead Agency Fax

wyleadfed@yahoo.com

$999000-0000$

Investigation Rationale

Proponent/Sponsor/Client

Reason for Investigation

A Fake Oil and Gas Inc.

Well and Access 
Short Description and

field supervisor

A proposed 10 acre well with approximately 3 miles of access roa -

Anne Aprehistorian

(Associated Undertaking)

1

\section{Proposed Activities}

Investigation Name / \#

Investigation Actions

04-AAA-01; 45-36 Fake Well

Cultural Resource Survey

Show expected acres of survey as whole numbers. Areas smaller than an acre should be entered as 1. Enter 9999 in Extensive-Private to indicate no acreage is given at this time.

Proposed Acreages (archaeological surveys) Grand total is compulsory

\begin{tabular}{|l||l||l|l|}
\hline & \multicolumn{1}{|l|}{$\begin{array}{l}\text { Intensive (Class } \\
\text { III) }\end{array}$} & Extensive & Total \\
\hline Federal & 10 & & 0 \\
\hline \begin{tabular}{l||l|l|} 
Other \\
Public
\end{tabular} & 0 & 10 \\
\hline Private & 0 & 0 & 0 \\
\hline Total & 10 & 0 & 0 \\
\hline
\end{tabular}

Scope/bias (surveys only)

All resources

Planned start date

( $\mathrm{mm} / \mathrm{dd} /$ yyyy)

$04 / 04 / 2004$

Planned end date

(mm/dd/yyyy)

$04 / 04 / 2004$

Reason for investigation is a short description of the general project type. For example: "seismic survey", "CBM POD", "housing development", "land exchange", etc.

Short description and field supervisor: Describe the fieldwork briefly in this field (e.g. survey of a proposed gas pipeline approximately 7.4 miles in length.)

Associated Undertaking: Enter the name of the Undertaking if applicable (e.g. Express Pipeline.)

Proposed activities: This section describes the general work that will be done in the investigation.

Investigation Name/Number: This is the performing organization investigation name or number or both.

You can enter additional numbers such as Federal Agency numbers or other report tracking numbers if you have them available. Please separate these numbers with semicolons. 
Investigation Actions: This is the most prominent part of the project or the major activity reported. A project with 1000 acres of survey and some testing would be reported as a survey. If it is really a mix of types, use OTHER and describe it in the description field.

Start Date/End Date: These are required by the application; however if you do not know the precise start date or end dates, choose the first of the month you anticipate the work to begin. You will want to send an explanatory message to the lead federal agency. You can revise these dates later at the investigation portion of the application. 
The next step is to enter the county or counties where the field work will occur.

FIELD WORK New Field work -->County-->Municipality-->Cadastral-->Maps--

$>$ Report

\section{Highlight at least one county, then choose "Add To List" (mandatory)}

\begin{tabular}{l|l|}
\hline AB, Albany & \\
BH, Big Horn & \\
CA, Campbell \\
CR, Carbon \\
CO, Converse \\
CK, Crook \\
FR, Fremont \\
GO, Goshen \\
HO, Hot Springs \\
JO, Johnson
\end{tabular}

\section{You have selected the following counties}

\section{Converse}

\section{Campbell}

***Note: You can enter multiple counties.

The next step is the Municipality. This is generally used for actions within incorporated cities and towns. You can enter named places if appropriate (e.g. Spotted Horse, Orin Junction, or Gillette)

FIELD WORK New Field work -->County-->Municipality-->Cadastral-->Maps-$>$ Report

Enter names of each town/city (if appropriate) then choose Add To List Municipality:

You have selected following municipalities:

\section{Buffalo, Wy.}


The next step is entering the Cadastral location.

***Note: The Range will be changed to the default of "W"

FIELD WORK New Field work -->County-->Municipality-->Cadastral-->Maps--

$>$ Report

Enter cadastral information and then choose "Add To List" (mandatory)

Township:

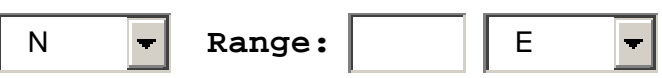

Meridian: 6 th Principal Mrdn

Choose individual sections by checking boxes in the township grid OR check the "All sections" box to choose all the 36 sections in the township. You must check at-least one box.

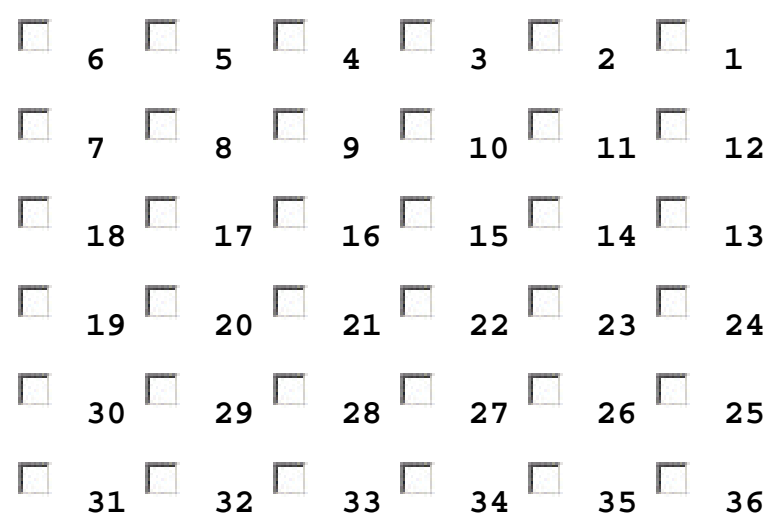

$\ulcorner$ All Sections

Clear data entry area 


\begin{tabular}{llllll}
\hline \multicolumn{2}{c}{ Township } & \multicolumn{2}{l}{ Range } & Meridian & Section \\
41 & N & 72 & W & 6 & 6 \\
41 & N & 72 & W & 6 & 7 \\
41 & N & 72 & W & 6 & 18 \\
41 & N & 72 & W & 6 & 19 \\
41 & N & 72 & W & 6 & 30 \\
41 & N & 72 & W & 6 & 31 \\
41 & N & 72 & W & 6 & 32 \\
41 & N & 72 & W & 6 & 33 \\
41 & N & 72 & W & 6 & 34 \\
41 & N & 72 & W & 6 & 35 \\
41 & N & 72 & W & 6 & 36
\end{tabular}

Enter the appropriate sections for the project.

Next step is to enter the appropriate USGS Topographic Map Names.

FIELD WORK New Field work -->County-->Municipality-->Cadastral-->Maps -$>$ Report

Choose at least one Map reference, then choose "Add To List" (mandatory)

Map Name: $\quad$ Abiathar Peak-24000(WY) 44110-H1

You have selected following maps

\begin{tabular}{|l|l|}
\hline Map name & Scale \\
\hline Alva & $\mathbf{2 4 0 0 0}$ \\
\hline Anderson Draw & $\mathbf{2 4 0 0 0}$ \\
\hline & \\
\hline \hline & \\
\hline
\end{tabular}


If you do not have the map reference, we have a MSAccess database created for lookup of appropriate maps. It is not part of the formal web application, but can be used on your local computer. There is a shortcut to this tool on your desktop.

Enter the Township, Range and Section and apply the "filter." The appropriate map names will be returned. If there are multiple maps, the bottom status bar will show " 1 of XXX" filtered. You can scroll through the list to find the appropriate map names.

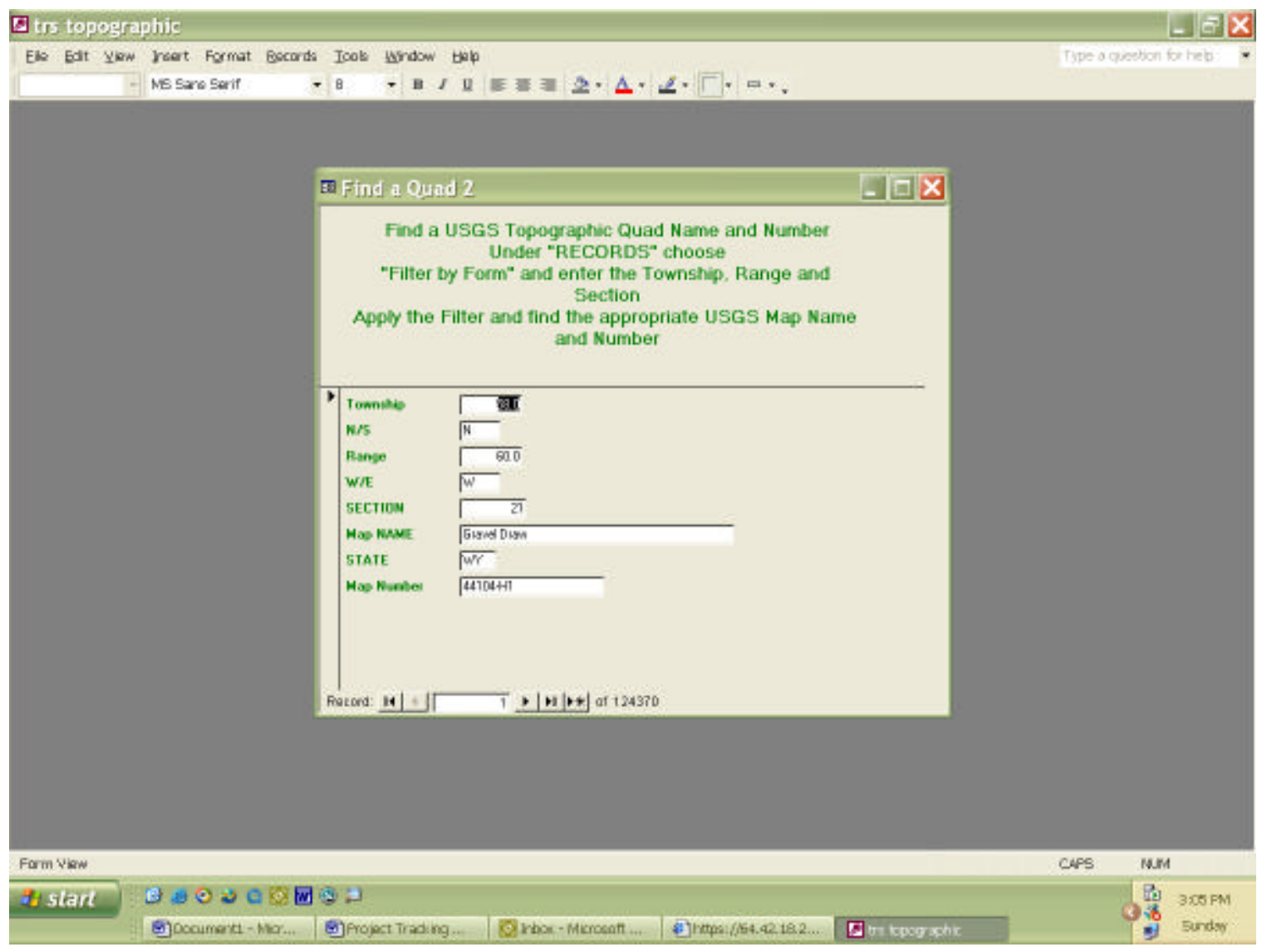

You can return to the website to enter the appropriate map names from the pick list. 
The next step is to confirm all information on the form and transmit the request to the appropriate agency.

FIELDWORK Fieldwork description -->County-->Municipality-->Cadastral-->Maps--

$>$ Report (confirm and transmit)

\section{Fieldwork Notification or Authorization Request - Confirmation and Transmittal}

Review all information carefully, edit as needed by selecting "Edit ... Info " button for appropriate section. When all information is confirmed choose "Finish-Send Request to Lead Agency" button at bottom. To cancel ALL entries choose "Cancel Entry Process" button at the bottom.

\begin{tabular}{|c|c|c|c|c|}
\hline State & \multicolumn{4}{|l|}{ WY } \\
\hline Notice or Request Date & \multicolumn{4}{|l|}{$4 / 4 / 2004$} \\
\hline Performing Organization & \multicolumn{4}{|c|}{ AAA Consultants } \\
\hline Permit \# & \multicolumn{4}{|c|}{ ZZ-2004 ARPA 12345} \\
\hline Organization POC & \multicolumn{4}{|c|}{ Prehistorian, Anne } \\
\hline POC Telephone & \multicolumn{4}{|c|}{$999000-0000$} \\
\hline POC Email & \multicolumn{4}{|c|}{ wyarchcons@yahoo.com } \\
\hline POC Fax & \multicolumn{4}{|c|}{$999000-0000$} \\
\hline Lead Agency Office & \multicolumn{4}{|c|}{ ABogusLeadAgency } \\
\hline Lead Agency POC & \multicolumn{4}{|c|}{ LeadArchaeologist, Andrew } \\
\hline Lead Agency Email & \multicolumn{4}{|c|}{ wyleadfed@yahoo.com } \\
\hline Lead Agency Fax & \multicolumn{4}{|c|}{$999000-0000$} \\
\hline Proponent/Sponsor/Client & \multicolumn{4}{|c|}{ A Fake Oil and Gas Inc. } \\
\hline Investigation Reason & \multicolumn{4}{|c|}{ Well and Access } \\
\hline $\begin{array}{l}\text { Short Description and } \\
\text { Field Supervisor }\end{array}$ & \multicolumn{4}{|c|}{$\begin{array}{l}\text { A proposed } 10 \text { acre well with approximately } 3 \text { miles of } \\
\text { access road. Anne Aprehistorian }\end{array}$} \\
\hline Associated Undertaking & \multicolumn{4}{|l|}{ none } \\
\hline Investigation Name / \# & \multicolumn{4}{|c|}{ 04-AAA-01; 45-36 Fake Well } \\
\hline Investigation Action & \multicolumn{4}{|c|}{ Cultural Resource Survey } \\
\hline $\begin{array}{l}\text { Proposed Acreages } \\
\text { (archaeological surveys; } \\
\text { 9999 indicates no estimate } \\
\text { given) }\end{array}$ & $\begin{array}{l}\text { Federal } \\
\text { Other } \\
\text { Public } \\
\text { Private }\end{array}$ & $\begin{array}{l}\text { Intensive } \\
\text { (Class III) } \\
10 \\
0 \\
0\end{array}$ & $\begin{array}{l}\text { Extensive } \\
0 \\
0 \\
0\end{array}$ & $\begin{array}{l}\text { Total } \\
10\end{array}$ \\
\hline & Private & & & \\
\hline
\end{tabular}




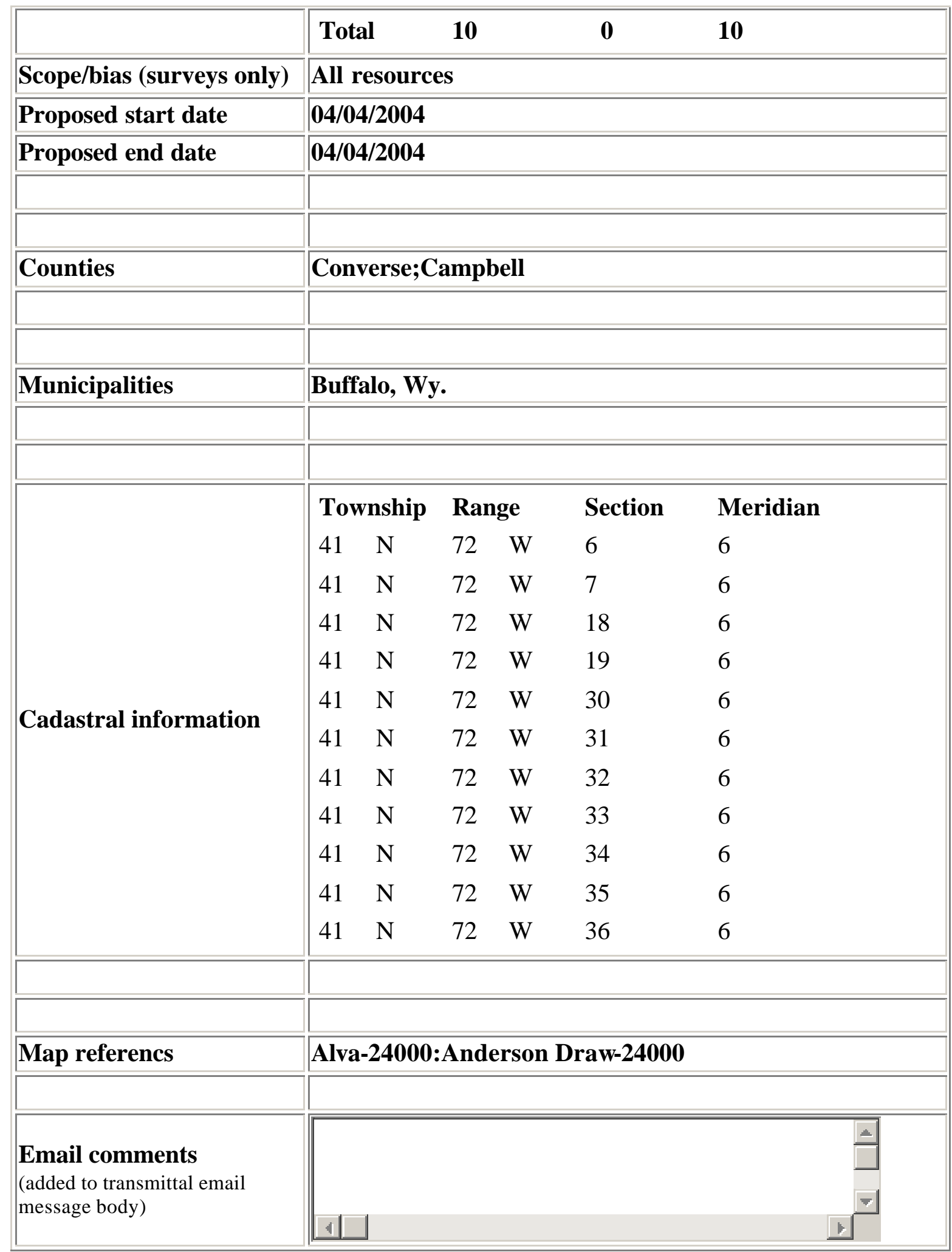


You can add email comment to the transmittal message.

You can print this page for your records, or as a faxed file search request to the SHPO.

Or

Before you send the record, go the "file" and "select all"

Copy the record ( $\operatorname{ctrl} \mathrm{C})$

Open your email

Paste the record (ctrl V)

This will be your file search request to the SHPO office. Below is an example:

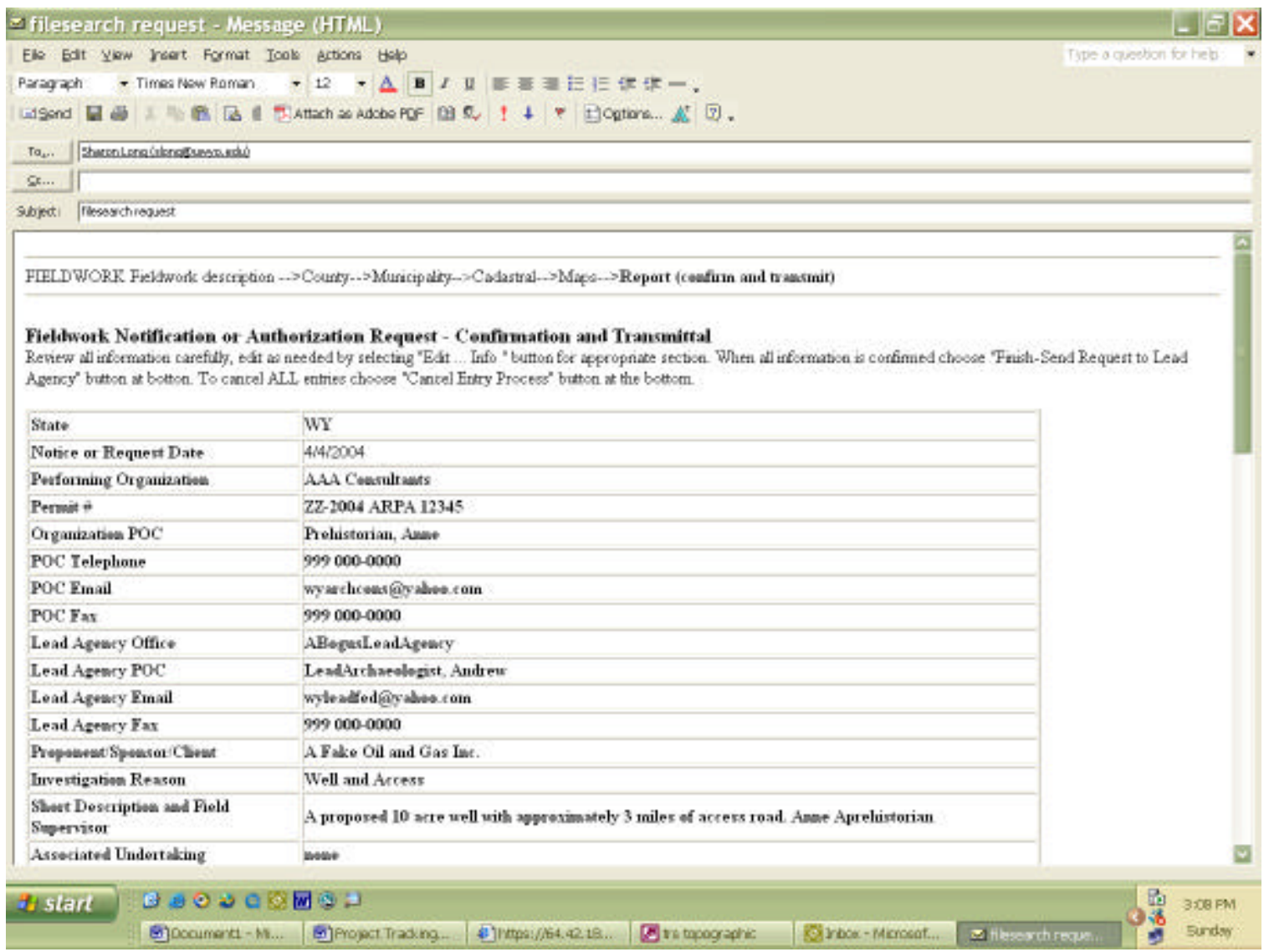


After you have submitted the record, you can send additional information or messages along with the record. This part of the application allows you to attach documents, maps or other appropriate attachments to the lead agency. If you have an email program on your computer, it will open for you to use. If you use an Internet mail program such as "Yahoo" or "Hotmail", the mail program will not open.

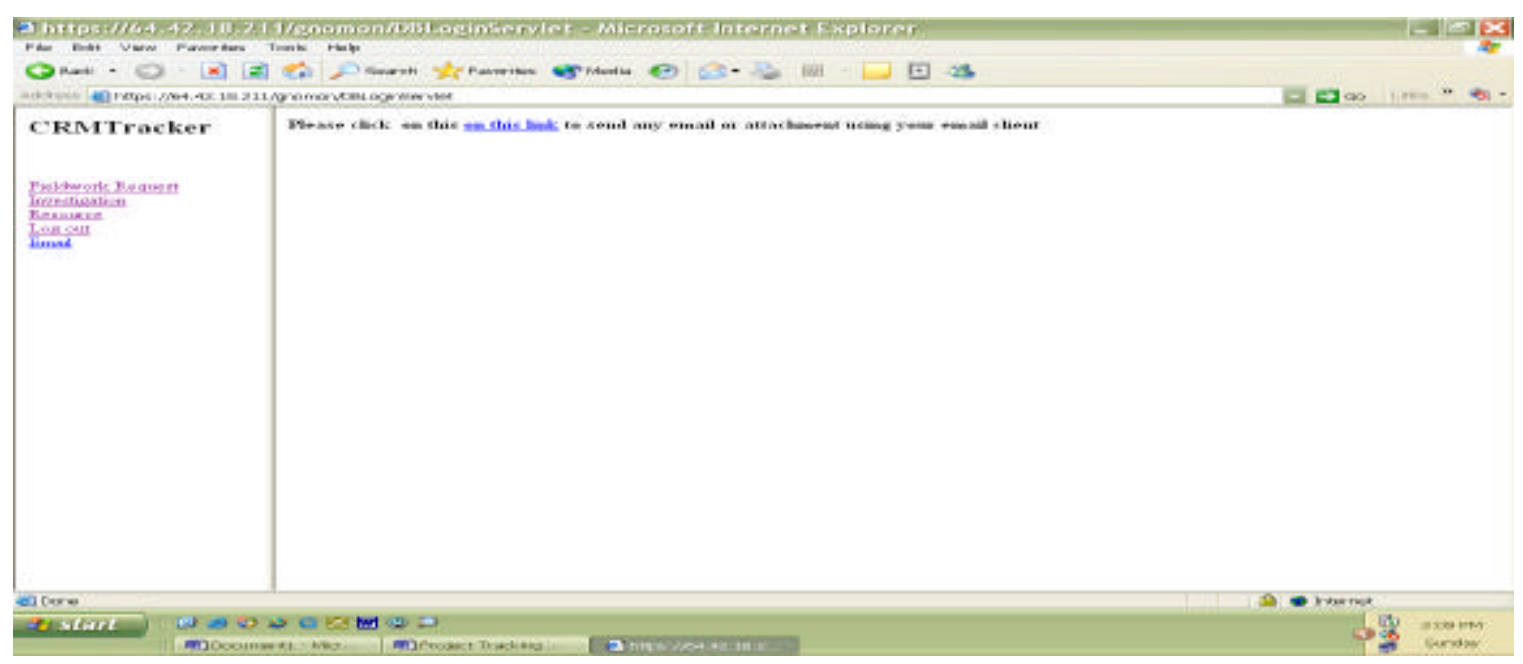

Below is an example of the default mail message created:

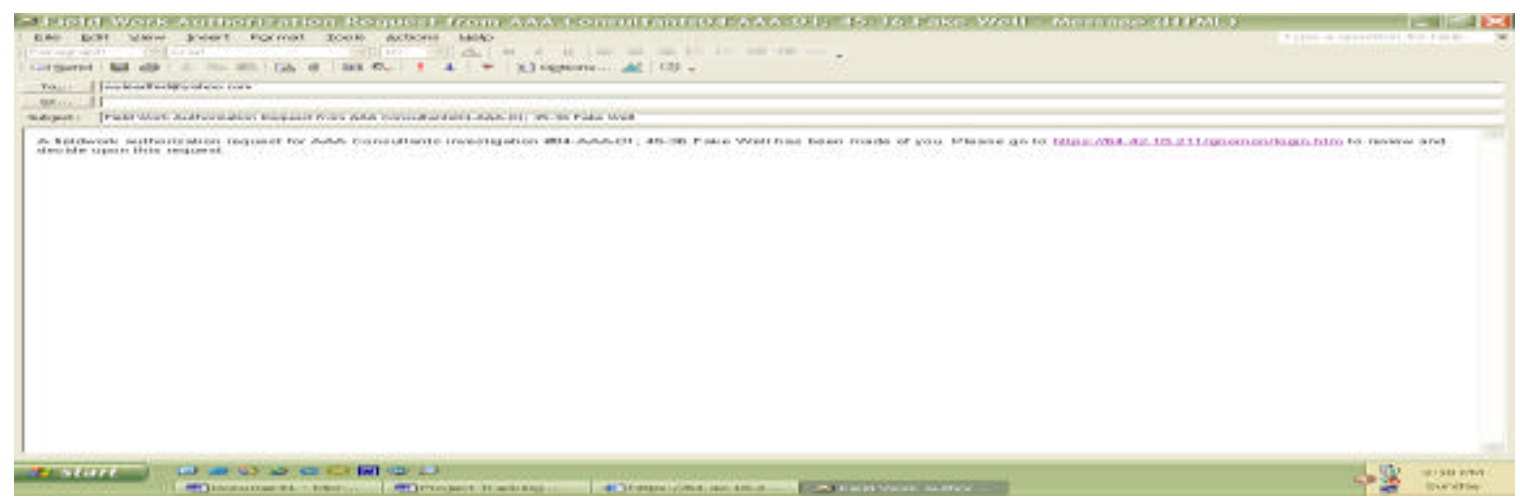


Log back on to the application.

Click on Fieldwork Request

Go to Check Existing Requests

The fieldwork request is listed "04-AAA-01" and has been submitted to the lead agency for approval

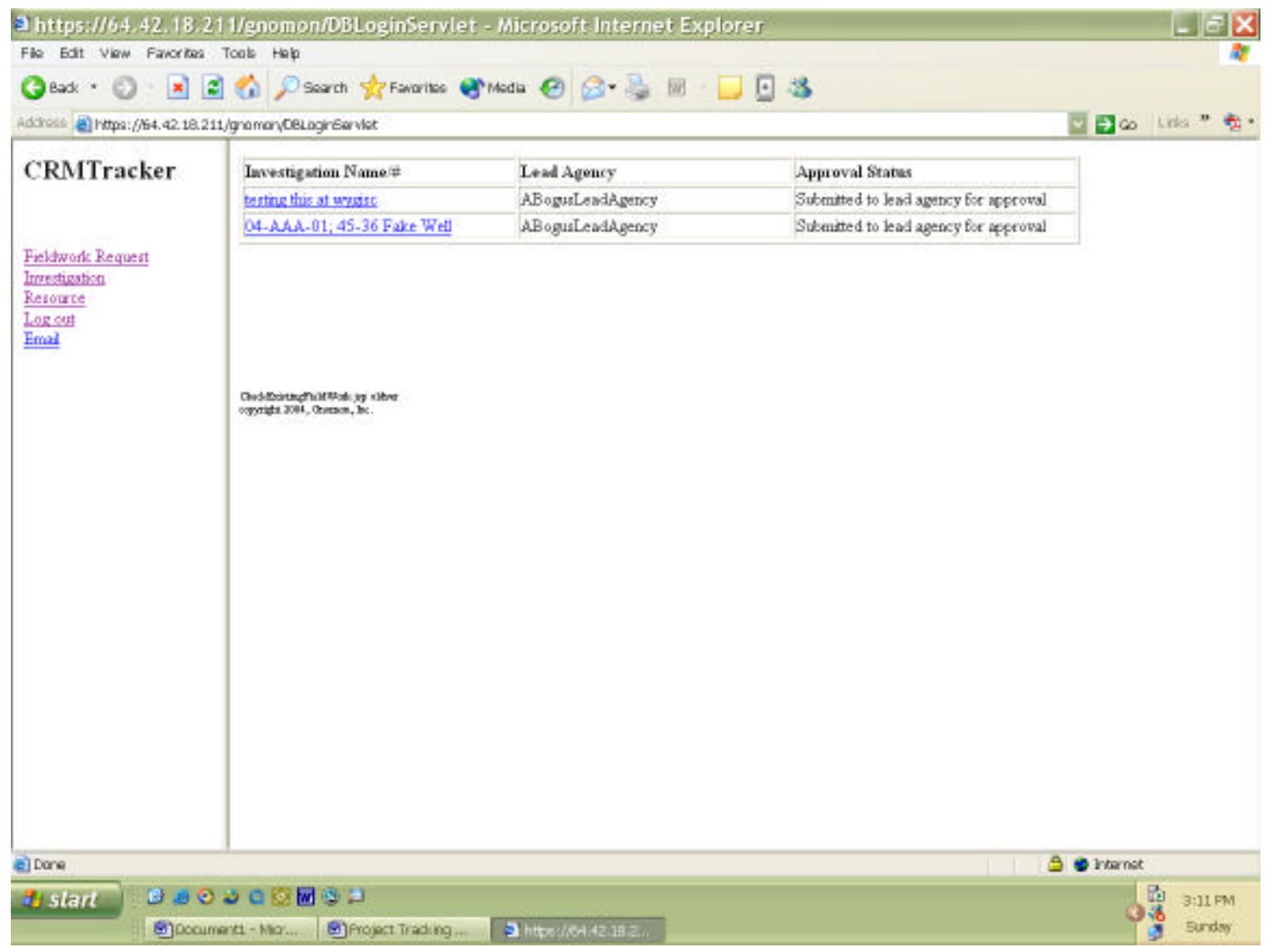


Now we'll log onto the e-mail of the lead agency.

There is an e-mail message waiting for the lead agency to logon to the project tracking system. Any messages included in the "e-mail" box in the application will be included.

If the "click Link" to send an e-mail message was chosen at the end of the data entry, there will be two messages waiting for the reviewer. One created by the project tracking application and one created by the mail account on the local computer.

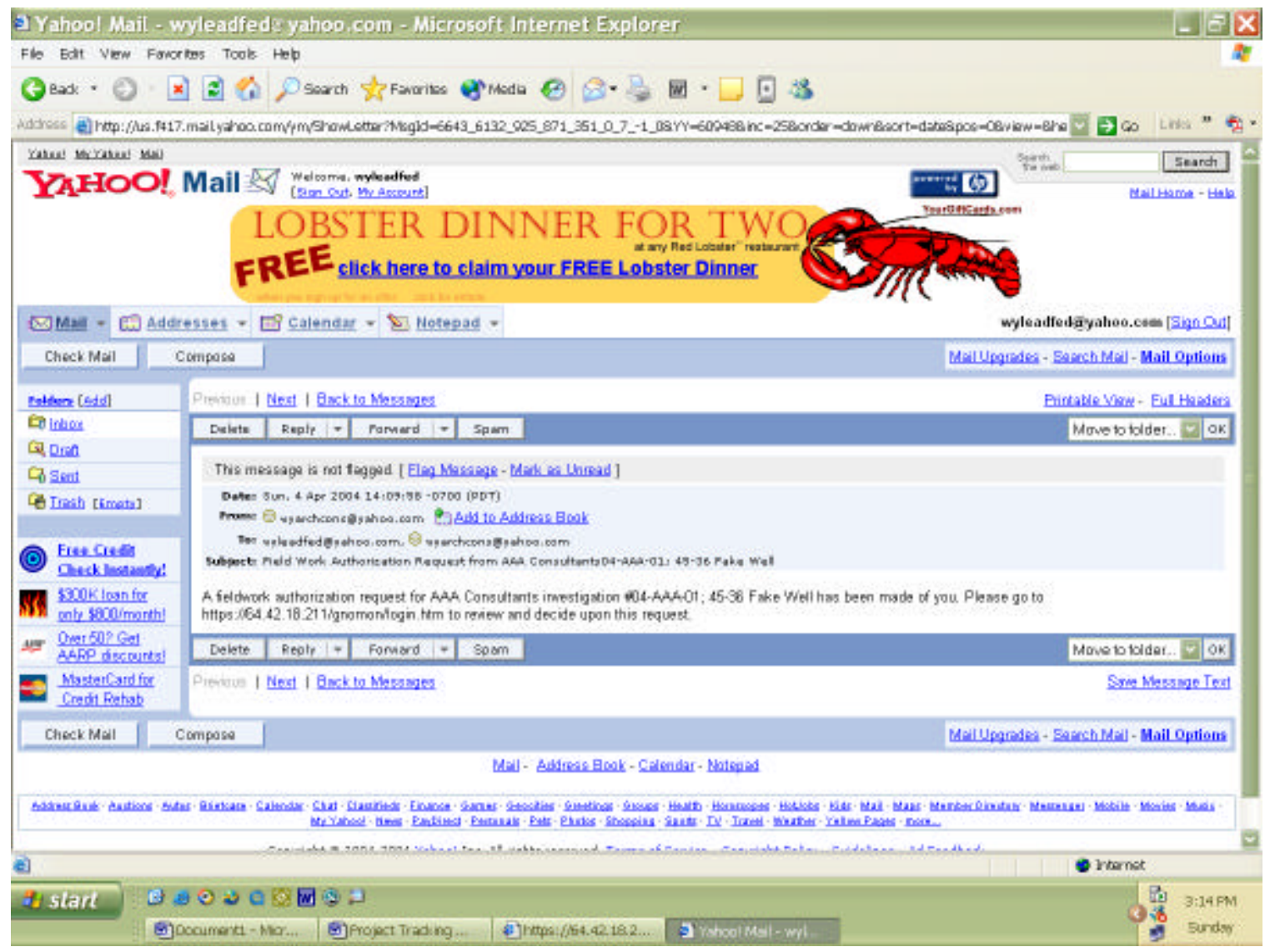


Now we will log on as the lead agency. Notice our menu items are different.

The user name and password is: aleadarch

Choose "Review New"
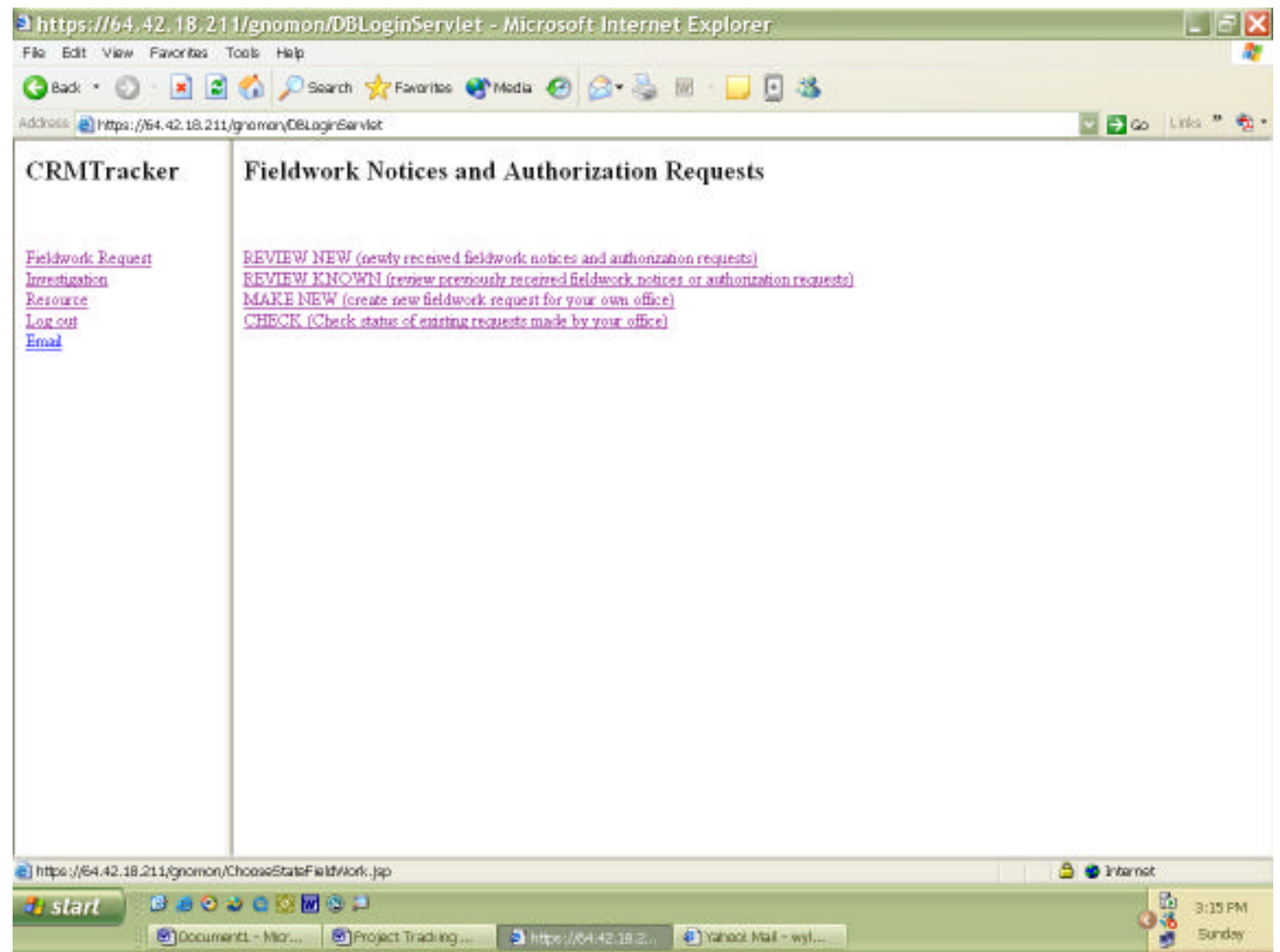
In the "Review New" list is the record submitted by "aprehistorian"

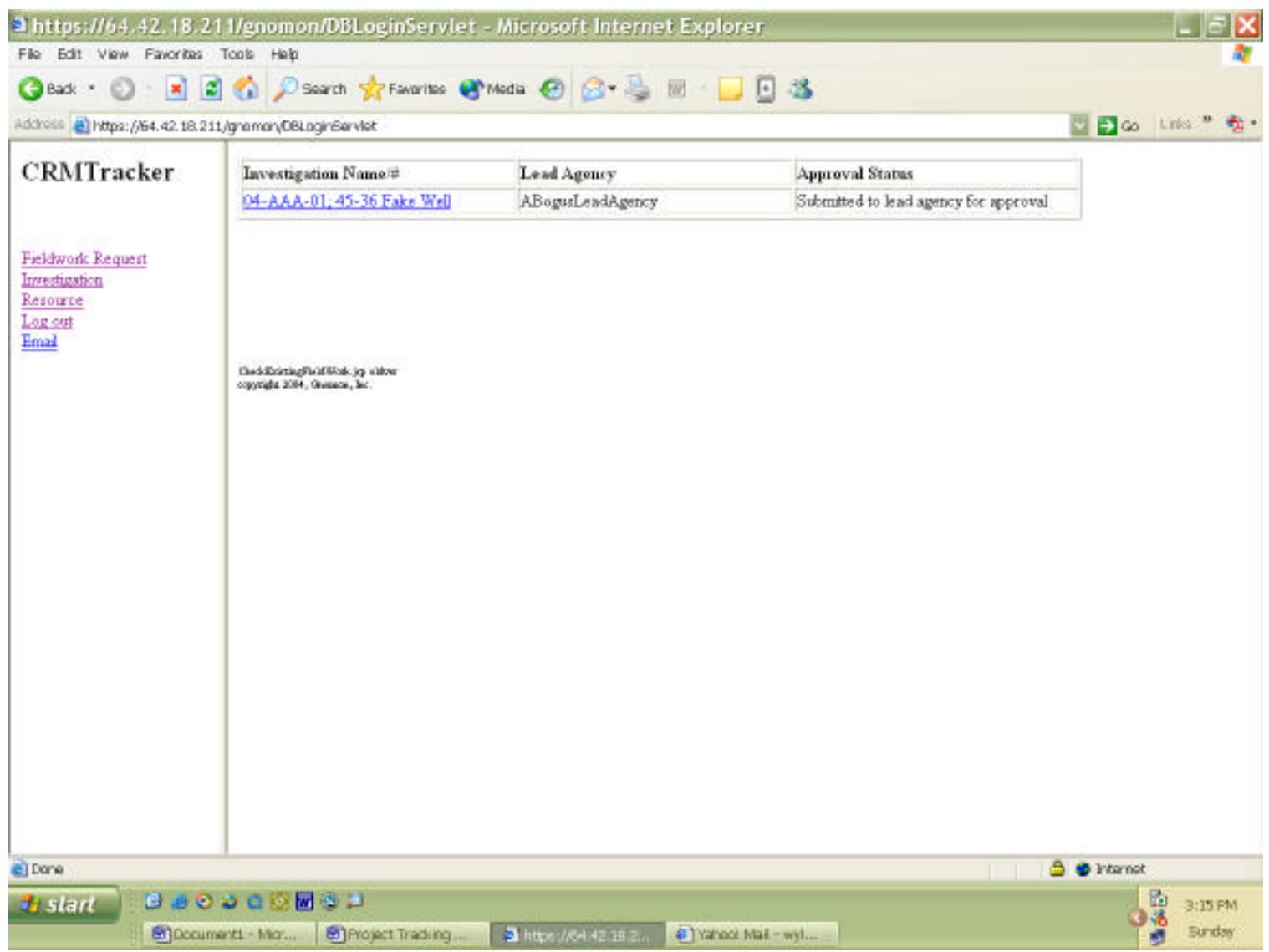


Choose the project record.

The Fieldwork Notification Request is displayed.

Scroll to the bottom of the page.

There are buttons available to save the record so you can return to it after later, disapprove the request or approve the request.

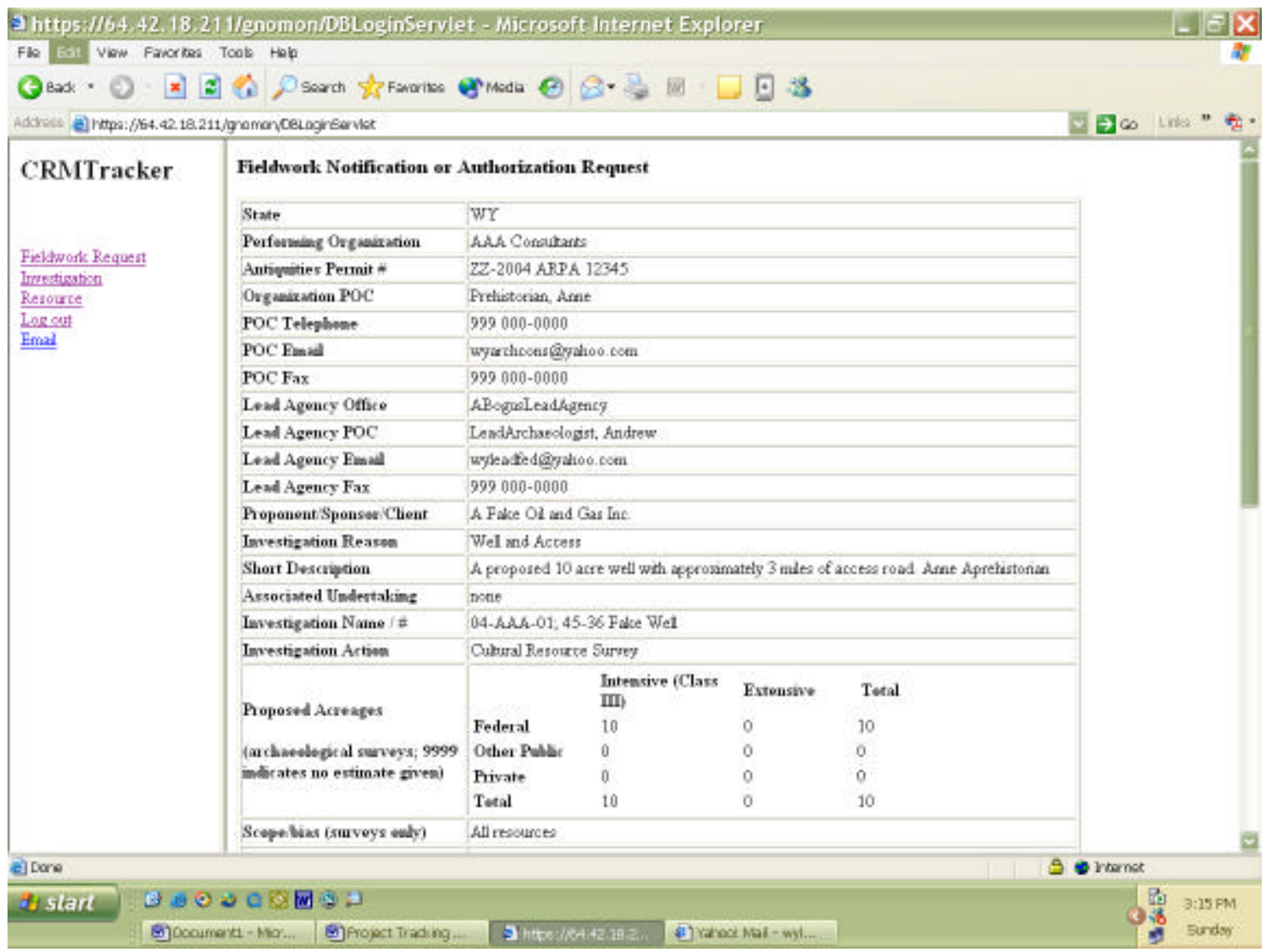


Once a decision has been made for the notification, a mail message is sent to the field agent. There is also the "click on link" to send e-mail message option. The lead agency can send special instructions, attachments, etc.

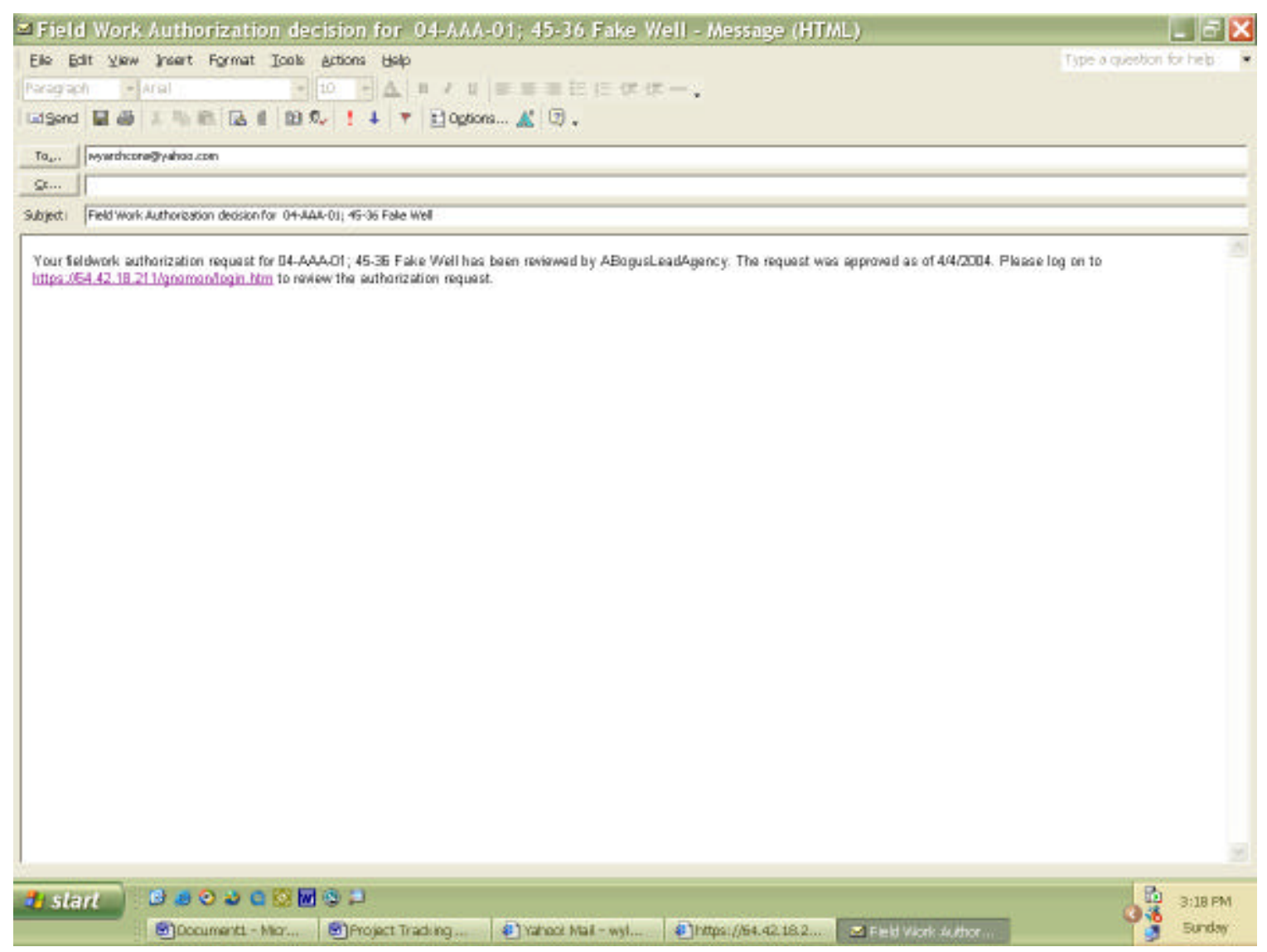


There will be a mail message waiting for the field investigator.

Log back onto the application as "aprehistorian"

Go to the "Fieldwork requests"

Check existing requests

There should be a record waiting for the approved fieldwork request.

Open the record and scroll to the bottom of the page.

You are given four options: Convert into Investigation, Cancel Field Work, Void the field work request or View printable report.

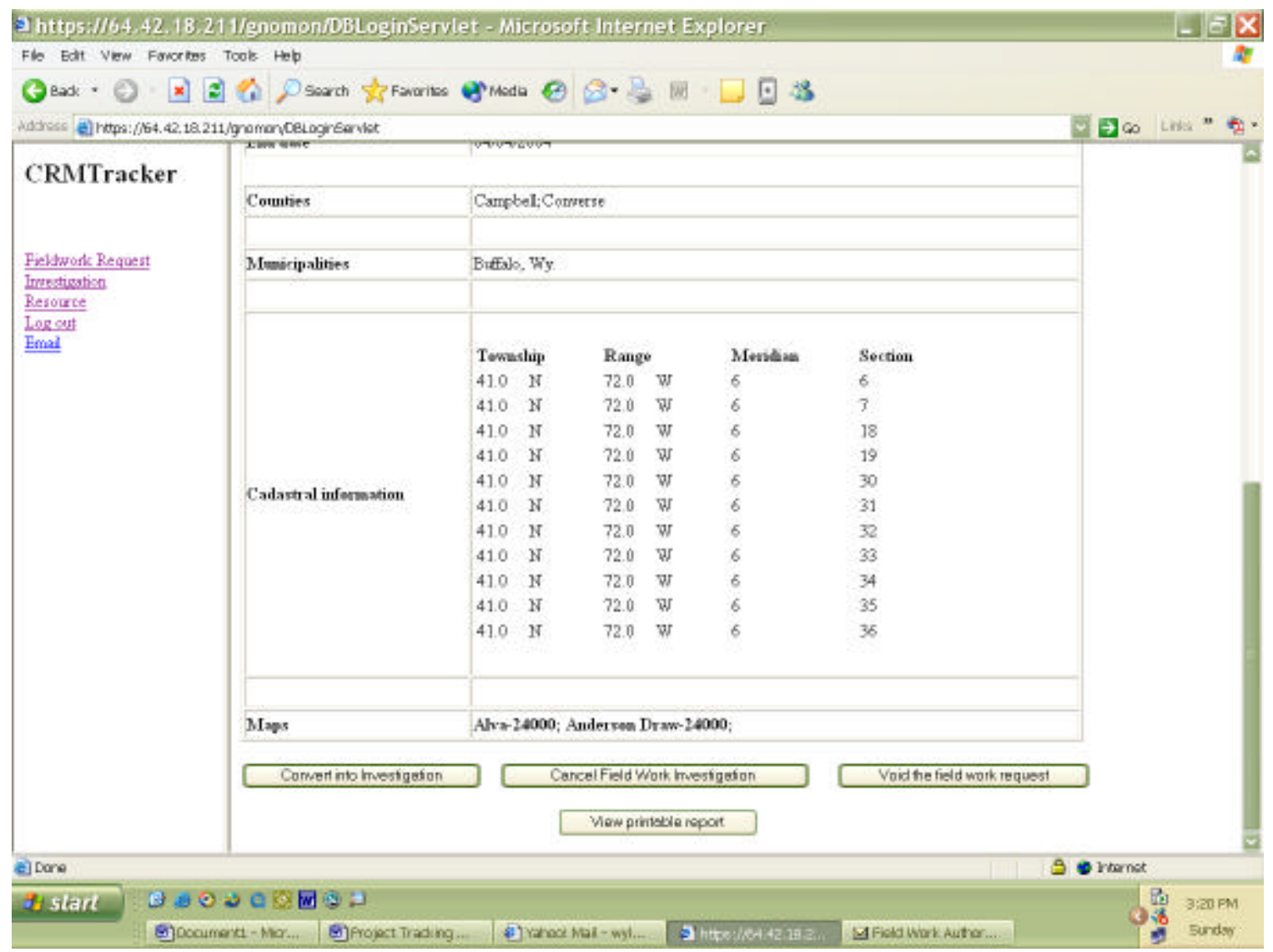


Choose "Convert into Investigation"

Previous entry is available to the user to change or update.

You can modify the field work dates, project descriptions, filed personnel, etc.

FIELD WORK Existing New Investigation -->County-->Municipality-->Cadastral--

>Maps-->Land-->Resources-->Report

\section{Cultural Resource Project Tracking Prototype}

Gnomon, Inc.

\section{Investigation Request}

Directions: Fill in ALL fields (use "unknown" as needed). Red fields are mandatory in all cases When finished, choose CONTINUE ENTRY to move to next page of request.

\section{General Location}

State

WY

\section{Performing \\ Organization and Point of Contact (POC)}

Performing Organization

Permit \#

AAA Consultants

Organization POC

ZZ-2004 ARPA 12345

POC Telephone

Prehistorian, Anne

POC Email

$999000-0000$

POC Fax

wyarchcons@yahoo.com

$999000-0000$

\section{Lead Agency}

Lead Agency Office

Lead Agency POC

Lead Agency Email

Lead Agency Fax

\begin{tabular}{|l|}
\hline ABogusLeadAgency \\
\hline LeadArchaeologist, Andrew \\
\hline wyleadfed@yahoo.com \\
\hline 999 000-0000
\end{tabular}

Investigation Rationale

Proponent/Sponsor/Client

A Fake Oil and Gas Inc.

Reason for Investigation

Well and Access 


Short Description and
field supervisor

\section{Proposed Activities}

Investigation Name / \#

04-AAA-01; 45-36 Fake Well

Investigation Actions

Cultural Resource Survey

Scope/bias (surveys only)

All resources

Start date (mm/dd/yyyy) $\longdiv { 0 4 / 0 4 / 2 0 0 4 }$

End date (mm/dd/yyyy) $\longdiv { 0 4 / 0 4 / 2 0 0 4 }$ 
You will step through many of the same pages.

You can delete and/or add to the information.

This is a common page included as an example. Municipality, Cadastral, and Maps are much the same.

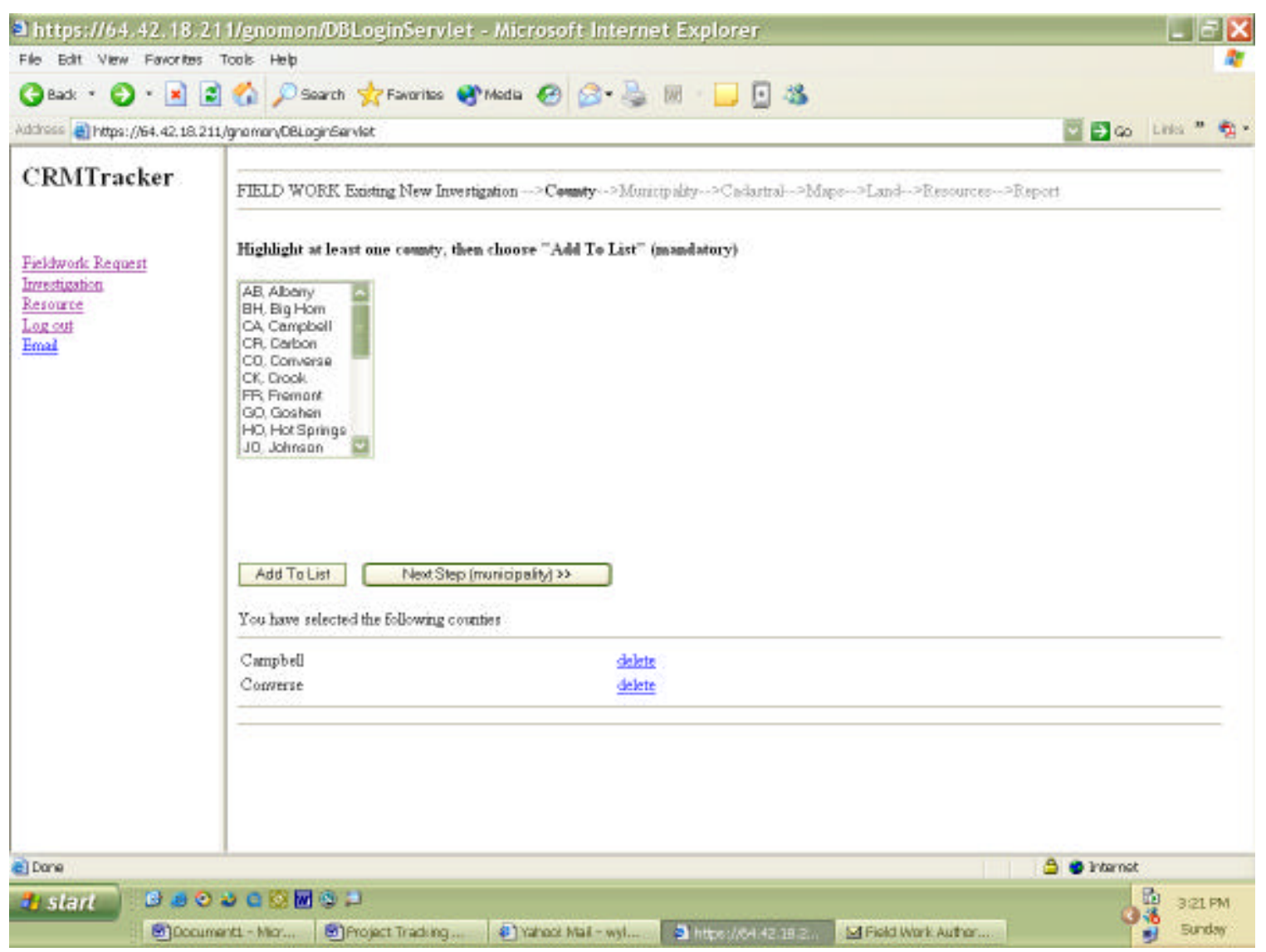


Next the entry of actual acreages included in the investigation is reported.

Choose the appropriate type from the Protocol drop down list

Choose the land owner.

Report acreages separately for each land owner

For linear acreage, choose the type of protocol and land owner; in the other box type "linear"

FIELD WORK Existing New Investigation -->County-->Municipality-->Cadastral-$>$ Maps-->Land-->Resources-->Report

For surveys, please enter survey protocol(s) and land owner(s). For other projects, choose "Other" for protocol, enter owner and put in actual acres or zero. Then choose "Add To List"(mandatory)

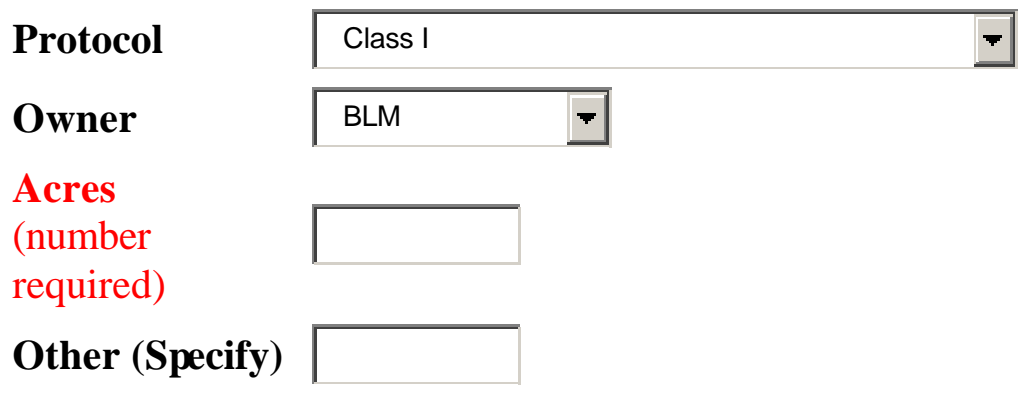

\begin{tabular}{lllll}
\hline Protocol & Owner & Acres & Other & Action \\
Class III & BLM & 10 & null & DELETE \\
Class III & BLM & 15.8 & linear & $\underline{\text { DELETE }}$
\end{tabular}


Next are resources located.

Report all resources where newly or previously recorded

If resources are reported within the ape and not relocated, report them and include comment in the "data entry note" field.

The format of the Resource Identifying number is 48 SW 939 . 1

(The last box on the right is for segment number for linear segments and localities within districts. If there is not a segment number for the resource, leave it blank.)

Loop through this part until all resources are included in the list.

If no resources were located, continue through the application.

FIELD WORK Existing New Investigation -->County-->Municipality-->Cadastral->Maps-->Land--> Resources-->Report

Enter resources (sites) associated with this investigation. Then choose "Add To List"

*Resource identifying number:

Other name/ID

Previously recorded?

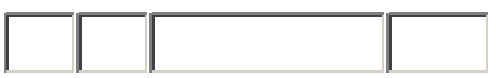

Prior eligibility (if known)

Eligibility Unknown

General age Prehistoric $\quad$ T

Current eligibility statement

Not Eligible

Property type

SITE

Resource description

NR Criteria (if eligible)

Contributing element of district?

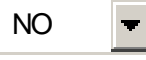

Data entry notes/b>

* Box 1:number(state \#, usually);Box 2 characters: county code or other prefix;Box 3:number;Box 4:characters or \#,suffix or segment number 


\begin{tabular}{|l|l|l|l|l|l|}
\hline Resource ID & Prev. Elig. & Age & Curr. Elig. & Property type & Delete? \\
\hline \begin{tabular}{l|l|l|l|} 
48-JO-345 04- \\
AAA-01-1
\end{tabular} & Not Eligible & Prehistoric & Not Eligible & SITE & DELETE \\
\hline & $\begin{array}{l}\text { SMALL SITE } \\
\text { WITH TWO } \\
\text { PROJECTILE } \\
\text { POINTS }\end{array}$ & & & \\
& & & \\
\hline
\end{tabular}

If you make a mistake, you can delete the record and start over.

Now you can print the record for inclusion with the paper report to be submitted to the agency.

\begin{tabular}{|c|c|}
\hline State & WY \\
\hline Performing Organization & AAA Consultants \\
\hline Antiquities Permit \# & ZZ-2004 ARPA 12345 \\
\hline Organization POC & Prehistorian, Anne \\
\hline POC Telephone & $999000-0000$ \\
\hline POC Email & wyarchcons@yahoo.com \\
\hline POC Fax & $999000-0000$ \\
\hline Lead Agency Office & ABogusLeadAgency \\
\hline Lead Agency POC & LeadArchaeologist, Andrew \\
\hline Lead Agency Email & wyleadfed@yahoo.com \\
\hline Lead Agency Fax & $999000-0000$ \\
\hline Proponent/Sponsor/Client & A Fake Oil and Gas Inc. \\
\hline Investigation Reason & Well and Access \\
\hline Short Description & $\begin{array}{l}\text { A proposed } 10 \text { acre well with approximately } 3 \text { miles of } \\
\text { access road. Anne Aprehistorian }\end{array}$ \\
\hline Associated Undertaking & none \\
\hline Investigation Name / \# & 04-AAA-01; 45-36 Fake Well \\
\hline Investigation Action & Cultural Resource Survey \\
\hline $\begin{array}{l}\text { Proposed Acreages: } \\
\text { (archaeological surveys) }\end{array}$ & $\begin{array}{lll} & \begin{array}{l}\text { Intensive } \\
\text { (Class III) }\end{array} \text { Extensive Total } \\
\text { Federal } & \\
\text { Other } & \\
\text { Public } & \\
\text { Private } & \end{array}$ \\
\hline
\end{tabular}




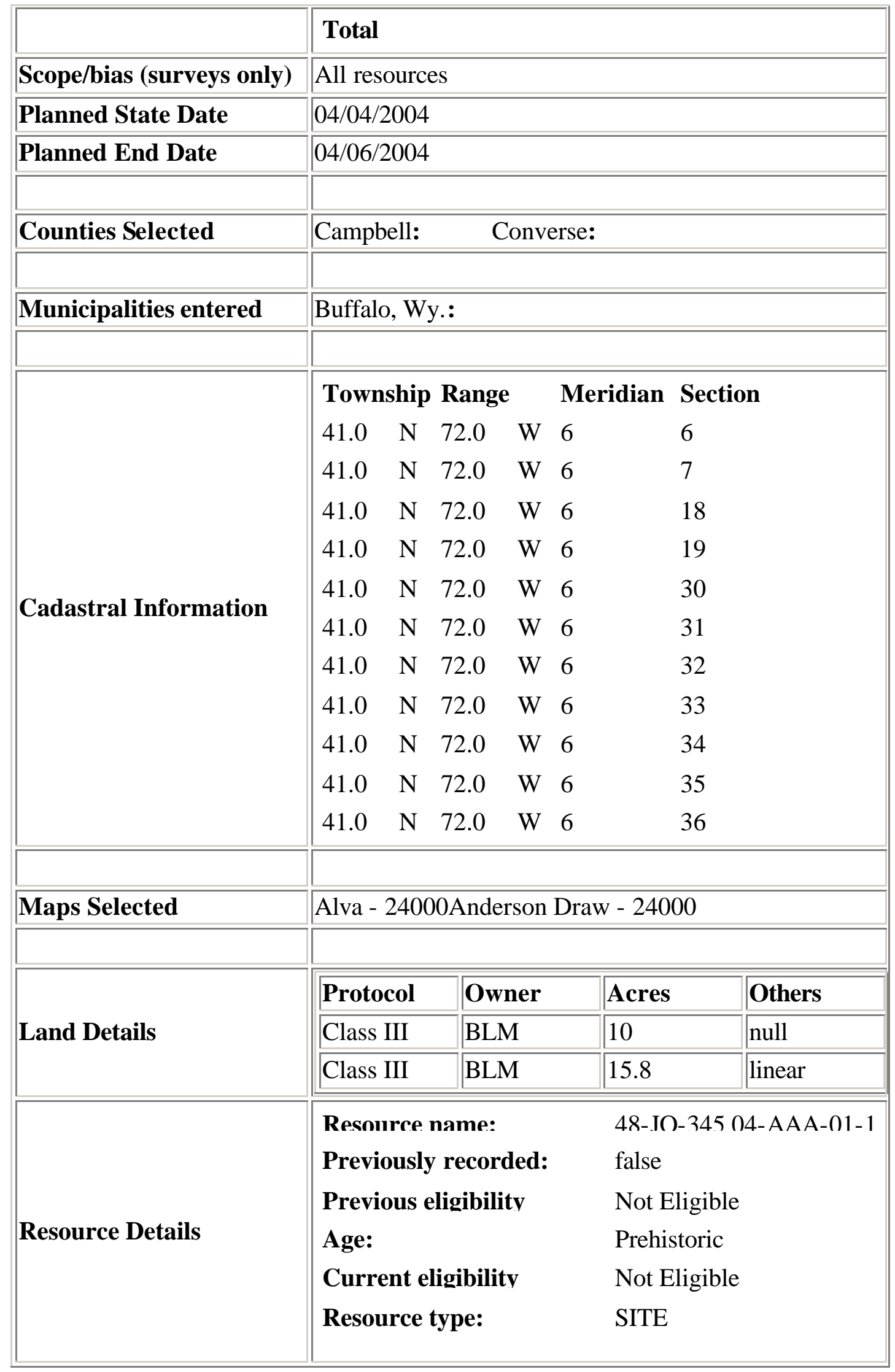




\begin{tabular}{|l|ll|}
\hline & $\begin{array}{l}\text { Resource type: } \\
\text { Criteria: }\end{array}$ & SITE \\
Contributing portion: & false \\
& SMALL SITE WITH \\
& Comments: & TWO PROJECTILE \\
& POINTS \\
\hline
\end{tabular}

You have now been assigned the project tracking number for this investigation. Open the Investigation.

The system has assigned the number DBI_WY_2004_28 to this investigation. Please use this number on all materials related to this investigation or to communicate with the system administrators about any problems.

\begin{tabular}{|l|l|l|l|l|}
\hline Investigation ID & $\begin{array}{l}\text { Investigation } \\
\text { Name/\# }\end{array}$ & Lead Agency & Sponsor & $\begin{array}{l}\text { Reason for } \\
\text { investigation }\end{array}$ \\
\hline \hline DBI_WY_2004_28 & $\begin{array}{l}\text { O4-AAA-01; 45-36 } \\
\text { Fake Well }\end{array}$ & ABogusLeadAgency & $\begin{array}{l}\text { A Fake Oil } \\
\text { and Gas } \\
\text { Inc. }\end{array}$ & $\begin{array}{l}\text { Well and } \\
\text { Access }\end{array}$ \\
\hline \hline & & \\
\hline
\end{tabular}

You will see the Report Cover sheet:

\section{Investigation Report Cover Sheet}

Review all information carefully, edit as needed by selecting "Edit ... Info >>" button for appropriate section. When all information is confirmed choose "Finish-Send Record to Lead Agency" button at bottom. To cancel ALL entries choose "Cancel Entry Process" button at the bottom. To save your work without submitting to the lead agency at this time, choose "Save Entry (do not send) " button at bottom.

\begin{tabular}{|l|l|}
\hline State & WY \\
\hline Performing organization & AAA Consultants \\
\hline Permit \# & ZZ-2004 ARPA 12345 \\
\hline Report date & \\
\hline Organization POC & Prehistorian, Anne \\
\hline POC Telephone & $999000-0000$ \\
\hline POC Email & wyarchcons@ yahoo.com \\
\hline
\end{tabular}




\begin{tabular}{|c|c|c|c|c|c|}
\hline POC Fax & \multicolumn{5}{|c|}{$999000-0000$} \\
\hline Lead agency office & \multicolumn{5}{|c|}{ ABogusLeadAgency } \\
\hline Lead agency POC & \multicolumn{5}{|c|}{ LeadArchaeologist, Andrew } \\
\hline Lead agency email & \multicolumn{5}{|c|}{ wyleadfed@yahoo.com } \\
\hline Lead agency fax & \multicolumn{5}{|c|}{$999000-0000$} \\
\hline Proponent/Sponsor/Client & \multicolumn{5}{|c|}{ A Fake Oil and Gas Inc. } \\
\hline Investigation reason & \multicolumn{5}{|c|}{ Well and Access } \\
\hline Short description & \multicolumn{5}{|c|}{$\begin{array}{l}\text { A proposed } 10 \text { acre well with approximately } 3 \text { miles of access } \\
\text { road. Anne Aprehistorian }\end{array}$} \\
\hline Associated undertaking & \multicolumn{5}{|c|}{ none } \\
\hline Investigation name / \# & \multicolumn{5}{|c|}{ 04-AAA-01; 45-36 Fake Well } \\
\hline Investigation action & \multicolumn{5}{|c|}{ Cultural Resource Survey } \\
\hline Scope/bias (surveys only) & \multicolumn{5}{|c|}{ All resources } \\
\hline Start date & \multicolumn{5}{|l|}{$04 / 04 / 2004$} \\
\hline End date & \multicolumn{5}{|l|}{$04 / 06 / 2004$} \\
\hline Counties & & Campbell; $\quad$ Converse; \\
\hline Municipalities & \multicolumn{5}{|c|}{ Buffalo, Wy.; } \\
\hline \multirow{11}{*}{ Cadastral information } & Township & \multicolumn{2}{|c|}{ Range } & Section & Meridian \\
\hline & $41.0 \quad \mathrm{~N}$ & 72.0 & $\mathrm{~W}$ & 6 & 6 \\
\hline & $41.0 \quad \mathrm{~N}$ & 72.0 & W & 7 & 6 \\
\hline & $41.0 \quad \mathrm{~N}$ & 72.0 & W & 18 & 6 \\
\hline & $41.0 \quad \mathrm{~N}$ & 72.0 & W & 19 & 6 \\
\hline & $41.0 \quad \mathrm{~N}$ & 72.0 & W & 30 & 6 \\
\hline & $41.0 \quad \mathrm{~N}$ & 72.0 & W & 31 & 6 \\
\hline & $41.0 \quad \mathrm{~N}$ & 72.0 & W & 32 & 6 \\
\hline & $41.0 \quad \mathrm{~N}$ & 72.0 & W & 33 & 6 \\
\hline & $41.0 \quad \mathrm{~N}$ & 72.0 & W & 34 & 6 \\
\hline & 41.0 & 72.0 & W & 35 & 6 \\
\hline
\end{tabular}




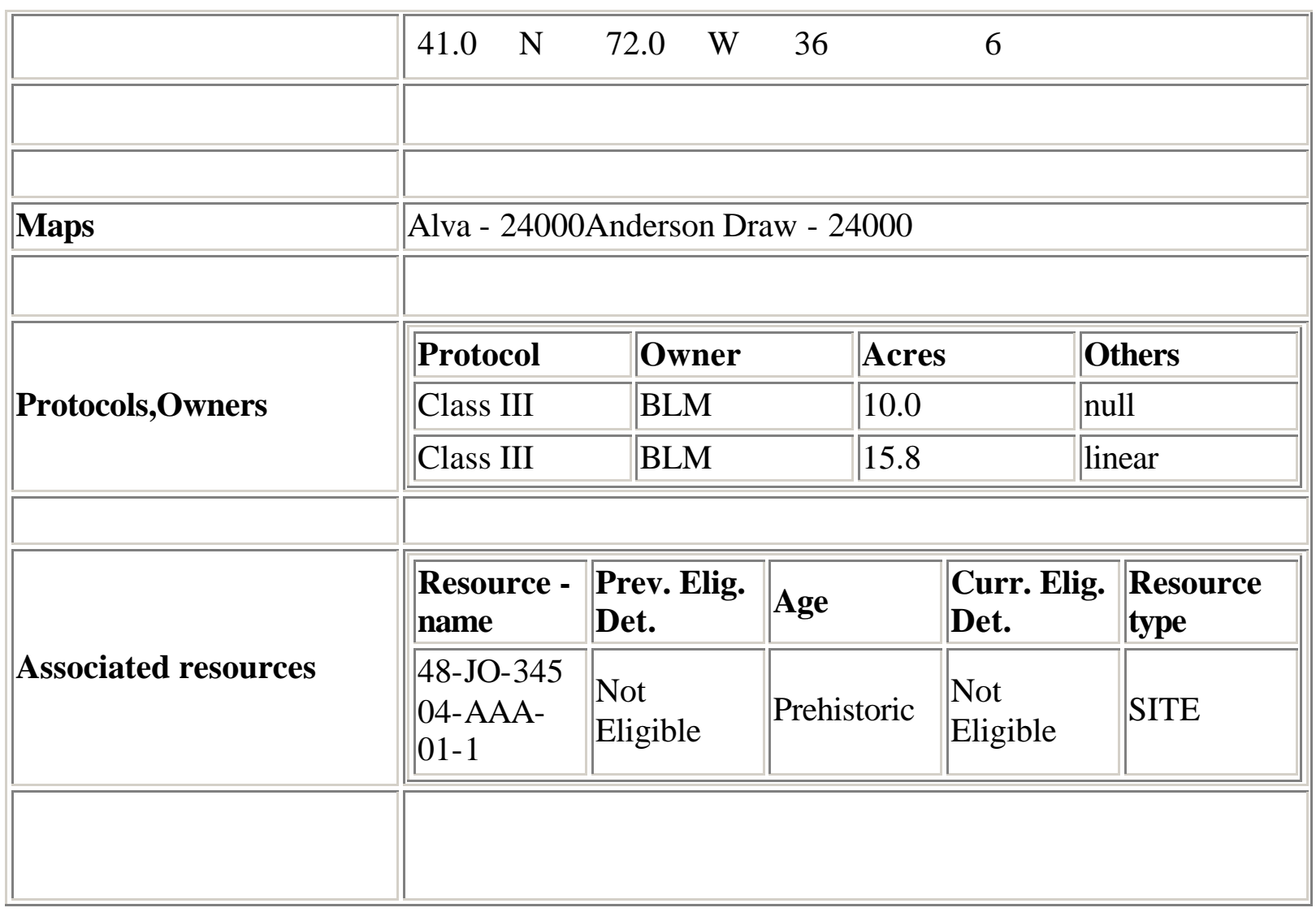

You can now submit the record to the lead agency for review. There will be an e-mail message sent to the lead agency for the record.

Now logon to the application as the lead agency

aleadarch

Choose "Investigation"

Choose "Review Log"

\section{Investigation Review Menu}

$\underline{\text { Review New (unreviewed items) }}$

$\underline{\text { Review In Progress (suspensed - held for entry) }}$ 
$\underline{\text { Review All - all reviews) }}$

\begin{tabular}{|l|l|l|l|l|}
\hline Investigation ID & $\begin{array}{l}\text { Performing } \\
\text { Organization } \\
\text { Name/\# }\end{array}$ & Sponsor & Start Date & $\begin{array}{l}\text { Reason for } \\
\text { investigation }\end{array}$ \\
\hline DBI_WY_2004_28 & AAA Consultants & $\begin{array}{l}\text { A Fake Oil and } \\
\text { Gas Inc. }\end{array}$ & 04/04/2004 & $\begin{array}{l}\text { Well and } \\
\text { Access }\end{array}$ \\
\hline \hline & \multicolumn{2}{|l|}{ Aares. } \\
\hline
\end{tabular}

Choose the DBI WY 200428 
The Investigation Report is available for review.

\section{Investigation Report}

Press "Next step(review form)" button at botton to take review decision or view the review history of this record. Press "Go Back To Investigation Details" button at bottom to go back to the investigation menu.

\begin{tabular}{|l|l||}
\hline State & WY \\
\hline Performing organization & AAA Consultants \\
\hline Permit \# & ZZ-2004 ARPA 12345 \\
\hline Organization POC & Prehistorian, Anne \\
\hline POC Telephone & 999 000-0000 \\
\hline POC Email & wyarchcons @ yahoo.com \\
\hline POC Fax & 999 000-0000 \\
\hline Lead agency office & ABogusLeadAgency \\
\hline Lead agency POC & LeadArchaeologist, Andrew \\
\hline Lead agency email & wyleadfed@ yahoo.com \\
\hline Lead agency fax & 999 000-0000 \\
\hline Proponent/Sponsor/Client & A Fake Oil and Gas Inc. \\
\hline Investigation reason & Well and Access \\
\hline Short description & $\begin{array}{l}\text { A proposed 10 acre well with approximately 3 miles of access } \\
\text { road. Anne Aprehistorian }\end{array}$ \\
\hline Associated undertaking & none \\
\hline Investigation name / \# & 04-AAA-01; 45-36 Fake Well \\
\hline Investigation action & Cultural Resource Survey \\
\hline Scope/bias (surveys only) & All resources \\
\hline Start date & 04/04/2004 \\
\hline End date & 04/06/2004 \\
\hline \hline Counties & Campbell; \\
\hline \hline Municipalities & Buffalo, Wy.; \\
\hline \hline & \\
\hline Cadastral information & Township Range \\
\hline & \\
\hline
\end{tabular}




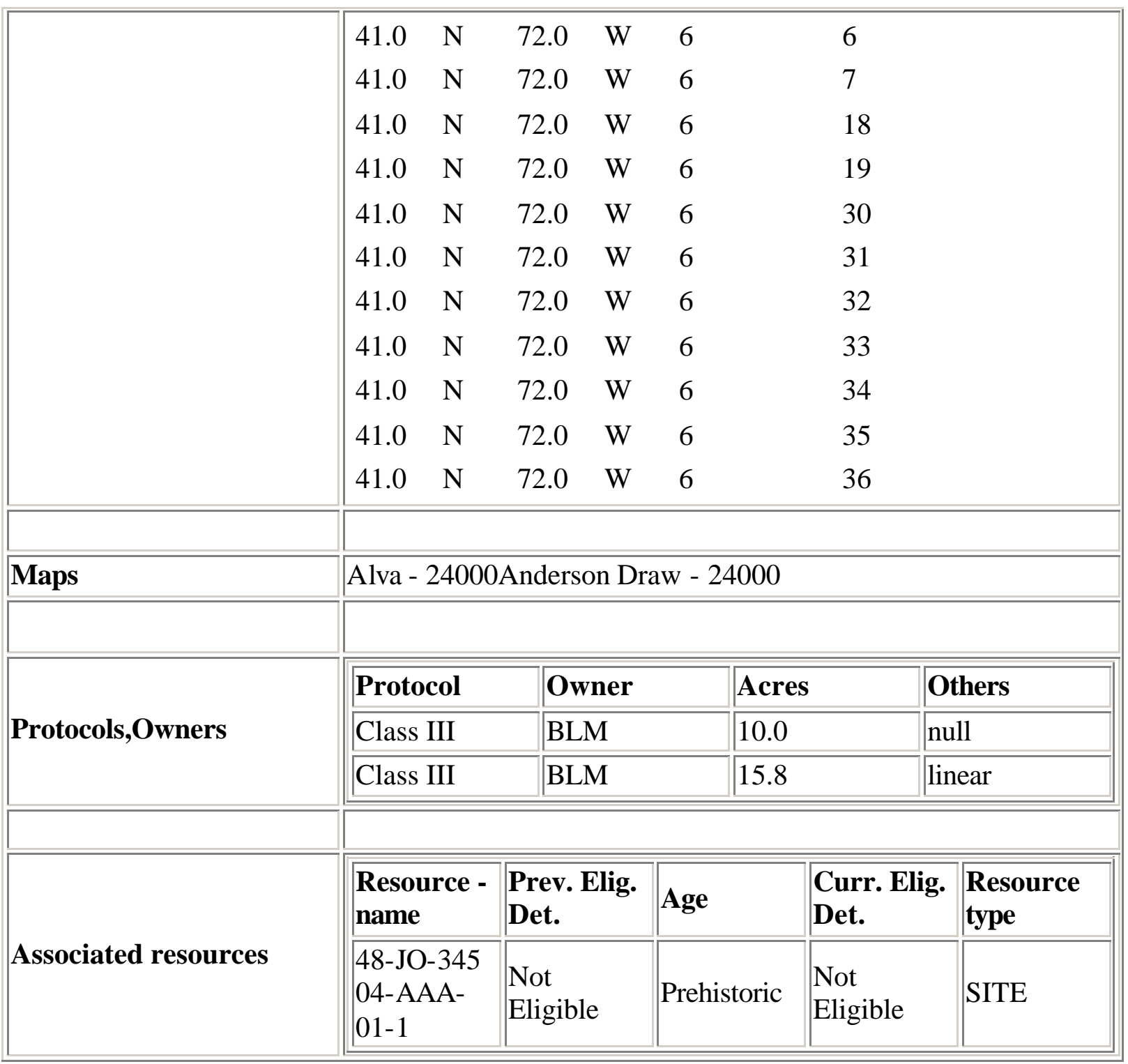


Next is the Make comments and view history screen

DBI_WY_2004_28-->Make comments and view history--> Transfer to next organization for next action

\section{Review Form}

Press "Cancel" button to take no action and return back to investigation menu. Press "Save Review" button to save your review comments. Press "Submit Review" to submit the review to other reviewing agency.

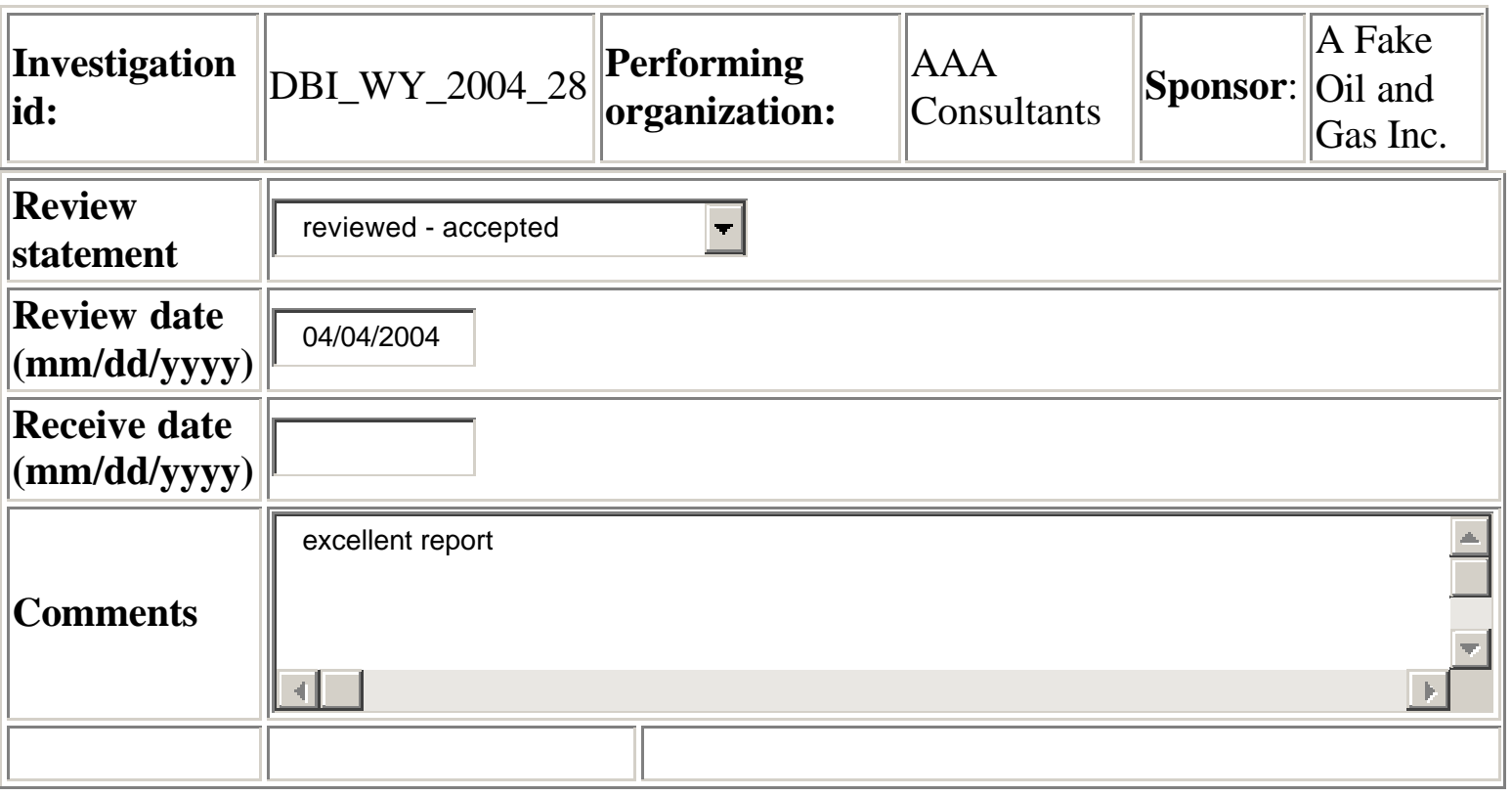

\begin{tabular}{|l|l|l|l|l|}
\hline $\begin{array}{l}\text { Review } \\
\text { date }\end{array}$ & $\begin{array}{l}\text { Reviewer user } \\
\text { name }\end{array}$ & $\begin{array}{l}\text { Reviewer } \\
\text { Organization }\end{array}$ & $\begin{array}{l}\text { Review } \\
\text { statement }\end{array}$ & Comments \\
\hline \begin{tabular}{l|l|l|} 
2004- \\
$04-04$
\end{tabular} & $\begin{array}{l}\text { LeadArchaeologist, } \\
\text { Andrew }\end{array}$ & ABogusLeadAgency & $\begin{array}{l}\text { reviewed - } \\
\text { accepted }\end{array}$ & excellent report \\
\hline \hline & & & \\
\hline
\end{tabular}


You will see a pop up message to the "routing slip" for the record. Be sure to save the review first.

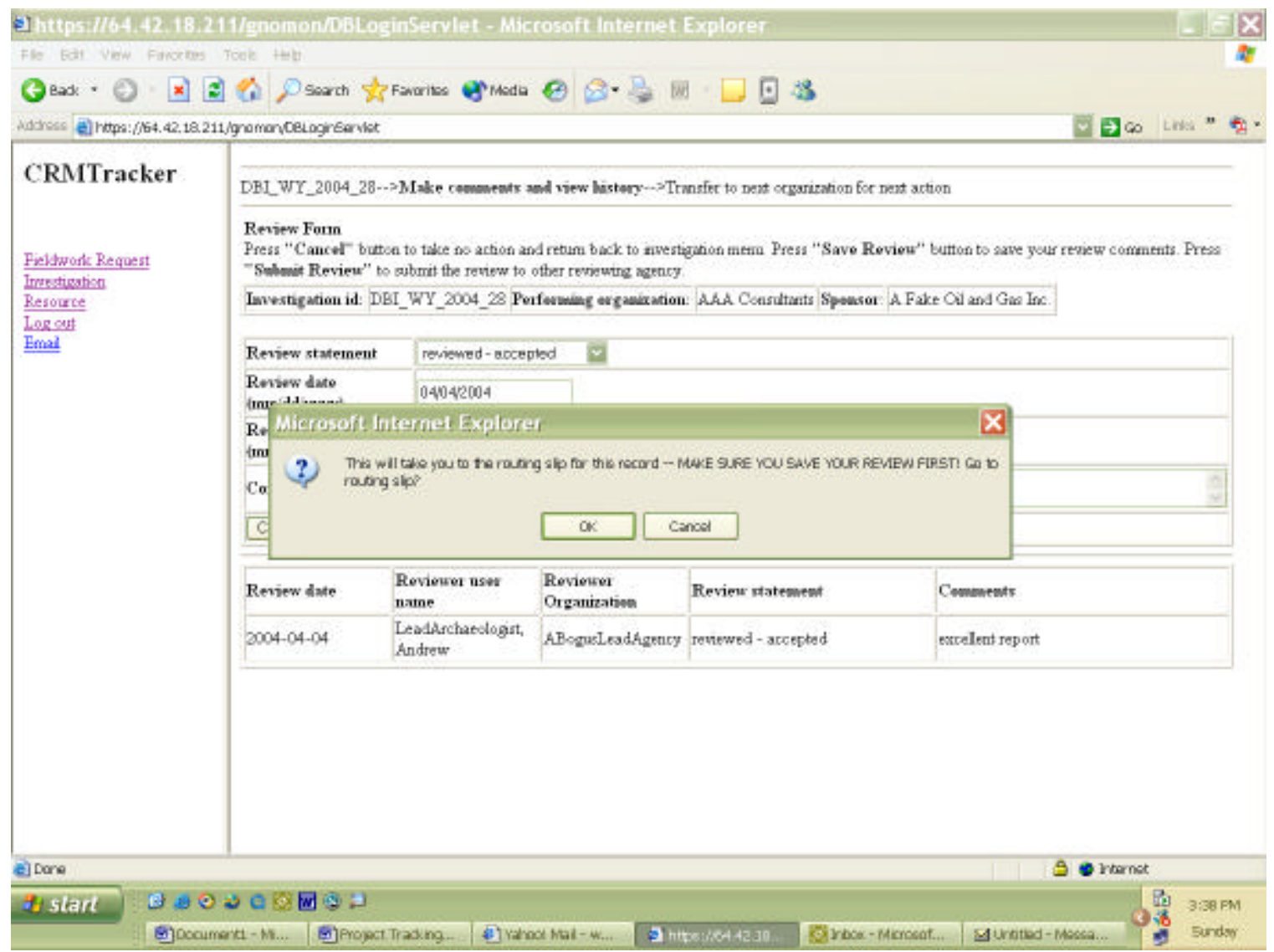


The record can then be routed back to the field consultant, to another lead archaeologist, or onto the SHPO.

DBI_WY_2004_28-->Make comments and view history--> Transfer to next organization for next action

Press the "Send Review" button to send this investigation record to another agency for review, edits, filing, etc. Press "Cancel" to go back to the main menu (your review will still be saved).

(This form is basically a routing slip that also has an action request on it. After you send this investigation record to the recipient they become the current owner of the database record.)

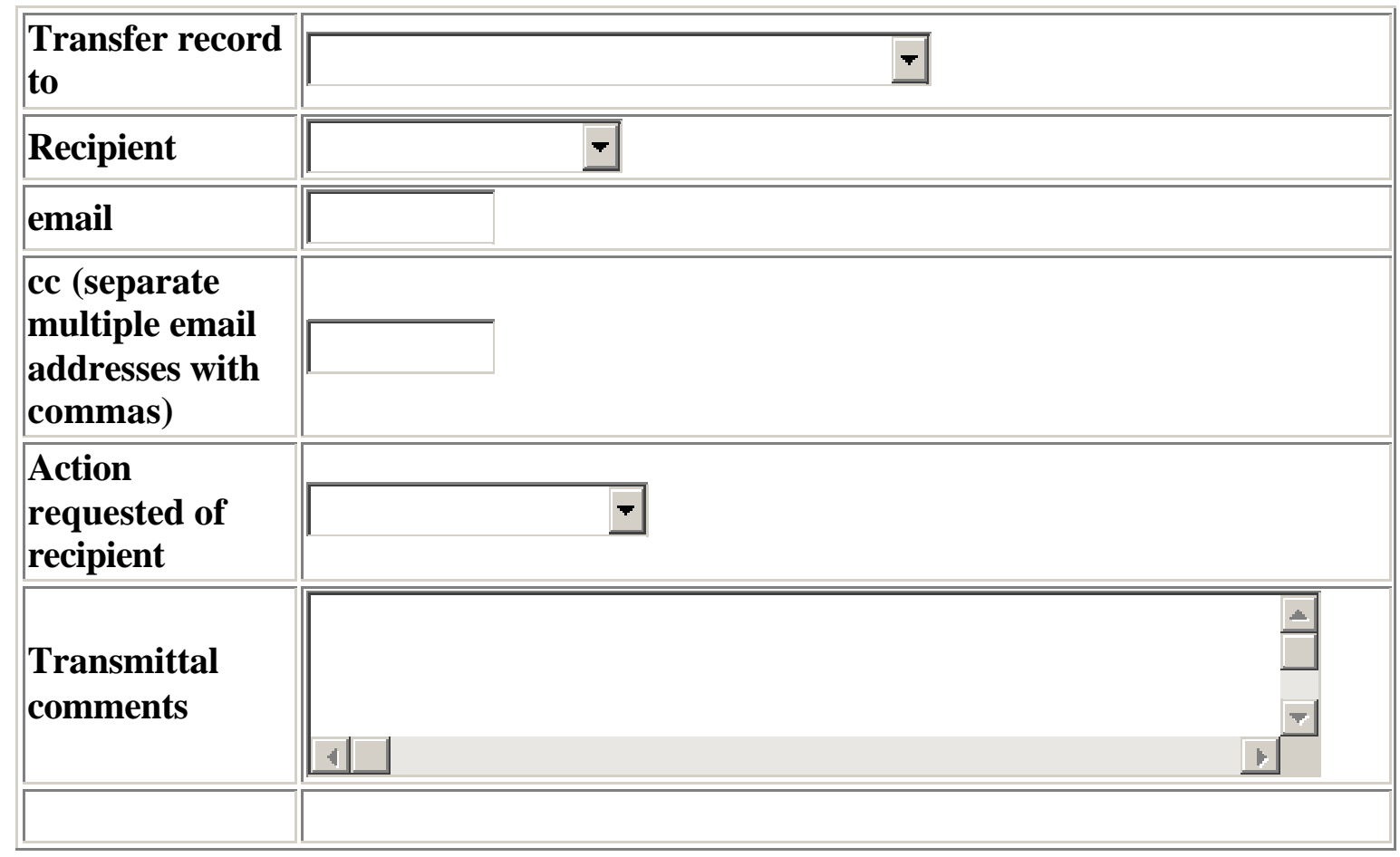


Now logon as the SHPO staff

Return to the main "investigation form" go to View (read-only) investigation records

\begin{tabular}{|c|c|c|c|c|c|}
\hline Investigation Id & Name/\# & Lead agency & Sponsor & Status & $\begin{array}{l}\text { Reason for } \\
\text { investigation }\end{array}$ \\
\hline DBI_WY_2004_28 & $\begin{array}{l}\text { 04-AAA- } \\
01 ; 45-36 \\
\text { Fake Well }\end{array}$ & ABogusLeadAgency & $\begin{array}{l}\text { A Fake } \\
\text { Oil and } \\
\text { Gas Inc. }\end{array}$ & $\begin{array}{l}\text { Submitted } \\
\text { to } \\
\text { sponsoring } \\
\text { or lead } \\
\text { agency }\end{array}$ & \\
\hline Well and Access & & & & & \\
\hline
\end{tabular}

The record is listed in the investigation records for the agency. 
SHPO has a similar application for the review of the project record.

DBI_WY_2004_28-->Make comments and view history--> Transfer to next organization for next action

\section{Review Form}

Press "Cancel" button to take no action and return back to investigation menu. Press

"Save Review" button to save your review comments. Press "Submit Review" to submit the review to other reviewing agency.

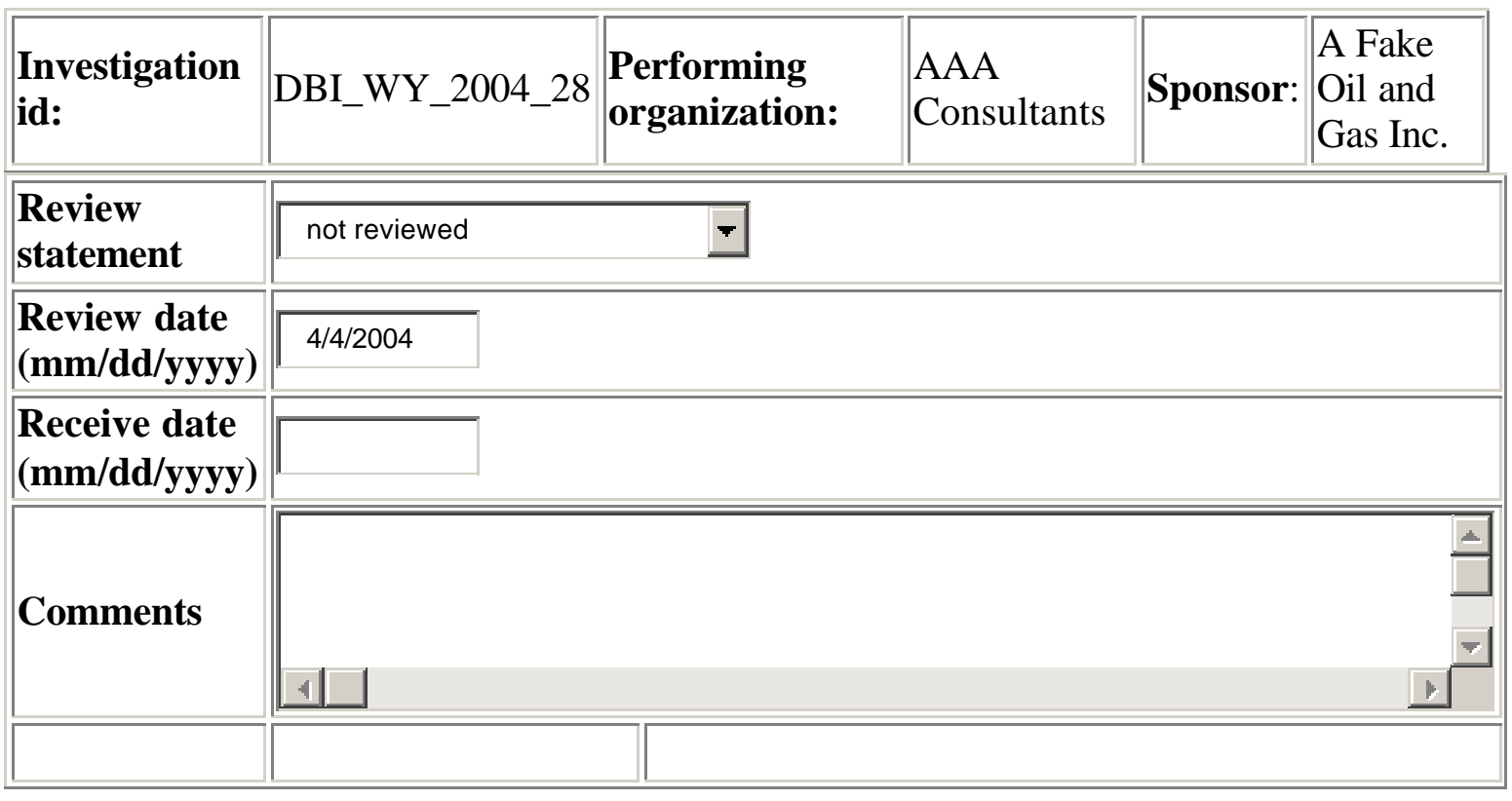

\begin{tabular}{|l|l|l|l|l|}
\hline $\begin{array}{l}\text { Review } \\
\text { date }\end{array}$ & $\begin{array}{l}\text { Reviewer user } \\
\text { name }\end{array}$ & $\begin{array}{l}\text { Reviewer } \\
\text { Organization }\end{array}$ & $\begin{array}{l}\text { Review } \\
\text { statement }\end{array}$ & Comments \\
\hline \begin{tabular}{l|l}
$2004-$ \\
$04-04$
\end{tabular} & $\begin{array}{l}\text { LeadArchaeologist, } \\
\text { Andrew }\end{array}$ & ABogusLeadAgency & $\begin{array}{l}\text { reviewed - } \\
\text { accepted }\end{array}$ & excellent report \\
\hline \hline
\end{tabular}

SHPO can send a response to the lead agency and turn ownership back to the agency. 


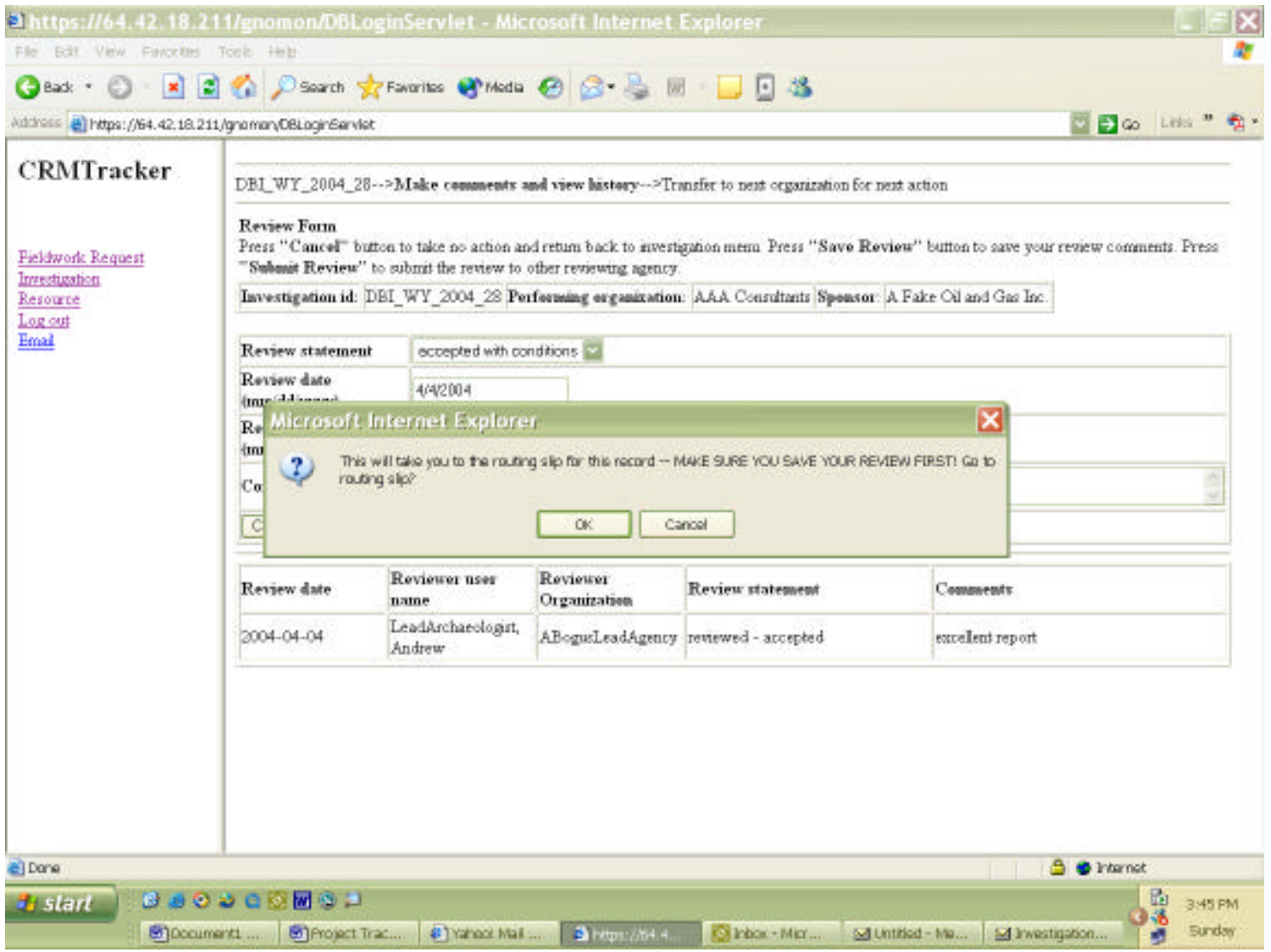


The same routing application is available to the next user.

DBI_WY_2004_28-->Make comments and view history--> Transfer to next organization for next action

Press the "Send Review" button to send this investigation record to another agency for review, edits, filing, etc. Press "Cancel" to go back to the main menu (your review will still be saved).

(This form is basically a routing slip that also has an action request on it. After you send this investigation record to the recipient they become the current owner of the database record.)

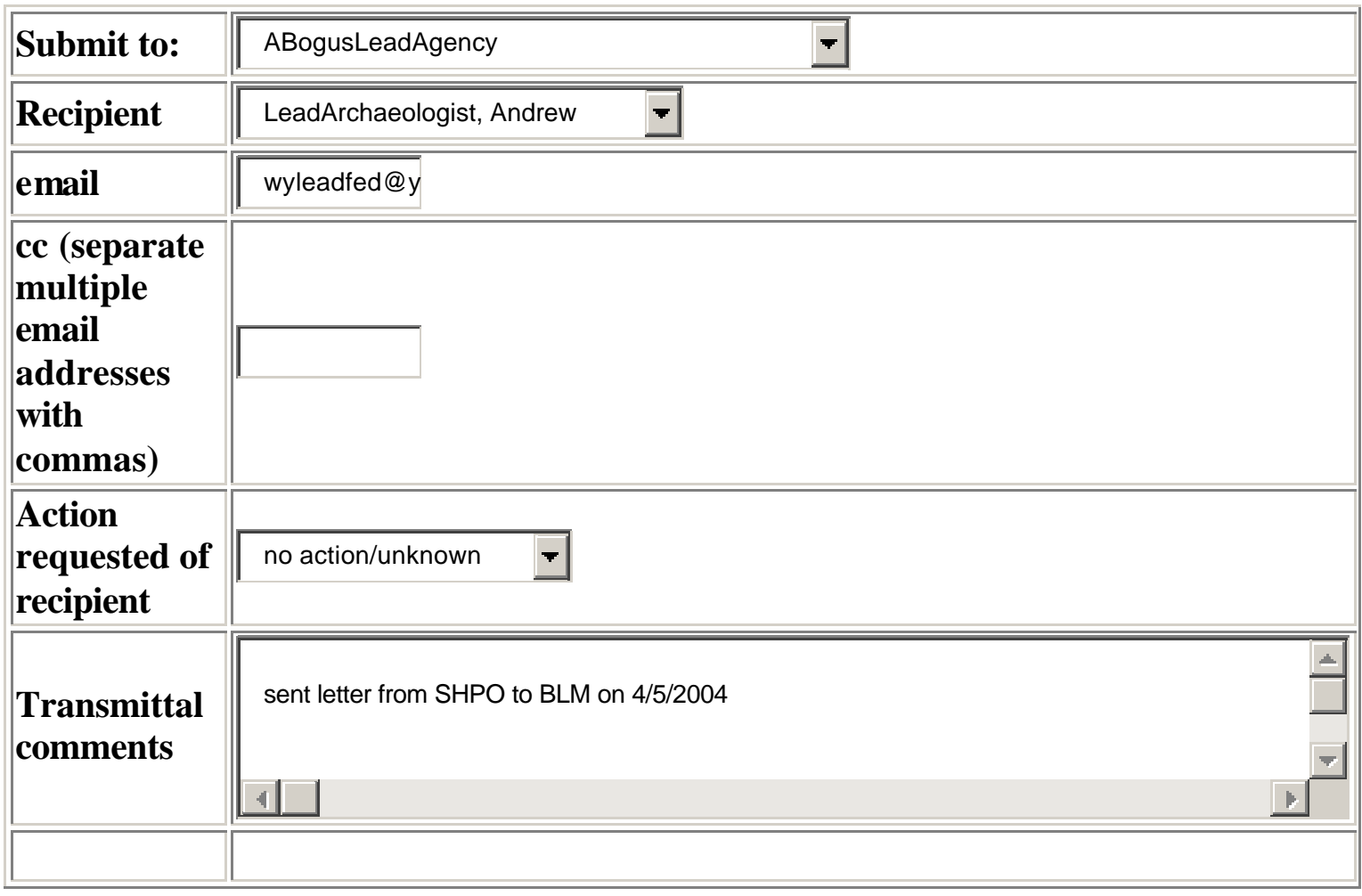


Back in the "review log" the record is now shown and "reviewed -accepted"

\begin{tabular}{|l|l|l|l|l|}
\hline Investigation ID & $\begin{array}{l}\text { Performing } \\
\text { Organization } \\
\text { Name/\# }\end{array}$ & Sponsor & $\begin{array}{l}\text { Review } \\
\text { Statement }\end{array}$ & $\begin{array}{l}\text { Reason for } \\
\text { investigation }\end{array}$ \\
\hline \hline DBI_WY_2004_28 & AAA Consultants & $\begin{array}{l}\text { A Fake } \\
\text { Oil and } \\
\text { Gas Inc. }\end{array}$ & $\begin{array}{l}\text { reviewed - } \\
\text { accepted }\end{array}$ & Well and Access \\
\hline \hline & & \\
\hline
\end{tabular}

The record is available in the database:

\section{Investigation Report}

Press "Next step(review form)" button at botton to take review decision or view the review history of this record. Press "Go Back To Investigation Details" button at bottom to go back to the investigation menu.

\begin{tabular}{|l|l||}
\hline State & WY \\
\hline Performing organization & AAA Consultants \\
\hline Permit \# & ZZ-2004 ARPA 12345 \\
\hline Organization POC & Prehistorian, Anne \\
\hline POC Telephone & 999 000-0000 \\
\hline POC Email & wyarchcons @ yahoo.com \\
\hline POC Fax & 999 000-0000 \\
\hline Lead agency office & ABogusLeadAgency \\
\hline Lead agency POC & LeadArchaeologist, Andrew \\
\hline Lead agency email & wyleadfed @ yahoo.com \\
\hline Lead agency fax & 999 000-0000 \\
\hline Proponent/Sponsor/Client & A Fake Oil and Gas Inc. \\
\hline Investigation reason & Well and Access \\
\hline Short description & $\begin{array}{l}\text { A proposed 10 acre well with approximately 3 miles of access } \\
\text { road. Anne Aprehistorian }\end{array}$ \\
\hline Associated undertaking & none \\
\hline Investigation name / \# & 04-AAA-01; 45-36 Fake Well \\
\hline Investigation action & Cultural Resource Survey \\
\hline Scope/bias (surveys only) & All resources \\
\hline Start date & 04/04/2004 \\
\hline
\end{tabular}




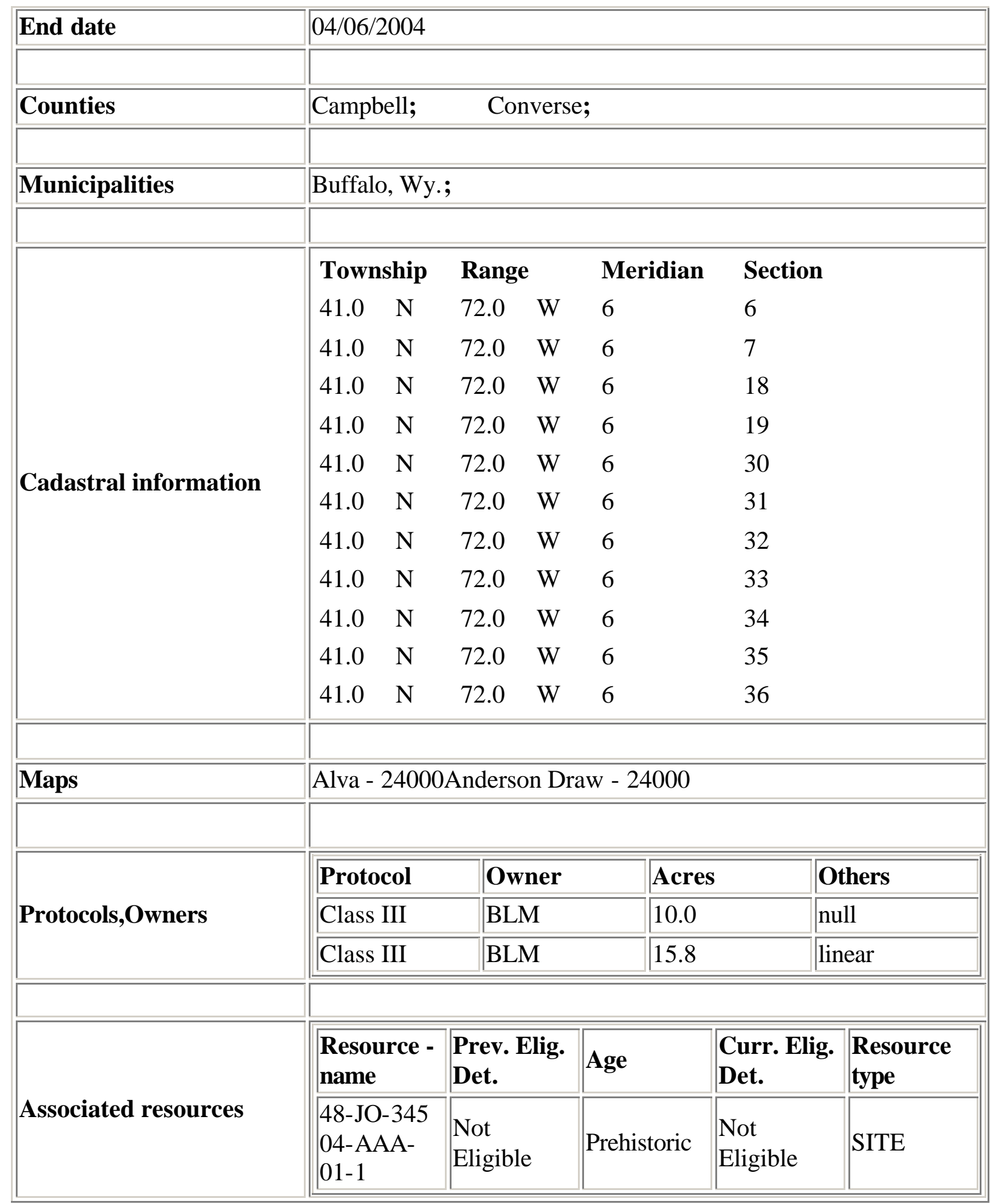


Below is an example of the e-mail messages received during the fieldwork notification and review process by the lead agency.

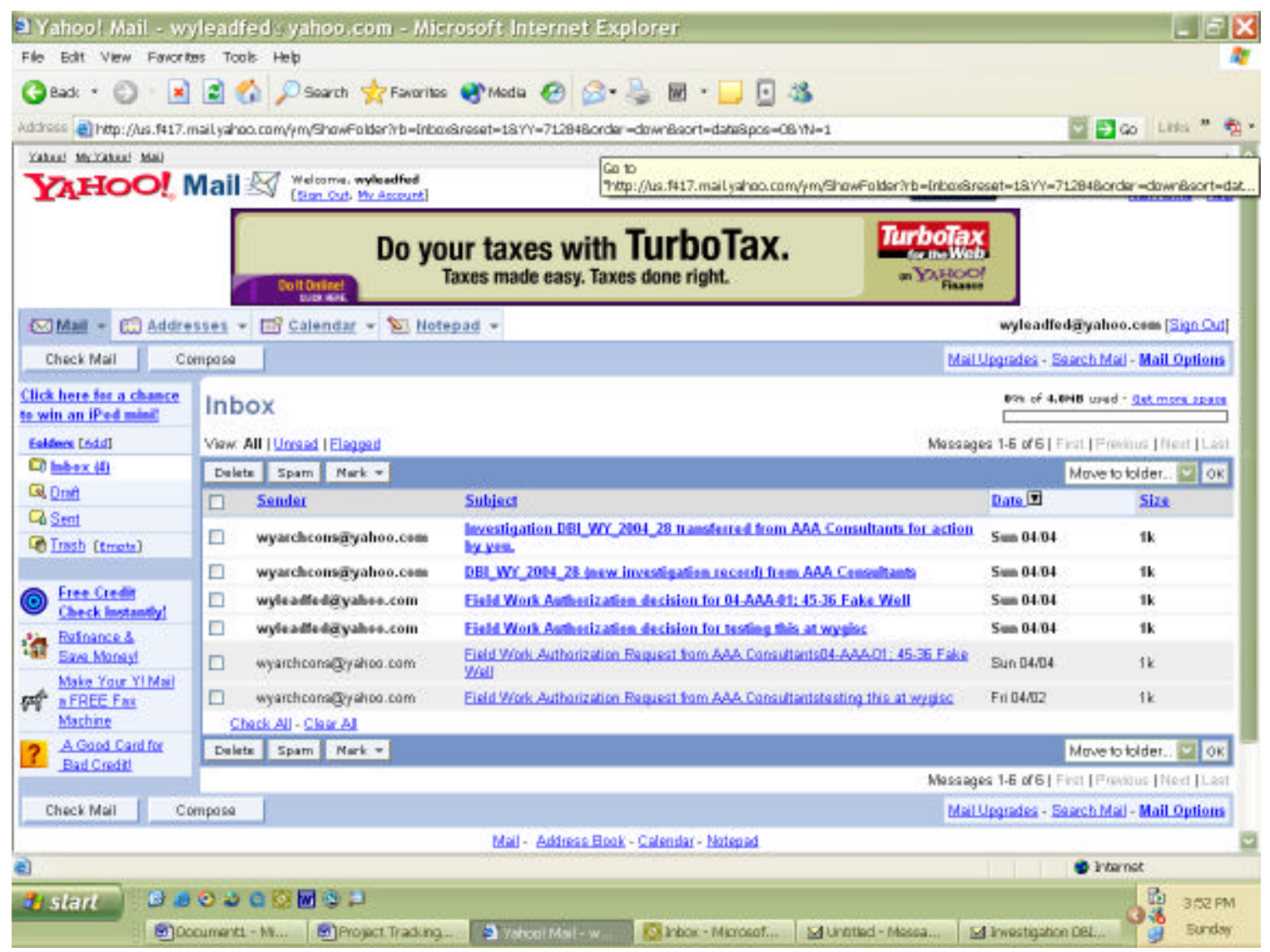




\section{APPENDIX F}

LIST OF PRESENTATIONS AND MEETINGS 

Jan 2003 Project start-up meeting for all participants and collaborators (W)

Peggy Robinson

Mar 2003 Project start-up meeting for WYSHPO staff, BLM state and field offices, U.S. Forest Service, and Bill Eckerle of Western GeoArch Research, WY (M)

Mary Hopkins

Apr $2003 \quad$ New Mexico study area technical meeting (W)

Lynne Sebastian

May 2003 Wyoming BLM State Historic Preservation Office Statewide Annual

Protocol Meeting (M)

Eric Ingbar, Mary Hopkins

Aug $2003 \quad$ Vermont SHPO (P)

Eric Ingbar

Presentation to the Independent Petroleum Association of America (IPAA) Annual Meeting and Land Access Strategy Meeting in Jackson Hole, WY (P)

Richard Currit (WYSHPO)

In preparation for proposing Cultural Resource Management (CRM) programmatic recommendations, met with BLM land managers in the Carlsbad and Las Cruces field offices (M)

Lynne Sebastian

Sep 2003 Project meeting in conjunction with the Rocky Mountain Anthropological Biannual Conference. The focus of the meeting was to gain input from potential users on how the project tracking application they are developing would be used in a Federal agency or in a private consulting firm. (M)

Mary Hopkins

Oct 2003 Technical meeting for entire project participants and collaborators, Albuquerque, NM (W)

Peggy Robinson

Dec 2003 Presentation to BLM Preservation Board (National Board), Alexandria, VA (P)

Stephen Fosberg

Feb 2004 A presentation on the current status of the New Mexico part of the project to the New Mexico BLM Resource Allocation Council (RAC) Meeting in Artesia, New Mexico (P)

Eric Ingbar and Tim Seaman 
May 2004 BLM and WY State Historic Preservation Office Statewide Annual Protocol Meeting (M)

Eric Ingbar, Mary Hopkins

Project meeting for cultural resources staff and contractors at the Rock Springs BLM field office. Participants were mostly from WY BLM offices and WYSHPO. (M)

Mary Hopkins (WYSHPO) gave a project update; Bill Eckerle (Wester

GeoArch Research) discussed the preliminary sensitivity models; and Eric Ingbar (Gnomon) discussed the project tracking tool.

Attended the Four Corners Oil and Gas Conference. This conference brings together producers, land managers, and other interested parties to discuss energy development in the Four Corners region. A poster presentation summarizing the Pump III project was created by Gnomon and displayed at the meeting. This lead to many interesting discussions with agency staff, producers, and other parties. (P)

Tim Seaman

Jun 2004 BLM Fluid Minerals Conference and National Petroleum Forum, Cheyenne, WY. (P)

E. Ingbar was invited to speak and give a poster presentation.

BLM Fluid Minerals Conference and National Petroleum Forum, Cheyenne, WY. (P)

WYSHPO gave a poster presentation.

Gnomon and WYSHPO met with National Park Service staff to discuss PUMP III project. (M)

Eric Ingbar

Aug 2004 First Annual Conference on Coalbed Natural Gas Research, Monitoring and Applications, Laramie, Wyoming (P)

Mary Hopkins

Oct 2004 Northeastern Nevada Stewardship Council, Elko, NV (P)

Eric Ingbar

CRM Tracker Training, NV BLM (T)

Eric Ingbar 
Telephone conference calls with representatives of the oil and gas industry in order to gather information for the management section of the New

Mexico report. (M)

Lynne Sebastian

Mr. Dan Girand

Director of Regulatory Affairs

Mr. Bob Monthei

Mack Energy Corporation

Operations Specialist

Roswell, NM

BP Amoco Corporations

Odessa, TX

Ms. Linda Guthrie

Regulatory Specialist

Mr. Dean Chumbley

Devon Energy Corporation

Landman

Oklahoma City, OK

Marbob Energy Corporation

Artesia, NM

Mr. Mickey Young

Mr. Clifton May

District Manager

Regulatory Agent

Mewbourne Oil Company

Hobbs, NM

Yates Petroleum Corporation

Artesia, NM

Mr. Joe Janica

President

Tierra Exploration, Inc.

Hobbs, NM

Nov $2004 \quad$ USFS, Humboldt Toiyabe Forest Supervisor's Office, Sparks, NV.

Presentation on PUMP III model development (M)

Eric Ingbar

Present DOE project to DOD, Santa Fe, NM

"Working Conference on Models in DOD Cultural Resources

Management" (M)

Eric Ingbar

Wyoming Water Planning Groups, Story, WY and Newcastle, WY. Poster presentation $(\mathrm{P})$

Mary Hopkins

Apr 2005 Eric Ingbar gave a presentation on the results coming out of the DOE

PUMP III project at the semi-annual Department of Defense (DOD)

"Working Conference on Models in DOD Cultural Resources

Management" in Salt Lake City 
May 2005 Eric Ingbar and Mary Hopkins gave a presentation to DOE-NETL on the current status of the project

Eric Ingbar gave a presentation on BLM Cultural Resources Data Management in a briefing to BLM Group Managers in Washington DC

Monthly BLM Cultural Resources Group Manager and Staff, teleconference Eric Ingbar

Other Extensive training has been held with consultants and federal agencies on the use of the on- line project-tracking tool (CRMTracker) and Internet Map Server (IMS). All data generated from this project is available through a secured IMS site. This application was extensively revised by Gnomon to make it more user-friendly. It is currently a state of the art application and can be accessed by cultural resource professionals who are registered users. $(\mathrm{T})$

There have been three conference calls with BLM, WYSHPO, and oil and gas people to demonstrate the new CRISP tool. This tool is in the testing phase and is available to 23 individuals who represent BLM, oil and gas, WY SHPO, and cultural resource consultants. (T)

As we receive feedback we enhance the tool. We hope to demonstrate these two tools at meetings and conferences from now through the end of the contract in December 2005.

\footnotetext{
$\mathrm{M}=$ Professional Meeting

$\mathrm{P}=$ Presentation

$\mathrm{T}=$ Training

$\mathrm{W}=\mathrm{DOE}$ Technical Partners Meeting
} 


\title{
Adaptive Management $\mathfrak{O}$ Planning Models for Cultural Resources in Oil $\mathcal{E}$ Gas Fields
}

\section{New Mexico Pump III Project}

\author{
$\Delta$ \\ B Y \\ Lynne Sebastian, Jeffrey H. Altschul, Chris M. Rohe, \\ Scott Thompson, and William E. Hayden
}

W ITH CONTRIBUTIONS B Y

Eric Ingbar, Stephen A. Hall, Tim Seaman, Stephanie A. Ford, David W. Cushman, Sarah Schlanger, and Carla R. Van West

DECEMBER 2005 



\section{Contents}

$\Delta$

C H A P T E R 1

Introduction

Lynne Sebastian, Eric Ingbar, Stephen A. Hall, Tim Seaman, \& Stephanie A. Ford

C H A P T E R 2

Adaptive Management, Planning, and Oil and Gas:

The Current Situation

Lynne Sebastian, David W. Cushman, \& Sarah Schlanger

C H A P T E R 3

Information Technology, Management of Cultural

Resources, and the New Mexico Pump III Study

Tim Seaman \& Eric Ingbar

C H A P T E R 4

Experimental: The New Mexico Modeling Project

Lynne Sebastian, Carla R. Van West, \& Jeffrey H. Altschul

C H A P T E R 5

Results and Discussion: The Loco Hills Study Area

Jeffrey H. Altschul, Lynne Sebastian, Chris M. Rohe, William E. Hayden, o Stephen A. Hall

C H A P T E R 6

Results and Discussion: The Azotea Mesa Study Area

Jeffrey H. Altschul, Lynne Sebastian, Chris M. Rohe, William E. Hayden, \& Stephen A. Hall

C H A P T E R 7

Results and Discussion: The Otero Mesa Study Area

Jeffrey H. Altschul, Lynne Sebastian, Chris M. Rohe, William E. Hayden, \& Stephen A. Hall

C H A P T E R 8

Historical Period Land Use on Otero Mesa

Scott Thompson

C H A P T E R 9

Conclusion and Management Recommendations

Lynne Sebastian, Eric Ingbar, \& David W. Cushman

LIST OF ACRONYMS

A P P E N D I X

GLO Transactions and Historic Features

Documented for the Otero Mesa Project Area

May 2004: Statistical Research, Inc. 



\section{Figures \\ $\Delta$}

Figure 1.1. New Mexico and Wyoming project areas .............................................................................. 1

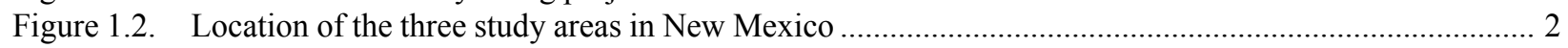

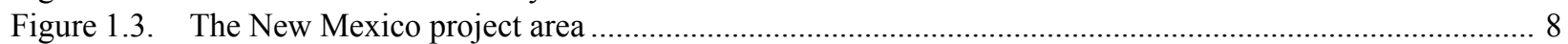

Figure 2.1. An example of the cumulative impact of oil and gas development ................................................... 15

Figure 5.1. Digital elevation model (DEM) of the Loco Hills study area ........................................................ 50

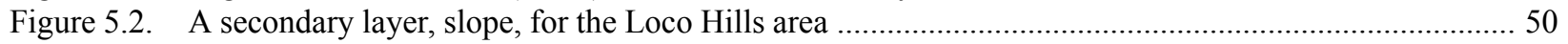

Figure 5.3. Drainages and ridges in the Loco Hills study area ........................................................................... 51

Figure 5.4. Vegetation in the Loco Hills study area .................................................................................... 52

Figure 5.5. Geomorphology of the Loco Hills study area ............................................................................... 53

Figure 5.6. Distribution of known archaeological sites, Loco Hills study area ................................................... 55

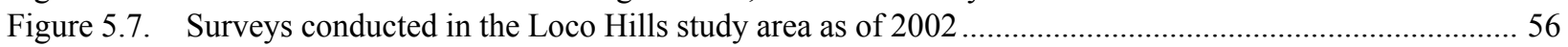

Figure 5.8. Slope values for entire Loco Hills study area ……...................................................................... 58

Figure 5.9. Slope values for surveyed cells within Loco Hills area ................................................................. 58

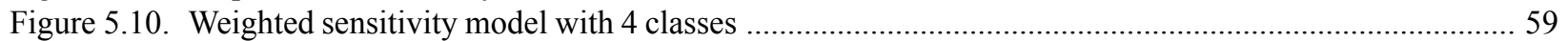

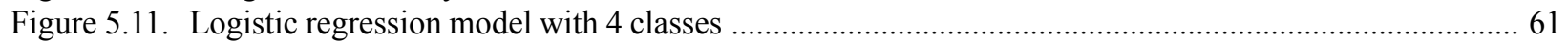

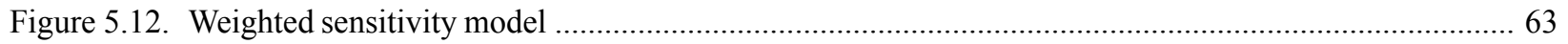

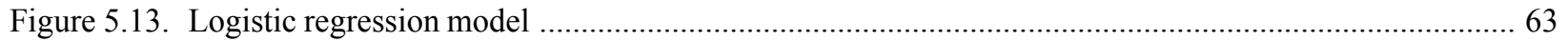

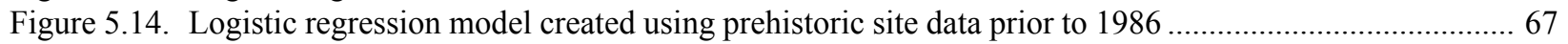

Figure 5.15. Logistic regression model created using prehistoric site data prior to 2003 ...................................... 67

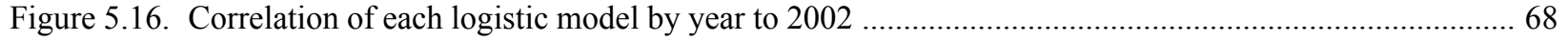

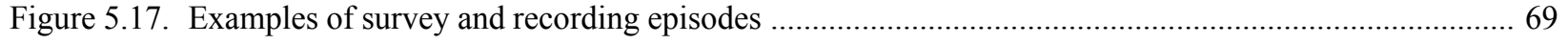

Figure 5.18. Example of survey coverage aggregated by year ............................................................................ 70

Figure 5.19. Time sequence for cumulative survey in the study area ..................................................................... 71

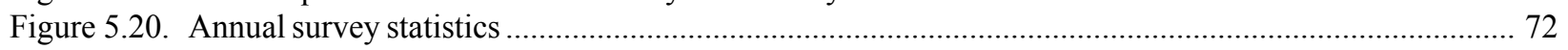

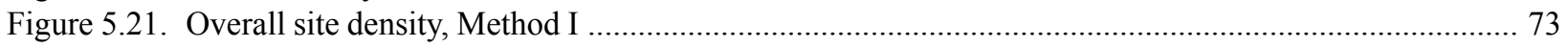

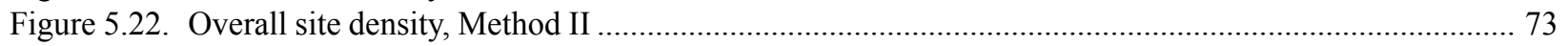

Figure 6.1. Digital elevation model (DEM) of the Azotea Mesa study area ....................................................... 78

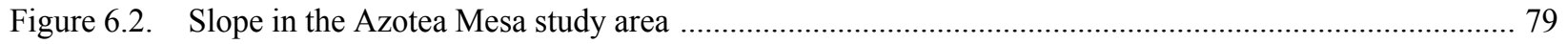

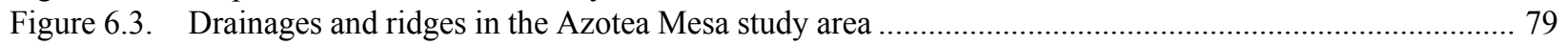

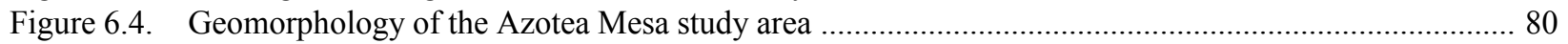

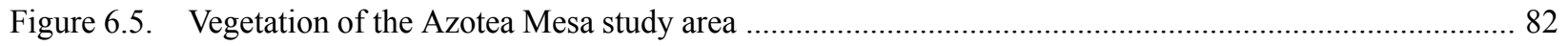

Figure 6.6. Precontact archaeological sites recorded in the Azotea Mesa study area ............................................ 83

Figure 6.7. Survey data from Azotea Mesa ............................................................................................... 85

Figure 6.8. Slope values for the entire Azotea Mesa study area ........................................................................ 87

Figure 6.9. Slope values for the surveyed cells within the Azotea Mesa study area ............................................ 87

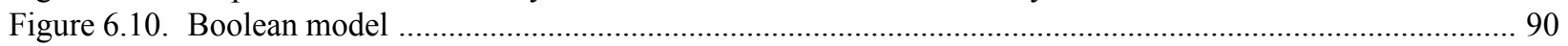

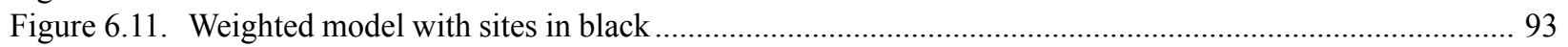

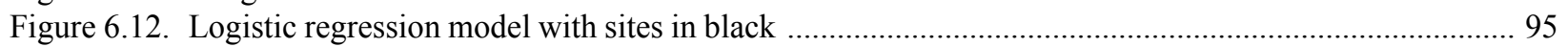

Figure 6.13. Logistic regression model created using all sites recorded through 1982 ......................................... 99

Figure 6.14. Logistic regression model created using all sites recorded through 1992 ........................................... 99

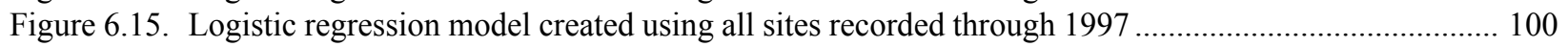

Figure 6.16. Logistic regression model created using all sites recorded through 2000 ........................................ 100

Figure 6.17. Logistic regression model created using data from all prehistoric sites recorded prior to 2002 .......... 101

Figure 6.18. Correlation of each logistic model by year to 2002 ..................................................................... 101

Figure 6.19. Examples of survey and recording episodes ................................................................................ 104

Figure 6.20. Example of survey coverage aggregated by year ............................................................................ 105

Figure 6.21. Time sequence for cumulative survey in the study area ............................................................... 106 
Figure 6.22. Annual survey statistics

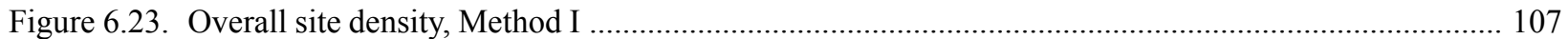

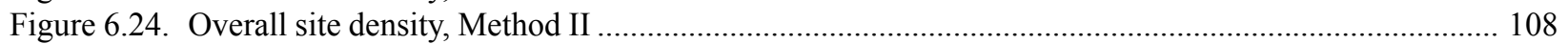

Figure 7.1. Digital elevation model of Otero Mesa and location of eastern and western study units ................. 112

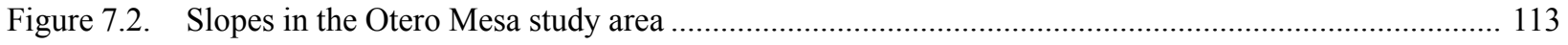

Figure 7.3. Drainages and ridges in the Otero Mesa study area .............................................................. 114

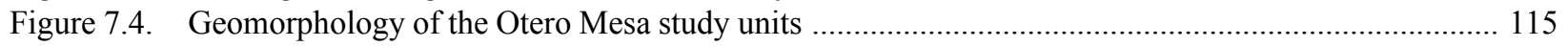

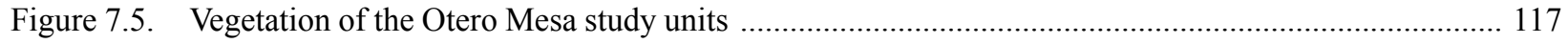

Figure 7.6. Prehistoric sites in the Otero Mesa study units ......................................................................... 118

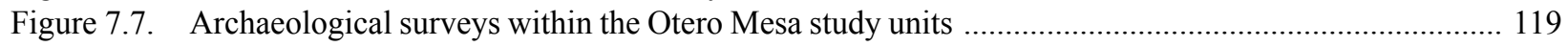

Figure 7.8. Western study unit Boolean model .................................................................................... 131

Figure 7.9. Eastern study unit Boolean model ...................................................................................... 131

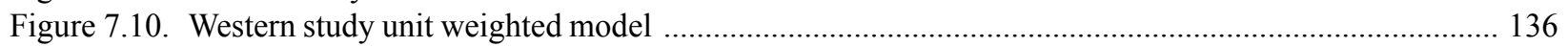

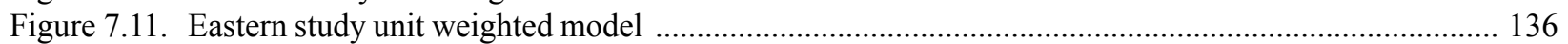

Figure 7.12. Logistic regression model for western study unit .................................................................... 138

Figure 7.13. Logistic regression model for eastern study unit ................................................................. 138

Figure 7.14. Comparison of the sample and full logistic regression favorability maps — western study unit .......... 142

Figure 7.15. Examples of survey and recording episodes ......................................................................... 144

Figure 7.16. Example of survey coverage aggregated by year ................................................................ 145

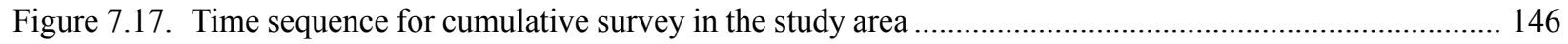

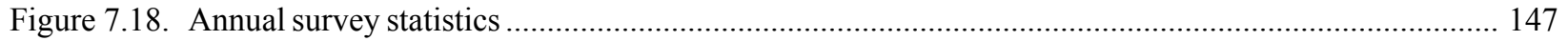

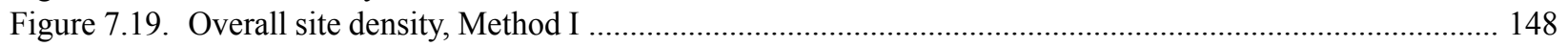

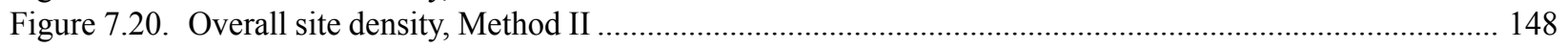

Figure 8.1. Portion of 1864 map of the Military Department of New Mexico .................................................... 154

Figure 8.2. 1926 GLO survey plat of Township 26 South, Range 13 East ................................................... 155

Figure 8.3. 1885 GLO survey plat of Township 25 South, Range 12 East ................................................... 159

Figure 8.4. 1912 GLO survey plat of Township 22 South, Range 13 East ....................................................... 160

Figure 8.5. 1912 GLO survey plat of Township 26 South, Range 18 East .................................................. 161

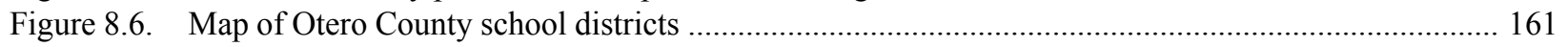

Figure A.1. Otero Mesa Project Area (East). May 2004: Statistical Research, Inc. ......................................... A.1

Figure A.2. Alamo Mountain Quadrangle. May 2004: Statistical Research, Inc. .......................................... A.2

Figure A.3. Alamo Mountain NE Quadrangle. May 2004: Statistical Research, Inc..................................... A.3

Figure A.4. B T Ranch Quadrangle. May 2004: Statistical Research, Inc. .................................................... A.4

Figure A.5. Cienega School Quadrangle. May 2004: Statistical Research, Inc. ............................................... A.5

Figure A.6. Cleones Tank Quadrangle. May 2004: Statistical Research, Inc. ................................................. A.6

Figure A.7. Gowdy Ranch Quadrangle. May 2004: Statistical Research, Inc. ................................................ A.7

Figure A.8. Lewis Canyon Quadrangle. May 2004: Statistical Research, Inc. .................................................. A.8

Figure A.9. Sheep Draw Quadrangle. May 2004: Statistical Research, Inc.................................................... A.9

Figure A.10. Sixteen Canyon Quadrangle. May 2004: Statistical Research, Inc. ............................................ A.10 


\section{Tables}

\section{$\Delta$}

Table 5.1. Pair-wise Spearman's $r$ Scores for Environmental Variables …....................................................... 58

Table 5.2. Weighting of Variable Classes for Weighted Sensitivity Model .......................................................... 59

Table 5.3. Prehistoric Site Data for a Sample from High and Low Model Sensitivity

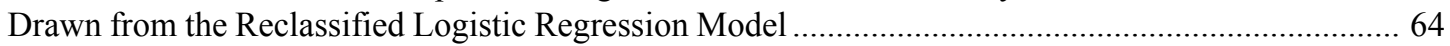

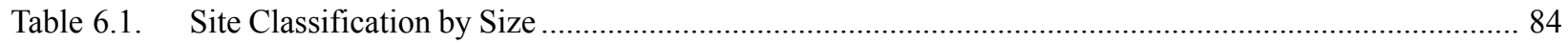

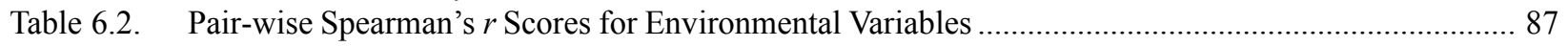

Table 6.3. Chi-square Goodness-of-Fit Scores for Significant Geomorphology Categories .................................. 88

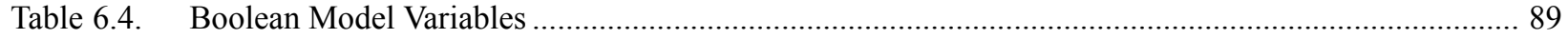

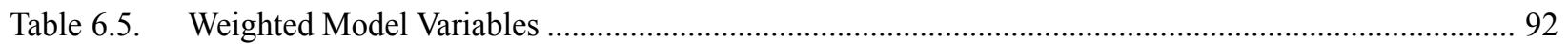

Table 6.6. Weighted Model Scores and Reclassification ................................................................................... 93

Table 6.7. Computed Coefficients for Variables Used in the Logistic Regression Model .................................. 94

Table 6.8. Logistic Regression Probability Scores and Reclassification Values ................................................... 94

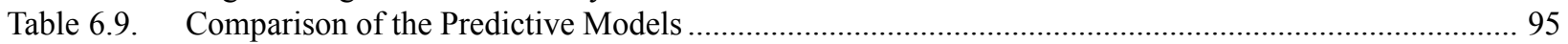

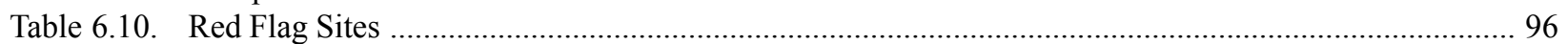

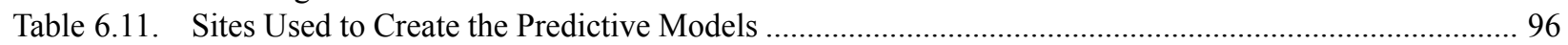

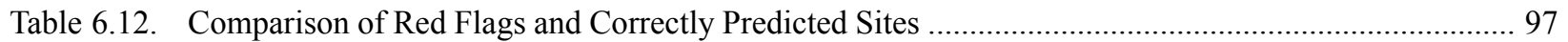

Table 6.13. Comparison of Logistic Regression Coefficients ............................................................................. 102

Table 7.1. Descriptive statistics on slope values, Eastern Otero Mesa Study Unit ............................................. 114

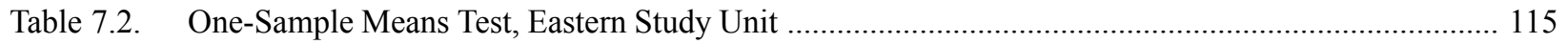

Table 7.3. Average Environmental Scores for Each Study Area .................................................................... 120

Table 7.4. One-Sample Means Test for Continuous Variables, Eastern Study Unit ........................................... 121

Table 7.5. One-Sample Means Test for Continuous Variables, Western Study Unit ........................................... 122

Table 7.6. Chi-Square Tests for Significant Association with Aspect, Eastern Study Unit ............................... 123

Table 7.7. Chi-Square Tests for Significant Association with Aspect, Western Study Unit ................................ 124

Table 7.8. Chi-Square Tests for Significant Association with Geomorphic Units, Eastern Study Unit ................ 124

Table 7.9. Chi-Square Tests for Significant Association with Geomorphic Units, Western Study Unit .............. 125

Table 7.10. Chi-Square Tests for Significant Association with Vegetation Units, Eastern Study Unit ................... 126

Table 7.11. Chi-Square Tests for Significant Association with Vegetation Units, Western Study Unit .................. 127

Table 7.12. Pair-wise Spearman's $r$ Scores for Eastern Study Unit Environmental Variables ............................... 128

Table 7.13. Pair-wise Spearman's Scores for Western Study Unit Environmental Variables ................................ 128

Table 7.14. Environmental Variables Used for Modeling the Study Units .......................................................... 129

Table 7.15. Boolean Model Variables, Eastern Study Unit .................................................................................. 130

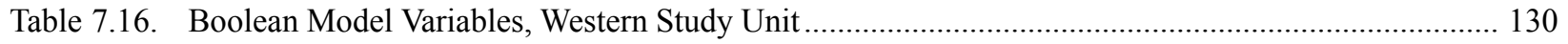

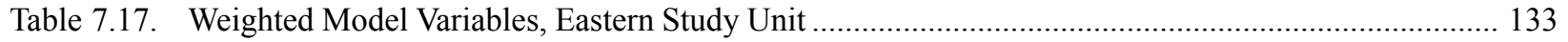

Table 7.18. Weighted Model Variables, Western Study Unit .............................................................................. 134

Table 7.19. Weighted Model Scores and Reclassification, Eastern Study Unit .................................................. 135

Table 7.20. Weighted Model Scores and Reclassification, Western Study Unit ................................................ 135

Table 7.21. Computed Coefficients for Variables Used in the Logistic Regression Model, Eastern Study Unit .... 137

Table 7.22. Computed Coefficients for Variables Used in the Logistic Regression Model, Western Study Unit ... 137

Table 7.23. Logistic Regression Probability Scores and Reclassification Values, Eastern Study Unit .................. 137

Table 7.24. Logistic Regression Probability Scores and Reclassification Values, Western Study Unit .................. 137

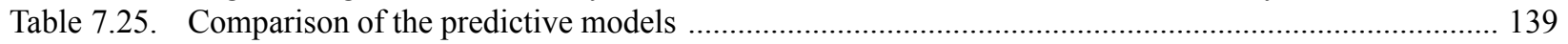

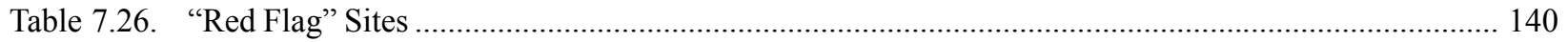

Table 7.27. Comparison of Red Flags and Correctly Predicted Sites ............................................................... 141

Table 7.28. Site Classes for the Western Study Unit, Otero Mesa ........................................................................ 142

Table 7.29. Comparison of Coefficients for Variables Used in the Original Western Logistic Regression

Model and the Random Site Sample Model ................................................................................... 142 
Table 8.1. GLO Transactions in the Project Area ............................................................................. 165-167

Table 8.2. Buildings, Cultivated Fields Depicted on General Land Office Survey Plats, 1885-1926 ................ 168

Table 8.3. Water Storage, Conveyance Features Depicted on General Land Office Survey Plats, 1885-1927 ... 169 


\title{
Introduction
}

\author{
Lynne Sebastian, Eric Ingbar, Stephen A. Hall, Tim Seaman, and Stephanie A. Ford
}

In 2002, Gnomon, Inc., entered into a cooperative agreement with the U.S. Department of Energy (DOE) National Energy Technology Laboratory (NETL) for a project entitled Adaptive Management and Planning Models for Cultural Resources in Oil and Gas Fields in New Mexico and Wyoming (DE-FC26-02NT15445). This project, funded through DOE's Preferred Upstream Management Practices (PUMP) grant program, examined cultural resource management practices in two major oil- and gas-producing areas: southeastern New Mexico and the Powder River Basin of Wyoming (Figure 1.1). The purpose of this project was to examine how cultural resources have been investigated and managed in these areas and to identify more effective management practices. The project also was designed to build information technology and modeling tools to meet both current and future management needs.

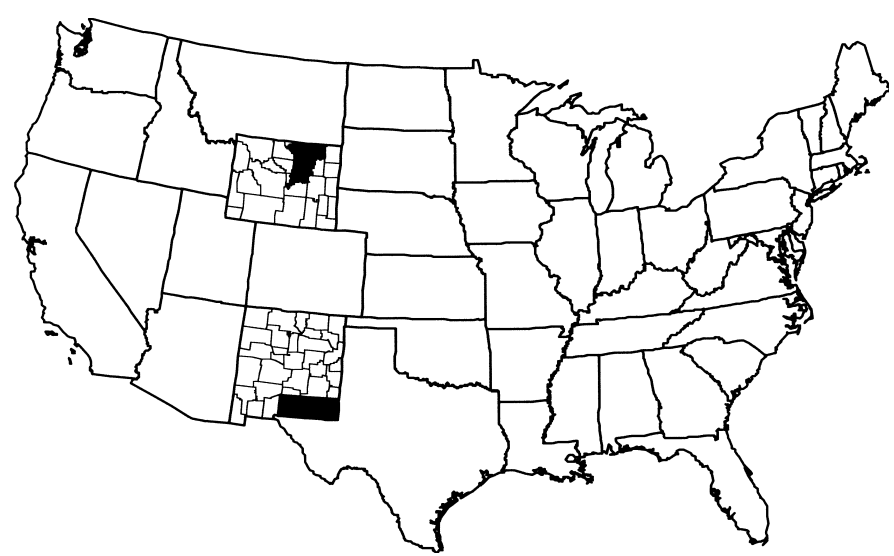

Figure 1.1. New Mexico and Wyoming project areas.

Gnomon, Inc., served as the managing partner in a consortium effort that involved many other firms and agencies. Our primary partnerships included the Wyoming State Historic Preservation Office (WYSHPO), Western GeoArch Research, SRI Foundation, the New Mexico Historic Preservation Division (NMHPD), Statistical Research, Inc., and Red Rock Geological Enterprises. The Bureau of Land Management state offices in Wyoming and New Mexico, the Carlsbad and Las Cruces field offices (New Mexico), and the Buffalo, Worland, Kemmerer, and Casper field offices (Wyoming) were federal partners. The oil and gas commissions, oil and gas industry associations, and specific energy firms were helpful collaborators.

Early on, this project was given the shorthand designation "PUMP III" in reference to the funding source - the third round of PUMP grants. Like most nicknames, "PUMP III" seems to have become a permanent label despite our best efforts to find some other, more descriptive name. And at that, it is probably a big improvement over the alternative, which would most likely have been some unpronounceable acronym, using the first letters of the formal project title: AMPMCROGF? PUMP III it is!

\section{The New Mexico Pump III Project}

The New Mexico component of the Pump III project focused on the southeastern quadrant of the state (Figure 1.2) and comprised three study areas: Loco Hills, Azotea Mesa, and Otero Mesa. The Loco Hills study area encompasses most of a mature, heavily developed oil and gas field in Lea and Eddy counties, managed by the Carlsbad Field Office of the Bureau of Land Management (BLM). Azotea Mesa, which is also managed by the Carlsbad Field Office, is a currently developing oil and gas field in Eddy County. Otero Mesa, which is under the jurisdiction of the BLM's Las Cruces Field Office, is an area that has experienced a marked increase of interest in oil and gas development and was covered in a recent Resource Management Plan amendment and Environmental Impact Statement for fluid mineral leasing and development (BLM Las Cruces Field Office 2003). 


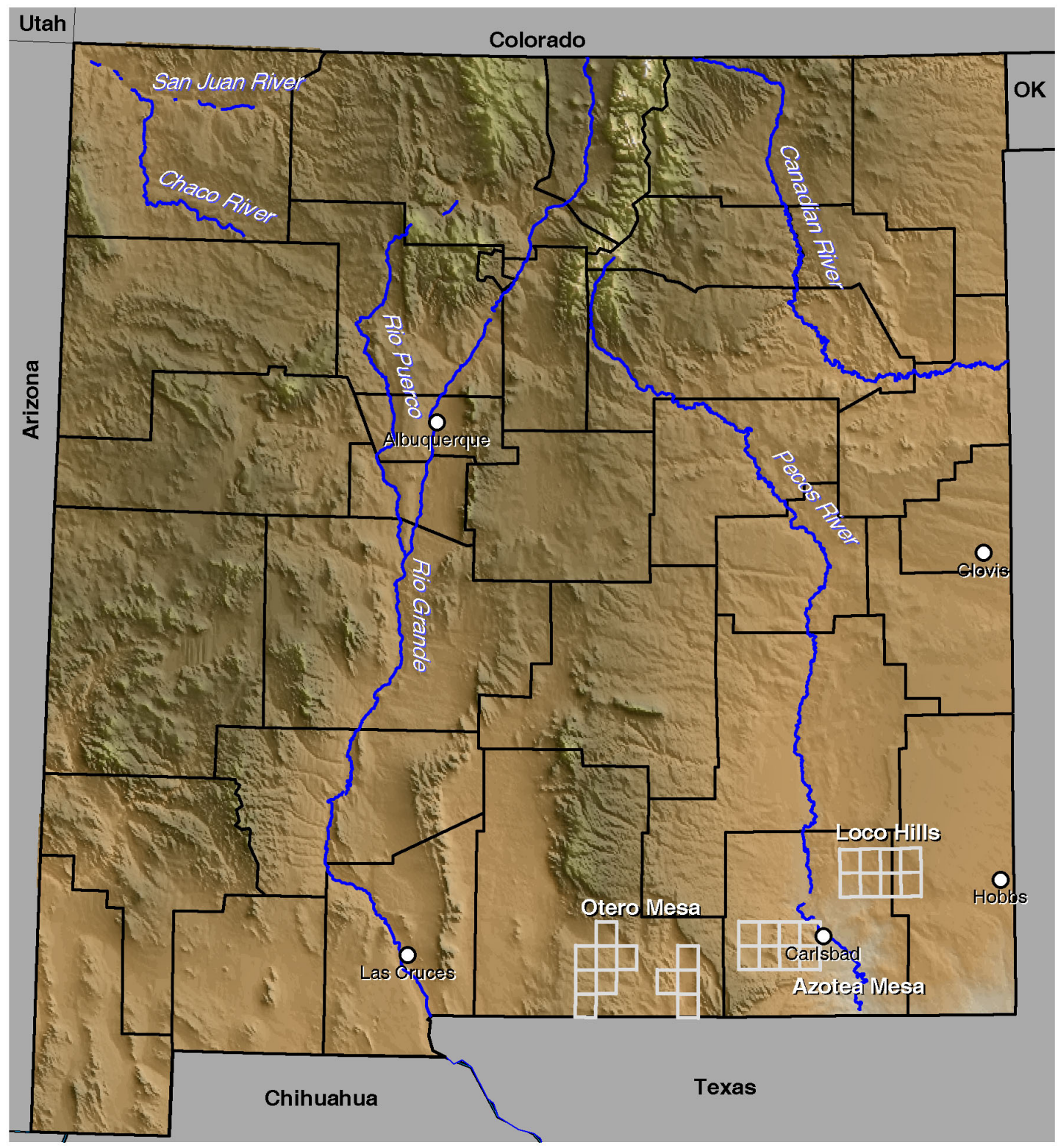

Figure 1.2. Location of the three study areas in New Mexico.

The New Mexico component of the Pump III project includes development of

- digitized archaeological survey and site location information for the entire project area; this information will be made available through the New Mexico Cultural Resource Information System (NMCRIS) maintained by the Historic Preservation Division

- a geomorphology study for each of the three study areas

- predictive models of archaeological site locations based on correlations with environmental variables for each of the three study areas

- inventory simulations to reconstruct the history and evaluate the effectiveness of archaeological survey within each of the study areas

- management recommendations for more predictable, efficient cultural resource compliance processes for oil and gas development as well as better management of cultural resources on public lands 


\section{INTRODUCTION}

The overall project area encompasses much of the current and projected venues for oil and gas development on public lands in the New Mexico portion of the Permian Basin. The three detailed study areas were chosen specifically because they represent different phases in the development life of oil and gas fields - a heavily developed field (Loco Hills), a currently developing field (Azotea Mesa), and a potential field that is the subject of ongoing land use planning (Otero Mesa). The underlying premise of the New Mexico project is that we can learn from the decisions that worked well in previous developments and from the decisions that did not work as well. Ultimately we hope to devise better, more efficient, and more effective management strategies for future developments.

The individual components of the New Mexico project are described briefly below.

\section{NMCRIS Data Project}

The New Mexico Historic Preservation Division's Archaeological Records Management Section (ARMS) maintains an inventory of all recorded archaeological sites and investigations in the state. ARMS is the official state clearinghouse and repository for data derived from more than 80 years of archaeological research, describing more than 145,000 archaeological sites and 93,255 inventory and excavation projects (Tim Seaman, ARMS, personal communication, August 2004).

In 1993, the original computerized ARMS database was upgraded to a more comprehensive system known as the New Mexico Cultural Resource Information System (NMCRIS), designed to serve the needs of a broader user community that includes industry as well as government and researchers. NMCRIS is based on modern relational database technology in a multiuser operating environment. The database can be accessed locally at the Laboratory of Anthropology in Santa $\mathrm{Fe}, \mathrm{New}$ Mexico, or at remote locations via the Internet. NMCRIS provides information to both government and private entities so that cultural resources can be considered in early stages of project planning, and damage to archaeological resources can be minimized.

\section{The NM Data Collection Effort}

The objectives of the New Mexico portion of the PUMP project required the development of a database to support the project's modeling efforts and to serve as a basis for future management. Although ARMS has been digitizing survey areas for many years, statewide coverage is not yet complete. Within the PUMP III project area the number of surveys in need of digitizing surpassed 20,000. ARMS approached this massive backlog by first identifying all surveys conducted within the project area prior to June 2002 using NMCRIS database tables. After merging this target list with the current NMCRIS GIS layers, ARMS identified surveys in need of digitizing and scheduled them for processing. Although archaeological sites already have statewide coverage in NMCRIS as centroids (points) and as simple proxy boundaries (polygons) computed from reported size figures, for the current project all site boundaries were digitized from the processed reports. Site boundaries were thus associated with multiple events in this GIS layer.

It is important to note that this process focused entirely on the information actually housed at the Laboratory of Anthropology. The effort was not coordinated with BLM field offices, where substantial numbers of reports are being held for submission to NM SHPO and ARMS. As these reports made their way to ARMS during the project, they were added to NMCRIS and extracted for analysis if the report was completed prior to June 2002. Based on survey registration data in NMCRIS, it is estimated that more than 150,000 acres of survey from the Carlsbad Field Office were not included in PUMP III modeling activities. This represents more than 260 reports dating prior to the June 2002 cutoff. PUMP III has made significant inroads in creating a seamless cultural resource database for southeastern New Mexico, but with persistently high volumes of survey work in the Carlsbad Field Office this backlog will continue to be a hurdle for management.

\section{Data Quality and Limitations}

NMCRIS data represent the cumulative record of archaeological survey investigations in southeastern New Mexico between approximately 1975 and June 2002. Data quantity and quality are variable, depending on the specific site form used, the intensity of the recording effort, and the level of experience of the recorders. Although each site and survey record in NMCRIS contains metadata that allows investigators to filter or control this variability when creating a dataset, the PUMP III modeling effort was of sufficiently broad scope to posit that these recording variations would not affect the validity of the modeling results.

By statewide standards, much of the data for southeastern New Mexico is of low quality, especially in areas of intensive oil and gas development. For example, more than $30 \%$ of the surveys processed in the Loco Hills study area could not be digitized owing to poor source graphics. Maps were often illegible and/or at insufficient scale, and the locations of site and survey boundaries could not be interpreted by the digitizers. 
Site data too are of low quality. Almost all survey in the Loco Hills and Azotea Mesa study areas has been conducted in response to industry requirements for leasing on BLM lands. Archaeological survey has been uncoordinated, redundant, and inefficient. Variability in recorded site data about chronology, site function, or settlement pattern are rarely if ever considered in any comparative or analytical framework. Because site recording events rarely take previous work into consideration, the analyst is left, in many cases, with a series of independent observations, often with varying descriptions and even different locations for the same archaeological sites. Sorting out the most reliable observations for any given site is extremely difficult. For PUMP III, the scale of analysis and the overwhelming size of the data collection task precluded any systematic approach to squeezing out the best information.

\section{Implications for NMCRIS}

PUMP III has provided ARMS with a unique opportunity. This project required a systematic, report-by-report method to process the backlog of survey reports quickly. This in turn allowed ARMS to build a historical GIS layer of site boundaries. With multiple, often highly variable boundaries for many archaeological sites, this layer has been troublesome for the analysts. We tend to assume in our models that survey covers an area once, and that once discovered, a site is located on a map, described on a form, and the records filed for future management and research needs. The truth in places like Loco Hills is that the same ground may be covered multiple times, and that archaeologists typically record known sites without taking previous observations into consideration. The apparent differences in a site's location, configuration, and description may be influenced by the action of eolian forces over extended periods of time, but one cannot rule out differences in observer perception (lumpers vs. splitters) or the pressure to flag-and-avoid sites to facilitate development. From this perspective, the site boundary layer should be worrisome for cultural resource managers and SHPO as well.

For ARMS, the PUMP III site boundary layer presents some conversion and database design challenges. To integrate the PUMP III site boundaries into the current NMCRIS design, ARMS will have two choices: (1) conflate all site boundaries into a single polygon for each site, or (2) choose a single boundary based on the latest (or first?) recording date. Both strategies are viable from a data-processing standpoint, but the historical associations will be lost. Alternatively, ARMS could develop a project-specific NMCRIS site boundary layer. Site boundaries would be linked to surveys as well as sites, thus maintaining a source lineage. A substantial redesign effort would be required, the new layer would foster some user confusion, and managers would need to think about "official" site boundaries in areas like Loco Hills, but the effort might well be worth it.

\section{Geomorphology Study}

Geomorphology was important to this project for two reasons: (1) Geomorphology is a major component of the natural environment and thus may be an important factor in site-location decisions by prehistoric people, and (2) Once a site is formed and abandoned, geomorphology and geomorphic processes are pivotal in determining whether the site is preserved or destroyed. Thus, the preserved archaeological record that can be seen and inventoried and analyzed is, in part or wholly, a consequence of geomorphology. Also, site visibility is a key ingredient of the archaeological record. If sites are mantled by sediments and bioturbation has not brought artifacts to the surface, the site is invisible and will not be detected in surface site surveys.

The geomorphic circumstances also pertain directly to site preservation. Sites that are covered by sand and invisible at the surface, ironically, may be well preserved in the subsurface. In contrast, the erosion that provides $100 \%$ site visibility also destroys those sites; their stratigraphic contexts are completely lost, and the spatial distribution of artifacts may be severely altered.

\section{Methodology}

The surficial geology of the Loco Hills, Azotea Mesa, and Otero Mesa areas in southern and southeastern New Mexico was evaluated using ( $a$ ) stereo-paired color infrared aerial photography (scale 1:58,000), $(b)$ stereo-paired black-andwhite aerial photography (scale 1:40,000), and (c) U.S. Geological Survey topographic maps (scale 1:24,000; contour interval 10 and 20 feet). The aerial photographs are available to the general public via the Internet from the EROS Data Center, Sioux Falls, South Dakota. Geomorphic and geologic features with archaeological significance were identified on the aerial photographs and the distribution of the features was transferred by hand onto topographic maps. The mapping of the sand dune-dominated Loco Hills area was facilitated by prior studies of the area by one of the authors of this chapter (Hall 2002). USDA county soil maps and various geologic maps of the study areas were of limited value owing to their more general nature, which does not show features or landforms that are applicable to the archaeological record. 


\section{INTRODUCTION}

Color infrared aerial photographs were especially valuable in the identification and mapping of small basins and associated wet ground in the arid lands of southeastern New Mexico. Wet-ground plant cover shows up as red or pink on the infrared photographs, in contrast to the gray colors of the surrounding shrub grassland plant communities. Some ephemeral basins that contain water only during wet seasons are unclear on black-and-white aerial photographs, and some smaller basins do not show up on topographic maps with 10 -foot or 20 -foot contour intervals. A disadvantage of the color infrared aerial photographs is their coarse scale compared with the finer scale of the black-and-white aerial photographs.

Surficial geology/geoarchaeological maps of the project areas were produced in the office and then field checked. For the most part, the maps produced from aerial photographs were accurate, although field inspection indicated that minor adjustments to the definition and boundaries of some mapping units were necessary.

\section{Mapping Categories}

Because of differences in bedrock geology and recent geologic history, the landforms and geoarchaeology of the three study areas are vastly different. Twenty-one mapping units were established for the three study areas. The 21 units are permutations of three separate, coarser categories that represent major aspects of archaeological-site geology: $(a)$ site landscape context, $(b)$ ages of surfaces/soils, and $(c)$ potential surface visibility.

Site Landscape Context. Landscape context refers to the major landform categories on which sites were formed. The three New Mexico study areas comprise five landform categories along with a sixth category of "unique places," such as caves, springs, or quarries.

1. Stable surfaces/soils: absence of or less than $0.3 \mathrm{~m}$ of late Quaternary sediments, presence of well-developed Pleistocene soils or paleosols, denuded surfaces, escarpments; sites likely have $100 \%$ visibility and poor preservation.

2. Eolian: sand sheets, dunes, loess; high variability in thickness over short distances.

3. Alluvium: floodplain and overbank deposits by small and large streams, fluvial terraces, alluvial fans; on the sand sheets, alluvium may be partly buried by eolian sand.

4. Lacustrine environments: playas, ponded sediments, wetlands; includes small depressions that likely held water during periods of wetter climate; tributaries feeding into playas are fluvial.

5. Colluvium: slope-wash deposits, landslides.

6. Other: unique places, such as rockshelters, caves, springs, quarries; marked on map with a dot.

Ages of Surfaces/Soils. The age of surfaces and soils can be estimated from geomorphic and soil-geomorphic field information in the absence of specific geochronological controls. For archaeological purposes, it is desirable to have, for example, surface-age determinations on a 1,000-year interval. However, the physical landscape does not operate on that time scale. Most surfaces in the project areas will be either more than 12,000 years of age, owing to long-term erosion, or less than 5,000 years old, owing to recent sediment accumulation.

A. $<5,000$ years: archaeological sites on this surface will be less than 5,000 years old; may include some sediments deposited since European contact.

B. $>12,000$ years: archaeological sites of all ages or of any age may be present on this surface as a result of deflation; a thin veneer of young sediments $<0.3 \mathrm{~m}$ thick may be present.

C. undetermined: the age of the deposits is unknown and could not be estimated in this study.

Potential Surface Visibility. Archaeological site "potential surface visibility" requires the presence of sediments of an age that could potentially contain sites. In the study areas, this means that sedimentary deposits would have to be less than 12,000 years old. "Potential surface visibility" does not imply that sites are present or are not present, only that they could be present. Implicit in this category of site visibility is the actual thickness of sediments less than 12,000 years old. If the sedimentary deposits are less than 1 meter in thickness, sites will likely be exposed and have a high visibility. If the deposits are of greater than 1 meter thickness, sites may be buried and thus have a low visibility. If the age of the sediments at the landscape surface is older than 12,000 years, sites of all ages will be at the surface.

H. High visibility. Sediments $<1 \mathrm{~m}$ thick; sites will be exposed and perhaps eroded.

L. Low visibility. Sediments $>1 \mathrm{~m}$ thick; sites may be buried and not exposed at the surface. 


\section{Mapping Categories and Mapping Units}

As already stated, different combinations of the three map categories defined above make up the mapping units that are drawn on the topographic maps. For example, all of the maps have a map unit "1" that is the same for all three project areas (not always the case). Map unit 1 is defined as "1-B-H." The $\mathbf{1}$ is stable surface, the $\mathbf{B}$ is a surface greater than 12,000 years old, and $\mathbf{H}$ is high visibility. As a second example, map unit 2 is defined a " $2-\mathrm{A}-\mathrm{H}$." The $\mathbf{2}$ is eolian, the $\mathbf{A}$ is surface younger than 5,000 years old, and $\mathbf{H}$ is high visibility.

We attempted to use the same definitions for the same numerical map units throughout the three project areas. In practice, however, the geomorphic features of one area are not identical to the features in another area. Alluvial deposits, for example, are not the same everywhere. In the Loco Hills area, the areal extent of alluvium is generally narrow and the deposits thin, whereas in Azotea Mesa alluvial valleys are comparatively wide and alluvial deposits are thick and varied. Nevertheless, the diversity of deposits was evaluated with the archaeological record in mind, so the geoarchaeological aspects of the landscape in one area should be similar to those of another.

\section{Site Preservation}

The preservation of stratigraphy, artifact distribution, and features at archaeological sites is pivotal to determining what the sites represent in the context of human behavior. In this project, however, we did not attempt to include site preservation potential as a mapping category because of the uncertainty involved in assessing site preservation at the scale of a map unit. Nevertheless, some comments can be made and some conclusions can be drawn from the other mapping categories with regard to site preservation.

In southern and southeastern New Mexico, archaeological site preservation tends to be poor. A realistic approach would be to assume that sites are severely disturbed and to look for field evidence that they are not, instead of the other way around. Sites on ancient, stable surfaces will be severely disturbed as well as eroded. Sites in sand sheets and colluvium may be severely disturbed by burrowing animals that tend to be drawn to soft sediments. Sites in alluvium, however, may be moderately well protected by deposits that cap and seal a floodplain site. In general, deeply buried sites may be better preserved than shallow sites. In practice, however, a deeply buried site may have been disturbed before younger deposits covered it. The state of preservation of the archaeological record must be assessed on a site-by-site basis.

\section{Predictive Models}

Predictive modeling is a term that covers a wide array of techniques, all of which capitalize on the empirical observation that archaeological site locations tend to be associated with particular environmental features. Mappable environmental features are treated as independent variables that are either individually or in combination associated with the dependent variable, archaeological site locations. Such techniques have been used in cultural resource management (CRM) for more than two decades (Altschul et al. 2003; Kohler 1988; Kohler and Parker 1986). Although quite variable in design, predictive models are developed following a fairly standard process (Altschul 1988, 1990).

Mathematically derived predictive models can be one of the most valuable tools available to land managers for managing archaeological resources. The end product of such a model is a set of probability statements, generally displayed as a map, that indicate the likelihood that an archaeological site will be found at a particular location. Such models are based on the correlation between known archaeological site locations and a variety of environmental variables, and they can be easily tested and upgraded as additional sites are recorded.

Models can be and often are developed intuitively, of course, based on experience and knowledge of the archaeology of a particular area: e.g., "agricultural villages will be located on low ridges overlooking shallow drainages." And such models may be quite accurate - that is, successful at predicting the locational characteristics of agricultural villages. But we have no means of estimating their precision - that is, of knowing how likely it is that the prediction will be correct. For land use planning purposes, it is critical to know the likelihood that significant archaeological resources will be found in specific areas, and this is only possible with statistically based models.

For each study area we assembled environmental data, which were then compared with the locations of known archaeological sites. Through statistical manipulations, some environmental variables were found to be positively correlated with the locations of past human activities and some were not, but in all cases it is important to note that these are simply mechanical correlations, not explanations. The models do not necessarily indicate which aspects of their environment indigenous people consciously valued; they simply track the cumulative record of human behavior. The results of the correlation models were displayed as sensitivity maps which graphically indicate the likelihood that archaeological sites will be found at any given point on the landscape. The modeling techniques used are described in Chapter 4; the environmental variables and archaeological data are discussed in Chapters 5-7. 


\section{Inventory Reconstruction}

In order for land-managing agencies such as the BLM to meet, in part, their responsibilities under federal law to consider the effects of their actions on historic properties, they generally require archaeological surveys prior to oil and gas development projects. Currently, these surveys are carried out on a case-by-case basis. Each individual request to the BLM for approval of a portion of a project triggers a requirement for an individual survey. Clearly this is inefficient, time-consuming, and potentially costly both for the oil and gas industry and for the BLM. For this project, we also wanted to assess the implications of the case-by-case survey process for effective management of archaeological resources on the public lands.

This issue will be addressed by reconstructing the history of inventory for each study area and then examining the results in terms of data needed for improved resource management and cost-effectiveness. The purpose of the reconstruction is to determine whether our level of archaeological knowledge and confidence in that knowledge could have been achieved more effectively and efficiently.

\section{Management Recommendations}

The ultimate purpose of the entire Pump III project is to provide recommendations and create tools that will help land managers to do a better, more effective and efficient job of managing cultural resources in oil and gas leasing and development situations. By "better," we mean both a more predictable, timely, and cost-effective process for oil and gas exploration and development and serving the public interest through more effective stewardship of the historical and prehistoric archaeological record.

The management recommendations component of the New Mexico Pump III project begins with the existing process, from resource management plans through lease parcel development, lease sales, and all the steps in development, production, abandonment, and reclamation. Through examination of the current process and discussions with BLM technical staff, state agencies, oil and gas industry representatives, cultural resource professionals, and Native American tribes, SRI Foundation has developed a set of management recommendations. These suggestions include both general recommendations for managing archaeological resources in oil and gas fields and specific recommendations for each of the three study areas.

\section{The Project Area}

\section{Geography}

The project area (Figure 1.3) encompasses a variety of landforms from mesas to mountains to valleys. The western portion of the project area lies within the Basin and Range physiographic province and includes the Sacramento Mountains and Guadalupe Mountains, as well as the Brokeoff Mountains and a number of lesser ranges such as the Cornucopia Hills. These uplands, which dominate the western half of the project area, are a southern branch of the Rocky Mountains.

The Sacramento escarpment rises abruptly some 4,000 feet above the neighboring Tularosa Basin; the highest peak, Sierra Blanca, attains an elevation of 11,977 feet. The southern terminus of the Sacramentos forms the eastern edge of Otero Mesa. The western and southern slopes of the mountains drain into the closed Tularosa Basin; the eastern slope drains into tributaries of the Pecos River.

The Guadalupe Mountains lie approximately 35 miles southwest of Carlsbad and continue south over the Texas border. The highest elevation in this range, at 8,749 feet, is Guadalupe Peak in Texas. Runoff from the west side of the mountains drains into the Salt Basin on the eastern edge of Otero Mesa. The east side runoff is part of the Pecos River watershed and includes the drainages running through Azotea Mesa.

South of the Sacramento Mountains and east of the Guadalupe Mountains lies Otero Mesa, which comprises some 1.2 million acres of Chihuahuan Desert grassland, the Collins Hills and Cornucopia Hills, and Crow Flats, a closed drainage basin that empties into the Salt Basin graben at the southwest end of the Brokeoff Mountains. The southern portion of the greater Otero Mesa area is dominated by the Cornudas Mountains, including Wind Mountain, which rises to a height of 7,280 feet, or 2,000 feet above the desert floor.

The eastern portion of the project area is located in the Pecos River Valley and the Llano Estacado. The Pecos River, which runs north to south through the eastern portion of the project area, flows for 926 miles from its headwaters in the Sangre de Cristo Mountains in north-central New Mexico into Texas, where it joins the Rio Grande. For most of the period of human occupation in southeastern New Mexico the Pecos has been the primary perennial water source and a major determinant of land use and settlement.

The Llano Estacado is a flat, semiarid plateau covering some 32,000 square miles in eastern New Mexico and west Texas and ranging in elevation from 5,000 feet on the northwest to less than 3,000 feet on the southeast. It is bounded on the 


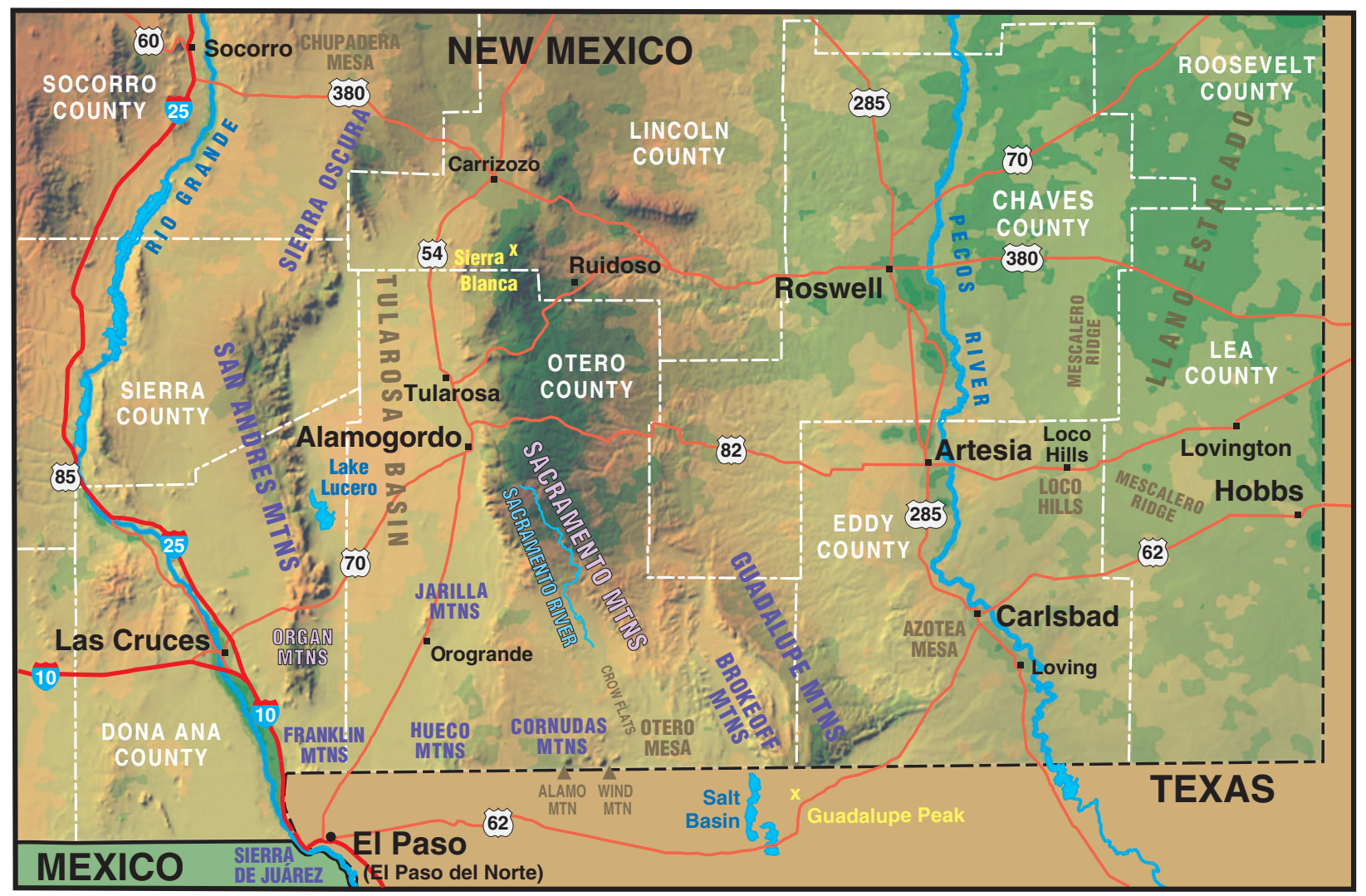

Figure 1.3. The New Mexico project area.

north by the Canadian River and on the west by the Mescalero Ridge, which forms the eastern edge of the Pecos River Valley. The eastern boundary of the Llano Estacado, the Caprock Escarpment, is a steep cliff about 300 feet high. The "caprock" layer is not really rock at all but is instead a layer of caliche, which is soil that has been hardened by minerals. The southern end of the Llano Estacado lacks a distinct physical boundary and blends into the Edwards Plateau of Texas.

\section{Climate}

The climate in the project area is semi-arid with hot summers and mild winters. The summer high temperatures average in the mid nineties (F), but daytime temperatures over 100 are very common. Temperatures in the $115^{\circ} \mathrm{F}$ range have been recorded at two stations within the project area. The summer low temperatures average in the high sixties, although nighttime temperatures in the seventies are very common. In winter, the high temperatures average in the high fifties and the low temperatures average in the high twenties. Winter daytime temperatures in the sixties and even seventies and nighttime temperatures in the teens are not uncommon, however. The frost-free season averages nearly 200 days per year.

The precipitation in the study area ranges from 10 to 16.5 inches per year. Average annual precipitation varies substantially with elevation, with higher precipitation occurring at higher elevations. Most of the precipitation falls between May and October. The primary source of summer precipitation is moist, warm air that pushes inland from the Gulf of Mexico. The moist air, combined with surface solar heating, results in localized afternoon and evening thunderstorms. During the winter months, the main source of moisture for precipitation is Pacific storm systems moving in from the west. The Guadalupe and Brokeoff mountains tend to block many of these systems from reaching the Azotea Mesa and Loco Hills study areas; Otero Mesa is more likely to receive some portion of this winter moisture. A combination of high evaporation rates and frequent, strong winds, especially in the spring, contributes to the aridity of the climate and the xeric nature of the vegetation. 


\section{INTRODUCTION}

\section{Paleoenvironment}

Although there are a number of important paleoenvironmental studies from the Southern Plains (Hall 1982; Johnson and Holliday 1989, 1995; Reeves 1972; Stafford 1981) and the northern Chihuahuan Desert, the only reconstructions specific to this general area are for the Guadalupe Mountains (Roney 1985; Van Devender 1980; Van Devender et al. 1979).

The earliest human occupation in southeastern New Mexico took place during the last Late Pleistocene/Early Holocene pluvial, which dates from approximately 13,000 to 6000 BP. The early part of this San Jon pluvial was a time of greater effective moisture owing to both increased precipitation and lower summer temperatures. The Southern Plains were covered with a mixed grassland/open woodland vegetation, and there were numerous small and large playas. After about 11,000 BP the climate became drier with warmer summers and possibly cooler winters. Precipitation was increasingly concentrated in the winter, and the vegetation shifted to largely grasslands. It was during this period from 11,000 to 10,000 BP that the Pleistocene megafauna - mammoths and Bison antiquus — went extinct. It was also during this time that the Pleistocene sand sheet, the earlier of the two major sand deposits that underlie the recent coppice and parabolic dunes in the project area, underwent considerable erosion.

Between approximately 10,500 and 9500 BP there was some fluctuation of wetter and drier periods, but generally the trend was one of increasing dryness. By 9000 BP woodland vegetation had disappeared from the Southern Plains, which now formed an immense desert grassland, and all but the largest playas dried up. The last period of increased moisture during the San Jon pluvial dates from about 8500 to 7000 BP; from that time onward the climate and vegetation of southeastern New Mexico came to resemble the modern climate and vegetation of the region.

Hall's (2002) Mescalero Sands study provides detailed information about recent paleoclimatic events in the Loco Hills area, but this level of information is not available for the other two study areas. In the Mescalero Sands area, between 9000 and 5000 BP the more recent of the two major sand sheets that underlie the modern coppice and parabolic dunes was deposited. From that time until about 500 years ago this Holocene sand sheet was covered with desert grassland and shrub grassland vegetation and remained largely stable or underwent a small amount of deflation. Between 500 and 100 years ago the landscape in this part of southeastern New Mexico was quite stable and a soil A horizon developed on the exposed Holocene and Pleistocene sand sheets in conjunction with a stable grassland and the expansion of shin oak.

As noted in the Loco Hills discussion (Chapter 5), during the past 100 years, owing to changes in land use that have disturbed the desert grasslands, the earlier sand sheets have been severely deflated. In areas where the sand sheet is thin, Torrey mesquite have expanded and a mantle of coppice dunes has formed. Where the sand sheet is thicker, shin oak and parabolic dune fields cover the earlier deposits.

\section{Project Area Culture History}

What follows is a very brief overview of the prehistory and history of the project area. For more detailed information the reader should consult the major syntheses for the region (Katz and Katz 2001; Kirkpatrick et al. 2001; Sebastian and Larralde 1989).

The earliest human inhabitants of the project area were the people referred to by archaeologists as Paleoindians, highly mobile hunters and gatherers adapted to the open savanna environment and abundant big game species of the late Pleistocene. Paleoindian sites are rare everywhere but are found most frequently above the caprock on the Llano Estacado, in the Guadalupe Mountains, and around the margins of Lake Lucero, the large, late Pleistocene ancestor of modern Lake Otero. Given the prevalence of recent sand sheets in the Loco Hills area, it is likely that most evidence of Paleoindian occupation will be buried and not detectable during surface survey in that part of the project area.

The earliest Paleoindian sites in the region date to the Clovis (ca. 11,000 years BP) and Folsom (ca. 10,500 years BP) periods. Famous for their extraordinary fluted spear points and for their apparent ability to use those fragile weapons to bring down large, now-extinct species such as mammoths and Bison antiquus, the Clovis and Folsom people remain shadowy figures to us. We have examples of kill sites and butchering sites, but because we have no material culture markers to help us identify the non-hunting components of their adaptation, we know very little about the rest of their technology and overall subsistence practices. Most recorded finds of early Paleoindian materials are isolated tools; selective collection of projectile points, both prehistorically and in recent times, has undoubtedly limited our ability to recognize these sites during surface surveys.

Later Paleoindian sites (8500-10,500 years BP) reflect the changing adaptation required by the drying and warming trends of the early Holocene. The smaller modern bison (Bison bison) became a major prey species, and there is some evidence to suggest specialization in bison hunting in the eastern portion of the project area. Again, however, our inability to identify the non-hunting-related components of the late Paleoindian settlement system has almost certainly 
skewed our understanding of the adaptation. In the western portion of the project area, later Paleoindian tool kits (those associated with Scottsbluff and Eden projectile point forms) suggest a more generalized subsistence strategy and a settlement pattern focused on playas and springs.

By about 7,000 years ago, the generalized hunting and gathering adaptation that archaeologists call the Archaic was firmly established in the project area. Much of what we know about the Archaic adaptation of this region is a result of excavations in dry caves in the Guadalupe Mountains, but a number of open-air sites in the Pecos Valley and southern Tularosa Basin have also been excavated. These excavation data indicate substantial dependence on plant foods of many types and consumption of a wide range of animal species from bison and antelope to rabbits and small rodents.

Archaic hunting technology was focused on dart points hafted to short shafts and thrown by means of an atlatl or spear thrower. A variety of scrapers and cutting tools as well as handstones and basin metates round out the nonperishable toolkit, but materials preserved in dry cave sites include a wealth of basketry, cordage, woven nets and snares, as well as hide and wooden implements of many varieties.

The large number of aceramic sites found within the study area indicates a substantial presence of mobile, broadspectrum hunters and gatherers. Some of these "sites" are very large scatters of lithic artifacts with multiple concentrations of burned caliche and other evidence of thermal features - most likely hearths or roasting pits. These locations are often interpreted as favored gathering or hunting areas where multiple reoccupations have created the appearance of a single, very large site. Other Archaic period sites are small, perhaps single-use locations, generally without surface-visible features.

Sometime in the mid to late Archaic period, prior to 1,000 BC, corn was introduced into southern New Mexico from Mexico. Over subsequent centuries this cultigen formed a minor part of the Archaic diet, but it was only in the early centuries AD after new and more productive varieties of corn as well as beans and possibly amaranth spread north from Mexico that dependence on cultivated plants increased.

The Archaic period in southern New Mexico is traditionally viewed as ending sometime between AD 600 and 900 with the introduction of ceramics and the bow and arrow. One of the interesting questions about this region, however, is whether the Archaic lifeway also ended at this time or whether these new technologies were simply added to the Archaic repertoire. There is clear evidence of corn agriculture and relatively sedentary village or farmstead settlements on alluvial fans at the edges of the desert basins in the western part of the project area and along east-flowing tributaries of the Pecos River in the eastern part by AD 900. There were some substantial pithouse sites in these favored locations for agriculture by the $\mathrm{AD} 1000 \mathrm{~s}$ and $1100 \mathrm{~s}$ and even some modest pueblo sites in the $\mathrm{AD} 1200 \mathrm{~s}$. What is particularly interesting about the project area, however, is that much of southeastern New Mexico does not conform to the traditional image of Formative cultures in the American Southwest. Rather than being based predominantly on corn, beans, and squash, much of the post-Archaic subsistence intensification in this region seems to have been based on agave and shin oak, and in many ways it appears to have been a continuation of an otherwise largely Archaic lifeway.

By approximately AD 1400 southeastern New Mexico was largely abandoned by agricultural peoples, and the population that remained became increasingly mobile and focused on bison hunting. In the western portion of the project area, agricultural villages were abandoned at this time as well, but there is no clear evidence of continued occupation by nonsedentary groups as there is in the east. At the time of European contact, the project area was within the territory of the Kiowa, the Mescalero Apache, and by the 1700s the Comanche. Once mounted on horseback, groups in the eastern part of the region became increasingly focused on bison hunting, although other resources such as agave were of considerable importance. In the western portions of the project area Apache people hunted and gathered in the mountainous regions and practiced some corn agriculture along the permanent streams. Although we know from historical records that these groups made considerable use of the project area, their considerable mobility resulted in ephemeral sites with very few diagnostic artifacts, making them difficult to identify in the archaeological record.

Chapter 8 provides an overview of historical period settlement in the western portions of the project area. Euroamerican settlement in the eastern portion of the project area did not occur until after the establishment of Fort Stanton in 1855, and even then was concentrated in the uplands and drainages to the northwest of our study area. It was not until after the Civil War that substantial settlement occurred within the Pecos Valley itself, nearly all of it based on cattle and sheep ranching. In the 1880s and 1890s, homesteading and land development based on actual and fictitious water and railroad development brought considerable additional settlement into the Pecos Valley.

As early as 1908, water well drillers noticed traces of oil in some of the wells in Lea and Eddy counties. Good shows of oil and some indications of natural gas were encountered at approximately 1,200 feet, but the technology of the time was not sufficient to prevent water contamination. By 1923, the search for economically recoverable oil and gas was well underway. Two successful wells had been drilled in northwestern New Mexico only a few months before, and in April of 1924 the Illinois \#3 became the first viable producing well in southeast New Mexico. In 1939, Martin Yates II and three partners brought in the first well in the Loco Hills field in what proved to be the second largest pool in the United States. 


\section{The New Mexico Pump III Project Report}

This report describes the current cultural resource management (CRM) process in the project area and the current and potential future uses of information technology in CRM in southeastern New Mexico. After a discussion of the theory and methods of predictive modeling, the predictive models and inventory simulations for the three study areas are presented. Because management of historical as well as prehistoric resources will be an issue for management on Otero Mesa, this report includes a brief historical overview and summary of known and potential historical resources for that study area. Finally, we provide a set of recommendations for future management of cultural resources in the study area and for developing oil and gas fields in general, along with some suggestions about the broader management implications of the New Mexico Pump III project.

\section{References Cited}

Altschul, Jeffrey H.

1988 Models and the Modeling Process. In Quantifying the Past and Predicting the Future: Theory, Method, and Application of Archaeological Predictive Modeling, edited by W. James Judge and Lynne Sebastian, pp. 61-96. Bureau of Land Management, Denver.

1990 Red Flag Models: The Use of Modeling in Management Contexts. In Interpreting Space: GIS and Archaeology, edited by Kathleen M. S. Allen, Stanton W. Green, and Ezra B. W. Zubrow, pp. 226238. Taylor and Francis, London.

Altschul, Jeffrey H., Lynne Sebastian, Chris M. Rohe, William E. Hayden, and Stephen A. Hall

2003 Adaptive Management and Planning Models for Cultural Resources in Oil and Gas Fields: The Loco Hills Technical Summary. SRI Foundation, Rio Rancho, New Mexico. Draft.

Altschul, Jeffrey H., Lynne Sebastian, and Kurt Heidelberg

2004 Predictive Modeling in the Military: Similar Goals, Divergent Paths. Preservation Research Series 1. SRI Foundation, Rio Rancho, New Mexico. Draft.

BLM Las Cruces Field Office

2003 Proposed Resource Management Plan Amendment and Final Environmental Impact Statement for Federal Fluid Mineral Leasing and Development in Sierra and Otero Counties. Bureau of Land Management, Las Cruces, New Mexico.

Hall, Stephen A.

1982 Late Holocene Paleoecology of the Southern Plains. Quaternary Research 17:391-407.

2002 Field Guide to the Geoarchaeology of the Mescalero Sands, Southeastern New Mexico. Bureau of Land Management and New Mexico Historic Preservation Division, Santa Fe.

Johnson, Eileen, and Vance T. Holliday

1989 Environmental Change on the Southern High Plains, USA. Journal of Quaternary Sciences 4(2):145165.

1995 Late Quaternary Environments and Archaeology of the Southern High Plains. Bulletin of the Texas Archeology Society 66:519-540.

Katz, Susana R., and Paul Katz

2001 The Southeast. In The Archaeological Record of Southern New Mexico: Sites and Sequences in Prehistory, edited by Susana R. Katz and Paul Katz. New Mexico Historic Preservation Division, Santa Fe.

Kirkpatrick, David T., Peter Eidenbach, Karl W. Laumbach, and Meliha S. Duran

2001 Basin and Range Archaeology an Overview of Prehistory in South-Central New Mexico. In The Archaeological Record of Southern New Mexico: Sites and Sequences in Prehistory, edited by Susana R. and Paul Katz. New Mexico Historic Preservation Division, Santa Fe.

Kohler, Timothy A.

1988 Predictive Locational Modeling: History and Current Practices. In Quantifying the Past and Predicting the Future: Theory, Method, and Application of Archaeological Predictive Modeling, edited by W. James Judge and Lynne Sebastian, pp. 19-60. Bureau of Land Management, Denver.

Kohler, Timothy A., and Sandra C. Parker

1986 Predictive Models for Archaeological Resource Location. In Advances in Archaeological Method and Theory, Vol. 9, edited by Michael B. Schiffer, pp. 397-452. Academic Press, New York. 
Roney, John R.

1985 Prehistory of the Guadalupe Mountains. MA Thesis, Department of Anthropology, Eastern New Mexico University, Portales.

Reeves, C. C., Jr.

1972 Tertiary-Quaternary Stratigraphy and Geomorphology of West Texas and Southeastern New Mexico. In Guidebook of East-Central New Mexico, edited by V. C. Kelley and F. D. Trauger, pp. 108-117. New Mexico Geological Society $23^{\text {rd }}$ Field Conference. New Mexico Bureau of Mines and Minerals, Socorro.

Sebastian, Lynne, and Signa Larralde

1989 Living on the Land: 11,000 Years of Human Adaptation in Southeastern New Mexico. Cultural Resources Series 6. Bureau of Land Management, Roswell District, Roswell, New Mexico.

Stafford, Thomas J.

1981 Alluvial Geology and Archaeological Potential of the Texas Southern High Plains. American Antiquity 46:548-565.

Van Devender, Thomas R.

1980 Holocene Plant Remains from Rocky Arroyo and Last Chance Canyon, Eddy County, New Mexico. The Southwestern Naturalist 25(3):361-372.

Van Devender, Thomas R., W. G. Spaulding, and M. R. Phillips

1979 Late Pleistocene Plant Communities in the Guadalupe Mountains. In Biological Investigations in the Guadalupe Mountains National Park, Texas, edited by Hugh H. Genoways and Robert J. Baker, pp. 13-30. National Park Service Proceedings and Transactions Series No. 4. Washington, D.C. 


\title{
Adaptive Management, Planning, and Oil and Gas: The Current Situation
}

\author{
Lynne Sebastian, David W. Cushman, and Sarah Schlanger
}

\begin{abstract}
D.
The overall goal of the PUMP III project is to evaluate current and past cultural resource management practices as they relate to archaeological sites in oil and gas leasing areas and to identify changes in management practices that would foster energy development while maintaining a high level of stewardship for these cultural resources. By analyzing the results of past cultural resource management practices in well-developed fields, we hope to recommend more efficient and appropriate management for future development both in the mature fields and in developing and proposed fields. Because effective decision-making requires interpretation of data, the secondary goal of the project is to create regional cultural resource information management tools and models whose potential utility extends beyond energy-specific uses to multi-agency regional land use planning.
\end{abstract}

\section{Adaptive Management}

As the title of this chapter and that of the report as a whole imply, the underlying philosophy of this project was adaptive management. Adaptive management, as the accompanying graphic indicates, is a systematic process for continually improving management policies and practices based on an evaluation of the outcomes of operational programs. Too often management practices become stuck in a loop at the implement and monitor stages. The PUMP III project was designed to move our understanding of cultural resource management practices in oil and gas fields in southeastern New Mexico through the evaluate stage and to propose adjustments. One of the challenges for the project is to suggest measures to ensure that the cycle will continue to be a cycle rather than once again getting stuck at implement or monitor.

The Bureau of Land Management (BLM) views adaptive management as an approach in which monitoring and feedback - the "monitor and evaluate" portion of the management cycle - are continually used to measure progress toward defined resource objectives or goals. The information captured in the monitoring programs informs decisions that either maintain the direction developed during the "implement solution" stage or change current management direction - the "adjust process" portion of the management cycle. The adaptive management paradigm depends on a clear understanding of operational program

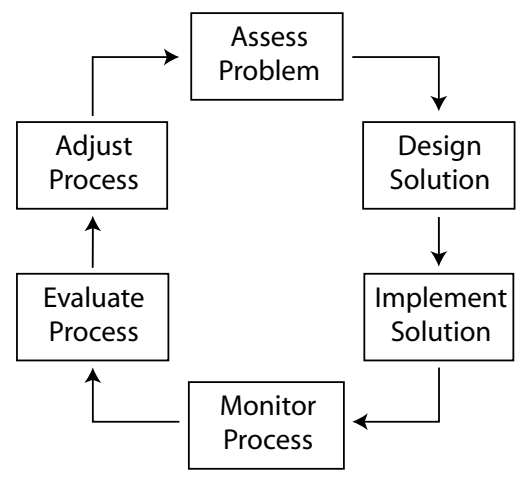
goals, an equally clear understanding of both management practices and operational outcomes, and a commitment to developing appropriate means to monitor and evaluate the effects of management decisions and implementation actions.

\section{Cultural Resource Management and the BLM}

The BLM administers 261 million surface acres of America's public lands, located primarily in 12 western states. In New Mexico, the BLM manages 13.4 million acres. The cultural resource program goals, both nationally and in New Mexico, are:

1. Respond in a legally and professionally adequate manner to the statutory authorities concerning historic preservation and cultural resource protection and to the principles of multiple use and ecosystem management;

2. Recognize the potential public and scientific uses of, and the values attributed to, cultural resources on the public lands, and manage the lands and cultural resources so that these uses and values are not diminished, but rather are maintained and enhanced; 
3. Contribute to land use planning and the multiple use management of the public lands in ways that make optimum use of the thousands of years of land use history inherent in cultural resource information, and that safeguard opportunities for attaining appropriate uses of cultural resources;

4. Protect and preserve in place representative examples of the full array of cultural resources on public lands for the benefit of scientific use and public use by present and future generations; and

5. Ensure that proposed land uses initiated or authorized by the BLM avoid inadvertent damage to federal and non-federal cultural resources.

The BLM actively manages a variety of cultural resources, such as historic structures and traditional cultural properties, but because the focus of this project is largely on archaeological resources, only the legal constraints and management practices related to archaeology are described below.

\section{Legal and Regulatory Constraints}

As a land-managing agency with a multiple-use mandate, the BLM operates under a myriad of statutory and regulatory constraints. The Federal Land Policy and Management Act of 1976 (P.L. 94-579) is often called the Bureau's "Organic Act" because it consolidated and articulated the BLM's many management responsibilities. The three major tenets of FLPMA can be summarized as multiple use, sustained yield, and environmental protection. As a general charge, FLPMA provides that

the national interest will be best realized if the public lands and their resources are periodically and systematically inventoried and their present and future use is projected through a land use planning process coordinated with other Federal and State planning efforts. [Section 102(2)]

In addition, FLPMA specifies that the United States will receive fair market value for the use of public lands and that

the public lands will be managed in a manner that will protect the quality of scientific, scenic, historical, ecological, environmental, air and atmospheric, water resource, and archeological values; that where appropriate, will preserve and protect certain public lands in their natural condition; that will provide food and habitat for fish and wildlife and domestic animals; and that will provide for outdoor recreation and human occupancy and use. [Section 102(8)]

Under FLPMA, the BLM strives to manage public lands so that they are used in whatever combination will best meet the present and future needs of the American people for renewable and nonrenewable resources.

The major federal statutes affecting the management of archaeological sites on federal lands are the National Environmental Policy Act (NEPA), the National Historic Preservation Act (NHPA), the Archeological Resources Protection Act (ARPA), and the Native American Graves Protection and Repatriation Act (NAGPRA). NEPA, NHPA, and NAGPRA also address cultural resources other than archaeological sites, and a number of additional federal laws and other authorities (e.g., Executive Orders) address these other kinds of cultural resources as well.

\section{NEPA}

Although many people think of NEPA as a law focused on impacts to the natural environment, in fact, Section 101(b) of NEPA describes the purpose of the law as being to "preserve important historic, cultural, and natural aspects of our National Heritage." In a general sense, NEPA compliance for oil and gas development begins with the development of a Resource Management Plan that is supported by analyses reported in an Environmental Impact Statement. The analysis developed for the RMP describes current conditions, outlines reasonably foreseeable developments, considers the cumulative impacts foreseeable under those development conditions, and describes management practices that will achieve or maintain desired resource conditions in light of those potential impacts.

NEPA compliance for most specific oil-and-gas-related actions is carried out on a right-of-way (ROW) or application for permit to drill (APD) basis. As part of agency decision-making, an Environmental Assessment (EA) is prepared for each action to determine whether that action will have a significant impact on the quality of the human environment. The EAs are based on the environmental impact analyses underlying the governing RMP, which explicitly addresses cumulative effects of foreseeable developments, including the actions ordinarily evaluated through the EA process. Not surprisingly, the finding, in virtually all cases, is that individual actions will not have a significant impact (a "finding of no significant impact" or FONSI). Actions that are anticipated to have a significant effect - that is, an effect not mitigated by the application of current management practices or of a scale or character that is outside the scope of the impacts considered 


\section{THE CURRENT SITUATION}

in the development of the RMP - will trigger the preparation of an Environmental Impact Statement (EIS).

The problem, from a cultural (and natural) resource standpoint, is that while each individual ROW or APD may not have a significant impact, over time thousands of such actions may be carried out within a very limited geographic area (Figure 2.1). This possibility, of course, is central to the development of a strong RMP, and particularly one that is based on an explicit adaptive management strategy. To date, BLM has not used the management opportunities inherent in the RMP process to best advantage where cultural resources are concerned. Unless the population of cultural resources is well-understood at the onset of development, the impacts of the development cannot be addressed or evaluated in a systematic fashion. Important aspects of the population of cultural resources include site type (i.e., habitation site, campsite, resource procurement site, chipping station, hunting blind, rock art panel, etc.); resource value, including National Register eligibility as well as scientific, recreational, and educational value; and the quantity and distribution of sites.

The traditional tool for both discovery of resources and evaluation of resource values is the archaeological survey. Survey in southeast New Mexico today is generally restricted to small samples of the larger area that will eventually be developed, and those samples are not chosen to maximize their potential to characterize the broader region. Therefore, cultural resource managers currently have no mechanism for determining how confident they should be that the sample approximates the true population of cultural resources that they manage. More importantly, what they know about archaeological resources from sampling the region in this way may not meet the program goals enumerated at the

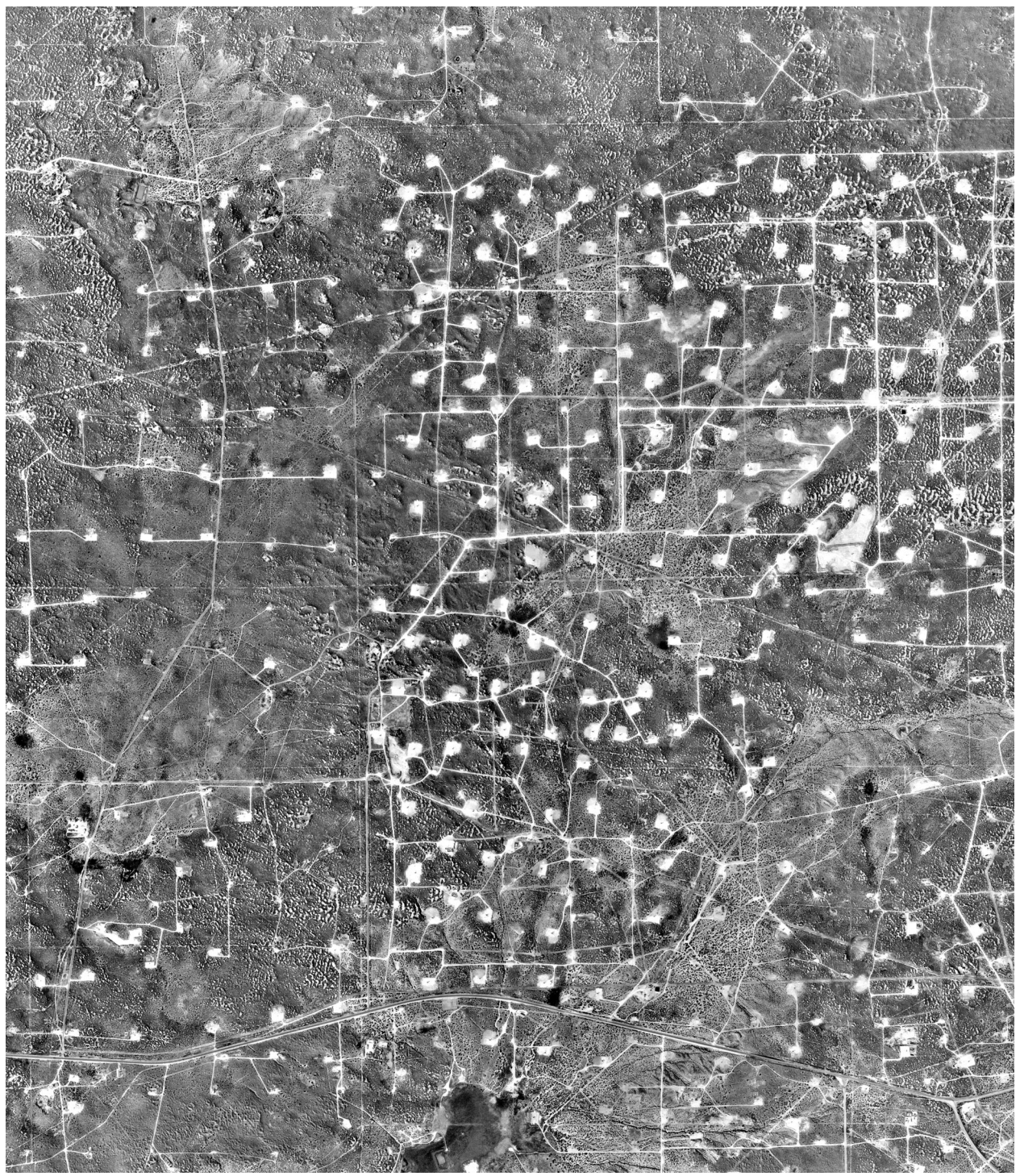

Figure 2.1. An example of the cumulative impact of oil and gas development. This 1996 image shows an area within the Loco Hills field. 
beginning of this section. Simply put, the practice of "surveying as you go," from well pad to well pad, does not ensure that the BLM will be able to maintain and enhance the values of cultural resources, use thousands of years of local occupancy to assist present land-use planning, protect and preserve representative samples of archaeological resources, or prevent proposed land uses from inadvertently damaging cultural resources.

One key way to address these difficulties would be to develop stronger RMPs, plans that specify how and where cultural resources may be impacted or involved in future land uses and where more resource data are needed. Such plans would also indicate how proposed management techniques would integrate anticipated uses with the collection of more data, allow for appropriate and timely evaluation of those data, and adjust management practices to achieve resource goals.

Another way to address the cumulative effects of multiple developments on cultural and natural resources would be to carry out NEPA compliance at a broader scale - a lease, a set of leases, a physiographic unit, etc. This is difficult to do, however, because of the nature of oil and gas development. Decisions about the location and nature of future development are contingent upon initial development, market conditions, and many other factors, so often there is insufficient information to evaluate impacts at a broader scale.

\section{NHPA}

The NHPA requires that the BLM both proactively manage archaeological sites and other cultural resources under its jurisdiction and reactively identify and take into account the effects of its actions on those resources. The proactive requirements of NHPA - to identify, evaluate, and nominate properties under federal jurisdiction to the National Register of Historic Places - are largely contained in Section 110 of the law, while the reactive requirements - to take into account the effects of proposed undertakings on historic properties - are established in Section 106 of the law and in the implementing regulation, 36 CFR Part 800 . Clearly, Section 110 's mandate to identify and evaluate properties could be used to gather information needed for broad-level management decisions relative to cultural resources, but this directive is unfunded. And the reality of the situation is that BLM cultural resource staff is stretched to, and often beyond, capacity simply managing the large number of ROW- and APD-based Section 106 undertakings each year. There is simply no time to gather non-project-specific data to supplement project-specific surveys.

\section{ARPA}

The Archeological Resources Protection Act requires permits for excavation of archaeological sites on federal and tribal lands and establishes criminal and civil penalties for violation of the law. This statute affects cultural resource management in oil and gas leasing and development situations both when permits are requested for scientific excavation of sites as part of Section 106 mitigation efforts and in cases of purposeful damage or destruction of sites during development activities.

\section{NAGPRA}

Both Section 106 of the NHPA and ARPA require consultation with Indian tribes when undertakings may affect properties of religious and/or cultural significance to the tribe. NAGPRA goes a step further and establishes tribal ownership or control of certain cultural items discovered or excavated on federal lands. Specifically the law applies to human remains and associated or unassociated funerary objects, sacred objects, and items of cultural patrimony. This statute affects cultural resource management in oil and gas leasing and development situations when any of these cultural items are encountered during archaeological excavations or in discovery during development activities.

\section{Current Archaeological Resource Management Practices}

The Bureau of Land Management has developed a series of national cultural resource management manuals, called the 8100 -series, which cover all aspects of the BLM's archaeological resource management practices. These manuals include

- 8100 The Foundations for Managing Cultural Resources

- 8110 Identifying and Evaluating of Cultural Resources

- 8120 Tribal Consultation under Cultural Resource Authorizations

- H-8120-1 Guidelines for Conducting Tribal Consultation

- 8130 Planning for Cultural Resources

- 8140 Protecting Cultural Resources

- 8150 Permitting Uses of Cultural Resources

- 8160 Preserving Collections of Cultural Resources

- 8170 Interpreting Cultural Resources for the Public 


\section{THE CURRENT SITUATION}

Under the 1997 Programmatic Agreement (PA) among the BLM, the Advisory Council on Historic Preservation, and the National Conference of State Historic Preservation Officers, the procedures outlined in the manuals, together with state-specific protocols for administering the PA, substitute for the 36 CFR Part 800 regulation. In addition, the New Mexico BLM has released statewide guidance for fieldwork and reporting in the form of a handbook: H-8100-1, Procedures for Performing Cultural Resource Fieldwork on Public Lands in the Area of New Mexico State BLM Responsibilities. Together the manual series and the state handbook guide archaeological resource management practice on public lands in New Mexico. Current management practice and procedures are described below. The Field Officelevel practices and procedures have been divided into those associated with planning, leasing, ground-disturbing projects, right-of-way applications, and monitoring. Planning and monitoring are the places where practice connects most clearly with the adaptive management model illustrated at the beginning of this chapter.

\section{Planning}

Field Office cultural resources staff participate in the development of long-range resource management plans (RMPs) by characterizing the archaeological resources within the management area and identifying areas within the field office's administrative responsibility that contain resources that require special management considerations. There areas may become Areas of Critical Environmental Concern (ACECs), Special Management Areas (SMAs), or Cultural Resource Management Areas (CRMAs); applications for public use of resources within ACEs, SMAs, or CRMAs are evaluated in accordance with both general guidance for protecting cultural resources and special management practices. These evaluations will result in stipulations to any use permits that may be approved. Existing RMPs and other land use plans are reviewed by field offices on a regular basis, either annually or following an established review cycle, to ensure that plans adequately meet current land use demands. RMPs that are not meeting current or anticipated management needs may be revised or amended. Recent changes in how RMPs are to be developed will now require Field Office staff to invite Native Americans to comment on, and/or participate in, the RMP drafting process. This will provide tribes with an opportunity to express any concerns they may have with the BLM's management of the planning area, and to determine whether there are any properties of traditional cultural and religious importance that should be considered in the BLM's planning effort.

The RMP process, and the land use planning process in general, is the bedrock of BLM's adaptive management strategy. The land use plan is based on an analysis that identifies current conditions and forecasts future conditions, considers potential impacts from uses and other environmental conditions, offers several management strategies to achieve desired conditions, and creates a plan for monitoring plan implementation and operation. The RMP revision or amendment process allows the BLM to examine and revise any of the "boxes" of the adaptive management model illustrated in the beginning of this chapter.

The revision or amendment process can afford cultural resources staff an opportunity to assess their understanding of the cultural resources present in their administrative area and the effects of their current management practices on those resources. This cultural resource management assessment can include consideration of any or all of the following:

- locations where cultural resource work has been conducted

- adequacy of our ability to characterize the resource population for management purposes

- evaluation of trends in impacts to resources and/or trends in development that may affect resources

- evaluation of the effectiveness of current management practices

- identification of additional information needed to improve management practices

The Carlsbad Field Office completed a resource management plan for oil and gas development in 1997. The Overall Field Office RMP is currently being amended to address the needs of special-status species, but this process is unlikely to substantially reduce the acreage open to oil and gas development. The Las Cruces District Office has just completed a major RMP revision for the area treated in the New Mexico PUMP III project.

\section{Leasing}

Field Office cultural specialists are afforded the opportunity to review proposed lease parcels as part of the internal lease development process. Prospective lease parcels are supposed to be identified to Field Office staff at least three months prior to their release to the public. In practice, however, BLM cultural resource specialists may not receive review materials until as little as one month before the proposed lease sale date. The cultural resources staff reviews the lease parcel locations and compares them with the locations of known archaeological sites, traditional cultural properties, and other resources of known Native American interest, and with the locations of special management areas such as 
ACECs, SMAs, and CRMAs. The cultural resource specialists also assess the potential of the area to include significant cultural resources that are not currently known.

Potential lease lots may include as many as 80 individual, spatially separated parcels; each of these parcels must be matched to paper and electronic records of site locations, previously surveyed areas, and special management areas. Cultural resource specialists may suggest stipulations be attached to the proposed parcel leases to protect cultural resources; these suggestions are incorporated into the lease packets at the discretion of the lease preparers. Cultural resource specialists do not have the opportunity to review lease stipulations once the review packet is returned to the preparer.

The BLM has just recently issued guidance regarding Native American consultation and involvement at the lease level for energy development. In those instances where tribal consultation was insufficient during the RMP process, the Field Offices will attach as a lease stipulation a notice stating that development will not be authorized until the agency fulfills its obligations under the National Historic Preservation Act and other applicable legal authorities. The agency may also restrict development or disapprove any activity that may adversely affect cultural resources if those effects cannot be successfully avoided, minimized, or mitigated. Currently, cultural resource specialists in the Carlsbad Field Office contact Native American tribes with expressed interests in their administrative areas when lease packets are released for internal review. The tribes are advised of the potential for leasing and their comments on the proposed lease locations are solicited. As noted, however, these procedures are changing.

\section{Exploration and Operations}

When exploration proposals are submitted to the BLM, the cultural resources staff is afforded the opportunity to review them as part of the internal EA review and sign-off procedures. The proposed exploration locations are matched against paper and electronic records of recorded sites and field inventories, and the cultural resources staff person makes a determination as to whether an archaeological inventory survey is required.

For geophysical exploration projects, archaeological inventories cover the entire impact area, including receiver and source lines. Ordinarily, these projects are subjected to the same survey requirements as all other proposed land uses. Exceptions to the survey requirement follow the guidance in the New Mexico Protocol (the state-specific agreement that implements the BLM's nationwide programmatic agreement) and the H-8100 handbook. For exploration projects, exceptions to the survey requirement will normally occur only when there is prior ground disturbance or when adequate survey has previously been completed.

In addition to requiring archaeological surveys, through the efforts of BLM staff archaeologists, biologists, and other resource specialists, the southeast New Mexico field offices have begun to apply other stipulations intended to minimize the potential for surface impacts. In the Carlsbad Field Office, for example, heavy vehicles involved in exploration are expected to be outfitted with oversized balloon tires that spread the vehicle load as widely and evenly as possible.

Permit applications for rights-of-way (ROWs) and drilling locations (APDs) are circulated among the Field Office staff with check-off or sign-off cover sheets specific to each type of application. Cultural resource and other specialists fill in these cover sheets as they complete their reviews. Cultural resource staff review must include both a consideration of NEPA and a consideration of NHPA, and this dual requirement can introduce some difficulties in the internal review process, as described in the description of APDs and rights-of-way below.

ROW applications come to the cultural resources staff through the realty specialists. The realty specialists may determine that, under NEPA, a ROW application meets the requirements of a Categorical Exclusion (CX), based on their understanding of the current environmental conditions. Usually, this is the case when the application is for use of a previously granted right-of-way or road corridor. In these cases, the realty specialist assumes there has been an archaeological survey at some earlier date. The archaeologist's review of this ROW application, however, may reveal that there was no prior survey, or that the survey did not extend to the corridor width required by the present use application, or that the proposed use will disturb previously uninventoried land.

Even though the application is a CX under NEPA, the procedures to comply with Section 106 of NHPA must still be followed. Because of their responsibilities under NHPA and because they have access to more complete records regarding previous survey and the presence or absence of cultural resources in the proposed project area, cultural resources staff may find themselves contradicting realty staff communications to the ROW applicant about the need for inventory survey or monitoring during construction.

When a project comes to the cultural resources staff for review, they look first to the location, and draw on their own familiarity with the area and its resources to make an initial determination of whether or not survey is required. They support this initial determination with a check of existing paper maps, which are updated by Field Office staff, as 


\section{THE CURRENT SITUATION}

well as with the ARMS database and existing data concerning prior survey quality and location.

APDs follow the same path through the field office as ROW applications. When the project review package is circulated to the cultural resources staff, however, it may or may not have an archaeological report attached to it because archaeological consulting firms submit their reports directly to the office. Most often, the staff must determine whether an archaeological report has been submitted by a contractor on behalf of the project sponsor/proponent and then locate the appropriate report, match it up with the project package, review the report for compliance with BLM and NHPA requirements, and determine if they can sign off on the application. Delays in this process occur when the project proponent has not contracted for an archaeological survey, when the archaeological inventory report has not been received and reviewed by the time other internal reviews of the APD have been completed, or when the archaeological inventory report fails to meet BLM requirements and must be revised, amended, or corrected.

The first problem, failure to include an archaeological report in the application package, is not uncommon, and it creates a substantial potential for delay. Cultural resources field staff may respond to this problem by contacting the proponent directly and asking them to initiate a survey; by conducting a records search to determine whether cultural resources are at risk from the proposed action; by conducting a rapid, emergency survey, especially when operations have commenced in the area; or through a combination of these actions. Failure to consider archaeology during project planning is generally a result of a lack of familiarity with federal requirements on the part of a project proponent. Field Office staff in southeast New Mexico hold annual educational programs for energy, communications, and other potential land use applicants, and it is very important that potential applicants take advantage of these educational opportunities. The second type of problem, missing archaeological survey reports, requires telephone calls or letters to the consulting firm in an attempt to locate the report or speed up its submission. The third problem, substandard inventory reports, requires written reviews that request corrections and, on occasion, repeated requests for missing or supplemental information.

It is not uncommon for cultural resource staff to find that inventory survey reports have been produced for areas that had been surveyed previously and that site records have been created for sites that were recorded previously, but were not recognized as such. Consulting archaeologists are required to review BLM records and records held by ARMS prior to initiating fieldwork, and to consult with BLM cultural resource staff before initiating fieldwork for large, complex, or out-of-the-ordinary projects. This requirement is not always met, and the resulting confusion from multiple surveys and site records can also introduce delay into the report review process. Field Office staff hold training courses for consultants on BLM standards for fieldwork and reporting and have revoked permits for consulting firms that consistently underperform.

Applications for land use permits are incomplete if they do not include a reviewed and approved archaeological inventory report. These reports must be available to the Field Office cultural resource staff before they receive the application package and review sign-off sheets and checklists. Coordinating receipt, review, and filing of cultural resource inventory reports for APDs and ROWs is a time-consuming and critical process; the potential for delay in the application review process is clear and frequently realized.

Field Office staff evaluate each project independently. Ordinarily, the decision as to whether a survey is needed is made by the cultural resource specialists. These specialists must consult a variety of records to make this determination in any particular case. Any changes in management practices or development of desktop tools that can reduce the search time for records, make records management simpler, and create the opportunity for evaluating survey needs and survey adequacy more easily will be of benefit to both BLM staff and applicants for land-use authorizations.

\section{Monitoring}

Monitoring is the other area of practice that articulates clearly with the previously presented model of adaptive management. The Field Office staff monitor the performance of the consulting archaeological firms operating in their administrative areas through field checks on projects to determine whether sites are being identified and recorded in accordance with BLM standards. In addition, Field Office staff are required to monitor up to $5 \%$ of the undertakings, once construction has been completed, to ensure site avoidance stipulations are being followed.

One of the most critical needs, in terms of closing the adaptive management loop for cultural resources, is for monitoring, evaluation, and synthesis of the data that have accumulated over the past 30 years. Data on archaeological resources and inventory surveys are contained in paper maps, electronic map-servers, electronic database summaries, and paper reports and records. At present, the feedback loop between field data and practice is limited to an evaluation as to whether a survey has been conducted in the proposed project area. Any more sophisticated evaluation is dependent on improving our ability to synthesize, evaluate, understand, and manage the paper and electronic records we have developed. 
The pressures of meeting day-to-day obligations have overridden consideration of larger cultural resource management questions: Can we adequately characterize the area covered by a particular land-use application based on work in nearby or similar areas? What is the research, or educational, or recreational value of an identified resource, based on what we have learned from inventory survey or archaeological fieldwork? Should assessment of resource values be adjusted in accordance with new information? Should field practice or review practice be modified in accordance with new information? Are resources that are at risk qualitatively different from currently protected resources? Will the cumulative impacts be detrimental to the entire population of resources? Are we preserving a representative sample of materials for future benefit?

\section{Oil and Gas Leasing and Development and the BLM}

The BLM is responsible for leasing oil and gas resources on all federally owned lands, including those lands managed by other federal agencies. This includes about 564 million acres of federal minerals estate. BLM reviews and approves permits and licenses to explore, develop, and produce oil and gas and is responsible for inspecting oil and gas wells and other development-related operations and enforcing lease requirements and regulations.

\section{Legal and Regulatory Constraints}

The Mineral Leasing Act of 1920, as amended, and the Mineral Leasing Act of 1947 for acquired lands provide the statutory authority for federal oil and gas leasing. 43 CFR 3100 provides the regulatory basis for BLM to administer federal oil and gas leasing. 43 CFR 3160 authorizes BLM to issue onshore oil and gas when necessary to promote the orderly and efficient exploration, development, and production of oil and gas.

There are currently seven Onshore Orders:

No. 1 - Approval of operations

No. 2 - Drilling

No. 3 - Site security

No. 4 - Measurement of oil

No. 5 - Measurement of gas

No. 6 - Hydrogen sulfide operations

No. 7 - Disposal of produced water

And two proposed orders

No. 8 - Well Completions/Workovers/Abandonment

No. 9 - Waste Prevention and Beneficial Use of Oil and Gas

The BLM, in partnership with the USDA Forest Service, has prepared and published Surface Operating Standards for Oil and Gas Exploration and Development (RMRCC 1989), also known as "The Gold Book," to provide lessees and operators with basic information about the statutory and regulatory requirements. The Gold Book provides guidance for all phases of development from geophysical exploration through drilling and production to reclamation and abandonment.

\section{Current Oil and Gas Management Practices \\ Planning}

Initial decisions about management of oil and gas resources are made as part of the BLM's land-use planning process. Resource Management Plans (RMPs) are developed for specific geographic areas — often BLM field office areas - and these RMPs are updated and revised on a periodic basis. One of the classes of information contained in an RMP is a categorization of land parcels that are open to oil and gas leasing, available for leasing with special stipulations, and closed to leasing. The only way that parcels can be closed to leasing is through the RMP process.

\section{Leasing}

Parcels to be offered in BLM lease sales are identified in two ways: through informal expressions of interest from potential lessees or formal pre-sale offers for noncompetitive leases of lands in expired, terminated, relinquished, or cancelled leases. Leases must have been terminated for at least a year before a pre-sale offer can be submitted. Both expressions of interest and pre-sale offers must be filed with the BLM State Office at least 17 weeks before a scheduled quarterly sale. 


\section{THE CURRENT SITUATION}

Information on the parcels that have been identified for the next lease sale is sent to the field offices for review at least 3 months before the sale, where they are compared with land-use plans and reviewed by the various resource specialists to identify possible resource conflicts. Any conflicts are addressed through recommendations for stipulations to be attached to the lease. The Field Office manager returns the information on the identified parcels to the State Office with stipulations attached or recommends that leasing of a parcel be deferred if additional information is needed or if a plan amendment is required.

Forty-five days prior to the sale, the State Office publishes a Notice of Competitive Lease Sale, which lists the parcels available at auction and includes information on stipulations attached to each lease. The maximum competitive lease parcel is 2,560 acres; the maximum non-competitive lease parcel size is 10,240 acres. The minimum parcel size is about 40 acres. Lease parcels may be noncontiguous, but separate parcels must be within 6 miles of one another.

Successful bidders at the auction execute a contract and pay a sale cost share, a year's rental in advance, and other fees. Parcels that are not sold during the auction are then leased to the pre-sale offeror, if one exists; otherwise they are available for noncompetitive leasing beginning the day after the lease sale and for a period of two years. Leases are good for 10 years as long as the rental is paid ( $\$ 1.50$ per acre for first 5 years; $\$ 2.00$ per acre beginning in year 6). Leases will automatically continue after the 10 -year period if drilling operations are in progress, if there is a well on the lease that produces in paying quantities, or if the lease can receive an allocation of production from an off-lease well. If a lessee fails to pay rental by a lease anniversary, and if the lease has not been drilled, the lease automatically terminates.

Lease interests are transferable - either record title interest or operating interest-but BLM must approve the transfer; a record title interest transfer must be for no less than 640 acres. Leases may be developed with one or multiple wells; spacing is determined by the State of New Mexico Oil Conservation Division. Anything that prevents a lessee from developing a leased parcel is considered a taking.

The lessee may explore and drill for, extract, remove, and dispose of oil and gas, but prior to any ground-disturbing activities, the lessee or operator must secure BLM approval and post a bond. Bonds for individual leases are at least $\$ 10,000$; statewide $(\$ 25,000)$ or nationwide $(\$ 150,000)$ bonds can also be established. A change in operator for a lease requires notice to BLM with information on whose bond (operator, lessee, single lease, or state or nationwide bond) will be used. Royalties for producing wells are $12.5 \%$.

All or part of a lease may be relinquished, but the lessee must plug any wells and reclaim disturbed areas according to BLM standards and have lease account payments up to date. Otherwise, the bond for the lease may be forfeited, and the lessee may be prohibited from leasing on federal land.

\section{Exploration and Operations}

Geophysical exploration can be carried out on most BLM land whether it has been leased or not; lessees may conduct geophysical exploration as a lease right. Geophysical operations must be bonded and approved by BLM; ground disturbance requires specific authorization. For split estate where the surface is nonfederal, no authorization from BLM is required.

Operators secure BLM approval for drilling operations through either the Notice of Staking (NOS) procedure or through an Application for Permit to Drill (APD). The APD process is more familiar to most operators and tends to be the preferred alternative in southeast New Mexico. The application consists of three parts: a downhole drilling plan, a surface use plan (covering a $600 \times 600$ foot area), and a safety plan. Once the APD has been reviewed by BLM for completeness, the Surface Protection staff completes an Environmental Assessment; attaches stipulations to the APD to ensure protection of surface resources, including archaeological resources; and schedules an onsite inspection. The applicant is notified within 7 working days of the completeness of the application and the onsite inspection is scheduled within 15 days.

During the onsite inspection, the BLM, the operator, and the operator's consultants examine the staked well pad, access road, and other facilities. They agree on construction standards, and the operator is advised of any deficiencies in the drilling or surface use plan either during the inspection or within 5 working days. Within 45 days after the inspection, the operator submits a completed APD with any needed revisions and an archaeological survey report if required. One of the problem areas identified by BLM cultural resource staff are flow lines that are included in an APD but, for whatever reason, are not included in the cultural resource inventory. This can be a source of delay or cause damage to unidentified archaeological sites. The approved APD is valid for 1 year.

Once the APD is approved, the operator develops the facilities and drills the well according to the submitted plans and files a report when the well is completed and another when it begins producing. Subsequent well operations require filing of Sundry Notices. Although some of the operations covered by Sundry Notices require prior approval, most do not, and most routine operations that do not involve ground disturbance require neither prior approval nor subsequent reporting. 


\section{Monitoring of Leases and Well Operations}

During the APD process, the Surface Protection staff ensures that appropriate stipulations are attached to the APD. Once the APD is approved, the Environmental Protection staff and Petroleum Engineering technicians monitor compliance with those stipulations during construction and subsequent operations. During well operations, leases are inspected periodically by Petroleum Engineering technicians and occasionally by the Environmental Protection staff; the former are more focused on production-related problems, the latter on environmental issues. The schedule for regular lease inspections is established by the Surface Protection staff based on the potential for problems. High priority leases are inspected annually; the target for inspecting less problematic leases is a 3-year rotation, but in fact the actual schedule is probably closer to a 5-year rotation owing to the huge number of leases in southeast New Mexico.

\section{Rights-of-Way}

Whereas on-lease activities related to well operations are carried out under Sundry Notices, off-lease activities (powerlines, produced water lines and injection wells, tanks, etc.) require a right-of-way (ROW) approval. A Realty Specialist evaluates the ROW, establishes any needed stipulations in consultation with the resource specialists, and prepares an EA. The stipulations apply throughout the life of the ROW (generally 30 years), but no notification of construction is required after the ROW grant is made. The process from application to ROW approval generally takes 45 days.

From an environmental and cultural resource standpoint, ROWs tend to be much more problematic than leases. Leases are inspected periodically; ROWs are not. Construction activities on leases require either prior approval or at least post facto notification; neither is required for ROWs. Even the as-built locations of pipelines and other buried features within ROWs are not reported, so it is impossible to know, for example, whether previous archaeological survey will be adequate for new construction.

\section{Abandonment/Relinquishment}

If a well doesn't produce or stops producing, the operator must secure approval to abandon the well and relinquish any ROWs. Protective stipulations can be placed on the abandonment approval; BLM Environmental Protection staff inspect the reclamation and relinquishment areas prior to final approval and release of the operator's bond.

\section{Challenges and Needs}

Based on discussions among the BLM, SHPO, and members of the New Mexico PUMP III project team and on interviews with representatives of the oil and gas industry in southeastern New Mexico, we have identified challenges posed by the current approach to cultural resource and fluid mineral management as well as some things that are needed to facilitate integration of cultural resource and oil and gas management.

\section{Cultural Resource Perspectives on Current Management Practices}

The current process for gathering archaeological information and managing archaeological sites on BLM lands in southeastern New Mexico is almost entirely driven by APDs and ROWs. As a result, we lack some basic data that are necessary to a rational and cost-effective management process. We don't know if the data we have gathered are representative or if our knowledge of the archaeological record is skewed by the requirements of locating oil and gas facilities. Would block surveys be better? Are they even feasible, given the nature of oil and gas development? Large geophysical exploration projects have produced some systematic grids of survey information: Are these grids providing us with sufficiently representative data to permit us to characterize the surface archaeological record?

In areas where oil and gas wells and facilities are being developed, the "flag and avoid" approach to cultural resource management means we have garnered very little excavation data relative to the very large amount of survey data. This has left us with no real understanding of the relationship between surface manifestations and subsurface archaeological deposits. We don't have a replicable process for defining site boundaries; we don't even know how to identify meaningful site types. And we have no mechanism for evaluating the reliability and consistency in survey and recording techniques.

The limited availability of excavation data is exacerbated by the lack of synthesis of those data that are available. What have we already learned? What do we still need to learn? These questions are not mere academic exercises; the lack of data means that management decisions must be based on an inadequate understanding of the archaeological record and thus tend to be very conservative. Have we learned all we can learn from surface survey in this area? We don't know, so we continue to survey. Is this site eligible to the National Register of Historic Places? We don't have adequate excavation data to assess this issue, so most sites are considered eligible - the consequences of erring in the 
"not eligible" direction are much greater, and more permanent, than the consequences of erring in the "eligible" direction.

The APD- and ROW-based approach to cultural resource management means that we have no opportunity to be proactive about locating energy development away from sensitive sites, we are unable to take advantage of economies of scale, and we have no way of taking into account the long-term and cumulative impacts of energy development on the archaeological record. Anecdotal evidence indicates that well-servicing activities, which are covered under Sundry Notices on leases and are uncontrolled entirely on rights-of-way, are having a significant cumulative effect on the sites that were so carefully and effectively avoided during initial drilling and construction. Is this true? We don't know, but if it is, we cannot address the problem using current standard procedures.

The problems created by the APD- and ROW-based approach to cultural resource management have been couched here in terms of their negative consequences for the archaeological resources, but they have negative consequences for energy development as well. Case-by-case decisions, inventory, and reporting are more time-consuming than larger scale efforts. Conservative decisions about eligibility may be causing needless avoidance of sites that, in fact, would not yield important information about the past and do not have other cultural or historical values. Operators are carefully adhering to provisions designed to avoid impacting sites during drilling and construction, yet cumulative impacts may be rendering their good faith efforts moot.

In examining cultural resource management procedures in oil and gas fields, the underlying questions that must guide our efforts are these: Do they constitute good stewardship of the archaeological resources? Are they compatible with best practices for energy development? Are they in the best public interest?

\title{
Oil and Gas Industry Perspectives on Current Management Practices
}

To determine how the problems associated with the APD and ROW approval processes are affecting energy development on the BLM lands in southeast New Mexico, interviews were conducted with representatives of seven oil and gas companies of varying sizes with established production histories in the area. Information identifying these companies was acquired from the BLM Carlsbad Office and the New Mexico Oil Conservation Division Offices in Artesia and Hobbs, New Mexico. Phone interviews were conducted in October and November 2004 with the following personnel, listed here with their company affiliation.

\author{
Clifton May, Regulatory Agent, Yates Petroleum Corporation \\ Mickey Young, District Manager, Mewbourne Oil Company \\ Linda Guthrie, Regulatory Specialist (Southeast NM), Devon Energy Corporation \\ Dan Girand, Director of Regulatory Affairs, Mack Energy Corporation \\ Dean Chumbley, Landman, Marbob Energy Corporation \\ Bob Monthei, Operations Specialist, BP Amoco \\ Joe Janica, President, Tierra Exploration Inc.
}

A questionnaire was developed to elicit the views of each company representative on the present problems with the BLM's cultural resources requirements and any potential solutions that should be considered as a part of this study. The questionnaire was sent via email prior to the interview along with a cover letter explaining the purpose of the PUMP III study and the intent of the interview questions. After each representative reviewed the questionnaire, the phone interview was conducted.

The first question asked the respondent to identify the most important problems that arise as a result of current BLM cultural resources management procedures. There was near unanimity on the part of the respondents: the current APD review process is fraught with delays, and the perceived source of these delays is the requirements that the BLM imposes relating to the management of archaeological sites. Other comments relating to these delays included the lack of sufficient BLM archaeology staff to conduct APD reviews, the effect of frequent staff turnover on the continuity of the APD review process, and internal conflict that exists within the BLM among the reviewing specialties.

The second most commonly identified "problem" had to do with the value of the archaeological record itself. Many questioned what has been, and could ever be, learned from the archaeological record in southeastern New Mexico, which these individuals view as inconsequential. Several respondents noted the importance of the archaeological record in the northwest corner of the state to illustrate how dissimilar, and thus unimportant, archaeological sites are in the Permian Basin. "It's not Chaco Canyon," as one industry representative put it. The lack of appreciation for sites in the southeast was not absolute, however. Many said they were aware of some sites that they thought particularly interesting, but added that the number of these places was "just a handful." Related to this was a common view that the archaeology of the twentieth century is so insignificant as to be unworthy of any management at all, being described by more than 
one respondent as "trash." It was assumed that there are better sources of information in records and archives and that preservation of sites dating to this time period is a waste of time and energy.

At the heart of the concern over site significance is the view expressed by several respondents that the National Register criteria are not being applied in accordance with regulation under 36 CFR 60.4. Historical sites dating to the 1930s and the small lithic scatters with fire-cracked rock that are typical of the area are not eligible for listing, in their opinion. The belief is that National Register determinations for sites of this nature are not, and cannot be, justified. One respondent thought that these more common site types, with little or no value, should be managed categorically - that is, declared to be ineligible as a class so that greater attention could be devoted to protecting more worthy sites. In a related comment, another industry representative expressed the view that not all sites on the BLM lands are important, and yet observed that all sites are being given equal management consideration. This gave him the impression that the agency itself is not able to make effective management decisions because it cannot discriminate between the (few in his opinion) sites that are truly worthy of protection and the (majority in his opinion) sites that are not.

These views are bolstered by another issue, which is the observation that so much archaeological work (survey) has been done in the past, and yet so little is currently known about the archaeological record. The respondents wanted to know why additional work is needed if so little has been learned after all this effort. The expressed frustrations are understandable given the years of compliance-driven archaeology for which industry has paid. The perception among those interviews was that, instead of seeing any dividends from this investment over time in the form of reduced regulatory burdens, the companies have encountered increased requirements that make their jobs more difficult. They do not understand why the agency is treating the archaeological record as worthy of management concern, and they feel that the BLM has not made sufficient effort to explain the cultural resources requirements in terms that they can understand. The only explanation offered is that "It's the law." As one frustrated company representative said, "Let's learn something," so that the knowledge can be used to change management practices on the ground.

The second question asked the respondents how their businesses were affected by the problems identified in question one. Again, as a group the respondents expressed the concern that delays inherent in the APD process increase costs, but more importantly, disrupt the planning cycle. One industry representative explained that his company needed to produce within 120 days of staking a well pad, which means that scheduling is tight from the very beginning. In addition, delays in the APD process can result in stand-by charges for an idle drilling rig and crew of up to $\$ 8,000$ per day, costs that cannot be sustained for long. More typically, delays result in decisions to switch drill locations, but when that happens, the producer must go back through the process with a new APD and the regulatory clock starts all over again. The respondents all noted that the permit approval is supposed to occur within 30 days, but all noted that it was taking longer. One respondent said that the approval time was typically between 45 and 120 days. Another noted that the 30day time limit on permits corresponds to the legally required public notice period, saying that if permit approvals could be granted within the ideal 30-day time frame, that would solve many of the problems from their perspective (see further discussion in Chapter 9).

Questions 3 and 5 are related in that the respondents were asked how they thought the procedures should be changed and whether there was information that, if available, would make it easier for their companies to work on BLM lands. The responses to these questions, having to do with potential solutions to the problems identified here, are discussed in Chapter 9.

Question 4 asked what aspects of the permitting process the respondents thought were working well. Most had no response, reflecting a generally negative view of the whole process. A few did note that the quality of information on previously surveyed areas and the accuracy of site locations have improved at the BLM office. When asked why this was important, they said that better information gave them a clearer idea of what to expect on the ground, thereby facilitating their planning. One company representative highlighted the new statewide standards for well pad construction as an example of the BLM working in concert with the oil and gas industry to solve a problem of mutual concern. He emphasized that the new standards were based on research-driven studies, the results of which everyone could accept. While not related to the cultural resources management practices per se, this was offered as an example of a process he thought oil and gas could follow in addressing the cultural resources issues (see additional discussion in Chapter 9). Several went out of their way to say they thought the BLM staff was "just doing their jobs," but noted that even with four archaeologists at the BLM Carlsbad office, there has been no decrease in the time it takes to process APDs and ROW applications.

The sixth question asked if there are critical points in the planning process where meeting the cultural resources requirement can be most problematic. As a follow-up question, the respondents were asked if considering cultural resources earlier in the planning process, prior to the APD stage, might be helpful in reducing conflicts. All agreed that the APD stage was a "choke point" for them, when meeting the BLM's cultural resources requirements is most likely to 


\section{THE CURRENT SITUATION}

cause delays owing to the presence of archaeological sites in the development area. As one industry representative noted, every time there is a problem with archaeology and a drill location has to be moved or modified, the regulatory clock starts all over again. In extreme cases, a well site will be abandoned in favor of a location that has fewer regulatory problems. It was also observed that there appears to be no coordination between the APD review process and the process that ROW applications go through. As a result, decisions can be made about the location of a pipeline that conflict with where a well pad access road will go. Both actions require that archaeology be done, with any overlapping areas surveyed twice.

As to whether the requirements could be met at an earlier stage, some agreed this would help — if the BLM conducted the necessary archaeological studies at its own expense. Most noted, however, that archaeological site clearance prior to the APD makes little economic sense from their perspective. This would require expending money to do the archaeology before the productive viability of an area could be demonstrated. If the well or wells are dry, then the cost of doing the archaeology just adds to their overall losses.

Several of the representatives from the larger companies said that they had conducted block surveys in areas targeted for the development of multiple well pads. Survey at this level has the advantage of assessing the regulatory liability of archaeological clearance on a large scale and can facilitate planning and development strategies while reducing the unit per acre cost of archaeology. Knowing where the sites are in relation to the planned location of well pads, access roads, pipelines, and power lines can enable a more comprehensive management strategy than is usually possible, which is why it is favored as a strategy by the BLM. Nonetheless, block surveys cost more than paying for individual well pad and ROW clearances and as such are not favored by most of the respondents over the status quo. In short, while the idea of archaeological site clearance earlier in the planning process sounds good, the respondents said that doing this is not feasible in all cases, particularly if the oil and gas industry is going to pay for it.

Follow-up questions were asked regarding the idea of using royalty relief or eco credits as a way of generating funds to do archaeological research in areas that are being developed as emergent fields. The idea is to fund the necessary studies in a manner that is decoupled from the APD/ROW approval process. This way research can be conducted on the nature and meaning of the archaeological record outside of the regulatory framework that normally drives the compliance process for individual components of emerging energy fields. The respondents were warm to this idea but questioned how it would work, noting that royalty relief, for instance, would require approval at both the federal and state levels and presents accounting difficulties. One industry representative suggested, however, that a program similar to the habitat restoration program in use on the BLM lands in Farmington might work (see further discussion in Chapter 9).

The last question asked if the respondents had any ideas as to how cultural resources management could be more effectively integrated with the way that the oil and gas industry operates. There were no ideas on better integration, and most reiterated concerns that had been expressed earlier. The BLM and the oil and gas industry have different priorities and operate on different time scales. One respondent took the view that industry is better able to react to changing conditions than the agency and that, because of this, industry's needs and the BLM's responsibilities are like a "square peg in a round hole." Several of the respondents echoed earlier comments, saying they thought that the requirements the oil and gas industry has to meet, including those relating to cultural resources, have expanded over the years, creating increasingly difficult conditions for energy development. The subtext of the whole discussion was that the oil and gas industry feels hampered by the agency. While the respondents acknowledged that the BLM has multiple responsibilities, the feeling expressed by the oil and gas industry representatives is that the APD and ROW approval processes are too cumbersome and take too long, and that archaeology is the principal source of the problem.

In general, the responses can be summed as follows.

- The APD and ROW approval processes are not operating within the BLM's 30-day turnaround period

- Delays increase costs and affect scheduling

- The value of the archaeological record is highly suspect

- The BLM treats all sites as if they are equally important, but few sites are viewed by the respondents as National Register-eligible

- Historical sites, especially those from the twentieth century, are not viewed as worthy of management concern

- The cultural resources requirements make little sense to the respondents because they have not been adequately explained or justified

- Archaeology at the APD stage is the "choke point" in lease development

- Archaeological investigation prior to the APD is not economically feasible if the oil and gas industry must pay for it

- The requirements that must be met to work on the BLM lands have increased over time

- The permit stipulations protecting archaeological sites are seen as the cause of most delays in the approval process 


\section{The "Ideal Outcome" for New Mexico PUMP III}

In discussions with BLM, SHPO, industry, and the members of the New Mexico PUMP III team, we have tried to identify an "ideal" outcome for this project. Although one project clearly cannot meet all of these objectives, we view this as a long-term goal statement for cultural resource management as it concerns archaeology in southeastern New Mexico, and we will return to these points in the concluding chapter, examining the contributions of this project toward these goals.

One important outcome of this project will be a set of management recommendations for how BLM might more effectively integrate cultural resource management procedures with the need for energy development on the public lands. A quick look at the concerns raised by oil and gas industry respondents in the previous section provides a number of ideas about what is needed from the industry perspectives: faster, more predictable turnaround times; decreased regulatory burden; and mechanisms for focusing time and dollars on the most significant archaeological resources. At the same time, any proposed management changes must be compatible with BLM's legal responsibilities and its multipleuse mandate. Additionally, the proposed changes should be specific, practical, and doable. Any proposed changes should also include implementation measures and training components as appropriate, as well as improved communication with lessees and operators. Finally, the management recommendations should be tied into ongoing planning within the BLM and should consider the need for coordination between any proposed cultural resource process and other environmental review processes.

A second important outcome of NM PUMP III will be a critical look at information and information management. The "U" in PUMP III stands for "upstream." We will be looking at approaches whereby cultural resources are considered earlier in the planning process, so that BLM can make better-informed decisions and industry will have more predictability and needed information on environmental issues at the "pre-lease" phase of energy development.

We will be looking at technological solutions that will enable us to focus time and money on good preservation outcomes and expedited energy development rather than needless, time-consuming process. Possible examples of technological solutions might be an automated screening system for determining inventory needs and cultural resource sensitivity of a lease or right-of-way or electronic submissions to streamline the consultation process.

One of the products from NM PUMP III will be a set of "sensitivity" maps based on predictive models. How can we ensure that these maps will be used appropriately — for planning and evaluation of alternatives, not to "blow off" the need for survey? How can we ensure that the models and the maps are maintained, updated, and refined? How do we ensure that modeling is seen as a process rather than being treated as product?

Third, this project will result in some recommendations for how to do better archaeology in service of both compliance with historic preservation laws and better stewardship. We need to critically evaluate current inventory procedures for archaeological resources. Are we gaining the information we need for management? Are time and money being well spent? Any recommendations to change inventory procedures have to be realistic, however. While upfront survey of entire leases or other blocks of land would undoubtedly be most effective and efficient, there is no regulatory or funding mechanism to enable this to happen.

Current procedures for managing oil and gas and cultural resources have not enabled us to deal with cumulative and indirect effects on archaeological sites. What can be done to address this issue? Are there means of examining the data that can give managers better ways to anticipate which sites will be adversely affected by indirect or cumulative effects?

One of the most pressing needs in terms of our ability to manage cultural resources in southeastern New Mexico is for subsurface data. The standard "flag and avoid" approach to managing archaeological sites has left us with so little excavation data that we don't know how to assess either the integrity of sites or their information potential from surface manifestations. It is critical that we find a way of assessing the subsurface potential and the surface/subsurface relationships of more sites in this region so that management and protection can be focused on the most significant resources. And the nature and significance of the archaeological record in the region needs to be communicated to public land users and the public.

Finally, although the NM PUMP III project is using management data from BLM lands in southeast New Mexico and evaluating management practices for archaeology in oil and gas fields, ultimately we want to develop products and suggest practices that can be more widely applied - to other agencies, to other development situations, and potentially even to other kinds of cultural resources. Possible products that could lend themselves to wider applications include technical data on the sensitivity modeling attributes and process used in this project, effective approaches to inventory, mechanisms for dealing with cumulative and indirect effects, flexible approaches to compliance requirements, and "upstream" approaches for moving consideration of cultural resources earlier in project planning. 


\section{THE CURRENT SITUATION}

\section{Conclusions}

Cultural resources management on the BLM lands in southeastern New Mexico is largely driven by oil and gas developments that are subject to environmental laws and regulation. These laws require the BLM to consider the effects of energy development on archaeological sites, among other cultural and environmental resources, as part of the agency's multiple-use mandate. The BLM follows an adaptive management strategy to guide the agency's planning process so that, ideally, agency personnel are able to use evaluation and analysis of the results of existing management strategies to make informed decisions about future management strategies. In practice, however, this is difficult to achieve.

Years of development-driven archaeological survey and the virtual absence of excavation data have produced a wealth of information on only two dimensions of a three-dimensional phenomenon. This, combined with the lack of synthesis of these existing data, has left BLM with a limited understanding of the resources that the agency is charged with managing. For this reason, day-to-day management decisions tend to be conservative, erring on the side of "being safe," even when those decisions may not be warranted. For these and other reasons, the adaptive management process, which should enable the agency to determine if what it does is effective, lacks critical information and the ability to evaluate and adjust cultural resource and oil and gas management processes.

The BLM strives to meet its legal obligations under a large variety of land-use, environmental, and historic preservation laws. Procedures for oil and gas development on BLM lands are designed to protect a wide range of environmental resources, including archaeological sites. An important purpose of the New Mexico PUMP III project is to evaluate the efficacy of these procedures as they relate to archaeological stewardship and efficient recovery of oil and gas reserves on the public lands. In this chapter we have identified a number of concerns about archaeological stewardship under the current procedures. Archaeological sites may be avoided in the siting and construction of a well pad, for example, only to be damaged repeatedly over time by maintenance and well-servicing activities. Rights-of-way are not subject to the same level of environmental review as leases.

We have also identified a variety of impediments to efficient energy production. The review and approval processes for APDs and ROWs, for example, could be more streamlined. And the necessarily conservative approach to site eligibility has led to avoidance and protection requirements that may not be warranted by the actual significance of some sites. As well pads and development infrastructure continue to be directed away from these sites, the current level of ignorance about them is perpetuated. Without the benefit of a growing knowledge base on the archaeology of the Permian Basin, it is difficult for the agency to change its management practices in order to achieve greater efficiencies and more effective resource protection.

These problems are compounded by increasing demand for energy production on the BLM lands and the concomitant pressures on the agency to respond to APD/ROW applications in a timely manner. Staffing constraints, procedural problems internal to the BLM, and applicants who fail to submit the necessary information all contribute to a management environment that can, and does, produce delays and duplication of effort, despite the best efforts of the BLM and the oil and gas industry.

Solving the problems touched on in this chapter, and more fully described in the rest of this report, will require a more comprehensive understanding of the archaeological record as well as flexible and creative procedures whereby the effects of energy production on archaeological sites can be addressed. What is needed are both short- and long-term planning goals with an implementation strategy that has the support of the agency and the energy producers. Identifying what's wrong with the current situation and recommending changes to solve these problems are important objectives of this study.

\section{Reference Cited}

\section{RMRCC}

1989 Surface Operating Standards for Oil and Gas Exploration and Development, third edition. BLM/FS Rocky Mountain Regional Coordinating Committee. 



\title{
Information Technology, Management of Cultural Resources, and the New Mexico Pump III Study
}

\author{
Tim Seaman and Eric Ingbar
}

D.

The Pump III study as a whole examines how resources are managed in light of the information that is known about them. This chapter examines technologies that convey information into the practice of archaeological resources management as it is currently performed and as it might be transformed in the future. We also discuss how information technology was used in the Pump III analytical and management studies.

The term "information technology" has come to mean digital data storage, query, and display in a wide variety of ways. This meaning, however, is overly limiting in the context of cultural resource management. Cultural resource experts and managers utilize many forms of information that are not digital in any comprehensive way. These information forms include paper records and maps, traditional photographs, documentary sources, experience in the field and laboratory, and a considerable body of person-to-person communications, both formal (e.g., professional presentations) and informal (e.g., professional discourse). Although we cannot address all of these different forms of information in anything like a comprehensive fashion, it is important to remember that "information technology" in its digital sense, referred to as "IT" throughout the chapter, is only one of several important information technologies.

The link between sound information and sound management and decision-making is so well known as to be a truism. In archaeology a high value has always been placed on sound sources of information because reliable data greatly facilitate fieldwork and decision-making. For instance, archaeological fieldwork is guided by a series of questions that can often be answered by sound information:

- Where have investigations been performed already?

- What did prior investigations find?

- How reliable are the findings?

If these questions can be answered well, then the fieldworker has more secure answers to some important operational questions:

- Where does one need to look for new, undiscovered resources?

- What sorts of archaeological materials are likely to be encountered?

- What level of effort will a new investigation require?

Until recently, these questions were answered using paper maps and records. As long as these were comprehensive and up-to-date, they worked very well. Paper records, especially large-format maps, are not necessarily difficult to keep, but they are very limited in their distribution. Most paper archives of archaeological investigations and resource information are unique collections of materials that must be visited to be used. Travel costs and the time it takes to conduct research that is usually geographic in extent involving records that are filed by date (e.g., site records are filed in sequential order regardless of site location) make the use of paper archives expensive. Digital information technology addresses many of these problems because it allows records (and maps) to be retrieved in many different ways: geographically, by index number, by information attributes or content, and by combinations of these methods.

The New Mexico Cultural Resources Information System

The New Mexico Historic Preservation Division (HPD) has long been a leader in archive management, both as a paper records system and in digital information technology. The Archaeological Records Management Section (ARMS; see www.nmhistoricpreservation.org/PROGRAMS/arms.html) has maintained statewide maps and files for more than 80 
years. For the past 25 years, ARMS has been automating its maps and the contents of its files into a geographic information system (GIS) and relational database management system (RDBMS) known as the New Mexico Cultural Resource Information System (NMCRIS).

NMCRIS captures initial information about investigations ("activities" in NMCRIS) and archaeological sites. These initial records are held in the system, and displayed in the web-based GIS component, until the record is received at ARMS and can be fully entered. GIS updates are done nightly from the initial records. ARMS staff perform custom data queries and aggregations of information for agencies or consultants if the information in the standard ARMS IT system does not meet their needs.

From an IT user perspective, NMCRIS contains two distinct forms of information: tabular data held within an RDBMS and spatial data (geographic boundaries, etc.). ARMS users are limited to qualified cultural resources professionals. Users can query tabular data from a text interface, enter preliminary information about investigations (activities) and sites, and generate full site records from the database without any associated imagery that may be in the paper file. Users can also employ a map interface to find, list, and see the locations of investigations (activities) and sites. Then, one can query by identifiers to find the full database record for each investigation or resource.

NMCRIS is an example of an information technology that conveys "what is known" about an area fairly rapidly. It is used by archaeological specialists in the private and public sector routinely. ARMS strives to be comprehensive in its geographic coverage of the state, with the exception of some tribal lands, and current in its data. Some of the major factors that hinder achieving this goal are:

- backlog of maps to digitize into GIS for investigations (activities)

- time lag between initial recording and receipt at ARMS for full entry and digitization

- agency offices holding onto reports with fieldwork results due to cancellation of projects after fieldwork was completed; these reports may never get to ARMS, so will never be part of NMCRIS

- lack of staff and/or funding to keep up with incoming work and cope with backlog

NMCRIS map services reliably show the location of all resources in the NMCRIS database, most of which are archaeological sites. This makes the map service very useful for planning where a proposed action should probably not be staged because known resources can be avoided using this information. However, because NMCRIS does not contain all of the investigation (activity) boundaries - "surveyed space" in NMCRIS terminology — it is not as useful for planning fieldwork, or even the need to do fieldwork, because one cannot tell where fieldwork has already been performed. Some parts of the state are fully digitized for investigation boundaries, and here one can utilize NMCRIS to identify areas of surveyed space. For many parts of New Mexico, one must perform a search by cadastral location first, then either get copies of the investigation reports revealed in this search or travel to ARMS to examine the reports and maps. In areas where NMCRIS is completely populated with sites and investigations in GIS, the map service is a tremendous tool for research, planning, and review of field reports.

ARMS is a substantial annual investment in software, hardware, and support staff. IT in cultural resource management is necessarily a complicated technological endeavor. Archaeological site records capture a wealth of information, much of which is list-like and thus requires sub-tables in order to query information reliably. Relationships between categories of information need encapsulation in the data too, adding to the intricacy of the data scheme. A table diagram of NMCRIS looks like a spider web or even a web of spider webs. The NMCRIS data model involves more than three dozen database tables, and six distinct GIS map layers. In a paper system (i.e., a paper CRIS), the researcher must track linkages between categories of information. NMCRIS's elaborate design is needed to allow IT to track these information links.

The introduction to this chapter discussed the series of questions that guide typical archaeological inquiry. NMCRIS was designed to answer many of these questions, especially those summarizing existing knowledge. NMCRIS was not designed, originally, to answer questions that include some forecast about the archaeological record. For example, NMCRIS has no inherent model display or model-building capability. This was not the intent of NMCRIS; how one uses a cultural resources IT system to answer model or summarizing questions is discussed further below.

\section{NMCRIS Activities for the Pump III Project}

ARMS entered data for all three of the study areas, updating the attributes held in the RDBMS for sites, updating site boundaries in GIS, digitizing investigations, and creating or updating the RDBMS attributes for investigations. An important part of the project was its coverage of the three one-degree blocks that run from the extreme southeast corner of New Mexico westward along New Mexico's southern boundary (i.e., 32 to 33 degrees North, 103 through 106 West). 
So, the area for which NMCRIS data was created or updated was far larger than the study areas themselves.

In all, ARMS staff accomplished a huge amount of data entry into, and quality control over, the NMCRIS database established for the three study areas:

- 18,000 survey reports were entered and/or verified in the RDBMS

- 17,500 survey reports were digitized

- 1,800 sites were entered/verified in the RDBMS

- 3,500 site boundaries were digitized

The difference of 500 reports between digitization and RDBMS entry is due to 500 reports with source graphics that were either absent or too poor to digitize. The 1,800 sites given attributes were new entries in both the RDBMS and the GIS. The 3,500 other sites digitized had boundaries created or updated for them in GIS.

\section{How NMCRIS Population Helps}

Populating NMCRIS with up-to-date records in GIS and the tables is more than an archival exercise. The NMCRIS data serve two purposes in the present study and in its on-going utility.

First, the NMCRIS GIS and attribute data are useful for answering the "what and where" questions that precede archaeological inquiry. Since archaeological inquiry is almost always triggered by some proposed land use, NMCRIS records also provide a scoping capability, if the land-use proponent, or their agent, consults these records early in the planning process.

Second, the NMCRIS data system provides a foundation for model-building. In the present study, the models pertained to surface archaeology, for the most part, and its density. An important prescription of the modeling studies is that models be reevaluated and refined more or less constantly. The only financially practical way to do this is by using a cultural resources IT system that contains the model data.

\section{Implications of PUMP III Modeling for NMCRIS}

A major part of the study involved model-building to forecast where archaeological sites are likely to occur in each of the three study areas. NMCRIS provided the data for each of these model formations. The analysts creating the models found NMCRIS data complex to work with, which presented challenges to the model-building process. The modeling effort would have been impractical without NMCRIS, but it is important to realize that IT systems built on cumulative processes, like NMCRIS, may require extra effort to be used successfully in a modeling study.

For this study, the NMCRIS data required the modelers to expend more time and energy in data manipulation than they had expected. The effort required to work with NMCRIS data in the predictive modeling effort was underestimated owing to two major factors:

1. The intensity of archaeological investigation in two of the three PUMP III study areas - specifically, the high number of multiple site recordings; and

2. The underlying complexity of the NMCRIS relational database, which complicated the task of data reduction.

Little can be done to make modeling and analysis much easier with regard to the first factor. Archaeological work in oil and gas fields in the Carlsbad area has been conducted on a well-by-well basis, so that the same archaeological site may be recorded by several different surveys. In addition, archaeological site boundaries are exceedingly difficult to define owing to geomorphological factors, especially in the Loco Hills area. So, an apparent boundary between two sites may later become no boundary at all.

This combination results in an observational record that is complex. For instance, an archaeological site may be recorded several times over the years. Each set of observations is properly independent of its predecessors. We expect some consistency among them, but we cannot truly assess whether differences are owing to geomorphology (e.g., dune movement that now reveals more of a site), observer effects, and so forth. Because of this NMCRIS treats each "event" of observation as a unique record.

Predictive modeling does not cope well with multiple observations of the same phenomenon. After all, the point of most archaeological modeling efforts is not to understand how archaeological practice changed through time, but to understand how the archaeological record itself changed through time. Modeling is most practical when one treats each 
observational entity as static. For archaeological sites, this means deciding upon the attributes of the site once, and only once, and not treating each archaeological site field observation — each site recording — as a separate "site."

A simple thought experiment can illustrate this. Suppose the first recording of an archaeological site found 3 hearths and 8 projectile points. A second recording of the same site reports 2 hearths and 10 projectile points. Did the first recording "miss" 2 projectile points and the second recording "miss" a hearth? Or, are there really just the maximum of each count: 3 hearths and 10 projectile points? Or, are there actually 5 hearths and 18 projectile points - the sum of all observations? Because there is rarely a clear answer to this sort of question, an IT system for site records treats each as an independent record. Of course, a modeler would like to have a single "correct" answer with which to work.

With regard to the second factor, the NMCRIS data model is necessarily complex and modification has risks and costs. Each observational event is treated as a record in NMCRIS because decisions are made on a record-by-record basis, and the NMCRIS staff are in no position to reassess archaeological fieldwork years and miles distant from it. NMCRIS is as complex as it needs to be. NMCRIS was designed to enhance basic information management for cultural resources on a statewide basis. It was not designed for predictive modeling. Certainly predictive modeling is becoming an important management tool, but it would be better to consider alternatives to simplification of the NMCRIS design.

There are several alternatives to simplification. One alternative is simply to prepare better documentation of NMCRIS for prospective analysts and modelers. Analysis of relational data is not simple, and statistical approaches assume a flat data structure. This makes data reduction a critical — and often time-consuming — first step in modeling. Multiple records need to be summarized or filtered to create a single record, or analytical approaches need to be modified to take different entities into consideration. For instance, either sites with multiple components must be translated to a single proxy classification (e.g. single-component, multicomponent), or analysis must proceed using temporal componentsrather than sites - as the analytical focus. Similarly, multiple feature observations can be used to classify sites (or components) by function prior to analysis. This approach still demands much from the prospective modeler, and the task of joining and processing multiple tables appropriately is left to the user, possibly leading to spurious results.

A better approach would be to create, and document, analytically useful SQL (Structured Query Language) "views" of the database. The ability to define SQL views, or virtual tables, is one of the strengths of relational databases. To the user, an SQL view looks just like a simple database table of rows and columns, even though it may be the result of joining several tables, and perhaps other manipulations. In this, a documented SQL view can provide a more coherent environment for the analyst. On the down side, using views for queries or reports may require intensive database performance tuning because complex views joining more than three or four tables can use larges amounts of system resources.

Similarly, summary tables can be maintained by a relational database and refreshed automatically at set intervals. These tables could, for example, summarize multiple site visits or Section 106 actions by selecting the most recent observations, or summarize site data by county, allowing expressions of variability based on larger populations of sites. Summary tables could be created and refreshed during periods of low use, providing a performance advantage over onthe-fly summary creation.

Perhaps the most sophisticated approach would be to implement business intelligence software such as Oracle Discoverer or Business Objects. These packages maintain structures similar to SQL views (a.k.a. End User Layers in Oracle) and summary tables in the underlying database. In addition, business intelligence products provide simple but powerful application interfaces that allow users to employ predefined views, develop new views and summaries, and export datasets in industry standard formats. These applications are built on existing system security rules in the underlying databases, yet they run over the internet and may also be set up with extensive help systems. From the user's perspective, they are readily accessible and, with some study, productive for answering questions. The disadvantage is cost. Oracle Discoverer, for example, requires additional license fees and annual support costs, and significant administrative costs would be required for setup and maintenance. Creation of different database views would also require a more intimate and continuous relationship with analysts in order to design useful views, query applications, and reports. The benefit of this technology is immense, however. The ability to simplify the NMCRIS database structure would open the database up to exploration by other, "non-traditional" users in historic preservation and cultural resource management, and so would have many other benefits for planning and research.

\section{IT and Cultural Resource Management}

Archives of information about "cultural resources" (National Register Bulletin 15 [National Park Service 1990]) are in transition from paper to digital formats, nationally. The creation and population of records in IT systems, now begun, won't stop. Paper records will continue to form the basis for most archives. IT enables swifter access to these records or some of the information on them. One role of information technology is simply to do what the archives always have done, only better. 
While one might argue over what criteria constitute a "better" archive, there is little doubt that the ability to see map information and tabular information and to query in and between them is an improvement over purely paper records. This is especially so when determining the need for archaeological fieldwork.

IT works well for cultural resource archives as a way to enhance record-keeping and basic archival functions. IT is not the perfect solution, however. The nature of IT is such that it requires records of any sort - markings on maps, site forms, reports - be fairly consistent in format and content. Cultural resource archives accumulate information over decades. The information in the archives is inconsistent, variable in quality, and differs in content over time. That's the nature of the beast (Ingbar et al. 1999). Automating this information does not make it more consistent, better in quality, or more similar in content. It does make it more accessible. Thus, IT's first role in cultural resource management is: make records accessible.

IT also works well for things that are done in consistent ways. Just as inconsistent records limit the utility of IT, consistent processes lend themselves well to IT. FedEx is able to use IT intensively for package tracking because each delivery step is very consistent. In cultural resource management, the "process" is well-specified for federalized actions under Section 106. This should lend itself quite well to IT. The Wyoming component of this project reports upon CRMTracker, an information management tool that links to the fieldwork and 106 process. Most IT solutions in cultural resource management, however, have chosen to automate some of the less-consistent parts of cultural resource management. We will discuss those below under data quality issues. The consistent processes in cultural resource management tend to be the ones that relate to legal decision-making: determinations of legal status of resources, determinations of project effects on resources, tracking of on-going projects, and status of authorizations, tax credits, and other services. Thus IT's second role, as yet to be fully realized, is: focus on consistent processes where a record of information is useful.

As mentioned above, IT works well in consistent settings. Field recording of archaeological sites is not a consistent endeavor. Although field recording of sites is done on standardized forms, there is no standardization as to who actually makes the observations that go on the form. There are requirements as to who can lead a field crew, author a report, and so on, but the actual person in the field may be inexperienced, in a hurry, or simply careless. Ideally, the field crew leader will catch problems or inconsistencies, but this is not guaranteed. Fieldwork is just too complicated, and knowledge of archaeology (or architecture, or rock art) is too subtle a calculus to rely upon each field archaeologist being consistent with the next. Even if we achieve consistent field results starting today, IT must still make available hundreds of thousands of older records of variable content and unknown quality.

Keeping that notion in context, then, NMCRIS has done an admirable job of enforcing consistency in preserving the observations of the field researcher. The data structure captures the complexity and interrelationships among pieces of information. Yet, NMCRIS in all its intricacy can never guarantee consistent quality of information. IT does not solve this problem. IT's third role is: to facilitate quality and consistency even though it cannot create them.

As the present study shows, IT can aid immensely in conducting studies of cultural resources, especially distributional analyses with GIS. IT does not "do" such studies, at least as we presently use it. For example, the models formulated in this project have no "re-run" button to press in five years that will show a new model created from the additional information. At a simpler level, one might even wish for a red flagging function that reports when a new archaeological site occurs where it is not expected based upon the model. This, too, we lack. Insofar as explicit models are a means for communicating our understanding about a phenomenon, IT in cultural resource management has really not helped convey information effectively. GIS is especially well suited to this and can be used consistently to place results or forecasts on a map. IT's fourth role, then, is: to summarize knowledge, not just observations.

This last role of IT in cultural resource management is really the key because it aids decision-making and hence effective management. Too often, "having the data in a database" is the end in itself, whereas, in reality, it is just the start. As this study has made clear, the need for IT in cultural resource management runs throughout. The product of cultural resources IT, of CRISs and paper archives, of maps and file drawers is not the bits, bytes, tapes, disks, or file folders but the knowledge they bring forward and the new knowledge to which they may lead.

\section{References Cited}

Ingbar, Eric, Mary Hopkins, and Tim Seaman

1999 Socks over Boots. Paper presented at the $64^{\text {th }}$ Annual Meeting of the Society for American Archaeology, March 24-28, Chicago.

National Park Service

1990 National Register Bulletin 15: How to Apply the National Register Criteria for Evaluation. Government Printing Office, Washington, D.C. 



\title{
Experimental: The New Mexico Modeling Project
}

\author{
Lynne Sebastian, Carla R. Van West, and Jeffrey H. Altschul
}

\begin{abstract}
$\Delta$
As noted in Chapter 2, the purpose of this project is to examine current archaeological resource management practices in the oil and gas fields of southeastern New Mexico and identify ways of making those practices more efficient for energy development and more effective for cultural resource preservation. Under an adaptive management approach, we would determine whether the current practices in archaeological resource management are working by monitoring and evaluating the results of the past 30 years of resource management in the area and then adjust the management practices accordingly.

Ideally, to plan for and manage energy development and its effects on archaeological sites, we would want to know a variety of things about the archaeological record:
\end{abstract}

- How are the known archaeological sites distributed, both in general and in relation to topography and other environmental variables?

- Are sites of different types or different time periods distributed differently?

- What factors condition site visibility and integrity?

- What kinds of sites have the potential to yield important information about the past?

- Is there a surface signature that would enable us to recognize these sites?

We would also want to know a variety of things about the effects of current practices on the archaeological record:

- Are current inventory procedures adequate to ensure that sites are identified and considered in planning for development projects?

- Are avoidance stipulations on APDs and ROWs sufficient to protect archaeological resources from damage during construction?

- Are archaeological resources being impacted by well-servicing and other post-construction activities?

and on energy development:

- Is sufficient information available to potential lessees to enable them to factor in potential costs (in both time and money) of cultural resource work on lease parcels?

- Is needed archaeological information available in a timely and appropriate manner to cultural resource personnel, other resource specialists, managers, and lessees and operators?

- What are the perceived and actual costs (in both time and money) of cultural resource compliance for operators and lessees, and where in the process do those costs occur?

With this and other information about the archaeology of southeastern New Mexico and the results of current management practices on both archaeological resources and energy development, we could begin to answer some critical questions:

- How do we know which archaeological resources are truly significant?

- Are there areas where the density of archaeological resources or the significance of the resources is so great that these areas should be identified in the RMP as unsuitable for leasing?

- Are there more efficient, timely, and cost-effective ways to identify and protect archaeological resources in the course of energy development activities? 
- Are there areas where archaeological survey is not needed, either because sites do not occur or because previous survey has been sufficient?

- How can we identify and monitor sites most likely to be inadvertently damaged by oil and gas development and operations?

- What process changes can we make to facilitate energy development while maintaining or improving archaeological resource management and protection?

One of the major impediments to examining and evaluating the current practices is the absence of any mechanism for synthesizing the results of previous archaeological surveys and excavations. We don't have a good characterization of the distribution, nature, visibility, integrity, or significance (in terms of the potential to yield information about the past) of the archaeological record of southeastern New Mexico. The Section 106 process, which drives most of the archaeological work related to energy development on BLM land in southeastern New Mexico, is "undertaking-specific." That is, each development project creates a stand-alone cultural resources report, and there is no provision in the law or in BLM procedures for compiling the knowledge gained thus far and adding the information from a given project to that body of knowledge. For this reason, it is very difficult to get an overall picture of the archaeological record itself, much less of the impacts of current management practices on that record. The approach to this problem of characterizing the archaeological record that was adopted by the New Mexico Pump III project was to develop sets of archaeological predictive models.

\section{What Is Archaeological Predictive Modeling?}

Predictive modeling is a set of techniques for characterizing and anticipating trends in sets of data. In archaeology, a predictive model can be defined as a "simplified set of testable hypotheses, based either on behavioral assumptions or on empirical correlations, which at a minimum attempts to predict the loci of past human activities resulting in the deposition of artifacts or alteration of the landscape" (Kohler 1988:33). Most archaeological predictive models address the basic question, "Where are sites located?" and generally they are based on correlations between environmental variables and site location. Most archaeologists who have worked for any length of time in a particular area develop an intuitive model of where sites are likely to be found, but it was only when quantitative methods became an important component of archaeological studies in the early 1970s that models began to be based on objective measures of environmental variables.

The earliest attempts to model site locations relative to environmental variables were bivariate. Site locations were associated with one environmental variable and then another. Archaeologists often made the statistical mistake of assuming that they could simply add the various bivariate studies together to form a powerful statistical statement about the types of locations favored by human settlement. The problem, however, is that environmental variables are usually not statistically independent of each other. Because the same variation in site location was being explained over and over, seemingly strong statements about site location were in actuality very weak.

Green (1973), in a study of prehistoric Mayan sites in northern British Honduras, pioneered the use of multiple linear regressions incorporating a series of environmental variables to predict the probability that a particular location would contain a site. Multiple regression, like many discrete multivariate statistical techniques, is designed to ensure that all independent variables are statistically independent of each other. Green's work demonstrated the potential of multivariate statistics in predicting site locations; it also pointed out the complexity of these studies.

By the late 1970s, archaeological predictive modeling had caught the attention of the large federal land-managing agencies. The passage of the National Historic Preservation Act (NHPA) in 1966 and the National Environmental Policy Act (NEPA) in 1969 had left these agencies struggling with mandates to identify and evaluate archaeological sites under their jurisdiction and to assess the potential effects of enormous development projects on archaeological sites. Fullscale surveys were considered economically prohibitive, and predictive models based on surveys of small samples of project areas seemed to have great potential. Large numbers of predictive models were developed the late 1970 and early 1980s (Thoms 1988), and the Bureau of Land Management (BLM) sponsored development of a comprehensive text on predictive modeling and the use of this technique in cultural resource management (Judge and Sebastian 1988).

In the late 1980s and 1990s, the field of archaeological predictive modeling was revolutionized by the advent of geographic information system (GIS) technology. A GIS is a set of related databases with the capability to capture, store, manipulate, and display geographically referenced data. Archaeologists can now acquire regional data on vegetation, soils, elevation, slope, aspect, hydrology, and climate and compare these with sites locations to model human settlement and land use behaviors. Because an entire category of environmental data (e.g., vegetation) can now be acquired from 
a single source, these data provide a less biased metric representation of the variable in question than data collected from multiple sources using different registration, scale, etc. Not only does GIS technology enable modelers to combine geographic data from different sources with different formats, scales, etc., the GIS can also be used to create maps that incorporate, synthesize, and combine the results of overlaying various data themes. Such maps become a product in themselves as well as a source of hypotheses about covariation among environmental attributes and cultural behavior that can be further tested (see Allen et al. 1990; Wescott and Brandon 2000).

The end product of an archaeological model is a set of probability statements, generally displayed as a map, that indicate the likelihood that an archaeological site will be found at a particular location. Such models are based on the correlation between known archaeological site locations and a variety of environmental variables, and can be easily tested and upgraded as additional sites are recorded.

There is a constant trade-off between accuracy and precision with predictive models. Accuracy refers to the success of the prediction-the number or proportion of "hits" as opposed to "misses." Precision refers to the statistical confidence we have in the predictions. To illustrate these concepts, imagine a predictive model defining three "sensitivity" areashigh, medium, and low-reflecting the likelihood of encountering archaeological sites in each area. If 85 of 100 sites fall within the medium and high sensitivity areas, the model may be said to have an accuracy of $85 \%$. On the surface, this may appear to be a good model. If the medium and high sensitivity areas constitute $85 \%$ of the study area, however, then the only statement that can be made is that $85 \%$ of the sites fall within $85 \%$ of the study area-a model as effective as a dart throw. If we can refine the model such that the medium and high sensitivity areas represent, let's say, $50 \%$ of the study area, while maintaining the same level of predictive accuracy, then our model is much more precise.

All agencies wrestle with these issues prior to using predictive models as part of a management strategy. Agencies must accept a certain amount of risk that sites will be missed in exchange for the ability to define appropriate levels of effort to identify sites, depending on site sensitivity within a given area. For example, the Minnesota Department of Transportation, in conjunction with the Minnesota SHPO, uses a predictive model (termed $\mathrm{Mn} / \mathrm{Model}$ ) to determine where to inventory and what sampling fraction to use. According to the Mn/Model web site (http:// www.mnmodel.dot.state.mn.us/pages/about_mnmodel.html):

$\mathrm{Mn} /$ Model development began in 1995. The goal of the project was to use Geographic Information Systems (GIS) and statistical analysis to produce archaeological predictive models that could be replicated by anyone using the same data and following the same procedures. The aim was that these models be accurate enough to predict $85 \%$ of known archaeological sites without designating more than $33 \%$ of the state's area as high and medium site probability.

From a management perspective, $\mathrm{Mn} / \mathrm{Model}$ has been very successful in cutting costs of cultural resource inventories and streamlining the compliance process. Archaeologists, however, still worry about the confidence regulators place on the model. Without continual testing, how do you know that the model has an accuracy rate of $85 \%$ ?

Archaeologists and regulators all over the world struggle with this question. In the Netherlands, for example, predictive models have been incorporated in the planning process of several provinces (Kamermans et al. 2005:15-16). Archaeologists in that country are split about the applicability of such models. Some believe the "American" approach, which is inductive in nature and management-focused, can never lead to confident predictions because the models have no explanatory power. In contrast, the "European" approach, which is derived from the cultural landscape school, can lead to interesting ideas about how past people distributed themselves but has little applicability to practical problems of modern land development (Kamermans et al. 2005:16).

We do not believe that the fault lines in predictive modeling are geographic, but instead reflect the different intended uses of the results. In the United States, as in Europe, managers need models that allow them to make land use decisions. These models historically have been inductive and correlative in nature. Researchers focused on understanding past behavior need models with explanatory strength. They have placed their energy into models that derive predictions from propositions about human behavior; predictions which focus less on specific locations than on types of landforms or environments.

With the continuing advances in GIS software, the gulf between management and research models is narrowing. In addition to algorithms based on the general linear regression model (the statistical model of choice for inductive, management-focused modelers), most software packages include a wide array of techniques based on behavior, such as agent-based modeling, directionality analysis, and expert systems. Predictive models that rely on a combination of deductive and inductive techniques are already being developed in management contexts. We suspect that over the next decade predictive models will become quite diverse and much more powerful. 


\section{How Are Predictive Models Developed?}

Predictive modeling is a term that covers a wide array of techniques, which capitalize on the empirical observation that archaeological site locations tend to be associated with particular environmental features. Mappable environmental features are treated as independent variables that either individually or in combination are associated with the dependent variable, archaeological site locations. Such techniques have been used in cultural resource management (CRM) for more than two decades (Altschul et al. 2004; Kohler 1988; Kohler and Parker 1986). Although quite variable in design, predictive models are developed following a fairly standard process (Altschul 1988, 1989, 1990; Wescott and Brandon 2000).

Models can be and often are developed intuitively, based on a researcher's experience and knowledge of the archaeology of a particular area; for example, "agricultural villages will be located on low ridges overlooking shallow drainages." And such models may be quite accurate, that is, successful at predicting the locational characteristics of agricultural villages. But we have no means of estimating their precision or knowing how likely it is that the prediction will be correct. For land use planning purposes, it is critical to know the likelihood that significant archaeological resources will be found in specific areas, and this is only possible with statistically based models. For such models, environmental variables such as elevation, slope, aspect, vegetation, geomorphology, and proximity to water are measured on interval, ordinal, or categorical scale, as appropriate, and then the scores on each variable are divided into sensitivity classes that represented relative probabilities of finding sites.

For the New Mexico Pump III project, we developed three different types of models: Boolean, weighted sensitivity, and logistic regression models. For all three types of models, we divided the study area into a grid of 30-meter-square cells and then examined correlations between site locations and particular values for a given set of environmental variables on a cell-by-cell basis. Boolean and weighted sensitivity models then overlay all the variables to create a mosaic in which areas are classified as high, medium, or low sensitivity, based on the combined sensitivity scores for all or most variables. This process is called the intersection method (BRW 1996). Regression models, the third type used for this project, evaluate the relative contribution of each variable to the predictive success of the model and focus on the most powerful predictors. By using multiple modeling approaches, we hoped to acquire both the predictive power of multivariate statistical techniques and the intuitive understanding that comes from models that examine simple correlations between dependent and independent variables.

\section{Boolean Models}

A Boolean model is perhaps the simplest of all predictive modeling techniques. Every cell of the digital study region is classified as either "site" or "non-site" based on one rule. "Sites" are defined as cells that score favorably on every environmental attribute or theme; "non-sites" contain one or more unfavorable environmental scores. For example, if $90 \%$ of all the known-site cells are located within $500 \mathrm{~m}$ of water, then the GIS layers for distance to streams can be transformed into a layer that has a value of 1 or 0 , where 1 indicates an area within $500 \mathrm{~m}$ of a stream and 0 indicates an area further away. Another layer can be constructed for slope. Let's assume that $90 \%$ of the sites are located on slopes of less than $2^{\circ}$. The slope layer can then be transformed into a slope "likelihood" layer of $0 \mathrm{~s}$ and $1 \mathrm{~s}$. The distance to water and slope layers can then be overlaid so that all cells that scored "1" on both layers are coded as "1" or likely to contain a site; all other cells are coded "0" or not likely to contain a site. Although simple, Boolean intersection models work well in areas characterized by strong spatial autocorrelation (that is, where the environmental values in a particular cell are strongly influenced by the values of neighboring cells) and where environmental variables exert an overwhelming influence on human settlement.

It is important to remember that Boolean models often have little statistical strength. The environmental variables are being treated as independent of each other and all are given the same weight in determining site sensitivity. In our example above, it is possible that prehistoric peoples selected locations solely on the basis of nearby water. Relatively flat land may be located near streams, but this environmental factor was secondary in decisions about settlement, if considered at all. Thus, by using both criteria, researchers are mistaking the correlation between environmental variables with factors involved in settlement decisions. More importantly, areas close to water, but on steeper slopes, are being coded as "unfavorable" when these areas may have been considered desirable by prehistoric people.

As with any model, the results must make sense to the researcher. The great advantage of a Boolean model is that the researcher can easily "tinker" with it. By adding and subtracting layers, great insight into settlement behavior can often be achieved.

The first step in creating a Boolean model is to define those states that are favorable for human settlement for each variable. For categorical variables, this step involves simply determining the appropriate states. For continuous variables we need to define break points, or cutoff ranges, for each variable that distinguish the cells likely to contain sites from 
those that probably do not. In Boolean models, it is preferable to be liberal in defining categorical states and cutoff ranges because the intersecting properties of the method have a tendency to greatly reduce the favorable zone. In our Boolean models, we chose states and cutoff ranges for each variable that would ensure that a large percentage (80-95\%) of the known site cells were included in the favorable category.

\section{Weighted Models}

Weighted models, like Boolean models, are created by the intersection method, in which each environmental theme is separated into cells that are associated with archaeological sites and cells that are not. When the themes are overlaid, the areas of intersection where multiple themes contain cells associated with sites are classified as high sensitivity zones; areas where multiple themes contain cells not associated with sites are classified as low sensitivity zones. Those areas where some environmental themes are correlated with sites and some are not are considered moderate sensitivity zones.

Weighted models are more sophisticated than Boolean models in that variable states within each theme are weighted based on their correlation with known archaeological sites, and the sensitivity ranking is determined by some type of mathematical formula. For the Pump III models we divided each environmental variable into discrete states and then calculated the expected percentage of the site-associated cells that should fall within each of the states if sites were randomly distributed. If, for example, the vegetation category "Chihuahuan desert scrub" constitutes $10 \%$ of the study area and sites are randomly distributed relative to vegetation, then $10 \%$ of the cells that contain sites should be found in Chihuahuan desert scrub areas. We then determined the observed percentage of cells containing sites within each vegetative category, and where the percentage of sites observed for a category was less than the percentage expected, we assigned that category a negative value. Conversely, if the percentage observed was greater than expected, we assigned the category a positive value. The greater the deviation in either direction, the higher the weight.

After deriving similar scores for each cell for the remaining environmental themes, the weighted model summed the scores for every cell. In order to map the results of the weighted model, we grouped the weights in sensitivity categories. The assignment of weights and sensitivity classes is somewhat subjective, but this is actually an advantage of this method. Because the scores are easily manipulated, the model can be re-created, and the results of these manipulations can be observed. It is important to note, however, that there is no "best" or "final" solution.

\section{Logistic Regression Models}

The problem with intersection models, whether we use weighted variables or not, is that all values for all variables become part of the model outcome when we overlay the various themes and identify the overlaps. On both theoretical and empirical grounds, we have good reason to believe that some environmental variables are more strongly correlated with human settlement behavior than are others. On a practical level, as more variables are overlaid, the complexity of the model increases at a geometric rate, often without a commensurate improvement in the end product. More sophisticated mathematical modeling techniques can reduce the complexity. Most of these techniques are based on linear regression approaches, with the most common being multilinear regression, discriminant function analysis, principal components analysis, and logistic regression (see Rose and Altschul 1988 for a description of these approaches).

Multivariate regression techniques examine the covariation among the independent (in our case, environmental) variables; only those environmental variables that independently explain sufficient variability in the dependent variable (that is, site location) become part of the regression analysis. The result of the analysis is an equation that calculates the probability that a grid cell will contain an archaeological site. The resulting probability scores are then used to create a three-dimensional isopleth map. Cells with the tallest probability "spikes" have the greatest likelihood of containing an archaeology site; cells with the lowest spikes are the least likely to contain a site.

Regression models are popular among archaeological predictive modelers because they can be quite powerful. Model "users," such as agency managers and cultural resource staff, however, tend to prefer intersection models, even though they are generally less accurate and precise. Multivariate regression models are statistically complex, and for those without advanced training in statistics, these models are difficult to understand and use. Intersection models, though less powerful, are easy to understand, and they make intuitive "sense." The best archaeological models for practical applications are those that combine the intuitive nature of intersection models with the power of multivariate statistics.

Is one kind of model "better" than the other? It depends on the intended use of the model and on the questions being asked. A logistic regression model is generally a better predictor of site location than an intersection model. If the question is, for example, whether a proposed lease is likely to contain archaeological sites, the best approach would be to overlay the lease boundaries on the surface probability map generated by a regression model. If, on the other hand, the question is what accounts for the surface distribution of sites, then developing a weighted model and running it 
repeatedly with different weights for the variables would be a good approach. By determining what variable weights maximize the predictive power of the weighted model, one can begin to understand what factors may have determined the nature of the archaeological landscape.

\section{Appropriate Use of Predictive Models in Cultural Resource Management and Planning}

As noted above, in the late 1970s and early 1980s, federal land managing agencies invested heavily in archaeological predictive models. Faced with the substantial costs of large, intensive archaeological surveys in anticipation of major energy development projects or broad-scale military training exercises, agency managers seized upon predictive modeling. They believed that by spending the money to create an objective and verifiable model, they could then avoid large-scale survey and instead use the predictions of the model as a substitute means for meeting the requirement to identify affected historic properties. This belief constituted a fundamental misconception about what predictive models can and cannot do, and most applications of this belief reflected a fundamental misunderstanding of the requirements of good resource stewardship under NHPA.

Within the archaeological profession there was an outcry against the misuse of predictive models as a means of "identifying" archaeological sites that would be affected by federal undertakings. The result of a predictive model is a set of probabilities that describe the likelihood that an archaeological site will or will not be found in a particular location. Section 106 of the NHPA, on the other hand, requires that agencies make a reasonable and good faith effort to identify actual historic properties, evaluate their eligibility to the National Register of Historic Places, and determine whether any of the qualities that make the property eligible to the Register will be affected by the agency's undertaking. None of these requirements can be met by consulting a sensitivity map or other representation of the results of a modeling effort and determining the probability that a site will be encountered at a particular place.

Critics of this misuse of modeling also pointed out, as Judge and Martin (1988:580) note, that "modeling is a cyclical process of ongoing refinement, rather than a one-time event, and thus models cannot be developed by outsiders and then simply 'turned over' to agency field office archaeologists for 'application."' Equally problematic, most models were being developed for arbitrarily defined areas - the area that would be affected by a large energy-development project or the land within the boundaries of particular military installation, for example. In such models, the patterning observed in site locations can be a response to factors outside the study area and thus not controlled for in the model, which makes the model much less accurate and interpretable (Kincaid 1988:552). Additionally, Native Americans often ascribe religious and cultural values to archaeological sites. These values generally are related to esoteric knowledge and oral traditions and not necessarily correlated with features of the natural environment. Because archaeological predictive models are based on environmental variables, sites with traditional cultural values could be underrepresented or overlooked entirely by the model.

Section 106 review agencies - that is, the Advisory Council on Historic Preservation and many of the State Historic Preservation Offices - were quickly convinced of the inadequacy of predictive models as a substitute for archaeological survey, and standard on-the-ground inventories became the norm for archaeological compliance (see Fish and Kowalewski 1990). This conservative approach satisfied the concerns of preservation-minded archaeologists and the Section 106 reviewing agencies but did not really address the problems of planning for large-scale development. And ironically, this approach also failed to provide a sufficient understanding of the archaeological record on which to base good management decisions - primarily because no mechanism emerged to synthesize the results of surveys from multiple projects.

Unfortunately, when it became clear that predictive models could not be substituted for intensive surveys, many land-managers abandoned the whole concept of archaeological models. Some agencies did continue to develop and refine models, however, because they realized that there are valid and important uses for models in the Section 106 process and in federal land management in general.

Kincaid (1988:554), for example, noted that

Perhaps the most cost-effective context for model development is within the framework of general planning by a land-managing agency or a local government. These programs can develop and sustain long-term approaches that are funded incrementally and result in cumulative and refined data bases. Such databases, and the models based on them, may take years to develop and test. The end result, however is a powerful and effective management tool.

One of the most effective and appropriate uses of predictive modeling is for project planning and project design. If Section 106 undertakings are designed from the beginning to avoid areas containing a high density of cultural resources, costly redesigns and reroutes as well as mitigation efforts can be minimized. Predictive models can also be used to 
structure the Section 106 identification efforts for archaeological historic properties. In some settings, land managers can use sensitivity maps to target proportionately greater survey effort in those areas most likely to contain the greatest number of the sites or the most significant sites, while surveying other areas at a lower intensity.

There is more to cultural resource management than Section 106, however. Section 110 of the NHPA, for example, requires that federal agencies establish a program to identify and evaluate historic properties under their jurisdiction and that they manage and maintain National Register-eligible properties under their jurisdiction in a way that preserves their historic qualities. Predictive models can assist land managers to meet their Section 110 obligations by informing their decisions about land uses and by enabling them to make the best use of the scarce dollars available for resource identification, stabilization, and protection.

The National Environmental Policy Act (NEPA) requires that federal agencies evaluate the impact of their actions on the "human environment," including cultural and historic resources. All federal projects require NEPA assessment at some level, but those that have the potential to cause major impacts require formal evaluation of effects and alternatives through the Environmental Assessment or Environmental Impact Statement processes. The purpose of these NEPA assessments is to enable federal agency managers to make informed decisions that consider, in an even-handed way, the environmental, cultural, and social consequences of alternative agency actions.

NEPA does not require that agencies identify all specific resources that will be impacted or that the agency acquire comprehensive, detailed data about all the alternatives that are being considered. Rather, NEPA requires that the agency have or gather sufficient data to evaluate the alternatives effectively and that those data be gathered and evaluated in a scientifically valid way. Predictive modeling, alone or combined with sample survey, is an excellent approach to NEPA compliance for archaeology. A thoroughly tested and refined predictive model can enable an agency to evaluate a wide variety of alternatives and assess their relative impacts in an impartial, scientifically sound process.

After a decade or more of being out of favor among land-managing agencies, predictive models are making a comeback. Existing models are being updated and improved, and agencies that abandoned their models after learning that they could not simply substitute models for survey are rethinking that decision. There are several reasons for this renewed interest in modeling. For one thing, despite a quarter of a century of cultural resource management work, we are still struggling with the problem of how to synthesize all the gathered data. Section 106, which drives most of the cultural resource work, is totally case-specific. We have no mechanism for taking what we learn from each individual survey or excavation project, combining that information with all the other surveys and excavations in the area, and using the synthesized data to inform future management decisions.

As the New Mexico Pump III project shows, there are areas where literally hundreds of surveys have been completed but where we know very little more about the nature and meaning of the archaeological record than we did in the beginning. Archaeological modeling enables us to combine all of the existing data and examine them for patterns of correlation or to evaluate the data against theory-based predictions. Archaeological synthesis is not only critical to our ability to interpret and explain human behavior in the past, it assists us to develop more sophisticated research and management strategies for the future.

One of the most critical needs in cultural resource management today is for better assessments of archaeological significance. As part of the Section 106 process, decisions must be made every day about the potential of archaeological sites to "yield important information" about the past. By synthesizing existing data and characterizing what is common and what is rare in the archaeological record, predictive modeling can assist with this process. Perhaps even more important, archaeological models can help us identify the things that require explanation.

The accuracy of predictive models is often given a great deal of emphasis, but it is important to note that predictive power does not correlate with archaeological importance. We might, for example, create a model that predicts archaeological site locations with an accuracy of $80 \%$ or more, which might lead managers to question the value of model refinements intended to better that accuracy by something less than the remaining $20 \%$. In all likelihood, however, it is the remaining $20 \%$ of sites that have the greatest potential to teach us important things about the past.

These "red flag" sites (Altschul 1989, 1990), which do not fit expected distributional patterns, result from human behaviors that are beyond our predictive capabilities. These sites are, by definition, are likely to yield important information on past settlement behavior and, therefore, are likely to be eligible for listing in the National Register of Historic Places. Predictive models will not identify these sites, and archaeological inventory alone will not indicate their significance. Through a combination of modeling to identify the common, environmentally predictable patterns and inventory to identify the exceptions, however, we can identify those sites that should be the focus of our research, mitigation, and site protection efforts.

Another reason for the renewed interest in predictive modeling is the current government-wide emphasis on environmental streamlining. One of the most effective ways to streamline environmental review is to move decision- 
making to a point earlier in the planning process. This is a good thing for preservation of archaeological sites and other kinds of cultural resources, since more avoidance and mitigation alternatives are available at the earliest stages of planning. Because early planning takes place well before Section 106-driven resource identification has been completed, however, land-managers need a mechanism for synthesizing, manipulating, and evaluating existing data in order to make effective, well-informed cultural resource management decisions. Archaeological modeling, combined with limited identification and testing, has much to contribute to environmentally responsible streamlining efforts.

Predictive modeling should be part of a management strategy for cultural resources. Yet, it is important to recognize that modeling is not a rote exercise. For models to be useful, archaeologists with regional expertise must work together with GIS specialists and archaeostatisticians. Many examples exist of the use of inappropriate modeling techniques resulting in models on which managers have relied that are, in reality, poor predictors and make little archaeological sense.

Finally, we sometimes learn very useful information about the past and about the resources being managed when models do not work. For example, the Yuma Proving Ground (YPG) encompasses about 850,000 acres in the Sonoran Desert of southwestern Arizona. The region is located in one of the harshest desert environments in the world, receiving less than 3 inches of rain a year and subjected to summer temperatures well in excess of $100^{\circ} \mathrm{F}$. Under contract to develop a predictive model for the installation, Altschul (2005) argued that environmentally based, correlative models should work well in this situation. After all, survival in this region depended on humans mapping onto a small set of environmental resources, all of which were distributed in very restricted areas. Yet, surprisingly, logistic regression and weighted models did not work well at all. Site locations were simply not correlated with environmental variables. How could this be?

The answer was not intuitively obvious, but after studying the archaeological and ethnohistoical records, Altschul realized that few people in the past actually went into this part of the desert to collect resources. Instead, they focused on the resources and established settlements along the permanent rivers of the region, the Colorado and Gila rivers. Sites in the desert were created by people traveling between the riverine settlements. To demonstrate this hypothesis, Altschul eschewed correlative models in favor of directional analysis which identified logical routes based criteria such as least effort and water availability. These routes were then correlated with the locations of known archaeological sites, and predictions were offered not only about where sites would be located but also about the types of sites that would be encountered. Altschul (2005) argued that almost all Native American resources on YPG could be attributed to a restricted set of behaviors (i.e., those associated with travel).

The management significance of this discovery is that the potential of both known and yet-to-be-recorded sites to yield important information on the past (criterion D of 36CFR60.4) could be addressed programmatically. Based on this knowledge, appropriate measures could be defined so that archaeological resources could be identified, evaluated, and treated simultaneously, greatly streamlining the compliance process. The Army is in consultation with the Arizona SHPO and tribes of the region to incorporate Altschul's suggestions into management practices.

Advances in predictive modeling, like most advances in science, are cumulative. They require that researchers apply appropriate techniques to particular questions about settlement systems. Some questions, such as where will sites be located, may only require simple techniques. As we probe deeper into past behavior, however, both to increase the accuracy of our predictions as well as to distinguish portions of the archaeological record worth saving, the questions become increasingly complex, as we will discuss in the following section of this chapter. Addressing these questions requires archaeologists to continually enlarge their predictive tool kit.

\section{How Does Modeling Contribute to Our Understanding of the Past?}

The predictive models described in this report are statistically derived techniques for anticipating probable densities of archaeological sites within three localities of southeastern New Mexico. The immediate application of this information is resource management, but predictive modeling has a much broader range of uses in archaeology. The long-range goal of archaeology as a scientific discipline is "the contribution of knowledge to objective understandings of human behavior" (Cordell et al. 1994:164). The scientific questions that interest archaeologists range from quite specific human acts at one end of the human behavioral spectrum to broad processes of cultural development and change at the other end (Cordell 1994:152). Nevertheless, most of the questions that archaeologists ask pertain not to individual behaviors or societies in general but rather to the behavior of cultural groups in given times and places. Further, the time frame of interest usually is the precontact or early historical period, although archaeologists as members of the professional anthropological community do, in fact, study modern societies to gain insight into ancient behavior and societal processes. 
Archaeologists investigate past human behavior through artifacts and their attributes, architecture and other constructed features, sites and settlement patterns, the residues of cultural and economic activities, and the many ways that humans alter and interact with their physical environments. Archaeologists researching historical-period groups also may investigate the past through written records, where available and applicable. Observations concerning the formal attributes of these remains of past activities, as well as their temporal and spatial associations, are recovered primarily during the course of systematic surveys and controlled excavations. The recorded observations become archaeological data, and it is these data that are described and analyzed. Analysis usually involves the search for patterning or regularities in form, function, association, or developmental sequence. Ideally, analysis of one or a few sets of data is compared with other data sets, and patterning at larger temporal and spatial scales can be perceived from this integration and synthesis of multiple data sets.

From these higher-level studies, conceptual models are developed to account for the behaviors of interest. We accept the definition of models offered by Clarke (1968:32), who suggests that models are hypotheses or sets of hypotheses that simplify complex observations but offer a largely accurate predictive framework to account for given behaviors. For example, a researcher may want to understand why large, late, precontact village sites that housed most of a given valley's population were more-or-less evenly spaced along a particular river system. Was this spacing a result of the distribution of arable land, competition for and defense of immediate territory, or the need to locate sites within easy distance of cooperative kin, trading partners, and potential mates? The researcher would develop alternate models describing what patterns we might expect to see in the archaeological record for each of these possible explanations of village spacing - in other words, economic self-sufficiency, competition, or cooperation.

The data examined in our example might include the distribution and amount of high-quality arable land and water, the presence or absence of territorial markers (e.g., field-side houses, shrines, petroglyphs, or large areas of unoccupied land), or the similarity or dissimilarity of culinary pottery among adjacent villages. The expectations (or predictions) generated by each model would then be compared with the available data. A model would be judged successful if the fit between the researcher's expectations and the actual observed data proved to be a strong one. If the fit was found to be poor, either the postulated behavior (e.g., competition) was not, in fact, responsible for the site distribution, or the model or the data were inadequate for the test. As this example shows, archaeological models are generalizations derived from pattern-recognition studies that postulate cause-and-effect relationships among clusters of environmental and social conditions and human behaviors and test these expectations against the archaeological record.

Seen in this way, all archaeological models are predictive, but the goal of the modeling effort is not to accurately project where sites will likely occur, but rather to understand the contexts, conditions, decisions, and human actions behind those archaeological patterns. The predictive models developed for the Loco Hills, Azotea Mesa, and Otero Mesa study areas were designed to discover general patterns in human settlement relative to aspects of the physical environment and to reveal something about the subsistence activities and economic decisions behind those patterns.

Other types of human decisions and behavioral patterns - those related to demographic or ideological considerations, for example - could not be considered in these models because few of the data needed for such models have been compiled, analyzed, and interpreted. Although hundreds of artifact scatters have been located, no comprehensive study has been undertaken to classify these scatters by their various functions (e.g., short- and long-term base camps or habitations, resource procurement locales, resource processing locales). No detailed studies of functionally important or temporally sensitive artifact classes have been undertaken. No synthetic study has been undertaken to resolve chronological issues or questions of cultural affiliation. The PUMP III models focus on economic decisionmaking in relationship to site location because the currently available archaeological data are best suited to models of this nature.

The PUMP III models, or at least the Loco Hills and Azotea Mesa models, were moderately successful in predicting site location, which would indicate that economic decision-making was an important influence on the location of human activities in this area. But the models were even more successful in generating questions about the past and the nature of the archaeological record. In all cases, they underscored the need for focused study and data recovery in southeastern New Mexico.

Let us suppose that such studies and archaeological data recovery were actually to take place. What, then, could we expect future modeling efforts to do for us in the PUMP III study areas? How can modeling contribute to our understanding of the past? To address these questions, we have briefly described below five examples of archaeological models that used spatial referenced site data, environmental variables, and GIS technology to contribute to our understanding of past human behavior. All of the examples are regional analyses, and each was developed to account for the known distribution of archaeological sites or settlement centers. 


\section{A Model of Trade and Cross-Cultural Interaction}

Archaeologist Kathleen Allen (1990) developed a model that used the demand for and direction of movement of trade goods as a predictor of settlement location and population distribution. Specifically, she wanted to understand the development of trade between native Iroquois populations and European colonizers in New York state from about AD 1600 to 1750 . To do this, she used a Network Analysis module within the ARIC/INFO GIS package to simulate the outward flow of specific trade goods from historically known population centers at three periods of time: the time before major European colonization in the mid- to late 1500 s, the time of the early establishment of trading posts in the early 1600s, and the mid-1700s the time by which European trading posts and forts were well established throughout the region. The major conduit for travel and trade were river valleys, and a hydrology layer in the GIS served as a proxy for trade routes. Allen used the location of known Iroquian villages and European trading posts and forts and the historical records of trade items to develop her model for the three temporal periods. She successfully replicated the broad patterns of historical-period trade, and she discovered that distribution of watercourses was more important in explaining the movement of goods and people than earlier researchers had conjectured.

\section{A Model of Territory and Social Organization}

Archaeologist Stephen Savage (1990) used geographic location theory to develop a model for the existence of a particular form of social organization in Late Archaic hunting and gathering societies in the southeastern United States. Savage's model suggests that the distribution of Late Archaic period sites in the Savannah River Valley of Georgia and South Carolina was the result of the creation of habitually used and exclusive territories by Late Archaic period huntergatherers. In this model, each small group (the minimal band) functioned as an independent subsistence unit connected to other groups through a large contiguous social network (the maximal band) which fulfilled mating, ritual, and defensive functions. Environmental data required to develop the model included elevation data (and one of its derivatives, terrain roughness) and hydrology. Archaeological data included site locations, site sizes, and site types based on tool and raw material variability. Savage displayed and analyzed his data with a GIS program called MAPCGI. Using a variety of spatial analysis techniques, including site catchment, nearest-neighbor, and least-cost movement analyses, as well as Thiessen polygons, Savage was able to delimit the habitual use areas (territories) of six minimum bands and estimate the population of each territory based on site size and complexity, overall population size, and the likelihood that a larger social network existed to satisfy higher-level societal functions.

\section{A Model of Population Growth and Migration}

Archaeologist Ezra Zubrow (1990) harnessed the power of GIS to simulate various models of European settlement, population growth, and migration in New York state for the interval between AD 1608 and 1810. His goal was to account for the location of settlements in the early nineteenth century and to understand the process of colonization. Also considered were the interactions of European settlers with native populations and a variety of obstacles to movement. Zubrow's methods included reconstructing the hydrological network that would have been usable for travel, establishing the locations and initial size of original populations and their rates of population growth, employing the Network Module of ARC/INFO to simulate and display the movement and distribution of migrants, and comparing the simulated results with historical records of actual examples of people moving and settling the landscape. From three initial centers along the Hudson River in eastern New York, the simulation charted the movements of colonists and their potential routes of migration. The model was run numerous times, in which each run specified different growth rates and dispersal assumptions. Through modeling and dynamic simulation, Zubrow was able to effectively model different migration patterns and sequences that accounted for the 83 known early European settlements during that two-century period. He also was able to suggest that populations moved along a larger number of watercourses and in different directions than previously realized. Finally, through the modeling exercise Zubrow came to understand much more about the factors that limited population growth and population movement during the settlement of what was then a frontier area.

\section{A Model of Cultural Contact and Shifting Economic Priorities}

Cultural anthropologist Clifford Behrens (1996:55-77) developed an economic model based on cultural ecological theory to account for the changing distribution of sites and site types in a region of the Peruvian Amazon at the end of the twentieth century. His goal was to better understand how increasing sedentism and growing market demand for products can lead to altered settlement patterns and increasingly intensive uses of land among indigenous Amazonians. The ecological effects of these human land-use practices included widespread deforestation and the reduction of biodiversity within the rainforest. Behrens used the GIS system GRASS to display and analyze classified Landsat satellite imagery (Thematic Mapper data) as a means to document developments in the Lower Pisqui River region of 
eastern Peru in the 1980s. The relationships between indigenous hamlets, mestizo and white villages, and various landuse categories (cropland, pasture, forest land, water, wetland, barren land) were explored with a variety of spatial techniques and statistical measures. From these exploratory data analyses, Behrens was able to construct a three-stage process model that accounted for the changes in settlement. Among the various factors were a desire on the part of natives to acquire more efficient tools and ready-made goods, to gain access to schools and health care, and to satisfy a desire to reduce travel distances to their workplaces. The effects of the changes in settlement and settlement duration were realized as shortened fallow periods for agricultural plots and cattle pasture, forest destruction, and disruption of former social and political networks. The apparent success of Behrens's methods and models in explaining the settlement patterns suggests that similar approaches could be taken to predict settlement change under similar pressures elsewhere.

\section{A Model of Environmental Variability, Agricultural Productivity, and Food Sharing}

Archaeologists Carla Van West and Timothy Kohler (1996:107-131) created a subsistence risk sensitivity model for the AD 900-1300 interval in southwestern Colorado to account for the cyclical pattern of population aggregation and dispersal that has been documented for that area. The data used in this modeling effort were developed in an earlier GIS-coordinated reconstruction by Van West (1994) of environmental variability and agricultural potential for the Mesa Verde area. Environmental variables used in the earlier study to estimate prehistoric agricultural yields were tree-ring-based reconstructions of precipitation and soil moisture, elevation information, soils data, soil productivity data, and historical crop yields by soil class. VICAR-IBIS, a mainframe raster system, and EPPL 7, a PC raster system, were used to process the data. Van West and Kohler drew on discussions of risk and uncertainty in behavioral ecology and microeconomics to develop their expectations. They expressed risk sensitivity to fluctuations in crop yield as a willingness to share or horde food. They predicted that time periods when maize yields were high but characterized by significant temporal and spatial variability would be associated with risk-averse behavior, food-sharing, and the establishment and growth of aggregated settlements (villages with public architecture). In contrast, they predicted that time periods when maize yields were low but accompanied by significant temporal and spatial variability would be associated with risk-seeking behavior, defection from the system of food-sharing (hording), the break-up of villages into smaller units, and dispersal into habitable areas. Their expectations were tested by comparing their predictions to the archaeological settlement history, which is well documented for the Mesa Verde region. Their expectations were met, and they concluded that the model effort was generally successful in predicting when and where villages were likely to have been established or abandoned. Perhaps more importantly, however, Van West and Kohler were able to argue that food sharing, perhaps the most basic of all cooperative behaviors, was a likely element in the complex set of factors that led to development of sociopolitical complexity in the northern Southwest.

\section{Conclusions}

We have offered these examples of more sophisticated archaeological models to indicate what is possible with more detailed archaeological data. Although each of the models described above used different theory, methods, and analytic techniques to explore site distributions, what they have in common is data on the formal and temporal characteristics and spatial distributions of artifacts, features, and sites in the targeted region. Such knowledge can only be gained through analysis of systematically recovered archaeological materials or, in the case of historical-period remains, written records. Significant insights concerning past human behavior in southeast New Mexico will be gained only when a sufficient sample of well-documented sites and their contents has been obtained, analyzed, and interpreted. Only then will archaeologists be able to suggest which human behaviors and social processes are the most powerful predictors of settlement patterns and accurately evaluate the potential of individual archaeological sites to yield data important to this understanding of the past.

\section{References Cited}

Allen, Kathleen M.S.

1990 Modeling Early Historic Trade in the Eastern Great Lakes Using Geographic Information Systems. In Interpreting Space: GIS and Archaeology, edited by K.M. S. Allen, S. W. Green, and E. B. Zubrow, pp. 319-329. Taylor and Francis, London.

Allen, Kathleen M. S., Stanton W. Green, Ezra B. W. Zubrow, editors

1990 Interpreting Space: GIS and Archaeology. Taylor and Francis, London. 
Altschul, Jeffrey H.

1988 Models and the Modeling Process. In Quantifying the Past and Predicting the Future: Theory, Method, and Application of Archaeological Predictive Modeling, edited by W. James Judge and Lynne Sebastian, pp. 61-96. U.S. Department of the Interior, Bureau of Land Management, Denver.

1989 Modeling as a Management Strategy. In Man, Models, and Management: An Overview of the Archaeology of the Arizona Strip and the Management of Its Cultural Resources, by Jeffrey H. Altschul and Helen C. Fairley, pp. 273-310. USDA Forest Service and USDI Bureau of Land Management, Washington, D.C.

1990 Red Flag Models: The Use of Modeling in Management Contexts. In Interpreting Space: GIS and Archaeology, edited by Kathleen M.S. Allen, Stanton W. Green, and Ezra B.W. Zubrow, pp. 226238. Taylor and Francis, London.

2005 On the Path of the Outer Yuman War Trail, the Cocomaricopa Trail, and the Trail of Dreams: Predictive Models of the Archaeological Record of Travel, Yuma Proving Ground, Arizona. Statistical Research Technical Series, Tucson, Arizona, Draft.

Altschul, Jeffrey H., Lynne Sebastian, and Kurt Heidelberg

2003 Predictive Modeling in the Military: Similar Goals, Divergent Paths. Preservation Research Series 1. SRI Foundation, Rio Rancho, New Mexico.

Behrens, Clifford A.

1996 A Formal Justification for the Application of GIS to the Cultural Ecological analysis of Land-Use Intensification and Deforestation in the Amazon. In Anthropology, Space, and Geographic Information Systems, edited by M. Aldenderfer and H. D. G. Maschner, pp. 55-77. Oxford University Press, New York and Oxford.

BRW, Inc.

1996 Draft Research Design for the Development of a High Probability Predictive Model for Identifying Archaeological Sites. Prepared for Minnesota Department of Transportation, Minneapolis

Clarke, David L.

1968 Analytic Archaeology. Methuen, London.

Cordell, Linda S.

1994 The Nature of Explanation in Archaeology: A Position Statement. In Understanding Complexity in the Prehistoric Southwest, edited by G. J. Gumerman and M. Gell-Mann, pp, 149-162. SFI Studies in the Sciences of Complexity Proceedings Volume 16. Addison-Wesley, Reading, Massachusetts.

Cordell, Linda S., Jane H. Kelley, Keith W. Kintigh, Stephen H. Lekson, and Rolf M. Sinclair

1994 Toward Increasing Our Knowledge of the Past: A Discussion. In Understanding Complexity in the Prehistoric Southwest, edited by G. J. Gumerman and M. Gell-Mann, pp, 163-191. SFI Studies in the Sciences of Complexity Proceedings Volume 16. Addison-Wesley, Reading, Massachusetts.

Fish, Suzanne K., and Stephen A. Kowalewski, editors

1990 The Archaeology of Regions: The Case for Full-Coverage Survey. Smithsonian Institution Press, Washington.

Green, Ernestine L.

1973 Location Analysis of Prehistoric Maya Sites in Northern British Honduras. American Antiquity 38:279_ 293.

Judge, W. James, and Daniel W. Martin

1988 An Appraisal. In Quantifying the Present and Predicting the Past: Theory, Method, and Application of Archaeological Predictive Modeling, edited by W. James Judge and Lynne Sebastian, pp. 571580. USDI Bureau of Land Management, Denver.

Judge, W. James, and Lynne Sebastian, editors

1988 Quantifying the Present and Predicting the Past: Theory, Method, and Application of Archaeological Predictive Modeling. USDI Bureau of Land Management, Denver.

Kamermans, Hans, Jos Deeben, Daan Hallewas, Paul Zoetbrood, Martijn van Leusen, and Philip Verhagen

2005 Project Proposal. In Predictive Modeling for Archaeological Heritage Management: A Research Agenda, edited by Martijn van Leusen and Hans Kamermans. Nerderlandse Archeologische Rapporten 29. Rijksdienst voor het Oudheidkundig Bodemonderzoek, Amersfoot. 
Kincaid, Chris

1988 Predictive Modeling and its Relationship to Cultural Resource Management Applications. In Quantifying the Present and Predicting the Past: Theory, Method, and Application of Archaeological Predictive Modeling, edited by W. James Judge and Lynne Sebastian, pp. 549-569. USDI Bureau of Land Management, Denver.

Kohler, Timothy A.

1988 Predictive Locational Modeling: History and Current Practice. In Quantifying the Present and Predicting the Past: Theory, Method, and Application of Archaeological Predictive Modeling, edited by W. James Judge and Lynne Sebastian, pp. 19-59. USDI Bureau of Land Management, Denver.

Kohler, Timothy A., and Sandra C. Parker

1986 Predictive Models for Archaeological Resource Location. In Advances in Archaeological Method and Theory, Vol. 9, edited by Michael B. Schiffer, pp. 397-452. Academic Press, New York.

Rose, Martin R., and Jeffrey H. Altschul

1988 An Overview of Statistical Method and Theory for Quantitative Model Building. In Quantifying the Present and Predicting the Past: Theory, Method, and Application of Archaeological Predictive Modeling, edited by W. James Judge and Lynne Sebastian, pp. 173-255. USDI Bureau of Land Management, Denver.

Savage, Stephen L.

1990 Modeling the Late Archaic Social Landscape. In Interpreting Space: GIS and Archaeology, edited by K.M. S. Allen, S. W. Green, and E. B. Zubrow, pp. 330-355. Taylor and Francis, London.

Thoms, Alston V.

1988 A Survey of Predictive Locational Models: Examples from the Late 1970s and Early 1980s. In Quantifying the Present and Predicting the Past: Theory, Method, and Application of Archaeological Predictive Modeling, edited by W. James Judge and Lynne Sebastian, Appendix pp. 581-645. USDI Bureau of Land Management, Denver.

Van West, Carla R.

1994 Modeling Prehistoric Agricultural Productivity in Southwestern Colorado: A GIS Approach. Reports of Investigation 67. Department of Anthropology, Washington State University, Pullman, and Crow Canyon Archaeological Center, Cortez, Colorado.

Van West, Carla, and Timothy A. Kohler

1996 A Time to Rend, A Time to Sew: New Perspectives on Northern Anasazi Sociopolitical Development in Later Prehistory. In Anthropology, Space, and Geographic Information Systems, edited by M. Aldenderfer and H. D. G. Maschner, pp. 107-131. Oxford University Press, New York and Oxford.

Wescott, K. L., and R. J. Brandon, editors

2000 Practical Applications of GIS for Archaeologists: A Predictive Modeling Kit. Taylor and Francis, London.

Zubrow, Ezra B.

1990 Modeling and Prediction with Geographic Information Systems: A Demographic Example from Prehistoric and Historic New York. In Interpreting Space: GIS and Archaeology, edited by K. M. S. Allen, S. W. Green, and E. B. Zubrow, pp. 307-318. Taylor and Francis, London. 



\title{
C H A P T E R \\ 5 \\ Results and Discussion: The Loco Hills Study Area
}

\author{
Jeffrey H. Altschul, Lynne Sebastian, Chris M. Rohe, William E. Hayden, and Stephen A. Hall
}

\begin{abstract}
$\Delta$
The Loco Hills study area (Figure 1.2) is a rectangle covering approximately 1,200 square kilometers (460 square miles) located between the towns of Hobbs and Artesia in southeastern New Mexico. Most of the study area lies within the Pecos River valley; the river itself is about 16 kilometers (10 miles) west of the study area's western boundary.

The northeastern corner of the study area includes a small segment of The Caprock or Mescalero Ridge, which forms the eastern edge of the river valley and the western edge of the Llano Estacado (Figure 1.3). Elevations within the study area vary from about 300 meters (1,000 feet) in the southwest to 390 meters (1,300 feet) in the northeast; most of the land within the study area is less than 360 meters $(1,200$ feet $)$ above mean sea level.

Much of the study area is covered by a thick sand sheet deposited some 5,000-9,000 years ago and topped with parabolic dunes that are very recent in age; in the western and southwestern portions of the study area, the sand sheet is thinner and covered with coppice dunes formed around mesquites and other shrubs. In the southwestern and south-central parts of the study area, exposures of eroded Permian-Triassic sedimentary rocks are covered with thin soils. The northeastern portion of the area lies within the Llano Estacado, which is a flat, nearly featureless landscape of eroded Ogallala caprock caliche characterized by thin soils and numerous, shallow drainage depressions and playas. Permian, Triassic, and Ogallala outcrops represent diverse geological ages and rock types and are collectively referred to here as "bedrock."
\end{abstract}

\section{The Predictive Models}

\section{Environmental Data}

In developing the Loco Hills predictive models, we began by assembling data on all types of environmental variables. Some of these variables were subsequently found to be correlated with archaeological sites; others were not. These relationships became clear during the next step in the model development process, but at this initial stage we needed to ensure that we cast our net wide enough so that the variables included in the model would, through a variety of statistical manipulations, cover as many aspects of the human decision-making process through which indigenous people placed themselves and their activities on the landscape as possible.

In compiling the environmental data for Loco Hills, we restricted our search to data that already existed in digital formats that could be converted easily into layers in a geographic information system (GIS). We used the IDRISI GIS package to store data, calculate the statistics, and display the results of the predictive models for Loco Hills. This GIS package is a raster-based system and uses a grid of a specified size superimposed over the area in question. We chose a $10 \times 10 \mathrm{~m}$ cell as our grid size, which generated 13,298,193 cells for the Loco Hills study area.

The environmental variables used in predictive models are best viewed as proxy variables. Humans use a complicated "calculus" in assessing potential locations in which to live, obtain and process resources, and commune with the gods. People do not generally measure the slope of the land where they place their houses or measure the exact distance to water, but they do choose land that is flat and near water. The indigenous people of Loco Hills probably did not know, much less care, at what elevation they placed their camps, but they certainly knew where the stands of black grama and tobosa grasses occurred. Elevation, though not part of the prehistoric "calculus," is strongly correlated with the vegetative communities of southeast New Mexico and thus can be used as a predictor of site location.

For environmental variables, we obtained GIS layers on elevation, vegetation, and geomorphology. Because the data relate to empirical observations (i.e., someone actually measured the elevation of some of the points in the project area), these layers are termed primary themes. It is important to point out that in GIS, the designation "primary theme" does not mean that the score of each cell was derived from an empirical observation, only that the interpolation is based on source data. For example, the elevation theme is a digital elevation model (DEM) created by the United States Geological Survey (USGS; Figure 5.1). DEMs are created by interpolating between a set of points with known elevations 


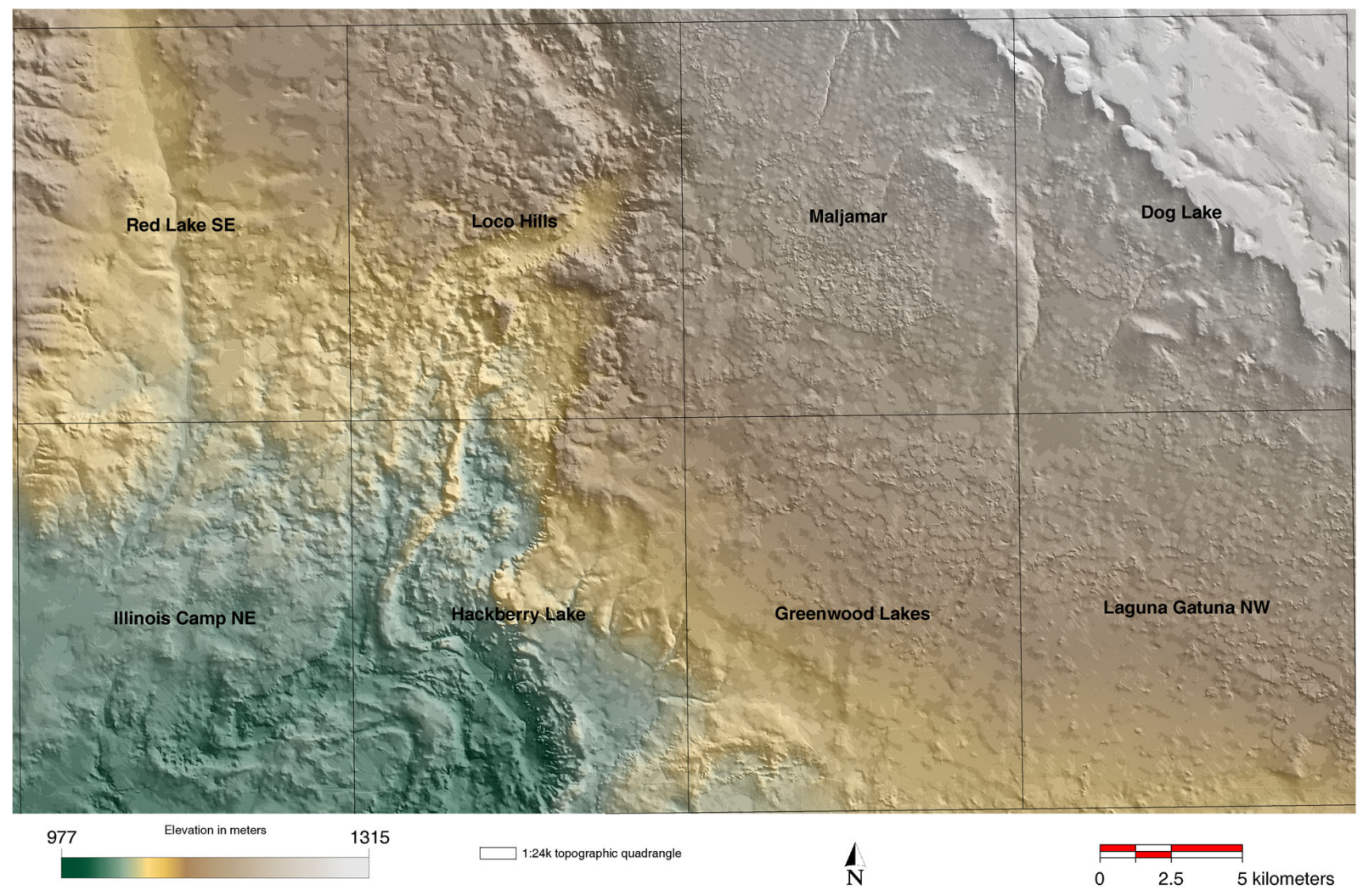

Figure 5.1. Digital elevation model (DEM) of the Loco Hills study area with USGS 7.5-minute quadrangles labeled. Note DEM extends slightly outside study area.

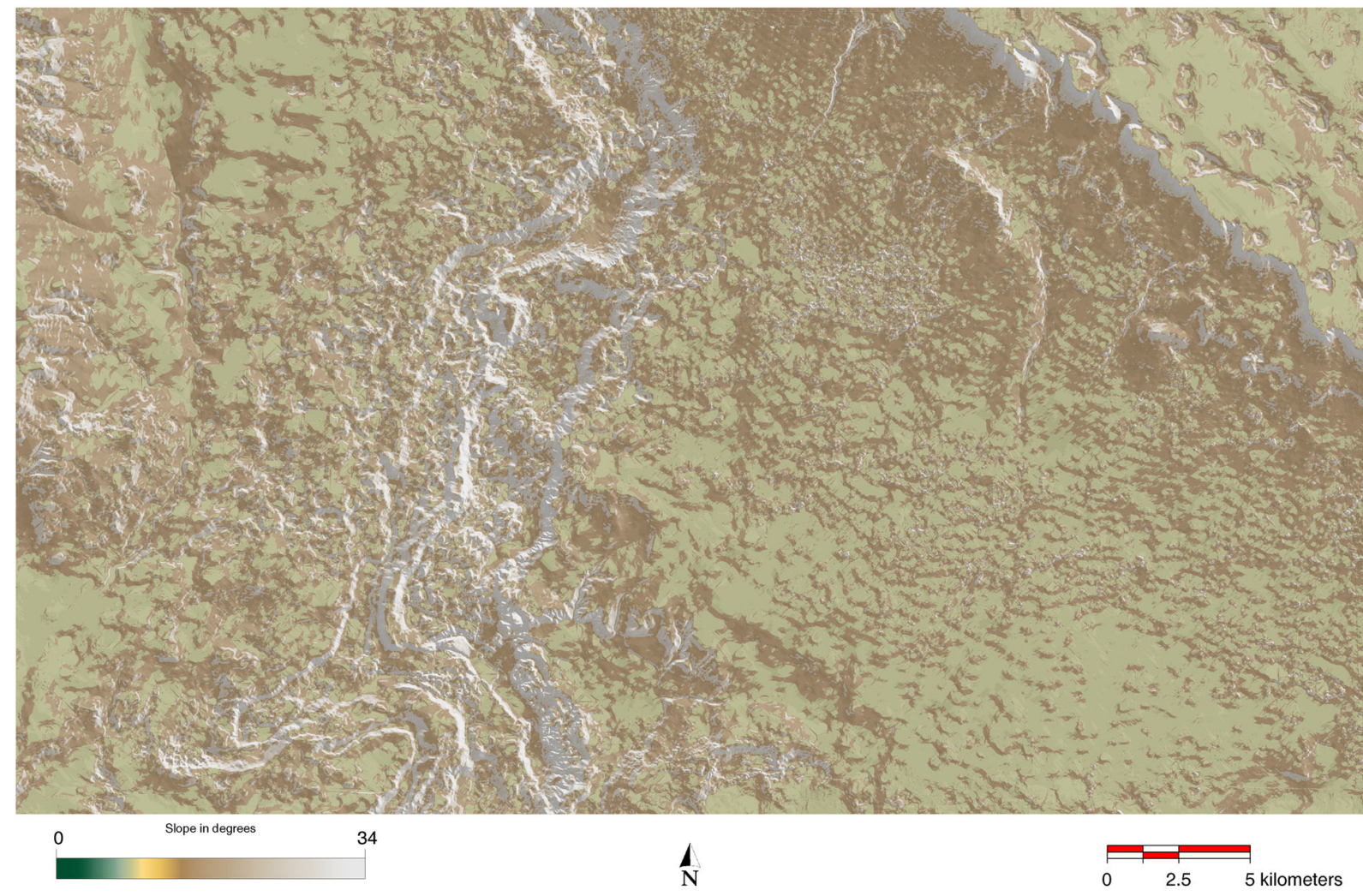

Figure 5.2. A secondary layer, slope, for the Loco Hills area; this layer was created from the DEM primary layer. 
at a specified contour interval. In the case of Loco Hills, the contour interval is 40 feet.

Algorithms exist within GIS packages to transform primary themes into derived, or secondary, environmental themes. In many cases, DEMs serve as the primary data theme from which secondary themes, such as slope and aspect, are created. For example, to calculate the slope of a cell, IDRISI uses the elevation scores of the four cells located to the north, south, east, and west of the one in question to compute an "average" slope (Figure 5.2). Similarly, aspect, or the prevailing exposure of the cell, is calculated by determining whether the elevation of the subject cell is higher or lower than each of its eight neighbors, and then assigning the direction to which the cell is "open" as its score.

Distance to water themes were also created from the DEMs by calculating either the shortest distance from a cell to an interpolated blue line feature (i.e., distance to water; streams are plotted on Figure 5.3) or the shortest distance following the flattest grade (cost distance to water). The interpolated stream systems may differ from the blue topographic lines because the GIS is computing where water will flow based on slope and elevation of the DEM. This is very useful for archaeological site modeling, since most topographic blue lines show only modern drainages.

\section{Vegetation}

In addition to the environmental themes based on the DEM, we acquired a vegetation layer from the Gap Analysis Program of the USGS, which provides information on biodiversity and conservation gaps. The data are displayed as major vegetation categories, which are divided into 21 subcategories based on common descriptions of vegetation.

As Figure 5.4 shows, more than $58 \%$ of the Loco Hills study area is covered by vegetation that is categorized as broadleaf sand scrub, with another $9 \%$ being categorized as some type of desert scrub. Of the remainder, most is shortgrass steppe (19\%) or some type of grassland (14\%). The major grass species are black grama (Bouteloua eriopoda) and tobosa (Hilaria mutica), along with various species of dropseed and sacaton (Sporobolus spp.). The main shrub species are creosote (Larrea tridentate), mesquite (both Prosopis julifora and gladulosa), and shin oak (Quercus havardii).

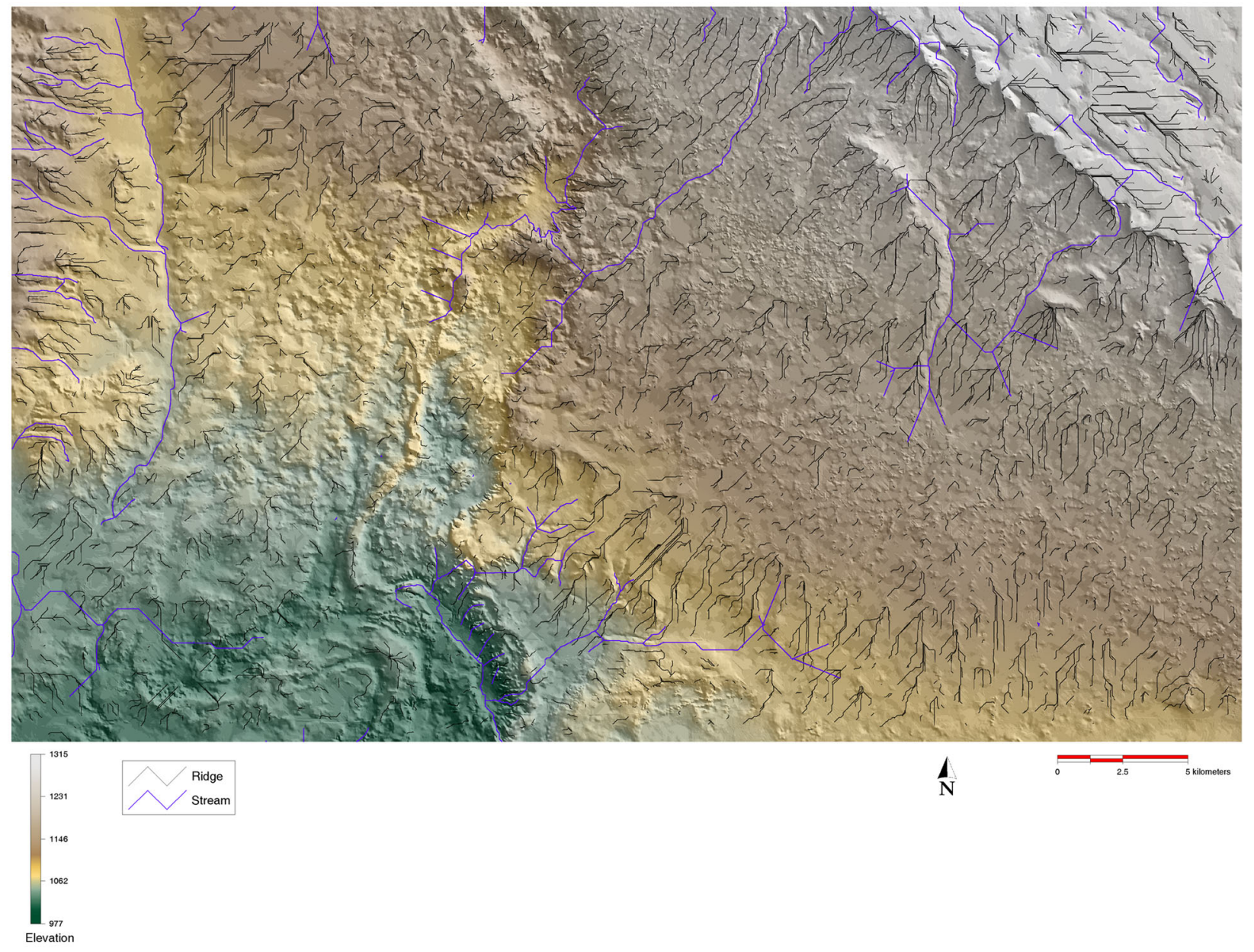

Figure 5.3. Drainages and ridges in the Loco Hills study area. 


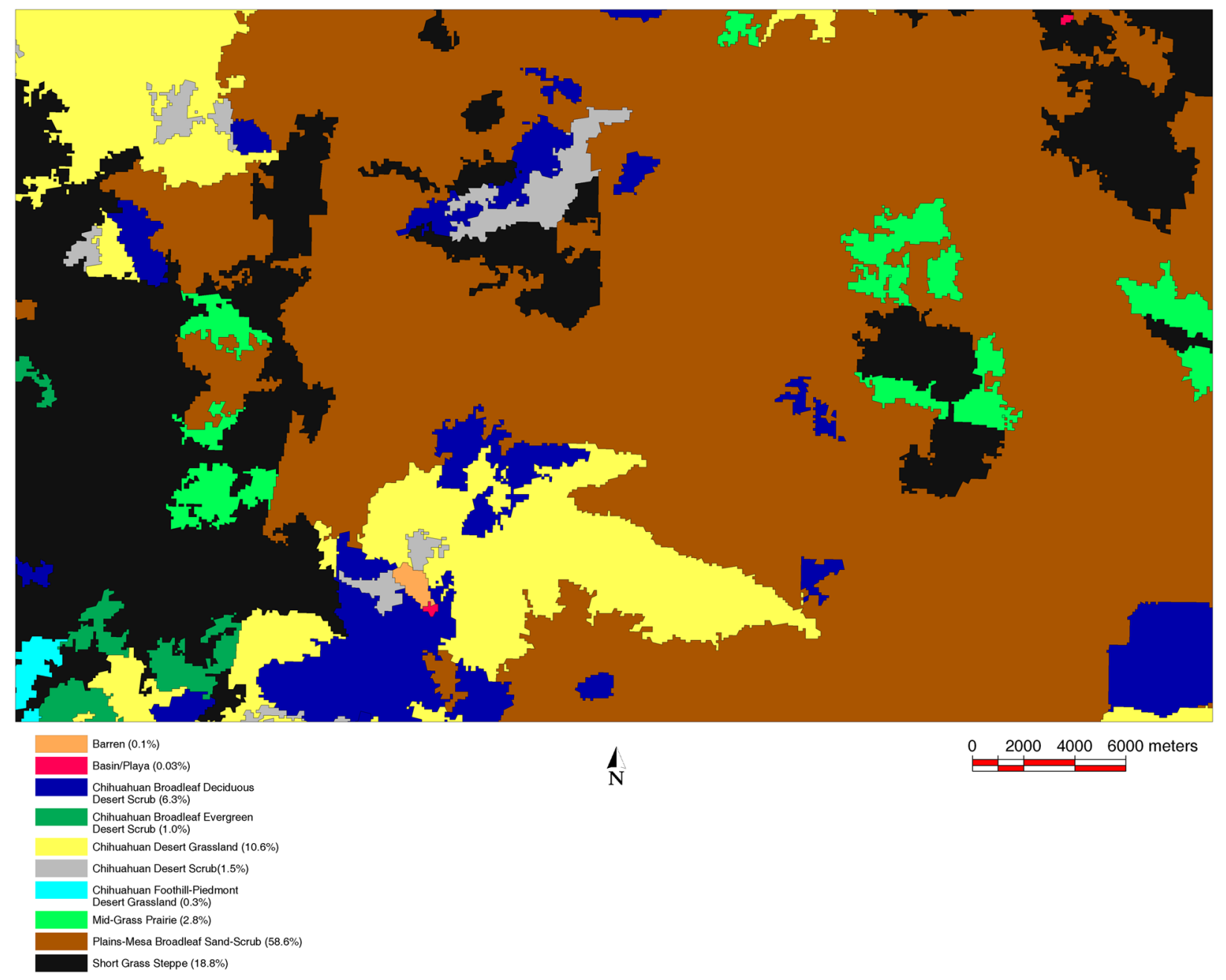

Figure 5.4. Vegetation in the Loco Hills study area

\section{Geomorphic Data}

The final category of environmental data used for the models was geomorphology data provided by Gnomon, Inc., based on maps prepared by Stephen Hall of Red Rock Geological Enterprises. The 500 square mile Loco Hills study area was mapped using black-and-white stereo aerial photographs (scale about 1:52,000) and color infrared stereo aerial photographs (scale about 1:86,000) available from the EROS Data Center, Sioux Falls, South Dakota. Landforms were identified from the stereo aerial photographs using a Topcon mirror binocular stereoscope at $3 \times$ magnification, and the location and spatial distribution of the landforms were then plotted on 7.5-minute topographic maps (scale $1: 24,000$ ), the base-map standard for this project. For reasons of practicality, landforms smaller than about 200 feet in greatest dimension (ca. 1/10 inch on topographic maps and smaller yet on the aerial photos) were not mapped.

The geomorphology of the Loco Hills study area (Figure 5.5) is characterized by Permian-Triassic shales and sandstone bedrock. Because of a rare combination of geologic circumstances operating actively over the past 100,000 years (and with precursors extending back millions of years), the Loco Hills area is today dominated by an eolian sand sheet. The central portion of the Mescalero Sands is comparatively thick and young (Holocene), whereas the edges of the sand sheet are thin and old (Pleistocene). The High Plains and Caprock escarpment occur in the northeast corner of the study area. The entire landscape slopes gently to the southwest.

Where the sand sheet is thick and covered by shin oak vegetation, recent erosion has produced small parabolic dunes. The blowout areas of the dunes are colonized by plants and become filled in with new sand. Thus, if sites are present and partially exposed by erosion, they become buried again, masked from surface surveys. In contrast, the margins of the sand sheet do not have shin oak vegetation. Here recent erosion has produced mesquite coppice dunes, 


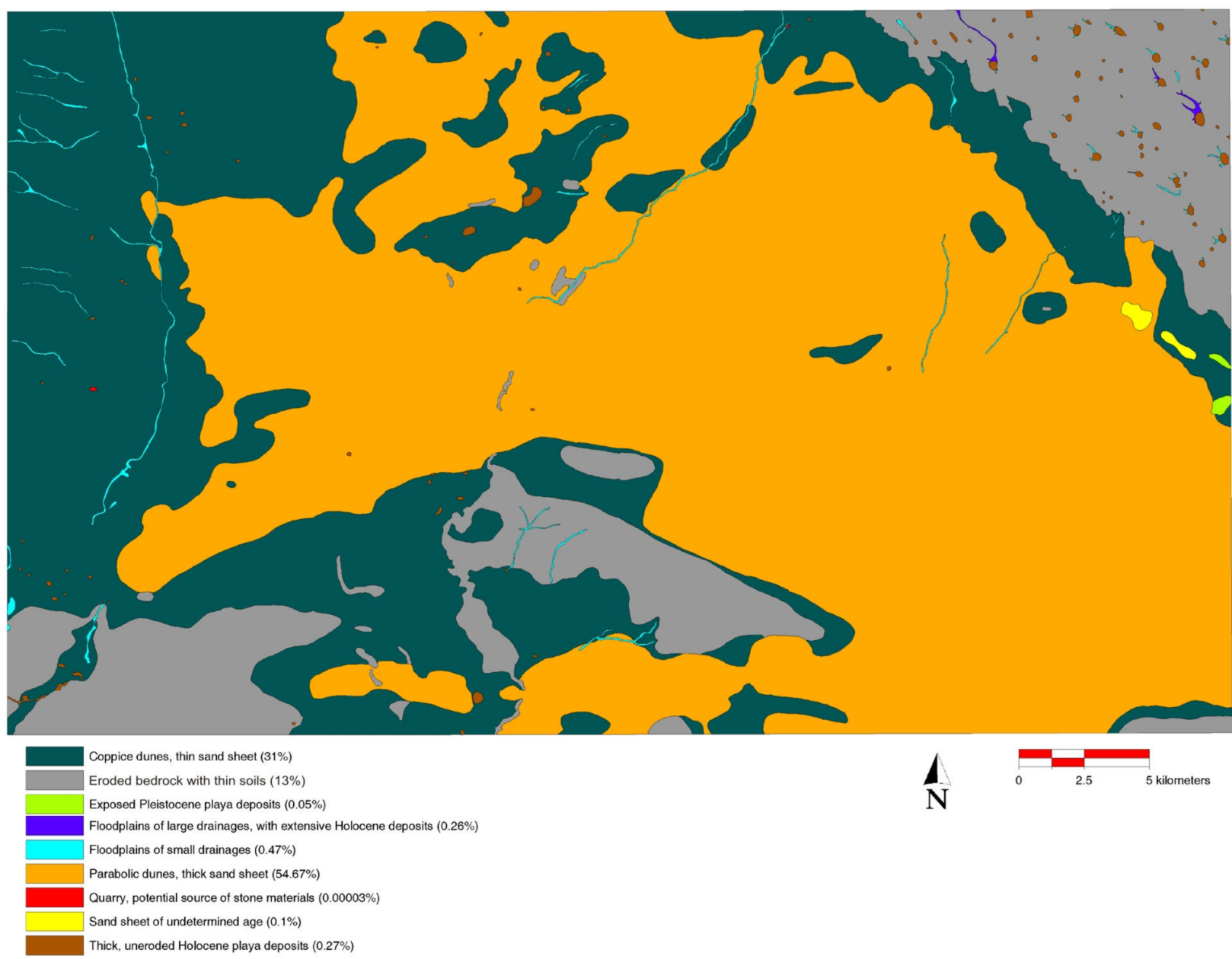

Figure 5.5. Geomorphology of the Loco Hills study area

sand hummocks that form around woody plants. Often coppice dunes are the result of desertification of former shrublands owing to land development or disturbance. The areas between the coppice dunes are severely deflated down to Pleistoceneage sand, exposing all sites that are present.

By mapping the distribution of the sand sheet and comparing it with the distribution of archaeological sites, we hoped to address both cultural and taphonomic questions: Did people choose to live on or off the sand sheet? Did they prefer the margins or the central portion? What has been the effect of recent geomorphology on the visibility of archaeological materials?

Eolian Sand. The sand sheet described above is the main geomorphic feature of the study area. The central portion of the sand sheet is comparatively thick ( 1 to $6+$ meters) and composed of sand that accumulated about 5,000 to 9,000 years ago (Hall 2002). The thicker sand is characterized by low, shrubby shin oak (Quercus havardii) vegetation and has been recently deflated, forming small parabolic dunes oriented east and east-northeast.

At the margins of the sand sheet, the eolian sand cover is comparatively thin, generally less than 1 meter in thickness. The thin sand is an eroded, older, red sand that has been dated to 70,000 to 90,000 years BP by optically stimulated luminescence. As noted above, erosion in the twentieth century has formed numerous coppice dunes around the Torrey mesquite (Prosopis glandulosa torreyana). Archaeological sites in this setting are both highly visible and disturbed by erosion, although intact cultural features may intrude into the old red sand or may be preserved beneath some coppice dunes. 
Beneath the sand sheet is a moderately well developed calcic paleosol (Mescalero paleosol) that formed on bedrock and that predates the sand sheet.

A weak A horizon soil (known as the Loco Hills soil) occurs throughout the study area. Radiocarbon ages for the soil range from 150 to 380 radiocarbon years BP. The soil likely formed in association with desert grassland vegetation during a slightly less arid period than today. The Loco Hills soil is the surface that was disturbed by deflation, resulting in parabolic and coppice dunes in the past century. The soil occurs on surfaces of all ages and may mantle sediments containing archaeological sites.

Alluvium. Stream deposits in the project area are largely hidden by recently deposited eolian sand. At various times in the past, around $\mathrm{AD} 1000$, for example, surface water may have been more abundant. Although difficult to assess, all alluvial deposits and small streams were mapped with the possibility in mind that surface water was more abundant in other times.

A few deposits of terrace gravels that contain rounded caliche clasts from the nearby Ogallala Formation were mapped. It has been noted in the field that many fire-cracked rocks are actually Ogallala caliche and not caliche from the local Mescalero paleosol that underlies the sand sheet.

Playas and Small Ponds. Numerous playa lakes occur on the High Plains surface in the northeastern corner of the project area. The lakes probably originated in the Pleistocene; some have established drainages leading into them. The playas likely all contain Holocene sediments as well as deflated remnants of Pleistocene deposits. All of these playa lakes were mapped, as were the alluvial sediments in associated drainages. It seems reasonable to expect that the playas, especially the larger ones, were sources of permanent water during periods of wetter climate and higher water tables.

Throughout the Mescalero Sands are several small ponds that may be related to karst activity (in the eastern area) or the presence of depressions on the irregular surface of the sand sheet. The larger, less ephemeral ones were identified by color infrared photography and included on the geomorphology maps.

Given a slightly wetter climate and more surface water, these small playas and ponds would have been sources of water for game animals and prehistoric inhabitants.

Eroded Bedrock Surfaces. Where not mantled by Quaternary deposits, the bedrock terrain is denuded and archaeological sites have $100 \%$ visibility. These surface sites may also be severely bioturbated. Sites of all ages occur on the surface of the eroded bedrock.

In the Loco Hills study area, thick deposits of sand dunes that may cover and mask the presence of buried archaeological sites characterize much of the landscape. On the other hand, the remaining portion of the area is severely eroded and denuded, and archaeological sites are visible. The dichotomy of site visibility related to geology makes the Loco Hills area a good case study.

\section{Archaeological Data}

For the Loco Hills models, the dependent variable is the presence or absence of precontact archaeological sites. Archaeological data were obtained from the New Mexico Historic Preservation Division's Archaeological Records Management System (ARMS). ARMS provides data on areas that have been the subject of archaeological surveys, the sites that have been recorded, and various characteristics of those sites. Ideally, we would like to have created a series of predictive models by dividing the sites into classes based on time of occupation and/or function. Unfortunately, current knowledge about the archaeological sites recorded in the Loco Hills region is not sufficient to allow us to classify sites into temporal or functional classes.

The basic distinction in the ARMS database is between artifact scatters and artifact scatters with features. Only a small set of sites has descriptive data on items such as the types of features, diagnostic artifacts, and depth of cultural deposits; presumably the other sites either lack these types of artifacts and features or they are not visible on the surface. At the time of our analysis, the ARMS data were not linked to the GIS files, so retrieving descriptive information was extremely time consuming and prone to error. Consequently, any information on site characteristics reported below was obtained by sampling the database through visual inspection of the individual records.

Although very few sites have been dated, we were able to distinguish between post-European contact and precontact sites. Because these two temporal categories represent fundamentally different cultural systems, we excluded historical period sites from the predictive models. 


\section{THE LOCO HILLS STUDY AREA}

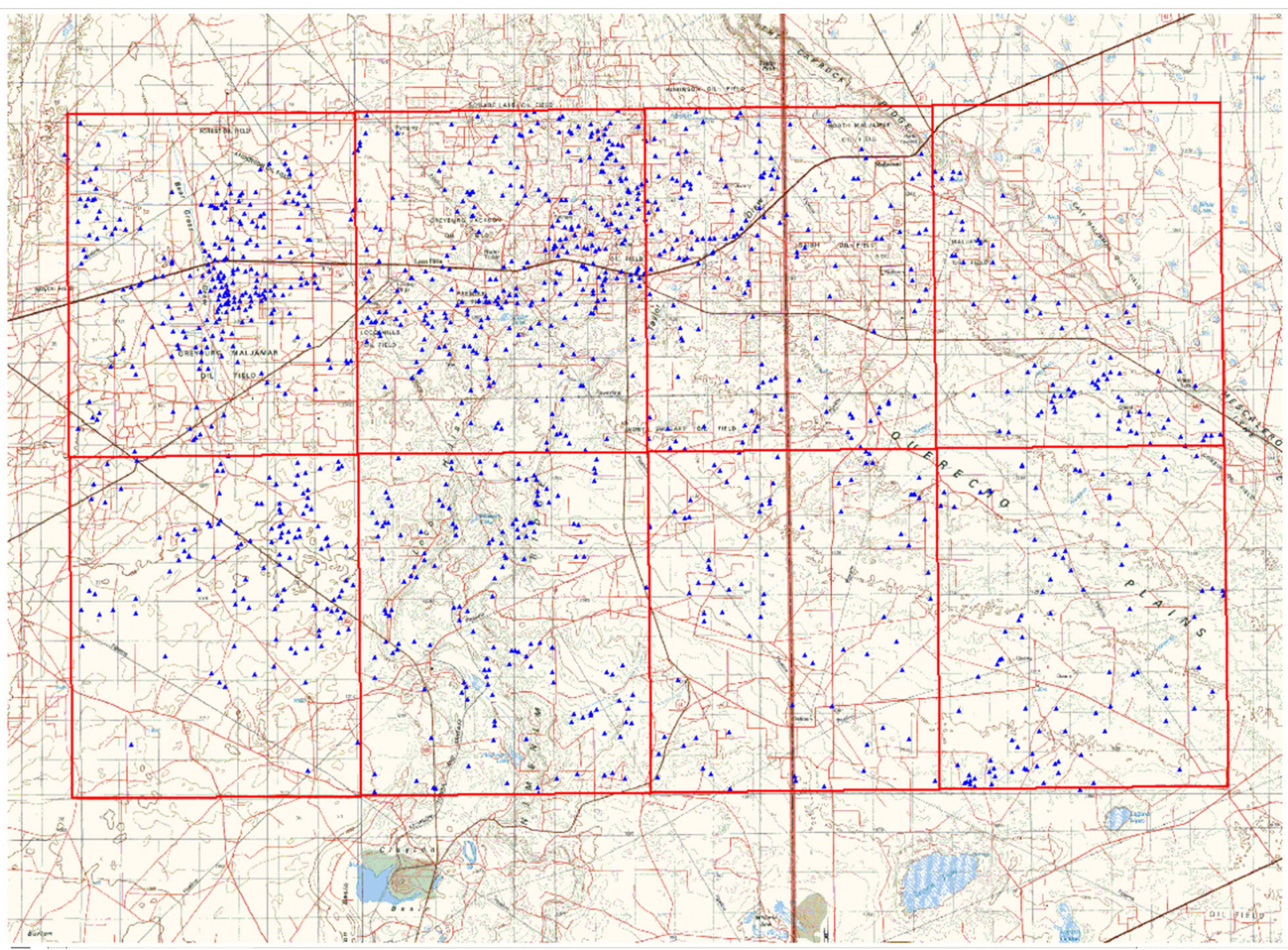

Figure 5.6. Distribution of known archaeological sites, Loco Hills study area

\section{Site Data}

The archaeological site data provided by ARMS are shown graphically in Figure 5.6. The data used in the models are in vector format, which is a geographic information system (GIS) convention that stores spatial data and databases with a corresponding point, line, or area feature. The site data were provided as polygon features, where every site is represented as an area within the GIS. Each site polygon is also linked to related information, such as area, site number, and a site description, within the vector database.

An important part of GIS data is its spatial orientation in real world coordinates. The ARMS data were already georeferenced in Universal Transverse Mercator (UTM), Zone 13 grid format, using the North American Datum of 1927 (NAD 27). The UTM georeference system is common for archaeological applications, and $x$ and $y$ coordinates are given in meters.

The site data originally contained 1,625 polygons. It was determined that this number could be reduced to 779 polygons by combining multiple recordings of the same site. These polygons from multiple recordings overlapped each other and could be fused into one without disrupting modeling goals. The original, unmodified site data layer was also used for some analyses.

\section{Survey Data}

The archaeological survey data provided by ARMS (Figure 5.7) are polygon features, in which every survey is represented as an area within the GIS. As with the site data, each survey polygon is linked to related information, such as area, identification number, and some basic methodological descriptions, within the vector database. The ARMS survey data were also georeferenced in Universal Transverse Mercator (UTM), Zone 13 grid format, using the NAD27 datum.

The survey data originally contained 5,196 polygons. For the purpose of modeling, overlapping surveys were merged to create fewer polygons. The Loco Hills boundary was then used to crop survey polygons to conform to the 


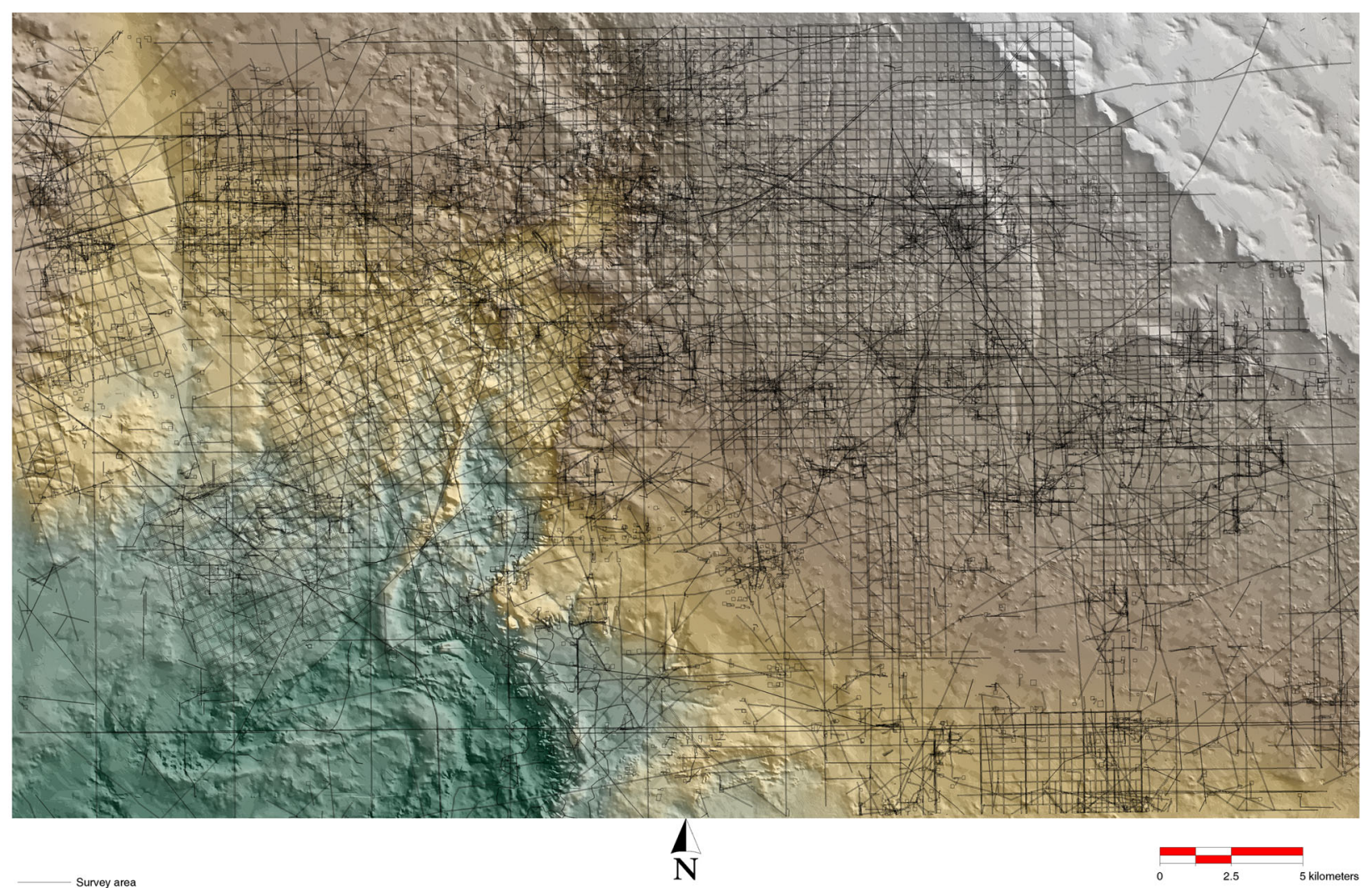

Figure 5.7. Surveys conducted in the Loco Hills study area as of 2002

rectangular study area. This process allowed us to convert the polygons into a raster format that was assigned unique values. The raster format was subsequently converted into a binary format. In binary format, every cell for all layers can be classed as surveyed (value is 1 ) or not surveyed (value is 0 ). The net result was 6,301 individual polygons comprising 5,099 individual survey episodes.

\section{Confidence and Statistical Independence}

Once the GIS layers had been assembled, each environmental theme was reviewed to determine whether the areas covered by archaeological surveys adequately represent the target environmental attributes. If coverage is adequate, we can have confidence that the association between the environmental variable and site location found in the surveyed areas mirrors their relationship in the larger study area. Although one could test for these relationships statistically, we have found that a simpler approach suffices. We begin by creating a histogram of the distribution of the individual values for a particular environmental variable for the entire study area. This histogram is then compared visually with a similar histogram for the areas covered by archaeological surveys. If the two histograms are similar in shape, then we can assume that the raster cells that fall in the surveyed areas can be taken as a representative sample for that particular environmental theme.

As an example of this process, the histogram for the slope of all cells in Loco Hills (Figure 5.8) is nearly identical to that for cells that have been covered by archaeological surveys (Figure 5.9), indicating that all slopes present in Loco Hills are adequately represented by the surveyed areas.

Visual comparisons for all of the histograms displaying environmental variables in the Loco Hills study area suggested that, with one exception, the surveyed cells adequately represent the values for each of the environmental variables. The exception occurs within the geomorphology theme. Eroded bedrock covers approximately $13 \%$ of Loco Hills, but only about $7 \%$ of the archaeologically surveyed areas fell within this geomorphic category. We decided, however, to include this variable in the predictive model. No sites have been found on the portions of the eroded bedrock that have been surveyed, and anecdotal evidence from archaeologists and geomorphologists indicates that, even if sites were to be found here, their integrity would be limited. Intact cultural deposits are very unlikely on this landform given the lack of soil development (see Hall 2002). Thus, even though the eroded bedrock has not been adequately surveyed, we believe 
that the relationship between this landform and archaeological site locations has been established and that the environmental variable can be a useful predictor of site locations (or in this case, of the absence of sites).

Beyond demonstrating that the environment of the surveyed areas adequately represents the general Loco Hills environment, we want to be sure that the environmental variables that will be used in the predictive models are statistically independent of each other. Statistical independence is an assumption of most statistical techniques that involve multiple variables. Violations of this assumption often lead to overstating the predictive power of the resulting model. For example, soils and vegetation are often very closely related; that is, certain vegetation only grows on particular soil types. By including both variables as predictors, one runs the risk of having the predictive value inflated.

To guard against including purportedly independent variables that are, in fact, related to each other, we calculated the pair-wise Spearman's $r$ scores for each pair of environmental variables (Table 5.1). No $r$ score exceeded 0.52, and all but two were below 0.4. Thus, no variable explains more than $25 \%$ of another $\left(r^{2}\right)$. Based on these results, the variables being used as predictors in the models can be taken as statistically independent. To reinforce this conclusion, we calculated the logistic regression model (see below) both with and without the two most interrelated variableselevation and cost distance to water. The logistic regression model calculated without these two variables was very close to the model calculated with all variables (comparing the two models, $r=0.78$ ). Accordingly, we only present the full model below.

A second concern of many geographic models is spatial autocorrelation. If knowing the value of one cell helps us guess the value of nearby cells, then the distribution of that variable is said to exhibit spatial autocorrelation. This property violates the assumption that variable scores are distributed randomly over the project area. But, of course, most of the variables used in the Loco Hills model are not randomly distributed. For example, the terrain in the Loco Hills areas gradually rises as one moves away from the Pecos Valley. Thus, knowing the slope of one cell allows one to guess within reason the slope of its neighbors.

To overcome spatial autocorrelation, we used a feature of IDRISI that places a "filter" over the Loco Hills grid. The program selects a $10 \%$ random sample of cells. The filter was applied to all environmental variables during the logistic regression; all cells for the dependent variable, site location, were included in the model calculations, however. With the filter in place, the regression equation was then applied to all cells in the study unit. No filter was used in the creation of the weighted models (see discussion of modeling techniques below).

\section{Sensitivity Maps}

There are many different types of predictive models (see discussion in Chapter 4), ranging from subjective statements about where archaeologists have found sites in a region to highly sophisticated multivariate statistical models. For Loco Hills, we used two modeling techniques: a weighted method and logistic regression. These two approaches capture both the predictive power of multivariate statistical techniques and the intuitive understanding that comes with intersection models, which examine simple correlations between dependent and independent variables.

\section{Weighted Model}

The Loco Hills weighted model can be considered a type of intersection model. Each environmental variable was divided into discrete states that were then weighted based on their correlation with known archaeological sites. For instance, the geomorphology theme was divided into nine classes as defined in Table 5.2. Based on the percentage of the study area that falls into each of the geomorphic categories, we calculated the expected percentage of the site cells that should fall within each of the nine categories if sites were randomly distributed. That is, if geomorphic class X constitutes $10 \%$ of the study area and sites are randomly distributed relative to geomorphology, then $10 \%$ of the cells that contain sites should be found in the area covered by geomorphic class X. The observed percentage of cells containing sites within each geomorphic class was then determined. If the percentage of sites observed for a geomorphic class is less than the percentage expected, then that class receives a negative value, and if the percentage is greater, the class is assigned a positive value. The greater the deviation in either direction, the higher the weight. Weights range from -3 to +3 .

Using the data presented in Table 5.2 on geomorphology as an example, we see that coppice dunes cover $31 \%$ of the study area, but $54 \%$ of cells with sites are located in these landforms. Coppice dunes, therefore, are strongly associated with archaeological sites and are weighted a score of 3 . In contrast, eroded bedrock covers $13 \%$ of the project area, but only slightly more than $1 \%$ of eroded bedrock cells contain sites. We must remember that eroded bedrock areas are underrepresented in archaeological surveys. Thus, the strong negative association between sites and eroded bedrock could be a function of insufficient archaeological investigation. We believe, nevertheless, that this negative association will hold up upon further survey, and accordingly we weighted the eroded bedrock class -3 .

We performed a similar analysis for the remaining seven environmental themes: aspect, slope, elevation, vegetation, 


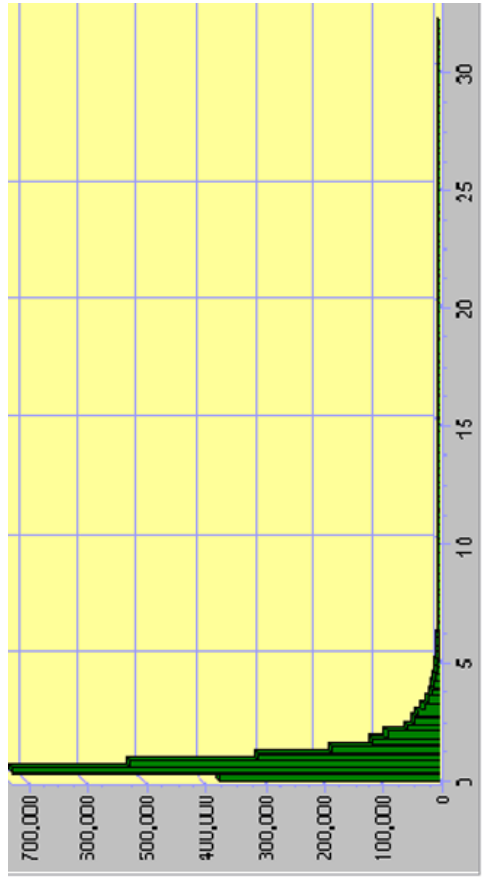

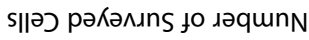

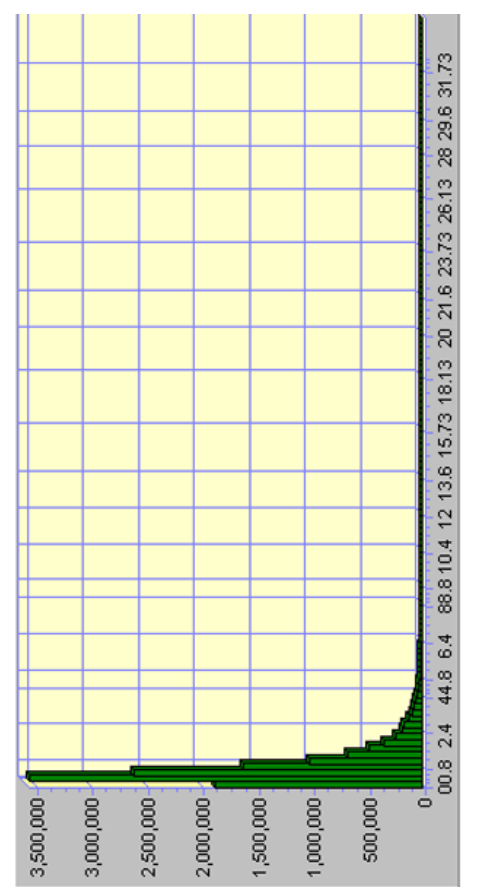

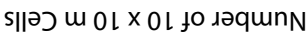

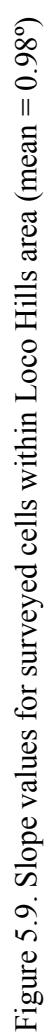

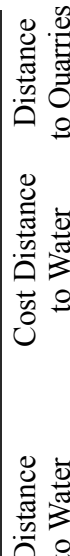

-

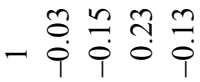

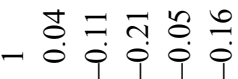

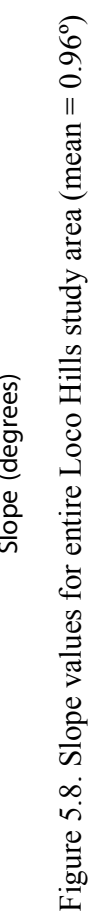

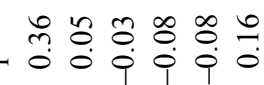

卷

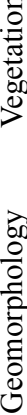

के

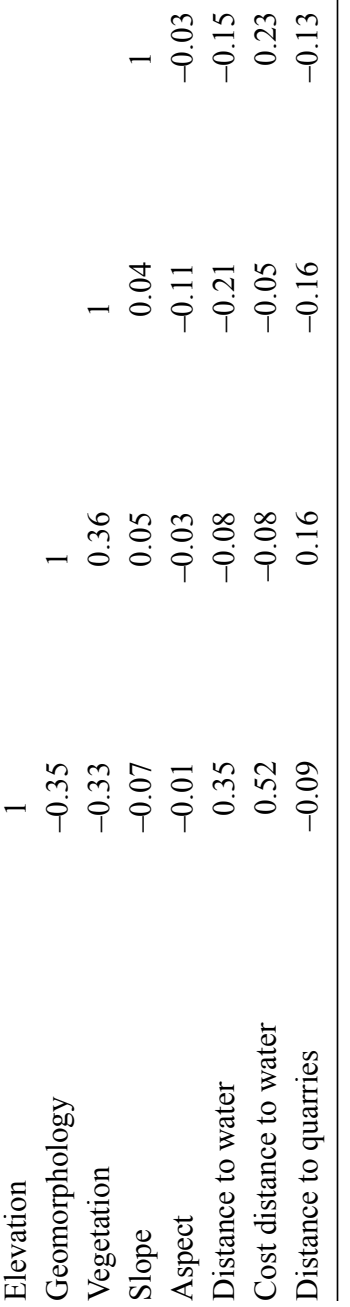


Table 5.2. Weighting of Variable Classes for Weighted Sensitivity Model

\begin{tabular}{clccc}
\hline Class & Description & $\begin{array}{c}\text { Expected \% of all cells } \\
\text { with sites that would } \\
\text { be found in this class }\end{array}$ & $\begin{array}{c}\text { Observed \% of cells } \\
\text { with sites that actually } \\
\text { fall in this class }\end{array}$ & Weight \\
\hline 1 & Coppice dunes, thin sand sheet & 31.0 & 54.0 & 3 \\
2 & Eroded bedrock surface, thin soils & 13.4 & 1.2 & -3 \\
3 & Exposed Pleistocene playa deposits & 0.05 & 0 & 0 \\
4 & Floodplains of large drainages, Holocene deposits & 0.26 & 0.21 & -1 \\
5 & Floodplains of small drainages & 0.47 & 44.31 & -1 \\
6 & Parabolic dunes, thick sand sheet & 54.67 & 0 & 0 \\
7 & Quarry, potential source of stone materials & 0.00003 & 0.08 & 0 \\
8 & Sand sheet of undetermined age & 0.1 & 0.15 & -1 \\
9 & Thick, uneroded Holocene playa deposits & 0.27 & & 0 \\
\hline
\end{tabular}

cost distance to water, distance to water, and distance to quarries. With the exception of cost distance to water, all themes had variable states that proved to be positively or negatively associated with archaeological site locations. Because cost distance to water did not exhibit any relationship, it was eliminated from the model.

The weighted scores for each cell were then summed for the seven environmental themes. Theoretically, scores can range from -21 to 21 . In practice, scores ranged from -12 to 21 . To eliminate the problems of dealing with negative scores, we added twelve points to each score so that the range of weights varied between 0 and 33. To make the results comparable with those of the logistic regression model, the possible weights were grouped to yield four sensitivity zones (Figure 5.10). Class 4 comprises those cells scoring 21-33 (excellent chance of containing a site); Class 3 contains those cells scoring between 18-21 (good chance); Class 2 contains cells scoring between 15-18 (average chance); and the cells in Class 1 had scores ranging between 0 and 15 (poor chance). Class 3 contains $45 \%$ of the cells with sites in $32 \%$ of the project area. Classes 2 through 4 combined contain $76 \%$ of cells with sites in $41 \%$ of the project area.

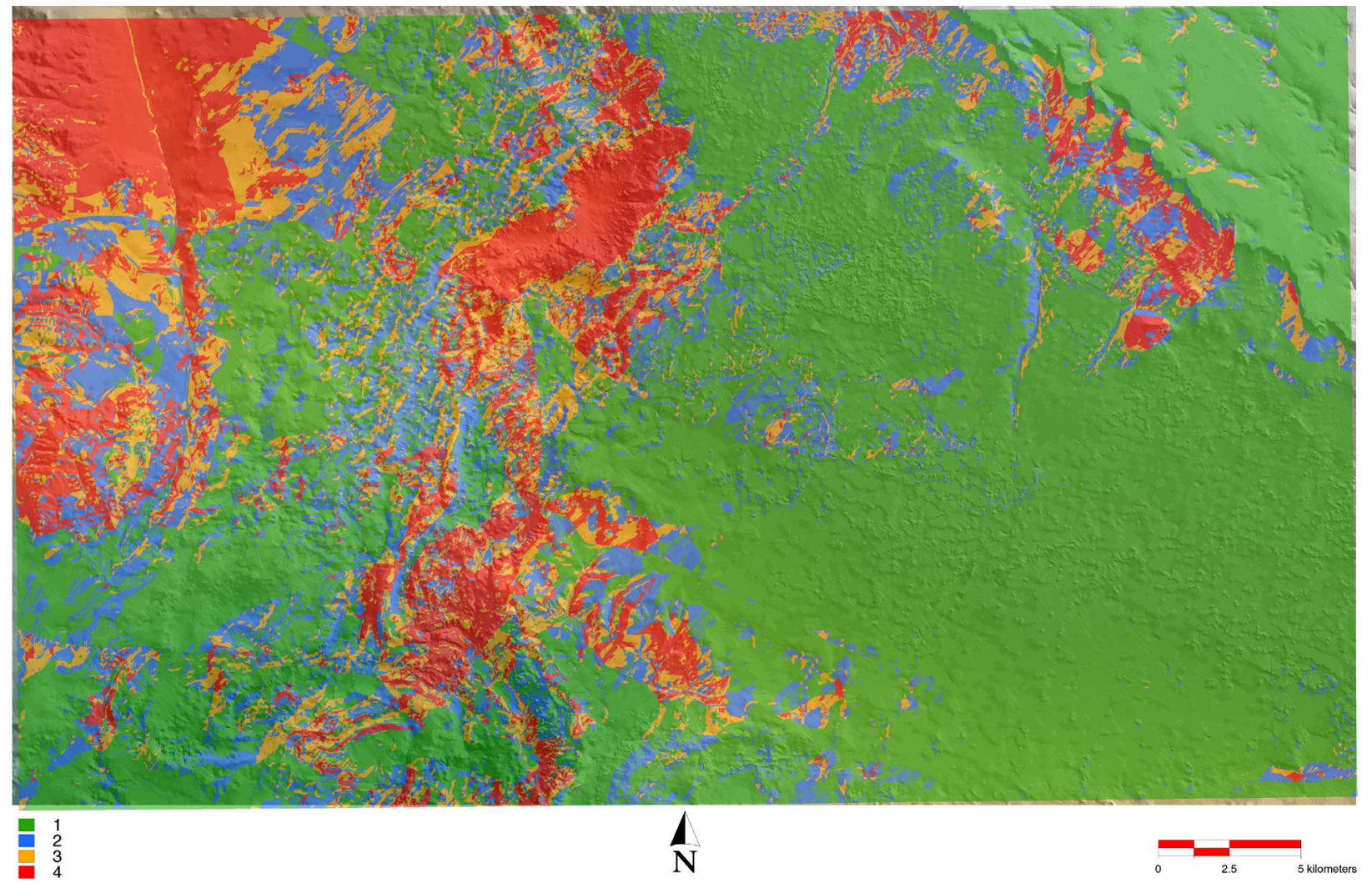

Figure 5.10. Weighted sensitivity model with 4 classes.

Portions of DEM not covered by the model are outside the boundaries of the study area. 
As the above discussion illustrates, the assignment of weights and sensitivity classes is somewhat subjective. One of the advantages of this method is that the scores are easily manipulated so the model can be re-created, and the results of those manipulations can be observed. It is important to note, however, that there is no "best" or "final" solution. In our original attempts to create a weighted model for Loco Hills we only used positive weights. We started by determining which classes have the highest proportion of cells with sites. Next, we combined the classes with the highest proportion of site cells into one class that contained minimally $65 \%$ of all cells with sites. This class was assigned a weight of 3 . Of the remaining classes, we then combined those with the highest site density to account for the next $20 \%$ of site cells; this class was given a weight of 2 . Finally, all remaining classes were combined and given a weight of 1 . The resulting model worked "poorly" as judged in relation to the logistic regression model. The Spearman's $r$ between the two models was less than 0.60. In contrast, when we changed the weighted model to include both positive and negative weights, based on relative percentages, the Spearman's $r$ between the logistic regression and weighted models increased to 0.74 .

\section{Logistic Regression Model}

As discussed in more detail in Chapter 4, regression models evaluate the covariation among the independent variables (in our case, environmental variables) and dependent variables (the location of archaeological sites). Only those environmental variables that independently explain sufficient variability in site location are used in the regression analysis. The result of the regression analysis is one or more equations that are used to calculate the probability that a cell within the study area will contain an archaeological site, and the result of the probability calculations is a probability map.

For Loco Hills, we used the IDRISI module LOGISTICREG to calculate the logistic regression. The resulting equation is:

$$
\begin{aligned}
\operatorname{Logit}(\text { site })= & 1.4146+0.545241 \text { (coppice dune })+0.003666 \text { (cost distance to water) }-0.000043 \text { (distance to } \\
& \text { quarries) }-0.000169 \text { (distance to water })-0.005068 \text { (elevation) }-2.489208 \text { (eroded bedrock) } \\
& -0.003594 \text { (north-south aspect) }-0.217984 \text { (slope })-1.075599 \text { (grass cover) }-0.317156 \text { (scrub) } \\
& +0.000689 \text { (east-west aspect) }
\end{aligned}
$$

In an ordinary least squares regression equation or a linear probability model, the slope coefficients are directly interpretable. The direction and size of the slope coefficient can be interpreted as the strength and nature (positive or negative) of the relationship between the independent and dependent variables. This is not the case in logistic regression. Instead of the slope coefficients being the rate of change in the dependent variable as the independent variable changes, in a logistic regression the slope coefficient is interpreted as the rate of change in the "log odds" as the independent variable changes. The magnitude of the slope coefficients, then, is not a direct reflection of the predictive strength of the independent variable. Although it is mathematically possible to compute the marginal effects of the values of the independent variables, such an option is not available with IDRISI, and this was not done for the Loco Hills model. Instead, we used the results of the weighted model to provide insight (see discussion below) into the relative importance of the environmental variables as predictors of site location.

The first step in assessing a logistical regression model is to evaluate its overall performance. Most linear regression models can be assessed with an $\mathrm{R}^{2}$ statistic, which is the proportion of the variance in the dependent variable explained by the variance in the independent variables. Unfortunately, there is no equivalent measure in logistic regression. There

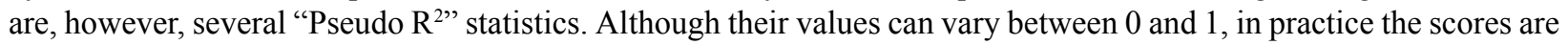
relatively low. A good regression model should have a Pseudo $\mathrm{R}^{2}$ greater than 0.2 . The Loco Hills model scored 0.1006, indicating a relatively weak fit. IDRISI also calculates a goodness-of-fit statistic, which measures the difference between the observed and predicted values of the dependent variable; the lower the score, the better the fit. The Loco Hills score of $1,621,930.25$ suggests a poor fit.

Both the Pseudo $\mathrm{R}^{2}$ and the goodness-of-fit scores of the Loco Hills model may be affected by the mismatch between the number of cells that contain sites $(8,500)$ and those representing the environment $(1,330,429)$. Another potential explanation relates to the substantial differences in site size. Sites in the highest sensitivity zone average $21,147 \mathrm{~m}^{2}($ minimum $=0.003$, maximum $=2,893,597$, s.d. $=143,316$ ), whereas those in the lowest sensitivity zone are, on average, $5,029 \mathrm{~m}^{2}$ (minimum $=26$, maximum $=48,900$, s.d. $\left.=12,523\right)$. Because each raster cell is treated the same by the model, large sites are given more weight than smaller ones. It is possible, then, that the logistic regression model is skewed by the inclusion of a few very large sites.

To test this notion, we ran the model again using only one cell to represent each site. A cell near the middle of the site was selected, and the resulting equation was termed the "centroid" model. To our surprise, the result of the centroid model was very close to that of the full model (Spearman's $r$ score of 0.74 ). Site size, therefore, is not a major factor in determining the shape or nature of the surface probability map. 
Although the Pseudo $\mathrm{R}^{2}$ and goodness-of-fit scores suggest a relatively weak model, the centroid model comparison indicates that the logistic regression is accurately reflecting the underlying relationship between the environment and human settlement. This inference also can be tested by a statistic termed the Relative Operating Characteristic (ROC). The ROC compares a Boolean map of "reality" to a suitability map. This measure varies between 0 and 1 , with 1 indicating a perfect fit and 0.5 a random fit. For the Loco Hills logistic regression model the ROC was 0.7953 . The relatively high ROC score combined with the comparison of the centroid and full model suggests that the environmental variables used as predictors are strongly associated with archaeological site location.

Once we were satisfied that the logistic regression result was an accurate reflection of the relationship between site locations and environmental variables, we needed to display the calculated probabilities. For each cell, the logistic regression calculates a probability score between 0 (site less likely) and 1 (site more likely). To display the results, we need to simplify the infinite number of possible probability scores into a more manageable number of "sensitivity" classes. We defined four classes:
$1 \quad(0.00-0.09$ : poor chance of site presence);
$2 \quad(0.10-0.39$ : average chance of site presence);
$3 \quad(0.40-0.59$ : good chance of site presence); and
$4 \quad(0.60-1.00$ : excellent chance of site presence)

Classes 3 and 4 together contain $95 \%$ of the site cells and cover $71 \%$ of the study area. Class 4 alone contains $58 \%$ of the site cells and constitutes only $21 \%$ of the project area. A probability surface map of these scores is displayed in Figure 5.11. Probability scores could not be calculated for the thin band of cells at the top of the figure; they are shown in gray.

\section{Comparison of the Sensitivity Models}

Visually, the main difference between the weighted model and the logistic regression model is that the former contains fewer high sensitivity cells and many more very low sensitivity ones. To a large extent, this is a result of the manner in which the independent variables are treated in the analysis. The logistic regression model maximizes the statistical association with the dependent variable of all the independent variables as a group. Some variables are weighted more

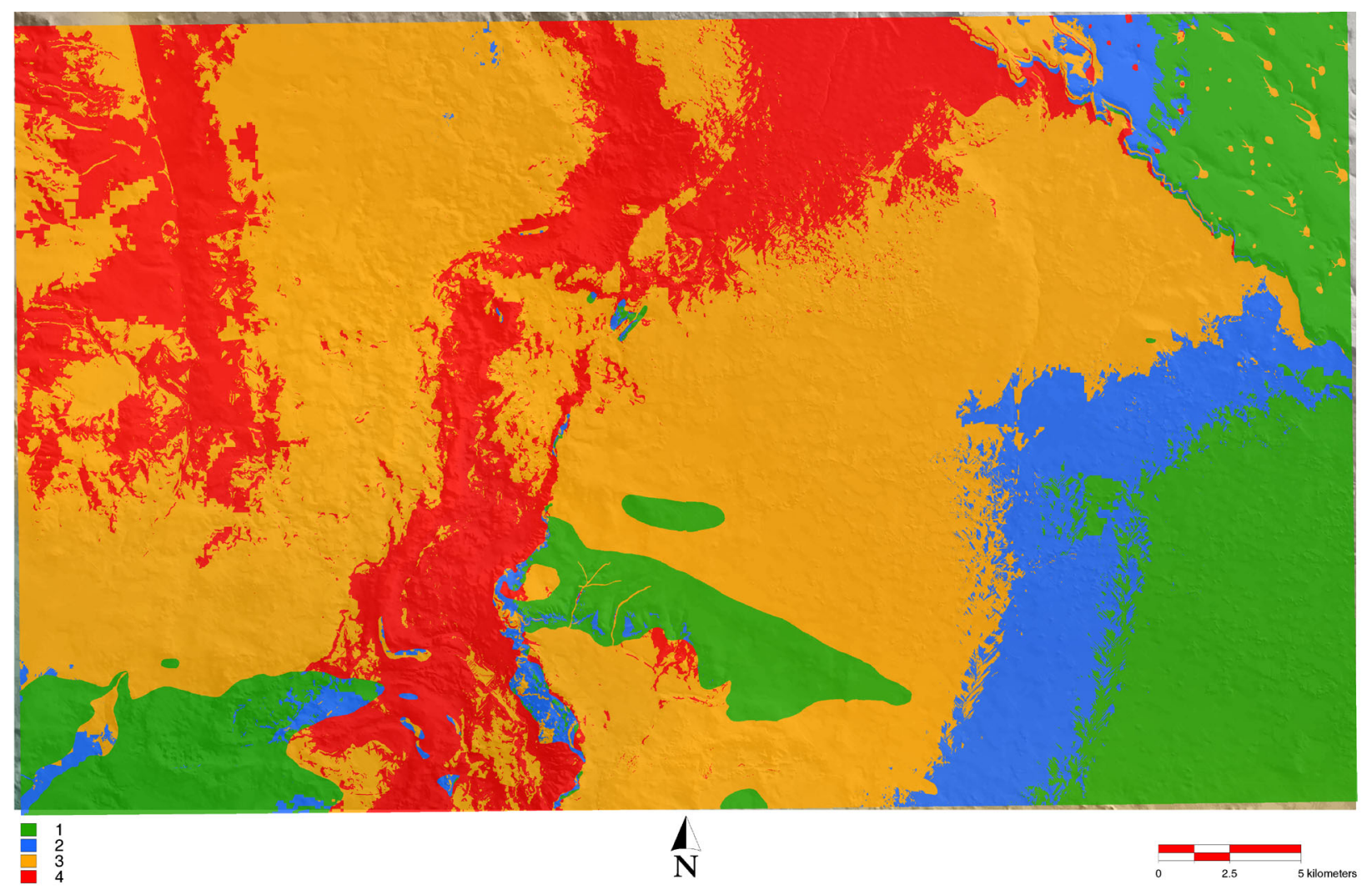

Figure 5.11. Logistic regression model with 4 classes (1-4). 
than others, not because they are more important in human decisions about settlement but because they account for more of the variation in site location. Because less of the variation in site location remained to be explained by the other proxy variables, those variables are much less important to the regression equation.

In contrast, all environmental variables have the same importance in the weighted model. This feature makes weighted models relatively easy to interpret. For example, parabolic dunes were assigned a weight of -2 (see Table 5.2) because few archaeological sites are visible on their surface. Because this landform covers such a large area of Loco Hills, this weighting has the effect of helping place a substantial part of the project area into the lowest sensitivity class (Class 1) (Figure 5.12). The logistic regression model, however, weights variables in relation to their association with the dependent variable. Parabolic dunes cover a far smaller percentage of the lowest sensitivity class in the logistic regression model (Figure 5.13) than they do in the weighted model (Figure 5.12) because logistic regression allows only the explanatory portions of environmental variables that are independent of explanatory portions of other environmental variables into the equation. Logistic regression is a much more efficient and more powerful statistic. However, because the statistical interactions between independent variables are complex, it is exceedingly difficult to isolate the association of a particular variable with site location.

The question immediately arises as to which is the better model. Ideally, we could test the models by performing a blind survey in which survey crews would be randomly assigned to high and low probability areas. Survey results could then be used to compare predicted and observed performance for each model. More important than determining which model works best is an effort to obtain a better understanding of site distribution. The common tendency for managers is to discard the model with the worst fit. Much could be learned, however, by understanding why the various models do not work and then refining them. For example, if we find that the weighted model works poorly, we might change the weights of the various variables manually to maximize its predictive power. This would be an excellent means of intuitively grasping the importance of particular variables. Such an exercise helps us begin to understand the archaeological landscape.

Instead of focusing on which model works better, it seems more profitable to discuss how and when the models can best be used for management purposes. The logistic regression model for Loco Hills is more powerful, and statistically it is a better predictor. If the proposed boundaries of a lease area are known, for example, then the best method for predicting whether a site will be found would be to place the lease area boundaries on the surface probability map from the regression model. The weighted model, in contrast, is best used as an analytical tool to guide future research whose ultimate goal is to allow managers to make better-informed decisions. The weighted model, as currently constructed, depends heavily on geomorphology. The distribution of coppice dunes mimics the highest sensitivity zones, whereas that of parabolic dunes mirrors the lowest sensitivity zones. This distribution raises the possibility that the models are not so much reflecting past human behavior as they are modeling depositional environments. Is it possible that archaeological sites are distributed much more evenly over these landforms, but are hidden beneath the parabolic dunes? This is a question that must be addressed if we are to manage cultural resources effectively in the Loco Hills.

\section{Interpreting the Results}

Predictive models can effectively identify patterns or trends in settlement. Some trends are easy to spot and intuitive to grasp. In Loco Hills, bigger, more complex sites are found along watercourses in the coppice dunes (Table 5.3). These settings, which would have supported economically important grasses and attracted small mammals, would have been ideal campgrounds for hunter-gatherers. Not surprisingly, sites in the high sensitivity class are larger, have more features, more formal flaked tools, more milling implements, and deeper cultural deposits. Sites in the lowest sensitivity zone are smaller and less complicated than their counterparts in the more sensitive zones, but these tendencies are ones of degree. Sites in the lowest sensitivity class contain the same types of artifacts and features, just in smaller numbers and densities than comparable sites in the other classes.

There are two plausible explanations for the observed differences in the nature of sites found in the lowest and highest sensitivity zones. First, the differences may reflect variability in human adaptation to the Loco Hills area. Sebastian and Larralde (1989) review the adaptive models that have been created for southeast New Mexico and note that for the Archaic period most archaeologists argue that humans placed themselves on the landscape in relation to the seasonal availability of particular resources. This system, termed serial foraging (Elyea and Hogan 1983), is based on residential as opposed to logistical mobility. Sebastian (1989a:55-56) describes the serial foraging settlement pattern as follows:

A strategy of serial foraging involves a small residential group that moves into the general vicinity of an abundant resource and camps there, uses the target resource and other hunted and gathered resources encountered in the general area until the target resource is gone, or until another desired resource is known to be available, and then 


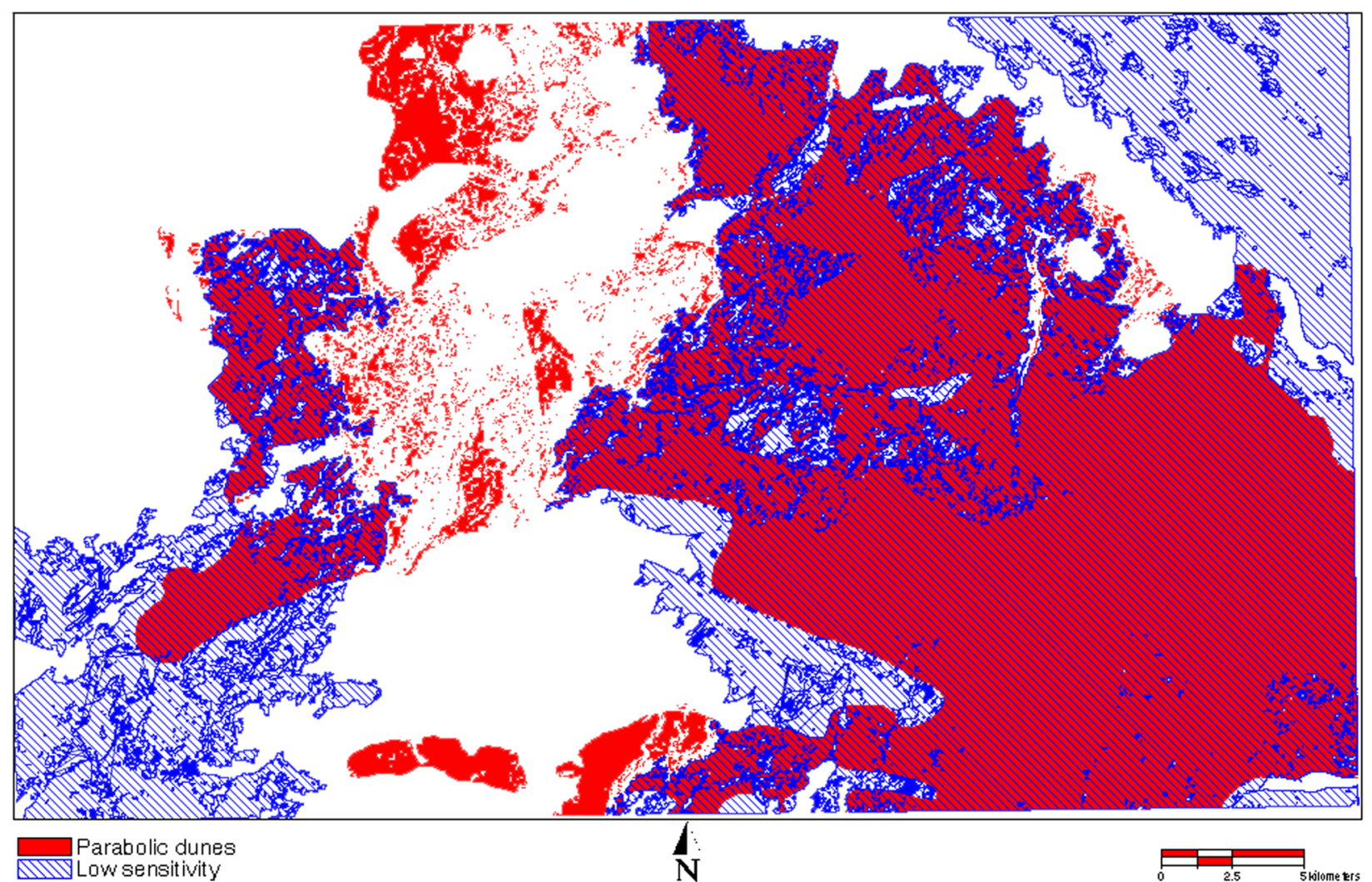

Figure 5.12. Weighted sensitivity model. Parabolic dunes cover $73 \%$ of the low sensitivity area

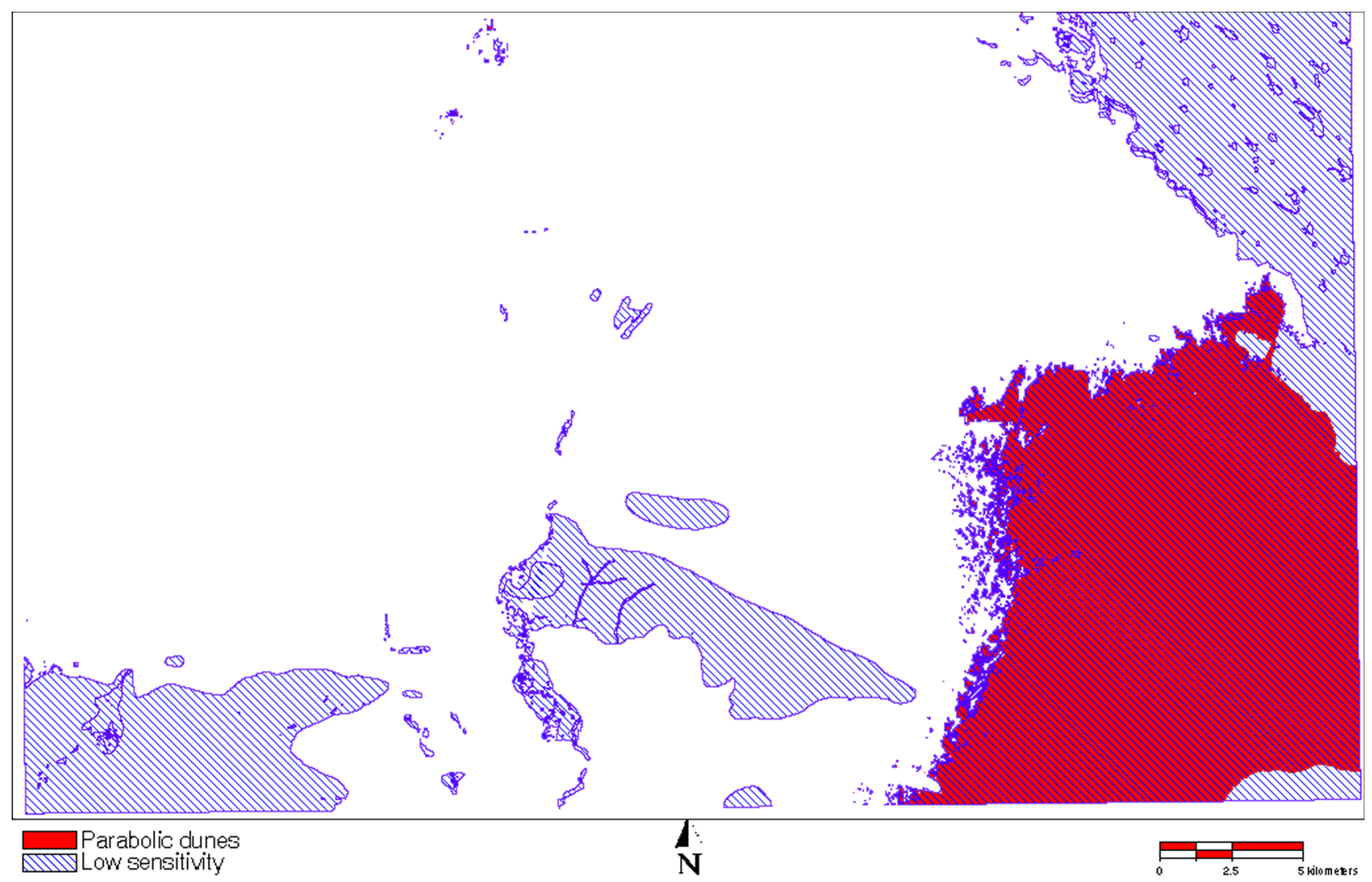

Figure 5.13. Logistic regression model. Parabolic dunes cover 53\% of the low sensitivity area. 
moves on to the next scheduled procurement area. Such a strategy could be expected to create a great deal of redundancy in the archaeological record — an endless series of small, residential camps from which daily huntingand-gathering parties move out over the surrounding landscape, returning to process and consume the acquired foods each evening. If the resources were randomly distributed, all the sites would look generally the same. But since many resources appear in the same place year after year or in some other cyclical pattern, some sites tend to be reoccupied.

Under a serial foraging model, all sites in the Loco Hills region would reflect small, mobile groups performing similar activities. Differences in site size, artifact density, and feature occurrence would not be the result of differences in the nature of group composition or site function but instead would reflect the distribution and availability of particular plant and animal resources and the resultant duration of occupation and likelihood of reoccupation. The probability surface map, under this scenario, could be viewed as a prehistoric resource use map.

During the subsequent Ceramic period, settlement may have become more complex (Sebastian 1989b:82-83). Groups practicing agriculture or focusing on intensive use of succulents or acorns may have established seasonally permanent sites, although they probably never achieved year-round permanence. These base camps would have housed larger groups who were practicing a wide range of domestic and economic activities. To guard against crop failure, these groups would have foraged far afield, gathering plants and hunting animals in the surrounding region, including Loco Hills, and creating small sites consisting primarily of artifact scatters. Alternatively, hunters-and-gatherers and agriculturalists or groups specializing in other resources may have coexisted in the same area, developing a mutually cooperative adaptive system. In either case, larger, more permanent sites would have been established near agriculturally viable areas or resources suitable for intensification, with small, impermanent camps located at or near targeted wild resources.

The archaeological record of these and other possible settlement systems would be different, although these differences would be slight and subtle. The differences hinge on the nature of the larger sites near the watercourses. Are these sites simply overlapping and repeatedly occupied locales or the remains of more structured base camps? Detailed surface mapping and analyses of distribution patterns of the artifacts and features could inform on these issues, although definitive answers would require data obtained via controlled excavation.

As for the relatively small sites found in the low sensitivity zones, superficially all appear to represent the same cultural behavior: small groups establishing a camp for a day or two near a particular resource, exhausting that resource, and then moving on. If this interpretation is correct, these sites have limited research potential and would not be considered eligible for listing in the National Register of Historic Places under criterion d on an individual basis. Even if they are eligible as a class, it is likely that data recovery will be needed at only a few before their research potential is exhausted.

Table 5.3. Prehistoric Site Data for a Sample from High and Low Model Sensitivity Drawn from the Reclassified Logistic Regression Model

\begin{tabular}{lcc}
\hline & Low Sensitivity & High Sensitivity \\
\hline Number of prehistoric sites & 36 & 101 \\
Average site size & $19,038 \mathrm{~m}^{2}$ & $173,107 \mathrm{~m}^{2}$ \\
Stratigraphy & Unknown & Subsurface deposits present \\
$\%$ with ceramics & 39 & 53 \\
$\%$ with ground stone tools & 69 & 86 \\
$\%$ with projectile points & 8 & 15 \\
$\%$ with hearths & 33 & 43 \\
$\%$ with fire-cracked rock concentrations & 11 & 20 \\
$\%$ with lithic quarries & 6 & 0 \\
$\%$ with middens & 0 & 2 \\
$\%$ in coppice dunes & 16 & 86 \\
$\%$ in parabolic dunes & 78 & 13 \\
Average distance to water & $1986 \mathrm{~m}$ & $538 \mathrm{~m}$ \\
$\%$ on north-facing slopes & 2 & 20 \\
$\%$ on south-facing slopes & 67 & 18 \\
$\%$ on east-facing slopes & 19 & 10 \\
$\%$ on west-facing slopes & 10 & 50 \\
\hline
\end{tabular}


Approximately a third of the sites in the low sensitivity zones, however, contain features, and more than two-thirds have groundstone tools, suggesting that at least some of these sites may have functioned as more than overnight procurement and processing camps. Are some of the sites in the low sensitivity classes remnants of repeatedly occupied locations? Could some be logistical base camps? If so, what resource or resources were so attractive that people returned to what was otherwise perceived as an inhospitable region? Is it possible that the model is failing to detect the environmental signature of a key part of the adaptive strategy?

These questions bring up the second possible explanation to account for sites occurring in low sensitivity zones: some of these areas were attractive to prehistoric humans, but postdepositional processes have erased all archaeological surface indications. Archaeological sites in Loco Hills are strongly associated with coppice dunes and rare in the parabolic dunes. Both landforms are recent geomorphic features, resulting from twentieth-century land use. The underlying parent sand sheets of the two types of dunes are different, and it is reasonable to infer that the vegetative communities established on these underlying sands would have differed as well. Thus, it is possible that the dunes serve as proxy indicators for the locations of resources targeted or ignored by prehistoric populations.

It is not clear, however, that the prehistoric inhabitants of Loco Hills would have favored one vegetative community over the other. Both of the earlier sand sheets would have supported plants and animals of the desert scrub grasslands, and many of these resources would have been sought after by prehistoric inhabitants. Although the relative biological productivity of the two underlying landforms is debatable, there is no question that surface visibility in the coppice dunes is far greater than within the parabolic dune fields. Coppice dunes are less stable than parabolic dunes, and thus the former have more blowouts where archaeological materials can be found eroding out of or lying on the exposed underlying sand sheet. Thus, if the same number of archaeological sites occurred on the sand sheets beneath the two recent landforms, we would expect to find more archaeological sites exposed on the surface within coppice dunes than in parabolic dunes.

This raises a third point about the meaning and significance of sites in low probability areas, particularly the parabolic dunes. If sites are, in fact, more rare in the parabolic dunes, and if they are more protected from erosion and thus have greater integrity, both factors would make them more likely to yield important information about the past. Low sensitivity zones should not be read to mean "not eligible to the National Register." The relationship between sensitivity modeling and significance in cultural resource management is more complex.

Such observations beg the question, "Are the differences in the archaeological record simply due to visibility?" Examining the distribution of sites relative to the two types of dunes provides mixed results. As noted above, the two geomorphic surfaces appear similar with regard to many environmental variables. For example, the average slope for coppice dunes is $1.56^{\circ}$, whereas it is $1.51^{\circ}$ for parabolic dunes. It is striking, therefore, that the two landforms diverge dramatically in their distance to water. Coppice dunes average $902 \mathrm{~m}$ from water; parabolic dunes are found at an average distance of $1,505 \mathrm{~m}$ from water.

Given the importance of water to human settlement in the region, we cannot simply dismiss the difference in site distribution between coppice and parabolic dunes as being a result of surface visibility. To determine the causes of variation in the archaeological site distribution will require more in-depth study, relying particularly on excavation data to assess issues of site function and integrity. To many, such a conclusion will be anticlimactic. Didn't we know this already? Can't predictive models do better than this?

We believe such questions, though common, miss the point. Predictive models like the ones presented here for Loco Hills are regional in scope. They are designed to assist in discerning large-scale relationships between archaeological sites and mappable environmental features. They are based on measurements of environmental data taken at a relatively crude scale and use archaeological data of dubious quality. Therefore, it is unreasonable to expect such models to discern anything but the most robust patterns in the distribution of archaeological sites.

Predictive models, however, can assist in tailoring excavation projects that address questions posed at finer scales. For example, it is a common refrain among archaeologists in southeast New Mexico that excavation is needed to further our understanding of issues of site function and regional chronology. But which sites need to be excavated? Most archaeologists would focus on those sites with obvious research potential, such as rockshelters with thick cultural deposits of good integrity. These are not the types of sites, however, that are found in Loco Hills. Instead, we need to focus on sites threatened by current and future development. Can these sites assist in answering regional research questions, and if so, which sites and which research questions?

It is here that predictive models can be of great utility. The Loco Hills models can assist in selecting sites from different environmental settings, such as a controlled group from coppice and parabolic dunes that will assess the nature, integrity, and ultimately, the research potential of sites in these landforms. By linking sites and their settings to regional interpretations, we can not only learn about the past but also offer managers useful information on the basis of 
which resource decisions can be made. If, for example, all the sites in the region represent the remnants of a single serial foraging system, any sites that may be buried under the parabolic dunes would be of limited significance, since the overall system could be adequately documented through the study of other, more accessible sites. If, however, sites in the parabolic dunes represent a unique portion of an adaptive system or an entirely different adaptive system, then these sites are of exceptional significance, and cultural resource management within the Loco Hills study area must take into account these differences. Predictive models represent one step in this research process. But they are only one step.

The failures of the past in using models often revolve around assuming models can answer fine-scale questions, such as, will this location contain a site? Models built on regional data cannot answer this question satisfactorily. Instead, models are useful because they provide a snapshot of a region and as they are refined over time, provide benchmarks that can be used to assess whether additional data are leading to a stronger correlation between environmental variables and the archaeological record. They can assist in focusing surveys and tailoring excavation projects. If viewed as part of a process whose goal is understanding and managing archaeological resources, then models are worth the time and effort needed to create them. If the expectation is that models by themselves will provide management answers, then all parties will be disappointed.

\section{Modeling and Management}

Evaluation of our predictive models demonstrated that they were reasonably successful in predicting the locations of surface-visible archaeological sites based on the correlation of site locations with a variety of environmental factors. The point of this project, however, is not prediction for its own sake, or even modeling as a means of understanding human behavior in the past. The goal of the New Mexico PUMP III project is to evaluate the effectiveness of current cultural resource management practices in oil and gas fields and to provide data, technical support tools, and procedural recommendations for improving management in the future. The final section of this chapter uses a variety of modeling approaches to examine the effectiveness of current management practices and identifies some implications of the results for future management practices. Chapter 9 will discuss in detail the management implications of the Loco Hills, Azotea Mesa, and Otero Mesa studies and provide recommendations for more efficient and effective cultural resource management strategies.

\section{Model Stability}

Our first approach to evaluating the effectiveness of current cultural resource management practices for Loco Hills was to address the question, "Has our understanding of site location patterns stabilized, or would additional survey data increase our predictive success?" To address this question, we developed a series of logistic regression models using the same environmental themes but including only the site and survey data that would have been available at various points in the past. The expectation underlying this exercise was that, as our knowledge of the archaeological record improved, so would the predictive success of the models. If we found that the models were continuing to improve with each new iteration, including the final 2002 version, then we would assume that collecting more archaeological data in the same ways would permit us to continue refining our model. Alternatively, if we found that the rate of improvement in predictive power had slowed or stopped, we could assume that we have enough site location data to create as strong a predictive model as possible based solely on environmental variables.

The predictive models developed here make the simplifying assumption that indigenous people located their activities on the landscape largely in response to the distribution of resources. If this assumption is correct, once the model stabilizes, the predictions should be fairly accurate. If the placement of activities was based primarily on cultural values, such as proximity to villages, shrines, or hostile groups, however, the model might become quite stable and still be a poor predictor of site location. It is important, therefore, to have independent sources of model verification, such as blind surveys, and potentially to develop theory-based models of settlement that explain the results prior to using the models in the management of resources.

To determine when, during the history of archaeological survey and identification in the Loco Hills study area, we would have been able to generate predictive models as accurate as the current model, we recalculated the logistic regression model based on data available in 1986, 1991, 1995, and 1998 and compared the resulting models with the model based on current data (2002). We chose 1985 as the start date because by that time approximately $10 \%$ of the 62,875 acres covered by 2002 had been surveyed. This total had risen to $20 \%$ by $1991,30 \%$ by 1995 , and $55 \%$ by 1998 .

When the models were run and mapped, we found that, visually, there was little difference among them. Figures 5.14 and 5.15 show the models based on the data available in 1986 and in 2002 data (already shown above in Figure 


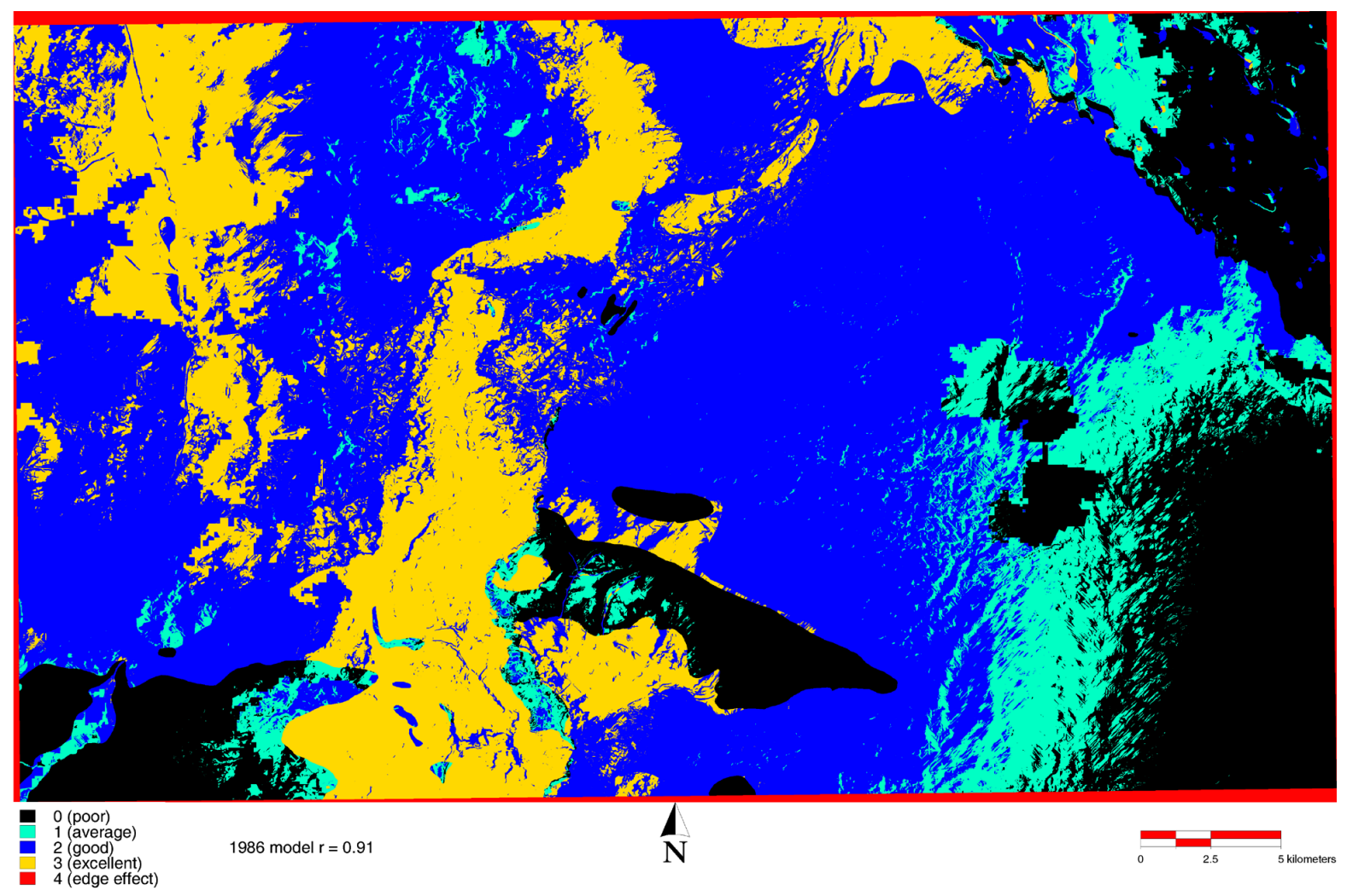

Figure 5.14. Logistic regression model created using prehistoric site data prior to 1986.

The correlation score is the relation to the 2002 model. The red areas are outside the study area.

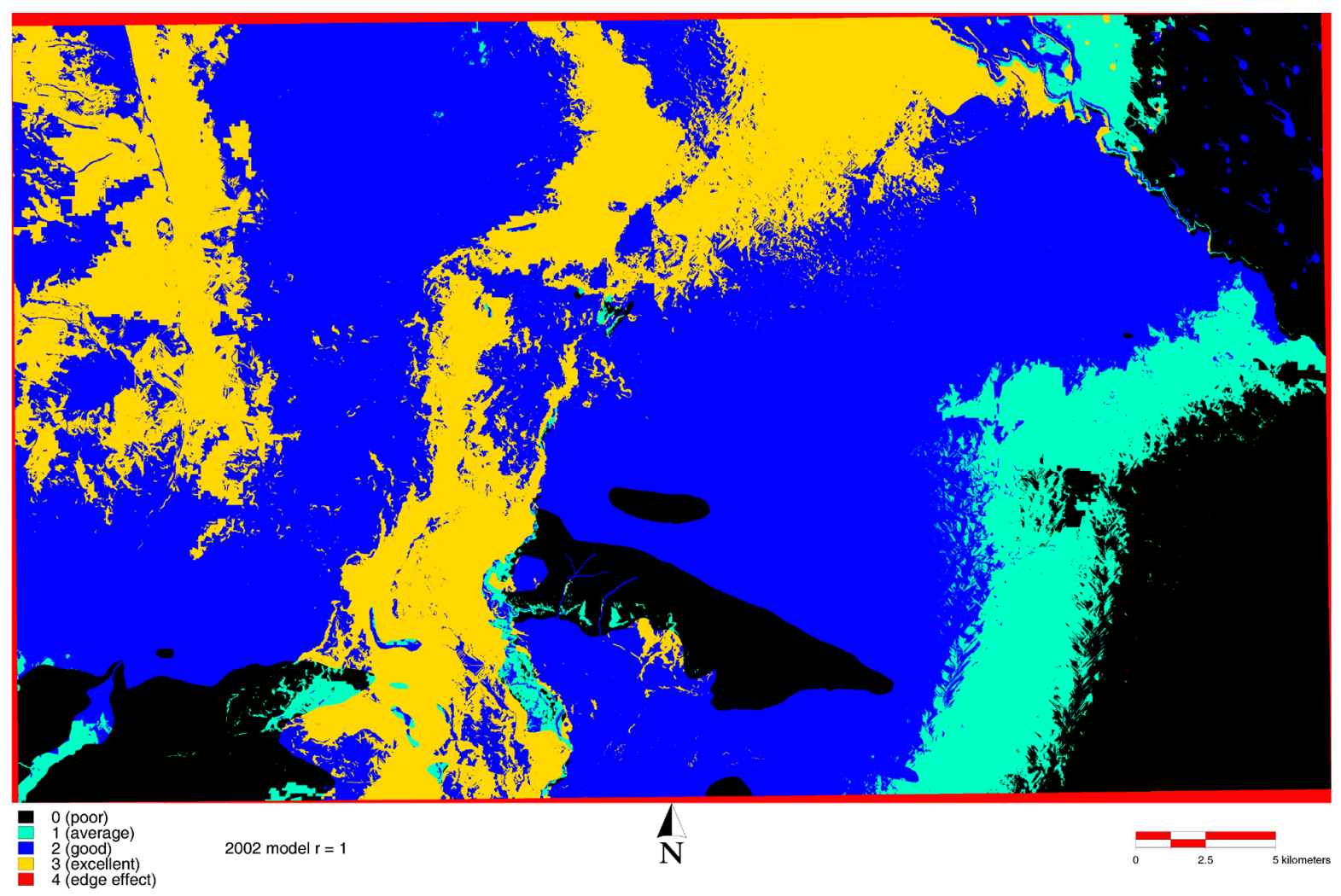

Figure 5.15. Logistic regression model created using prehistoric site data prior to 2003. The correlation score is 1 because this is the 2002 model against which the others were compared. The red areas are outside the study area. 
5.11). Spearman's $r$ scores were computed to compare each model's performance against the 2002 model. These scores ranged from a low of 0.88 in 1991 to 0.98 in 1998. The regression line depicted in Figure 5.16 is nearly flat, indicating that there has been little gain in predictive power since 1985. In short, we knew, or could have known, the basic pattern of site locations in relation to the Loco Hills environment after only $10 \%$ of the region had been surveyed.

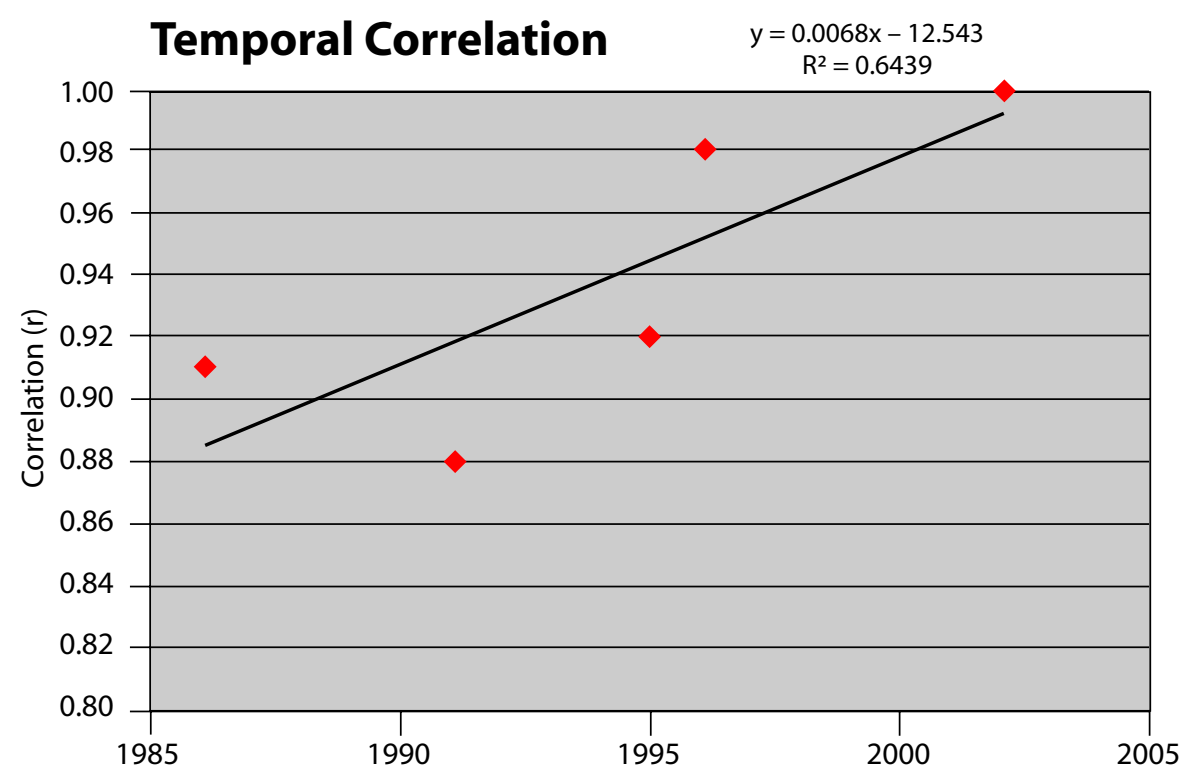

Figure 5.16. Correlation of each logistic model by year to 2002.

\section{Inventory Reconstruction}

In the previous section, we demonstrated that the structure of the logistic regression model of archaeological site location stabilized very early in the development of the Loco Hills field. Areas highly likely to contain sites could have been differentiated from those less likely to contain resources within five years of the onset of large-scale gas exploration. This finding begs the questions of whether, armed with this knowledge, we would have spent so much time and effort carrying out the same kinds of cultural resource identification efforts, and whether we would have managed either the energy development or the cultural resources differently. To a large extent, answering these questions depends on the confidence we place in the statistical models. Although the stability in the predictive model indicates that the underlying patterns of site distribution relative to environmental variables are quite strong, the complexity of the statistical techniques makes it difficult for the non-statistician to assess how much faith should be placed in the results.

In this section, we provide a more intuitive and simpler means of making this assessment. Using the dates when surveys were conducted and sites were recorded, we reconstructed the history of archaeological inventory in the Loco Hills study area. Then we examined this history to determine when, in an ideal setting, we would have been able to recognize that we were not learning significantly more about site distribution.

At first glance, the inventory reconstruction seemed simple. The ARMS staff had digitized and entered associated attributed data for all surveys and all individual recording episodes at each site. All we had to do was associate surveys and sites with the year in which they were conducted and recorded. With these data, we could calculate for each year the number of acres of sites recorded and the number of acres surveyed. By dividing the number of "site" acres by the number of surveyed acres in any given year, we would arrive at a site density for that year, which could then be compared with a running density figure that included all sites and acres surveyed up to that date.

We assumed that the cumulative site density figure for all years including 2002 was an accurate estimate of site density for the entire Loco Hills study area. This assumption allowed us to use the yearly running site density figures to compute the standard deviation and confidence intervals around the 2002 figure which captured $95 \%$ of the estimates. We then examined the annual history and determined at what year the running site density consistently fell within the confidence intervals.

As we examined the ARMS data, however, it became clear that the task would be more involved. Many areas had been surveyed multiple times, and many sites had been re-recorded; sometimes these events occurred in the same year. The survey history of Loco Hills was so complex that it was impossible to create an accurate summary or even to visually interpret the raw information. 
Figures 5.17 and 5.18 demonstrate the problem. These two figures show a small portion of the study area which, though somewhat more intensively inventoried than the majority of the area, is by no means exceptional in its complexity. Figure 5.17 shows the raw data captured by ARMS. Each survey was recorded fully, including portions that overlap previous surveys. The site recording episodes reflect the extent to which a site or portion of a site was recorded during any particular survey event. In this example, the large number of coincident boundaries is the result of one large site being repeatedly recorded to differing extents.

To circumvent these problems, we aggregated the data by year. All surveys and site-recording episodes were assigned to the year in which field activity concluded, as reflected in the ARMS data set. Figure 5.18 shows surveys within the same small portion of the study area, coded by year, and Figure 5.19 shows a time sequence of cumulative survey, aggregated by year, within the whole study area.

Even after aggregating the data, we found that the process of estimating site density on an annual basis was complicated by the large amount of resurvey and the concomitant re-recording of sites that was taking place each year. The magnitude

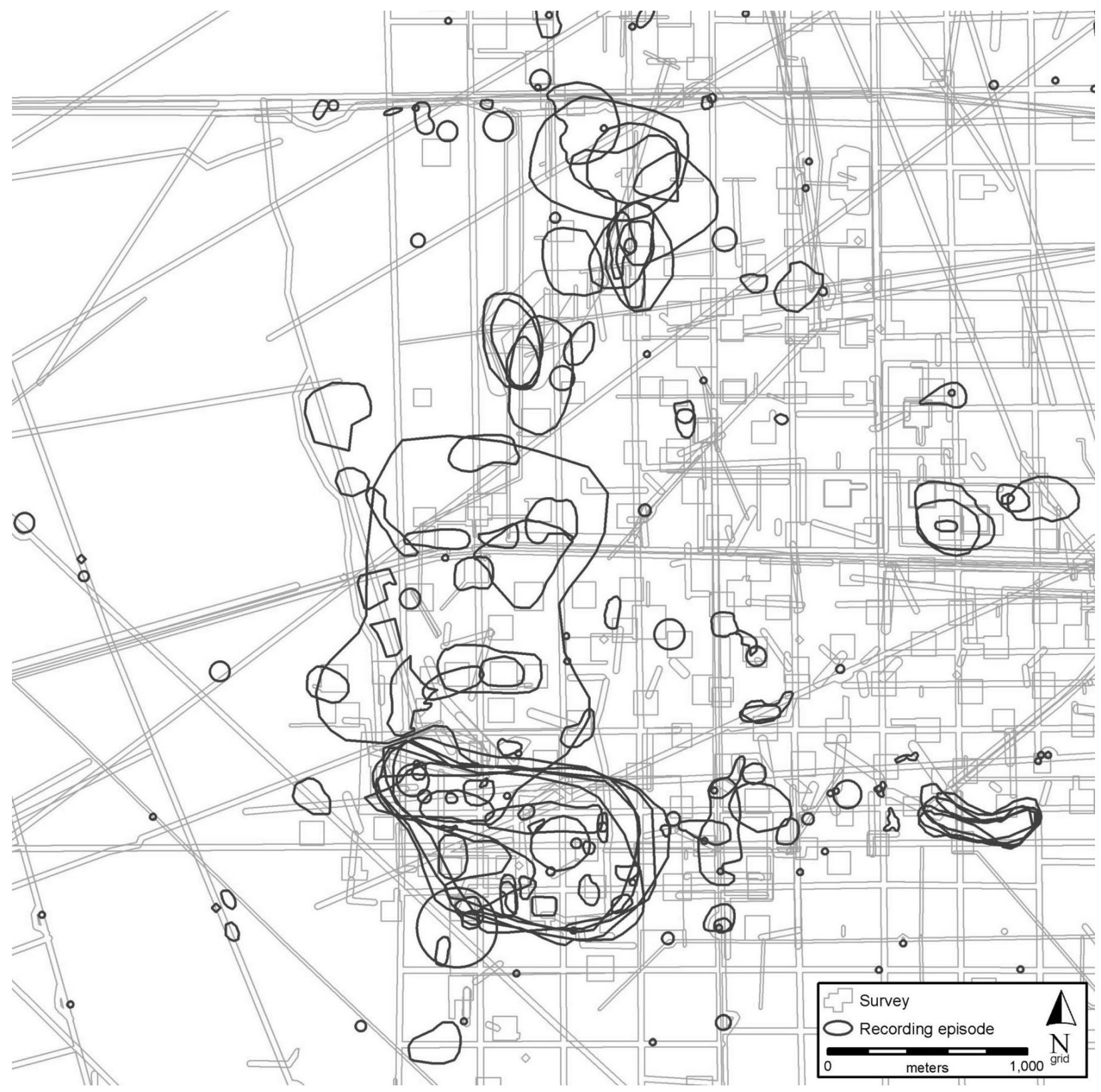

Figure 5.17. Examples of survey and recording episodes. 


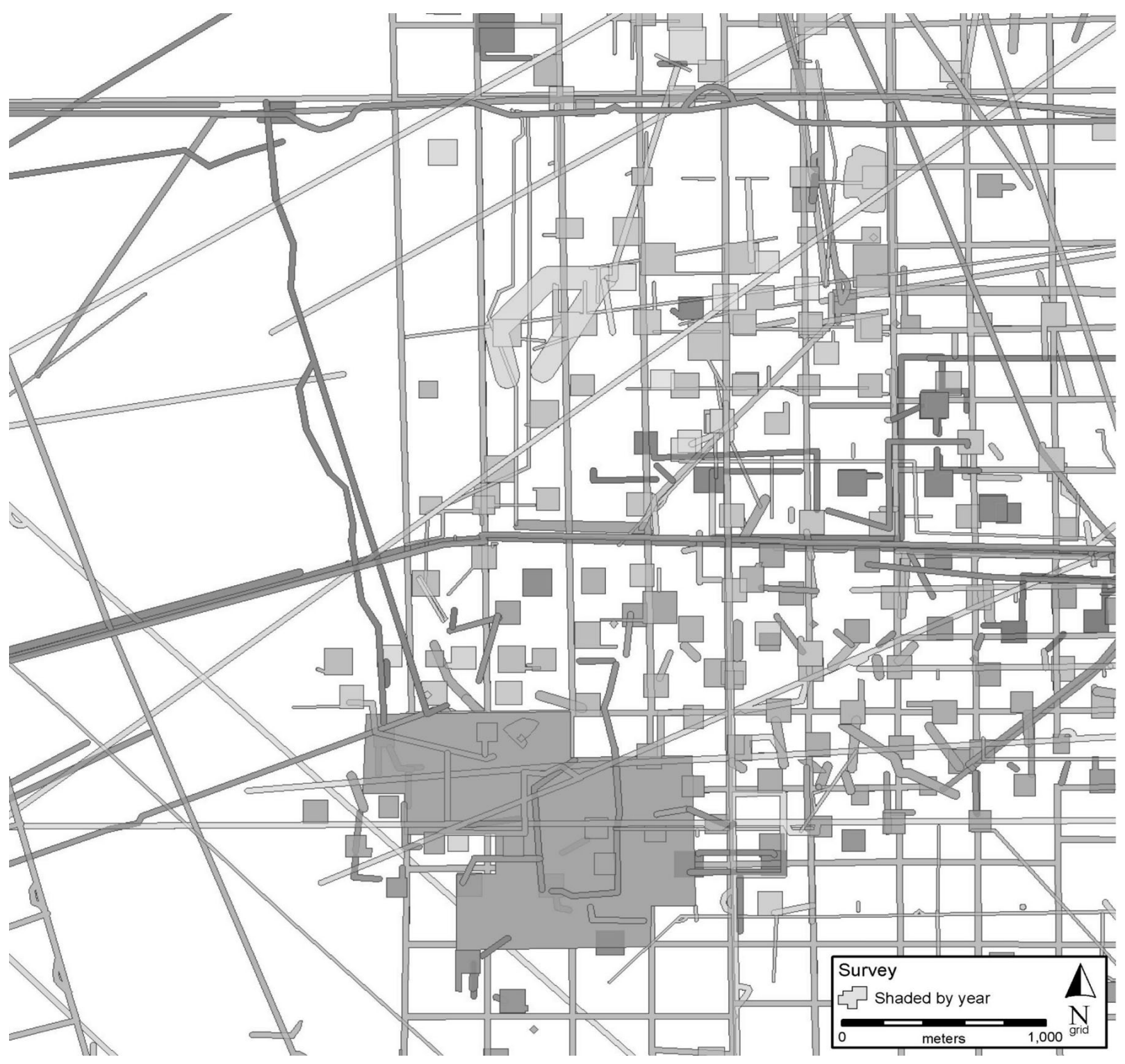

Figure 5.18. Example of survey coverage aggregated by year.

of this problem is hard to overemphasize. Between 1975 and 2002, surveys in the study area covered 75,223 acres, yet only 62,875 acres of ground ( $19.25 \%$ of the study area) were actually inventoried; the 12,348 -acre difference results from resurvey. More than 19 sections of land were resurveyed over the years. A quick look at Figure 5.20 makes it clear why and how this happened. As roads and pipelines and seismic grids were overlaid one on top of the other, it became virtually impossible to complete a project-specific inventory without resurveying at least some ground that had already been surveyed. We want to be clear. We are not suggesting that resurvey per se is a bad thing -in an active geomorphic environment like Loco Hills, purposeful resurvey is an important management tool. But resurvey should be the result of a management decision, not of an endless, uncontrolled series of inadvertent overlaps and do-overs.

Figure 5.20 graphically displays the history of survey in the Loco Hills study area with special attention to this issue of resurvey. For each year there are three bars, one representing the reported number of surveyed acres, one representing the reported acreage minus the overlapping surveys within that year, and one representing the actual new ground surveyed with all overlaps removed.

These data allowed us to calculate site density (site acres per surveyed acres) using two different methods. Method I (Figure 5.21) is based on survey as it was actually performed. In this analysis, sites that were recorded more than once 


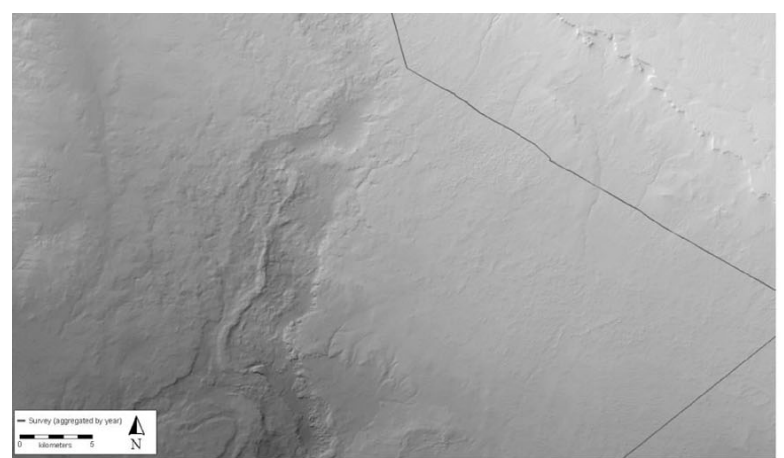

1975

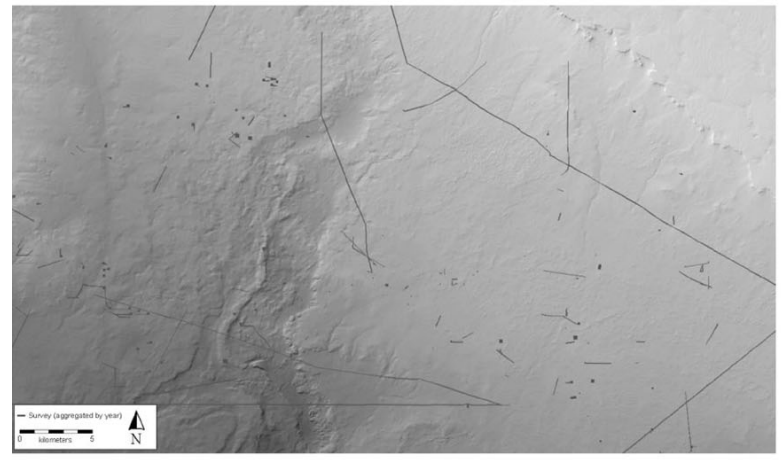

1980

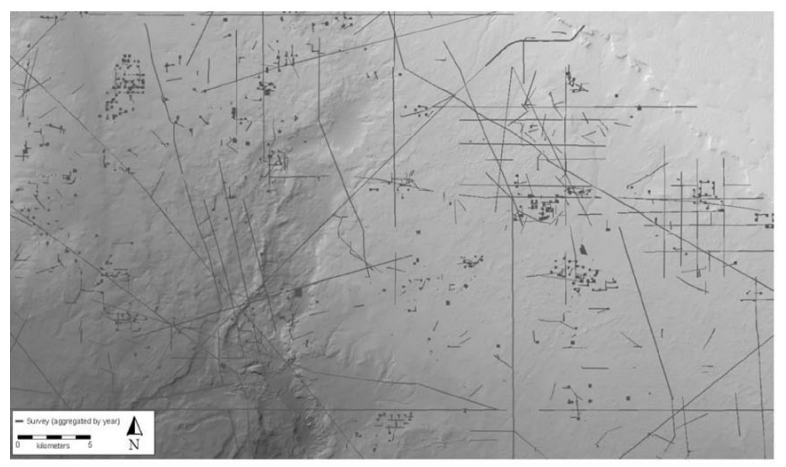

1985

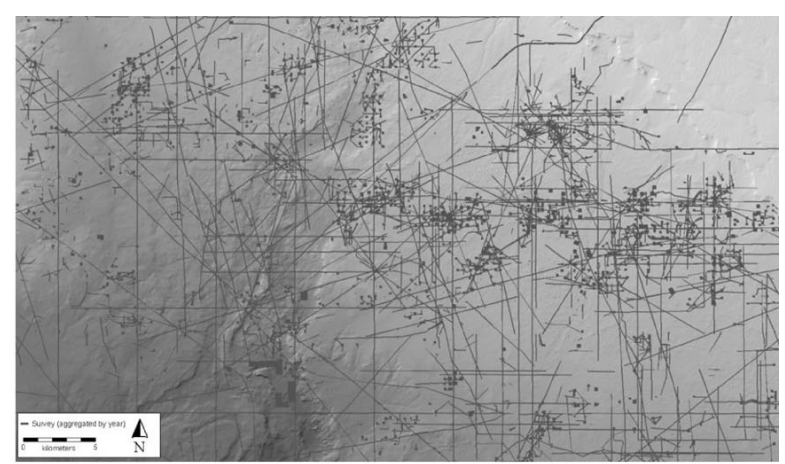

1991

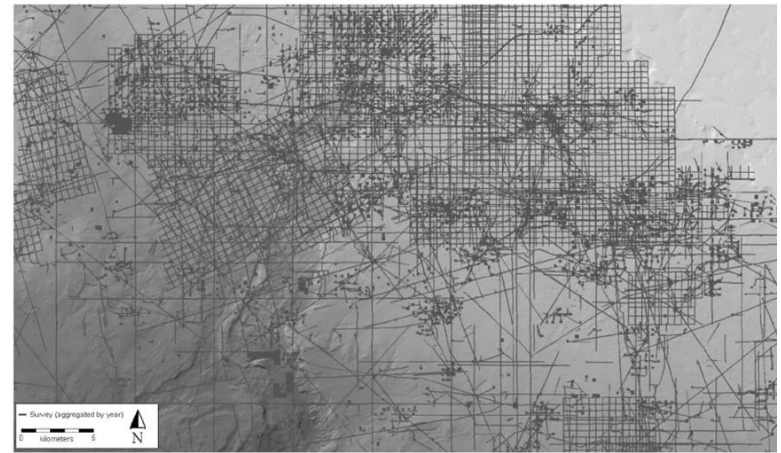

1997

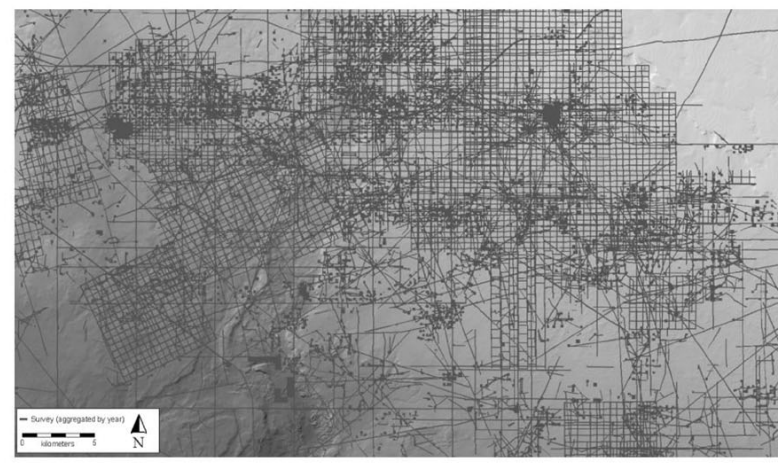

2002

Figure 5.19. Time sequence for cumulative survey in the study area, aggregated by year.

and areas that were surveyed more than once in different years are included in the calculations for each year that fieldwork took place. The site density figures in Method I, therefore, are inflated. Method II (Figure 5.22) eliminates survey overlap and site re-recording; it provides a more accurate estimate of site density but masks the inefficiency of the piecemeal survey history. In short, Method I calculates site density as it would have been available to managers under existing survey strategies, whereas Method II provides the density figure that would have been available in an ideal world where there were no survey overlaps or site re-recording. It is important to note that one of the products of the overall PUMP III project is a computerized system (the pilot being developed for portions of Wyoming) that allows data to be recorded in real time. The calculation of site density as well as other similar descriptive statistics should move from Method I to Method II in the near future.

For each year represented in Figures 5.21 and 5.22, we present an annual site density and a cumulative running site density. The first bar (gray) for each year presents the site density calculated by dividing the number of site acres recorded in that year by the number of acres surveyed in that year. The second bar is cumulative density, and it is calculated by dividing the total number of site acres recorded up to the end of the year in question by the total number of acres surveyed up until that time. The second bar is shaded either light gray or black, depending on whether it falls 


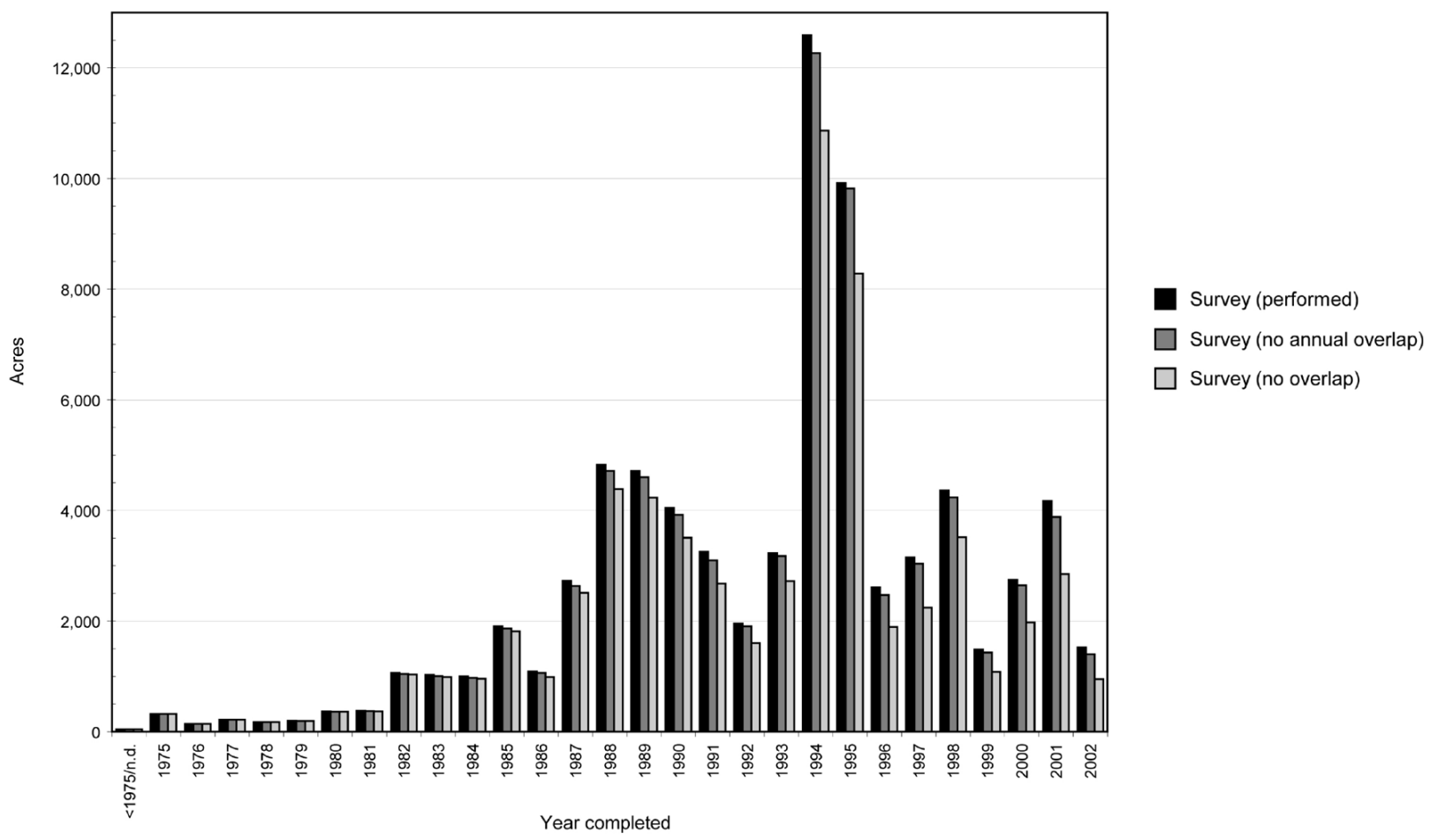

Figure 5.20. Annual survey statistics.

outside (light gray) or inside (black) the 95\% confidence intervals. Visually, we expect to see fluctuations in annual density throughout the sequence, whereas the cumulative site density figure should vary early on and then stabilize as the proportion of the study area surveyed becomes larger.

The results of the annual site density analyses meet our expectations but are intriguing nonetheless. Both the Method I and Method II graphs show a general rise in site density that peaks in 1997 and then falls off. It is unclear why 1997 is such an anomalous year; it may be the result of targeted survey of one or more very large sites in the Bear Grass Draw area. During normal, compliance-driven surveys, the portions of a site outside the boundaries of the survey corridor are not included as "surveyed space." With this very large site or sites in Bear Grass Draw, however, the entire site area was included as surveyed space, greatly increasing the proportion of site area relative to survey area for that year and thus skewing the annual density figure.

Even with the one anomalous year, the trend in running site density figures is clear. Site density stabilizes at about 0.43 under Method I and 0.40 under Method II. Under Method I, running density falls in the $95 \%$ confidence intervals between 1984 and 1986, in 1994, and then consistently from 1997 until 2002. About half of the 19 years in question fall outside the confidence intervals, though none in the last 6 years of the dataset. In contrast, under Method II the running site density stabilizes much earlier, around 1984, and only falls out of the $95 \%$ confidence intervals in two of the 19 years in question.

The results are consistent with those of the logistical regression. The estimate of site density stabilizes relatively early, though not as early as the environmental correlation findings of the logistical regression model. The robustness of the predictive model reflects the very strong associations of archaeological site location and mappable environmental variables, and it indicates that human behavior in this arid region was strongly shaped by the distribution of economic resources. The results of the logistical regression model give us confidence that the environmental themes used in the model proxy the factors influencing human settlement choices.

Site density, however, is simply a measure of the intensity of human use of a landscape. We are not interested in this figure because it necessarily tells us anything about human behavior. Rather, site density is a good measure of how rapidly we can characterize the archaeological record. This measure is important because surveys are not proceeding according to a sampling design that would allow us to calculate the precision or the reliability of the estimates, but instead survey locations have historically been driven by the patterns of oil and gas development. 
THE LOCO HILLS STUDY AREA

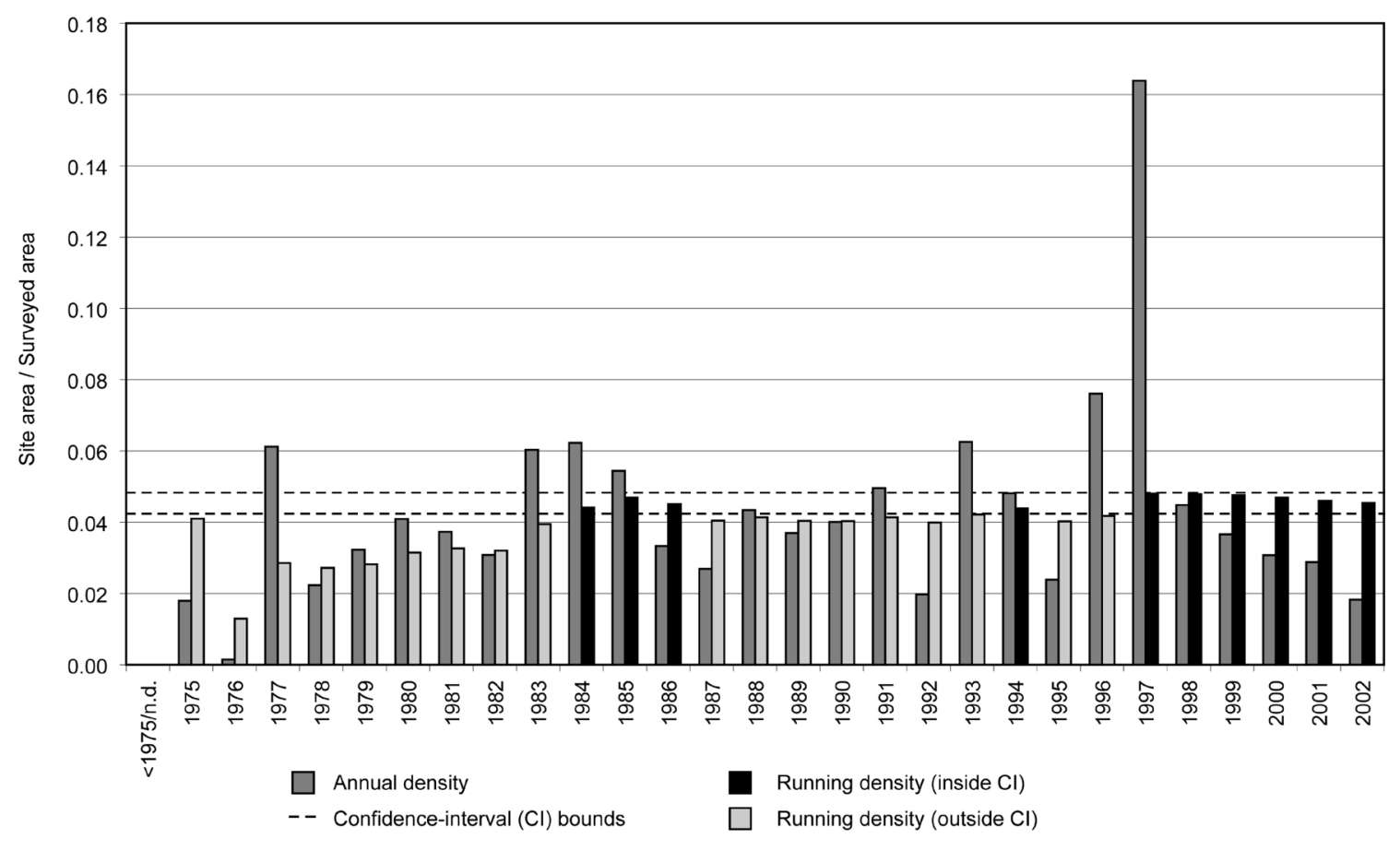

Figure 5.21. Overall site density, Method I.

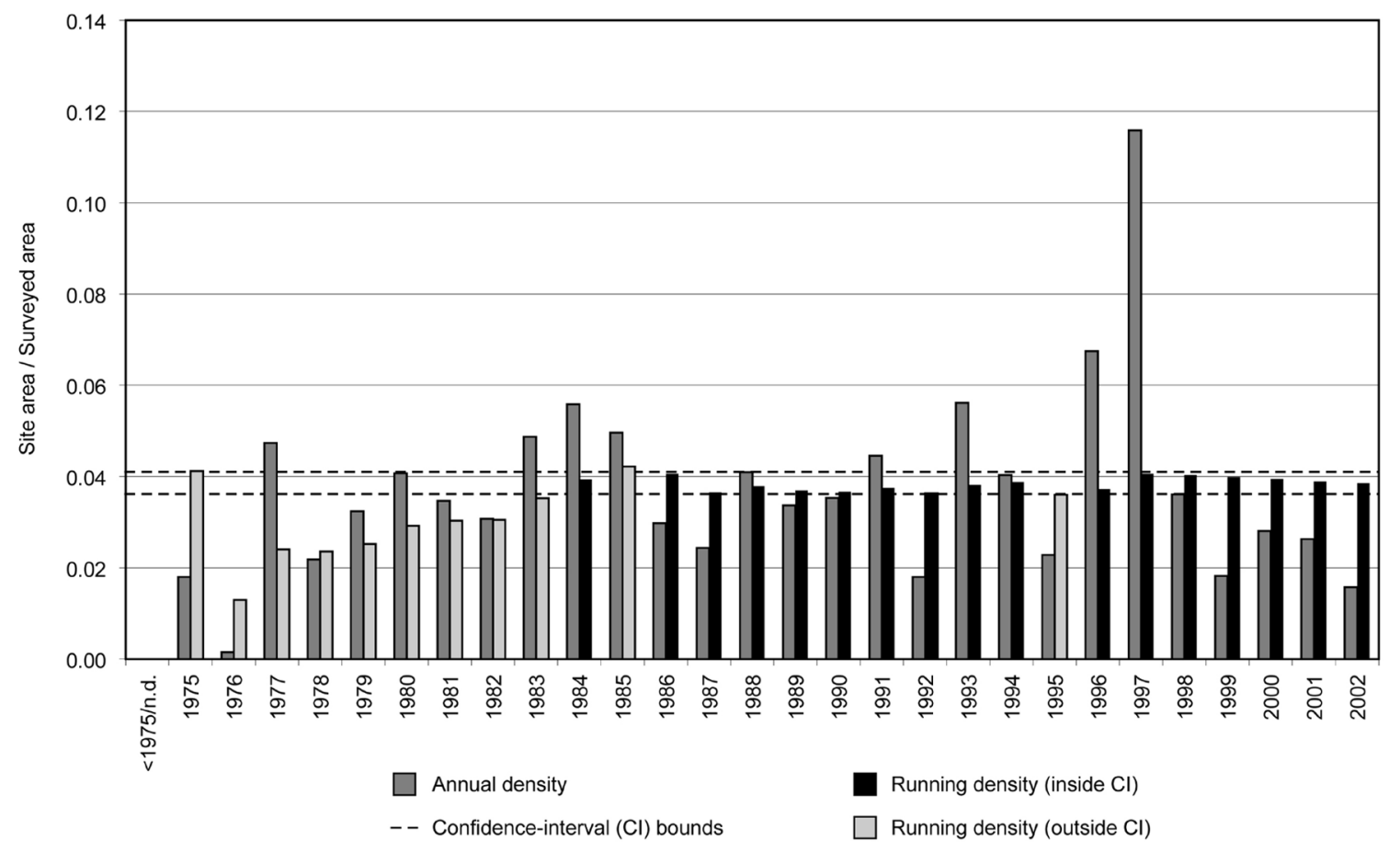

Figure 5.22. Overall site density, Method II. 
The logistic regression models and site density results presented above show that we stopped learning useful information about the distribution of cultural resources in the Loco Hills study area more than a decade ago. Based on a visual inspection of the 2002 survey map shown in Figure 5.19, we might be tempted to conclude that this is because such a high proportion of the study area has been examined. Surprisingly, however, only about $20 \%$ of the total acreage has been inventoried. The appearance of greater intensity of coverage is a result of the sheer volume of narrow survey corridors represented by bounding lines, each of which is often nearly as wide as the width of the true survey corridor. An examination of the original paper maps on which the surveys were recorded makes this clear - the width of a pencil line represents approximately 12 meters on a 1:24,000 scale map. Even with GIS-generated maps, the boundary lines have to be represented at a scale that makes them visible on electronic or printed media. Thus, narrowly spaced linear surveys appear to cover more ground than was actually examined in the field.

Nonetheles, both the logistical regression models and the site density analysis demonstrate that site distribution in Loco Hills is highly predictable, and that we could have known virtually as much as we know now about the distribution of the surface manifestations of the archaeological record well before even the $20 \%$ level of survey coverage was reached. How is this possible? One reason is that oil and gas development is often preceded by seismic testing, which involves locations arrayed in long linear patterns. The rows of test locations and the associated roads all require survey, which has the effect of creating long transects across much of the study area. Oil and gas development and production also create long linear features, such as pipelines and powerlines; surveys for these facilities create still more long transects, and all of these transects almost invariably crosscut the various environmental zones represented in the study area. Because human settlement is strongly correlated with environmental features in southeast New Mexico, these linear surveys provide exactly the types of data required for predictive modeling.

Long linear transects also have a large edge effect and thus can be expected to "find" a higher proportion of the total universe of sites than small, square quadrats covering the same amount of ground. A large number of sites are, therefore, found rather quickly. Given the nature of development and concomitant survey in the Loco Hills study area, it is not surprising that the archaeological record of Loco Hills could be characterized quite accurately when only a relatively small percentage of the study area had been inventoried.

We now return to our original question: when could we have had confidence in our predictions? To answer this question, we return to the site density analyses. The graphs of running densities for Method I and II (Figures 5.21 and 5.22) exhibit similar trends, but their differences should not be minimized. As noted above, Method I graphs archaeological inventory results in "real time" - that is, as survey was actually conducted, overlaps and all — and uses data on the total amount of surveyed acres and the reported number of archaeological sites. If we assume a management standard that defines "stability" as five years of stable trends, then confidence in the site density estimate would not be reached until 2003. This assessment seems reasonable given the relatively wide annual fluctuations in site density in the late 1990s. In contrast, applying the same management standard using Method II, reliable density figures would have been available by the end of 1990 .

Managers could have performed the same calculations of site density as presented above in real time. Although the cumulative site density figure would change on an annual basis, it would have reached five-year stability in the early to mid 1990s. These results, combined with the stable logistical regression models, would have enabled cultural resource managers to have as good an understanding of site densities and site locations relative to environmental parameters by the mid 1990s as we have today, despite the large amount of additional archaeological survey since that time.

\section{Management Implications}

For all the survey that has been completed in Loco Hills, our understanding of the prehistory of the region has not dramatically increased, and this is not an academic issue. Time and money are being spent on efforts that neither advance our ability to manage cultural resources nor improve our ability to balance resource protection and energy development. One of the purposes of cultural resource surveys in Loco Hills is to meet the BLM's legal obligation under Section 106 of the National Historic Preservation Act to identify historic properties that may be affected by oil and gas development, and the 5,196 surveys between 1975 and 2002 have met that need.

There is more to Section 106 than identification, however. The agency is required to determine whether properties are eligible to the National Register of Historic Places, for example. But BLM still has difficulty making this determination with any confidence, even with all the survey data from Loco Hills, so as a matter of good stewardship BLM must err on the side of calling too many sites eligible. Projects are delayed, redesigned, moved, and moved again to avoid sites that may or may not truly have the potential to yield important information. In part, the difficulty with determinations of eligibility is a result of so little effort having gone into studying the relationship between surface cultural manifestations 
and subsurface cultural deposits. Then, too, the absence of regional research designs or historic contexts means that property types eligible for the National Register have not been defined. Thus, we cannot readily evaluate the sites already recorded or even be certain that sufficient data are being recorded.

Equally to the point, Section 106 is not BLM's only legal mandate concerning cultural resources. Since cultural resource identification efforts are being paid for by the American people, either directly through tax dollars appropriated to the BLM or indirectly through the pass-through costs of energy products, these surveys should also be contributing new or improved management information needed to meet BLM's responsibilities under Section 110 of the National Historic Preservation Act, the National Environmental Policy Act, and other mandates. Simply finding sites, and finding the same sites over and over, is not enough. The models and inventory reconstruction suggest that elements of site distribution are known for the Loco Hills area, and could have been known for some time. In the absence of a parallel interpretive regional analysis, however, no amount of data collection will move cultural resource management forward.

Several lessons for cultural resource management in southeastern New Mexico have been suggested by the results of our inventory reconstruction and modeling efforts. First, oil and gas development, although not a random process, is conducted in a way that provides reasonable data for the creation of predictive models that associate human settlement with environmental features, especially when linear arrays of seismic tests or pipelines are producing a substantial portion of the data. Despite the appearance of the maps showing surveyed space, however, only approximately $20 \%$ of the actual ground surface within the Loco Hills study area has been surveyed.

Second, there has been a great deal of re-survey of land and re-recording of sites in the Loco Hills study area. Cumulatively, more than 75,000 acres have been surveyed, of which about 12,500 acres represent areas that have been surveyed more than once. Approximately 1,625 sites have been recorded, and of these, 508 have been recorded more than once. By any measure, the history of archaeological investigation is one of inefficiency. The overlapping nature of the development, combined with the current, case-by-case approach to inventory, makes a certain amount of duplication unavoidable, but the magnitude of the duplicated effort was surprising.

Third, the logistic regression models and the inventory reconstruction demonstrate that sufficient data were available to support important decisions about cultural resource management and oil and gas development when as little as 6 to $7 \%$ of the land in the Loco Hills study area had been inventoried. At approximately that point, site density analysis would have indicated that our understanding of where sites are located had stabilized, and predictive modeling would have indicated which environmental variables and values were strong predictors. Because there has been no mechanism for synthesizing previously acquired survey data, cultural resource managers neither have been able to use previous data to limit duplication of effort nor had available models and other tools to focus management and preservation efforts.

Fourth, our understanding of the past has not increased proportional to the amount of survey or the number of sites recorded. The research questions posed for southeast New Mexico prepared in the 1980s have still not been addressed (Sebastian and Larralde 1989). Our knowledge of the archaeology of Loco Hills is rudimentary. We do not know if the sites visible on the surface reflect the distribution of archaeological deposits; we are no closer to understanding prehistoric adaptation.

How might we have done things differently? An obvious answer, but a difficult one to implement, given the nature of oil and gas development, is that a systematic inventory completed prior to all development would have eliminated all duplication of survey and site recording efforts. This level of information on cultural resources is not necessary, however, for effective management. If surveyed space data and GIS or other sophisticated data management technology had been available from the beginning of development in Loco Hills, the BLM would have been able, as early as 1990 , to make informed decisions as to where, within a lease or set of leases, energy-related development should be concentrated and what areas should be avoided in order to minimize both immediate and, especially, cumulative, long-term effects to cultural resources. Decisions could have been made about where archaeological inventory efforts should be intensive and where they could be less intensive, and some, though by no means all, of the overlapping, duplicative efforts could have been avoided.

These approaches would have provided both better cultural resource management and greater cost-effectiveness for oil and gas development, but they would only have eliminated duplication; they would not have answered our questions about buried sites or cultural adaptation or enabled us to make better decisions about the significance of archaeological resources. Currently, decisions about the scientific importance, and thus the National Register eligibility, of archaeological sites in southeast New Mexico are based almost entirely on surface manifestations. Given the active geomorphic setting and the relative lack of excavation data, these decisions tend to be extremely conservative: we don't know enough about the integrity and data potential of these sites to know which ones have the potential to yield important information and which ones do not. 


\section{ADAPTIVE MANAGEMENT ※゙PLANNING MODELS FOR CULTURAL RESOURCES IN OIL ※゙ GAS FIELDS}

To address these issues, we would have to drastically change our objective from simply documenting surfacevisible archaeological sites and avoiding them to determining and understanding the nature and distribution of archaeological sites and deposits. We have enough information now to model basic settlement patterns. Our challenge is to build a better survey — one that will provide management information in addition to simply finding sites. We need to implement adequate subsurface testing as a standard part of site evaluation. We need to assess site formation and site destruction processes along with documenting the cultural content, so that we can determine the information potential of deposits underlying surface sites. In this way we can begin to model likely locations of buried sites with important information to offer and to explain both the distribution and the nature of sites in the Loco Hills area.

\section{References Cited}

Elyea, James M., and Patrick Hogan

1983 Regional Interaction: The Archaic Adaptation. In Economy and Interaction along the Lower Chaco River: The Navajo Mine Archeology Program, edited by Patrick Hogan and Joseph C. Winter, pp. 393-402. Office of Contract Archeology and Maxwell Museum of Anthropology, University of New Mexico, Albuquerque.

Hall, Stephen A.

2002 Field Guide to the Geoarchaeology of the Mescalero Sands, Southeastern New Mexico. Bureau of Land Management and New Mexico Historic Preservation Division, Santa Fe.

Sebastian, Lynne

1989a The Archaic Period. In Living on the Land: 11,000 Years of Human Adaptation in Southeastern New Mexico, by Lynne Sebastian and Signa Larralde, pp. 41-58. Cultural Resources Series 6. Bureau of Land Management, Roswell District, Roswell, New Mexico.

1989b The Ceramic Period. In Living on the Land: 11,000 Years of Human Adaptation in Southeastern New Mexico, by Lynne Sebastian and Signa Larralde, pp. 73-92. Cultural Resources Series 6. Bureau of Land Management, Roswell District, Roswell, New Mexico.

Sebastian, Lynne, and Signa Larralde

1989 Living on the Land: 11,000 Years of Human Adaptation in Southeastern New Mexico. Cultural Resources Series 6. Bureau of Land Management, Roswell District, Roswell, New Mexico. 


\title{
Results and Discussion: The Azotea Mesa Study Area
}

\author{
Jeffrey H. Altschul, Lynne Sebastian, Chris M. Rohe, William E. Hayden, and Stephen A. Hall
}

\begin{abstract}
$\Delta$
The Azotea Mesa study area (Figure 1.2) is rectangle covering approximately 1,200 square kilometers (460 square miles) and located immediately west and southwest of the city of Carlsbad; the easternmost edge of the study area actually includes part of the city. The Pecos River runs through the northeastern corner of the study area, and the western escarpment of the river valley runs north/south through the approximate center of the study area. The southwestern corner of the study area contains a small section of the lower slopes of the Guadalupe Mountains. Elevations within the Azotea Mesa study area vary from about 1,700 meters (5,600 feet) in the southwest to 950 meters $(3,100$ feet) in the northeast; the edge of the Pecos Valley escarpment is at about 1,200 meters (3,950 feet).
\end{abstract}

\section{The Predictive Models}

As discussed in Chapter 4, the premise of the modeling component of the Pump III project is that human behavior is patterned, and that decisions about where to locate activities on the landscape are likewise patterned. These patterns are conditioned by a variety of influences, many of them environmental. The archaeological remains of human activities should, therefore, be correlated to some degree with environmental features.

The Azotea Mesa study area does not represent an ideal setting for predictive modeling because it incorporates relatively little environmental diversity and consists mostly of eroded bedrock surfaces. Soil is thin and dissected by a braided network of small drainages that ultimately feed two larger, east-flowing washes. Much of this area would have been marginal in terms of the types of resources sought by indigenous people. The lack of places where either a particularly favored resource exists in abundance or a variety of resources coalesce leads us to suspect that there was no impetus to establish seasonal or permanent settlements or even logistical base camps. Observations of modern and ethnohistoric foragers suggest two possibilities: If indigenous people were specifically targeting resources in the study area, they would most likely have established short-term camps at or near specifically targeted resources, exhausted those resources, and then moved on to another similarly situated camp. Alternatively, this portion of Azotea Mesa may have contained a variety of travel routes between the relatively resource-rich river valley and uplands; in this scenario, small patches of useful resources would have been exploited opportunistically by groups and individuals who were otherwise simply passing through.

Either of these alternatives would be consistent with the nature of the archaeological resources recorded during surveys that have been performed in conjunction with lease development in the Azotea Mesa oil and gas field. The vast majority of the 550 recorded archaeological sites are small artifact scatters that cannot be distinguished from one another in terms of time of occupation or function. This lack of both environmental and cultural diversity within the study area means that correlative models that use environmental variables to predict archaeological site locations will not work well.

Although not ideal, Azotea Mesa does represent a real-life situation. It is where energy-related development is occurring, and it is where cultural resources will be affected by that development. The immediate management goal for this project is to determine where cultural resources are most likely to be found so that informed decisions can be made about development locations. In our modeling efforts, we have attempted to identify subtle associations between past land use and the environment and, to the extent that we can identify these associations, to magnify them so that their predictive power is increased.

\section{Environmental Data}

The environmental variables used in predictive models are best viewed as proxy variables and not as aspects of the environment that humans would have specifically targeted when making decisions about where to locate activities. 
Elevation, for example, would not have been a factor in decisions by indigenous people about where to locate camps and other activities, but vegetative communities would have been an important factor in such decisions. Because elevation is strongly correlated with vegetative communities in southeast New Mexico, it can be used as a proxy for vegetation in models attempting to predict site location.

We began the modeling component of the Azotea Mesa study by assembling data on a variety of environmental variables that may have affected the decisions that people in the past made about where to locate their activities. We restricted our search for environmental data to those that already existed in digital formats and could easily be converted into layers in a geographic information system (GIS). Predictive models are only as good as the data upon which they are based. The use of regional environmental data with crude resolution along with cultural data of variable quality means that the resulting models are not precise predictors of actual site locations, but are better viewed as indicators of regional trends in site distribution.

Once again we used the IDRISI GIS package to store data, calculate the statistics, and display the results of the predictive models for Azotea Mesa. This GIS package is a raster-based system, as opposed to a vector-based system; that is, instead of storing the data in shape files, the program imposes a grid of a specified size over the area and codes each cell with specific information. We chose a $30 \times 30 \mathrm{~m}$ cell as our grid size, which generated 1,622,691 cells for the Azotea Mesa study area.

To build the layers of environmental variables, we obtained GIS data covering elevation, vegetation, and geomorphology. The elevation theme is a digital elevation model (DEM) created by the United States Geological Survey. DEMs are created by interpolating between a set of points with known elevations at a specified contour interval. In the case of Azotea Mesa, the contour interval is 40 feet. The DEM for Azotea Mesa is shown in Figure 6.1. As described in Chapter 5, IDRISI uses the DEM, a primary theme, to produce secondary themes, such as slope (Figure 6.2) and aspect.

Five secondary themes were developed to display the distance from a particular cell to specific environmental variables: distance to drainages, distance to ridges, distance to drainage intersections, cost distance to drainages (drainage cost), and cost distance to ridges (ridge cost). To create these variables, we first had the GIS use the DEM data to create a layer showing major drainages and ridgelines (Figure 6.3). From this layer, the GIS then computed the shortest distance from each cell to the closest drainage or ridge line. Distances from major drainage intersections were also computed.

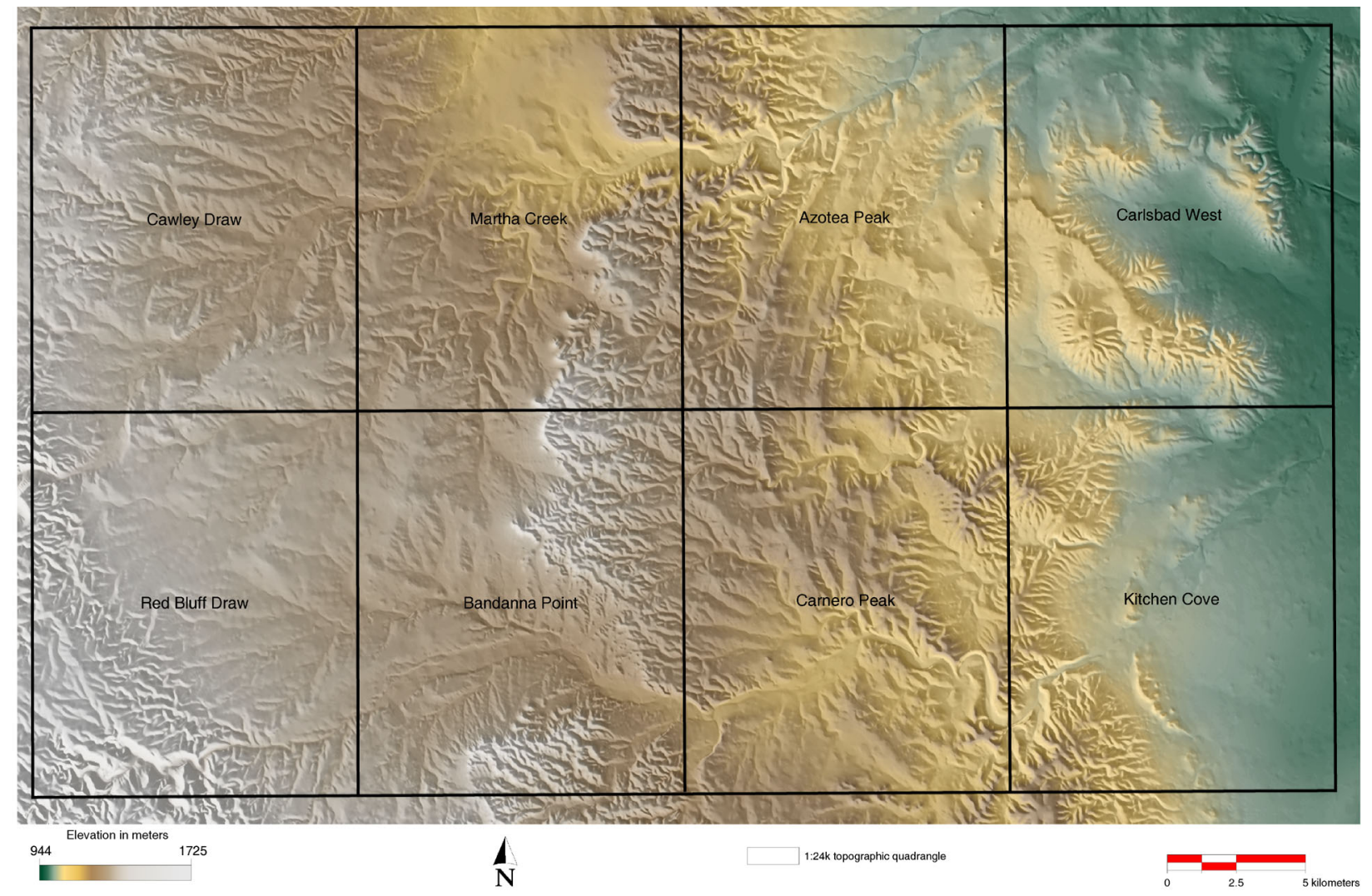

Figure 6.1. Digital elevation model (DEM) of the Azotea Mesa study area with USGS 7.5-minute quadrangles labeled. Note DEM extends slightly outside study area. 


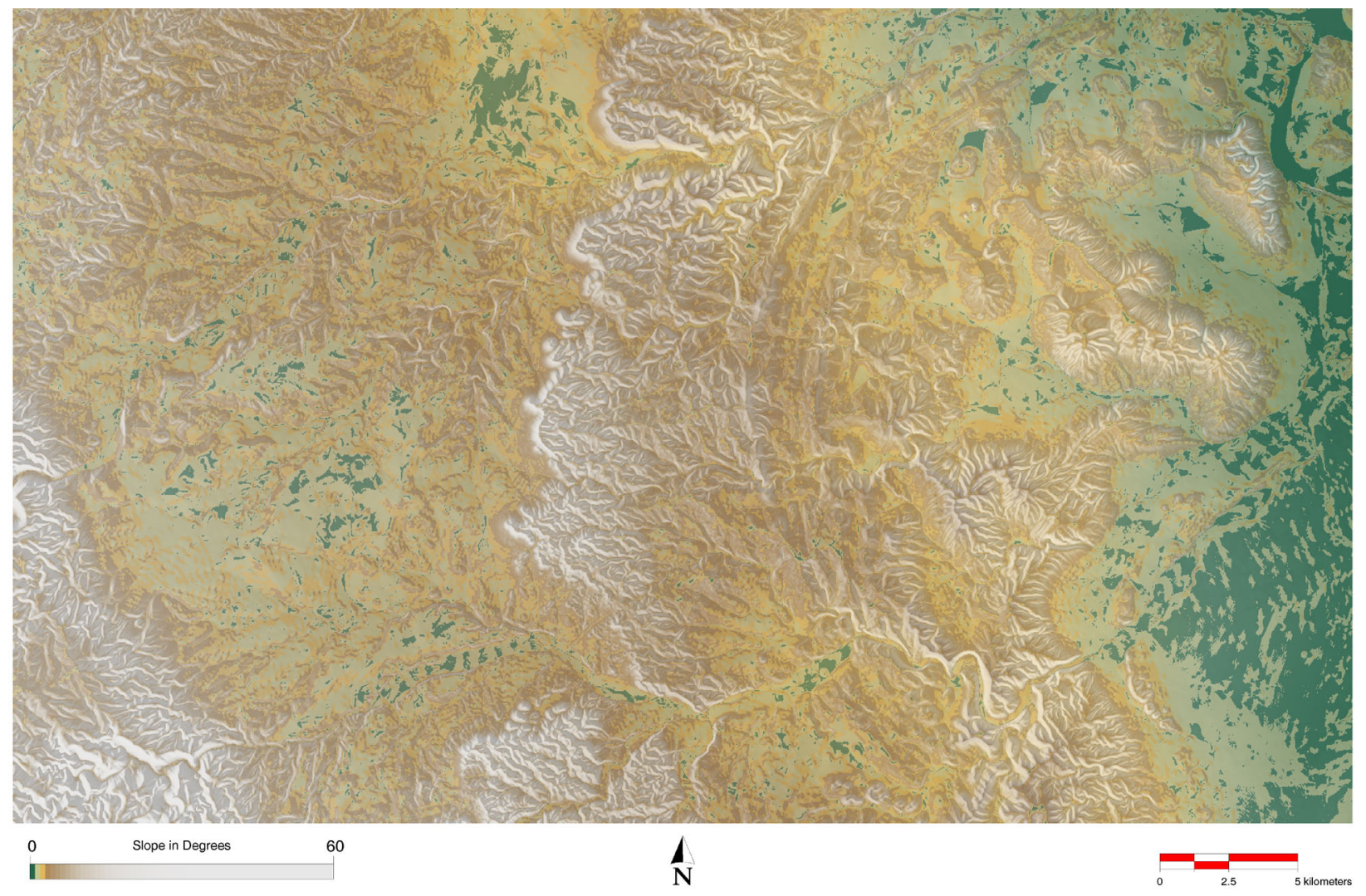

Figure 6.2. Slope in the Azotea Mesa study area.

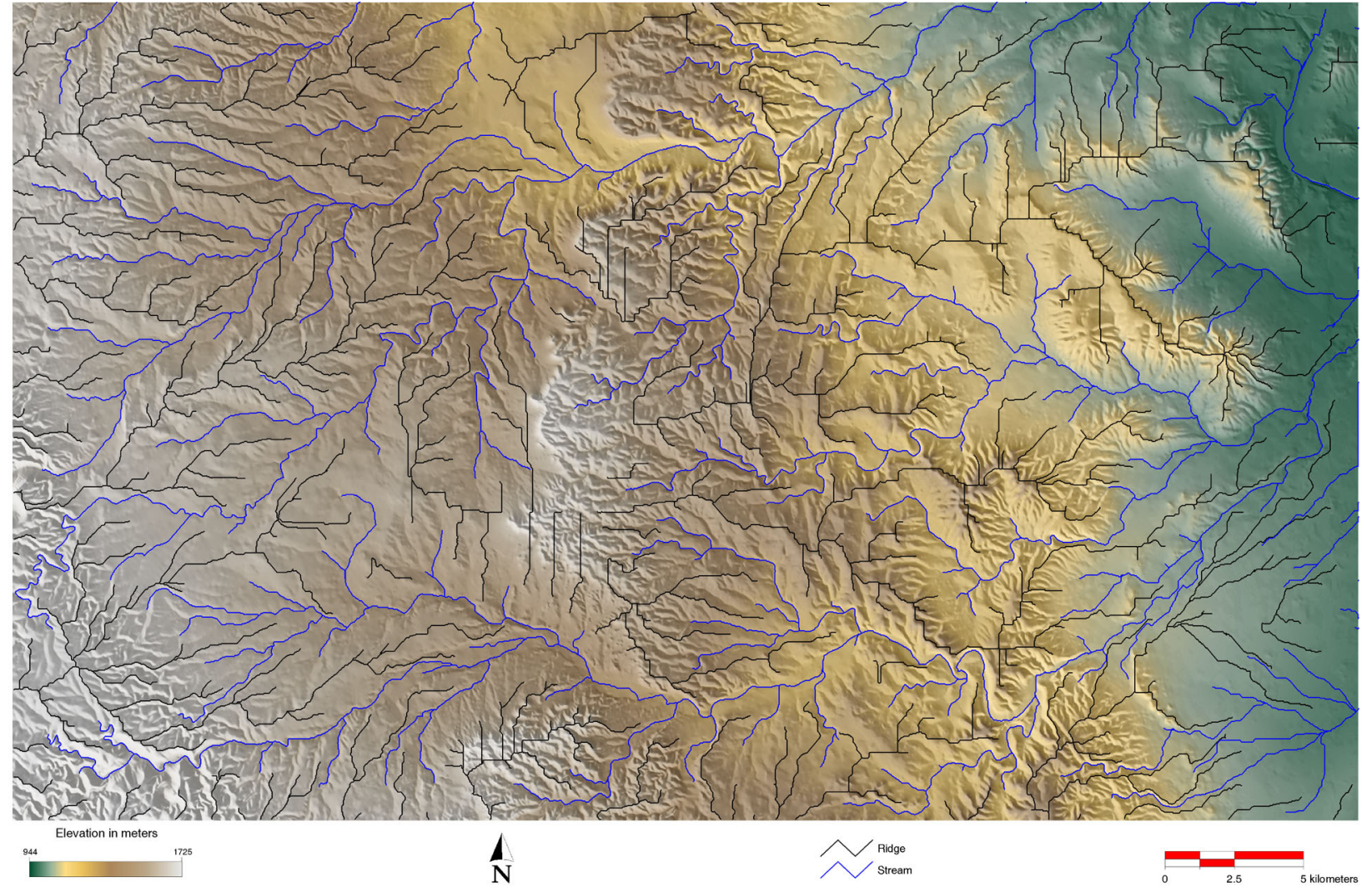

Figure 6.3. Drainages and ridges in the Azotea Mesa study area. 

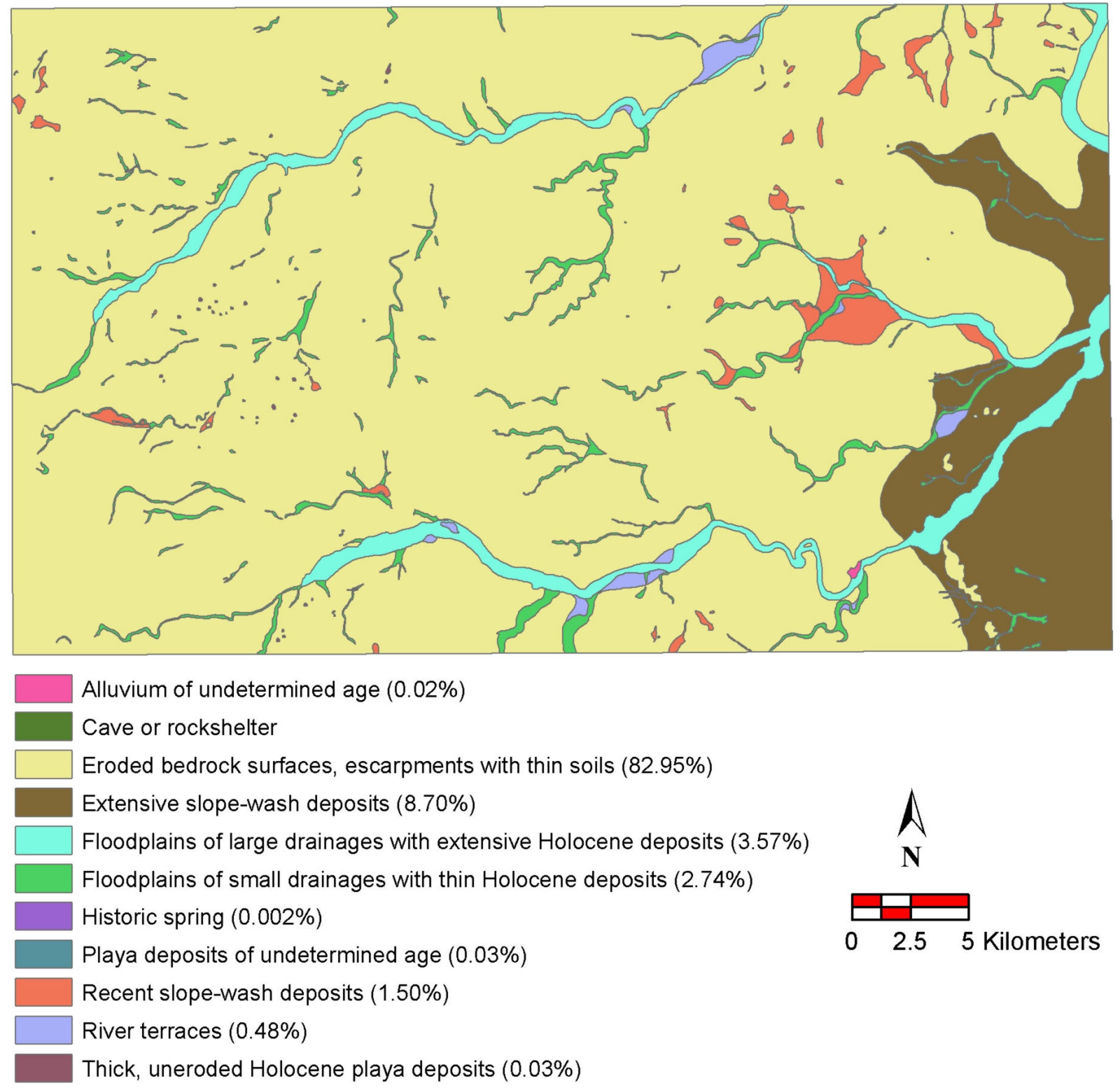

Figure 6.4. Geomorphology of the Azotea Mesa study area.

The cost distance variables use slope and distance to compute the effort required to travel between a cell and the nearest drainage or ridge line. The algorithm used by IDRISI generates a distance/proximity surface (also referred to as a cost surface) in which distance is measured as the least effort required to move over a friction surface. For Azotea Mesa, the friction surface was defined as the slope. The unit of measurement in the cost variables is termed "grid cell equivalents" (gce). A gce of 1 is the cost of moving through a grid cell when the friction equals 1 . A cost of 5 gces might arise from a movement through 5 cells with a friction of 1 , or 1 cell with a friction of 5 . Thus, a high cost indicates either a long distance over a flat surface or a much shorter distance up a steep slope.

\section{Geomorphic Data}

The geomorphology data (Figure 6.4) were provided by Gnomon, Inc., based on maps prepared by Steve Hall of Red Rock Geological Enterprises. The Azotea Mesa study area was mapped using black-and-white stereo aerial photographs (scale about 1:52,000) and color infrared stereo aerial photographs (scale about 1:86,000) available from the EROS 
Data Center, Sioux Falls, South Dakota. Landforms were identified from the stereo aerial photographs using a Topcon mirror binocular stereoscope at $3 \times$ magnification, and the location and spatial distribution of the landforms were then plotted on 7.5-minute topographic maps (scale 1:24,000), the base-map standard for this project. Landforms smaller than about 200 feet in greatest dimension (ca. one-tenth of an inch on topographic maps and smaller yet on the aerial photos) were not mapped.

The geomorphology of the Azotea Mesa study area is characterized by marine Permian (late Paleozoic) limestone bedrock. A few small streams have eroded moderately deep canyons. The limestone hills are largely denuded of sediments and soils. The limestone is karstic with several sinkhole depressions, especially in the western portion of the study area.

Eroded Bedrock Surfaces. The most prominent geomorphic characteristic of the study area is denuded limestone bedrock. The modern surface of the entire study area is eroded limestone with the exception of stream deposits and areas of lowgradient colluvial flats.

Erosion of old soils that once mantled the landscape and the continued denudation of the limestone may have been initiated during the transition from glacial to postglacial vegetation and climate about 14,000 to 12,000 years ago. Today, the old soils are gone and Permian limestone occurs at the surface. Accordingly, most archaeological sites away from drainages are likely to be found on the eroded surface and are not buried in soils or deposits. Thus, these sites will have near $100 \%$ visibility, although site integrity may have been impacted by erosion and other postdepositional processes.

Alluvium. The drainages in the area are generally high-gradient and incorporate thick deposits of limestone gravels. Topographically high Late Pleistocene terraces are preserved in wider stretches of the narrow canyons, while the stream channels and adjacent floodplains are characterized by Holocene deposits. Most of the deposits are coarse gravels, and very little of the sediment fill is fine-textured. Although many stream valleys contain young deposits, buried archaeological sites may be rare because of continued scour-and-fill processes that dominate the development of these streams. Sites are more likely to be preserved on higher, flat terrace surfaces adjacent to stream channels and along valley margins.

Colluvium. Colluvial silt deposits occupy a large area west of the community of Carlsbad in the eastern portion of the study area. The colluvium is composed of uniformly massive silt (44\%), very fine sand (25\%), and clay (24\%) with occasional scattered small pebbles of caliche and limestone. The colluvium in the Carlsbad area is in excess of $1 \mathrm{~m}$ thick and mantles coarse limestone gravels that represent older (Pleistocene) alluvium and alluvial fans derived from adjacent canyons. Thin mantles of recent colluvium also occur in small areas of low-gradient terrain in the eroded limestone hill country, especially along stream valleys and upland drainages.

The nature and origin of the colluvial deposits have not been previously investigated. The fine texture and recent age of the sediments suggest that they may represent a thin veneer of late Pleistocene loess on the limestone hills that subsequently has been washed and eroded from the hills and redeposited as fine alluvium and colluvium. A second possible explanation is that the fine-textured sediments are a clastic residue from the weathered Permian limestone. Given the relatively recent age of the colluvium, buried sites are possible in this area.

Summary. Most of the Azotea Mesa study area is terrain characterized by denuded Permian limestone. Archaeological sites on these surfaces will have high visibility, but the integrity of artifact distributions and the preservation of features may have been impacted by erosion and other kinds of disturbance. Large and small areas of colluvium may contain buried archaeological materials, although the colluvium is likely to be strongly bioturbated, resulting in some loss of site integrity. Streams in the area are characterized by thick deposits of coarse limestone gravels. While buried sites may occur in the coarse alluvium, they are more likely to occur on flat terrace surfaces topographically above the channels and along valley margins.

\section{Vegetation}

The vegetation data (Figure 6.5) are from the Gap Analysis Program (GAP) of the USGS, which provides information on biodiversity and conservation gaps. The data comprise major vegetation categories that are divided into 17 subcategories, based on common descriptions of vegetation.

As Figure 6.5 shows, most of the vegetation in the study area is Chihuahuan desert grassland, dominated by black grama (Bouteloua eriopoda) and dropseed (Sporobolus flexuosus), and desert scrub dominated by creosotebrush (Larrea 
tridentate), with some areas of chaparral. In the highest elevations is an open woodland of one-seed juniper (Juniperus monosperma). The gross scale at which the vegetation is mapped and the general nature of the vegetation categories do not allow us to observe or model the effects of relatively small patches of highly valued resources such as succulents or seed grasses on the location of past human activities. At best, we can only evaluate general land-use patterns related to vegetation categories.

\section{Archaeological Data}

The dependent variable in the Azotea Mesa model is the presence or absence of precontact archaeological sites. Archaeological data were obtained from the New Mexico Historic Preservation Division's Archaeological Records Management System (ARMS). ARMS provides data on areas that have been the subject of archaeological surveys, the sites that have been recorded, and various characteristics of those sites. Ideally, for this predictive modeling exercise we would have created a series of models by dividing the sites into classes based on time of occupation and/or function. Unfortunately, current knowledge about the archaeological record within the Azotea Mesa study area is not sufficiently detailed to allow us to classify sites into temporal or functional classes. In the absence of clear temporal and functional data, we used site size to create analytical groups. This choice was based on the assumption that size could be an indicator of differences in site function, length of use, and/or the number of times a location was used. Although very

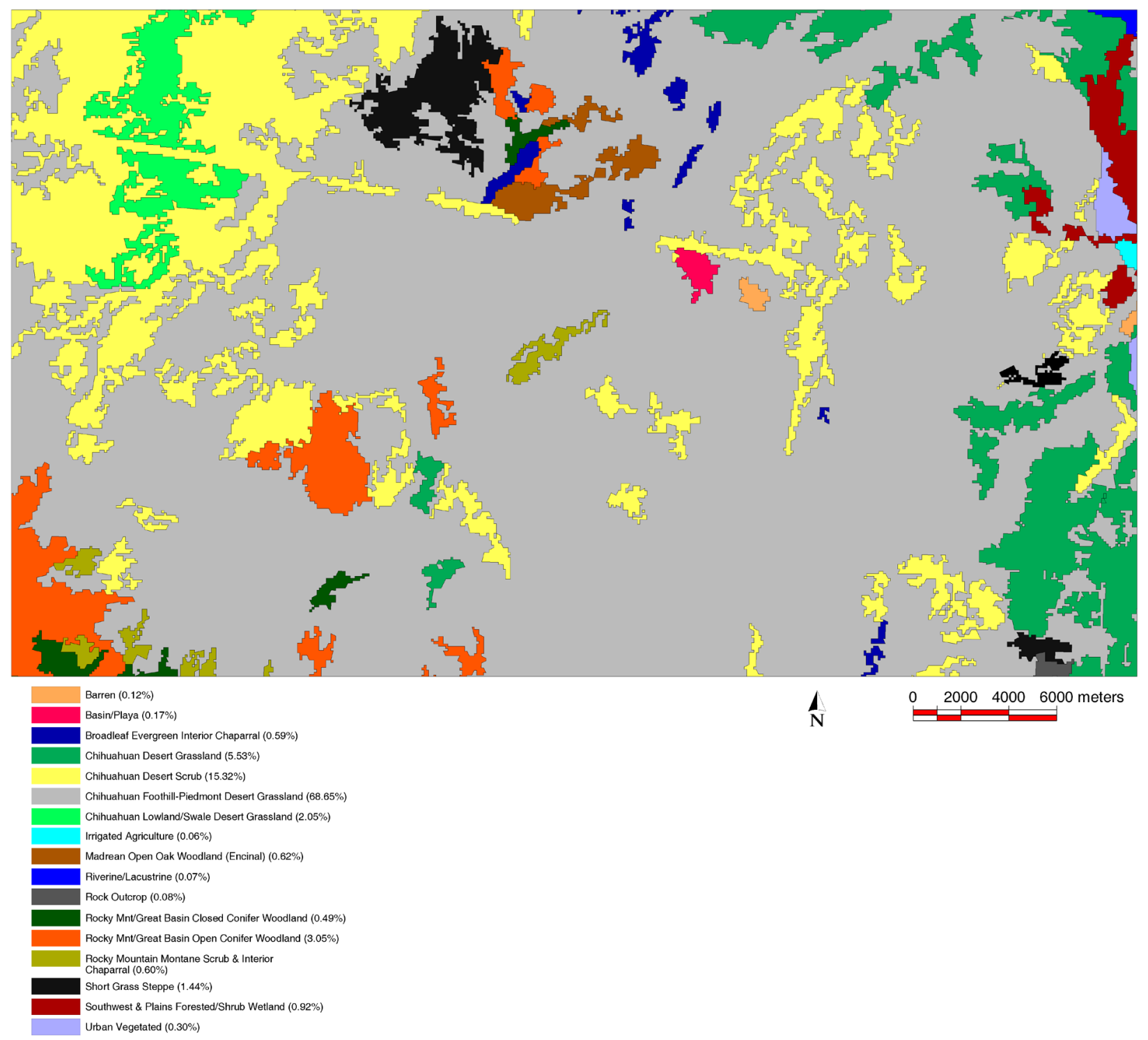

Figure 6.5. Vegetation of the Azotea Mesa study area 
few sites in this area have dates associated with them, we were at least able to distinguish between post-European contact and precontact sites. Because these two temporal categories represent fundamentally different cultural systems, and because other sources of information are available for the later sites, we excluded postcontact period sites from the predictive models.

\section{Site Data}

The archaeological site data provided by ARMS are shown graphically in Figure 6.6. Because the data used in the models are in vector format (a GIS convention that stores spatial data using corresponding point, line, or area features), the site data were provided as polygons, where every site is represented as an area within the GIS theme. Each site polygon is also linked to related information, such as area, site number, and a site description.

GIS data are spatially oriented in real-world coordinates. The ARMS data were already georeferenced in Universal Transverse Mercator (UTM), Zone 13 grid format, using the North American Datum of 1927, which was converted to the North American Datum of 1983. The UTM georeference system is common for archaeological applications, and $x$ and $y$ coordinates are given in meters.

The site data originally contained 935 polygons, each of which supposedly represented one archaeological site. This number was reduced to 550 polygons by combining sites whose polygons overlapped and removing all singlecomponent, postcontact sites. The resulting 550 polygons were converted to raster format for modeling purposes. Sites were transformed into blocks of $30 \times 30 \mathrm{~m}$ cells that encompassed each polygon. The site layer created in this fashion consisted of 12,155 cells coded with 1 when a portion of one of the sites was found in that cell and 1,610,536 cells coded with 0 when they did not contain any portion of any of the sites.

Nearly all sites in the Azotea Mesa study area data were recorded as artifact scatters. Few are described as having features, and even fewer as having temporally diagnostic artifacts. Because the only measurable differences among the sites was size, we divided them into five size classes: very small, small, medium, large, and very large (Table 6.1). Ninety percent of the sites on Azotea Mesa can be classified as very small ( $<7$ acres), with another $7 \%$ falling into the small category (8-26 acres). The sites falling into the medium class ( $27-60$ acres) account for nearly $2.5 \%$ of the total number of sites.

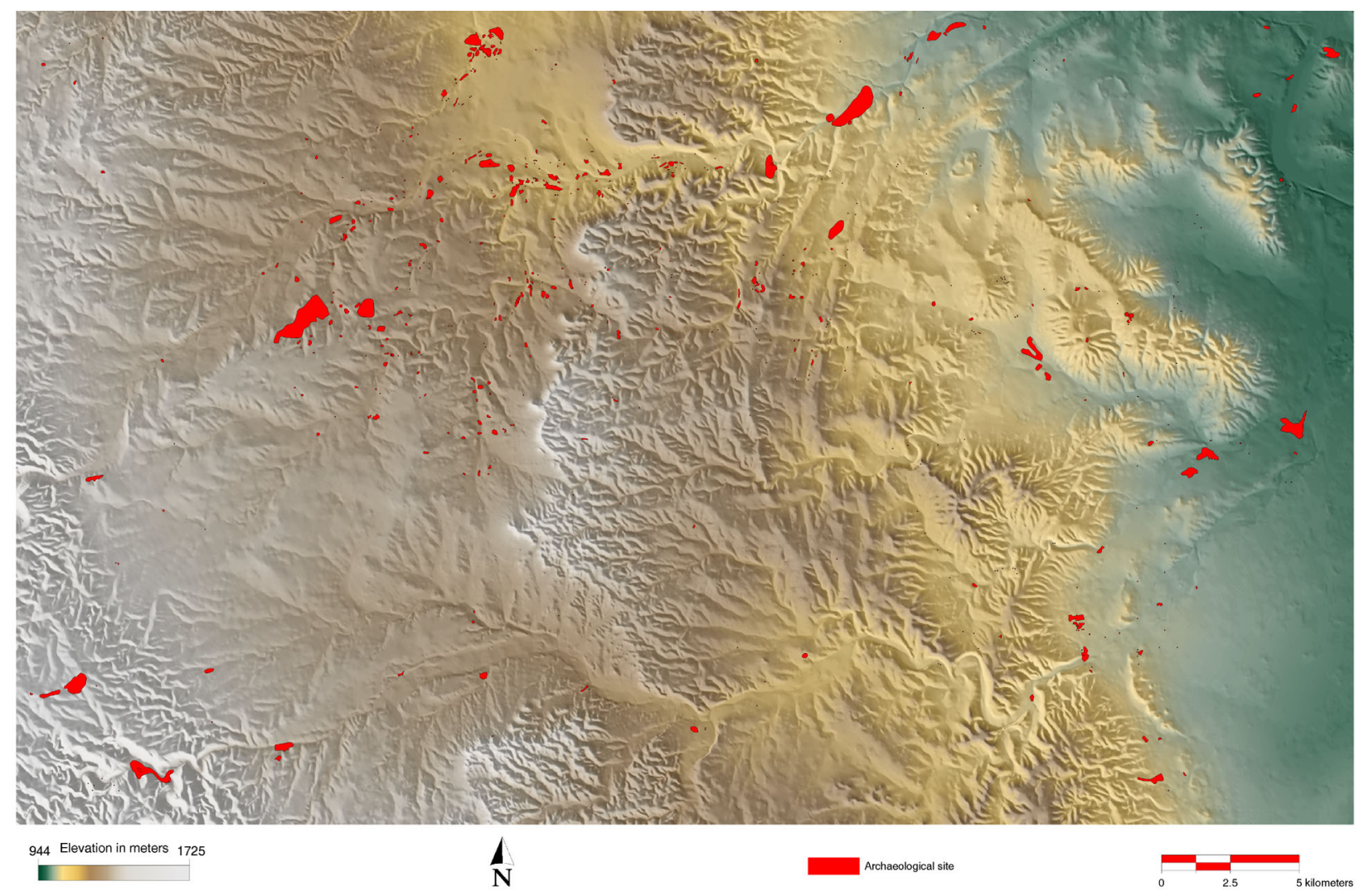

Figure 6.6. Precontact archaeological sites recorded in the Azotea Mesa study area 
Very small sites represent $90 \%$ of all sites, yet they constitute less than $25 \%$ of all site cells; large and very large sites (those exceeding 61 acres), which, combined, constitute just over $1 \%$ of all sites, encompass more than $35 \%$ of all site cells. Although the "very small" site category ranges as large as 7 acres (which would cover 31 cells), the vast majority of these sites are much smaller. The average numbers of cells per site in the very small category is 5.9, or 5,310 $\mathrm{m}^{2}$. Based on our assessment of the ARMS data, most very small sites are sparse artifact scatters.

We wanted to explore the disparity in site size in the course of the modeling exercise, because we postulated that the differences in site size might reflect prehistoric behavioral patterns. If the size differences did, in fact, represent functional differences, we would expect the placement of these sites to be governed by different cultural rules. The choice of location for a camp should be based on a number of factors, such as availability of potable water and flat spaces suitable for basic domestic activities. Resource procurement locations, on the other hand, should be close to the targeted resource and show less regard for factors of slope and the availability of water. Of course, other behavioral interpretations could be put forth. Our purpose here is not so much to provide an analytical interpretation as to discern patterns in the data that could guide and inform future research.

To assess whether site size is related to settlement location, we split the sample. Very small sites were not used in the initial model formulation; instead they served as "test" cases. If we found no difference in the settlement preferences for sites of very different sizes, then we could argue that sites of all sizes followed the same behavioral "rules" in terms of placement. If, on the other hand, sites of different sizes were found to be located in slightly different environmental settings, this might indicate that adaptive patterns on Azotea Mesa were more complex than simple foraging and involved a number of related but differentiated site types.

Table 6.1. Site Classification by Size

\begin{tabular}{lccccc}
\hline Classification & Acres & $\begin{array}{c}\text { Number } \\
\text { of Sites }\end{array}$ & $\begin{array}{c}\text { Number } \\
\text { of Site Cells }\end{array}$ & $\begin{array}{c}\text { Percentage } \\
\text { of Site Cells }\end{array}$ & $\begin{array}{r}\text { Average Number } \\
\text { of Cells per Site }\end{array}$ \\
\hline Very small & $0.1-7$ & 494 & 2917 & 24 & 5.9 \\
Small & $8-26$ & 37 & 2188 & 18 & 59.1 \\
Medium & $27-60$ & 13 & 2674 & 22 & 205.7 \\
Large & $61-100$ & 4 & 1337 & 11 & 334.3 \\
Very large & $>100$ & 2 & 3039 & 25 & $1,519.5$ \\
Total & N/A & 550 & 12,155 & 100 & 22.1 \\
\hline
\end{tabular}

\section{Survey Data}

In addition to providing the archaeological site data, ARMS provided data on all of the archaeological surveys that had been performed within the Azotea Mesa study area through the 2002 cutoff date (Figure 6.7). As with the site data, each survey polygon is linked to related information, such as area, identification number, and some basic methodological descriptions, within the vector database. The ARMS data contained information on 1,233 surveys totaling 33,960 acres.

\section{Confidence and Statistical Independence}

Once the environmental and cultural resource data had been acquired and the GIS layers assembled, each environmental theme was reviewed to determine whether the areas covered by archaeological surveys adequately represent the target environmental attributes. If the environmental variability within the survey areas is representative of the environmental variability within the study area as a whole, we can have confidence that any association between the environmental variables and site locations found in the models discussed below is an accurate reflection of the relationship between environment and site locations in the larger study area.

Ideally, of course, surveys would have been designed and carried out to ensure adequate sampling of the environmental zones through probabilistic techniques. In reality, the surveys were performed as part of compliance procedures for oil and gas development; they were located without reference to environmental factors and with no attention to providing a "random" sample in the statistical sense.

We began our efforts to assess the representativeness of the Azotea Mesa survey data by examining Figure 6.7. It is clear that linear surveys, such as those performed prior to road construction or seismic exploration, have occurred throughout Azotea Mesa. These surveys have sampled all environmental settings to some degree. Leasehold developments, in contrast, have been concentrated in two blocks in the northwest and north-central portions of the study area. It is possible, then, that strong biases exist in the sample represented by the archaeological surveys. 


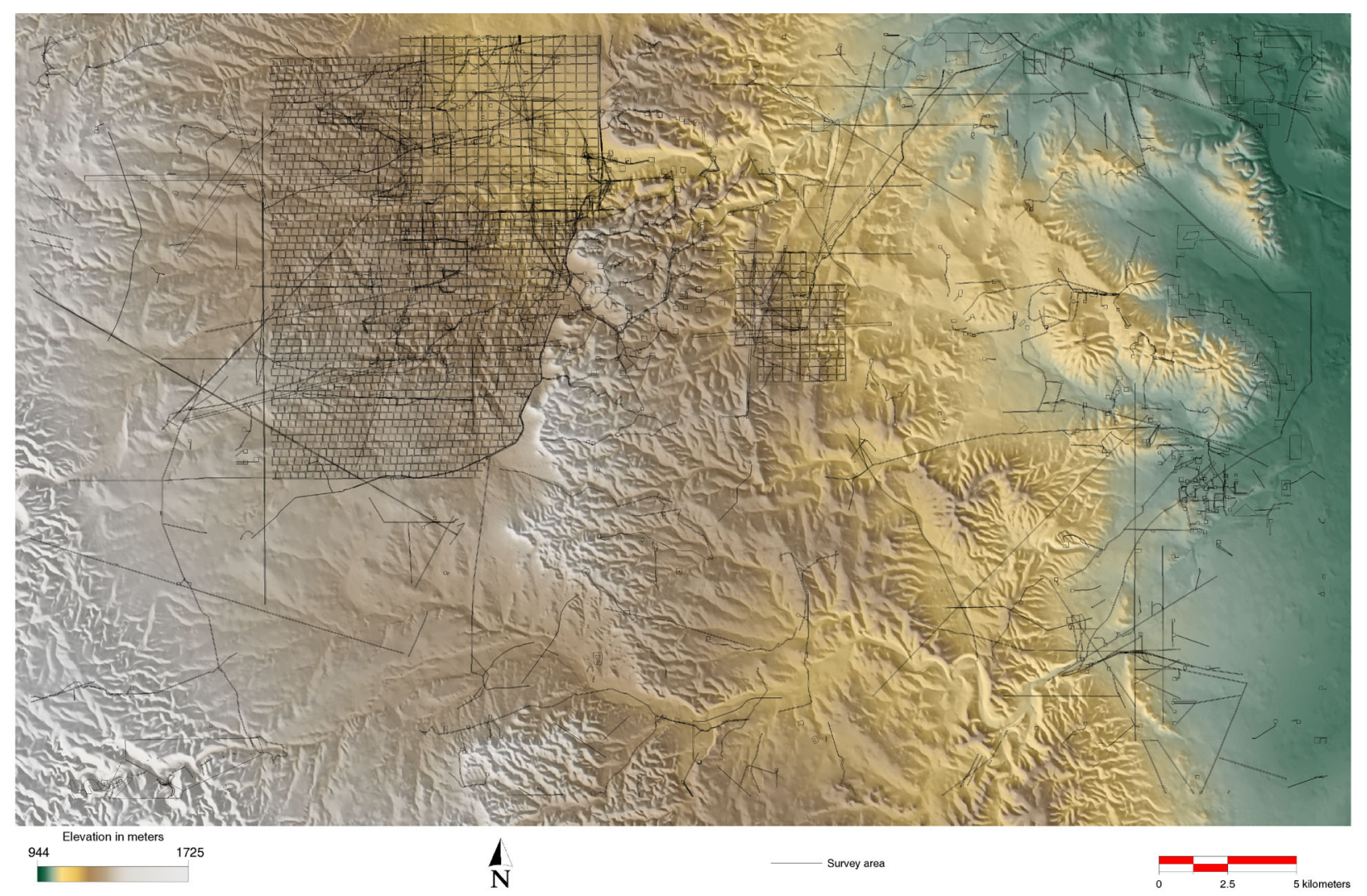

Figure 6.7. Survey data from Azotea Mesa

If we are going to generalize from the results of the compliance-driven cultural resource surveys, we must first demonstrate that there is no bias in the survey coverage. If we are unable to demonstrate that the survey data are unbiased, we need to compensate for any bias before generalizing to the larger study area the relationship between environmental variables and archaeological site locations found in the surveyed areas. One approach would be to compute a difference of means test between the area surveyed and the entire GIS raster for each variable. Given the number of cells in the study area, such a test will almost assuredly show a significant difference between the population and the sample at a 0.05 or 0.001 significance level. We are less concerned, however, that the surveyed areas meet a statistical benchmark than we are with ensuring that there are no gross differences between the sample and the population. To gain this confidence, we have found that a simple visual assessment often provides the confidence needed to proceed with the modeling exercise.

We begin by creating a histogram of the distribution of the individual values for a particular environmental variable for the entire study area. This histogram is then compared visually with a similar histogram for the areas covered by archaeological surveys. If the two histograms are similar in shape, and if the surveys cover at least $9-10 \%$ of the variable's area, then we can assume that the raster cells that fall in the surveyed areas can be taken as a representative sample for that particular environmental variable. As an example of this process, the histogram for the slope of all cells in Azotea Mesa shown in Figure 6.8 is nearly identical to that for cells that have been covered by archaeological surveys (Figure 6.9), indicating that all slopes present in Azotea Mesa are adequately represented by the surveyed areas.

Similar pairs of histograms were generated and visually compared for all environmental variables. This analysis indicated that the surveyed cells adequately represent the values for all environmental variables.

Beyond demonstrating that the environment of the surveyed areas adequately represents the general Azotea Mesa environment, we want to be sure that the environmental variables that will be used in the predictive models are statistically independent of each other. Statistical independence is an assumption of most statistical techniques that involve multiple variables. Violations of this assumption often lead to overstating the predictive power of the resulting model. For example, soils and vegetation are often very closely related; that is, certain vegetation only grows on particular soil types. By including both variables as predictors, one runs the risk of having the predictive value inflated. 
To guard against inclusion of independent variables that are related to each other, we used IDRISI to calculate the pair-wise Spearman's $r$ scores for each set of environmental variables (Table 6.2). IDRISI takes each raster layer, which represents a single variable, and calculates a pair-wise Spearman's $r$ score with all other raster layers. Because Spearman's $r$ assumes variables scored on a continuous scale, the results for rank-order variables are meant more as an indication of possible variable interactions than as a meaningful score. Even with this caveat, it is instructive that no $r$ score exceeded 0.6 , and all but three were below 0.5. Based on these results, the variables being used as predictors in the models can be accepted as statistically independent. To test this conclusion further, we calculated the logistic regression model (developed and discussed below) both with and without the three most interrelated variables: slope, cost distance to drainages, and cost distance to ridges. The results of the two logistic regression models were very similar $(r=0.92)$.

A second concern when developing geographic models is spatial autocorrelation. If knowing the value of one cell helps us to guess the value of nearby cells, then the distribution of that variable is said to exhibit spatial autocorrelation. This property violates the assumption that variable scores are distributed randomly over the study area. Yet, most of the variables used in the Azotea Mesa model are not randomly distributed. Knowing the slope of one cell, for example, allows one to guess within reason the slope of its neighbor. To overcome spatial autocorrelation, we used a feature of IDRISI that placed a "filter" over the Azotea Mesa grid. The program selects a 10\% random sample of cells, which we then used to represent the environment.

It is important to note that this filter was not used on the archaeological site layer. For that layer, all cells containing portions of sites in all size categories except "very small" were used in the initial modeling. Spatial autocorrelation, then, could enter into the models because large sites contain many contiguous cells. By separating small sites as a test case, we have an independent test of the influence of spatial autocorrelation. If the models for large sites and small sites are similar then spatial autocorrelation is not a factor. Otherwise, we will need to revisit this issue.

\section{Variable Evaluation}

The next step in the modeling process is to determine which environmental variables are associated with site location. Those that are found to have been either favored or avoided by humans are then used in the modeling efforts. For continuous variables (i.e., those with values measured on an interval scale, such as slope, elevation, and distance to drainages), we tested for significance by using simple one-mean $z$-score tests. If a $z$-score was significant at the 0.05 level (>1.96), the layer was deemed statistically significant with reference to site distribution. The $z$-score is computed by the formula

$$
z=\frac{\text { sample mean }- \text { population mean }}{\text { population standard deviation / square root of sample size }}
$$

where the "population" is made up of cells representing the entire study region and the "sample" is composed of cells that contain archaeological sites. The test determines how different the sample (cells with sites) is from the overall background environment (population). According to Kvamme (1990), the $z$-score test is better than a conventional $t$-test at identifying associations between variables. The $z$-score test is less influenced by spatial autocorrelation and more sensitive to variable association because it considers the entire study area as a population and the sites as a sample of that population. For modeling purposes, we want to include those variables for which sites cells are found to be significantly different from the general population of cells.

An example may make this evaluation process more clear. For slope, we find that the mean score for cells with larger archaeological sites (i.e., eliminating the very small site category) is $3.457^{\circ}$, whereas the average slope for the entire study area is $4.57^{\circ}$. To determine if sites really fall on less-steep landforms, we need to divide the population mean by the quotient of its standard deviation (5.068) divided by the square root of the number of cells containing sites. Or,

$$
z=(3.457-4.57) /(5.068 / \sqrt{ } 9526)=-21.43
$$

The $z$-score should fall between -1.96 and 1.96 if there is no relationship between site location and slope, assuming a relatively low risk (5\%) of being wrong by chance alone. A score of -21.43 indicates there is a relationship between the variables. Accordingly, slope will be included in the modeling effort.

For categorical variables (i.e., variables measured by mutually exclusive states, as is the case for geomorphology or vegetation), we assessed the relationship between cells that contain portions of sites and cells that represent the entire study area using a chi-square goodness-of-fit test. Each state of a categorical variable was tested separately. For example, eroded limestone is a state of the geomorphology variable. Cells with eroded limestone and sites were compared with 


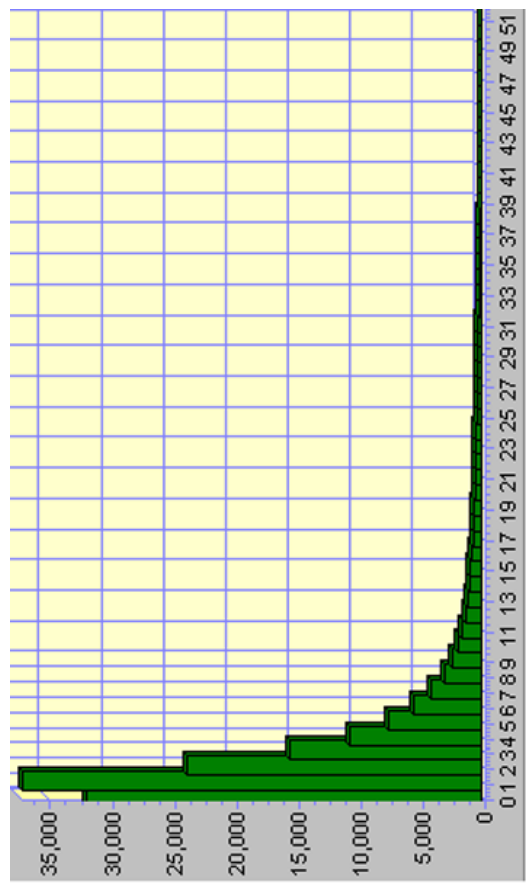

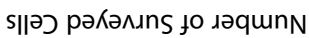

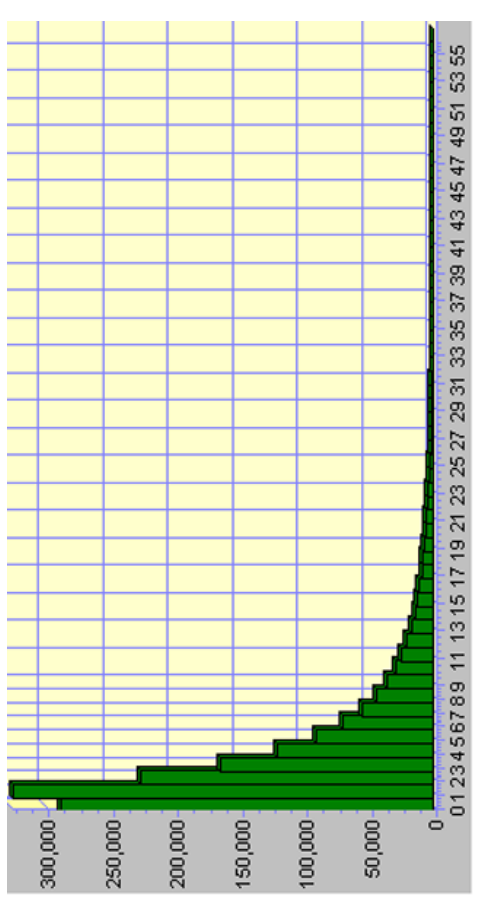

s॥ə弓 m Ol x ol fo גəqunN

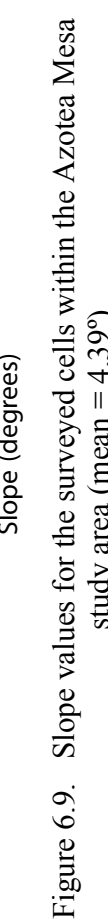

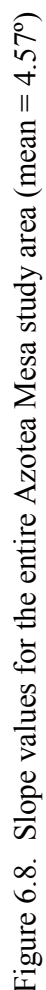

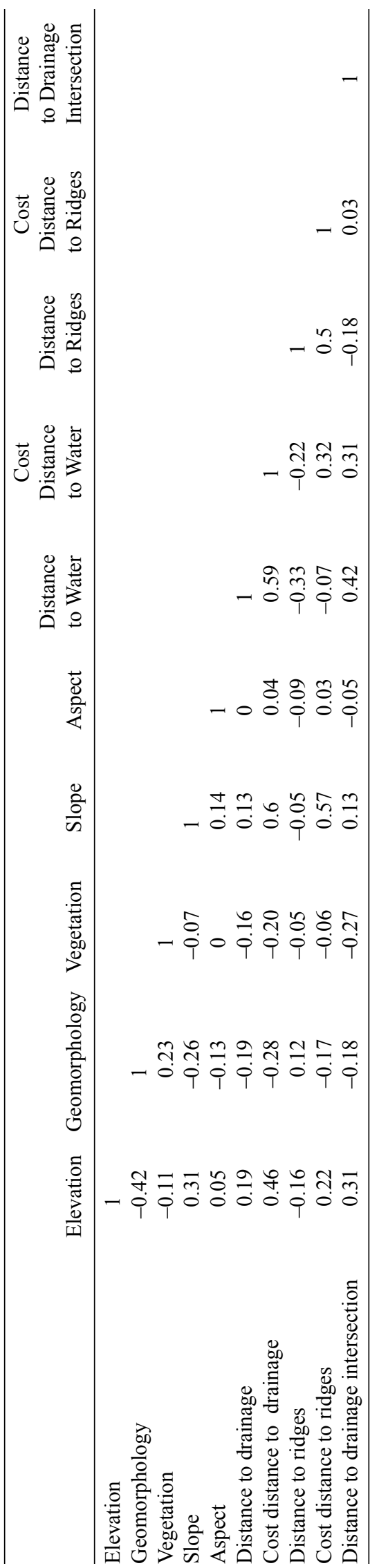


all cells characterized by eroded limestone. If a significant relationship at the 0.05 level was found to exist, that state for that categorical value was used for modeling.

Chi-square values are computed according to the following formula:

$$
\chi^{2}=\sum_{i=1}^{c} \frac{\left(\mathrm{O}_{i}-\mathrm{E}_{i}\right)^{2}}{\mathrm{E}_{i}}
$$

where $\mathrm{O}$ is the observed number of cells with sites in each state of a categorical variable and $\mathrm{E}$ is the expected number of cells with sites based on the proportion of the study area covered by that variable state. For example, if eroded limestone covers $50 \%$ of the study area then the expected number of site cells found on eroded limestone should be $50 \%$ of the total number of site cells. Chi-square scores exceeding 124.34 at 100 degrees of freedom are significant at the 0.05 level. Using 100 degrees of freedom is extremely conservative for categorical variables. For example, the degrees of freedom for a matrix of three categorical geomorphic variables (e.g., eroded bedrock, floodplains, and river terraces) is 2 (number of categories [3] - 1). A chi-square score of 5.99, well under the score of 124.34 used here, is significant at the 0.05 level. For continuous variables, however, the degrees of freedom can be much larger than 100 . We chose this figure because the probability calculations for 100 degrees of freedom are readily available. Table 6.3 presents the geomorphological variables that have significant chi-square scores.

Based on the $z$ - and chi-square scores, we included 11 environmental variables in the Azotea Mesa predictive models: four variables related to aspect (north-, south-, east-, and west-facing), two vegetative zones (short grass steppe and Chihuahuan foothill-piedmont desert grassland), two geomorphic variables (river terraces and eroded bedrock), elevation, distance to streams, and slope. The last three variables are continuous variables measured on an interval scale, whereas the aspect, vegetative, and geomorphic variables are all categorical.

Table 6.3. Chi-square Goodness-of-Fit Scores for Significant Geomorphology Categories

\begin{tabular}{lccc}
\hline Geomorphology & Eroded Bedrock & $\begin{array}{c}\text { Floodplains of Small Drainages } \\
\text { with Thin Holocene Deposits }\end{array}$ & River Terraces \\
\hline Proportion & 0.827 & 0.027 & 0.005 \\
Site cells & 5640 & 494 & 397 \\
Expected & 7878 & 257 & 48 \\
Chi-square & 636 & 219 & 2538 \\
\hline
\end{tabular}

\section{Sensitivity Models}

There are many different types of predictive models, ranging from subjective statements about where archaeologists have found sites in a region to highly sophisticated multivariate statistical models (see Chapter 4). For Azotea Mesa, we used three modeling techniques: Boolean intersection, weighted method, and logistic regression. All three allow the use of variables measured on different scales, although the first two require transforming data measured on interval scales into data measured on ordinal or nominal scales. The weighted method and logistic regression are discussed in briefly in Chapter 5 and in more detail in Chapter 4; the Boolean model, which was not used in Loco Hills, is described briefly below and in more detail in Chapter 4.

A Boolean model is perhaps the simplest of all predictive modeling techniques. Every cell of the digital study region is classified as either "site" or "non-site" based on one rule. "Sites" are defined as cells that score favorably on every environmental variable; "non-sites" contain one or more unfavorable environmental scores. For example, if $90 \%$ of all the cells with known sites are located within $500 \mathrm{~m}$ of drainages and on slopes of less than $10^{\circ}$, then the GIS layers for distance to drainage and slope can be "clipped" to those ranges and intersected within the GIS. The result is a single layer that has a value of 1 or 0 , where 1 indicates an area likely to contain a site and 0 indicates an area that is not likely to contain a site. Although simple, Boolean intersection models work well in areas characterized by strong spatial autocorrelation and where environmental variables exert an overwhelming influence on human settlement. In the remainder of this section, we present the results of the three modeling techniques. We begin with the simplest (Boolean) and end with the most complex (logistic regression). 


\section{Boolean Model}

The first step in creating a Boolean model is to define those states that are favorable for human settlement for each variable. For categorical variables, this step involves simply determining the appropriate states. For continuous variables we need to define break points, or cutoff ranges, for each variable that distinguish the cells likely to contain sites from those that probably do not. In Boolean models, it is preferable to be generous with categorical states and cutoff ranges because the intersecting properties of the method have a tendency to greatly reduce the favorable zone. For each variable, we chose states and cutoff ranges such that a large percentage (80-95\%) of the known site cells were included in the favorable category (Table 6.4).

For continuous variables, we used the variable range that contained $90 \%$ of the site cells in the smallest area. For categorical variables, states were chosen for inclusion based on their proportional significance; that is, variable states that had the highest proportion of site cells to total cells were chosen first as favorable until $90 \%$ of all site cells were included in the favorable state. This approach may seem counterintuitive because it allows some states, such as the Rocky Mountain/Great Basin Conifer vegetative community, to be considered favorable, when this area is exceedingly small and contains few site cells. Yet, proportionally, this vegetative community meets the selection criteria. To eliminate it simply because of its size would make the modeling process subjective and impossible to replicate objectively.

The sensitivity map generated by the Boolean model is presented in Figure 6.10. The locations of sites used to develop the model are shown in white. The blue polygons represent site areas that are not correctly predicted by the model. For the Boolean model, 11 sites contain cells located in areas identified as unlikely to contain sites. Two of these sites were also not correctly predicted by the other two modeling techniques. These two sites will be discussed in more detail below.

The Boolean model was tested using the Gain Statistic (Kvamme 1988), which compares the proportion of site cells correctly located with the proportion of the model area that contains sites. The score can range from $-\infty$ to 1 , where 1 is a perfect relationship. A score of 1 does not necessarily mean the model works well. More often, a high score is indicative of overmodeling in which the variables are so highly trained on the data set that they are not reflective of larger settlement patterns. For instance, in the case of Azotea Mesa, if the Gain score were 1 then the model would predict that sites would only occur at the locations of the site cells used in model development. This would be a very poor model because it would not predict where sites could be found in the future.

Table 6.4. Boolean Model Variables

\begin{tabular}{lccc}
\hline $\begin{array}{l}\text { Environmental Variable } \\
\text { (favored categorical states) }\end{array}$ & $\begin{array}{c}\text { Cutoff Range for } \\
\text { Continuous Variables }\end{array}$ & $\begin{array}{c}\text { \% of Site Cells } \\
\text { Contained in Favored } \\
\text { State/Range }\end{array}$ & $\begin{array}{c}\text { \% of Study Area } \\
\text { Contained in Favored } \\
\text { State/Range }\end{array}$ \\
\hline Elevation & $958-1400 \mathrm{~m}$ & 89 & 94 \\
GEOMORPHOLOGY & - & 5 & 0.47 \\
River terraces & - & 10 & 4 \\
Floodplains of large drainages & - & 67 & 82 \\
Eroded bedrock & - & 6 & 3 \\
Floodplains of small drainages & - & 4 & 1 \\
VEGETATION & - & 0.1 & 0.5 \\
Shortgrass steppe & - & 65 & 15 \\
Rocky Mtn./Great Basin closed conifer & - & 94 & 68 \\
Chihuahuan desert scrub & $0-195$ & 96 & 96 \\
Chihuahuan foothill-piedmont grassland & $0-1180 \mathrm{~m}$ & 94 & 96 \\
Distance cost to ridge & $0-170$ & 93 & 89 \\
Distance from ridges & $0-1300 \mathrm{~m}$ & 91 & 90 \\
Distance cost to drainage & $\mathrm{N}, \mathrm{S}, \mathrm{E}$ & 96 & 84 \\
Distance from drainages & $0-9^{\circ}$ & 93 & 89 \\
Aspect & $0-3200 \mathrm{~m}$ & & 92 \\
Slope & & & \\
Distance from drainage intersection & & & \\
\hline
\end{tabular}




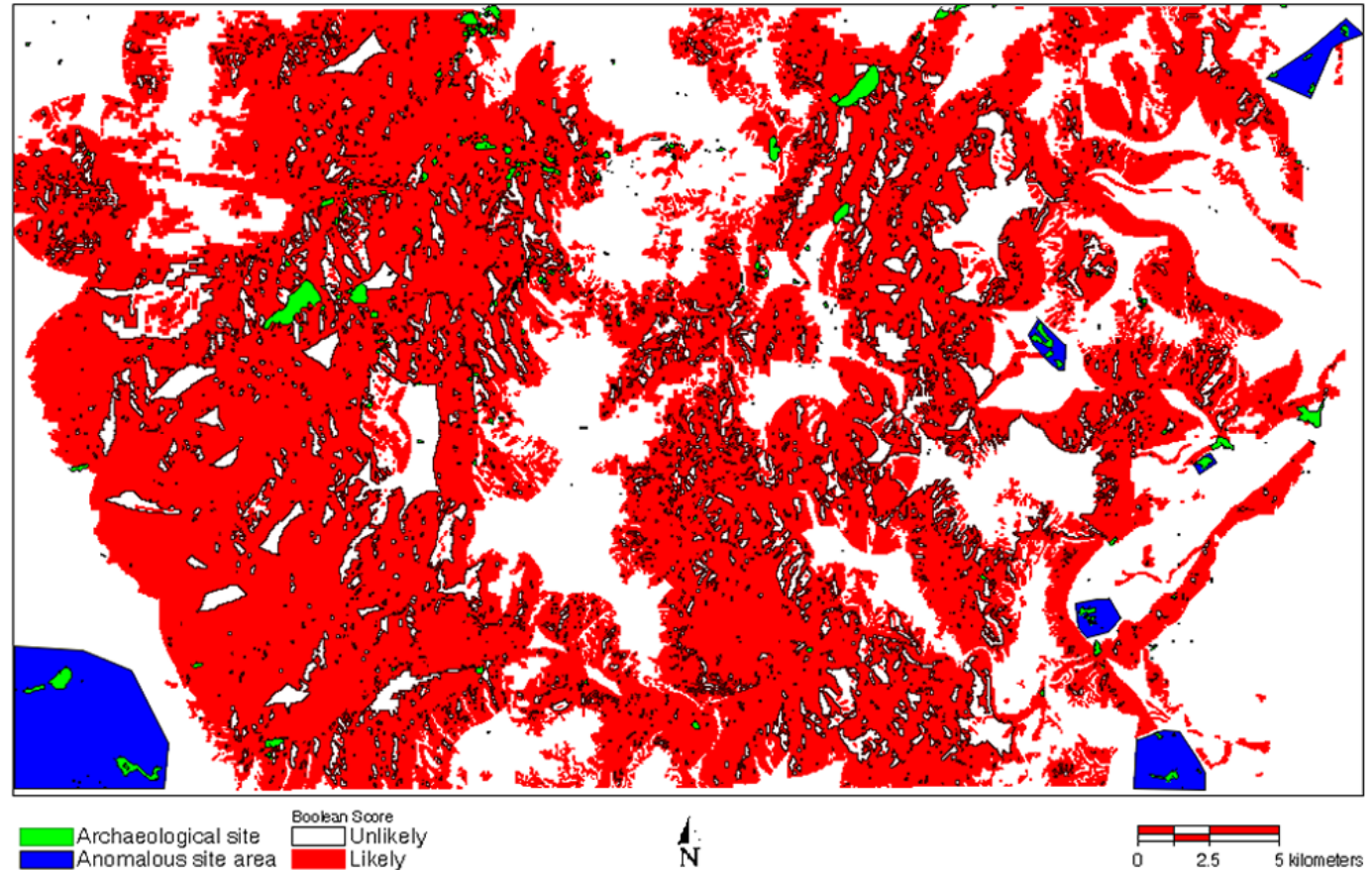

Figure 6.10. Boolean model: 0 (white) = site unlikely, $1(\mathrm{red})=$ site likely; sites are in green, and blue polygons are sites that are not captured by the model (i.e., that occur in "unlikely" locations).

The Gain Statistic is calculated as

Gain Statistic $=1-$ (proportion of model area / proportion of site cells correctly located) Gain $=1-(0.46 / 0.58)=0.21$

A gain score of 0.21 indicates a weak model. To measure exactly how weak, we calculated the model's performance relative to a random predictor by applying the equation

Gain over random $=$ proportion of site cells correctly located - proportion of model Gain over random $=0.58-0.46=0.12$

This score means that our chance of locating an archaeological site cell by using the Boolean model is only about $12 \%$ better than if we were to pick areas randomly.

Finally, we used the locations of sites in the "very small" site class as independent test data. The scores for very small sites are:

Gain Statistic for small site class $=1-(0.46 / 0.62)=0.26$

Gain over random $=0.62-0.46=0.16$

The Boolean model predicts the locations of very small sites with about the same success rate as it predicts the locations of the larger ones used to develop the model. This could mean that small sites are located in settings similar to those of large sites. Alternatively, because the model is a relatively poor predictor, it may be that only a small proportion of small and large sites follows the same settlement rules, with other sites in each category reflecting behavioral patterns that are not captured. Indeed, what the statistics really demonstrate is that, at least in this particular environmental setting, the Boolean model is not a strong predictor of any type of archaeological site. The exercise of developing this model was important, however, because many archaeologists and managers rely entirely on these types of intersection models and, at least for Azotea Mesa, such reliance would be misplaced. 


\section{Weighted Model}

The weighted model depends on a more sophisticated intersection technique than the Boolean model. Each variable is divided into categorical states that are then weighted by virtue of the strength of their relationship with archaeological site location. For Azotea Mesa, we calculated the weights by first determining the proportion of the study area covered by each categorical variable as well as the proportion of site cells coded as being in each category. By subtracting the proportional representation of each categorical variable in the environment from the proportional site coverage, we derive weights, rounded to the nearest integer value, that vary from -26 to 27 . Negative weights indicate that humans tended to avoid these environment features when selecting locations for their activities; positive weights suggest just the opposite.

Table 6.5 lists the environmental variables, the cutoff ranges, the proportion of site cells in each variable state/ range, and the proportion of the study area in each variable state/range. The last column in the table provides the weighted scores for each variable that were used to construct the weighted model.

Once the variables were weighted, the variable scores for each cell were added together. Table 6.6 presents the results in relation to the area and the proportion of site cells associated with various score ranges. The final step was to reclassify the scores into four categories that best represent site sensitivity. In this case, the four sensitivity categories were coded as poor (1), average (2), good (3), and excellent (4). A fifth category (coded 0 in Table 6.6) was disregarded because of the small size of the area it covered.

Figure 6.11 presents the sensitivity map for the weighted model with sites overlain in black. Seven sites had more than $90 \%$ of their cells fall in poor areas; these are outlined with white polygons (the size of the polygons has been enlarged to enhance visibility). Of these, three sites were also classified as being in average or poor areas by the logistic regression model; these sites are discussed later in this chapter.

As with the Boolean model, we used two statistics, Gain Statistic and Gain over Random, to evaluate the weighted model. For these statistics, the proportion of the model area is defined as the cells classified as good and excellent for site sensitivity.

Gain Statistic $=1-$ (proportion of model area $/$ proportion of sites correctly located)

Gain $=1-(0.43 / 0.70)=0.39$

The Gain score shows that the weighted model performs considerably better than the Boolean model. We also tested the weighted model using a Gain over Random score:

Gain over Random $=$ proportion of sites correctly located - proportion of model

Gain over Random $=0.70-0.43=0.27$

The weighted model allows one to predict archaeological site locations with about a $27 \%$ better chance of being correct than if one guesses randomly. The weighted model, then, is about $6 \%$ more accurate than the Boolean model.

We also tested the weighted model using the cells containing sites in the "very small" category as an independent test group. As stated above, the very small sites were not used in the development of the model, and thus can be used as a blind test group.

Gain Statistic for small site class $=1-(0.43 / 0.67)=0.36$

Gain over Random $=0.67-0.43=0.24$

The placement of small sites is predicted with about the same accuracy as that of larger sites. This suggests that small sites are located according to the same human "calculus" as larger sites. The weights in Table 6.6 make it clear that the most important factor in human settlement on Azotea Mesa involves water. Sites are found close to drainages, away from ridges, and in places where the effort to reach water was minimal (i.e., flat land near drainages). The effects of these variables are illustrated in Figure 6.11, which shows the linear and dendritic nature of site sensitivity.

Although the model accurately predicts about $70 \%$ of site locations, it is not a particularly powerful model. We need almost $40 \%$ of the area to be classified as good or excellent in terms of site sensitivity to capture this high a proportion of sites. The inability to hone the area down to a smaller "favored" zone suggests that the Azotea Mesa study area lacks the environmental diversity that would have been necessary to shape human behavior into more recognizable patterns. The weighted model indicates that people spread out over much of Azotea Mesa, with only a modest tendency to keep close to drainages. 
Table 6.5. Weighted Model Variables

\begin{tabular}{|c|c|c|c|c|}
\hline Environmental Variable & $\begin{array}{c}\text { Cutoff Range for } \\
\text { Continuous Variables }\end{array}$ & $\begin{array}{c}\% \text { of Site Cells } \\
\text { Contained in State/Range }\end{array}$ & $\begin{array}{c}\% \text { of Study Area } \\
\text { Contained in State/Range }\end{array}$ & $\begin{array}{l}\text { Weighted } \\
\text { Score }\end{array}$ \\
\hline \multicolumn{5}{|l|}{ VEGETATION } \\
\hline Rocky Mtn. closed conifer & - & 0.1 & 0.5 & 0 \\
\hline Rocky Mtn. open conifer & - & 5.27 & 3.01 & 2 \\
\hline Madrean open oak woodland & - & 0 & 0.6 & -1 \\
\hline Rocky Mtn. montane scrub & - & 1.6 & 0.6 & 1 \\
\hline Broadleaf evergreen interior chaparral & - & 0 & 0.6 & -1 \\
\hline Chihuahuan desert scrub & - & 17 & 15 & 2 \\
\hline Shortgrass steppe & - & 4 & 1 & 3 \\
\hline Chihuahuan desert grassland & - & 4.23 & 5.47 & -1 \\
\hline Chihuahuan foothill-piedmont grassland & - & 65 & 68 & -3 \\
\hline Chihuahuan lowland/swale desert grassla & land & 0 & 2 & -2 \\
\hline Southwest plains forested/shrub wetland & - & 0.5 & 0.9 & 0 \\
\hline Irrigated agriculture & - & 0 & 0.06 & 0 \\
\hline Barren & - & 0 & 0.1 & 0 \\
\hline Rock outcrop & - & 0 & 0.08 & 0 \\
\hline Urban vegetated & - & 0 & 0.3 & 0 \\
\hline Riverine/lacustrine & - & 0.05 & 0.07 & 0 \\
\hline Basin playa & - & 0 & 0.2 & 0 \\
\hline \multicolumn{5}{|l|}{ GEOMORPHOLOGY } \\
\hline Eroded bedrock & - & 67 & 82 & -15 \\
\hline Floodplains of small drainages & - & 6 & 3 & 3 \\
\hline Floodplains of large drainages & - & 10 & 4 & 6 \\
\hline River terraces & - & 5 & .5 & 5 \\
\hline Alluvium & - & 0 & 0.02 & 0 \\
\hline Thick, uneroded Holocene deposits & - & 0 & 0.03 & 0 \\
\hline Playa deposits & - & 0 & 0.003 & 0 \\
\hline Recent slope-wash deposits & - & 3.3 & 1.48 & 2 \\
\hline Extensive slope-wash deposits & - & 8.07 & 8.6 & -1 \\
\hline Cave or rockshelter & - & 0 & 0.0007 & 0 \\
\hline Historically recorded spring & - & 0.03 & 0.002 & 0 \\
\hline \multirow[t]{3}{*}{ Elevation } & $950-1320 \mathrm{~m}$ & 85.85 & 81.48 & 4 \\
\hline & $1320-1500 \mathrm{~m}$ & 7.94 & 15.17 & -7 \\
\hline & $1500-1720 \mathrm{~m}$ & 6.21 & 3.35 & 3 \\
\hline \multirow[t]{3}{*}{ Distance cost to ridges } & $0-102$ & 89.43 & 88.08 & 1 \\
\hline & $102-230$ & 4.58 & 8.71 & -4 \\
\hline & $230-500$ & 5.99 & 3.21 & 3 \\
\hline \multirow[t]{4}{*}{ Distance from ridges } & $0-470 \mathrm{~m}$ & 40.75 & 61.67 & -21 \\
\hline & $470-1180 \mathrm{~m}$ & 54.86 & 34.56 & 20 \\
\hline & $1180-2000 \mathrm{~m}$ & 4.39 & 2.47 & 2 \\
\hline & $>2000 \mathrm{~m}$ & 0 & 1.3 & -1 \\
\hline \multirow[t]{4}{*}{ Distance cost to drainages } & $0-50$ & 73.23 & 53.64 & 20 \\
\hline & $50-120$ & 18.08 & 28.55 & -10 \\
\hline & $120-250$ & 8.69 & 13.59 & -5 \\
\hline & $>250$ & 0 & 4.22 & -4 \\
\hline \multirow[t]{4}{*}{ Distance from drainages } & $0-600 \mathrm{~m}$ & 82.17 & 54.88 & 27 \\
\hline & $600-1400 \mathrm{~m}$ & 11.61 & 37.62 & -26 \\
\hline & $1400-1920 \mathrm{~m}$ & 6.22 & 5.69 & 1 \\
\hline & $>1920 \mathrm{~m}$ & 0 & 1.81 & -2 \\
\hline \multirow[t]{4}{*}{ Distance from drainage intersections } & $0-2100 \mathrm{~m}$ & 62.57 & 66.86 & -4 \\
\hline & $2100-3600 \mathrm{~m}$ & 35.65 & 28 & 8 \\
\hline & $3600-4860 \mathrm{~m}$ & 1.78 & 3.09 & -1 \\
\hline & $>4860$ & 0 & 2.05 & -2 \\
\hline \multirow[t]{4}{*}{ Aspect } & North & 34.91 & 27.81 & 7 \\
\hline & East & 39.34 & 37.76 & 2 \\
\hline & South & 16.52 & 19.33 & -3 \\
\hline & West & 9.23 & 15.1 & -6 \\
\hline \multirow[t]{4}{*}{ Slope } & $0-9^{\circ}$ & 94.03 & 85.25 & 9 \\
\hline & $9-17^{\circ}$ & 3.64 & 10.03 & -6 \\
\hline & $17-33^{\circ}$ & 2.33 & 3.41 & -1 \\
\hline & $>33^{\circ}$ & 0 & 1.31 & -1 \\
\hline
\end{tabular}


THE AZOTEA MESA STUDY AREA

Table 6.6. Weighted Model Scores and Reclassification

\begin{tabular}{cccc}
\hline Model Score & $\begin{array}{c}\text { Proportion } \\
\text { of Study Area }\end{array}$ & $\begin{array}{c}\text { Proportion } \\
\text { of Site Cells }\end{array}$ & Reclassification \\
\hline-100 to -80 & 0.62 & 0 & 0 \\
-79 to -60 & 10.05 & 0.84 & 1 \\
-59 to -40 & 12.65 & 7.23 & 1 \\
-39 to -20 & 12.09 & 6.28 & 2 \\
-19 to 0 & 12.65 & 7.25 & 2 \\
$1-20$ & 9.04 & 8.11 & 2 \\
$21-40$ & 15.29 & 15.36 & 3 \\
$41-60$ & 8.77 & 9.53 & 3 \\
$61-80$ & 14.32 & 28.06 & 4 \\
$81-100$ & 4.51 & 16.94 & 4 \\
$101-120$ & 0.02 & 0.4 & 4 \\
\hline
\end{tabular}

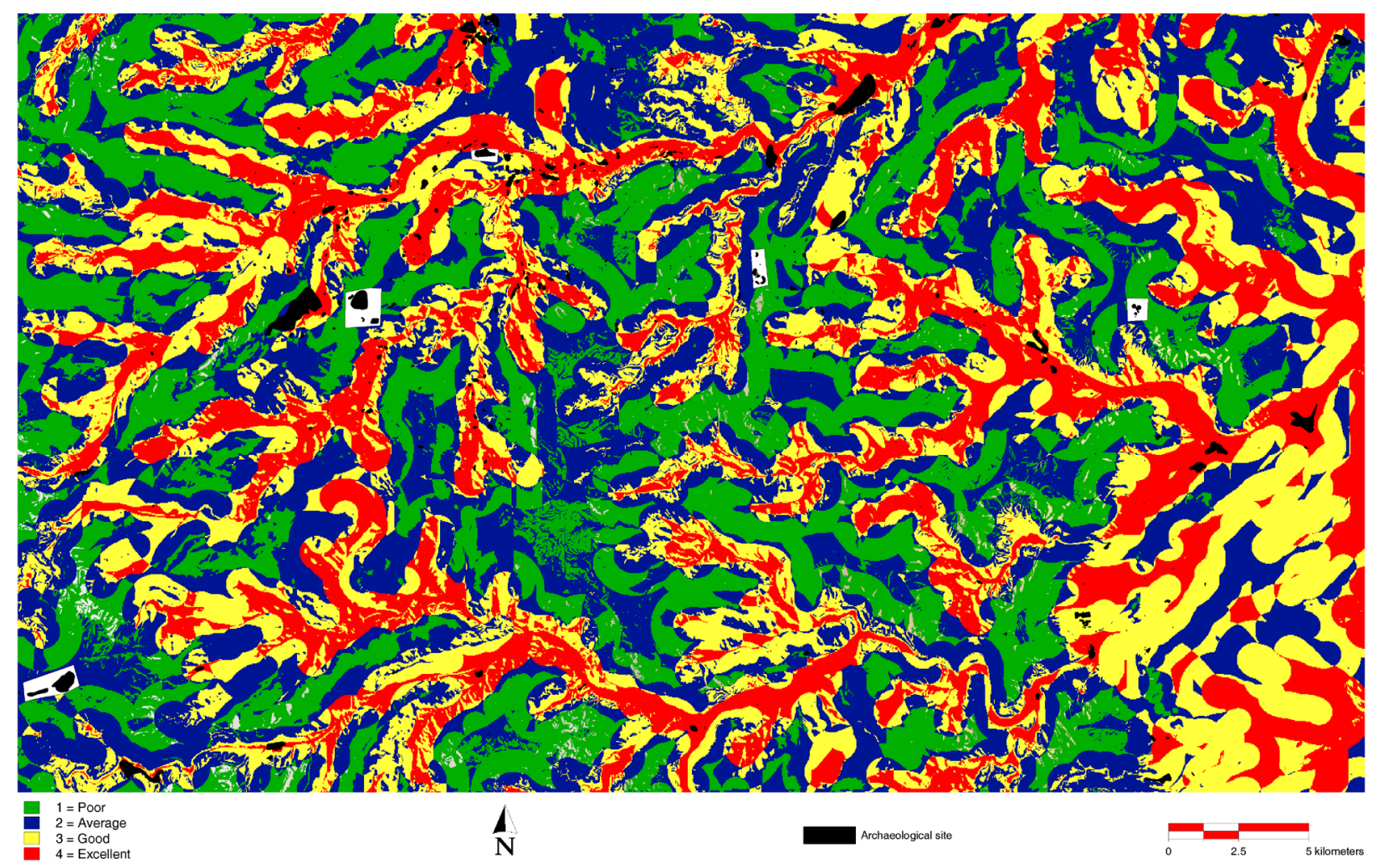

Figure 6.11. Weighted model with sites in black.

White polygons encompass recorded sites in areas modeled as poor or average candidates for site presence.

\section{Logistic Regression Model}

Logistic regression is a complex statistical technique (see Chapter 4). The great advantage of logistic regression over other modeling techniques is the ability to incorporate variables measured on various scales: the relationships between site location and environmental variables measured on interval scales are not sacrificed in logistic regression, as they are in Boolean and weighted modeling techniques. The great disadvantage is that the results of logistic regression models are not as easily interpreted as those of the other modeling techniques.

Table 6.7 presents the environmental variables used in the logistic regression and the coefficients created by the regression formula. At first glance, it appears that some of the variables are much more important in predicting site location than others. The coefficient for distance to drainage, for example, is only slightly negative $(-0.001)$, whereas north aspects have a relatively large positive coefficient (2.960). But these coefficients are not comparable. Distance to drainages on Azotea Mesa varies from 0 to more than 2,000 m, so that the regression coefficient is multiplied by numbers varying from zero to very large. For North Aspect, on the other hand, a cell can only have one of two scores: 0 or 1 . This score is then multiplied by a coefficient that takes into account the categorical nature of the variable. 
ADAPTIVE MANAGEMENT \& PLANNING MODELS FOR CULTURAL RESOURCES IN OIL \& GAS FIELDS

Table 6.7. Computed Coefficients for Variables Used in the Logistic Regression Model

\begin{tabular}{lcc}
\hline Variable & Coefficient & $\begin{array}{c}\text { Coefficient } \\
\text { without Aspect }\end{array}$ \\
\hline Distance from drainages & -0.00122318 & -0.00122661 \\
Distance from ridges & 0.00054383 & 0.00054599 \\
Chihuahuan foothill-piedmont & 0.07353178 & 0.06888962 \\
Shortgrass steppe & 1.33956144 & 1.30428528 \\
Slope & -0.04192440 & -0.04463399 \\
North-facing & 2.96050762 & $\mathrm{~N} / \mathrm{A}$ \\
South-facing & 2.57331814 & $\mathrm{~N} / \mathrm{A}$ \\
East-facing & 2.74273073 & $\mathrm{~N} / \mathrm{A}$ \\
West-facing & 2.48460818 & $\mathrm{~N} / \mathrm{A}$ \\
River terraces & 1.96534996 & 1.97969398 \\
Extensive slope wash & 0.12737117 & 0.13443338 \\
Elevation & 0.00201439 & 0.00200162 \\
Drainage intersection distance & -0.00014958 & -0.00013742 \\
\hline
\end{tabular}

To check this interpretation, we re-ran the logistic regression without aspect. The regression coefficients were very similar to those of the full model, and the correlation between the two models was 0.78 . Thus, although it may appear that aspect is an extremely important variable, statistically the impact of view and sunlight on the placement of activities is not strong. In short, when examining logistic regression coefficients, it is important to compare variables measured on the same scale with each other.

Table 6.8 summarizes the results of the logistic regression. The results have been collapsed into 10 probability classes, with details presented on the size of the area captured by each probability class and the percentage of site cells found in each class. The probability classes were then reclassified into four groups - poor (1), average (2), good (3), and excellent (4) - in terms of their site sensitivity. The cutoffs between the four sensitivity groups were chosen to capture the most site cells in the smallest area. There is no hard and fast rule about selecting these cutoffs, which may be changed by others to enhance different aspects of the sensitivity map.

Figure 6.12 is a sensitivity map displaying the results of the logistic regression model after the reclassification. The number of sites located in poor or average areas has dropped from seven in the weighted model to three in the logistic regression, but the amount of land classified as good or excellent has shifted from around $45 \%$ in the Boolean and weighted models to more than $60 \%$ in the logistic regression model. These shifts are reflected in the relatively low Gain and Gain over Random scores, as seen below:

Gain $=1-($ proportion of model area / proportion of correctly identified sites)

Gain $=1-(63.34 / 85.36)=0.26$

Gain over Random $=$ proportion of correctly identified sites - proportion of model

Gain over Random $=85.36-63.34=22$

These statistics also were calculated for the "very small" site category.

Table 6.8. Logistic Regression Probability Scores and Reclassification Values

\begin{tabular}{cccc}
\hline Probability & $\begin{array}{c}\text { Percentage of } \\
\text { Study Area }\end{array}$ & $\begin{array}{c}\text { Percentage of } \\
\text { Site Cells }\end{array}$ & Reclassification \\
\hline $0-10$ & 0.18 & 0.02 & 1 \\
$11-20$ & 1.97 & 0 & 1 \\
$21-30$ & 6.28 & 0.27 & 1 \\
$31-40$ & 11.23 & 3.86 & 2 \\
$41-50$ & 17.01 & 10.49 & 2 \\
$51-60$ & 21.57 & 12.52 & 3 \\
$61-70$ & 23.14 & 36.16 & 3 \\
$71-80$ & 15.11 & 25.65 & 4 \\
$81-90$ & 2.9 & 5.19 & 4 \\
$91-100$ & 0.62 & 5.84 & 4 \\
\hline
\end{tabular}




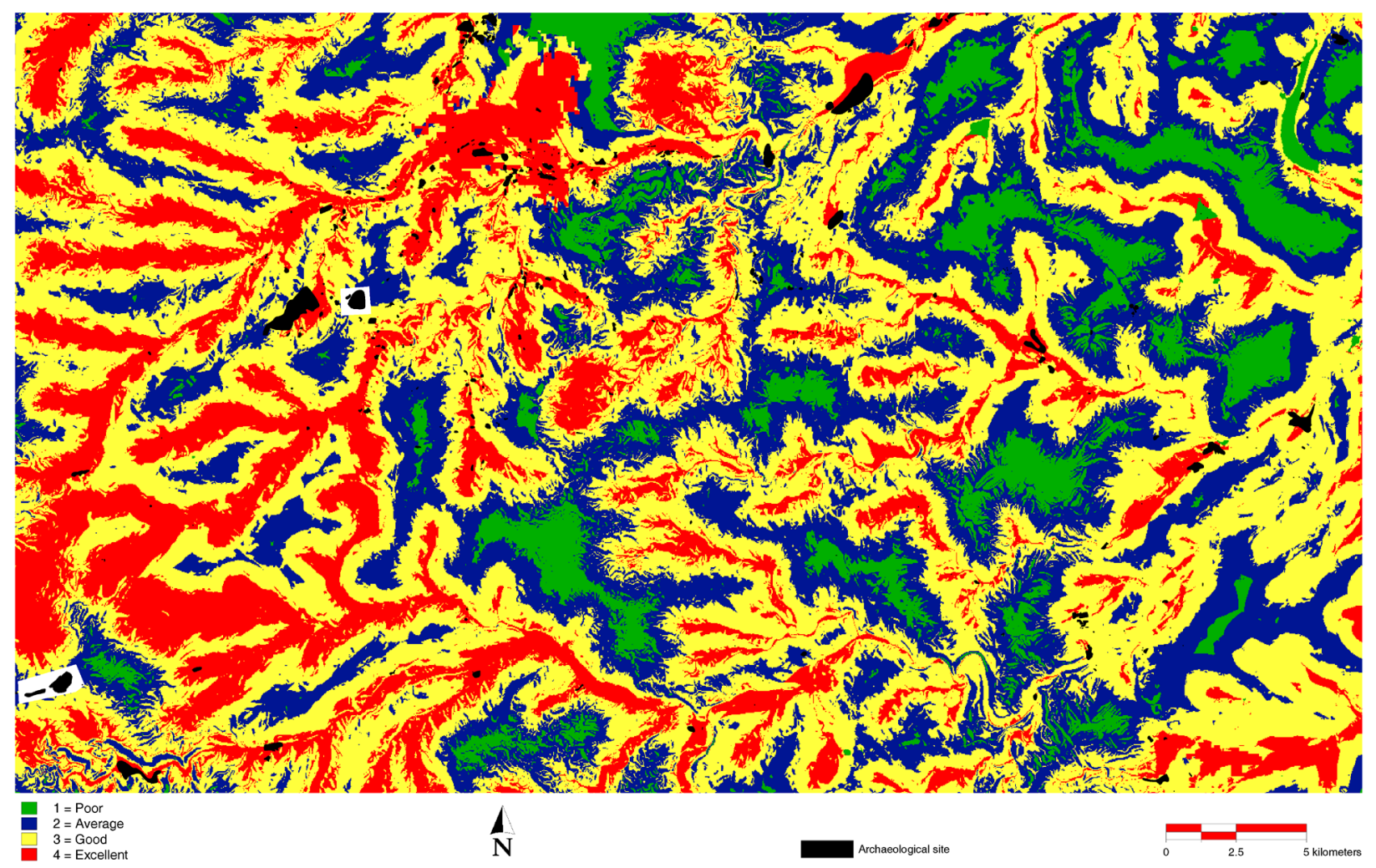

Figure 6.12. Logistic regression model with sites in black. White polygons are site areas that are in the poor or average class.

Gain $=1-(63.34 / 85.09)=0.26$

Gain over Random $=85.09-63.34=22$

The logistic regression model works slightly worse as a predictor than the weighted model ( $27 \%$ better than random for the weighted model versus $22 \%$ better than random for the logistic regression model). Both models, however, have about the same accuracy (22-24\% better than random) in correctly classifying the independent group into sensitivity areas. Visually, both models appear to be capitalizing on the distance to drainage variable, though this is much more pronounced in the weighted model than in the logistic regression model.

\section{Comparison of the Sensitivity Models}

A comparison of the three predictive models is presented in Table 6.9. The weighted model scores the highest on the Gain Statistic because it provides the smallest sensitive area relative to the number of sites correctly identified. The logistic regression model, however, is statistically more robust. It accurately placed about $85 \%$ of the test group, a gain of about 20 percentage points on the other models. All three models predict large and small site locations correctly in roughly the same proportions. The size of a site, therefore, has little bearing on where it was placed on Azotea Mesa. A probable corollary is that site size is not associated with differences in site function.

Table 6.9. Comparison of the Predictive Models

\begin{tabular}{lcccc}
\hline Model & $\begin{array}{c}\text { Proportion of area } \\
\text { that is good or excellent }\end{array}$ & $\begin{array}{c}\text { Proportion of large } \\
\text { site cells classified } \\
\text { as good or excellent }\end{array}$ & $\begin{array}{c}\text { Proportion of small } \\
\text { site test class classified } \\
\text { as good or excellent }\end{array}$ & Gain Score \\
\hline Boolean & .46 & .58 & .62 & .21 \\
Weighted & .43 & .70 & .67 & .39 \\
Logistic regression & .63 & .85 & .85 & .26 \\
\hline
\end{tabular}




\section{Interpreting the Results}

In our discussions of the three models presented above, we noted cases where known sites exist in areas that the models have classified as being unlikely to contain sites. Two such sites are common to all three models; one additional site was shared by the weighted model and the logistic regression model. Altschul (1990) has termed sites that are conspicuously located where models predict that they won't be "red flags." He has argued that these red flag sites often provide insights into both prehistoric land-use and the inner workings of predictive models. In an attempt to account for these sites in locations where they would not be expected based on the predictions of the models, we examined the characteristics of the three sites (Table 6.10) and the characteristics of the set of large sites used to develop the models (Table 6.11). We then compared the environmental characteristics of red flag sites and with those of the correctly predicted sites (Table 6.12); note that because of the small sample size, these sets of sites are only compared descriptively, not statistically.

It is tempting to speculate that the predictive models reflect primarily "Mogollon" settlement patterns. This time period represents nearly $60 \%$ of the components of known time periods recorded in the ARMS database. If we assume that the sites in the "unknown" temporal category represent similar proportions of the different temporal periods, then this inference becomes even more reasonable. Unfortunately, only more fieldwork can resolve this question. Even so, it is interesting to point out that the two red flag sites for which temporal information is available are predominantly Archaic, with only a minor Mogollon component (based on one projectile point) represented at LA 130417/LA 83187.

Table 6.10. Red Flag Sites

\begin{tabular}{llcccc}
\hline $\begin{array}{l}\text { ARMS/ NMCRIS } \\
\text { Site No. }\end{array}$ & Time Period & $\begin{array}{c}\text { Area } \\
\text { (Acres) }\end{array}$ & $\begin{array}{c}\text { Number of } \\
\text { Features }\end{array}$ & $\begin{array}{c}\text { Number of } \\
\text { Artifacts }\end{array}$ & $\begin{array}{c}\text { Multi- } \\
\text { component? }\end{array}$ \\
\hline LA $67519 / 26732$ & Early Archaic & 23.21 & 5 & $>1000$ & No \\
LA $67520 / 24731$ & Unspecified prehistoric & 90.68 & 9 & $>1000$ & No \\
LA $130417 / 83187$ & Late Archaic; Mogollon & 81.49 & 3 & $>1000$ & Yes \\
\hline
\end{tabular}

Table 6.11. Sites Used to Create the Predictive Models

\begin{tabular}{|c|c|c|c|c|}
\hline \multicolumn{2}{|l|}{$\begin{array}{l}\text { Time Period/ } \\
\text { No. of components }(\mathrm{N})\end{array}$} & $\begin{array}{c}\text { Area } \\
\text { (Acres) }\end{array}$ & $\begin{array}{l}\text { Number of } \\
\text { Features }\end{array}$ & $\begin{array}{c}\% \text { of Sites with } \\
>1,000 \text { Artifacts }\end{array}$ \\
\hline \multicolumn{2}{|l|}{ Clovis (1) } & 8.97 & 3 & 0 \\
\hline \multicolumn{2}{|l|}{ Late Paleoindian (1) } & 36.61 & 0 & 100 \\
\hline \multicolumn{2}{|c|}{ Unspecified Paleoindian (1) } & 313.82 & 0 & 100 \\
\hline \multirow[t]{3}{*}{ Early Archaic (2) } & $\mathrm{N}$ & 45.19 & 39 & 100 \\
\hline & mean & 22.59 & 19.5 & \\
\hline & std. dev. & 0.86 & 21 & \\
\hline Middle Archaic (1) & & 7.23 & 6 & 0 \\
\hline \multirow{3}{*}{ Late Archaic (6) } & $\mathrm{N}$ & 293.13 & 64 & 50 \\
\hline & mean & 48.86 & 13 & \\
\hline & std. dev. & 36.07 & 11 & \\
\hline \multirow[t]{3}{*}{ Unspecified Archaic (2) } & $\mathrm{N}$ & 324.78 & 3 & 50 \\
\hline & mean & 162.388 & 2 & \\
\hline & std. dev. & 214.16 & 1 & \\
\hline \multirow[t]{3}{*}{ Mogollon (21) } & $\mathrm{N}$ & 478.68 & 246 & 33 \\
\hline & mean & 22.79 & 12 & \\
\hline & std. dev. & 18.26 & 11 & \\
\hline Protohistoric (1) & & 36.39 & 0 & 0 \\
\hline \multirow[t]{3}{*}{ Unknown (24) } & $\mathrm{N}$ & 739.251 & 218 & 25 \\
\hline & mean & 30.80 & 9 & \\
\hline & std. dev. & 45.81 & 17 & \\
\hline \multirow[t]{3}{*}{ All sites $(53) \dagger$} & $\mathrm{N}$ & 1729.39 & 527 & 28.3 \\
\hline & mean & 32.64 & 10 & \\
\hline & std. dev. & 51.99 & 14 & \\
\hline
\end{tabular}

$\dagger$ Because some sites have multiple components, the total number of sites (53) is lower than the total number of components (60). 
THE AZOTEA MESA STUDY AREA

Table 6.12. Comparison of Red Flags and Correctly Predicted Sites

\begin{tabular}{lcc}
\hline Variable & Red Flag Sites & Correctly Predicted Sites \\
\hline Site area in acres & & \\
Range & $22-91$ & $7-314$ \\
Mean & 65.14 & 32.64 \\
Std. dev. & 36.60 & 51.99 \\
Elevation (m) & $1264-1686$ & $952-1452$ \\
Range & 1493.747 & 1151.976 \\
Mean & 182.38 & 131.958 \\
Std. dev. & & \\
Distance from drainages (m) & $880-1620$ & $0-1197$ \\
Range & 1458.304 & 264.368 \\
Mean & 306.337 & 231.065 \\
Std. dev. & & \\
Slope (degrees ) & $0-7$ & $0-31$ \\
Range & 3.942 & 3.40 \\
Mean & 2.068 & 4.228 \\
Std. dev. & & \\
Aspect & South $(45 \%)$ & East $(39 \%)$ \\
Largest percentage & East $(37 \%)$ & North (38\%) \\
Second largest percentage & & \\
Geomorphology & Eroded bedrock (100\%) & Eloodplains of large drainages $(11 \%)$ \\
Largest percentage & Extensive slope-wash $(9 \%)$ \\
Second largest percentage & & \\
Third largest percentage & & \\
\hline
\end{tabular}

Although this conclusion is speculative, it is intriguing to suggest that because the Mogollon sites are so much more heavily represented in the archaeological record, the predictive models are largely modeling the activities of Formative groups who would have been based at residential sites elsewhere, most likely on the Pecos River. What types of activities were being carried out within the study area? The dendritic distribution of the high-probability areas in both the weighted and the regression models makes clear that these activities were focused on the drainages. Were they gathering specific plant resources along the drainage bottoms or terraces? Were the terraces or small alluvial fans from side drainages part of an agricultural strategy that emphasized use of a wide variety of field settings? Or were these drainage networks being used as routes of travel between the Guadalupe uplands and the river valley? The small size and undifferentiated surface expression of the sites in the study area would be consistent with any or all of these explanations. It will require detailed, targeted data recovery at a sample of these sites for us to begin to understand the functions of the Azotea Mesa sites within the larger settlement system or systems of which they were a part.

In contrast, the numerically rare Archaic sites occur in a very different environmental setting from that common to the Formative sites and may reflect an adaptation focused on seasonal hunting. Relative to the sites that were correctly predicted by the models, the Archaic sites are larger, located at higher elevations, and tend to be farther away from drainages. They face south and east as opposed to the more common orientation of north and east. Visibility of prey as well as the need to keep away from or downwind of areas where game animals tended to travel may have factored into the establishment and repeated use of camps at higher elevations at some distance from drainages.

As the preceding discussion indicates, correlative predictive models may allow us to discern patterns in settlement. They do not explain such patterns, but they can point out potential avenues of research that may eventually lead to such explanations.

\section{Modeling and Management}

Evaluation of our predictive models demonstrated that they are limited in their predictive power. The goal of the New Mexico Pump III project is not just to develop successful predictive models, however, but to evaluate the effectiveness of current cultural resource management practices in oil and gas fields and to provide data, technical support tools, and procedural recommendations for improving management in the future. The final section of this chapter describes a variety of modeling approaches that we used to examine the effectiveness of current management practices and identifies some implications of the results for future management practices. Chapter 9 will provide more detailed management recommendations. 


\section{Model Stability}

The logistic regression model for Azotea Mesa correctly predicted the locations of $85 \%$ of the sites, a considerable gain in accuracy over the other two models. It is, nonetheless, a poor predictor of site location because more than $60 \%$ of the study area is classified as having a good or excellent likelihood of containing sites. One possible explanation for this poor performance is that not enough sites have been located to provide a clear "environmental signature." Alternatively, it may be that sites within this study area are not strongly correlated with environmental variables, and that no matter how many more sites were recorded, the predictive performance of the model would not improve. This might be the case if, for example, the "resource" for which the study area was valued was one or more favored routes of travel.

To examine these issues, we developed a series of logistic regression models using the same environmental themes but including only the site and survey data that would have been available at various points in the past. If we were to find that the models continued to improve with each new iteration, including the final 2002 version, then we would be able to infer that additional archaeological data would permit additional model refinement. Alternatively, if we were to find that the rate of improvement in predictive power has slowed or stopped at the very poor level that we see in the 2002 model, we would conclude that the proxy variables are not capturing aspects of the environment critical to human settlement behavior and/or that other factors were more important than the physical environment in placing humans on this landscape.

To be consistent with our work in Loco Hills, we recalculated the logistic regression model for Azotea Mesa based on data available in 1982, 1992, 1997, and 2000 and compared the resulting models with the model based on current (2002) data. At the end of 1982, approximately $6 \%$ of the 33,960 acres covered by 2002 had been surveyed. This total had risen to $34 \%$ by $1992,64 \%$ by 1997 , and $94 \%$ by 2000 . Only $7 \%$ of the 550 currently known sites had been recorded by 1982 . By 1992, 29\% of the currently known sites had been recorded; by 1997, 58\% of these sites had been found; and by $2000,78 \%$ of all currently known prehistoric sites had been recorded.

Figures 6.13-6.17 show the results of models based on the data available in 1982, 1992, 1997, and 2000, and the results of a model based on all available site data from 2002. The 2002 model shown in Figure 6.17 differs slightly from the model displayed in Figure 6.12 in the previous section, which excluded the data from the very small sites. The Spearman's $r$ score for the two 2002 models is 0.90 .

Visually, the models appear quite similar. This impression is reinforced by Spearman's $r$ scores, which were computed to compare each model's performance against the 2002 "all sites" model (Figure 6.18). These scores ranged from a low of 0.7 for the 1982 model to 0.999 for the 2000 model. Beginning in 1997, additional data do not cause any significant change in the predictive success of the models; no correlation is below 0.995. A review of the regression coefficients for the five models (Table 6.13) reinforces this observation. Although wide fluctuations are noted in the 1982 and 1992 models, the coefficients vary little in the last three models.

This analysis demonstrates clearly that a predictive model can be very stable and still be a poor predictor of site location. In the case of Azotea Mesa, it is unlikely that additional data will improve the model. Does this result indicate that humans in this area did not place their settlements with regard to local environmental conditions? We don't think so. Instead, we believe the model's behavior reflects a failure to appreciate the proper scale of human adaptive systems in this portion of the Pecos Valley.

We suspect that the human adaptation to this environment included resources from the mountains to the west and resources found along the Pecos River to the east. Larger residential settlements were almost certainly located outside our study area. People would have moved into and through the study area in small groups, sometimes specifically to procure targeted animal, plant, or mineral resources and other times expediently collecting plants and game animals as they passed from one resource zone to another. Under this scenario, the areas of higher site probability are associated with drainages because this is where most of the specifically targeted resources would have been found and because these would have been the routes of travel between the riverine and montane resource zones.

If we look only at the small window on past human adaptations provided by the study area, it appears that human settlement was rather arbitrary; most places on Azotea Mesa were as good as any other. Environmental diversity is minimal and the targeted resources appear to have been widely distributed. But would this characterization hold if we enlarged the study window? It is possible that Azotea Mesa as a unit held a unique environmental signature that was quite distinct from other areas in this part of the Pecos Valley. In this case, a strong predictive model could be developed in which Azotea Mesa as a unit might be correlated with a specific part of the archaeological record.

The danger of developing a model of past human behavior based on an arbitrarily defined segment of the environment can be easily illustrated with an "outtake" from our experience during this project. In our first round of modeling, none of the three techniques described above produced a usable predictive model. Given the environmental uniformity of the study area, we had not expected great predictive performance, but this was ridiculous! The modelers, Altschul and 


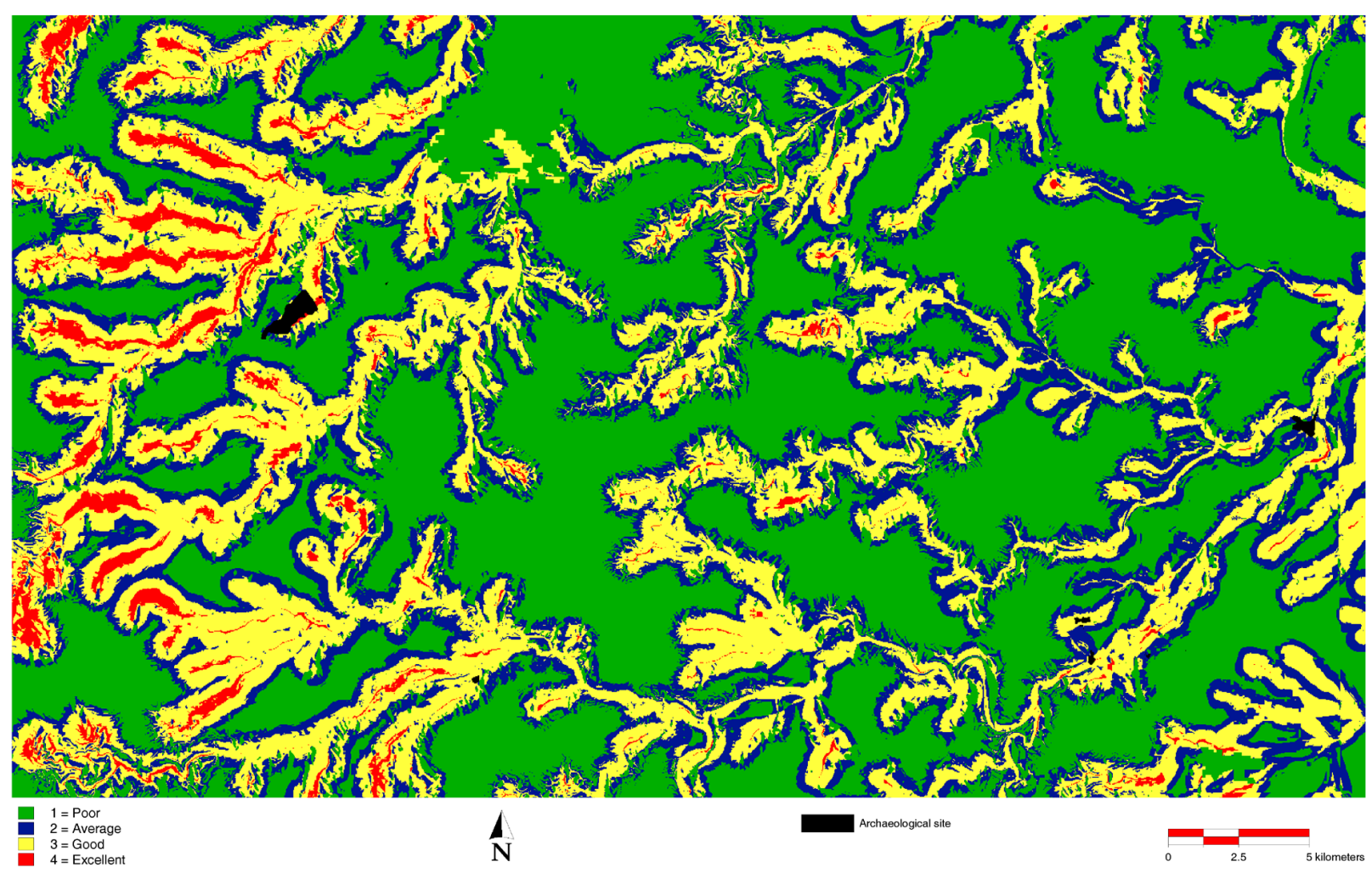

Figure 6.13. Logistic regression model created using all sites recorded through 1982. The correlation in relation to the model based on 2002 data is 0.7 .

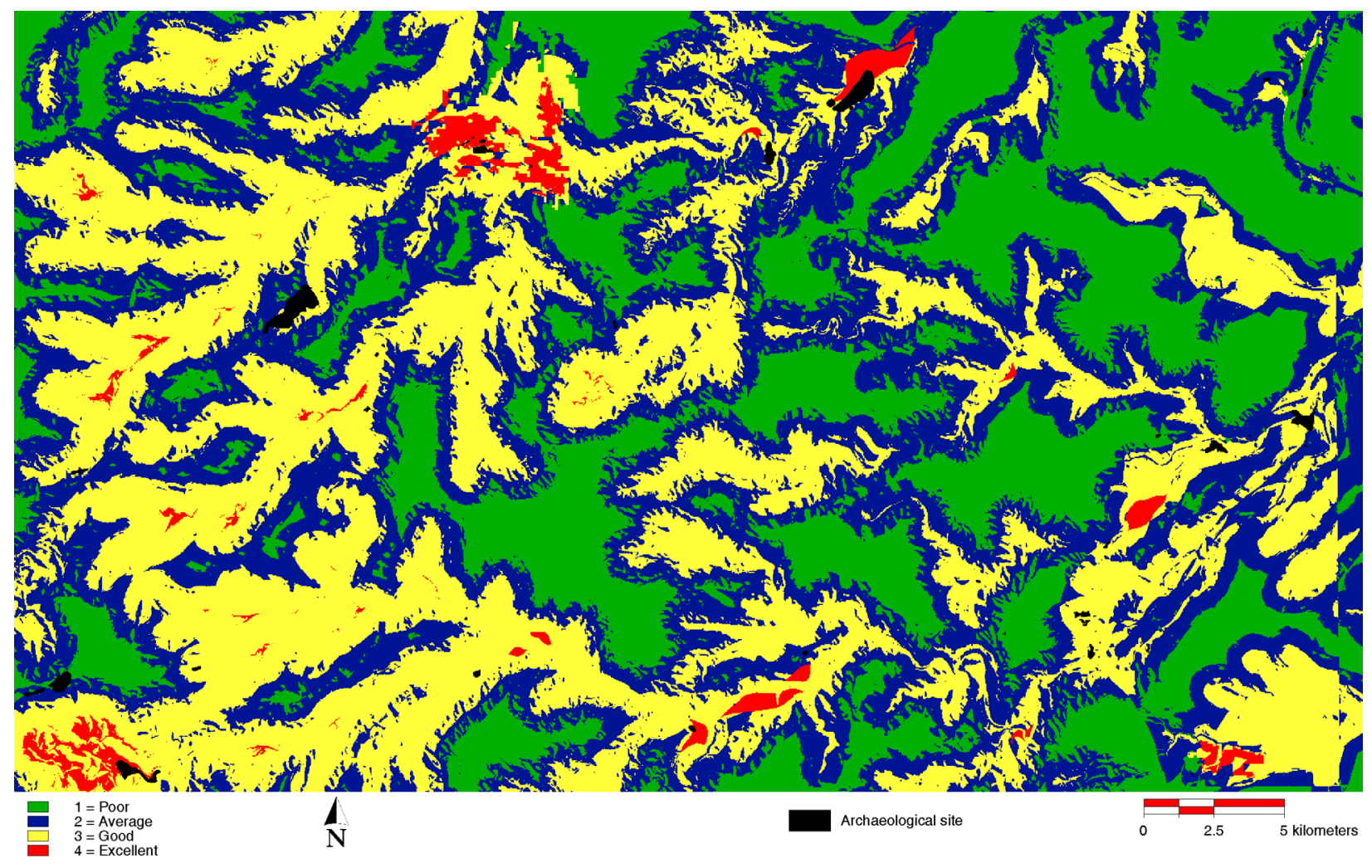

Figure 6.14. Logistic regression model created using all sites recorded through 1992. The correlation in relation to the model based on 2002 data is 0.87 . 


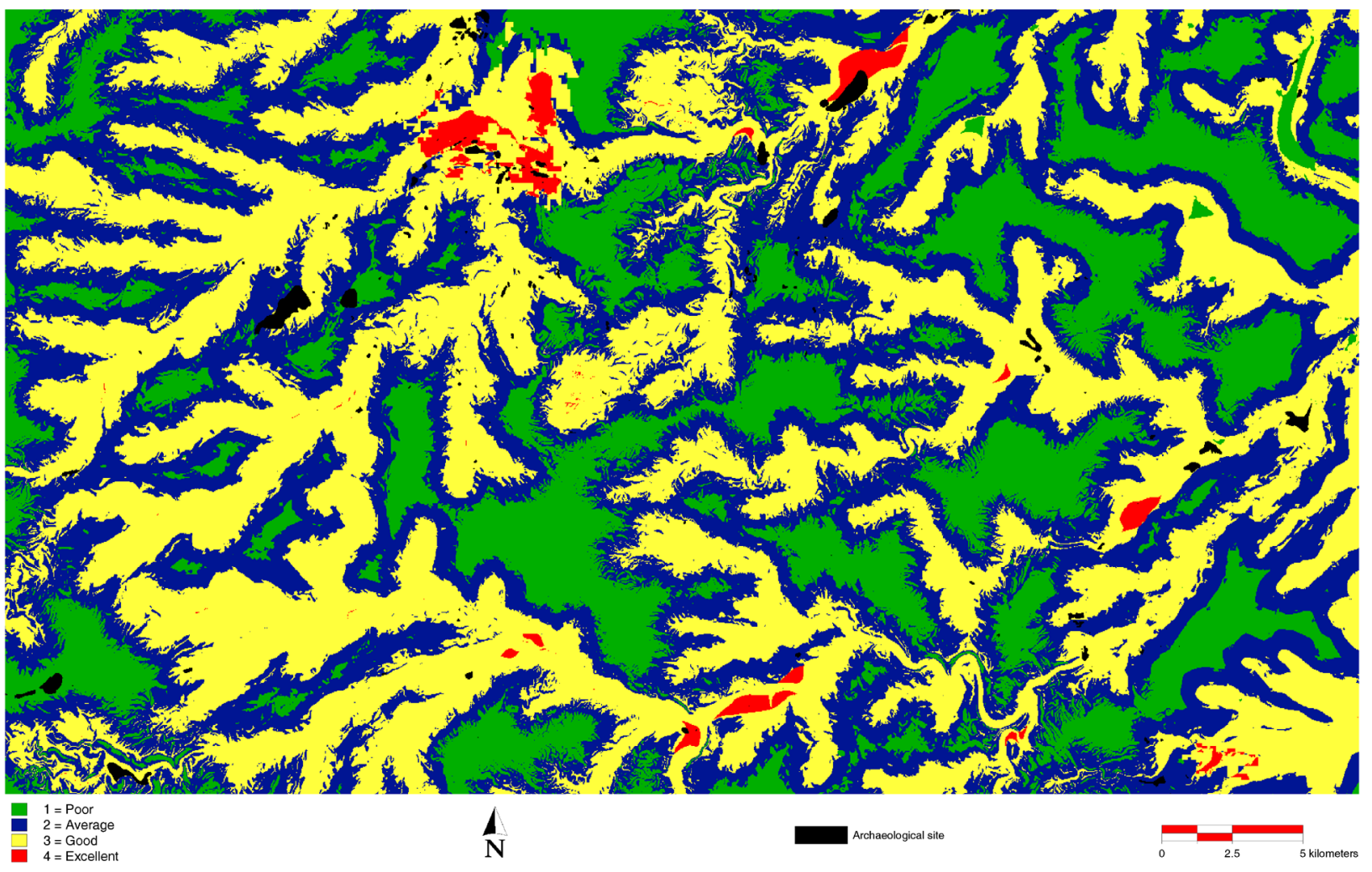

Figure 6.15 Logistic regression model created using all sites recorded through 1997. The correlation score in relation to the model based on 2002 data is 0.995 .

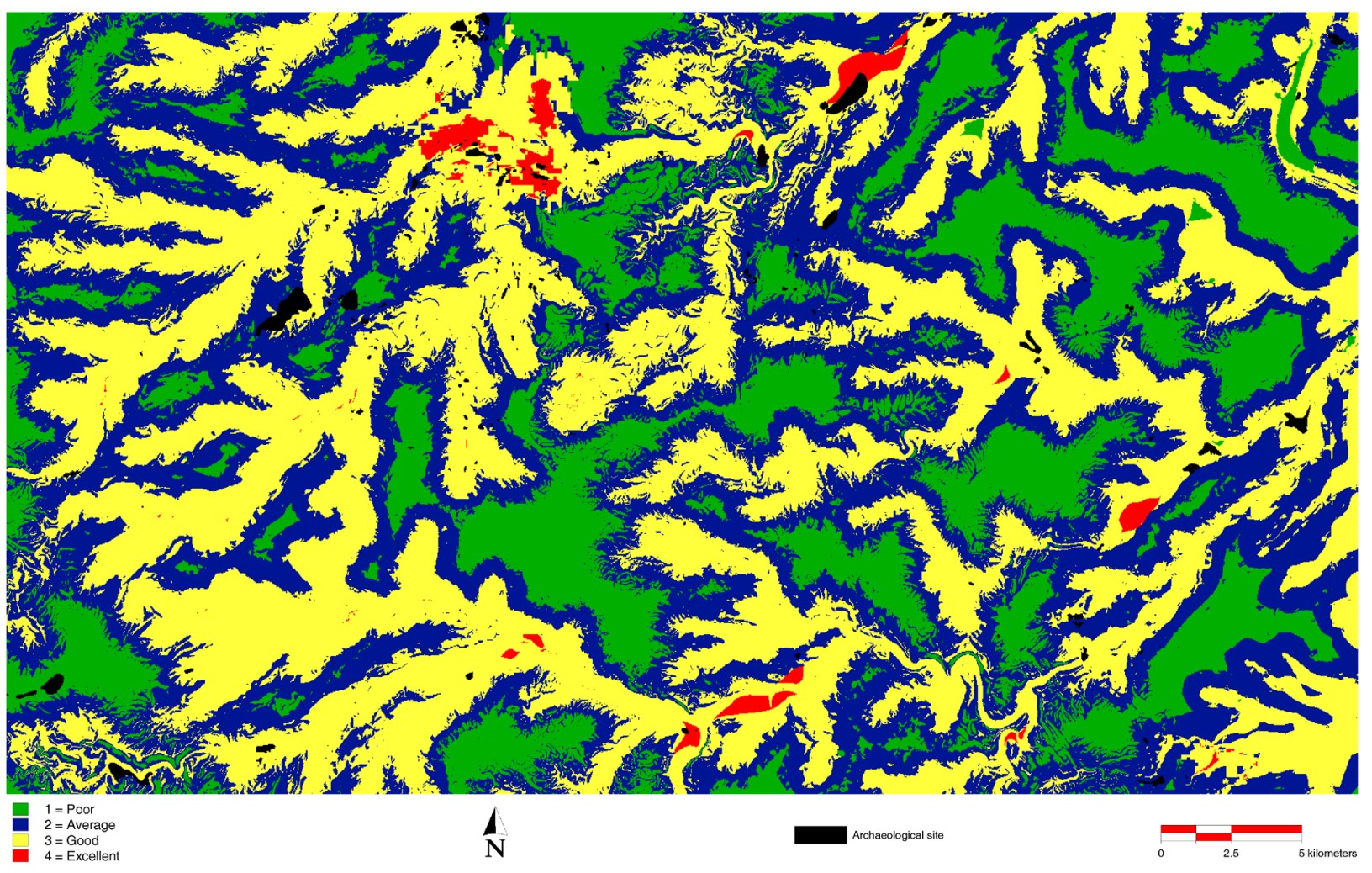

Figure 6.16. Logistic regression model created using all sites recorded through 2000. The correlation score in relation to the model based on 2002 data is 0.999 . 


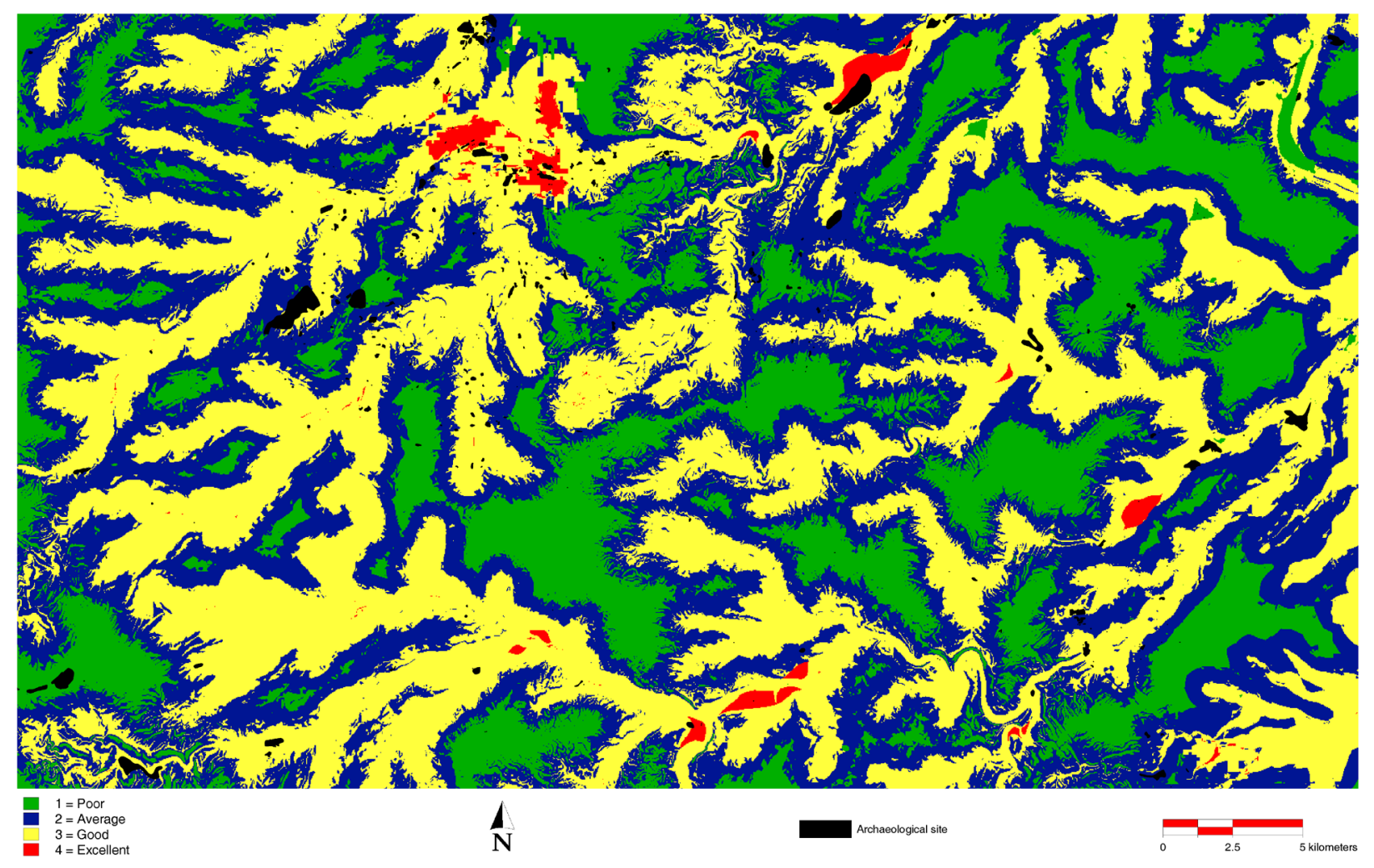

Figure 16.17. Logistic regression model created using data from all prehistoric sites recorded prior to 2002.

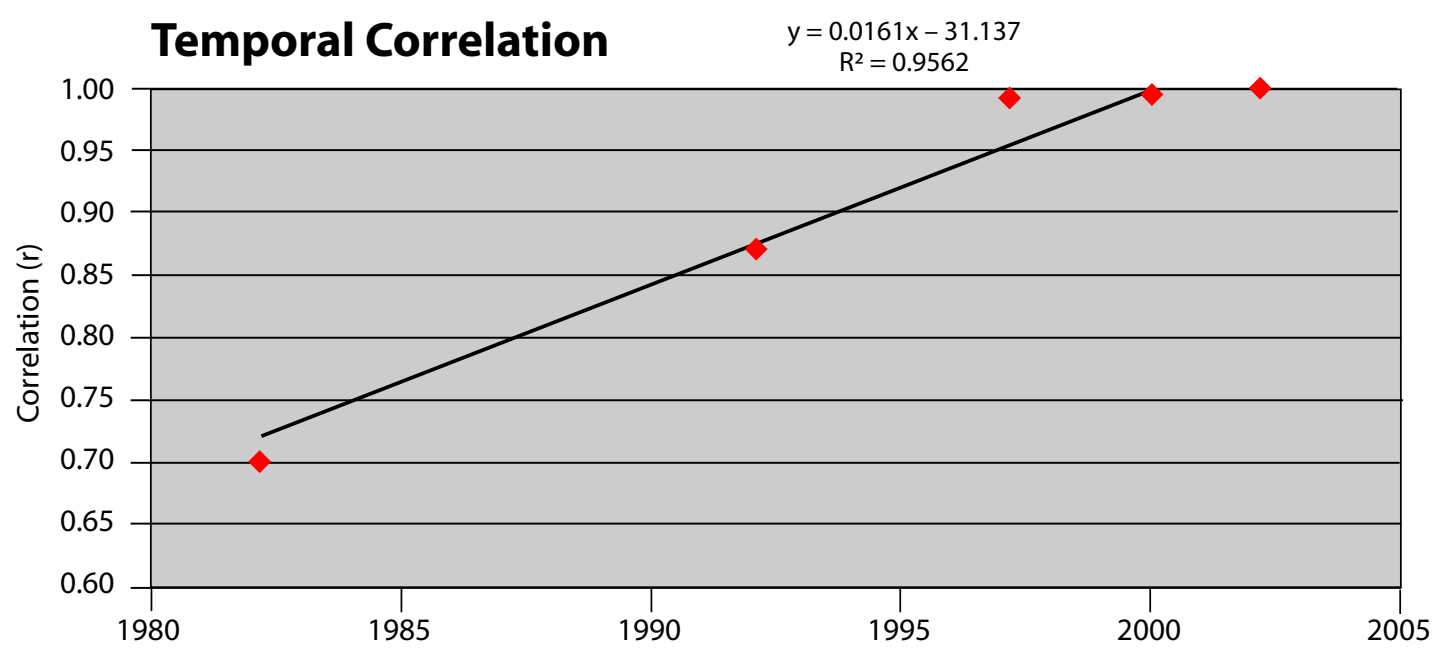

Figure 6.18. Correlation of each logistic model by year to $2002(r=0.98)$. 
Table 6.13. Comparison of Logistic Regression Coefficients

\begin{tabular}{|c|c|c|c|c|c|}
\hline & 1982 & 1992 & 1997 & 2000 & 2002 \\
\hline Distance from drainages & -0.00338826 & -0.00133068 & -0.00124655 & -0.00117728 & -0.00121604 \\
\hline Distance from ridges & -0.00091792 & 0.00026141 & 0.00051181 & 0.00044912 & 0.00045861 \\
\hline $\begin{array}{l}\text { Chihuahuan foothill-piedmont desert } \\
\text { grassland }\end{array}$ & -0.51498404 & -0.13275334 & -0.00686350 & 0.00335138 & 0.00215109 \\
\hline Shortgrass steppe & -18.95510762 & 1.54981816 & 1.39244750 & 1.25407640 & 1.23422307 \\
\hline Slope & -0.06301770 & -0.01121114 & -0.04376925 & -0.04645208 & -0.04570684 \\
\hline North-facing & 18.49441267 & 1.37578453 & 2.19733547 & 2.33641498 & 2.24024762 \\
\hline South-facing & 18.46219677 & 0.97058514 & 1.77860719 & 1.91828232 & 1.82313037 \\
\hline East-facing & 18.68033657 & 1.30033149 & 1.96868271 & 2.07221704 & 1.97888617 \\
\hline West-facing & 17.19018185 & 0.78585357 & 1.84743658 & 2.01590354 & 1.93885246 \\
\hline River terraces & -0.91378613 & 2.53793309 & 1.73569545 & 1.63539326 & 1.60230620 \\
\hline Extensive slope wash & 0.62766508 & 0.63787012 & -0.05461136 & -0.20132832 & -0.23994516 \\
\hline Elevation & 0.00180167 & 0.00342427 & 0.00117176 & 0.00115405 & 0.00106291 \\
\hline Distance from drainage intersections & 0.00014312 & -0.00031192 & -0.00009975 & -0.00013687 & -0.00013192 \\
\hline
\end{tabular}

Rohe, began to think that the environment of Azotea Mesa was not a strong influence on human settlement and might have continued to argue in this vein had not Sebastian, who is more familiar with the region's archaeology and environments, pointed out that the drainage map did not seem to include the Pecos River.

How could we have made such a fundamental error? The answer is surprisingly simple. To create a "stream" layer, we used the DEM layer to compute a hydrological score for each cell. This score is a measure of how much water would pass by this cell based on its slope and elevation relative to other cells. Those cells having scores higher than an arbitrary number that the modeler selects are designated streams. Our problem was that the Pecos River just barely cuts through the northeastern corner of the study area. Because only a very small portion of the river's catchment is actually inside the study area, the hydrological score of its constituent cells was lower than the score we had chosen for streams. After Sebastian pointed out the problem, we lowered the hydrological score needed to classify a cell as a drainage in order to capture the Pecos River. Not surprisingly, the predictive power of each of the models increased dramatically. The lesson is that GIS models do not automatically represent the physical or cultural environment. Instead, human judgment is required at all steps of the modeling process, including the selection of an appropriate study area.

For a manager, the results of the Azotea Mesa modeling effort may appear discouraging because the limited predictive success of the models does not allow us to confidently identify high and low archaeological probability areas for planning purposes. The dendritic patterning of those areas that have been identified as having higher probability of containing sites is very clear, however, which could be useful for planning. In the still-to-be developed portions of the Azotea lease area, concentrating lease-related developments, including roads and ancillary facilities such as power lines, in low-probability areas could reduce both the risk of encountering sites during lease development and the risk of indirect and cumulative damage to sites as a result of well servicing.

The modeling results lead us to believe that the study area does not provide the proper scale at which to evaluate the archaeological record on Azotea Mesa. If we could include a broader area in the model, we could determine what role the Azotea Mesa sites played in the regional archaeological record and how the mesa was used during the course of prehistory. By placing these sites within various human adaptive systems, we could better evaluate their significance as part of the Section 106 process. Clearly the "red flag" sites that do not follow the pattern established by the majority of sites on which the models are based would require additional evaluation, but if the majority of the Azotea Mesa archaeological record proves to be as homogeneous as it appears, we could identify research questions to be addressed through sampling and provide archaeologists, managers, and lease holders with a scientifically based and predictable management process.

\section{Inventory Reconstruction}

One of the goals of the Pump III project is to investigate the effectiveness of existing cultural resource management practices, in particular whether the current Section 106 compliance practices lead to inefficient or redundant results. For the Loco Hills study area (Chapter 5), we found that the logistic regression models stabilized very early in the history of gas field development. By reconstructing the history of archaeological inventory in the Loco Hills study area, we determined that our understanding of site density within the study area also stabilized early. What this means is that constant and consistent application of standard "well pad" archaeology, in which individual development areas are 
surveyed and facilities are moved if a site is found, has led to a situation where we are expending time and money without a commensurate gain in information that would lead to better resource management and efficient energy development.

Having demonstrated, as described in the previous section, that the logistic regression model for Azotea Mesa has stabilized, we next examined the history of inventory in this area to determine whether the same is true of site density. As with the Loco Hills study area, we used the dates when surveys were conducted and sites were recorded to reconstruct the history of archaeological inventory in the Azotea Mesa study area. Using the digitized data provided by the ARMS staff, we associated surveys with the year in which they were conducted and sites with the year in which they were recorded. Based on these data, we calculated for each year the number of acres of sites recorded and the number of acres surveyed. By dividing the number of "site" acres by the total number of acres surveyed in any given year, we arrived at a site density figure for that year, which was then compared with a running density figure that included all sites and acres surveyed up to that date.

We assumed that the cumulative site density figure for all years through the year 2002 was an accurate estimate of site density within the entire Azotea Mesa study area. This assumption allowed us to use the yearly running site density figures to compute the standard deviation and confidence intervals around the 2002 figure, which captured $95 \%$ of the estimates. We then examined the annual history to determine when the running site density began to fall consistently within the confidence intervals.

As we examined the ARMS data, however, it became clear that the task would be more complicated than we thought. Many areas had been surveyed multiple times and many sites had been re-recorded, sometimes within the same year. There were the usual data glitches that are unavoidable in a large regional data base with contributions by a wide variety of researchers - the same site being recorded more than $10 \mathrm{~km}$ away from itself, recording episodes tied to surveys that were nowhere in the vicinity, etc. A more difficult problem involved "site boundaries" that are actually arbitrary buffers around map points. Some of these seem to be randomly sized and inconsistent with the written descriptions of site size. For example, there is at least one instance of a site with a recorded area of approximately 180,000 square meters which appears in the data base as a $30 \mathrm{~m}$ diameter circle.

Figure 6.19 illustrates some of the overlap and re-recording problems. This figure shows a small portion of the study area which, though somewhat more densely inventoried than the majority of the area, is by no means exceptional in its complexity. The figure reflects the raw data as captured by ARMS. Each survey was recorded fully, including portions that overlap previous surveys. The site recording episodes reflect the extent to which a site or a portion of a site was recorded during any particular survey event.

To compensate for these problems, we aggregated the data by year. All surveys and site recording episodes were assigned to the year in which field activity concluded, as reflected in the ARMS data. Figure 6.20 shows surveys within the same small portion of the study area, coded by year, and Figure 6.21 shows a time sequence of cumulative survey, aggregated by year, within the whole study area.

Even after aggregating the data, we found that the process of estimating site density on an annual basis was complicated by the large amount of resurvey and the concomitant re-recording of sites. Between 1976 and 2002, surveys in the study area covered 33,960 acres, yet only 29,720 acres of ground were actually inventoried; the 4,240 acre difference results from resurvey. Nearly seven sections of land were resurveyed over the years. A quick look at Figure 6.20 makes it clear why and how this happened. As roads and pipelines and seismic grids were overlaid one on top of the other, it became virtually impossible to complete a project-specific inventory without resurveying at least some ground that had already been surveyed. We do not mean to imply that resurvey, per se, is a bad thing; decisions to resurvey an area or re-record a site when there are reasons to do so are important management choices. The resurvey and re-recording documented here were generally not the result of a management decision, however. Rather, these duplicative efforts were the result of a case-by-case approach to inventory driven by the pattern of oil and gas development and not by cultural resource management needs.

Figure 6.22 graphically displays the history of survey in the Azotea Mesa study area with special attention to this issue of resurvey. For each year there are three bars, one which represents the reported number of surveyed acres, one which represents the reported acreage minus the overlapping surveys that occurred within that same year, and one which represents the actual new ground surveyed with all overlaps removed.

These data allow us to calculate site density using two different methods. Method I (Figure 6.23) was based on survey as it was actually performed. In this analysis, sites that were recorded more than once and areas that were surveyed more than once in different years are included in the calculations for each year fieldwork took place. Site density for a particular year is calculated by dividing the number of "site" acres by the total number of acres surveyed in that year. The site density figures calculated using Method I are, therefore, inflated. Method II (Figure 6.24) eliminated 


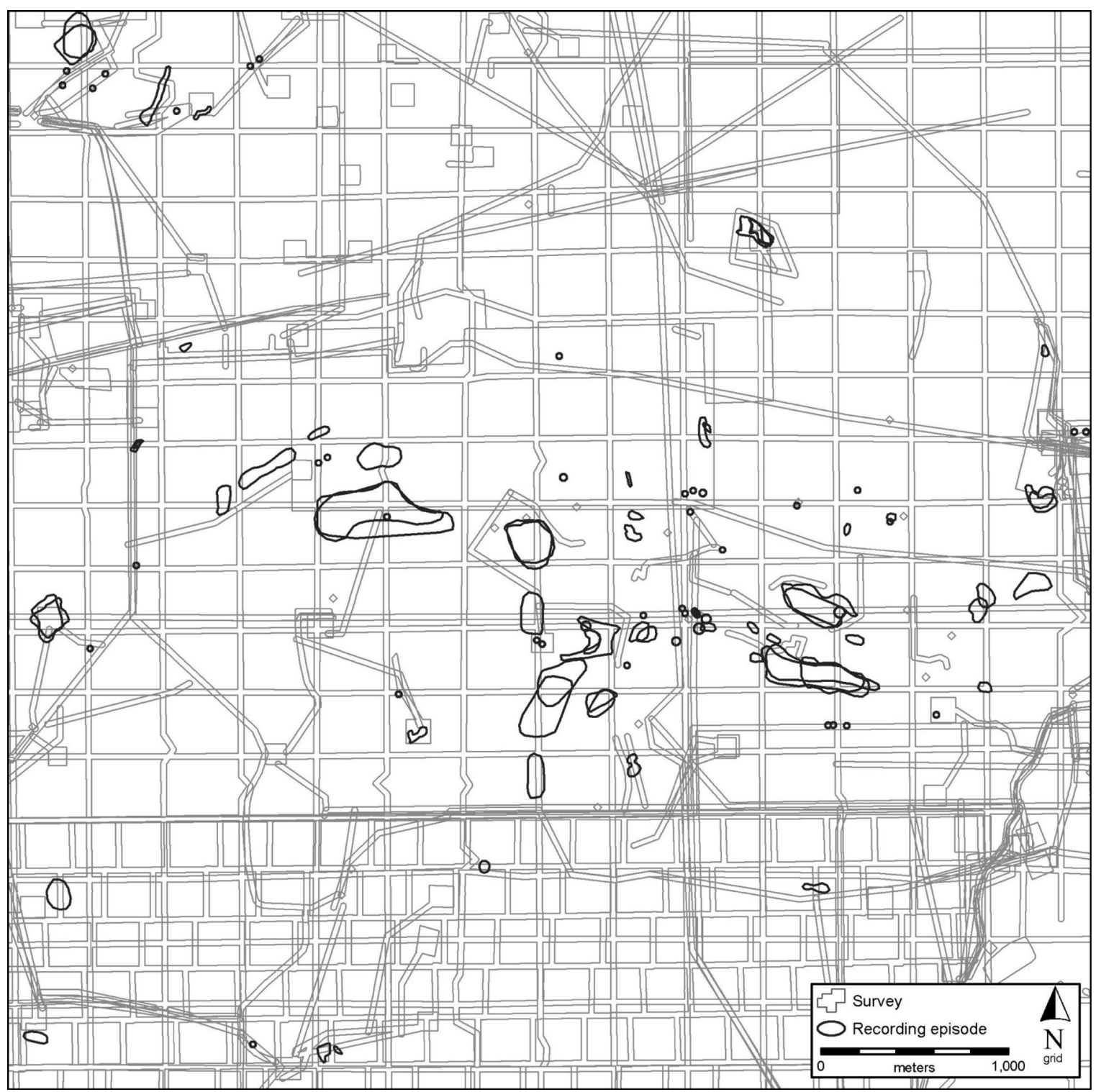

Figure 6.19. Examples of survey and recording episodes.

survey overlap and site re-recording; it provides a more accurate estimate of site density but masks the inefficiency of the piecemeal survey history. In short, Method I calculates site density as it would have been available to managers under existing survey strategies, whereas Method II provides the density figure that would have been available in an ideal world where there were no unplanned survey overlaps or inadvertent site re-recording.

The trend in running site density figures is very clear, despite the one anomalous year. Site density stabilizes at about 0.031 under Method I and 0.024 under Method II. Running density falls in the $95 \%$ confidence intervals beginning in 1988 under Method I and in 1991 under Method II.

The results of the inventory reconstruction indicate that sites are adequately represented by the survey results in terms of size and distribution. Most are small and evenly distributed throughout the study area. This is consistent with the results of the logistic regression model, which had limited predictive success because of the lack of environmental diversity within the study area. As noted above, this does not necessarily mean that the locations of human activities were not correlated with environmental factors. It is more likely that the scale on which those activities were organized is simply far larger than the study area. 


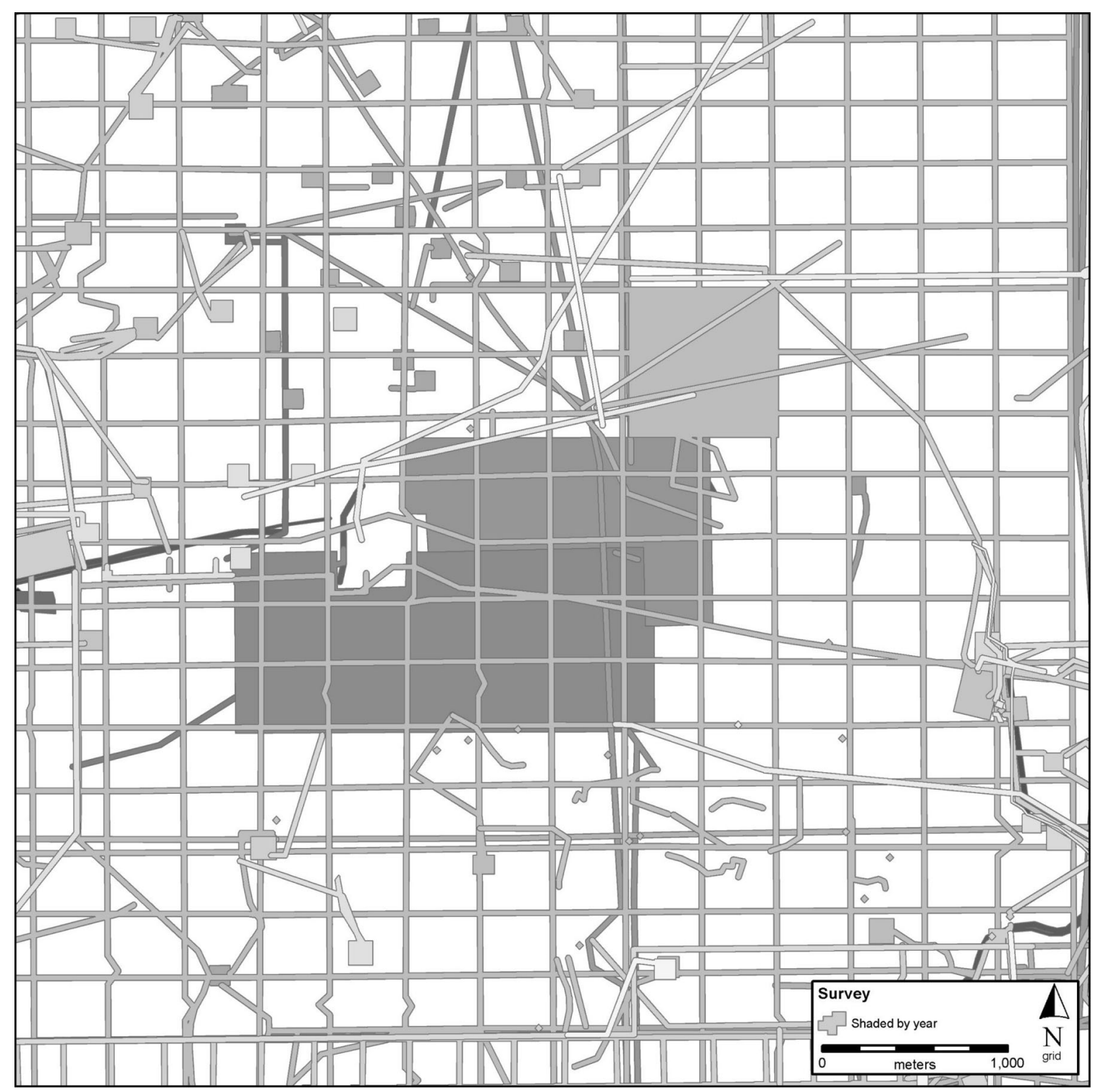

Figure 6.20. Example of survey coverage aggregated by year.

\section{Management Implications}

In some ways our findings for Azotea Mesa are like those for the Loco Hills study area. As was the case with Loco Hills, we found that on Azotea Mesa oil and gas development, although not a random process, has yielded archaeological data that are sufficiently representative to be used in predictive modeling, largely because seismic investigations and other linear projects like roads and pipelines produced a substantial portion of the data. Also as in the Loco Hills case, we found a great deal of resurvey of land and re-recording of sites in the Azotea Mesa study area. For example, surveys totaling 33,960 acres have been completed, but only 29,720 of those acres were new ground; the rest is overlap. This is not an efficient approach, but given the overlapping nature of the development, under the current, case-by-case approach to inventory such duplication is unavoidable. And again, as at Loco Hills, both the logistic regression models and the site density estimates stabilized quite early in the development of the field, with subsequent survey yielding new observations but not improving our understanding of the archaeological record.

There are, however, some observations that are particular to Azotea Mesa. One clear lesson learned is that just because archaeological surveys record the same type of sites distributed in the same manner, this does not mean the "redundant" locational pattern translates into redundant information. In truth, we know very little about what these patterns mean. To move toward such an understanding, we need to place the environmentally homogeneous Azotea Mesa study area into its proper context and acquire some level of functional information about the archaeological sites 


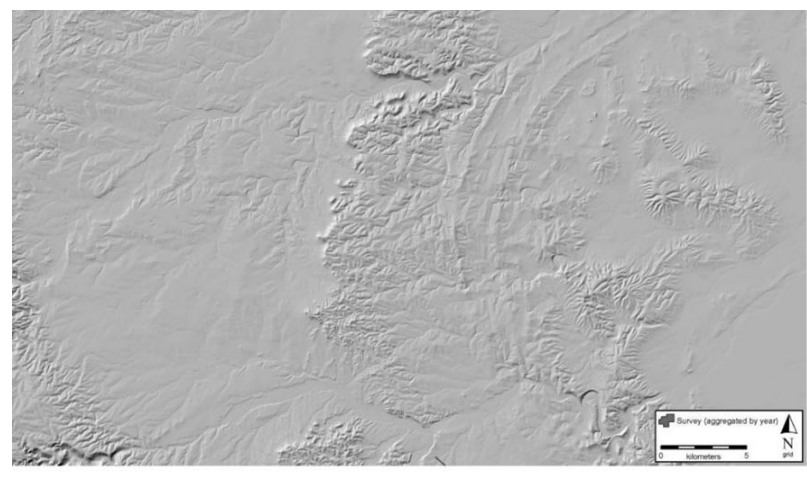

1978

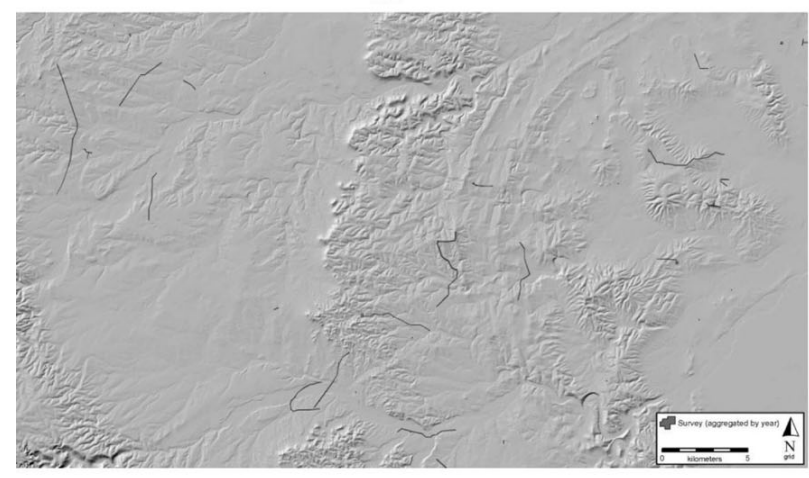

1880

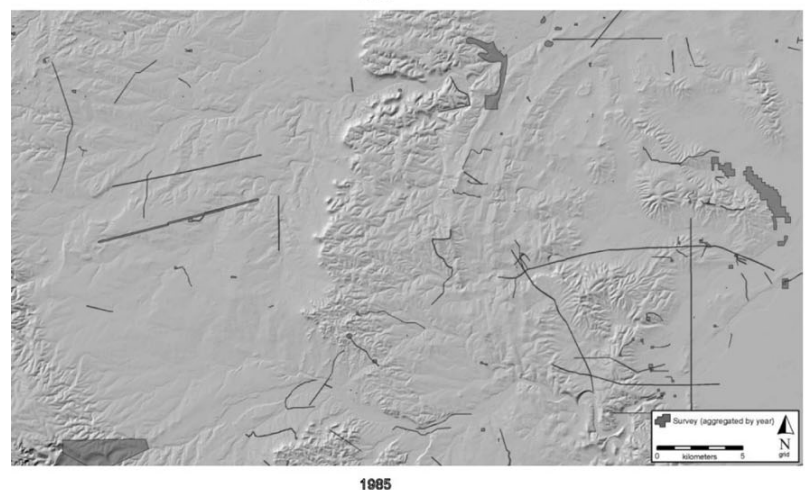

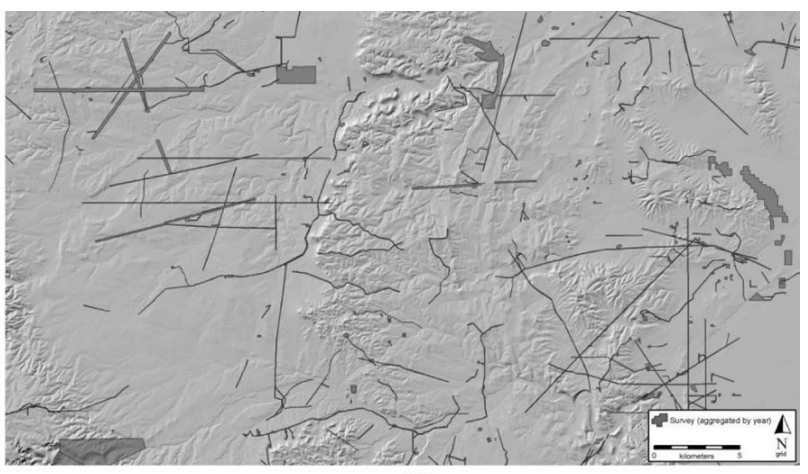

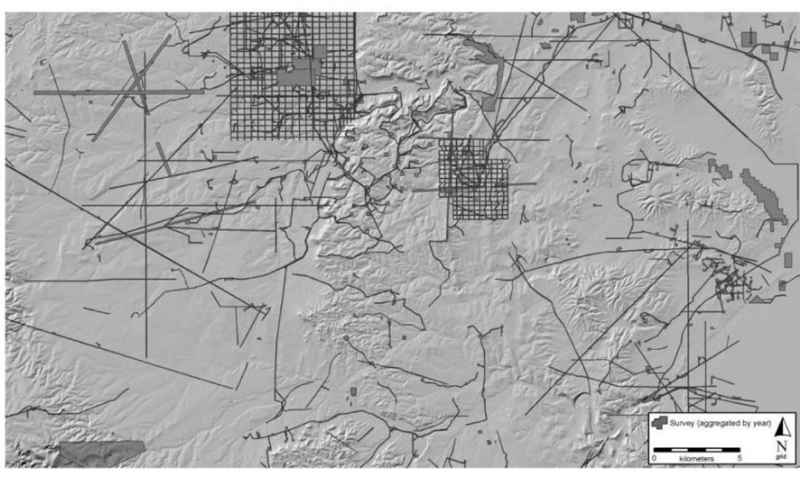

1887

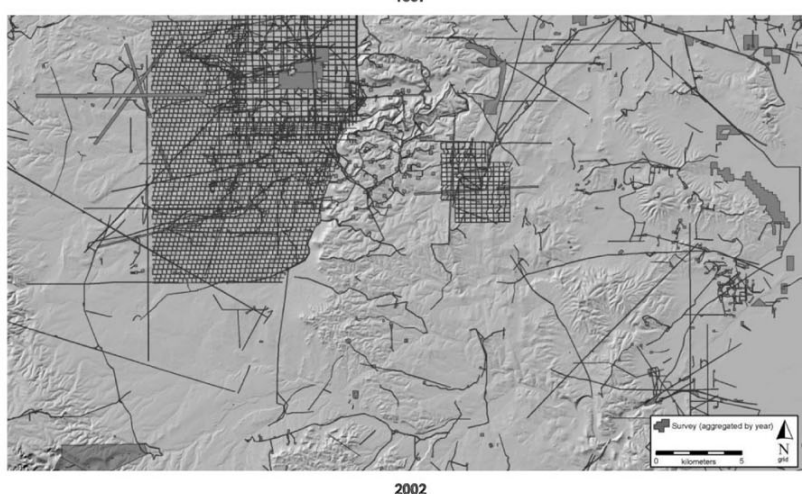

Figure 6.21. Time sequence for cumulative survey in the study area, aggregated by year.

in the area. Human use of the region clearly extends beyond the oil and gas lease areas. By focusing solely on the study area, we do not have a large enough spatial window to discern adaptive patterns and consequently cannot evaluate how sites in the study unit might or might not inform on these patterns. Likewise, the sites within the Azotea Mesa study area were part of larger settlement systems, and without functional information about these sites, it is not possible for us to understand their significance within those larger systems.

One might argue that a second lesson of Azotea Mesa is that not all areas are candidates for predictive modeling. While it is true that the developed models are relatively weak, we believe that drawing such a conclusion would be wrong. Indeed, we suggest that predictive modeling is more useful in situations such as Azotea Mesa than in areas where site distribution patterns are so strong that they can be discerned simply by looking at a map. The logistic regression models for Azotea Mesa demonstrate that no amount of survey and site discovery is likely to increase our knowledge of how humans used the study area. We know that people came into the area, possibly in small, mobile groups that exploited locally available resources and then left, or as travelers following a favored route from the river to the uplands, or possibly even as part-time agriculturalists establishing opportunistic fields at favorable locations to capture runoff. What we don't know is which one or ones of these strategies they were pursuing, where they came from and where they went, how use of this area changed through time, and whether the structure of use changed as a result of organizational changes at a larger scale. 


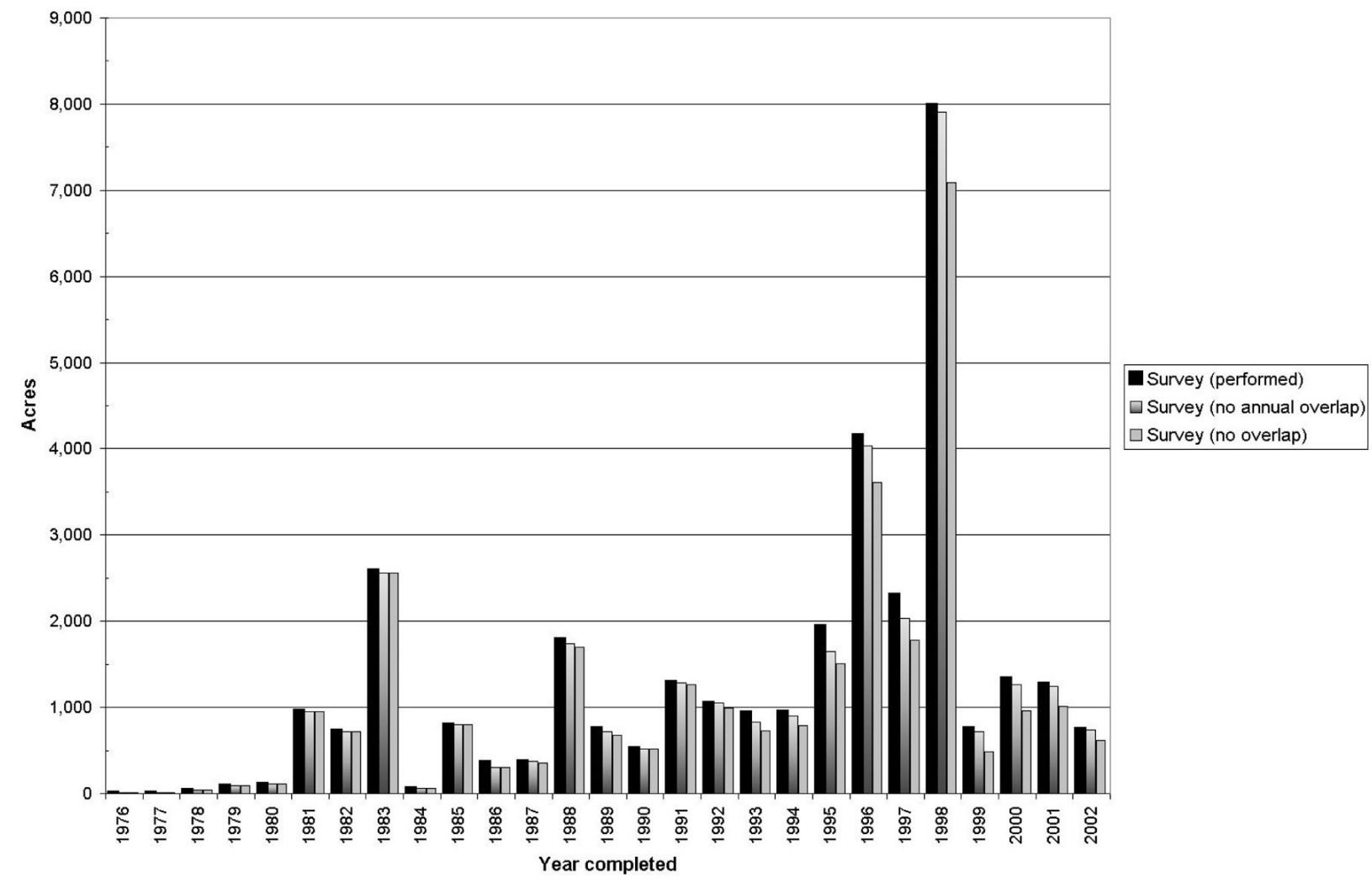

Figure 6.22. Annual survey statistics.

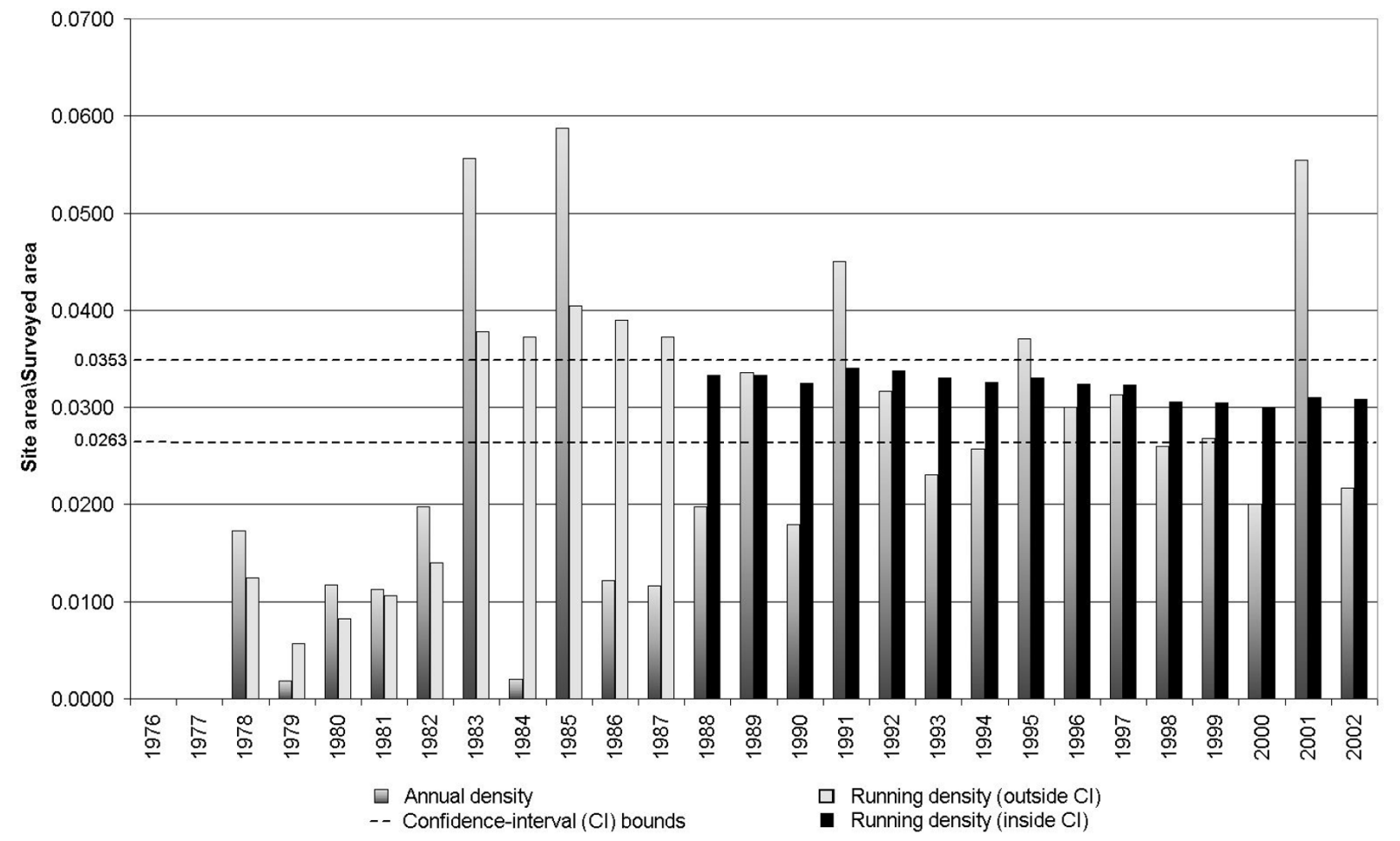

Figure 6.23. Overall site density, Method I. 


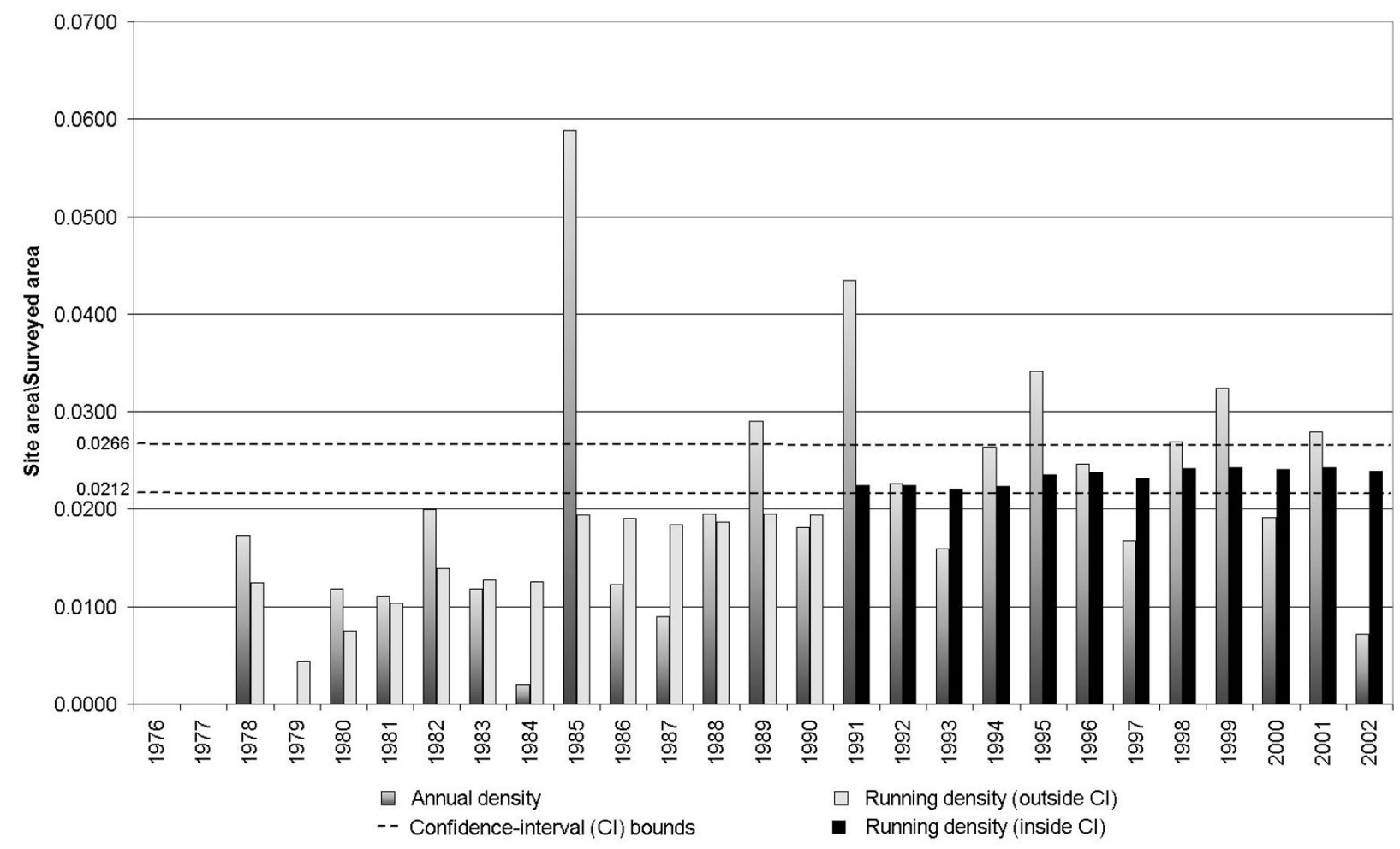

Figure 6.24. Overall site density, Method II.

In the absence of such knowledge, we cannot make good decisions about the significance of the sites within the Azotea Mesa study area. Were they part of a ubiquitous pattern of dispersed, low-intensity resource acquisition? Was this a unique resource zone where residents of the Pecos Valley went to acquire specific plants, animals, or minerals that were not available in the riverine zone? Was this an environmentally marginal zone for resources other than travel routes? Was simple floodwater agriculture possible, and was it practiced here? As with Loco Hills, we need excavation data from Azotea Mesa sites to enable us to understand what activities were being carried out, what resources were being targeted, and what time period or periods are reflected in these remnants of human activities. Without an understanding of the larger environmental and settlement picture, however, it may be difficult to gain sufficient insights on which to base management decisions. A regional perspective is critically needed, and GIS-based predictive modeling is one tool for creating such a perspective.

We have three basic management recommendations for Azotea Mesa. First, the study area is too small to discern human patterns in settlement and land use. We need to increase the size of the modeling area to at least include the adjacent portions of the Pecos River and the foothills of the Guadalupe Mountains. In this way, the model could be expanded to reflect the actual environmental diversity of this portion of the Pecos River Valley and the effects of that diversity on human settlement decisions.

Second, we need excavation data from a representative sample of the sites in the Azotea Mesa lease area. Only if we understand the function and temporal placement of sites in this area, and their potential role in the larger settlement system of which they were a part, can we make well-founded decisions about the significance of the archaeological sites found on Azotea Mesa.

And third, we need to be cognizant of the highly variable quality of the data that have been contributed to NMCRIS over the years. The inventory reconstruction assumes that errors in the ARMS data will cancel out, so that small sites with large boundaries will compensate for large sites recorded as points. Both errors are known to exist. The former type of error appears to be much more prevalent, however, and it is possible that the stabilization in site density that we found during the inventory reconstruction is the result of systematic errors in recording. This problem may be extremely difficult to correct for data already in the ARMS database; at the very least, it indicates the need for a strong qualityassurance program to ensure that future work does not repeat these errors. 


\section{References}

Altschul, Jeffrey H.

1990 Red Flag Models: The Use of Modeling in Management Contexts. In Interpreting Space: GIS and Archaeology, edited by Kathleen M.S. Allen, Stanton W. Green, and Ezra B.W. Zubrow, pp. 226-238. Taylor and Francis, London.

Kvamme, Kenneth L.

1988 Delopment and Testing of Quantitative Models. In Quantifying the Past and Predicting the Future: Theory, Method, and Application of Archaeological Predictive Modeling, edited by W. James Judge and Lynne Sebastian, pp. 325-428. U.S. Department of the Interior, Bureau of Land Management, Denver.

1990 One Sample Tests in Regional Archaeological Analysis: New Possibilities through Computer Technology. American Antiquity 55:367-381. 



\title{
Results and Discussion: The Otero Mesa Study Area
}

\author{
Jeffrey H. Altschul, Lynne Sebastian, Chris M. Rohe, William E. Hayden, and Stephen A. Hall
}

\begin{abstract}
$\Delta$
$\mathbf{T}_{\mathrm{h}}$ The Otero Mesa study area is located in Otero County on the southen border of New Mexico, northeast of El Paso, Texas, and southwest of the Guadalupe Mountains (Figure 1.2). The region in which our study area falls is generally referred to as "greater Otero Mesa" since it includes not only the landform of Otero Mesa, but a wedge of rugged canyon country that constitutes the southernmost extension of the Sacramento Mountains, as well as the Cornudas Mountains, and the Salt Basin, a large internal drainage basin that lies between the Guadalupe and Brokeoff Mountains on the east and Otero Mesa proper on the west. Generally the term "mesa" refers to an erosional feature, a flat-topped expanse of land demarcated by steep eroded edges, but Otero Mesa is actually a horst, an elevated block of land separated by faults from the Tularosa Basin to the west and the Salt Basin to the east.

Originally the Otero Mesa study area was planned as a rectangle of eight 7.5-minute quadrangles like the Loco Hills and Azotea Mesa study areas. In order to increase the environmental diversity for modeling purposes, however, and to include the locations currently leased for oil and gas exploration, the study area was redesigned as two separate blocks comprising a total of eleven quadrangles (Figure 7.1).
\end{abstract}

\section{The Predictive Models}

Otero Mesa presents a classic problem in predictive modeling: the region has received little archaeological attention. The predictive model, therefore, is based on limited information, much of which is dated and of suspect quality. The models for Loco Hills and Azotea Mesa have shown, however, that the relationship between site locations and environmental attributes can be discerned with surprisingly limited data. As we have seen, predictive models always yield results. The question of overriding concern to managers and archaeologists alike is, "How much confidence can we have in these results?" In large part the answer lies in our ability to assess model performance statistically. But perhaps just as important as objective measures is our subjective assessment of whether the model mimics our perception of how humans would have placed themselves on the landscape. In essence, we must be assured that the models not only work, but also make sense.

The eastern Otero Mesa study unit encompasses four quadrangles or 65,400 hectares (253 square miles), and the western study unit covers seven quadrangles, or 114,443 hectares (440 square miles). The two study units reflect different physiographic areas. The eastern unit encompasses the closed drainage basin of Crow Flats and the western unit consists largely of rolling desert grasslands. Only $0.4 \%$ of the eastern unit has been surveyed and 20 sites have been recorded, representing both postcontact and prehistoric time periods. The western unit is one of the better-studied areas of Otero Mesa. Here, 3.0\% of the unit has been surveyed and 83 prehistoric and historical sites have been recorded.

As with Loco Hills and Azotea Mesa, the predictive models created for Otero Mesa are correlative models (see discussion in Chapter 4), which examine correlations between archaeological site locations and environmental features. The modeling process began with a compilation of available data on the environment and archaeology of Otero Mesa. We restricted our search to data that already existed in digital formats and could easily be converted into layers in a geographic information system (GIS). We used the IDRISI GIS package to store data, calculate the statistics, and display the results of the predictive models for Otero Mesa. This GIS package is a raster-based system, which uses a grid of a specified size superimposed over the area in question. We chose a $10 \times 10 \mathrm{~m}$ cell as our grid size, which generated 6,185,909 cells for the eastern study unit and 10,827,725 cells for the western study unit. 


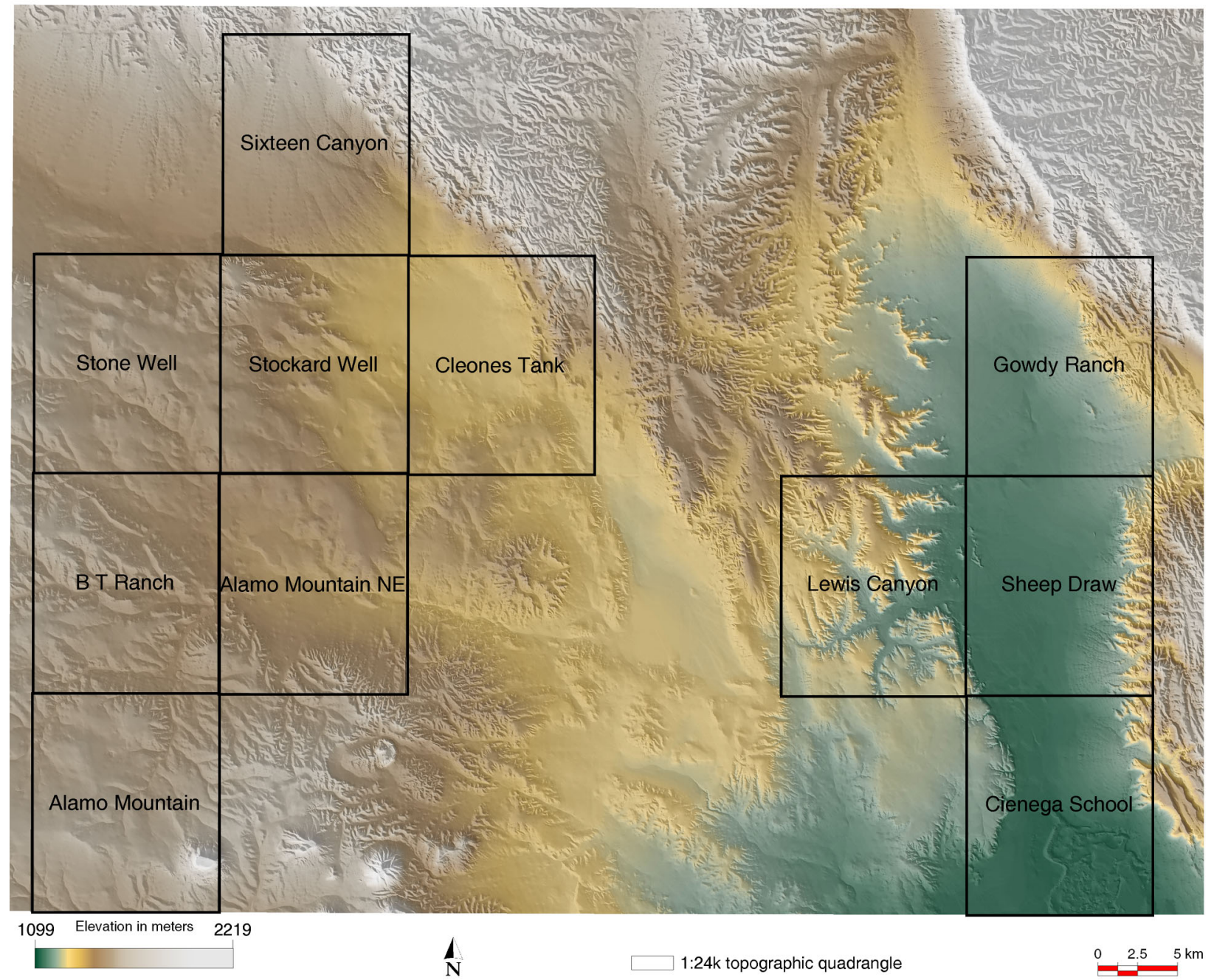

Figure 7.1. Digital elevation model of Otero Mesa and location of eastern and western study units with USGS 7.5-minute quadrangles labeled.

\section{Environmental Data}

As with Loco Hills and Azotea Mesa, the first step was to assemble data on a variety of environmental characteristics of Otero Mesa. We obtained GIS layers on elevation, vegetation, and geomorphology. The elevation theme is a digital elevation model (DEM; Figure 7.1) created by the United States Geological Survey. In the case of Otero Mesa, the contour interval is 20 feet. In many cases, DEMs serve as the primary data theme from which secondary themes, such as slope (Figure 7.2) and aspect, are created.

A data layer for major streams and ridgelines was also created using the DEM as a primary data layer (Figure 7.3). Once streams and ridges are defined, distance and cost surfaces can be computed from them. The GIS uses the streams and ridges as points of origins and can determine the distance or cost of travel to any cell in the study area. Cost is an estimation of the expenditure of energy required when traveling from a source, such as a stream or a ridgeline. Cost can be computed a number of ways: we could sum the slope values, slope squared values, or the square root slope values for each cell traversed. That is, the GIS could begin at cells coded as streams and sum the cost of crossing each cell encountered when traveling away from those sources. If, for example, the two cells to the east of a stream cell have slope values of 4 and 9, then the cost value for the second cell would be 13 if the slope values are summed, 97 if the slope values are squared, and 5 if the square roots of the slope values are summed. If the terrain is flatter, then the cost to reach the second cell would be less. Cost surfaces can be used to determine whether locations are easier or more difficult to access in relation to the surrounding landscape, but they do not necessarily identify actual travel routes used by people in the past. 


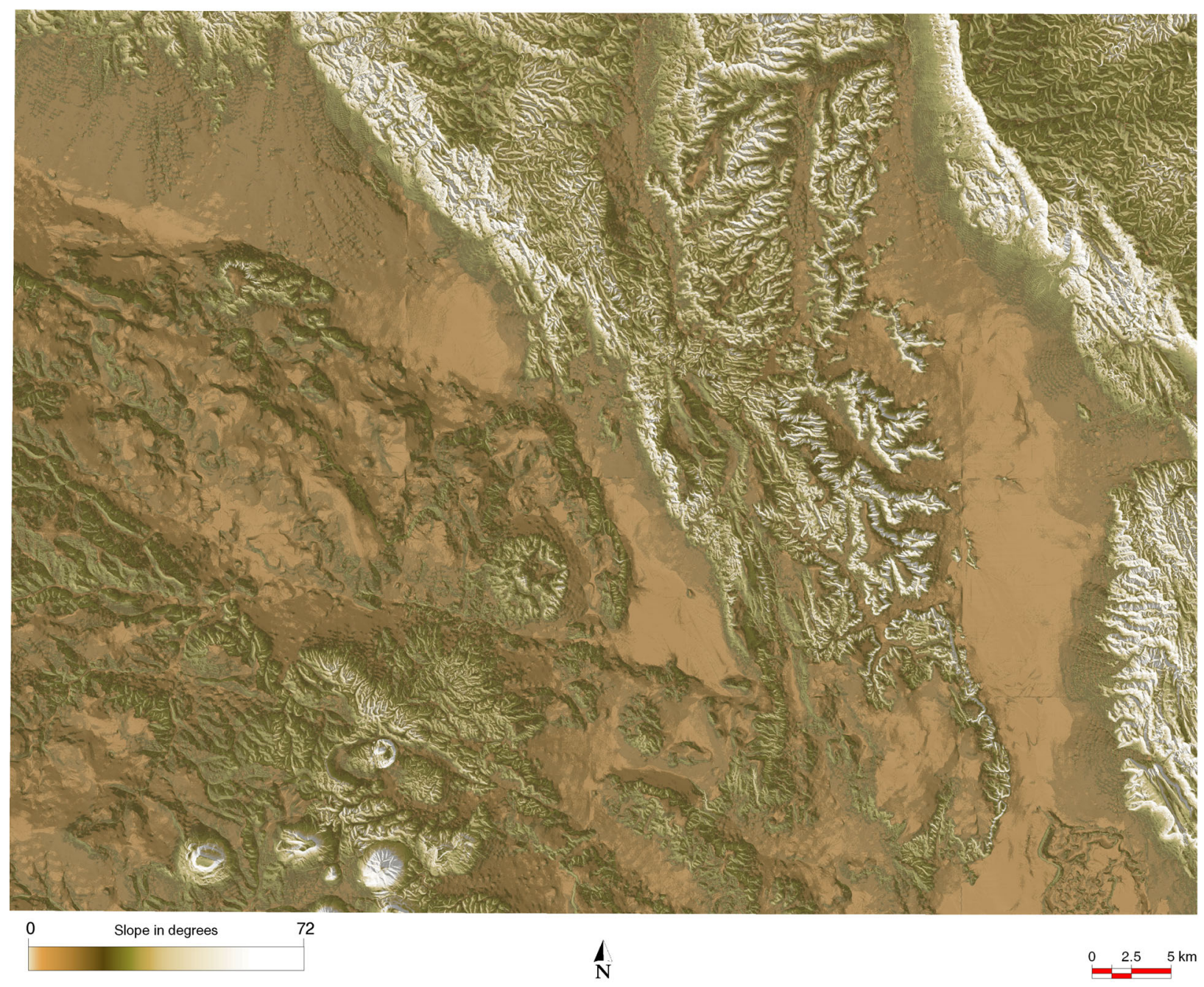

Figure 7.2. Slopes in the Otero Mesa study area.

To determine which cost value to use, we computed one-sample means tests for the three methods outlined above for the eastern study area (Tables 7.1 and 7.2). All three methods yield statistically significant results, though squaring the slope values yields a non-intuitive result — that sites are located at higher cost distances from streams than non-sites. For purposes of this study we chose to calculate cost distance using the slope value itself, without any transformation.

\section{Geomorphology}

The geomorphology data were provided by Gnomon, Inc., based on maps prepared by Steve Hall of Red Rock Geological Enterprises. The Otero Mesa study area was mapped using black-and-white stereo aerial photographs (scale about 1:52,000) and color infrared stereo aerial photographs (scale about 1:86,000) available from the EROS Data Center, Sioux Falls, South Dakota. Landforms were identified from the stereo aerial photographs using a Topcon mirror binocular stereoscope at $3 \times$ magnification, and the location and spatial distribution of the landforms were then plotted on 7.5 -minute topographic maps (scale 1:24,000), the base-map standard for this project. Landforms smaller than about 200 feet in greatest dimension (ca. one-tenth of an inch on topographic maps and smaller yet on the aerial photos) were not mapped.

The geomorphology of the Otero Mesa study area (Figure 7.4) is characterized by limestone bedrock composed of the Yeso and San Andreas formations (Permian) with broad areas of colluvial-alluvial-lacustrine deposits. Eolian and playa deposits occur in the Salt Basin in the eastern study unit. Large and small alluvial fans occur at the mouths of small canyons that are eroded into Permian limestone bedrock. 


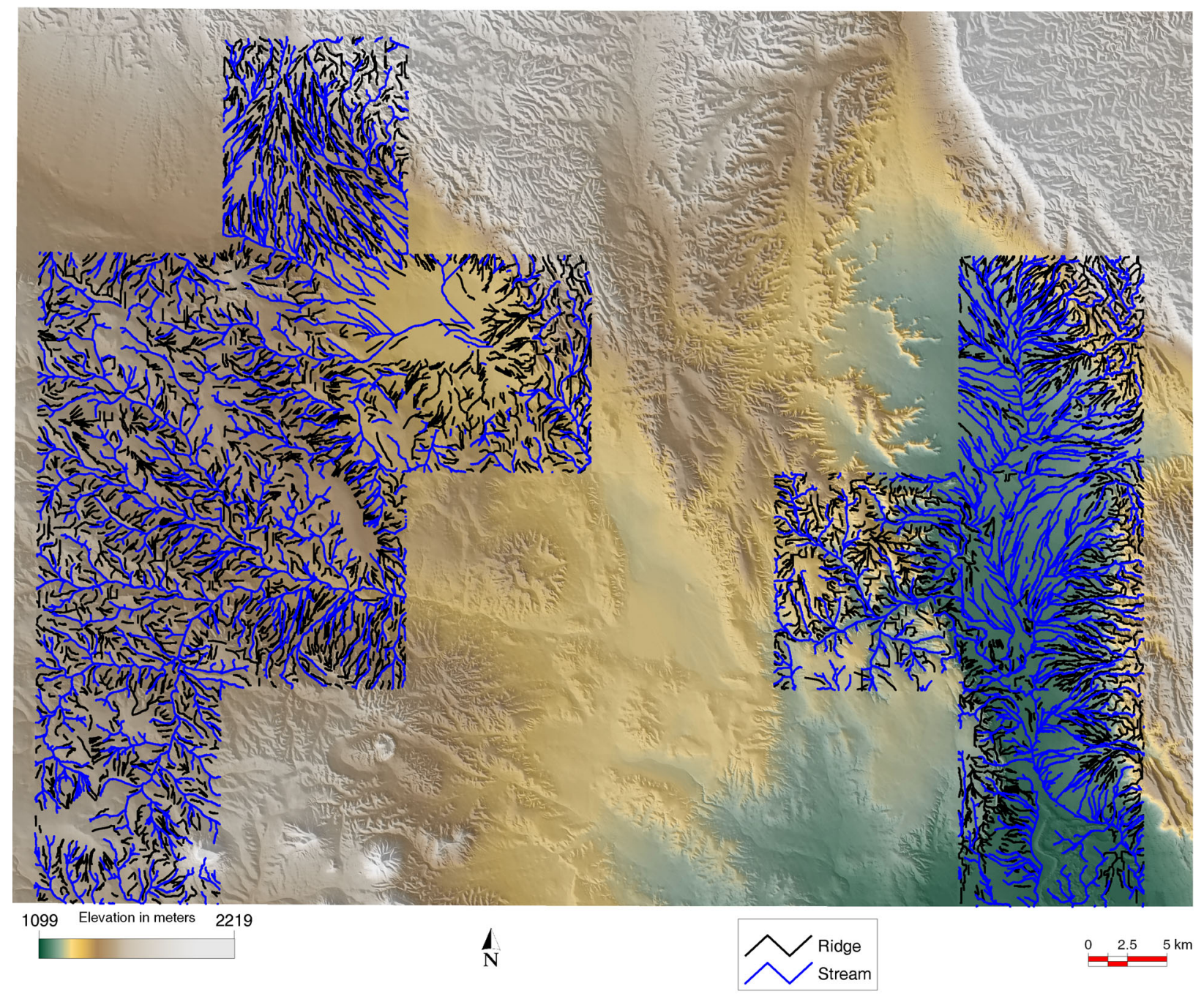

Figure 7.3. Drainages and ridges in the Otero Mesa study area.

Table 7.1. Descriptive statistics on slope values for the Eastern Otero Mesa Study Unit and for Sites within the Eastern Study Unit

\begin{tabular}{lrcc}
\hline & $\begin{array}{c}\text { Slope } \\
\text { Cost Surface } \\
\text { from Streams }\end{array}$ & $\begin{array}{c}\text { Slope Squared } \\
\text { Cost Surface } \\
\text { from Streams }\end{array}$ & $\begin{array}{c}\text { Slope Square Root } \\
\text { Cost Surface } \\
\text { from Streams }\end{array}$ \\
\hline $\begin{array}{l}\text { EASTERN STUDY UNIT } \\
\text { mean }\end{array}$ & 84.18 & 1085.39 & \\
std. dev. & 171.67 & 3114.42 & 47.44 \\
$\quad$ range & $0-1809.96$ & $0-38,846.66$ & $0-425.11$ \\
SITES & & & \\
$\quad$ mean & 94.59 & 149.32 & 56.87 \\
std. dev. & 64.93 & 154.43 & 40.99 \\
range & $0-224.02$ & $0-1679.75$ & $0-138.42$ \\
\hline
\end{tabular}




\section{THE OTERO MESA STUDY AREA}

Table 7.2. One-Sample Means Test for the Eastern Study Unit

\begin{tabular}{|c|c|c|}
\hline $\begin{array}{l}\text { Cost Distance } \\
\text { from Streams }\end{array}$ & Means Test & Significance Assessment \\
\hline for slope itself & $\begin{aligned} Z & =(94.59-84.18) /(175 / \sqrt{ } 3164) \\
& =32.39\end{aligned}$ & $\begin{array}{l}\text { Yes; site cells tend to have higher } \\
\text { cost distances than non-site cells }\end{array}$ \\
\hline for slope squared & $\begin{aligned} Z & =(149.32-1085.39) /(3114.42 / \sqrt{ } 3164) \\
& =-16.91\end{aligned}$ & $\begin{array}{l}\text { Yes; site cells tend to have lower } \\
\text { cost distances than non-site cells }\end{array}$ \\
\hline for slope square root & $\begin{aligned} Z & =(56.87-29.56) /(47.44 / \sqrt{ } 3164) \\
& =32.38\end{aligned}$ & $\begin{array}{l}\text { Yes; site cells tend to have higher } \\
\text { cost distances than non-site cells }\end{array}$ \\
\hline
\end{tabular}
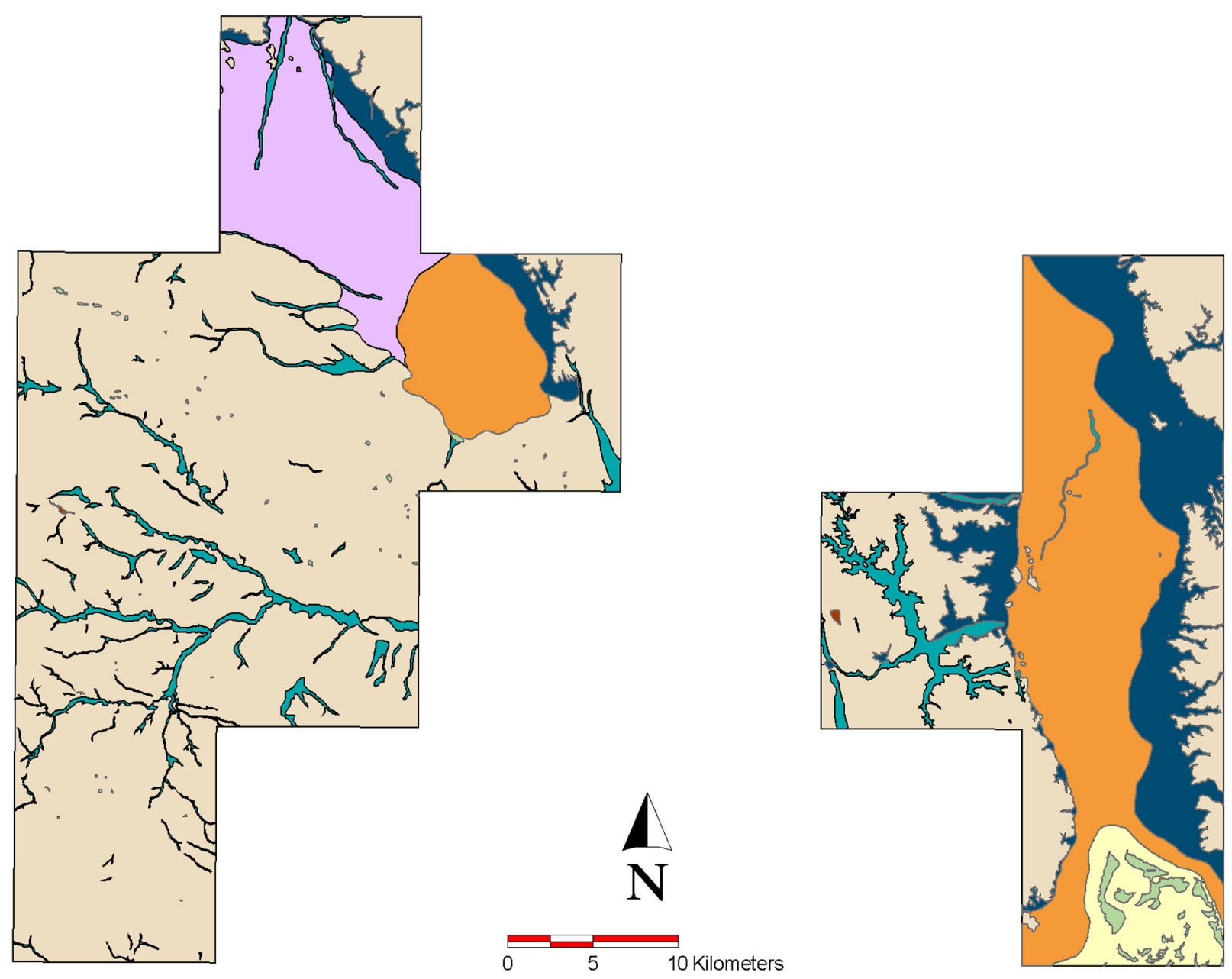

Alluvial fans, undetermined age, probably Pleistocene (9.68\%)

Colluvial deposits, gravelly silt, $<1 \mathrm{~m}$ thick, Holocene, low-gradient surfaces, uplands, may grade laterally into alluvium $(0.03 \%)$

Colluvial deposits, gravelly silt, $>1 \mathrm{~m}$ thick, Holocene, low-gradient surfaces, broad valleys, may mantle alluvial fan (16.02\%)

Eroded bedrock surfaces, escarpments with thin soils $(59.73 \%)$

Historic spring $(0.0002 \%)$

Playa deposits, undetermined age $(0.60 \%)$

Pleistocene alluvial fan at mouth of Sacramento River; mantled by $<1 \mathrm{~m}$ colluvial silt and fine sand $(7.36 \%)$

Sand sheet of undetermined age $(2.38 \%)$

Valley fill alluvium, undissected valleys, may include thin deposits of colluvium, fines and gravels, channels-floodplain (4.21\%)

Figure 7.4. Geomorphology of the Otero Mesa study units. 
Eroded bedrock surfaces. Most of the project area is classified as eroded limestone bedrock. Soils and geomorphic deposits are generally absent. If an ancient (Pleistocene) soil was present on the limestone hills and low-relief limestone mountains, it is gone now.

Archaeological sites located on areas of exposed limestone bedrock will be highly visible. These sites may have poor integrity, however, as deposits at the sites may be compromised by bioturbation, potentially destroying any original site stratigraphy.

Broad areas of low relief that are underlain by Permian limestone may have a mantle of recent colluvial sand and silt that is comparatively thin, generally less than $0.5 \mathrm{~m}$ in thickness. The absence of soil development indicates a recent age of the sandy silt. Archaeological sites may be partly buried by the colluvial mantle.

Alluvium. A few ephemeral streams with thin alluvial deposits occur in the area. Streams that originate in canyons cut into limestone bedrock may have alluvial deposits of considerable thickness, especially at the mouths of small canyons where alluvial fans have formed. The age of the thicker alluvium appears to be largely pre-Holocene, however, so archaeological sites are likely to occur on the present-day surface of the alluvial fill or at shallow depth.

Alluvial fans. Alluvial fans form broad, sloping surfaces along limestone escarpments. Where exposed, the fans are composed of gravels, some of which are cemented by carbonates, indicating a pre-Holocene age. Archaeological sites may be found on the surfaces of these old alluvial fans. Site integrity may be low, however, owing to postoccupational bioturbation.

Deposits at Salt Basin. The Salt Basin in the southern portion of the eastern study unit is a down-faulted graben with playas and associated eolian deposits. The playas are characterized by saline water, and their deposits are evaporites of late Pleistocene age. Along the margins of the playas are gypsiferous eolian sands of Holocene age. Extensive archaeological deposits buried in the sheet sand/coppice dunes along the eastern flank of the Salt Basin have recently been recorded (Tim Kearns, Western Cultural Resources Management, Farmington, NM, personal communication 2004). These data were not available for this study, however.

Summary. Denuded limestone and thin colluvial-alluvial deposits characterize a large proportion of the Otero Mesa study area. Archaeological sites in these settings will be highly visible, although site integrity may be affected by postoccupation bioturbation. Thin alluvial deposits associated with small ephemeral streams may also incorporate archaeological sites. Some thicker alluvial deposits at the mouths of canyons may be older, and sites will likely occur at the present-day surface. The eolian sands along the eastern margins of the Salt Basin are now known to contain buried archaeological sites as well.

\section{Vegetation}

The vegetation data (Figure 7.5) are from the Gap Analysis Program (GAP) of the USGS, which provides information on biodiversity and conservation gaps. The data comprise major vegetation categories that are divided into 17 subcategories based on common descriptions of vegetation.

As Figure 7.5 shows, most of the vegetation in the study area is Chihuahuan desert scrub, dominated by creosotebrush (Larrea tridentata), with substantial areas of Chihuahuan foothill-piedmont desert grasslands along the western edges of the western study unit and the eastern edges of the eastern study unit. The central and southern portions of the eastern study unit are dominated by Chihuahuan lowland desert grasslands. The grasslands are characterized by several species of grama grass (Bouteloua sp.) and by alkali sacaton (Sporobolus airoides) and various other species of dropseed (Sporobolus sp.), as well as a variety of forbs.

\section{Archaeological Data}

As with the Loco Hills and Azotea Mesa predictive models, the next step for the Otero Mesa models was to examine the dependent variable, the presence or absence of archaeological sites dating prior to European contact. Archaeological data were obtained from the New Mexico Historic Preservation Division's Archaeological Records Management System (ARMS). ARMS provides data on areas that have been the subject of archaeological surveys, the sites that have been recorded, and various characteristics of those sites. As with Loco Hills and Azotea Mesa, the ARMS data were accepted at face value and no fieldwork or additional archival investigations were completed.

Ideally, we would have created predictive models for each site class and/or temporal period. With only 95 total sites (78 in the western study unit and 17 in the eastern study unit), however, we were forced to combine all site data for each 

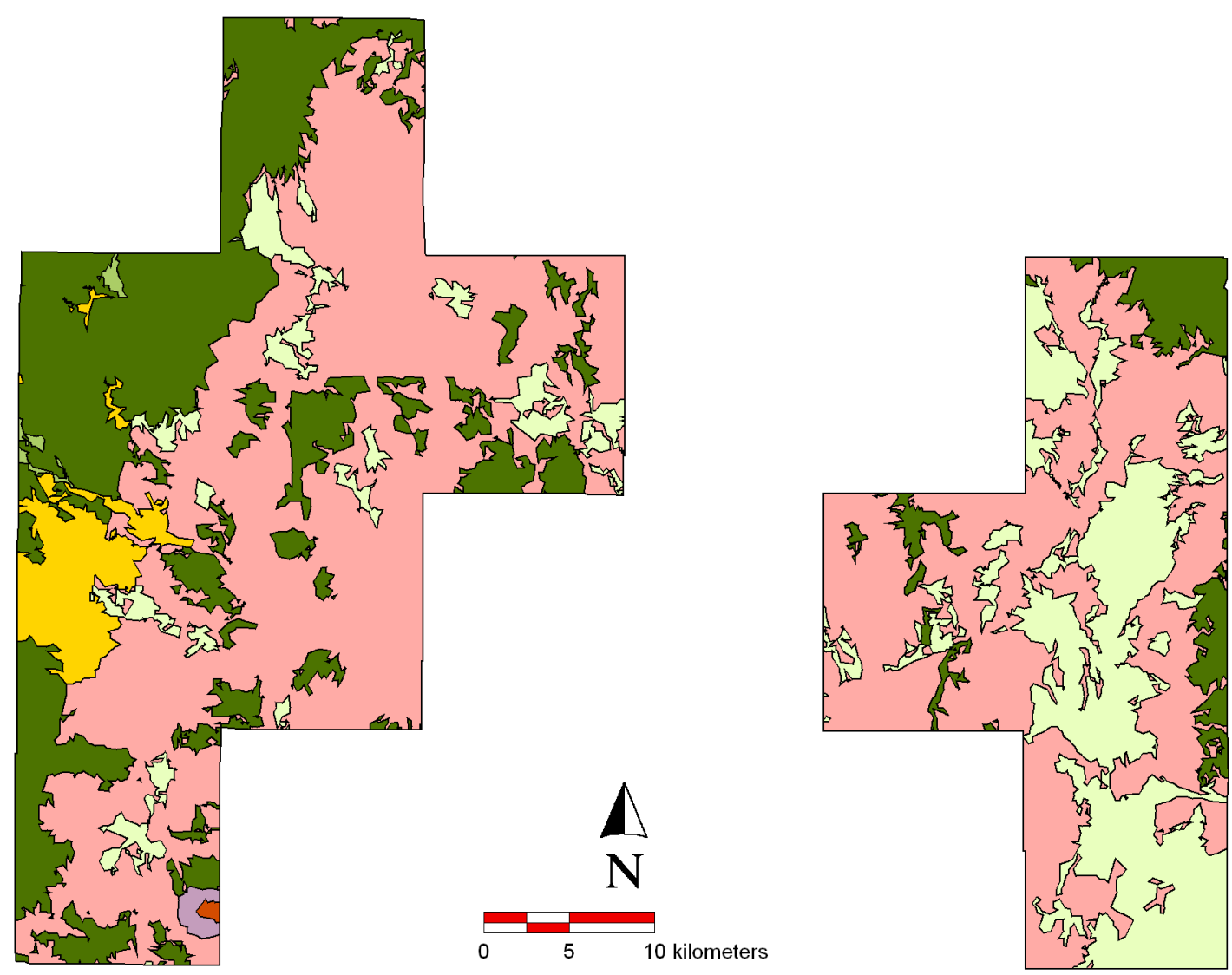

Broadleaf Evergreen Interior Chaparral (0.07\%)

Chihuahuan Broadleaf Deciduous Desert Scrub (3.41\%)

Chihuahuan Desert Scrub (56.19\%)

Chihuahuan Foothill-Piedmont Desert Grassland (24.01\%)

Chihuahuan Lowland/Swale Desert Grassland (15.83\%)

Rock Outcrop (0.28\%)

Rocky Mountain/Great Basin Open Conifer Woodland (0.005\%)

Short Grass Steppe $(0.22 \%)$

Figure 7.5. Vegetation of the Otero Mesa study units.

study area. The small sample even precluded us from distinguishing sites based on size as we did for Azotea Mesa. As before, we were able to separate historical from precontact components and exclude the former from the models. The site data, while sparse, did allow for statistical analysis; the necessity of combining all the site data did, however, impose limitations on the predictive value of the modeling as discussed below.

\section{Site Data}

The archaeological site data provided by ARMS are shown graphically in Figure 7.6. The site data were provided as polygon features, with each site polygon linked to available information, such as area, site number, and a site description.

An important part of GIS data is its spatial orientation in real world coordinates. The ARMS data were already georeferenced in Universal Transverse Mercator (UTM), Zone 13 grid format, using the North American Datum of 1927. The UTM georeference system is common for archaeological applications, and $x$ and $y$ coordinates are given in meters.

The GIS site data layer contains 324 polygons overall for Otero Mesa. This number is reduced to 103 when only our eastern and western study units are included. Eight of these sites date exclusively to the historical period, leaving 95 polygons to be used in the creation of the predictive models. 


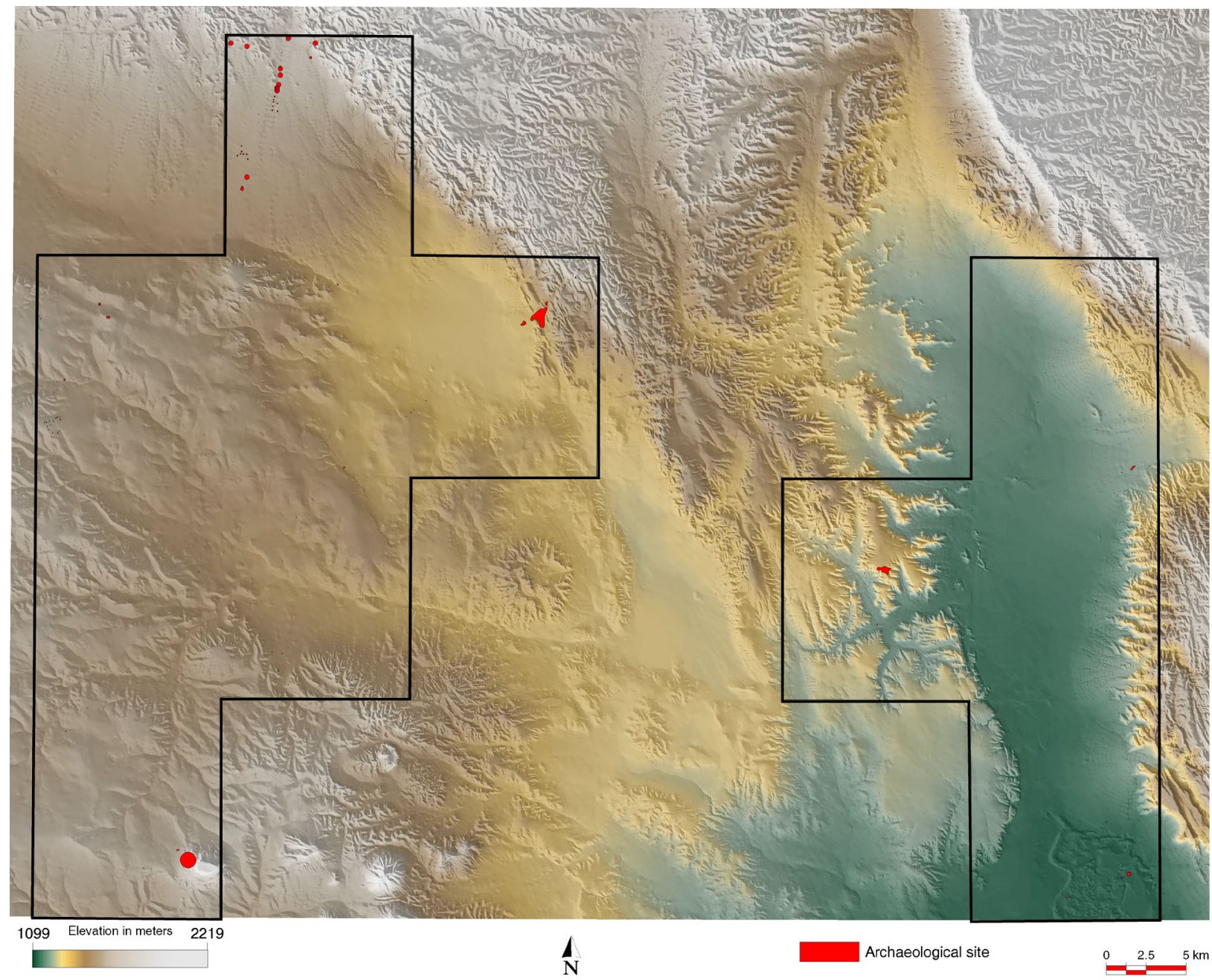

Figure 7.6. Prehistoric sites in the Otero Mesa study units $(n=95)$.

\section{Survey Data}

The survey data originally contained 143 polygons. For the purposes of our analysis, the survey data were clipped to only those surveyed areas falling within the boundaries of the two study areas, as shown in Figure 7.7. This resulted in a total of 119 polygons. As the figure shows, surveys have been rare in the east; the western unit's survey coverage is slightly better, but it is still largely unknown. As with the site data, the survey polygons were linked to information on the nature and year of the survey. These data were used to develop the survey histories presented later in this chapter.

\section{Evaluating the Data}

As a general rule, predictive modelers warn that unless $10 \%$ of each possible value for each environmental variable has been surveyed for archaeological sites, it is best to eliminate that variable from consideration. The problem with Otero Mesa, however, is that none of the values for any of the environmental variables meet this criterion. Although stopping at this point would probably have been prudent, we were committed to performing the modeling exercise. We tried to gain confidence in our ability to use the outcome of our modeling effort by comparing the Otero Mesa study areas with those at Loco Hills and Azotea Mesa. We reasoned that if the environments were roughly comparable, then even though the Otero Mesa region is poorly studied, we might be able to use the modeling results at least heuristically. Unfortunately, as shown in Table 7.3, the environments are not similar. We proceed with the Otero Mesa model despite the data limitations, but we urge extreme skepticism about the meaningfulness of the results. 


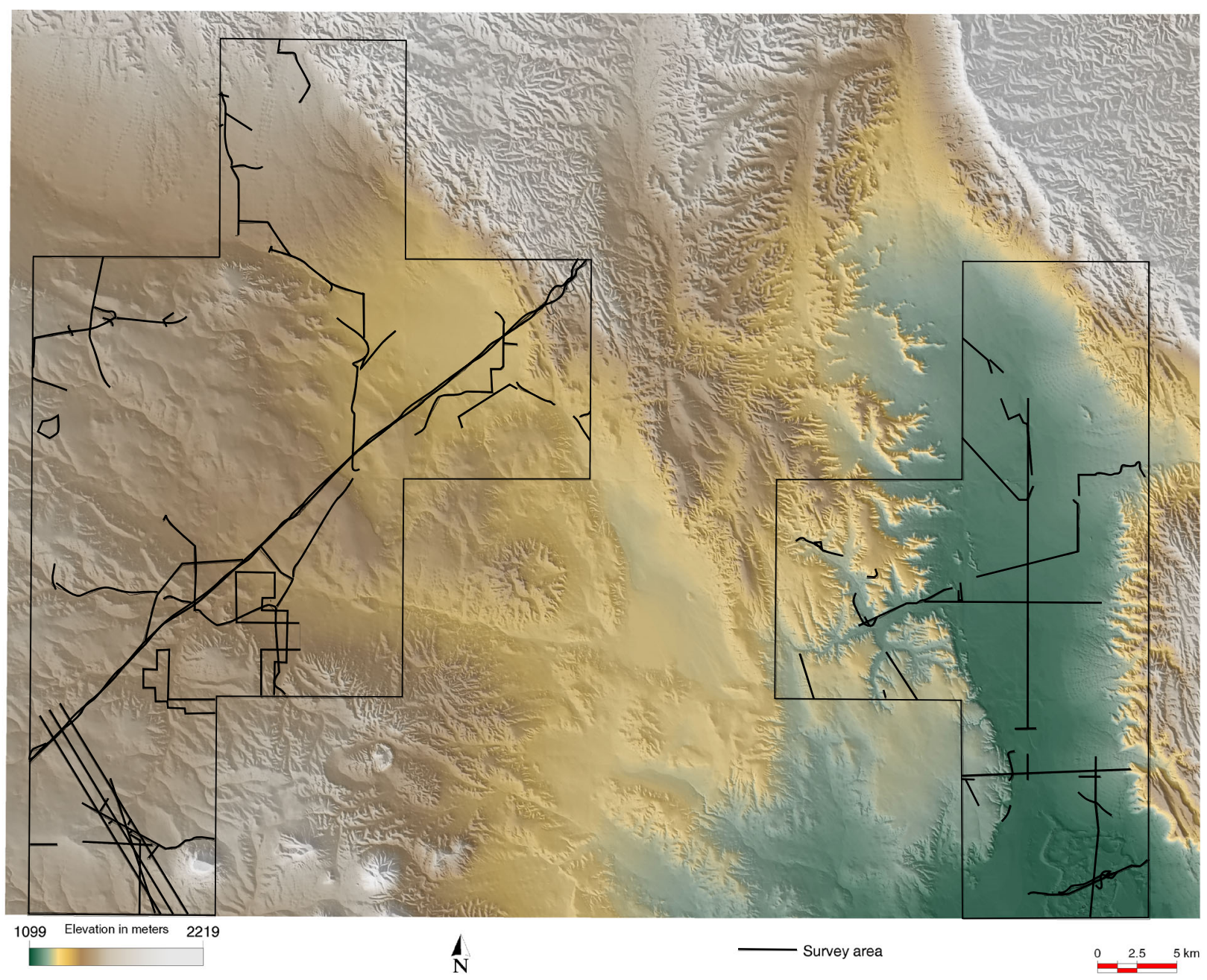

Figure 7.7. Archaeological surveys within the Otero Mesa study units.

\section{The Association between Environmental Variables and Site Location}

Two statistical testing methods were employed to test environmental data layers for significance in relation to site location. Continuous layers such as slope and elevation were tested using a one-sample means test. Categorical variables such as geomorphology and vegetation were evaluated using chi-square tests.

One-Sample Means Test. A one-sample means test can be conducted with GIS data by treating the environment of the archaeological site locations as a sample of the environmental background (total population), and testing the difference between the sample and population means. Because so little of Otero Mesa has been surveyed, we were concerned that the surveyed areas might not be representative of the entire environment. To test this possibility, we also calculated the one-sample means test by treating the surveyed area (rather than the entire study area) as the environmental background.

The means test is conducted by computing a z-score as described in Chapter 6 . If the difference is significant at the 0.05 level $(z>1.96)$, then the sample (in this case, archaeological sites) is unique and does not follow a normal distribution with relation to the background environment. Such a result would suggest that the sites are located within specific environmental niches rather than being randomly distributed throughout the study area.

In our models of Loco Hills and Azotea Mesa, we used site cells as the unit of analysis, so the sample size was not the number of sites but rather the number of pixels coded as sites. In his review of the draft technical summary of Otero Mesa, Keith Kintigh pointed out that the use of site cells as opposed to sites had the effect of inflating the $z$-scores and chi-square scores, making it easier to obtain a significant relationship between site cell locations and environmental features. In his review comments, Kintigh noted that: 
Particularly with respect to environmental variables, a chi-square test or for that matter the means test assumes that the observations are independent. Because of spatial autocorrelation, the observations for multiple cells for a single site are manifestly not independent observations.

There is no easy solution to this problem. The predictive model being developed predicts site cells, not sites. We do, however, recognize that by splitting sites into large numbers of cells we have inflated the chi-square and $z$-scores. To address this problem, we calculated the scores for Otero Mesa using both site cells and sites as the unit of analysis. To establish the environmental measurement for a site on each environmental variable, we had the GIS average the scores for that variable from the constituent site cells.

A second problem pointed out by Kintigh was the use of all cells in the study area to represent the environmental background as opposed to only those cells that had been surveyed. Using the entire study area provides the best representation of the environmental features of the region, but Kintigh is correct in pointing out that we can only measure the association between environmental variables and site location for areas that we have surveyed. If we were to use surveyed areas only in a situation like Otero Mesa, where survey coverage is limited and many environmental variables have been underrepresented, the results would be problematic. To evaluate this issue, for Otero Mesa we calculated the associational tests independently, using first the entire study area and then the surveyed areas only to represent the environmental background.

The one-sample means test results that show a significant relationship between site location and environmental variables are presented in Tables 7.4 and 7.5 for the eastern and western study units, respectively. The tables present first the results for tests that used the entire study area as the population (Column 2) and then the results for tests that used only surveyed areas as the population (Column 3).

In both the east and west study units, sites appear to be found in counterintuitive locations-away from stream intersections and at higher elevations. Other relationships appear when site cells are used (as opposed to whole sites), but these are likely to be the result of the large numbers of cells inflating the results, as discussed above. Most of these relationships between site cells and environmental variables vanish when polygons are used to represent sites, suggesting that these relationships are weak or nonexistent.

Table 7.3. Average Environmental Scores for Each Study Area

\begin{tabular}{|c|c|c|c|c|}
\hline & Loco Hills & Azotea Mesa & Otero Mesa West & Otero Mesa East \\
\hline $\begin{array}{l}\text { Elevation }(\mathrm{m}) \\
\text { mean } \pm \text { s.d. }\end{array}$ & $1,121 \pm 70$ & $1,198 \pm 144$ & $1,468 \pm 91$ & $1,207 \pm 105$ \\
\hline Geomorphology $\dagger$ & $\begin{array}{l}\text { Parabolic dunes, } 55 \% \\
\text { Coppice dunes, } 13 \% \\
\text { Eroded bedrock, } 13 \%\end{array}$ & $\begin{array}{l}\text { Eroded limestone, } 83 \% \\
\text { Extensive slope-wash } \\
\text { deposits, } 9 \% \\
\text { Floodplains of large } \\
\text { drainages, } 4 \%\end{array}$ & $\begin{array}{l}\text { Eroded bedrock, } 75 \% \\
\text { Pleistocene alluvial fan } \\
\text { at mouth of Sacramento } \\
\text { River, } 12 \% \\
\text { Holocene colluvial } \\
\text { deposits, gravelly silt } \\
>1 \mathrm{~m} \text { thick, } 4 \%\end{array}$ & $\begin{array}{l}\text { Holocene colluvial deposits, } \\
\text { gravelly silt }>1 \mathrm{~m} \text { thick, } 33 \% \\
\text { Eroded bedrock, } 32 \% \\
\text { Alluvial fans of undetermined } \\
\text { age, } 22 \%\end{array}$ \\
\hline Vegetation $\dagger$ & $\begin{array}{l}\text { Chihuahuan desert } \\
\text { grassland, } 59 \% \\
\text { Chihuahuan desert } \\
\text { scrub, } 19 \% \\
\text { Broadleaf evergreen } \\
\text { interior chaparral, 11\% }\end{array}$ & $\begin{array}{l}\text { Chihuahuan foothill- } \\
\text { piedmont desert } \\
\text { grassland, } 69 \% \\
\text { Chihuahuan desert } \\
\text { scrub, } 15 \% \\
\text { Chihuahuan desert } \\
\text { grassland, } 6 \%\end{array}$ & $\begin{array}{l}\text { Chihuahuan Desert } \\
\text { scrub, } 56 \% \\
\text { Chihuahuan foothill- } \\
\text { piedmont desert } \\
\text { grassland, } 32 \% \\
\text { Chihuahuan lowland/ } \\
\text { swale desert } \\
\text { grassland, } 6 \%\end{array}$ & $\begin{array}{l}\text { Chihuahuan Desert scrub, } 57 \% \\
\text { Chihuahuan lowland/swale } \\
\text { desert grassland, } 34 \% \\
\text { Chihuahuan foothill-piedmont } \\
\text { desert grassland, } 9 \%\end{array}$ \\
\hline $\begin{array}{l}\text { Distance to water }(\mathrm{m}) \\
\text { mean } \pm \text { s.d. }\end{array}$ & $1,967 \pm 1,694$ & $636 \pm 478$ & $209 \pm 212$ & $284 \pm 324$ \\
\hline $\begin{array}{l}\text { Survey coverage } \\
\text { (\% of total area) } \\
\text { Prehistoric sites }\end{array}$ & $19 \%$ & $10 \%$ & $3 \%$ & $0.4 \%$ \\
\hline Number of polygons & 779 & 550 & 78 & 17 \\
\hline Acreage (range) & $0.01-890.95$ & $0.15-313.82$ & $0.05-193$ & $0.17-56.03$ \\
\hline Acreage (mean \pm s.d.) & $7.14 \pm 41.1$ & $4.62 \pm 19.22$ & $7.94 \pm 28.48$ & $4.85 \pm 13.52$ \\
\hline
\end{tabular}

$\dagger$ Top three geomorphology and vegetation categories by area are reported with percent of total study area represented. 
THE OTERO MESA STUDY AREA

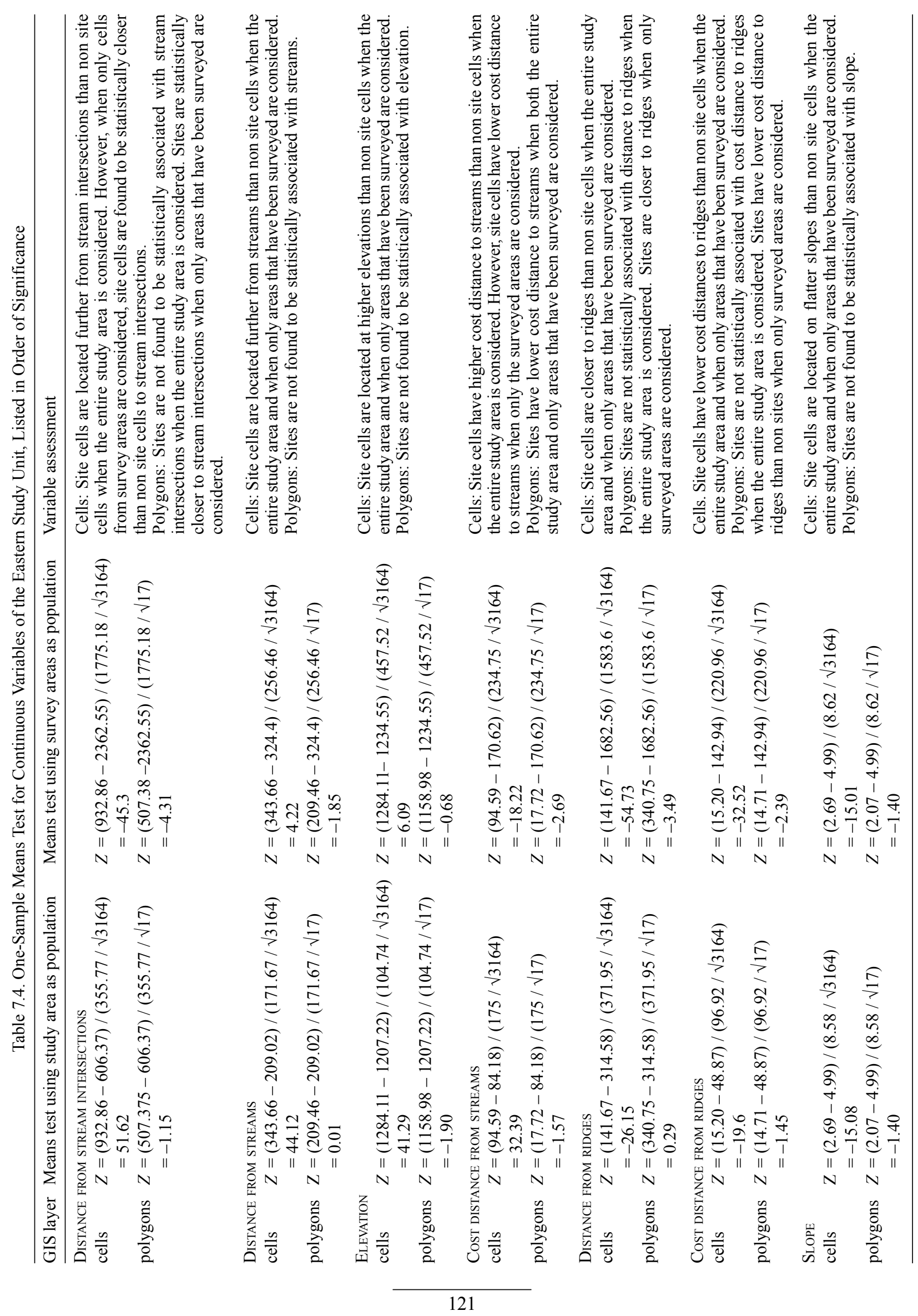




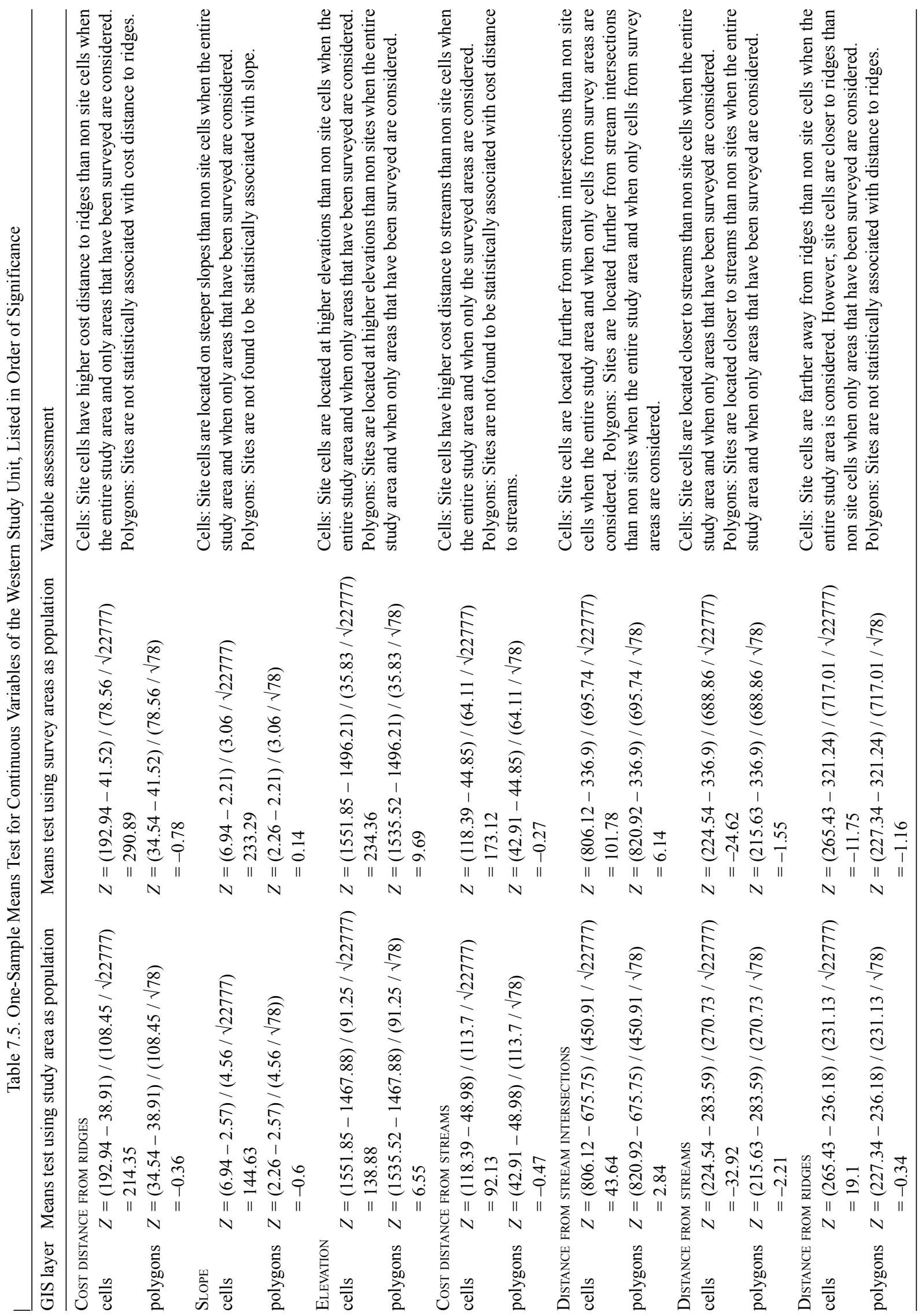


Categorical Chi-Square Goodness-of-Fit Test. The categorical variables-aspect, geomorphology, and vegetationwere tested for significance using a chi-square test at the 0.05 critical value level. The test assesses each environmental layer for significant differences between expected numbers of archaeological sites (if placement is random with respect to that variable) and observed numbers numbers of sites. The chi-square value is calculated using the formula provided in Chapter 6. For example, if a category covers $50 \%$ of the study area then the expected number of site cells should be $50 \%$ of the total site cells. The number actually observed is computed using the GIS to determine the actual number of site cells within the category. If an expected score is less than 5 then that category is combined with others until a value of 5 or greater is reached, thereby meeting statistical requirements of the test.

The degree of freedom (df) for these matrices is defined as the number of columns minus one multiplied by the number of rows minus one. We defined chi-square scores over 9.488 as indicative of a nonrandom relationship between site location and aspect variables, for example $(\mathrm{df}=4)$, whereas for geomorphic variables we used a chi-square score of $14.067(\mathrm{df}=7)$. In both cases, scores of more than the cutoff value occur less than 5 times in 100 as a result of chance alone. The highest score for each category is reported in bold in the accompanying tables to facilitate comparison of testing results between variables.

We determined the chi-square score for site polygons by transferring the data to TNTmipps GIS software. TNTmipps enabled us to transform raster statistics to vector data. One problem with this algorithm is that it handles the typology of polygons by dividing overlapping polygons into separate shapes and counting the resultant pieces as extra areas, thus increasing the site polygon count. For this reason, the number of polygons evaluated in this test is larger than the actual number of sites - 20 for the eastern study unit (rather than 17) and 83 for the western study unit (rather than 78).

The results of the chi-square tests for significant association with aspect are presented in Tables 7.6 and 7.7. In the eastern study unit, site cells tend to be open to the south and east in greater proportions than expected; in the western study unit, site cells are mostly oriented to the west. In both areas, northern exposure occurs less often than expected. None of these associations, however, is significant when the unit of analysis switches from site cells to site polygons.

For geomorphology (Tables 7.8 and 7.9), the chi-square results are consistent with those for the one-sample means test. Site cells and sites in the eastern study unit are found on bedrock; site cells, but not sites, are also found in significant numbers on sand sheets but not on alluvium. Such conditions are found away from water and on elevated surfaces. In the western study unit, sites are found on almost the opposite landforms. Here, site cells and sites tend to be located on alluvial fan deposits and valley alluvium. Sites in the west are less often found on eroded bedrock. In both units, site cells and sites are rare on colluvial deposits. Though prehistoric peoples may have avoided these surfaces, it is also possible that the absence of sites is a result of postdepositional processes that have buried precontact cultural materials. The presence of archaeological deposits buried under shallow colluvial soils is indicated by recent, as yet

Table 7.6. Chi-Square Tests for Significant Association with Aspect in the Eastern Study Unit

\begin{tabular}{|c|c|c|c|c|c|}
\hline & $\begin{array}{c}\text { North } \\
\left(315-360^{\circ}, 0-45^{\circ}\right)\end{array}$ & $\begin{array}{c}\text { East } \\
\left(45-135^{\circ}\right)\end{array}$ & $\begin{array}{c}\text { South } \\
\left(135-225^{\circ}\right)\end{array}$ & $\begin{array}{c}\text { West } \\
\left(225-315^{\circ}\right)\end{array}$ & No Slope Direction \\
\hline Background percentage & 11.86 & 21.27 & 34.61 & 30.01 & 2.25 \\
\hline Survey percentage & 16.03 & 40.49 & 29.69 & 13.73 & 0.06 \\
\hline Site cells & 208 & 830 & 1743 & 365 & 19 \\
\hline Site polygons & 3 & 5 & 7 & 5 & 0 \\
\hline Background cells expected & 375.37 & 673.2 & 1095.41 & 949.82 & 71.21 \\
\hline Background site polygons expected & $\begin{array}{c}2.37 \\
\text { (combine with east) }\end{array}$ & 4.25 & 6.92 & 6.00 & $\begin{array}{c}0.45 \\
\text { (combine with west) }\end{array}$ \\
\hline Survey site cells expected & 507.35 & 1281.51 & 939.69 & 434.55 & 71.21 \\
\hline Survey site polygons expected & $\begin{array}{c}3.21 \\
\text { (combine with west) }\end{array}$ & 8.1 & 5.94 & 2.75 & $\begin{array}{c}0.01 \\
\text { (combine with west) }\end{array}$ \\
\hline Background site cell $\mathrm{P}^{2}$ & 74.63 & 36.52 & 382.85 & 360.08 & 38.28 \\
\hline Background site polygon $\mathrm{P}^{2}$ & (combined with east) & 0.17 & 0.001 & 0.33 & (combined with west) \\
\hline Survey site cell $\mathrm{P}^{2}$ & 176.62 & 159.08 & 686.72 & 11.13 & 38.28 \\
\hline Survey site polygon $\mathrm{P}^{2}$ & (combined with west) & 1.19 & 0.19 & 2.03 & (combined with west) \\
\hline Survey coverage $\%$ & 0.01 & 0.35 & 0.5 & 0.22 & 0.12 \\
\hline
\end{tabular}

Background site cell $\mathrm{P}^{2}=74.62+36.52+382.85+360.08+38.28=892.35$

Background site polygon $\mathrm{P}^{2}=0.17+0.001+0.33=0.501$

Survey site cell $\mathrm{P}^{2}=176.62+159.08+686.72+11.13+38.28=1071.83$

Survey site polygon $\mathrm{P}^{2}=1.19+0.19+2.03=3.41$ 


\section{ADAPTIVE MANAGEMENT ぶLANNING MODELS FOR CULTURAL RESOURCES IN OIL ※ GAS FIELDS}

Table 7.7. Chi-Square Tests for Significant Association with Aspect in the Western Study Unit

\begin{tabular}{|c|c|c|c|c|c|}
\hline & $\begin{array}{c}\text { North } \\
\left(315-360^{\circ}, 0-45^{\circ}\right)\end{array}$ & $\begin{array}{c}\text { East } \\
\left(45-135^{\circ}\right)\end{array}$ & $\begin{array}{c}\text { South } \\
\left(135-225^{\circ}\right)\end{array}$ & $\begin{array}{c}\text { West } \\
\left(225-315^{\circ}\right)\end{array}$ & No Slope Direction \\
\hline Background percentage & 23.77 & 30.83 & 30.31 & 14.79 & 0.25 \\
\hline Survey percentage & 27.93 & 31.83 & 31.68 & 8.56 & 0 \\
\hline Site cells & 2580 & 1453 & 6988 & 11757 & 0 \\
\hline Site polygons & 22 & 18 & 31 & 13 & 0 \\
\hline Background site cells expected & 5414.09 & 7022.46 & 6904.01 & 3368.72 & 56.94 \\
\hline Background site polygons expected & 19.97 & 25.9 & 25.46 & 12.42 & $\begin{array}{c}0.21 \\
\text { (combined with west) }\end{array}$ \\
\hline Survey site cells expected & 6361.90 & 7250.24 & 7216.07 & 1949.80 & 0 \\
\hline Survey site polygons expected & 23.46 & 26.74 & 26.61 & 7.19 & 0 \\
\hline Background site cell $\mathrm{P}^{2}$ & 1483.55 & 4416.8 & 1.03 & 20887.23 & 56.95 \\
\hline Background site polygons $\mathrm{P}^{2}$ & 0.21 & 2.41 & 1.21 & 0.01 & (combined with west) \\
\hline Survey site cell $\mathrm{P}^{2}$ & 2248.19 & 4635.43 & 7.21 & 49328.74 & \\
\hline Survey site polygons $\mathrm{P}^{2}$ & 0.09 & 2.86 & 0.72 & 4.69 & 0 \\
\hline Survey coverage $\%$ & 0.42 & 1.57 & 1.38 & 1.4 & 0.77 \\
\hline
\end{tabular}

Background site cell $\mathrm{P}^{2}=1,483.55+4,416.8+1.03+20,887.23+56.95=26,845.56$

Background site polygon $\mathrm{P}^{2}=0.21+2.41+1.21+0.01=3.84$

Survey site cell $\mathrm{P}^{2}=2248.19+4635.43+7.21+49328.74=56219.57$

Survey site polygon $\mathrm{P}^{2}=0.09+2.86+0.72+4.69=8.36$

Table 7.8. Chi-Square Tests for Significant Association with Geomorphic Units in the Eastern Study Unit

\begin{tabular}{|c|c|c|c|c|c|c|c|}
\hline & $\begin{array}{c}\text { Eroded } \\
\text { bedrock }\end{array}$ & $\begin{array}{l}\text { Sand } \\
\text { sheet }\end{array}$ & $\begin{array}{l}\text { Valley fill } \\
\text { alluvium }\end{array}$ & $\begin{array}{l}\text { Alluvial } \\
\text { fans }\end{array}$ & $\begin{array}{c}\text { Playa } \\
\text { deposits }\end{array}$ & $\begin{array}{l}\text { Colluvial } \\
\text { deposits } \\
<1 \text { m thick }\end{array}$ & $\begin{array}{c}\text { Colluvial } \\
\text { deposits } \\
>1 \text { m thick }\end{array}$ \\
\hline Background percentage & 32.29 & 6.49 & 3.88 & 22.23 & 1.44 & 0.05 & 33.62 \\
\hline Survey percentage & 74.62 & 0 & 11.03 & 14.35 & 0 & 0 & 0 \\
\hline Site cells & 2153 & 569 & 28 & 324 & 0 & 0 & 85 \\
\hline Site polygons & 2 & 5 & 2 & 5 & 0 & 0 & 6 \\
\hline Background site cells expected & 1020.04 & 205.02 & 122.57 & 702.25 & 45.49 & 1.58 & 1062.06 \\
\hline Background site polygons expected & 6.46 & $1.30 \dagger$ & $0.78 \dagger$ & 4.45 & $0.29 \dagger$ & $0.01 \dagger$ & 0 \\
\hline Survey site cells expected & 2357.25 & 0 & 348.44 & 453.32 & 0 & 0 & 0 \\
\hline Survey site polygons expected & 14.92 & 0 & 2.21 & 2.87 & 0 & 0 & 0 \\
\hline Background site cell $\mathrm{P}^{2}$ & 1258.38 & 646.19 & 72.97 & 203.74 & 45.49 & 1.58 & 898.86 \\
\hline Background site polygon $\mathrm{P}^{2}$ & 3.08 & $\dagger$ & $\dagger$ & 0.49 & $\dagger$ & $\dagger$ & 6 \\
\hline Survey site cell $\mathrm{P}^{2}$ & 17.7 & 569 & 294.69 & 36.89 & 0 & 0 & 85 \\
\hline Survey site polygon $\mathrm{P}^{2}$ & 11.19 & $\dagger$ & $\dagger$ & 3.91 & $\dagger$ & $\dagger$ & 6 \\
\hline Survey coverage $\%$ & 0.24 & 0.14 & 0.3 & 0.07 & 0 & 0 & 0.004 \\
\hline
\end{tabular}

Background site cell $\mathrm{P}^{2}=1258.38+646.19+72.97+203.74+45.49+1.58+898.86=3127.21$

Background site polygon $\mathrm{P}^{2}=3.08+0.49+6=9.57$

Survey site cell $\mathrm{P}^{2}=17.7+569+294.69+36.89+85=1003.28$

Survey site polygon $\mathrm{P}^{2}=11.19+3.91+6=21.1$

$\dagger$ Cells combined with Alluvial fans 
THE OTERO MESA STUDY AREA

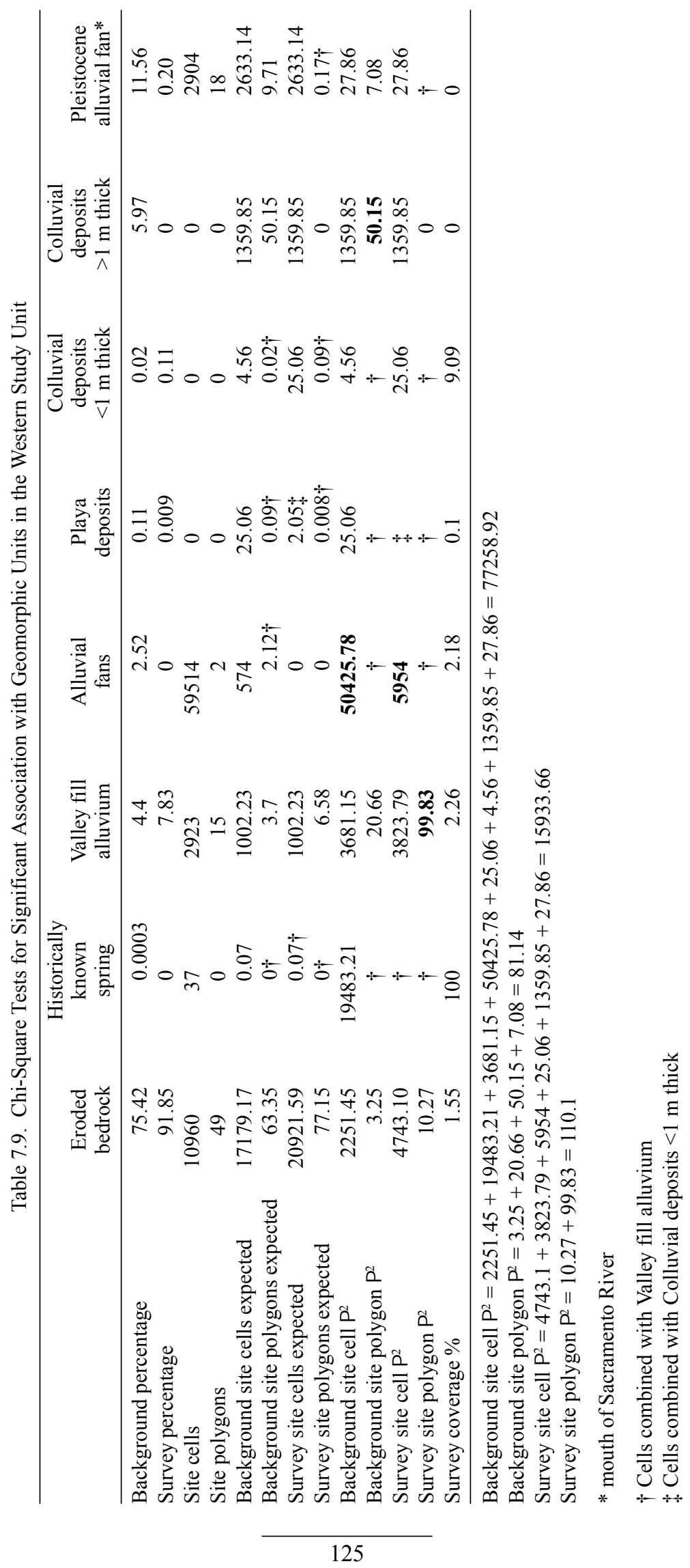


unreported fieldwork within the eastern study unit (Tim Kearns, personal communication). This underscores the difficultly of modeling the relationship between site location and landforms in the absence of sufficient site and survey data.

The results of the chi-square tests for significant association with vegetation units are presented in Tables 7.10 and 7.11. In order to meet the statistical assumptions of the chi-square test, many of the vegetative communities needed to be combined. In the east, we found significant associations between site cells and cells coded for Chihuahan desert scrub, Chihuahuan foothill/piedmont, and Chihuahuan lowland/swale, though no significant relationships emerged when site polygons were used. In the west, a variety of "combined" environmental zones were related at significant levels to both site cells and site polygons.

\section{Statistical Independence}

In the preceding section, we often remarked that the relationship between site locations and one environmental theme was similar to that found with another theme. Such results are expected because environmental variables are closely related to one another. Plants of a particular vegetative community will occur only on well-watered, well-drained soils, for example. Conversely, areas devoid of vegetation generally lack soils or water or both - an exposed rock surface, for example.

While the interrelationship between environmental variables is expected, it also violates a fundamental assumption of most statistical tests: that the independent variables used in the analysis are statistically independent of one another. Complete independence is rare in the social sciences. Modelers of real world situations, therefore, accept that there are problems of interdependence and concentrate on understanding the statistical effect of interrelationships of independent variables on model predictions.

In general, violations of the independence assumption lead to an overstating of the predictive power of the statistical model. Intuitively, such a result makes sense. Assume, for example, that a specific vegetative community is found only on a particular geomorphic landform. If both variables are included in the model without accounting for the interrelationship, the predictive power of the model will likely be overstated.

To guard against including supposedly independent variables that are, in fact, related to each other, for each study area we calculated the pair-wise Spearman's $r$ between each pair of those environmental variables that were measured on a continuous scale (Tables 7.12 and 7.13). Any $r$ score that exceeded 0.5 was noted, and the pair of variables was examined. The one with the weaker relationship to site location was removed before model development.

Table 7.10. Chi-Square Tests for Significant Association with Vegetation Units in the Eastern Study Unit

\begin{tabular}{|c|c|c|c|c|}
\hline & $\begin{array}{l}\text { Rky Mtn/Great Basin } \\
\text { open conifer }\end{array}$ & $\begin{array}{l}\text { Chihuahuan } \\
\text { Desert scrub }\end{array}$ & $\begin{array}{c}\text { Chihuahuan } \\
\text { foothill-piedmont }\end{array}$ & $\begin{array}{l}\text { Chihuahuan } \\
\text { lowland/swale }\end{array}$ \\
\hline Background percentage & 0.01 & 57.01 & 9.44 & 33.53 \\
\hline Survey percentage & 0 & 83.62 & 6.33 & 10.05 \\
\hline Site cells & 0 & 442 & 21 & 2702 \\
\hline Site polygons & 0 & 7 & 1 & 12 \\
\hline Background site cells expected & 0.32 & 1804.37 & 298.78 & 1061.22 \\
\hline Background site polygons expected & $0.002 \uparrow$ & 11.4 & $1.89 \dagger$ & 6.71 \\
\hline Survey site cells expected & 0 & 2646.57 & 200.34 & 318.08 \\
\hline Survey site polygons expected & 0 & 16.72 & $1.27 \dagger$ & $2.01 \dagger$ \\
\hline Background site cell $\chi^{2}$ & 0.32 & 1028.64 & 258.25 & 2536.85 \\
\hline Background site polygon $\chi^{2}$ & $0 \dagger$ & 1.70 & $0 \dagger$ & 2.25 \\
\hline Survey site cell $\chi^{2}$ & 0 & 1836.39 & 160.51 & 17866.81 \\
\hline Survey site polygon $\chi^{2}$ & 0 & 0 & $\dagger$ & $\dagger$ \\
\hline Survey coverage $\%$ & 0 & 0.15 & 0.07 & 0.03 \\
\hline
\end{tabular}

Background site cell $\chi^{2}=0.32+1028.64+258.25+2536.85=3824.06$

Background site polygon $\chi^{2}=1.70+2.25=3.95$

Survey site cell $\chi^{2}=1836.39+160.51+17866.81=19863.71$

Survey site polygon $\chi^{2}=0$

$\uparrow$ Cells combined with Chihuahuan Desert scrub 
THE OTERO MESA STUDY AREA

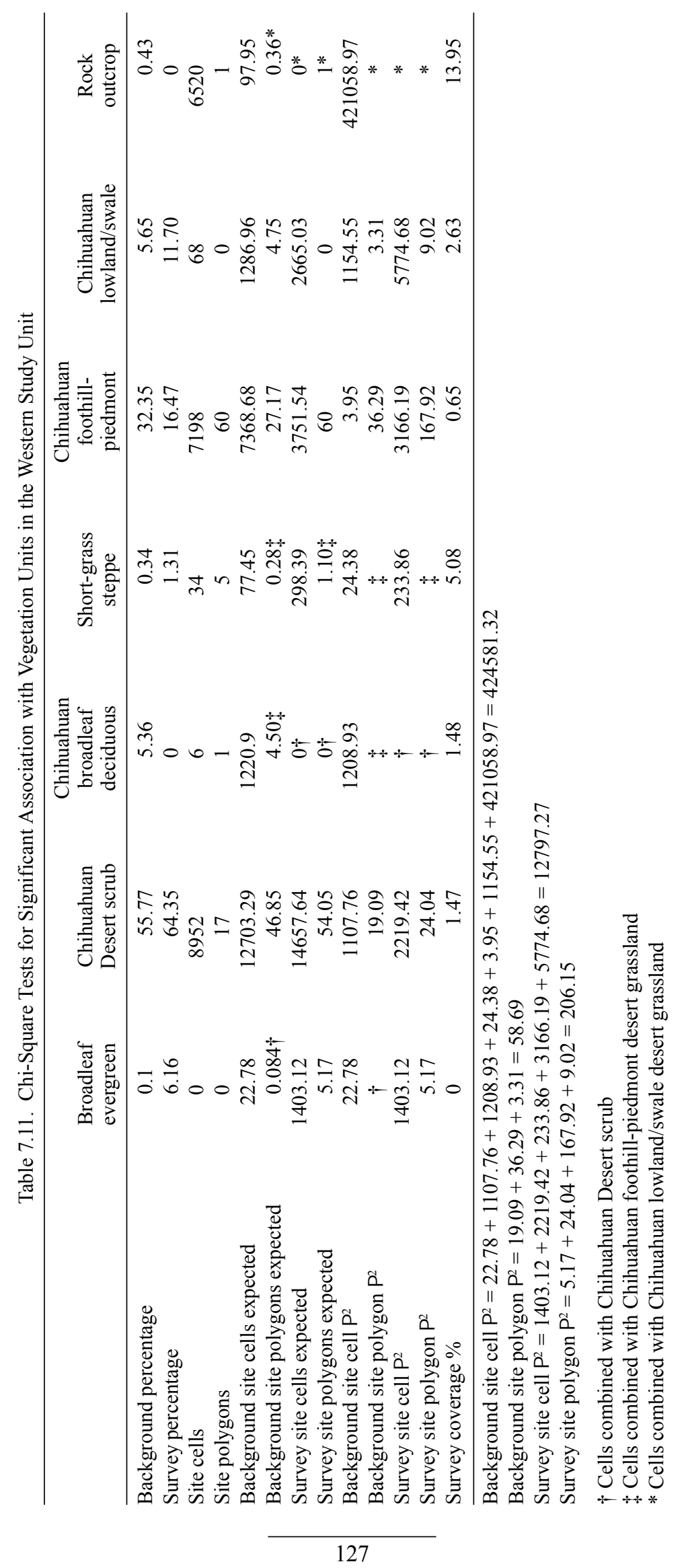



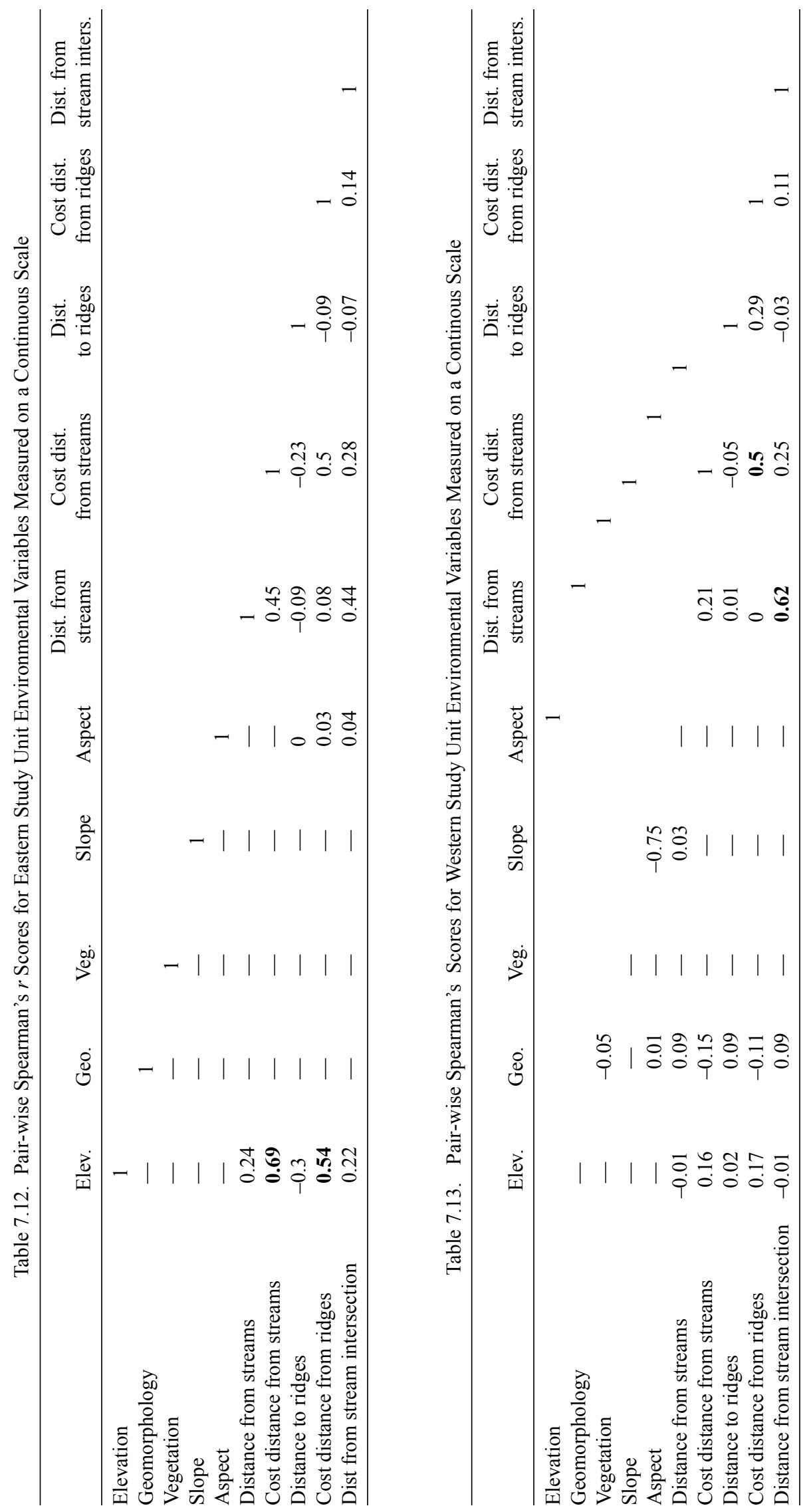


\section{Selection of Independent Variables}

The foregoing sections describe our evaluation of the statistical association between environmental variables and the targeted cultural variables as well as the degree of statistical independence between environmental variables. Based on these analyses, we chose a set of environmental variables to serve as the independent variables in the predictive models (Table 7.14). Although we would have preferred to have each independent variable strongly correlated with site locations, as defined by sites cells and polygons, such a selection criterion would have left us with few variables. We strongly suspect that it is the lack of survey on Otero Mesa, and not cultural behavior, that explains the weak relationships. In selecting independent variables we were guided by the results of the statistical tests, but we also used the knowledge gained from the better studied locales of Loco Hills and Azotea Mesa.

Table 7.14. Environmental Variables Used for Modeling the Study Units

\begin{tabular}{ll}
\hline Section & Environmental Variables Used in Model \\
\hline East & $\begin{array}{l}\text { Elevation, geomorphology, vegetation, slope, aspect, distance from } \\
\text { streams, distance from ridges, and distance from stream intersections }\end{array}$ \\
West & $\begin{array}{l}\text { Geomorphology, vegetation, slope, aspect, distance from streams*, } \\
\text { distance from ridges, and cost distance from ridges }\end{array}$ \\
\hline
\end{tabular}

* Distance from streams was chosen rather than the distance from stream intersections layer because distance from streams is more likely to have affected human behavior.

\section{Sensitivity Models}

There are many different types of predictive models, ranging from subjective statements about where archaeologists have found sites in a region to highly sophisticated multivariate statistical models. For Otero Mesa, we used the same three modeling techniques that were employed at Azotea Mesa: Boolean intersection, weighted method, and logistic regression. All three allow the use of variables measured on different scales, although the first two require that data measured on interval scales be transformed into data measured on ordinal or nominal scales. In our previous technical summaries, we have described each of the methods. The reader is referred to Chapter 4 for a description of these modeling methods.

\section{Boolean Model}

The first step in creating a Boolean model is to define the states that are favorable for human settlement for each environmental variable. For categorical variables, this step consists simply of defining the appropriate environmental features, such as eroded bedrock or historically known springs. For continuous variables we need to define a break point, or cutoff range, for each variable that distinguishes cells likely to contain sites (e.g., sites located between 1,103 and 1,360 $\mathrm{m}$ above sea level) from those that probably do not (e.g., above 1,360 or below 1,103 $\mathrm{m}$ above sea level). In Boolean models, it is preferable to be generous with categorical states and cutoff ranges because the intersecting properties of the method have a tendency to greatly reduce the favorable zone. For each variable, we chose states and cutoff ranges so that a large percentage (90-100\%) of the known site cells were included in the favorable category (Tables 7.15 and 7.16).

The Boolean model for the western study unit is presented in Figure 7.8 and the model for the eastern study unit in Figure 7.9. The locations of sites used to develop the model are shown in green. The blue polygons represent anomalies, site areas that are not correctly predicted by the model. For the Boolean model, 11 sites were misidentified; 8 sites were correctly identified. Two of these sites were misidentified by the other two modeling techniques as well. These two sites, along with other sites with anomalous locations, will be discussed later in this chapter.

Each Boolean model was tested using the Gain Statistic. This statistic is discussed in Chapter 4; for more detail, the reader is referred to the original source (Kvamme 1988).

Gain Statistic $=1-($ proportion of model area / proportion of sites correctly located $)$

East Gain $=1-(0.31 / 0.81)=0.62$

A gain score of 0.62 indicates a relatively good model. To measure exactly how good a predictor the model is, we calculate the model's performance relative to a random predictor by applying the equation,

Gain over random $=$ proportion of site cells correctly located - proportion of model

East gain over random $=0.81-0.31=0.5$ 


\section{ADAPTIVE MANAGEMENT ※゙PLANNING MODELS FOR CULTURAL RESOURCES IN OIL ※゙ GAS FIELDS}

From this score, our chance of locating an archaeological site by using the Boolean model is $50 \%$ better than if we randomly pick areas.

$$
\text { West Gain }=1-(0.56 / 0.87)=0.36
$$

A gain score of 0.36 for the west study unit indicates a decent model. To measure exactly how strong, we calculated the model's performance relative to a random predictor:

West gain over random $=0.87-0.56=0.31$

From this score, our chance of locating an archaeological site using the Boolean model is $31 \%$ better than if we randomly pick areas.

Table 7.15. Boolean Model Variables for the Eastern Study Unit

\begin{tabular}{|c|c|c|c|}
\hline & $\begin{array}{l}\text { Cutoff range for } \\
\text { continuous variables }\end{array}$ & $\begin{array}{l}\% \text { of site cells contained } \\
\text { in favored state/range }\end{array}$ & $\begin{array}{l}\% \text { of study unit contained } \\
\text { in favored state/range }\end{array}$ \\
\hline Elevation & $1103-1360 \mathrm{~m}$ & 100 & 91 \\
\hline \multicolumn{4}{|l|}{ GEOMORPHOLOGY } \\
\hline Alluvial fans & - & 26 & 3 \\
\hline Historically recorded spring & - & 0.2 & 0.0003 \\
\hline Eroded bedrock & - & 48 & 75 \\
\hline \multicolumn{4}{|l|}{ Pleistocene alluvial deposits at } \\
\hline mouth of Sacramento River & - & 13 & 12 \\
\hline Valley fill alluvium & - & 13 & 4 \\
\hline \multicolumn{4}{|l|}{ VEGETATION } \\
\hline Rock outcrop & - & 29 & 0.43 \\
\hline Chihuahuan foothill-piedmont & - & 32 & 32 \\
\hline Chihuahuan Desert scrub & - & 39 & 56 \\
\hline ASPECT & - & 17 & 15 \\
\hline North & $315-361^{\circ}, 0-45^{\circ}$ & 11 & 24 \\
\hline South & $135-225^{\circ}$ & 31 & 30 \\
\hline West & $225-315^{\circ}$ & 52 & 15 \\
\hline Slope & $0-27^{\circ}$ & 95 & 99 \\
\hline Distance from streams & $0-600 \mathrm{~m}$ & 100 & 97 \\
\hline Distance from ridges & $0-425 \mathrm{~m}$ & 95 & 77 \\
\hline Distance from stream intersections & $0-1308 \mathrm{~m}$ & 95 & 96 \\
\hline
\end{tabular}

Table 7.16. Boolean Model Variables for the Western Study Unit

\begin{tabular}{lccc}
\hline & $\begin{array}{c}\text { Cutoff range for } \\
\text { continuous variables }\end{array}$ & $\begin{array}{c}\text { \% of site cells contained } \\
\text { in favored state/range }\end{array}$ & $\begin{array}{c}\text { \% of study unit contained } \\
\text { in favored state/range }\end{array}$ \\
\hline GEOMORPHOLOGY & - & 68 & 32 \\
Eroded bedrock & - & 18 & 6 \\
Sand sheet & - & 10 & 22 \\
Alluvial fans & - & 85 & 34 \\
VEGETATION & - & 14 & 57 \\
Chihuahuan lowland/swale & - & 17 & 15 \\
Chihuahuan Desert scrub & $45-135^{\circ}$ & 26 & 21 \\
AsPECT & $135-225^{\circ}$ & 55 & 35 \\
East & $225-315^{\circ}$ & 12 & 30 \\
South & $0-27^{\circ}$ & 100 & 95 \\
West & $0-910 \mathrm{~m}$ & 100 & 97 \\
Slope & $0-751 \mathrm{~m}$ & 95 & 96 \\
Distance from streams & $0-1484$ & 100 & 99 \\
Distance from ridges & & & \\
Cost distance to ridge & & & \\
\hline
\end{tabular}




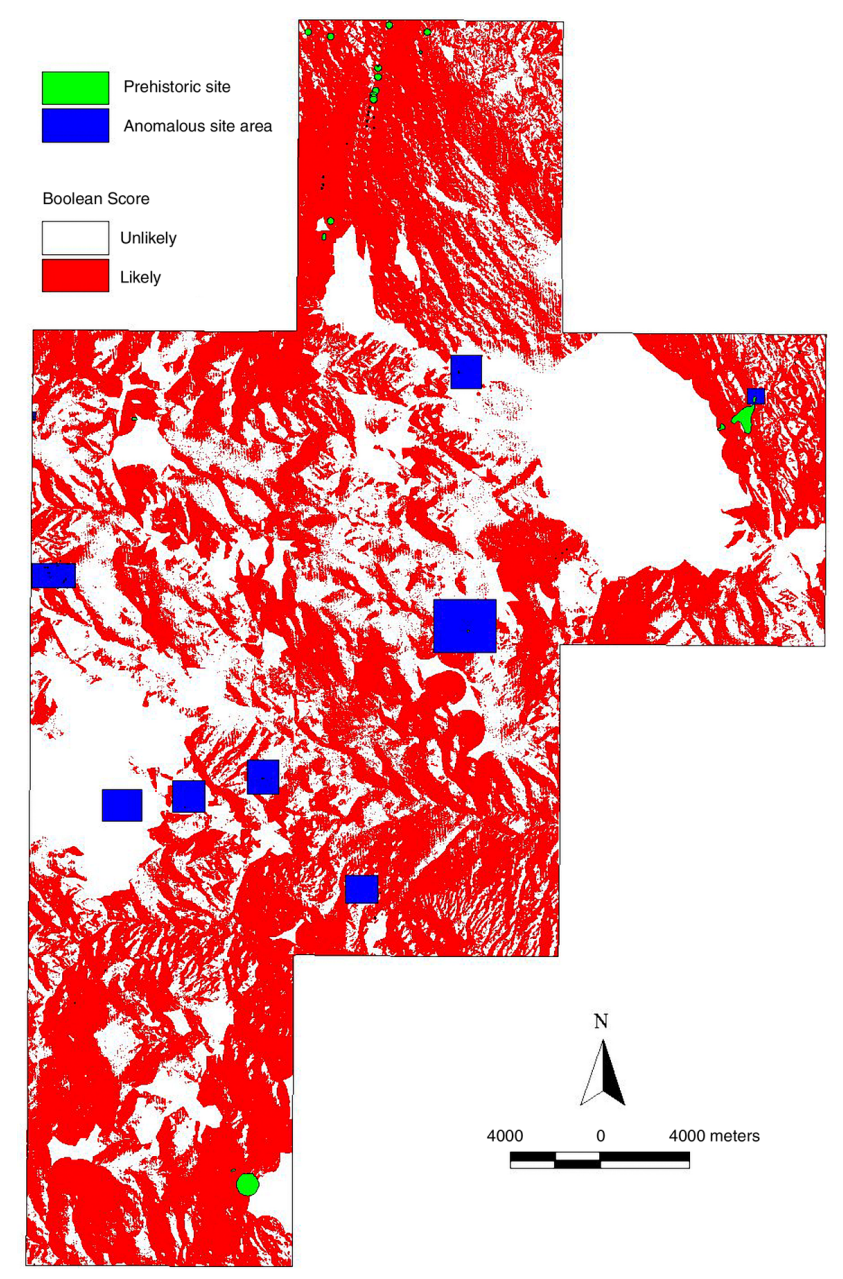

Figure 7.8. Western study unit Boolean model. Sites are in green, and blue polygons are sites that are not captured by the model.

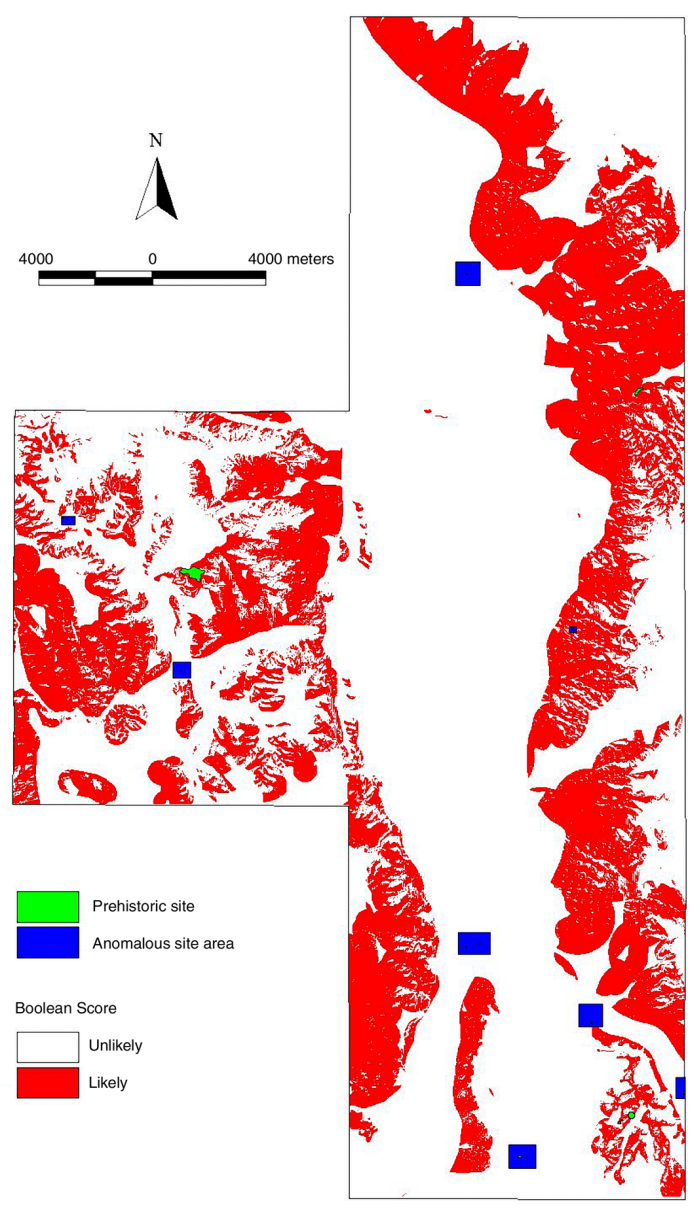

Figure 7.9. Eastern study unit Boolean model. Sites are in green, and blue polygons are sites that are not captured by the model.

The Boolean model for the western study unit portrays an environment generally favorable to site location, with three "holes" marking unfavorable locations. Comparisons with Figures 7.4 and 7.5 help to explain much of this pattern. The large "hole" in the eastern part of the western study unit marks the location of a large, contiguous deposit of colluvium that appears either to have been avoided by the indigenous inhabitants or to be masking any traces of their activities.

The large "hole" along the western edge marks the location of a unique vegetation community for this study area: Chihuahuan broadleaf deciduous desert scrub. Because this vegetation community provides few edible resources and makes travel difficult, it is possible that this "hole" is real — that the area was avoided by indigenous inhabitants. There has only been one archaeological survey within this area, however, and three of the anomalous sites indicated in Figure 7.8 are from that survey. So the apparent "hole" could also be the result of limited survey and the fact that this vegetation community is massed here and occurs nowhere else in the study unit.

The third "hole" is Alamo Mountain, located in the southeast corner of the western study unit. This is the location of a very large, multicomponent, historical stage station/Jornada Mogollon site (LA 9076) situated in a unique vegetation zone "rock outcrop," which is likely to have unduly influenced the models. Because the Boolean model gives equal credence to all environmental variables and because the rock outcrop vegetation zone is small and localized, the Boolean model is not as affected by the skewed correlation between the rock outcrop vegetation zone and site locations as are the other two models. The Boolean model, probably appropriately, classifies this area as unfavorable owing to slope, aspect, etc.

Although the western Boolean model points to environmental attributes avoided by humans, it does not provide great insight into settings favored for use or settlement. The poor predictive power of this model is reflected in the low Gain score. 
The eastern Boolean model is clearly heavily influenced by the large expanse of colluvial deposits in the northeastern arm of the Salt Basin, which runs north/south through the center of this study area. As in the western study unit, archaeological surveys on this colluvium indicate an absence of sites or at least of surface-visible sites. The most interesting aspect of this map is the cluster of "anomalous" sites in the southernmost block of the study unit. This area, like both the zone of deciduous desert scrub and Alamo Mountain in the western study unit, is a unique environment relative to the rest of the study unit.

This Alkali Lakes area of sand sheet deposits and playas would intuitively appear to have been a relatively attractive zone for indigenous peoples - as the cluster of "anomalous" sites affirms. We coded the area as "site unlikely" for the Boolean model, however, because the percentage of site cells in the region is about the same as the percentage of area surveyed. This would, in part, account for the relatively weak predictive power of the eastern Boolean model as reflected in the Gain score. As previously mentioned, however, recent archaeological investigations along the eastern margin of the Salt Basin suggests a more extensive use of this area by human populations in the past than previous surveys have indicated. It is interesting to note that neither the weighted nor the regression models classify this area as unfavorable.

\section{The Weighted Model}

The weighted model is a more sophisticated intersection modeling technique than the Boolean method. Each variable is divided into categorical states that are then weighted in terms of the strength of their relationship with archaeological site location. For Otero Mesa, we calculated the weights by first determining the proportion of the study area covered by each categorical variable as well as the proportion of site cells coded for each of these categories. By subtracting the percentage representation of each categorical variable in the environment from the percentage of site coverage, we derived weights, rounded to the nearest integer value, that vary from -215 to 301 for the eastern study unit and -132 to 151 for the western study unit. Negative weights indicate that humans tended to avoid these environmental features in locating their activities, whereas positive weights suggest the opposite.

Tables 7.17 and 7.18 list the environmental variables for each study area, the cutoff ranges, the percentage of site cells in each variable state/range, and the proportion of the study area in each variable state/range. The last column in the table provides the weighted score for each variable that was used to construct the weighted model.

Once the variables were weighted, the variable scores for each cell were added together. Tables 7.19 and 7.20 present the results in relation to the area and the percentage of site cells associated with various score ranges. The final step was to reclassify the scores into four states that best represent site sensitivity. In this case, the four sensitivity states were coded as poor (1), average (2), good (3), and excellent (4).

Figures 7.10 and 7.11 present the weighted models with sites overlain in black. In the eastern study unit, 10 sites fell in average or poor areas, whereas 40 sites fell in average or poor areas in the western study unit; these sites are outlined with white polygons on both maps. Sites that fall into poor areas throughout each model are discussed later; however, it is apparent that very small sites are the most likely to be predicted incorrectly.

As with the Boolean model, we used two statistics - Gain Statistic and Gain over Random - to evaluate the weighted model. For these statistics, the proportion of the model area is defined as the cells classified as good and excellent for site sensitivity.

$$
\begin{aligned}
& \text { East Gain }=1-(0.43 / 0.88)=0.51 \\
& \text { East gain over random }=0.88-0.43=0.45
\end{aligned}
$$

The weighted model allows us to predict archaeological site locations in the eastern study unit with about a $45 \%$ better chance of being correct than if we guessed randomly.

$$
\begin{aligned}
& \text { West Gain }=1-(0.25 / 0.87)=0.71 \\
& \text { West gain over random }=0.87-0.25=0.62
\end{aligned}
$$

The weighted model allows us to predict archaeological site locations in the western study unti with about a $62 \%$ better chance of being correct than if we guessed randomly.

A comparison of the images of the weighted models and the Boolean models is striking. Gone from the weighted models are the large, unfavorable "holes" or generalized favorable areas. Based on the Gain statistics, the western weighted model clearly outperforms the eastern weighted model and both Boolean models, though the fact that nearly half the sites lie in unfavorable settings is disconcerting. We are hopeful that this latter situation will improve when the model is rerun without the heavy weight currently being given to the "rock outcrop" vegetation community, as discussed below. 
THE OTERO MESA STUDY AREA

Table 7.17. Weighted Model Variables for the Eastern Study Unit

\begin{tabular}{|c|c|c|c|c|}
\hline & $\begin{array}{l}\text { Cutoff } \\
\text { range for } \\
\text { continuous } \\
\text { variables }\end{array}$ & $\begin{array}{l}\text { Percentage } \\
\text { of site cells } \\
\text { contained in } \\
\text { state/range }\end{array}$ & $\begin{array}{l}\text { Percentage } \\
\text { of study area } \\
\text { contained in } \\
\text { state/range }\end{array}$ & $\begin{array}{c}\text { Weighted } \\
\text { score }\end{array}$ \\
\hline \multicolumn{5}{|l|}{ VEGETATION } \\
\hline Rky.Mtn/Great Basin open conifer & - & 0 & 0.01 & 0 \\
\hline Chihuahuan Desert scrub & - & 13.97 & 57.3 & -43 \\
\hline Chihuahuan foothill-piedmont grassland & - & 0.7 & 9.49 & -9 \\
\hline Chihuahuan lowland/swale desert grassland & - & 85.37 & 33.67 & 52 \\
\hline GEOMORPHOLOGY & - & 0 & 0.6 & -1 \\
\hline Eroded bedrock surface & - & 68.03 & 32.23 & 36 \\
\hline Sand sheet & - & 17.98 & 6.47 & 12 \\
\hline Valley fill alluvium & - & 0.88 & 3.88 & -3 \\
\hline Alluvial fans & - & 10.24 & 22.2 & -12 \\
\hline Playa deposits & - & 0 & 1.44 & -1 \\
\hline Colluvial deposits $<1 \mathrm{~m}$ thick & - & 0 & 0.05 & 0 \\
\hline Colluvial deposits $>1 \mathrm{~m}$ thick & - & 0 & 33.59 & -34 \\
\hline ASPECT & - & 0 & 0.1 & 0 \\
\hline North-facing & $315-360^{\circ}, 0-45^{\circ}$ & 6.57 & 11.86 & -5 \\
\hline East-facing & $45-135^{\circ}$ & 26.22 & 21.26 & 5 \\
\hline South-facing & $135-225^{\circ}$ & 55.07 & 34.58 & 20 \\
\hline West-facing & $225-315^{\circ}$ & 11.34 & 30 & -19 \\
\hline \multirow{6}{*}{ ELEVATION } & $<1104 \mathrm{~m}$ & 0 & 2.30 & -2 \\
\hline & $1104-1112 \mathrm{~m}$ & 19.4 & 7.44 & 12 \\
\hline & $1112-1270 \mathrm{~m}$ & 12.13 & 70.02 & -58 \\
\hline & $1270-1359 \mathrm{~m}$ & 68.47 & 12.96 & 56 \\
\hline & $>1359 \mathrm{~m}$ & 0 & 7.28 & -7 \\
\hline & $0-5^{\circ}$ & 86.1 & 75.57 & 11 \\
\hline \multirow[t]{3}{*}{ Slope } & $5-15^{\circ}$ & 12.67 & 10.57 & 2 \\
\hline & $15-27^{\circ}$ & 1.23 & 9.15 & -8 \\
\hline & $>27^{\circ}$ & 0 & 4.71 & -5 \\
\hline \multirow[t]{4}{*}{ DistanCE FROM STREAMS } & $0-70 \mathrm{~m}$ & 5.12 & 24.17 & -19 \\
\hline & $70-300 \mathrm{~m}$ & 24.42 & 50.26 & -26 \\
\hline & $300-600 \mathrm{~m}$ & 70.46 & 22.19 & 48 \\
\hline & $>600 \mathrm{~m}$ & 0 & 3.38 & -3 \\
\hline \multirow[t]{5}{*}{ DistanCE From StREAm InTERSECTIONS } & $<150 \mathrm{~m}$ & 0 & 6.59 & -7 \\
\hline & $150-335 \mathrm{~m}$ & 2.84 & 18.93 & -16 \\
\hline & $335-805 \mathrm{~m}$ & 27.33 & 48.05 & -21 \\
\hline & $805-1385 \mathrm{~m}$ & 69.83 & 23.34 & 46 \\
\hline & $>1385 \mathrm{~m}$ & 0 & 3.09 & -3 \\
\hline \multirow[t]{4}{*}{ DistanCE FROM RidGES } & $0-170 \mathrm{~m}$ & 80.22 & 48.47 & 32 \\
\hline & $170-420 \mathrm{~m}$ & 14.53 & 27.92 & -13 \\
\hline & $420-1415 \mathrm{~m}$ & 5.24 & 20.88 & -16 \\
\hline & $>1415 \mathrm{~m}$ & 0 & 2.73 & -3 \\
\hline
\end{tabular}

One of the noticeable features of the western study unit weighted model is the classification of the dissected upland remnants of the Sacramento Mountains, which run through the northeast corner of the study area, as excellent. This same tendency to classify dissected upland terrain as excellent is observable near the southern edge of the southeastern block of the study unit and near the corner where the northern and northwestern blocks come together. These are the only other places in the study area where dissected upland terrain is found. This pattern is very clear and, thankfully, is unlikely to be affected by the Alamo Mountain "rock outcrop" vegetation zone problem. The near absence of surveys in these dissected areas makes it difficult to know, however, whether this pattern is real or is a reflection of the presence of one large site cluster in this environmental setting in the eastern block of the study unit, or both. The classification of the dissected upland areas as excellent is consistent with settlement data from the Guadalupe Mountains and elsewhere (Tim Kearns, Western Cultural Resources Management, Farmington, NM, personal communication 2004). Presumably, this setting offers more diverse biotic and abiotic resources and is better watered and sheltered than much of the other areas. 
Table 7.18. Weighted Model Variables for the Western Study Unit

\begin{tabular}{|c|c|c|c|c|}
\hline & $\begin{array}{c}\text { Cutoff } \\
\text { range for } \\
\text { continuous } \\
\text { variables }\end{array}$ & $\begin{array}{c}\text { Percentage } \\
\text { of site cells } \\
\text { contained in } \\
\text { state/range }\end{array}$ & $\begin{array}{l}\text { Percentage } \\
\text { of study area } \\
\text { contained in } \\
\text { state/range }\end{array}$ & $\begin{array}{c}\text { Weighted } \\
\text { score }\end{array}$ \\
\hline \multicolumn{5}{|l|}{ VEGETATION } \\
\hline Broadleaf interior chaparral & - & 0 & 0.1 & 0 \\
\hline Chihuahuan Desert scrub & - & 39.3 & 55.77 & -17 \\
\hline Chihuahuan broadleaf deciduous desert scrub & - & 0.03 & 5.36 & -5 \\
\hline Short-grass steppe & - & 0.15 & 0.34 & 0 \\
\hline Chihuahuan foothill-piedmont desert grassland & & 31.6 & 32.35 & -1 \\
\hline Chihuahuan lowland/swale desert grassland & - & 0.3 & 5.65 & -5 \\
\hline Rock outcrop & - & 28.63 & 0.43 & 28 \\
\hline \multicolumn{5}{|l|}{ GEOMORPHOLOGY } \\
\hline Eroded bedrock surface & - & 48.12 & 75.42 & -27 \\
\hline Valley fill alluvium & - & 12.83 & 4.4 & 8 \\
\hline Alluvial fans & - & 26.14 & 2.52 & 24 \\
\hline Playa deposits & - & 0 & 0.11 & 0 \\
\hline Colluvial deposits $<1 \mathrm{~m}$ thick & - & 0 & 0.02 & 0 \\
\hline Colluvial deposits $>1 \mathrm{~m}$ thick & - & 0 & 5.97 & -6 \\
\hline Historically known spring & - & 37 & 0.003 & 37 \\
\hline Pleistocene alluvial fan of Sacramento River & - & 12.75 & 11.56 & 1 \\
\hline \multicolumn{5}{|l|}{ ASPECT } \\
\hline North-facing & $315-360^{\circ}, 0-45^{\circ}$ & 11.33 & 23.77 & -12 \\
\hline East-facing & $45-135^{\circ}$ & 6.38 & 30.83 & -24 \\
\hline South-facing & $135-225^{\circ}$ & 30.68 & 30.31 & 0 \\
\hline West-facing & $225-315^{\circ}$ & 51.62 & 14.79 & 37 \\
\hline \multirow[t]{3}{*}{ SLOPE } & $0-6^{\circ}$ & 62.29 & 91.36 & -29 \\
\hline & $6-29^{\circ}$ & 33.81 & 7.9 & 26 \\
\hline & $>29^{\circ}$ & 3.91 & 0.74 & 3 \\
\hline \multirow[t]{3}{*}{ Distance From Streams } & $0-400 \mathrm{~m}$ & 80.65 & 76.66 & 4 \\
\hline & $400-600 \mathrm{~m}$ & 15.48 & 14.46 & 1 \\
\hline & $>600 \mathrm{~m}$ & 3.87 & 8.88 & -5 \\
\hline \multirow[t]{3}{*}{ Cost Distance from Ridges } & $0-155$ & 70.33 & 96.14 & -26 \\
\hline & $155-660$ & 17.5 & 3.36 & 14 \\
\hline & $>660$ & 12.17 & 0.5 & 12 \\
\hline \multirow[t]{4}{*}{ Distance FROM Ridges } & $0-75 \mathrm{~m}$ & 23.99 & 23.97 & 0 \\
\hline & $75-150 \mathrm{~m}$ & 16.55 & 20.15 & -4 \\
\hline & $150-1130 \mathrm{~m}$ & 59.46 & 54.04 & 5 \\
\hline & $>1130 \mathrm{~m}$ & 0 & 1.11 & -1 \\
\hline
\end{tabular}

A second notable feature of the western weighted model is the classification of a large swath of alluvium in the western half of the northern block as good or excellent. As Figure 7.4 shows, all of the northern block except for the dissected uplands in the northeast corner is mapped as alluvium. A comparison with Figure 7.5 makes it clear that the weighted model classifies only the portion of the alluvium that lies in the desert grassland vegetation zone as good or excellent. The portion of the alluvium that lies in the desert scrub vegetation zone is classified as average. It is very possible that this pattern is a true reflection of precontact resource use in the area; grasslands may have provided more usable resources and easier travel and camping terrain in the past than the desert scrub vegetative zone. It is also important to note, however, that there has been no archaeological survey in the desert scrub portion of the alluvium, whereas a number of surveys have been completed in the grasslands portion. This apparent pattern warrants additional research and modeling efforts in the future.

The third notable feature of the western weighted model is a clear result of the LA 9076 problem at Alamo Mountain in the southeastern corner of the southern block. The model outcome is skewed by what is almost certainly a major overrepresentation of the size of the Jornada Mogollon component at that site. By the very nature of the way that weighted models are derived, the apparent association of a very large number of site cells with the unique vegetation zone "rock outcrop" has caused the model to classify this zone as excellent. 
THE OTERO MESA STUDY AREA

Table 7.19. Weighted Model Scores and Reclassification for the Eastern Study Unit

\begin{tabular}{lccc}
\hline Model Score & $\begin{array}{c}\text { Percentage of } \\
\text { Study Area }\end{array}$ & $\begin{array}{c}\text { Percentage of } \\
\text { Site Cells }\end{array}$ & Reclassification \\
\hline-215 to -165 & 5.85 & 0.16 & 1 \\
-165 to -115 & 14.44 & 6.41 & 2 \\
-115 to -75 & 15.85 & 1.74 & 2 \\
-75 to -25 & 20.66 & 3.41 & 2 \\
-25 to 25 & 16.78 & 1.93 & 3 \\
$25-65$ & 10.86 & 0.88 & 3 \\
$65-115$ & 8.62 & 2.53 & 3 \\
$115-165$ & 5.06 & 10.65 & 4 \\
$165-205$ & 1.42 & 11.66 & 4 \\
$205-255$ & 0.36 & 18.61 & 4 \\
$255-301$ & 0.08 & 42.02 & \\
\hline
\end{tabular}

Table 7.20. Weighted Model Scores and Reclassification for the Western Study Unit

\begin{tabular}{lccc}
\hline Model Score & $\begin{array}{c}\text { Percentage of } \\
\text { Study Area }\end{array}$ & $\begin{array}{c}\text { Percentage of } \\
\text { Site Cells }\end{array}$ & Reclassification \\
\hline-132 to -107 & 15.98 & 1.44 & 1 \\
-107 to -82 & 42.18 & 4.34 & 2 \\
-82 to -57 & 17.19 & 7.38 & 2 \\
-57 to -32 & 16.94 & 26.99 & 3 \\
-32 to -7 & 3.22 & 12.73 & 3 \\
-7 to 18 & 2.92 & 18.43 & 3 \\
$18-43$ & 0.92 & 7.51 & 4 \\
$43-68$ & 0.52 & 5.44 & 4 \\
$68-93$ & 0.11 & 15.59 & 4 \\
$93-118$ & 0.02 & 0.04 & 4 \\
$118-143$ & 0.00005 & 0.02 & 4 \\
$143-151$ & 0.0002 & 0.01 & 4 \\
\hline
\end{tabular}

Like the eastern Boolean model, the weighted model for the eastern study unit portrays the upland dissected areas along the eastern and western margins as good or excellent and the central lowland colluvium as average or poor. The major difference between the weighted and Boolean models for the eastern study unit is that the weighted model classifies the sand sheet and playa environment of the Alkali Lakes area in the southern block as good to excellent whereas the Boolean model classified it as unfavorable.

It is very intriguing that both the eastern and western weighted models classify dissected uplands as high probability zones for archaeological sites. It is notable that, despite limited survey, clusters of sites have been found in the dissected uplands at the southern end of the Sacramento Mountains in both our eastern and western study units. For this reason, we think it likely that the good to excellent scores in the weighted models reflect an actual preference among indigenous people for locating activities in the dissected uplands, at least those of the Sacramento uplift. Given the complete absence of survey data from the other dissected upland zones in the two study units - the lower slopes of the Guadalupe and Brokeoff Mountains in the eastern study unit and the dissected zone north of the Cornudas Mountains in the western unit - we cannot yet determine whether these uplands were favored zones as well. This is one of the future research and modeling issues that will need to be addressed for greater Otero Mesa.

\section{Logistic Regression Model}

Logistic regression is a complex statistical technique (see discussion in Chapter 4). The results of models based on logistic regression are not easily interpreted. Yet, the great advantage that logistic regression has over other modeling techniques is its ability to incorporate variables measured on various scales. The relationships between site location and environmental variables measured on interval scales are not sacrificed in logistic regression as they are in Boolean and weighted modeling techniques.

One difficulty with the logistic regression for Otero Mesa is the irregular shape of the two study areas. Irregularly shaped rasters cannot be incorporated directly into many of IDRISI's raster manipulation algorithms. For the logistic 


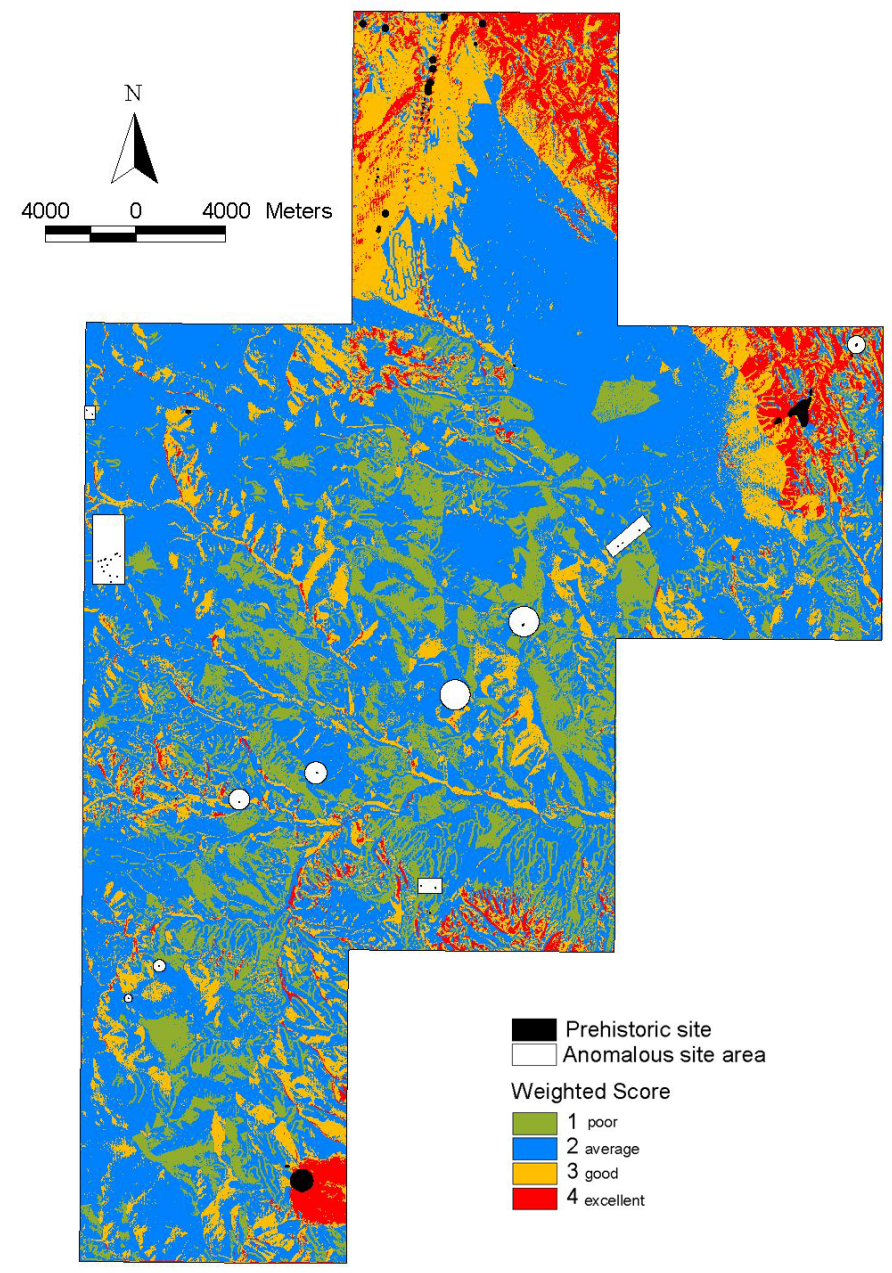

Figure 7.10. Western study unit weighted model.

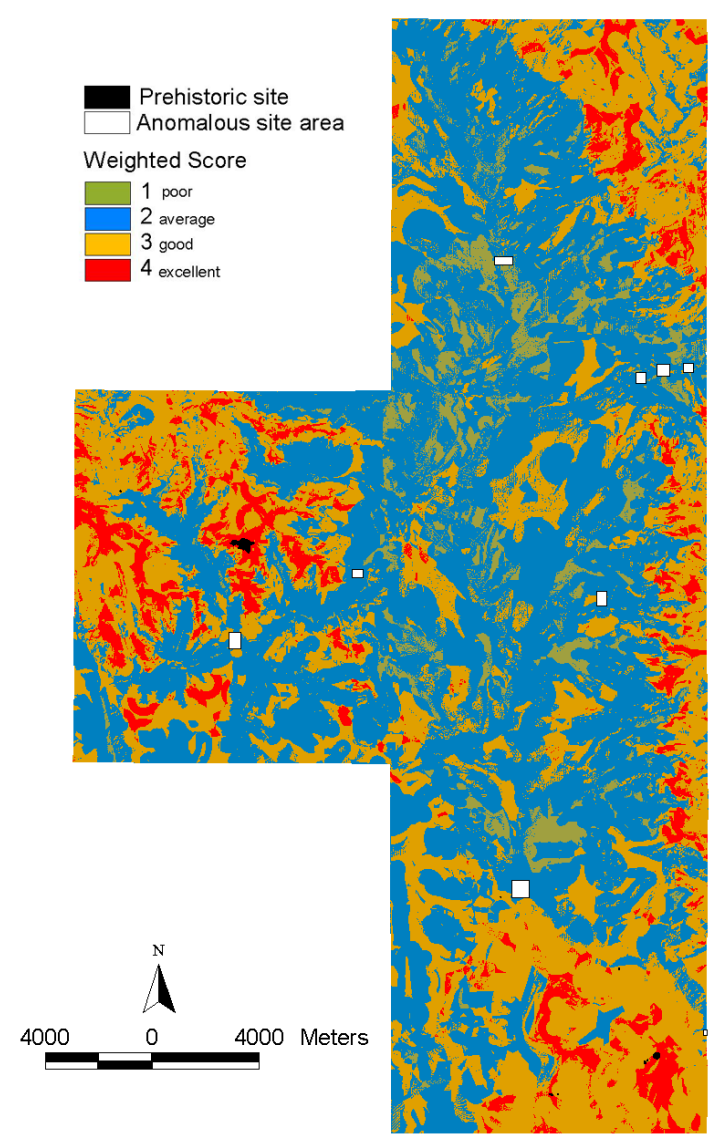

Figure 7.11. Eastern study unit weighted model.

regression function, the algorithm creates a rectangle that encompasses not only the study area, but also outside areas needed to complete the rectangle. For example, the eastern study unit is shaped like a $\mathrm{T}$ tilted on its side. The algorithm creates a rectangle by filling the northwest and southwest quadrangles with cells coded as null values on each variable. IDRISI ignores the null values in producing the logistic regression equation, but the program computes a logistic score for each cell in the rectangle. To produce the model image, we clipped the portion of the rectangle outside the study area and eliminated these scores from further consideration.

Tables 7.21 and 7.22 present the environmental variables used in the logistic regression and the coefficients created by the regression formula. At first glance, it appears that some of the variables are much more important in predicting site location than others. For example, the coefficient for distance from streams in Table 7.21 is only slightly negative $(-0.001)$, whereas eroded bedrock has a relatively large positive coefficient (2.14642). But these coefficients are not comparable. Distance from streams in Otero Mesa varies from zero to thousands of meters. The regression coefficient, then, is multiplied by numbers varying from zero to very large. A cell can only have two scores for a categorical variable, such as eroded bedrock ( 0 or 1 ), which is then multiplied by a coefficient that takes into account the restricted range of the variable. When examining logistic regression coefficients, it is important to compare variables measured on the same scale with each other.

In examining the tables of regression coefficients, the differences between the two study units are evident. In the east, the most important categorical variables are the Chihuahuan foothill-piedmont and Chihuahuan lowland/swale vegetative communities, with the sand sheet and eroded bedrock geomorphic variables being a distant second in statistical importance. In the west, geomorphology assumes a more equal, if not slightly more dominant, statistical position for categorical variables. Thick colluvial deposits and the Chihuahuan broadleaf deciduous vegetative community are the 


\section{THE OTERO MESA STUDY AREA}

Table 7.21. Computed Coefficients for Variables Used in the Logistic Regression Model for the Eastern Study Unit

\begin{tabular}{lc}
\hline Variable & Coefficient \\
\hline Eroded bedrock & 2.14642 \\
Colluvial deposits >1 m thick & -1.80939 \\
Alluvial fans & 0.05042 \\
Sand sheet & 2.934188 \\
Chihuahuan foothill-piedmont & -5.7748496 \\
Chihuahuan lowland/swale & 4.5608234 \\
South-facing aspect & 0.68843053 \\
West-facing aspect & 0.253798944 \\
Elevation & 0.01430186 \\
Slope & -0.14297992 \\
Distance from Streams & -0.00115654 \\
Distance from Stream Intersections & 0.00185916 \\
Distance from Ridges & -0.00234531 \\
\hline
\end{tabular}

Table 7.22. Computed Coefficients for Variables Used in the Logistic Regression Model for the Western Study Unit

\begin{tabular}{lc}
\hline Variable & Coefficient \\
\hline Eroded bedrock & -1.86807250 \\
Alluvial fans & 1.24345371 \\
Colluvial deposits $>1 \mathrm{~m}$ thick & -16.96504835 \\
Chihuahuan broadleaf deciduous & -16.51966538 \\
Rock outcrop & 6.25818135 \\
Chihuahuan lowland/swale & -3.18205604 \\
West-facing aspect & 1.3662265 \\
East-facing aspect & -0.68437538 \\
Slope & 0.00957143 \\
Distance from Streams & -0.00161888 \\
Cost Distance to Ridges & 0.00129103 \\
Distance from Ridges & -0.00362474 \\
\hline
\end{tabular}

most important categorical variables followed at a distance by rock outcrops and further still, the Chihuahuan lowland/ swale vegetative community.

This is another point at which it is important to note that the apparent significance of the vegetation category "rock outcrop" is the result of a substantial overestimation of site size for a single site component located in this vegetation category. With the exception of the area immediately around Alamo Mountain (noted in the discussion of the modeling results below), we do not believe that this problem had a major impact on the modeling results as mapped in Figure 7.13.

Tables 7.23 and 7.24 present the reclassification values for the two study units. The results have been collapsed into ten probability classes, with details presented on the size of the area captured by each probability class and the proportions of sites found in each class. The probability classes were then reclassified into four groups-poor (1), average (2), good (3), and excellent (4) - in terms of their site sensitivity.

Figures 7.12 and 7.13 show the outcome of the logistic regression models after the reclassification. For the eastern section, eight sites fall into the poor to average category compared with ten sites in the weighted model. The sites that are found in anomalous settings are almost identical in both models (see below). In the western section the number of sites located in poor or average areas is 40 , which is the same number and generally represents the same sites as were located in poor or average areas in the weighted model. The amount of land classified as good or excellent, however, has shifted from around $25 \%$ in the weighted models to $34 \%$ in the logistic regression model. These shifts are reflected in the relatively low gain and gain-over-random scores.

$$
\begin{aligned}
& \text { East Gain }=1-(44.88 / 91.58)=0.51 \\
& \text { East gain over random }=91.58-44.88=46.7 \\
& \text { West Gain }=1-(34 / 90.26)=0.62 \\
& \text { West gain over random }=90.26-34=56.26
\end{aligned}
$$

Table 7.23. Logistic Regression Probability Scores and Reclassification Values for the Eastern Study Unit

\begin{tabular}{lccc}
\hline Probability & $\begin{array}{c}\text { Percentage of } \\
\text { Study Area }\end{array}$ & $\begin{array}{c}\text { Percentage of } \\
\text { Site Cells }\end{array}$ & Reclassification \\
\hline $0-10$ & 0 & 0.19 & 1 \\
$11-20$ & 0.02 & 0 & 1 \\
$21-30$ & 1.04 & 0 & 1 \\
$31-40$ & 7.19 & 0.66 & 2 \\
$41-50$ & 17.2 & 0.32 & 2 \\
$51-60$ & 29.67 & 7.27 & 2 \\
$61-70$ & 30 & 2.69 & 3 \\
$71-80$ & 12.67 & 14.38 & 3 \\
$81-90$ & 2.03 & 15.36 & 4 \\
$91-100$ & 0.18 & 59.15 & 4 \\
\hline
\end{tabular}

Table 7.24. Logistic Regression Probability Scores and Reclassification Values for the Western Study Unit

\begin{tabular}{lccc}
\hline Probability & $\begin{array}{c}\text { Percentage of } \\
\text { Study Area }\end{array}$ & $\begin{array}{c}\text { Percentage of } \\
\text { Site Cells }\end{array}$ & Reclassification \\
\hline $0-10$ & 0 & 0 & 0 \\
$11-20$ & 3.01 & 0 & 1 \\
$21-30$ & 8.31 & 0.03 & 1 \\
$31-40$ & 0 & 0 & 1 \\
$41-50$ & 0.05 & 0 & 1 \\
$51-60$ & 4.28 & 0.58 & 2 \\
$61-70$ & 50.34 & 9.15 & 2 \\
$71-80$ & 31.01 & 31.95 & 3 \\
$81-90$ & 2.87 & 33.70 & 3 \\
$91-100$ & 0.14 & 24.61 & 4 \\
\hline
\end{tabular}



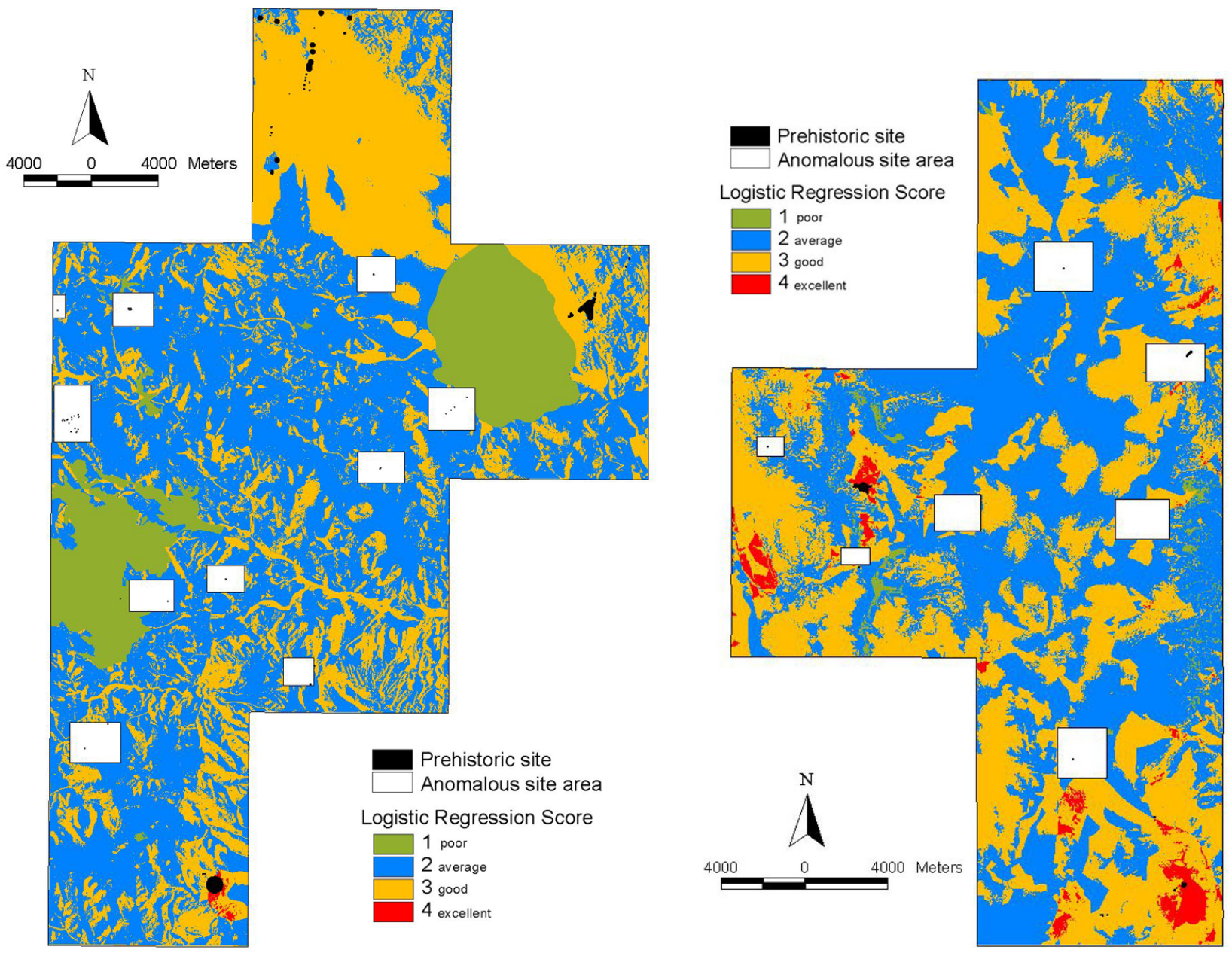

Figure 7.12. Logistic regression model for western study unit.

Figure 7.13. Logistic regression model for eastern study unit.

The eastern logistical regression model works almost exactly as well as the eastern weighted model ( $47 \%$ better than random for the logistic regression model versus $45 \%$ better than random for the weighted model). The western logistic regression model, however, works slightly worse as a predictor than the weighted model for the same unit (56\% better than random for the logistic regression model versus $62 \%$ better than random for the weighted model).

Figures 7.12 and 7.13 give rise to several interesting observations. First, the two large "holes" of unfavorable environmental settings noted in the Boolean model reappear in the logistic regression model for the western study unit. They are associated with a large area of colluvium in the eastern block of the study unit and an environmentally unique area of broadleaf deciduous desert scrub along the western edge.

The second observation is that, once again, the skewing effect of the very large, multicomponent site at Alamo Mountain is apparent in the high probability classification of the area in the southeastern corner of the western study unit. Decreasing the number of cells covered by the precontact component of this site could reduce the sensitivity of this area.

Third, the regression model classifies the entire expanse of alluvial deposits in the northern block of the western study unit as good, whereas the weighted model classified only the grasslands portion of the alluvium favorably. A comparison of the vegetation map (Figure 7.5) with the sensitivity maps from all three modeling techniques gives the impression that desert grassland vs. desert scrub vegetation was not an important factor in determining the location of precontact human activities.

The fourth observation is that the regression models, like the Boolean and weighted models, classify the wedge of the southern Sacramento Mountain uplift, which extends between and into the edges of the two study units, as good to excellent. But unlike the weighted models, the regression models do not generalize this favorable classification to all dissected uplands. This is especially noticeable along the eastern edge of the eastern study unit. Although Figure 7.12 
makes it appear that the portion of the Sacramento uplands in the western study unit is not as favorable to site location as the portion in the eastern study unit, this is most likely a function of different cutoff points having been used for the reclassification of the probability scores for the two study units (see Tables 7.23 and 7.24).

The fifth observation is that the eastern regression model, like the eastern weighted model, classifies the Alkali Lakes at the southern end of the study area as a good to excellent location for encountering the remains of the human activities. The two most robust patterns produced by the Otero Mesa models, and thus the ones most likely to be a reflection of precontact human behavior, are the high favorability scores for the southern Sacramento uplift and for the Alkali Lakes. These will be addressed in the interpretations offered in the next section of this chapter.

\section{Interpreting the Results}

The performance of the predictive models is compared in Table 7.25. The weighted model for the western section scores the highest Gain Statistic because it provides the smallest sensitive area relative to the number of sites correctly identified. The logistic regression models, however, are statistically more robust. They accurately placed, on average, about $91 \%$ of the site cells, a gain of about five percentage points over the other models.

Sites that have been located in "poor" or "average" areas have been noted above in the discussions of the model outcomes; those sites located in poor or average areas that are common to at least two models are shown in Table 7.26. Altschul (1990) has argued that sites in anomalous settings, which he terms "red flags," often provide insight into prehistoric settlement and the inner workings of predictive models. General information about these anomalous sites, as provided by ARMS, is listed in the table. The environmental setting and size characteristics of the red flag, or incorrectly predicted sites and those of the correctly predicted sites are compared in Table 7.27.

The large number of anomalous sites is the best indicator that the models are poor predictors, which is not surprising given the very limited amount of archaeological data available. The fact that nearly half the sites in each study unit are found in poor or average sensitivity locations does not bode well for use of these models to guide management decisions. But not all anomalous sites are equal. The models correctly predict the large sites, a plus for managers because these sites are the most costly in terms of time and money. Examining Table 7.26, we are struck by the nondescript nature of the red flag sites. We presume that most of these sites were limited activity areas; it is possible that the models are poor predictors only of places where people went to gather specific plants or hunt particular animals, and not of all sites.

The models may be much better at portraying the regional settlement structure. In the modeling results are patterns indicating that the indigenous, precontact occupants of the greater Otero Mesa area were focusing their activities in three very different areas: the broad expanse of alluvium in the northern block of the western study unit, the sand sheet and playa environment of Alkali Lakes in the southern block of the eastern study unit, and the southernmost end of the Sacramento Mountain uplift, which forms a wedge of dissected upland between and extending into the edges of the two study units.

The alluvium in the northern block of the western study unit has been laid down by two major drainages - the Sacramento River and Chatfield Canyon - as well as a series of smaller canyons in the uplift across the northwest of the block. All of these sources of runoff from different parts of the Sacramento Mountains would have made this a favorable location for wild resources and potentially for simple floodwater farming during periods of better-than-average rainfall.

The Alkali Lakes area would have been especially favorable during Paleoindian and early Archaic times, but the presence or intermittent presence of water and playa-associated faunal resources would have made this area a locus for human activities during many periods in the past.

Table 7.25. Comparison of the predictive models

\begin{tabular}{lcccc}
\hline Model & $\begin{array}{c}\text { Percentage } \\
\text { of area that is } \\
\text { good or excellent }\end{array}$ & $\begin{array}{c}\text { Percentage of } \\
\text { site cells classified } \\
\text { as good or excellent }\end{array}$ & Gain score & $\begin{array}{c}\text { Gain over } \\
\text { random chance }\end{array}$ \\
\hline Boolean East & 31 & 81 & 0.62 & 0.50 \\
Boolean West & 56 & 87 & 0.36 & 0.31 \\
Weighted East & 43 & 88 & 0.51 & 0.45 \\
Weighted West & 25 & 87 & 0.71 & 0.62 \\
Logistic regression east & 45 & 92 & 0.51 & 0.47 \\
Logistic regression west & 34 & 90 & 0.62 & 0.56 \\
\hline
\end{tabular}


Table 7.26. "Red Flag" Sites

\begin{tabular}{|c|c|c|c|}
\hline ARMS Site Number (LA) & Area (Acres) & Features & Artifacts \\
\hline \multicolumn{4}{|l|}{ EASTERN UNIT } \\
\hline 14736 & 1.017 & 0 & $<1000$ \\
\hline 26922 & 0.174 & 1 (hearth) & $<1000$ \\
\hline 45889 & 0.174 & 1 (hearth) & Unknown \\
\hline 45891 & 0.175 & 1 & Unknown \\
\hline 45899 & 0.175 & 1 (hearth) & Unknown \\
\hline 46138 & 0.175 & 0 & Unknown \\
\hline 49281 & 0.174 & 1 (hearth) & Unknown \\
\hline 49282 & 7.685 & 1 (ring midden) & Unknown \\
\hline 54963 & 0.537 & 1 (burned rock midden) & Unknown \\
\hline \multicolumn{4}{|l|}{ WESTERN UNIT } \\
\hline 56759 & 0.175 & 1 (ring midden) & Unknown \\
\hline 56760 & 0.175 & 1 (ring midden) & $<10$ \\
\hline 65457 & 0.634 & None & $<100$ \\
\hline 72840 & 1.392 & 1 (hearth) & $<1000$ \\
\hline 87907 & 0.175 & 1 (FCR concentration) & $<100$ \\
\hline 107586 & 0.174 & None & $<10$ \\
\hline 107587 & 0.175 & None & $<10$ \\
\hline 107589 & 1.598 & None & $<10$ \\
\hline 107590 & 0.174 & None & $<10$ \\
\hline 107592 & 0.175 & None & $<10$ \\
\hline 107593 & 0.175 & None & $<10$ \\
\hline 107594 & 0.175 & None & $<10$ \\
\hline 117031 & 0.049 & None & $<10$ \\
\hline 117032 & 0.049 & None & $<10$ \\
\hline 117034 & 0.198 & None & $<10$ \\
\hline 117037 & 0.049 & None & Unknown \\
\hline 120882 & 0.175 & None & $<10$ \\
\hline 120883 & 0.174 & None & $<10$ \\
\hline 120884 & 0.174 & None & $<10$ \\
\hline 120885 & 0.174 & None & $<10$ \\
\hline 120886 & 0.174 & None & $<10$ \\
\hline 120887 & 0.174 & None & $<10$ \\
\hline 120888 & 0.174 & None & $<10$ \\
\hline 120889 & 0.174 & None & $<10$ \\
\hline 120890 & 0.174 & None & $<10$ \\
\hline 120891 & 0.174 & None & $<10$ \\
\hline 120892 & 0.174 & None & $<10$ \\
\hline 120893 & 0.174 & None & $<10$ \\
\hline 120894 & 0.174 & None & $<10$ \\
\hline 120895 & 0.174 & None & $<10$ \\
\hline 120896 & 0.174 & None & $<10$ \\
\hline 120897 & 0.174 & None & $<10$ \\
\hline 120898 & 0.174 & None & $<10$ \\
\hline 120899 & 0.174 & None & $<10$ \\
\hline 120900 & 0.174 & None & $<10$ \\
\hline 120901 & 0.174 & None & $<10$ \\
\hline 120902 & 0.174 & None & $<10$ \\
\hline 120903 & 0.174 & None & $<10$ \\
\hline 120904 & 0.174 & None & $<10$ \\
\hline
\end{tabular}


THE OTERO MESA STUDY AREA

Table 7.27. Comparison of Red Flags and Correctly Predicted Sites

\begin{tabular}{|c|c|c|c|c|}
\hline & East Red Flag & West Red Flag & $\begin{array}{l}\text { East Correctly } \\
\text { Predicted }\end{array}$ & $\begin{array}{l}\text { West Correctly } \\
\text { Predicted }\end{array}$ \\
\hline \multicolumn{5}{|l|}{ Site ArEa (in acres) } \\
\hline range & $0.2-8$ & $0.05-7$ & $0.2-56$ & $0.2-193$ \\
\hline mean & 1 & 0.4 & 9 & 16 \\
\hline std. dev. & 2.5 & 1 & 19 & 39 \\
\hline \multicolumn{5}{|l|}{ ELEVATION (m) } \\
\hline range & $1110-1274$ & $1340-1556$ & $1104-1358$ & $1333-1877$ \\
\hline mean & 1197 & 1469 & 1297 & 1553 \\
\hline std. dev. & 421 & 76 & 101 & 138 \\
\hline \multicolumn{5}{|l|}{ DistanCE FROM STREAMS (m) } \\
\hline range & $30-381$ & $10-612$ & $0-594$ & $0-910$ \\
\hline mean & 98 & 264 & 379 & 224 \\
\hline std. dev. & 52 & 242 & 112 & 185 \\
\hline \multicolumn{5}{|l|}{ SLOPE (degrees) } \\
\hline range & $0-10$ & $0-4$ & $0-27$ & $0-57$ \\
\hline mean & 2 & 2 & 3 & 7 \\
\hline std. dev. & 3 & 1 & 3 & 9 \\
\hline \multicolumn{5}{|l|}{ ASPECT } \\
\hline largest percentage & South $(70 \%)$ & East $(49 \%)$ & West $(52 \%)$ & South $(53 \%)$ \\
\hline second largest percentage & West (19\%) & North $(31 \%)$ & South $(31 \%)$ & West (29\%) \\
\hline \multicolumn{5}{|l|}{ GEOMORPHOLOGY } \\
\hline largest percentage & Alluvial fans $(80 \%)$ & Eroded bedrock (83\%) & Eroded bedrock $(78 \%)$ & Eroded bedrock (48\%) \\
\hline second largest percentage & $\begin{array}{l}\text { Colluvial deposits } \\
>1 \mathrm{~m} \text { thick }(13 \%)\end{array}$ & Valley fill alluvium (9\%) & Sand sheet $(21 \%)$ & Alluvial fans (27\%) \\
\hline
\end{tabular}

The nature of precontact human use of the dissected uplands of the southern Sacramento uplift cannot be projected based on what we know now. We have evidence to indicate that this was a favored zone. Additional survey and modeling to verify this pattern, and additional research to determine the nature of human uses and the resources on which they were focused, should be a priority for the future.

The places where sites are not found or predicted to be found by the models are perhaps just as informative about human behavior in the study areas as the places where sites are found or predicted. The large expanses of colluvium mapped in Figure 7.4 are conspicuous in this regard. Either the areas of colluvium did not get a high score in the sitelocation "calculus" of the indigenous people in this area, or activities were sited there but the colluvium is masking the presence of buried sites. This is an issue to which we will return in the management section below.

It is readily apparent from Figure 7.7 that the most extensively surveyed area covered by the models is the southern three blocks of the western study unit. Yet a quick comparison with Figure 7.6 reveals the virtual absence of sites recorded during these surveys. From an anthropological standpoint, this isn't surprising. The area is flat, away from the drainage network, and on eroded bedrock surfaces; the availability of resources in this area is likely to have been very limited. From a management standpoint, as will be discussed below, this tantalizing evidence that there may be marked differences in archaeological site densities in the different environments of greater Otero Mesa offers the promise of some important management opportunities.

Only additional survey will provide data to test the accuracy of the models and our interpretations. We did, however, evaluate the effect of the big sites on the models by re-analyzing the data for the western study unit after diminishing the influence of site size. Using a module in ArcView, we divided the sites into three classes - small, medium and largebased on natural breaks in the range of site sizes (Table 7.28). We then determined the mean number of cells for each site. Ten percent of the mean number of cells was then chosen as the number of cells to represent each site in the class. Through an ArcView extension, a random selection of cells was chosen for each site. All sites had at least one cell selected. Because most small sites are represented by fewer than four cells, this process over-represented small sites when a new logistic regression model was generated using this data set. The results of the "sample" logistic regression model are compared with those of the "full" model in Table 7.29 and Figure 7.14.

The largest differences occur in the nominal data, particularly in the thick colluvial deposits and the Chihuahuan broadleaf deciduous areas. The effects of these variables are depressed, which can be seen in the favorability maps as a decrease in the size of the unfavorable zones. The impact of the site size issue for the multicomponent site at Alamo 
Table 7.28. Site Classes for the Western Study Unit, Otero Mesa

\begin{tabular}{lccc}
\hline & \multicolumn{3}{c}{ Site Classes } \\
\cline { 2 - 4 } & Small & Medium & Large \\
\hline Site size $\left(\mathrm{m}^{2}\right)$ & $199.5-27437.5$ & $27437.5-71454$ & $71454-781064$ \\
Number of sites & 63 & 13 & 2 \\
Mean number of cells & 4 & 67 & 799 \\
Number of random points generated per site & 1 & 7 & 80 \\
\hline
\end{tabular}

Table 7.29. Comparison of Coefficients for Variables Used in the Original Western Logistic Regression Model and the Random Site Sample Model

\begin{tabular}{lcc}
\hline Variable & $\begin{array}{c}\text { Full Model } \\
\text { Coefficient }\end{array}$ & $\begin{array}{c}\text { Sample Model } \\
\text { Coefficient }\end{array}$ \\
\hline Eroded bedrock & -1.86807250 & -1.4487918 \\
Alluvial fans & 1.24345371 & 1.46807467 \\
Colluvial deposits $>1$ m thick & -16.96504835 & -2.37375768 \\
Chihuahuan broadleaf deciduous & -16.51966538 & -1.95976601 \\
Rock outcrop & 6.25818135 & 5.67053689 \\
Chihuahuan lowland/swale & -3.18205604 & -1.73397543 \\
West-facing aspect & 1.3662265 & 0.97048214 \\
East-facing aspect & -0.68437538 & -0.42596248 \\
Slope & 0.00957143 & 0.00903231 \\
Distance from streams & -0.00161888 & -0.00154771 \\
Cost distance from ridges & 0.00129103 & 0.00097066 \\
Distance from ridges & -0.00362474 & -0.00307946 \\
\hline
\end{tabular}

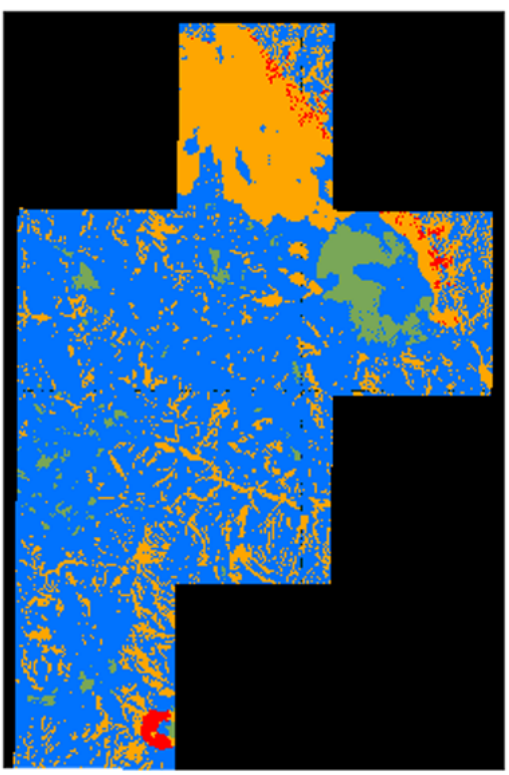

Sample

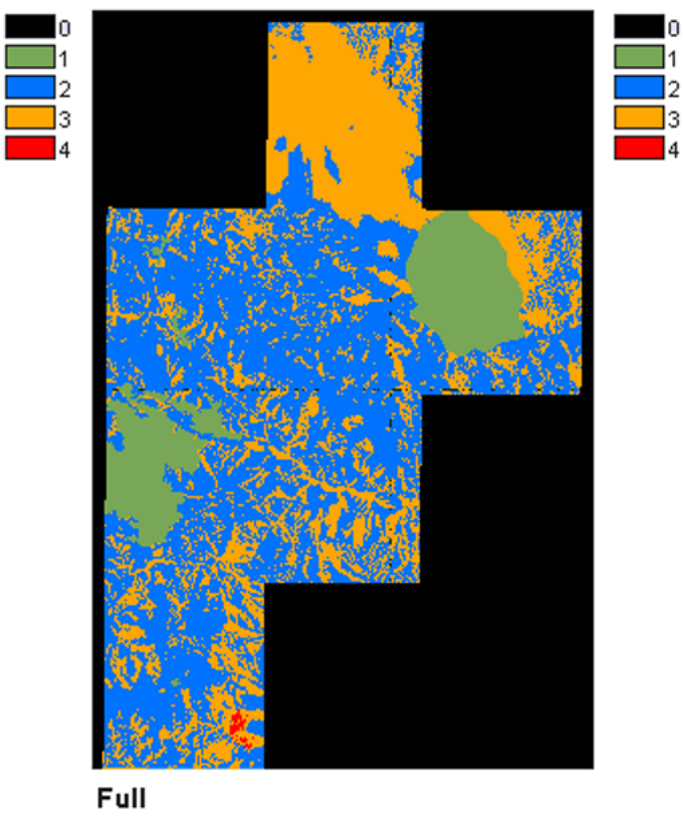

Full

Figure 7.14. Comparison of the sample and full logistic regression favorability maps for the western study unit. Black areas (0) are outside the study area. 
Mountain is also apparent in the differences between these maps. In most other ways, however, the two models are quite similar and show the same settlement trends. Overall, the similarity of the models is striking; statistically, the models are relatively close with a pair-wise Spearman's $r$ score of 0.76 . The inference we draw, therefore, is that while site size is an overriding influence in the models, it is not masking settlement trends.

There is no question but that the predictive models for Otero Mesa are based on inadequate data. We expect that future work will greatly refine certain aspects of the relationship between the environment of Otero Mesa and past human settlement. We do, however, believe that the models accurately portray broad settlement trends. In assessing the modeling results, it is important to remember that the models in the eastern and western study units were developed independently. Different environmental variables dominate the models in the two study units. Even so, the complex calculus that past humans used to place themselves on the landscape, a calculus that thus far eludes us, appears to have subsumed regional environmental differences into a broader perception of settlement and land use.

\section{Inventory Reconstruction}

Unlike Loco Hills (Chapter 5) and Azotea Mesa (Chapter 6), Otero Mesa has an archaeological record that is relatively unexplored. It may seem foolhardy, then, to perform the same type of inventory reconstruction for the Otero Mesa study area as was presented in the preceding chapters. Although we acknowledge the data deficiencies, we thought that the reconstruction of survey history might still provide some insights. Given the extremely limited survey coverage, our expectation was that the annual computations of site density for Otero Mesa should fluctuate widely. But what if they do not? What should managers and archaeologists infer from such results?

As we did for the Loco Hills and Azotea Mesa study areas, we used the dates when surveys were concluded and sites were recorded to reconstruct the history of archaeological inventory on Otero Mesa. Using the digitized data provided by ARMS, we associated surveys with the year in which they were completed and sites with the completion year of the survey in which they were recorded. Based on these data, we calculated for each year the number of acres of sites recorded and the number of acres surveyed. By dividing the number of "site" acres by the total number of acres surveyed in any given year, we arrived at a site density figure for that year, which was then compared with a running density figure that included all sites and acres surveyed up to that date.

We assumed that the cumulative site density figure for all years through the year 2000 was an accurate estimate of site density within the entire Otero Mesa study area. This assumption allowed us to use the yearly running site density figures to compute the standard deviation and confidence intervals around the 2000 figure, which captured $95 \%$ of the estimates. We then examined the annual history to determine if and when during the history of archaeological survey in the area the running site density began to fall consistently within the confidence intervals.

Although we encountered many of the same issues of resurvey and data quality previously identified during the Loco Hills and Azotea Mesa studies, the dearth of survey in the Otero Mesa study area actually lessens the impact of these problems. Still, some areas had been surveyed multiple times and some sites had been re-recorded, sometimes within the same year. The problem of "site boundaries," with the polygons consisting of arbitrary buffers around map points, is present in the data set from Otero Mesa as it was for the other study areas. As in the other areas, some site boundaries seem to be randomly sized and inconsistent with the written site descriptions.

Figure 7.15 illustrates some of the overlap and re-recording problems. The figure reflects the raw data as captured by ARMS. Each survey was recorded fully, including portions that overlap previous surveys. The site recording episodes reflect the extent to which a site or a portion of a site was recorded during any particular survey event.

To compensate for these problems, we aggregated the data by year. All surveys and site recording episodes were assigned to the year in which field activity concluded, as reflected in the ARMS data. Figure 7.16 shows surveys within a small portion of the study area, coded by year, along with the aggregated site boundaries (note the large, arbitrary circle "boundary"). Figure 7.17 shows a time sequence of cumulative survey, aggregated by year, within the whole study area.

After aggregating the data, we found that the process of estimating site density on an annual basis was only slightly complicated by the amount of resurvey and the concomitant re-recording of sites. Between 1976 and 2000, surveys in the study area covered 7,820 acres, but only 7,638 acres of ground were actually inventoried; the 182-acre difference results from resurvey. This is clearly a minor matter compared with the Loco Hills and Azotea Mesa results. Far less actual survey has been performed: approximately $1.7 \%$ of the entire Otero Mesa study area has been inventoried, and the percentage of resurvey included in the inventory figure is only approximately $2.3 \%$. Despite the limited nature of the resurvey problem, we analyzed the Otero Mesa inventory history using both "survey as performed" data and "survey with overlap omitted" data in order to ensure that the results would be consistent with the Loco Hills and Azotea Mesa studies. 


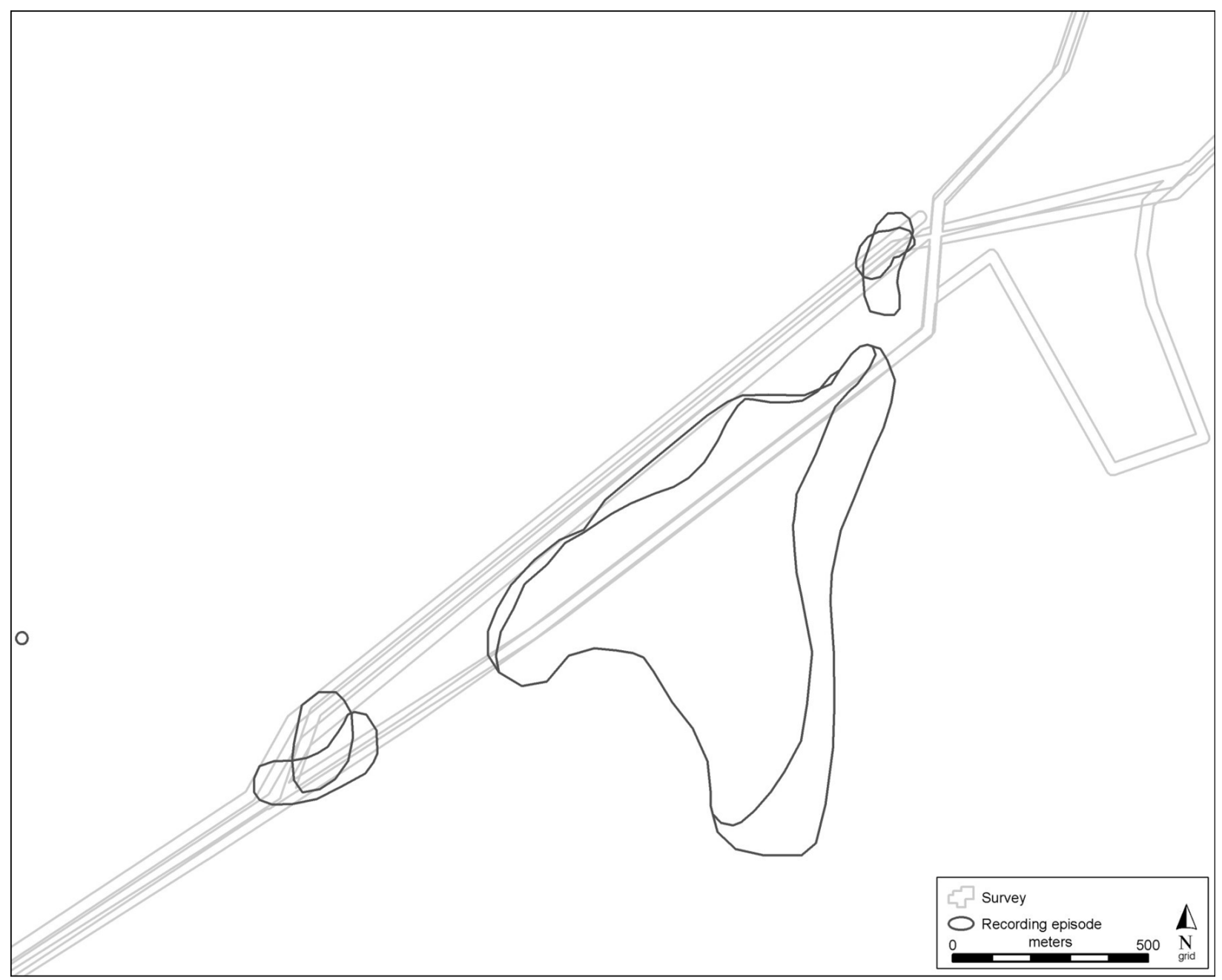

Figure 7.15. Examples of survey and recording episodes.

Figure 7.18 graphically displays the history of survey in the Otero Mesa study area with special attention to this issue of resurvey. For each year there are three bars, one that represents the reported number of surveyed acres, one that represents the reported acreage minus the overlapping surveys that occurred within that same year, and one that represents the actual new ground surveyed with all overlaps removed.

These data allow us to calculate site density using the two different methods developed for the Loco Hills and Azotea Mesa study areas. Method I (Figure 7.19) is based on survey as it was actually performed. In this analysis, sites that were recorded more than once and areas that were surveyed more than once in different years are included in the calculations for each year that the fieldwork took place. The site density figures calculated using Method I are, therefore, inflated. Method II (Figure 7.20) eliminates survey overlap and site re-recording, providing a slightly more accurate estimate of site density. In short, Method I calculates site density as this information would have been available to managers under existing survey strategies, whereas Method II provides the density figures that would have been available in an ideal world where there were no survey overlaps or site re-recording.

The trend in running site density figures is far from clear in this study. Site density stabilizes at about 0.0051 under Method I and 0.0052 under Method II. Running density for both methods initially falls in the $95 \%$ confidence intervals in 1980, then again from 1986 to 1991, and 1996 to 2000. The peak in site density in 1996 is responsible for substantially raising the running density. The sites portrayed in Figure 7.15 are largely responsible for this phenomenon; these extensive sites were recorded twice in the same year by two different surveys, thus effectively doubling their representation in the site density statistic. Although this is a minor discrepancy in acreage when compared with the Loco Hills and Azotea Mesa studies, it is over represented because of the extremely small sample size. 


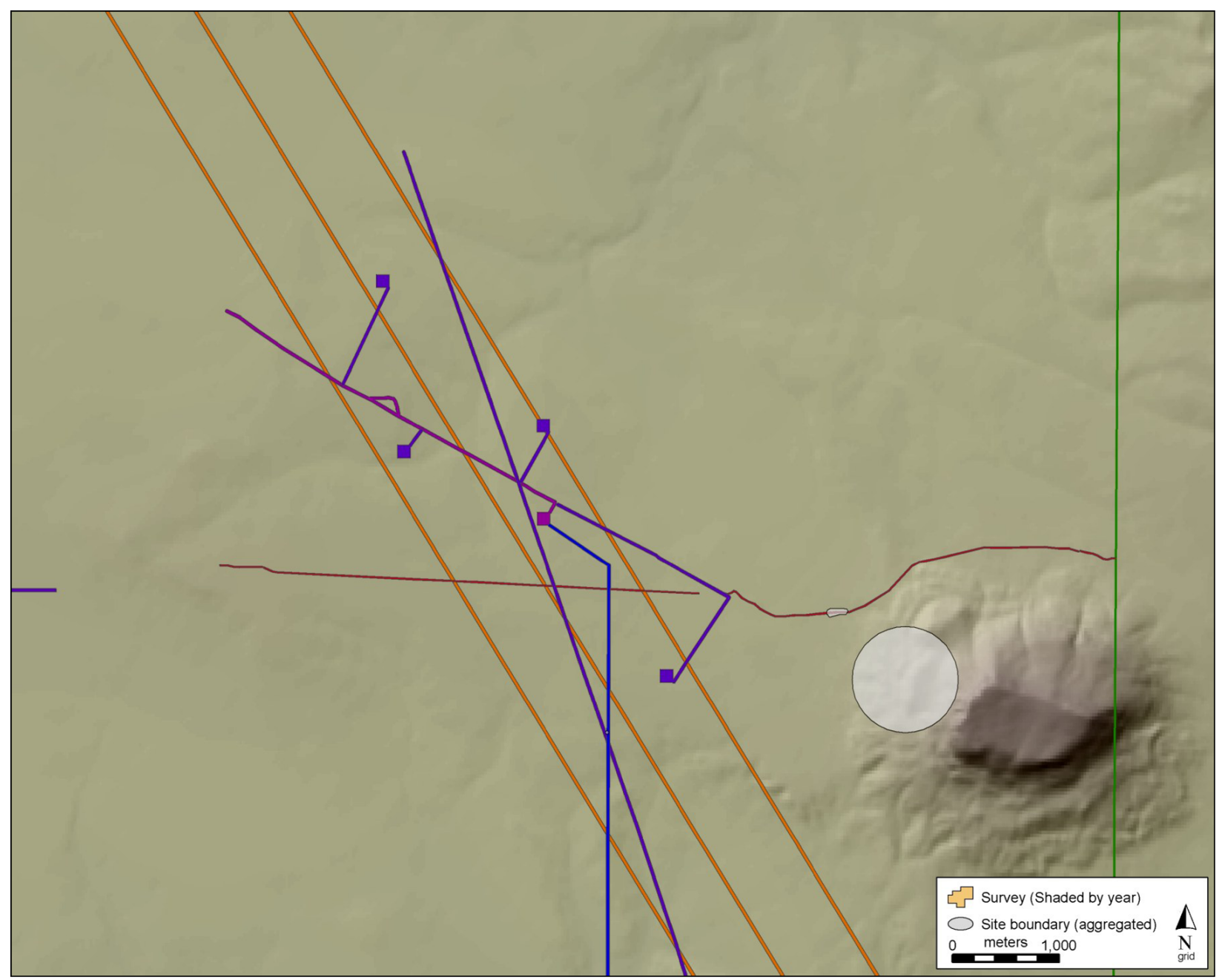

Figure 7.16. Example of survey coverage aggregated by year.

Although the running site density on Otero Mesa appears to be quite stable, we believe that such an inference in unwarranted. The wide fluctuations in the annual site density figures are telling a different story, one in which our perception of the archaeology of Otero Mesa is constantly changing.

\section{Conclusions}

Because they are based on very limited data, the archaeological site location models of Otero Mesa are poor predictors. Yet, we believe that they have some utility for both managers and archaeologists. The models point out areas that are likely to contain sites and areas where site density is apparently quite low. For all their shortcomings, both the eastern and the western study area models identify some similar trends, which gives us greater confidence in them than we might otherwise have. Moreover, a comparison of models developed using full and sampled data sets indicates that the results of the two modeling efforts are very similar.

The models from Otero Mesa cannot be used to tell us exactly where we will find sites, but they can be used to guide us as to where we should look for sites. The models can also give us some general guidance about conditions that should be placed on oil and gas exploration. The models all point to the uplifted, dissected regions of greater Otero Mesa, and especially the southernmost extension of the Sacramento Mountain uplift, as likely places for archaeological sites. The models also identify the Alkali Lakes region in the southern part of the eastern study unit and the alluvium of the northern block of the western study unit as higher-probability areas for cultural resources. Since Alkali Lakes is 
ADAPTIVE MANAGEMENT ※゙PLANNING MODELS FOR CULTURAL RESOURCES IN OIL ※゙ GAS FIELDS

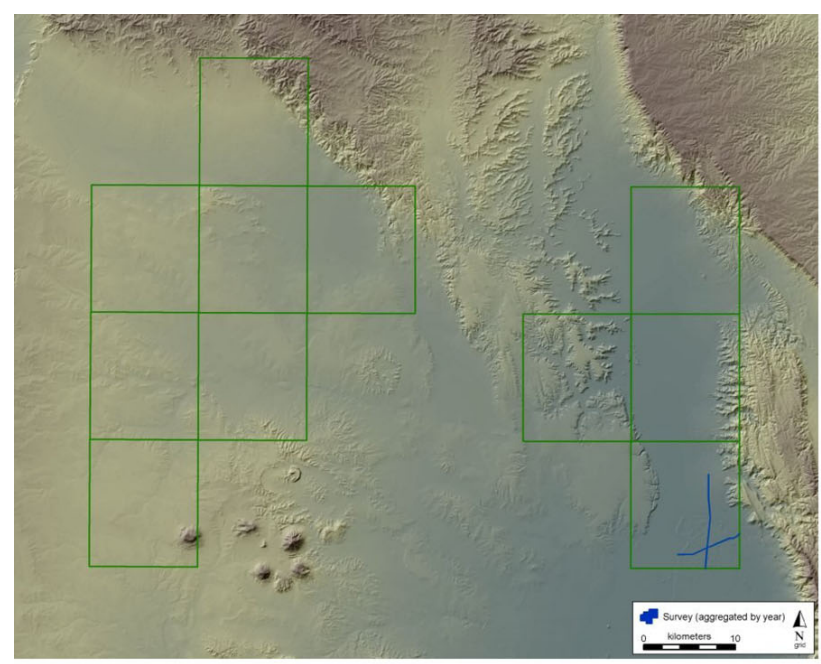

1976

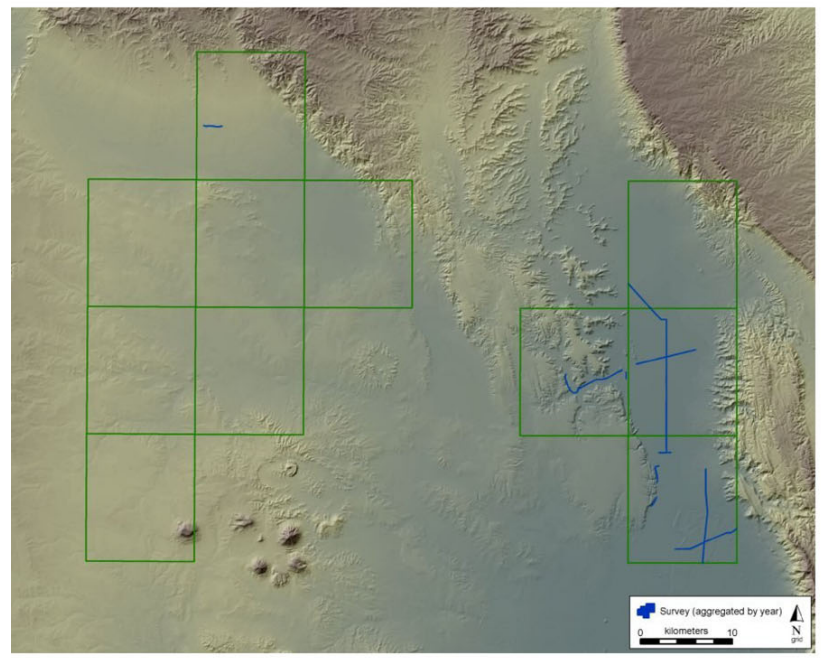

1980

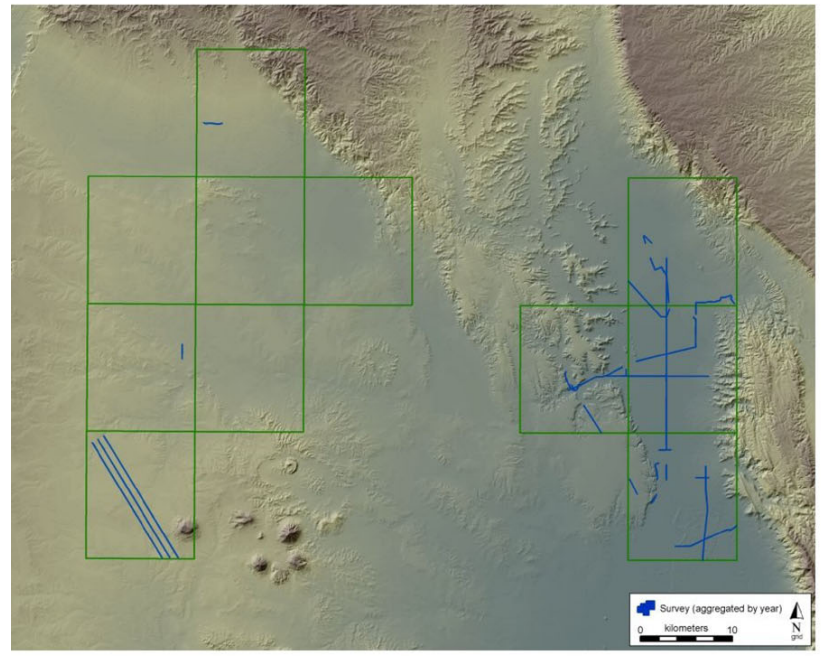

1985

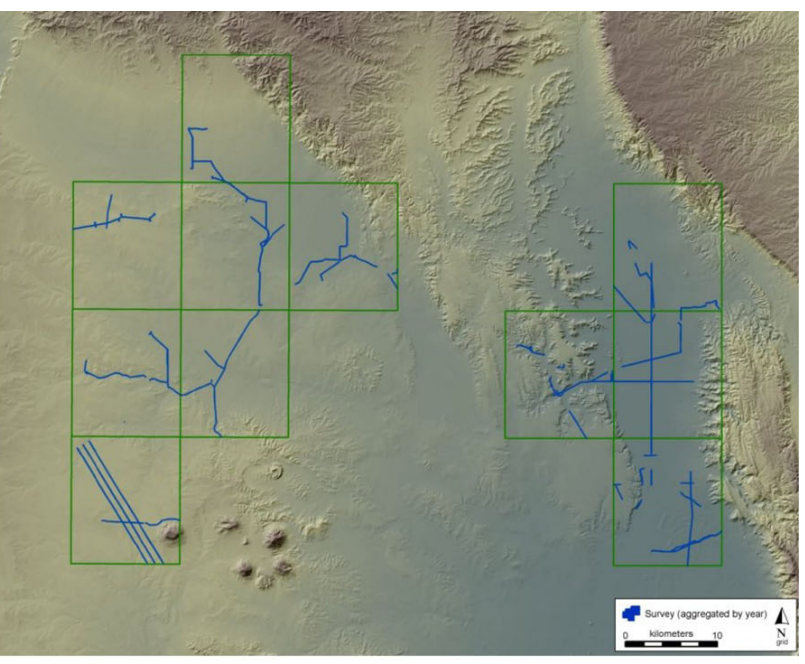

1990

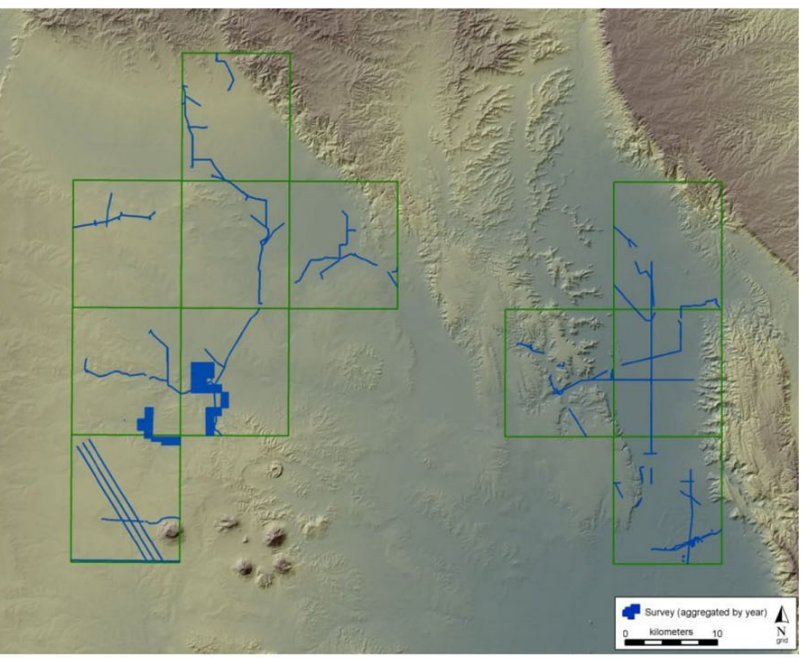

1995

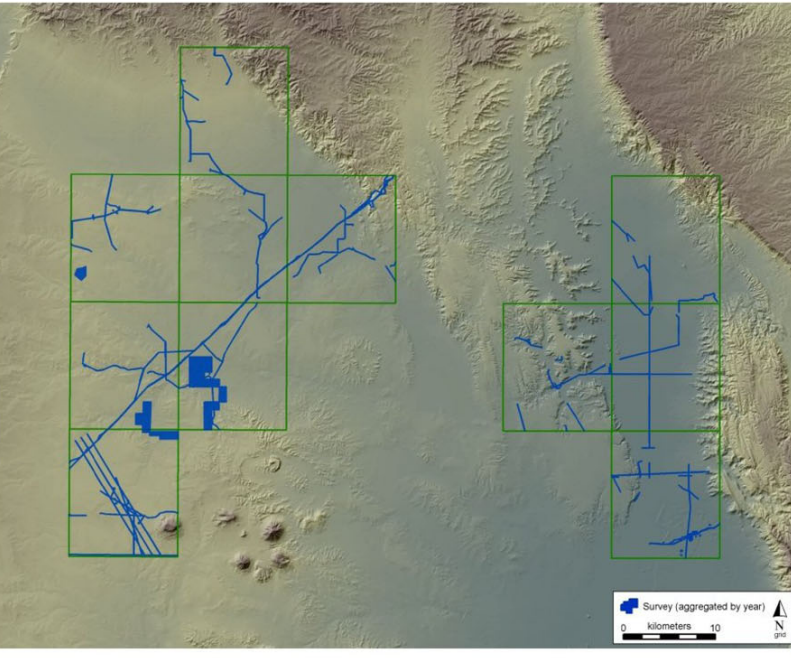

2000

Figure 7.17. Time sequence for cumulative survey in the study area, aggregated by year. 
THE OTERO MESA STUDY AREA

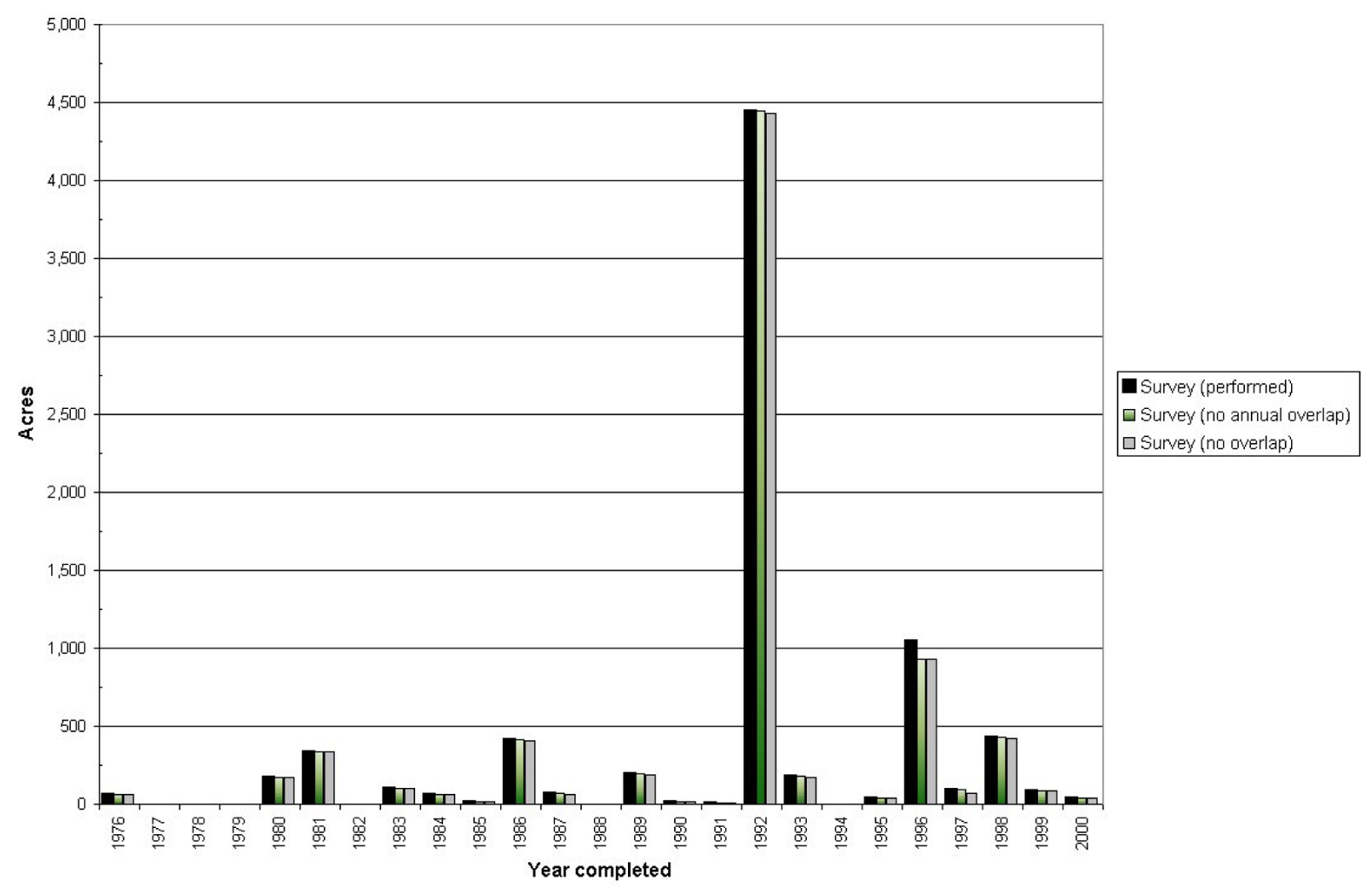

Figure 7.18. Annual survey statistics.

already managed as an Area of Critical Environmental Concern by BLM for its waterfowl, shorebird nesting sites, rare plants, and ecological diversity values, there may be important management opportunities for cultural resource management in this area as well.

Whereas the uplifted, dissected areas of Otero Mesa are predicted to contain sites, the models predict that few sites will be found during surface survey in colluviated areas. While it is possible that humans avoided these areas, it is also possible that the model results have less to do with the correlation between environment and human land use than with visibility of the archaeological record, a possibility that seems to be supported by recent archaeological work in the area. Buried sites are frequently found in colluvial settings, and surface survey may not be sufficient to identify historic properties that would be affected by oil and gas development activities in some areas. Subsurface testing, possibly shovel tests or use of shallow probes, may be needed to identify shallowly buried sites in colluvium and should be required as part of inventories until BLM can determine whether such sites are likely to exist.

Archaeologists need to confirm and explain the patterns suggested by these preliminary models, and the archaeological record needs to be more fully characterized: What types of sites are found in the high potential locations? What activities took place here in the past? What was the full range of human activities in the greater Otero Mesa area and how were all of these activities distributed on the landscape? At the very least, managers need to be aware of the potential highdensity and low-density areas in order to develop appropriate inventory strategies. At the same time, potential lessees can be forewarned about the likelihood of additional costs and constraints and develop their own human calculus about the resource costs and benefits to be found in the Otero Mesa landscape.

Finally, we recommend that the BLM continue the predictive modeling process for Otero Mesa. The current models indicate that there may be fairly strong patterns of high density and low density areas for archaeological sites, but that our understanding of site density has not yet stabilized. If additional survey and additional modeling refine these patterns and provide us with greater confidence in their validity, the opportunities for innovative management of cultural resources during future oil and gas development in the greater Otero Mesa area will be greatly enhanced. 
ADAPTIVE MANAGEMENT \&PLANNING MODELS FOR CULTURAL RESOURCES IN OIL \& GAS FIELDS

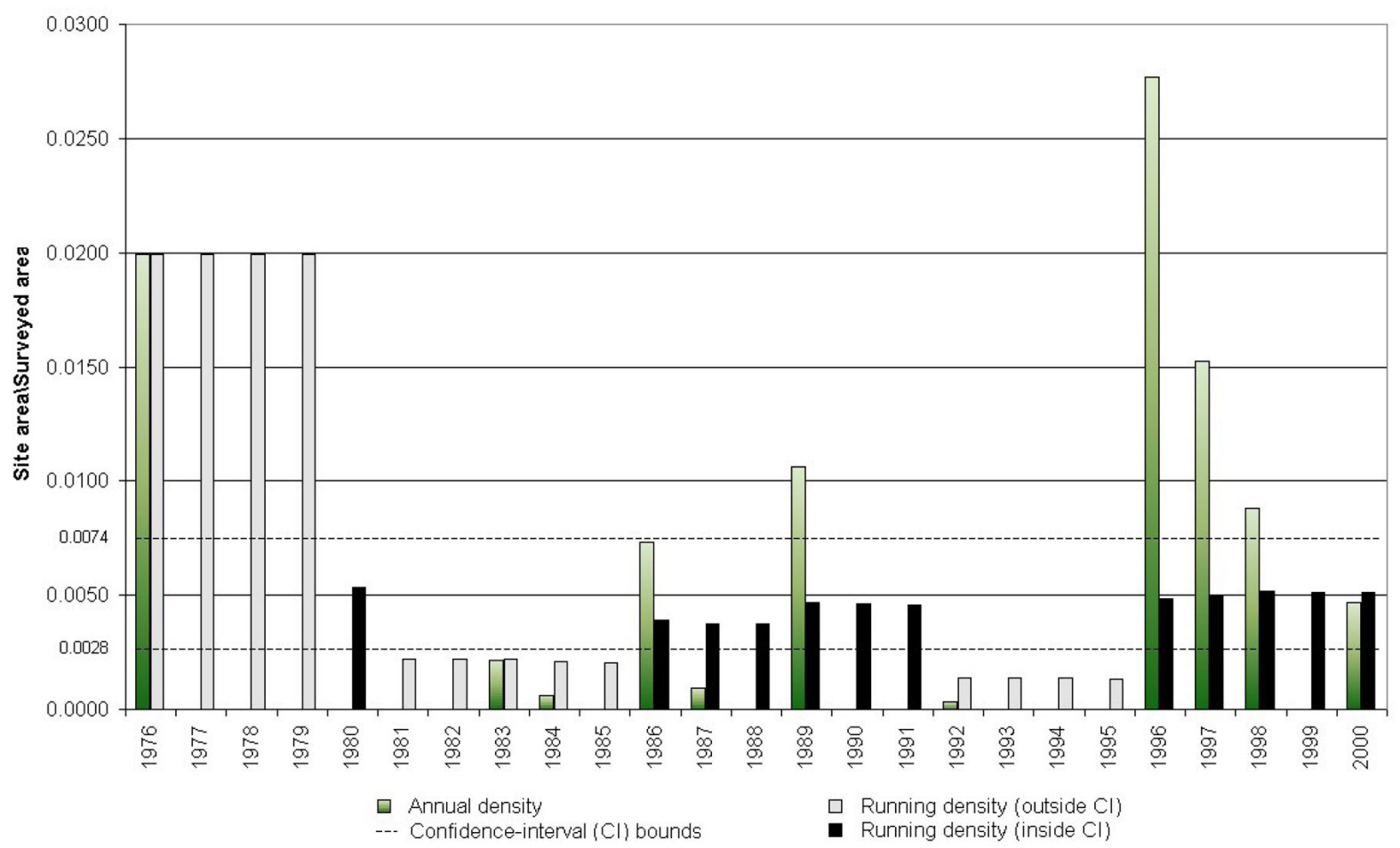

Figure 7.19. Overall site density, Method I.

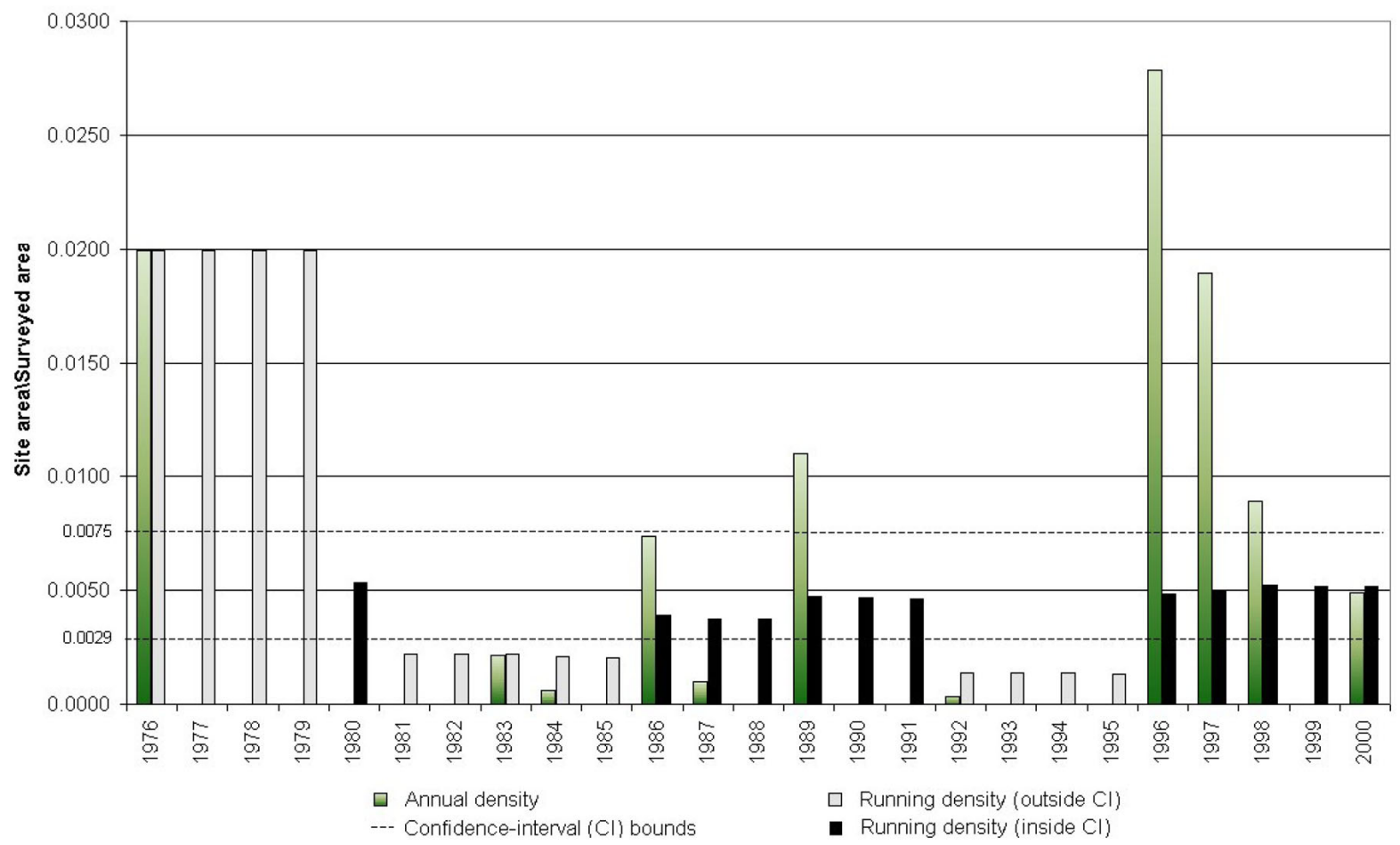

Figure 7.20. Overall site density, Method II. 


\section{THE OTERO MESA STUDY AREA}

\section{References Cited}

Altschul, Jeffrey H.

1990 Flag Models: The Use of Modeling in Management Contexts. In Interpreting Space: GIS and Archaeology, edited by Kathleen M.S. Allen, Stanton W. Green, and Ezra B.W. Zubrow, pp. 226-238. Taylor and Francis, London.

Kvamme, Kenneth L.

1988 Development and Testing of Quantitative Models. In Quantifying the Past and Predicting the Future: Theory, Method, and Application of Archaeological Predictive Modeling, edited by W. James Judge and Lynne Sebastian, pp. 325-428. U.S. Department of the Interior, Bureau of Land Management, Denver. 



\title{
C H A P T E R \\ 8 \\ Historical Period Land Use on Otero Mesa
}

\author{
Scott Thompson
}

D.

As noted in Chapter 1, much of the historical landscape within the Loco Hills and Azotea Mesa study areas has been irrevocably altered by modern development_roads, communities, and especially in Loco Hills, oil and gas development. Otero Mesa, however, has seen very little in the way of modern development and still retains many of the subtle physical traces of early Euroamerican settlement and land use. For this reason, we have provided this chapter of baseline information on the Euroamerican culture history and resources of the Otero Mesa study area. This chapter will provide general information about the kinds of historical resources that may be encountered if oil and gas development takes place in this area, and a context for interpreting and evaluating the significance of those resources.

\section{Archival Research Methods}

In March and April 2004, project personnel visited or contacted the following institutions and repositories to identify and evaluate sources documenting the period of occupation and use of lands within the Otero Mesa project area: Alamogordo Public Library; Bureau of Land Management (BLM) Office, Las Cruces; Directorate of the Environment, U.S. Army Air Defense Artillery Center, Fort Bliss, Texas; New Mexico State Land Office, Santa Fe; New Mexico State University Library, Rio Grande Historical Collections, and Special Collections, Las Cruces; Tularosa Basin Historical Society, Alamogordo; U.S. Army Corps of Engineers, New Mexico Real Estate Office, Albuquerque; and the University of Arizona Main Library and Special Collections, Tucson.

During the course of archival research a variety of textual and nontextual documents, comprising both primary and secondary sources, was evaluated for information content and significance. Relevant sources were copied, compiled, verified, and analyzed. From the documents reviewed and data collected, information was gleaned regarding the general history of the study area and surrounding vicinity as well as a history of settlement and land tenure. The records search was the first step in determining the locations of cultural resources in the study area.

At the BLM office in Las Cruces, we studied the General Land Office (GLO) survey plat maps of the Otero Mesa study area spanning the years 1885-1939. The locations of historic buildings, structures, and water storage and conveyance features were geo-referenced and overlaid onto the eleven U.S. Geological Survey (USGS) 7.5-minute-series topographic maps illustrating the project area. In addition to reviewing documentary materials on file at the aforementioned facilities, SRI obtained the GLO files of patented homesteads within the project area from the BLM web site (http:// www.glorecords.blm.gov/). These records provide specific information on patented claims, including the names of patentees, the year the patents were received, the authority under which the claims were patented (e.g., Homestead Act, Enlarged Homestead Act, Stock Raising Homestead Act), total number of acres per patented claim, and the legal descriptions for the claims. Locational information for the homestead parcels was digitized and transferred onto USGS topographic maps of the study area.

The records search was by no means exhaustive. Further research in the form of oral history interviews with local personages and examining Otero County deed and land records could furnish additional information concerning the occupation and use of lands on Otero Mesa. Specifically, oral history interviews with longtime residents could explore in detail the farming and ranching activities from the viewpoints of those who engaged in them.

\section{Historical Overview of Exploration and Settlement on Otero Mesa}

As described in Chapters 1 and 7, Otero Mesa lies in Otero County in south-central New Mexico (Figure 1.2). Otero Mesa encompasses 1.2 million acres of Chihuahuan Desert grassland and extends from the Hueco Mountains on the west to the Guadalupe Mountains on the east, and from approximately the Texas-New Mexico border north to the 
Sacramento Mountains (Figure 1.3). For most of the historical period, both Native Americans and Euroamericans treated this region as a place to pass through on the way to somewhere else or as one to avoid altogether.

Very little has been written about the history of Otero Mesa; much more information is available about the neighboring Tularosa Basin, owing to the basin's mineral resources and the earlier and more extensive Euroamerican settlement of that area. The Tularosa Basin adjoins Otero Mesa on the west and is approximately 150 miles long and 60 miles wide, encompassing an area of 6,000 square miles. It is bordered on the north by the Sierra Oscura range and the Chupadera Plateau, on the east by the Sacramento Mountains, and by the San Andres and Organ Mountains on the west. The Jarilla, Franklin, and Hueco Mountain ranges border the Tularosa Basin to the south (Schneider-Hector 1993:3).

To create a framework for understanding Euroamerican settlement, land tenure, and historical resources on Otero Mesa, we can examine the culture history of the Tularosa Basin, which has similar climatic and landscape characteristics as well as having experienced similar historical processes. Both regions have dry, harsh, marginal environments that militated against historical period settlement. Semi-nomadic Native American groups such as the Manso, Suma, and Mescalero Apache used the lands of the Tularosa Basin and Otero Mesa for hunting and gathering food, but they did not establish permanent or long-term settlements in these forbidding landscapes. Rather, their base camps were located near reliable water sources in the surrounding mountain ranges and in the Rio Grande Valley. During the Spanish and Mexican periods and the early years of the American period, the Tularosa Basin/Otero Mesa region was seen as less than desirable owing to the lack of water and to the Apache presence. Only after the Apaches were settled onto reservations did significant settlement occur here (Faunce 2000:4-5,23).

\section{The Spanish Colonial Period}

Between 1581 and 1583, two Spanish expeditions entered what is now south-central New Mexico through the pass between the Franklin Mountains and the Sierra de Juárez that later became known as El Paso del Norte. The first expedition, under the command of Captain Francisco Sanchez Chamuscado, paralleled the Rio Grande in search of gold and converts to Christianity. In 1583, Don Antonio de Espejo led a group of two priests and 15 soldiers north of El Paso del Norte along the Rio Grande. Accounts of the journey indicate the group did not enter the Tularosa Basin owing to a lack of water and to their perception that the region held nothing of value. Espejo's group was interested in finding a route around the inhospitable area to other regions rich in resources.

In 1595, King Philip II of Spain commissioned Juan de Oñate to conquer and settle the northern territories of New Spain. Oñate claimed the territory for the Spanish crown in 1598, establishing settlements near the Indian pueblos of Acoma, Isleta, Soccoro, and Santo Domingo, and subsequently founded the Spanish villages of Española, Santa Fe, and Bernalillo. Oñate's expedition avoided the Tularosa Basin altogether (Faunce 2000:27-28). Consequently, when the colonial government established the Camino Real, or Royal Highway, to connect the settlements of the northern frontier to Mexico City, the route lay well to the west of the Tularosa Basin and Otero Mesa (Schneider-Hector 1993:32).

During the Spanish colonial period the Tularosa Basin and the entire south-central region of present-day New Mexico were perceived as a wasteland with little to offer in the way of resources. Interest in the area was minimized even further by the Apache presence in the Organ and Sacramento Mountains. Instead, Spanish settlement centered in and around Santa Fe and along the Rio Grande, where farms tended to dominate the rural landscape (Culbert 1941:155). The first documented use of the Tularosa Basin by the Spaniards was in 1647 when the Salt Trail was established to exploit substantial salt deposits in the region. Initially, the trail extended north from the silver mining districts of Durango, Mexico, through El Paso del Norte (present-day El Paso, Texas), along the eastern edge of the Organ Mountains to Lake Lucero, an ephemeral lake on the present-day White Sands National Monument located due west of Alamogordo. In 1691, the Spaniards discovered additional salt deposits in the eastern Tularosa Basin. The Salt Trail between El Paso and the basin deposits was abandoned in 1862, after a superior source was discovered near Guadalupe Peak in Texas (Faunce 2000:23-24; Sonnichsen 1960:7).

Apart from extracting salt from deposits within the basin, Spanish activity in the area consisted largely of punitive expeditions against the Apaches. Throughout the eighteenth century, the Spanish military responded to Apache depredations by launching several campaigns to flush the raiders out of their mountain strongholds and recover stolen property. In 1786, Bernardo de Gálvez, the viceroy of New Spain, instituted a policy of continuous military harassment coupled with a promise of kind treatment and supplies if the hostile bands would agree to live in peace. By waging vigorous campaigns against the Apache, the Spaniards hoped to make peace more appealing than war. Those who sued for peace had to agree to remain within a bounded area. In return for their "settled" lifestyle, they received rations from the colonial government. This dependency system was costly for the Spanish crown, but it brought peace to the northern frontier throughout the remainder of the Colonial period. From 1793 to 1821, the region experienced relative peace as only a few raiding Apache bands required action on the part of the frontier garrisons (Faunce 2000:28-35; Hawthorne 1994:12). 


\section{The Mexican Period}

After Mexico won its independence from Spain in 1821, the new government dismantled the pacification system that paid the Apaches for peace, and the Indians began raiding once again. The Salt Trail continued to be used to transport salt from the Tularosa Basin south to El Paso and on to the mining districts of Chihuahua and Durango (Faunce 2000:4041). Like its predecessor, the Mexican government looked upon south-central New Mexico as an inhospitable area offering nothing of value other than the salt deposits that continued to be mined. The absence of reliable water sources and the presence of the Apache in the nearby mountains continued to discourage Euroamerican settlement.

The first commercial use of the Tularosa Basin other than for salt mining involved the construction and operation of a water-powered sawmill on the Tularosa River, processing timber from the Sacramento Mountains. According to Sale et al. (1996), this took place in 1845 and mill workers cut vigas, or beams, for use in the construction of a church in El Paso. Three trips were made to transport the cut lumber to El Paso, and on the first trip they were attacked by a band of Mescalero Apaches (Sale et al. 1996:22). In contrast to this account of a short-lived commercial activity, Sonnichsen's Tularosa (1960:10) refers to a sawmill operation on the river "which had supplied timber for churches and other buildings up and down the Rio Grande since before the year 1800." Whatever the actual dates of the sawmill's operation, it constituted the first documented non-Native American settlement in the region.

As it had during the colonial period, the Apache presence in the region deterred exploration and settlement of the Tularosa Basin and Otero Mesa during the Mexican period. Those who ventured into the region either traveled along the Salt Trail or were in pursuit of Apache raiders and stolen livestock. According to Faunce (2000:43), some grazing of livestock occurred in the area along the present-day New Mexico-Texas border during the Mexican period, but it was not until the United States gained control of the territory that large numbers of Euroamerican miners and settlers moved into the region.

\section{The American Period}

In May 1846, the United States went to war with Mexico over the annexation of Texas and President James Polk's interest in the Mexican territory of California. After U.S. troops seized Mexico City in September 1847, representatives of the two countries signed the Treaty of Guadalupe-Hidalgo, which Congress ratified in March of the following year. Under the terms of the treaty, Mexico recognized the United States' claim to Texas and ceded the territories of California and New Mexico. Along with the acquisition of this huge expanse of territory, the U.S. government inherited the Apache problem.

Shortly after acquiring the territory of New Mexico, the United States established military posts to protect settlements and began to explore and map the region. The first documented foray into the Tularosa Basin by U.S. military forces occurred in 1849 when a small contingent entered the basin in pursuit of Apache raiders (Sale et al. 1996:22). That same year, several U.S. Army expeditions traveled either through or around the basin. In their respective reports they commented on the abundant grasslands east and north of El Paso and determined that the area would be suitable for grazing livestock if sufficient water could be secured (Faunce 2000:51).

In September 1849, Capt. Randolph B. Marcy came to New Mexico territory under a directive to establish a route from Fort Smith, Arkansas, to New Mexico and California. On the return trip to Fort Smith, Marcy's party entered the Tularosa Basin from the west, seeking a southern route from Santa Fe to Fort Smith. Marcy relied on a local guide to lead his expedition through the territory east of the Organ Mountains. Shortly after Marcy's expedition, Lt. William F. Smith and a small escort surveyed the Sacramento Mountains on the east side of the basin in search of a practicable wagon route. Traveling from the military post at El Paso, the party headed north on the Salt Trail along the eastern slope of the Organ Mountains before turning east toward the Sacramentos. Smith's reconnaissance concluded that the rugged terrain was unsuitable for a wagon road (Schneider-Hector 1993:5, 39-41).

In 1857, the Butterfield Overland Mail established a route through southern New Mexico following a portion of the trail blazed by Captain Marcy eight years earlier. The stageline was organized by John Butterfield of Utica, New York, in response to increasing demand for improved and regular communication between the eastern states and the western territories and California (Conkling and Conkling 1947). Westbound travelers crossed into New Mexico from Texas just west of the Guadalupe Mountains and passed through the Otero Mesa region near the subsequent and now-deserted settlement of Orange (established in 1904) before reaching the station at Cornudas de los Alamos (Figure 8.1). Passenger Waterman L. Ormsby, Jr., who traveled the entire route from Missouri to San Francisco in 1858, provided the following description of the stagestop at Cornudas:

There is quite a large station here, and we procured a fresh team and a side driver and set out for Waco Tanks [Hueco, meaning "hollow" or "trough" in Spanish], thirty-six miles distant [cited in Greene 1994:74]. 


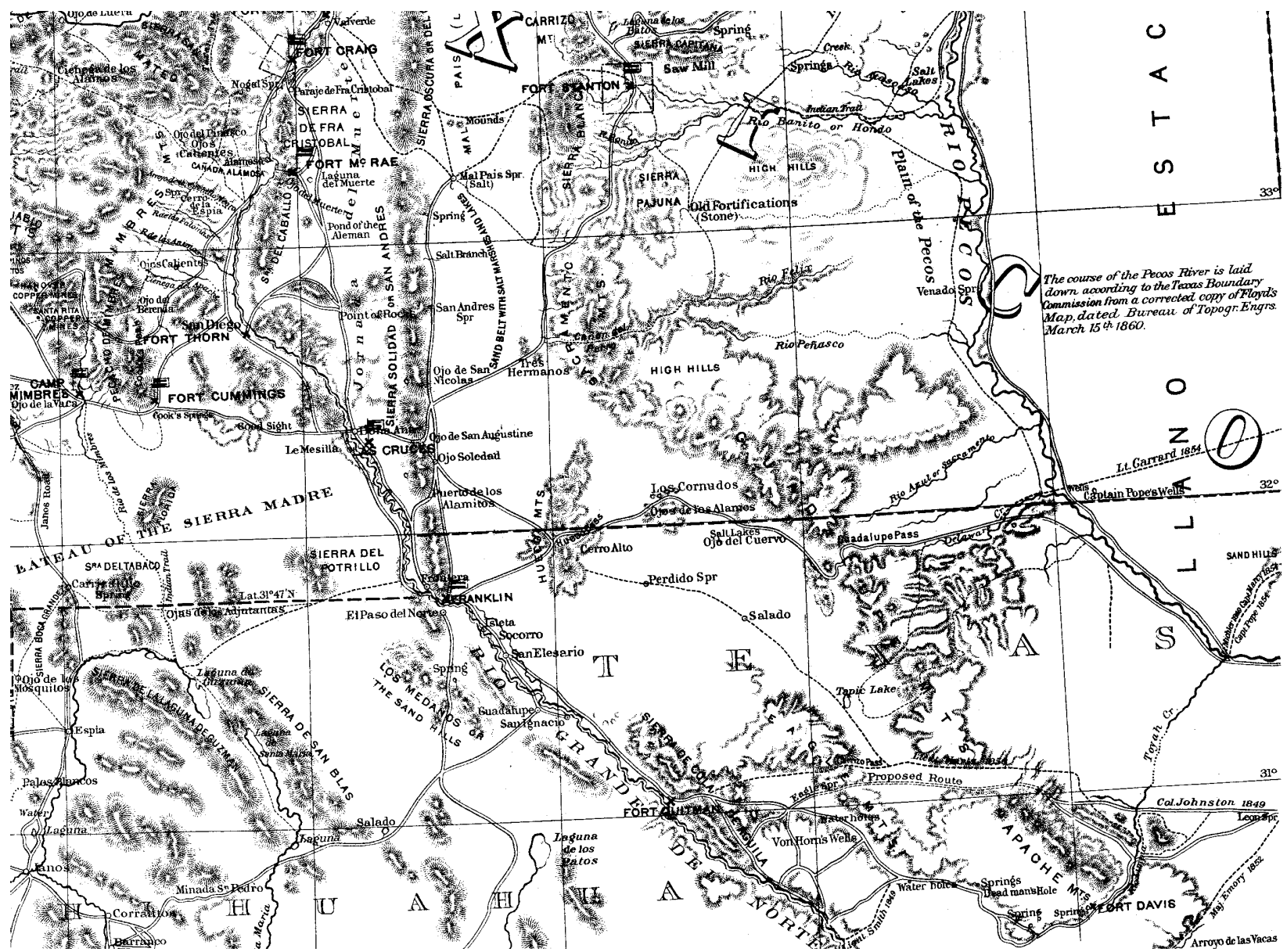

Figure 8.1. Portion of 1864 map of the Military Department of New Mexico by Capt. Allen Anderson, Fifth U.S. Infantry (accompanying report of Brig. Gen. J. H. Carleton, U.S. Army Series I, Vol. LXVIII; reproduced from Gerow 1996).

From Cornudas de los Alamos the trail continued about 16 miles in a generally westerly direction to the station at Ojos de los Alamos (Figure 8.2), also known as Cottonwood Springs. Situated one-half mile from a perennial spring, the station house was large and both exterior and interior walls were built of stone and adobe (Greene 1994:75). Upon leaving Ojos de los Alamos, the stagecoaches headed west and then dipped south across the border into Texas for a stop at Hueco Tanks before reaching El Paso.

The Butterfield Overland Company operated successfully until the outbreak of the Civil War when the United States government canceled the contract and rerouted the mail through the central states. During its period of operation, the stageline moved passengers, mail, and light cargo, serving as the primary and sometimes only means of transportation before the railroads connected the New Mexico territory to the east and west. Even after the Butterfield Company abandoned the line, the route continued to be used by emigrants, freighters, and the military (Conkling and Conkling 1947; Faunce 2000:56: Greene 1994:74-75, 182).

Raiding by Apache bands continued throughout the 1860 s, and the military launched several campaigns against the raiders during that period (Faunce 2000:57). By the early 1870s, conflict with the Apaches had begun to lessen, and several bands had settled near Fort Stanton (established in 1855) in the Sacramento Mountains. On May 29, 1873, President Ulysses S. Grant established, by executive order, the Mescalero Apache Indian Reservation (Hawthorne 1994:14; Mehren 1969:68). Over the next decade there were sporadic outbreaks of violence, but in general, the era of Apache raids was over. By the mid-1880s, with the reservation system firmly in place, farmers and ranchers began moving into the region. 


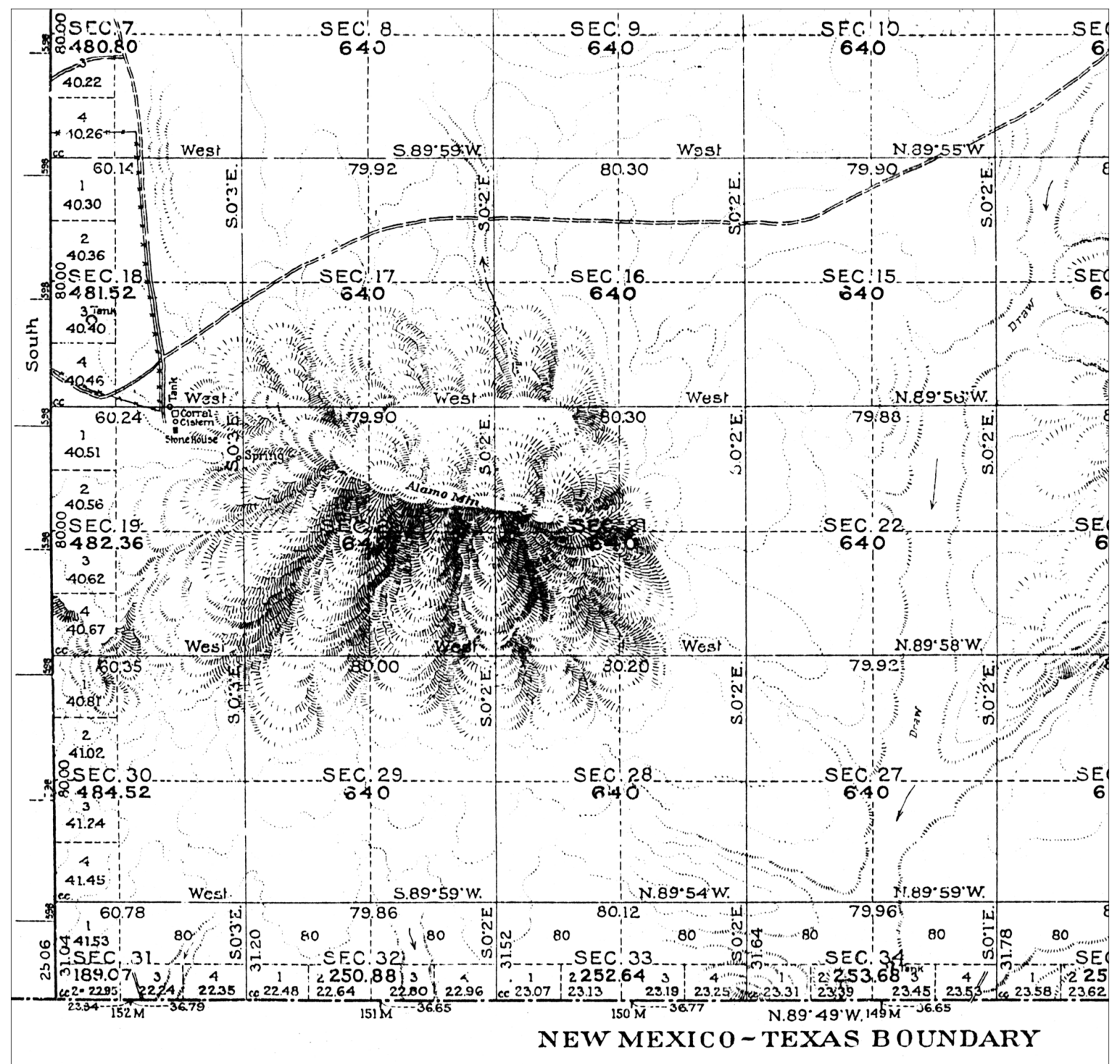

Figure 8.2. 1926 GLO survey plat of Township 26 South, Range 13 East indicating the location of the Ojos de los Alamos stagestop on the Butterfield trail (GLO 1926).

\section{Farming}

The first non-Native American settlers in present-day Otero County arrived in the 1860s. In 1862, Hispanic pioneers who had been forced by repeated floods of the Rio Grande to abandon their homes and fields in the Mesilla Valley established the community of Tularosa on the Tularosa River at the western base of the Sacramento Mountains. They planted fields of vegetables and grain as well as fruit orchards on the outskirts of town and diverted water from the river to irrigate their crops. This was not the first attempt to settle the area. Two years before, a small group of farmers had cleared fields and planted crops but were driven out by the Apaches before the first harvest. A year after Tularosa was founded, another group of Hispanic emigrants, this time from the flood-ravaged Socorro area on the Rio Grande, established a colony beside La Luz Creek, 15 miles south of Tularosa. Because of the village's proximity to Apache camps in the nearby Sacramento Mountains, the residents of La Luz built an adobe fortress for defense. They also built a community ditch to irrigate fields planted with corn and wheat, and they raised small herds of cattle, sheep, and goats as well (Hawthorne 1994:14-15; Schneider-Hector 1993:42; Sonnichsen 1960:11; Townsend and McDonald 1999:95-96). An abundant supply of water and the U.S. military presence at Fort Stanton enabled these communities to grow and prosper. 


\section{Ranching}

The majority of the lands in the Tularosa Basin were unsuitable for farming owing to the lack of water, but the vast expanses of grasslands in the basin and on Otero Mesa to the east attracted ranchers from Texas, where years of drought and overgrazing had limited their opportunities. Stockraising had been one of the primary industries in New Mexico since Juan de Oñate introduced the first breeding stock of cattle and sheep in the late sixteenth century. Spanish ranchers found a market for their cattle and sheep in the mining camps of Nueva Vizcaya, in what today are the states of Chihuahua and Durango, Mexico. Cattle ranching began its climb to prominence during the 1850s, however, when the U.S. government established military garrisons across the territory in response to increased raiding by the Apache and other nomadic Indian tribes. The ranchers benefited not only from the protection offered by the military presence but also from the new market as these installations required a steady supply of beef to feed the troops (Simmons 1988:7-9; Townsend and McDonald 1999:121).

With the confinement of the nomadic Indian tribes on reservations and the near extinction of the great buffalo herds on the high plains of eastern New Mexico, the way was paved for cattlemen to drive their herds into the territory and establish ranches on the open range. By the 1880s, stockraising was the dominant economic activity in Otero County (Lowery and Gibbs 1999:39). Census figures for 1880 report 400,000 head of cattle and 5,000,000 sheep in the territory. Bust followed the boom years of the early 1880s. Nationwide, cattle prices dropped between 1884 and 1891, and severe droughts devastated the industry in 1903-1904 and 1907-1908 (Simmons 1988:11-12). The industry recovered as ranch operations became more efficient by improving breeds, sinking wells and building windmills. Federal policies established grazing districts, leases, and fees to regulate the ranchers' access to public lands.

During the period of the open range, ranchers' herds grazed on the public domain and relied on natural water sources. In 1934, Congress passed the Taylor Grazing Act to regulate grazing on federal land. Under the provisions of the act, the Grazing Service (later the BLM) of the Department of the Interior divided federal land into grazing districts and issued permits in order to manage livestock grazing within each district. This ended the open range system. Ranchers adapted to these new requirements and made improvements to leased public lands by constructing wells, windmills, and stock tanks. Such improvements, however, had to be authorized by the Grazing Service (Hawthorne-Tagg 1997:31-32).

By the outbreak of World War II, cow-calf operations were the most common ranch type in the state. These operations sold young animals and only retained breedingstock. The war created an expanded demand for beef, as ranchers contracted with the government to supply meat to military installations. During the war years (1942-1945) New Mexico ranches marketed a half-million head of cattle annually (Simmons 1988:12-13). Throughout the twentieth century, New Mexico's cattle ranching industry experienced periods of success and decline, but it has survived into the twenty-first century as a viable business enterprise. Several studies provide an extensive history of ranching in the Tularosa Basin (e.g., Faunce 2000; Hawthorne 1994; Hawthorne-Tagg 1997), so only a summary is presented in the following paragraphs.

Owing to the scarcity of water, the majority of basin and mesa lands proved more suitable for grazing livestock than for growing crops. Ranchers began moving their herds into what is now Otero County during the 1860s and early 1870s. Most of the ranchers were from Texas. They were attracted by the region's vast expanse of public domain land that was suitable for year-round grazing. Typically, ranchers resided on deeded land, where they maintained their ranch headquarters, but claimed range rights to the best water sources on the public domain where they grazed their livestock (Hawthorne-Tagg 1997:29-30).

Perhaps the most prominent Texas rancher to emigrate to the Tularosa Basin was Oliver M. Lee. He established his headquarters near Dog Canyon in the Sacramento Mountains in 1884. Over the years Lee expanded his holdings and gained control over valuable water sources in the basin and on Otero Mesa. His extensive system of wells, pipelines, and stock tanks allowed his herds to survive periods of drought that ruined other ranchers in the area (Faunce 1997:69). At one point, Lee controlled approximately one million acres of deeded land and open range, stretching from the Sacramento Mountains south to the Texas border (Townsend and McDonald 1999:127).

Public domain and state land constitute the vast majority of lands on Otero Mesa, although there are pockets of privately owned land, most of which are used for ranching. Private holdings are generally located at or near a water source. Ranchers built earthen stock tanks to collect water from natural drainage channels, or placed pipelines in areas where there was little or no surface runoff. Wells were drilled to supply water to metal stock tanks. According to Faunce (2000:281-282), well depths on Otero Mesa typically reached 1,200 to 1,500 feet. Even at these depths, wells did not always produce large amounts of water. Between 1935 and 1936, the Civilian Conservation Corps constructed earthen stock tanks and maintained existing tanks on federal land to benefit both the ranchers and the local economy (Faunce 2000:173). Today's ranchers graze their herds on state lands leased from the New Mexico State Land Office and on federal lands through the BLM. 


\section{Railroad}

The Otero Mesa study area has always been slightly removed from the state's early transportation system. During the Spanish and Mexican periods, the major north-south transportation routes were the Camino Real and the Salt Trail, both of which bypassed the study area to the west. A wagon road extending north from El Paso through the Tularosa Basin connected Fort Bliss and Fort Stanton and was frequented by soldiers traveling between the posts or in pursuit of Apaches. Beginning in 1857, the Butterfield Overland Mail route passed through a portion of the study area. This route generally followed the trail established by Captain Marcy in 1849. The Apache threat that delayed Euroamerican settlement of the Otero Mesa and Tularosa Basin likely slowed the development of major transportation routes through the region. In May 1881, after the confinement of the Apache on reservations, the Southern Pacific Railroad reached El Paso from New Mexico. Shortly thereafter plans were initiated to extend a railroad line from El Paso north through the Tularosa Basin to the coal deposits at White Oaks; however, a series of setbacks delayed construction for 16 years (Myrick 1970:58, 66-72).

South-central New Mexico remained relatively isolated until 1898. At that time, the El Paso and Northeastern Railway was extended from El Paso 85 miles north to the newly founded town of Alamogordo at the western base of the Sacramento Mountains. Alamogordo served as the headquarters of the railroad, with offices, machine shops, and a company hospital. The railroad built a line east into the Sacramento Mountains to tap the rich timber resources. Work also commenced to extend the railroad north of Alamogordo to Carrizozo and the coal fields of the Capitan Mountains. By 1902, the El Paso and Northeastern reached Santa Rosa, where it met the Rock Island Line (Myrick 1970:71-77).

The railroad brought major changes to the Tularosa Basin by connecting the region to larger markets and encouraging settlement. Area ranchers could now drive their herds to the nearest siding for shipment to national markets. Within days of the line reaching Alamogordo, prospective farmers filed homestead claims on 4,000 acres of federal land in the vicinity of the newly established town (Faunce 2000:76). Alamogordo and the surrounding communities grew at a rapid pace, and on January 30, 1899, the territorial legislature created Otero County from parts of Doña Ana, Lincoln, and Socorro counties. The county is named after Miguel A. Otero, the territorial governor at the time (Coan 1925:572). The railroad was initially built to exploit the region's coal and timber resources, but it also had a significant impact on settlement of the basin and surrounding areas. The railroad launched an era of economic development by providing relatively easy and inexpensive access to national markets. Mines and ranches also now had outlets for their products and a ready source of necessary supplies.

\section{Mining}

Apart from farming and ranching, mining was the other major economic pursuit that historically characterized southcentral New Mexico. The first group to extract mineral resources from what is now Otero County was probably the Apaches, who surface-mined turquoise in the Jarilla Mountains. Around 1841, the Refugio Mine was established in the Organ Mountains, an area known for its silver deposits since the Spanish colonial era. During the 1880s, mining began in earnest in the Jarilla Mountains with the discovery of copper, gold, silver, and iron deposits. By 1883 a number of mining operations were in full swing, including the St. Louis United Copper Company which was extracting ore from seven mining claims (Faunce 2000:85, 91).

The completion of the El Paso and Northeastern Railroad in 1898 led to increases in mining activity in the Jarillas by improving access to the area and opening markets for mineral products. A gold rush started in 1905 in the Jarillas when a prospector from Alamogordo found a large gold nugget. As more people arrived to capitalize on the mineral resources, land and town development followed. In November 1905, the South West Smelting and Refining Company laid out lots and streets at Jarilla Junction. The company also constructed a smelter for processing ore, eliminating the need to ship the ore to El Paso. In April 1906, the burgeoning community changed the name of the mining town from Jarilla Junction to Orogrande (Spanish for "Big Gold"). To facilitate growth and secure a dependable water source for the smelter and the town, the South West Smelting and Refining Company constructed a 27-mile water pipeline from the Sacramento River to Orogrande. The community grew rapidly, and by 1907 it had more than one hundred buildings, including a school, hospital, pharmacy, church, cement block factory, bank, two saloons, a water company, and headquarters for many mining companies. Prosperity did not last long once the minerals started to play out. In 1908 the South West Smelting and Refining Company abandoned the smelter, and shortly thereafter the company went bankrupt. Iron mining followed the earlier gold and copper booms but declining iron prices in the 1920s forced many of these mines to close (Faunce 2000:92-95; Townsend and McDonald 1999:83-89). 


\section{Oil and Gas Exploration}

In 1919, mineralogists and geologists discovered Pennsylvania-series fossils in the Sacramento Mountains and Tularosa Basin and thick, porous sand beneath the basin floor. Both discoveries indicated the presence of oil deposits below the surface. Once word spread of these discoveries, oil companies from California and nearby states flocked to New Mexico. This flurry of activity attracted ranchers and homesteaders, eager to get rich from the subsurface resources. By April 1919, more than 5,000 mineral claims for oil and gas exploration had been filed in the Tularosa Basin. Several local oil and gas exploration companies formed, including the Alamogordo Shale and Oil Company and Cox Oil Company, The latter was organized by W. W. Cox, a local rancher. In October, the Cox Oil Company prepared to drill its first well. Cox never struck oil. He and his shareholders lost their investments and Cox subsequently went bankrupt. By the early 1920s, few companies had struck oil. The oil craze had a significant impact on the basin and surrounding areas as speculators, ranchers, and homesteaders invested and then lost a great deal of time and money (Faunce 2000:97-100).

\section{Military}

In the mid-1930s, with the specter of war looming over Europe, the U.S. Congress enacted legislation to maintain its policy of isolation and neutrality. By the fall of 1939, Germany invaded Poland and an all-out war was raging in China. These events forced the United States to abandon neutrality and begin a massive buildup of its air, land, and sea forces. As the nation prepared for war in Europe, the Army Air Corps expanded dramatically. This expansion incorporated three major tasks: the production of aircraft, the recruiting and training of personnel, and the acquisition of land for the construction of airfields and training facilities (Cate and Williams 1983:104-105). Vast expanses of inexpensive desert land and weather suitable for flying year-round attracted military planners to the Southwest.

The Tularosa Basin, with its sparse population; vast, unencumbered airspace; and large amount of public land, was an ideal location for a military training facility. In 1942, the federal government began withdrawing public lands and condemning ranches and homesteads for the purpose of establishing the Alamogordo Bombing and Gunnery Range. As part of the land withdrawal the government suspended grazing permits, denying area ranchers access to grazing lands. Construction of Alamogordo Army Air Field, located immediately west of Alamogordo, began in 1942. Throughout the war the base served as a training facility for British pilots and American bomber crews. On July 16, 1945, the first atomic bomb was detonated at the Trinity site in the northern part of the range (Hawthorne 1994:23). The Alamogordo Bombing and Gunnery Range and Alamogordo Army Air Field were subsequently integrated into the White Sands Proving Grounds (now known as the White Sands Missile Range) at the end of the war. Alamogordo Army Air Field was renamed Holloman Air Force Base in 1947 and officially separated from the proving grounds (Lowery and Gibbs 1999:1). During the ensuing years the U.S. Air Force and Army acquired large tracts of both improved and undeveloped land to accommodate the testing and training needs of their respective forces. Military testing and training have supplanted stockraising as the primary use of the basin.

\section{A Historical Perspective on American Period Settlement and Land Tenure in the Otero Mesa Study Area}

In 1880, the study area and much of the south-central portion of the New Mexico Territory was unplatted (Cram 1880). The nearest communities were San Augustine to the west (near the Organ Mountains) and La Luz and Tularosa to the north. The earliest evidence of Euroamerican settlement in the study area appears on GLO survey plats published in 1885. In March-April 1884, a survey of the township lines and subdivisions of Township 24 South, Range 12 East (New Mexico Principal Meridian) noted a ranch in the southeast quarter of Section 29 (GLO 1885a). A survey of Township 25 South, Range 12 East, performed during the same time period, recorded a ranch in the southwest quarter of Section 10 (Figure 8.3) (GLO 1885b). Both locations are labeled "Ranch," with no other information on the plat map or in the surveyor's notes. Later GLO surveys encompassing the Otero Mesa study area recorded ranches, farmsteads, and houses. These settlements likely represent legitimate homestead claims, deeded or patented land, or squatter activity. In her study of historical settlement of Holloman AFB, Hawthorne (1994:185) suggests squatters on public land in the Tularosa Basin did not file their claims because of the distance to the nearest land office in Las Cruces, more than 70 miles away. This was probably also the case for Otero Mesa. For example, the 1912 GLO survey plat for Township 22 South, Range 13 East depicts the "Trammell's" farmstead (GLO 1912b). Adrian A. Trammell moved his family to Otero Mesa around 1898, yet he did not patent a homestead until January 11, 1919 (Faunce 1997:98; GLO 1919). How the settlers in the study area acquired their land is poorly understood and requires further research.

As noted above, the first substantial wave of settlers arrived in the southern Tularosa Basin in 1898 and filed homestead claims totaling 4,000 acres to the south and west of Alamogordo (Faunce 2000:76). Under the provisions of 


\section{HISTORICAL PERIOD LAND USE ON OTERO MESA}

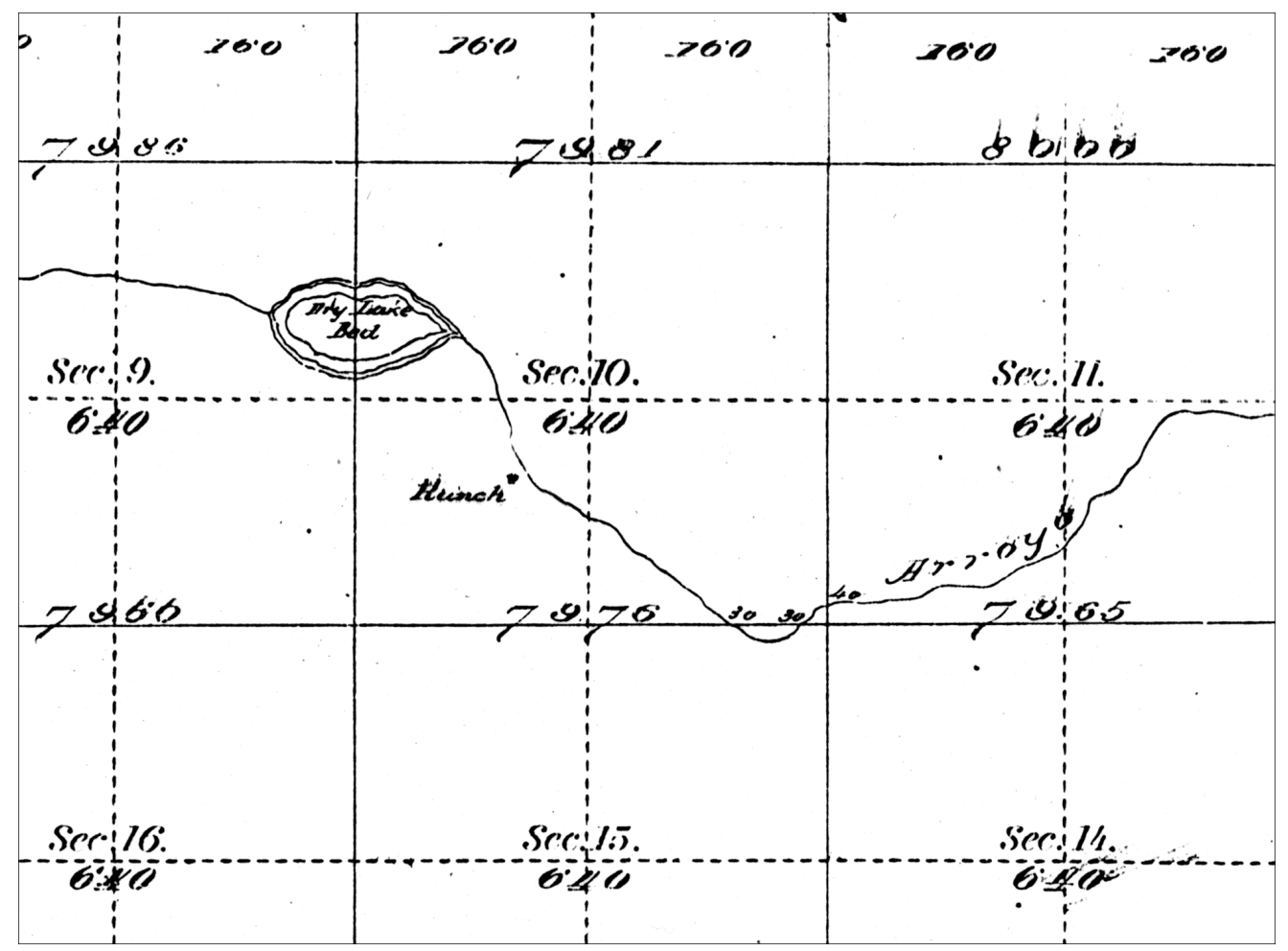

Figure 8.3. 1885 GLO survey plat of Township 25 South, Range 12 East (GLO 1885b).

the Homestead Act of 1862, U.S. citizens (or resident aliens who declared their intention of becoming U.S. citizens) could acquire up to 160 acres of free land, provided they resided on the land continuously for five years and cultivated a portion of the land in the final four years. At the end of the five-year period, and upon fulfilling the settlement requirements, claimants made final proof and received a patent for their land (Stein 1990:4). The earliest record of a patented homestead claim in the study area is 1914. On January 29 of that year Emma Kaler patented 160 acres in Township 22 South, Range 13 East, Sections 14 and 15 (GLO 1914).

Significant changes to the homestead law occurred in 1909 when Congress passed the Enlarged Homestead Act, also known as the Dry Farming Homestead Act. Most land in the western United States was too arid for growing highly water-dependent crops, but proponents of the act believed that by employing dry farming techniques the land could be productive. Successful dry farming required an annual rainfall of more than 10 inches, emphasizing the cultivation of drought-tolerant crops, plowing deeply in the fall, and harrowing the soil during fallow periods to help it retain moisture. Under the provisions of the act, each claimant received up to 320 acres of non-irrigable, non-mineral land (land for which the federal government retains rights to subsurface mineral deposits) that required five years of continuous residence and a graduated scale of cultivation before a patent was issued. Congress, in an effort to promote the settlement of public land, reduced the five-year residency requirement to three years in 1912 (Layton 1988:21; Stein 1990:5).

Evidence of farming within the study area is depicted on a GLO survey plat filed in 1912 (Figure 8.4) (GLO 1912b). Three cultivated fields and several flood ditches (presumably used for diverting seasonal floodwater from the normally dry Sacramento River) are shown on the portion of the township that lies in the study area. Two of the fields are clearly associated with the residences of Don Porter and Adrian A. Trammell, located in Sections 14 and 21, respectively. Both Trammell and Porter were enumerated in the 1910 census. Trammell gave his occupation as "farmer" and Porter, who was enumerated with the family of John A. Prather as a hired hand, listed "horse trainer" as his occupation (U.S. Bureau of the Census 1910a). The 1920 census lists Trammell as "farmer." Porter's name does not appear in either the 1920 or 1930 censuses (U.S. Bureau of the Census 1920a, 1930a). Several small farming operations were underway in the vicinity of Orange, New Mexico, located in Township 26 South, Range 18 East (Figure 8.5) (GLO 1912a). Dry farming on the marginal lands of south-central New Mexico was a risky endeavor. Extended periods of droughts during the 1920s and 1930s effectively ended dry farming in Otero County, and farmers either sold their land to ranchers in the area or relinquished their homestead claims to the government (Townsend and McDonald 1999:104). 


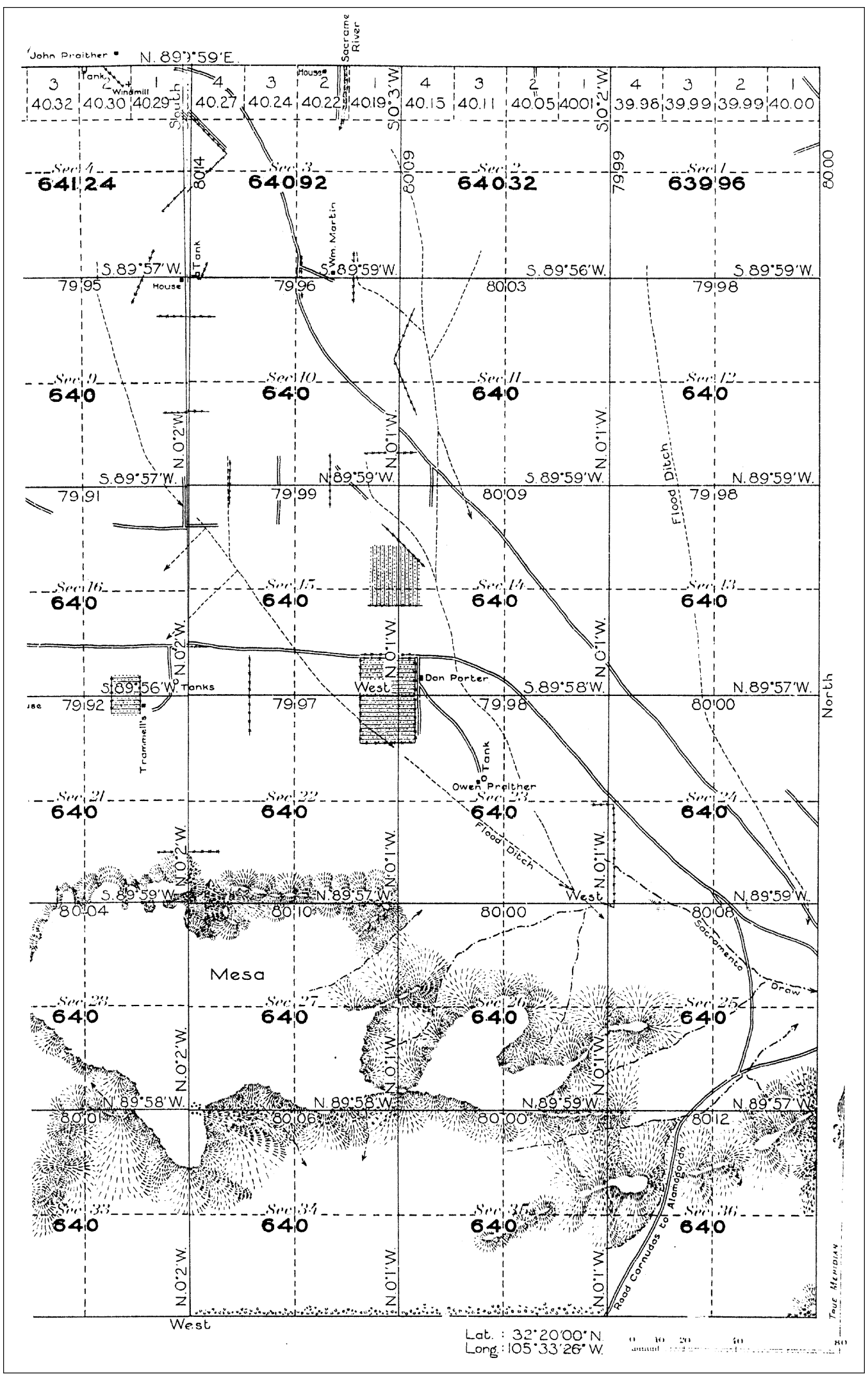

Figure 8.4. 1912 GLO survey plat of Township 22 South, Range 13 East depicting cultivated fields and floodwater ditches in study area (GLO 1912b). 


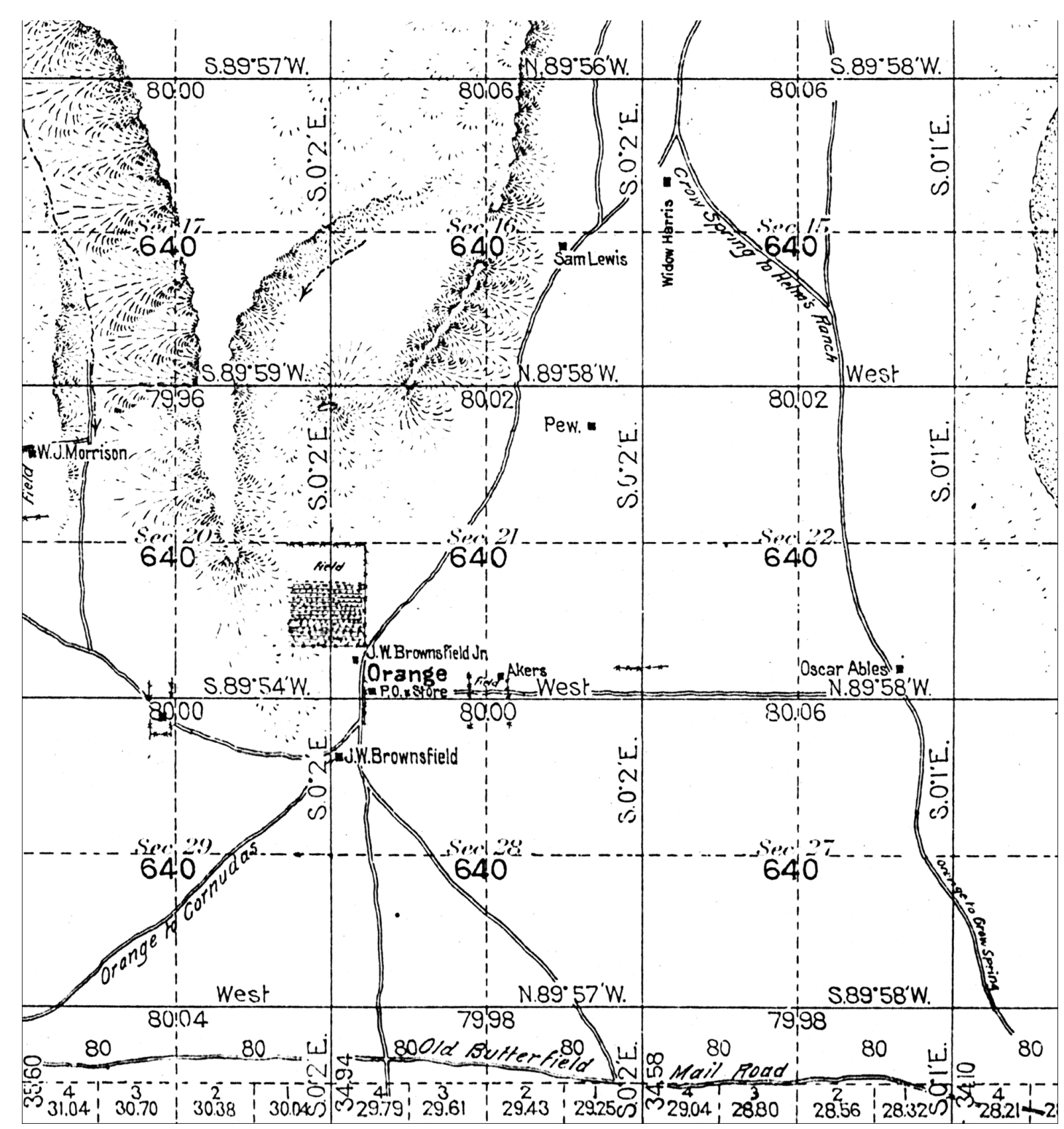

Figure 8.5. 1912 GLO survey plat of Township 26 South, Range 18 East. Note the route of the Butterfield Overland Mail shown at the bottom (GLO 1912a).

In 1916 Congress passed another homestead law, the Stock Raising Homestead Act, to promote the settlement of non-irrigable and non-mineral remnant lands with no commercial timber. The act (also known as the Grazing Homestead Act) provided for homesteads of 640 acres on land valued primarily for grazing livestock and producing forage crops. While claimants did not have to cultivate the land, the act required improvements of $\$ 1.25$ per acre before a patent was issued (Layton 1988:61). Both the Enlarged Homestead and Stock Raising Homestead Acts altered the landscape in Otero County by allowing settlers to claim larger parcels of land.

The Prather family is representative of those who emigrated to Otero Mesa to try their hands at farming and ranching. John Ellis Prather abandoned his farm in Van Zandt County, Texas, in 1884, after a devastating drought. The family traveled by train and wagon to New Mexico where they homesteaded 160 acres on the Agua Chiquita River in the Sacramento Mountains. Around 1898, John E. Prather and his wife, Mattie Browning Prather, moved to the area on Otero Mesa where the Sacramento River empties into the flat lands. They dry farmed, relying on a combination of rainfall and floodwater diverted from the Sacramento River. Other farmers by the names of Grisak, Langford, Martin, Trammell, and Van Winkle also homesteaded this area, known as "the flats" (Tularosa Basin Historical Society 1981:387-388). 
John E. Prather's sons—-Samuel (Tink), John A., and Owen — preferred ranching to farming and soon amassed their own land and livestock (Tularosa Basin Historical Society 1981:388). Shortly after settling on the flats, the Prathers purchased homesteads from those who failed to prove up their claims (Faunce 2000:223). Like other successful ranchers in the area, they bought up land both to increase their holdings and to obtain additional, reliable water sources for their herds. By the 1950s, John A. Prather's ranch encompassed 4,000 acres of deeded land and 20,000 acres of leased federal and state land. He mainly raised horses and mules, both of which require less water and forage than cattle (Faunce 2000:308; Tularosa Basin Historical Society 1981:389). In 1956, the U.S. Army, as part of its plan to expand the McGregor Guided Missile Range, attempted to purchase Prather's deeded land and grazing leases. Prather refused to sell and the federal government proceeded to condemn his land. After three years of trying to evict Prather, and much negative publicity, the Army settled with Prather, giving him $\$ 106,985$ for his property and a lifetime lease on his ranch house and 15 surrounding acres. Prather died in 1965 and is buried on his ranch, which is now part of McGregor Range (Faunce 1997:125).

Several farming and ranch communities sprang up in the study area, each with its own post office. Between June 1898 and May 1900, a post office distributed mail in the area known as Crow Flat. The now-abandoned town of Orange, located less than 2 miles north of the New Mexico-Texas border, maintained a post office from May 19, 1904, to May 29, 1925 (Julyan 1996:250). Around 1912, the post office was housed in a store located on the east side of the road connecting Orange to the community of Weed in the Sacramento Mountains (GLO 1912a). To the northwest of Orange, in the area settled by the Prathers and Trammels, the Lulu Post Office served the community between August 22, 1913, and August 31, 1923. The settlement known as Cienega was located in the southeast part of Otero County, approximately four miles north of the New Mexico-Texas border. A post office was established on March 31, 1927, and later discontinued on February 28, 1942 (Tularosa Basin Historical Society 1985:xi).

During the late nineteenth and early twentieth centuries, school-age children in the diffusely populated region were educated by their parents, or in the case of families with the financial means, by private teachers who worked for wages as well as room and board (Tularosa Basin Historical Society 1981:388). The Otero County Board of Education established public schools in the communities of Orange and Lulu around 1920, possibly earlier. Orange was designated as District 19 and Lulu District 20 (Figure 8.6) (Otero County Board of Education 1921). In the spring of 1921, District 19 had an enrollment of 22 students. The following is a description of the District 19 school written by the school's students.

Our school house is located in a valley; on the west are low hills and on the east are the beautiful Guadalupe Mountains. The winters here are warm and pleasant except for an occasional snowstorm which lasts only a few days.

We have a large playground with a well and pump in the southeast corner. The school building is a one story adobe building. The outside is pebble-dashed and the inside is plastered. The ceiling is painted a light green.

The room is heated by a large stove in the center of the room, and is lighted and ventilated by large double windows. There are three rows of double seats.

We have a set of reference books, several supplementary books, maps, a globe and a new unabridged dictionary.

We have an organ and have opening exercises every morning. On the different holidays we have some splendid programs. The house was beautifully decorated at Christmas and the tree and program were enjoyed. There is a Sunday school each Sunday.

We are proud of our little school and would be glad to have anyone visit it and let us show what we are doing [Otero County Board of Education 1921:30-31].

Families in District 20 sent their children to the school at Lulu. The community was situated in the upper center of Township 22 South, Range 13 East along the road that extended southeast to Orange (see Figure 8.4). Mrs. J. R. McMurrough served as teacher for the 1920-1921 school year with a total enrollment of 12 students (Otero County Board of Education 1921:32). Little is known about the communities of Orange and Lulu. Further archival and oral historical research may yield valuable information on these now-abandoned villages.

\section{Analysis of Census Records}

Archival research included the review of decennial census records for the years 1910, 1920, and 1930. Settlers on lands within the Otero Mesa study area were enumerated in Precincts 12 and 14. Precinct 12 covered the eastern portion of the Otero Mesa study area and included the settlement of Orange and part of Alamo (Guadalupe) National Forest. Precinct 14 incorporated the western portion of the study area, including Lulu and part of Alamo (Sacramento) National Forest.

The 1910 New Mexico Territorial Census enumerated 176 residents in Precinct 12, and 184 in Precinct 14 (U.S. Bureau of the Census 1910b). E. O. Brownfield, the enumerator for both precincts, recorded the road between Pinon 


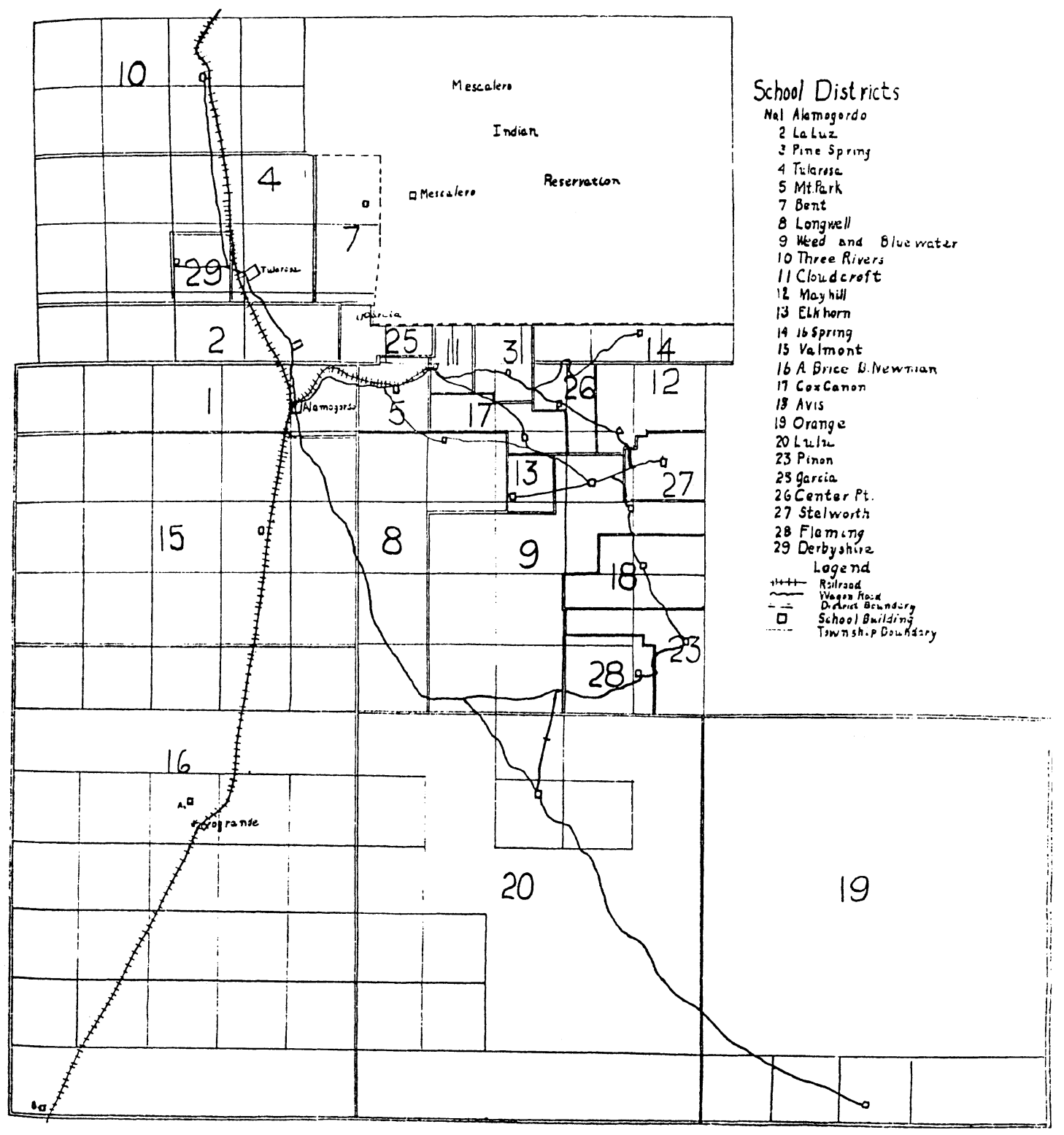

Figure 8.6. Map of Otero County school districts (Otero County Board of Education 1921:12).

and Orange as the general location of those counted in Precinct 12, and the Sacramento River Road as the at-large address of those enumerated in Precinct 14 (U.S. Bureau of the Census 1910a, 1910c). Sixty-four of the 176 residents in Precinct 12 were employed, with 44 engaged in ranching. Of those 44, 27 owned their ranching operations. Only three farmers were listed in the precinct (U.S. Bureau of the Census 1910c). In Precinct 14, 59 of 186 were employed, with 30 engaged in ranching. Another 16 gave their occupation as "farmer" (U.S. Bureau of the Census 1910a). Other occupations in Precincts 12 and 14 included a store merchant, freighter, two teachers for private families, several well drillers, horse tamers, carpenters, and general laborers (U.S. Bureau of the Census 1910a, 1910c).

By 1920, 153 people resided in Precinct 12. Sixty-three were employed and 38 of those were engaged in ranching (21 ranch owners/operators; 17 ranch hands). None was involved in commercial farming. Two teachers were enumerated; one taught on a ranch, the other at the Orange School (U.S. Bureau of the Census 1920b). Census figures for Precinct 14 dropped dramatically from 186 in 1910 to 80 in 1920. Among the 40 who were employed, 38 were engaged in ranching. Interestingly, the ranch laborers (35) far outnumbered the ranch owners (3). Census records listed the remaining two individuals as a farmer and a public school teacher (U.S. Bureau of the Census 1920a). 
The 1930 census recorded 51 residents in Precinct 12, a significant drop from the 153 enumerated 10 years earlier. Of the 18 who gave their occupational status, all were engaged in ranching, with 12 ranch owners and 6 laborers (U.S. Bureau of the Census 1930b). Only 25 residents were enumerated in Precinct 14, with seven in ranching. Of particular note is that one of the ranchers raised sheep (U.S. Bureau of the Census 1930a).

Both farming and ranching were difficult endeavors, requiring the acquisition and effective management of water. As stated previously, farming on Otero Mesa with its dry, harsh climate proved difficult at best. Homesteaders likely had a false perception of the land, believing there was enough water for successful dry farming. This is supported by an analysis of the census records for Precincts 12 and 14, as the number of farmers diminished over the years. By 1930, the census records no longer document farming activity (U.S. Bureau of the Census 1930a, 1930b). Ranching proved to be the dominant and enduring economic activity on Otero Mesa, largely because it was easier to graze livestock than grow crops with a limited amount of water. Ranching on the Otero Mesa was still a challenge and many ranches failed, as evidenced by the census figures for the period 1910-1930. For example, census records for 1910 indicate there were 27 independent ranchers in Precinct 12. By 1920, the number of ranchers had dropped slightly to 21 . Ten years later the number had dwindled to 12. For the same time period, the number of ranch laborers in Precinct 12 diminished from 26 in 1920 to only 6 in 1930 (U.S. Bureau of the Census 1910c, 1920b, 1930b). This suggests decreases in herd size within the area. Successful ranchers developed wells, stock tanks, and pipelines to control scarce water resources.

\section{General Land Office Transactions in the Study Area}

To document Otero Mesa settlement patterns, SRI searched the GLO files at the Las Cruces BLMoffice and accessed the BLM's Internet database of GLO records (http://www.glorecords.blm.gov/). The GLO records search encompassed all lands within the Otero Mesa study area, as depicted on current USGS 7.5-minute-series topographic maps.

Table 8.1 summarizes the results of this research and lists the completed GLO transactions in the study area. The parcel distribution covered by these transactions is depicted on maps in the Appendix. It should be noted that only successful claims and cash sales are included in the table and on the corresponding maps. The maps also represent only the earliest claimant for a parcel and do not reflect later ownership of parcels.

The 56 transactions in Table 8.1 span the years 1914-1969, with an unequal distribution by decade (1910-1919, $n=13 ; 1920-1929,23 ; 1930-1939,14 ; 1940-1949,0 ; 1950-1959,1 ; 1960-1969,5)$. Of the 56 transactions, five were cash sales, five were obtained under the Desert Land Act, one was an exchange for National Forest land, one was a private land claim, 14 were homestead patents, 13 were obtained under the Enlarged Homestead Act, and 17 were authorized under the Stock Raising Homestead Act. The settlement distribution is fairly uneven throughout the study area. The largest concentration of parcels is in the area known as Crow Flat (near the former town of Orange), located in Townships 25 and 26 South, Range 18 East (Cienega School, New Mexico, 7.5-minute quadrangle). The largest land transaction consists of several noncontiguous parcels comprising 13,193 acres patented by the Otero Investment Company. (Oliver M. Lee, a powerful rancher and businessman, teamed with El Paso banker James G. McNary to form the Otero Investment Company in 1930 as a means to acquire the struggling Circle Cross Cattle Company.) In 1936, the Otero Investment Company received a legal land patent to 62,013 acres, of which 13,193 lie within the study area ([Faunce 1997:70; GLO 1936].). Table 8.1 is a composite of land ownership and does not provide a complete picture of settlement for the period 1914-1969.

In addition to the GLO transactions, SRI consulted GLO survey plats filed between 1885 and 1939. The locations of constructed features (e.g., buildings, fields, water storage and conveyance features, and other structures) depicted on the GLO survey plats were digitized and overlaid onto current USGS topographic maps (see Appendix). Tables 8.2 and 8.3 present the data obtained from the GLO plats.

\section{Summary}

A review of GLO survey plats, records of patented claims, and census figures indicate a sizeable number of ranchers and homesteaders settled in the study area, with the period of greatest settlement occurring around 1900-1930. The focus for survival in this arid region has always been on water and the ability to secure and manage an adequate supply. Struggling to carve out a livelihood in the dry climate of Otero Mesa, settlers modified the landscape with buildings, fence lines, water control features, and other structures. Stockraising operations dominated the landscape on Otero Mesa, although periods of boom and bust caused some ranching operations to fail. Despite these hardships, some ranchers succeeded and ranching remains the primary economic activity on Otero Mesa. 


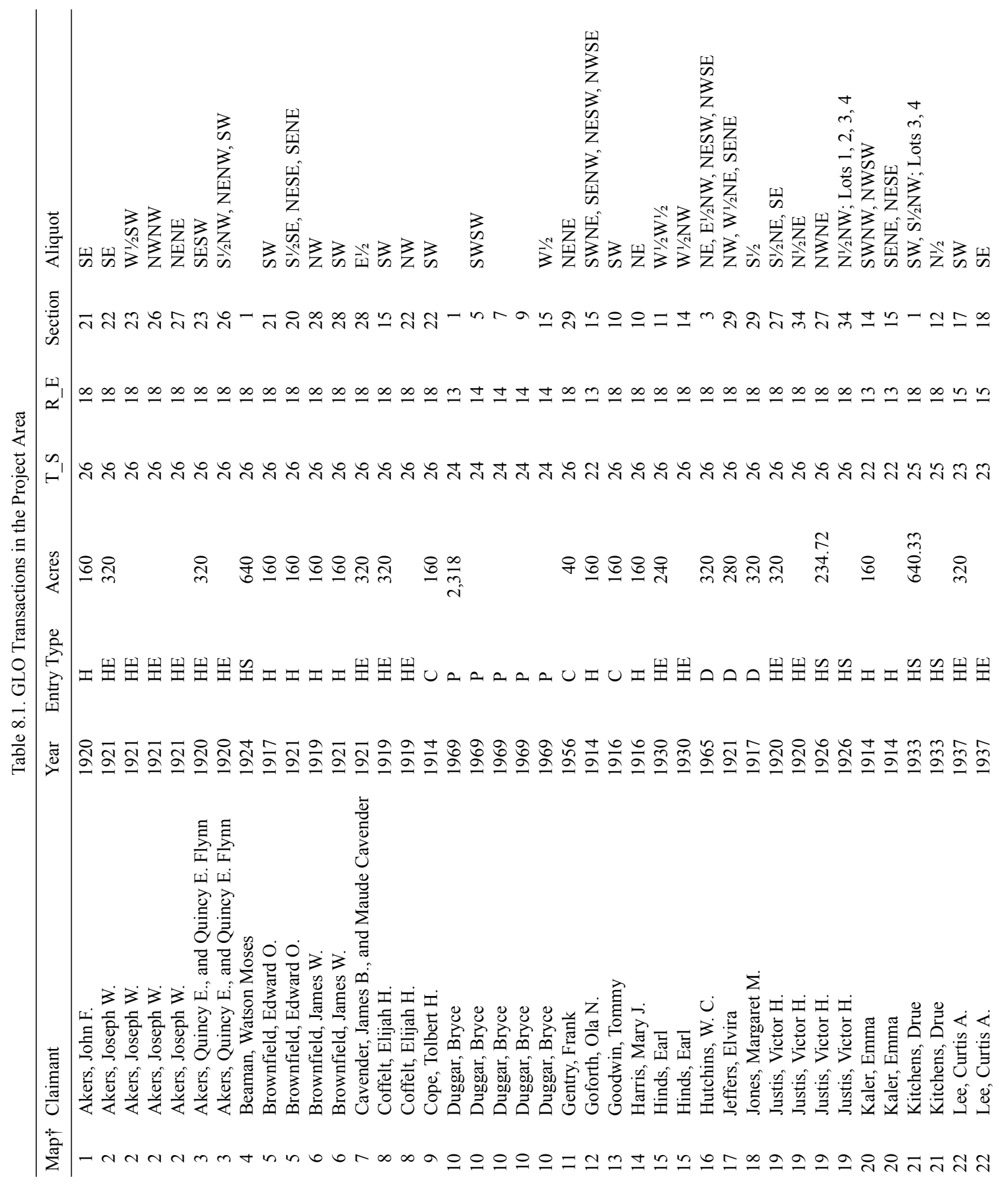




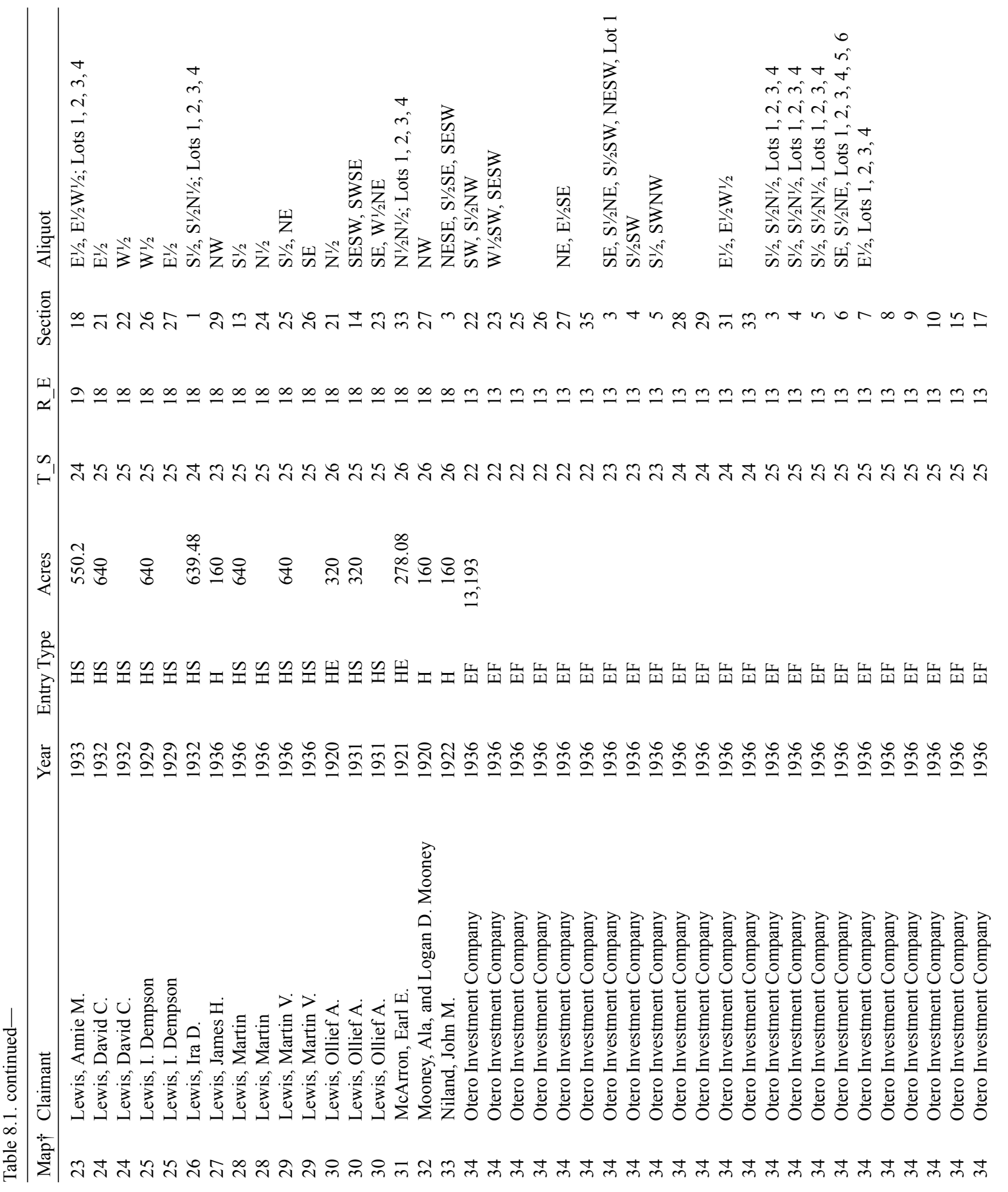




\section{HISTORICAL PERIOD LAND USE ON OTERO MESA}

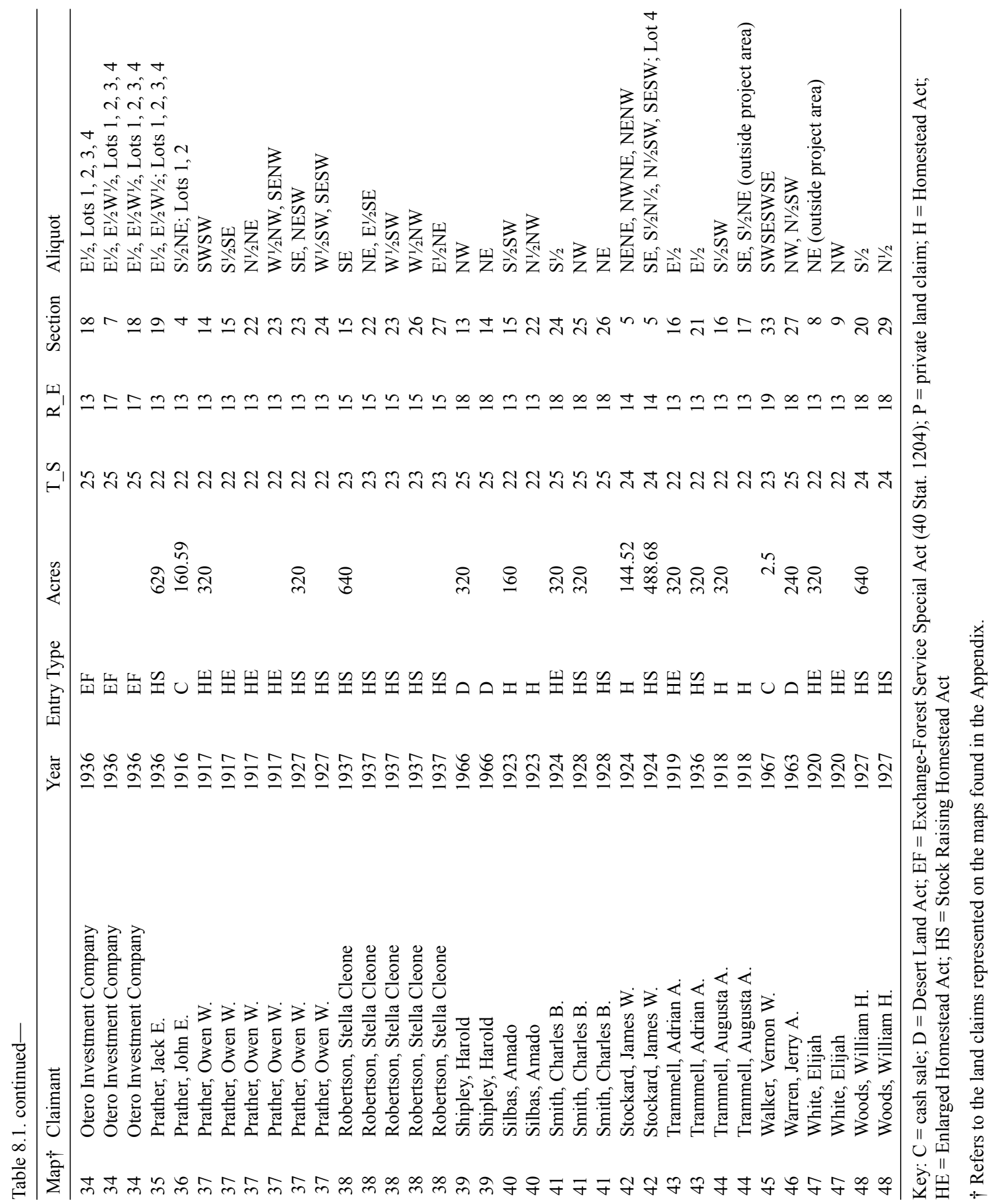


Table 8.2. Buildings and Cultivated Fields as Depicted on General Land Office Survey Plats, 1885-1926

\begin{tabular}{|c|c|c|c|c|c|c|}
\hline Map $\dagger$ & Feature Name on Map & Feature Type & T_S & R_E & Section & GLO Date \\
\hline 1 & Akers & Building & 26 & 18 & 21 & 1912 \\
\hline 2 & Orange Post Office and store & Building & 26 & 18 & 21 & 1912 \\
\hline 3 & Field & Field & 26 & 18 & 21 & 1912 \\
\hline 4 & Field & Field & 26 & 18 & 20,21 & 1912 \\
\hline 5 & J. W. Brownsfield, Jr. & Building & 26 & 18 & 21 & 1912 \\
\hline 6 & J. W. Brownsfield & Building & 26 & 18 & 28 & 1912 \\
\hline 7 & Sam Lewis & Building & 26 & 18 & 16 & 1912 \\
\hline 8 & Pew & Building & 26 & 18 & 21 & 1912 \\
\hline 9 & Widow Harris & Building & 26 & 18 & 15 & 1912 \\
\hline 10 & Oscar Ables (sic) & Building & 26 & 18 & 23 & 1912 \\
\hline 11 & Turney & Building & 26 & 18 & 3 & 1912 \\
\hline 12 & Field & Field & 26 & 18 & 3 & 1912 \\
\hline 13 & House & Building & 25 & 18 & 35 & 1921 \\
\hline 14 & House & Building & 25 & 18 & 25 & 1921 \\
\hline 15 & House $\left(\mathrm{SE}^{1} / 4\right)$ & Building & 25 & 18 & 24 & 1921 \\
\hline 16 & House & Building & 25 & 18 & 12 & 1921 \\
\hline 17 & Ranch house & Building & 25 & 18 & 8 & 1921 \\
\hline 18 & Ranch house (NE $1 / 4)$ & Building & 25 & 18 & 21 & 1921 \\
\hline 19 & Ranch house (SE1/4) & Building & 25 & 18 & 21 & 1921 \\
\hline 20 & M. Lewis & Building & 24 & 17 & 27 & 1921 \\
\hline 21 & Wood's Ranch & Building & 24 & 18 & 29 & 1921 \\
\hline 22 & Sam Lewis & Building & 24 & 19 & 18 & 1921 \\
\hline 23 & P. H. Walde & Building & 22 & 14 & 30 & 1912 \\
\hline 24 & Chester Stephens & Building & 22 & 14 & 4 & 1912 \\
\hline 25 & F. Williams & Building & 23 & 12 & 23 & 1919 \\
\hline 26 & House & Building & 24 & 13 & 35 & 1921 \\
\hline 27 & Vacant house & Building & 24 & 13 & 10 & 1921 \\
\hline 28 & Ranch & Building & 24 & 13 & 32 & 1921 \\
\hline 29 & Stone house & Building & 26 & 13 & 19 & 1926 \\
\hline 30 & Corral & Corral & 26 & 13 & 19 & 1926 \\
\hline 31 & Ranch & Building & 25 & 12 & 10 & 1885 \\
\hline 32 & Ranch & Building & 24 & 12 & 29 & 1885 \\
\hline 33 & Don Porter & Building & 22 & 13 & 14 & 1912 \\
\hline 34 & Owen Prather & Building & 22 & 13 & 23 & 1912 \\
\hline 35 & & Field & 22 & 13 & 14,15 & 1912 \\
\hline 36 & & Field & 22 & 13 & $14,15,22,23$ & 1912 \\
\hline 37 & Trammell's & Building & 22 & 13 & 21 & 1912 \\
\hline 38 & Field & Field & 22 & 13 & 16,21 & 1912 \\
\hline 39 & & Building & 25 & 17 & 5 & 1921 \\
\hline 40 & House & Building & 22 & 13 & 9 & 1912 \\
\hline 41 & House & Building & 22 & 13 & 3 & 1912 \\
\hline 42 & William Martin & Building & 22 & 13 & 3 & 1912 \\
\hline 43 & House $\left(\mathrm{NW}^{1} / 4\right)$ & Building & 25 & 18 & 24 & 1921 \\
\hline 44 & House & Building & 24 & 14 & 28 & 1920 \\
\hline
\end{tabular}

$\dagger$ Refers to the historic features depicted on the maps found in the Appendix. 


\section{HISTORICAL PERIOD LAND USE ON OTERO MESA}

Table 8.3. Water Storage and Conveyance Features as Depicted on General Land Office Survey Plats, 1885-1927

\begin{tabular}{|c|c|c|c|c|c|c|}
\hline Map $\dagger$ & Feature Name on Map & Feature Type & T_S & R_E & Section & GLO Date \\
\hline 1 & & Windmill & 25 & 18 & 35 & 1921 \\
\hline 2 & & Well & 25 & 18 & 35 & 1921 \\
\hline 3 & Tank & Tank & 24 & 17 & 6 & 1921 \\
\hline 4 & Wood's Ranch & Well & 24 & 18 & 29 & 1921 \\
\hline 5 & Wood's Ranch & Windmill & 24 & 18 & 29 & 1921 \\
\hline 6 & Windmill & Windmill & 24 & 18 & 11 & 1921 \\
\hline 7 & & Well & 24 & 18 & 11 & 1921 \\
\hline 8 & Windmill & Windmill & 24 & 18 & 36 & 1921 \\
\hline 9 & Windmill & Windmill & 24 & 18 & 36 & 1921 \\
\hline 10 & Sam Lewis & Windmill & 24 & 19 & 18 & 1921 \\
\hline 11 & Windmill and well & Windmill, well & 23 & 18 & 9 & 1927 \\
\hline 12 & Windmill and well & Windmill, well & 23 & 18 & 22 & 1927 \\
\hline 13 & Tank & Tank & 23 & 12 & 16 & 1919 \\
\hline 14 & Jernigan windmill & Windmill & 24 & 13 & 35 & 1921 \\
\hline 15 & Dirt tanks & Tank & 24 & 13 & 26 & 1921 \\
\hline 16 & Tank & Tank & 26 & 13 & 18 & 1926 \\
\hline 17 & Tank & Tank & 26 & 13 & 19 & 1926 \\
\hline 18 & Cistern & Cistern & 26 & 13 & 19 & 1926 \\
\hline 21 & Tank & Tank & 22 & 12 & 25 & 1919 \\
\hline 23 & Dry surface tank & Tank & 26 & 12 & 32 & 1926 \\
\hline 24 & Tank & Tank & 24 & 14 & 29 & 1920 \\
\hline 25 & Windmill & Windmill & 24 & 14 & 28 & 1920 \\
\hline 27 & Well & Well & 24 & 14 & 5 & 1920 \\
\hline 28 & Tank & Tank & 25 & 17 & 11 & 1921 \\
\hline 29 & Tank & Tank & 25 & 17 & 12 & 1921 \\
\hline 30 & Tank & Tank & 25 & 13 & 14 & 1926 \\
\hline 31 & Dry Lake Bed & Tank & 25 & 12 & 10 & 1885 \\
\hline 32 & Tank & Tank & 22 & 13 & 16 & 1912 \\
\hline 33 & Tank & Tank & 22 & 13 & 3 & 1912 \\
\hline 34 & Windmill & Windmill & 22 & 13 & 4 & 1912 \\
\hline 35 & Tank & Windmill & 22 & 13 & 4 & 1912 \\
\hline
\end{tabular}

$\dagger$ Refers to the historic features depicted on the maps found in the Appendix. 


\section{References Cited}

Cate, James L., and E. Kathleen Williams

1983 The Air Corps Prepares for War, 1939-41. In The Army Air Forces in World War II, Vol. One: Plans and Early Operations, January 1939 to August 1942. Reprinted. Office of Air Force History, Washington, D.C. Originally published 1948, University of Chicago Press, Chicago.

Coan, Charles F.

1925 A History of New Mexico, Vol. I. American Historical Society, Chicago.

Conkling, Roscoe B., and Margaret B. Conkling

1947 The Butterfield Overland Mail, 1857-1869. 3 vols. Arthur H. Clark, Glendale, California.

Cram, George Franklin

1880 Railroad and Township Map of New Mexico. Western Map Depot, Chicago. On file, University of Arizona Special Collections, Tucson.

Culbert, James I.

1941 Cattle Industry of New Mexico. Economic Geography 17:155-168.

Faunce, Kenneth V.

1997 The Fort Bliss Preacquisition Project: A History of the Southern Tularosa Basin. Conservation Division, Directorate of Environment, U.S. Army Air Defense Artillery Center, Fort Bliss, Texas.

2000 The Perception of Landscape in the Use and Settlement of the Tularosa Basin, New Mexico. Unpublished Ph.D. dissertation, Department of History, University of Idaho, Moscow.

General Land Office (GLO)

1885a Survey Plat of Township 24 South, Range 12 East, New Mexico Principal Meridian. On file, Bureau of Land Management, Las Cruces Office, New Mexico.

1885b Survey Plat of Township 25 South, Range 12 East, New Mexico Principal Meridian. On file, Bureau of Land Management, Las Cruces Office, New Mexico.

1912a Survey Plat of Township 26 South, Range 18 East, New Mexico Principal Meridian. On file, Bureau of Land Management, Las Cruces Office, New Mexico.

1912b Survey Plat of Township 22 South, Range 13 East, New Mexico Principal Meridian. On file, Bureau of Land Management, Las Cruces Office, New Mexico.

1914 Legal Land Patent, Emma Kaler, Serial Number 380956. U.S. Department of the Interior, Bureau of Land Management, Washington, D.C. <http://www.glorecords.blm.gov/>

1919 Legal Land Patent, Adrian A. Trammell, Serial Number 658593. U.S. Department of the Interior, Bureau of Land Management, Washington, D.C. <http://www.glorecords.blm.gov/>

1926 Survey Plat of Township 26 South, Range 13 East, New Mexico Principal Meridian. On file, Bureau of Land Management, Las Cruces Office, New Mexico.

1936 Legal Land Patent, Otero Investment Company, Serial Numbers 0041723, 0042196, 0042430. U.S. Department of the Interior, Bureau of Land Management, Washington, D.C. <http:// www.glorecords.blm.gov/>

Gerow, Peggy A.

1996 Along the Butterfield Trail II: A Reconnaissance Survey of 12 miles in the Cornudas and Alamo Mountains, New Mexico. UNM/OCA 185-541. Office of Contract Archeology, University of New Mexico, Albuquerque.

Greene, A. C.

1994900 Miles on the Butterfield Trail. University of North Texas Press, Denton.

Hawthorne, Lori S.

1994 INever Left a Place That I Didn't Clean Up: The Legacy of Historic Settlement on Lands Administered by Holloman Air Force Base. Cultural Resources Publication No. 1. U.S. Department of Defense, U.S. Air Force, Air Combat Command, Holloman Air Force Base, New Mexico.

Hawthorne-Tagg, Lori S.

1997 A Life Like No Other: Ranch Life on Lands Now Administered by Holloman Air Force Base. Cultural Resources Publication No. 4. U.S. Department of Defense, U.S. Air Force, Air Combat Command, Holloman Air Force Base, New Mexico.

Julyan, Robert

1996 The Place Names of New Mexico. University of New Mexico Press, Albuquerque. 


\section{HISTORICAL PERIOD LAND USE ON OTERO MESA}

Layton, Stanford J.

1988 To No Privileged Class: The Rationalization of Homesteading and Rural Life in the Early Twentieth-Century American West. Charles Redd Center for Western Studies, Brigham Young University, Provo, Utah.

Lowery, Chris, and Victor Gibbs

1999 Projectile Points, Potsherds, Horseshoes, and Hand Grenades: Evidence of the Human Legacy on Holloman Air Force Base From a Cultural Resource Sample Survey, Otero County, New Mexico, Vol. I. U.S. Department of Defense, U.S. Air Force, Air Combat Command, Holloman Air Force Base, New Mexico.

Mehren, Lawrence L.

1969 A History of the Mescalero Apache Reservation, 1869-1881. Unpublished Master's thesis, Department of History, University of Arizona, Tucson.

Myrick, David F.

1970 New Mexico’s Railroads: An Historical Survey. Colorado Railroad Museum, Golden.

Otero County Board of Education

1921 The Rural Schools of Otero County New Mexico, 1920-1921. On file, Alamogordo Public Library, Alamogordo, New Mexico.

Sale, Mark, Victor Gibbs, Melinda Landreth, Moira Ernst, and Brian McCarson

1996 North Main Base Cultural Resources Survey, Holloman Air Force Base, Otero County, New Mexico, Vol. 1. Geo-Marine, Plano, Texas.

Schneider-Hector, Dietmar

1993 White Sands: The History of a National Monument. University of New Mexico Press, Albuquerque.

Simmons, Marc

1988 The Rise of New Mexico Cattle Ranching. El Palacio 93(3):5-13.

Sonnichsen, C. L.

1960 Tularosa: Last of the Frontier West. Devin-Adair Company, New York.

Stein, Pat H.

1990 Homesteading in Arizona: 1862-1940. Arizona State Historic Preservation Office, Phoenix.

Townsend, David, and Cliff McDonald

1999 Centennial: Where the Old West Meets the New Frontier. Alamogordo/Otero County Centennial Celebration, Alamogordo, New Mexico.

Tularosa Basin Historical Society

1981 Otero County Pioneer Family Histories, Vol. 1. Tularosa Basin Historical Society, Alamogordo, New Mexico.

1985 Otero County Pioneer Family Histories, Vol. 2. Tularosa Basin Historical Society, Alamogordo, New Mexico.

United States Bureau of the Census

1910a Thirteenth Census of the United States, Enumeration District 140, Precinct 14, Otero County, New Mexico. National Archives and Records Administration, Washington, D.C.

1910b State of New Mexico, Supervisor's District, Plan of Division into Enumeration Districts, Vol. 27. National Archives and Records Administration, Washington, D.C.

1910c Thirteenth Census of the United States, Enumeration District 140, Precinct 12, Otero County, New Mexico. National Archives and Records Administration, Washington, D.C.

1920a Fourteenth Census of the United States, Enumeration District 140, Precinct 14, Otero County, New Mexico. National Archives and Records Administration, Washington, D.C.

1920b Fourteenth Census of the United States, Enumeration District 140, Precinct 12, Otero County, New Mexico. National Archives and Records Administration, Washington, D.C.

1930a Fifteenth Census of the United States, Enumeration District 140, Precinct 14, Otero County, New Mexico. National Archives and Records Administration, Washington, D.C.

1930b Fifteenth Census of the United States, Enumeration District 140, Precinct 12, Otero County, New Mexico. National Archives and Records Administration, Washington, D.C. 



\title{
C H A P T E R \\ 9 \\ Conclusions and Management Recommendations
}

\author{
Lynne Sebastian, Eric Ingbar, and David W. Cushman
}

\begin{abstract}
$\Delta$
In Chapter 2 we introduced the concept of adaptive management, which can be defined as a systematic process for continually improving management policies and practices by learning from the outcomes of operational programs. As noted in that chapter, one of the problems faced by BLM managers and cultural resource staff in southeastern New Mexico is that the sheer volume of oil and gas development has created a situation in which management of cultural resources is stuck at the implement solution step in this process. At current staffing levels, simply keeping up with the flood of applications for permits to drill, rights-of-way, and other exploration and development actions is so timeconsuming that there is little opportunity to monitor and evaluate the results of current practices, much less design adjustments to that process.

The New Mexico Pump III project is an initial effort to determine what the results of current practices have been, both for cultural resource management and for oil and gas development, to evaluate those results, and to propose adjustments. Chapter 2 described the current process for cultural resource management and oil and gas leasing and development in southeast New Mexico and identified areas where the current process is viewed as problematic within the BLM and by stakeholders in both the historic preservation and oil and gas communities. Chapters 5, 6, and 7 presented and evaluated current data on cultural resource management in three study areas - the mature oil and gas field of Loco Hills, the developing field of Azotea Mesa, and the proposed field of Otero Mesa - and provided information and management tools that will be used to support process

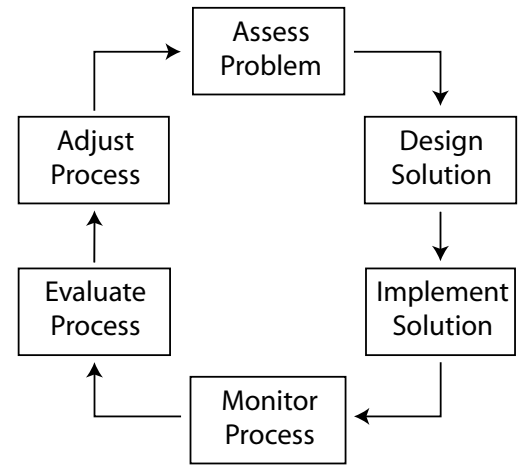
evaluations and proposed adjustments described in this chapter.

In developing the management recommendations offered in this chapter we were guided by two principles. The first principle is balance between the need for energy development on the public lands and the stewardship and multipleuse mandates of public land management agencies. The National Environmental Policy Act and the National Historic Preservation Act use the following virtually identical words in describing the balanced approach envisioned by Congress:

NEPA says:

It is the continuing policy of the Federal Government ... to create and maintain conditions under which man and nature can exist in productive harmony, and fulfill the social, economic, and other requirements of present and future generations of Americans.

NHPA says:

It shall be the policy of the Federal Government ... to foster conditions under which our modern society and our prehistoric and historic resources can exist in productive harmony and fulfill the social, economic, and other requirements of present and future generations.
\end{abstract}

The second principle governing our recommendations is feasibility. There are many management strategies that would greatly facilitate planning for and management of archaeological resources in oil and gas fields. The ideal situation would be one in which all archaeological sites in a prospective field would be identified and evaluated for eligibility to the National Register before the first lease sale was even planned. Under this dream scenario, a Resource Management Plan (RMP) amendment would then be completed to provide protection for the most significant sites and perhaps for a representative sample of all site types. Then a data recovery program would be completed to recover information from a scientifically valid sample of the remaining sites in the proposed development field, and the results would be reported in detail, including a broad education and public outreach component.

Once these efforts were completed, historic preservation compliance for leasing, exploration, and development within the entire field would consist simply of ensuring avoidance of the protected sample of sites and possibly monitoring 
of ground disturbance in areas where buried archaeological sites were likely to be present. This idyllic approach would be, by far, the most effective and efficient means of managing archaeological resources in oil and gas fields, but it ain't gonna happen. BLM has neither the personnel nor the funding to survey large tracts of the public lands and carry out extensive excavations to prepare the way for private energy development. The oil and gas industry's exploration and development actions are driven by constantly changing market forces, geophysical information, and production data. This makes broad-scale, up-front investment in cultural resource investigations uneconomical and impractical for the industry, especially given the short time frames within which many decisions must be made.

Faced with an ideal scenario that is unachievable, we have tried to focus in this chapter on achievable changes that could largely be carried out with existing federal funding and personnel and would be compatible with the economic realities of the oil and gas industry. Our recommendations must also be consistent with BLM's statutory and regulatory responsibilities and move cultural resource management in southeast New Mexico toward the goals outlined by BLM and the various stakeholders who were interviewed for this project.

These are serious constraints on our ability to formulate "adjustments" to the existing management process that would truly make a difference; something has to give. And that "something" is preconceptions about shoulds, oughts, and can 'ts as well as inflexible, "we've always done it this way" attitudes. If we are going to adaptively manage cultural resources and energy development in a less-than-perfect world, all of the participants in this process have to recognize the limitations and accept practical rather than ideal strategies.

The need for change is undeniable. In the mid 1980s, one of us (Sebastian) was the senior researcher on the first published synthesis of the archaeology of what was then called the Roswell District of the New Mexico BLM (Sebastian and Larralde 1989). Nearly 20 years have passed since the research was completed, and we know very little more about the archaeological record of that area than we did in 1987, despite the fact that as of this writing 18,158 additional surveys have been completed. Thousands of sites have been minimally recorded and, based on surface evidence, considered eligible to the National Register and avoided by initial construction, sometimes at substantial cost and delay. Unknown numbers of these sites have subsequently been destroyed or degraded by the intensity of later activities on leases and rights-of-way. Despite all the time and effort and money spent, we are still not able to make well-informed decisions about the integrity or significance of archaeological sites in this area, and we have not learned important and exciting things about our nation's heritage that we can share with the American people. If anything, we are in an information deficit; not only are we not learning anything new in support of either better management or better science from the work that we are doing, we are losing information from the cumulative, long-term effects of intensive development.

Some of the "adjustments" in BLM's cultural resource management process for oil and gas fields that are proposed in this chapter will seem very radical — with good reason. They are radical, and necessarily so. The alternative is that for another 20 years we continue doing the same things that we have done for the past 20, giving us the opportunity to know less and less about more and more oil and gas fields. Section 106 of the National Historic Preservation Act has enormous potential for flexibility and creative approaches. There is a desperate need to tap into that potential in the oil and gas development areas of southeast New Mexico if we ever hope to have effective stewardship, informed management decisions, and productive harmony between the needs of our modern society and the remains of our ancient ones.

In the following sections of this chapter we first offer an evaluation of the problems that have arisen from the current management process and recommend adjustments to the process. Then we suggest specific strategies to improve management within the Loco Hills, Azotea Mesa, and Otero Mesa fields. Some of these recommendations could stand alone and be implemented independently of the others. Most of the recommendations, however, are interdependent, a package of trade-offs designed to improve resource management while facilitating multiple use. Finally, we address mechanisms for applying the insights gained from this project in the future and for ensuring that a true adaptive management cycle continues to inform cultural resource management decisions.

\section{Managing Cultural Resources in Oil \& Gas Fields}

Management recommendations for archaeological resources in oil and gas fields must take into account the needs and goals of both the BLM and industry. Industry is looking for ways to maximize the predictability of the regulatory process and minimize the costs in time and money. BLM is trying to acquire adequate information on which to base management decisions, meet its legal obligations, and maintain and enhance resource values under its multiple-use mandate. The following observations about shortcomings of the current process and recommendations for adjustments are organized by the phases of energy development. It is important to note once again that this discussion addresses only archaeological sites that are or may be eligible to the National Register of Historic Places because of their potential to yield important information about the past. Management for other values associated with such sites is not addressed here. 


\section{Planning and Leasing}

One of BLM's most important needs is cultural resource information for broad-scale planning, up to and including planning at the RMP level. The New Mexico PUMP III project, which includes digitization of surveyed space over a broad area and development of predictive models and sensitivity maps for three sizeable study areas, provides a strong basis on which to build and expand the needed information.

Recommendation 1: Expand the Loco Hills and Azotea Mesa models to cover as much as possible of current and likely lease areas - all of the data needed are already available except geomorphology. A project currently underway by the Office of Contract Archeology (OCA) at the University of New Mexico is, among other things, developing 1:500,000scale geomorphology information for southeast New Mexico. This information should be used to plan a more detailed mapping project, and BLM should seek funding to complete finer-scale mapping and expand and maintain the current models. Possible funding sources might include future Department of Energy PUMP grants and, if the models are used to target, streamline, and improve the compliance process as suggested below, the oil and gas industry itself.

The archaeological sensitivity maps from such a project could be used by BLM as the basis for RMP revisions, including identification of areas unsuitable for leasing; planning for road, pipeline, and utility corridors within oil and gas fields; and a broader-scale approach to NEPA compliance, as discussed below. Surface protection specialists, working with cultural resource staff, could use these data to plan their schedule of leases to inspect. Cultural resource specialists could use these data in a wide variety of ways specified in later recommendations.

Recommendation 2: Make the sensitivity maps developed in the PUMP III project (and the expanded maps described in Recommendation 1) available to landmen, lessees, and operators in the BLM Public Room or other venue, such as the online access tool developed for the Wyoming component of this project. The Cultural Resources Information Summary Program (CRISP) is a web browser-based tool that makes sensitivity maps and summaries of cultural resources information available to land use proponents and nonspecialists in cultural resources. CRISP is specifically aimed at the audiences that use the BLM Public Rooms.

The oil and gas industry could use this archaeological sensitivity information to evaluate potential leases and to plan developments on current leases. An important component of this effort would be a commitment on BLM's part to maintaining, reevaluating, and updating the models. This could best be accomplished if model revision were linked to a specific planning cycle already in use within BLM.

Recommendation 3: BLM needs to inform its management strategies by compiling basic archaeological data from subsurface contexts. We have recorded at least minimal surface information from thousands of sites, but without data from controlled excavations and detailed study of the recovered materials we cannot ascribe a function or temporal period or cultural affiliation to most of these sites or understand the general relationship between surface archaeological manifestations and subsurface deposits in this area. A better understanding of all these things is critical to determining the significance of and appropriate management strategies for the archaeological record of southeastern New Mexico.

Although relatively little archaeological excavation has been done in southeastern New Mexico compared with other oil-and-gas-producing areas in the state, some important work has been done. BLM should give high priority to funding a compilation and synthesis of all available excavation data from the region, perhaps using the joint outreach, education, and data synthesis funds identified in the state protocol implementing the nationwide programmatic agreement. This project should specifically include provisions for creation and dissemination of a popular summary of the results and of other educational materials.

Recommendation 4: Both cultural resource management and oil and gas development can be better served if NEPA compliance is moved "upstream" to the planning and leasing phases of energy development. Currently, NEPA compliance for oil and gas explorations and operations on BLM land in southeastern New Mexico is carried out on an APD-by-APD and ROW-by-ROW basis. This is problematic for a number of reasons, but the most serious is the near impossibility of effectively considering cumulative impacts at this scale. To illustrate this point, we have reproduced the aerial photo of a portion of Loco Hills from Chapter 2 here. Almost certainly, every one of the individual well pads, roads, powerlines, pipelines, and other features visible in this photo was classified under NEPA as a Categorical Exclusion or analyzed through an Environmental

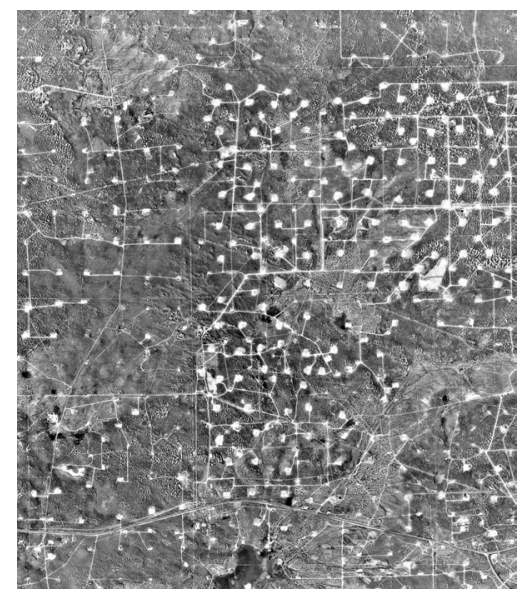


Assessment and found to have no significant impact. Yet can there be any doubt that, in the aggregate, field development at this level of intensity has had a significant impact on the quality of the natural and cultural environment?

BLM needs to find a way to carry out NEPA compliance for oil and gas development at a broader scale - minimally at the level of the lease, preferably at the level of some much larger natural or developmental unit. For example, the previously referenced OCA project will include identification of logical environmental units based on physiographic characteristics. These units would provide an appropriate scale for considering both cultural and natural resources. Only through such broader-scale NEPA analysis can cumulative impacts be effectively addressed and appropriate mitigation measures devised. We recommend that BLM put together a small working group of people with extensive NEPA experience to explore ways of broadening the context of NEPA compliance in southeastern New Mexico.

It is important to note in regard to the problem of cumulative impacts on cultural resources from intensive oil and gas development that two of the BLM's national cultural resource program goals are: "to ensure that proposed land uses initiated or authorized by the BLM avoid inadvertent damage to federal and non-federal cultural resources" and "to protect and preserve in place representative examples of the full array of cultural resources on public lands for the benefit of scientific use and public use by present and future generations." Preservation of a representative sample of sites within a planning unit could be one of the mitigation measures considered for ongoing impacts from intensive development.

Not only would broadening the scale of NEPA compliance lead to more effective archaeological resource management, it could also be designed to solve coordination problems between realty specialists and cultural resource staff for rights-of-way that are Categorical Exclusions (CXs) under NEPA (see discussion in Chapter 2). Improved coordination should reduce or even eliminate at least one of the problems of nonconcurrent, delayed, or conflicting reviews that were identified during interviews with the oil and gas industry representatives. One possibility that should be examined is programmatic NEPA assessments that predefine issues such as levels of effort and evaluation of impacts for whole resource categories. If BLM convenes a NEPA working group, establishing a protocol for coordination of NEPA and Section 106 compliance for CX rights-of-way should be the group's first priority.

BLM's Instruction Memorandum No. 2005-247 of 9/30/2006 spells out additional categorical exclusions established under Section 390 of the Energy Policy Act of 2005. One of the new exclusions created in the statute is specific to rights-of-way, and another exclusion speaks to small disturbance areas within larger NEPA-analyzed developed fields. As of this writing, it is unclear how BLM will implement all of the measures in the Energy Policy Act. What is clear, however, is that some measures in the Act make possible, and even encourage, implementation of some of the recommendations made here.

\section{Oil and Gas Exploration and Operations}

The results of the PUMP III studies and our interviews with BLM staff and stakeholders identified four areas of concern relative to archaeological resource management and oil and gas exploration and operations: level of effort to identify archaeological resources; decisions about the eligibility of identified sites to the National Register of Historic Places; processing of APDs and ROW applications; and monitoring and protection of "avoided" archaeological sites. The first two concerns are addressed together in the next section, the other two separately below.

\section{Identification and Evaluation of Archaeological Sites}

The regulation implementing Section 106 of the National Historic Preservation Act requires that federal agencies "make a reasonable and good faith effort to carry out appropriate identification" of historic properties that may be affected by their undertakings, and notes that they should take into account (among other things) "the likely nature and location of historic properties within the area of potential effects" in deciding what that level of effort should be (36 CFR 800.4[b][1]). The regulation further defines a historic property as a "prehistoric or historic district, site, building, structure, or object included in, or eligible for inclusion in, the National Register of Historic Places" (36 CFR 800.16[1][1]).

For the past 30 years the archaeological component of this requirement has been met in southeastern New Mexico by carrying out intensive pedestrian survey of the area of potential effects for virtually every project. This approach has the advantage of being simple, straightforward, and predictable. It also has a number of disadvantages, however. As Chapters 5,6, and 7 of this report show, this approach has led to an astonishing amount of resurvey of the same pieces of ground and re-recording of the same sites. With modern GIS technology and with the data on surveyed space in this area now being available in NMCRIS as a result of the PUMP III project, some of this resurvey and re-recording could be eliminated, but given the constant overlap of project areas in heavily developed fields, it is often more cost effective simply to survey the whole project area rather than try to establish on the ground which pieces have been surveyed and which have not. 


\section{MANAGEMENT RECOMMENDATIONS}

Another disadvantage of this approach to identifying historic properties is that what we are actually identifying are the locations of archaeological artifacts and features. In southeast New Mexico, we have no real context within which to determine whether those artifacts and features indicate the presence of historic properties (that is, sites eligible to the National Register) or not. Two of the authors of this chapter (Sebastian and Cushman) spent years of our professional lives as Section 106 reviewers in the New Mexico Historic Preservation Division. Both of us, at one time or another, were assigned to review submissions from the BLM Roswell and Carlsbad Offices, and between us we reviewed thousands of survey reports and site forms.

For all the years before our tenure at SHPO, sites in the oil patch of southeast New Mexico had been found, minimally recorded, and avoided; found, minimally recorded, and avoided; found, minimally recorded, and avoided. The result? An immense archaeological record whose potential to yield important information about the past was untested and unknown. Faced with the extremely limited information on the significance of this archaeological record, we, like the reviewers before us and those since, had no real alternative but to err on the side of caution. The archaeological record is finite and nonrenewable. If we decide, without any scientific basis, that a site is not eligible and it is destroyed, there is no going back if we learn later that, in fact, it did have the potential to yield important information about the past. So we continued the conservative approach of considering a large proportion of the sites to be eligible — because we had no basis for saying that they weren't — and agreeing that they should be avoided.

This, of course, leaves us with several problems. (1) Our lack of information about the significance of the archaeological record in this area is self-perpetuating; we never gain any more information on which to base decisions about eligibility, so we have to keep making the same conservative decisions over and over. (2) Money and time are, without any doubt, being spent on redesigning projects or even abandoning projects to avoid archaeological sites that would not be found eligible to the National Register if we had enough information to truly evaluate them. (3) As more and more projects and more and more conservatively evaluated sites are packed into mature development fields, avoidance becomes increasingly difficult and redesigns increasing common. (4) Ironically we are not even really protecting these avoided sites in any long-term sense; "avoidance" means that the site is not directly affected by initial construction. Long-term operations within leases and rights-of-way are constantly degrading all those carefully "avoided" sites. As one BLM Surface Protection Specialist said during an interview, "If you think we're preserving sites by avoiding them, you're fooling yourselves."

How, then, can we make better decisions about good faith efforts to identify historic properties, determine the eligibility of archaeological sites, and generate requirements to avoid archaeological remains, while at the same time doing a better job of preserving truly significant sites? We don't have much information about the subsurface nature of the archaeological record in southeast New Mexico, but we have a huge amount of information about the surface manifestations. And thanks to this DOE-funded study, we have some of the tools that we need to begin using that surface information to make tough decisions about allocating effort for acquiring additional inventory data vs. other needed data.

Recommendation 5: In areas for which predictive models have been developed and for which it has been demonstrated that model outcomes and site density projections have stabilized (as described in Chapters 5, 6, and 7), BLM should use that information, in conjunction with geomorphic information about potential for surface visibility and NMCRIS information about intensity of previous survey, to make decisions about the need for survey in anticipation of future projects.

The Wyoming component of this project created a framework similar to that proposed above. The likelihood of buried archaeological sites was assessed systematically across the Wyoming study area. This map (available on-line through the CRISP tool described above) and the observed incidence of inventory have become important tools for cultural resource managers when they decide whether a survey is required.

In Wyoming, at present, the decision-making is on a case-by-case basis. Here, we advocate going a step further and creating a decision matrix that would be programmatic in its use. The basis of the matrix is the forecast surface occurrence of cultural resources, site visibility (and the likelihood of encountering buried sites), and existing adequate inventory for cultural resources. The specific matrix should be designed by BLM in consultation with SHPO and the archaeological community. Once the matrix is in place and an electronic interface has been set up, oil and gas lessees and operators would be able to input locational information and get immediate feedback for planning as well as specific information about cultural resource requirements for a specific development project.

Just as a heuristic, we might imagine a matrix that would look something like this: 
ADAPTIVE MANAGEMENT \& PLANNING MODELS FOR CULTURAL RESOURCES IN OIL \& GAS FIELDS

\begin{tabular}{|c|c|c|c|}
\hline \multirow{2}{*}{} & \multicolumn{3}{|c|}{ Projected Site Density from Predictive Model } \\
\cline { 2 - 4 } & High & Medium & Low \\
\hline Surface visibility & & & \\
\hline high & & & \\
\hline low & & & \\
\hline $\begin{array}{c}\text { Surveyed acreage in } \\
\text { surrounding square mile }\end{array}$ & & & \\
\hline$>10 \%$ & & & \\
\hline$<10 \%$ & & & \\
\hline
\end{tabular}

The "surface visibility" values indicate the likelihood that an area contains buried sites - in "high surface visibility" areas, the potential for buried sites is small and if sites occur in that area, they will generally be visible on the surface. For this example, outcomes might be set in the matrix design as:

For all projects, avoid known sites AND

If site density $=$ high

and surface visibility $=$ high

and previous survey $<10 \%=$ pedestrian survey

and previous survey $>10 \%=$ every 5 th project, $\dagger$ pedestrian survey

and surface visibility low

and previous survey $<10 \%=$ sample backhoe trench

and previous survey $>10 \%=$ sample backhoe trench

If site density $=$ medium

and surface visibility $=$ high

and previous survey $<10 \%=$ every 5 th project, pedestrian survey

and previous survey $>10 \%=$ every 10 th project, pedestrian survey

and surface visibility $=$ low

and previous survey $<10 \%=$ every 5 th project, sample backhoe trench

and previous survey $>10 \%=$ every 10 th project, sample backhoe trench

If site density $=$ low

and surface visibility $=$ high

and previous survey $<10 \%=$ every 10 th project, pedestrian survey

and previous survey $>10 \%=$ every 15 th project, pedestrian survey

and surface visibility $=$ low

and previous survey $<10 \%=$ every 10 th project, sample backhoe trench

and previous survey $>10 \%=$ every 15 th project, sample backhoe trench

$\dagger$ The electronic interface would include a counter to identify the 5th or 10th or whatever project registered in a particular matrix category

Again, this matrix and these outcomes are not specific recommendations - they are simply designed to convey the concept. And before our industry partners break out the champagne and the historic preservation crowd breaks out the tar and feathers, we hasten to point out that there is one more important component to this suggestion. The point of this triage approach to identifying historic properties is to move from the current total focus on identifying and to gather data needed to make informed decisions about which identified sites are historic properties, that is, properties eligible to the National Register. 


\section{MANAGEMENT RECOMMENDATIONS}

The needed data have to do with potential for entirely buried sites, age of soils and other sediments, the relationship between surface manifestations and subsurface content of sites, site integrity, and detailed information on site function, age, and other archaeological research domains. Some of these data would be acquired through a program of backhoe trenching in lieu of surface survey in areas of low surface visibility. The trenches would be monitored by professional archaeologists who would record both stratigraphic and archaeological data (note that this may require that BLM provide some training for permittees). The trenching/monitoring program would be designed to be similar in cost to what conventional archaeological survey would have been for the project.

The rest of the needed data can only be acquired through archaeological excavation, which brings us to:

Recommendation 6: BLM should implement a scientifically designed program of testing of archaeological sites within the areas covered by current (or expanded) archaeological models. This testing program should be based on the data needs, research questions, and excavation strategies being identified as part of the previously mentioned BLM-sponsored OCA research project. The testing program would be funded through cultural resource assessments paid by oil and gas operators on a project-by-project basis for those projects which were not selected for either survey or trenching during the matrix evaluation explained under Recommendation 5. The assessment would be equal to the average cost of a standard pedestrian survey for a project of the appropriate type and would be placed in a restricted fund that could only be used for the testing program. Another potential source of funding for these efforts is the provision in Section 365 of the Energy Policy Act of 2005 allowing use of rental receipts from leases for costs of coordinating and processing oil and gas use authorizations.

Now, before our industry partners resort to the tar and feathers and the historic preservation crowd joins them, let's think about the implications here.

First, from the industry perspective:

- The overall cost to industry of "doing archaeology" should stay the same.

- For projects that "win the lottery" and are not required to do either survey or trenching, there would be a substantial time saving. (We also have suggestions below about time savings for projects that are selected for survey or trenching.)

- A subset of the money being spent to "do archaeology" would actually go toward learning about the past and about the value of the archaeological record. The testing program could (and should) be set up to include periodic summaries written for a public audience, school programs and curriculum materials, museum exhibits, etc.

- Over time, as our understanding of the true information potential of archaeological sites in southeastern New Mexico increases, there will almost certainly be fewer sites that require avoidance, making siting of wells and other developments easier rather than increasingly difficult.

And from the historic preservation perspective:

- BLM will still be able to meet its regulatory requirement to make a reasonable and good faith effort to identify historic properties that may be affected by oil and gas developments that it authorizes.

- Determinations of eligibility can be based on a scientifically valid, three-dimensional understanding of the significance of the archaeological record rather than on surface manifestations alone.

- BLM cultural resource managers will have the information needed to identify and preserve a representative sample of significant archaeological sites for long-term research, education, and heritage tourism

- BLM will have the information needed to explain the significance and value of the archaeological heritage of southeastern New Mexico in a way that engenders support for preservation and research among public land users and the local communities.

Will archaeological sites be damaged or destroyed as a result of the triage approach advocated above? Without question, sites will be lost. But sites are being damaged or destroyed now, and we don't even know enough to decide whether they are mundane scatters of debitage and burned caliche or a key piece of the puzzle of the past that should have been protected at all costs.

The alternative to a radical approach such as that proposed above is to continue with business as usual. As noted above, in the 18 years since Sebastian finished her research for the Roswell BLM District overview (Sebastian and Larralde 1989), 18,158 archaeological surveys have been conducted within that study area. At an average of, say, $\$ 500$ per survey, more than $\$ 9$ million has been spent to find, minimally record, and sort of avoid 13,296 archaeological sites of unknown significance and meaning. Surely we can do better. 


\section{Processing of APDs and Right-of-Way Grants}

Processing of APDs was identified by both industry representatives and BLM cultural resource staff as being prone to archaeology-related delays. According to cultural resource staff, these delays are of three types: (1) An applicant who is unfamiliar with the APD process fails to have an archaeological survey done before submitting the application. (2) The archaeological survey has been done but the report isn't submitted with the application. (3) The archaeological survey has been done and the report accompanies the application, but the report has missing or substandard information.

Right-of-way grant applications also experience delays of these three types, plus as described in Chapter 2 and noted above, there are coordination problems within BLM for ROWs that are Categorical Exclusions under NEPA but require full compliance under Section 106. We have suggested above that BLM convene a working group of BLM staff with substantial NEPA experience to brainstorm solutions to the NEPA/Section 106 coordination problem and other NEPA-related issues. Here we focus on the three problems identified in the previous paragraph.

Recommendation 7: The question of how best to inform applicants for land-use authorizations about cultural resource requirements is one that should be resolved through advice from industry representatives. They understand the needs, mindset, information flow, and culture of their colleagues better than any of us on the outside. An informal working group of industry representatives should be asked for advice about how BLM can most effectively prevent problems of the first type. Above, we suggested that a matrix-based approach could be useful. This could be automated, perhaps best with a map-like interface, so that project proponents, potential lessees, and managers have an early opportunity to find out cultural resource requirements.

Recommendation 8: Although missing and incomplete survey reports are problems in their own right, what is needed to process an APD or ROW application is information about the outcome of the survey, not the physical report per se. Consider developing an immediate post-fieldwork electronic submission form for the critical information needed to process an APD or ROW application. Applications could then be approved based on the electronic submission, with the full report to follow. Again, work with industry advisors to design a system for ensuring that the reports would, in fact, follow in a timely fashion. If this recommendation is implemented, it will be important for BLM cultural resource staff, in consultation with NMSHPO, to establish criteria for determining when expedited approval might not be appropriate.

The Wyoming component of this project has elaborated upon an existing SHPO-BLM tool called CRMTracker that follows the cultural resource investigation process from its inception through the decision-making process to the paper archive itself. This system could serve as a model for eliminating much of the current paper submittal prior to decision-making. Currently in Wyoming, paper reports are still passed between agencies, and decisions are recorded in CRMTracker. Wyoming BLM and Wyoming SHPO are presently discussing eliminating the use of paper documents during the decision phases for no effect and no adverse effect projects. Paper documents would still be the permanent record, but basic critical information would be provided through and decisions would be based on the electronic system.

Recommendation 9: For negative surveys, allow the electronic submission to serve as the report. The development currently underway of a paper "NMCRIS Investigative Abstract Form," which serves in lieu of a negative survey report, could be expanded to all electronic submission. What is gained, in terms of management or understanding or preservation of the archaeological record, from the generation of hundreds of boilerplate-filled negative survey reports? Again, the CRMTracker system discussed briefly above could be useful in implementing this recommendation.

Recommendation 10: In exchange for the time applicants save by having APDs and ROW grants approved on the basis of the electronic submissions and for the money applicants save by having the electronic submissions stand as the full report for negative surveys, BLM should increase site evaluation requirements for those surveys that do encounter archaeological sites. These requirements might include in-field analysis of artifacts, trowel-testing of features, and shovel-testing or other forms of subsurface evaluation where approriate. In this report we have identified the need for subsurface testing and excavation to gather data to allow us to make better-informed determinations of eligibility. We need to collect commensurate data from newly recorded surface sites in order to apply the insights gained from excavations.

\section{Improving Protection of Avoided Sites}

A number of structural aspects of the BLM environmental program allow the activities that currently cause most of the damage to archaeological sites that have supposedly been avoided to slip through the cracks. For example, leases, APDs, and construction get most of the environmental attention, and as a result, these are not the activities that are causing most of the site preservation problems. On-lease activities carried out under sundry notices are uncontrolled, as 
are most post-construction activities on rights-of-way. For the latter, however, the problem is exacerbated because ROWs are not monitored in the way that leases are.

Recommendation 11: BLM should work toward the creation of development corridors, placed in areas identified by the models as exhibiting low site sensitivity. These corridors could be used for pipelines and power lines serving multiple leases. If some acceptable arrangement for sharing facilities can be developed and brokered by BLM, this should provide cost and time savings for lease operators as well as providing better protection for cultural resources. The Energy Policy Act of 2005 contemplates establishing formal corridors for intense study and scrutiny. Our recommendation is feasible, regardless of the legislation, but we think the legislation gives it added momentum.

Recommendation 12: For unitized leases, site sensitivity information from the models should be emphasized as a factor in locating all development.

Recommendation 13: BLM should work toward providing the same levels of monitoring for rights-of-way as are currently applied to leases, at least in high and medium site sensitivity areas.

Recommendation 14: In establishing their priorities for leases to monitor each year, Surface Protection Specialists should include the presence of known sites or, for pre-Section 106 era developments, leases with high or medium site sensitivity among the selection criteria. Training for Surface Protection Specialists in use of the models and sensitivity maps and in evaluating impacts to archaeological sites might be included in implementation of this recommendation.

Recommendation 15: BLM should convene a summit with industry to develop strategies for avoiding or at least limiting the damage to "avoided" archaeological sites that is being caused by well-servicing operations.

\title{
Specific Recommendations for the New Mexico Pump III Study Areas
}

The management implications of our work in each of the PUMP III study areas are detailed in Chapters 5, 6, and 7. Specific management recommendations for Loco Hills, Azotea Mesa, and Otero Mesa are offered below.

\section{Loco Hills}

Recommendation 16: If there is any willingness to consider the whole approach of survey-requirement matrices, subsurface trenching, archaeological testing, and the accompanying trade-offs, as described in Recommendations 5 and 6, Loco Hills is the place to start. As well spacing and other development becomes denser and denser in Loco Hills, avoidance of sites becomes increasingly problematic, and the need to determine which sites actually have the potential to yield important information and which don't becomes increasingly critical.

\begin{abstract}
Azotea Mesa
Recommendation 1 dealt with the importance of expanding the PUMP III models to cover more of the current and projected oil and gas development areas in southeast New Mexico. Azotea Mesa would be an excellent place to start.

Recommendation 17: The Azotea Mesa model should be expanded not only to cover adjacent oil and gas development areas, but also to incorporate representative segments of the surrounding environmental zones to which it is likely to have had close functional ties - that is, the slopes of the Guadalupe Mountains and the Pecos River valley.

Recommendation 18: There has, in the past, been discussion of a "pooled mitigation" approach in portions of Azotea Mesa wherein a sample of archaeological sites would be excavated and subsequent development on the designated leases could be carried out without avoidance or further mitigation of effects to archaeological sites. BLM should continue to pursue this possibility as one means to gain high-quality information about the subsurface archaeology of this study area.
\end{abstract}

\section{Otero Mesa}

Of our three study areas, the undeveloped field of Otero Mesa offers the greatest potential for innovative management approaches, especially given BLM's decision to require unitization in response to other resources' sensitivities. Because of the limited previous survey in this study area, however, we also have the least secure basis for management decisions. 
Recommendation 19: BLM should seek funding to carry out targeted surveys to test and refine the predictive model. Are the apparent high-, medium-, and low-sensitivity patterns real? If so, they offer some real possibilities for future management decisions.

Recommendation 20: Based on the results of the recommended survey, refine the model and make the resulting site sensitivity data available to prospective lessees to encourage pre-sale offers and expressions of interest for lease parcels in low sensitivity areas.

Recommendation 21: For unitized leases, make location of common facilities (power lines, pipelines, roads) in low sensitivity areas a Condition of Approval.

Recommendation 22: For seismic projects in the areas of recent colluvium, require a program of sample trenching to test for buried sites (rather than traditional surface survey) as the mechanism for identifying potentially affected historic properties.

\section{Adaptive Management and the Future in Southeastern New Mexico}

One reaction we received from colleagues who were told about this project was "Oh, another one of those shelf studies." Shelf studies are documents of great initial interest that then fall out of favor (and out of use) to languish in a bookcase. We began our discussion in this chapter with diagrams that illustrated the cycle of adaptive management. We noted that management efforts tend to get stuck at "implement solution." Projects become shelf studies because they get stuck in the implementation phase. Sometimes the solution continues to be implemented without regard to continuing effectiveness; other times the solution being implemented is no longer seen as relevant to the situation at hand, so it is discarded (i.e., shelved). Sometimes, this starts a search for a new solution (ignoring earlier work). In other cases, no new cycle of adaptive management ensues, and implementation becomes idiosyncratic. In this section, we suggest ways to keep adaptive management approaches cycling in both this southeast New Mexico study area and elsewhere.

Another reaction that we received when contacting people about this project was "we really need to get this cultural resource management thing fixed." Above, we described some of the problem area within the "cultural resource management thing"; it is important to note that there will never be just one set of repairs. The recommendations in this chapter address cultural resource problems in oil and gas settings as we see them now. Even if we were to fix all of the problems that we see today, tomorrow's problems may be different from today's. Management is a process - adaptation happens over time as conditions vary. Successful management should yield meaningful cultural resource investigations and preservation actions. How do we keep monitoring, evaluating, and adjusting the operation of cultural resource management so as to continually identify new problems and address them? That is the question we focus on in the rest of this section.

\section{Creating a Culture of Adaptive Management}

BLM Field Offices in active oil and gas development areas are extraordinarily busy workplaces. Staff have little time to do anything but apply current work procedures. Applying new procedures and approaches appears risky: at least doing what worked in the past has predictable demands and outcomes. Trying something new could result in an increase in workload (e.g., what if the SHPO rejects our plan and it has to be rewritten?). In short, there is a deeply conservative streak in the approach to cultural resources with little organizational support and few resources for real innovation.

The problems we found in our study could be solved without changing the "culture" of management itself, but this would accomplish a short-term change: a single loop of the adaptive management cycle. Long-term problem solving for cultural resources will require a change from the tedious safety of a focus on work process to a focus on achieving cultural resource management products and outcomes through innovation (for ideas on this subject see Sebastian 2005).

Time savings have to come from the existing work days of Field Office staff. Above, we have suggested several ways in which desk work can be reduced and in some cases eliminated. Most suggestions focus on simplifying reporting on negative inventories and no effect projects, and eliminating unneeded paperwork. Management must then task the staff to use this newly-minted time for adaptive management activities (rather than simply filling the time with more of the same work load).

Training is critical if any change in approach is desired. Overall, agency staff are well-trained in national policies and procedures. Yet, only over time does staff gain the professional archaeological and managerial experience to be really effective in their jobs. The amount of time that this takes is variable, but it could certainly be made shorter through 
training. Training in using new tools is equally important. We have emphasized the value of model-based approaches and programmatic strategies - but models and information systems require training to be used correctly.

Creating the time to do this more outcome-oriented (as opposed to process-oriented) work does not actually get adaptive management done. Field staff in oil and gas offices need to be encouraged to adapt their own approaches, knowledge, and professionalism over time. One way is to make "management planning" a work accomplishment. Even something as simple as periodically reviewing the site records that do not "match" the existing site occurrence models should be credited in a staffer's work effort.

This study had the luxury of funding support to do research and consider how to do management differently. Agency staff do not have such support. The single greatest step toward a culture of adaptive management could be designation of at least $5 \%$ of a senior cultural resources staff person's time each year to be spent in evaluating and improving the ways in which the Field Office does cultural resource management. Some framework and guidance for their work would be essential and should probably come from a national-level group of cultural resource experts within the agency. In the case of BLM, this expert body is the Preservation Board. The role of the larger body of experts is to seek examples from the field level and to disseminate information on successful (and unsuccessful) strategies and tactics from different Field Offices.

\section{Putting Products in Place}

Creating the time for agency professionals to change management approaches does not put the new management tools in place. Many of the suggestions we have made involve changing aspects of how archaeology is done on the public lands. Having the time to do things differently is not enough; time must be accompanied by the wherewithal as well. For example, one of the findings at the start of our work on the overall Pump III project was that relatively few BLM cultural resource specialists were comfortable using geographic information systems (GIS) software on a daily basis. Almost every one of them felt that GIS was a useful tool; they just did not have the time to learn it or to use it.

Some of the products of this project, which we think should be put in place for future use are:

- Models of site likelihood in each study area

- Geomorphology maps showing Holocene deposits

- Much-improved GIS and database information on projects and resources

Field staff, field managers, landmen, and lessees need to be introduced to these tools as appropriate, and then they need to truly use them. Many of these tools are (or can be) on-line systems. Other "products" have been cited above too: tools that eliminate paperwork, save time, and simply make current work go faster. Some of these "products" are procedural changes, others are virtual or physical things like software, maps, and documents. In any case, the initial steps are (1) to decide which of the many recommendations and tools created during this study have highest value now; (2) to train people in their use and enable that use; (3) to evaluate the gains (or losses) in quarterly or six-month increments.

Perhaps an example will make this more clear. When the CRMTracker tool was first introduced to the Wyoming BLM, an eight-week period was allotted for comment. Despite everyone agreeing to test the system in those eight weeks, only one person did. What happened? First, it was too hard to use without more training. Second, everyone agreed to make this effort just as the summer field season began - the busiest part of their professional year. Third, there was no negative outcome for not testing the tool. Finding the software confusing but lacking the time to learn it, and facing no penalty for not using it, most people did the obvious thing: they just did not bother. Now that the system has been in use for over a year, it has been possible to gather useful evaluations from its users: they know what helps their work and what is inessential or even a hindrance. Two years after the initial introduction of CRMTracker, the Wyoming component of the Pump III project is in a position to build a better management tool.

Introduction of new tools and new work processes will take persistence and some multi-year commitments by all parties. Adaptive approaches to cultural resources will take time to yield results, and patience is going to be a virtue. This does not mean, however, that some progress cannot happen immediately. Several of our recommendations, streamlining the reports for negative field inventories, for example, could be implemented quickly with relatively minor amendments to the New Mexico protocol for Section 106 compliance. Another example might be reporting of no effect and no adverse effect projects in electronic form to be followed by the paper report. Other changes simply involve some training and familiarization: the maps of potential site density are readily understood after a brief explanation and can be made available in agency GIS systems quite swiftly. 


\section{Keeping the Cycle Going}

How do we ensure that, at least for cultural resources, adaptive management will become a cycle as intended rather than swinging around the dial and getting stuck at "implement" again? Our suggestions above include making more information about cultural resources available early in the lease/development timeline, making cultural resource management decisions in a larger framework of regional knowledge, and broadening the definition of appropriate identification and mitigation.

These procedural changes are great places to start the cycle of adaptive management, which must then be kept dynamic. Starting this cycle requires:

- Managerial sponsorship

- Negotiation with preservation partners

- Training of appropriate staff, stakeholders

- Use of new processes

- Formal evaluation of the benefits and drawbacks of new processes

- "Tweaking" process or replacing it

This is the cycle discussed at the start of this chapter. We think a key component of starting the cycle and keeping it going is managerial sponsorship. Sponsorship is active support (not just permission) to try new tactics, perhaps to take on "risky" activities under current perceptions, and to take the work time to effect change. The other points above follow from sponsorship and cannot occur without it. For the BLM, in its current organization, the managerial sponsorship may best be sought at something like the statewide leadership meetings held by the BLM State Director.

Our recommendations involve the use of many technical products: information tools like database systems and automated maps, geomorphological studies, archaeological studies, and predictive models. The evolutionary nature of information technology and scientific inquiry (geomorphology, archaeology) is well known, as are the concomitant needs for maintenance and investment. What is less often recognized is the need to continually test and maintain the models as well as the technical systems and data. The "shelf study" syndrome alluded to above is very common with predictive models. Models fall out of use because new data are not used to test them and reaffirm confidence in the model, or model predictions are found to be at odds with new data. Or both things happen at different times. Either way, a basically sound model may be discarded for lack of "maintenance."

For the models generated by the New Mexico Pump III project, we think that the information technology framework already present in the NMCRIS system could be developed into a continuous testing tool for the models presented in this study. How would this work? With a modest amount of funding, NMCRIS could be augmented to update simple model statistics as new inventories in the study areas are reported. Information on the current (at time of model development or revision) values for those statistics and information on the updated values would be available to managers, CRM staff, and researchers interested in monitoring model performance. The automated system could be programmed to constantly compare current statistics for the existing model with the updated statistics, and to automatically notify senior BLM cultural resources staff of any changes in the statistics that exceed parameters established in the program.

On a regular basis (quarterly, semi-annually) and/or when notified by NMCRIS that model statistics have gone out of the established range, the designated BLM cultural resources staff members would then evaluate the model itself and determine whether revisions to the model and the density maps are needed. Simple revisions could potentially be done in partnership between BLM and ARMS; more complicated reworking of the model might require a contractor. The key point here is that no one has to "rebuild" the model forecasts tediously: much of the work and the calculations will already have been done by the NMCRIS program.

There is more to maintaining these models than monitoring them for out-of-range statistics on the existing variables, however. We would hope that new information and new kinds of information will accumulate. In addition to assessing and updating the performance of the current models, BLM staff or outside contractors should periodically evaluate available information and determine how to keep existing predictors useful and accurate or create new or finer-grained predictors. Currently, for example, the models lump all precontact archaeological sites together because the data are insufficient to permit us to divide most sites into functional or temporal categories. As in-field artifact analysis, subsurface testing, and data recovery take place in the future, it is likely that we will be able to categorize many more sites based on their surface manifestations. Finally, in addition to updating and upgrading the existing models with new data and new kinds of data, BLM staff or contractors need to evaluate alternative modeling approaches that can, for example, incorporate social variables or test theoretical predictions. 


\section{The Future}

In the tradition of a good adaptive management approach, we have come back to the point where we began this chapter- to the need for feasible approaches to achieving a better balance between the need for energy development on the public lands and the stewardship and multiple-use mandates under which BLM operates. The future of cultural resource management in southeast New Mexico can be more of the same, or it can move in some vital new directions. All of the recommendations made above could be implemented in large part through a reallocation of existing resources of time, money, and personnel. What is needed is leadership, a willingness to accept radical change, and a shift from focusing on rote compliance process to focusing on preservation outcomes, public benefit, true resource management, and good public policy.

\section{References Cited}

Sebastian, Lynne

2005 What is the Preservation Payoff? In A Working Conference on Enhancing \& Streamlining Section 106 Compliance \& Transportation Project Delivery, by Terry H. Klein and Lynne Sebastian, pp. 35-39. SRI Foundation Preservation Research Series 3. Rio Rancho, New Mexico.

Sebastian, Lynne, and Signa Larralde

1989 Living on the Land: 11,000 Years of Human Adaptation in Southeastern New Mexico. Cultural Resources Series 6. Bureau of Land Management, Roswell District, Roswell, New Mexico. 



\section{List of Acronyms}

$\Delta$

ACEC - Area of Critical Environmental Concern

APD - Application for Permit to Drill

ARMS - Archaeological Records Management Section (of NMHPD)

ARPA - Archeological Resources Protection Act

BLM - Bureau of Land Management

CRM - Cultural Resource Management

CRMA - Cultural Resource Management Area

CRISP - Cultural Resources Information Summary Program

CX - Categorical Exclusion (under NEPA)

DEM - digital elevation model

EA - Environmental Assessment (under NEPA)

EIS - Environmental Impact Statement (under NEPA)

FLPMA - Federal Land Policy Management Act of 1976

FONSI - Finding of No Significant Impact (under NEPA)

GAP - the US Geological Survey's Gap Analysis Program on protecting biodiversity

GIS - Geographic Information System

GLO - General Land Office

IDRISI - is not an acronym! Idrisi was an important medieval cartographer and geographer, and the geographic analysis software package used in this project was named after him.
NAGPRA - Native American Graves Protection and Repatriation Act of 1990

NEPA - National Environmental Policy Act of 1969

NHPA - National Historic Preservation Act of 1966

NMCRIS - New Mexico Cultural Resource Information System

NMHPD - New Mexico State Historic Preservation Division

NMSHPO - New Mexico State Historic Preservation Office or Officer

NOS - Notice of Staking

OCA - Office of Contract Archeology (at the University of New Mexico)

PA - programmatic agreement (under NHPA)

PUMP - Preferred Upstream Management Practices

RDBMS - relational database management system

RMP - Resource Management Plan

ROW - right-of-way

SHPO - State Historic Preservation Office or Officer

SMA - Special Management Area

SQL - Structured Query Language

USDA - US Department of Agriculture

UTM - Universal Transverse Mercator

WYSHPO - Wyoming State Historic Preservation Office or Officer

IT - information technology 



\section{GLO Transactions and Historic Features Documented for Otero Mesa Project Area}

May 2004: Statistical Research, Inc.

D

A.1. Otero Mesa Project Area (East)

A.2. Alamo Mountain Quadrangle

A.3. Alamo Mountain NE Quadrangle

A.4. B T Ranch Quadrangle

A.5. Cienega School Quadrangle

A.6. Cleones Tank Quadrangle

A.7. Gowdy Ranch Quadrangle

A.8. Lewis Canyon Quadrangle

A.9. Sheep Draw Quadrangle

A.10. Sixteen Canyon Quadrangle 



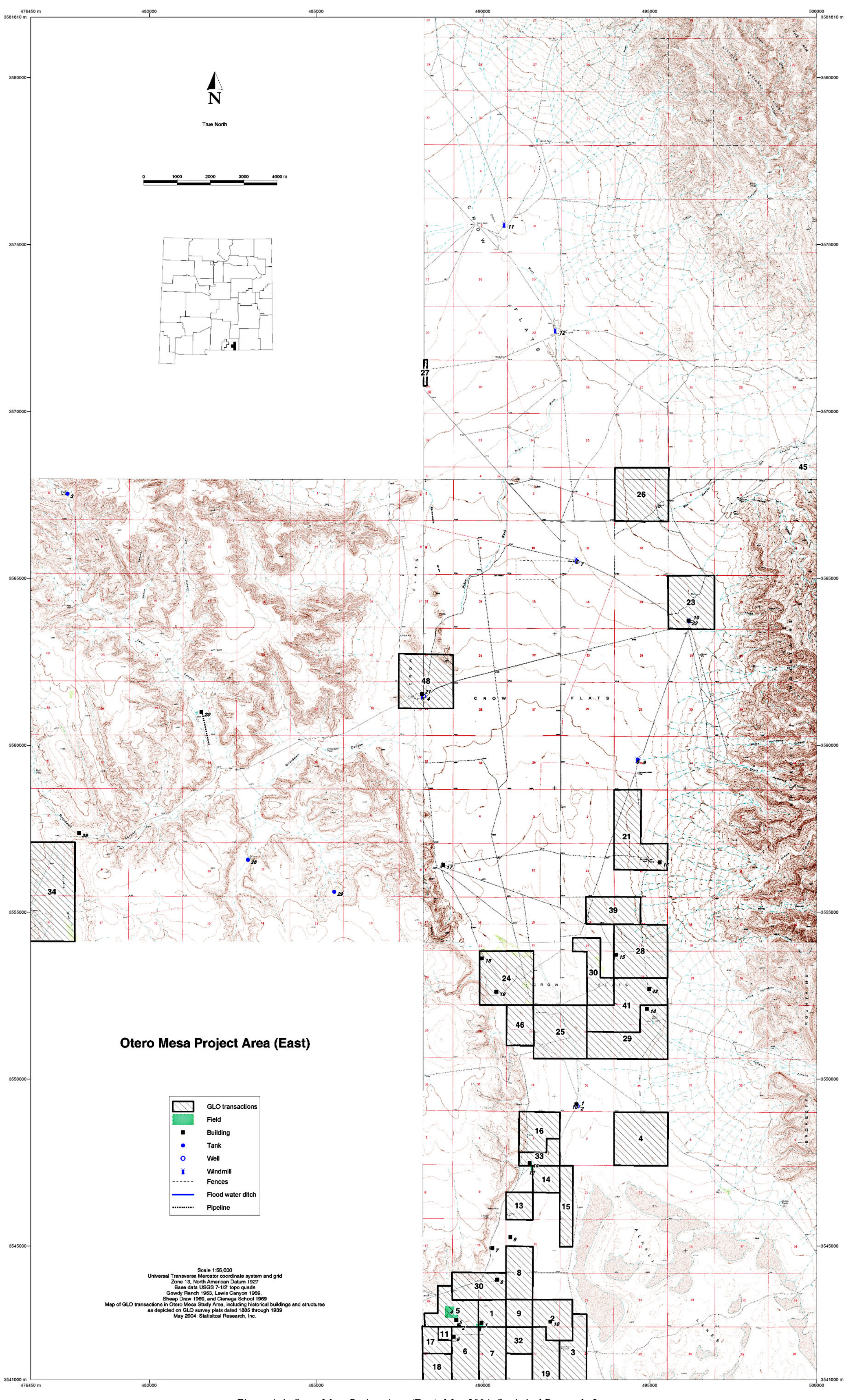

Figure A.1. Otero Mesa Project Area (East). May 2004: Statistical Research, Inc. 


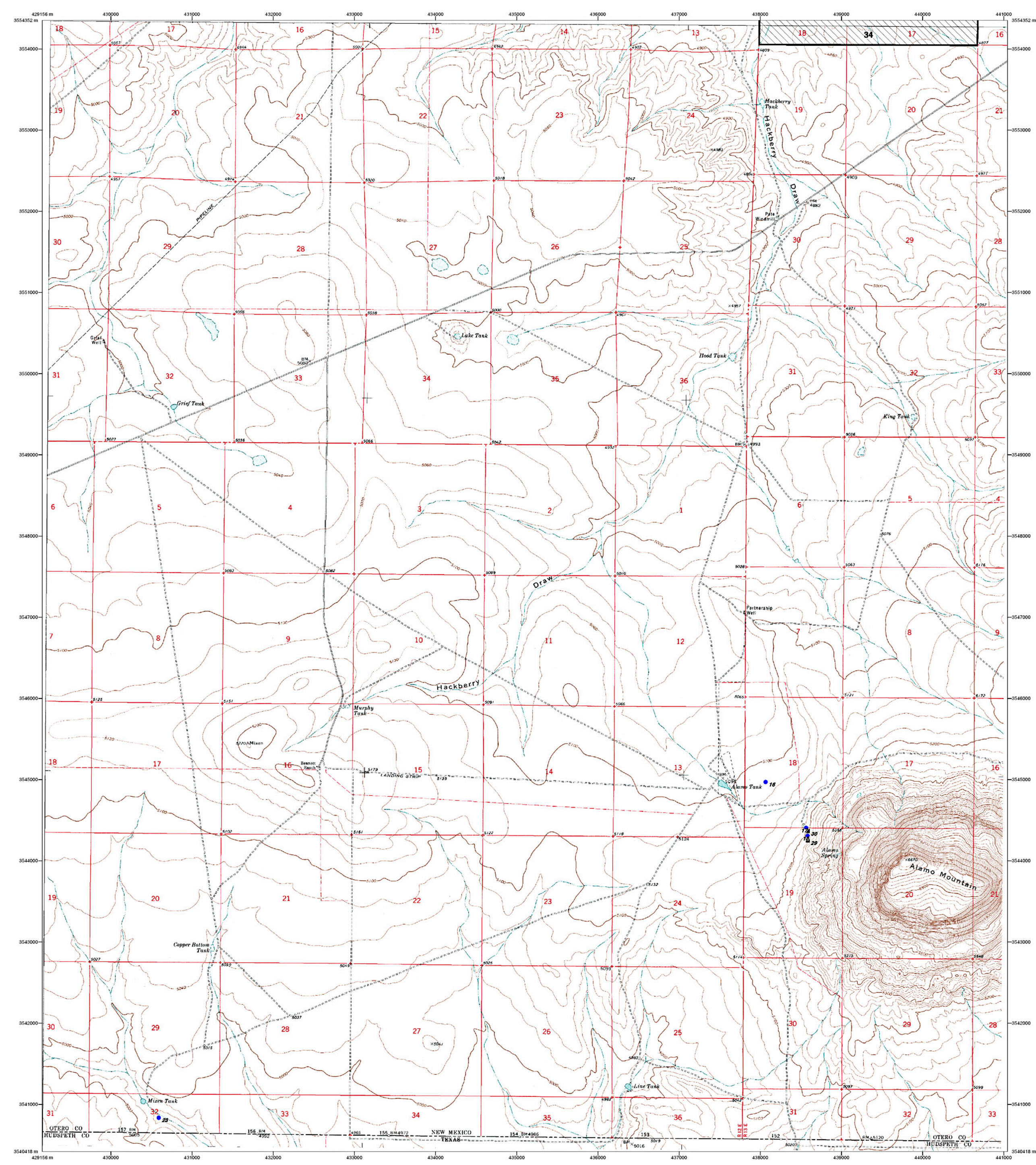

Alamo Mtn Quadrangle
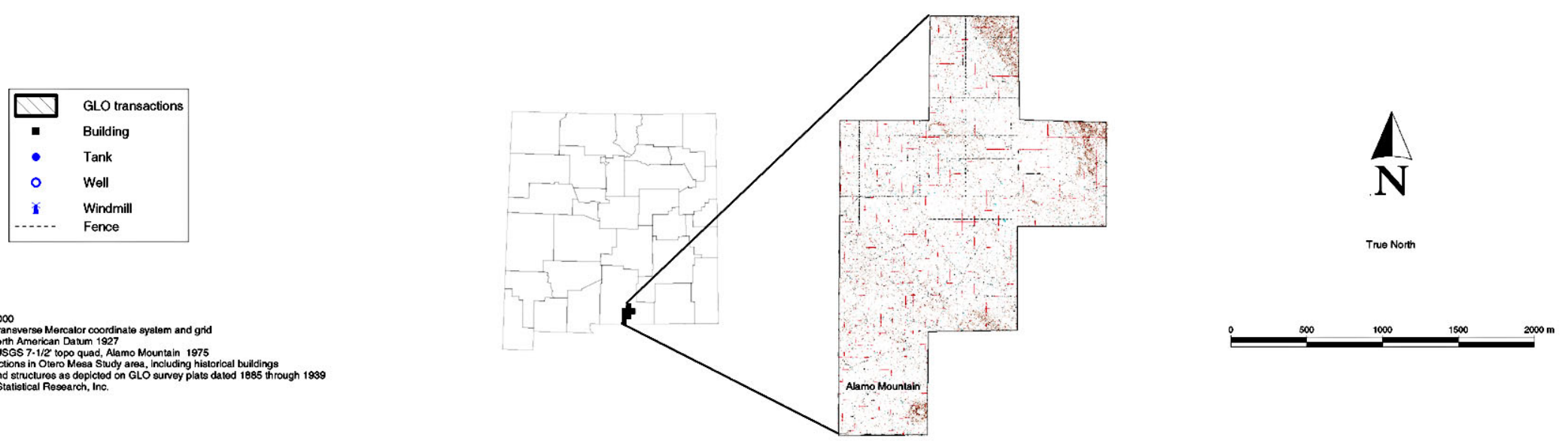

$\Delta$

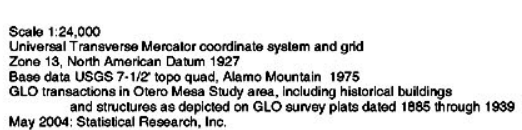

Figure A.2. Alamo Mountain Quadrangle. May 2004: Statistical Research, Inc. 


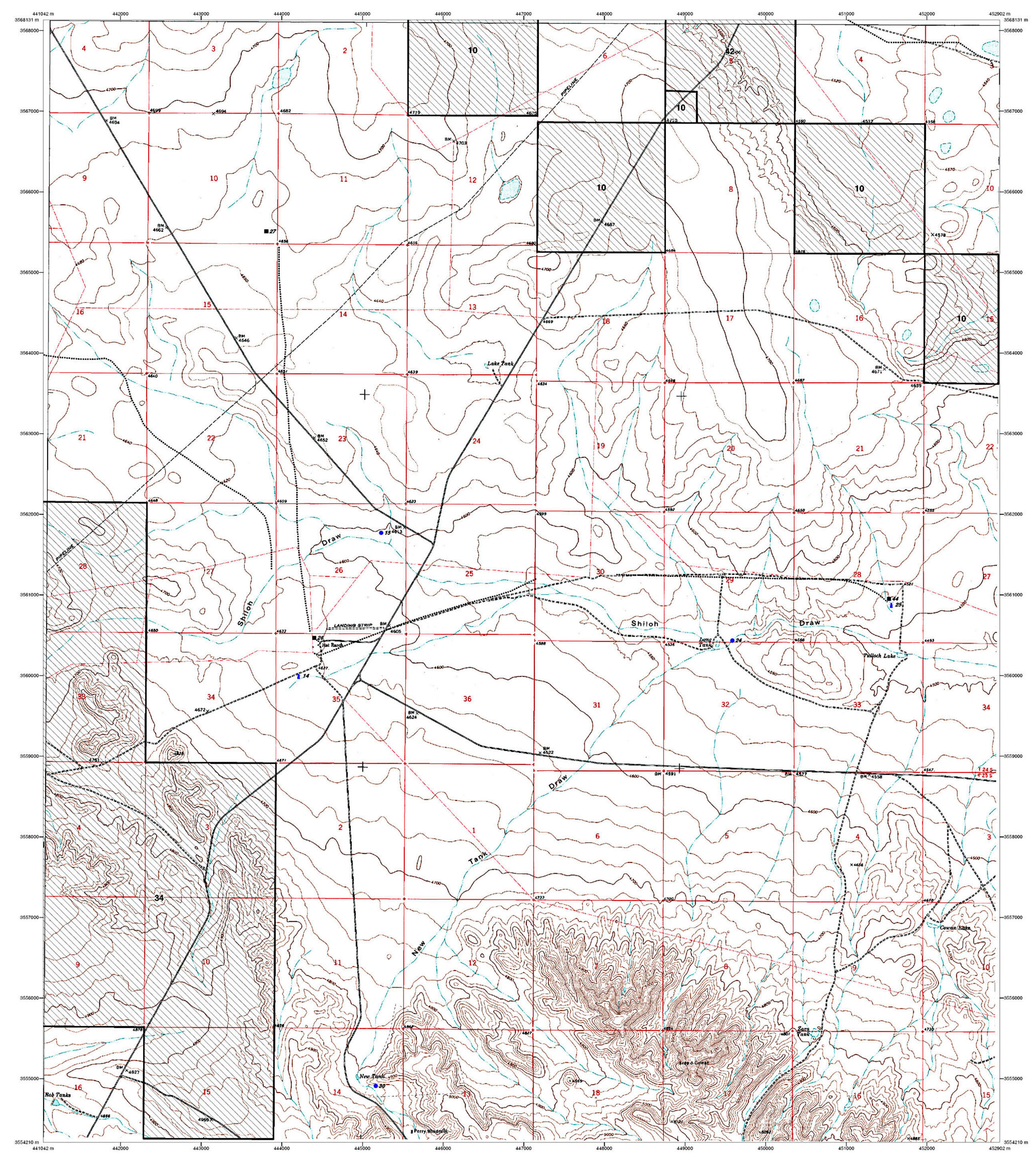

Alamo Mtn NE Quadrangle
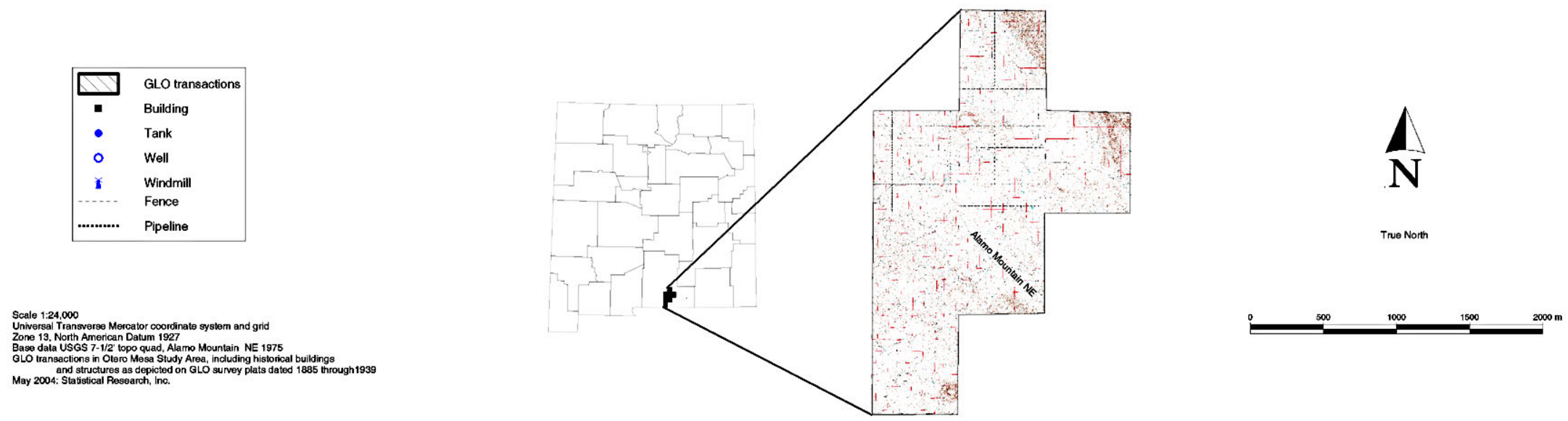


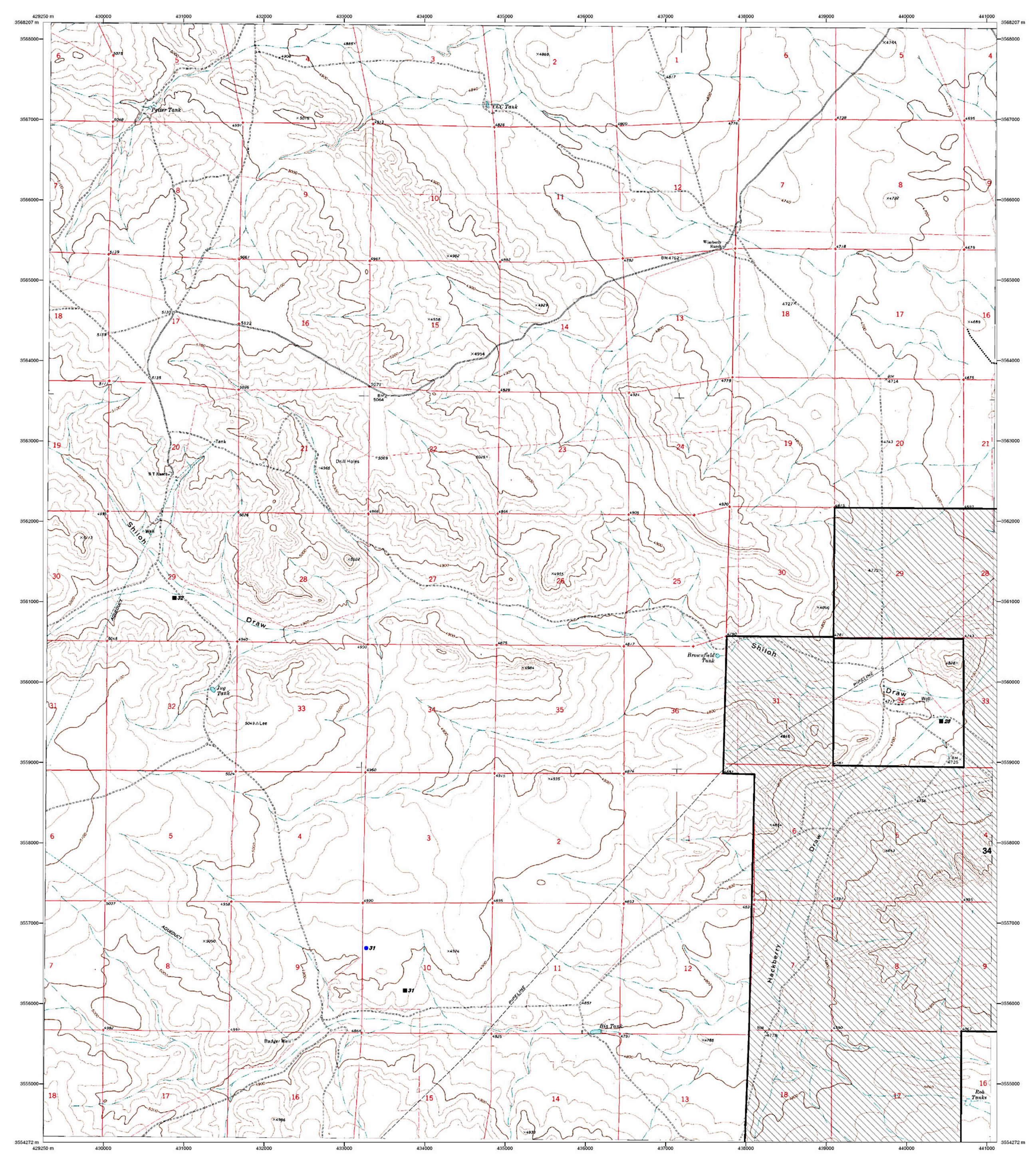

B T Ranch Quadrangle
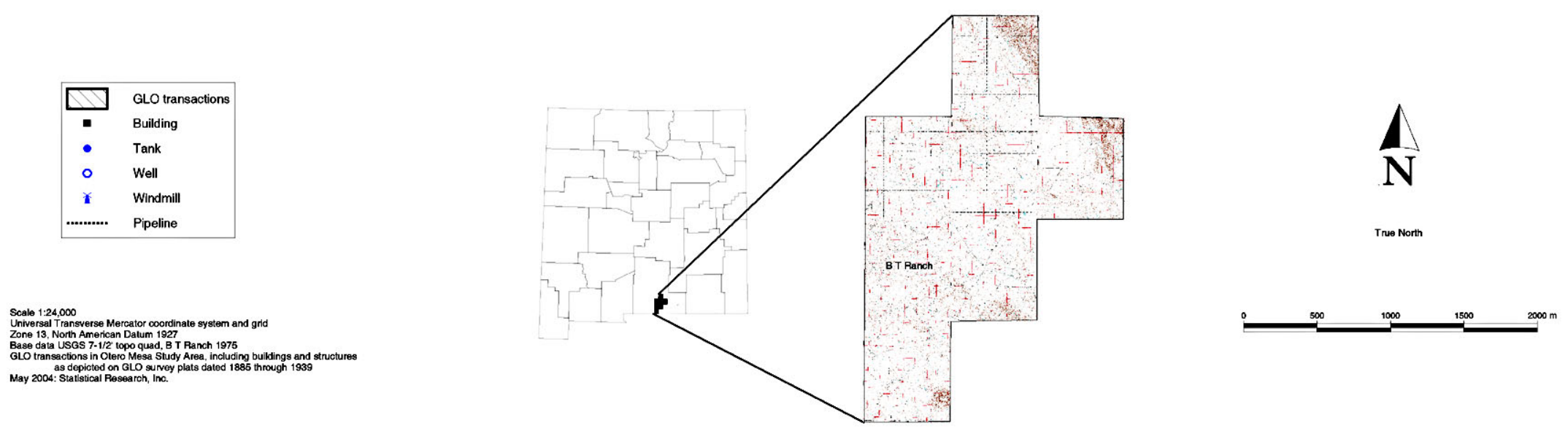

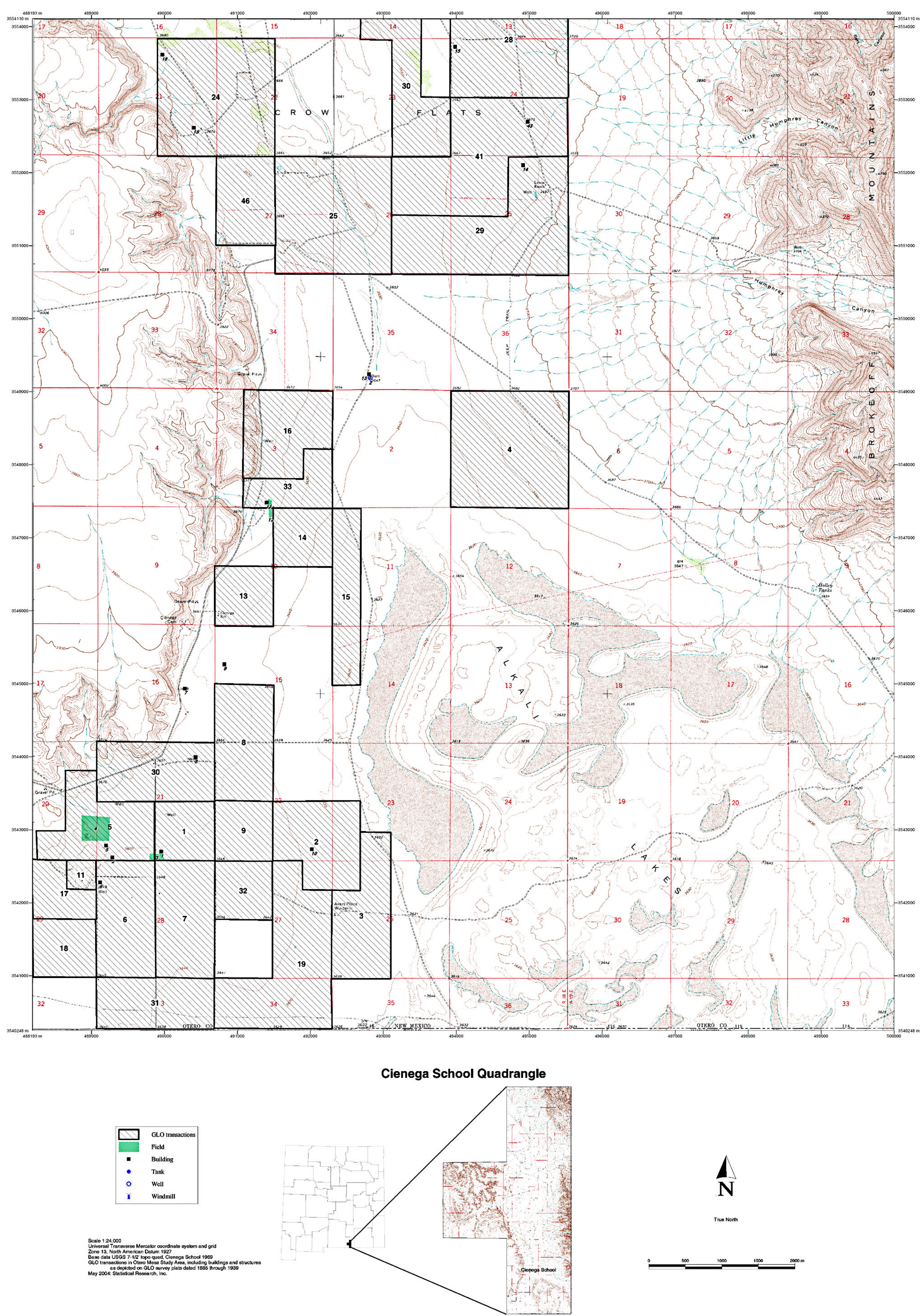

Figure A.5. Cienega School Quadrangle. May 2004: Statistical Research, Inc. 


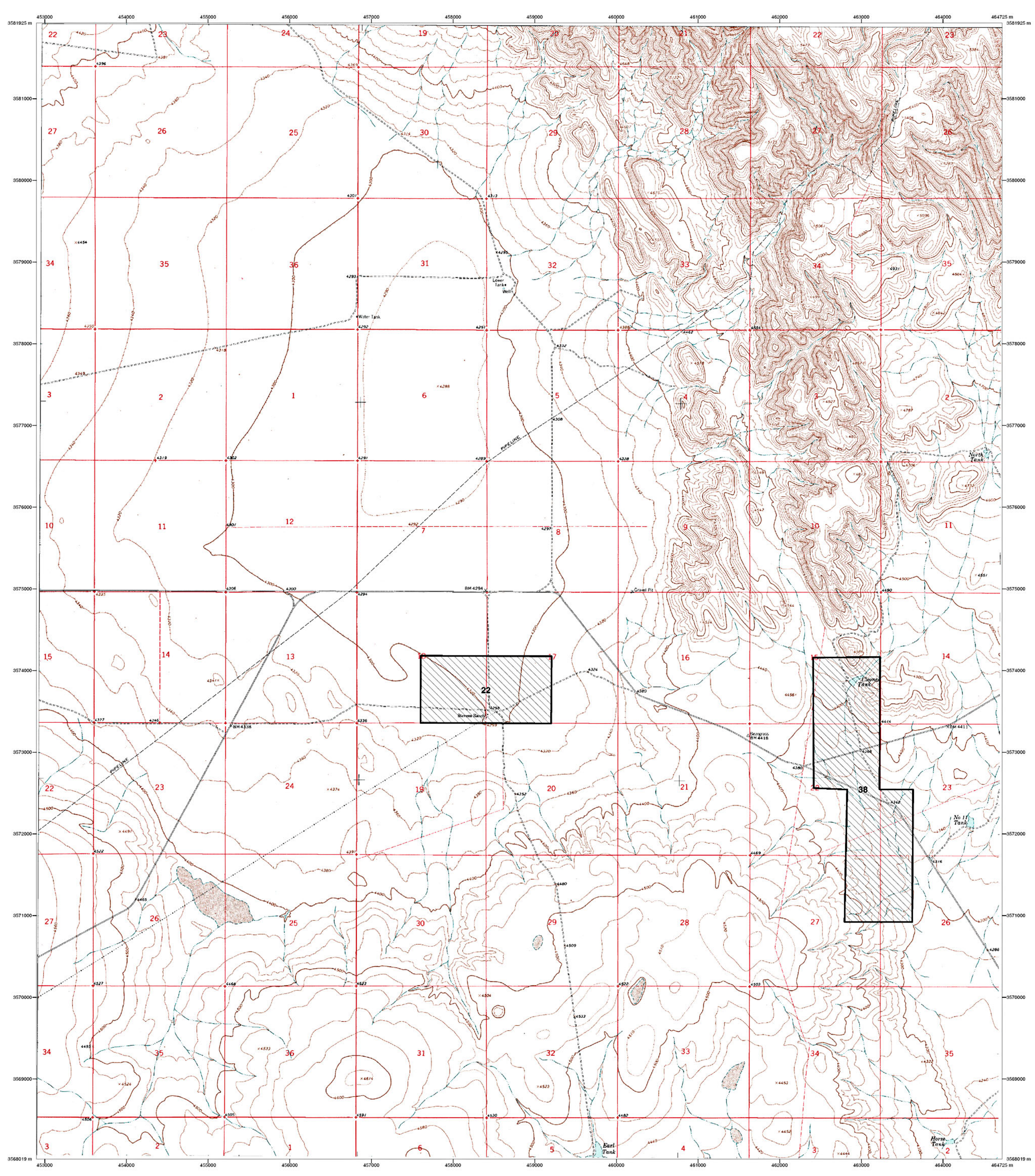

Cleones Tank Quadrangle
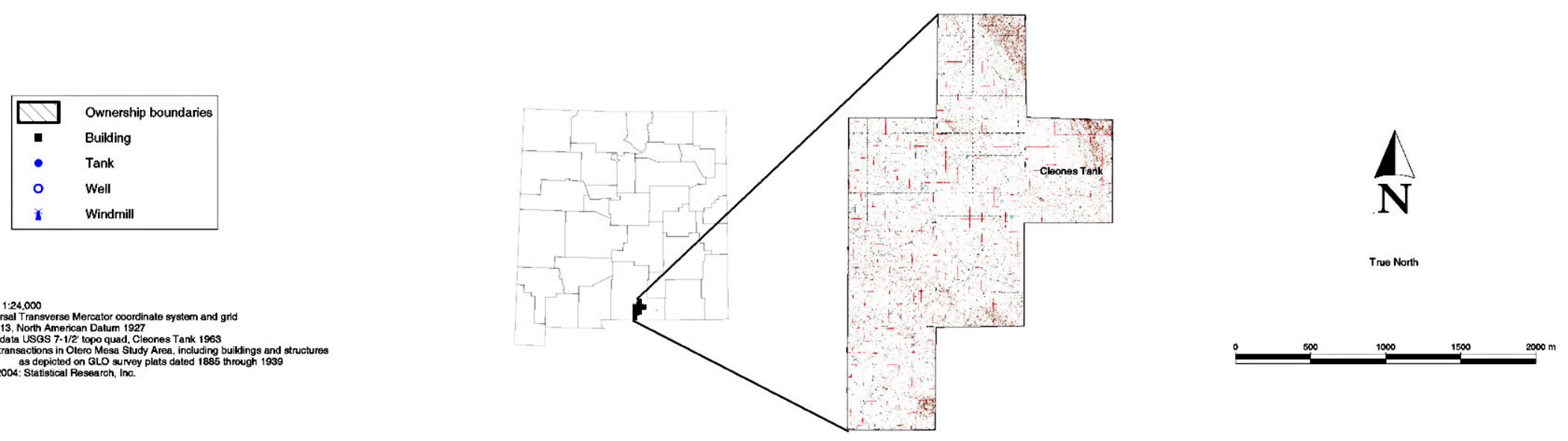

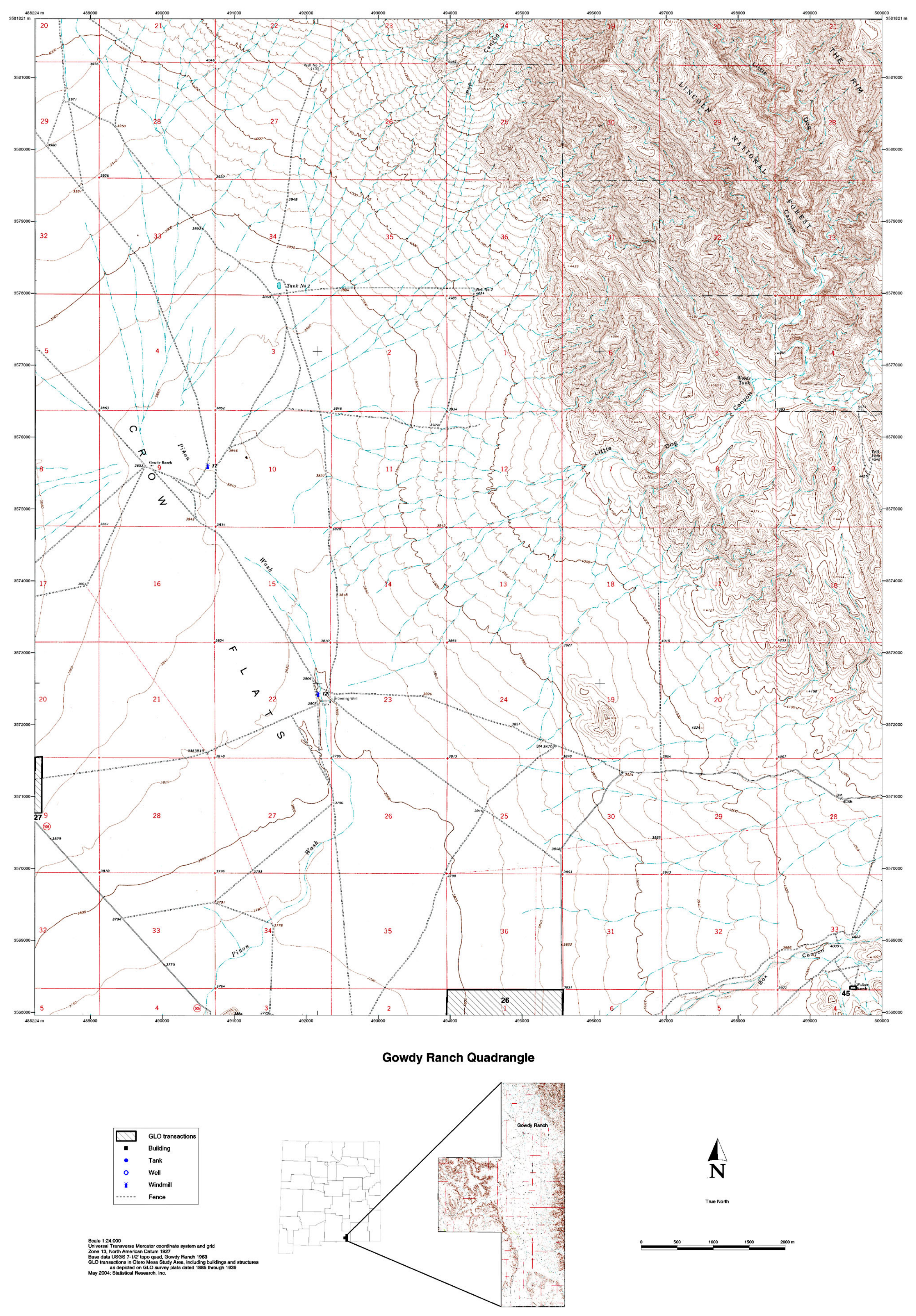

Figure A.7. Gowdy Ranch Quadrangle. May 2004: Statistical Research, Inc. 


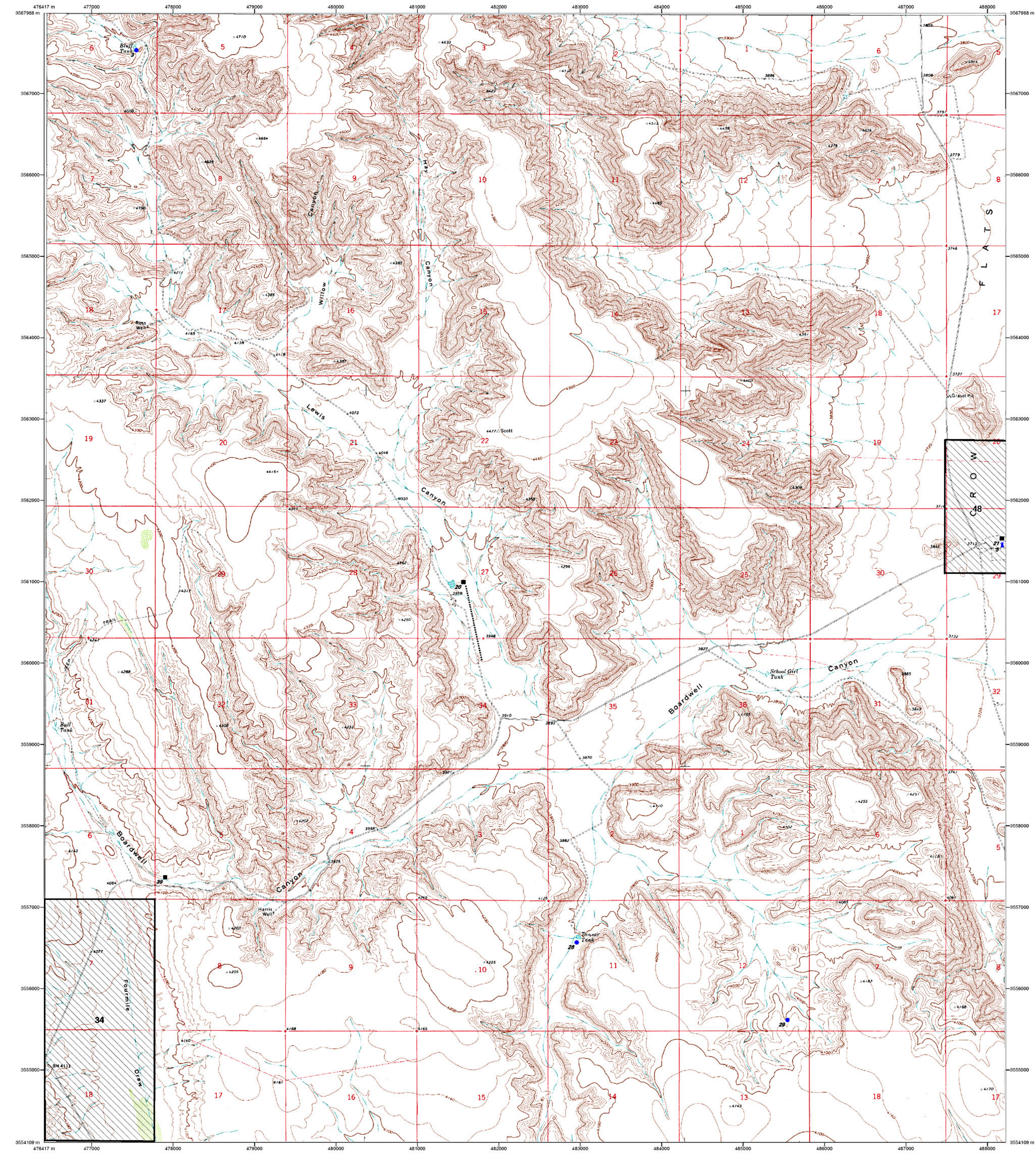

Lewis Canyon Quadrangle
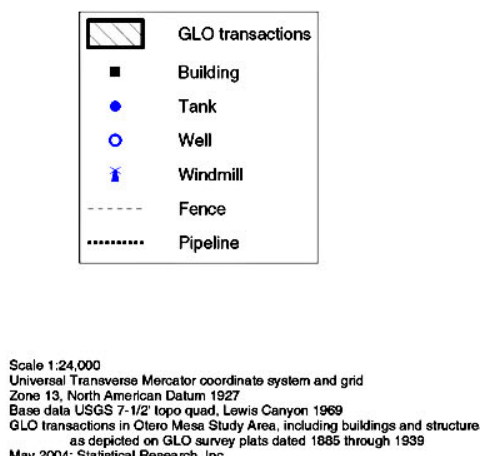

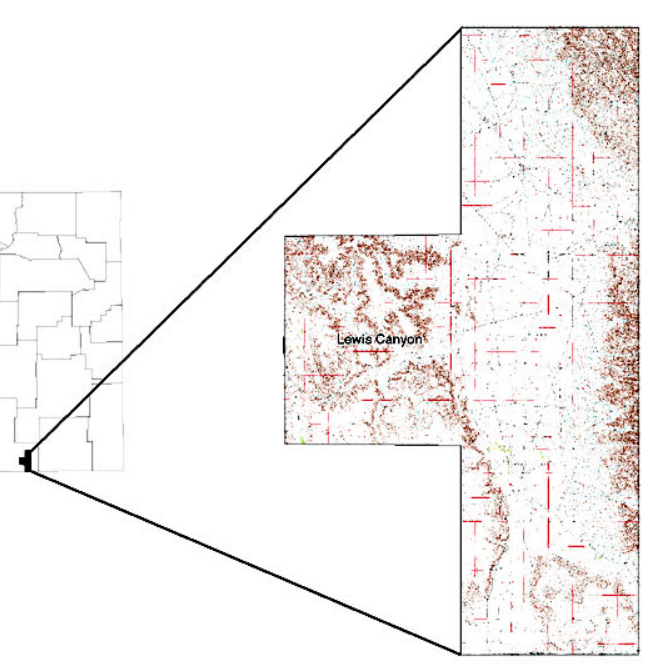

$\stackrel{\Lambda}{N}$ 


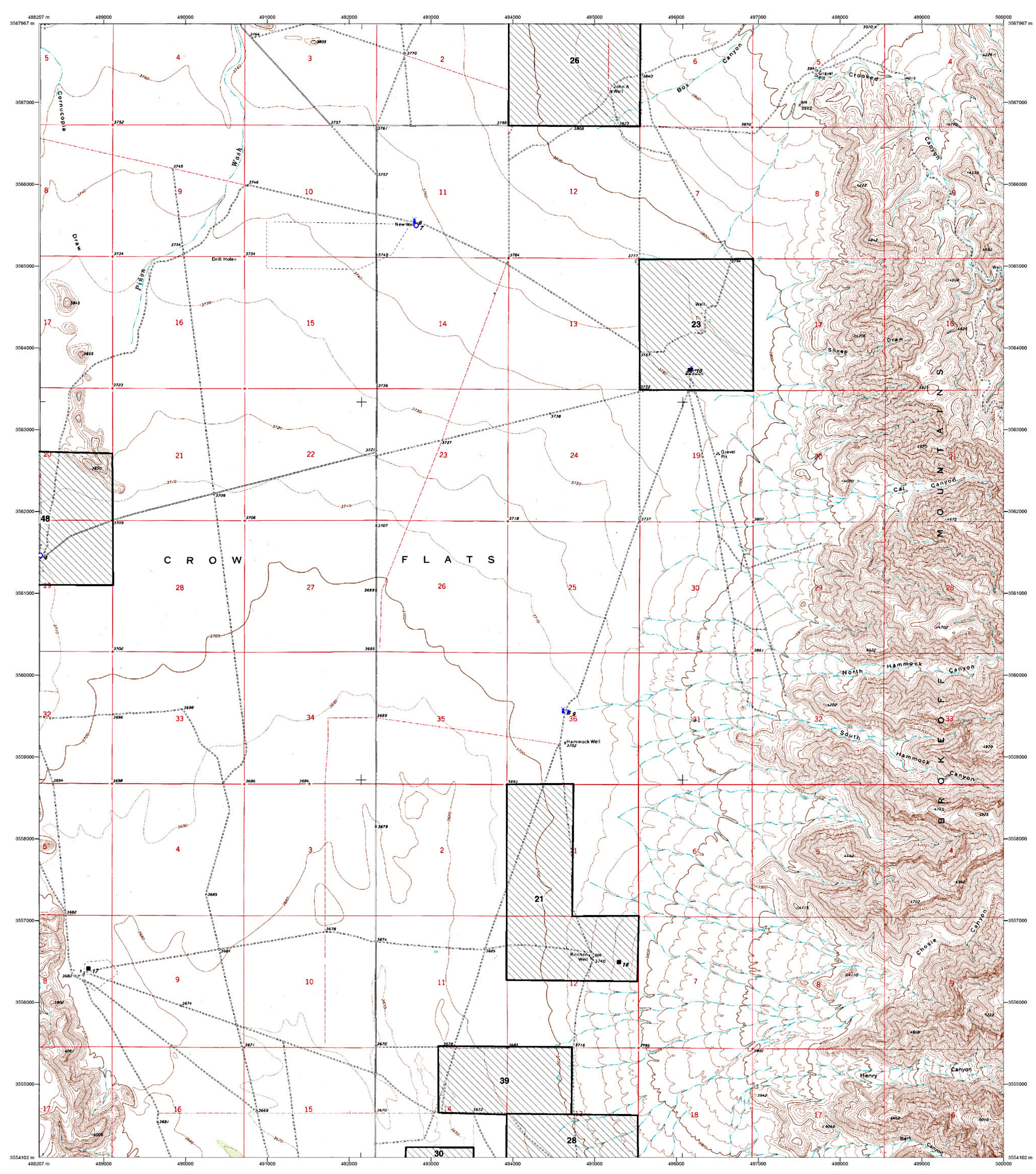

Sheep Draw Quadrangle
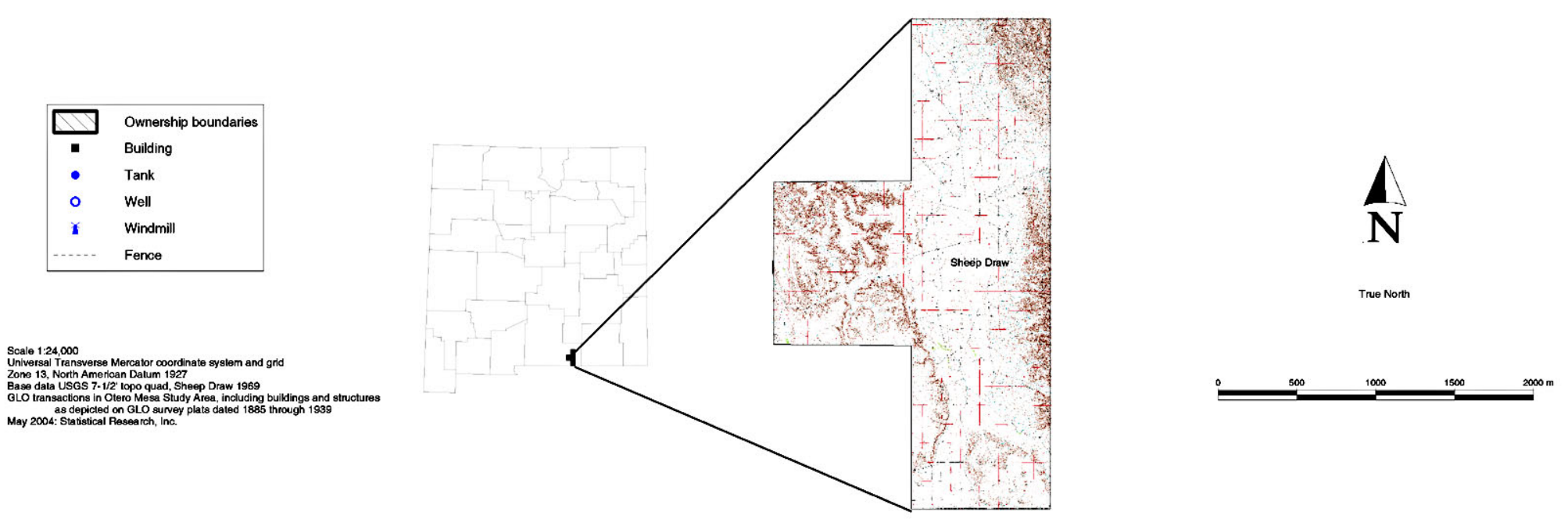

Figure A.9. Sheep Draw Quadrangle. May 2004: Statistical Research, Inc. 


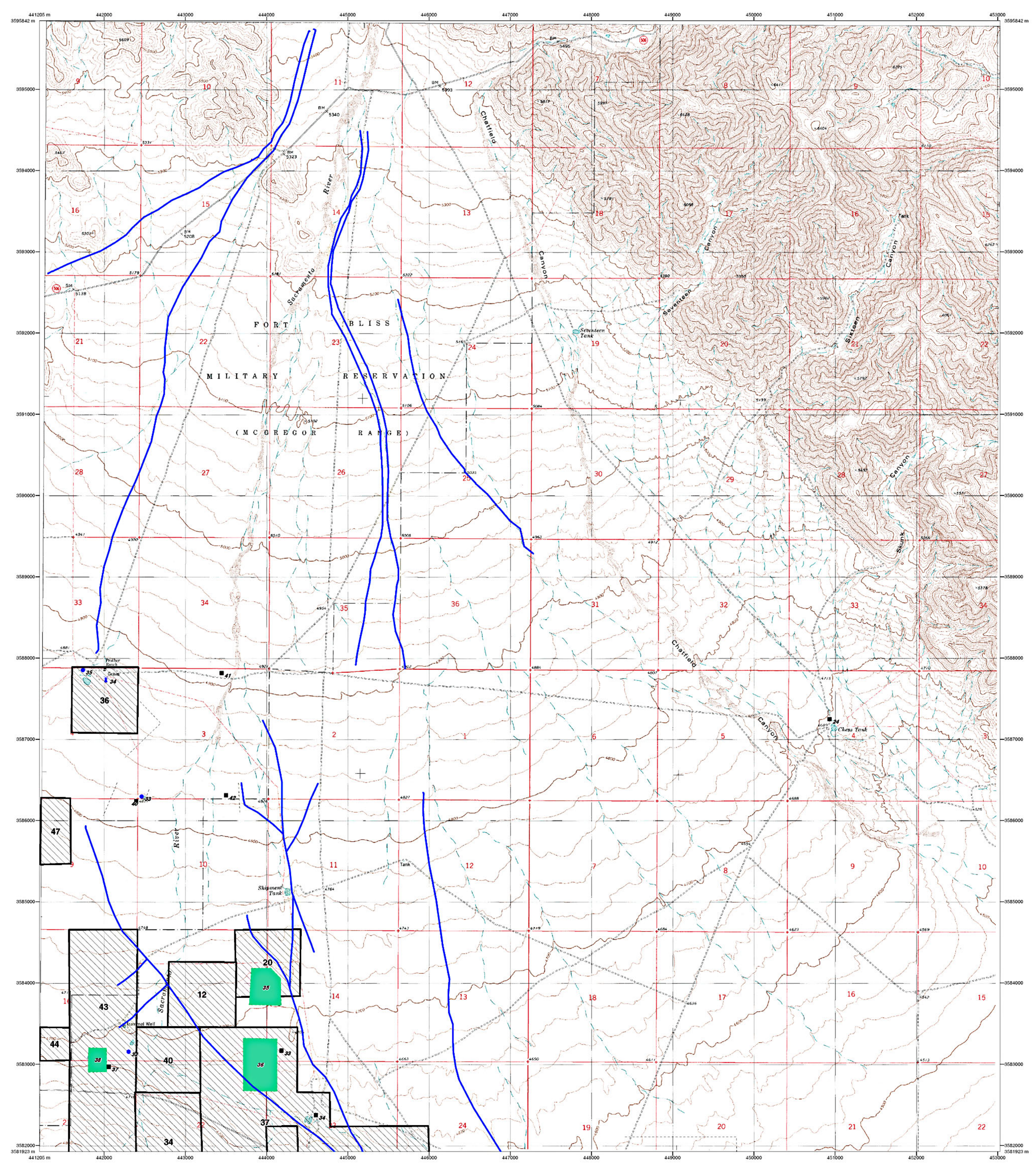

Sixteen Canyon Quadrangle
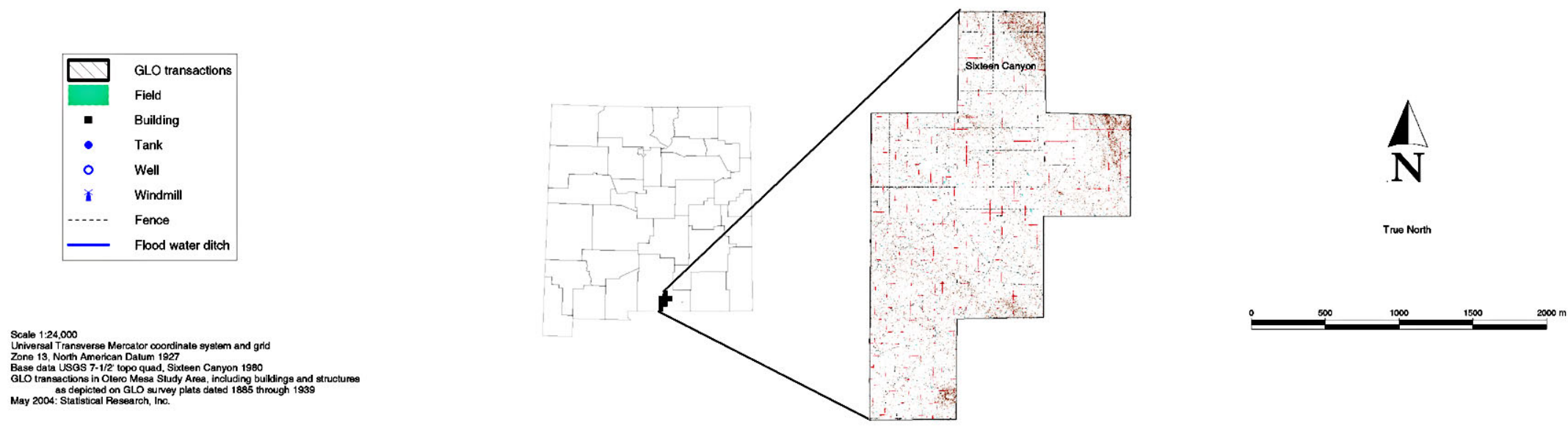

Figure A.10. Sixteen Canyon Quadrangle. May 2004: Statistical Research, Inc. 